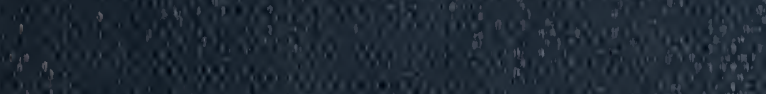

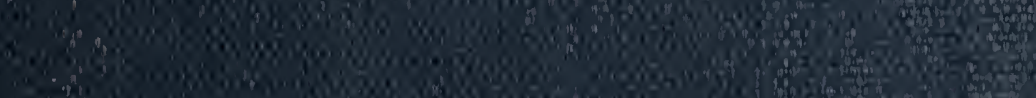

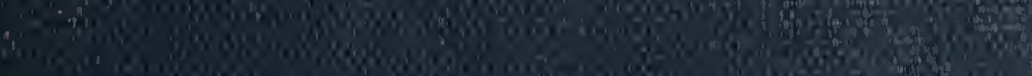

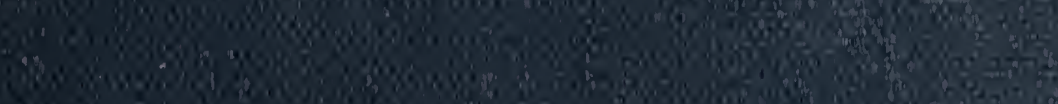

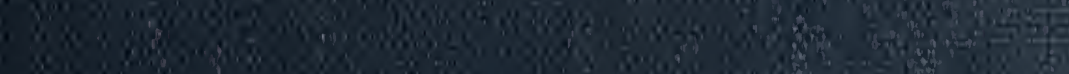

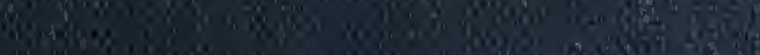

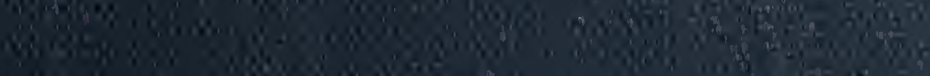

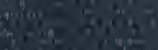

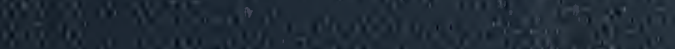

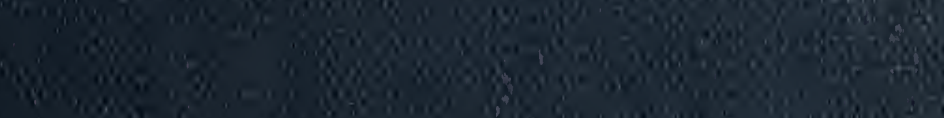

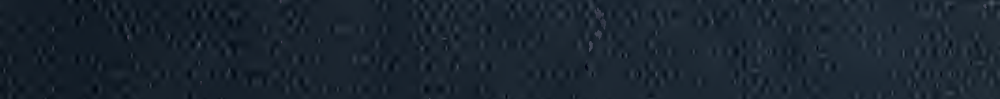

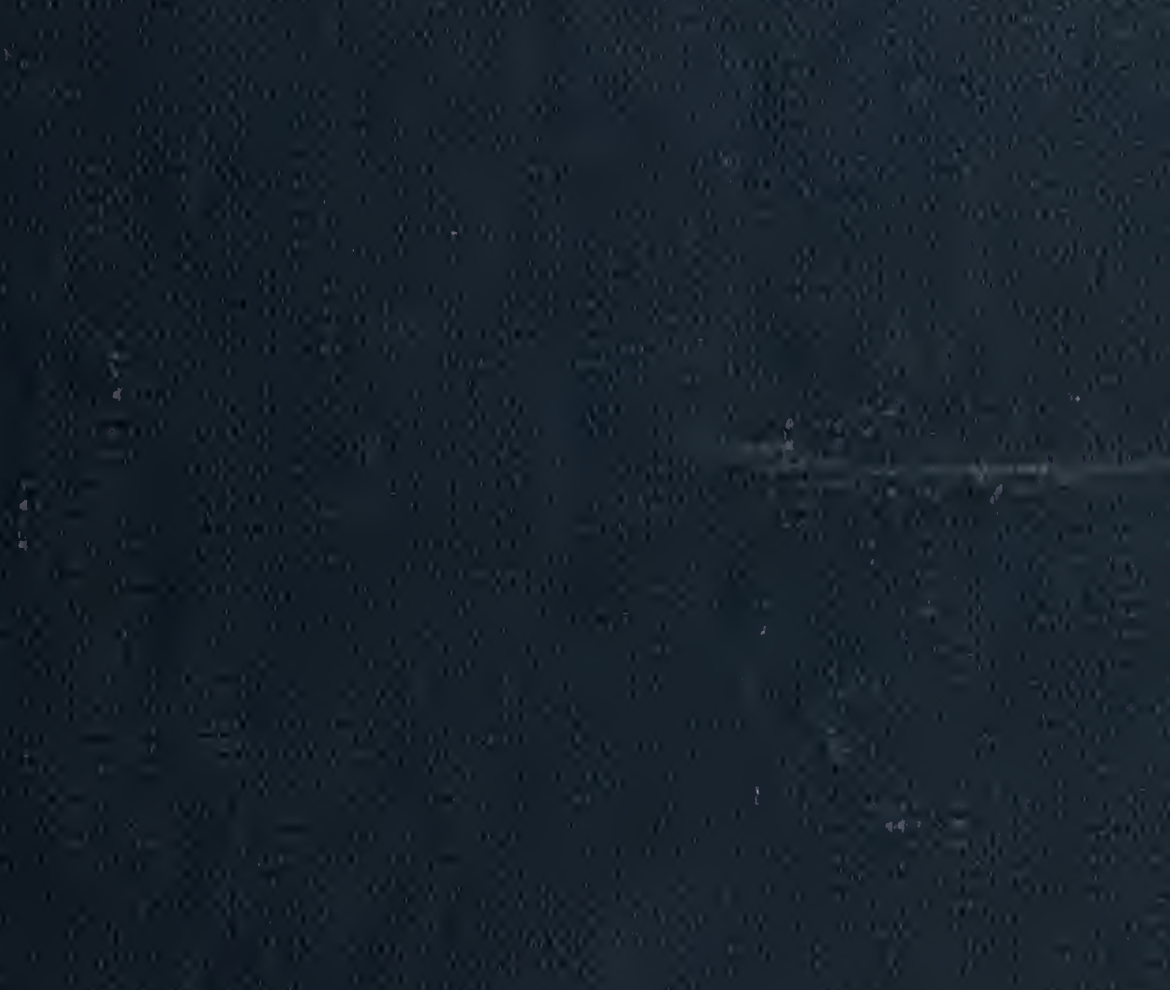

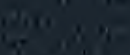

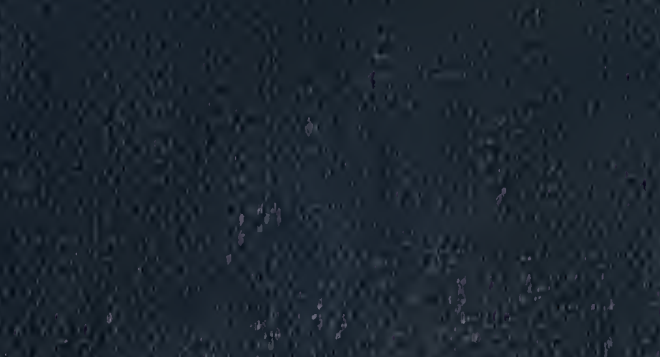



$$
\text { . }
$$ 




Buil Soc. bot Fr.

T. LII (1905) Mém 3, Pl. I.
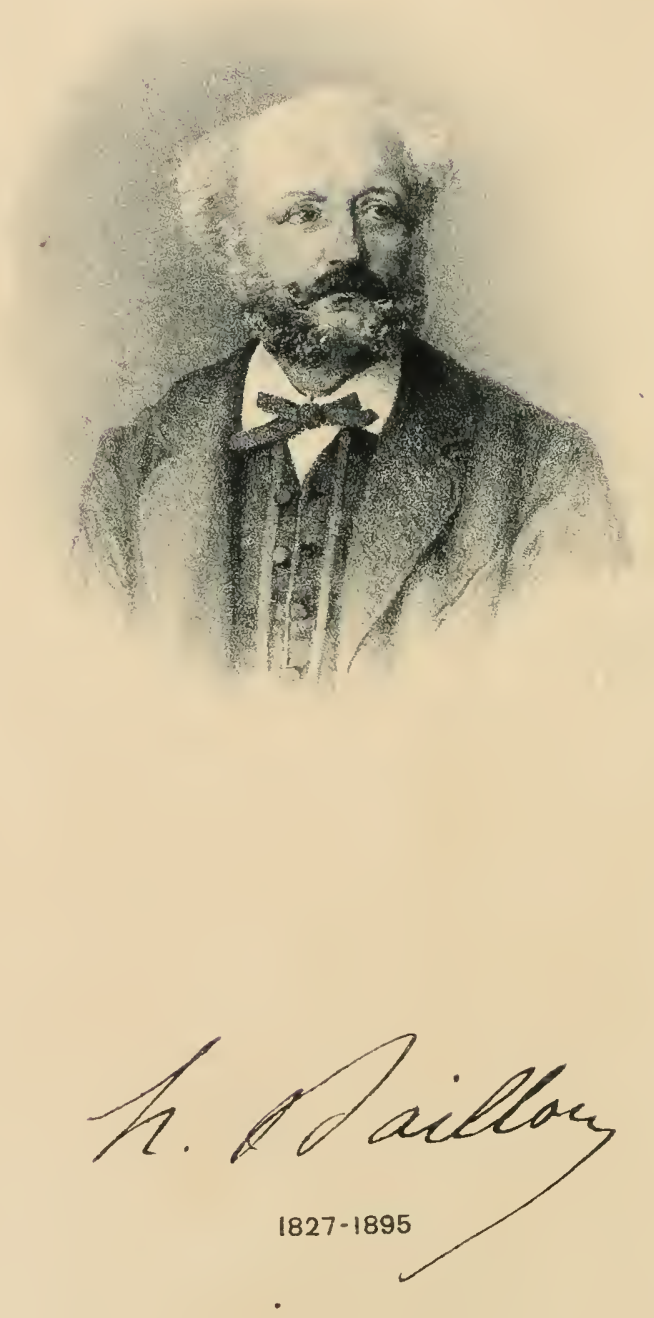


\section{SOCIÉTÉ BOTANIQUE}

\section{DE FRANCE}

MÉMOIRES

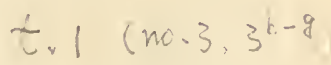

:)

\section{Plantæ Brasiliæ centralis a Glaziou lectæ.}

nov. 1905!

LISTE

DES PLANTES DU BRÉSIL CENTRAL RECUEILLIES

EN I $861-1895$

P.IR A.-F.-II. GILAZIOU,

Directeur en retraite des Jardins publics et des Forêts

DE Rio-de-Janeiro, etc.

\section{INTRODLCTION.}

Arant mon séjour de $3 \%$ années au Brésil, pendant lesquelles a été réunie une abondante collection botanique, plusieurs voyageur's araient récolté des plantes dans les mêmes régions. Je ne fis que glaner après Maritus, Riedel, Gardver, Sellow, Pohl, Weddell, Raddi, Gavdichatd, Miers, Wanuisg, Mikay et d'autres savants. Auguste de Sast-Hilahe principalement a toujours été mon gruide. Ses livres de royages me suiraient partout et, soixante-dix ans après lui, je trouvai l'intérieur de ce beau pays exactement encore tel qu'il le vit, ainsi que les usages domestiques de ses aimables et homnêtes liabitants si exactement décrits par lui avec une sincérité absolue. Aussi c'est joyeusement, et avec la plus grande attention, que je suivis son itinéraire, mais je m'en écartai souvent pour explorer des forêts vierges et des points élevés qu'il navait pas 
visités : c'est à ces endroits icartés, péniblement accessibles, que la science doit beaucoup de plantes nouvelles que j'eus la bonne chance de lui procurer.

Durant ces 33 années passées au Brésil, je profitai spontanément de mon libre arbitre pour chercher des plantes vivantes propres à orner les jardins publies de la ville de Rio-de-Janeiro et du Parc Impérial de São Christovão. En même temps je portais mon attention sur les matériaux propres a former un herbier dans le but d'acquérir une bonne connaissance de la flore du pays. Naturellement je commençai par l'exploration, a cet effet, de l'État de Rio-de-Janeiro : d'alord les alentours de la capitale fédérale, en débutant par les plaine's basses et sablonneuses appelées restingas qui bordent la mer entre Cabo Frio à l'est et Paraty à l'ouest. Entre ces restingus et la base des collines granitiques, il s'est formé des plaines d'alluvion, entrecoupées de lacs d'eau saumâtre où on trouve une infinité de plantes herbarées propres aux régions maritimes. Sur ces terrains nouveaux, il y a aussi une végétation ligneuse très leétérogène composée d'arbustes rabougris, venus pour la plupart des montagnes et acclimatés dans ces lieux presque stériles. Vers le nord-ouest de ces plaines se trouvent déjà des points élevés, tels que le Corcovado, la Tijuca, Gavea, Jacarepagna, Lagarto, etc., qui ne sont que des contreforts de la grande chaine maritime (Serra do Miar). Tous ces endroits qui ont encore conservé beancoup de bois, grâce au souci du gouvernement, furent explorés souvent dans les différentes saisons de l'année. Ensuite, toujours dlans l'état de Rio-de-Janeiro, les régions franchement montasneuses comprises entre Natividade et la Serra da Pedra Sellada, oir il y a des forèts sans fin, furent également fonillées dans les endroits les plus intéressants : par exemple, la Serra dos Orgĩos (2920̈ mètres d'altitude), richissime en Cryptogames vasculaires et en Bromeliacées, le Alto Nacahé et Nova Friburgo, la Serra das Almas, dos Grubixaes, do Tingua, das Frecheiras et particulièrement le Pico do Itatiaia, qui est certainement la plus haute montagne du Brésil ${ }^{1}$. Je l'explorai pour la premiere fois en juin 1871, par le versant de Campo Bello jusqu'au point culminant, c'est-i-dire huit ans avant l'ascension de cette pittoresque montagne' que fit le D $^{\mathrm{r}}$ Wawra de Ferxsee et dont il a publić, en 1880, une relation de touriste.

Le climat de l'État de Rio-de-Janeiro est humide et cliaud dlans la partie méridionale, oủ le sol est bas et marécageux; (lans la région septentriomale au-dessus de la cordillère maritime (Serra do Mar), qui est la plus vaste et la plus cultivée, le climat est tempéré, salubre et très

1. 2840 metres solon $\mathrm{x}$. Louis Cruls, directeur de lobservatoire de Rio-de-danciro. 
agréable. Entre les arêtes granitoïles de ces hauteur's, il y a rles vallées fertiles et géućralement arrosées par de urmbreus cours d'eau. L'est dans cette région que se sont établies les grandes cultures de Caféiers, ete., souvent interrompues par de fertiles pâturages.

Dans la partienord-onest de l'État de São Paulo, où je fis tant d'excursions faciles et rapides, wrâce aux nombreuses lignes ferrées qui s'y trouvent aujourd'hui, jo récoltai une foule de plantes : les lotalités principales qui me les foumirent sont : les Campos da liocaina. où est la source du Rio Parahyba, la Serra do Varejão, Itapecerica, Serra do Cubatroo, Nogy das Cruzes, São José do Parahytinga, Ubatuba, São Sebastico, Cunha, Natividade, Sorocaba, Itú, Camp̧o Largo, Piracicaba, Patrocinio, Jacarehy, Serra da Cantareira, Morro do Jaragua, Santa Isabel, Ipanema, Jundiahy, Lagoinha, Areas, Sĩo José do Barreiro, Guaratingueta, Serra Negra, etc.

Le climat de la province de São Paulo est très sain, surtout dans l'intérieur. Le sol est d'une fertilité extrème et convient à toutes especes de cultures, le Caféier y prospìre d'une facon admirable qu'on ne voit nulle part ailleurs; c'est le café qui for'ne le principal revenu de cet opulent Etat. Les montagnes qui s'y trourent ont toujour's pour base le gneiss porphỵroüde.

L'Etat de Espirito Santo, qui touche la partie Est de celui de Rio-deJaneiro, est celui que j'ai le moins exploré, n'ayant visité que trois fois les localités suivantes : Itapenirim, Benevente, Serra do Pombal, Colonia del Castello, Serra do Ipollinario, Villa Nova do Mucury, Serra de Muribeca, Pico do Garafĩo, Caclıoeira do Itapemirim, Megre, Serra dos Purys, Pao d'Alho, Serra do Funil et Itabapoana.

L'aspect plysique de cette petite province est toujours celui de la chaine maritine (Serra do Mar', aussi bien par la végétation de ses grandes forèts que par ses nombreuses montagnes granitiques entre lesquelles les plaines sont peu étendues. Le climat est chaud et humide, cependant plus tempéré dans le voisinage de la mer et surtout dans les haules vallées, oì il y a aussi d'excellents pàturages qui nourrissent de nombreux troupeaux de bétail. Partout on rencontre des ruisscaux arec do leau fraichle et cristalline.

L'Etat do Minas Geraes, qui possède beaucoup de chemins de fer le sillonnant dans toutes les directions, m’offrit d'abondantes récoltes. Cette région au doux climat, labitíe prar un monde aimable, hospitalier et plein de bienveillance vis-à-vis de l'étranger, se parcourt sans trop de fatigue et remplit d'enthousiasme l'esprit de l'herborisant, par la très grande abondance des especes qu'il trouve, surtout dans les rampos. La flore des bois dans ces hauteurs varie peu de celle des graudes forèts de la chaîne maritime (Serra do Mar). Les lieux élevés, au-dessus de ces riches et 
admirables eampos, que j'ai si souvent explorés et toujours arec suctès, sont : Serra da Mantiquevra, Serra do Ouro Branco, où se trouvent en abondance les Vellosia en arbre, ensuite le Pico do Ilacolumy, la Serra do Ouro Preto, Serra da Piedade et do Caraça, où il y a tant de végétaux remarquables; plus au Nord se trouve le plateau de Diamantina, qui a dans ses terrains quartzeux et presque stériles uıe flore toute spéciale composée d'arbustes à fourrure laineuse, tels que Sipolisia, Lychnophora, Wrunderlichia, etc., et d'une foule de plus petites plantes xérophiles; puis la Serra do Cipó ou do Espinhaco; le Pico d'Itabira do Campo; la Serra do Lenheiro et de São José, près São João d'El Rei; Serra dos Vertentes, près Oliveira; Pouso Alto; Serra do Picú; Serro do Frio, près Ayuruoca et Baependy; Morro Cavado; Paracatú et ses environs; Serra da Canastra; Alegre; Serra do Sella Ginete, près Curvello; As Agulılos; Negras ou Itatiaia, du côté de Minas, par le versant des campos du Rio Preto.

L'élévation, au-dessus du niveau de la mer, de la plus grande partie de la province de Minas Geraes rend son climat frais et très salubre; ce n'est que dans les bas-fonds des grandes rivières que la chaleur se fait sentir : c'est là cependant que se font les grandes cultures de Caféier's, de Maïs, de Haricot, de Canne à sucre, de Mandioca, etc. Les immenses plaines, où le sol est presque partout sablomneus, constituent des pàturages où se fait l'élevage du bétail, principale industrie de ces régions; ces plaines sout dominées par de longues chaines de montagnes schisteuses, telles que les Serra do Espinhaço, dos Vertentes, do Cipó, da Mantiqueira, qui donnent naissance à une infinité de sources. C'est là que se trouve vraiment le paradis des naturalistes, si fidèlement déerit par Auguste de Saint-Hhallie, le premier Français qui pareourut ce pays enchanteur.

Les deux dernières années que je passai au Brésil furent exclusive. ment consacrées à l'exploration de l'ancienue province de Goyaz, dont la végétation se raltache beaucoup à celle de Minas. Les principaux endroits notables parcourus sont : Serra dos Pyreneos; Rio Vaga Lume; Morro Grande et do Albbade, près Neia-Ponte: Serra do Albano ou das Divisies; Corumba et ses environs; Serra de Louranco Castanha; Lagoa Feia, près Santa-Luzia: Serra da Baliza: Chapadio dos Veadeiros ou de Porto Seguro; Urucuia: Pouso Alto; Cabereiras do Rio Sant'Anna, près Cavalcanti; Morro do Salto dans la Serra de Sìo José, le plus haut point de la provinee, 1 อั30 mètres environ; Morro Canastra, près Lagoa de Mestre d'Ar'mas; les alentours de la ville de Goyaz, capitale de l'Etat où j'explorai partieulièrement les arêtes et les campos de la Serra Dourada, uù seulement on troure le Tibouchina papyrus (Pao papel): Serra de Sĩo Pedro; Rio dos Indios, près des limites de Hatto Grosso; le village 
d'Almocafre dans la grande Serra dos Crystaes, dernier point de mon royage dans l'État de Goyaz, d'où il fallut traverser le sertio (désert) entre les deux provinces, passant par Porto do Buritei, Lagoa do Siquieiro, pour venir prendre le chemin de fer central à São José de Matosinho.

Le clinat de Goyaz est sec et chaud, salubre cependant, les nuits sont fraiches et très agréables; le sol des campos est peu fertile, composé de micaschiste et de sable; il est néanmoins couvert de pâturages et d'une foule d'espèces petites et xérophiles; les chaines de montagnes qui séparent les grands bassins des Amazones, de la Plata et de São Francisco sont : Serra de Santa Martha, Escalvado, dos Pyreneos, de Sĩo José, dos Crystan, Chapada das Mangabeiras, de Dona Feliciana, etc. Toutes ces arêtes ont pour base le grès, le schiste paléozoïque, le gneiss granitoïde et d'énormes blocs d'itacolumite. La végétation forestière diffère peu dans ses espèces de celle du littoral. Il y a encore la végétation des cerrados, d'un aspect tout différent, fórmée de petits arbres clairsemés, généralement tortueux, à grosse écorce et perdant leur feuillage dans la saison sèche. Aux mêmes hauteur's se trouvent aussi les carascaes des terrains sees et pierreux, peuplés de petits arbustes très serrés, toujour's verts, qui rappellent beaucoup dans leur ensemble la régétation des restingas des bords de la mer entre Cabo Frio et Paraty.

Dans le cours de mes explorations si souvent répétées aux mêmes endroits dans les États de Rio-de-Janeiro, de São Paulo et de Minas Geraes surtout, je pus recueillir plus de douze milte espèces de plantes occupant les numéros d'ordres de 1 à 22770 , ayant environ 1000 numéros bissés. Tous ces végétaux, entre lesquels il y a des centaines d'espèces nouvelles et beaucoup de genres nouveaux (marqués $n$. sp. et nov. gemus), furent libéralement distribués entre les principaux herbiers d'Europe et de l'Amérique du Sud : Paris; Saint-Pétersbourg, Kew, Berlin, Copenhague, Genève, Bruxelles, Stockholm, Montpellier, Rio-de-Janeiro, etr.

C'est cette large distribution de mes exsiccatas qui contribua le plus à leurs déterminations. Elles sont énumérées en partie dans une foule de publications généralement récentes, outre la place naturellement très grande qui leur est faite dans le magistral ouvrage de Martius, le Flora Brasiliensis. Citons ici les principaux botanistes qui ont collaboré aux déterminations de mes récoltes :

\begin{tabular}{|c|c|c|c|}
\hline $\begin{array}{l}\text { Baker, } \\
\text { Berkeley, } \\
\text { Bockeler, } \\
\text { Brand, } \\
\text { Buchenau, } \\
\text { Christ, } \\
\text { Cognaux, } \\
\text { Hackel, }\end{array}$ & $\begin{array}{l}\text { Engler, } \\
\text { Eichler, } \\
\text { Fée, } \\
\text { Fries, } \\
\text { Ilampe, } \\
\text { Hennigs, } \\
\text { llemsley, } \\
\text { loohne, }\end{array}$ & $\begin{array}{l}\text { Lindau, } \\
\text { Loesener, } \\
\text { Martin, } \\
\text { Mez, } \\
\text { Molins, } \\
\text { Müller, } \\
\text { Niedenzu, } \\
\text { Nylander, }\end{array}$ & $\begin{array}{l}\text { Oliver, } \\
\text { Perkins, } \\
\text { Ruhland, } \\
\text { Schumann, } \\
\text { Taubert, } \\
\text { Urban, } \\
\text { Warming. }\end{array}$ \\
\hline
\end{tabular}


A tous ces botanistes qu'il me soit permis d'exprimer ici mes plus sincères remerciments et en particulier à Eichlen, Schuman, Talbint, à

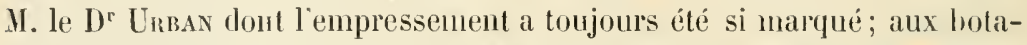
nistes du Jardin royal de Kew, MM. J.-G. Baken, Ouven, Hexsis; à

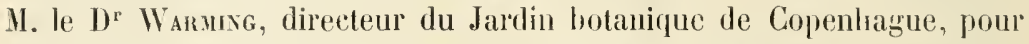
l'étude spéciale qu'il fit de mes Podostémacées; enfin je suis sincirement reconnaissant aux botanistes attachés aux herbiers du Muséun de Paris, qui m’ont toujours témoigné un sympathique intérèt dans mes recherches et mes comparaisons.

De ma part, les longues et persévérantes investigations ponr réunir les matériaux sur lesquels le présent travail est fondé, ont été spontanément faites aux dépens de mes menues ressources personmelles de fonctionnaire public, heureusement doué d'une constitntion robuste et d'une excellente santé. En outre, si j'ai pu arriver en ceci à quelque résultat susceptible d'intéresser les hommes de science, cela est dù aussi à la liberté absolue que mes chef's, les Ministres du Gouvernement Impérial de feu Don Pedro II me laissaient, ansi que, plus tard, ceux du Gouvernement de la République des États-Unis du Brésil. A tous ces hommes d'État, à ces hauts fonctionnaires, j'exprime respectueusement une vive et profonde gratitude, non seulement pour cette liberté d'action, mais encore pour la haute considération et l'extrème bienveillance dont ils me donnèrent des preuves multiples ì la suite des travaux d'art que j'exécutai sous leurs ordres.

Pour terminer ce long travail de récoltes et de déterminations, il semblait utile d'en dresser la liste générale. Ce Catalogue aura donc plus d'un avantage, car non seulement il groupera dans un ensemble méthodique lous les documents de systématique qui en résultent, mais il contiendra des déterminations tardives qui n'ont pu prendre place ni dans le grand ouvrage de llarmus, ni dans les multiples publications des nombreux spécialistes qui ont été mes savants collaborateurs. De plus l'abondante distribution des exsiccatas ayant rendu impossible la rédaction desétiquettes complètes, on trouvera ici d'utiles indications sur la distribution précise, les noms remaculaires, les dates de floraison et de fructification des plantes récoltées.

La nonenclature adoptée par les monographes du Flora Brasiliensis, faisant toujours autorité, je l'ai scrupuleusement suivie sans tenir compte de la synonymie, inutile pour un simple Catalogue; toutefois il m'est arrivé de mentionner quelques synonymes quand cela m'a paru susceptible d'intérèt.

L'ordre systématique du Genera plantarum de Bextнaи et Ноокеr, suivi si généralement par les botanistes sous la forme si pratique que lui a donné II. Tir. Durand, dans son Index generum Phanerogamarum, a 
1.-F.-H. GLIZIOL. - LISTE DES PLAXIES DL BRESIL GEYTRAL.

donné le plan général, adopté dans la rédaction le cet ourrage. Aussi souvent qu'il a été possible de le faire, l'ordre des espèces a été celui du Flora Brasiliensis de Martus.

Je ne doute pas que ce Catalogue ne soit de quelque utilité pour les botanistes. Je serais igalement heureux de savoir qu'il encouragera les recherrhes de ceux qui désireraient aussi marcher sur les traces des illustres Martius, St-Hilaire, Gardner, Pohl, etc., ell se livrant corps et âme à l'étude si attrayante de cette flore du Brésil, si riche qu' elle en est inépuisable. Puissent-ils, comme moi, après l'été et l'automne de leur vie consacrés à des explorations scientifiques, renouveler le charme des découvertes en revoyant en leur vieillesse les lıerbes sèches, jadis récoltées au sein de la végétation féerique des forêts géantes et des campos enchanteurs !

A. Glaziou.

Le Bouscat, mai 190.i.

\section{Dicotylédones.}

\section{POLYPÉTALES}

Fam. 1 : Renonculacées.

1. Clematis Hilarii Spreng.; Fl. Bras. XIII, I, p. 146. - Itatiaia, aux bords des bois et des chemins, Rio-JAN., n ${ }^{\circ}$ 6461. Liane, fl. blanches. Janvier-février. C.

2. Cl. campestris St-1til.; Fl. Bras. XIII, I, p. 140. - Itatiaia, dans le campo, Rio-JAx., $1^{\circ} 6461 \%$. Liane, fl. blanches très odorantes. Janvier-février. R.

3. $\mathrm{Cl}$. dioica L.; Fl. Bras. Xlll, I, p. 147. - Alto Macahé de Nova Friburgo, dans la forêt, Rio-Jax., nos 3851 , 16686. Liane, fl. blanches. Mars-avril. C.

var. antrllensis Eichl. in $\mathrm{Fl}$. Bras. XIII, I, 1. 147. - Serras dos Orgãos, dans la forèt, Rio-JAx., n ${ }^{\text {os }} 5721$, 5722; Serra do Picú, à Barreira, Minas, $11^{\circ}$ 10219. Liane, fl. blanches. Jars-avril. C.

var. brasiliana Eichll. in Fl. Brols. XIII, I, p. 148. - Corcovado, à Paineiras, Rıo-Jan., $n^{\circ}$ 1302; Pico do Ayuruoca, Misas, nº 9346. Liane, fl. blanches. Avril-juillet. CC.

var. australis Eichl. in Fl. Bras. XIIl, I, p. 1'18. - Juiz de Fora, dans les haies, Mrsas, $n^{\circ}$ 2477; Serral dos Orgãos, Rio-Jas., $1^{\circ} 5723$. Liane, fl. blanches. Mars-avril. C. 
MEMOIRE 3.

4. Anemone decapetala L.; H. Bras. XIII, I, p. 1:̈1. - Campos da Bocaina, São Palto, $11^{\circ} 4744 a$. Herbe viv., ll. blanc rosé. Marsavril. li.

๖. A. Glazioviana Urb. in Linnea, XVIII 1880-1882), p. 2.3. Itatiaia, Rio-Jan., dans les hois humides, $n^{\circ}$ 4744. Herbe viv., fl. roses. Juin-juillet. R.

6. Ranunculus flagelliformis Smitlı; Fl. Brts. XIII, I, p. 156. Serra da Bocaina, Sĩo Paulo, $n^{\circ}$ 6080. Ilerbe viv., f1. jaunes. Novembredécembre. C.

7. R. bonariensis Poir.; Fl. Bras. XIII, I, p. 1:37. - Source du Rio Suberbo, en haut de la Serra Ios Orgãos, $n^{\circ} 3852$ et à Itatiaia, dans le eampo, Rio-Jax., $\mathbf{n}^{0} 8561$. Herbe viv., fl. jaunes. C.

8. R. repens L, in Species Plant., p. Зั4. - Serra dos Orgãos, à Theresopolis, Rio-Jas., $n^{\circ} 6080$. Herbe viv., f1. jaunes. Novembredécembre. $\mathrm{C}$.

\section{Fam. 2 : Dilléniacées.}

1. Davilla suaveolens Glaz.; n. sp. ? in herb. Berol., Kew., Brux., Paris., etc. - Meia Ponte, dans les bois, Goraz, $n^{0}$ 20631. Arbuste sarmenteux, fl. jaunes très odorantes. Août-septembre. C.

2. D. angustifolia St-Hil.; Fl. Lras. XIII, I, 1) 101. - Près de Diamantina, Mrsas, $n^{\circ}$ 18835. Grande liane, fl. jaune pâle. Mars-avril. R.

3. D. elliptica St-Hil.; Fl. Bras. XIII, I, p. 103. - Caraca, chemin d'Arassuahy, Mrxas, nº 14461, 13502; Lagoa Formoza, Goyaz, nº 20633. Arbuste un peu sarmenteux, fl. jaunes. Janvier-arril. C.

4. D. neurophylla Gilg.; n. sp. in herb. Berol., Kew., Paris., etc. 一 Fazenda do Lambary, Goyaz, $n^{\circ}$ 20633. Grande liane, fl. jaunes. Janvierféviier. R.

3. D. rugosa Poir.; Fl. Bras. XIII, I, p. 106. - Floresta da Tijuca, $\mathrm{n}^{\circ} 2478$ et à Petropolis, Rio-Jav., $n^{\circ}$ 8257. Arbuste sarmenteux, fl. james. Avril-mai. CG.

6. D. pseudo-rugosa Glaz.; n. sp. in herb. Berol., Kew., Paris., Genev., etc. - Restinga de Cabo Frio, Rio-Jax., no 10221. Arbuste sarmenteux, fl. jaunâtres. Juillet-août. R.

7. D. multiflora St-Hil.; Fl. Bras. XIII, I, 1. 108. - Campos dans les bois, Rio-Jav., $n^{\circ}$ 9601, 10220. Arbuste sarmenteux, fl. jaunes. Janvier-mars. C.

8. D. latifolia Casar.; Fl. Bras. XIII, I, p. 96. - Corrovado, ¿ Lagoinha, Rio-Jax., $n^{\circ}$ 6462. Grande liane, fl. jaunes. Mar's-avril. C. 
9. D. Glaziovii Eichl. in Warm. Symb. ad Fl. Bras. p. 226. Serra do Couto et it Palmeiras, Rio-Jax., $11^{\circ}$ 2916, 17461. Arbuste sarmenteux, f1. jaunes. Mars-avril. R.

10. D. Goyazensis Glaz.; n. sp. ? in herb. Berol., Kew., Brux., Paris., etc. - Serra dos Yeadeiros, au Pouso Alto, Goraz, n²0633 $a$. Arbuste sarmenteux, fl. blanc jaunâtre. Janvier-février. R.

11. Curatella americana L.; Fl. Brus. XIII, I, p. 68. - Arassuahy, llixas, nos 12403, 13501; Pouso Alto, au Surdo, Goyaz, n 20632. Arbrisseau, f1. jaunes. Aoùt-septembre. CC. Tulgo Sambuiba.

12. C. Glazioviana Gilg.; n. sp. in herb. Berolin., Kew., Paris., etc. - Riberão de Taquaruçu, Mıss, nº 18838. Arbuste à demi sarmenteux, fl. jaunes. Mai-juin. R.

13. Doliocarpus grandiflorus Eichl. in Mart. Fl. Bras. XIII, I, p. 73. - Restinga de Maria, Rio-JAx., $1^{\circ}$ 18123. Arbuste sarment., fl. blanchâtres. Arril-mai. R.

14. D. sessiliflorus Mart.; Fl. Brus. XIII, I, p. 73. - Corcovado, Restinga de Copacabana, Praia Grande, Rı-J4x., n ${ }^{05}$ 4076, 11782. Arbuste un peu sarmenteux, f1. blanchâtres. Novembre-décembre. C.

1\%. D. elegans Eiclll. in Fl. Bras. XIII, I, p. T6. - Biribiry, aux bords des rivières, Mrsas, $n^{\circ}$ 18827. Arbuste sarmenteux, f1. james. Maijuin. C.

16. Tetracera calophy-lla Gilg in Engler Botan. Jahrb. XVIII, p. 29. - Perpetua, près Diamantina, Mrsas, $n^{\circ} 18836$ a. Arbuste sarment., fl. jaunàtres. Mars-avril. R.

17. T. Brejmiana Schl. in Fl. Bras. XIII, I, p. 89. - Cabo Frio, Rio-Jax., no 11781. Arbuste, f1. jaunes. Septembre-octobre. R.

18. T. ovalifolia DC; Fl. Bras. XIII, I, p. 88. - Araruama, près Cabo Frio, Rio-Jax., n $11781 a$. Arbuste sarmenteux, f1. jaunes. Septembre octobre. R.

19. T. oblongata DG; Fl. Bras. XIII, I, p. 90. - Fluresta da Tijuca, Rı-JAx., $n^{0}$ 2478 $\iota$. Grande liane, fl. blanc jaunâtre. Marsarril. C.

\section{Fan. 3 : Magnoliacéées.}

1. Drimys Winteri Forst. forma revoluta FY. Brus. XIII, I, p. I36. - Itacolumy, no 14462 et Caraca, Irsas, n 14463. Irbuste, t1. blanches. Février-niars. C.

var. granatexsis forma $\mathrm{V}$, in $\mathrm{Fl}$. Bras. XIII, I, p. 13̈. - Serra dos 
Orgãos, Rı-Jax., nos 3740 et 3854 . Arbuste, fl. blanches. Février-mars. CC. Vulgo Casca d'Ainlt.

2. Talauma ovata St-Hil.; H7. Bras. XIII, I, p. 125. - Serra dos Orgaios, à Theresopolis, dans les endroits humides, Rio-Jax., $11^{\circ 5} 8226$, 10222; Caraça, Mısas, $n^{\circ}$ 15821. Grand arbre, f1. jaunes odorantes. Décembre. C. Vulgo Baguassú.

3. Michelia Champaca L. : Spec. Plant.7866. - Petropolis, Rio-JaN., $n^{\circ}$ 6463. Grand arbre cultivé, fl. jaunes, odorantes. Février-mars. CC.

\section{Fam. 4 : Anonacées.}

1. Uvaria trigyna Eichl.; Fl. Bras. XIII, I, p. 40. - Floresta da Tijuca, Caxambu, dans les bois vierges, Rı-J $J_{A N}, n^{0 s} 8253,15824$. Arbrisseau, fl. roux verdâtre. Janvier-mar's. C.

2. Guatteria australis St-Hil.; Fl. Bras. XIII, I, p. 26. - Serra da Babylonia, Mıxas, $1^{\circ}$ 1596; Corcovado, Tijuca, Copacabana, Rio-Jax., $1^{\text {os }}$ 2677, 4746, 7506 et 8254. Novembre-décembre. CC. Vulgo Imbiú.

3. G. Hookeriana St-Hil.; Amn. Sc. Nat. Ser. II, v. 17, p. 132. Cosme Velho, au pied du Curcovado, Rı-JAn., no 7505. Arbrisseau, fi. rousses. Arutt-septembre. R.

4. G. psilopus Eichl. in Fl. Brus. XIII, I, 1. 27. - Serra da Estrella, à Vlandioca, Alto Macahé, Rıo-JAx., $n^{0 s} 7507$ a et 17462. Arbrisseau, 1l. rousses. Janvier-février. C.

5. G. Pohliana Schlecht.; F1. Bros. XIII, I, p. 28. - Corcovado, Tijuca, Serra da Estrella, Rio-J $J_{A N}$, $11^{\text {os }} 1028$, 10223, 11783. 14465; Rasgĩo, près Corumba, Goraz, $n^{\circ}$ 20637. Arbrisseau, 11. blanchâtres. Mai-jıillet. CC.

6. G. Martiana Schlecht.; Fl. Bras. XIII, I, p. 29. - College de Caraça, Mıxas, $n^{\circ}$ 16687. Arbre cultivé, bon fruit, fl. jaunâtres. Octobrenovembre. C.

7. G. Candolleana Schleeht.; Fl. Bras. XIII, I, p. 30. - Restinga de Nauá, Rro-JAx., $\mathbf{n}^{0}$ 7504. Arbrisseau, fl. roux verdàtre. Octobrenovembre. R.

8. G. Selloniana Schlecht.; Fl. Bras. XIII, I, p. 30. - Cabo Frio, Rı-Jax., $n^{\circ}$ 9603; Biribiry, Mrsas, $n^{\circ}$ 18847. Arbrisseau, 11. jaunàtres. Février-mar's. C..

9. G. pubescens Glaz.; 11. sp.? il herb. Berol., Kew., Paris., Brux., etc. - Biribiry, près Diamantina, Mısas, $n^{\circ}$ 18845. Arbrisseau 11., rousses. Mars-avril. R. 
10. G. villosissima St-Hil.; Fl. Brus. XIIl, I, p. 30. - Petropolis à Itamaraty, Rio-Jas., $1^{\circ} 2922$; Sìo Julicio, Mrsas, $1^{\circ}$ 17463. Arbrisseau, f1. rousses. Décembre. C.

11. G. Klotzschiana Ilart. in F\%. Bres. XIII, I, p. 32. - Praia Grande au Ilorro da Viraciio, Rio-Jav., nos 3858, 5725. Arbrisseau, f1. rousses. Novembre-décembre. C.

12. G. foliosa Benth. in Hooker Lond. Jomrn. Bot. II, p. 360. Morro do Coco, Rio-Jax., nº 13505. Arbrisseau, t1. jaunâtres. Férriermars. R.

13. G. oligocarpa llart. in Fl. Bras. XIII, I, p. 33. - Floresta da Tijuca, Serra do Picú, Rı-JAx., n² 252, 2481. Arbrisseau, fl. rousses. Décembre-janvier. R.

14. G. Schlechtendaliana Hart. in Fl. Bras. XIII, I, p. 34. Fazenda de Santa Maria, Goyaz, $n^{\circ}$ 20636. Grand arbre, f1. jaunes. Aoutseptembre. C. Vulgo Banana de macaco.

1\%. G. pogonopus llart. in Fl. Bras. XIII, I, p. 34. - Jacarepagua, Serra de Nova Friburgo, Rı-JAx., $n^{0 s}$ 2677, 3855, 7508, 10233. Arbrisseau, fl. ruusses. Janvier-férrier. C.

var. latifola Fries in Beitr. Anom. p. 1\%. - Nova Friburgo, RioJAx.. n ${ }^{0}$ 10232. Arbrisseau, fl. verdâtres. Février-mars. R.

16. G. Hilariana Schlecht. var. prlbescens Fries in Beitr. Anon. p. 1\%. - Jurujuba, à Praia Grande, Rio-JAN., nos 3855 , 3857. Arbrisseau, fl. rousses. Février-mars. R.

17. G. ferruginea St-Hil.; Fl. Bras. XIII, I, p. 35ั. - Alto Macahé dans la furèt vierge, Rio-JAx., $\mathbf{n}^{\circ}$ 6690. Arbrisseau, fl. lousses. Mlarsarril. C.

18. G. Glazioviana Fries in Beitr. Anon. p. 19. - Alto da Boa Vista de Nova Friburgo, Rio-JAx., $n^{\circ}$ 6856. Arbrisseau, fl. rousses. Janvier-février. $R$.

19. G. cauliflora Mart. in Fl. Bras. XIII, I, p. 33. - São Fidelis, Rio-Jax., $n^{0 s}$ 9605, 10233. Arbrisseau, f1. rousses. Février-mars. C.

20. G. inundata Mlart. in Fl. Brus. Xlll, I, p. 36. - Mar dEspanha, Nixas, $n^{0}$ 13504. Arbrisseau, f1. jaunatres. Avril-mai. R.

21. G. Ouregou Dunal; Fl. Bras. XIII, I, p. 36. - Arassuahy, dans le campo, Misas, n ${ }^{\circ}$ 14466; Rio vaga Fogo, Goraz, no 20638. Arbrisseau, fl. blanchâtres. Août-septembre. C.

22. G. blepharophylla Mart. in Fl. Brus. XIII, 1, p. 38. - Rio Hanso, Mrsas, $n^{0}$ 13506. Arbrisseau, f1. grisâtres. Février-mars. R. 
23. Duguetia lanceolata St-Hil; Fl. Bras. XIII, 1, p. 22. - Petropolis, à Santo Antonio, Riestinga de Cabon Frio, Rio-Jas,, $n^{05} 8255$, 10230. Arbrisseau, f1. grisâtres. Septembre-octobre. C.

24. D. Schlechtendaliana Mart. in Fl. Bras. XIII, I, P. 24. Petropolis, au Horro da Carangola, Rı-Jan., $\mathrm{n}^{\circ}$ 13513; liasgòa près Corumba, Goraz, no 20637. Arbre, li. jaunes. Novenbre-décembre. R. Vulgo Bínuna de mucaco.

2อ. Aberemoa microplyylla Fries in Beitr. Anon. p. 23. - Serra do Alto Nacahé, Rı-JaN., $n^{0}$ 16689. Arbrisseau, fl. blanc jaunâtre. Novembre-décembre. R.

26. Trigynæa oblongifolia Schit. in Fries Beitr. Anon. p. T. liestinga de Jauá, Rio-Jax., $n^{\circ} 8562$. Arbrisseau, fl. rousses. Avrilmai. R.

27. Anaxagorea prinoides St-Hil.; Fl. Bras. XIII, I, p. 40. Petropolis, au Morin, Rro-Jav., $11^{\circ} 12406$. Arbrisseau, ll. rousses. Mlarsavril. R.

28. Rollinia longifolia St-Hil.; Fl. Bras. XIII, 1, p. 17. - Restinga de Capacahana, Rı-Jan., no 138. Arbrisseau, fl. rousses. Février. Vulgo Araticú brava.

99. R. dolabripetala St-Hil. in Fries Beitr. Anon. p. 4:. - Corcovado et Restinga da Tijuca, Rro-Jax., $11^{05}$ 2482, 6078. Arbrisseau, 11. rousses. Août-septembre. CG.

30. R. laurifolia Schlect.; Fl. Bras. XIII, I, p. 18. - Arassualıy, Misas, $n^{05} 10229$, 15825; Ypiranza, Rio-JAN., $n^{\circ}$ 11785. Arbrisseau, fl. rousses. Novembre-décembre. CG.

31. R. silvatica Mart.; Fl. Bras. XIII, I, p. 18; Anomu silvestris Vell. - Serra da Bocaina, São Paclo, $n^{0}$ 12405; Serra do Pirú, Minas, $n^{0} 2484 a$. Arbrisseau, fl. roux foncé. Mar's-Avril. C.

32. R. resinosa Spr. in Fries Beitr. Anon. p. 46. - São Sebastião, Rı-JAx., $n^{o s} 10228,13503$. Arbrisseau, 11. rousses. Septembre-octobre. R.

33. R. orthopetala A. DG; Fl. Bras. XIII, I, p. 18. - Passeio Publico, Ruo-J An., nº 2483. Arbrisseau cultivé, bon fruit, fl. blanchàtres. Févriermars. C. Vulgo Biribá.

34. R. lanceolata Fries in Beitr. Anon. p. 49. - Serra do Alto Vacahé, Rio-JAN., $11^{\text {os }} 13509$ et 16691. Arbuste, fl. rousses. Janvierfévrier. R.

3i. R. Warmingii Fries in Beitr. Anon. p. 49. - Floresta da 
A.-F.-M. GLAZIOU. LISTE DES PLANTES D

BRESIL CEYTRIL.

Tijuca, Rı-JAN., $\mathrm{n}^{0 \mathrm{~s}} 2919,6079$. Arbrisseau, f1. rousses. Novembredécembre. C.

36. R. parviflora St-Hil.; var. latifolia in Fl. Bras. XIII, I, p. 19. Floresta da Tijuca, Copacabana, Rio-Jas., nos 2120, 3839, 6077. Arbrisseau, 11. rousses. Novembre. CC.

37. R. leptopetala Fries in Beitr. Sud-Am. Anon. p. 50. - Serra da Caraça, dans le bois, Mrsas, $n^{\circ}$ 13508. Arbrisseau, 11. rousses. Septembre-octobre. C.

38. R. rugulosa Schlecht.; Fl. Bras. XIII, I, p. ⒛ - Serra da Cantareira, S. Paulo, no $12405 a$. Arbrisseau, fl. r'ousses. C.

39. R. salicifolia Schlecht.; Fl. Bras. XIII, I, p. 21. - Caraça et Catas Altas, Mıvas, $n^{\text {os }}$ 12407, 13507, 14470. Arbrisseau, fl. blanchâtres. Septembre-octobre. C. Vulgo Brmana de mararo.

40. R. enarginata Schlecht.; Fl. Bres. XIII, I, p. 21. - Ipiranga, au bord du Rio Parahı̣ba, Sete Pontes, Rıo-Jas., $\mathrm{n}^{\text {os }}$ 685, 11784. Arbuste, fl. rousses. Décembre-Janvier. C. Vulgo Araticú mirim.

41. R. glaucescens Sund. in Linner, vol. XXII, p. 3.57. - Campos da Bocaina, S. Paulo, no 11784 \%. Arbuste, 11. rougeâtres. Juin-juillet. R. Vulgo Araticú mirim.

42. Anona muricata L.; Fl. Brets. XIII, I, p. 4. - Quința da Boa Vista, Rı-Jav., $11^{\circ}$ 13512. Arbrisseau cultivé, 11. jaunes. Décembre-janvier. CG. Vulgo Fructu de conde.

43. A. Pisonis Nart. in Fl. Bras. XIII, I, p. : - - Sete Pontes, à Barreto, Rio-JAs., n ${ }^{\circ}$ 17464. Arbrisseau cultivé. 11. jaunâtres. Novembre. R. Vulgo Araticú apé.

44. A. coriacea Vart. in Fl. Bras. XIII, I, p. 6. - Entre Ribeirào et Ponte de Paracatú, Misas, $1^{\circ} 20641$ Arbrisseau, fl. jaunâtres. Aoǹtseptembre. C. Vulgo Araticú do campo.

4... A. crassiflora Ilart. in Fl. Bras. XIII, I, p. 7. - Anonu Rodriguesii et A. macrocurpa B. Rodr. - Iguas Santas et à Biribiry, près Diamantina, Wrvas, ${ }^{05}$ 16688, 18844; Sobradinlı, Goraz, ${ }^{\circ} 20640$. Arbrisseau, fl. jaunes. Septembre-octobre. C. VuIgo Marollo, Araticú cabeca de negro, Paná.

46. A. monticola Mart. in Fl. Bros. XIII, I, p. T. - Aldeia de Onro Branco et à Sĩo Julião, Mıxas, nos 14446 et 18125 . Arbrisseau, ll. jaunâtres. Novembre-décembre. C.

4T. A. dioica St-Hil.; Fl. Bras. XIII, I, p. 8. - Amma cuyabensis et Aberemoa dioica B. Rod. - Rio Torto dans le cerrado, Goraz, $\mathrm{II}^{\circ} 20639 a$. 
Arbrisseau, tl. jaunâtres. Octobre-novembre. C. Vulgo lralirú grande.

48. Anona furfuracea St-Hil.; Fl. Bras. Xll, 1, p. 8. - Sorocaba, Säo Paulo. $11^{\circ} 12404$; Arassuahy, Misas, dims le campo, $11^{\circ} 12409$. Arbuste, fl. jaune grisâtre. Avril-mai. Ci.

49. A. rhizantha Eichl. in Jaheb. Berl. II (1883), p. 320. - Serra da Bica près Cascarlura, dans le bois, et à Imbitiba, Rıo-JAx., n ${ }^{05} 13511$ et 18842. Arbrisseau, fl. rouges. Janvier-février. R.

30. A. falsifolia Glaz.; n. sp. in herb, Berolin., Kew., Paris, etc. Villa Nova, dans les sables, Rio-JAx., $n^{\circ}{ }^{\circ} 13510$, 15822. Arbre pyramidal, t1. grisitres. Novembre-décembre. C.

31. A. cacans Warm. in Symb. ad Fl. Brrs., p. 432. - Floresta da Tijuca, Ruo-Jax., $11^{\circ}$ 7509. Arbrisseau cultivé, fl. jaunâtres. Novembredécembre. R.

32. A. palustris L. ; Fl. Bras. XIII, I, p. 11. - Entre Belem et Queimados, lmbitiba, diuns les bourbiers, Ro-JAx., $n^{05} 7509 a, 18841$ et 18843. Arbuste, fl. jaunes. Septembre-octobre. CC. Vulgo Araticú du brejo.

53. A. imbitibana Glaz.; n. sp. in herb. Berol., Kew., Paris., Genev., etc. - Imbitiba, dans les bourbiers près de la mer, Rıo-Jav., $n^{\circ}$ 18126. Arbuste, fl. verdâtres. Aoùt-septembre. C.

34. A. cornifolia St-Hil.; Fl. Brrs. XIII, 1, p. 12. - Arassuahy, dans les bourbiers, Minas, $n^{\circ}$ 12408. Arbuste. fl. jaunatres. Novembre. C. Vulgo Araticut do brejo.

5ั. A. hypoglauca Mart. in Fl. Brus. XIII, I, p. 13. - São Fidelis, près Campos, Rı-Jax., no 9604. Arbuste, fl. blanchàtres. Févriermars. C.

56. A. squamosa L.; Fl. Brus. XIII, I, p. 1'. - Quinta de Sĩo Christovĩo, Riı-Jav., $1^{\circ} 17464 a$. Arbrisseau cultivé, bon fruit, fl. blanchitres. Janvier-février. C. Vulgo Fructu de conde, Pinho.

:7. A. sericea Dunal; Fl. Bros. XllI, 1, p. 14. - Faria, près de Sabara, Mrvas, $11^{\circ}$ 18839. Arbuste, 11. Hanchatres, Janvier-février. C.

58. A. Cherimolia Mill.; Fl. Bros. XIII, I, p. 15. - Quinta São Christovio, Rio-Jan., $n^{\circ} 750$ l. Arbuste cultivé, bon fruit, 11 . jaune foncé. Novembre-décembre. R. Vulgo Cherimolia.

39. A crotonifolia Hart. in Fl.Bras. XIII, 1, p. 46. - Entre Cabeceiros du Rio Torto et Sobradinho, Goyaz, $n^{0}$ 20639. Arluuste, fl. jaunàtres. Novembre-décembre. C. Vulgo dralicú do campon.

60. A minensis Glaz. n. sp.? in herb. Berol., Kew., Paris, Havn., etc. 
1.-F.-M. GLAZIOU. - LISTE DES PLANTES DI BRESIL CENTRIL. 15 - Entre Caraça et Inficionado, dans le campo, Mrsas, $n^{\circ}$ 14467. Arbrisseau, 11. jaunâtres. Janvier-février. C.

61. A. lavigata Nart. in Fl. Brus. XIII, I, p. 17. - Corcovado, a Paineiras, Rı-Jax., $11^{\text {os }} 6464$ et 10226. Arbrissean, f1. grisâtres. Aoùtseptembre. C.

62. Xylopía fintescezz Aubl. var. ferruginea Fries in Beitr. Antm., p. 30. - Sete Pontes, au Barreto, Rio-Jax., no 15826. Arbrisseau, t1. jaunâtres. Janvier-férrier. C. Vulgo P'indahibu.

63. X. brasiliensis Spreng.; Fl. Bras. XIII, I, p. 420. - Floresta da Tijuca, Rı-Jax., nos 9347, 18840. Arbrisseau, fl. blanchâtres. Févriermars. CC. Vulgo Imbiri, Hervo doce.

var. gracnis Fries in Brilr. Anon., J. 31. - Floresta da Tijuca, Rro-Jax., $n^{0}$ 662, 3856. Arbrisseau, 11. jaunâtres. Juin-juillet. Vulgo Pán dore.

64. X. internedia Fries in Leitr. Anun., p. 32. - Restinga de Cabo Frio, Rio-Jax., no 10225. Arbrisseau, f1. jaunâtres. Férrier-mars. R.

6.). X. emarginata Nart. in F7. Bras. XIII, I, p. 42. - Diamantina. aux bords des rivieres, Mlsas, ${ }^{\text {os }}$ 14468, 18846 ; Rio Lagedo, tioraz. $\mathrm{n}^{\circ}$ 20635. Arbre pyramidal, f1. blanthes. Janvier-mars. Vulg. Pindahibri. CC.

66. X. carminata Aruda; Fries in Beitr. Sud-1mer. Anon., p. 32. - Floresta da Tijuca, Rio-Jax., nos 88, 661, 7507; Serra da Caraca, Ilxas, $n^{0}$ 14469; Serra Negri, à João Ignacio, Govaz, n² 20634. Arbrisseau, fl. blanches. Octobre-novembre. Ci.

67. X. grandiflora St-III.; Fl. Bres. XIII, I, p. 44. - Cabo Frio, Rio-Jax., $1^{\circ}$ 13401: Biribiry, près de Diamantina, Mrsas, $n^{\circ} 18848$. Arbre, fl. blanches. Mars-arril. C.

68. X. lavigata Fries in Brite. Sud.Amer. Anon., p. 37. - Corcovado à Cova da Onça, Rı-JAx., $1^{\circ}$ 1530. Arbrisseau, fl. blanchâtres. Juillet-août. C.

\section{Fam. : : Ménispermées.}

1. Disciphania Ernestii Eichl. in Jahrb. Bul. Gorl. Berl. 1883). p. 329. - Villa Isabel, pries Sìo Clıpistovão, Rı-JAx., nº 18130, 20188. Liane, fl. verdàtres. Décembre-janvier. R.

פ. D. Glaziovii Taub. ; n. sp. in Lerb. Berol., Lew., Paris., Harn., etc. - Serra Vermelha, Rio-JAx, $n^{\circ}$ 15827. Liane, f1. verdattres. Octobre. R.

3. Taubertia peltata K. Schum; in Engl. Bolan. Jahrb. (1893), p. .002, 
p. :303. - Corcovalu, $\mathrm{n}^{\circ \mathrm{s}} 3862,6702$; S. Chrristovão, $\mathrm{I}^{\circ} 12188$; Irapitinga, $11^{\circ} 18132$, Rio-Jav. Liane, fl. verditres. Janvier-mars. C.

4. Anomospermum grandifolizm Eichl. in Fl. Bras. XIII, I, p. 169. - Quinta da Bua Vista, Rio-Jax., n 9610. Grande liane cultivée, I1. verditres. Janvier-février. R.

¿. A. Incidum Miers in Contrib. to Bot. IlI, p. 72, tab. I03. - Villa de Cosa, Rio-Jav., I $^{0}$ 13516. Liane, fl. rousses. Novembre. R.

6. A. Schomburgliii Niers; Fl. Bras. XIII, 1, p. 171. - Cabo Frio et à Petropolis, Rı-JAN., $11^{\text {ss }} 13515,13517$. Grande liane, fl. verdâtres. Septembre-octobre. C.

7. Abuta rufescens Aubl.; Fl. Bros. XIII, I, p. 174. - Corcovado, Riro-J $J_{A x}$, $n^{\text {os }}$ 2918, 3860; Ganea, près la mer, n 7869. Grosse liane, f1. rousses. Décembre. C.

8. A. Selloana Eichl. in Fl. Bras. XIIl, I, p. 178. - Petropolis, Rı-JAn., $1^{\text {os }} 8250,13519$; N. Friburgo au Conego, $n^{0 \mathrm{~s}} 13403,18128$. Grande liane, f1. verdatres. Novembre-décembre. C.

9. Cocculus Filipendula Ilart.; Fl. Brrts. XIII, I, p. I83. - CanŁagallo, $\mathrm{n}^{\text {0s }} 8563,18129$; et São Christovio, Rı-JAN., $\mathrm{n}^{\circ}$ 13520; Sĩo Vicente, S. Paulo, n ${ }^{0} 13520$. Liane, fl. rousses. Novembre-décembre.

10. Cissampelos ovalifolia DC; Fl. Bras. XIII, I, p. 187. - Arassuahy, Hıxas, $n^{\circ}$ 12413, 14472: Faria, Mixas, $n^{\circ}$ 18127; Rio Forto, Goraz, $n^{\circ}$ 20642. Arbuste des campos, it. blanchàtres. Novembredécembre. Vulgo Orellat de Onert.

II. C. Pareira L.; Fl. IBras. XIII, I, p. 188. - Petropolis, RioJAN., $n^{\circ}$ 9608; Diamantina, $n^{\circ} 18851$ et Santa Luzia, Mıvas, $n^{\circ} 20189$. Liane, f1. verdàtres. Novembre-décembre.

[2. C. Glaziovii Taub; n. sp. in herb. Berol., Kew., Paris., etc. Arassuahy, Mrvas, $n^{0}$ 12412. Liane, 11. grisâtres. Janvier-février. C. Vulgo Milom .

13. C. glaberrima St-Hil.; Fl. Bras. XIII, I, 1. 192. - Serra da Babylonia, Mısas, n 7510. Liane, fl. verdàtres. Janvier-février.

1'4. C. tamoides Willd.; F. Bres. XIII, I, p. 193. - Nova Friburgo, au Conego, Rio-JAx., n ${ }^{\circ} 18129 \lll$. Liane, fl. verdàtres. Octobrenovembre. Mars.

15. C. sympodialis Eichl. in Fl. Bras. XIII, I, p. 192. - S. Fidelis, Rio-Jav., $1^{\circ} 10236$; Caho Frio, près de la mer, $1^{\circ} 18850$. Liane, 17 . verdàtres. R.

16. C. fasciculata Bentlı,; Fl. Bras. XIII, I, p. 194. - Serra dos 
1.-F.-M. GLAZIOL. - LISTL DES PLANTES UU BRÉSIL CEXTRAL. 17 Orỗos, Rio-Jax., $n^{\text {os }} 4748$, 18131. Liane, fl. verdàtres. Aoùt-septembre.

17. C. andromorpha DG: Fl. Bros. XII, I, p. 193. - Arassuahy, Mivas, $n^{\circ}$ 12411. Liane, fl. rousses. Janvier-février. Vulgo Milona.

18. C. Vitis Vell. Fl. Flum. X, tab. 137. - Corcovado, à Paineiras, Rio-Jax., nos $2917,14474,14475$. Liane, fl. brunes, fruits noirs. Octobrenovermbre. C.

19. Pachygone oblongifolia Eichl. in Fl. liras. XIII, I, 1. 197.Morro da Babylonia, liı-Jax., $n^{0} 4986$; Icarahy, près de la mer, $11^{\circ} 5726$. Haute liane, fl. roux foncé. Aoùt-septembre.

20. P. domingensis Eichl. in Fl. Bras. XIII, I, p. 197. - Petropolis, ¿̇ Cachambu, Rio-Jax., $1^{\circ 4}$ 7870, 13518. Liane, fl. jaunàtres. Janviel.

21. Botryopsis platyphylla Miers; Fl. lirus. XIIl, I, p. 199. Serra da Estrella, Rio-Jax., $11^{\circ} 11786$; Corcovarlo, nos 3861, 4487; Mandioca, $n^{\circ}$ 9348. Grosse liane, 1l. rerdàtres. Janvier-février. C. Vulgo Abulua.

22. Sychnosepalum paraense Eichl. in Fl. Bras. XIII, I, p. 203. - Quinta da Boa Vista, liı-JAx., $11^{\circ}$ 13514. Liane cultivée, fl. blanchitres. Norembre-décembre. F.

23. Detandra pubistaminea K. Sch. in Engl. Bot. Jahro., 1893, 1. 4. - Arassuhay, Misss, $n^{\circ}$ 14473. Liane, fl. grises. Février-mars.

\section{Fan. 6. : Berbéridées.}

1. Berberis lamina Billb.; Fl. Bres. XIII, I, 1. 230. - Itatiaia, Rio-Jax., $n^{\text {os }}$ 4749, 6645; Serra da Bocaina, São Pallo, n 10237. Arbuste, fl. jaunes. Septembre.

2. B. itatiaiæ Glaz. : n. sp. in herb. Berol., Kew., Harn., Paris., etr. - Itatiaia, dans le campo, côté nord, Mrsas, nº 8790. Arbuste sans tieurs. Novembre. C.

3. B. ruscifolia Lamk; Fl. Lirus. XIII, 1, 1. 232. - Itatiaia, entre les rochers, hio-JAx., $n^{\circ}$ 4750. Pelit arbuste, 11. jaunes. Sejtembre.

\section{Fanl. 7 : Ny゙mphceacées.}

1. Cabombo aquatica Aubl.; Fl. Bras. IV, II, p. I38. - Lampos, líro-JAx., nº 13521. Aquatique, fl. lilas. Février-mar's.

2. C. Warmingii Casp. in Fl. Bras. IV, II, 1) 142. - Lagoa Feia, Goyaz, no 20643. Arpuatique, fl. rose jâle. Décembre. 
3. Nymphæa ampla IIC; 1\%. lirus. IV, II, p. 156. - Lagoa de Tijuca, Rio-dan., $1^{05}$ 1258, 6083. Aquatique, fl. Wanches. Septembreoctuhre. Vulgo Gorfo.

var. pulchella Casp. in Fl. Bres. IV. II, p. 1:59. - Lagoa da liabyIonia. Mrsas, $n^{\circ}$ 12414. Aquatique, fl. blanc rosé. Septembre-octobre. C.

4. N. Rudgeana Meyer; Fl. Brus. IV, II, p. 160. - Lagoa, de Araruma, Rio-Jav., nº 9611. Aquatique, fl. blanches. Février-mars.

\section{Fam. 8: Papavéracées.}

1. Argemone mexicana L.; Fl. Bras. XIII, I, p. 316. - Calo Frio, Rio-Jax., n ${ }^{\circ} 3863$. Herbacé, fl. jaunes. Septembre-octobre.

\section{Fam. 9 : Crucifères.}

1. Nasturtium officinale R. Br.; Fl. Brus. XIII, I, p. $997 .-$ Inhauma, Rio-Jav., $n^{0}$ 8258. Herbe, fl. blanches. Décembre-janvier. Vulgo Ariáo.

2. N. bonariense DG; Fl. Bras. XIII, I, p. 299. - Serra da Bocaina, dans le campo, SAo-PAlLo, $\mathrm{n}^{\circ} 13522 a$. Herbacé, fl. blanchâtres. Février-mars. C.

3. N. pumilum Camb.; Fl. Bras. XIII, I, p. 299. - Près de Carara, Ihwas, dans les bourbiers, $n^{\text {os }} 12415,13522$. Herbe, fl. blanches. Juilletaoùt-septembre.

4. Cardamine chenopodifolia Pers.: Fl. Bras. XIII, I, p. 301. Chemin du Corcovado, Rı-Jan., $n^{0}$ 6466. Herbacé, fl. blanches. Octobrenovembre.

๖. C. flnminensis Eichl. in Warm. Symbole, II, p. 2233. - Passeio i’ublico, Rı-Jan., no 1526. Herbacé, ll. blanches. Septembre.

6. Senebiera pinnatifida DC; Fl. Brus. XIII, I, p. 308. - Campo da Acclamaçĩo, hio-Jav., $n^{\circ}$ 9349. Herbaré, fl. blanches. Janvierfévrier.

7. Lepidium ruderale L.; Fl. Bras. XIII, I, p. 310. - Botofago, aux hords des chemins, et à Copacalıana, Rio-Jav., $\mathbf{n}^{\circ}$ 1525. Herbacé, 11. blanches. Janvier-juillet. C.

\section{Fam. 10 : Capparidées.}

1. Dactylæna microphylla Eichl.; Fl. Bras. XIII, I, p. ㄴ41. Restinga de Tijuca, Rio-Jan., no 6174. Sous-frutescent, fl. roses. Septembre. R. 
A.-F.-Y. GLAZIOC. - LISTE DES PLANTES DU BRESIL CEXTRAL. I!

2. D. Glaziovii Taub. in Botan. Jalub. XV, Reibl., и. 3.. - Balbacena, dans les bois, Mrxas, $n^{\circ}$ 12420. Sous-frutescent, fl. rosées. Juinjuillet. C.

3. Cleome gigantea L.; Fl. Brus. XIII, I, p. 248; Cl. pedunculutu Vell. Fl. Flum. VI, t. 11ב. - Santi-Cruz, Rio-Jax., no 3865. Sous-frutescent, ll. violacées. Octobre-novembre. C.

4. C. dendroides Schult.; F\%. Biors. XIII, I, p. 249: (\%. doderıphyll. Vell., Fl. Flum. VI, t. 110. - Novi Friburgo, Rio-Jav., n० 4751. Sous-fruteseent, f1. roses, pourprées. Mars-avril. C.

¿. G. glabra Taub. : n. sp.? in herb. Berol., Kew., Havn., Paris., etc. - Barbacena, dans les plaines humides, Misas, no 12417. Sous-frutescent, fl. blanc rosé. Janvier-février. C.

6. C. scabrella Eichl. in Warm. Symb., II, p. 236. - Theresopolis, Rio Jax., $n^{\circ}$ 1595. Sous-frutescent, fl. rose pâle. Ortobre-novembre.

7. C. spinosa L.; H. Bros. XIII, I, p. 292. - Petropolis, au Padre Correa, Rir-Jan., $n^{\circ} 1595$ a. Srus-frutescent, fl. rose pâle. Octobrenovembre. $\mathrm{C}$.

S. C. rosea Vahl., DG; Fl. Bras. XIII, I, p. 294; Cl. penlaphylla Tell. Fl. Flum. Vl, t. 111. - Botafogo, Rio-Jax., n ${ }^{2}$ 233. Sous-frutescent, fl. rose pâle. Septembre-rictobre. C.

9. C. affinis DC; Fl. Bras. XIII, I, p. 2:38; Cl. tripleylla Vell. Fl. Flum., VI, t. 113. - Rio-de-Janeiro, dans les jardins, $n^{\circ} 343$, 685, 4959. Sous-frutescent, f1. roses. Octobre-novembre. CC.

10. Physostemon intermedium Horic.; Fl. Bras. XIII, 1, p. 243. - Arassuahy, Misas, $n^{0 s} 12416,14776$. Sous-frutescent, fl. blanc jaunàtre. Décembre-janvier.

11. Ph. lanceolatum Mart.; Fl. Bras. XIII, I, p. 244. - Campos, Riı-Jax., no 10238. Sous-frutescent, f1. rose pâte. Septembre-octobre. C.

12. Gynandropsis pentaphylla DG; Fl. Bras. XIII, I, p. 261. Fazenda de Santa-Gruz, Rı-JAn., nº 8261. Sous-frutescent, fleur's roses. Mai-juin. C.

13. Steriphoma peruvianum Spr. in Fl. Birs. XIII, I, p. 267. Quinta de São Christovioo, Rro-Jan., n 12419 ". Arbuste cultivé, fl. jaunâtres. Janvier-février. R.

14. Capparis Eichleriana Urb. in Fl. Sud-Am., p. 20;\%. - Serra de Iacarepagua, Rio-JAN., $\mathrm{n}^{0}$ 6711. Arbuste, fl. blanc jaunatre. Octobrenovembre. C.

1\%. C. Yeo Martius et Eichl. in Fl. Bras. XIII, I, p. 272. - Campos, 
dans les bois, Rı-Jav., nº 10240 a. Arbrisseau, ll. jannatres. Norembredicembre. R.

16. Capparis Jacobina Moric.; Fl. Bras. XIII, I, p. 277. - Sia Fidelis, pris Campos, lino-JAx., no 10240. Arbrisseau, ll. jamnatres. Iécembre-janvier. C.

17. C. lineata Domb.: Fl. Bras. XIII, I, p. 2977; C. srandens Vell. Fl. Flum. I, t. 109. - Santa Cruz, Rio-Jax., $1^{\circ}$ 6801. Arbuste sarmenteux, fl. blanches. Octohre-novembre. C.

18. C. brasiliana DC; Fl. Lirus. XIII, I, P. 279. - Corcovado, à Paineiras, Rio-Jax., $n^{\text {os }} 6082$, 9350; Arassualıy, Misas, $n^{\circ} 12418$. Arluste, 11. rose pàle. Septembre-octobre. C.

19. C. flexnosa Vell.; Fl. Brus. XIII, I, p. 280. - Jorro do Carallão et au Corcovado, Rı-Jan., $11^{05} 4754,15241$. Arbuste, 11. blanc rerditre. Octobre-novembre. C.

20. C. macrophylla Humb. B. et K.; Fl. Bros. XHI, I, p. 281. -Campos, au Collegio dans le bois, hı-Jav., n ${ }^{\circ}$ 9612. Arbuste, fi. blanc jaunâtre. Novembre-décenbre. R.

21. C. crnophallophora L.; F\%. Bras. XIII, I, p. 282. - Entre Gavea et Tijura, Rı-Jax., nos 828 , 2925. Arbuste, fl. blanchâtres. Novembre-décembre. C.

val. axgustifolia in Fl. Bras. XIII, I, p. 283. - Cillaça, Minas, $\mathrm{n}^{\circ}$ 12419. Arbuste, fl. jaunâtres. Septembre-octobre. C.

var. uatifolia Mart.; Fl. Brus. XIII, I, p. 283; C. declinala Vell. Fl. Flum., V, І. 111. - São Christurão, Rı-JAY., $n^{\circ}$ 10329. Arbuste, fl. blanc rosé. Février.

2... Cratævia Tapia L.; Fl. Bros. XIII, I, 1. 206'; Vell. Fl. Flum. V, t. 3. - Sìo Christovio, Rio-Jax., no 4752. Arbre, ll. blanc verdatre. Novembre-décembre. C.

\section{Fim. 11 : Violariées.}

1. Noisettia longifolia Huml. B. et K.; Fl. Bres. XIII, I, p. 3:i. - Floresta da Tijuca, Rı-Jav., $n^{03} 4167,20650$. Herbacé, fl. blanchàtres. Novembre-décembre. C.

2. Anchietea salntaris St-Hil.; Fl. Brus. XIII, I, p. 333. - Gavea, Tijuca, Copacabana, Rı-JAx., nos 66, 130, 3795, 3796, 3867 et 7518. Grande liane, 11. violettes. Aoùt-septembre. CC. Vulgo Cipo suma.

var. hilariana Eichl.; Fl. Bras. XIII, I, fp. 39\%. - Tijuca, Rio- 
1.-F.-M. GLAZIOL. - LISTE DES PLANTES DU BRESIL CEXTRAI. 21 JAx, $n^{\circ}$ 12428. Liane, fl. violettes. Août-septembre. CC. Vulgo Cijo Suma.

var. martana Eichl. in Fl. Bros. XIII, I, p. 3̈4. - Serra do Tingua, Rí-JAx., $\mathrm{n}^{\text {os }}$ 5733, 18856. Liane, fl. violettes. Aoùt-septembre. C. Vulgo Cijo Suma.

3. A. Selloana Cham. Schlt.; Fl. Bras. XIII, I, p. 3̈̈\%. - Itatiaia, Rio-Jax., no $3796 a$. Liane, 11. violettes. Juillet-aoùt. C. Vulgo Cipo suma.

4. Schweiggeria floribunda St-Hil.; Fl. Bras. Xll1, I, p. 3 ist. - Serra da Estrella et Serra da Bira, liı-JAN., $n^{0 s} 9351,10256,15828$, 18855. Arliuste, fl. blanc jaunâtre. Juin-juillet. CC.

Ӟ. Viola gracillima St-Hil. ; Fl. Bras. XIIl, I, p. 359. - Serra da Bocaina, Säo Patzo, $\mathbf{n}^{\circ} 8263 a$. Herhacé, fl. blanc pâle. Janvierfévrier. R.

6. I. subdimiata St-Hil.; Fl. Bras. XIII, 1, p. 360. - Itatiaia, dans la forêt, et à Serra dos Orgàos, Rio-Jax., nos 6085, 6472, 8263, 11788 pt 17500. Herbacé, fl. violet pàle. Octobre-décembre. C.

7. V. cerasifolia St-Hil.; Fl. Bras. XIII, I, p. 360. - Serra dos Orgĩos, Rio-Jax., nos 1138, 2490, 6471; Giandarela, Mıxas, no 14481. Herbacé, 11. violettes. Février-avril. CC.

8. Ionidium Ipecacuanha Vent.; Fl. Rrus. XIII, I, p. 363.Praia Grande, liı-Jax., $n^{\circ} 4755$; Arassuahy, Mısas, nos 10255, 12427. Herbaré, ft. blanches. Juin-juillet. C.

9. I. Poaya St-Hil.; Fl. Bras. XIIl, I, p. 36\%; - Serra dos Pyreneus, entre les rochers, Goraz, $n^{0}$ 20651. Herbacé, fl. blanches. Aoùtseptembre. C. Vulgo Paraya.

10. I. lanatum St-Hil.; Fl. Bras. XIII, I, p. 365. - Serra da Divisa ou do Libano, Goraz, $\mathrm{n}^{\circ}$ 20652; Biribiry, Misas, $n^{\circ}$ 18871. Herbaté, 11. blanc blenàtre. Juillet-septembre.

11. I. setigerum St-Hil.; Fl. Liras. XIII, 1, p. 367. - Serra dos Mrgìos, Rio-Jax., $n^{\text {os }} 8465,10254$. Frutescent, 11. jaunâtres. Mai-juin.

12. I. commune St-Hil.; Fl. Brers. XIII, 1, p. 369. - Caraça, dans les bois, Mixas, nos 10254 a, 13531. Frutescent, fl. blanc pôle. Marsavil. C.C.

13. I. Glaziovii Eichl.; n. sp. in lıerh. Berol., Kew., Paris., etc. Marianna, près Ouro, dans les bois humides, Misas, $n^{0} 12426$. Frutescent, fl. blanchitres. Janvier-mars. C. 
14. Ionidium bigibbosum St-Hil.; fil. Bras. XIII, 1, p. 371. Limeira, S. Pacloo, $1^{0} 12424$. Arbuste, fl. Hauc rosé. Arril-mai. (..

1:. Hybanthus (Ionidium) strigoides Taub. in Beilr. FIIrou C'enlrul A m., p. 44:. - Serra dos Pyreneus, dans le campo, Goraz, $11^{\prime \prime} 20651 a$. Frutestent, ll. lilas. Aoutt-septembre. C.

16. Amphirrox longifolia Spreng.: Fl. IBrus., XIII, I, 1\% 37\%. Serra da Estrella et au Corcovado, Rio-JaN., $11^{0.5} 118,6084,6474$. Arbuste, ll. blanches. Aoùt-septembre. C..

17. Paypayrola Glazioviana Taub. in Engl. Bol. Jahrb., p. Q2, N. 3't. - Entre Lagua do Peixe et Rio Bonito, Rio-Jax., n ${ }^{\circ}$ 12530. Arbuste, fl. jaunatres. Septembre-octobre. h.

18. Alsodeia physiphora Mart.; Fl. bras. Xlll, I, p. 382. - Corcovado, Floresta da Tijuca, Riı-Jax., $n^{05} 347,2962,3676$. Arbuste. I1. blanches. Mai-juillet. C.C.

19. A. castanecefolia Spreng.; Fl. Bres. XIII, I, p. 38ュ. - Corrovalo, Rino-JAN., $\mathbf{1}^{\text {os }} 747,4071,7519$. Arbrisseau, fl. jaune pâle. Décembre-janvier. C.

20. A. macrocarpa Mart. ill Fl. Brus. XIII, I, p. 38\%. - Quinta da lioa Vista, Ruo-Jan., nº 7519 a. Arbrisseau cultivé, fl. blanc jaunàtre. Octobre-novembre. $\mathrm{R}$.

21. A. falcata Nart. in F\%. Bros. XIII, I, p. 386. - Corcovado, à Paineiras, Rio-Jan., nº 6069. Arbuste, fl. jaunâtres. Février-mars.

22. A. guianensis Eichl. in Fl. Brus. XIII, 1, p. 387. - Campos, près de S. Fidelis, Riı-JAx., $\mathbf{n}^{0}$ 1086. Arbrisseau, fl. blanc jaunàtre. Décembrejanvier. R.

23. A. ramiziana Glaz.; n. sp. in herb. Berol., Kew., Paris., etc. - Campos, à ltaoci, lì-Jax., $n^{\circ}$ 12425. Arbuste, fl. blanchâtres. Avrilmai. C.

24. Leonia glycycarpa Ruiz. et Pav.; Fl. Bras. X111, I, p. 391. Quinta de Sĩo Christovio, Rı-Jar., no 9877. Arbuste cultivé, fl. blanchâtres. Fóvrier-mars. R.

9:. Sauvagesia racemosa St-Hil.; Fl. Brus. XllI, 1, 1. 406. - Barbacena, Minas, $n^{o s} 1275$, 10274, 15833; Mestre d'Armos, Goraz, $n^{0}$ 20646. Sous-firutescent, fl. rosées. CG.

26. S. Sprengelii St-Hil.; Fl. Bras. XIII, I, p. 407. - Cabo Frio, dans le bois, Rı-Jax., $1^{\circ}$ 10273. Frutescent, fl. blanc rosé. Juilletaoût. C.

27. S. erecta L.; Fl. Bras. XIII, 1, p. 408. - Jurujuba, Rio-Jan., 
1.-F.-M. GLAZIOC. - LISTE DES PLANTES DL BRESH CENTRAL. :3 $\mathrm{n}^{\text {os }}$ 739, 840, 2098, 2491, 6086; Arassuahy, Mrsas, nos 12435, 12436 ; liin Fama, Goraz, $n^{0}$ 20649. Sous-frutescent, f1. rosées. Juin-aout.

var. rebiginosa St-Hil. in F\% Bras. XIII, I, p. 409. - Rio Forto, Goraz, $n^{\circ}$ 20645; Caraça, Mrsas, $n^{\circ}$ 18875. Sous-frutescent, fl. blane rosé. Novembre.

28. S. linearifolia St-Hil.; F\%. Bras. NIII, I, 1. 411. - Diamantina, Yriss, no 18878; Cabeceiras lo Rio Gama, Gosaz, nos 20647, 20648. Sous-fíutesrent, fl. blane rosé. Octobre-norembre. Ca.

99. Lavardia glandulosa St-Hil.; H. Brus. XIII, I, p. 41̈̈. - Sìo Joĩo dEl Rei, Mras, no 15834; Diamantina, Mras, $n^{\circ}$ 18874. Sous-frutescent, fl. roses. Décembre-Janvier. C.

30. L. Telloziana Vand. : F\%. Bras. XIII. 1, p. 416. - Petropolis et Nova Friburgo, Rio-Jax., no 8265, 6478, 16699. Sous-frutescent, fl. rose pâle. retobre-décembre. C:

31. L. capillaris St-Hil.; \%l. Bras. XIII, I, p. 116. - Itacolumy et Serra do Funil, Mris, $n^{o s}$ 14496, 18877. Sous-frutescent, fl. roses. Février-avril. C.

32. L. ericoides St-Hil.; Fl. Bras. XIII, I, 1. 417. - Curaca, Misas, 11 14495. Sous-frutescent, f1. roses. Juin-juillet. C.

33. L. alpestris Mart. in Fl. Lirus. XIII, I, p. 148. - Serra dos Mangabeiras, Mrxas, no 20192. Sous-frutescent, fl. roses. Avril-mai. R.

34. L. spicata Glaz.; n. sp. in lierb. Berol., Kew., Paris. - Morru do São Vicente, Mrsas, $n^{\circ} 14496$ a. Sous-frutescent, 11. roses. Juin. juillet. R.

\section{Fam. 12: Canellacées.}

1. Cinnamodendron axillare Endl.; Fl. Bras. XIII, I, p. …3. Entre Caraga et Inficionado, Hıxas, no 14531. Arbuste touffu, 11. Irunes. C.

\section{Fam. 13 : Bixinées.}

1. Cochlospermum insigne St-Hil.; Fl. Bras. XIII, I, p. 429.Arassualıy, dans les bois, Mrsas, n 12423. Frand arbre, 11. jaunes. Juillet-anit. C.

var. polmana in Fl. Brols. XIII, I, 1) 430. - Santa Luzia, Mrist, n² 20190 : Serril da Iniviz, Goraz, n² 20654. Arhuste des campos et des cerrados, 11. james. Août-septembre. Vulgo Bulur. 
๑. Bixa Orellana L.; Fl. Brus. XIII, I, p. 483. - Rio-JaN ('nltiví), $u^{\circ}$ 5732. Arbrisseau, 11. roses. Arril-mai. Vulgo Lrucu.

3. Oncoba maynensis Eirhl. in Fl. Brers. XIII, I, p. 4'1. - Quintil São Christovin, Rı-Jax., ${ }^{0 s} 10073$, 10077. Arbrisseau cultivé, 17. blanchàtres. Janvier-février. Ri.

4. Carpotroche brasiliensis Endl.; Fl. Bras. XIII, I, 1. 4.36. Corcovado, Rin-JAN., $1^{0 s}$ 2479, 2480, 18854. Arlorissean, fl. blanclies odorantes. Janvier-février. Vulgo Supucainlur.

5. Lætia suaveolens Benth.; Fl. Bras. XIII, I, p. 4\%' - Entre Mendanha et Realengo, Riı-Jav., $n^{\circ} 11787$ ॥. Arbrisseau, fl. hlanılhâtres. Aoùt-septembre. li.

6. L. cupulata Spruce in Fl. Brus. XIII, I, p. 45\%. - Quinta da Boa Vista, Rı-JAx., nº 14477 u. Arbrisseau cultivé, fl. blanc jannàtre. Avril-mai. R.

\section{Fam. 14: Pillosporées.}

1. Pittosporum glabrum LindI. in Regel Journ. Hort. Soce. Imp., p. 230. - Petropolis, liı-JAx., ${ }^{\text {os }} 8315,14494$. Arbrisseau cultivó, fl. blanches. Janvier-février. C.

2. Xylosma Salzmanni Eichl. in Fl. Bras. XIII, I, p. 4'18. - Corcovado, Restinga da Tijuca, Rio-Jas., nos 217, 2964, 6467; Serra do Batatal, Mryas, $n^{\circ}$ 14477. Abrisseau, fl. rousses. Juillet-août. C.

3. X. ciliatifolia Eichl. in Fl. Bres. XIII, 1, p. 449. - Serra dos Orgàos, Rıo-Jax., nos 2895, 7512. Arbrisseau, fl. jaunes. Juillet-arût. C.

$$
\text { Fam. 15: Polygalées. }
$$

1. Polygala violoides St-Hil.; Fl. Bras. XIII, III, p. 5. - Nyteroi, à Praia Grande, Rio-JAN., no ${ }^{\circ}$ 9352. Frutescent, fl. violacées. Féviiermars. C.

2. P. ligustroides St-Hil. : Fl. Bras. XIII, III, p. 6. - Serra dos Orgãos, $n^{\circ s} 2883,3870,14486$. Arluuste, f1. violet pâle. Septemhreoctobre.

3. P. oleafolia St-Hil.; Fl. Brus. XIII, III, p. 7. - Quartel do Biribiry, Mrnas, $n^{\circ}$ 18869. Arbuste lilas. Mars-arril. C.

4. P. laureola St-Hil.; Fl. Bres. XIII, III, p. 7. - Curcovado, nos 732 , 2494; Tijuca, R10-Jan., $11^{\text {os }} 3869,5736$, Albuste, f1. violet pâle. Févriermars. R.

๖. P. spectabilis DC; Fl. Brus. XIII, III, D. 9. - Cabeceiras do 
1.-F.-H. GLAZIOU. - LISTE DES PLAYTLS DU BRESII, CENTRIL. 25 Riı Forto, Goraz, n² 20672. Frutescent, ll. lilas. Octobre-novembre. C.

6. P. grandifolia St-Hil.; Fl. Bres. XIII, III, p. 9. - Murundí, Rio-Jan., $n^{0}$ 4925. Sous-fiutescent, t1. violettes. Septembre-nctobre. Ri.

7. P. hebeclada DC; I7. Brus. XIII, III, p. 10. - Ititiaia, dans le campo, Rio-JAx., $1^{\circ} 6476 a$. Sous-firutescent, 11. rose violacé. Novemuledécembre. R.

S. P. rhodoptera Mart.; Fl. Bros. XIII, III, p. 11... Serra da Piedade, Mıss, no 20195. Sous-fiutescent, f1. violacées. Novembre. C.

9. P. Martiana Benn. in Fl. Bras. Xlll, III. p. 13. - Itapemirin, Esp. Saxto, $n^{\circ}$ 10264; Apialy, Irsas, $n^{\circ}$ 12433. Sous-frutescent. Il. blanc rosé. Octobre-novembre. C.

I0. P. subtilis Humb. B. et K.: Fl. Bros. XIII, III, p. 16. - Cabeceiras do Rin Gama, Goraz, $n^{\circ}$ 20664. Herbacé, 11. blanches. Arrilmai. C.

11. P. sulphurea Benn. in Fl. Brus. XIII, III, 1. 17. - Sitio de Barbacena, $n^{0} 10272$ et Cachoeira do Campo, Mrsas, n² 20194. Sous-fiutescent, f1. jaunâtres. Juin-juillet.

I2. P. tenuis DC; Fl. Bros. XIII, III, p. I8. - Itatiaia, Rio-JAx., $\mathrm{n}^{\text {os }} 6475,18861,20662$. Sous-frutescent, fl. blanc rosé. Janvier-février. C.

13. P. equisetoides St-Hil.; Fl. Bras. XIII, III, p. 19. - Cabeceiras do Rio Gama, Gosaz, $n^{\text {os }} 20660,20661$. Frutescent, fl. Hlanc rusé. Octubre-septembre. C.

14. P. cymorsurus Chod.; n. sp. in litt. - Serra dos Ciristaes, près du village d'Almocafre, Gosaz, nos 20658, 20659. Firutescent, f1. blanc rosé. Septembie. C.

1\%. P. Gardneriana Benn. in Fl. Bras. XIII, III, p. 19. - Itatiaia, dans le campo sec, Rio-Jax., no 6475. Frutescent, 11. violacres. Septembre-nctubre. R.

16. P. atropurpurea St-Hil.; Fl. Bras. XIII, Ill, p. 21. - Serra do Cipo, Mrsas, no 15831 a; Cabeceiras do Rio Gana, Goraz, n² 27661. Suusfrutescent, fl. pourpres. Octobre-novembre. C.

17. P. Pseudo-Erica St-Hil.; Fl. Bros. XIII, III, P. 23. - Fazenda do Macaco, Goraz, $n^{0}$ 20667. Sous-frutescent, 11. violettes. Ortubre. C:.

18. P. bryoides St-Hil.; Fl. Bras. XIII, III, p. 23 - Serra do Ouro Branco, Mrsas, $n^{0}$ 14491. Suus-frutescent, 11. blanches. Nurembredécembre. $\mathrm{C}$.

19. P. densifolia St-Ilil.; FT. Bras. XIII. III, 1. 24. - Perpenn,, 
près de Diamantina, Mrvas, nos $14489,18866,18867$. Sous-fiutescent, fl. roses. Avril-mai. C.

0. P. rigida St-IIil.; Fl. Bras. XIII, III, 1. ㄴ4. - Biribiry, pris de I)ianantina, Mixis, $11^{\text {os }} 18863,18864,18865$. Sous-fiutescent, ll. lolanches. Nars-avril. C.

21. P. Cyparissias St-Hil.; Fl. Brus. XIII, IHI, p. 2:.) - Copacabana, danıs te salıle, Rı-JAx., $1^{\text {os }} 1301$, 10268. Herbacé, ll. blanchâtres. Ilars-juin. CC:

22. P. stricta St-Hil.; Fl. Bres. XIII, III, 1). 266. - Sino Joino d'El Rei, Mixas, $n^{\circ}$ 16694. Sous-frutescent, f1. blanc verdatre. Octohre-norembre. C.

23. P. sedoides Benn. in Fl. Bras. XIII, III, p. 27. - Itapemirim, Esprutro Savto, $11^{\circ}$ 9628. Herbacé, fl. blanches. Janvier-février. C.

24. P. goyazensis Glaz.; 11. sp.? in herb. Berol., Kew.. Gen., Paris., etc. - Cabereiras do Rio Gama, Goyaz, n² 20665. Herbacé, fl. blanches. Avril-mai. R.

Q... P. galioides Poir.; Fl. Bras. XIII, III, p. 28. — Chapadão dos Veadeiros, Goraz, ${ }^{\circ}$ 20674. Herlacé, t1. blanc rosé. Janvier. C.

26. P. glochidiata Humb. B. et K.; Fl. Bras. XIII, III, p. 30. Itapemirim, Espinto-Santo, nos 9630, 10271; Nova Rriburgo, Rio-Jax., nº 12430; Sĩo João d'El liei, Vinas, n 16697. Herbacé, fl. blanches. Février-ayril. C.

27. P. paniculata L.; Fl. Bres. XIII, III, p. 31. - Rio-Janeiro, $n^{\text {os }} 112$, 10269; Nova Frilurgon $1^{\circ} 11790$; et Cabu Frio, Rio-Jax., $11^{\circ}$ 12432; Barbacena, Mlısas, $n^{\circ}$ 10270. Herbacé, fl. blanclıes. Juinoctobre. C.C.

28. P. Timoutou Aubl.; Fl. Bras. XIII, III, p. 31. - Barbacena, Uisas, $n^{\circ} 15830$; Serra dos Veadelios, Govaz, $n^{\circ s} 20669$, 20670. Herbacé, f1. blanchâtres. Juin-juillet. CC.

49. P. hygrophila Humb. B. et K.; Fl. Brets. XIII, III, p. 32.Diamantina, Mrxas, $n^{\circ} 18868$; Cachoeira do Campo, Nivas, no 20193. Herbacé, fl. rose jaunàtre. Décembre-février. C.

30. P. longicanlis Humb. B. et K.; Fl. Brets. XIII, III, p. 33. Itapemirim, Esprrito Santo, ${ }^{\text {os }}$ 9626, 10259 ; Serra do Lenheiro, Mrnas, $n^{\circ s}$ 16698, 17465; Itiquira, Govaz, $n^{\circ}$ 20673. Herbacé, fl. rose. Févrierarril. C.

31. P. adenophora DG; Fl. Bras. XIII, III, p. 33. - Campos, à Sĩo Fidelis, Rı-Jax., $1^{\circ}$ 9624. Herbacé, fl. roses. Janvier-février. R. 
A.-F.-M. GLAZIOU. - LISTE DLS PLANTES DL BRÉSIL CENTRAL. 27

32. P. variabilis Humb. L. et K.; Fl. Bras. AlII, III, p. 34. - Campus à Situ Fidelis, Rio-Jax., $\Perp^{\text {os }} 9625,9627$. Herbacé, fl. rose pâle. Janvierfévier. R.

33. P. gracilis IIumb. B. et K. : Fl. Bras. XIII, III, p. 3\%. - Biribiry, près de Diamantina, Mnas, $11^{\circ}$ 18862. Sous-fiutescent, fl. roses. Mars-avril. R.

3't. P. celosioides Nart. in Fl. Bras. XIII, III, p. 30̈. - Diamantina, à Furmario, Mnss, nos 18859 , 18860. Herbe, ll. blanches. Avil-Jlai. C.

3.i. P. Roubienna St-Hil.; Fl. Bias. XIII, III, 1). 37. - Nova Friburgo, Rio-Jan., no 16695. Herbe, H. blanches. Juillet-août. C..

36. P. appressa Bentlı.; Fl. Bras. XllI, HII, p. 39. - Boa Vista, Rio Parahılıa, Rio-Jax., n" 12431. Herbacé, fl. blane rosé. Juinjuillet. (C.

37. P. brasiliensis L. ; Fl. Bras. XIII, III, p. 39. - Haut de I'Itatiaia, Rio-Jax., $n^{05}$ 4758, 6477, 8568. Herbace, 11. Blanches. Juin-juillet. C.

38. P. angulata UC; Fl. Bras. XIII, III, p. 41. - Serra do Ourn Brancu. Mıxs, $n^{\circ}$ 14490; Ponte Alta, Goraz, n² 20676. Sous-frutescent, 11. violet pâle. Septembre-novembre. C.

39. P. Francheti Chodat; n. sp. in litt. - Prìs du Rio Parauana, dans le campo, Goraz, $n^{\circ}$ 20668. Frutescent, fl. blanc jaunâtre. Janvier-février. C.

40. P. ustulata Chodat; n. sp. in litt. - Serra do Lrbano el Canastrĩo, Goraz, nos 20666, 20667, 20677. Frutescent, H. blanches. Septembre. C.

4I. P. coriacea St-H.; Fl. Brus. XIII, III, p. 41. - Mol'ro dos Lage, pres de la ville de Goraz, $n^{\circ}$ 20668. Sous-frutescent. C. Vulgo Porya.

42. P. lancifolia St-Hil.; Fl. Birs. XIII, III, p. 42. - Campos do Itatiaia, Rio-Jav., $n^{\circ}$ 4934, 6476; Ayurnoca, Mtsas, no 15838. Sı!us-frutescent, ft. violacées. Janvier-février. C.

43. P. revoluta Gardn.; Fl. Bras. XIII, III, p. 44. - Sommet de la Serra dos Orgions, Rio-Jax., ${ }^{\text {os }} 4759$, 5734, 14448. Sous-frutescent, fl. roses. Juin-novembre. C..

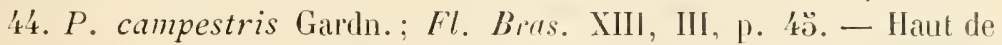
l'Itatiaia, liı-Jax., nº 3746 ; Sella dos Orgños, à Theresopolis, liı-Jax., $n^{\circ} 6117$. Herbe, fl. bleues. Hai-juillet. Ii.

4\%. Acanthocladus brasiliensis Klutz.: Fl. Bras. XIII, III, P. 46. - Campos da Bocaina, S $\tilde{A} 0$ Pavlo, nc 14493 (. Arbuste, fl. Mlanclies. septemlore. R. 
46. A. caraçænsis Glaz.; 11. sp.? in herl. Berol., Kew.. Paris., Gener., ele. - Entre Lulicionato et Carara, dans le campo, Mınas, $11^{0}$ 14493. Arbuste, 11. blanclıitres. Juin-juillet. C.

4. A. albicaus Benn. in Fl. ISros. XIII, III, P. 46. - Praia Grande, au Jor'o do Cavallin, Rio-Jax., n5820. Arbrisseau, fl. blanches. Aoùtseptembre. C.

48. Bredemeyera floribunda Willd.; Fl. Bras. NIII, III, p. 18. Corcovarlo, Tijuca, Rio-Jax., ${ }^{05}$ 853. 2493, 5738; entre Sitio et liarbacena, Mxas, $1^{\circ s}$ 10263, 12434, 13534. Arbuste, 1l. jaunâtres. Janviermars. Ci.

49. B. Martiana Bemn. in Fl. Bras. XIII, III, p. 49. - Diamantina, chemin d'Arassuahy, Mixas, $1^{\circ}$ 13535. Arbuste, fl. blanc jaunitre. Juilletaoùt. C.

:0. B. brevifolia Klotz.; Fl. Bras. XIII, III, p. 49. - Arassualiy et pris Diamantina, dans le campo, H1Nas, $n^{\circ s} 10265,3536,13537$. Arbuste, f1. rougeâtres. Janvier-mars. C.

¿̈l. B. laurifolia K'lıtz.; Fl. Bras. XIII, III, p. ̈̈2. - Serra dos Orgãos, Rio-Jax., nos 5737, 10262; Lambary, Goyaz, $1^{\circ} 20678$ a. Arbuste f1. rougeitres. Janvier-mar's, C.

:2. B. Kunthiana Klolz.; Fl. Bras. XIII, III, 1. 气3. - Jacarepagua, liro-JAx., nos 329 b, 2492. Arluuste, 11. rougeatres. Mars-avril. C.

i3. Securidaca volubilis L.; Fl. Bras. XIII, III, 1. 61. - Arassualıy, Msxas, nos 9620, 13538 ; Serra do Tingua, au lio d'Ouro, Rio-Jas., $n^{\circ}$ 11600. Sarmenteux, fl. lilas. Juillet-anùt. C.

var. Mollis in Fl. Bras. XIII, III, p. (j2) - Nova Friburgo, Rıo-Jan., $n^{\circ}$ 13405. Sarmenteux, fl. lilas. Novembre. C.

:34. S. lanceolata St-Hil.; Fl. Bras. XIII, III, p. 62. - Guaxindiba, Riı-Jan., nos 7853, 11789; Mendanha, près d'Arassuahy, Mısas, $n^{\circ} 13539$. Sarmenteux, fl. lilas. Octobre. C.

5.. S. acuminata St-Hil.; Fl, Brus. XIII, III, p. 62. - Serra da Estrella, Rio-Jax., no 10267. Sarmenteux, f1. lilas. Mars-avril. R.

506. S. oralifolia St-Hil.; Fl. Bras. XIII, III, p. 63. - S. Clu'istovĩo, Rio-Jan., ${ }^{0 s} 4756,9353,13096$. Sarmenteux, fll. lilas pâle. Septembrenovembre. C.C.

37. S. Sellowiana Klotz.; Fl. Bras. XIII, III, 1. 63. - Corcovado et Tijuca, Rio-JAx., $n^{\circ}$ s $834,2100,18873$. Sarmenteux, fl. Iilas. Novembre. CC.

58. S. pubescens DC.; Fl. Bras. XIII, III, p. 64. - Arassuahy, 
1.-F.-Y. GLAZIOC. - HSTE DES PLAXTES IO BIESIL CENTIII. 29 Misas, $0^{\text {os }}$ 10266, 14492. Sarmenteux, fl. lilas pâle. Arril-mai. C. ¿9. S. tomentosa St-Hil.: Fl. Bras. XIII, III, [1. 6't. - Colcovado, liı-Jax., nº 3871. Sarmentem, fl. Iilas. Décembre-janvier. C.

60. S. rivinafolia St-Hil.; val. p.rviforia in Fl. Bras. XIII, III, 1. (i.). - Serra da Mantiqueira, Msis, $n^{05} 9622$, 13533. Sarmenteux, f1. lilas. Janvier-février. R.

(i). S. bialata Benth.; Fl. Bras. XIII, İl, p. 6ti. - Serra da Mantiчqueira, Mwss, no 9621. Liane, fl. violettes. Janvier. Li.

62. S. Hostinanni Vir.; Fl. Bras. XII. III, p. (iS. - Restinga de Cabo Frio, Rio-Jax., n 13532. Arbuste sarmenteux, fl. lilas. Aoùt septembre. Ti.

63. Monnina insignis Bemn. in Fl. Bras. XIII, III. P. D6. -- Mul’undủ, pris de Gampos. Riı-Jax., nº 9623. Herbaré, fl. rose pâle. Janvier-février. R.

64. M. stenoply-lla st-Hil. : Fl. Bras. XIII, III, p. :37. - Serra do Lenlıeiro, Mıxas, $n^{0 .}$ 16693, 18872: Rio Gama, Goraz, $n^{0}$ 20655. Sousfiutescent, fl. violacées. Octobre. C.

63. M. Richardiana St-Hil.: Fl. Bras. XIII, III, 1. ̈̈s. - Serra de Lenheiro, près de S. Joĩo d'El Rei, Irsas, nº 16693 a. Sous-frutescent, 11. rose paile. Octolore. Ii.

66. M. exalata Benn. in Fl. Bitas. XII, III, p. .79. - Cabecen'a do Rio Gama, (royaz, $n^{\circ}$ 20656. Sous-frutescent, fl. grises. Octobre-norembre. R.

65. Krameria tomentosa St-Hil.; Fl. Bras. XIII, III, 1). 70. Fidalga, priss Cogonhas do Campo, Nixas, nos 9619, 10261. Arbuste touttu, f1. violacées. Mars-arril. C.

68. K. argentea I!art.; Fl. Bras. XIII, III, p. 7I. - Diamantina, dans le campo, Vixas, no 18870: Ponte Alta, Goraz, n²0657. Arbuste, 11. violacées. Loùt-octobre. CC.

(i). K. spartioides Berg.; Fl. Bras. XII, III, p. Z2. - Itapemirim, dans le campo, Espirito Saxto, ${ }^{\circ}$ 10260; Rio Descoberto, Goraz, n²0657a. Arluuste, fl. rougeâtres. Septembre-octolıre. R.

\section{Fan. I6 : Vochysiacées.}

1. Callisthene fasciculata Mart.: Fl. Bras. XIII. II, 1. 23. - Sì Fidelis. au bord dı Rio Parahyba, Rıo-JAx., nº 10741. Arbrisseau, fl. blanc jaunàtre. Mai-juin. R.

2. C. major Mart. : Fl. Bras. XIII, II, p. 24. - 1)ianantina, Mlss, 
$11^{\circ}$ 20297; Paracatí, Msas, $1^{\circ}$ 20682. Grand arbre, 11. blanc jaunatre. Anut-septembre. CC. Vulgo Itıpiemri, Tiribu.

9. C. mollissima Warm. in Fl. Bras. XIII, II, p. 26. - Bals de la Sorra dus Prreneos ot à Pichoa, Goyaz, no 20681. Arbrisscan, fl. Blanc jaunâtre. Aoùt-sejtembre. C.

4. C. mucronata Glaz. 1. sp. ? in herb. Berol., Kew., Paris., etc. - Borls du Rio Descoberto, Goxaz, no 20680. Arbrisseau, bl. blanches tries odorantes. Août-septembre. C.

¿. C. robusta Glaz. sp. n. ? in herb. Berol. Kiew., Paris.. etc. Rio das Pedras, au Valu, Mixas, n 19152; Parauana, Goraz, I $^{\circ} 20679$. Arbrisseau, fl. blane jaunâtre. Janvier-février. C.

6. Qualea retusa Spruce in Fl. Brus. XIII, II, p. 34. - Campus de Inficionado, Mrss, $n^{\circ}$ 13810. Arbre, fl. blanc jaunâtre. Septembre-octobre. R.

7. Q. elegans Tauh. n. sp. in litt. ined. - Biribiry, pries de Diamantina, Mısas, $n^{\circ}$ 19153. Arbrisseau, fl. blanc jaunâtre. Nars-avril. R.

8. Q. grandiflora Mart.: Fl. Brus. XIII, II, p. 41. - Ser'a do Lenlieiro, près de S. Joĩo d'El Rei, Mssas, nº 9794, 14696, 17112: Diamantina, Misas, $n^{\circ}$ 19154. Arbrisseau tortueux des cerrados, fl. blanc lilacé. Janviel-mars. CC.

var. nov. brevifolia Taub. in litt. inedit. - Serra de Ouro Pranco, Mrsas, $n^{0}$ 17611. Arbrisseau, fl. jaunes. Décembre. R.

9. Q. parviflora Mart.; Fl. Bres. XIII, II, p. 43. - Arassuahy, Mivas, $n^{\text {os }}$ 10738, 12662, 13808; Alto do Famandoa, près de S. Luzia, Misas, $n^{\circ s} 19150,20298$. Arbrisseau rabougri, 11 . violetles. Norembremars. C.C.

10. Q. multiflora Mart.; Fl. Bras. XIII, II, 1. 44. - Serra do Lenheiro, près de S. João d'El Rei, Mrsas, $n^{\circ}$ 17613. Arbrisseau, f1. blanches. Janvier-mars. C.

11. Q. pilosa Warm. in Fl. Bras. XIII, II, p. 45. - Diamantina, Mrnas, $n^{\circ} 19150$ a. Arbrisseau, fl. jaune pâle. Janvier-mars. R.

12. Q. Jundialy Warm. in Fl. Bras. XIII, II, p. 45. - Carhoceiras, $n^{\circ} 3956$ et Nova Friburgo, Rio-Jav., nº 19148. Grand arbre, fl. jaunatres. Mars-avril. VuIgo Louro-tinga.

13. Q. Lundii Warm. in Fl. Brus. XIII. II, p. 47. - Caraca, chemin d'Arassuahy, Mrnas, $n^{\circ}$ 14697. Arbre des cerrados, fl. blanclaatres. Décembre-janvier. C.

14. Q. dichotoma Warm. in Fl. Bras. XIII, II, p. 48. - Fazenda do 
A.-F.-M. GLAZIOL. - LISTE DES PLAYTES DU BRESIL GEYTRAL. 31

Rajarlinho, Goraz, 11 20685. Grand arbre. fl. blanc jaunâtre. Décembrejanvier. C. Vulgo Casıudo.

1\%. Q. glauca Warm. in FI. Brus. XIII, II, p. 49. -- Nova Friburgo, dans le bois vierge, hio-JAx. n ${ }^{0}$ 12664. Graud arbre, fl. blanc lilacé. Ortobre-novembre. C.

16. Q. densiflora Warm. in Fl. Rrus. XIII, II, p. С̈0. - Campos da Bocaino, São Pallo, nº $12664 a$. Arbre, fl. blanc jaunâtre. Norembredécembre. R.

17. Q. cordata Spreng.: Fl. Bros. XIII, II, p. :3. - Dianlantina, à Perpetua, Mixs. $1^{\text {os }} 12663,14695,19149$. Arlrisseau, fl. blanc jaunâtre. Décembre-arril. C.

18. Q. excelsa Glaz,; n. sp. ? in herb. Berol., Kew., Paris., etc. Rio Talona, dans le bois, Goraz, n 20686. Très grand arbre, fruit jaunâtre. Mai-juin. C. Vulğo Jacréé.

19. Q. minænsis Fraz.; n. sp. ? in herb. Kew., Berol., Paris., etc. - Valla Funda, Mrisa, nos 10740 , 19151. Arbre, fruit noir. Janvier-février. C.

20. Q. cryptantha Warm. in Fl. Bras. XII, II, p. :3. - Nla Macahé de Nova Friburgo, Rio-Jax., ${ }^{\text {os }}$ 16766, 19147. Grand arbre des bois vierges, fl. blanches.

21. Q. Glaziovii Warm. in Fl. Bras. XIlI, II, p. \%3. - Floresta da Tijuca, Rio-JAx. $n^{\circ 5}$ 2567, 2926, 3957, 6473. Arlnisseau, fl. blavc bleuitre. C.

22. Q. Gestasiana St.-Hil.; Fl. Bras. XIII, II, p. ̈̈4. - Chemin de Caxambú, à Petropolis. Rio-JAn., ${ }^{\text {os }}$ 9416, 10731. Bel et grand arbre, f1. jaunes. Octobre-novembre. C.

23. Erisma calcaratum Warm. in Fl. Bras. XIII, II, p. 111.Onuinta de Sĩo Christovãu, Rio-Jıx., no 13809. Arbre, fl. bleuâtres. Février-mars. Vient des Amazones par Riedel. R.

24. V. herbacea Pohl; Fl. Brus. XIII, II, p. 64. - Entre Cuba et Morrinhos, Goraz, no 20690. Arbuste de 1 mètre, fl. jaunes. Aoùt-septemble. C.

23. V. cinnamomea Pohl: Fl: Brus. XIII, II, p. 6.3. - Entre Ayuruoca et Caxambu, Mivas, no 15947. Arbrisseau des campos, fl. jaunes. Janvier-févier. C. Vulgo Pro doce.

26. V. rufa Mart.; Fl. Bras. XIII, II, p. 63. - Entre Corrego secco et Jequiliba, Mris, $n^{\circ}$ 19160. Arbrisseau des campos, f1. jaunes. C. Vulgo Pán doce. 


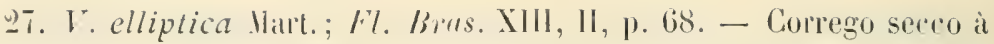
Jequitiba, dans le campo, Hivis, $11^{\circ}$ 19158. Arbrisseau, fl. jaunes. Ci. Mar'sarril.

28. Vochysia micrantla Polı\}; FI. Brus. XIII, II, p. 71. - Mossamedes, dans les bois et le rarastal, Goyaz, $11^{\circ} 20693$ " et b. Arbre avec fruit. Septembre-octolre. Vulgo P'áo mulatho.

29. V. emarginata Vahl, Fl. Bras. XIII, II, p. 80. - Morro do Inficionado, à Carara, لlısas, nos 14691, 14692; Serra do Sino Joño d'leI Rei, Mıxas, $n^{\circ}$ 16765; Biribiry, près de Diamantina. Mıxas, nº 19156. Grand arbre, fl. jaunes. Mars-juin. C.

30. V. bifalcata Warm. in Fl. Bras. XIII, II, p. 84. - Chenin de Nova Frilıurgo, à Cachoceira, Rı-JAx., $11^{\circ} 3952$. Grand arbre, fl. jaunes. Hars-arril. R.

31. V. magnifica Warm. in Fl. Bras. XIII, II, p. 83. - Serra dos Orgĩos, ¿̀ Quebra fraseo, lino-Jax., $11^{\text {os }} 11948$, 11949. Grand arbre, tl. jaunes. C. Vulgo l'áo Novo.

32. V. Glazioviana Warm. in Fl. Bras. XIII, II, p. 86. - Alto Ilacahé de Nova Friburgo, lio-JAx., n 3953 . Très grand arbre, fl. jaunes. Mars-avilil. R.

33. V. oppugnata Warul. in Fl. Brus. XIII, II, p. 87. - Corcovado et Tijuca, Rio-Jax., nos 671, 3954, 10763 ; Queluz, nº 14694, et São João d'EJ Rei, Mixas, $1^{\circ}$ 16762. Grand arbre, fl. jaunes. Octobre-décembre. CG. Vulgo Rabo de arara.

3'4. V. thyrsoidea Pohl; Fl. Bras. XIII, II, p. 88. - Serra do Batatal, près de Caraça, $\mathbf{n}^{\text {os }}$ 1265, 10736, 20299: et Arassuahy, Minas, ${ }_{11}^{\text {os }}$ 13806, 14693; Entre Sobradinho et Sagoa do Mestre d'Arinas, Goraz, 11" 20692. Grand antre, fl. jaunes. Octobre-décembre. CG. Vulgo Páo de Vinho, Gommeira, Gomma arabiea.

33. I. fucanor un Mart.; Fl. Brus. XIII, II, p. 89. - Serra da Bocaina, São Paulo, $\mathbf{n}^{\circ}$ 8336; Ayurnoca, $\mathbf{n}^{\circ} 15946$ et Serra de Caraça, Mrxas, $n^{\circ}$ 12666; Nova Friburgo, Rio-Jax., $n^{\circ}$ 16764. Arbrisseau, fl. jaunes. Décenbre-février. Cli. Vulgo C'ongonha de bougre, Vimheiro, P'á dore.

3i. V. ferruginea Mart.; Fl. Brus. XIII, II, p. 92. - Quinta de Sĩo Clinistovio, ho-Jax., $11^{\circ} 8671$ a. Grand arbre cultivé, fl. jaunes. R.

37. V. pyranidalis Mart.; Fl. Bras. XIII, II, p. 92. - Abbade, près de lleia Ponte, Goraz, $n^{\circ}$ 20693. Grand arbre, bon bois de construction. C. Vulgo Joá. Septembre-octobre.

38. V. tomentosa DC.; Fl. Liras. XIII, II, p. 94. - Retiro, prìs de 
Petropolis et Cantagallo, Rio-Jas., $1^{\text {os }} 8671$, 10737. Grandarbre, 11. jaunes. Décembre-janvier. R.

39. V. dasyantha Warm. iı Fl. Bras. XIII, II, p. 9\%. - Alto Nacahé de Nova Friluurgo, Rio-Jav., nº 20296. Grand arbre, f1. jaunes. Octobreseptembre. R.

40. V. rectiflora Warm. in Fl. Bras. XIII, II, p. 96. - Alto Nacahé de Nova Friburgo, Rio-JAx., ${ }^{\circ}$ 13434. Grand arbre, fl. jaunes. Novembre. C.

价. V. laurifolia Warm. in F\%. Bras. XIII, II, p. 96. - Corcovado et Tijuca, $\mathrm{II}^{\text {ss }} 672,3950,3951,6141$ et Serra dos Orgãos, Rio-Jay., $n^{\circ s} 8672,6873,10735$. Grand arbre, fl. jaunes. Novembre-décembre. CG. Vulgo Canella murici et Canella Santa.

42. V. quadrangulata Warm. in Fl. Bras. XIII, II, p. 97. - Serra dos Orgios au Ilundemo, Rro-Jan., n 10734. Grand arbre, fl. jaunes. Novembre-lécembre. C. Vulgo Canella ruiva.

43. V. Schwackeana Warm.; n. sp. in herb. Kew., Havn., Brux., Paris., etc. - Serra dos Orgãos, à Theresopolis, Rı-Jas., no 6872. Graud arbre, fl. jaunes. Février-mars. C. Vulgo Canella Santa.

'́' V. Saldanhana Warm.; n. sp. in herb. Berol., Havn., Paris., etc. - Serra Estrella et Alto Macahé, Rio-Jax., nos 6875. 7608. Grand arbre, fl jaunes. Janvier-février. C. Vulgo Canella Santa.

佮. V. spathulata Warm.; n. sp. in herb. Berol., Kew., Harn., Paris., etc. - Nova Friburgo, au Alto, Rio-JAx., n 6876. Grand arbre, 11. jaunes. Janvier-février. C. Vulgo Canella Santa.

ifi. V. Warmingiana Taub.; n. sp. in herb. Berol., Kew., Brux., Harn., etc. - Serra do Cipo, dans le campo, Msas, n 19159. Plante naine, fi. jaunes. Mar's-arril. C.

47. V. Nettoana Taub.; n. sp. in herb. Berol., Havn., Kew., Paris., etc. - Biribiry, près Diamantina dans le campo, Mısas, nº 19157. l'etite plante, fl. jaunes. Mars-avril. C.

4s. V. alternifolia Glaz.; n. sp. ? in herb. Berol. Kew., Paris., Genev., etc. - Serra dos Pyreneos, dans le campo, Goraz, $n^{\text {os }} 20688$, 20689. Plante naine, fl. jaunes. Juillet-anùt. C.

49. Salvertia convallariodora St-Hil.; Fl. Bras. XIII, II, p. 10:3. - Corrego secco, Mivas, no ${ }^{19155}$. Arbrisseau des canipos, fl. llanc rosé. Mars-avril. CC. Vulgo Coller de varueiro.

50. Trigonia minutiflora Glaz.; n. sp. in herb. Kew., Brux., Paris., Petrop., etc. - Restinga de Copacabana, Rıo-Jan., n 833. Arluste sarmenteux, f1. blanchâtres. Février-mars. C. 
B1. T. crotonoides Camb.; Fl. Brus. XIII, II, p. 127. - Restinga de Copacalona, Rio-Jan., $n^{\text {os }} 2114,3881,9417$; Arassualıy, Minas, $11^{\circ 5} 13480,13811,14689$. Arluste, 11. blanches. Janvier-juillet. CG.

52. T. Glazioviana Warm. in F\%. Brus. XIll, II, 1. 129. - Corcovalo et Tijuca, Rı-Jas., $n^{\text {os }} 733,2506,3670,10729,12499$; Nendanha, près de Caraça, Mıvas, $1^{\circ}$ 14688. Arbuste un peu sarmenteux, 11. Hlanches. Décembre-avril. GC.

33. T. Spruceana Benth. in Fl. Bras. XIII, II, p. 130. - Quinta de Sĩo Cihristovão, Riı-Jax., $n^{\circ} 14688 a$. Arbuste sarmenteux, cultivé, f1. blanchâtres. Mars-avril. R.

כૅ4. T. paniculata Warm. in Fl. Bras. XIII, II, p. 132. - Corcovado, $n^{0 s}$ 2938, 3882, 6485 et Petropolis, à Santo Antonio, Rio-Jan., $n^{0} 5783$. Arbuste, fl. blanchâtres. Mar's-avril. CC.

55. T. Schottiana Warm. in Fl. Bras. XIII, II, p. 133. - Serra da Estrella, Rio-JAv., $1^{0}$ 10728. Arbuste sarmenteux, 11. blanc jaunâtre. Mai-juin. C.

56. T. nivea Camb.; Fl. Bras. XIII, II, p. 134. - Serra do Pieú, au Paulo, Rio-JaN., $\mathbf{n}^{\circ}$ 10730. Arbuste sarmenteux, 11. blanc jaunâtre. Février-mars. C.

57. T. mollis Mart.; Fl. Bras. XIII, II, p. 136. - S. Clıristovĩo, près de Rio-Jan., $1^{\text {os }} 1337,2939$. Arbuste sirmenteux, fl. blanches. Juin-juillet. R.

58. T. candida Warm. in Fl. Bras. XIII, II, p. 139. - Corrovado, a Paineiras, Rio-JAx., $\mathrm{n}^{\text {os }}$ 2505, 8670. Arbuste sarmenteux, f1. blanc jaunâtre. Février-mar's. C. Vulgo Cipo P'áo.

59. T. ovalifolia Glaz.; n. sp. ? in herb. Berol., Kew., Havn., Paris., etc. - Eutre Capanema et Caraça, dans le campo, Misas, no 14690. Arbuste sarmenteux, fl. blanchıitres. Janvier-février. C.

\section{Fam. 17 : Caryophyllées.}

1. Silene gallica L.; Fl. Bras. XIV, II, 290. - Petropolis, dans les chemins, hio-Jan., no 7520. Herbacé, 11. blanchâtres. Novembredécembre.

4. S. Armeria L.; Fl. Bras. XIV, II, p, 291. - S. Christovão, dans les champs cultivés, Rı-Jav., $\mathrm{n}^{\circ}$ 6821. Herbacé, 11. roses. Septembre-octobre. C.

3. Cerastium Commersonianum Ser.; Fl. Bras. XIV, II, p. 281. - Itatiaia, au Morro Grande, Rio-J $\mathrm{JN}_{\mathrm{N}}$, $\mathrm{n}^{\circ} 8569$ a. Herbacé, ll. blanches. Juillet-août. G. 
A.-F.-M. GLAZIOU. — LISTE IDS PLANTES DU BRESIL, CENTRAL. 35

4. C. inlgatum L. ; Fl. Brus. XIV, II, p. 284. - Itatiaia, dans le campo, Rio-Jan., nº 8569. Herbacé, fl. blanches. Novembre. C.

כ. Stellaria media Vill.; Fl. Brus. XIV, II, p. 276. - S. Christovĩo, au bord de la mer", Rio-Jas., nº 5740 a. Herbacé, fl. blanc pâle. Aoùt-septembre. C.

6. Spergularia arvensis L.; Fl. Bras. XIV, II, p. 263. - Itatiaia, dins le campo, Rio-JAx., nº 4930 u. Herbacé, 11. blanchâtres. Juin-juillet. C.

7. S. villosa Caml. ; Fl. Bras. XIV, II, p. 268. - Campos da Bocaina, Sĩo Paulo, $1^{\circ}$ 19401. Herbacé, f1. blanches. Novembre. G.

8. Drymaria cordata Willd.; Fl. Brus. XIV, II, p. 259. - S. Christovio, daus les sables, Rı-Jas., $n^{\circ}$ 5740. Herbacé, f1. blanc jaunâtre. Juin-juillet. C.

9. Polycarpon tetraphyllum L. ; Fl. Bras. XIV, II, p. 2066. - Cor-

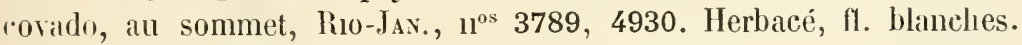
Septembre-octobre. C.

10. Polycarpæa corymbosı Lamk; Fl. Bras. XIV, II, p. 25'4. Sommet de la Serra dos Orgãos, Rı-Jan., no $3789 a$; Pinheiro, près Jiamantina, Mrvas, $\mathrm{n}^{\circ}$ 19397. Herbacé, fl. blanches. Novembre. C.

\section{Fam. 18 : Portulacées.}

1. Portulaca oleracea L. : Fl. Bras. XIV, II, p. 299. - Quinta de S. Christovão, Rı-JAx., $11^{\circ}$ 6076. Herbacé, fl. verdàtres. Octobre-novembre. CG. Vulgo Beldroegu.

2. P. mucronata Link.; Fl. Bras. XIV, II, p. 300. - Maxambomba, dans les sables, Rı-JAx., nº 8723. Herbacé, fl. roses. Octobrenovembre. C.

3. P. pilosa I.; Fl. Bras. XIV, II, p. 303. - Maxambomba, dans les sables, Rio-Jan., nº 8722; Nutuca, près de Diamantina, Mısas, nº 14858. Herbacé, fl. rosées. CG.

4. Talinum patens Willd.; Fl. Bras. XIV, II, p. 296. - Quiuta de S. Cluristovio, Rio-Jax., $11^{\circ}$ 3995. Herbacé, fl. rose pâle. Févriermars. C.C.

:. T. racenosum Rohrb. form. flor. roseis in Fil. Bras. XIV, II, p. 297. - Campos, au Collegio, Rro-Jax., $n^{0} 12430$ «. Herbacé, fl. roses. Janvier-février. C.

Fam. 1!) : Elatinées.

1. Elatine Lindbergii Rolub. in Fl. Brus. XIV, II, p. 321. - Dia- 
mantina, an hord de la rivicre, Ilsas, $n^{\circ} 14858$ ". Herbacé, fl. rose pâle. R.

Fam. „0: Hypéricincés.

1. Hypericum mutilum L.; Fl. Bras. XII, I, p. 186. - Itatiaia, dans le campo, Rı-Jax., $11^{\circ} 8284$. Sous-frutescent, 11. james. Novembredécenbre. C.

2. H. myrianthum Cham. et Schl. ; Fl. Bros. XII, I, p. 187. - Entre Bandeirinha et As Dattas, Misas, $n^{\circ}$ 18912. Sous-frutescent, Il. jaunes. Avril-mai. C.

3. H. Pelleterianum St-Hil.; Fl. Bras. XII, I, p. 187. - Congonhas do Campo, Mwas, $11^{\circ} 11803$. Sous-frutescent, fl. jaunes. Décembrejanvier. C.

4. H. rigidum St-Hil.: Fl. Bras. XII, I, p. 189. - Rodrigo Silva on Capro, près Ouro Preto, MIsas, $n^{0} 18913$. Frutescent, fl. jaunes. Maijuin. C.

5. H. denudatum St-Ilil. in Fl. Brus. Merid. 1, p. 338. - Fazenda do hio Preto et à llogg das Cruzes, São Pavto, $11^{\circ} 8575$, 17476. Sousfrutescent, fl. jaunes. Novembre-décent)re. R.

6. H. cordiforme St-llil.: Fl. liras. XII, I, p. 190. - Ipanema, Sa PaUlo, nos 10396, 15858; Serta do Capanema, Misas, ${ }^{\circ} 14534$. Sous-frutescent, 11. jaunes. Hars-juin. C.

7. H. brasiliense Choisy; Fl. Brus. XII, I, p. 193. - Serra dos Orgains, $11^{\circ 5} 3745,10397$ et Itatiaia, daus le campo, Ro-JAx., $11^{\circ s} 4761$, 4762. Sous-frutescent, 11. jaunes. Mai-juin. CG.

8. H. rufescens Klotz. in Fl. lirus. XII, I, p. 194. - Près d'Ipanemil, Sĩo Paulo, $n^{0}$ 15854. Sous-frutescent, fl. jaunes. Mars. R.

9. Vismia micrantha Mart.; Fl. Bres. XII, I, p. 197. - Caraça, Mrsas, nos 14532,1532 . Arbuste, fl. blanc jaunttre. Février-Mars. C.

10. V. brasiliensis Choisy; var. \% hasiantha in Fl. Bras. XII, I, p. 198. - Cachoceira lo Campo, Mıss, no 20216. Arbuste, fl. blanc jaunàtre. Décembre-janvier. C.

11. V. cayentuensis Pers.; Fl. Brus. XII, I, p. 199. - Cabo Frio, Rio-JAx., $10^{\circ}$ 9659. Arbuste, Il. blanc jannàtre. C.

12. V. guianensis Choisy; Fl. Bras. XII, İ, p. 202. - Mossamedes, près de Ouro Preto, Mivas, $n^{0} 20216$ u. Arbuste, fl. jaunàtres. Décembre. R.

13. V. magnolice folia Cham. et Schl.; Fl. Bras. XII, I, p. 203. - 
1.-F.-y. GLAZIOU. - LISTE IDES PLATTES DU BRESIL CENTRAL. 37

Seriia da Estrella et de Nova Friburgo, liı-Jax., nos 2946, 11804 . Arbuste, f1. gris jaunàtre. Novembre-décembre. C.

14. I. Martiana Reich. in Fl. Bras. XII, I, p. 204. - Nora Friburgo, Rio-JAx., nos 12463, 13572. Arhuste, fl. gris jaunâtre. Décembre. C.

1\%. V. decipiens Cham. et Schl.; Fl. Bras. XII, I, p. 20\%. - Cabo Frio et Maui, Rio-Jax., nos 7524, 9660, 9661, 10341; Ouro Preto, Mnss, n² 20215. Arbuste, 11. jaunàtres. Norembre-décembre. C.

16. V. Glaziovii Rouhl. : n. sp. in herb. Berul., Kew., Paris., etc. - Riacho Fundo, pres Jaragua et au Rio Areias, Gostz, $11^{05} 20694$, 20695. Arbuste des bois, fl. blanc jaunâtre. Aoùt-septembre. C.

17. V. japurensis Reicls. in Fl. Bras. Xll, I, p. 209. - Caraça, dans le campo, Mrsas, $n^{\circ}$ 13571. Arbuste, fl. jaunàtres. Septembre. R.

\section{Fan. 니 : Guttifères.}

1. Clusia fragrans Garlı.; Fl. Bros. XII, I, p. 404. - Petropolis, sur les roches liumides, Rı-J.x., nos 7528. 10344. Arbrisseau, fl. blanches. Mars-avril. C.

2. C. parviflora Engl. in Fl. Bras. XII, I, p. 406. - Corcovado, sur les roclies, $n^{0 s}$ 2503, 15863; et Campo Bello, Rio-Jax., II $^{0} 6483$. Arbrisseau, 11. blanches. C.

3. C. Criuva Camb.; Fl. Brus. XII, I, p. 407. - Copacabana et Pico Santa Cruz, Rio-Jax., nos 6852, 17478; São João d'El Rei, Mıss, $n^{\circ} 15862$; Rasgĩo, Goraz, $n^{\circ}$ 20696. Arbrisseau, ft. blanches. Novembredécembre. CG. Vulgo Piri.

4. C. Ildefonsiana A. Rich.; Fl. Bras. XII, I, p. 408. - Gavea près des rochers, $n^{\text {os }} 6860,10345$; et Alto Macahé, Rro-JAx., $n^{\text {os }} 13577$, 16716. Arbrisseau, fl. blanclies. Novembre-décembre. C. Vulgo Pirá.

๑. C. Riedeliana Engl. in Fl. Bras. XII, I, p. 410. - Serra do Funil, près des rivières, Misas, $n^{\circ} 18915 a$. Arbrisseau, 11. blanclies. Mars-avril. R.

6. C. Arrudea Planch. et Tr.: Fl. Bras. XII, I, p. 4I: - Serra da Estrella, Rio-JAx., nº 8576; São João d'El Rei, no 14535, 15861: et Ouro Preto, Msis, $n^{\circ}$ 14336. Arbrisseau, fl. blanches. Décembrefévier. C.

7. C. lanceolata Camb.; Fl. Bras. XII, I, p. 418. - Corcovado, Rio-JAx., $n^{\text {os }} 1300,8281,15860$. Arbuste, t1. rouge foncé. Mars-avril. C.

8. C. insignis Mart.; Fl. Bras. XII, I, p. 423. - Quinta de Såo Christorào, Rı-Jax., no 9663. Arbuste cultivé, 11. roses. Juin-juillet. R. 
MÉMOIRE 3.

9. Clusia palmicida L.-G. Rich.; Fl. Bras. XII, I, p. 䛱. var. parvirolia Ver(f. - Itabapoana, Rio-Jax., ${ }^{03}$ 10402, 10403. Irlorissealu, fl. blanches. Juillet. R.

10. C. organensis Planch. et Tr.; Fl. Bras. XIl, l, P. 428. Petropolis, Serra da Estrella, Tijuca, Serral dos Orgĩos, Rio-Jan., $n^{\text {os }} 897,1299,8280$ et 17482 . Arbuste, 11. blanc jaunâtre. Septembreoctobre. CG.

11. C. fluminensis Triana et Pl.; Fl. Bras. XII, I, p. 428. - Copacabana, dans le sable, Rio-JAx., $\mathrm{n}^{\circ \mathrm{s}} 10400,17479,17480$. Arbrisseau, f1. blanches. Octobre-novembre. C.

12. C. Spruceana Planch. et Tr.; Fl. Birus. XIl, I, p. 430. - Serra de São José d’El Rei, Mınas, nº 17477. Arbrisseau, R. blanches. Janvierfévrier. R.

13. C. Planchoniana Engl. in Fl. Bras. XII, I, p. 431. - Serra dos Orgãos, à Theresopolis, Rı-JAx., n ${ }^{0} 1299$ a. Arbrisseau, 11. blanc rougeâtre. Janvier-février. R.

14. Tovomitopsis paniculata Planclı. et Tr.; Fl. Bras. XII, I, p. 456. - Serra da Estrella, Rro-JaN., $\mathrm{n}^{\text {os }}$ 7529, 12466. Arbuste, fl. verdâtres. Mars-mai. C.

15. T. Saldanha Engl. in Fl. Bras. XII, 1, p. 487. - Petropolis, au sommet du Morro da Carrangola et à Nova Eriburgo, lito-Jas., ${ }^{\text {os }}$ 13404, 13576, 15864 a. Arbuste, 11. rougeâtres. Novembre-rlécembre. C.

16. Tovomita brasiliensis Walp.; Fl. Bras. XII, I, p. 443. - São Fidelis, près Campos, dans le bois, Rio-J $\mathrm{J}_{\mathrm{A}}$., $\mathrm{n}^{\circ}$ 9904. Arbuste, fl. blanches. Février-mars. C.

17. T. amazonica Walp.; Fl. Bras. XII, I, p. 444. - Restinga de Cabo Frio, Rio-JAx., no 10398. Arbrisseau, 11. blanchàtres. Juinjuillet. R.

18. T. brevistaminea Engl.? in Fl. Bras. XII, I, p. 446. - Serra do Alto Macalıé, dans la forèt vierge, Rio-JAN., nº 16714. Arbuste, fl. verdâtres. Février-mars. C.

19. T. Glazioviana Engl. in Fl. Bras. XII, I, p. 440. - Serra dos Orgãos, Rı-J $\mathrm{J}_{\Lambda \mathrm{N}}, \mathrm{I}^{\text {os }} 13409,13578,14537,16715$. Arbuste, 11 . jaunâtres. Novembre-janvier. C.

20. T. leucantha Planch. et Tr.; Fl. Bras. XII, I, p. 4.)1. - Floresta da Tijuca, ${ }^{\text {os }}$ 6099, 6851; Corcovado, Rio-JAN., $n^{\text {os }} 8279,15864$. Arbuste, fl. verdâtres. Novembre-décembre. CC.

21. T. pyrifolia Planch. et Tr.; Fl. Bras. XII, I, p. 4̌̈4. - Pro- 
montoire de Cabo Frio, Rı-JAx., no 13572 (. . Arluste, 11. jaunâtres. Septembre-octobre. R.

22. Symphonia globulifera L. fil.; Fl. Bras. XII, I, P. 469.Quinta da São Christovão, Rio-JAx., nos 9631,10404 . Arbrisseau cultivé, 11. rougeâtres. Février-mars. R. Vulgo Urunari.

23. Platonia insignis Mart.; Fl. Bras. XII, I, p. 468. - Gavea, ì Tras-Vendas, Rro-Jax., nos 5748, 9664. Arbre fruitier, cultivé, f1. blanc rosé. Décembre-janvier. R. Vulgo Bacuri.

2't. Rheedia macrophylla Planch. et Tr.; Fl. Bras. XII, 1, p. 460. - Quinto de São Christovão, Riı-JaN., ${ }^{\text {os }} 7526,15858$. Arhre fruitier, cultivé, f1. jaune pâle. Février-mars. C. Vulgo Bacupari.

2). R. brasiliensis Planch. et Tr.; Fl. Brus. XlI, I, p. 461. - Restinga de Copacabana, de Mauá et Quinta da lioa Vista, Rı-JAx., n ${ }^{\text {os }} 57$, 4972, 8282, 15856 et 18154. Arbrisseau sauvage et cultivé, fl. jaunâtres. Novembre-décembre. CG. Vulgo Abricó, Bucupari, Limão do matto.

26. R. calyptrata Planch. et Tr.; Fl. Bras. XII, I, p. 462. - Alto Macahé de Nova Friburgo et Serra dos Orgãos, au Frade, Riı-Jan., $n^{\text {s }} 15157$, 18155, 18914. Arbrisseau, fl. blanc jaunâtre. Novembredécembre. C.

27. R. Gardneriana Planch. et Tr.; Fl. Bras. XII, I, P. 462.Corcovado et Tijuca, Rio-Jax., $n^{\text {os }} 3668$, 10399, 15857. Arbrisseau, 11. blanchâtres. Septembre. C. Vulgo Bacuri domato.

var. glaziovin Engl.; Fl. Bras. XII, I, p. 463. - Floresta da Tijuca et Taipu, Rı-Jax., nos 5749, 7527, 13579. Arbrisseau, fl. jaune verdâtre. Aoùt-septembre. C. Vulgo Bacuri, Bacupary.

28. R. floribunda Planch. et Tr.; Fl. Bras. XII, I, p. 464. - Itaboralıy, liı-Jax., no 8283. Arbrisseau, fl. blanc verdâtre. Aoùt-septembre. R.

29. Calophyllum pachyphyllum Planch. et Tr.; Fl. Bras. XII, I, p. 397. - Congonhas do Campo, Mrsas, no 13580 ; Cachoceira do Rasgão, Goraz, no 20844. Grand arbre, f1. blanchâtres, bon bois de construction. Aont-septembre. C. Vulgo Landi.

30. C. brasiliense Camb.; Fl. Bras. XII, I, p. 398. - Sĩo Jnio d'El Rei, Mısas, nos 16717, 14541. Arbre, fl. blanches. Mai-juillet. C. Vulgo Landi.

Val. elongatum Engl. in Fl. Bras. XII, I, p. 399. - Rio Manso, IIxas, $n^{\circ}$ 13575; Langa Feia, près de Formosa, Goraz, n² 20844a. Bel arbre, tl. blanches. Décembre. C. Vulgo Landi.

31. Mammea americana L., Fl. Bras. XII, I, p. 39\%. - Quinta de 
São Christovio, Ro-Jax., $n^{0}$ 7525. Grand arbre cultive, 11. blanches. Dérenbre-janvier. C. Vulgo Abricen do P'arir.

3. Quiina Gla;iovii Engl. Fl. Bres. XII, I, p. 482. - Corcovado et Tijuca, Rio-Jax., $11^{08} 894,2611,6197$. Arbre énorme, fl. blinc jaulnatre. Octobre-novembre. C. Vulgo Andamen branro.

33. Q. sessilis Choisy in Fl. Bias. XII, I, p. 484. - Cabo Frio, liıJar., $n^{0}$ 9881. Grand arbre. Septembre-ortobre li.

34. Q. decastyla Radelk. in herb. Schwack. et Berol. - Serra da Babylonia, Jisas, $n^{\circ}$ 18915. Grand arbre, fl. blanchâtres. Ortobrenovembie. Vulgo $L_{\text {aca. }}$

3i. Q. Magalhano-Gomesii Schw. in Plantas Novas Min., fasc. 1, p. 6. - Serra dos Orgãos, à Tabuilıas, Rio-JAx., no 14891. Arbrisseau, f1. blanchâtres. Septembre-octobre. R. Vulgo Andaco braneo.

36. Q. Iucida Glaz. 11. sp.? in herb. Petrop., Havn., Gener., ete. Petropolis, au Retiro, Rio-JAx., nº $894 a$. Grand arbre a beau bois, sans fleurs. Vulgo Andaco.

\section{Fam. 2르: Ternstromiacées}

I. Caryocar glabrum Pers.; Fl. Bras. XII, I, P. 348. - Restinga de Cabo Frio, liı-JAN., $n^{0}$ 9697. Arhre, fl. jaune verdâtre. Janvierfévrier. R.

2. C. crenatum Wittm. in Fl. Brus. XII, I, p. 3ïl. - Près de Cachoceira, Rı-Jax., $n^{\circ}$ 3895. Grand arbre, ft. jaune pàle. Févriermars. R.

3. C. brasiliense Camb.; Fl. Bras. XII, I, p. 383. - Sta Luzia do liio das Velhas, Mrsas, $n^{03} 14573,20234$. Petit arbre, f1. jaunâtres. Novembre-décembre. CG. Vulgo Piqui.

4. Marcgravia polyantha Delp.; Fl. Bras. XII, I, p. 224. Tijuca, sur les rochers, Rio-Jax., nos 2703, 7530; Ouro Preto, Mrsas, no 20217. Sarmenteux, fl. pourpre verdâtre. Octobre-décembre. C.

Э. M. myriostigma Triana et Pl.; Fl. Bras. XII, I, p. 224. - Gavea, sur les rochers, Rio-Jax., $n^{\circ}$ 2504. Sarmenteux, fl. verdatres. Mai. R.

6. M. neurophylla Gilg, in Engler Botan.Jahrb. (1898), p. 23. Carandahy, entre les rochers, Minas, $n^{0}$ 13581. Liane, fl. brun verdattre. Juin-juillet. C.

7. Norantea cuneifolia Delp.; Fl. Bras. XII, I, p. 237. - Pedra do Cunto, près de Petropolis, Rio-JAN., nos 2937, 14540. Arbuste sarmenteux, fl, verdâtres. Mar's-mai. R. 
A.-F,-M. GLAZIOU. LISTE DES PLANTES DU BRESIL CENTIAL.

8. N. adamantium Camb.; Fl. Bras. XII, I, 1. 238. - Pinheiro, près de Diamantina, Mrsas, $n^{\circ}$ 18916; Abbadia, sur les rorhers, Goraz, $n^{0}$ 20698. Arbuste sarmenteux, fl. noirätres. Septembre-octobre. Vulgo Parpiru du Pedro.

9. N. goyazensis Camb.; Fl. Bras. XIl, I, p. 244. - Morro das Lagas, près de la ville de Goraz, $n^{\circ} 20697$. Arbrisseau, fl. pourpre foncé. Juillet-septembre. C.

10. N. brasiliensis Choisy: Fl. Bras. XII, I, p. 24:3. - Restinga de Copalcabana, Rio-Jax., $\mathrm{n}^{\text {os }}$ 1356, 3879. Arbuste, fl. pourpre foncé. Février-mars. CG.

II. Ruyschia platyadenia Gilg. in herb. Berol., Kew., Gener., Paris., etc. - Petropolis, aux bords du Rio Piabanha, Rı-JAx , $n^{\circ} 16365$. Arbuste sarmenteux, fl. brun verdàtre. Mars-avril. C.

12. Souroubea gnianensis Aubl.; Fl. Bras. Xll, I, p. 20.1. Restinga de Cabo Frio, Rio-JAx., nº 9665. Arbuste, fl. pourprées. Janvier-mars. R.

13. Ternstrœmia brasiliensis Camb.; Fl. Bras. XII, I, p. 271. Restinga de \lauá, hio-JAx., nos 7740, 8278, 10388, 10389; Arassuahy, Misas, $n^{0} 14526$; Riacho Fundo, Goyaz, $n^{0}$ 20709. Arbrisseau, fl. rougeàtres. Novembre-rlécembre. CC.

var. in Fl. Biras. XII, I, p. 272. - Alto Hacahé de Nora Friburgo, Rı-JAx., $\mathrm{n}^{\circ}$ 18908. Arbuste, fl. rougeâtres. Octobre-novembre. R.

var. micraytha Wittr: Fl. Bras. XII, I, p. 972. - Petrepolis, ad Morin, Rio-JAx., $\mathrm{n}^{0}$ 13566. Grand arbre du bois vierge, fl. rougeattres. Janvier-fév rier. R.

14. T. cuneifolia Gardn.; Fl. Bras. XII, 1, p. 276. - Serra dos Orgãos et à Theresopolis au Morro das Mraras, liı-JAx., $n^{0} 16708$. Arbuste, fl. rougeàtres. Janvier-février. C.

var. glutinosa Wawra; $\mathrm{Fl}$. Bras. XII, I, p. 276. - Campos da Bocaina, Sĩo PAulo, $n^{\circ}$ 8277; Itacolumy, près Ouro Preto, Hrxas, $n^{0}$ 14525. Arbuste, fl. rougeâtres. C.

19. T. oleafolia Wawra val. Latifolia; Fl. Bras. XII, I, p. 279. liacho Fundo, près Jaguara, dans les bois, Goyaz, n² 20709. Arbrisseau, f1. rougeâtres. Aviril-mars. R.

16. Laplacea semiserrata Camb.; Fl. Bras. XII, I, p. 289. - Restinga de Hauà, Nova Friburgo, Floresta da Tijuca, Rı-JAx., n ${ }^{\text {cs }} 887$, 2936, 7800, 11799. Arbuste, fl. blanches. Octobre-novembre. C. 
17. Laplacea semiserrata Camb. var. $\beta$. merophy lea, fl. Bras. XII, I, - Petropolis, au Morro do Cubiçado, Rio-Jan., no 10339. Arbuste, p. 289. fl. blanches. Juillet-août. R.

Var. acutrfolia Wawra; Fl. Bras. XII, I, p. 2990. - Serra dos Orgins,

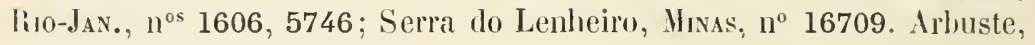
11. blanches. Avril-mai. C.

var. sericea in $\mathrm{Fl}$. Bras. XII, I, p. 290. - Nova Friburgo et Alto Nacahé, Rio-Jan., $n^{\text {os }} 11798,18905$. Arbuste, fl. blanches. Juin-octubre. R.

18. L. tomentosa Walp.; Fl. Brus. XII, I, p. 291. - Campo de São Sebastião, à Ouro Pretı, Minas, nos 14527,20211 . Arbrisseau, fl. blanches. Décembre-février. C.

19. Camellia Thea Link.; Fl. Bras. XII, I, p. 292. - Gavea chez Frei Custodio Serio, Rio-Jax., $n^{\circ}$ 6482. Arbuste rultivé, fl. blanches. Avril-mai. C. Vulgo Chá da India.

20. Kielmeyera rosea Mart.; Fl. Brus. XII, I, p. 29't. - Entre le Rio Porto ef le Rio Bananal, Goraz, $n^{\circ}$ 20708. Petit arbuste, ft. ruses. Mars-avril. C.

21. K. rubriflora Camb.; F1. Bras. XII, I, p. 29:3. - Curalinho, près de Diamantina, Mrxas, $n^{\circ}$ 18907. Arbrisseau, f1. rose pourpré. Avril-mai. G.

29. K. neriifolia Camb.; Fl. Bras. XII, I, p. 297. - Rio Gama, dans le campo, Goraz, $n^{0}$ 20704. Petit arbuste, fl. rose pâle. Septembre-octobre. C.

23. K. pumila Pohl; Fl. Bras. XII, I, p. 297. - Arrial do Ouro Braco, Serra do Lenheiro dans le campo, Minas, nos 14523,15850 ; entre Ponte Alta et Rio Areas, Goraz, $n^{\text {os }}$ 20706. Petit arbuste, fl. rose pâle. Septembre-décembre. CG.

24. K. angustifolia Pohl; Fl. Bras. Xll, I, p. 299. - Uberaba, dans le campo, Misas Geraes, $1^{0} 20706 a$. Petit arbuste, fl. roses. Juinaoùt. C.

23. K. corymbosa Mart.; Fl. Brus. XII, I, p. 299. - Bernardo Lobo, près de Meia P'onte, Goraz, $n^{\circ}$ 20703; Ulueraba, Misas, $n^{0}$ 20707. Petit arbuste, fl. blanches. Juillet-août. C.

26. K. coriacea Nart.; Fl. Bras. XII, I, p. 301. - Arraial de Ouro Branco, São João d'El Rei, Ilınas, ${ }^{\text {os }} 14521,14522,15851$; Ipanema, Sĩo Paulo, $\mathrm{n}^{\circ}$ 16711; Sobradinho, Goyaz, n ${ }^{\text {os }}$ 20699, 20700, 20702 Arbrisseau, fl. blanc rosé. Octobre-novembre. C.C. 
1.-F.-M. GLAZ10U. - LISTE DES PLAYTES DU BRESIL CENTRAL. /3

var. oblonga in Fl. Bras. III, I, p. 302. - São Joĩo d'El Rei, Mrsas, $n^{\circ}$ 16710, 17471. Arbrisseau, fl. blanchâtres. Décembre-janvier. C.

var. n.? nervosa Glaz. in herb. Berol., Kew., Paris., Genev., Brux., etc. - Sobradinho, dans le eampo, Goraz, no 20701. Arbrisseau, f1. blanches. Octobre-novembre. R.

27. K. tomentosa Camb.: Fl. Brus. XII, I, p. 303. - Arassuahy, Wris, $n^{\text {os }} 12463,13564$. Arbrisseau, fl. blanc jaunâtre. Septembreoctobre. R.

28. K. humifusa Camb.; Fl. Brus. XII, I, p. 30\%. - Serra do Urbano ou das Divisoẽs, Goraz, $n^{\circ}$ 20705. Frutescent, f1. roses. Septembre-octobre. CC

99. K. variabilis Mart.; Fl. Bras. XII, I, p. 30't. - Arraial do Ouro Branco, Mras, $n^{\circ}$ 14524; Hogy dos Cruzes, S̃̃o Paulo, n 17472; Rio Gama, Goraz, $n^{\circ} 20707 a$. Petit arluste, f1. blanc rosé. Norembrefévrier. C.

30. K. petiolaris Mart.: Fl. Bras. XII, I, p. 306. - Arassuahy, Yıxas, ${ }^{\text {os }} 12462,13563,14620$ : Serla dos Orgãos, Rio-Jan., nos 3878. 11800. Arbrisseau, f1. blanches. Octobre-février. C. Vulgo I'ío sarto.

31. K. excelsa Camb.; Fl. Bras. XII, I, p. 308. -- Gavea et à Imluetiba près de la mer, Rio-Jax., nos 3877,18906 . Arbrisseau, 11. Hlanrlies. Décembre-février. R.

32. Caraipa fasciculata Camb.; Fl. Bras. XII, I, p. 322. - Lagoa de Rodrigo de Freitas, à Tres Vendas, Rı-Jax., no $11828 a$. Arbre cultivé, fl. jaunâtres. Mars-arril. R. VuIgo, Trımuquari.

\section{Fam. 23: Malvacées.}

1. Malvastrum coronandelianum Gürcke; Fl. Bras. XIlI, III, p. 268. - Sĩo Christovão, dans les roças, Rio-Jax., $11^{\text {s }} 233,10303$. Sous-frutescent, fl. jaune pâle. Novembre-décembre. CC.

2. M. scabrum Garcke; Fl. Bras. XII, III, p. 270. - Villa Nova, dans les sables humides, Rio-JAx., $n^{\circ}$ 10296. Sous-frutescent, f1. rose pàle. Juin-juillet. C.

3. M. spicatum A. Gray; Fl. Bras. XIl, IIl, p. 271. - Praia de São Christovão, Rı-Jax., nos 5741, 10280. Sous-frutescent, fl. jaunatres. CC.

4. Gaya Gaudichaudiana St-Hil.; Fl. Bras. XII, III. p. 349. Rio Manso, dans la Capocira, Mısss, nos 12442, 1243; Imbetiba, entre 
les rochers, au hord de la mer, lin-d.w., 11" 18133. Sious-frutercent, 11. jaune pâte. Mai-aoùt. C..

5. Gaya Gürkeana K. Sch. in Fl. Bres. XII, III, p. :3̈\%. - Serra do Tingua, lho-d.x., $1^{\circ} 5741$ a. Sous-frutescent, 11. jannâtres. Mars-juin. C.

6. G. pilosa K. Schum. in Fl. Brus. XII, III, p. 3̈े\%. - Serra to Tingua, Ro-Jn., $n^{\circ} 5741$ a. Sous-fiutescent, ll. blanchatres. Juinjuillet. IR.

7. Sida ciliaris L.; Fl. Rrus. XII, III, p. 283. - Restinga de Co-

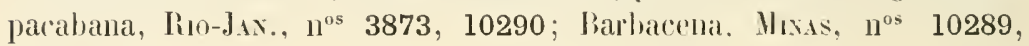
10290. 10298. Sous-frutescent, t1. jaunes. Juillet-septembre. C.

8. S. anomala St-Hil.; Fl. Brus. XII, III, 1. 286. - Restinga de Gaho Frio, hio-Jas., $11^{\circ}$ 10276. Sous-frutescent, 11. jaunitres. Juilletaoùt. C.

9. S. densiflora Hook. et Arn. : Fl. Bras. XII, 111, p. 287. - Floresta de Tijuca, Rio-Jax, $n^{\circ} 1115 a$. Arbrisseau, II. hanches. Juinjuillet. C.

10. S. macrodon DC; Fl. Bras. XIl. 111, 1). 289. - Tripuhy, Mrias, $n^{\circ} 14509$ a. Sous-frutescent, 11. verdatres. Décembre. li.

11. S. linifolia Cav.; Fl. Bras. XII, III, p. @9». - Restinga de Cabo Frio, Rio-Jax., $n^{\text {os }} 10300,10301$; Praia Grande et Quinta da Boa Vista, $n^{\circ 5}$ 207, 5745, 9657; Serra de Caraca, Ilıxas, nº 14505. Sous-frutescent, fl. jaune pâle. Janvier-mar's. CC.

12. S. panniculata L.: Fl. Bras. XIl, III, p. 293. - Praia Grande, Rı-Jax., nº 1315. Sous-frutescent, t1. jaune pâle. Juin-juillet. C.

13. S. micrantha St-Hil.; Fl. Bras. XIl, Ill, p. 29:. - Corcovado et Juriijubo, Rı-J $\mathrm{J}_{A \mathrm{~N}}$, $\mathrm{n}^{\mathrm{ds}} 5743,20198$. Sous-frutescent, fl. jaınâtres. Aoutt-octolire. C. Vulgo Guaxima.

I'4. S. spinosa L.; Fl. Bras. XII, III, 1. 297. - São Christovão, Rio-Jax., $n^{\circ}$ 6098. Sous-frutescent, fl. blanc jaunatre. Août-octobre. CC. Vulgo Vassoura.

13. S. acrantha Link.; Fl. Bras. Xll, III, p. 303. - São Julião de Ouro Branco, Mrsss, $1^{\circ}$ 18138. Sous-frutescent, fl. jaunes. Mars-juin. C.

16. S. guianensis K. Sch. in Fl. Brus. XII, III, p. 30̋̈. - Restinga de Cabo Frio, Rio-Jax., no 10279. Sous-frutescent, fl, jaunes. Juillet. CG.

17. S. urens L.; Fl. Bras. XII, III, p. 306. - Corcovado, Rio-JAx, $11^{0}$ 1314. Sous-frutescent, ll. jaune pâle. C.

18. S. tomentella Hiq.; Fl. Brus. XII, IIl, p. 309. - Petropolis, à José Correio, Rı-JAx., nº 3872. Sous-frutescent, fl. jaunes. C. 
1.-F.-I. GLAZIOL. L LISTE DES MIATES DU BRESIL CEMTRAL. \&

19. S. aurantiaca St-Hil.; val. P. fragrantissima K. Sch. in Fl. Bras. XII, III, p. 312. - I Iimmantina, at Tombador, Mixas, no 1883. Sousfrutescent, 11. jaunes. Arril-mai. C.

20. S. decumbens St-Hil.; Fl. Bras. XII, III, p. 318. - Calo Frio, Rio-JAx., nos 10292, 12451, 13549; Sitio de Barbacena, Mıss, $n^{\circ} 12451$. Herbe, tl. jaunatres. C.

21. S. Glazionii K. Sch. in Fl. Bras. XII, III, p. 222. - Casa Branca, Mixs, $n^{\circ}$ 14510. Sous-frutescent, 11. jaune pille. Férriermars. C.

22. S. glomerata Cav.: Fl. Brus. XII, III, p. 323. - Corcovarlo, aux borls des chemins, Rı-Jix., $n^{\circ} 10302$; Arassualıy. Hixis, $n^{\circ} 12441$. Sous-frutescent, fl. jaune pàle. Janvier-décembre. C.C. Vulgo Tassouimha.

23. S. acuta Burm.; Fl. Brus. XII, IİI, p. 32ّ. - Floresta «a Tijuca, aux hords des chemins, Rio-J.x., $n^{\circ}$ 10304. Sous-frutescent, 1). jaune pâle. Janvier-décembre. C.C. Vulgo Vassowimha.

24. S. cordifolia L.; Fl. Bras. XII, III, p. 329. - Copacabana et Officinos, Rio-Jix., nos 36, 3801, 5744, 10286; Rio Manso, Mrsas, $n^{\circ}$ 13551. Sous-frutescent, 11. jame pâle. Mai-septembre. C.C.

3.). S. potentilloides St-Hil.; Fl. Bras. XIl, III, p. 334. - Caho Frio, Pio-Jax., $n^{\circ}$ 10291. Sous-frutescent, fl. Jlanc jaunatre. Juillet-aoùt. R.

26. S. rhombifolia L. ; Fl. Brus. XII, III, 1. 337. - Serra do Cionto,

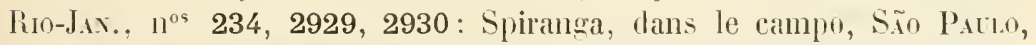
$n^{\circ}$ 10305; Tripuhy, Msis, $n^{\text {os }} 10287,20197$. Sous-frutescent, fl. jaune pâle. Décemisre-mars. LiC.

27. Bastardea conferta Gïlche et K. Sich. in Fl. Bras. XII, III, p. 362. - Campos de Caraça, à Inficionado, Masas, $n^{\circ}$ 14516. Frutescent, Il. jaunes. C.

29. B. bivalvis Kunth; Fl. Bras. XII, III, p. 363. - Serra de Caraca, Mıxs, nos 12449, 13552. Arbuste, 11. rose pâle. Décembrefévrier. C.

29. Kydia calycina Roxh.; Hort. Beng., p. 50. - K. Urasiliensis B. Rod. - Quinta de S. Clnristovão et Passeio Publico, Rio-Jâ, $11^{\text {os }} 1115,20204$. Cultivé. Arlorisseau, fl. blanches. Mars-arvil.

30. Wissadula hernandioides Gürcke; Fl. B»ls. XII, III, p. 439. - Cabo Frio, Rio-Jix., nos 12446, 12450. Sous-frutescent, fl. blanc jaunâtre. Septembre-octobre. C.

31. W. periplocifolia Presl; Fl. Brus. XII, III, p. 441. - Campos 
de Caraça, Mixas, $1^{\text {os }} 10283,13546$. Sous-frutescent, fl. jaunâtre. Juilletseptemlire. C.

32. Wissadula patens Gürche; Fl. Bras. XII, III, p. 443. - Serrinla de Santa Barbara, Mlsas, $\iota^{\circ} 18884$. Sous-frutescent, 11. blanc-jaunâtre. Mai-juillet, C.

33. Wr. Lirsuta Presl; Fl. liras. XII, III, 1. 44\%. - Entre Queluz et Congonlo de Campo, Mıxss, $1^{\circ}$ 12445. Sous-frutescent, 11. blanc jaunître. Février-mars. CC.

34. II. spicata Presl; Fl. Birls. XII, III, p. 447. - São Fidelis, près de Campos, Rio-Jax., $n^{0}$ 10285. Sous-frutescent, 11. blanchâtres. Novembre-décembre. R.

33̈. Abutilon raniflorum St-Hil.; Fl. Bras. XII, III, p. 378. - Rio Arassuahy, Mlsxs, $\mathbf{1}^{\circ}$ 12447. Sous-frutescent, 11. blanc jaunâtre. Juilletaoùt. C.

36. A. crispum L.; Fl. Bras. XII, III, p. 382. - Praia Grande, hin$J_{A x}, 1^{108} 3767,10295$. Sous-frutescent, f1. blanc jaunâtre. Mai-juin. C.

37. A. neovidense K. Sch. in Fl. Bras. XII, III, p. 386. - Floresta da Tijuca, Rio-Jax., I $^{0}$ 1313. Sous-frutescent, 11. blanc jaunàtre. \ai-juin. C.

38. A. megapotamicum St-Hil.; Fl. Bras. XII, III, p. 400. Quinta de São Clıristovão, cultivé, Rı-JAx., $1^{0}$ 9355. Sous-frutescent, fi. rouges. Ci.

39. A. pauciflorum St-Hil.; Fl. Bras. XII, III, p. 404. - Restinga de Copacabana, Rı-JAx., no 235. Sous-frutescent, t1. blanches. C.

40. A. Glaziovii K. Sch. in Fl. Brus. XII, III, p. 408. - Petropolis, au Retiro, Ro-Jর., no 10307. Arbuste, ll. rouge jaunàtre. Juilleta)ût. R.

41. A. lanatum Niı. ; Fl. Bras. XII, III, p. 409. - Serra da Bocaina, Sĩo Pallo, nº $8272 a$. Arbuste, fl. blane rosé. Février-mars. R.

42. A. Mourai K. Sch. in Fl. Bras. XII, III, p. 410. - Serra da Mantiqueira, Mnss, n ${ }^{\circ}$ 13542. Arbuste, fl. rouges. Juillet-septembre. C.

43. A. scabridum K. Sch. in Fl. Bras. XII, III, p. 4I3. - Serra do Lenheiro, près de S. J. d'El Rei, Mrsas, $1^{\circ}$ 15837. Arbuste, fl. jaunâtres. Décembre-janvier. R.

44. A. rufinerve St-Hil.; Fl. Brus. XII, III, p. 4I3. - Grandarela, Mnis, $11^{\circ}$ 14503: Nova Friburgo, Rio-JAx., $n^{\text {os }}$ 1599, 12439, 14502 , 18136. Arbuste, 11. jaunàtres. Jars-aoùt. CG.

45े. A. rufivelum K. Sch., n. sp. in lterl. Berol., Kew. - Alto 
Nacahé de Nora Friburgoo, Rió-Jax, $n^{\circ}$ 18138. Arbuste, fl. blanches. Mars. R.

46. A. Bedfordianum St-Hil.; Fl. Bras. XII, III, p. 417. - Entre Sitio et Joa Ayres, Mrsas, $n^{0 s} 1600,10306$. Arbuste, fl. rouge jaunàtre. Juin-juillet. C.

47. A. purpurascens K. Sch. in Fl. Brus. XII, III, p. 419. - Copacahana et Jurujuba, Rio-JAx., $\mathrm{n}^{\text {os }} 847,1312,3768,8272$, 16703. Arhuste, fl. rouges. Avril-juin. CG.

48. A. macrophyllum St-HiI.; Fl. Bras. XII, III, 1. 422. - Coreovado, à Paineiras, Rı-Jı., $n^{0} 18889 a$. Arbuste, fl. rouges. Novembredécembre. C.

49. A. senile K. Schum. in Fl. Brus. XII, III, p. 42y. - Quinta de São Christovão, Rio-Jıx., ${ }^{\circ}$ 12438. Arbuste, fl. Mlanc rosé. Juilletaoùt. R.

э0. A. Sellowianum Regel; Fl. Bras. XII, III, p. 439. - Corcorado, à Paineiras, Rro-J.x., $n^{0 s} 1457,18889$. Arbuste, f1. blanc jaunâtre. Aoùt-novembre. C.

3l. A. striatum Dicks; Fl. Brus. XII, III, p. 426. - Passeio Publico, Rio-Jis., $\mathbf{n}^{\circ}$ 13779. Arbuste, fl. rouge jaunâtre. Septembreoctobre.

马2. A. Regnelli Mliq.; Fl. Bras. XII, III, p. 498. - Serra dos Orgãos, Rı-Jix., no 18891. Arbuste, fl. rouge jaunàtre. Avril-juin. C.

5.3. A. venosum Walp.; Fl. Brus. XII, III, p. 431. - São Cilnistıvà Quinta, Ruo-Jıx, $n^{\text {os }}$ 10308, 14504. Arlıuste, fl. rougeâtres. Marsjuillet. C.

3'4. Malachra fasciata Jacif.; Fl. Brus. XII, III, p. 463. - Près de Sĩo Fidelis, Rin-Jax., nº 9653. Herbacé, ft. rose pâle. Janvier-février. CG.

כ... M. rudis Benth.; Fl. Brus. XII, III, p. 46女́ - São Christovin,

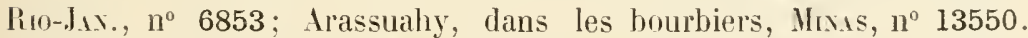
Sous-frutescent, fl. roses. Novembre-janvier. C.

o6. M. heptaphylla Fisch.; Fl. Bras. XII, III, p. 468. - SantaCruz, Rio-Jır, no 2700. Sous-frutescent, fl. roses. Janvier-mar's. R.

5ั7. Urena lobata var. americaxa Gïrke in Fl. Bras. XII, III, p. 4i1. - Copacabana, dans les endroits humides, Rio-Jax., nos 1147, 5743. Sousfrutescent, f1. roses. Avril-juillet. CG. Vulgo Guaximba.

var. reticulata Gürke in $\mathrm{Fl}$. Bras. XiI, III, p. 471. - Rio Nanso, Mrx.s; $n^{\circ}$ 12444. Sous-frutescent, fl. roses. Mai-juillet. CG. Vulgo Guaximba. 
:8. Pavonia spinifex Cav.; Fl. Brus. XII, III, p. 480. - Petropolis,

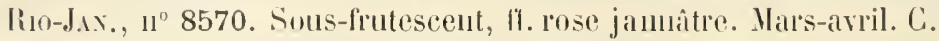

59. P. sepim st-Hil.; Fl. Brus. XII, III, p. 4sI. - Corcovarlo, Rio-Jis., nos 3766, 11791. Sons-frutescent, ll. jaunes. Mars-mai. CG.

60. P. rosea Sidilecht.; Fl. Bres. XII, III, p. 's'. - Corcovado, Rin-J.x., nos 1114,2498 . Sous-frutescent, f1. rose pâle. Janvier-avril. C.

(il. P. sessiliflora Humb. B. et K. ; var. ortusifola in Fl. Bres. XII, III, p. 492. - Queloz, Mlivas, $1^{\text {os }} 9652$, 18135. Sous-frutesceut, ll. jaunâtres. Janvier-mai. C.

var. 3. acutifolia Gürche in $\mathrm{Fl}$. Brels. XII, III, p. 493. - Tha do Goveruador, Rio-J $J_{A N}$, ${ }^{o s} 2932,7879$. Sous-firutescent, fl. jaunitres. Mars-avil. C.

62. P. speciosa Humb. B. et K. var. a. hostmann Gürcke in Fl. Bras. XII, III, p. 4!\%"). - Faria, près de Sahara, Misas, no 18135 *. Sous-frutescent, fl. roses. Janvier-février. R.

var. polyaroras Gürcke in $\mathrm{Fl}$, Bras. XII, III, p. 495\%. - Campos da Bocaina, Sĩo P.ulo. nos 8271, 10297, 14508; Ponte Alta, Goraz, no 20711. Sous-frutescent, fl. roses. Octolıre-décemlre. C.

63. P. Garcheana Gürcke in Fl. Brus. XII, III, p. 496. - Arassuahy, Miras, $\mathrm{n}^{0}$ 13545. Sous-frutescent, fl. roses. Juin-juillet. C.

6'. P. Schrankii Spreng. : Fl. Bres. XII, III, p. 498. - Tripuhy, Hišs, $11^{\text {os }} 14509$, 20196; Campos da Bocaina, Sĩo Paclo, $11^{05} 18881$, 18890. Sous-frutescent, fl. rouges. Décembre-janvier. C.

69. P. hastata Cavan. : Fl. Bras. XII, III, n. 499. - Ilheos, près de Sitio, Mhas, $n^{\circ}$ 15836. Sous-frutescent, 11. roses. Novembre-décembre. R.

66. P. sagittata A. Juss.; Fl. Bras. XII, III, p. .001. - São Juliño, Misis, $n^{0 s} 14506,18134$. Sous-fiutescent, fl. roses. Mars-avril. C.

67. P. panniculata Cav.; Fl. Brres. XII, III, p. 504. - Uberaha, Mixas, $n^{0}$ 20713. Sous-frutescent, ft. rouge jaunattre. Juillet. C.

68. P. geminiflora Horic,; Fl. Bras. XII, III, p. :06. - São Fidelis, Riı-J.1., $11^{\circ}$ 10282. Sous-frutescent, fl. blanc rosé. Novemlıre. R.

69. P. sidifolia Humb. B. et K.; Fl. Bras. XII, III, p. 508. - Rio Manso, Mtris, ${ }^{0 s}$ 10294, 13547. Sous-frutescent, fl. jaunes. Septembreoctolire. C.

70. P. Kunthii Gürcke; Fl. Brus. XII, III, p. \$10. - Vlendaha, Mixas, $n^{\text {os }} 13543,15842$. Sous-frutescent, 11. rouges. Août-septembre. R.

71. P. Rosa-canpestris Juss.; Fl. Brets. XII, III, p. :3I2. - Dona 
A.-F.-I. GLAZIOL. - LISTE DES ILANTES DU BRESIL CENTRAI.. 49

Barbara et Sobradinho, Goriz, $1^{\circ}$ 20710. Sous-frutescent, fl. rouge poupre. Lout-septembre. CC.

iュ. P. cancellata Car.; Fl. Brres. XII, III, p. 引l'4. - Rio Manso, Mixis, $n^{\text {os }} 9658,13548$. Sous-frutescent, fl. jaunes. Mai-aoùt. C.

73. P. subhastata Triana et PI.: Fl. Bros. XII, III. p. ö17. - Biribiry, Hixs, no 18885 a. Sous-frutescent, fl. rouges. Nars-avril. RiR.

T'́ P. Pohlii Gürche in Fl. Brus. XII, III, p. ̈̈17. - Entre Rio Torto et Rio Bananal, Goraz, $n^{0}$ 20715. Frutescent, l1. roses. Mars-avril. CC.

7\%. P. viscosa A. Juss.: Fl. Bras. XII, III, p. ̈̈IS. - Serra do Lenheiro, Hris, $n^{\text {os }} 16702$, 20200. Arbuste, fl. rouge pourpre. Juinjuillet. R.

76. P. malacophylla Gürche; Fl. Bras. XII, III, p. J19. - Ciarandahy et Queluz, Mrxis, $n^{\text {os }} 9655$, 10278: près de Norrinhos, dans le bois, Goraz, no 20716. Arbuste, fl. rose foncé. Mai-aoùt. C.

T. P. montana Gürche: Fl. Bras. XII, III, p. Jّ2z. - Norra de São Vicente, Mrsa, n 14507 . Arbuste, 11. rouge pourpre. Juin-juillet. Ii.

var. velutivi Gïlcke in Fl. Bras. XII. III, p. 523. - Rio Manso, Mixas, $n^{0}$ 13544. Arbuste, fl. rouge pourpre. Juin-juillet. C.

78. P. alnifolia A. Juss.; Fl. Bras. XIII, III, p. Ӟ26. - Restinga de Taipu, Rı-Jix., nos 3780, 18140. Arbrisseau, 11. jaune verdâtre. Septembre-octolire. C.

79. P. multiflora A. Juss.; Fl. Bras. XII, III, p. ə̃əS. - Serra de Caraça, Mıxss, $n^{\circ}$ 13541. Arbuste, fl. jaunattres. Décembre-janvier. R.

S0. P. Selloi Gürcke in Fl. Bras. XII, III, p. ̈330. - Ayuruoca, Hrisas. $n^{\circ}$ 13540. Arbuste, f1. rose pourpré. Octobre-novembre. R.

81. Gœthea cauliflora Nees et Mart.: Fl. Bras. XII, III, p. 533. - Floresta da Tijuca, Rio-Jax., n 18140 a. Arbuste cultivé, fl. rouges Janvier-février. R.

82. Hibiscus Rosa-Sinensis L. ; Fl. Bras. XII, III, p. “̈ł. - Passeio Publico, Rro-Jıx., nº 15555. Arbuste cultivé, ll. rouge pourpre. Maijuillet. CC.

83. H. mutabilis L.; Fl. Bras. XII, III, p. כ̌49. - Quinta de São Christovio, Rio-Jıx., no 20203. Arbuste cultivé, fl. blanc rosé ensuite pourpres. Novembre-avril. C.

84. H. Lambertianus Humb. B. et K. : Fl. Bras. XII, III, p. Ö̈. Lagoa, près de Arassuahy, Mıxıs, $n^{\circ}$ 12440. Sous-fiutescent, f1. roses. Novembre-décembre. $C$.

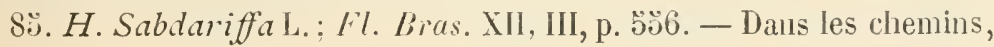


i Santa Luzia, Goyz, $0^{\circ}$ 20712. Sous-frutescent, cultivé. Ivril-mai. C.

S6. Hibiscus cucurbitaceus St-Hil.; Fl. Bras. XII, III, p. :3iT. Pouso Alto, au Chapardan dos Veadeiros, fioxuz, $1^{\circ \mathrm{s}}$ 20202. 20717, 20718. Sous-frutescent, 11. rouge foncé. Janvier. C.

87. H. laxiflorus St-llil.; Fl. Brus. Xll, III, p. Ö.8. - Pris de la ville de Goriz, $1^{\circ}$ 20719. Sous-fiutescent, 11. roses. C. Vulgo Crème.

88. H. bifurcatus Cav.; Fl. Bras. XII, III, 1). :̈60. - Praia Grande, Rı-Jı., no 1310; llheos, près de S. J. d'El Rei, Mıxas, ${ }^{\circ} 17466$. Sous-frutescent, f1. roses. Janvier-février. C.

89. H. furcellatus Desv. in Lamk. ; Fl. Brus. XII, 1II, p. C62. Riaclıo das Varas, Mixis, $n^{\circ}$ 18879. Sous-frutescent, fl. roses. Mar'savril. C.

90. H. flagelliformis St-Hil.: Fl. Brus. XIl, III, 1. ̈̈63. - Sĩo Julião de Ouro Branco, Mrxs, n 18137. Sous-frutescent, fl. roses. Marsmai. R. Vulgo Jardineira.

9I. H. tiliaceus St-Hil.; Fl. Brus. XII, IIl, p. ̋̈67. - Praia Grande, Gopacabana, Imbetiba, près de la mer, Ro-JAx., nos 1309, 2497, 18886, 18887. Arhrisseau, fl. jaunes. Décembre-janvier. C. Vulgo Manhoc.

val. H. elatus Sw.; Fl. Bras. XII, IIl, p. ̈̈68. - Quinta de Sĩo Christovĩo, liut-JAN., $n^{\circ}$ 18888. Arbre cultivé, fl. jaunes. Janvieravril. C.

92. H. esculentus L.; Fl. Bros. XII, III, p. :69. - Quinta de São Christovão, Rı-Jav., $1^{\circ}$ 20201. Sous-fiutescent, cultivé, fl. jaunes. Février-mai. C. Vulgo Quimgombo.

93. Cienfuegosia phlomidifolia Garcke; Fl. Brus. XII, III, p. 574. - Riaclio das Varas, Mrsas, n 18882 ; Ponte Lavrado, Gorız, nº 20714. Sous-lintescent, fl. jaunes. Juin-aunt. R.

9'. Thespesia populnea Corr. in DC, Prodr. vol. I, p. 4.\%. - Passeio Publico, Rio-JAx., nº 668. Arbrisseau cultivé, fl. blanc rosé. Févriermals. R.

93̊. Gossypium religiosnm L.; Fl. Brus. Xll, Ill, p. ̈̈83. - Quinta de São Clıristovão, Rio-Jax., $n^{\circ}$ 18880. MPuste cultivé, 1l. jaunes. Janvier-mai. CG. Vulgo Algodoeiro.

96. Pachira aquatica Iubl. : Fl. Bras. XII, III, 1. 233. - Passeio Publico, Ro-J.x., nos 2500, 14511, 16704. Grand arbre cultivé, th. blane rosé. Mars-avril. Ci. Vulgo Castunheiro do Maranheio.

97. P. petropolitana Glaz.; ı. sp. in herb. Berol., Kew., Brux., Paris., etc. - Petropolis à Itamaraty, clans la forêt, Rı-J Jx., n 9309. Grand arbre, fl. blanchàtres. Mai-juin. C. 
A.-F.-M. GLAZIOU. - LISTE DES PLANTES DU BRÉSIL CEATRAL. 51

98. Bombax tomentosum St-Hil.; Fl. Bras. XII, III, 217. - Bella Vista, Gorzz, n² 20722. Alıre rahougri, fl. blanclies. Août-septembre. C.

99. B. Candolleanum K. Sch. in Fl. Bras. XII, III, p. 218. - Nto Nacahé de Nova Friburgo, Rio-J.x., nos 6480, 18892. Grand arbre, 11. blanches. Octobre. R.

100. B. crenulatum K. Sch. in Fl. Bras. XII, III, p. 2I9. - Entre Tijuco et Gingibre, Goraz, $\mathbf{n}^{\circ}$ 20721. Arbrisseau, f1. blanches. Aoùt-septembre. C. Vulgo Puneira.

101. B. chastifolium K. Sch. n. s]. in herb. Berol., Kew., Paris., etc. - Corregu do Brejo à Chico Lobo, dans le bois, Goraz, $n^{0} 20722 a$. Arbre énorme, fl. blanc jaunâtre. Juin-juillet. R.

102. B. macrophyllum K. Sch. in Fl. Bras. XII, III, p. 220. - Nova Friburgo, Rio-JAx., $n^{\circ}$ 18144. Très grand arbre, fl. blanches. Novembre. R.

I03. B. Wittrockianum K. Sch. in Fl. Bras. XII, III, p. 222. Petropolis, à Itamarahy, Rı-JAx., nº 14512. Grand arbre, fl. blanches. Octobre-novembre. C.

104. B. pentaphyllum Vell.; Fl. Bras. XII, III, J. 222. - Serra da Estrella, Rio-JAx., $n^{\circ}$ 2902. Grand arbre, f1. blanches. Septembre. C.

10\%. B. marginatum K. Schum. in Fl. Bras. XII, III, p. 223. - Morro da Canastra, Goriz, n 20720. Arbuste, fl. blanches. Novembre-dédécembre. C. Vulgo Imbirussú.

I06. B. Martianum K. Schum. in Fl. Bras. XII, III, p. 224. - Lagoa da Fidalga, Mıss, $11^{0}$ 18896; entre le Rio Torto et Bananal, Govas, $n^{\circ} 20720 a$. Arbre, l'. blanches. Septembre. C.

107. B. stenopetalum K. Schum.; Fl. Brus. XII, III, p. 22:). - Passeio Publico, Rio-Jax., no 2502; Juiz de Force, Mısas, n 3666. Grand arbre cultivé, fl. blanches. Mar's-avril. Vulgo Caslanheiro do Maranhão.

108. B. endecaphyllum Vell.; Fl. Bras. XII, III. p. 227. - Alto Ilacahé de Nova Friburgo, Rı-JAN., 11 ${ }^{0 \mathrm{~s}}$ 10311, 10312, 18442. Grand arble, fl. blanc rosé. Novembre. C. Vulgo Imbirussú.

109. B. callophyllum K. Schum. in Fl. Bras. XII, III, p. 227. - Floresta da Tijuca, Rı-JAx., n ${ }^{0}$ 2935. Grand arbre, fl. blanches. Févriermars. R.

110. B. longiflorum K. Schum. in Fl. Bras. XII, III, p. 228. - Serra das Vertentes, près de Oliveira, Mrsas, $n^{03}$ 18145, 20205. Arbrisseau, 11. blanches. Juin-juillet. C. Vulgo Paineira.

111. B. cyathophorum K. Schum. in Fl. Bras. XII, III, p. 228. - 


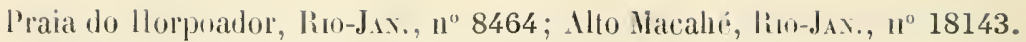
(irand arhre, 1\%. ham ltes. Mai-juin. C.

112. Bombax campestre K. Schum, in Fl. Brus. XII, III, p. 229). Diamantina, Msvss, $n^{\text {os }} 18894$, 18895. Arbuste, 11. Hanches. Avril-mai. C.

113. Ceiba erianthos K. Schum.; Fl. Brus. XII, III, p. 211. - Botafogo, pres de la mer, Ruo-Jıx., $11^{\text {os }} 3765,235$ a; Rio Mrassualıy, Mıxis, $n^{\circ}$ 1245:3: Ipiranga, S.o Patu, $1^{0} 18145$ a. Arbre, fl. blanches. Juinnovembre. C. Vulgo Burrigudo.

114. G. Glaziovii 0. Kuntze n. sp. in litt. - Sìo Christovĩo, au Pedregulho, Rio-Jax, $1^{05} 17467,18145 a$. Grand arbre, fl. blanches, superbes. Aout-septembre. R.

115. C. Rivieri K. Schum. in F\%. Bias. XII, III, p. 212. - Serra da Estrella, liro-Jus., $11^{\text {os }} 6479$, 20207. Grand arbre, f1. rouges. Juinoctobre. C. Vulgo Paineira do Mato.

116. C. Sipolisii K. S»lı. n. sp. in herb. Berol., Kew., Paris., etc. Jiamantina, dans le campo, Mrxas, $n^{\circ}$ 18893, 20206. Arbuste, fl. odorantes, rose pâle. Mars-arril.

117. Chorisia speciosa St-Hil.; Fl. Bras. XII, III, p. 206. - Petropolis, dans la forêt, Rı-Jax., nos $3875,10313,15838$. Grand arbre, fl. roses. Mars-arril. CC. Vulgo P'aineira.

118. C. crispiflora Humb. B. et K.; Fl. Bras. XII, III, p. 207. Curcorado, Rio-Jix., n ${ }^{0}$ 2494. Grand arbre, fl. roses. Mars-avril. C. Vulgo I'aineira.

119. Matisia Riedeliana Glaz. n. sp. in herb. Berol., Brux., Kew., Paris., etc. — Quinta da Boa Vista, Rı-JAs., $1^{\circ}$ 9636. Arbrisseau cultivé, fl. jaunâtres. Décembre-janvier. K.

\section{Fam. 2't : Sterculiacées.}

1. Sterculia Chicha St-Hil.; Fl. Bras. XII, III, p. 9. - Corcovado et Quinta, Rı-Jax., $n^{0.5} 2501,11792,18148$. Très grand arbre, saurage et cultivé, fl, rouge foncé. Novembre-févirier. C.

2. S. striata St-Hil.; Fl. Bras. XII, III, p. 10. - Rio Arassualy, Mixıs, $\mathrm{n}^{\text {os }} 9637,10075,15841$. Très grand arbre, fl. fauves. Janvierfévrier. C. Vulgo Castunheiro do malo.

3. S. foetida L.; Fl. Bras. XII, III, 1) I2. - Quinta de Säo Christovão, Rı-Jı., $n^{0}$ 11793. Grand arbre cultivé, fl. rouge foncé. Novembre-décembre. G. Vulgo Chichu.

4. S. goyazensis Glaz. n. sp. in herb. Berol., Kew., Paris., Hawn., 
A.-F. M. GLAZIOU. - L.ISTE DES PLAYTES DL BRESIL CEMTRIL. 53 elc. - Serrimlia à Mossamedes, Gorız, no 20723. Très grand arbre superbe, sans fleur en aout-septembre. C. Vulgo C'hicha.

5. Cola acuminata R. Br.; Fl. Bras. XII, III, p. 12. - Jardín Botanico da Lagoa de Freitos et Quita da Boa Vista, Rio-JAx., nos 5800 , 18146. Arbrisseau cultivé, fl. faures, jaunitres. Férrier-mars. C.

6. Basiloxylon Rex Schum.; Fl. Bras. XII, Ill, p. 12, Obs. et P. 250. - Rio Manson, Mıss, n 10310: Lagoa do Peice et Cantagallo, Rio-Jas., $n^{\text {os }} 12452,15840$. Arbre gigantesque, 11. fiaures. Férrier-mars. C. Vulgo Pao Rei.

7. Myrodia (Quararibea) floribunda K. Sch.: Fl. Brus. XII, III, p. 242. - Corcovado, Cascadura, Rin-Jax., nos 11794, 16706: Ponte do Rio Abadé, Mrras, $n^{\circ}$ 20724. Arbrisseau, fl. blanclues à très bonne odeur. Avril-mai. C.

8. M. (Quararibea) turbinata Sw.; Fl. Bras. XII, III, p. 243. Corcovado, à Paineiras, Rıo-JAx., n² 20210. Arbrisseau, fl. blanches très odorantes. Mars-avril. R.

val. axgustifolia K. Schum. in Fl. Bras. XII, III, p. 243. - Corcorado, Serra da Estrella, Rı-JAx., nos 666, 1113, 2933 et 2934. Arbrisseau, 11. blanches à très bonne odeur. Mars-arril. CC.

9. Helicteres Sacarolla St-Hil.; Fl. Bras. XII, III, p. 16. Ipanema, dans le campo, Sĩo Palco, $1^{0}$ 12454. Arbuste, fl. rouges. Arril-mai. CC. Vulgo Sacarolho.

10. H. guazumifolia Humb. B. et K.: Fl. Bras. XII, III, 1) 17.-

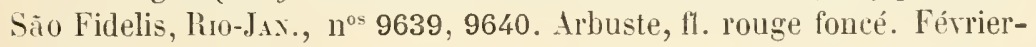
mars. C.

11. H. Bamensis Jacq. ; Fl. Bras. XII, III, p. 20. -- Campos, dans la capoceira, liı-Jxi, $n^{\circ}$ 10315. Arbuste, fl. rouges. Décombre-janvier. $\mathrm{R}$.

I2. H. ovata Lamk.; Fl. Bras. XII, III, p. 23. - Corcovado et Mendanlıa, Rio-JAs,., $\mathrm{n}^{\text {os }}$ 1308, 1456, 11796. Arbuste, f1. rouges. Avril-juin. CC.

13. H. bresispira St-Hil.; Fl. Bras. XII, III, p. 24. - Fazenda do Cipo, Mris, $n^{\text {os }} 15843,18899$; Meia Ponte, Goraz, $n^{\circ}$ 20725. Arbuste, fl. rouges. Aoùt-septembre. CC. Vulgo Mutama.

I't. H. macropetala St-Hil. ; Fl. Bras. XII, III, p. 2.). - Campos, près de São Fidelis, Rin-Jax., $n^{\circ}$ 10316. Arbuste, fl. rouges. Décembrejanvier. li.

1ั. H. muscosa Mart.; Fl. Brus. XII, III, p. „6. - Campos da 
Bocaina, São Pauto, nos 9638 , 13407. Arbuste, 11. rouges. Févriermars. C.

16. Helicteres longepedunculata K. Sch. in Fl. Bras. XII, III, p. 26 . - Mendanha, Mrsas, $n^{\circ}$ 13554. Arbuste des bois, fl. rouges. Février-mars. G.

17. Dombeya mollis Hook. in Bot. Hag. tal, 4578. - Passeio Publico, Rı-JAx., $11^{\circ}$ 1553. Grand arbre cultivé, f1. blanc rosé. Août-septemblre. GG.

18. D. Amelice Gull.; Archiv. Bot. I, p. 367. - Passeio Publico, Rro-JAx., $1^{\circ}$ 1554. Arbrisseau cultivé, fl. roses. Mars-avril. C.

19. Melochia betonicifolia St-Hil.: Fl. Bras. XII, III, p. 33. Serra da Estrella, Rıo-Jax., $n^{0}$ 12459. Sous-frutescent, 11. jaunes. Décembre-janvier. CG.

20. M. pyramidata L.; Fl. Bros. XII, HI, p. 34. - Araruana, près de Cabo Frio, Rio-Jax., no 10326. Sous-frutescent, 1l. jaunes. C.

21. M. Lupulina Sw.; Fl. Bras. XII, III, p. 3\%. - Cabo Frio, RinJax., $n^{\text {os }} 10321,10883,1560$. Sous-frutescent, f1. jaunes. Février-mar's. GC.

22. M. nodiflora Sw.? Prodr. Veg. Ind. Occ. 97. - Cabo Frio, Restinga, Rio-JAx., $n^{\circ}$ 10327. Sous-frutescent, fi. jaunes. Décembrejanvier. C.

23. M. venosa Sw.; Fl. Bras. XII, III, p. 37. - Près des eaux de Caxambú, Mrsas, $n^{\circ}$ 15848. Sous-frutescent, f1. jaunes. Janvier-février. C.

24. M. sorocabensis K. Schum. in Fl. Bras. XII, III, p. 42. - Brejo Riacho Fundo, Goyaz, no 20735. Sous-frutescent, fl. rose vif. Férriermars. Ci.

2:. M. cephalodes K. Sch. in Fl. Bras. XII, III, p. 4:̈. - Rios das Pedros, au Vallú, Mixas, $n^{0} 18901$. Sous-frutescent, fr. blanc jaunittre. Mars-avril. C.

26. M. hirsuta Cav.; Fl. Bras. XII, III, p. 4วั. - Morro de Caxambú, près des eaux, Mixas, n 15849, 18902 ; Rio Gama, dans les bourbier's, Goyaz, $n^{\circ}$ 20734. Sous-frutescent, fl. jaunâtres. Novembre-janvier. CC.

var. $\beta$. grandiflora K. Sch. in Fl. Bras. XII, IIl, p. 46. - Cabo Frio, Rio-JAx., $n^{\circ}$ 13406. Sous-frutescent, f1. jaunattres. Septembre-octobre. C.

var. ò. regnelli K. Sch. in Fl. Bras. XIl, III, p. 46. - Rio Arassualiy, Minss, $n^{0}$ 12460. Sous-firutescent, fl. jaunâtres. Juillet-septembre. C. 
A.-F.-Y. GLAZIOU. - LISTE des plaxtes DU BRÉSIL CextRAL.

27. M. cordiformis St-Hil.; Fl. Bras. XII, III, p. 48. - Rio Manso, Mrsı, n ${ }^{0}$ 13557. Arbuste, tl. banc jaunâtre. Février-mars. C.

28. Waltheria viscosissima St-Hil.; Fl. Bras. XII, III, p. 53. Campo Grande, Riı-Jی,., ${ }^{\text {os }}$ 4924, 12459 /. Sous-frutescent, fi. jaunes. Janvier-mars. C.

29. W. Selloana K. Sch. in Fl. Brus. XII, III, p. ริ. - Pinheiro, près de Diamantina, Mris, $n^{\circ}$ 18904. Arluste, 11. jaune pâte. C.

30. W. aspera K. Sch. in Fl. Bras. XII, III, p. ร̆̋ั. - Restinga da Tijuca, Rı-Jı., $1^{\circ}$ 6097. Sous-frutescent, ft. blanchâtres. Septembreoctobre. IR.

31. W. ferruginea St-Hil.: Fl. Bras. XII, III, p. 35. - Morro dos Cristaes, à Diamantina, Mrus, $n^{\circ} 18903$. Arluste, fl. jaunâtres. Avrilmai. (:.

11. var.? glabrescens Glaz. in herb. Berol., Kew., etc. - Campos, à Sĩo Fidelis, Rı-JAx., n ${ }^{\text {os }} 9645,10319$. Frutescent, fl. jaunâtres. Vlarsavril. C.

32. W. communis St-Hil.: Fl. Bras. XII, III, p. 88. - Serra de São José d'El Rei et à Serra do Lenheiro, dans le campo, Mixas, $11^{0 \mathrm{~s}} 16701,18139$. Herhacé, fl. blanc jaunâtre. Octobre-novembre. CC.

var. Laxata K. Schum. in $\mathrm{Fl}$. Brels. XII, IH, p. 58. - Caraça, campo de Fora, Hrxas, n 12457. Herbacé, f1. jaunes. Juin-juillet. CC.

33. W. petiolata K. Sch. in Fl. Bras. XII, III, p. 61. - Haut du Iorro Queimado, Rio-Jax,, $\mathrm{n}^{0}$ 3874. Sous-frutescent, li. jaunes. Novembre-décembre. C.

3'. W. rotundifolia Schrank: Fl. Bras. XII, III, p. 62. - Cabo Frio, Rro-Jıx, $n^{0}$ 10320. Sous-frutescent, fl. jaunâtres. Décembre. R.

33. W. Glazioviana K. Srhum. in Fl. Bras. XII, III, p. 63. - Forteresse du Pico de Santa Cruz, Rio-Jax., $\mathrm{n}^{0}$ 8273. Sous-frutescent, 1l. jaunes. Mars-avril. C.

36. W. americana L.; Fl. Bras. XII, III, p. 63. - Morro da Babylonia, $\mathrm{n}^{\text {os }} 34,4969$; et São Christovâo, Rro-JAx., $n^{0 \text { s }} 2931,10317,18141$. Sous-frutescent, f1. jaunes. Décembre-janvier. CC.

n. var. vulgaris K. Sch, - Restinga da Tijuca, Rio-JAx, nos 9647 , 9648. Sous-frutescent, fl. jaunes, Janvier-février. C.

var. Elliptica K. Sch. in Fl. Bras. XII, III, p. 65. - Rio Manso à Mendanha, Mrxas, $n^{0}$ 14518. Sous-frutescent, n. blanchâtres. Févriermars. C. 
37. Waltheria macropoda Tur\%: Fl. Bras. XII, III, P. 66. Arassualı̣, llıxıs, $10^{09} 9651,12458$. Sous-frutescent, 11. jaune pâle. Juinjuillet. C.

38. WV. Douradinha St-Hil.; Fl. Brus. XII, III, 1) 67. - Vacacos à Chico Costil, Goraz, nos 20732, 20733. Herhacé, 11. jaunes. Octolıre. C. Vulgo Doradinha do campo.

39. Theobroma Marice K. Scll. in Fl. Bres. XII, III, p. 71. Quinta de São Christovio, Rro-JAx., $11^{\circ}$ 9635. Arbrisseau cultivé, fl. rousses. Décembre-janvier. R.

40. T. Cacao L.; Fl. Bras. XII, III, 1. 72. - Quinta de São Christorão, Rro-Jax., ${ }^{\circ \text { os }} 9644,12190$. Arbrisseau cultive, fl. rouge foncé. Novembre-décembre. C.

41. T. bicolor IIumb. B. et K.: Fl. Bras. XII, III, p. 73. - Quinta de São Christovĩo, Rro-JAx., no 9633. Arbrisseau cultivé, fl. rouge pourpre. Janvier-février. R. Vulgo Cupuassú. A musone.

42. T. grandiflor $u m$ K. Sch. in Fl. Bras. XII, III, 1. 76. - Quinta de São Clıristovão, Rıo-JAx., n 9643. Alrisseau cultivé, fl. rouge foncé. Janvier-février. R. Vulgoo Cupuassú, Amazones.

13. T. subincanum Mart.; Fl. Bras. XII, III, p. 77. - Quinta de São Christovão, Rio-Jax. no 9633 ". Arbrisseau des Amazones planté par L. Riedel. Vulg. Cupuai.

44. Guazuma crinita Mart.; Fl. Bras. XII, III, p. 79. - Corcovado, Rio-Jax., $n^{\text {os }}$ 14, 663, 7521. Arlre, fl. rousses. Avril-mai. C. Vulgo Nulamba.

40.. G. ulmifolia Lamk.; Fl. Bras. XII, III, p. 80. - Corcovado, à Paineiras, Rin-JAx., $11^{05} 9641,9642,12455$; Diamantina à Mendanha, Ilsus, $n^{\text {os }} 10325,12455,12456,13555,13556$. Arlure, fl. rousses. Octobre-novembre. CC. Vulgo Nutamba.

var. $\beta$. tomentele K. Sch. in Fl. Bras. XII, III, p. 81. - Entre Cabo Frio et São Pedro, dans les bois, Rio-JAx., nos 10323, 10324. Arlure, fl. rousses. Juillet-aoùt. C. Vulgo Mutamba.

var. \%. tomentosa K. Sch. in Fl. Bras. Xil, III, p. 81. - Santa Thereza, au Corcovado, Rio-Jax, $n^{0 s} 664,11797$. Arbre, fl. rousses. Novembre-décembre. CG. Vulgo Mulamba.

46. Ayenia fruticosa K. Sch. n. sp. in herh. Berol., kew., Paris., Hawn. - Formaça, près de Diamantina, Mrsas, n 18898. Arbuste, f1. brunâtres. AvriI-mai. C.

47. A. angustifolia St-Hil. et N.; Fl. Bras. XIl, III, p. 103. - 
1.-F.-M. GLAZIOU. - LISTE DES PLANTES DU BRÉSIL CENTRAL. 57 Vargem Grande, Goyaz, no 20731. Sous-frutescent, 11. brunes. Janvierfévrier $\mathrm{C}$.

48. A. Riedeliana K. Schum. in Fl. Bras. XII, III. p. 104. - Riacho das Varas, Mrxa, $n^{0}$ 18897: Vachoeira da Vargem Glande, Goyaz, $n^{\circ}$ 20731. Sous-frutescent, fl. rousses. C.

49. A. tomentosa L.: Fl. Bras. XII, III, p. 104. - Matacavollos Corcorado, Rio-Jux., $n^{\circ}$ 18149; Sous-frutescent, fl. rousses. Mlaijuin. C.

:0. Büttneria scabra Loefl.; Fl. Bras. XII, III, p. 87. - Onro Preto, Mixas, $n^{\circ}$ 14514, 15839; Serra do Picu, SAO PAlıo, $n^{\circ} 10328$ : Fazenda do Cocal, Goraz, $n^{\circ}$ 20730. Arbuste, fl. verdâtres. Tovembredécembre. CC.

ॐ1. B. sagittifolia St-Hil.: F7. Bras. XII, III, 1. 88. - Serra do P'icú, Sĩo Palıo, $n^{\circ} 10328 a$. Arlouste. ll. verdattres. Aoùt-septembre. C.

32. B. scalpellata Pohl: Fl. Bras. XII, III, p. 89. - Ponte Alta, dans le campo, Goraz, $n^{0} 20727$ a. Albuste, ll. brunes. Octobre. C.

53. B. subulifolia K. Sclı. n. sp. in herb. Berol., Kew., Paris. Entre le Rio Tocantino et Os Porcos, Gorrz, $11^{\circ}$ 20729. Frutescent, fl. liunes. R.

3̈4. B. melastomafolia St-Hil.; Fl. Bras. XII, III, P. 90. - Rio liasgão, près de Corumba, Goraz, $n^{\circ}$ 20727, 20728. Arbuste, fl. Irunes. Septembre-octolire. C.

var. pubescens K. Sch. in litt. inedit. - Vào de Parana, Gorız, $\mathrm{n}^{0}$ 20726. Arbustes des campos, fl. brunes. Septembre-octolre. C.

Эั. B. catalpifolia Jacq. ; Fl. Bras. XII, HI, p. 91. - Cantagallo, a Larangeiras, Rı-JAx., $n^{\circ \mathrm{s}}$ 10322, 15451. Albuste samenteux, fl. rousses. Janvier-février. C.

56. B. Gayana St-Hil.: Fl. Bras. XII, III, p. 93. - Rio do Ouro, Rio-Jax., n 10330; mine d'or de Faria, près de Sahara, Mıxı, $n^{\circ} 18150$. Liane, fl. blanchàtres. Janvier-février. C.

$5 \%$. B. filipes Mart. in $\mathrm{Fl}$. Bras. XII, III, p. 9气. - Cabo Frio, RioJAx., $n^{\circ}$ 10329. Arbuste un peu sarmenteux, fl. brunes. Décennlore. R.

5̋8. B. Beyrichiana K. Sch. val. grazrovrana K. Sch. in lil. Bras. XII, III, p. 96. - Petropolis, Rio-dax., n 8571. Arbuste samenteux, fl. grisâtres. Jlars-avril. R.

3̆9. B. hirsuta Ruiz et P.; Fl. Bras. XIl, III, p. 99. - Petropolis, à Santo Antonio, Rio-JAx., n 7605. Arluste sarmenteux, fl. lrunes. Juinjuillet. Vulgo Espinha Mariana. 
60. Buittneria divaricata Benth.: Fl. Liras. XII, III, p. 100. bords du Rio das Velhas, i Santa Luzia, Muxas, $\mathrm{n}^{\circ} 18150$ a. Arbuste sarmenteux, fl. blanchâtres. Mai-juin. (C.

\section{Fam. 2:: Tiliacées.}

1. Christiania africana UC; Fl. Bras. XII, III, p. 122. - Quinta da Boa Vista, Rio-JAx., $11^{\circ \text { s }} 10314,14513,16705$. Grand arbre cultivé, fl. rougeitres. Avril-mai. Vulgo Caaguassú.

2. Triumfetta romboidea Jacq. ; F\%. Bras. XII, III, p. 132. - Corcuvado, Caminho to Enforcado, liı-d.1x., $n^{\text {os }} 667,1148$. Sous-frutescent, fl. jaunes. CG. Vulgo Carrapicho.

3. T. semitriloba L.; Fl. Bras. XII, III, p. 134. - Bas de la Tijuca, luro-Jax., $\mathrm{n}^{\circ 8}$ 8274, 10335; Ipiranga, Sĩo Pauro. no 13539. Sous-frutesrent, 11. jaunes. CC. Vulgo Carrapicho.

4. T. althavides Lamk.; Fl. Bras. XII, III, p. 137. - Serra da Estrella, près du Botequim, Rio-JAx., $11^{0:} 9356,17470$. Arbuste, fl. jaunes. C. Vulgo Carrapicho.

כ. Heliocarpus americantus L.; Fl. Bras. XII, III, p. 14I. - Bois de la colline d'Ipiranga, S $\tilde{A} 0$ Pavio, $n^{\circ} 13559$ a. Arbuste, ll. jaunâtres. Avril-mai. R.

6. Corchorus olitorius L.; Fl. liras. XII, III, p. 126. - São Christovão, Rio-JAv., ${ }^{\circ}$ 15847. Sous-frutescent, Il. jaunes. Avril-juillet. C. Vulgo Hoyo, pl. alimentaire.

7. C. hirtus L. var. ріцоводus K. Sch. in Fl. Bras. XII, III, p. 128. - São Christovĩo, São Fidelis, près Campos, Rı-JAx., $n^{\circ s} 9332$, 10336, 20209. Sous-frutescent, fl. jaunes. Janvier-mai. CG.

8. Luhea uniflora St-Hil.; Fl. Bras. XII, III, p. 153. - Rio Arassualıy, Mıxıs, nos 10337,13561 . Grand arbre, fl. blanc jaunâtre. Janvierfévrier. C.

9. L. Conventzii K. Schum. in Fl. Bras. XII, III, p. 15̆4.Campos da Bocaina, Sĩo Patuo, $1^{\circ} 11785$. Grand arbre, fl. blane rosé. Septembre-octobre. R.

10. L. speciosa Willd.; Fl. Bras. XII, III, p. IS\%. - Chemin du Corcovado, Rio-JAN., $\mathrm{n}^{\circ}$ 1149: près de Caraça, au Horro Redondo, Nixis, $n^{\circ}$ 14519. Grand arbre, ft. blanc rosé. CG. Vulgo Açoita cavallo.

11. L. rufescens St-Hil.; Fl. Bras. XII, III, p. 15̆7. - Ponte do Rio Paranana, Goraz, n 20736. Grand arbre, f1. blanches. Juin-juillet. C. Vulgo Acoita cavallo.

12. L. divaricata Mart.; Fl. Bras. XII, III, p. 159. - Soledade, 
A.-F.-Y. GLAZIOU. - JISTE DES PIANTES DU BLESIL CEXTRAI. 59 près de Caxambú, Misas, no 8275; St-Anna dos Topos, Rio-Jax., n' 15844. Grand et bel arbre, f1. blanc rosé. Janvier-février. C. Vulgo A coita cruallo.

13. L. paniculata Mart.; Fl. Bras. XII, III, p. 160. - Cabo Frio, dans le bois, Rio-JAx., nos 10338, 20737. Petit arbre, fl. blanc rosé. R.

14. L. ochrophylla Mart.; Fl. Bres. XII, III, p. 161. - Serra de Jacarépagrua, Rio-Jax., $n^{0}$ 3876. Grand arbre, f1. blanc rosé. Novembredécembre. R. Vulgo Acoila cavallo.

1:. Mollia speciosa Ilart. et Zucc.: Fl. Brus. XII, III, p. 14!). Quinta de São Christovio, Rı-J.x., nº 9634. Arbrisseau cultivé, fl. blanchâtres. Janvier-février. R.

16. M. lepidota Spruce: Fl. Bras. XII, III, p. 10̈0. - Quinta de São Christovão, Rı-J.ı., no 13563 a. Arbrisseau cultivé, fl. blanc rosé. Janvier-février. R.

17. Apeiba Tibourbou Aubl.; Fl. Bras. XII, III, p. 143. - Quinta de Sä́n Christovão, Ríı-Jıx., n ${ }^{\text {os }}$ 2899, 8276, 10331 : Fazenda da Cava près de Mestre d'Armos, Goraz, n 20738. Arbre cultivé, fl. jaunes. Maiaoùt. C. Vulgo Prio de Jangudia.

18. Prockia Cruicis L.; Fl. Brus. XIII, I, p. ¿03. - Fazenda de Santa Gruz, Rin-Jix., nos 6088, 10247, 10251, 20191. Arbuste, fl. jaunes. Oetobre-novembre. CC.

19. Hasseltia laxiflora Eichl. : Fl. Bras. XII, III, p. 168. - Passeio Publico, Rıo-J.x., $n^{\circ}$ 13524. Plante cultivée, plantée par L. Riedel: liane, fl. blanchâtres. Avril-mai. R.

20. Sloanea Garckea K. Sch. in Fl. Bras. XII, III, p. 177. - Larangeires, au pied du Corcovado, Rio-JAx., $n^{\text {os }}$ 15845, 15846. Arlorisseau, f1. jaunitres. Avril-mai. CC.

21. S. obtusifolia K. Sch. in Fl. Bras. XII, III, I. 181.- Rio d'Ouro, au Tingua, Rio-JAx., $n^{\circ}$ 10332. Arbrisseau, fl. jaunàtres. Aoùlseptembre. C.

2ュ. S. monosperma Vell.; Fl. Bras. XIl. III, p. 18*. - Corcovado et Tijuca, Rıo-JAx., $n^{\text {os }} 5731$, 10333, 7517; Alto Macalıé de Nova Friburgo, Rı-Jx., nos 17468, 17469, 20208. Arbrisseau, f1. jaunâtres. Janvier-mars. CC. Vulgo Orico.

val. pulverulenta K. Sch. in Fl. Bras. XII, III, p. 186. - Floresta da Tijuca, Rı-Jax., n 2489. Arbrisseau, f1. jaunâtres. Férrier-mars. C. Vulgo Orico.

23. S. alnifolia Mart.; Fl. Bras. XII, IlI, p. 193. - Corcovado ou 
Camiuho do Euforeado, Floresta de Tijuca, Serra Estrella, Ruo-dax, $n^{0 \leq} 866,867,2908,6481,7517$. Petit arlure, ll. Wanchlithes. Jauvierdécembre. CC. Vulgo Oriço.

\section{Fam. 20; : Linées.}

1. Linum organense Gardn.; Fl. Bras. X1I, II, p. 459. - Serra tos Orgàos, au Frade, Rio-JAv., $1^{\circ}$ 3744. Sous-frutescent, jaunâtres. Avrilmai. G.

2. L. palustre Gardn.; Fl. Brus. XII, II, p. 461. - Caraça au Morro da Ciurapuça, Mıxss, no 14500 . Sous-frutescent, ll. jaunes. Juin-juillet. C.

3. L. brevifolium St-Hil.; Fl. Bras. XII, II, p. 462. - Serra Negra, au Iorro Gavado, Misas, $n^{\circ}{ }^{\circ} 7622$, 14499. Sous-frutescent, fl. jaunes.

4. L. littorale St-Hil.; var. 3. glandulosum St-Hil.; Fl. Bras. XII, II, p. 463. - Corrego do Brejo, Goysz, n 20739. Herluacé, fl. jaunes. Novemlire. C.

3. L. junceum St-Hil.; var. oblongrfolium Url. in Fl. Bras. XII, II, p. 467. - Serrados Orgãos, Rıo-Jıx., nos 14501, 15835; Campos da Bocaina, $S_{A 0}$ PActo, n 8283. Sous-frutescent, fl. jaunes. Janvier. C.

6. L. usitatissimum L.; Spec. Plant., p. 277. - Chapadão dos Veadeiros, à la Fuzenda de Boa Vista. Goraz, $11^{\circ} 20739 a$. Herbacé, fl. bleues. Cultivé. C.

7. L. selaginoides Lank.; Fl. Bras. XIl, II, p. 468. - Entre Paraty et Campos de Bocaina, São Pillo, $\mathbf{1}^{\circ} 8285 a$. Herbacé, fl. blanc jaunâtre. Janvier. R.

8. Erythroxylon betulaceum Nart.; Fl. Bras. XII, I, p. 132. Entre Ponte de Severiano et Barreira do Veado, Govaz, n² 20740. Petit buisson, fl. banches. Octohre-novembre. R.

9. E. microphyllum St-Hil.; Fl. Bras. XII, I, p. 133. - Petropolis, au Morro Carangola et Nlto Macahé, Røo-J $\mathrm{J}_{\Lambda N}$., $n^{0 \mathrm{os}} 13587,13588$. Arbuste, fl. blanches. Décembre. C.

var. angustifolia Peyr. in $\mathrm{Fl}$. Bras. XII, I, p. 134. - Campos de Nogydos das Cruzes, Sĩo Parlo, n 17487. Petit Juisson, fl. blanches. Janvier-février. C.

var. cuneifolia Peyr. in Fl. Bras. XlI, I, p. 134. - Ouro Preto, au campo de S. Sebastião, Mıxas, no 14549. Arbuste, fl. Banches. Févriermars. C.

var. amplifolia Peyr. in $\mathrm{Fl}$. Bras. XII, I, p. 134. - Alto Macahé de 
1. F.-M. GLAZIOL. - LISTE DES PLAYTES DU BRLSIL CENTRAL. 6I

Nova Friburgo, Rio-Jax., nos 18161, 18921; Ouro Preto, Mıns, n* 18918, 18919. Arbuste, 11. blanches. Nai-octohre. G.

10. E. ovalifolinm Peyr. in Fl. Bras. XII, I, p. I3马. - Copacabana et Ciabo Frio, Rio-J Ax., $n^{\text {os }}$ 85, 2102, 1324, 14547, 10385, 12470; Ouro Preto, Mixas, $n^{\circ}$ 20224. Arbuste, fl. hlanches. Norembre-décem!re. GG.

11. E. Buxus Peyr. in Fl. Bras. XII, I, p. 137. - Petropolis, au Moriu, Rio-Jax., no 13589. Arhuste, fl. blanches. Janvier. G.

12. E. Myrsinites Mart. ; Fl. Bras. XII, I, p. 137. - Campos de Barbacena, Mixs, $n^{\circ}$ 14550. Arluste, fi. blanches. Novembre-décembre. R.

13. E. distortum Mart.; Fl. Bras. XII, I, p. 138. - Restinga de Cabo Frio, Rio-Jax., $1^{\text {os }}$ 10386, 12471. Arbuste, fl. blanches. Septembre. G.

14. E. Mikanii Peyr. in Fl: Bras. XII, I, p. 138. - Restinga de Cabu Frio, Rio-Jax., no 9359. Arbuste, ll. blanches. Mars-avril. R.

I... E. Pelleterianmm St-Hil.; Fl. Bras. XII, I, p. 139. - Alto Macalıé, Rio-Jıx., $n^{\circ s}$ 10353, 18920; Mossamedes. près de Ouro Preto, Mixas, $n^{\text {os }} 16721,20223$. Arbuste, fl. blanches. Octobre-novembre. GC. Vulgo Fructa de Pomba.

16. E. goyazensis Taub. in Beiträge Kenn. Flora Bras., p. 440. Heia Ponte, Goraz, $\mathbf{1}^{\circ}$ 20742. Arbuste, fl. blanchâtres. Août-septembre. C.

17. E. subrotundum St-Hil. : Fl. Bras. XII, I, p. 1'1. - Gavea et Praia Grande, Rin-Jax., $n^{\text {os }}$ 1545. 7534, 10352. Arbuste, 11. blanches. Aout-septembie. CC.

18 E. fiangulafolinm St-Hil.; Fl. Bras. XII, I, p. 143. - Julujulı, à Praïa Grande, Restinga da Tijuca, près de la mer, Rio-JAx., $\mathrm{n}^{\text {os }}$ 4764, 6022, 6111, 7535 et 7536. Arluuste, fl. blanc verdâtre. Aoùt-septembre. GG.

19. E. lancifolinm Peyr. in Fl. Bras. XII, I, p. 14\%. - Petropolis, à Itanaraty, Rio-Jax., $n^{0 s} 6486,14551$. Arbuste, fl. blanchâtres. Aoûtseptembre. R.

20. E. ellipticum Peyr. in Fl. Bras. XII, I, p. 14:. - Alto Macahé de Nova Friburgo et à Serra do Tingua, Rio-Jax., nos 9360, 13411, 13586 , 16722. Arbuste, 11. blanc verdâtre. Octubre-novembre. CC.

21. E. Bongardianmm Neyer in Fl. Bras. XII, I, p. 140̈. - Formaçio, près de Diamantina, Mixis, no 12473. Arbuste, fl. blanches. Marsavril. R. 
29. Eirythroxy-lon cincinnatum Nart.; Fil. Bras. X11, I, p. 146. -

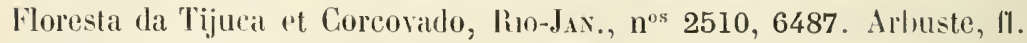
verdâtres. Février-mars. CC.

23. E. revolutum Vart.; Fl. Bras. XII, I, p. 1'T. - Promontoire de Cabo Frio, Ro-JAx., $\mathrm{n}^{0} 10387$ u. Arbuste, 1l. Wlanches. Juilletaoút. R.

24. E. Daphnites Nart.; Fl. Bres. XII, I, p. 149. - Colline de Cabo Frio, Rio-Jax., $10^{03}$ 9669, 10387. Arhuste touffu, f1. blanches. Juinjuillet. R.

2.:. E. intermedium Peyr. in Fl. Bras. XII, 1, p. 1:31. - Corcovado, Gavea et Floresta da Tijuca, Rio-Jax, $n^{0}$ 1437. Arbuste, fl. Wanches. Novembre-décembre. C.

26. E. exaltatum Bong. in Fl. Brus. XII, I, p. 18̈1. - Corcovado, à Paineiras, Rin-Jax., $n^{0 s} 3883,6110,9361$. Arbuste, fl. blanches. Septembre-octohre. CC.

27. E. calophlebium Mart.; Fl. Bras. XII, I, p. 193. - Restinga de Nana, Rin-Jux, ${ }^{\text {os }} 8310$, 14552. Arbrisseau, fl. blanches. Aoùt-septembre. C.

28. E. petiolatum Peyr. in Fl. Bras. XII, I, p. 153. - Serra de Jacarepagua et à Engenho de Dentro, Rio-JAx., n ${ }^{\text {os }} 2943,5757$.

99. E. pulchrum St-Hil.; Erythr. utile Sald. Fl. Bros. XII, I, p. 13\%. - Corevado et Tijuca, Rin-JAx., ${ }^{\text {os }} 839,6108,8578,10349$, 11809. Arthre, fl. banches. Décembre-janvier. CG. Très bon hois de construction. Vulgo Areo de Pipa.

30. E. Coca Lamk; Fl. Brres. XII, I, p. 156. - Quinta de Sìo Christovĩo, Rin-Jux., $\mathrm{u}^{\text {os }} 9670,14554,18160$. Arbuste cultivé, fl. blanches. Avril-mai. G. Vulgo Ipadu-Coca.

31. E. citrifolium St-Hil.; Fl. Bras. XII, I, p. I68. - Corcovado et Tijuca, Rio-Jax., nos 2941, 7533, 9671, 10351; Chacara do Caraça, Mivis, $n^{\circ}$ 14553. Arbuste, fl. banches. Octobre-novembre. CC.

32. E. ficifolium Peyr. in Fl. Bras. XII, I, p. 169. - Larangeiras, au Cosme Velho, Ru-Jux., nos 4763, 9358. Arbuste, 1l. blanches. Octobre-septembre. C.

32. E. suberosum St-Hil.; Fl. Bras. XII, I, p. 170. - Campos de Barbacena, Mixis, $1^{\circ \mathrm{s}} 10348,14545$. Arbuste, fl. blanches. Novemlredécembre. CG. Vulgo Mercurio do campo.

3't. E. nitidum Sprengel; Fl. Bras. XII, I, p. 171. - Entre Barbacena et Sitio et à Italuira do Campo, Minss, $n^{o s}$ 12472, 14548, 16720 ; 
1.-F.-M. GLAZIOU. - LISTE DES PLANTES DU BRÉSIL CENTRAL. 63 Fazenda dos Macacos, Gor.z, nº 20743. Arbuste, 11. blanches. Octobrenovemhre. C.

33. E. tortuosum Mart.; Fl. Bras. XII, I, p. 172. - Arraial de Ouro Branco, Msxas, $n^{\circ}$ 14546; Meia Ponte, Goraz, $1^{\circ}$ 20741. Arbuste, 11. blanc verdâtre. Loùt-septembre. C.

36. E. campestre St-Hil.; Fl. Bres. XII, I, p. 173. - Entre Caraça et Gandarela, Winas, $n^{\circ \text { s }}$ 12474, 13585; Clico Costa, Goyz, $n^{\circ} 20744$. Arbuste, fl. blanches. Aoùt-septembre. C.

37. E. excelsum Glaz. n. sp.? in herl. Berol., Kew., Paris., Harn., etc. - Floresta da Tijuca, Corcovado, Rio-Jıx., nos 6109, 8461, 11808. Très grand arthe, superbe, fl. blanches. Septembre-octobre. C. Vulgo Areo de Pipa.

\section{Fam. 27. : Humiriacées.}

1. Vantanea panniculata Urb. in Fl. Bras. XII, II, p. 490. - Petropolis, dans la forèt vierge, Rro-Jix., $n^{\circ>} 11828,11829$. Grand arbre, fll. jaunàtres. Mars-avril. R. Vulgo Maçarandubinha.

2. V. obovata Benth.; Fl. Bras. XII, II, p. 4̌l. - Biribiry, près de Diamantina, Mısıs, $n^{\circ}$ 18963. Arbuste, fl. blanches. Nar's-avril. G.

3. V. gaianensis Aubl.; Fl. Bras. XII, II, p. 4.92. - Restinga de Cabo Frio, Rro-Jax., n ${ }^{\circ}$ 10078. Arbrisseau, fi. r'ougeàtres. Décembrejanvier. R.

4. V. contracta Urb. in Engl. Bot. Jahrb. (1892), p. 3. - Alto Vlacalıé de Nova Friburgo, Rı-JAx, $n^{\circ}$ 18182. Arthrisseau, ll. blanc jaunâtre. Avril-mai. C.

var. grandforora Urb. in Engler Botan. Jahrb. (1892, Beibl.), p. 3. - Alto Jacahé de Nova Friburgo, Rio-JAx., nº 16723, 18181. Arlıisseau, f1. blanc jaunatre. Mar's-avril. C.

Э. Humiria floribunda Mart.; Fl. Bras. XII, II, p. '138. — Restinga de Cabo Frio, Rio-Jıs., n ${ }^{\circ}$ 10437. Arbrisseau, ll. blanc jaunàtre. Juilletavùt. R.

var. parvifolia Urlo. in Fl. Bras. XII, Il, p. 438. - Restinga de Mana et de Tijuca, Ruo-JAx., n ${ }^{\text {os }}$ 731, 6196, 7765, 18180; Restinga de Cabo Frio, Rı-Jax., no 12515. Arbrisseau toulfiu, fl. blane jaunàtre. Juillet-septembre. GG.

var. montana Urb. in Fl. Bras. XII, II, p. 438. Biribiry, près Diamantina, Mınas, $\mathrm{n}^{\circ}$ 18962. Arbrisseau, 11. hlanchâtres. Mars-avril. G.

6. Saccoglotis cuspidata Urb, in Fl. Brus. XII, II, p. 444. - Entre 
Cidho frio el Lagua Peice, Rio-Jax, $1^{0}$ 13573. Arbre, fl. verdâtres. Septembre. C.

7. Sacoglottis dentata Urb. in Fl. Brus. XII, II, p. 4k任 - liestinga de Hana, Rio-Jax., $\mathrm{n}^{\text {os }}$ 7766, 18178, 18179. Arbrisseau, fl. blance verdâtre. C.

S. S. Glaziovii Urb. in Engl. Bol. Juhrb., (1893)p. 503. - Alto Macahé, de Nova Friburgo, Rio-JAx., nº 18964. Grand arbre, l1. blane verdatte. R.

9. S. dealbata Urb. in Engl. Bol. Juhrb., (1893). - Alto Nacahé de Nuva Friburgo, Ro-dı., $n^{0}$ 16724. Arbre, fl. blanc verdatre. R.

10. S. guianensis Benth.; Fl. Bras. XII, II, p. 448. - Quinta de Sào Christovâo, liı-Jıx., $n^{\circ}$ 13574. Arbrisseau cultivé, fl. verdâtres. Octobre-novembre R.

Fam. ๖8 : Malpighiacées.

1. Byrsonima Berteroana Niedz. in Arbeil.den botan. Insl., 1) 4. - Couralinho, près Diamantina, Mrxs, nº 18924. Arbrisseau, fl. jaunes. Arril-mai. C. Vulgo Murici.

2. B. sericea DC.; Fl. Bras. XII, I, p. 11. - Restinga de Copacahana, Corcorarlo et Tijuca, liı-Jıx., $n^{05} 61,724,725$. Arbuste, 11. jaunes . Janvier-mars. CG. Vulgo Nurici.

3. B. lancifolia Juss.; Fl. Brus. XII, I, p. T; Niedz. in Arbeit. botan. Instil., p. 7. - Formosa, dans les cerralos, Goraz, n 20778. Arbrisseau tortueux, fl. jaunes. Norembre-lécembre. C.

rar. phauhensis Niedz. in Arbeil. bolan. Inslil., p. 7. - Serra dos Puris, Estrmo Savto, no 9695. Arbuste, fl. jaunes. Novemlıre. R.

4. B. internedia Juss. : Fl. Bras. XII, I, p. 8; var. Latıfoura Niedz. - Calreceira do Rio Gama, en Colombisti, Gorrz, nos 9688, 20779. Arlnisseau, fl. jaunes. Novembre-rlécembre. C.

forma vulgaris Niellz. Arb. botan. Inst. p. 9. - Entre Sitio et Barliarena, dans le campo, Iloxss, $1^{0}$ 10354. Alluste, ll. jaunes. Juin-juillet. G.

5. B. oxyphylla Juss.: Fl. Brus. XII, I, p. 22. - Serra da Nangalecira, au Cipó, Mıxas, nº 18925. Arbuste, fl. jaunes. Mars-avril. C.

6. B. cornifolia Nierlz. in Arbeit. bolan. Instil., p. 12. - Entre Hector et Lagerlo, Cabeceiras do Rio Gama, Gor.1z, $11^{03}$ 20775, 20776. Petit arbuste, fl. jaunes. Décembre-janvier. R.

7. B. laxiflora Griseb, in Fl. Bras. XII, I, 1. 10. - Floresta da 
A.-F. -.1. GLAZ10U. — LISTE DES PLAXTES DU BRESH, CENTIAL. 65 Tijura, Corcovado, Rio-Jax., nos 6862, 8579, 10384. Arbrisseau, fl. jaunes. Janvier-février. C. Vulgo Murici.

S. B. oblanceolata Niedz.; Arbeit. botan. Instit., p. 14. - Entre Sambaitiba et Porto das Caixas, Rio-Jıx., no 11818. Grand arbre, f1. jaunes. Octolre. R.

9. B. Glazioviana Niedz., Arbeit. botan. Instit., p. 14. - Serra dos Crystaes, près Diamantina, Mrxs, nº 18925 a. Arlıuste, fl. jaunes. Marsavril. C.

10. B. crassifolia Kunth; Fl. Bras. XII, I, p. 18: var. trpica Niedz. in Albeit. botan. Instil., p. 16. - Congonhas do Campo, Mrias, n 13412. Alluste, fl. jaunes. Mars-avril. R. Vulgo Murici.

var. cinerea Niedz. in Arbeit. botan. Instit., p. 17. -. Quinta de São Christovão, Riı-Jax., nos 4766, 6861. Arbuste cultivé, fl. jaunes. Janvier-février. C. Vulgo Murici.

11. B. variabilis Juss.; Fl. Bras. XII, I, p. 7 ; var. velurna Niedz., Arbeit. botan. Instil., p. 22. - Entre Sitio Barluacena et Queluz, Mivas, $n^{\text {os }}$ 10355, 14560, 20225. Arbuste, f1. jaunes. Janvier-mars. Vulgo Hurici.

f. 2 oblongifolia Niedz. Arbeit. botan. Instit., p. 22. - Campos da Bocaina, Sĩo Paclo, nº 8294; Sitio de Barbacena, Mlsas, $1^{0 s} 10355$, 14560, 20225 ; Pedra do Conego, à Nova Friburgo, Rio-Jax., n 11817. Arluste, fl. jaunes. Janvier-nıars. CC. Vulgo Murici.

12. B. viminalifolia Juss.; Fl. Bras. XIl, I, p. 21 ; var. Latifola Niedz. in Albeit. botan. Instit., p. 23. - Cabeceiras do Rio Torto dans le rampo, Govaz, no 20777. Petit arbuste, fl. jaunes. Octobre-novemire. C.

val. velgaris Niedz. in Avb. bot. Ihst., p. 23. - Cabeceira do Rio Cramia, dans le campo, Goyaz, $n^{0}$ 20773. Plante naine, fl. jaunes. Or.tolre-novemlore. C.

var. numbis Niedz. Arbeit. botan. Instil., p. 24. - Pichoa et Cabeceiras do Rio Torto, Goyaz, ${ }^{\circ s}$ 20771, 20772. Plante naine, fl. jaunes. Oetobre-novembre. CC.

13. B. Orbignyana Juss.; Niedz., Arbeit. botan. Instit., p. 29..kio Manço et Congonhas do Campo, Mivas, nos 12478, 12479, 14559. Arbuste, 11. jaunes. Octobre. C. Vulgo Murici.

1't. B. cydoniifolia Juss. var. cureurtensis Nied. in Arbeit. bolan. 
Instil., p. 29.3. - Forma!âa, près Diamantina, Minas, $\mathbf{n}^{0}$ 18923. Arluste. 11. jaunes. Avril-mai. R.

1\%. Byrsonima Guilleminiana Juss.; Fl. Bras. XII, I, p. 6. Cabeceiras do lio Gami. dans le campo, Govaz, n² 20769. Arbuste, t1. jaunes. Octolse. C.

16. B. pachyphylla Juss.; Fl. Bras. XII, I, p.6; var. latrolia Niedz. - Gimpos de S. Sebastiño, près de Ouro Preto, Mısas, no 14558. Arbrisseau, fl. jaunes. Février. C.

var. Lamceolata Niedz. Arbeit. botan. Instit., p. 27. - Ayuruoca, dans le campo, Mıxas, $n^{0}$ 14557. Arbuste, fl. jaunes. Juillet-août. R.

17. B. verbascifolia Rich.: Fl. Bras. XII, I, p. ॐّ; var. \%. discolor Grisel. in Niedz. Arbeit. botan. Instit., p. 28. - Ayuruoca, Mlsas, $\mathrm{n}^{0}$ 9366. Plante naine, f1. james. Mar's-avril. C.

var. vulgaris Niedz. in Arbeit. bolan. Instit., p. 28. - Ayuruoca, dans le eampo, Mrsas, no 9366 a. Arbuste, fl. jaunes. Mars. C.

var. villosa Griseb. in Nietz., Arb. botan. Instit., p. 28. - Serra dos Pyreneos et Chapadão ilos Veadeiros, Goraz, n ${ }^{\text {os }}$ 20767, 20768. Plante naine, fl. jaunes. Janvier. C.

18. B. crassa Niedz. in Arbeil. dem. bolan. Inst., p. 30. - Guariroba, dans le cimpo, Goyaz, $\mathbf{n}^{0}$ 20770. Plante naine, fl. jaunes. Octobrenovembre. C.

19. B. basiloba Juss.; Fl. Bras. XII, I, p. 21. - Serra dos Veadeiros et à Guariroba, dans le campo, Govız, nos 20781, 20782, 20783. Plante naine, fl. jaunes. Octolire-novembre. C.

20. B. myrcifolia Griseb.; var. glandulosa Niedz., Warming Syzmb. ad Fl. Bras. I, p. 12.: - Serra dos Orgãos, Tingua et Alto Hacahé, Rio-JAx., nos 3893, 8591, 10358, 13596, 17489. Arbuste, fi. roses. Janvier-avril. CC.

var. eglandulosa Niedz., Warm. Symb. Fl. Bras. I, p. 125. - Alto Hacahé, Rio-Jax., $1^{0 s} 16727,16728,17490$. Arbuste, fl. james. Févriermars. G.

21. B. ligustrifolia Juss.; Fl. Bras. XII, I, p. 8. - Pico da Tijura, Rio-Jax., $n^{\circ} 4949$; campos de Barbacena, Misas, nos 8292, 20232. Arbrisseau, ft. jaunes. Octobre-novembre. C. Vulgo Murici.

29. B. yernicosa Niedz. in Arbeit. botanisch. Instit., p. 33. - Petropolis, à Itamaraty, Rı-J $\mathrm{JN}_{\mathrm{N}}, \mathrm{n}^{\text {os }}$ 10906, 12476. Arbrisseau, fl. jaunes. Janviel-mars. C. Vulgo Murici. 
A.-F.-M. GLAZIOU. - I.ISTE des l'LANTES DU BRÉSIL CENTral.

23. B. decipiens Niedz. Arbeit. bot. Instit., p. 35. - Retiro, près Petropolis, Rio-Jax., n 6490. Grand arbre, 11. jaunes. Février-mars. C.

2'. B. umbellata Mart.; Fl. Bras. XII, I, p. 1T. - Cabeceira do Rio das Pedras, Goraz, n² 20780. Arbuste, fl. rose pâle. Mars-avril. R.

¿气̆. B. noulifera Spr.; Niedz. Arbeit. botan. Instit., p. 37. - Araruama, près Cabo Frio, Rio-Jax., nº 9694. Arbuste, f1. jaunes. Décembrejanvier. R.

26. B. bryoniifolia Nielz. ill Arlseit. botanisch. Instit., p. 38. Serra do Lenheiro et Caraça, Mras, $1^{03}$ 12480, 13597, 14561. Arbuste, 11. jaunes. Septembre-octobre. C.

27. B. cocolobifolia Humb. B. et K. : Niedz. Arbeit. botan. Instit., p. 38. - Arraial de Ouro Branco, Biribiry, Misus, no ${ }^{0 s}$ 14556, 18922; Serra Dourada, Goraz, $n^{\circ}$ 20774. Arbrisseau tortueux, f1. roses. Octobrenovembre. C.C.

28. B. cuprea Griseb. in Fl. Bras. XII, 1, p. 19. - Cabo Frio, RioJax., $n^{0} 9693$; Serra da Bocaina, SAo PAulo, $n^{\circ} 9696$. Arbuste, f1. jaunes. Décembre-janvier. C.

29. B. uroceras Niedz. in Arbeit. dem botan. Instit., p. 42. - São Pedro dos Indios, près Ciabo Frio, Rio-JAx., $1^{\circ}$ 9692. Arbuste, 1l. jaunes. Févier-mars. R.

30. Malpighia punicifolia L.; Fl. Brus. XII, I, p. 31. - Quinta de São Christovão, Rio-Jı., nos 3886,14555 . Petit arbuste cultivé, fl. roses. Norembre-décembre. C.

31. Bunchosia fluminensis Griseb. in Fl. Bras. XII, 1, p. 31.Floresta da Tijuca, Rio-Jax, no 726. Arbuste, f1. jaunes. Mars-avril. C.

32. Burdachia prismatocarpa Nart.; Fl. Bras. XII, I, p. 23.Quinta de São Christovão, liıo-JAx., nº 726 a. Arlıuste cultivé, fl. jaunes. Septembre-octobre. R.

33. Dicella bracteosa Griseb. ill Fl. Bras. XII, I, p. 32. - Campos da Bocaina, Sĩo Pavto, no 10366 a Serra do Caraça, au Bom Jardim, Mıxı, n ${ }^{\circ}$ 14563. Liane, 11. jaunes, Février-mars. C.

34. Emanthera latifolia Griseb. in Fl. Bras. XII, I, p. 29. - Caraç, Caminho da Chacara, Miss, $n^{\circ}$ 13593. Arbuste, 11. jaunes. Septembreoctobre. R.

3อ.. Pterandra pjroidea Juss.; Fl. Bras. Xll, I, p. 30. - Carandahy, Misis, nos 14562, 18930, 20233 ; Maracos, au Morro dos Crystaes, Goraz, $n^{\circ} 20766$ a. Arbuste des campos, fl. roses. Juillet-Septembre. C. Vulgo Roño. 
36. Thryallis latifolia Mart. var. acumnata Niedz. Fl. Bras. XII, I, p. 34. - Bord du Rio Paranna, Mrsas, $1^{\circ}$ 18946. Grande liane, 11. rose pâle, Mars-arril. C.

37. T. brachystachys Lindl.; Fl. liras. XII, l, p. 34. - Corrovalo, aux Bois Jimãos, Rı-JAx., nos 723, 1058. Liane, fl. jaunes. Novembredécembre.

38. Galphimia brasiliensis Juss.; Fl. Bras. XII, I, p. 28. - Santa Luzia do Rio das Vellas, Nisas, $n^{\circ} 20228$; Fazenda Cova, près Monjolo, Goraz, $11^{\circ}$ 20766. Petit arbuste, ll. jaunes. Novembre. C.

39. Lophanthera longifolia Griseb. in Fl. Brus. XII, I, p. 2.:. Quinta de São Christovão, Ro-J $\mathrm{J}_{\mathrm{A} .}, \mathrm{n}^{\circ}$ 9690. Arbuste cultivé, fl. jaunes. Janvier-février. Li.

40. Heteropteris trigonice folia Juss.; H. Brus. XII, I, p. 66. Serra do Ouro Branco, Mixas, $n^{\circ \mathrm{s}} 13599$, 14568. Arbuste des campos, fl. jaunes. Janvier-novembre. C.

41. H. confertiflora Juss.; Fl. Bras. XII, I, p. 6ï. - Villa Nova, Ro-Jav., $n^{\circ} 7542$; campos da Ayuruoca, Mıxas, $n^{\circ} 18944 a$. Liane, fl. roses. Avril-mai. 1 .

42. H. rufula Mart.; Fl. Bras. XII, I, 1. 68. - Floresta da Tijuca, Rio-Jax., no 8462. Arbuste sarmenteux, h. roses. Miti-juin. C.

43. H. campestris Juss.; Fl. Bras. XII, 1, p. 66. - Biribiry, près de Diamantina, Mlixas, no 18944 u. Liane, fi. roses. Mars-avril. C. Vulgo Bobento.

44. H. rubiginosa Juss.; Fl. Brus. XII, I, 1) 6̈̈. - Barhacena, Hixas, no 10374 ; Chico Lobo, daus le campo, Goraz, no 20759. Arbuste, fl. rougeâtres. Juillet-avit. C.

40. H. pteropetala Juss.; Fl. Bras. XII, I, 1. 66. - Petropolis, à Santo Antonio, Rit-Jax., $11^{\circ} 8581 a$. Grosse liane, fl. jaunâtres. Décenbre-janvier. R.

46. H. cordifolia Moric. : Fl. Bras. XII, I, 1. 6\%. - Serra do Picú, Mixas, no 10380. Liane, fl. jaunes. Avril-mai. C.

47. H. trichanthera Juss.; Fl. Bras. XII, I, 1. 60. - Rio Manso, dans le campo, llıxs, $1^{\text {os }}$ 13605, 13609, 13610, 13611. Árbuste sarmenteux, fl. jaunes. Nai-juillet, CG.

48. H. Martiana Juss.; Fl. Bras. XII, I, p. 64. - Curitiba, dans le campo, Paravi, $n^{0}$ 15867. Arbuste salmenteux, f1. jaunes. Marsavril. C.

49. H. verbascifolia Gr.; Niedz. in Arbeiten dem bolun. Instit., 1. 16. 
- Diamantina, dans le campo, Mrss, $11^{\text {os }} 15866 a, 18943 a$ et $20759 a$. Arbuste sarmenteux, f1. jaunes. Mars-avril. C.

50. H. syringafolia Griseb.; Fl. Bras. XII, I, p. 64. - São José dos Pinhaes, Paraxa, $n^{\circ} 15867$ a. Arbuste sarmenteux, fl. jaunes. Marsarril. C.

8.1. H. angustifolia Gris.; Fl. Bras. XII, I, p. 64. - Entre Sitio et Barbacena, Mrxs, nº 14569 a. Arbuste, fl. jaunes. Septembre-octobre. R.

52. H. glabra Ilooh. et Arn.; Niedenzu Arbeiten botun. Inst., p. ㄴ.3. - Entre Barbacena et le Sitio, dans le campo, Mrsas, $n^{\circ}$ 14569. Arbuste, 11. rosées. Octohre-novembre. C.

53. H. umbellata Juss.; Fl. Brus. XII, I, p. 63. - Arraial de Ouro Branco, Mrsas, no 14568 a. Arluuste touffu, fl. jaunes. Janvier-férrier. C. 5.'. H. bicolor Juss.; Fl. Bress. XII, I, J. 64. - Norro do Pico de Santa Cruz, Rio-Jis., nº 6849. Arbuste, Il. jaunes. Novembre. R.

3\%. H. Glasioviana Niedz. in Arbeiten dem botan. Instit., 1. 2-7. Morro do Morin, près Petropolis, Rro-Jax., $1^{05}$ 8590, 10359, 13595, 16730. Superbe arbuste, fl. jaunâtres. Janvier-février. C.

56. H. chrysophylla liunth; Fl. Bras. XII, I, p. 7't. - Copacabana et à Gavea, Rio-J.s., $n^{\text {os }} 86,6106$. Arbuste sarmenteux, fl. jaunes. Décembre-janvier. C.

5ั. H. sericea Juss.; Fl. Brus. XII, I, 11. 73. - Tijuca et Corcovado, $n^{0 s}$ 4769, 18943; et Serra dos Orgãos, Iho-JAx., $n^{05}$ 7541, 16726; Serra da Babylonia, Mrsis, $n^{\circ 5} 3669$, 20226. Arbuste sarmenteux, 11. jaunes. Septembre-norembre. CC.

58. H. banksicefolia Griseb.: Fl. Brus. XII, I, p. 7't. - São Christorão, Rio Trapixeiro, Tijuca, Rio-Jax., $1^{05}$ 720, 1062, 10367. Arbuste, 11. jaunes. Janvier-mar's. CC. Vulgo: Cipó preto.

59. H. nitida huntlı; Fl. Brus. XII, I, P. 74. - Rio Trapixeiro, Rio-Jax., $n^{03}$ 720, 10367: Petropolis, au Morin, Rio-Jas., $1^{\text {os }} 8590$, 10359, 13595, 16730. Arbuste sarmenteux, fl. jaunes. Janvier-mar's. C.

60. H. coleoptera Juss.; Niedenzu in Arbeiten botan. Instit., p. 32. - Restinga de Cabo Frio, Rio-J.x., ${ }^{\circ}$ 10382. Arbuste sarmenteux, f1. jaunâtres. Juin-juillet. R.

61. H. aceroides Griseb. in Fl. Bras. XII. I, p. 63. - Gavea et Serra de Estrella, Rio-Jav., $\mathrm{n}^{\text {os }} 716,1063.3889,3890,6107$. Arbuste sarmenteux, fl. jaunes. Décembre-janvier. CC.

var. angustata Griseb. in Warm. Symb. fl. Bras, centr., I, p. 137. 
- Magé, Rı-JAx., $n^{0}$ 1590. Arbuste sarmenteux, fl. jaunes. Octobre. C.

var. pachyphlla Griseb.; Warm. Symb. F\%. Bras. cent., I, p. 137. - Magé, près de Jacú, hio-Jax., nos 6105, 9676. Arbuste sarmenteux, fl. jaunes. Novembre-décembre. R.

6.2. Heteropteris crenulata Mart. in Fl. Bras. XII, I, 1. 62. - Rio Manso, dans le eampo, Mivas, $n^{\circ}$ 13608. Arbuste sarmenteux, fl. janne rougeâtre. Février-mars. C.

63. H. panciflora Juss.; Fl. Bras. XII, I, P. 62. - Corcovado el Gavea, Rio-JAN., n ${ }^{\circ \mathrm{s}} 1500,7854,8291$, 10356. Liane, fl. jaunes. Juinjuillet. C.

64. H. Leschenaultiana Juss.; Fl. Bras. XIl, I, p. 61. - Restinga da Tijuca, Rio-J $\mathrm{AN}_{\mathrm{N}}, \mathrm{n}^{\mathrm{os}} 1060,1327$. Arbuste un peu sarmenteux, fl. jaunes. Juillet-août. C.

6\%. H. transiens Nierlz. in Arbeiten dem botun. Instit., p. 39. Alto Macahé de Nova Friburgo, Rı-JAn., no 16725. Grande liane, 11. jaunes. Février-mars. R.

66. H. crinigera Griseb. Symb. Fl. Bras. cent., 1, 1. 136. - Serri de Jacarepagua, Rı-JAN., $\mathbf{n}^{\text {os }} 3885,4767$. Arbuste sarmenteux, fl. jaunes. Novembre-lécembre. R.

67. H. ilicifolia Griseb.; Fl. Bras. XII, I, p. 61. - Jurujuba, près de la mer, Rio-Jax., $n^{\circ}$ 6848. Arbuste un peu sarmenteux, fl. jaunes. Novembre-décembre. C.

68. H. anomala Juss.: Fl. Bras. XII, I, 1. 59. - Corcovado et Tijuca, Rio-Jan., nos 2944, 2945; Serra do Mar, à Petropolis, Rio-Jan. $\mathrm{n}^{\text {os }} 8299,10369,11814,18165$. Arbuste sarmenteux, fl. jaunes. Haijuin. C.

69. H. thyrsoidea Juss.; Fl. Bras. XII, I, p. 58. - Rio do Ouro, Rio-JAN., n ${ }^{\circ}$ 10369. Arbuste un peu sarmenteux, fl. rougeâtres. Féviermars. R.

70. H. ciliata Niedz. in Arbeiten dem botan. Instit, p. 42. - São Fidelis, près Campos, Rı-Jax.: n 9678. Arbuste sarmenteux, fl. rougeâtres. Janvier-février. C.

71. H. procoriacea Nielz. in Arbciten botan. Instit., p. 43. Ponte Lavrado, Goyaz, nos 20760, 20763 a et 20764. Arluuste, 11. jaumes. Aout-septembre. C.

72. H. coriacea Juss.: Fl. Bras. XII, I, p. 69. - Fazenda do Palmital, dans le campo, Goraz, $n^{\circ}$ 20765. Arbuste, f1. jaunes. Mai-juin. li.

73. H. xanthophylla Juss.; Fl. Bras. Xll, I, 1. 69. - Forquilha à 
Faria dans le cerrado, Goyaz, nº 20762. Arbrisseau tortueux, fl. jaunes. toùt-septembre. C.

74. H. byrsonimifolia Juss.: ex Nierlz. Arbeit. dem botan. Inst., p. 4̌̈. - João Lobo, dans le cerrado, Goraz, n 20763: Carandahy, Hras, $n^{\circ}$ 12488. Arbuste, f1. rougeâtres. Aoùt-septembre. C.

7\%. H. escalloniafolia Juss.: FT. Bras. XII, I, p. 69. - Campos da Bocilina, Sĩo Padlo, no 10376 ; Serra de Ouro Branco, Mrxas, nos 14570 , 20229. Arluuste, fl. jaunes. Norembre-décembre. C.

76. H. grandiflora Juss., Mart.; Fl. Bras. XII, I, p. T1. - Entre Saiavelhal et Santa Luzia, Goraz, n ${ }^{\circ 8} 20230,20761$. Arluuste un peu sarmenteux, t1. jaunes. Aoùt-septembre. C.

7. H. anoptera Juss.: Fl. Bras. XII, I, p. T0. - Diamantina, dans le campo, Hras, $n^{\circ}$ 18941. Arbuste samenteux, t1. jaunes. Avril-mai. R.

78. H. eglandulosa Juss.?; Fl. Bras. XII, I, p. 71. - Verces do Arrassuahy, Mrras, $n^{\text {os }} 13612$, 13614. Arbuste sarmenteux, f1. jaunes Avril-mai.

79. H. acutifolia Juss.; Fl. Bras. XII, I, p. 70. - Campos da Bocaina, Sio P.tco, no 10377; Diamantina, à Jendanha, Nıss, nos 13613, 13590, 15866. Arbuste sarmenteux, f1. jaunes. doût-septembre. CG.

80. Brachypteris borealis Iuss.; Fl. Bras. XII, 1, p. 3̈̈. - Sâo joão da liarra, pris Campos, Rio-Jax., n 9684. Petit arbuste, fl. rougeâtres. Février-mars. R.

81. B. australis Juss.; Fl. Bras. XlI, I, p. 3ٌ. - Restinga da Tijuca, Rio-Jax,, $n^{\circ}$ 5755. Arbuste, fl. rougeâtres. Septembre-octobre. C.

82. Stigmaphyllon urencefolium Juss.; Fl. Bras. XII, 1, p. 41.Entre Caraça et Mendanlıa, Misss, $n^{\text {os }} 12482$, 13604. Petite liane, f1. jaunes. Mars-avril. C.

83. S. Lalandinum Juss.; Niedenzu in Index Lection., p. 6. Lagoa de Rodrigo de Freitas et Petropolis, Rio-JAx., n ${ }^{\text {os }}$ 715, 8580. Petite liane, fl. jaunes. Février-mars. C.

8't. S. convolvulifolium Juss.; Fl. Bras. XIl, I, p. 38. - São Sebastião, près de Itabapoana, Rı-JAN., $n^{\circ}$ 9674. Liane, fl. jaunes. Février-mars. C.

8.i. S. rotundifolium Juss. : Fl. Bras. XII, I, p. 38. - Angra dos Reis et Cabo Frio, Rio-Jax., no 4936, 13594. Petite liane, 11. jaunes. Novembre-décembre. C.

86. S. fulgens Juss.; Fl. Bras. XII, I, p. 39. - São Sebastião, près de Itabapoana, Rio-Jax., nº 9672. Grande liane, f1. jaunes. Février. C. 
87. Stigmaphy-llon Gayanum Juss.: Fl. Bras. XII, I, p. 10. Serra do Guro Branco, Mrsas, $1^{\circ}$ 12481. Graude liane, fl. jaunes. Avrilmai. C.

88. S. affine Juss.; Fl. Bras. XII, I, p. 40. - Quinta de São Christovão, Rro-Jav., $n^{0}$ 5767. Petite liane, fl. jaunes. Mai-juin. G.

89. S. psilocarpodium Nied\% in Index Lectionum, 1). 1\%. - Serra do Picú à Boa Vista, Rio-Jax., n 10362. Grande liane, fl. jaunes. Avril-mai. R.

90. S. auriculatum Juss.; Fl. Bras. XII, I, p. 37. - Restinga da Tijuca, au Ponto do Mariseo, Riı-JAv., no 10373. Liane, fl. jaunes. Novembre-décembre. G.

91. S. jatrophifolinm Juss.: Fil. Bras. XII, I, p. 36. - Restinga da Gavea, près de la mer, Rio-Jan., $11^{\circ} 1146 a$. Volubile, fl. jaunes. Octobre-novembre. C.

92. S. vitifolizm Juss.; Fl. Bras. XII, I, p. 36. - Lagoa de Freitas, Rı-JAx, $\mathrm{n}^{\text {os }} 1146$, 10372. Liane, f1. jaunes. Septembreoctobre. C.

93. S. angustifolium Juss.; $\mathrm{Fl}$. Bras. XII, I, 1. 4.1. - Valanea, Boa Vista, Cachoeira et Petropolis, Rro-Jan., nos 2141, 4935, 8463 et 10360. Petite liane, fl. jaunes. Avril-juin. CG.

94. S. littorale Juss.; Fl. Bras. XII, I, p. 40. - Corcovado, Copacabana et Tijuca, Rio-JAN., nos 227, 1061, 2115, 10361. Petite liane, fl. jaunes. Décembre-janvier. CC.

93. S. ciliatum Juss.; Fl. Bras. XII, I, p. 37. - Gavea, près de la mer. Rio-Jax., no 717. Petite liane, fl. jaunes. Novembre-décembrn. GC.

96. Banisteria ferruginea Car. : Fl. Brus. XII, I, p. 42. - Corcovado, à Paineira et à Sapopemba, Rio-Jax,, $11^{\text {os }} 1325,6489,8588$. Arbuste un peu sarmenteux, fl. jaunes. Avril-mai. C.

97. B. ovata Niedz. Index Lectionum, p. 7. - Entre Caraça et Arassualıy, dans le bois, MlNas, ${ }^{\text {os }} 12492,13607,13615$. Arbuste un peu sarmenteux, fl. jaunes. Janvier-mars. C.

98. B. Sellowiana Juss.; Fl. Bras. XII, I, p. 4't. - Entre Belem et Queimados, Rıo-Jax, $n^{\text {os }} 8587$, 9676; clımin d'Arassuahy, Mrsas, $n^{\circ}$ 12484. Grande liane, fl. jaunes. Octobre-novembre. C.

99. B. Gardneriana Juss.; Fl. Bras. XII, I, p. 44. - Riacho das Varas, Misas, ${ }^{\text {os }}{ }^{2} 12490,18942$. Grande liane, fl. jaunes. Marsavril. G. 
A.-F.-M. GLAZIOG. — LISTE DES PLANTES DU BRESIL CEXTRAL. i3

100. B. Clausseniana Juss.; Fl. Bras. XII, I, P. 44. - Serra da Estrella, Rio-Jax., $n^{\circ}$ 12489; Rio Areas et pres de Neia Ponte, Goriz, $n^{0 .} 20754,20756,20756 a$. Grande liane, fl. jaunes. Iout-septemlore. C.

101. B. parviflora Juss.: Fl. Bras. XII, I, p. öt. - Serra do Picú, Rı-Jax., nº 10365. Liane, tr. james. Mars-avril. R.

102. B. scutellata Griseh.: Warm. Symb. Fl. Bras. cent. I, p. 131. - Corcarado el Tijuca, $n^{\text {os }}$ 2512, 3894, 8583, 10370 et Petropolis, Serra da Estrella, Rin-Jix., nos 11811, 11812. Liane, fl. jaunes. Janvier-février. C.

Var. oвtusa Nied\%. Ind. Lect., 1. 12. - Ayuruoca, au Pico do Papagaio, Mrsss, n 16362. Liane, fl. james. Décembre-janvier. R.

103. B. lavifolia Juss.: Fl. Bras. XII, I, p. 48. - Serra de Ouro Branco, Mrsas, $11^{\circ}$ 18163; haut du Morro do Conego, à Nova Friburgo, Rio-J.s., n $18162 a$. Arluste un peu samenteux, fl. jaunes. Févriermars. C.

104. B. argyrophylla Juss.; Fl. Bras. XII, I, p. 49. - Serra do Ouro Branco, Мrss, $\mathbf{1}^{\circ}$ 18162. Grande liane, f1. jaunes. Mars-avril. C. Vulgo Cipo prata.

105. B. megaphylla Juss.; Fl. Bras. XII, I, p. \$1. - Corrego secco, Mixas, $n^{\circ}$ 18938. Arbuste des campos, fl. jaune rosé. Mars-arril. C.

106. B. campestris Juss.; Fl. Bras. XII, I, p. ॐ0. — Serra da Bocaina, Sto Patlo, nos 8293, 13602. Petit arbuste, f1. jaunes. Févriermars. C.

107. B. lanceolata Nierlz. in Index Lectionum, p. 17. - Serra do Caraça, dans le campo, Msis, $n^{\circ}$ 13606. Arbuste, fl. jaunes. Férriermars. R.

108. B. angustifolia Juss.; Fl. Bras. XII, I, P. ๖ั0. - Serra do Caraça, au Calvario, Mrras, $n^{\circ}$ 14567; Morro da Gloria, prẻs de Sabará, Mrsas, $1^{\circ}$ 18164. Arluuste, fï. jaunes. Janvier-février. C.

109. B. latifolia Juss.; Fl. Bras. XII, I, p. „33. - Santa Luzia, dans les cerrados, Govaz, $n^{05}$ 20750, 20751. Arbrisseau, fl. jaunes. Marsavril. C.

110. B. crotonifolia Juss.; Fl. Brus. XII, 1, p. Ӟ1. - Entre Diamantina, Mendanha et Morra do Ramão, Mrsas, nos 12486, 13598, 18927, 18928; Santa Luzia. Goraz, $n^{\circ}$ 20752. Arbuste, fl. rougeâtres. Avriljuin. CG.

111. B. schizoptera Juss.; Fl. Bras. XIl, I, p. 48. - Barueri et Campinas, SaO Pacto, $n^{\circ} 12475 a$. Grande liane, fl. jaunes. Marsavril. R. 
11․ Banisteria intermedia Juss.; Niedenzu, Index Lection., p. 21. - Rio Nanso et Serra dos Crystaes, pres Diamantina, Misas, nos 12485 , 18939. Liane, 11. jaunes. Juillet-aoùt. C.

113. B. stellaris Griseh.; Fl. Bras. XII, I, p. 47. - São João da Barra, Rio-Jax., nos 9682, 10381. Petite liane, tl. jaunes. Pévriermars. R.

114. B. multifoliata Juss.; Fl. Bras. XII, I, p. 53. - Santa Thereza, au Corcovado, Rin-J $J_{A x}$, $n^{\text {os }}$ 1059, 8586, 9363. Liane, 11. jaunes. Juillet-aoùt. C.

113. B. membranifolia Juss.; Fl. Bras. XII, 1, p. 52. - Petropolis et Alto Nlacahé, Rio-JAx., nos 10357 et 18950. Grande liane, t1. james. Vars-avril. C.

116. B. adenopoda Juss.; Fl. Bras. XII, I, p. 52. - Petropolis, à Santo Antonio, Rin-JAx., $n^{\text {os }} 8582$, 9364; Barueri et Mogydas Cruzas, Sĩo Paclo, nos 12475, 17488; Serrinha, Minas, $1^{08} 18947$, 18948. Liane, 11. jaunes. Arril-mai. CC.

117. B. oxyclada Juss.; Fl. Bras. XII, I, p. 5̈2. - Lagos, près de Saluara, Hıxas, $n^{\circ} 18945$; Santa Luzia, Goraz, $n^{\circ}$ 20755. Grande liane, fi. roses. Mars-avril. C.

118. B. metallicolor Juss.; Fl. Bras. XII, I, p. 53. - Entre Bocaina et Pinheiro, Sĩo Paclo, $n^{\circ} 16362 a$; Santa Luzia do Rio das Vellas, Mrvas, $1^{\circ} 20231 a$. Grosse liane, fl. jaunes. Jécembre-janvier. C.

119. B. pruinosa Vart ; Fl. Bras. XIl, I, p. 83. - Serra dos Orgãos, Rio-Jax., $11^{03} 3888,9673,11816$. Liane, f1. jaunes. Mars-avril. C.

120. B. hypericifolia Juss.: Fl. Bras. XII, I, p. 47. - Paranauna, dans le campo, Minas, $1^{\circ} 18935$. Petit arbuste, fl. jaunes. Avril-mai. R.

121. B. virgultosa Mart.; Niedenzu Index Lection., p. 13. - Morro Queimado, près Nova Friburgo, Rı-JAx., $n^{\circ} 3884$. Arbuste, fl. jaunes. Octobre-novembre. R.

129. B. nigrescens Juss. : Fl. Bras. XII, I, p. 47. - Entre Caraça et Vendanha, Minas, n 12483. Arbuste, fl. jaunes. Novembre-décembre. R.

123. B. rigida Juss.; Fl. Bras. XII, I, p. 46. - Serra do Cipo, près du Rio das Pedras, Mris, $n^{0}$ 18936. Arbuste, f1. jaunes. Mars-avril. R.

124. B. Lucida Rich.; Niedenzu in Index Lection., 1) 16. - Horro do Cavallão, à Praia Grande, Rio-Jax., nº $8588 a$. Arbuste, fi. jaunes. Février-mar's. R.

129. B. pubipetala Juss.; Fl. Bras. XII, I, p. 40̈. - São João da Barra, Rio-Jan., $\mathrm{n}^{08} 9679$, 10383; Riberrão de Caldas, au Ponso Alexandre, Goysz, nos 20231, 20758. Arbuste, fl. jaunes. Juillet-aoùt. G. 
1.-F.-M. GLAZIOU. - LISTE DES PLANTES DU BRÉSIL CENTRAL. 75

126. Peixotoa glabra Juss.; Fl. Bras. XII, I, p. \#̈. - Serra dos Ciristaes, près de Diamantina, Mısas, $n^{\circ}$ 18937. Petit arbuste, fl. jaunes. Avril-mai. R.

1277. P. hispidula Juss.; Fl. Lras. XII, I, p. :̈5̆. - Praia Grande, à Taipú, Rı-JAx., nos 1328, 3891, 11815. Petit arbuste, fl. jaunes. Févriermars. C.

128. P. Jussienana Mart. : Fl. Bras. XII, I, p. З̌6. - São João da Borra, Rio-Jax., no 9680; Fazendo Palmital, Goraz, n² 20749. Liane, fl. jaunes. Iuin-juillet. C.

129. P. cordistipula Juss. : Fl. Bras. XII, I, p. ¿6. - Petropolis, a Santo Antonio, Rio-Jax., no 8581. Liane, fl. jaunes. Février-mars. C.

130. P. reticulata Gris.; Fl. Bras. XII, I, p. ̈6. - Diamantina, au Tombador, Mras, no 18930. Arbuste sarmenteux, fl. jaunes. Marsavril. C.

131. P. tomentosa Juss.: Fl. Bras. XII, I, p. :7. - Serra do Lenheiro, près de S. Juão d'El Rei, Mras, nos 16731, 20749u. Liane, fl. jaunes. Octobre. C.

132. P. macrophylla Griseb.; Fl. Bras. XII, I, p. : 77.- Petropolis, à

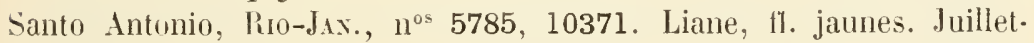
aoùt. C.

133. P. parviflora Juss.: Fl. Bras. XII, I, p. 5̈ . - Taquaruçu, à Serrinla, Mısas, $n^{\circ}$ 18929. Liane, fl. jaunes. Mai-juin. C.

134. Ptilochæta glabra Nierlz. n. var. lanceolata in herb. Berol., Kew, etc. - Caraça, au Bom Jardim, Mrsas, n ${ }^{\circ}$ 15446. Arbuste, ff. blanchàtres Juillet.

var. latifolia in lıerh. Berol., Kew., etc. - Caraça, chemin de Mendanha, Mixs, no ${ }^{0}$ 13485. Arbuste, 11.? fruit laineux. Ociobre-norembre.

13\%. Hiptage Madablota Giertn. Fruct. I1, p. 169, t. 116. - Quinta de São Christorão, Rio-Jıx., n² 2900. Arbuste sarmenteux, 11. roses. loût-septembre. R.

136. Tetrapteris rotundifolia Juss.; Fl. Bras. XII, I, p. 78. Gavea et Tijuca, liı-JAx., $\mathrm{n}^{0 \mathrm{~s}} 55,1145,12477,10363$. Arbuste sarmenteux, f1. jaunes. Mlars-avril. C.

var. vibunntrolia Mart. in Fl. Bras. XII, I, p. 78. - Gavea, près de la mer, Rio-Jax., $n^{0 \mathrm{~s}}$ 5762, 18926. Arbuste sarmenteux, 11. jaunes. Mai-juin. G.

137. T. bracteolata Grisel..; Fl. Bras. XII, I, p. 79. - Santa Thereza, au Corcovado, Riro-Jax., nos 3892, 9687. Arbuste sarmenteux, fl. jaunes. Février-mars. C. 
138. Tetrapteris crebriflora Juss.: Fl. Bras. XII, 1, 1. 80. - Corcovato et Tijucal, Rio-Jas., $\mathrm{H}^{\text {os }} 5758,5760,7538,5766,8583$; Caminho do Caraça it Mendiulla, Mrxss, $11^{08} 13600,14564$. Irbuste 111 peu sarmenteux, 11. jaunes. Juillet-ioùt. C.

139. T. Guilleminiana juss.; Fl. Brrs. XII, I, P. 80. - Larangeiras, au pied du Corcovado, lino-JAx., nos 719, 7543, 8290; Serra do llar, à Palmeiras, Rio-Jix.. $n^{0 s}$ 8584, 8589. Arbuste sarmenteux, 11. jaunes. Juillet-septembre. C.

140. T. mogoriifolia Juss.: Fl. Bras. XII, I, 1. 81. - Copacahana, Caminho do Lemos, Rio-JAN., $n^{o s} 1326,5761$. Arbuste, 11. jaunes. Juinjuillet. C.

141. T. parvifolia Glaz. n. sp? in herb. Kew., Berol., Harn., Paris., ete. - São Pedro dos Indios, près Cabo Frio, Rio-Jax., nos 9365, 9683. Arbuste sarmenteux, 11. jaunes. Février-mar's. C.

142. T. glabra Griseh. in Fl. Brrs. XII, 1, p. 82. - Dois Imãis, au Corcovado, Rio-Jax, $1^{\text {os }} 348,721$. Arbuste sarmenteux, fl. jannes. Février-mai. ci.

143. T. sericea Juss.: Fl. Brus. XII, I, p. 83. - Porto das Caixas, Rı-Jıx., nos 7539, 11813. Arluste sarmenteux, f1. jaunes. Octobre-novembre. C.

14'4. T. multiglandulosa Juss. : Fl. Bras. XII, I, p. 83. - Biribiry, près de Diamantina, Mlxas, $n^{\text {os }} 12491,18940$. Arbuste sarmenteux, 11. jaunes. Mars-avril. C.

143. T. squarrosa Griseb. in Fl. Bras. XII, I, p. 87. - São João da Barra, près de Campos, Rio-JAn., no 9675. Arhuste, 11. jaunes. Févriermars. R.

146. Mascagnia (Hirca) argentea Griseb. in Fl. Bras. XII, I, p. 90. - Entre le Rio Torto et Banaual, Goxaz, $n^{\circ}$ 20748. Petit arbuste des campos, il. jaunes. Juillet-aoùt. L.

147. M. salicifolia Griseb. in Fl. Bras. XII, I, p. 90. - Campos da Bocaina, Sĩo Piulo, no $8293 a$. Petit arbuste, ll. jaunes. Férriermars. R.

148. M. rigida Grisel. in Fl. Bras. XII, I, p. 92. - Serra do Caraça a Inficionado, Mrsas, $1^{\text {os }} 12493,13601$. Grande liane, i1. jaunes. Janvieravril. C.

149. M. coriacea Griseb. in Fl. Bras. XII, I, p. 92. - Floresta da Tijuca, Rı-Jax., no 1501. Arbuste sarmenteux, 11. jaunâtres. Aoùt-septembre. C. 
A.-F.-M. GLAZIOU. — LISTE DES PLANTES DU BRESIL CEXTHAL. 77

1:0. M. anisopetala Grisel,. in Fl. Bras. XII, 1, p. 9\%. - Serra do Picú, Río-Jax., nº 16364. Grande liane, 1l. jaunes. Arril-mai. R.

1:1. M. parnahybensis Glaz. n. sp.? in herb. Berol., Kew., Paris., Gener, etc. - Bord du Rio Parnahỵa, Goraz, n²0757. Grande liane, fl. jaunes. Juillet-aoùt. G.

152. M. cordifolia firisel, in Fl. Bras. XlI, I, p. 9:. - Serra do Funil, au Rio Parauna, Mısas, $n^{0 s}$ 14565, 18949; Santa Luzia du Rio das Velhas, Hıxs, $n^{\circ}$ 20227. Grande liane, 11. jaunes. Novemlıre. G.

13̈3. M. sepium Grisel. in Fl. Bras. XII, I, p. 96. - Floresta da Tijuca, Rio-Jax., $n^{0 s} 5756,5765,13603$. Grande liane, fl. jaunes. Septembre-octohre. C.

1:44. M. microphylla Grisel, in Fl. Bras. XII, I, p. 98. - Serra do Caraça, Mrsas, nos 14566,16729 , 18933. Petit arbuste, fl. jaunes. Juinjuillet. C.

var. cornifolia Niedz. in herl,. Berol., Kew, Paris, Harn., ete. Serra do Caraça, Mssas, no 18934. Arluuste, fl. jaunes. Juillet. R.

(ï.). Hiræa Gaudichaudiana Juss.; Fl. Bras. XII, I, p. 98. - Serra dos Orgãos, liı-Jıx., nos 6104, 7540: Floresta da Tjuca, Rio-JAx., $\mathrm{n}^{\mathrm{os}} 722,3887$. Grande liane, f1. jaunes. Novembre-décembre. CC.

1.̈6. H. Salimanniana Juss. : Fl. Bras. XII, I, p. 99. - São Fidelis, près de Campos, Rio-JAx., $n^{0}$ 9696. Arbuste sarmenteux, fl. jaunes. Janvier-février. R.

1รั. H. cuneata Griseh. : Fl. Bras. XII, I, p. 99. - Serra de Jacarépagua, Riı-J.x., $\mathrm{n}^{\text {os }}$ 4768, 11810. Arluste sarmenteux, 11. jaunes. Novembre-décembre. C..

1:8. H. chrysophylla luss.; Fl. Bras. XII, 1, p. 100. - São Sebastião, près de Itahapoana, Rı-JAx., $1^{\circ}$ 9685. Arbuste sarmenteux, fl. jaunes. Férrier-mars. R.

109. Mezia (IIrien) Aranjei Schw. in herb. Berol., Kew, Paris., Gener., etc. - Rio do Ouro, a la lase du Tingua, lio-Jax., no 9367. Grosse liane, fl. jaunatres. Oetobre-norembre. C.

160. Camarea ericoides St-Hil.; Fl. Bras. Xll, I, p. 103 - Serra do Ouro Branco, Misas, no 14572; Serra dos Gristaes et do Abhade, Goraz, n² 20746. Frutescent, 11. jaunes. Septembre-oetobre. C.

161. C. affinis St-Hil. : Fl. Bras. XII, I, p. 106. - Campo de Ipiranga, Sĩo Parlo, no 15868, 17491; Vão do Paranana, Govaz, nº 20745. Frutescent, f1. jaunes. Février-mars. C. 
162. Camarea hirsuta St-Hil.; Fl. Bras. XII, I, p. 106. - Serra do Ouro Branco, Misas, $\mathbf{1 1}^{\circ}$ 14571. Frutescent, fl. jaunes. Novembredécembre. R.

163. C. sericea St-Hil. : Fl. Bras. XII, I, p. 106. - Abbade, près de Ileia Ponte, Goraz, $n^{\circ}$ 20747. Plante bulleuse, sous-frutescente, fl. jaunes. Septembre-octobre. C.

16'. C. triphylla Mart.; Fl. Bras. XII, I, 1. 108. - Serra dos Cristaes, près de Diamantina, Mıxas, $\mathrm{n}^{\circ}$ 18931. Frutescent, fl. jaunes. Marsarril. R.

168. Janusia muricata Griseb. in Fl. Bras. XII, I, p. 103. - Gavea, aux Dois Imãos, Rio-JaN., ${ }^{\text {os }} 3672$. 5763. Liane, fl. jaunes. Avrilmai. R.

166. Schwania elegans Juss.; Fl. Bras. XII, 1, p. 102. - São Julião, Mıvas, $n^{\text {os }} 5759,10366$; Fazenda do Lambary, Goyaz, no 20758. Grande liane, fl. jaunes. Janvier-mars. C.

\section{Fan. 29: Zygophyllées.}

1. Kallstrœmia tribuloides Wight.; Fil. Bras. XII, II, p. 70. -

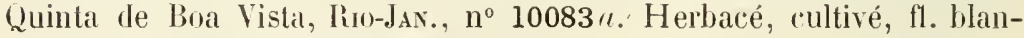
rhâtres. Juin-juillet. R. Vulgo Saboeiro.

\section{Fam. 30 : Géraniacées.}

1. Geranium brasiliense Prog. in Fl. Bras. XII, II, p. 522. Campos do Itatiaia, Rı-Jax., $n^{\text {os }} 4776$, 8613. Herlacé, f1. roses. Janvier-férrier. C.

2. Chymocarpus pentaphyllus Don; Fl. Bras. XIV, II, p. 2205. - Itatiaia, dans le bois, Rio-JAr., $1^{\circ} 10445 a$. Grimpant, fl. rouge verdàtre. Juin-juillet. R.

3. Tropæolum brasiliense Casar.; Fl. Bras. XIV, II. p. 2206.Gavea, entre les rochers au bord de la mer, Rio-Jas., n' ${ }^{\text {os }} 3913$, 10445 ; Rio llanęo, Husas, $n^{\circ}$ 14581. Herbacé, grimpant, fl. jaunes. Février. C.

4. T. digitatum Don; Otto et Dietr. in Allg. Gartens, vol. XIX, 1. 301. - Serra do Caraça, dans le bois, Misas, $11^{\circ}$ 14581. Grimpant, fl. jaunes. Mai-juin. C.

3. Cæsarea ovata Klotz; Fl. Bras. XII, II, p. 527. - Serra do Cipo, près Congonhas, dans le pàturage, Mrsas, $n^{\circ}$ 19433. Herbacé, f1. blanc rosé. Avril-mai. C.

6. C. Sellowii Taub. 11. sp. in herb. Berol., Kew., Paris., etc. - 
A.-F.-II. GLAZIOU. - LISTE UES PLAXTES UL BRESIL CEATRAL. T9

Serra do Funil, près du Rio Paramna, llwss, n $19433 a$. Herbacé, fl. blanchâtres. Avril-mai. R.

T. Oxalis Regnellii Miq.; Fl. Bras. XII, II, p. 48כ̃. - Pedra do Conego, à Nova Friburgo, Riı-JAx., n 12517; Ayuruoca, $1^{\circ} 15884$; Cachaeiro do Campo, Misas, n² $20245 a$. Herbacé bulbeux, fl. roses. Janvier-février. C.

8. O. triangularis St-Hil.: Fl. Bras. XII, II, p. 48\%. - Bas de Ia Serra da Piedade, Misas, no 20245. Herbacé bulbeux, f1. roses. Novembre. $R$.

9. O. calva Prog. in Fl. Bras. XII, II, p. 486. - Sommet de Ia Serra dos Orgãos, Rı-JAx., n³ 3914. Herbacé bulbeux; fl. roses. Décembre. R.

10. O. Martiana Zuce.; Fl. Brus. XII, II, P. 486. - São Christovão, Rı́-Jax., n 4778. Herbacé bulbeux, fl. roses. Août-septembre. C.

11. O. palustris St-Hil.; Fl. Bras. XII, II, p. 486. - Campos da Bocaina, Sĩo-Patlo, nº 8335 a. Herbacé, fl. roses. Février. C.

12. O. oxjptera Prog. in Fl. Bras. XII, II, p. 489. - Biribiry, près de Diamantina, Mrys, no $18970 a$. Herbacé bulbeux, fl. looses. Mars. R.

13. O. corniculata L.; Fl. Bras. XII, Il, p. 492. - Quinta de São Chlıristovão, Rı-JAx., nos 4955, 5519. Herbacé, fl. jaunes. Septembre. CC. Vulgo Azedinha.

14. O. confertissima St-Hil.; Fl. Bras. XII, II, p. 493. - Ayuruoca, au Pico do Papagaio, Mrvas, $n^{0}$ 15885. Sous-frutescent, f1. jaunes. Janvier-février. C.

13.. O. erioclados Prog. in Fl. Bras. XII, II, p. 494. - Campos da Bocaina, Sĩo Paulo, $n^{\circ}$ 8335. Sous-frutescent, f1. jaunes. Févriermars. R.

16. O. Glazioviana Prog. in Fl. Biras. XII, II, p. 49't. - Itatiaia, dans le campo, Rio-JAx., $n^{\text {os }} 4779$, , 8614. Sous-frutescent, f1. jaunes. Novembre-décembre. C.

17. O. arachnoidea Prog. in Fl. Bras. XII, II, p. 49' t. - Fazenda da Bocaina, Sĩo Prulo, $n^{\circ}$ 8334. Sous-frutescent, fl. jaunes. Janvierf'évrier. C.

18. O. densifolia Mart. et Zuce.; Fl. Bras. XII. II, p. 496. - Valla Funda, Ilras, no 18967 ; Ribeirão de Caldas et Chico Lobo, Govaz, $n^{\text {os }}$ 20785, 20786, 20787. Sous-frutescent, fl. jaunes. Aoutt-septembre. C.

19. O. linearis Zucc.; Fl. Bras. XII, II, p. 497. - Entre Cabo et Morrinhos, Goraz, $n^{\circ}$ 20792. Sous-frutescent, f1. jaunes. Aoùt-septembre. P. 
20. Oxalis areolata Taubert in EngI. Bot. Jahrb. (1893), p. 504. Serra do Funil, au Rio Paranna, Mlsas, $1^{0 s} 16968 a$, 20788. Sous-frutescent, 11. jaunes. Avril-mai. R.

21. O. delicata PohI in Fl. Bras. XII, II, p. 498. - São João da Barra, près de Campos, Rio-Jax., $n^{\circ}$ 10447. Sous-frutescent, fl. jaunes. Février-mars. R.

29. O. campestris Nart. et Zucc. : Fl. Bras. XII, II, p. 498. - Congoulhas do Campo, Mixas, $n^{\text {os }} 133647$, 20790. Sous-frutescent, fi. jaunes. danvier-février. $R$.

23. O. pilosissima Turcz.; Fl. Bras. XII, II, p. ̋01. - Cabo Frio, frès de Ia mer, Rı-JAx., $11^{0 s} 10448,10449$. Sous-frutescent, fl. jaunes. Juin-juillet. C.

24. O. elatior Prog. in Fl. Bras. XII, II, p. 504. - Porto do Rio Paracatu, Mixas, $n^{\circ}$ 20791. Sous-frutescent, fl. jaunes. Septembreoctobre. C.

25. O. Barelieri Jacı.; Fl. Brus. XII, II, p. 304. - Floresta da Tijuca, Rio-Jux., n 9379. Sous-frutescent, ll. roses. Octobre-novembre. C.

26. O. sepium St-Hil.; Fl. Bras. XII, II, p. ̈00ั. - Tijuca et Corcovado, Rio-Jax., nos $352,1334,1355,9378,12520$. Sous-frutescent, fit. jaunes. Octobre-septembre. CC.

var. picta Prog. in Fl. Bras. XII, II, p. "00\%. - São Christorâo, Rio-JAx, $n^{\text {os }} 4777,12519$. Sous-frutescent, fl. jaunes Septembre-octobro. CC.

27. O. radiata Polıl in Fl. Bras. XII, II, P. :066. - Serra de Antonio Pereira, llıxas, $n^{0}$ 14586. Sous-frutescent, ft. jaunes. Févriermars. C.

28. O. decipiens Prog. in Fl. Bras. XII, II, 507. - Casal, près d'Uba, Rio-Jax., nº 7561. Sous-frutescent, tl. jaunes. Janvier-février. R.

29. O. rhombeo-ovata St-Hil.; Fl. Bras. XII, II, p. 508. - Serra da Babylonia, Mıxas, n 7562; Serra da Bica, près de Cascadura, Rio-Jan., $n^{0} 13648 a$. Petit arbuste, lit. jaunes. Janvier. R.

30. O. psoraleoides Humb. B. et K.; Fl. Bras. XII, II, p. 510. Restinga de Cabo Frio, Rio-JAx., $11^{08}$ 10446, 10450. Sous-frutescent, 11. jaunes. Juillet-aoùt. C.

31. O. hirsutissima Vart. et Zuec.; Fl. Bras. XII, II, p. 512. Entre Rancho et Taboquinha, Misas, $1^{08}$ 18968, 18970 ; campement du Rio Porto, Govaz, nos 20793, 20794. Sous-frutescent, tit. jaunes. Ilaijuillet. CG. 
1.-F.-M. GLAZIOU. - LISTE DES PLAXTES DU BRÉSIL CENTRAL. 81

Var. calthefola Prog. in Fl. Bras. XlI, Il, p. 3̈2. - Guriroba et Rio Descoberto, Goriz, $n^{\text {s }}$ 20795, 20796; Diamantina à Formação, Mrsas, $n^{\circ}$ 18969. Sous-frutescent, f1. jaunes. Avril-mai. C.

32. O. mandinccana Raddi; Fl. Bras. XII, Il, p. 314. - Serra da Estrella, Rio-Jax., $n^{\text {os }} 4954,6500,12518$. Sous-fiutescent, f1. jaunes. Aoùt-septembre. C.

33. O. rusciformis Mik.; Fl. Bras. XlI, II, p. ̈̈l:. - Serra da Bira, près de Cascadura, Rio-JAx., n ${ }^{03} 9380,13649$, 18648. Petit arbuste, 11. jaunes. Norembre-décembre. CC.

34. O. bupleurifolia St-Hil.; Fl. Bras. XII, II, p. כ̆lö. - Entre Tijuca et Garea, Rio-J.s., $n^{\circ s}$ 2522, 6501. Petit arbuste, fl. jaunes. Décembre. R.

3\%. O. mimosoides St-Hil. : Fl. Bras. XII, II, p. ॐ̈16. - Cazal, près d'Uba, Rio-Jas., nº 16737. Petit arbuste, fl. jaunes. Mars-avril. R.

36. Averrhoa Carambola L.; Fl. Bras. XII, II, p. 520. - São Christorão, Rı-Jax., nos 2521, 9377. Arbrisseau cultivé, fl. roses, bon fruit. Décembre-janvier.

Fam. 31 : Rutacées.

1. Spiranthera odoratissima St-Hil.; Fl. Bras. XII, II, p. 87. --Entre Chico Lobo et Paranana, Goyaz, n² 20797. Arbuste des campos, fl. blanc pur à excellente odeur. Novembre. CC.

2. Almeidea longifolia Engl. in Fl. Bras. XII, II, p. 89. - Corcuvado, a Caixa d'Agua. Rı-JAx., n 677. Arbuste, f1. lilas. Janvierfévrier. C.

3. A. carulea Engl. in Fl. Bras. XII, II, p. 90. - Serra da Bica et Corcovado, Rio-Jix., ${ }^{\circ \mathrm{os}} 122,677,4781$. Arbuste, fl. lilas. Janvierfévrier. C.

4. A. rubra St-Hil.; Fl. Bras. XII, II, p. 91. - Cova do Onça, au Corcovado, Rio-JAx., $\mathrm{n}^{\circ}$ 1527. Arbuste, fl. verdâtres. Septembrevetolire. C.

כ. Erythrochiton brasiliensis N. et Hart.; Fl. Bras. XII, II, p. 107. - Serra da Babylonia, Mısıs, n 1069: Serra Vermelha, Rio-JAx., $n^{\circ}$ 1589. Arbuste, fl. blanches, calice rouge. Janvier-octobre. R.

6. Galipea jasminiflora Engl.; Fl. Bras. XII, II, p. 97. - Floresta de Tijuca, Rio-Jax., nos 856, 12528; Morro Azul, Sĩo Paulo, nº 12527. Arbuste, fl. blanches. C. 
7. Galipea ciliata Taul. in Engl. Bol. Jahrb., vol. 34, p. 3. - Serra de Ciaraģa, Misas, $n^{0}$ 12521. Apluste, fl. blanches. Oetobre-novembre. C.

8. Raputia alba Engl. in Fl. Bras. XII, II. p. 102. - Cova da Onça, au Corcovado, Rin-JAx., $1^{\text {os }} 679,6137,10459$. Grand athre, 11. blanche's. Norembre-décembre. C. Vulgo Arapoca.

9. R. magnifica Engl. in Fl. Bres. XII, II, p. 102. - Serra da Estrella, Rim-JAv., $n^{\circ}$ 6138. Grand arhre, bon hois de construction, II. Llanches. Décembre. C. Vulgo Arapoca.

10. R. trifoliata Engl. in Fl. Bras. XII, II, p. 103. - Floresta da Tijuca, Rı-JAx., nº $679 a$. Arbrisseau, Il. hlanches. Novembre. R.

11. Cusparia macrophylla Engl. in Fl. Bras. XII, II, p. 115; Obentonia castrata Vell. - Serra da Estrella et Corcovalo, Rio-JAN., $n^{\text {os }}$ 676, 2523; Antonio Pereira, Mrxas, $n^{\circ}$ 15886. Arbuste, 11. hleuâtres. Novembre. CG.

12. C. Gaudichaudiana Engl. in Fl. Bras. XII, II, 1) 116. - Serra da Estrella, près du ruisseau, Rı-JAv., n 1068. Petit arluste, 11. grisaitres. Février-mars. C.

13. C. ovata Engl. in Fl. Bias. XII, II, p. 117. - Restinga de Copacalana, Ro-JAN., $n^{\circ} 2109,3915$. Arbuste, fl. gris verdatre. Juilletoctobre. C.

14. C. Glazioviana Taub. in Engl. Bot. Jahrb., v. 34, p. 3. - Caminho do Enforcado, au Corcovado, Ru-JAN., n ${ }^{\circ}$ 13650. Arbuste, fl. gris jaunâtre. Nove mbre-décemlıre. R.

13i. C. paniculata Engl. in Fl. Bras. XII, II, p. 120. - Caminho do Nacaco, liı-JAx., n5 5798. Arbuste, f1. gris perle. Janvier-février. R.

16. C. Engleriana Taub. in Engl. Bol. Jahrb., vol. 34, p. 4. - Larangeiras, ì Cantagallo, Rro-JAs., I" 15890. Arbuste, fl. gris foncé. Octobrenovembre. $R$.

17. C. macrocarpa Engl. in Fl. Bras. XII, II, p. 121. - Corcovado, en haut de Paineiras, Rı-JAx, n $n^{\circ}$ 7563. Arbuste, fl. gris foncé. Octobrenovembre. C.

18. C. elegans Engl. in Fl. Bras. XII, II, p. 121. - Santa Thereza, au Corcovado, Rio-Jan., $n^{\circ}$ 3916. Arbuste, fl. gris cendré. Novembredécembre. C.

19. C. pentagya Engl, in Fl. Bras. XII, II, p. 122. - Grande restinga de Imbitiba, Rio-JAv., nos 11857,18175 . Arbuste, fl. blanches. Août-septembre. C.

20. Rauia resinosa N. et Mart.; Fl. Bras. XII, II, p. 94. - Pai- 
1.-F.-I. GLAZIOU. - LISTE DES PLANTES DU BRÉSIL CENTRAL.

neiras, au Corcovado, Rio-Jax., nos 674, 11854 . Albuste, fl. blanches. Janvier-février. R.

21. Monnieria trifolia L.; Fl. Bras. XII, II, p. 127. - Restinga de Cabo Frio, Rio-Jax., no 10083. Sous-frutescent, fl. blanchâtres. Juilletaoùt. C.

22. Ruta bracteosa DG: Fl. Bras. XII, II, p. 84. - Quinta de São Christurão, Rio-Jax., nº 10083 a. Sous-frutescent, cultivé, fl. rerdâtres. Juillet-décembre. C. Vulgo Arruda.

93. Zanthoxylum hiemale St-Hil.; Fl. Bras. XIl, II, p. 153.Nova Friburgo, Rio-Jix., nos 11864,18977 . Arlsisseau, fl. brun verlâtre. Octobre. C. Vulgo Arruda do mato.

294. Z. Pecholtianum Engl. in Fl. Bras. XII, II, p. lö. - Cantagallo, à Lorangeiros, Rı-JAx., $n^{\circ}$ 18197. Arbrisseau, fl. noirâtres. Juillet. C. Vulgo Arruda domato.

2:). Z. elegans Engl. in Fl. Bras. XlI, II. p. 1599. - Caminlo do Nacaco, à Vista Clineza, Rio-JAs., nº 8615. Grand arbre, fl. verdâtres. Janviel'février. C.

26. Z. subserratum Engl. in Fl. Bras. XIl, 1I, p. 160. - Serra do Campanema, Mrsas, $n^{0}$ 11863, 12523. Arbrisseau, fl. blanches. Octobre. C. Yulgo Catinga de Bode.

27. Z. Glaziovianum Engl. n. sp. in herb. Berol., kew., Paris., Genev., ett. - Restinga de Imbetiba, près la mer, Rro-Jax., nº 18976. Grand arbre, fl. blanches. Aoùt-septembre. C.

28. Z. nigrum Hart. in Fl. Bras. XII, II, p. 162. - Botolago, au Horr do Telegrapho, Rio-JAx., no 10455. Grand arbre, fl. blanches. )ctobre-norembre. C.

29. Z. Eichleri Engl. n. sp. in herl, Berol., Kew., Paris., Genev., ett. - Ilha do Governador, Ris-Jax., n 8617. Grand arbre, fl. blanches. Décembre-janvier. C.

30. Z. Gardneri Engl. in Fl. Bras. XII, II, p. 16:. - São Pedra dos Indios, près Calıo Frio, Rio-Jax., no 11863. Grand arbre, 11. blanches. Juin-juillet. C.

31. Z. tuberculatum Engl. in Fl. Bras. XII, II, p. 166. - Serra da Bocaina, Sĩo PAcLo, $1^{\circ} 14055 a$. Grand arbre, fl. blanches. Juillet-aoùt. C. Vulgo Mamminha de porco.

32. Z. nemorale Mart. in Fl. Bras. XII, II, p. 169. - Campos da Pocaina, Sĩo Paclo, n 10457. Arbrisseau, f1. noirâtres. Février-mars. C. 33. Z. obscurum Engl. in Fl. Bras. XII, II, p. 169. - Serra dos 
Orgãos, Rio-Jax., $1^{\circ} 13658$ ". Petit arbre, ll. blanches. C. Juilletaoût. C.

31. Zanthoxylum acutifolium Eugl. in Fl. Bras. XII, II, p. 170.Santa Rosa, ì Praia Grande, Rio-JAs., nº 9382. Grand arbure, fl. blanchâtres. Juillet-août. C.

3.i. Z. chiloperone Engl. in Fl. Bras. XII, II, p. 170. - Larangeiras, „u pied du Corcovado, Rro-Jan., n 1611. Grand arhre, ll. rougeâtres. Octobre. C. Vulgo Tametarú.

36. Z. rhoifolium Lank, ; Fl. Bras. XII, II, p. I74. - Caixa d'Agua, au Corcovado, Rio-Jax, no 734. Petit arlse, 11. verdâtres. Novembre. CG. Vulgo Espinho de vintem.

var. ว. pubescens ill Fl. Bras. XII, II, p. I76. - Barreto, à Praia Grande, Rio-Jax., nos 7566, 9381, 11862; Serra da Mantiquiera, Mısas, n 10456,12524 . Arbrisseau, fl. verdàtres. Octobre-décembre. CC.

37. Z. rugosum St-Hil, Fl. Bras. XII, II, p. 179. - Floresta da Tijuca, Rı-Jax., n $1611 a$. Grand arbre, fl. brumes. Octobre-novemlore. C.

38. Pilocarpus spicatus St-Hil.; Fl. Bras. XII, II, p. 133. - Botafogo, au Morro da Viuva et do Telegrapho, Rı-Jax., $11^{\text {ps }} 2953,3919$, 11855, 18971. Arbuste, f1. brunes. Janvier-mars. C.

39. P. subcoriaceus Engl. in Fl. Bras. XII, II, p. 134. - Restingi de Copacahana, Rro-Jax., n 14. Arbuste, fl. noiràtres. Février-mars. C.

40. P. pauciflorus St-Hil, Fl. Bras. XII, II, p. 13't. - Corcovado, au Caminha do Enforcado, Rio-Jan., n 1070. Arluste, f1. noirâties. Juillet. R.

41. P. giganteus Engl. in Fl. Bras. XII, II, p. 136. - Serra da Estrella, jrès de l'eau, Rı-Jax., no 14587. Alluste, fl. noirùtres. Aoûtseptembre. $\mathrm{R}$.

42. P. pinnatifolius Lem.; Fl. Bras. XII, II. 1). 197. - Pris de Morimhos, Govaz, $n^{\circ} 20798 a$. Arbuste, fl. brun rougeatre. Aouit-septembre.

43. P. longeracemosus Engl. in Fl. Bras. XII, II, p. 13:. - São João da Barra, près Campos, Rio-Jax., $11^{\circ}$ 13417. Arbuste, 11. brunes. Février-mar's. R.

44. Esenbeckia febrifuga Juss.; Fl. Bras. XII, II, p. 141. - Restinga de Cabo Frio, Rro-JAx., $1^{\circ}$ 11853; Fazenda do Cipo et Serra da Piedade, Mısas, $n^{\text {os }} 18973,20246$. Arbuste, fl. blanches. Novembredécembre. C. Vulgo Grumarim. 
1.-F.-y. GLAZIOU. - LISTE DES plaxteS DU BRÉSIL CEXTRAl. 85

4. E. mollis Viq.; Fl. Bras. XII, II, p. 142. - Itabapoana, RıJav., n ${ }^{\text {ss }} 10451,10452$. Arbuste, f1. noirâtres. Février-mars. C.

46. E. pumila Pohl; Fl. Bras. XIJ, 1I, p. 143. - Entre Alexandre et As Antas, Goraz, $n^{\circ}$ 20798. Petit arbuste des campos. fl. verdatres. Aoùt. C.

47. E. leiocarpa Engl. in Fl. Bras. XII, II, p. 145̈. - Dois Ismãos, au Corcovado, Rio-JAx., nos 675, 1392, 3917, 10460. Grand arbre, 11. verdaitres. Décembre-janvier. C.

4. E. grandiflora Nart.; $\mathrm{Fl}$. Bras. XII, II, p. 146. - Restinga de Caho Frio, Ro-Jax., no ${ }^{\circ} 1856$. Arluste touffu, fl. verdàtres. Novembredécembre. C.

49. E. intermededia Iart.; Fl. Bras. NIl, II. p. 147. - Haut du Corcovado et Tijuca, $\mathrm{n}^{\text {os }} 678,1390,2525,3918,10438$; Restinga de Ilaua et de Piratininga, Rio-JAx., $n^{03} 8330,18172$. Arbuste touffu, fl. verdàtres. Novembre-décembre. CG.

50. E. Glaziovii Engl. in litt. - Alto Macahé de Nova Frihurgo, Rio-JAs., no 18171. Grand arbre, fl. verdattres. Bon bois de construction. Vulgo T'resfolhas ou Larangeira.

31. Metrodorea gracilis K. Sch. n. sp. in herb. Berol., Kew., Paris., Gener., etc. - Serra da Piedade, dans les bois, Mlsas, nº 20246. Arbuste, fl. blanches. Novembre-décembre. C.

5․ M. pubescens St-Hil.; Fl. Bras. XII, II, p. 149. - Faria, près de Sahara, Hrsas, n 18173; Yorro Azul, São Paclo, nº 12526. Grand arbre, fl. rougeattres. Septembre-octobre. Vulgo Limeira ou Larangeira do matto.

53. M. nigra St-Hil,; Fl. Bras. XII, II, p. 1500. - Serra do Nar, Rodeio et Corcovado, Rio-Jan., ${ }^{0 s}$ 1391, 2526, 4870; Atalaia, à Paraia Grande, Rı-JAn., nos 11851, 11852. Arbrisseau, f1. rougeâtres. Décembre. C.

亏ั4. M. brevifolia Engl. n. sp. in herb. Berol., Kew., Paris., Havn., etc. - Diamantina, Estrada du Nendanha, Nisas, $n^{0 s}$ 13651, 14589. Arbrisseau, fl. rougeâtres. Décembre-janvier. C.

3... M. mollis Taub. in Engl. Bot. Jahrb II, p. :. - Serra da Caraça, Mıvas, $n^{\text {os }}$ 14588, 15887. Arbuste des bois, fl. verdâtres. Avrilmai. C.

var. glabrata in Engl. Bot. Jahrb. II, כ. - Serra do Lenheiro, près de São João d'El Rei, Minas, nº 11850 . Arbuste, fl. verdâtres. Maijuin. R.

כ̋. Hortia brasiliana Vand.; Fl. Bras. XII, II, p. 182. - For- 
yuilha dos Fornos, dans le campo, Goraz, no 20799. Petil arhuste, fl. rouge pourpre. toût-septembre. Cili.

37. Hortia arborea Engl. in Fl. Brus. XII, II, p. 183. - Serra dos Orgãos, Rı-Jan., nº 11849, 18174; Fazenda do Cipo, Mısas, no 18972. Arbrisseau des hois, fl. rouge pourpre. Mai-juin. C. Vulgo Casca d'Anta ou Pao para tudo.

58. H. megaphylla Taub. n. sp. in litt. inedit. - Quinta de São Christovão, Rro-Jan., $\mathrm{n}^{0}$ 13656. Arbrisseau cultivé, fl. rouge pourpre. Mars-avril. R.

89. Helietta multiflora Engl. in Fl. Bras. XII, II, p. 18\%. -Fazenda do Norro Azul, $S_{A O} P_{A L} 1,0, n^{\circ} 12526 a$. Arthre, fl. blane jaunittre. Avril-mai. C.

60. Triphasia aurantiola Lour.; Risso, Hist. des Orang., p. 1:iS, tå่. 10S. - Quinta de São Christovão, Rio-JıN., nº 11802 . Arbuste cultivé, fl. blanclıes. Novembre-décembre. C.

61. Murraya exotica L., Mant. II, p. 563. - Quinta de São Christovâo, Ru-Jax., no 11801. Arbuste cultivé, fl. blanches. Février-mar's. Cli.

62. Clausena punctata Oliv.; Fl. Bras. XII, II, p. 187. - São Christovão, liı-Jax., nº 1338. Arhuste cultivé, fl. blanches. Novembre. C.

63. Citrus aurantium Risso var. selecta in Fl. Bras. XII, II, p. 189. - Quinta de São Christovão, Rı-J $\mathrm{JN}_{\mathrm{N} .}, \mathrm{n}^{0}$ 1549. Arbuste cultivé, fl. blanches. Septembre-octobre. CG.

var. tangerixa in Fl. Bras. XII, II, p. 189. - Passeio Pullico, RioJan., no 1548. Arbuste cultivé, fl. blanclies. Septembre-octobre. GG.

\section{Fam. 32 : Simarubacées.}

1. Simaba guianensis Engl. in Fl. Bras. XII, II, p. 211. - Quinta de São Chıistorão, Rio-J $\mathrm{JN}_{\text {. }} \mathrm{n}^{\circ}$ 13655. Arbrisseau cultivé, fl. verdàtres. Nai-juin. R.

9. S. nigrescens Engl. in Fl. Bras. XII, II, p. 213. - Quinta de São Christovão, Rio-JaN., $1^{\circ}$ 9713. Arbuste cultivé, fl. verdâtres. Janvier-février. R. Vient du Para.

3. S. suffiruticosa Engl。 in Fl. Bras. XII, II, p. 213. - Engenho, à José de Souza, près de Santa Luzia, Goyaz, $n^{\circ} 20800$. Acaule, fl. vertes. Septembre. R. Vulgo Calunga.

4. S. subcymosa St-Hil.; Fl. Bras. XII, II, p. 215. - Caraça, en 
A.-F.-M. GLAZIOU. - LISTE DES PLANTES DU BIÉSIL CENTRAL. 8T bas dı Morro da Carapuça, Mıxas, n 14590 . Arbrisseau, fl. verdàtres. Février-mar's. C.

๖. S. cuneata St-Hil.; Fl. Bras. XII, II, p. 216. - Aldeia de São Pedros dos Indios, Riı-Jan., $n^{0 s}$ 1366, 12529; Serra do Capanemo, Misas, no 12525. Arbuste, fl. verdaitres. Juin. C. Vulgo Casca pera tudo.

6. S. floribunda St-Hil.; Fl. Bras. XII, II, p. 218. - Corcovado, Riı-JAx., $n^{\text {os }}$ 2528, 2959, 17574. Arbrisseau, 11. verdâtres. Févriermars. C.

7. S. glandulifera Gardn.; Fl. Bras. XII, 11, p. 219. - Caixa d'agua, au Corcovado, Rio-JAx., n ${ }^{\text {os }}$ 2904, 6135, 9384. Arbuste, fl. blanclies. Septembre-octobre. R.

8. S. trichiliodes S.-Hil.; Fl. Bras. XII, II, p. 2200. -- Serra do Caraça, Msss, nos 11858, 15869; bas de la Serra Dourada, dans le canpo, Goxaz, no 20802. Arbuste, fl. blanc verdâtre. Juillet-aoùt. C.

9. S. Maiana Casar.; Fl. Bras. XII, II, p. 22I. - Restinga da Tijuca, Rı-JAx., $n^{0}$ 6136. Arbuste, 11 . blanc jaunâtre. Septembreoctobre. R.

10. Simaruba amara Aubl.; Fl. Bras. XII, II, p. 223. - Serra dos Orgãos, à Theresopolis, Rio-Jan., nos 11860, 17234; Santa Luzia do Rio dos Velhas, Mıxas, $n^{\circ}$ 13653, 18974. Bel arbre, 11. verdâtres. Aoùt-septelubre. C.

I1. S. versicolor St-Hil.; Fl. Bras. XII, II, p. 22马̈. 一 São João da Barra, $n^{\circ s}$ 10462, 10463; entre Guaxindiba et Alcantara, Rio-Jax., $\mathrm{n}^{\text {os }} 8333$, 11859; bord du Rio Corumba, Goyaz, no 20801. Arbrisseau, 11. verdatres. Septembre-octobre. C.

12. Picræna Vellozii Planch.; Fl. Bras. XII, II, p. 227. - Nova Friburgo, liı-JAx., $n^{\text {os }} 1192,18198,19008$. Grand arbre, fl. blanc verdàtre. Octobre-novembre. R.

13. Dictyoloma incanescens DC.; Fl. Bras. XIl, II, y. 205. - Corcovado, Rı-Jax., nos 680, 1452, 2527, 5799 ; Alegria, Mısas, no 13652. Arbre, tl. blanc jaunâtre. Juiu-juillet. C.

14. Picramnia Sellowii Planch.; Fl. Bras. XII, II, p. 232. S. Sebastiào, près d'Itabapoana, Rio-Jan., no 10453. Arbuste, fl. rousses. Février-nars. C.

13.. P. Spruceana Engl. in Fl. Bras. XII, II, p. 238. - Rio Arassuahy, Mrsas, $n^{\circ} 136586$. Arbuste, fruit rouge pourpre. Février. R.

16. P. Camboita Engl. in Fl. Bras. XII, II, p. 239. - Corcovado, à Paineiras, lìo-Jan., $\mathrm{n}^{\circ}$ 1536. Arbuste, fruit rouge. Aoùt. C. Vulgo Camboata. 
17. Picramnia bahiensis Turcz; Fl. Bras. XII, II, p. 240 . - Arassuahy, à Rio Manco, Mixas, $11^{\circ 8} 13657,13658$. Arluuste à teinture violette, fruit rougeâtre. Février.

18. P. Ricdelii Ruiz. et P.; Fl. Bras. XII, II, p. 240. - Caixa d'Agua, au Corcovado, Rio-Jav., $1^{\text {os }} 1319,18975$. Arbuste, fl. rousses, fruit rouge corail. Février-mars. C.

19. P. ciliata Hart.; Fl. Bras. XIl, Il, p. 241. - Corcovado, Rio$J_{\text {AN. }}, \mathrm{n}^{\text {os }}$ 2515, 7545, 11861, 18176. Arbuste, f1. rousses. Janvierfévrier. CG.

20. P. Regnellii Engl. in Fl. Brus. XII, II, p. 2!1. - Serra do Caraça, Misas, no 13658 a. Arbuste, 11. rousses, fruit rouge. Janvierfévrier. R.

21. P. Glazioviana Engl. in Fl. Bras. XIl, Il, p. 242. - Serra dos Orgãos, Rı-J J ., nos 795, 1589. Arbuste, 11. noirâtres, fruit rouge. Octobre-septembre. C.

\section{Fam. 33. : Ochnacées.}

1. Ouratea Fieldingiana Engl. in Fl. Bras. XII, II, p. 309. Quinta da Boa Vista, Rio-JAN., n 9717. Arbuste cultivé, fl. jaunes. Décembre-janvier. k

2. O. castanea folia Engl. in Fl. Bras. XlI, Il, p. 309. - Guaxindiba, Rio-Jan, $n^{0 s} 9717$, 11869 ; Serra do Lenheiro, Minas, ${ }^{05} 15893$, 16739 ; Porto de São Bartholomen, Goyaz, n² 20811. Arbuste, fl. jaunes. Septembre. C.

3. O. nitida Engl. in Fl. Bras. XII, 1I, p. 310. - Passeio Pullico, Rio-Jan., no $12533 a$. Arbuste cultivé, fl. jaunes. Aoùt-septembre. R.A

4. O. crassifolia Engl. in Fl. Bras. XII, II, p. 311. - Fazenda do Nlacaco, dans le campo, Goyaz, $n^{0}$ 20803. Arbuste, fl. jaunes. Septembreoctobre. R.

5. O. Riedeliana Engl. in Fl. Bras. XII, II, p. 322. - Morinhos, dans le campo, Goyaz, no 20812 a. Arluuste, fl. jaunes. Août-septembre. R.

6. O. semiserrata Engl, in $\mathrm{Fl}$. Bras. XIl, Il, p. 323. - Morro Queimado, près de Tijuca, Rio-J $\mathrm{Jn}_{\mathrm{N}}, \mathrm{n}^{\circ}$ 3920. Arbrisseau, fl. jaunes. Novembre-décembre. C.

7. O. tenuifolia Engl, in Fl. Bras. XIl, Il, p. 324. - Rio Santo Antonio, au Tingua, Rio-JAx., $n^{\circ}$ 9386. Arbuste, fl. jaunes. Octobrenovembre. G. 
1.-F.-Y. GLAZIOU. - LISTE DES PLANTES DU BRÉSIL CENTRAL. 89

8. O. salicifolia Engl, in $\mathrm{Fl}$. Bras. XII, II, p. 324. - Caraça à Inficionado, Mrsas, $n^{0 s}$ 12533, 15892. Arbuste, fl. jannes. Septembre. C.

9. O. oleafolia Engl. in Fl. Bias. XII, II, p. 320\%. - Campo da Bocaina, Sĩo Paulo, no 11866. Arłuuste, 11. jaunes. Férrier. C. Vulgo Batiputı.

10. O. nana Engl. in Fl. Bras. XII, II, 1. 326. - Entre As Antas et Alexandre, Goyaz, n 20812. Arbuste des campos, fl. jaunes. Aoùt-septembre. C.

11. O. ovalis Engl. in Fl. Bras. XII, II, p. 326. - Entre Santa Rita et Divoxa, Goyaz, n² 20804. Arbuste des campos, f1. jannes. Aout-septembre. C.

12. O. lanceolata Engl. in Fl. Bras. XII, II, p. 327. - Biribiry, au Hocoto, Hixas, $n^{0 s} 18979 b, 20249$. Petit arbuste des campos, fi. jaunes. Mars-avril. R.

13. O. confertiflora Engl. in Fl. Bras. XII, II, p. 328. - Ponte Alta, dans le campo, Goraz, $n^{06}$ 20806, 20807. Petit arbuste, f1. jaunes. Septembre. C.

14. O. vaccinioides Engl. in Fl. Bras. XII, II, p. 329. - Serra dos Orgãos, Rio-Jax., nos $3652,5802,16738$. Arluste, f1. jaunes. Férriermars. C.

13̈. O. spectabilis Engl. in Fl. Bras. XII, II, p. 330. - Serra da Bocaina, près des rocher's, SaO Paulo, nos $11866,13661 a$. Arluste, 11. jaunes. Février. IR.

16. O. humilis Engl. in Fl. Bras. XII, II, p. 330. - Guariroha, dans le campo, Goyaz, nº 20803 a. Plante naine, fl. jaunes. Juin-juillet. C.

17. T. floribunda Engl. in Fl. Bras. XII, II, p. 331. - Itabira do Campo, Mixus, nos 13660, 16740; Santa Luzia et Caraça, Mıxas. $\mathrm{n}^{\mathrm{os}}$ 11867, 12532, 20248. Arbuste des campos, f1. jaunes. Septembreoctobre. CG.

18. O. nervosa Engl, in Fl. Bras. XII, II, p. 332. - Serra do Caraça, Vixas, nos 13659, 14591. Arbuste des campos, fl. jaunes. Aoǹtseptemlore. C.

19. O. gigantophylla Engl. in $\mathrm{Fl}$. Bras. XII, II, p. 338. - Riestinga de Maua et Andayassu, Rio-JAN., nos 7567, 12534, 25894, 18980. Arbuste des salbles, fl. jaunes. Novembre-décembre. C.

20. O. paruiflora Baill.; Fl. Bras. XII, II, p. 340. - Alto de Nova Friburgo, Rio-JAN., nº 13663. Arbuste, fl. jaunes. Décembre-janvier. R. 
var. pulchella Tiub, in litt. - Petropolis, au Morin, Rio-Jax., $n^{0}$ 9385. Arhuste des hois, 11. james. Janvier-février. R.

21. Ouratea pulchella Eugl. in Fl. Bress. XII, II, p. 340. - Grotão de

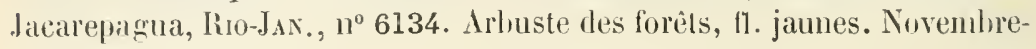
dérembre. R.

22. O. multiflora Engl. in Fl. Bras. XII, II, p. 341. - Sara dia Caraça, dans le eampo, Misas, $n^{0}$ 13662. Arbuste, fl. jannes. Octohre novembre. $\mathrm{C}$.

23. O. conduplicata Engl. in Fl. Bras. XII, II, p. 343. - Morinhos,

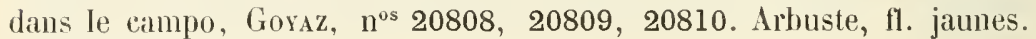
Aoùt-septembre. C.

2'4. O. oliva formis Engl. in Fl. Bras. XII, II, p. 34t. - Paineiras, au Corcorado, Rio-JaN., $n^{0}$ 1347. Arbuste, th. jaunes. Aoìt-septembre. R.

20.. O. cuspidata EngI. in Fl. Bras. XII, II, p. 345. - Restinga de Copacabana et de Taipu, Rio-JAN, ${ }^{05}$ 826, 1083, 1348, 5801 ; Petropolis, Rio-Jax., nos 3920, 11868. Arbuste, fl. jaunes. Mai-juin. CC.

26. O. Sellowii Engl. in Fl. Bras. XII, II, p. 34T. - Serra dos Orgãos, au Frade, Rio-d An. $n^{0}$ 2861. Arbuste des forèts, fl. jaunes. Aoûtseptembre. C.

27. O. stipulacea Engl. in Fl. Bras. XII, II, p. 347. - Corcovado,

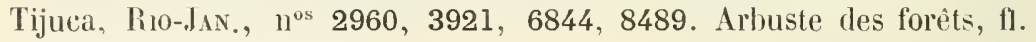
jaunes. Février-mars. CC.

var. tridentata ill Fl. Bras. XII, JI, p. 348. - Restinga de Copacahana, Rio-JAN., $n^{\text {os }}$ 140, 2860. Arluuste, f1. jaunes. Mars-avril. C.

var. major in Fl. Bras. XII, II, p. 348. - Jurujuba, à Praia Grande, Rio-JAx., $n^{o s} 1346,6843$. Arbuste, 11. jaunes. Octobre-novembre. C.

28. Luxemburgia ciliosa Planch.; Fl. Bras. XII, II, p. 3\%8.Serra do Funil, au Rio Parauna, Mrsas, $1^{0} 18979$ a. Arbuste, fl. jaumes. Arril-mars. R.

29. L. polyandra St-Hil.: Fl. Bras. XII, II, p. 338. - Serra do Cipo, au Rio Parama, Minas, $n^{\circ}$ 18982. Arlouste des campos, fl. jaunes. Tovembre-décembre.

var. glazloviana Engl. in Fl. Bras. XII, II, p. 3:9. - Petropolis, au Palatinato, Rio-Jan., $n^{\text {os }} 884,2709.8618,12531$. Arbuste, f1. james. Juillet-aout. C.

30. L. octandra St-Hil.; Fl. Bras. XII, II, p. 360. - Itacolumy, 
A.-F.-M. GLAZIOU. - LISTE DES PLANTES DU BRÉSIL CENTRAL. 91

près de Ouro Preto et Arraial, de Ouro Branco, Mrsas, n ${ }^{05}$ 14593, 18979 , 20247. Arbuste, tl. jaunes. Novembre-décembre. C.

31. L. nobilis Eich. in Fl. Bias. XII, II, p. 360. - Campo de São João, près de Ouro Preto, Mrvas, no $14592 a$, Arbuste, fl. jaunes. Févriermars. R.

32. L. Schzvackeana Taub. in Engl. Bot. Jahrb., v. ๖ै, 1. 5๊04. - Près de Diamantina, au Biribiry, llsas, no 18978. Petit arbuste des campos, 11. jaunes. Férrier-mar's.

33. L. speciosa St-Hil.; Fl. Bras. XII, II, p. 361. - Arraial de Ouro Branco. Mixas, ${ }^{o s} 14592,18781$. Arbuste, fl. jaunes. Novembre-dérembre. C.

34. Pœcilandra retusa Tul.; Fl. Bras. XII, II, p. 364. - Quinta de São Christovão, Rro-Jax., nº 13418. Arluste rultivé, fl. jaunes. Octolse. R. Vient du Para?

\section{Fam. : 34 : Burséracées.}

1. Garuga Schomburghiana Engl. in Fl. Bras. XII, II, p. 287. Alto Nlacahé de Nova Friburgo, Rio-Jax., no 10497. Grand arlse, fl. rousses. Décembre-janvier. C.

2. G. pinnata Roxb., Rheede Hort. Mal. 4, p. 33. - Quinta de São Christovão, Riı-JAx., $\mathrm{n}^{\circ \mathrm{s}}$ 2903, 6846. Grand arbre cultivé, fl. blanchâtres. Octolire-novembre. R.

3. Protium heptaplyyllum March.; Fl. Bras. XII, II, P. 262.Floresta da Tijuca et à Jacarepagua, Riı-Jax., nos 6713, 8332, 10495, 14611. Grand arbre, fl. brunes. Aoùt-septembre. CC. Vulgo Almescica.

4. P. venosum Engl. in Fl. Bras. XII, II, p. 264. - Serra de Gerecino, près de Campo Grande, Riı-Јax.. n 10496. Grand arbre, 11. brunes. Norembre-rlécembre. C. Vulgo Almecega.

Э. P. trifoliolatum Engl. in Fl. Bras. XII, II, p. 266. - Serra da Estrella, à Mandioca, Rio-Jas., n 13674. Grand arbre, bon bois. Vulgo Almecega.

6. P. Icicariba March.; Fl. Bras. XII, II, p. 267. - Alto Macahé, de Nova Frilıurgo, Rio-Jan., no $19014 a$. Arbrisseau, fl. rousses. Octobre. R. Vulgo Almescica.

7. P. brasiliense Engl. in Fl. Bras. XII, II, p. 268. - Restinga de Taipu et de Tijuca, $n^{\text {os }} 1317,6114,19012$, 19013; Serra dos Orgãos, Rio-Jax., $\mathrm{n}^{\text {os }}$ 8331, 12545, 19015; Itabisa do Campo, Minas, $\mathrm{n}^{\circ} 16751$. Arbrisseau, 11. rousses. Octohre-novembre. CC. 
8. Protium Almecega March.; Fl. Iiras. XII, II, 1. 269. - Alto Macahé, de Nova Frilurgo, Rio-dax., nº $19014 a$. Grand arbre, fl. brunes. Octolure-noventbre. C.

9. P. Widgrenii Engl, in Fl. Bras. XII. II, p. 272. - Serra de Jerécino, près de Campo Grande, liro-J Ax., $1^{\circ}$ 19014. Très bel arlıre, il. hrmes. Janvier. C. Vulgo Socosoco ou Jequitiba vermelho.

10. P. multiflorum Engl. in Fl. Bras. XII, II, 1. 273. - Quinta de Sào Christovão, Rio-Jax., $n^{\circ}$ 13674. Arbrisseau cultivé, fl. brunes. Octobre-novemlire. R.

11. P. Spruceanum Engl. in Fl. Bras. XII, II, p. 276. - Serra do Jerecino, près Campo Grande, Rio-J IN., $^{\circ}$ 9710. Grand arbre, fl. lorunes. Aout-septemlire. R.

12. P. Riedelianum Engl, in Fl. Bras. XII, II, p. 279. -- Serra do Jacarepagua, Rio-JAN., $11^{\circ}$ 6717. Grand arbre, sans tleurs. Octobre. C.

13. Hedwigia balsanifera Engl. in Fl. Bras. XII, II, p. 28วั. Quinta de São Christovão, Rio-Jan., nº 9743. Grand arlore, fl. rousses. Octolre-novembre. R.

1't. Trattinickia Schwackeana Glaz. n. sp. in herl). Berol., Kew., Harn., etc. - Quinta da Boa Vista, Rro-Jas., no 13675. Grand arbre cultivé, fl. rousses, Juin-juillet.

\section{Fam. 3: : Méliacées.}

1. Melia Azedarach L.; Fl. Bras. XI, I, p. 167. - Quinta da Boa Vista, Rio-JAN., $n^{\circ} 116,673$. Grand arbre cultivé, f1. lilas. Mlars-avril. CC. Vulgo Cinamomo.

2. Cabralea estrellensis C.DC. in Fl. Bras. XI, I, p. 171. - Petropolis, au Caxambu, Rio-JAv., nos 11837, 13641. Grand arbre, bon bois, fl. blanches. Décenbre. C. Vulg. Cangerana.

3. C. Glaziovii C.DC. in Fl. Bras. XI, I, p. 172. - Corcovado, à Paineiras, Rio-JAx., nos 1140, 1439. Grand arbre, bon bois, fruit rouge. Février-mars-avril. C.

4. C. pedunculata C. IC. in Fl. Bras. XI, I, p. 179. - Corcovarlo et Tijuca, $n^{\text {os }} 7557,7559,14583$; Petropolis, Rio-Jav., nos $13414,14584$. Grand arbre, bon bois, fl. blanches. Octobre-décembre. C. Vulgo Cangerana.

5. C. silvatica C. DC. in Fl. Bras. XI, I, p. 173. - Petropolis, au Morin, liro-JAN., nos 11838, 12513. Grand arbre, bon bois, fruit rouge. Aoùt. C. Vulgo Cangerana. 
A.-F.M. GLAZIOL. - I.ISTE IES PLANTES DE BLESIL CENIIAL.

6. C. Eichleriana C. DC. in Fl. Bras. XI, I, p. 174. - Alto Macahé de Nova Friburgo, Rio-Jax., $n^{\text {os }} 7558$, 15879, 20240. Grand arbre, fl. blanches. C. Vulgo Cangerana.

n. var. macrantha Harms, in litt. - Nova Friburgo, Rı0-JAx., $n^{\circ} 11831$. Grand arbre, bon bois, ll. blanches. Octolse. C. Vulgo Cangerana.

7. C. multijuga C. UC. in Fl. Bras. XI, I, p. 17\%. - Serra do Mar, à Rodeio, Rio-Jax., nos 7555, 12514, 15880. Grand arbre, bon bois, 11. blanches. Aout-septembre. C. Vulgo Cangerana.

8. C. pallescens C. DG. in Fl. Bras. XI, I, p. 17:3. - Petropolis, au Morto do Retiro, liso-JAx., nos 1139, 1140, 4775, 13635, 13636. Grand arlse, hon bois, ll. blanches. Décembre-janvier. C. Vulgo Cangerana.

9. G. fluminensis Glaz. 11. sp.? in lerb. Berol., Kew., Paris., Brux., etc. - Paineiras au Corcovato, Rio-JAs., $n^{\circ}$ 7578. Grand arbre, f1. blanches. Janvier-férrier. (A. Vulgo Cangerana.

10. C. corcovadensis C. DC.: Fl. Bras. XI, I, p. 17T. - Corcovado, à Paineiras, Rio-Jas., $n^{\circ} 7556$. Grand arbre, hon bois, f1. blanches. Octobre. C. Vulgo Cangerana.

11. C. Cangerana Saldan: Fl. Bras. X1, 1, p. 177. - Serra da Estrella, près de Petropolis, Ro-Jdx., $n^{\text {os }} 13641 a, 16734$. Grand arbre, bon bois, 11. blanches. Décembre. C. Vulgo Cangerana.

12. C. Warmingiana C. DC. in Fl. Bras. XI, 1, p. 178. - Fazenda do itatiaia, hio-dax., no 4775. Grand arbre, fruit rougeâtre. Juin. R. Vulgo Cangerana.

13. C. lagoensis G. DC. in Fl. Bras. XI, I, p. 178. - Nova Friburgo, au Conegu, Ro-Jax., $n^{\circ}$ 13416. Grand arbre, bon bois, fl. blanches. Novembre. C. Vulgo Cangerana.

14. C. microcaly $x$ Harns in Engler Botan. Jahrb. (1901), p. 34. Entre Lagoa do Ciercalo et Paiol, Mixas, $n^{\circ}$ 20814. Arbuste, l1. blanches. Octobre-novembre. C.

13. C. polytricha Juss.; Fl. Bras. XI, I, p. 179. - Santa Luzia do Iiio das Velhas, Mrxas, $n^{0} 20241$; entre Canastrão et Voradinha, Govaz. $n^{\circ s} 20815,20816$. Arluuste, f1. blanches. Octobre-norembre. C.

16. C. Lundii C. DC. in Fl. Brus. XI, I, p. 180. - Parahyba do Sul et Nova Friburgo, Rio-dav., nos 11836,13415 . Grand arbre, bon bois, 11. blanches. Octobre-novembre. C. Vulgo Cangerana.

17. Guarea trichilioides L.; Fl. Bras. XI, I. 1. 183. - Gavea et Corcovado, Rıo-JAx., $n^{o s} 1141,11840$; Serra da Estrella et IIaná, Rio- 
dix., nos 7553, 9374, 15873. Arbre, th. hlanches. Ortobre-novembre. GG. Vulgo Camboata.

var. brachystachy in Fl. Bras. XI, I, p. 184. - Corcovado, Rio-Jan., $n^{0 s} 5795,8608$. Arlıe, 1l. blanches. Janvier. C. Vulgo Carapeta.

18. Guarea pallida C. DC. in Fl. Bras. XI, I, p. 18:3. - Larangeiras, au has đu Corcovado, liro-Jax., n² 2953. Arbre, fl. blanches. Décembrejanvier. C. Tulgo Carapeta.

19. G. rosea C. DG. in Fl. Bras. XI, I, p. 186. - Serra dos Pyreneos, Goraz, $n^{\circ} 20817 a$. Arbre rabougri, 1 . roses. Septenibre. octobre. R.

20. G. alternans C. DC. in Fl. Bras. XI, I, p. 186. -- Corcovado et Belem, Rin-lan., nos 4774, 15875; Alegre, près du ruisseau, Mrsas, $n^{\circ}$ 20818. Petit arbre, fl. blanc rosé. Octobre-décembre. C.

21. G. Glaziovii C. DC. in Fl. Bras. XI, 1, p. 188. - Porto das Caixas, Rin-JAx., $n^{\circ}$ 7554. Petit arbre, 11. blanc jaunâtre. Févriermars. R.

22. G. tuberculata Vell.; Fl. Bras. XI, I, p. 191. - Corcovado, à Paineiras, Rio-Jax., $n^{0 s} 1440$, 11843. Petit arbre, fl. blanc rosé. Décembre-janvier. C.

23. G. Lindbergii L. DC. in Fl. Bias. X1, I, p. 192. - Mendanha près Cimpo Grande, liı-Jax., $1^{\circ} 11840 a$. Arbre, (1. blanches. Aoùt-septembre. C. Vulgo Carapeta.

24. G. Pohlii C. DC. in Fl. Bras. Xl, I, p. 19:. - Floresta da Tijuea, Rıo-Jas., nos 11842, 17571; Meia Ponte, Goyaz, no $20818 a$. Grand arbre, fl. blanc rosé. Novembre-décembre. C.

23. G. verruculosa C. DC. in Fl. lBras. XI, 1, p. 198. - São Christovão à Pedregulho, Rı-Jax, $n^{\circ}$ 11841. Petit arbre, fl. blanc rosé. Décemlıre-janvier. C.

26. Aglaia claganoides Benth., Fl. Austral. I, p. 383. - Quinta de São Christovão, Ru-Jax., n 10461. Arhuste cultivé, fl. jaunàtres tris odorantes. Janvier-février. C.

27. Trichilia Weddellii G. DG. in Fl. Bras. XI, I, p. 201. - Ipanema, Jans le bois près la mine de fer, Sĩo Paulo, $n^{0} 12510 a$. Arbrisseau, 11. blanches. C.

28. T. Riedelii G. DG. in Fl. Bras. X1, I, p. 202. - Serra da Estrella, à llandioca, liı-JAN., no $13642 a$. Arbrisseau, fl. blanches. Février-mars. C. 
1.-F.-M. GLAZ10U. - LISTE DES PLANTES DU BRÉLIL CENTRAL. 95

99. T. oxyphylla C. DC. in Fl. Bras. XI, I, p. 204. - Nlto Macahé de Nova Friburgo, Rio-Jax., $n^{\text {os }}$ 20242, 20244. Arbrisseau, fl. blanches. Janvier-février. R.

30. T. gracilis Loes. n. sp. in herb. Berol., kew., (iener., etc. Larangeiras, près Cantagallo, Rin-Jix., nº 15876. Arbrisseau, ft. blanrhittres. Octohre. R.

31. T. cathartica Nart.; FI. Bras. XI, I, p. 20\%. - Serra da Caraça, Mivis, $\mathrm{n}^{\text {os }} 12512$, 13644. Artuste, fl. blanches. Octobre-novembre. C. Vulgo Purga de Variuheiro.

32. T. Glaziovii G. DC. in Fl. Bras. XI, I, p. 205. - Fazenda de Santa Cruz, Rro-JAx., n 6103. Arhrisseau, fl. Wanches. Octobre. R.

33. T. longeracemosa Glaz. n. sp. in herb. Berol., Kew., Paris., Brux., etc. - Serra de Itabayuana, Esphito Santo, no 9712. Arbrisseau, t1. hlanches. Août-septembre. R.

3'. T. goyazensis Glaz. n. sp.? in herb. Berol., Kew., Paris., Genev, etc. - Rio Vasa Fogo, près Ileia Ponte, Gorsz, nº 20817. Grand arbre, fl. blanchâtres. Aoùt-septembre. C.

39. T. insignis C. DC. in Fl. Bras. XI, I, p. 206. - Lagoa de Freitas, au pied du Corcovado, Ro-J J ., $\mathrm{n}^{\text {os }} 6139$, 8616. Arbrisseau, 11. blanches. Novembre-décembre. C.

36. T. Clausseni C. DC. in Fil. Bras. XI, 1, p. 207. - Nora Fri-

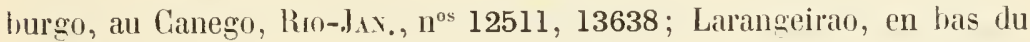
Corcovado, Rion-Jav., $\mathrm{n}^{\circ}$ 15877. Arbrisseau, it. blanches. Octohrenovembre. G.

37. T. pteleafolia A. Juss.; Fl. Bras. X1, 1, p. 208. - Aldeia de São Pedro, près de Caho Frio, Rio-Jav., $n^{\circ}$ 12522. Arbuste, ll. blanchâtres. Janvier-février. R.

38. T. Catigua A. Juss.; Fl. Bras. X1, I, p. 210. - Serra da Estrella, Rro-JAv., nos 8626, 18960 ; Arassuhay, Misas, $n^{\text {os }} 13642,13643$; Ipanema, São Pallo, no 12510. Arbrisseau, fl. hlanches. Avril-mai. R.

var. glabrior in $F l$. Bras. XI, I, p. 211. - Ipanema, près de la mine de fer, Sĩo Paulo, n 12510 a. Arhrissean, fl. blanches. Avril. C.

39. T. tetrapetala G. DC, in Fl. Bras. XI, I, p. 211. - Copacabana et Andarahy Grande, Rio-Jas., $\mathrm{n}^{\text {os }} 2952,3903,10428$. Arbrisseau, 11. jaunâtres. Janvier-février. C.

40. T. silvatica C. DC. in Fl. Bras. XI, I, p. 212. - Corcovado, à Paineiras, Rı-JAs., n ${ }^{\circ}$ 1330. Arbre, tl. blane verdâtre. Octobre. R. 
4. Trichilia emarginata C. I)C. in Fl. Bras. XI, I. 1. 2I2. - Nlto Macahé de Nova Friburgo, Rio-lax., $\mathrm{n}^{0 \mathrm{~s}}$ 10425, 13637. Arbrisseau, 11. Hanchâtres. Décembre. C. Vulgo Batinga.

42. T. psendostipularis C. DC. in Fl. Bras. XI, I, p. 213. - São Christorão, au Pedregulho, Rı-J.x., nº 6494. Arluste, fl. verdâtres. Aoùt-septembre. C.

43. T. corconadensis C. DC. in Fl. lirus. XI, I, p. 2I:3. - Coreovado, à Paneiras, Rio-dax., no 5779. Arbuste, n. verdatres. Septembre. C. Vulgo Camboata.

44. T. prramidata Harms in Engler Botan. Jahrb. (1901), p. 32. - Andaralıy Grande, Riro-JAx., nos 11834,11835 . Arlorisseau. f1. blanehes, Décembre-janvier. R.

45ั. T. Casaretti C. DG. in Fl. Bras. XI, I, p. 217. - Santit Theresa, au Corcovado, Rı-JAx., no 794, 1318, 3906, 18959. Arbrisseau, f1. verdattres. Décembre-janvier. C. Vulgo Camboalu.

46. T. trachythyrsus Harms n. sp. in herb. Berol., Kew., Paris., Genev., etc. - Serra da Estrella et à Moro Queimado, Rio-Jan., $n^{\text {os }} 14582,20243$. Arlırisseau, fl. blanches. Janvier-décembre. C.

4ī. T. oblonga C. DG. in Fl. Bras. XI, I, p. 218. - Floresta da Rio-JAv., $n^{\text {os }} 8307,11830,13639$. Arbrisseau, fl. blanches. Novembre. C. Vulgo Carapeta.

48. T. pallens C. DC. in Fl. Bras. XI, I, p. 218. - Sta Thereza, au Corcovado, Rio-J $\mathrm{JN}_{\mathrm{N}}, \mathrm{n}^{0}$ 10435, 12509. Arbuste, fl. blanches. JanvierFévrier. C.

49. T. Richardiana Juss.; Fl. Bras. XI, I, p. 220. - Corcovado, à Paineiras, Rio-Jav., $n^{0 s} 4773,15878$. Arbuste, fl. blanches. Décembrejanvier. C.

var. macrophyla G. DC. Fl. Bius. XI, I, p. 221. - Cova da Onca, Corcovado, Rio-JAN., no 11833. Artrisseau, fl. blanclıes. Janvier-février. R.

50. T. angustior Harms in Engler's Botan. Jahrb. (190I), p. :34. Alto Nacalıé de Nova Friluurgo, Rø-JAx., ${ }^{\circ}$ 17572. Arlorisseau, fl. blanc jaunâtre. Janvier-décembre. C.

31. T. Schunanniana Harms in Engler's Bolan. Jahrb. (1901), p. 33. - Corcovado, à Paineiras, Rio-J Jx., nos 2934, 11832. Grand arbre, fl. blanc jaunâtre. Novembre-décembre. C.

:2. T. glabra L., Syst. ed. X, p. 10ュ0. - Passeio Publico, Rio-Jan., $n^{0}$ 10340. Arhuste, fl. blanches, très odorantes, cultivé. Aon̂t-septembre.

53. Carapa gutianensis Aubl.; Fl. Bras. XI, I, p. 223. - Quinta de 
A.-F.-M. GLAZIOU. - LISTE DES PLANTES DU BRÉSIl, CENTRAL.

São Clıristovão, Rio-Jax., $n^{0} 2954$ a. Grand arbre cultivé, fl. brunes. Dérembre. C. Vulgo Andiroba.

5'4. Cedrela fissilis Vellozo; Fl. Bras. XI, I, p. 224. - Nova Friburgo, Rio-Jav., $\mathbf{1}^{\circ}$ 15881. Très grand arble, fl. blanc roux, bon bois. Novembre. C. Vulgo Cedra Batata.

var. multijuga C. DC. in Fl. Bras. XI, I, p. 224. - Theresopolis, Rı-JAx., $n^{\text {os }} 9375,11845$. Trés grand arbre, bou bois, 11. blanc roux. Novembre-décembre. C. Vulgo Cedro Branco.

var. Glabrior C. DC. in Fl. Bras. XI, I, p. 224. - Serra da Estrella, Rio-JAN., $\mathrm{n}^{\text {os }} 8287,9375,10434,11844,11845,16735$. Très grand arbre, bon bois, fl. blanc roux. Octohre-novembre. CC. Vulgo Cedro Branco ou Batata.

5.. C. Glaziovii C. DC. in Fl. Bras. XI, I, p. 224. - Floresta da Tijuca et Serra da Estrella, Rro-JAs., $n^{0 s} 6102,11846$. Grand arbre, beau hois, t1. blanches. Septembre-octobre. C. Vulgo Cedro rose.

¿6. C. paraguariensis Rom.; Fl. Bras. XI, I, p. 225ั. - Corregu do Brejo, Goyaz, n 20819. Grand arbre, beau bois de construction. Vulgo Cedro Bravo.

эั7. C. Velloziana Raem.; Fl. Bras. XI, I, p. 226. - Theresopolis, à São Luiz, Rio-Jax., no 8609. Grand arbre, hon bois, ll. blanches. Avril-mai. R. Vulgo Cedro.

\section{Fam. 36 : Dichapétalées.}

1. Dichapetalum vestitum Baill. in Fl. Bras. XII, I, p. 371. São Sebastião, près ltabapoana, Riı-Jas., n ${ }^{0}$ 1080. Arbuste, ll. l)lanches. Févilier-mar's. R.

2. Stephanopodium estrellense Baill. in $\mathrm{Fl}$. Bras. XII, I, p. 378. - Serra da Estrella, Rio-JAx., $n^{\circ}$ 13795. Arbrisseau, fruits roux. bécembre-janvier. R.

3. S. Engleri Baill. in Fl. Bras. XlI, I, p. 378. - Santa Luzia do Rio das Velhas, Mhras, $n^{\circ}$ 19612. Arbrisseau, fl. rousses. Octobre-novembre. C.

4. Tapura guianensis AubI.; Fl. Bras. XII, I, p. 373. - Sobradinlıo, aux bords des rivières, Goyaz, $n^{\circ}$ 20820. Arbrisseau, fl. rousses. Févriel-mars.

Э. T. amazonica Poepp. et EndI.; Fl. Bras. XlI, J, p. 374. - São João da Barra, près de Campos, Rio-Jan., n 9922. Arbrisseau, fl. blanc jaunâtre. Février-mars. C. 


\section{Fam. 37: Olacinées.}

1. Heisteria coccinea Jacr.; H. guianensis Engler; Fl. Bras. XII, II, p. 16. - Entre Forquilha et As Fornas, Goyaz, n 20825. Grand arbre, fl. verdâtres. Juillet-aoùt. C.

2. H. ovata Benth.; Fl. Bras. XII, II, p. 16. - Inficionado, dans le campo, Mras Geraes, n 15201. Arbrisseau, fl. rose verdâtre. Septembreoctobre. C.

3. H. densifirons Engl.? in Fl. Bras. XII, II, p. 19. - Serra do Capanema, dans le campo, Mrsas Geraes, $1^{\circ}$ 20824. Arbrisseau, fl. verdìtres. Septembre-octobre. C.

4. H. cyanocarpa Pøpp. et Endl. : Fl. Brus. XII, II, p. 17. - Cabo Frio, dans les broussailles, liro-Jax., n ${ }^{\circ}$ 10392. Arbrisseau, fl. rousses. Juillet-aoùt. C.

๖. H. minor Glaz. n. sp.? in herb. Berol., Kew., Paris., etr. - Entre São Pedro dos Indios et Cabo Frio, Ro--Jax., $1^{\circ}$ 10390. Arbrisseau, fl. rousses. Juillet-aoùt. C.

6. H. brasiliensis Engl. in Fl. Bras. XII, II, p. 19. - Itapuca, à Praia Grinde, Rro-Jax., $n^{\text {os }} 660,10391$. Arbrisseau, calice rouge. Ortobre-norembie. C.

7. H. laxiflora Engl.; Fl. Bras. XII, II, p. 19. - Rio Parauauá, ‘̀ Cochoeira Grande, Goy.ız, $n^{0}$ 20824. Arbuste, fl. verdâtres. Mai-juin. C.

8. H. salicifolia Engl.; Fl. Bres. XII, II, p. 20. - Praia Grande, Rio-Jax., nos 9506, 18152. Arbrisseau, calice rouge pourpre, fl. rousses. Novembre-décemlıre. C.

9. H. Silviani Schw. in Plantas novas Mineiras, t. I, p. 3. - Serra de Ouro Branco, dans le bois, Mrxas, $n^{\circ} 14529$ a. Arbrisseau, fl. blanchâtres. Novembre-décembre. C.

10. H. stereoneura Pierre n. sp. in herb. Mus. Paris., Berol., Kew., etc. - Cachambù et Itamaraty, Rio-Jax., nº 7656. Arbrisseau, fl. brunes. R. Novembre-(lécembre.

11. H. Iucida Glaz. n. sp. ? in herb. Berol., Kew., Paris., ete. Congonhas do Campo, dans le bois, Mrxas, $n^{\circ}$ 15852. Arbrisseau. Il. brunes. Décembre-janvier. $\mathrm{R}$.

1ュ. Ximenia americana L.; Fl. Bras. XII, II, p. 9. - Rio Manso, dans le campo, Minas, $n^{\circ}$ 12464; Praia de Sepitiba, près Santa Cruz, RioJax., n 9599. Arbuste, ll. rousses. Décembre. C. 
A.-F.-M. GLAZIOU. - LISTE DES ILATTES DU BRESIL CENTRAL.

13. X. coriacea Engl. in Fl. Bras. XII, II, p. 10. - Restinga de Ciabo Frio, Rio-Jax., $11^{\circ}$ 10394. Arbuste, 1l. rousses. Décembre-janvier. R.

14. Liriosma Velloziana A. DG.; Fl. Bras. XII, II, p. 24. - Horro Queimado, près de Tijuca, Rio-l.1., n ${ }^{05} 3783,4182,5747$. Arbuste, fl. blanches. Octobre-novembre. CiC.

1\%. L. Glazioniana Taub. in Engler's Bolan. Juhrb. ๖. 34, p. Т. - Haut du Corcovado, hio-Jax., $n^{\circ}$ 6101. Arbuste, f1. blanches. Septembre-octobre. C.

16. L. grandiflora Glaz. 11. sp. in herbar. Berol., Kew., Paris, etc. - Pio d'Alho, Esprriro Sarro, $n^{\circ}$ 13570. Arbuste, 11. blanches. Naijuin. C.

17. Cathedra Gardneriana Miers: Fl. Brus, XII, II, p. 31. - Cosme Velho, à Larangeiras, Rio-JAx., $n^{0}$ 109. Petit arbre, fl. rousses. Juilletaoùt. CC.

18. C. rubricaulis Mliers; Fl. Bras. XII, II, p. 32. - Corcovado, Rio-JAx., $\mathrm{n}^{\text {os }} 853,5889,6118,7522$. Petit arbre, fl. rousses. Octobrenovembre. GG.

19. C. grandiflora Las. n. sp. in herb. Berol., Kew., Paris., Gener., ele. - Alto Macahé de Nova Friburgo, Ruo-Jax., $n^{05} 16712$, 17474. Arbre, fl. brunes. Octobre-norembre. R.

0. Schœpfia obliquifolia Turc\%: Fl. Bras. XII, II, p. 3ั..Restinga de liacahé, près d'Imbetilıa, Fazenda de Santá Ciruz, Corcovalo, etc. Rio-JAx., n ${ }^{\circ \mathrm{s}} 6619,13569,17475$ et 18154 . Arbuste, f1. brunes. tout-septembre. Cli.

21. Sch. (Ribeirea) callophy-lla Fr. All. Comm. Scient. do Ceuru Secc. bol.. p. 29, tal. VIII. - Fazenda de Santa Cruz, Rio-dax., $1^{\circ 5} 11486$, 14530. Arbuste. 11. brunes. Septembre. C.

22. Sch. (Ribeireu) cupulata Fr. All. Comm. Scient. do Ceara, Secc. bol., p. 92., tah. IX. - Restinga de Sepitiba, Ru-Jax., nº 11485. Arbuste, 11. brunes. Septembre-octolse. C.

23. Sch. (Ribeirea) elliptica Fr. All. Comm. Scient. do Cearu, Secc. bet., p. 34. tai. X. - Itabapana, Rio-Jas., no 11484. Arbuste, fl. brunes. Mars-avril. C.

24. Sch. (Ribeirea) calva F. All. Comm. Scient. do Ceara Secc. bot., p. 38, tal,. XI. - Itabapmana, Rio-JAx., nos 11482, 11483. Arbuste, f1. brunes. Mar's-arril. C.

ㅍ‥ Tetrastylidium Engleri Schw, n. sl. in herb. Berol., Kew., 
Paris., ete. - Seria de Nova Friburgo, au Alto, Rro-lax., $1^{0}$ 20213. Grand arbre, lt. lorunes. Décembre-janvier. C. Vulgo Pa T'atú.

26. Agonandra brasiliensis Miers; Fl. Brus. XII, II, p. 38. - Vlorro do Frota, près de Neia Ponte, Goraz, n* 20843; Arraial de Ouro Branco, Mrxas, $11^{\circ}$ 10393, 11587. Arlırisseau tortueux des cerrados, ll. verdâtres. Septembre. CC. Vulgo Cammudo.

27. Mappia cordata Engler in F'l. Bras. XII, II, p. 50. - Villa Nova, Rı-JAx, $n^{\text {os }} 7531$, 10346. Arbrisseau, fl. blanc verdâtre. Mai-juin. C.

28. Poraqueiba sericea Tul.; Fl. Bras. XII, II, p. 49. - Quinta da Boa Vista, Rio-Jax., n ${ }^{\circ}$ 13801. Grand arbre cultivé, fl. blanchâtres. Février-mar's. R.

29. P. guianensis Aulll.; Fl. Bras. XII, II, p. 48. - Quinta da Boa Vista, liı-J Jax., $n^{\circ}$ 9790. Grand arbre, fl. blanclıatres. Janvier-février. R.

30. Emmotum nitens Niers; Fl. Bras. XII, II. p. 46. - Biribiry, près de Dianantina, Mlıss, $n^{\text {os }} 15380$, 19772; Barra de Lagoa Formosa, Goyaz, $1^{\circ 5}$ 22041, 22042. Grand arbre, lon bois, fl. rousses. Ianvier. CG. Vulgo sobre on Limain do Jallo.

31. Villaresia megaphylla Miers; Fl. Bras. XII, II, p. 34 . - Floresta da Tijura, Rin-JAx., nos 1851, 8288. Arbrisseau, fl. Jlanches. Juin-juillet. C.

32. V. paniculata Niers: Fl. Bres. XII. II, p. 53. - Floresta da Tijuca, Gavea, Petropolis, Rio-Jax., $11^{0 \mathrm{~s}}$ 1226, 1442, 7529, 10395. Arırisseau, ll. banches. Juillet-aoùt. CG.

33. V. Congonha Viers; Fl. Brots. XII, II, p. 3̈. - Campos da Bocaina, Sio Pauso, $n^{\circ} 11232$ a. Petit arbre. Li. Vulgo Herva de Arla, Falso Mati.

var. puxgexs in Fl. Bras. XII, II, p. ¿ 77 . - Bords du Rio Guará, Goyaz, $n^{\circ}$ 20823. Arbrisseau, H. blancluss. C.

34. V. Engleriana Lœs. n. sp. in herb. Berol., Kew., Paris, etc. - Serra do Orgãos, au sommet, Rio-Jax., n 17575 . Arluste, li. blanches. Octobre-novembre. C.

Fam. 38: Ilicinées.

I. Ilex Taubertiana Los. in J/onogr. Aquif., p. 12̈. - Alto Vacalıé de Nova Frilurgo, Rı-JAx., $1^{0 s}$ 18188, 18189, 18998. Arbrisseau, ll. verdâtres. Décem'ıre-janvier. C. 
A.-F.-M. GLAZIOI. - LISTE DES plaNtes DU BRÉSIL CENTHAL. 101

2. I. sapotifolia Reiss. in Fl. Bras. XI, I. p. 44. - Alto Macahé de Nova Friburgo, Riro-Jax., $n^{\text {os }} 10482$, 16749. Arbrisseau, 1l. rerdâtres. Février-mars. C.

3. I. loranthoides Mart. in Fl. Bras. XI. I, 1. 47. - Serra da Caraca, Mlıss, $\mathrm{n}^{\text {os }}$ 15455, 17583. Arbuste, fl. verdâtres. Décembre-janvier. R.

4. I. Vitis-Idara Loes. Monogr. Aquif., p. 130. - Alto Macalıé de Nova Friburgo, Rio-Jax., n 9006; Serra da Piedade, Mrsas, n 20257. Arbuste, fl. blanches. Novembre-décembre. R.

־. I. phillyreafolia Reiss. in Fl. Bras. XI, I, p. 60 var. teccocalyx Las. - Serra do Lenheiro, à S. J. d’El Rei, Nisas, n ${ }^{\circ}$ 17581. Arbuste, fruit rougeâtre. Décenbre-janvier. C.

6. I. diuretica Mart. in Fl. Bras. XI, I, p. 61. - Alto Macahé de Nova Friburgo, Rio-Jas., u $^{\text {os }}$ 19005. 19007. Arbuste, fl. blanches. Novembre-janvier. C.

7. I. suber Loes. Monory. Aquif., p. 188. - Chapadão dos Veadeiros, Goraz. nos $20262 a$, 20826. Arbrisseau, fruit brun. Janvier. C.

8. 1. Glazioviana Lors. Monogr. Aquif., p. 194. - Haut de la Serra dos Orgãos, Rio-Jax., no 15901. Arbuste, fl. blanrhes. Janvier-févriel. C.

9. I. virgata Loss. Momory. Aquif., p. 191. - Alto Hacahé de Nova Friburgo, Rio-Jax., $11^{\circ} 883$. Arbuste, fl. hlanches. Juillet-aoùt. F.

10. I. chamadryfolia lieiss. in Fl. Bras. XI, I, p. 73. - Rodrigo Silva, près d'Ouro Preto, Mixas, $n^{\circ}$ 18997. Arluste touffu, fl. Hanches. Mai-juin. C. Vulgo Conyonhinha.

var. uugiensis Lus. Monogr. Aquif., p. 196. - Serra de Ouro Branco, Misas, $n^{\circ}$ 14598. Arbuste touffu, fl. blanches. Novembre-décembre. C. Vulgo Congonhinha.

11. I. Pseudo-Vaccinium Reiss. var. scumformondes Laes. in Monogr. Aquif. p. 211. - Serra da Piedade, Misas, $n^{0}$ 20259. Petit arbuste, fl. verdâtres. Novembre-décembre. C.

12. I. scutifformis var. Loesenen Schacke, in Lœs. Monogr. Aquif., p. 212. - Morro do Inficionado, près Caraça, Mısas, nº 15187 u.

13. I. hypopsila Les. Monogr. Aquif.. p. 213. - Entre Morro Redondo et Manael .João, daus le carascal, Goraz, nº 20827. Arbuste, fl. verdâtres. Octobre. C.

1'. I. subcordata var. тrpica Fl. Bras. XI, 1. p. 49. - Ouro Preto, Misas, nos 15187, 19870, 20258. Petit arbuste, 11. rerditres. Févriermars. C. 
var. $\beta$ meizocarpa Los. p. 216. - Birribiry, près Diamantina, Minas, $n^{0}$ 18993. Petit arhuste, fruit vert. Février-mars. C.

var. $\gamma$ xummulariordes Lirs. p. 217. - Perpetua, près Diamautina, Mixas, $n^{0 s}$ 18994, 1899, 18996, 20260. Petit arbuste, ll. verdâtres. Janviermars. C.

1\%. I. asperula Nlart.; Fl. Bras. XI, I, p. 48, var. a pyrenea Lars.p. 218. - Serra dos Pyreneos, Govaz, no 20828. Petit arbuste, ll. blanches. Aoûtseptembre. C.

var. $\beta$ martiana Los. p. 218 . - Campos da Bocaina, São Paulo. $n^{\circ} 18996$ a. Arbuste. Aoît. C.

16. I. Congonhinha Los. Monngr. Aquif. p. 223. - Morro Cavado près de Serra Negra, Mixas, $n^{\text {os }} 7575,15899$. Arbrisseau, fl. verditres. Septembre-octohre. C. Vulgo Congonhinha.

17. I. buxifolia Gardn.; Fl. Bras, XI, I, p. 40. - Saut de la Serra dos Orgãos, Rıo-Jax., nos $6194,14597,15900,16747$. Arbrisseau, 11. verdâtres. Novembre-décembre. C.

18. I. brevicuspis Reiss. in Fl. Bras. XI, I, p. . 66 . - Serra la Estrella

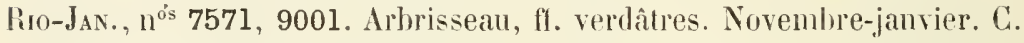

19. I. cerasifolia Reiss. in Fl. Bras. XI. I, p. 气̆. - Chemin du Rio Jequitinhanha, Musas, no 14602. Arbrisseau, li. blanches. Novembredécembre. C.

var. glazioviana Lees. Monogr. Aquif., p. 298. - Corcovado à Guaximdiha, Rıo-Jan., nos 1284,11878 . Arbrisseau, 17 . verdatres. Septembreoctobre. G.

20. I. paraguariensis St-Hil.; var. $\alpha$ domestica Riess. Fl. Bras. XI, I, p. 62. - Serra dos Orgãos, Rio-Jan., $11^{\text {os }}$ 2508, 4000, 6123. Aюbrisseau, fl. verdâtres. Novembre-décembre. CC. Vulgo Congonha ou IIerva Mati.

var. sobrus Los. Monogr. Aquif. 1. 307. - Alto Macahé de Nova Frilıurgo, Rıo-J $\mathrm{AN}_{\mathrm{N}}$, $\mathrm{n}^{\mathrm{os}}$ 18187, 18999. Arbrisseau, fl. blanc jaunâtre. Décembre. C. Vulgo Congonha ou Herva Mati.

var. confusa Lœs., Momogr. Aquif., p. 308. - Alto Macahé de Nova Friburgo, Rro-JAN., no 18187, 19002. Arbrisseau, fl. lifanc verditre. Octobre-novembre. C. Vulgo Congonha ou Ilerva Maté.

21. I. brasiliensis var. pubiflora Less. Monogr. Aquif., p. 369.Norro do Jaragua, Sño Patlo, $n^{\circ} 10480 a$; Serra dos Veadeiros, Goraz, $n^{\circ}$ 2831. Arbrisseau, n. verdatres. Novembre-décembre. C.

2ّ. I. pseudotheezans Lers. Monogr. Aquif., p. 370. - Rasgão, au 
A.-F.-M. GLAZIOU. LISTE DES PLANTES DU BRESIL CENTRAL. 103

bord du Rio Corumba, Goraz, $11^{\circ}$ 20829. Arbrisseau, fl. blancles. Septembre-octobre. C.

23. I. friburgensis Loes. Monogr. Aquif., p. 391. - Nto Macahé de Nova Frihurgo, Rio-Jax., nos 18191, 18191 a. Arlırisseau, f1. hant. verdâtre. Septembre-octobre. R.

24. I. theezans Mart.; Fl. Bras. XI, I, p. 5̈1. - Alto Narahé de Nova Friburgo, Rı-J Jax, n $n^{\circ} 18186 a$. Grand arbre, fl. verdatres. Loût-septembre. C.

var. augustr Loes. Monogr. Aquif., p. 37̈. - Serra dos Orgãos, línJax., n ${ }^{\text {os }}$ 14599, 16746. Arlorisseau, fl. verdâtres. Novembre-décembre. C.

var. acrodonta Loes. Honogr. Aquif., p. 375. - Alto Macahé, RioJAx., n 19003; Sourdo, dans le bois, près des Buritis, Goxaz, n 20830. Arbrisseau, fl. blanches. Octolre-novembre. C.

var. gracilion Lers. in Monogr. Aquif., p. 376. - Floresta da Tijuca, Gavea, Alto Marahé, Rio-JAx., nos 8491, 10484, 17579, 18186. 20255. Arbrisseau, fl. verdâtres. Juin-juillet. C.C.

var. warmagraxa Los. Monogr. Aquif., p. 377. - Petropolis, à Itamaraty, Alto Nacahé de Nova Friburgo, Rio-JAx., $n^{0 s}$ 14600, 17582 , 20254. Arlurisseau, f1. verdàtres. Septembre-ortobre. CC.

forma puberula Loes. in Jomogr. Aquif., p. 377. - Fazenda do Tayuaral, au Rio Preto, Mrss, n 7574. Arbrisseau, fl. rerditres. Septembre-ortobre. C.

folma Riedelii Las. Monoyr. Aquif., p. 377. - Haut de la Serra da Piedade, لlıxas, $n^{0}$ 20261. Arbrisseau, f1. verdâtres. Novembredécembre. C.

var. pachypyla Las. Nonogr. Aquif., p. 377. - Rodrigo Silva, pres Ouro Preto, Minas, n 19004. Arlrisseau, fruit noir. Mai. R.

23. I. integerrima var. enenacea Lues. Monogr. Aquif., p. 380.Gavea, près la mer, Rio-JAx., n 4875; Serra dos Veadeiros, à Ciabeceira do Rio Santa Anna, Goraz, nº 20831. Arbrisseau, fl. verdàtres. Octobre. C.

var. typica Loes. Monogr. Aquif., p. 380. - Paço Isabel à Larangeiras, Rı-JAN., nos 1509, 15902. Arbrisseau, fl. verdâtres. Octobrenorembre. C.

26. I. grandis heiss. in Fl. Bras. XI, I, p. 47. - Ouro Preto, Serra da Saramenha, Misas, $n^{0}$ 20399. Arbrisseau, fl. blanc jaunâtre. Novembre-décembre. li. 
27. I. longipetiolata Les., Monogr. Aquif., p. 383. - Alto Macahé de Nova Friburgo, Rı-Jax., n $^{\text {os }} 13418$ b, 13670, 16748, 18190, 20262. Arhrisseau, fr. verdâtres. Décemhre-janvier. C.

28. I. Lundii Warm. forma ignatiana Less. Monogr. A'puif., 1. 389. - Campos da Bocaina, Sĩo Paulo, no 18996 b. Arlore, 11. blane verdìtre. Iécembre. R.

29. I. floribunda Reiss. var. minor Los. in litt. inedit. - Ihiapaha, Sĩo Paulo, $11^{\circ}$ 10480. Arbrisseau, fl. Hanchâtres. Décembre. R.

30. I. Schuackeana Loes. Monogr. Aquif., p. 416. - Alto Maeahé de Nova Friburgo, Rio-Jax., $n^{\circ}$ 18192. Arbuste, fl. blanc jaunitre. Octobre-novembre. R.

31. I. affinis Gardn. var. genurn, forma angustifolia Laes. Monogr. 1 quif., p. 444. - Serra da Baliza et liio dos Couros, Goraz, nos 20835, 20836, 20837, 20838 et 20839. Arbuste, fl. blanches. Janvier-férrier. CC.

forma brachyphy-lla Lers. - Santa Luzia do Rio dos Velhas, Mhxis, $n^{\circ} 12540$ a. Arbrisseau, fl. blanches. Juillet-août. C. Vulgo Congonha.

var. hivularis Lœe. Monogr. Aquif., p. 44:. - Lagoa do Mestre d'Armas, dans les hourbiers, Goraz, $\mathrm{n}^{0}$ 20833. Arbuste, f1. blanches. Novemlıre-décembre. C.

var. pachyoda Les. Monogr. Aquif., p. 4.46. - Cocal an bord du Rihevião, Goyaz, n² 20835. Arbrisseau, fl. blanches. Novembre-décembre. CG. Vulgo Congonha.

var. genuma Las. Monogr. Aquif., p. 4't6. - Jequitinhonha et à Cachoeira do Campo, Mrvas, $n^{\text {os }} 12540$, 20256. Arbrisseau, ll. blanches. Juin-juillet. C. Yulgo Congonha.

var. valida Les. Monogr. Aquif., 1) 446. - Campos do Jequitinhonha, Mrxas, no 13669. Arbrisseau, 11. blanches. Septembreoctobre. R.

32. I. conocarpa Reiss. in Fl. Bras. XI, I, p. 6\%. var. $\alpha$ genurna Las. - Serra dos Pyreneos et Sobradinho, Goraz, $n^{\text {os }}$ 20832, 20834. Arbrisseau, fl. blanches. Septembre. C.

var. $\beta$ sex.z Les. - Barbarena, Mrnas, $11^{\circ}$ 19000. Arbrisseau, fl. blanches. C. Janvier-février.

var. $\gamma$ brevipetiolata Loes. p. 45\%. - Campos do Jequitinhonha, Misas, $\mathrm{n}^{0}$ 14601. Arbrisseau, fl. blanches. Norembre-décembre-janvier. C.

33. I. amara; val. a nigropunctata Lœe. Monogr. Aquif., p. 459. Restinga de Maná, dans le sable, Rı-Jav., n 7573. Arlorisseau, I1. blanches. Novembre. C. 
A.-F.-Y. GLAZIOC. - LISTE DES PLAYTES DU BRÉSIL CEMTRIL. 105

forma corcovadensis Lies. Monogr. Aquif., p. 461.: Chomellia amara Vell. Fl. Flum. I, tab. 106. - Corcovado, Rio-J.s., nos 6122 , 11873. Arlorisseau, fl. blanclıs. Septembre. CC.

var. $\gamma$ muenteriana Loes. Monogr. Aquif.. p. 462. - Araruama, près Cabo Frio, Riı-Jas., no 1048. Arlırisseau, 11. verdâtres. Férrier-mars. R.

var. f. trucensis Laes. Monogi. Aquif., p. 463; Chomellia amara.

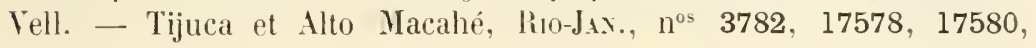
18193. Arbrisseau, 11. blanches. Novembre-décembre. CC.

34. I. biserrulata Las. Monogr. Aquif., p. 463. - Fazenda do Taquaral, au Rio Preto, Mrss, n ${ }^{\circ}$ 7576. Arbrisseau. fl. rerdàtres. Septembre. R. Vulgo Congonlia.

\section{Fam. 39: Célastrinées.}

1. Maytenus aquifolium Mart.: Fl. Bras. XI, I, P. 4. - Fazenda da Limeira. au Tingua et à Parahỵba do Sul, Rio-Jas., nos 9590, 10471, 11610, 12535. Grand arbre, Jon bois, fl. l,lanches. Aout-septembre. C.C. Vulgo Bainha d'Espada.

2. M. oxyodonta Reiss. in Fl. Bras. XI, I, p. ॐ. -- Serra dos Orgãos, à Theresopolis, Rio-Jax., no 11871. Grand arbre, bon bois, fl. blanches. Hai-juin. C. Vulgo Bainhu d'Espada A rmamé.

3. M. acanthophy-lla Reiss. in Fl. Bras. XI, I, p. 6. - Andarahy, près de Tijuca, Rio-JAx., n 4931. Arbrisseau, fl. jaunâtres. Aoùtseptembre. R.

4. M. ilicifolia Hart. in Fl. Bras. XI, 1, 1. S. - Barbacena, dans le campo, Misas, n 18985. Arbrisseau, h. Hanches. Janvier-février. R.

¿. M. Boaria Molin.: Fl. Bras. XI, I, p. 9. - Campos de Itatiaia, au Rio Preto, Rro-Jas., n $n^{0}$ 8619. Arbrirseau rabougri, f1. blanchâtres. Novembre. R.

6. M. salicifolia Reiss. in Fl. Bras. XI, I, p. 10. - Barbacena, dans le campo, Mrss, $n^{0}$ 18985. $a$. Arbuste, fl. verdâtres. Janvier-février. C.

7. M. samydaformis Reiss. in Fl. Bras. XI, I, p. 11. - Serra de Caraça, Mıxss, no 13665; Serra da Estrella, Rio-JAx., $n^{\circ}$ 13664. Arhuste des forìts, fl. blanchâtres. C.

8. M. evonymoides Reiss. in Fl. Bras. XI, 1, p. 11. - Entre Diamantina et Mendanha, Mrss, $n^{0 s}$ 12538, 12539. Arbuste, fl. blanches. Juillet. C. 
9. M. Pseudocascaria Reiss. in FI. Brets. XI, 1, p. 11. - Floresta da Tijuca, Rio-JAN., n' 4183. Ailuste, ll. brunes. Septembre-octobre. C.

10. M. gonoclados Mart.; Fl. Bras. XI, I, p. 12. - Serra dos Orgãos, à Theresopolis, hio-Jan., $\mathrm{n}^{\text {os }} 1459,6121$. Arbuste, fl. verdâtres Uctolire-novembre. C.

11. M. subalata Rieiss. in Fl. Bras. XI, I, p. 12. - Campos da Bocaina, Sĩo PAulo, $n^{\circ s} 10472,18986$. Arbuste, fl. verdâtres. Septembreoctolire. C.

12. M. pulviniflora Reiss. in Fl. Bras. XI, I, p. 14. - Floresta da Tijuca, Rro-JAx., $\mathrm{n}^{0 \leq}$ 3646, 6468. Arbrisseau, fl. verdâtres. Juin-juillet. C.

13. M. floribunda Reiss. in F'l. Bras. XI, I, p. 16. - Alto Nlacalé, Rı-Jax., $n^{\circ}$ 18983; Cassu, près d'Uberaba, Mısıs, $n^{\circ}$ 20841. Arbuste, fl. verdàtres. Juillet-anût. C.

14. M. Urbaniana Lies. in Engler's Bot. Juhrb. (1893), p. 10. - Alto Macahé de Nova Friburgo, Rin-JAx., nos 3732, 15895, 16742, 20251. Arbuste, fl. brun rougeâtre. Décembre-janvier. C.

15. M. imbricata Mlart. in Fl. Bras. XI, I, p. 16. - Ouro Preto, aux Campos de S. Sehastião, Mivas, $n^{0 s} 14595,18984 a$. Petit arbuste, fl. brunes. Février-mars. R.

16. M. macrophylla Mart.; Fl. Bres. XI, I, p. 19. - Corcovado à Paineiras, Rı-Jax., nº 2965. Arbuste, li. brunes. Janvier-février. C.

17. M. erythroxylon Reiss. in Fl. Bras. XI, I, p. 21. - Serra do Capanema, Mrsas, $n^{\text {os }}$ 13666, 15897 : Cabo lirio, Rio-Jav. $1^{\circ}$ 10467. Arbuste, ll. brun verdâtre. Septembre. C.

18. M. communis Reiss. in Fl. Bras. XI, I, p. 22. - Corcovado et Tijuca, Rio-Jax., $n^{\text {os }} 1320,7568,7570,10466$. Arbuste, ll. brun verdatre. Septembre-uctobre. CG.

var. grañdifolia in Fl. Bras. XI, I, p. 22. - Corcovado, lino-Jax., $11^{\text {os }} 1506,4204,7569$. Arbuste, fl. brun verlâtre. Septembre-octobre. CG.

19. M. multiflora Reiss. in Fl. Brus. XI, I, p. 24. - Serra da Estrella, Rio- $J_{\Lambda x}, n^{\text {os }} 8620,12537$. Arbuste, fl. brun verlattre. Janvierfévrier. C.

20. M. Glazioviana Los. in Engler's Bot. Jahrb. (1893), p. 与ั. - Cova da Onça, au Corcovado, Rio-Jax., $n^{\text {os }} 1573,18183$. Arbrisseau, fl. rerdâtres. Septembre-octobre. C.

1. M. cestrifolia Reiss. in Fl. Bras. XI, I, p. 24. - Alto Macahé 
A.-F.-M. Glaziou. - LISTE DEs PlaNtes dU BRÉsil CENTRAL. 107

de Nova Friburgo, Rio-Jan., no 17577. Arbuste, fl. verdâtres. Janvierfévrier. C.

22. M. ligustrina Reiss. in Fl. Bras. XI, I, p. 23. - Corcovado et Tijuca, Rı-JAN., n ${ }^{\text {os }} 739,2876$. Arbuste, f1. brun rougeâtre. Décembrejanvier. C.

23. M. oblongata Reiss. in Fl. Bras. XI, I, p. 25. - Fazenda da Mendanha, à Campo Grande, Rio-Jax., n ${ }^{\circ}$ 11870. Arbuste, f1. verdâtres. Aoùt-septembre. R.

24. M. obtusifolia Mart.; Fl. Bras. XI, l, p. 27. - Praia de Maria Angù et da Penha, Rıo-JAv., n ${ }^{\text {os }}$ 8812. 8813; Congonhas do Campo, Uinas, $n^{0 s} 10465,10469,14596$. Arbuste, fl. brunes. Septembre. CC.

var. elliptica Reiss. in Fl. Bras. XI, I, p. 28. - Praia da Gavea et da Tijuca, Rro-Jan., $n^{\text {os }} 3$, 1550, 4933. Arluste, fl. brumes. Févriermars. CC.

var. ovata Reiss. in Fl. Bras. XI, J, p. 28. - Picada do Nacaco, au Morro Queimado, Rro-Jav., $n^{\circ}$ 6693. Arbuste, 11. verdàtres. Loüt-septembre. C.

20ั. M. longifolia Reiss. teste Loes. - Entre Lagoa do Peixe et Rio Bonito, Rio-Jan., $\mathrm{n}^{\circ}$ 12536. Arluuste. Septembre.

26. Plenckia populnea Reiss. in Fl. Bras. XI, I, p. 31. - Arraial de Ouro Branco, Misas, $n^{\circ}$ 15456. Arbrisseau tortueux, 1 . grisâtres. Norembre-décembre. CC.

var. cordifolia Reiss. in Fl. Bras. XI, I, p. 31. - Rio Corumba, au Rasção, Goyaz, $n^{0}$ 20842. Arbrisseau tortueux, f1. grisâtres. Septembre. GC.

var. elliptica Reiss. Fl. Bras. XI, I, p. 31. - Congonhas do Campo, Hinas, no 13410. Arbrisseau tortueux, 11. blanchâtres. Nars-avril. C.

var. rhombea? Fl. Bras. XI, I, p. 31. - Serra de São José d'El Rei, Misas, $n^{\circ}$ 16741. Arbrisseau tortueux; fl. grisittres. Octobrenovemlire. C.

27. Goupia glabra Aubl. Fl. Guian. I, p. 296. t. 116. - Quinta de São Christovão. Rı-Jax., $\mathrm{n}^{0} 12536$ a. Arbrisseau cultivé, f1. brunes. Janvier-février. R.

\section{Fam. 40: Hippocratéacées.}

1. Hippocratea ovata Lamk.; Fl. Bras. XI, I, p. 130. - Restinga de Cabo Frio, Rio-Jax., n ${ }^{\text {os }}$ 10407, 10408. Arbuste sarmenteux, 11. brunes. Novembre-décembre. C. 
var. grandilora Peyt.; Fl. Bres. XI, I, p. 131. - Araruama, prìs Ciabo Frio. Arbuste sarmenteux, 11. verditres. Novembre-décembre. R.

9. H. diffusa Niers. in Trans. Limn. Soc. XXVH1, p. 346. - Restinga de Copacahana el Icarahy, à Praia Grande, Rio-JAx., nos 54, 3816, 5753. Arbuste sarmenteux, fl. brunes. Aoit-septembre. C.

3. H. flaccida Peyr. in Fl. Bras. XI, I, p. 132. - Restinga de Copacabanil, liı-JAx, n ${ }^{\circ}$ 10407. Arbuste sarmenteux, 11. verdâtres. Janvierfévrier. R.

4. H. micrantha Camb.; Fl. Bras. XI, 1, p. 134. - Alto Marahé de Nova Friburgo, Rio-Jax., $11^{\circ}$ 18158. Arbuste sarmenteux, fl. verdatres. Août-septembre. C.

¿. H. floribunda Benth.; Fl. Bras. XI, 1, p. 134. - Restinga da Tijuca, $\mathrm{n}^{\text {os }}$ 6120, 10405 ; Petropolis, à Itamaraty, Rı-JAx., $\mathrm{n}^{\circ} 6484$. Grande liane, fl. verdatres. Septembre. C.

6. H. inundata Mart. in Fl. Bras. XI. I, p. 136. - Andarahy, au Rio Trapixeiro, Rı-dax., $11^{\circ}$ 10347. Arbuste sarmenteux, fl. brunes, fruit vert. Février-avril. Ii.

7. H. decussata Peyt. var. lanceolata in Fl. Bras. XI, I, p. 239. Rio Comprido, Ro-dax., $11^{\circ}$ 11806. Grande liane, 11. brunes. Décembrejanvier. C.

8. Salacia serrata Camb.; Fl. Bras. XI, I, p. 143. - Restinga de Copacabana, Riı-Jax., $\mathrm{n}^{\text {us }}$ 2, 5751; Nlto Macalıé de Nova Friburgo, $11^{\text {os }}$ 16718, 17484, 20221. Arbuste sarmenteux, 11. verdâtres. Févriermars. C. Vulgo Bacupari.

9. S. corcovadensis Glaz. 11. sp.? in herb. Berol., Kew., Paris., Gener., etr. - Gorcovado, à Paineiras, Rı-JAx., $11^{\circ}$ 11807. Grande liane, fi. verdattres. Janvier-février. R.

10. S. cognata Peyr. in Fl. Bras. XI, I, p. 144. - Serra dos Orgãos et da Estrella, liro-dav., $11^{05} 6100,6707,14542,17483$. Arbuste, fl. verdâtres. Septembre-octobre. CG.

11. S. Riedeliana Peyr. in Fl Bras. XI, 1, p. 147. - Rio St-Antonio, au Tingua, lino-dax., nos 2940, 10410. Arbuste sarmenteux, f1. verdâtres. Aoùt-septembre. C.

12. S. micrantha Peyr. in Fl. Bros. X1, I, p. 147. - Arassuahy, Howas, $1^{\circ}$ 12469; entre Serra dos Cristaes et Chapada, Goraz, $n^{\circ}$ 20846. Petit arbuste des campos, li. vertes. Septembre-octobre. CC.

13. S. attennata Peyr. in Fl. Bras. XI, I, p. 149. - Gliemin du 
A.-F.-1I. GLAZ10C

IASTE DES PLANTES DU BRESIL CEXTRAL,

109

Corcovado, Rio-J.x., $n^{\text {os }} 5754,6119,8577$. Grande liane, fl. rerdàtres. Novembre-décembre. C.

I'4. S. lanceolata Miers in Trans. Linn. Soc. XXVIII, p. 37T. - Alto Iacahé de Nova Friburgo, Rio-JAx., n 18157. Grande liane, IT. verdâtres. Février-mars. R.

1ว้. S. fluminensis Peyr. in Fl. Bras. XI, I, 1). 149. - Icarahy, à Praia Grande, Rı-JAx., $n^{\circ}$ 16719. Grande liane, fl. Irunes. Octobrenovembre. C.

16. S. brachypoda Peyr. in Fl. Bras. XI, I, p. 150. - Alto Macahé de Nova Friburgo, Rino-Jax., $n^{0}$ 13584. Grande liane, fl. verdatres. Décembre-janvier. C.

17. S. silvestris WaIp.: Fl. Bras., XI, I, p. 1\%ँ0. - Riestinga de Copacabana, Rio-Jax., no 56 , 5750. Arlouste sarmenteux. fl. brunes. Mars-avril. C.

18. S. campestris.Walp.; Fl. Bras. XI, I, p. 1:1. - Ipanema, S̃̃o Pallo, no 12468; Pouso do Corrego do Cachoro, Mixas, n 20845. Petit arbuste, 1 . verdatres. Aout-septembre. CC.

19. S. dulcis lienth.; Fl. Bras. XI, I, p. 102. - Itahapoana, près de la mer, Rio-Jan., ${ }^{\circ}$ 10406. Arbuste sarmenteux, ll. verdâtres. Févriermars. C.

20. S. obovata Peyr. in Fl. Bras. XI, I, p. 1:\%4. - Serra da Estrella

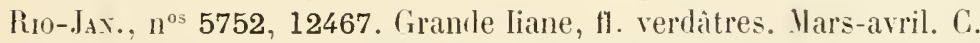

21. S. paniculata Peyr. in Fl. BHas. XI, I, p. 1\%̈. - S. Christovão, au Pedregulho, Rio-Jax., nº 838. Arlırisseau. fl. verditres. Mars-avil. C.

22. S. arborea Peyr. in Fl. Bras. XI, I, p. L̈̈6. - liestinga de Copacabana, Rio-Jıx, $n^{0 s} 3674,4956,18159$. Arbrisseau, fl. verdàtres. Septembre-octohre. C. Vulgo Cança Queixo et Trapeta.

23. S. grandifolia Perr. in Fl. Bras. XI, I, p. I56. -.- Foresta da Tijuca, Rı-Jı., nº 17485. Mrbrisseau, fl. lrunes. Mai-juin. R.

2't. S. elliptica Peyr. in Fl. Bras. XI, I, p. T̈̈̈. - Entre Caraça et Infrcianado, Mris, $n^{\text {os }} 14543,15865$. Arbuste des bois, fl. jaunâtres. Septembre-octobre. C.

25. S. affinis Perr. in F\%. Brrs. XI, I. p. 1:99. - Alto Macalıe de Nova Friburgo et à Petropolis, Riı-JAx., n ${ }^{\text {ss }}$ 9667. 13582, 17237, 17486 , 18917 et 20222. Arbuste, il. jaunatres. Mars-avril. CG.

26. S. obtusifolia Camb. in Fl. Bras. méridion., II, p. 10引̈. - Alo Macahé de Nova Friburgo, Rio-JAx., nos 18917, 20218. Arbuste, 11. jaunàtres. Octobre-novembre. C. 
27. S. amy-gdalina Peyr.; Fl. Bras. XI, 1, p. 159. - Alto Marahé de Nova Friburgo, Rio-J Ax., $n^{\text {os }} 12160,18156,20219$. Arluste, fl. jaune verdâtre. Juillet-ioût. Ci.

28. S. glomerata Peyr. in Fl. Bros. XI, I, p. 160. - Bord du Rio Itamaraty, a Petropolis, liı-JÀ, $\mathrm{n}^{\circ}$ 11805. Arbuste. R.

49. S. crassifolia Peyr. in Fl. Bres. XI, I, p. 160. - Campos do Caraça, Mıras, $11^{\circ}$ 15896. Septemlıre-octolıre. CC.

var. ovalifolia Loes. - Bella Vista à Barro Amarello, Goyz, $n^{0}$ 20840. Buisson tortueux, ll. verdattres. Aoùt-septembre. C.

\section{Fam. 41 : Rhamnées.}

1. Zizyphus undulata Reiss. in Fl. Bras. XI, I, p. 88. - São Joâo da Barra, Rı-Jax., nos 10068, 10479. Arlıre, t1. blane jauǹtre. Févier-mars. C. Vulgo Joazeiro.

2. Z. Glaziovii Warm. in Symb. Fl. Bras., vol. II, p. 378. - Santa Theresa, au Corcovado, Rio-Jax., nos 864,1474 . Arlore à racine touffue, 11. blanc verditre. Juillet-septembre. C.

3. Z. Allemâovii n. sp. in herb. Berol., Kew., Paris., ete. - Serra do Jericino, près Campo Grande, Rı-dax., no 18991. Grand arbre, fl. verdâtres. Juin-juillet. k.

4. Condalia buxifolia Reiss. in Fl. Brus. XI, I, p. 89. - São Christovão, près de la mer, Rı-Jax., $1^{\circ}$ 8794. Arbuste, fl. jaunâtres. IIai-juin. C.

3. Frangula polymorpha Reiss. in Fl. Bros. XI, I, p. 91. - Tijuca, au Bico do Papagaio, Rio-Jdx., nºs 844,2097 , 4927. Arbrisseau, fl. jaunâtres. Ortobre-novembre. CC.

var. glabra in Fl. Bras. XI, I, p. 91. - Serra da Piedade, Mosas, $n^{0}$ 20252. Arlure, fl. jaunâtres. C.

6. Rhamnidium elcocarpum Rieiss. in Fl. Bras. XI, 1, p. 49. Petropolis, au Quarteirĩo Brazileiro, Rio-JAr., $11^{\circ}$ 13668; entre Indaya et Bocaina, Goxaz, n 20847. Grand arbre, hon hois, fl. brunes. Décembre-janvier. C. Vulgo Faguarayibe.

7. R. Moreireanum Glaz. n. sp.? in herb. Berol., Kew., Paris., Genev., etc. - Logoa de Rodrigo de Freitas, Ruo-Jav., no 15898 ", 16743. Arbrisseau, fl. rousses. Mai-juin. C.

8. Scutia arenicola Reiss. in Fl. Bras. XI, I, p. 93. - Restinga de Nacahé et N. Sra da Penlıa, Rio-Jax., $1^{08} 8314$, 18185. Arbuste touffu, 17. brunes. Aoutt-septembre. C. 
A.-F.-M. Glaziou. - Liste Des Plantes DC brésil CeNTRAL. 111

9. S. buxifolia var, obtusifolia Reiss. in Fl. Bras. Xl, 1, p. 93. Paraty, près la mer, Ro-JAN., $11^{\text {os }} 18990$, 18991. Arbuste, 11. brunes. Décembre-janvier. Ci.

10. Cormonema spinosum lieiss, in Fl. Brus. XI, 1, p. 96; Cirsia spinosa Vell. - Serra da Rica, à Cascadura, Ro-JAx., n ${ }^{\text {os }} 12184$, 13568, 16744, 18992. Alluste, 11. Irunes. Juillet-aoùt. C.

11. Colubrina rufa Reiss. in Fl. Brus. XI, I, p. 98. - Caixa d'Agua, au Corcovado, Rı-JAx., nos 665, 1307, 10474. Grand arbre, hon bois de construction, fl. rousses. Janvier-février. CC. Vulgo Sobragi.

12. C. cordifolia Reiss. in Fl. Bras. XI, 1, p. 98. - São Fidelis, près de Campos, Rio-Jax., n 10475. Grand arbre, hon bois, fl. rousses. Février-mars. C.

13. Colletia cruciata Gill. et Hook.; Fl. Bras. XI, I, p. 99.Passeio Publico, Rio-Jan., $n^{0} 18992 a$. Arhuste de Porto Alegre, cultivé, fl. blane jaunâtre. Février-mars. Ii.

14. Crumenaria erecta lieiss. in Fl. Bras. XI, I, p. 114. - Serra dos Cristaes, Govaz, $n^{\circ}$ 20849. Sous-frutescent, fl. blanches. Aout-septembre. Ii.

I5. C. choretroides Mart. in Fl. Bias. XI, 1, p. 114. - Serra dos Pyreneus, pris de Meia Ponte, Goyaz, $n^{\circ}$ 20850. Sous-frutescent, 11. blanches. Septembre. CC.

16. C. Gla ioviana Urb. in Engler's Bot. Jahrb. (1898), p. 1. - Cabeceira dos Rio Sambambaia et Ponso do Barbatinão, Goraz, ॥ $^{\circ} 20848$. Sous-frutescent. fl. blanches. Septemhre. R.

17. Gouania mollis lieiss. in Fl. Brus. XI, I, p. 104. - Rio Parahyba, près de Desengano, Rio-Jax., n² 2699. Arbuste sarmenteux, 11. rousses. Mars-avril. CC.

18. G. virgata Reiss.; Fl. Bras. XI, I, p. 104. - Corcovado, à Paineiras. liı-JAx., $n^{\circ} 8311$ a. Arbuste sarmenteux, fi. blanchìtres. Févriermars. C.

19. G. Blanchetiana Miq.; Fl. Bras. XI, I, 1. 10\%. - Piedade, près de Magé et Theresopolis, Rio-Jax., n ${ }^{\circ-5} 8311,8621$. Arbuste sarmenteux, fl. ßlanchâtres. Avril-mai. CG.

20. G. petiolaris Reiss. in Fl. Bras. XI, 1, p. 108. - Larandahy, Mivas, $n^{0}$ 13667. Arbuste sarmenteux, fl. blanchâtres. Mars-avril. C.

21. G. corylifolia Raddi; Fl. Brus. XI, I, p. 109. - Piratiminga, à Praia Grande, Rio-JAx., nos 5803, 10477. Arbuste sarmenteux, f1. hlanchàtres. Novembre-décemlı́e. C. 
22. Ressekia cordifolia Steud.; Fl. Bras. XI, I, p. 112. - Restinga de Copacalıana, Rı-JAx., nos 1109, 2112. Arbuste tris sarmenteux, f1. verdatres. Septembre-octobre. C.

\section{Fam. 42 : Ampélidées.}

1. Vitis campestris Baker in Fl. Bras. XIV, II, p. 200. - Mestre d'Armas, à Fazenda da Cova, Goraz, no 20853. Sous-frutescent, fl. verdàtres. Novembre-décembre. R.

2. V. aplyylla Presl., Reliq., p. ל33. - São Gonçalo, à Laranjal, Rio-Jax., nos 8610,11847 . Sous-frutescent, fl. verdàtres. Juillet-août. R.

3. V. sicyoides Baker in Fl. Bras. XIV, II, p. 202. - Serra de Jacarepagua, liı-.JAx., $n^{0 s} 3912$, 5796. Sous-frutescent, fl. verdâtres. Novembre-décembie. CG.

forma lobata Fl. Bras. XlV, II, p. 203. - Serra de Jacarepagua et

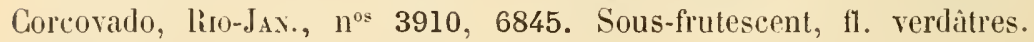
Octobre. C.

forma laciniata Fl. Brus. XlY, II, p. 203. - Formosa da Imperatriz, Goraz, $n^{\circ} 20851$ a. Sous-fiutescent, fl. verdatres. Décembre-janvier. $\mathbf{R}$.

val. $\beta$. ovata in Fl. Bras. XIV, II, p. 203. - Tijuca et Corcovado, Rio-JAx., $n^{\text {os }} 10439,18965$. Sous-frutescent, f1. verdâtres. Novembredécembre. $\mathrm{R}$.

var. smllacixa in Fl. Bras. XIV, II, p. 203. - Petropolis, vieille route de Minas Geraes, Rio-Jax., nos 8611 , 14585. Sous-frutescent, I1. verdâtres. Février-mars. C.

4. V. Selloana Baker in Fl. Bras. XIV, Il, p. 204. - Araruama, près de Cabo Frio, Rio-Jax., n ${ }^{\circ}$ 10441. Sous-frutescent, fT. verdattres. Décembre-janvier. R.

\%. V. suberecta Baker in Fl. Bras. XIV, II, p. 206. - Serra do Lenheiro, Mris, no 15883; Mestre d'Armas, Goyaz, no 20851. Sous-frutescent, fl. rouge foncé. Novembre-décembre. G.

6. V. rhombifolia Baker in Fl. Bras. XIV, II, p. 208. - Serra do Conto et da Estrella, Rio-JAx., nos 2950, 12516, 15882. Frutescent, très sarmenteux, tl. verdàtres. Janvier. C.

7. V. sulcicanlis liaker in Fl. Bras. XIV, II, p. 208. - Serra de Jacarepagua, Ro-Jax., n³911; Corrego do Brejo, Goyaz, $n^{\circ} 20852$. Arbuste sarmenteux, ll. verdâtres. Décembre. C. Vulgo Condurango.

S. V. salutaris baker in Fl. Bras. XIV, II, p. 211. - Praia Grande 


\section{BUREAU ET CONSEIL DADMINISTRATION DE LA SOCIÉTE}

\section{POUR 1905}

Président : M. Ẻ̉. Bureau.

Vice-présidents :

M.M. Malinvaud, Bois, Camus, Hua.

Secrétaire gënéral: M. L. Lutz.

Secretaires :

MM. Buchet, Molliard.

Trésorier :

M. Delacour.
Vice-secrétaires :

MM. Gagnepain, Ph. de Vilmorin. Archiviste :

M. Éd. Bornet.

Membres du Conseil :

MM. Bonaparte (prince Roland), |M.M. Finet,

Bonnier, Costantin,

Dismier.
Guêrin, Guignard, Maugeret.
MM. Morot, Mouillefarise, Poisson, Zeiller. 


\section{8. \\ AVIS IMPORTANTS relatifs à la Publication du BULLETIN}

I. - Les manuscrits, réligẻs ne varietur et lisiblement, doivent être dẻposès le jour méme ou sont faites les conmunications, faute de quoi leur impression est ajournèe sans que les auteurs puissent élever de rẻclamation à cet égard.

Il. - Si les manuscrits sont accompagnés de figures destinées à ètre insérées dans Ic texte, celles-ci dloivent être dessinces à la plume et au trait, ou bien au crayon Wollf sur papier procédé, ou consister en bonnes photographies, de manière à en permettre la reproduction par les procédés zincograpliques. L'insertion de toute figure ne pouvant être reprodıite que par des procèdés dilfẻrents reste soumise á l'approbation de la Conıuission du Bulletin.

111. - Les auteurs reçoivent une épreuve en placards et en double exemplaire de leurs communications, la corrcction des autres épreuves étant faite par le Sccrétariat. Les corrections doivent c̀tre retournées dans le délai maximm de trois jours au Secrétaire-rédacteur, faute de quoi la correction est faite d'office par le Secrétariat

IV. - Lorsque les manuscrits dépassent la longueur réglementaire de 8 pages ct qu'ils ne comportent pas le question de priorite. ils peuvent être pulslies sons la rubrique : Mémoires pulliés par la Société botanique de France. Ces Mémoires sont éditès avec toute la célérité possible, mais sans garantic de date. lis prennent place dans les volumes annuels à la suite des communications insérées aux séances ordinaires et sont fournis aux Membres de la Société sans majoration rle leur cotisation.

V. -- Afin de permellre l'établissement des convocations aux sẻances, MI. les Autcurs sont instamınent priès d'aviser lé Secrétaire général huit jours à l'avance des communications qu'ils ont l'intention de présenter.

VI. -- En vue d'assurer l'unité typographique du Bulletin, le Conseil a arrêté le protocole ci-dessous, réglant les caractcres cmployés dans les descriptions et les listes de végètaux. Il ne sera admis aucune dérogation a cette règle.

\begin{tabular}{|c|c|c|}
\hline & NOUVELLES & ANCIENNES \\
\hline Faulle. & 1. Labiées. & 2. Labiées. \\
\hline $\begin{array}{l}\text { Sous-Famlle. } \\
\text { Tribe. }\end{array}$ & 3. LAMIÉES. & 4. LAMIÉES. \\
\hline $\begin{array}{l}\text { SOUS-ThiBU. } \\
\text { GENRE. }\end{array}$ & $\begin{array}{l}\text { 5. Stachydeæ. } \\
\text { Sonchus. }\end{array}$ & $\begin{array}{l}\text { 6. Stachydeæ. } \\
\text { Sonchus. }\end{array}$ \\
\hline SECTION. & 7. Autalpinia. & 8. AUtalpinia. \\
\hline EsPèce. & 9. Communis. & 10. Communis. \\
\hline $\begin{array}{l}\text { SoUS-EsPĖCE. } \\
\text { VARIÉTÉ. }\end{array}$ & 11. Pilosa. & 12. Pilosa. \\
\hline Forme. & 13. Laciniata. & 14. Laciniata. \\
\hline
\end{tabular}

Tont ce qui concerne l'administration de la Sociéte doit être adressé au Secrétaire gẻnèral à l'atresse suivante:

11. Lutz, professeur agrégé à l'École supérieure de pharmacie, 4, avenue de l'Observatoire, Paris $\left(\mathrm{Vl}^{\mathrm{e}}\right)$.

\section{Le Serrétnire-rédacteur, Gérant du Bulletin:}

F. Gagnepaln.

Coulommiers. $-1 \mathrm{mp}$. P. Brodard 
Voir, p. 2 de la courerture, des renseignements sur la publication des Mémoires.

\section{BULLETIN}

DE LA

\section{SOCIÉTÉ BOTANIOUE}

\section{DE FRANCE}

FONDÉE LE 23 AVRIL 1854

ET RECONNUE CONNE ÉTABLISSEMENT D'UTJLITÉ PUBLIQUE

PAR DÉCRET DU 17 AOUT 1875

\section{TOME CINQUANTE-TROISIEMUE}

(Quatrième série - Towe VI)

1906

MÉ MOIRES

$3^{b}$

\section{PARIS}

AU SIEGE DE LA SOCIÉTÉ

RUE DE GRENELLE, 8́

Le Bulletin de la Société botanique de France parait par livraisons mensuelles. Publiẻ en juillet 1906. 


\section{MEVOIRES PUBLIÉS}

1. Christ. Fougères de la Chine, 69 p. (mai 1905̈), terminé.

2. Terracciano. Gagea du nord de l'Afrique, 26 p. (nov. 1903 ), terminé.

3. Graziov. Plantes du Brésil central, 112 p. (nov. 1903), à suivre.

4. Finet el Gagnepain. Flore de l'Asie orientale, 54 p., 8 pl. qui seront distribuées avec la table de $190 \unlhd$ (mars 1906), à suivre.

8. Lignier. Anatomie des Renonculacées (juin 1906), 38 p., terminé.

3b. Graziov. Plantes du Brésil central, p. 113-200, sous presse.

4b. Finet et Gagnepais. Fl. de l'Asie or., en prépar., pour paraitre en déc. 1906 , à suivere.

Notı. - Les Mém. 2-3 ont paru dans le même fascicule.

\section{BUREAU ET CONSEIL DADIINISTRATION DE LA SOCIÉTÉ} POUR 1906

Président : M. Ern. Malinvaud.

Vice-présidents :

MM. Costantin, Dismier, Guérin, Molliard. Secrétaire général : M. L. Lutz.

Secrétaires :

MM. Buchet, Gagnepain.

Trésorier :

M. Delacour.
Vice-secretaires :

MM. Ph. de Vilmorin, Gatin. Archivisle :

M. Éd. Bornet.

Membres du Conseil :

MM. Bonaparte (prince Roland), MM. Finet, Bonnier, Bureau, Camus (F.). Guignard, Hibon, Maugeret.
MiM. Morot, Perrot, Poisson, Zeiller. 
A.-F.-M, GLAZIOL, - LISTE DES PLANTES DU BRESHL CENTRIL.

au Barreto, Rio-Jax., nos 9715, 2949; Serra do Lenheiro, Hisas, $n^{\text {os }} 10440,17573$. Sarmenteux, fl. rougeâtres. Février. C.

9. V. Gibertii Baker in Fl. Bras. XIV, II, p. 2I1. - Paineiras, au Corcovodo, Rio-Jax., nos 3909, 10444. Sarmenteux, fl. blanchâtres. Janvier-février. C.

I0. V. Simsiana Baker in Fl. Bras. XIV, II, p. 214. - Entre Gavea et Tijuca, Rio-Jas., $n^{08}$ 5797, 7858, 10443. Sous-frutescent, 11. blanchâtres. Décembre-janvier. C.

I1. V. striata Baker in Fl. Bras. XI, II, p. 215. - Serra da Estrella, à Mandioca, Rı--JAx. nº 18966. Sarmenteux, 11. rougeâtres. Mars-avril. C.

12. V. ternata Baker in Fl. Bras. XIV. II, p. 216. - Petropolis, chemin de Cachambú, Rıo-Jas., nº 9376. Arbuste sarmenteux, fl. blanches. Décembre-janvier. R.

13. V. paullinifolia Planch. in Vell. Fl. Flum. I, tab. 102. - Gavea, Tijuca et Villa Nova, Rı-JAs., nos 2520, 7560, 10442. Sarmenteux, f1. rouges. Décembre-janvier. C.

14. V. (Cissus) pulcherrima Vell. Fl. Flum. I, tab. 101. - Corcovado, Tijuca et Alto Macahé de N. Friburgo, Ro-JAn., n ${ }^{\text {os }} 6865,8612$, 16736. Grande liane, fl. rouge pourpre. Janvier-février. C.

I气. V. Serroniana Glaz. n. sp. in herb. Berol., Kew., Paris., etc. - Gavea, Tijuca, Rio-Jay., nos 7857, 13646. Grande liane, tl. blanchâtres, sur le vieux bois. Janvier-février. C.

16. I. sicioides var. Jacquinii Planch. in herb. Berol., Kew., Brux., etc. - Entre Matta Grande et Fazenda Cipo, Misas, n ${ }^{0} 18965 u$. Grande liane, sans fleur en avril. R.

\section{Fam. 43 : Sapindacées.}

1. Serjania tenuis Radlk. in Fl. Bras. XIII, III, p. 249. - Gavea Praia Grande, Rı-Jan., nos 4771, 5772; Congonhas do Campo, Mrsas, $\mathrm{n}^{\circ}$ 13626. Liane, fl. blanclies. Mars-avril. GC.

๖. S. Regnellii Schlecht.; Fl. Bras. XIII, III, p. 291. - Serra do Lenheiro, près de São d'El Rei, Mıxas, n $12508 a$. Liane, fl. blanc jaunâtre. Janvier-février.

3. S. cuspidata Camb. ; Fl. Bras. XIII, III, p. 20̈2. - Morro da Babylonia et Praia Grande, Rro-JAv., $n^{0 s}$ 46, 136, 6498, 4985. Grande liane, f1. blanches. Aoùt-septembre. CG.

4. S. communis Camb.; Fl. Bras., XIII, III, p. 2อั6. - Serra dos 
Orgãos et Tịjuca, lìo-Jav., $n^{\circ s}$ 8592, 8597, 8598, 8963, 11819. Liane, 11. blanches. Mai-juin. CG.

̈. Serjania confertiflora Radlk.; Fl. Bras. XIII, III, p. 262. Piratininga, à Praia Grande, Ro-Jax., no 18169. Liane, f1. blanches. Avril-mai. $\mathrm{h}$

6. S. platycarpa Benth.; Fl. Bras. XIII, III, p. 263. - Bernardo, près de Neia Ponte, Goraz, $n^{\circ}$ 20859. Liane á odeur d'ail pourri. Maijuillet. Ii.

7. S. deflexa Gardn.; Fl. Bras. XIII, III, p. 273. - Serra dos Orgãos, Rro-Jax., nos 141, 8595. Liane, fl. blanc jaunàtre. Avril-mai. C.

8. S. elegans Camb. ; Fl. Bras. XIII, III, p. 274. - Itatiaia, près de Campro Bello, $n^{0} 5775$ et Petropolis, au Caclıambu, Rio-Jax., nos 7550, 8296, 14579. Liane, fl. rouges. Juillet-septembre. CG.

9. S. corrugata Radlk. in Fl. Bras. XIII, III, p. 279. - Gavea, aux bois d'Irmãos, Rı-JAN., $1^{0}$ 5771. Liane, fl. blanc rosé. Mai-juin. C.

10. S. paradoxa Radlk. in Fl. Bras. XIII, III, p. 277. — Campos do Itatiaia. Rio-JAx., nº 5775. Liane, fl. blanches. Juillet-aoùt. R.

11. S. gracilis Radlk. in Fl. Bras. XIII, III, p. 278. - Hogy dos Cruzes, Sao Paulo, no 17494; Floresta de Tijuca, Rıo-Jax., $11^{\circ} 20236$. Liane, f1. blanches. Juin-juillet. C.

12. S. macrostachya Radlh. in Fl. Bras. XIII, III, p. 280. - Taipù, à Praia Grande, Rı-Jax., nº 5768. Liane, fl. blanches. Mai-juin. R.

13. S. dentata Radlk. in Fl. Bras. XIII, III, p. 282. - Restinga de Copacabana, $\mathrm{n}^{\circ *}$ 3898, 4772 et Corcovado, Rio-J Jav., $\mathrm{n}^{\circ}$ 8599; Inficionado, à Caraca, Minas, n ${ }^{\circ}$ 12504, 13630. Liane, f1. blanches. Nars-mai. C.

14. S. caracasana Willd.; Fl. Bras. XIII, III, p. 283. - Sapopemba et Gavea, Rio-Jav., $\mathrm{n}^{\text {os }} 7549,7860,10414$; Paraizo, au Rio Tocantins, Goyaz, no 20858. Liane, fl. blanches. Juin-juillet. C. Vulgo Timbo da Campo. Plante réputée très vénéneuse, à Goyaz.

1.). S. grandiflora Camb.; Fl. Bras. XIII, III, D. 288. - Entre Queluz et Carandahy, Mıxas, $\mathrm{n}^{\circ}$ 12507. Belle liane, 11 . blanches. Juinjuillet. G.

16. S. Laroutteana Camb.; Fl. Bras. XIII, III, p. 291. - Fazenda do Morro Azul, S. Pavlo, no 12497, 18953. Grande liane, fl. blanches. Mars-avril. C.

17. S. reticulata Camb.; Fl. Bras. XIII, III, p. 293. - Petropolis, à Santo Antonio, Rio-Jax., no 5774; Mogydas Cruzes, S. Paclo, nº 17493 Rio das Pedras, au Vallu, Mısas, $n^{\circ} 18952$. Liane, fl. blanches. Ci. 
18. S. piscatoria Radlk. in Fl. Bras. XIII, III, p. 296. - Corcovado, $\mathrm{n}^{\text {os }} 6603,6699,7861$ et Petropolis, Rio-Jas., ${ }^{\text {os }} 15450,15869$. Liane, fl. blanches. Février-mars. Ci.

19. S. marginata Casar.; Fl. Bras. XIII, III, p. 297. - Serra de Jacarepagua, Rı-JAN., nº 1023. Liane, fl. blanches. Juillet-août. R.

20. S. erecta liadlk. in Fl. Bras. XIII, III, p. 299. - Serra do Lenheiro, $\mathrm{n}^{\text {os }}$ 15870, 17492 et Serra de Ouro Branco, Minas, $\mathrm{n}^{\circ}$ 18168; Lagoa Feia, près de Formoza, Goraz, $1^{\circ}$ 20857. Arbuste, fl. blanches. Décembre-janvier. CG.

21. S. grandifolia Sagot; Fl. Bras. XIII, III, p. 302. - Itapemirim, Espirito Santo, no 13620. Liane, fl. blanches. Février-mars. R.

22. S. glabrata Kunth; Fl. Bras. XIII, III, p. 303. - Campos da Bocaina, Sao Paulo, $\mathrm{n}^{0}$ 10417. Liane, fl. blanches. Novembre-décembre. R.

23. S. fuscifolia Radlk. in Fl. Bras. XIII, III, p. 309. - Petropolis, à Santo Antonio, Rio-Jav., nos 8292, 8603. Grande liane, f1. blanches. Ilai-juin. C.

24. S. clematidifolia Camb.; Fl. Bras. XIII, III, p. 311. - São Gonçalo et Gavea, Rio-Jav., $n^{0 s} 1322,5770,8604$. Grande liane, f1. blanches. Juillet-aoùt. C.

פอ. S. pinnatifolia Radlk. in Fl. Bras. XIII, III, p. 314. - Serra da Bocaina, Sao Pallo, n $10417 a$. Grande liane, fruit. Février. R.

26. S. lethalis St-Hil.; Fl. Bras. XIII, III, p. 316. - Serra da BabyIonia, Minas, $n^{\circ}$ 9705; Meia Ponte, Goraz, $n^{\circ}$ 20860. Belle liane, fl. blanches. Septembre. C. VuIgo Cipo Timbo.

2-7. S. scopulifera Radlk. in Fl. Bras. XIII, III, p. 31s. - Rio Parahyba, au Cazal, Rio-Jan., nº 18952 a. Grande liane, fl. blanches. Avril-mai. R.

28. S. ichthyoctona Radlh. in Fl. Bras. XIII, III, p. 319. - Restinga de Copacabana, $n^{\circ} 47$ et Corcovado, Rio-JAx, $n^{\circ}$ 7862. Très grande liane, fi. blanches. Janvier-février. C.

29. S. paucidentata DC.; Fl. Bras. XIII, III, p. 320. - São João da Barra, près de Campos, Rio-Jan., n 9702 . Liane, fl. blanches. Janvier-février. R.

30. S. acutidentata Radlk. in Fl. Bras. XIII, III, p. 322. - Bord du

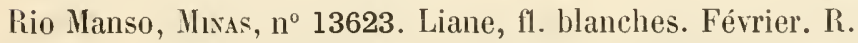

31. S. lamelligera Radlk. in Fl. Bras. XIII, III, p. 326. - Carą̧a au Rio Manso, Mixas, $n^{\circ}$ 12506. Liane, fl. blanches. Juillet-aoùt. C. 
32. Serjania suborbicularis Radlk. in Fl. Bras. XIII, III, p. 329. Biribiry, près de Diamantina, Mıxas, $n^{\circ}$ 18951. Liane des campos, fl. blanches. Mars-avril. C.

33. S. orbicularis Radlk. in Fl. Brus. XIII, III. p. 330. - Norro Azul, à Limeira, S. Paulo, no 12497 u. Grande liane, f1. blanches. Avrilmai. C.

34. S. tristis Radlk. in Fl. Bras. XIII, III, p. 331. - Rio Vaga Lume, près Neia Ponte, Goraz, $11^{\circ} 20860 a$. Grande liane, fruit rougeatre. Septembre. C.

3ə. S. hebecarpa Benth.; Fl. Bras. XIII, III, p. 335. - Campos da Bocaina, S. Pallo, n ${ }^{\circ}$ 10416. Grande liane, fl. blanches. Février-mars. R.

36. S. mansiana Mart. : Fl. Bras. XIII, III, p. 336. - Fazenda do Morro Azul, São Pallo, no $12497 a$. Grosse liane, ll. blanches. Avrilmai. C.

37. S. multiflora Camb.: Fl. Bras. XIII, III, p. 340. - Morro dd Atalaia, à Praia Grande, Rio-JAN., no $18169 a$. Grande liane, fl. blanches. Avril-mai. G.

38. Paullinia pinnata L.; Fl. Bras. XIII, III, p. 360. - Campos, au Collegio, $\mathrm{n}^{\text {os }}$ 9703, 9698 et Serra da Estrella, près de Petropolis, Rio-Jan., ${ }^{\text {os }} 10413,10415$. Liane, fl. blanches. Septembre. C.

39. P. spicata Benth.; Fl. Bras. XIII, III. p. 364. - Santa Luzia do Rio da Vellıas, Minas, $1^{\circ}$ 20237. Grosse liane, fl. blanches. Novembre. C.

40. P. obovata Pers.: Fl. Bras. XIII, III, p. 36\%. - S. Fideliz, près de Campos, Rı-JAx., no 9700. Grosse liane, fl. blanches. Juin-juillet. R.

41. P. rubiginosa Camb.; Fl. Bras. XIII, III, p. 367. - Entre Villa Nova et Porto das Caixas, Rı-JAs., $0^{\text {os }}$ 7551, 7552, 12495. Grande liane, fl. blanchâtres. Mars-avril. C.

42. P. urvilleoides Radlk.; Fl. Bras. XIII, III, p. 372. - São João d'El Rei, Mısas, no 12508. Liane, fl. blanches. Février. C.

43. P. cupana Kunth; $\mathrm{Fl}$. Bras. XIII, III, p. 372. - Tres Vendas, ¿' Lagoa de Freitas, Riı-Jas., $n^{\circ}$ 9707. Grosse liane cultivée, fl. blanches. Mai-juin. Vulgo : Guarana.

44. P. latifolia Bentlı.: Fl. Bras. XIII, III, p. 378. - Quinta de São Christovão, Rio Jax., I $^{\circ}$ 13619. Grande liane cultivée, fl. blanches. Février-mars. R.

45. P. subcordata Benth.; Fl. Bras. XIII, III, p. 377. - Gavea, chez Frei Custodio, R10-J $\mathrm{JN}_{\mathrm{N}}, \mathrm{n}^{0}$ 13618. Grande liane cultivée, f1. blanches, Mai-juin. R. 
A.-F.-M. GLAZIOL. - LISTE DES PLANTES DU BRESIL CENTRAL.

46. P. ferruginea Lasar.; Fl. Bras. XIII, III, p. 378. - Restinga da Tijuca, près de la mer, Rio-Jax., $n^{\text {os }}$ 1323, 4984. Liane, fl. lousses. Octobre-novembre. C.

47. P. fusiformis Radlk.; Fl. Bras. XIII, III, p. 379. - Petropolis, clımin de Cachambú, Rio-Jas., $n^{\circ s} 6495,8295,11820$. Grosse liane, f. jaunàtres. Mai-juin. G.

48. P. marginata Casar.; Fl. Bras. XIII, III, p. 380. - Serra da Estrella, Rı-JAx., nos 142, 2947, 6497, 7548. Arbuste sarmenteux, fl. blanches. Juin-juillet. CG.

49. P. carpodea Camb. forma 1 in Fl. Bras. XIII, III, p. 383. Petropolis, au Retiro, Rio-JAx., $n^{\text {os }}$ 6499, 8601; Ipiranga, S. Pallo, $\mathrm{n}^{\circ}$ 12496. Arbuste sarmenteux, fl. blanches. Février-mars. C.

forma 2 in Fl. Bras. XIII, III, p. 383. - Diamantina, Minas, $\mathrm{n}^{\circ}$ 18954. Arbuste laiteux, fl. blanches. Avril-mai. C.

50. P. grandifolia Benth.; Fl. Bras. XIII, III, p. 384. - Chacara de Caraça, Mınas, $n^{\circ}$ 12633. Grande liane, fl. rousses. Février-mars. R.

ら้. P. ternata Radlk.: Fl. Bras. XIII, III, p. 395ั. - Andarahy Grande, Rio-Jax., nº 10432. Grosse liane, fl. blanches. Janvier-février. C.

๖2. P. meliafolia Juss.: Fl. Bras., XIII, IIl, p. 39ð. - Morro da Babylonia, Rio-Jax., $n^{\text {os }} 796$, 4983. Longue et fine liane, fl. blanches. Septembre-octobre. C.

var. hirsuta Camb.; Fl. Bras. XIII, III, p. 397. - Petropolis, RioJas., $n^{\circ}$ 13622. Longue liane, 11 . blanches. Décembre-janvier. C.

э3. P. nobilis Radlk.; Fl. Bras. XIII. III, p. 398. - Campos, dans le bois, Riro-Jax., nos 9699, 9701. Longue liane, f1. blanches. Avrilmai. C.

54. P. thalictrifolia Juss.; Fl. Bras. XIII, III, p. 402. - Palmeiras et Engenho de Dentro, Rio-JAn., nos 4770, 5769, 8602. Petite liane, fl. blanches. Mai-juin. CG.

5ร. P. coriacea Casar. ; Fl. Bras. XIII, III, p. 403. - Praia Grande, à Jurujuba, Rı-JAs., $n^{\circ}$ 3900. Arbuste, fl. blanc jaunâtre. Févriermars. CG.

56. P. racemosa Wawra; Fl. Bras. XIII, III, p. 406. - Larangeiras, au pied du Corcovado, Rio-Jan., I $^{\text {os }} 3901$, 10411. Arbuste sarmenteux, 11. blanches. Janvier-février. C.

57. P. rhomboidea Radlk.; F'. Bras. XIII, III, p. 407. - Itatiaia, dans le bois vierge, Rı-JAx., $n^{\circ} 5769 a$. Liane fine, fl. blanches. Juinjuillet. $\mathrm{R}$. 
58. Paullinia neinmanniafolia Mart.: Fl. Bras. XIII, III, p. 408. - Restinga de Copacabana, Rı-J J . $11^{0 s} 40,8605$. Arbuste sarmenteux, f1. blanc jaunâtre. Mars-avril. CC.

59. P. micrantha Camb.; Fl. Bras. XIII, IIl, p. 410. - Floresta de Tijuca, Rio-Jas., $n^{\circ}$ 3896. Arbuste un peu sarmenteux, fl. blanc jaunàtre. Février. R.

60. Urvillea triphylla Radlk.: Fl. Bras. XIII, III, p. 417. - Alto Macahé de Nova Friburgo, $n^{\circ}$ 19872; Restinga de Nlaua, $n^{\circ} 8300$; Corcovado et Serra dos Orgãos, Rı-Jax., $11^{\text {os }} 11819,8596,2429$. Liane, fl. blanches. Mai-juin. CG.

61. U. glabra Camb.; Fl. Bras. XIII, III, p. 419. - Tahipu, près de la mer, Rio-Jax., $\mathbf{n}^{\circ}$ 1342. Liane fine, fl. blanches. Mai-juin. C.

62. U.rufescens Camb.: Fl. Bras. XIH, III, p. 419. - Petropolis, au Jacob, lio-Jas., $1^{0}$ 6496; Caraça, Minas, $n^{\text {os }} 13625,13626,13628$, 13629. Grande liane, fl. blanchâtres. Mai-juin-juillet. CG.

63. U. ulmacea Kunth; Fl. Bras. XIll, III, p. 420. - Serra do Caraẹa, Mis. Ger., n ${ }^{\circ} 1362 a$. Grosse liane, fl. blanchittres. Juin. C.

64. U. uniloba Radlk.; Fl. Bras. XIII, III, p. 423. - Campos da Bocaina, Sĩo Paclo, $n^{0} 10416 a$. Liane fine. f1. llanches. Février. R.

68. Cardiospermum grandiflorum Sw.; Fl. Bras. XIII, III, p. 433. - Petropolis, à Santo Antonio, Rio-Jav., n 8297, 11603; São João d'El Rei, Mısas, n 12505. Grande liane, tl. blanches. Févriermars. CG.

var. genuinum Radlk.; Fl. Bras. XIIl. III, p. 436. - Alegria, Minas, $n^{\circ}$ 13627. Grande liane, fl. blanches. Mai-juin. C.

var. elegans liadlk.; Fl. Bras. XIII, III, p. 436. - Cabeceiras do Rio Gama, Goysz, $1^{\circ}$ 20856, 20856 a. Grande liane, fl. blanches. Juillet-août.

66. G. Halicacabum L.; Fl. Bras. XIII, III, p. 438. - Quinta de São Christovão, Rı-JAn., $n^{\text {os }} 8302,9704,9706$. Petite liane, fl. blanches. Décembre-janvier. C.

var. microcarpum Bl.; Fl. Bras. XIII, III, p. 442. - Quinta de São Christovão, Rio-Jan, $n^{\circ}$ 8301. Petite liane, fl. blanches. Décembrejanvier. C.

67. C. strictum Radlk.; Fl. Bras. XIII, III, p. 4E00. - Formosa, dans les cerrados, Goyaz, $\mathrm{n}^{\circ}$ 20854. Plante naine, fl. blanches. Décembre. C.

var. stenophyllum in Fl. Bras. XIII, III, p. 40\%. - As Bracas, Goyaz, 
A.-F.-M. GLAZIOU. - LISTE DES PlaNtes DU RRÉSIL CENTR.AL. 119 $n^{\circ}$ 20855. Plante naine des campos, fl. blanches. Décembre-janvier. R.

68. Thinouia mucronata Radlk. : Fl. Bras. XIII, III, p. 4:6. - Itatiaia, dans le bois, liı-JAx., $\mathrm{n}^{\circ} 5773 a$. Arbuste sarmenteux, fruit rougeatre. Février. R.

69. T. paraguaiensis Radlk.: Fl. Bras. XIII, III, p. 457. - Larangeiras, à Cantagallo, Ri-J vier. R.

70. T. scandens Triana et Pl. ; Fl. Bras. XIII, III, p. 460. - Praia Grande, $n^{\text {os }} 857,3897,3899,5773,3902,17499,18170$ et Larangeiras, à Cantagallo, Rı-JAx., nos 6864,15449 . Grande liane, fl. Hanches. Décembre-janvier. CC.

71. Diatenopterix sorbifolia Radlk. : Fl. Bras. XIII, III, p. 466.Entre Carandahy et Queluz, dans le bois, Misas, $n^{\text {os }} 13723,14613$. Arbrisseau, f1. blanchàtres. Novembre-décembre. C.

72. Allophyllus heterophy-llus Radlk.; Fl. Bras. XIII, III, p. 474. - Corcovado et Gavea, Rio-JAn., nos 2514, 2956, 2957. Arbuste, f1. blanchâtres. Novembre. CC.

73. A. sericeus Radlk.: Fl. Bras. XIII, III, 1. 476. - Barbacena, dans le campo, Misas, $n^{\circ}$ 14577. Arbuste, fl. blanches. Novembre-janvier. C.

74. A. melanophloeus Radlk.; Fl. Bras. XIII, III. p. 478. Lagoa de Rodigo de Freitas, Rı-JAx., n 2951. Arbrisseau, tl. blanches. Janvier-février. C.

7ö. A. puberulus Radlk.; Fl. Bras. XIII, III, p. 481. - Restinga da Gavea, au bord de la mer, Copacabana, Serra da Estrella, Rı-JAx., $\mathrm{n}^{\text {os }} 204,6678,14578$. Arbuste, f1. blanches. Janvier-mai. CC.

76. A. edulis Radlk.; Fl. Bras. XIII, III, p. 484. - Serra da Estrella, Sete Pontes, Cabo Frio et Serra Vermelha, Rio-JAs., n ${ }^{\text {s }} 8608$, 9373, 10419, 12498, 15888. Arbrisseau, fl. blanches. Janvier-mars. CC.

77. A. petiolulatus Radli.; Fl. Bras. XIII, III, p. 490. - Corcovado, Serra da Estrella, Floresta da Tijuca, Rı-JAx., n ${ }^{0 *} 1357,2955$, 5778, 9372, 10424, 10429. Arbrisseau, fl. blanches. Mars-mai. CC.

78. Toulicia lavigata Radlk.; Fl. Bras. XIII, III, p. 5002. - Roclia de São João, à Tijuca et au Corcovado, Rio-JAx., n nos 9370, 9371, 11824. Grand arbre, fl. blanches. Juillet-aoùt. C.

79. T. acuminata Radlk. : Fl. Bras. XIII, III, p. 50马ั. - Manaos, 
Schwack et Quninta de São Christorão, Rı-Jan., no 13631 a. Arbrisseau, h. blanches. Février. R.

80. Toulicia tomentosa Radlk.; H7. Bras. XIII. III, p. 5006. - Entre Alexandre et As Antas, Goyaz, $n^{\circ}$ 20861. Arbuste, il. blanches. Juilletaoùt. C.

81. Sapindus Saponaria L.; Fl. Bras. XIII, III, p. :12. - Corrovado, Sete Pontes, Araruama, S. Christovão, Rı-JAN., nos 1523, 6847, $8308,10423,15872,16733$. Grand arbre, 11. blanches. Septembre-novemhre. CG. Vulgo: Páo Sabio, Guiti, Sabonete.

8ュ. Melicocca lepidopetala Radlk.; Fl. Bras. Xlll, III, p. 5ั25. Sete Pontes, au Barreto, Rro-Jan., n ${ }^{\text {os }}$ 6863, 16732. Arbuste cultivé, 11. blanches. Octobre-novembre. R. Vulgo : Jba pomo, Papa mundo.

83. Talisia intermedia Radlk. in Fl. Bras. XIII, III, p. 236. Serra de Caraça, dans le bois, Mivas, n ${ }^{\circ}$ 15447. Arbre, fl. blanchâtres. Septembre. C.

84. T. esculenta Radlk.; F1. Bras. XIII, III, p. 537. - Jacarepagua, Barreto, Rio-JAx., $1^{0 s} 801,6491,8309,10424,10559$; Alegre, dans le bois, Mrsas, $n^{\circ}$ 20862. Grand arbre, tr. hlanc rosé. Septembre-octobre. C. Vulgo : l'itombeira.

85. T. cupularis Radlk.; Fl. Bras. XIII, IIl, p. 5้̋4. - Quinta de São Chıristovão, Rı-Jax., $n^{\circ}$ 13616. Arbrisseau cultivé, fi. verdâtres. Nai-juin. R. Vulgo : Pritombeira.

86. Cupania castaneafolia Nart.; F\%. Bras. XIII, III, p. 570. Petropolis, à Santo Antonio et au Alto Nacahé de Nova Friburgo, Rio$J_{A x}, n^{\circ s}$ 10427, 17498, 18166. Grand arbre, fl. blanches. Décembre. CG.

87. C. Zanthoxyloides Camb.; Fl. Bras. XIII, III, p. 570. - Itatiaia, dans le bois, Rro-JAs., n $8304 a$. Arbrisseau, fl. blanches. Janvierfévrier. R.

88. G. dentata Glaz. n. sp.? in herb. Paris., Berol., Kew., etc. Entre Jacarepagua et Tijuca, Riro-JAx., nº 800. Grand arbre, sans tleur en décembre. C.

89. C. oblongifolia Mart.; Fl. Bras. XIII, III, p. 573. - Petropolis et au Corcovado, Rio-Jan., nos 2518, 7546. Grand arbre, il. blanches. Janvier-arril. C.

90. C. tenuivalvis Radlk.; F7. Bras. XIIl, III, p. 576. - Parahyba do Sul, Fazenda do Sobral, Rı-JAx., $n^{\circ} 12494$ : Riheirão de Taquaraçu, Mrnas, $n^{0}$ 18958. Arbrisseau, t1. blanches. Mai-juin. C.

91. C. Gysneiriana Glaz. 11. sp.? in herb. Paris., Berol., Kew., etc. 
- Serra de Itabapoana, Esprikto Saxto, n 10426. Arbre, fi. blanchâtres. Septembre-octobre. R.

92. C. crassifolia Radlk, in Fl. Bras. XIII, III, p. 874. - Petropolis, à ltamaraty, Rio-JAx., $\mathrm{n}^{\circ}$ 15871. Grand arbre, fl. blanches. Septembre-octobre. C.

93. C. paniculata Camb.; Fl. Bras. XIII, III, p. :76. - Queluz, dans le campo et Arassuahy, Mssas, $n^{\circ}$ 13501, 13631. Arbrisseau, fl. blanches. Nai-juin. G.

94. G. rotundifolia Glaz. n. sp.? in herb. Paris., Berol., Kew., etc. - Piratininga, Rı-JAx., nº 10079. Arbrisseau, 11. blanchâtres. Févriermars. R.

9.5. C. bullata Glaz. n. sp.? in herb. Paris., Berol., Kew., etc. Entre Rio do Ouro et Queimados, Rio-Jdx., n 11605. Arbre superbe, sans fleur en août. C.

96. C. hispida Radlh.: Fl. Bras. XIII, 1II. p. 380. - Quinta da Boa Vista, Rio-JAx., no 13617. Arbrisseau cultivé, l1. blanc jaunâtre. Avril-mai. R.

97. C. furfuracea ladlk.; Fl. Bras. XIII, III, p. 584. - Floresta da Tijuca et Serra dos Orgãos, Rio-Jax., nos 2517, 11825, 11826. Arbre, f1. blanches. Mar's-mai. C.

98. C. platycarpa Radlk.; Fl. Bras. XIII, III, p. อ̈8\%. - Fazenda do Cipo, Mısss, no 18957. Grand arbre, fl. blanchâtres. Avril-mai. C.

99. G. Saldanhæ Glaz. n. sp.? in herb. Paris., Berol., Kew, etc. - Petropolis, au Morin, Rı-JAx., n 10430. Grand arbre, fl, blanches. Février-mars. C.

100. C. racemosa Radlk.; Fl. Bras. XIII, III, p. 586. - Copacabana, Corcovado, Gavea, Praia Grande, Rio-Jax., nos 127, 4207, 5766, 5777, 8304, 8305. Arbre, fl. blanches. Avril-mai. CG. Vulgo : Camboala.

101. C. concolor Radlk. in Fl. Bras. XIIl, III, p. 887 . - Serra dos Orgãos, à Theresopolis, Rıo-Jav., $n^{0}$ 3904. Arbrisseau, fl. blanches. Mars-arril. R.

102. C. villosa Glaz. n. sp.? in herb. Paris., Berol., Kew., etc. Cabo Frio, près de São Pedro, Rı-JAx., nº 10436. Arbrisseau, fl. blanches. Juin-juillet. C. Vulgo : Batinha.

103. C. emarginata Camb. : Fl. Bras. XIII, III, p. 587. - Piratininga, Villa Nova, Gavea, Alto Macahé de Nova Friburgo, Rio-JAx., $\mathrm{n}^{0 \mathrm{~s}}$ 2516, 7547, 17496, 18167. Arbrisseau, f1. blanches. Mars-arril. CC.

10'. Dilodendron bipinnatum Radlk.; Fl. Bras. XlII, Ill, p. 99. 
- Entre Natta Grande et Fazenda do Cipo, Minas, n 18956. Grand arbre, fl. blanches. Janvier-avril. C. Vulgo: Pao pobre, Mulher pobre, Farinha seca.

108. Matayba adenanthera Radlk. in Fl. Bras. XIII, III, p. 615. Porto das Caixas, Rio-Jan., $n^{05}$ 9709, 10422. Grand arbre, 11. blanclies. Septembre-octobre. R.

106. M. silvatica Radlk. : Fl. Bras. XIII, III, p. 618. - Corcovado, Serra dos Orgãos, Tijuca, Rı-J $\mathrm{J}_{\mathrm{A}}$., $\mathrm{n}^{\circ \mathrm{s}}$ 798, 1584, 6113, 6115. Arbre, fl. blanches. Octolıre-novembre. CC. Vulgo : Camboata.

107. M. talisioides Radlk, in Fl. Bras. XIII, III, p. 618. - Entre Campo Grande et Mendanha, Rio-J $J_{A N}, n^{\circ} 11839$. Bel arbre, sans fleurs en aoùt.

108. M. intermedia Radlk. in Fl. Bias. XIII, III, p. 619. - Floresta da Tijuca, Rro-Jan., $n^{\circ 5} 8607$, 11821. Grand arbre, f1. blanclies. Novembre-décembre. C.

109. M. guianensis Radlk.; Fl. Bras. XIII, III, p. 620. - Campo Grande, Rio d'Ouro, Serra dos Orgãos, Rio-Jan., nos 1587, 6493, 9368, 10420, 10421, 11606, 17495: Serra da Mantiquera, Queluz, etc., Mixas, $\mathrm{n}^{0 \mathrm{~s}}$ 12502, 12503, 13634, 20239, 20863. Arbre, fl. blanches. Aoùtnovembre. CG. Vuggo: Camboata branca, Jatuauba.

1I0. M. mollis Radlk.; Fl. Bras. XIII, III, P. 624. - Cachoeira do Campo, près de l'eau, Mısss, $n^{\circ}$ 20235. Arbrisseau, fl. blanchâtres, Décembre. C.

111. M. punctata Radlk.; Fl. Bras. XIII, III, p. 624. - Serra de Ouro Preto, dans le campo, Minas, ${ }^{\circ}$ 14575. Arbrisseau, fl. blanches. Septembre-octobre. C.

112. M. marginata Radlk.; Fl. Bras. XIII, III, p. 625. - Nova Friburgo, au Nlorro do Suspiro, Rio-Jav., n 13413. Arbrisseau, fl. blanches. Octobre-novembre. C.

113. M. juglandifolia Radlk.; Fl. Bras. XIII, III, p. 627. - Serra da Estrella, Nova Friburgo, Mendanha, Rio-Jan., n ${ }^{\text {os }}$ 6492, 6709, 11823, 11827 ; Sào Bartholomeu, Santa Luzia do Rio das Velhas, Minas, $\mathrm{n}^{0 s} 14576,20238$. Arbrisseau, f1. Hanches. Août-octobre. CC. Vulgo : Camboata.

114. M. pallens Radlk. in Fl. Bras. XIII, III, p. 628. - Près de São Bartholomeu, dans le bois, Mınas, no $14576 a$. Arbrisseau, fl. blanchâtres. Octobre. R.

113. M. leucodictya Radlk. in Fl. Bras. XIII, III, p. 628. - Alto 
A.-F.- H. GLAZIOU. — LISTE DES PLANTES DE BRESIL CENTIAL. 123

Nacahé de Nova Friburgo et à Petropolis, Rio-Jax., nos 13621, 18955. Grand arbre, fl. blanches. Janvier-février. C.

116. Tripterodendron filicifolium Raldk.: Fl. Bras. XIII, III, p. 633. - Corcovado, Tijuca, Villa Nova, Rı-JAs., nºs 797, 1472, 11822 , 14574. Grand arbre, fl. rousses. Juin-juillet. C. Vulgo : Carna de Vacca.

117. Pseudima frutescens Radlk.: Fl. Bras. XIIl, Ill, p. 633.Campos, au Collegio, dans le bois, Rıo-JAx., n 9711. Aririsseau, fl. blanches. Mai-juin. R.

118. Dodonæa viscosa Jacq. ; Fl. Brus. XIll, 11l, p. 639. - Restinga de Copacabana, Taipu, Ru-JAx., n52, 730; Arassuahy, Queluz, dans le Campo, Hinas Geraes, nos 13632 , 14580. Aibuste, f1. blanchâtres. Janvier-juillet. CG.

119. Magonia pubescens St-Hil.; Fl. Bras. XIII, 11I, 1. 654.Congonhas do Campo, Misas Geraes, n 9714; Vao do Paraña, près de Formosa, Goraz, n² 20864. Grand arbre, 11. rerdâtres. Janvier-mars. CC. Vulgo : Tingui.

120. M. glabrata St-Hil.; Fl. Bras. Xlll, III, p. 6ว̈.̆. - Près de Congonhas do Campo, dans le bois, Minas Geraes, $n^{\circ}$ 12500. Grand arbre, fl. verdâtres. Janvier-mars. CC. Vulgo : Tingui.

Fam. 44: Sabiacées.

1. Meliosma brasiliensis Urb. in Symb. Antill. vol. 1, p. 5ั09.Cova da Onça, au Corcovado, Nova Friburgo, Rı-JAx., $\mathbf{n}^{\circ \times} 8099,17729$; Rio Vaga Lume, Goyaz, nos 20397, 20865. Arbrisseau, fl. rousses. Octobre-novembre. C.

2. M. Glaziovii Urb. in Symb. Antill., vol. I, p. 508. - Alto Macahé de Nova Friburgo, Rı-Jas., $n^{\text {os }}$ 12131, 19587. Grand arlure, fl. rousses. Octobre-novembre. C.

3. M. Itatiaice Urb. in Symb. Antill., vol. 1, p. 30. - Itatiaia, Fazenda do Taquaral, Minas Geraes, ${ }^{05} 6697$, 7565. Arbrisseau, 11. rousses. Septembre. R.

4. M. sinuata Urb. in Symb. Antill. vol. I, p. SI1. - Petropolis, au Retiro dans le bois vierge, Rio-JAx., $n^{\circ}$ 16707. Grand arbre, 1 . rousses. Novembre. C.

\section{Fam. 4. : Anacardiacées.}

1. Mangifera indica L.; Fl. Bras. XII, II, p. 406. - Quinta de São Cihristovão, Rı-Jan., $n^{0} 1559$; Morrinhos, Goyaz, $n^{0} 1559 a$. Grand arbre cultivé, bon fruit, fl. blanc jaunâtre. Aoùt-octobre. CC. 
2. Anacardium occidentale L.; Fl. Bras. XII, II, p. 409. - liestinga de Copacabana, Rı-JAN., $n^{\text {os }}$ 13, 19016; Illa lo Governador, no 9387 ; Ponso Alto, au Surdo, Goyaz, n² 20868. Arbre tortueux, fl. blane rosé, bon firuit. CC. Dérembre-janvier. Vulgo : Cajueiro.

3. A. humile St-Hil.; Fl. Bras. XII. II, P. 411 . - Bella.Vista, frotaz, $\mathrm{n}^{\circ}$ 20866. Petit arbuste des campos, fl. blanc rosé. Aoùt-septemlnre. C. Vulgo : Cajueiro do Camp.

4. A. pumilum St-Hil. ; Fl. Bras. XII, II, p. 411 , - Entre Rio Manso et Arassuahy, Mıss, $n^{\text {os }} 12541,14610$; entre Cuba et Norinhos, Goviz, $n^{\circ}$ 20867. Petit arbuste des campos, bon fruit, 1l. rougeâtres. Août. CC.

ऽ. Spondias purpurea L.; Fl. Bras. XIl, II, p. 373. - Sete Pontes, au Barreto. Rı-JAx., n ${ }^{\circ}$ 17584. Arbre cultivé, fl. blanches. Septembreoctobre. C. Vulgo : Imbuzeiro.

var. vexulosa Mart. in $\mathrm{Fl}$. Liras. XII, II, p. 373. - Morro do Inglez, au Corcovado, Rı-JAx., $\mathrm{n}^{\text {os }} 827,10494$. Arbre cultivé, fl. blanches, fruit jaune. Septembre-octobre. CC. Vulgo : Cajazeiro.

6. S. lutea L.; Fl. Bras. XII, II, p. 374. - Floresta da Tijuca, près de la rivière, liı-.JAx., $n^{\text {os }} 9388,13677$. Grand arthre cultivé, fl. blanches. Septembre-octohre. C. Vulgo : Cajazeiro.

var. glabra Engl. in Fl. Bras. XII, II, p. 374. - Passeio Publico, Rro-JAN., $n^{\circ}$ 2912. Grand arhre cultivé, 1l. blanches, bon fruit. Septembre-octobre. C. Vulgo : Cajazeiro Mangue.

7. S. macrocarpa Engl.; Fl. Bras. XII, II, p. 37\%. - Serra da Alegria, près de Caraça, Mssas, n 13678. Oetolıre. C. Vulgo : Cajazeiro do Nutto.

8. Tapirira guianensis Aubl.; Fl. Bras. XII, II, p. 377. - Copa całana, $\mathrm{n}^{0 \mathrm{~s}}$ 58, 96, 115, 727, 10431; Serra dos Orgãos, Rı-Jax. $n^{0: 5} 6116,9369,9744$; Serra do Caraça, Nıxas, $n^{0 s} 10487,12544,14609$, 19009. Arbre, fl. jaunàtres. Octobre-décembre. CC. Vulgo : Camboata.

9. T. Marchandii Engl, in Fl. Bras. XII, II, p. 379. - Diamantina à Mendanlıa, Mrsas, $n^{0 s} 12544 a, 14607,14608$. Arbre, fl. blanc jaunâtre. Octohre-novenbre. C.

var. paоpomba Netto; Fl. Bras. XII, II, p. 380. - São João d'El liei, Mivas, $n^{\circ}$ 1675; Rio Areas, Goyaz, $n^{\circ}$ 20813. Grand arbre, ll. blanc jaunâtre. Octolıre. CC.

10. T. Pecholtiana Engl. in Fl. Bras. XII, Il, p. 380. - Nova Friburgo, liro-Jax., $1^{\circ 5} 11874,12546$. Grand arbre, H. rousses. Octobrenovembre. C. 
A.-F.-Y. GLAZIOU. - I.ISTE DES PLANTES DU BRÉSIL CENTRAL.

11. Mauria multiflora Mart. in Hooker's Kew Journ. IV, p. I4. Quinta da Boa Vista, Rino-Jax., nº $9744 a$. Arbrisseau cultivé, 11. jaunâtres. Octobre-novembre. R.

12. Schinus molle L. : Fl. Bras. XII, II, p. 382. - Passeio Publico, cultivé, Riro-Jax., $n^{\circ} 218,5806$. Arbre, fl. blanches. Septembre-octobre. C. Vulgo : Aroeira do liio Grande.

13. S. terebinthifolius Raddi; Fl. Bras. XII, II, p. 383. - Floresta da Tijuca, Rio-JAx., $n^{\circ}$ 9389. Arbuste, fl. blanches, fruit rouge. Janvier-février. CG. Vulgo : Aroeira do Parana.

var. raddina Engl. in Fl. Bras. XII, II, p. 384. - Restinga de Copacabana, Rio-Jix., $n^{0 \varsigma} 12,1056,1381$. Arbuste, 11. blanches, fruit rouge. Janvier-février. CG. Vulgo : A roeira.

var. acutrfolta Engl. in Fl. Liras. XII, II, p. 384. - Juiz de Fora, Mrsas, $n^{\text {os }} 3667,7579$. Arbuste, fl. blanches, fruit rouge. Juillet-aoùt. CG. Vulgo : Aroeira.

var. Glazioviana Engl. in Fl. Bras, XII, II, p. 384. - Petropolis, à Santo Antonio, Rio-J Ax., $n^{0}$ 5805. Arbuste, 11. blanches, fruit rouge. Février-mars. CC. Vulgo: Aroeira.

I4. S. weinmannicefolius Engl.; Fl. Bras. XII, II, p. 38.̈. - Serra do Mar, près de Paraty, Rı-J.x., $n^{\circ}$ 19010. Arl,risseau, 11. blanc jaunàtre. Janvier. C. Vulgo : Aroeirinha.

I̋̈. Lithræa molleoides Engl. in F\%, Bias. XII, II, p. 394. - Barbacena. Mtwis, $n^{05} 10486,13679$. Arbuste, fl. blanches. Aoùt-septembre. CC. Vulgo : Aroeirinha.

I6. L. brasiliensis March.; Fl. Bras. XII, II, p. 398. - Restinga de Cabo Frio, Rio-JAx., nos 12547, 18199. Arbuste, fl. blanches. Septembreoctobre. C.

17. Astronium fraxinifolium Schott: Fl. Bras. XII, II, p. 397. - Serra da Mantiqueira, Misas, ${ }^{05} 10490,10491$. Grand arbre, bon bois, 11. blanches. Septembre. C. Vulgo: Gonçalo et Lralunha.

ral. glabrum Engl. in DC. Mon. Phan., IV, p. 40̈6. -- Entre Sitio et Barbacena, Misas, $n^{\circ}$ 12542. Grand arbre, hon hois. fl. blanches. Octobre. C. Vulgo : Gonçalo.

18. A. gracile Engl. in DC. Mon. Phan. IV, p. 40̈4. - Entre Gavea et Tijuca, Rı-Jıs., no 80, 9390. Grand arbre, ll. blanches, bon bois. C. Juillet-aoùt. C. Vulgo : Ubatũ.

19. Myracrodruon Urundeuva Fr. Allam.; Fl. Iras. XII, II, p. 400. - Entre Rio Nlanso et Arassuahy, Mixas, nos 10489, 12543; 
Passa Tres à luâo Lobo, Goyaz, $n^{0}$ 20869. Grand arbre, bon hois, $n$. rougeâtres. CiC. Vulgo : Aroeira et Vrundeuva.

20. Myracrodruon macrocalyx Engl. in $\mathrm{Fl}$. Bras. XII, II, p. 402.Larangeiras, près de Cantagallo, Rio-.las., n ${ }^{\text {os }} 10485$, 15903. Très grand arbre, 11. brunes, bois excellent. Octohre. C. Vulgo : Aroeira Mucury.

21. Schinopsis brasiliensis Engl. in Fl. Bras. XII, II, p. 404. Promontoire de Cabo Frio. Rio-Jan., n ${ }^{\circ}$ 10488. Arbrisseau, 1l. brun rougeàtre. Juillet-août. R.

\section{Fam. 46 : Connaracées.}

1. Bernardinia fluminensis Planch.; Fl. Bras. XIV, II, p. 170̈.Gavea, Corcovado, Tijuca, etc., Rio-JAx., n ${ }^{\text {ss }} 124,804,805,6520$. Arbuste sarmenteux, fl. blanchàtres. Aoùt-septembre. CC. Vulgo : Mata Cachorio.

2. Rourea infuta Planch.: Fl. Bras. XIV, II, p. 178. - Entre Capelinha et Ponte Alta, Goraz, $n^{\circ}$ 20872. Arhuste, 11 . blanches à odeur de rose. Octobre-septembre. CC.

3. R. Martiana Bak. in Fl. Bras. XIV, II, 1. 178. - hezende, RıJax., $n^{0}$ 8625. Arbuste sarmenteux, fruit rougeâtre. Novembre-décembre. C.

4. R. chrysomala Glaz. 1. sp.? in herb. Paris, Berol., Kew., etc. Paranana et Chico Loho, Goyız, $n^{\circ}$ 20871. Petit buisson, fruit brun. Novembre-décembre. C.

5. R. Gardneriana Planch.; Fl. Bras. XIV, II, p. 181. - Serra de Itahapoana, Esprrito Savto, $1^{0}$ 9757. Arbrisseau, 11. llanches. Septembreoctobre. R.

6. R. glabra Humb. B. et K. ; Fl. Bras. XIV, II, p. 182. - Quinta da Boa Vista, à São Christovão, Rı-Jax., $n^{\circ}$ 13432. Arbuste cultivé, f1. blanc jaunâtre. Novembre-décembre. R.

7. R. cuspidata Benth.: Fl. Bras. XIV, II, p. 181. - Serra da Estrella, à Nandioca, Rı-JAx., no 8329. Arbuste, fl. blanches. Octobrenovembre. R.

8. Connarus marginatus Planch. :Fl. Bras. XI, II, p. I85. - Morro da Bahylonia, à Botafogo, Rı-Jax., n 4968. Arbuste sarmenteux, 11. blanches. Octohre-novembre. C.

9. C. favosus Planch.; Fl. Bras. XIV, II, p. 186. - São João da Chapada, Mıxas, nos 14605, 14606: Morro do Coco, Rio-Jax., no 10664. Arbuste des cerrados, 11. rousses. Décembre-janvier. CC. 
A.-F.-H. GLAZIOU. LISTE DES PLANTES DU BRÉSIL CENTRAL.

10. C. Blanchetii Planth.; Fl. Bros. XIY. II, p. 187. - Sapopemba, $n^{0 s} 9600,8624$ et Imbetiba, près de la mer, Rı-Jax., $n^{\circ}$ 19019. Arbuste sarmenteux, 11. Hanchitres. Octobre-novembre. C.

11. C. guianensis Lamb.; Fl. Bras. XIV, II, p. 188. - Caraça, Estrada do Rio Manso. dans le bois, Mixds, $n^{\circ}$ 13876. Arbuste sarmenteux, 1l. blane jaunitre. Février-mars. C.

I2. C. ruber Planch.; Fl. Bras. XIY. II, j. 188. - Luartel do Biribiry, Mras, n 19017. Arbuste des cerrados, 11. jaunâtres. Mars-arril. C.

13. C. Beyrichii Planch. : Fl. Bras. XIV, II, p. 189. - Serra da Estrella, à Quitandinha. Rı-JAx., $n^{\circ} 8329$ a. Arbuste, 11. jaunâtres. Septembre-octobre. C.

14. C. cymosus Planch.; Fl. Bras. XIV, II, p. 190. - Fazenda de Santa Cruz, Rio-Jax., n ${ }^{\circ}$ 6133. Arbuste sarmenteux, f1. jaunâtres. Octobre-novembre. C.

15. C. suberosus Planch.; Fl. Birus. XIY, II, p. 191. - Entre Tijuca et Santa Maria, Goyaz, n 20874. Arbrissseau rabougri des cerrados, 11 . rousses. Aoùt-septembre. C.

16. C. fulvus Planch.; Fl. Bras. XIY, II, p. 192. - Horro do Frota, près de Neia Ponte, Goyaz, $n^{\circ}$ 20873. Arbuste des campos, 11. rousses. Septembre-octobre. C.

17. C. detersus Planch.; Fl. Bras. XIV, II, p. 194. - Morro da Babylonia, à Botafago, Rı-Jax., $n^{05} 8303,19018$; São João da Chapada, Mrsas, no 14604 . Arbuste, 11. rousses. Septembre-décembre. C.

18. Cnestidium lasiocarpum Bak. in Fl. Bras. XIV, p. 195̈. - Itabira do Campo, Misıs, $n^{\circ}$ 17477. drbrisseau, 11. blanchâtres, fruit roux. Décenbre. R.

\section{Fam. 4ĩ. - Légumineuses (PAPILIONACÉES).}

1. Crotalaria pterocaula Desr.; Fl. Bras. XV, I, 19. - Serra da Babylonia. Misas Geraes, $n^{\circ}$ 7595. Sous-frutescent, 11. jaunes. Décembrejanvier. C.

2. C. subdecurrens Mart. in Fl. Bras. XV, I, 1. 20. - Congonhas do Campos, Mrvis-Geraes, $1^{\circ}$ 13698. Sous-frutescent, fl. jaunes. Juinjuillet. C.

3. C. Vespertilio Benth.; Fl. Bras. XV, I, p. 2I. - Ayuruoca, dans le campo, Hisis Geraes, $n^{\circ}$ 15904. Sous-frutescent, 11. jaunes. Décembrejanvier. C. 
4. Crotalaria retusa L.; Fl. Bras. XV, I, p. 22. - S. Christovão, dans les champs incultes, Rı-JAs., ${ }^{\text {os }}$ 5516, 6196. Annuel, 11. jaune foncé. Noventhre-décembre. CC.

5. C. paulina Schranck; Fl. Bres. XV, I, p. 29. - Iyuruoca, au Pico do Papagaio, dans le campo, Mixas Geraes, no $15904 a$; Pirranaua, dans le campo, Goraz, $n^{\circ}$ 20935. Sous-frutescent, ll. jaunes. Décembrejanvier. C.

6. C. foliosa Benth.; Fl. Bras. XV, I, p. 24. - Entre Caraça et Inficionado, Mrsas, $11^{\circ}$ 12583. Sous-frutescent, f1. jaune clair. Juilletseptembre. C.

7. C. znifoliolata Benth. in Ann. Nat. Hist., III, p. 430 - Caraça, Mrvas Geraes, $n^{\circ} 17586$; Chapada dos Veadeiros, dans le campo, Goyaz, $n^{\circ}$ 20937. Sous-frutescent, fl. jaunes. Janvier. R.

8. C. flavicoma Benth.; Fl. Bras. XV, I, p. 24. - Diamantina, dans le campo, Misas Geraes, $n^{\circ} 19031$; Lagoa Formosa, dans le campo, Goraz, n² 20934. Sous-frutescent, 11. jaunes. Janvier-mars. CC.

9. C. striata DC.; Fl. Bras. XV, I, P. 26. - Campos de Caraça,

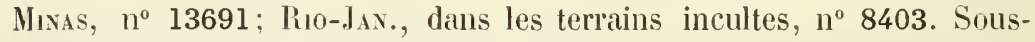
frutescent, f1. jaunes. Janvier-mars. CC.

10. C. incana L.; Fl. Bras. XV, I, p. 27. - Haut de le Serra do Picú, São Paubo, no 10501 a. Sous-fiutescent, f1. jaunes. Avril. R.

11. C. rufipila Benth. in Fl. Bras. XV, 1, p. 28. - Serra dos Orgãos, Rio-.las,, no 3715; Serra da Piedade, Mhxas, nos 10498, 20283. Sous-frutescent, fl. jaunes. Novembre-mars. C.

12. C. holosericea N. et II.; Fl. Bras. XV, I, p. 28. - Entre Rio Torto et le Rio Bananal, Goraz, $n^{\circ} 20934 a$. Sous-frutescent, fl. jaunes. Aoùt-septembre. R.

13. C. vitellina Ker.; Fl. Bras. XV, 1, p. 29. - Haut du Corcovado, $n^{05} 604,3793,8647$ et Serra dos Orgĩos, liı-Jas., nº 1572: Birihiry, dans le campo, Mlixas Geraes, $n^{\circ}$ 19029. Frutescent, f1. jaunes. Septembre-octubre. CC.

14. C. maypurensis Humb. B. et K.; Fl. Bras. XV, I, p. 30. Barhacena, Hixas Geraes, dans le campo, $\mathrm{n}^{0} 13691$ a. Sous-frutescent, f1. jaunes. Septembre. C.

15. C. anagyroides Humb. B. et K.; Fl. Bras. XV, I, p. 31.Serra dos Orgãos et Itatiaia, Rı-Jax., ${ }^{\text {os }}$ 1571, 6506; Biribiry, Mıxas Geraes, $n^{0}$ 19030; Hestre d'Armas, Goyaz, $1^{\circ}$ 20936. Frutescent, f1. jaunes. Janvier-octobre. CG. 
A.-F, - Y. GLAZIOU. - LISTE DES PLANTES DU BRÉSIL CEXTRAL.

16. C. brachystachya Benth.: Fl. Bras. XV, I, p. 32. - Engenho da Serra, au Picú, Sĩo Pacio, no ${ }^{0 s}$ 10499, 10561. Frutescent, fl. jaunes. Mars-avril. C.

17. Lupinus crotalarioides Nart. in Fl. Bras. XV, I, p. 11. - Quituti, près de Formosa, Goraz, dans les campos, n² 20933. Sous-frutescent, fl. bleu pâle. Décembre-janvier. C.

18. L. vaginans Benth. in Fl. Bras. XV, I, p. 12. - Itatiaia, dans le campo, Rio-Jis.. $11^{0 \mathrm{~s}}$ 4787, 6507; entre As Brancas et Cocal, Goraz, $n^{0}$ 20930. Sous-frutescent, fl. bleues. Juin-juillet. C.

19. L. velutinus Benth.; Fl. Bras. XV, I, p. 12. - Chico Costa Goriz, dans le campo, n² 20932. Sous-frutescent, f1. bleu pâle. Octobrenovembre. C.

90. L. insignis Glaz. n. sp.? in herb. Paris. Berol., Kew., etc. Entre Rio dos Couros et Pizario, Goraz, n 20931. Sous-frutescent, fl. bleu rose. Janvier-février. C.

21. L. bracteolaris Desr.; Fl. Bras. XV, I, p. 15. - Barbacena, dans le campo, Mrxas, ${ }^{\circ}$ 18211. Sous-frutescent, fl. bleues. Novembredécembre. R.

22. L. Hilarianus Benth. in Fl. Bras. XV, I, p. 1.ั. - Campos do Itatiaia, Rro-JAx., $n^{\text {os }} 8643,10576$. Sous-frutescent, fl. bleuâtres. Novembre. $R$.

23. Adenocarpus parvifolius DC., Podrom. Syst. Natur. II. p. 15̈8. - Diamantina, Chacra do collegio, Mrsas, no 19021. Sous-frutescent, cultivé, fl. jaunâtres. Avril. C.

24. Trifolium repens L. : Fl. Brus. XV, I, p. 3əั. - Itatiaia, dans le campo, Rı-JAx., I $^{0}$ 4788. Virace, fl. rose pâle. Mai-juin. C.

2:. T. filiforme L. Sp. Plant. p. 773. - Petropolis, aux bords des chemins, Rio-Jax., $1^{\circ}$ 7598. Vivace, fl. jaunâtres. Novembre-décembre. CG.

26. Lotus pedunculatus Cav. Icon. 11, p. 52, t. 164; L. uliginosus Chk. - Itatiaia, dans le campo, Rio-Jıs., nº 6505. Vivace, fl. jaunes. Mars-avril. C.

27. Indigofera gracilis Bong.; Fl. Bras. XV, I, p. 37. - Entre Caheceiros do Rio Sambambaia et le Pouso de Barbatimão, dans le campo, Goraz, $n^{0 s} 19020$, 20924. Sous-fiutescent, fl. orange. Août-septembre. C.

28. I. lespedezioides Humb. B. et K.; Fl. Bras. XV, I, p. 39. Rio da Gama, dans le campo, Goraz, $\mathrm{n}^{\circ}$ 20928. Sous-fiutescent, f1. rouge pourpré. Novembre-décembre. C. 
29. Indigofera microcarpa Desv.; Fl. Bras. XV, I, p. 39. - São Francisco de Paulo, près de Campos, Rio-J $\mathrm{JN}_{\mathrm{N}}$, $\mathrm{n}^{\mathrm{os}} 9734$, 10502. Sousfrutescent, 11. rose pâle. Juin-juillet. R.

30. I. subulata Vahl. in Poir. Suppl, III, p. 1500. - São Franciseo de Paulo, dans le pâturage, Rı-JAx., no 10501. Herbacé, 11. roses. Juinjuillet.

31. I. Anil L.; Fl. Bras. XV, I, p. 1. - Praia Grande et Caho Frio, hio-Jax., $1^{0 s} 5821$, 12550. Sous-frutescent, fl. lilas. Aout-septembre. CG. Vulgo : Anil.

32. Harpalyce brasiliana Benth.; Fl. Bras. XV, I, p. :0. - Capão, à l'entrée du Sertão, Mivas, ${ }^{\text {os }} 9731$, 19026. Arbuste, fl. rouges. Marsavril. $\mathrm{C}$.

33. H. speciosa Taub. in Beiträge der Floracentr. Bras., p. 13... Entre Lagedo et le Rio Tocantins, dans le campo, Goyaz, nº 20886. Arbuste, fl. rouges. Janvier-février. C.

34. Tephrosia toxicaria Pers.; Fl. Bras. XV, I, p. 46. -- Quinta de São Christovão, cult., $\mathrm{n}^{\text {os }} 9741,10503$. Sous-frutescent, fl. jaunâtres. Juillet-aoùt. Vulgo : Arnicu bravo.

3\%. T. rufescens Benth.; Fl. Bras. XV, I, p. 4T. - Entre Santa Luzia et Serra da Piedade, Mrxas, n $20266 u$. Herbacé, ll. roses. Octohrenovembre. C.

36. T. adunca Benth.; Fl. Bras. XV, I, p. 47. - Santa Luzia do liios rlos Velhas, Misas, nos 19024, 20266; Morro da Canastra, Goyaz, $n^{0} 20924 a$. Herbacé, fl. rouges. Novembre-décembre. Ci. Vulgo : l'ostemeira.

37. T. cinerea Pers.; Fl. Bras. XV, 1, p. 48. - Serra da Piedade, Minas Gemaes, ${ }^{08} 10504,19022$. Herbacé rougeâtre. Novembre. R.

38. Sesbania exasperata Humb. B. et K.; Fl. Bras., XV, I, p. 42. - Entre Sitio et Barbacena, dans les bourbiers, Minas Geraes, no 12574. Arbuste, f1. jaunes. Juin-juillet. C.

39. S. punicea Benth.; Fl. Bras. XV, I, p. 43. - Hlicaba, S̃̃o Pavlo, $\mathrm{n}^{\text {os }} 10505,12553$. Arbuste, fi. jaune pourpré. Avril-mai. C.

40. S. oligosperma n. sp. in herb. Paris., Berolin., Kew., etc. Carandahy, dans le bois, Mixss, $1^{0} 14670 a$. Frutescent, fl. jaunes. Janvier-février. R.

41. Ornithopus compressus L. Sp. Pl., p. 744. - Entre S. Pedio dos Indios et Rio Bonito, dans les pâturages, Rio-JAx., n 10500 . Herbacé, Il. rougeâtres. Juillet. C. 
A.-F.-M. GLAZIOU. - LISTE DES PLANTES DU BRÉSIL CENTRAL.

42. Chætocalyx brasiliensis Benth. in Fl. Bras. XV, I, p. 73̈. Serra da Bocaina, Sĩo Paulo, $n^{\circ}$ 10508. Volubile, fl. blanc jaunâtre. Février-mars. C.

43. C. polyphylla Benth. in Fl. Bras. XV, I, p. 76. - Campos do Caraça, Mixas, nos 13703, 13704; Petropolis, à Santo-Antonio, RioJav., $n^{\text {os }} 5813,10707$, 13702. Volubile, fl. blanc jaunattre. Juinoctobre. CC.

44. Poiretia scandens Vent.; Fl. Bras. XV, 1, , 78. - Sapopemba, dans la plaine, Rio-Jax., $n^{\circ}$ 6504; Morro Azul, Sĩo Paulo, nos 12558 , 12577. Volubile, fl. jaunes. Avril-juin. CG.

43. P. angustifolia Vog.; Fl. Bras. XV, 1, p. 78. - Sìo Juliño de Ouro Branco, Mixas, nos 18214, 20265; Chiro Lobo, dans le campo, Goyaz, $11^{\circ}$ 20914. Herlacé, fl. jaunes. Janvier-mars. C.

46. P. psoralioides DC. ; Fl. Bras. XV, I, p. 79. - Entre Paiol et Lagoa do Cercado, Goraz, $n^{0}$ 20915. Sous-frutescent, 11. jaunes. Octobre. R.

47. P. latifolia Vog.; Fl. Bras. XV, 1, p. 79. - Cocal, Chapada de Porto Seguro, Goviz, nº 20916. Arbuste, fl. jaunes. Décembre. C.

Var. corifolia in Fl. Bras. XV, I, p. 79. - Serra do theo, près de Sitio, Minas Geraes, nos $17592,19040,19041$. Arbuste, fl. jaunes. Janvier. C.

48. Eschynomene Selloi Vog.; Fl. Bras. XV, I, p. ə̈8. - São Gonçalo, dans les bourbiers, Rı-JAv., $\mathrm{n}^{\text {os }} 8632,8633,12572$. Arbuste, 11. jaune pourpré. Aoùt-octobre. CC.

49. E. sensitiva Sw.; Fl. Bras. XV, I, p. 58. - Belem, dans les bourbiers, $\mathrm{n}^{\text {os }} 4210,8629,8631$; Petropolis, Rio-JAx., nos $8629,8630$. Sous-frutescent, fl. jaune rougâtre. Aoùt-octobre. CC.

50. E. hispida Willd,; Fl. Bras. XV, I, p. 39. - São Christovão, Rı-J rougeâtre. CC.

51. E. americana L.; Fl. Bras. XV, I, p. 61. - Carandahy, dans les marécages, Mrsas, $n^{\circ}$ 12573. Sous-frutescent, fl. jaune fonıé. Juinjuillet. C.

52. LE. pauciflora Vog.; Fl. Bras. XV, I, p. 64. - Ponte .llta, dans le campo, Goyaz, $n^{0}$ 20922. Frutescent, 11. rougeâtres. Octobre-novembre. CG.

๖3. E. oroboides Benth. in Fl. Bras. XV, I, p. 64. - Piracicalıa, 
dans le campo, Sĩo Pacto. no 19023 . Herbacé, fl. jaunâtres. Décembrejanvier. C.

:4. Eschynomene paniculata Willd.; Fl. Bras. XV, I, 67. - Saia Vellıa, dans les marécages, Goyaz, $n^{\circ}$ 20923; Caraça, idem, Mıxas, $n^{\text {os }} 12571$, 19028. Sous-frutescent, f1. jaune rougeâtre. Janvier-mar's. C.

5\%. E. falcata DC; Fl. Bras. XV, I, p. 67. - São Christorão, Rio-JAx., $n^{0 s} 6503,10506$. Sous-frutescent, étalé sur le sol, f1. jaunàtres. Mar's-avril. C.

5\%6. E. Hystrix Poir.; Fl. Bras. XV, I, p. 69. - Entre Inficionado et Caraça, daus le campo, Misas Geraes, $n^{0}$ 12575. Sous-frutescent, fl. jaune pourpre. Juillet. C.

57. A. tijucensis Taub. n. sp. in lerb. Berol, Kew., etc. - Biribiry, pres de Diamantina, Mrxas Geraes, $n^{\circ}$ 19027. Sous-frutescent, fl. jaune rougeâtre. R.

58. Aॄ. nana Glaz. n. sp.? in herb. Paris., Berol., Kew., etc. - Entre As Brancas et le Rio lioncador, dans le campo, Goraz, $n^{\circ}$ 20921. Plante naine, fl. jaunes. Décembre-janvier. R.

59. Sammeringia semperflorens Mart.: Fl. bras. XV, I, p. 70. - São João da Barra, Rio-Jax., nº 9740. Herbacé, fl. jaunes. Février. R.

60. Stylosanthes bracteata Vog.; Fl. Bras. XV, I, p. 89. - Entre Seriaco et Guariroha, Goraz, $n^{\circ} 20920$; São João d'EI liei, Mixas, $\mathrm{n}^{\circ}$ 16754. Sous-frutescent, fl. jaunes. Anût-octobre. C.

61. S. capitata Vog.; Fl. Brus. XV, I, p. 90. - Serra do Ouro Branco, dans le campo sablonneux, Mixas, $1^{\circ}$ 10510. Sous-frutescent, fl, jaunes. Norembre-décembre. R.

62. S. scabra Vog.; Fl. Bras. XV, I, p. 90, - Diamantina, au Tombador, Nıxıs, no 19033; São Joũo da Barra, Rı-Jıx., nº 9733. Sous-frutescent, ft. jaunes. Mars-avril. C.

63. S. viscosa Sw. : F\%. Kras. XV. I, p. 91. - Restinga de Copacabana et Taipu, ${ }^{\circ s} 1374,5817$; sommet du Corcovado, Rio-Jar., $1^{\circ} 11876$. Sous-frutescent, fl, jaunes. Juin-décembre. CC. Vulgo : Pitubida prain.

64. S. guyanensis Sw.; Fl. Bras. XV, I, p. 91. - Petropolis, $\mathrm{n}^{\text {os }} 650,9718,9720$; Taipu, au bord de la mer, Rı-J $\mathrm{J}_{\mathrm{x}}$, $\mathrm{n}^{\text {os }} 1375,6175$. Sous-frutescent, fl. jaunes. Février-juin. CC.

Var. gracilis Vog.; Fl. Bras. XV, I, p. 92. - Pinheiro, prẻs de Diamantina, Misas, $n^{\circ}$ 19033. Sous-frutescent, f1. jaunes. Mars-avril. C.

63. S. humilis Humb. B. et K.; Fl. Bras. XV, I, p. 92. - Cahı Frio, Rio-JAN., no 10512. Sous-firutescent, 11. jaunes, Juillet-septembre. R. 
66. S. angustifolia Vog.: Fl. Bras. XV, I, p. 93. - Restinga de Cabo Frio, Rio-Jax., $1^{0} 10511$; Corrego do Brejo, Goraz, n² 20919. Sousfrutescent, fl. jaunes. Mai-juillet. C.

67. Arachis hypogaa L. ; Fl. Bras. XV, I, p. 86. - Quinta de São Christorão, cult., Rio-JAN., $11^{0} 8642$. Herb. annuelle, f1. jaunes. Janvier. C. Vulgo : Amendoim ou Mendubim.

68. A. pusilla Benth.; Fl. Bras. XV, I, p. 86. - Mendanha, près de Diamantina, Msis, ${ }^{\text {os }} 12584,13695$. Herbe annuelle, fl. jaunes. Octobre-novembre. C. Vulgo : Amendoim de poseo.

69. A. prostrata Bentlı.; Fl. Bras. XV, I, p. 87. - Campos da Bocaina, Sĩo Paclo, n 10513. Herbe annuelle, fl. jaunes. Septembre. R.

70. Zornia diphylla Pers. var. $\propto$. тнумifola Bentlı, Fl. Bras. XV. 1 , p. 80. - Curalinho, près de Diamantina, Nıss, $n^{\circ}$ 19032; Barbacena, Mixas, $n^{\text {os }} 15910$, 17587. Sous-fiutescent, fl. jaunes. Avril-mai. C.

Val. E. latefolia Benth.; 1.l. Bras. XY, I, p. 81. - Congonhas do Campo, Mrvas Geraes, $n^{\circ}$ 12570. Sous-frutes cent, f1. jaunes. Octolre. C.

Var. \%. gracilis Fl. Bras. XY, I, p. 83. - Restinga de Copacabana, Rio-JAx., $n^{\circ}$ 1376. Sous-frutescent, fl. jaunes. Mai-juillet. CC.

Var. ò elation in Warm. Symb. ad Fl. Bras., p. つ̌ł. - Chemin de la Gavea, Rio-J.r., $n^{0 s} 2125,5809$. Sous-frutescent, fl. jaunes. Janvieroctobre. CG.

71. Z. virgata Moric.; Fl. Bras. XV, I, p. 83. - Chapadão do Corrego do Brejo, Goraz, ${ }^{\circ}$ 20918; Serra de Ouro Branco, Mtxas Geraes, nos 16753, 18213. Sous-frutescent, fl. jaunes. Mars-mai. CG.

72. Z. villosa Glaz. n. sp.? in herb. Paris., Berol., Kew., etc. -Entre Rio Bananal et le Rio Torto, Goraz, $1^{\circ}$ 20917. Rampante, fl. jaunàtres. Avril-mai. C.

73. Desmodium triflorum DC.; Fl. Bras. XV, I, p. 9:. - Fazenda de Santa-Cruz, Rro-Jan., $\mathrm{n}^{\circ} 5811$ a. Herbacé, rampant, fl. roses. Mar'savril. R.

T'́ D. bracteatum Nicheli in Warm. Symb, ad. Fl. Bras. I, p. 843. - São Christovăo, Rio-Jax., $n^{0}$ 4784. Sous-frutescent, f1. roses. Juinjuillet. C.

7.) D. barbatum Benth.; Fl. Bras. XV, I, p. 9\%. - Floresta da Tijuca, Rro-J $\mathrm{J}_{\text {.. }}, \mathrm{n}^{0 \mathrm{~s}}$ 2969, 6176, 10515. Sous-frutescent, t1. roses. Octobre-décembre. CC. Vulgo : Amor do campo.

76. D. uncinatum DC.; Fl. Bras. XV, I, p. 96. - Jurujuha, près de la mer, Rio-Jax., no 8405. Sous-frutescent, f1. bleuâtres. Arril-juillet. C. 
77. Desmodium adscendens DC.; Fl. Bras. XV, I, p. 97. - São Christovão, Rı-JAN., nº $4996 a$. Sous-frutescent, fl. bleuâtres. Décembrejanvier. C.

78. D. incanum DC.; Fl. Bras., XV, I, p. 98. - São Christovĩo, Rio-dAN., $1^{05} 4996,5810,5811,9723,13696$. Herbacé, rampant, ll. bleu rosé. Février-mai. C. Vulgo: Mala-posto.

79. D. cajanifolium DC.; Fl. Bras. XV, I, p. 100. - Campos do Rio Manso, Mrxas Geraes, $n^{\circ}$ 12576. Sous-frutescent, 11. bleuàtres. Nars. juillet. Ci.

80. D. platy carpum Benth. in Fl. Bras. XV, I, p. 100. - Campos da Bocaina. Säo Padlo, $n^{\circ} 10514 a$. Sous-frutescent, fl. bleuâtres. Février-avilil. R.

81. D. pachyrhizum Vog.; Fl. Bras. XV, I, p. 101. - Campos da Bocaina, au Bom Jardim, Sĩo PActo, $n^{\circ} 10514$ b. Sous-firutescent, 11. bleuittres. C.

82. D. sclerophyllum Bentlı. in Fl. Bras. XV, I, p. 102. - Entre As Antos et Pedro Sardinha, Goraz, $n^{\circ}$ 20925. Sous-frutescent, fl. lilas. Aoùt. C.

83. D. discolor Vog.; Fl. Bras. XV, I, p. 103. - Quinta da Boa Vista, à Sĩo Christovão, Rı-JAN., $1^{\circ}$ 3716. Sous-frutescent, fl. lilas. Juin-juillet. C.

84. D. leiocarpum G. Don.; Fl. Brus. XV, I, p. 103. - Itatiaia, dans le campo, Rı-Jax., n ${ }^{\circ} 3716 a$. Sous-frutescent, fl. rose pâle. Maijuillet. R.

8̈. D. molle DG.; Fl. Bras. XV, I, p. 104. - Campos da Bocaina, S̃̃o Patlo, $11^{\circ}$ 10514. Sous-frutescent, fl. violacées. Janvier-mars. R.

86. Vicia graminea Sm.; Fl. Bras. XV, I, p. 109. - Ilheo, près de Sitio, Mrxas, nº 15906 a. Herbacé grimpant, fl. lilas rosé. Novembredécembre. C.

87. I'. obscura Vogel.; Fl. Bras. XV, I, p. 110. - Ilheo, près de Sitio, Mras Geraes, no 15906. Herbacé grimpant, fl. bleues. Décembre. (.)

88. Abrus precatorius L.; Fl. Bras. XV, I, p. 215. - Andarahy Grande. Rio Trapixeiro, etc., Rio-JAx., nos 10509, 12557, 12559, 15907. Suns-frutescent, volubile; fl. verdàtre rosé. Mars-avril. CC. Vulgo : Priquita ou Juriquiti.

89. A. tenuiflorus Spruce in Fl. Bras. XV, I, p. 216. - Quinta de São Christoyão, Rı-JAx., nº $12559 a$. Petite liane, fl. jaunàtres. Janvierfévrier. Gult. li. 
90. Centrosema platycarpum Benth.; Fl. Bras. XV, I, p. 126. São João da Barra, Rı-JAx., nº 9742. Herbacé, grimpant, fl. jaunâtres. Février-mars. C.

91. C. Plumieri Benth.; Fl. Bras. XV, I, p. 127. - Quinta de São Clıristovão, Rio-Jax., nº 3714. Herbacé, grimpant, f1. bleues. Maijuin. C.

92. C. brasilianum Benth.; Fl. Bras. XV, I, p. 128. - São João da Barra, nos 9730, 9737; Cabo Frio, Rio-Jax., nos 10519, 12581, 19034. Herbacé, grimpant, fl. violacées. Février. C.

93. C. grandiflorum Benth.; Fl. Bras. XV, I, p. 130. - Serra da Bocaina, dans le campo, Sĩo Pıılo, no 10522; Corrego do Brejo, Goraz, $1^{\circ}$ 20910. Liane, fl. lilas rougeâtre. Mai-septembre. C.

94. C. pubescens Benth.; Fl. Bras. XV, I, p. 131. - Serra dos Orgãos, à S. Luiz, Rio-Jan., $n^{0 s} 11878$, 13689. Liane, fl. lilas pâle. Mars-mai. B.

93. C. virginianum Benth.; Fl. Bras. XV, I, p. 132. - Serra da Estrella, Rio-JAx., $n^{\circ s} 8639$, 12579. Liane, f1. violacées. Mars-avril. C.

96. C. pascuorum Mart.; Fl. Bras. XV, I, p. 133. - Serra do Picú Riı-JAx., nº 10520. Liane, fl. lilas foncé. Avril-mai. C.

97. C. bracteosum Benth.; Fl. Bras. XV, I, p. 133. - São João d'El Rei, Mısas, n 15914; Rio Gama, dans le cerrado, Goraz, nos 20892 , 20911. Rampante, f1. violacées. Octobre-noremlıre. C.

98. C. hastatum Benth.; Fl. Bras. XV, I, p. 133. - Serra do Caraç, dans le bois, Mrxss, nos 10521, 13706, 14674, 15912. Liane, herbacé, fl. lilas pàle. Janvier-février. CC.

99. G. spicata Glaz. n. sp.? in herb. Paris., Berol., Kew., etc. São Fidelis, près Campos dans le bois, Rı-Jax., nº 9738. Arbuste sarmenteux, fl. rougeâtres. Févriel'-mars. C.

100. Periandra dulcis Mart.; Fl. Bras. XV, I, p. 13̋. - Caraca, dans les campos, Mixas, $n^{\circ \mathrm{s}}$ 12525, 17590: Serra dos Pyreneos, Goraz, $n^{\circ}$ 20940. Sous-frutescent, fl. lilas. Mai-aoùt. CC.

101. P. coccinea Benth.; Fl. Bras. XV, I, p. 136. - Serra do Inficionado, dans le campo, Msxas, nos 9728,12582 b, 13699. Herbacé grimpant, fl. rouges. Aoùt-septembre. C.

102. P. acutifolia Benth.; Fl. Bras. XV, I, p. 136. - Serra da Mantiqueira, à l'entrée des campos, Mrss, nº 11926. Herbacé, 11. rouges. Septembre. C. 
103. Periandra densiflora Benth.; Fl. Bras. XV, I, p. 136. Caraça, au campo de Fora, Mrxas, $n^{\circ}$ 15915. Rampant, fl. lilas. Févriermars. C.

104. Clitoria termata L.; Fl. Bras. XV, I, p. 118. - Quinta de São Christovão, Rio-Jax., no 11879. Herbacé, grimpant, fl. bleues. décembre. C.

10əั. C. glycinoides DG.; Fl. Brus. XV, I, p. 118 . - Itha do Governador, Rı-Jan., nº 8638; Serra da Bocaina, SÄo Pallo, nos 10524 , 12580. Herbacé, grimpant, fl. rouges. Janvier-février. C.

106. C. guyanensis Benth.; Fl. Biras. XV, I, p. 121. - Campos de Caraça, Mrvas Geraes, nº 15913 ; Meia Ponte, Goyaz, n² 20908. Herbacé, f1. bleues. Janvier-mars. CG.

107. C. cajanifolia Benth. in Fl. Bras. XV, I, p. 121. - Sapopembat, Rio-Jay., $n^{\text {os }}$ 8645, 10517. Sous-frutescent, fl. bleues. Septembre, octobre. R.

108. C. densiflora Benth. in Fl. Bras. XV, I, p. 122. - São João d'El Rei, Minas Geraes, $n^{\circ}$ 17589. Herbacé, fl. bleues. Janvier. C.

109. C. javitensis Benth. in Fl. Bras. XV, I, p. 123. - Entre Lagoa do Peixe et Rio Bonito, Rio-Jav., $1^{\circ}$ 12548. Liane, 11. rouges. Aoutt-septembre. R.

110. Teramnus uncimatus Sw.; Fl. Bras. XV, I, p. 138. - Serra do Picú, Rio-JAN., no $10520 a$. Sous-frutescent, fl. rougeâtres. Févriermai. R.

111. Platyciamus Regnellii Benth. in Fl. Bras. XV, I, p. 323. Chemin de Nova Friburgo, à Boca do Matto, Rio-Jas., no 2536 ; Tijuca, $\mathrm{n}^{\circ}$ 6836. Grand arbre, fl. roses. Mai-juillet. G. Vulgo: Angelim rosa.

112. Erythrina Crista-galli L.; Fl. Bras. XV, 1, p. 172. - Santa Anna dos Topos, Rı-Jax., no ${ }^{\circ}$ 8408. Arbrisseau, fl. rouges, Févriermars. C.

113. E. falcata Benth. in Fl. Bras. XV, I, p. 172. - Theresopolis, Serra dos Orgãos, Rio-Jix. nos 6906, 12552, 18210, 19049, 19874. Grand arbre, fl, rouges. Aoùt-septemlre. CC. Vulgo: Ganivete, Sanandú.

114. E. Mulungu Nart. in Fl. Bras. XV, 1, p. 173. - São Clıristovão,, cult., Rio-JAN., $\mathbf{H}^{\circ} 5822$; entre Cattas Altas et Caraça, Mnas, $\mathrm{n}^{\circ}$ 12586. Arbre, fl. rouges. Juillet-aout. C. Vulgo : Ganivete et Mulungú.

11ร. E. glauca Willd.; Fl, Bras. XV, I, p. 173. - Passeio Publico cult., Rio-Jas., nº 19050. Grand arhre, fl. orange. Août-septembre. C. 
A.-F.-.H. GLAZIOU. - LISTE DES PLANTES DU BRESIL CENTIIL.

116. E. velutina Willd.; Fl. Bras. XV, I, 1. 173. - Cantogallo et Nova Friburgo, Rino-Jax., 11 ${ }^{\text {s }}$ 289, 290, 6171, 10574, 11881, 20284. Grand arbre, fl. rouges. Novembre-lécembre. CC. Vulgo : Sanandú.

usea 117. E. reticulata Presl.; Fl. Bras. XV, I, p. 174. - Lagoa de Tijuca, dans les bourbiers, Pio-JAx., $n^{\circ} 8636$; bas de la Serra do Caraça, dans les marécages, Mrxas Geraes, n 13714. Arbuste, fl. rouge corail. Juin-aoùt. C.

118. E. indica Lamk Encycl. Bot. II, p. 391. - Passeio Publico, cult., Rio-JAx., no 10575. Grand arbre, f1. orange. Aoùt-septembre. C.

119. Mucuna pruriens DC.? Fl. Bras. XV, I, p. 169. - Cattas Altas, dans les bois, Mrras, $n^{\circ} 14675 a$. Grande liane, fl. brunes. Février-mars. C.

120. M. altissima DC.; Fl. Bras. XV, I, p. 170. - Garea, près de la mer, Rio-Jux., nos 5808, 13424; entre Cattas Altas et Caraça, Mrsus, $\mathrm{n}^{\text {os }}$ 13701, 14675. Grande liane, fl. blanc verdâtre. Janvier-février. CC.

121. Stenolobium caruleum Benth.; Fl. Bras. XV, I, p. 13!).Fazenda do Morro Azul, S̃̃o PAlLo, nos 10523, 12569; Petropolis, RoJax., $n^{\circ} 8641$. Liane, sous-frutescent. Avril-mars. C.

122. S. galactioides Benth.; Fl. Bras. XV, I, p. 140. - Caraça, dans le bois, Mrsas, nº 15915 a. Liane, sous-frutescent, fl. rougeàtres. C.

123. Galactia pyrenea Taul., in Beitr. Fl. Centralbl., p. 438. Ribeirão de Caldas et à Pichoa, dans le campo, Goraz, nos 20906, 20907. Herbacé, vivace, fl. lilas. Août-octobre. CC.

12'. G. Glaziovii Harms in Engler B'otan. Jahib. (1903), p. 228. -Pichoa, au Espigão, dans le campo, Goraz. n² 20906. Herbacé vivace, 11. lilas. Octobre-novembre. C.

12:. G. eriosematoides Harms n. sp. in Engler Botan. Jahrb. (1903), p. 2̌- - Fazenda da Cova, au Morro Canastra, Goraz, $11^{0} 20902$. Sous-frutescent, fl. jaunâtres. Novembre. C.

126. G. lamprophylla Harms in Engler Botan. Jahrb. (1903), p. 228. - Chapadinha, dans le campo, Goxaz, $n^{\circ}$ 20898. Sous-frutescent, f1. violettes. Octobre-novembre. C.

127. G. crassifolia Taub. n. sp. in herb. Berol., Kew., etc. Santa Luzia, dans le campo, Goraz, $n^{\circ}$ 20280. Sous-frutescent, fl. rose violacé. C.

128. G. Jussiceana Humb. B. et K.; Fl. Bras. XV, I, p. 142. Serra da Mantiquiera, Mrsas Ger.ses, nos 6170,10527 . Liane, 11. rouges. Septembre-octobre. R. 
129. Galactia tenuiflora W. et Arn.; Fl. Bras. XV, I, p. 143. Cabo Frio. Rir(o-JAx, n ${ }^{0 s}$ 10525, 10526. Petite liane, fl. rouges. Juillet. C.

130. Collæa speciosa DG.; Fl. Bras. XV, I, p. 146. - Campos da Bocaina, S̃̃o Pacto, $n^{0 s} 8637,7596,10573$; Petropolis, à Maria Comprida, Rro-Jax., nº 10570; S̃̃o Joño d'El Rei, Mısıs, $1^{\circ} 16725$; Corrego do Brejo, dans le bois, Goraz, nos 20938, 20939. Arbuste, 11. rouge violacé. Nars-aoùt. GG.

131. C. rigida Glaz. n. sp.? in herb. Paris., Berol., Kew., etc. Morro Canastra, près Mestre d'Armas, Goraz, no 20900. Frutescent, f1. blanches. Novembre-décembre. C.

132. C. grewiafolia Benth.; Fl. Bras. XV, I, p. 148. - Ponte Alta, dans le campo, Goraz, $n^{\circ}$ 20897. Sous-frutescent, fl. lilas. Octobrenovembre. C.

133. C. glaucescens Benth.; Fl. Bras. XV, I, p. 1500. - Serra dos Pyreneos, Goraz, no 20926. Petit arbuste, fl. rouge foncé. Septembreoctobre. G.

134. C. crassifolia Benth.; Fl. Brus. XV, I, p. 13̈1. - Campos da

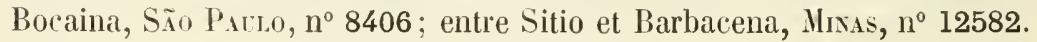
Sous-frutescent, f1. lilas. Décembre-janvier. C.

13\%. C. coriacea Glaz. n. sp.? in herb. Paris., Berol., Kew., ete. Paranana, dans le campo, Goxiz, $n^{\circ}$ 20899. Sous-frutescent, fl. lilas. Mai-juin. C.

136. C. Neesii Bentl.; Fl. Bras. XV, I, p. 152. - Diamantina, Estrada de Arassuahy, Mhras Geraes, $\mathrm{n}^{\circ}$ 13697. Sous-frutescent, fl. rouges. Janvier-mars. R.

137. C. Martii Benth.; Fl. Bras. XV, I, p. 152. - Diamantina, Serra dos Cristaes, Mrsis, no 19035. Petite liane, f1. lilas. C.

138. C. scarlatina Mart.; Fl. Bras. XV, I, p. 153. - Serra dos Orgãos, Piı-Jix., $n^{\circ}$ 6180. Liane, fl. rouge écarlate. G.

139. Camptosema coccineum Benth. in $\mathrm{Fl}$. Bras. XV, I, p. 194. - Serra do Funil, Minas Geraes, no 19039. Arbuste des campos, f1. rouges. Mars-mai. C.

140. C. pedicellatum Benth.; Fl. Bras. XV, 1, p. 15\%. - Campos da Bocaina, São Patlo, nº 10528. Arbuste, f1. rouges. Février. R.

141. C. coriaceum Benth, in Fl. Bras. XV, I, p. 18\%. - Queluz, dans le campo, Mixas, nos $13700,19039 a$. Arbuste, fl. rouges. C.

142. C. rubicundum Hook.; Fl. Bras, XV, I, p. 1506. - Campos, au Collegio, Rro-Jax., n ${ }^{\circ}$ 13422. Liane fine, fl. rouges. C. 
143. C. bellum Benth.? in Fl. Bras. XV, I, p. 15\%6. - Entre Carandahy et Queluz, dans le campo, Misas, $n^{\circ} 13694$. Volubile, fl. violacées. Juin-juillet. R.

144. C. erythrinoides Benth. in Fl. Bras. XV, I, p. 156. - Restinga de Taipu, Rio-Jax., $\mathrm{n}^{0 \mathrm{~s}}$ 1372, 8410. Arbuste, fl, rouges. CG.

14วั. C. grandiflorum Benth.; Fl. Bras. XV, I, p. 15ั7. - Serra do Picú, à Boa Vista, Rı-Jax., nos 12554,12555 ; Caraça, Mıxıs, nº 14667. Grande liane, fl. rouges. Avril-mai. CG.

146. C. pinnatum Benth.; Fl. Bras. XV, I, p. 328. - Floresta da Tijuca, Rio-Jax., nos 2968, 8627, 17591. Arbuste, f1. roses. Décembrejanvier. C.

1'í. Cratylia hypargyrea llart. in Fl. Brols. XV, I, p. 1:8.Praia Grande, Rio-Jax., nos 1039, 4785, 10529. Arbuste un peu sarmenteux, fl. rose violacé. Février-mars. CG.

148. C. mollis Yart.: Fl. Bras. XV, I, p. 1.99. - Cabo Frio, RioJar., $n^{\circ}$ 10530. Arbuste un peu sarmenteux, fl. rouges. Juillet. C.

149. Dioclea violacea Mart. in Fl. Bras. XV, I, p. 162. - Gavea, près de la mer, Rio-Jar., ${ }^{0 s} 601,18215$. Grande liane, fl. lilas. Iarsavril. C.

15ั0. D. reflexa Hook. ; Fl. Bras. XV, I, p. 162. - Realengo, près de Sapopemba, Rio-J.1., $\mathrm{n}^{0 s}$ 10532, 10563. Grande liane, fl. violacées. Janvier-mars. C.

13ั1. D. rufescens Benth.; Fl. Brus. XV. 1, p. 163. - Cachambú, près de Petropolis, Rio-Jax., no 7599; Serra do Coelho, Mısas, no 8644. Grande liane, fl. blanc rosé. Novembre-décembre. G.

19.9. D. glabra Benth. ; Fl. Bras. XV, I, p. 164. - Entre Carandahy et Queluz, dans le bois, Mrsas, $n^{\circ} 13687$. Grande liane, f1. lilas. Ilai-juin. C.

193. D. lasiophylla Mart. in Fl. Bras. XT, I, p. 166. - Serra da Bahylonia, Mrsas Geraes, no 3717; Restinga de Cabo Frio, Rio-Jax. $\mathrm{n}^{0}$ 10531. Liane, 11. rouge foncé. Juillet-août. C.

1.94. Cleobulia multiflora Mart. in Fl. Bras. XV, I, p. 167. - Restinga de Mana et Magi, Rio-J.x.. nos 2540, 8455. Grande liane, f1. rouges. Avril-juillet. CG.

15\%. Canavalia picta Mart. in Fl. Bras. XV, I, p. 176. - Corcovado, à Paineras, Rio-Jax., no $8508 a$. Haute liane, fl. violacées. Férriermai. C.

156. C. bonariensis Lindl.; Fl. Bras. XV, I, p. 17T. - Corcovado, 
à Caixa d'Agua, Rı-JAn., no 6179. Haute liane, lt. violacées. Novembredécembre. $\mathrm{R}$.

157. Canavalia parviflora Benth. in Fl. Bras. XV, I, p. 177. - Corcovalo, à Paineiras, Rı-J $J_{A N}, n^{\circ} 12561$. Haute liane, fl. violacées. R.

1:88. C. gladiata DC; Fl. Bras. XV, I, p. 178. - Botafogo, près de la mer, Rio-Jax., nos 5816, 6508; Ouro Preto, Misas, nos 13705, 13707. Grande liane, f1. violacées. Avril-mai. CG.

Forma erythrocarpa Taub. in litt. - São Christovĩo, Rı-JAn., n 19037. Grande liane, fl. violettes. Mars-avril. C. Vulgo : Feijüo Sıo Ignacio.

Forma leucocarpa Taub. in litt. - São Christovão, Rı-Jıx., $n^{\circ}$ 19038. Haute liane, fl. violettes. Mars-avril. C. Vulgo : Feijão Bravo.

1399. C. obtusifolia DC.; Fl. Bras. XV, I, p. 178. - Restinga de Copacabana et ì Praia Grande, au bord de la mer, Rio-JAx., n ${ }^{\circ 5} 3924$, 4786, 20272. Grande liane, fl. roses. Mars-avril. C.

160. C. ensiformis DC. in Prods. Syst. Nat. 11, p. 404. - Andarahy Grande, Rio-Jan., $\mathrm{n}^{\text {os }} 11902$, 12567. Haute liane, fl. violacées. Mai. R.

161. Phaseolus appendiculatus Benth.; Fl. Bras. XV, I, p. 182. Larangeiros, au Cosme Velho, Rro-JAN., $n^{\text {os }}$ 1368, 1373; Ouro Preto, Misas, $n^{0}$ 15911. Grimpant, fl. lilas. Mai-juillet. CC.

162. P. membranacens Bentlı.; Fl. Bras. XV, I, p. 183. - Entre Carandahy et Queluz, Mrsas, n 13692. Grimpant, fl. blanc jaunàtre. Juin, C.

163. P. peduncularis Humb. B. et K.; Fl. Bras. XY, I, p. 184.Aldeia de Ouro Branco, Misas, $n^{\circ}$ 10535. Volubile, fl. blanchàtres. Avril-mai. C.

164. P. firmulus Nart. in Fl. Bras. XV, 1, p. 188. - Cachoeira do Rio Nacaco, Goyaz, $n^{\circ}$ 20909. Frutescent, fl. blanc jaunatre. Juinjuillet. C.

165. P. truxillensis Humb. B. et K.; Fl. Bras. XV, I, p. 186. Floresta da Tijuca, nos 3923, 5823; Petropolis, Rio-JAx., n ${ }^{0}$ 11875. Grimpant, f1. blanc jaunâtre. Janvier-avril. CG.

166. P. linearis Humb. B. et K.; Fl. Bras. XV, 1, p. 187. - São João da Barra, près de Campos, Riı-Jax., ${ }^{\circ} 9372 u$. Volubile, fl. violettes. Février-mars. R.

167. P. longifolizıs Benth. in Fl. Bras. XV, I, p. 187. - Campos 
A.-F,-N. GLAZIOU. - LISTE DES PLANTES DU BRÉSIL CENTRAL. 141 de Santa Cruz, Rro-Jan., n ${ }^{\circ}$ 9372. Grimpant, fl. blanchâtres. Décembre. R.

168. P. semierectus L.; Fl. Bras. XV, I, P. 189. — Quinta de São Christovão, Rio-Jıx., nº 2970; Chacara de Caraça, Mrxas, no 12578. Herbacé, fl. rouge pourpre. Janvier. CC.

169. P. erjethroloma Mart. in Fl. Bras. XV, I, p. 191. - Fazenda do Morro Azul, Säo Pallo, no 10533. Grimpant, fl. rougeatres. Avril. R.

170. P. prostratus Benth. in Fl. Bras. XV, I, p. 192. - Inficionado, près de Caraça, dans le hois, Mıxıs, $\mathrm{n}^{\circ \mathrm{s}} 12568$, 13693. Rampant, fl. rougeâtres. Juin-juilleı. C.

171. P. villosus Glaz. n. sp.? in herb. Paris., Berol., Kew., Brux., etc. - São João da Barla, prìs Campos, Rio-JAx., nos 9721, 9722. Volubile, f1. blanchâtres. Février-mars. C.

172. Vigna luteola Benth. in Fl. Bras. XV, 1, p. 19'4.- Praia de Sepitiba, Rio-J.s., nº 9393. Rampant, f1. jaunâtres. Décemlre. C.

173. Pachyrrhizus angulatus Rich.; Fl. Bras. XV, I, p. 199.Santo Antonio, près de Petropolis, Rro-JAx., n 10566. Grosse liane des forèts, f1. rougeâtres. Novembre-décembre. R.

17'́. Dolichos Lablab L.; Fl. Bras. XV, 1, 1. 197. - Quinta de São Christovio, cult., Rio-Jax., no 11880. Grande liane, fl. blanches. Mai-juillet. C. Vulgo : Feijũo da India.

17ว̈. Cajanus indicus Spreng. ; Fl. Bras. XV, I, p. 199. - Larangeiras, cult., Rio-Jax., no 1370. Sous-frutescent, fl. jaunes. Arril juin. CC. Vulgo : Guando.

176. Rhynchosia platyphylla Benth. in Fl. Bras. XV, 1, p. $201 .-$ Rego do Chico Costa, dans le campo, Goyaz, n² 20912. Herbacé, vivace, fl. jaunes. Novenbre-décembre. C.

177. R. Clausseni Benth. in Fl. Bras. XV. I, p. 201. - Rio da Gama, dans le campo, Goraz, $n^{\text {ss }}$ 20905, 20913. Herbe bulbeuse, fl. jaunàtres. Novembre-décembre. CC.

178. R. reticulata DC. ; Fl. Bras. XV, I, p. 203. - Barbacena, dans le campo, Mrsas, $n^{0} 14673$ a. Volubile, fl. blanc jaunâtre. Novembredécembre. C.

179. R. phaseoloides I)C.; Fl. Bras. XV, 1, p. 203. - Santa Theleza, au Corcovado, Rı-Jax., no 3922 ; Barbacena, Mixas Geraes, $n^{\text {os }}$ 10536, 14673. Frutescent volubile, fl. blanc jaunâtre. Novembredécembre. C.

180. R. picúensis Glaz. n. sp.? in herb. Paris., Berol. Kew., etc.- 
Serra do Picú, au Paulo, Rio-Jav., no 9726. Liane, f1. blanchâtres. Avrilmai. l.

181. Rhynchosia minima DC.; Fl. Bras. XV, 1, p. 204. - Andarahy, au Rio Tapixeiro, Rio-Jax., no 12526 ; Serra da Mantiqueira, Mixas, $n^{\text {os }} 9736,1537,13705 a$. Frutescent, volubile, fl. blanc rosé. CC.

182. Eriosema longifolium Benth.; Fl. Bras. XV, I, p. 207.Serra do Picú, dans le campo, Mnvas, $n^{\circ} 9739 a$. Frutescent, fl. rouge violacé. Novembre-décembre. R.

183. E. stenophyllum Harms in Engler Botan. Jahrb. (1903), p. 31. - Areas, dans le campo pierreux, Goraz, $n^{\circ}$ 20827. Sous-frutescent, fl. violacées. Août-septembre. R.

184. E. strictum Benth.; Fl. Bras. XV, I p. 208. - Haut du Rio Gama, Goraz, $n^{\circ}$ 20894. Frutescent, fl. rouge violacé. Novembre. décembre. C.

183̈. E. brachystachys Harms in Engler Botan. Jahrb. (1903), p. 30. - Ponte Alta, dans les campos pierreux, Goraz, no 20893. Herbacé, Il. jaunes. Aoùt-septemlıre. C.

186. E. stipulare Benth.; F/. Bras. XV, I, p. 208. - Ponte Alta, dans le campo, Govaz, $n^{\circ}$ 20893; Caraena, au Bom Jardim, Inss, $n^{\circ} 13420$. Frutescent rampant, fl. violacées. Octobre-novemlire. C.

187. E. crinitum E. Мey.; Fl. Bras. XV, I, p. 208. - Campos de llogg das Cruz, Sĩo Padlo, nos 9724, 10518, 17588; Serra dos Veadeiros, Goraz, $n^{0}$ 20904. Frutescent, f1. violacées. Janvier-avril. CG. Vulgo : Postemeira do campo.

188. E. violaceum E. Mey.; Fl. Bras. XV, I, p. 209. - Campos de São Fidelis, Rı-Jıx., nos 9739 , 13421. Frutescent, fl. rouge violacé. Janvier-mars, C.

189. E. heterophyllum Bentlı.; Fl. Bras. XV, I, p. 210. - Entre Sitio et Barbacena, dans le campo, MnNas Geraes, $n^{\circ}$ 14672. Frutescent, f1. violacées. Novembre-décembre. C.

190. E. laxiflorum Harms in Engler Botan. Jahrb. (1903): 1. 30. - Rio Arèas, dans le campo pierreux, Govaz, n² 20929. Herlıcé, vivace, fl. jaunes. Septembre. C.

191. E. Glaziovii Harms in Engler. bolan. Jahtb. (1903), p. 31. - Rio Torto, au Morro das Melancias, Goyaz, no 20891. Herbe étalée, f1. jaunes. Novembre. C.

192. E. Benthamianum Mart. in Fl. Bras. XT, I, p. 210. - Serra dos Vertentes, près de Oliverra, Mrus Geraes, $n^{\circ} 20271$; entre Ponga et Joũo Vierra, Goyız, n² 20889. Sous-frutescent, t1. jaunes. Juin-juillet. CC. 


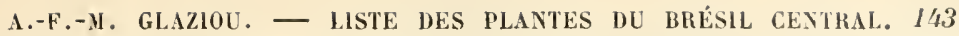

193. E. erythropilizm Harms in Engler Botan. Jahrb. (1903), p. 32. - Entre as Brancas et Hector, dans le campo, Goraz, $n^{0} 20887$. Sous-frutescent, f1. jaunes. Octobre-novembre. C.

194. E. cupreum Harms in Engler. Botan. Jahrb. 1903), p. 32. - Morro Canastra de Mestre d'Armas, dans le campo, Goraz, n 20888. Sous-frutescent, t1. jaunes. Novembre-décembre. C.

198. E. pycnanthum Benth. in F. Bras. XV, I, p. 212. - Sào João d'El Rei, Imrss, no 9729; Chico Costa, dans le canıo, Goraz, $\mathrm{n}^{0}$ 20895. Sous-fiutescent, fl. jaunâtres. Octobre-novembre. C.

196. E. glabrum Mart. in Fl. Bras. XV, I, p. 213. - Barbacena, dans le campo, Niras Geraes, n 14671; Guariroba, Goyn, no 20890. Frutescent, fl. jaunes. Octobre-novembre. CC.

197. E. rufum E. Ney.; Fl. lirus. XV, I, p. 213. - Tombador, près de Diamantina, Mınas, $n^{0}$ 19025. Sous-frutescent, fl. violacées. Avril-mai. Ri.

198. E. congestum Benth. in Fl. Bras. XV, I, p. 2I'. - Abbado, près de Meia Ponte, dans le campo, Goraz, n² 20896. Sous-fiutescent, f1. rougeâtres. Mai-juin. C.

199. E. defoliatum Benth.: Fl. Bras. XV, I, p. 215. - Entre Rio Gama et Bananal, dans le campo, Gorız, $n^{\circ}$ 20903. Frutescent, fl. violacées. Juin-août. C.

200. E. cordifolium Glaz. n. sp.? in herb. Paris., Berol., Kew., Havn., etc. - Bella Vista, dans le campo, Gorsz, $n^{\circ}$ 20901. Sous-frutescent, f1. jaunâtres. Juillet-aoùt. C.

201. Dalbergia lariabilis Vog.; Fl. Brus. XV, I, p. 220. - Praia Grande, au Morro do Cavallão et à Gavea, Rio-JAN., nº 1541, 2544, 9766, 18209; Serra da Mlantiquiera. Mrss, $n^{\text {os }} 10541$, 10542, 10543, 12587, 15920. Arbre sarmenteux, fl. blanc jaunâtre. Septembre-décembre. CC. Vulgo : Cipo violete.

202. D. riparia Benth. in Fl. Bros. XV, I, p. 221. - Copacabana, au Enforcado, Rıo-JAx., n ${ }^{\circ}$ 802. Arbuste sarmenteux, fl. blanchâtres. Janvier-février.

203. D. miscolobium Benth. in Fl. Bras. XV, I, p. 222․․ - Sãu João d'El Rei, Serra de Lenheiro, Nivas, $n^{\circ s}$ 12589, 14666, 17599 ; Ponte Alta, Goraz, dans les cerrados, $n^{\circ} 20885$; Floresta de Tijuca, cult. Rio-Jax., nos 9735,11883 . Arbrisseau, fl. noiràtres. Janvier-février. CC. Vulgo: Jacaranda l'reta.

204. D. cuiabensis Benth. in Fl. Bras. XV, I, p. 224. - Larangeiras, à Cosme Velho, Rı-JAx., n 11882 et à Cabo Frio, no 12551. Grand arbre, fl. blanc jaunâtre. Janvier-février. CC. 
20\%. Dalbergia nigra Fr. Allem. in Fl. Bras. XV, I, p. 224. Serra do Jererino, prìs de Campo Grande, Rı-Jas., nº $17598 a$. Grand arbre, sans tleur. R. Vulgo : Cabiuna. C'est le Palissandre!

206. D. glaucescens Mart. in Fl. Bras. XV, I, p. 294. - Pedra Bonita a Gavea, Rio-Jan., $1^{\circ}$ 6510. Arbre, bon bois de construction, sans fleur. CG. Vulgo: Jacaranda.

207. D. lateriflora Benth. in Fl. Brus. XV, I, p. 22:3. - Floresta da Tijuca, cult., Rio-Jax., n 17598; Nar d'Espanha, près de Rio Novo, Mivas, $n^{\circ}$ 20276. Grand arbre, fl. blanc jaunâtre. Beau bois. C. Vulgo : Jacaranda cabiuma.

208. D. foliolosa Benth. in Fl. Bras. XV, I, p. 22:. - Petropolis, à Cachambù, Rio-JAx., nos 11889,15909 , 17597, 19047. Grand arbre, f1. blane jaunâtre. Mars-avril. CC. Vulgo : Jacaranda rosa.

209. D. gracilis Benth. in Fl. Bras. XV, I, p. 2206. - João Ayres, à l'entrée des campos, Misas, $n^{\circ}$ 10544. Grand arbre, fl. blanc jaunâtre. Août-septembre. R. Vulgo : Páo violete.

210. D. inundata Spr. in Fl. Bras. XV, I, p. 22T. - Rio Parahyba, au Collegio, Rio-Jan., $n^{\mathrm{e}}$ 13686. Arbuste sarmenteux, fl. rougeâtres. Janvier-mars. R.

211. D. ferruginea Glaz. n. sp.? in herb. Paris., Berol., Kew., Brux., ete. - Alto Nacahé de Nova Friburgo, Rio-Jas., $n^{\circ}$ 13425. Grand arbre, fl. blanc jaunâtre. Novembre. C.

212. Hecastophyllum Brownei Pers. in Fl. Bras. XV, 1, p. 228. Lagoa de Rodrigro de Freitas et à Praia Grande, Rı-Jıx., nos 98 , 1365, 8648. Arbuste, f1. blanc jaunâtre. Décembre. CG.

213. H. Monetaria Pas.; Fl. Brus. XV, I, p. 2298. - Quinta da Boa Vista, à São Christovão, Rı-JAN., $1^{\circ} 8648$ a. Arbuste cultivé, fl. blanc jaunâtre. Janvier-février. R.

214. Cyclolobium Clausseni Benth.; Fl. Bras. XV, I, p. 230.Casa Branca, dans le bois, Misas, $n^{\circ}$ 14615. Grand arbre, fl. blanchâtres. Août-septembre. C.

21\%. C. Hostmanni Benth. in Journ. Limn. Soc. 1V, 39. - Quinta de São Chıristovão, cult., Rı-Jıx., nº 13687. Grand arbre, fl. rougeâtres. Mai-juin.

216. Machærium angustifolium Vog.; Fl. Bras. XV, I, p. 23כ. Corcovado et Theresopolis, Rı-JAx., $n^{\text {os }}$ 2531, 11885; Rio Manço, linas, $n^{\text {os }} 13713,14664$. Grand arbre, fl. lilas. Février-mars. CG. Vulgo : Sete cusacas. 
A.-F.-M. GLAZIOU.

LISTE DES PLANTES DU BRÉSIL CENTRAL. 145

217. M. Glaziovii Taub. nov. sp. in herb. Paris., Berol., ete. Entre Piedade et Santa-Luzia do Rio das Velhas, Misas Geraes, no 20281. Arluste sarmenteux, fl. lilas. Novembre. R.

218. M. aculeatum Raddi; Fl. Bras. XV, 1, p. 237. - Serra da Estrella, Tijuca et Corcovado, Rio-Jav., ns 2967, 7863, 11890. Arluste sarmenteux, fl. lilas foncé. Février-mars. CC.

219. M. incinatum Benth.: Fl. Bras. XV, I, p. 237. - Serra da Estrella et Floresta de Tijuca, Rio-Jav., n ${ }^{\text {ss }}$ 12560, 17593; Fazenda de Taboquinha, Minas Geraes, ${ }^{\circ}$ 20875. Arbuste sarmenteux, fl. blanc violacé. Février-mars. C.

220. $M$. discolor Vogel; Fl. Bras. XV, 1, p. 239. - Jacarepagua et Gavea, Rı-JAv., $\mathrm{n}^{\text {os }} 3925,3926$. Arbuste sarmenteux, fl. lilas foncé. Janvier-février. G.

221. M. Vellosianum Benth.; Fl. Bras. XV, 1, p. 239. - Petropolis, à Itamaraty, Rı-J $\mathrm{J}_{\mathrm{Av}}, \mathrm{n}^{\circ}$ 14665. Arbuste sarmenteux, f1. violet pâle. Nar's-avril. R.

229. M. nictitans Benth.; Fl. Bras. XV, 1, p. 40. - São Chrislovào, au Norro do Telegrapho, Rı-Jav., nos 8404, 8646; Serra dos Orgaios et da Estrella, Rio-Jax., $\mathrm{n}^{0 \mathrm{~s}} 10560,11886$. Grand arbre, fl. rougeâtres. Mars-avril. CC.

2刃3. M. scleroxylon Tul.; Fl. Bras. XV, I, p. 240. - Mlegria, dans la Serra da Caraça, Minas Geraes, $n^{\circ}$ 13718. Grand arbre, fl. brun rougeâtre. Mars-avril. C. Vulgo : Pao Ferro.

2․․․ M. Gardneri Benth. in Fl. Bras. XV, I, 1. 242. - Serra dos (Orgios, à Theresopolis, Rio-Jan., ${ }^{o s} 5814,11891$. Grand arlure, fl. roux noiràtre. Mars-avril. CC.

2295. M. parviflorum Benth. in Fl. Bras. XV, I, p. 242. - Serra do Inficionado, près de Caraça, Wivas Geraes, nos 13709, 14661; Campos da Bocaina, Sĩo Paulo, $n^{\circ}$ 8407. Grand arbre, f1. jaune rougeâtre. C.

2206. M. incorruptibile F. Allem.; Fl. Brus. XV, 1, p. 243. - Serra de Jacarepagua, Rı-JAx., $\mathrm{n}^{0}$ 10569. Grand arbre, fl. jaunàtres. Novembre-décembre. C. Vulgo: Jacaranga Preto.

2927. M. formum Benth. in Fl. Bros. XV, 1, p. 29.3. - Praia Grande, au Barreto, Rio-Jax., $n^{\circ s}$ 2529, 18212, 19046. Grand arbre, li. noirâtres. Février-mars. CG. Vulgo: Jacaranda piranga.

2928. M. le gale Benth.; Fl. Bras. XV, I, p. 243. - Serra dos Orgios à Theresopolis, Rıo-Jax., nos 11888 , 13423: Rio Manço, Vluas Geraes, $11^{\circ}$ 14662. Grand arbre, fl. lrrunes. Mars. C. Vulgo : Jacarandu roxo. 


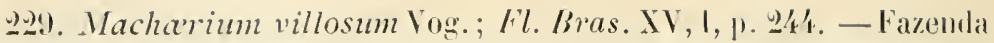
do Morro Azul, Sĩo Patio, $n^{\circ} 12563$; Santa Luzia do hío das Velhas, Misas. $11^{\circ 5} 20277,20278$. Grand arbre, fl. brune's. CG. Vulgo : Jacarundu.

230. M. acutifolizm Vog.; Fl. liras. XV, I, 1. 2ü. - Chemin de Hacacos at Vista Chinez, Lio-.Jax., n ${ }^{\circ}$ 2535; entre Santa Luzia et Porto de Jequitiba, Maxas, $1^{\circ}$ 20279. Grand arbre, 11. blanchâtres. Janvierévier. C.

231. M. stipitatum Vog.; Fl. Bras. XV, I, p. 240̈. - Petropolis, Floresta da Tijuca, Rio-Jan., $n^{o s} 5812,9394,11887,12562$; Rio Manso. Nixas, $n^{\text {os }} 13708,13683$ et 15918. Grand arbre, M. blanchàtres. Janvierfévrier. Vulgo: Jacuranda roxo. CiC.

232. M. leucopterum Vug.; Fl. Bas. XV, I, p. 246. - Lagoa de Marica, jrès de Nyteroi, Rio-Jax., ${ }^{\circ}{ }^{\circ} 10538,11884$. Grand arbre, fl. rousses. Février-mars. R. Vulgo : Jacaranda d'espinho.

233. M. glabrum Vog.; Fl. Bras. XV, I, p. 246. - Caminho do Maraco à Vistal Chineza, lio-J Jav., $1^{\text {as }} 212,2121,10568$. Grand arbre, fruclifié. Janvier-mar's. C. Vulg. Jacaranda vermelho.

234. M. secundiflorum Mart.; Fl. Bras. XV, I, p. 247. - Restinga (1o Ilarpoador, Rio-Jax., no 10562 . Arbrisseau, f1. brunes. Mars-avril. C.

23.. M. Allcmani Benth. in Fl. Bras. XV, I, p. 248. - Corcovado, à Paineiras, Rı-ذAv., $0^{\circ}$ 6178. Grand arbre, f1. lurun jaunâtre. Vulgo : Jacaranda tan.

236. M. brasiliense Vog.; Fl. Bras. XV, I, p. 248. - Gavea et Lagoa do Peixe, liı-JAx., nos 4783, 6177, 12564, 13733. Grand arbre, 11. roux jaunattres. Aoùt-octobre. CC.

237. M. vestitum Vog.; Fl. Bras. XV, I, p. 249. - Nova Friburgo au Morro Queimado, liıo-JAN., no 17594. Grand arbre, fl. brunes. Novembre. R.

238. M. oblongifolium Vug.; Fl. Bras. XV, I, p. 250. - Santa Thereza, au Corcovalo et à Gavea, Rı-JAx., nos 4782, 9396, 10572, 13682: Serra da Caraça, Mivas, $n^{\circ s} 12590,13712$. (irand arbre, fl. noiràtres. Septembre-octobre. CiC.

239. M. opacum Vog.: Fl. Bras. XV, I, p. 251. - Guariroba, dans les cerrados, Goyaz, $1^{\circ} 20876$; Palmital, dans le campo, Mıxas, $11^{\circ} 15917$. Grand arbre, fl. brunes. Ortobre. CG. Vulgo : Jacaranda.

240. M. lanatum Tul.; Fl. Bras. XV, I, p. 252. - Fazenda do Morro Azul, São PAulo, n 14663 a. Grand arbre, f1. rousses. Arrilmai. R. 


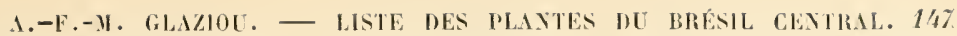

241. M. nigrum Vog.: Fl. Brols. XV, 1, p. 2:3.) - Atalaia et Realengo, Rı-Jix., nos 2534, 10564. Grand arlıre, fl. brunes. Janvier-février. C.

24. M. ferruginenm Pers.; Fl. Bras. XV, I, p. 2:3. - Estrada de Rio Manso, Mixis, nos 13711, 14669. Grant arble, l1. violacées. Février. C.

243. M. eriostemon Benth. in Fl. Bras. XV, 1, p. 20̈4. - Floresta de Tijuca et Serra da Estrella, Rio-J.s., $n^{\circ s}$ 3718, 7864, 9393. Arbuste sarmenteux, f1. brunes. tout-septembre. CG.

2'ł' M. sarmentosum Glaz. n. sp.? in herl. Paris., Berol., kew., Harn., etc. - Lagoinha, au Corcovado, Rio-JAx., n 3929. Sarmenteux, fl. brunes. Novembre-décembre. R.

¿彷. M. tomentosum Glaz. n. sp.? in her,. Paris., Berol, Kew., Harn., etc. - Petropolis, au Retiro, Ro-JAx., n 15908. Grand arbre, fl. rousses. Mars-avril. $C_{\text {. }}$.

느6. M. ovalifolium Glaz. n. sp.? Paris., in herb. Berol., Kew., Harn., etc. - Carandahy, dans le bois, Mıxas, $n^{\circ}$ 13710. Grand arbre, 11. rousses. Nars-avril. C.

247. M. ferox Glaz. 11. slı? in herb. Paris., Berol., Kew., Brux, etr. - Lagoinha dos Porcos, au Corcovado, Ruo-J.ıx., n 9396 a. Arbrisseau sans il. en juillet.

218. Drepanocarpus lunatus Ney.; Fl. Bras. XV, I, p. 20. Alto Macalıé de Nova Frihurgo, Pio-JAx., 10 ${ }^{\text {s }} 9725$, 20273; Fazenda da Taboquinha, Goraz, no 20875. Arbrisseau samenteux. fl. lilas. Arriljuilı. C.

24. D. floridus Ma॰t.; Fl. Bras. XV, I, p. 2:7. - Serra da Babylonia, au Pian, Mıvas, $n^{\text {os }} 7601$, 19042. Albuste sarmenteux, 11. violacées. Janvier-février. (..

200. D. cristacastrensis Mart.; Fl. Birs. XV, 1, p. 2:T. - Quinta de Sĩo Christovĩo, Rı-Jax., $11^{\circ} 10540$ a. Gland arlure cultivé, 11. rousses. Avril-mai. R.

9:i. Tipuana macrocarpa Benth. in K\%. Bras, XV, I, P. 29:?. Cabo Fro dans le bois, Rio-JAn., n 10540. (rirand arbre, 11. roses. Maijuin. R.

20̈2. T. heteroptera Benth. in Fl. Bras. XV, I, p. 2060. — Santa Thereza, au Corcovado, Rio-Jas., nos 10565, 15905. Grand arbre, 11. roses. Août-septembre. li. Vulgo : Angelion.

933. T. auriculata F. Allem. in Expl. Scienl., Secc. Bot., p. 21. - 
Cearí, dans les endroits pierreux, $n^{0}$ 9755. Abrisseau, fl. jaumes. Octobre-novembre. CC. Vulgo : Páo de moco.

204. Platypodium elegans Vog.; Fl. Bras. XV, I, p. 262. - Petropolis et Nova Friburgo, Rio-JAN., $\mathrm{n}^{\text {os }} 8418$, 8445, 8640, 11893, 14660, 17595; Rio Paranaúa, Goraz, $n^{\circ}$ 20883. Grand arlse, 11. jaunes. Octobirenovembre. CC. Vulgo : Jacaranda branco.

בू:3. Centrolobium robustum Mart.; Fl. Bras. XV, I, p. 263. - Caminho do Macaco à Vista Chinez, Rio-JAx., $n^{\circ}$ 15921. Grand arbre, fl. blanc rosé. Décembre. CC. Vulgo : Arariba vermetho.

2.6. C. tomentosum Benth.; Fl. Bras. XV, I, p. 260. - Serra de Jacarépaguá, Rio-Jan., ${ }^{\text {os }} 2539$, 15922. Grand arlıre, fl. blanc rosé. Ilars-avril. C. Vulgo : Arariba.

2:37. Pterocarpus Rohrii Vahl.; Fl. Bras. XV, I, p. 267. - Ponta

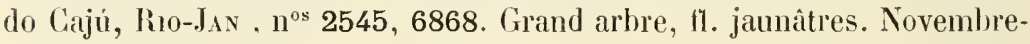
décembre. C.

20ั8. P. violaceus Vog., Fl. Bras. XV, I, p. 268. - Ponta do Variscu, à Lagoa da Tijuca, Rio-JAx., n ${ }^{\text {os }} 5824,10567,11895$; Rio Manso, Mixas, $\mathrm{n}^{0 \mathrm{~s}} 13719,14659$. Grand arbre, f1. jaune violacé, odorantes. Octobre-110vembre. C.

2599. P. ancyclocalyx Benth. in Fl. Bras. XV, I, p. 269. - Nova Friburgo au Conego, Rio-Jax $11^{0 s} 11894$, 19048. Très grand arbre, fl. jaunes odorantes. Octobre-norembre. C.

260. Pœcilanthe grandiflora Benth. in Fl. Brus. XV, I, p. 270. - Adeal de Sĩo Pedro, près de Cabo Frio, Rio-Jan., ${ }^{0 s}$ 2546, 6172, 10551, 12549; Nlendanlia, près de Diamantina, Misas, n ${ }^{0 s} 1259,13716$. Arbrisseau, 11. ruses. Aoùt-octobre. CC. Vulgo : Carroncudo.

261. Platymiscium precox Mart.; Fl. Brets. XV, I, p. 297. - Caminho de Jendanha, près de Diamantina, Mixas, ${ }^{0 s} 12594$, 13715. Arbuste, fl. jaunes. Aoùt-septembre. C. Vulgo : Putumujú.

262. P. gracile Benth. in Journ. Limm. Soc. IV, Suppl. p. 82. Entre Nldea de Sio Pedro dos Indios et Mataruna, hito-Jax., $1{ }^{\circ} 10554$. Aibuste, fl. jannes. R.

263. P. cordifolium Taub. n. sp. in lierb. Berol., etc. - Entre Queluz et Congonhas do Canno, Misis, $n^{\circ}$ 12595. Arbuste, 11. jaunes, C.

264. P. floribundum Vog.; Fl. Bras. XV, 1, p. 273. - La!rangeiras et Gavea, an borl de la mer, Ro-Jux., $1^{05}$ 1142, 1371, 2537; Itacolumy, près d'Ouro Pretn, Mrvas Geraes, $n^{o s}$ 12596. Irbuste, fl. jaunes. Févrierarril. CC. Vulgo : liabugem. 
A.-F.-M. GLAZIOU. - LISTE DES PlaNtes DU BRÉSIL CExTral. 149

265. P. Gysnevroii Glaz. 11. sp.? in herb. Paris., Berol., Kew., Havn., etc. - Entre Gavea et Tijuca, Rio-Jax., n $1142 a$. Arbuste, fl. jaunes. Mars-avril. R.

266. P. piliferum Taub. n. sp.? in herb. Paris., Berol., Kew., ete. - Cachoeira do Campo, dans le bois, Misis, n 19044. Arbrisseau, f1. jaunes. Novembre-décembre. C.

267. P. nitens Vogel; Fl. Brus. XV, 1, p. 273. - Entre Cabo Frio et Aldeia de São Pedro dos Indios, Rio-Jax., no 10553. Arluuste, tr. jaunes, Mai-juin. C.

268. Lonchocarpus sericeus Humb. B. et K.; Fl. Brus. XV, I, p. 277. - Entre Nataruna et Rio Bonito. Rio-Jax., n ${ }^{0}$ 10552. Grand arhse, fl. roses. Mai-juin. R. Vulgo : Inga-im Inga-brabo.

269. L. neuroscapha Benth. in Fl. Bras. XV, I, p. 278. - Sete Pontes, à Praia Grande, Rio-Jix., n ${ }^{\circ 5} 6867,12600$; San Bartholomeu. Mrse, ${ }^{\circ s} 13720,14612$. Grand arbre, fl. roses. Janvier-février. CC.

Var. pubigera in Fl. Brus. XT, I, p. 298. - Petropolis, aux bords du Rin Piabanha, Rio-Jar., no 1029. Grand arbre, 11. ruses. Mars. CG.

270. L. nitidus? Benth. in Fl. Bras. XV, I, p. 279. - Entre Sitio et Barbacena, Mixas Gerites, $1^{0} 14612$ a. Arbrisseau, 11. roses. Novembre. R.

피. L. Glaziovii Taub. in Flora (1892), 1. 33. - Nto llacahé de Nova Friburgo, Rio-Jas, $\mathrm{n}^{\text {os }} 13680,19043$. Grand arbre, 11. violettes. Janvier-mars. C.

272. L. flipes Benth. in Fl. Bras. XV. I, p. 280. - Mendanha, près de Campo Grande, Rio-Jix., nº 11900. Grand arbre, fl. jaunattres. R.

273. L. virgilioides Benth.; F\%. Bras. XV, I, p. 280. - Restinga de Cipacalana, Rio-Jax., $1^{\circ} 2124$ : Serra de Antonio Pereira, Mısıs, nº 12592 , 13722. Arbrisseau, f1. roses. Septembre-octolre. C.

27't. L. campestris Mart. in FI. Biras. XV, I, p. 281. - Campos da Bocaina, Sĩo Paclo, no 10550 a. Arbrisseau, fl. violacées. Févriermars. C.

27.). L. obtusus Benth. in Fl. Brus. XV, 1, p. 282. - Serra da llantiqueira, lans le bois, Mris Geknes, $1^{0 s}$ 12593, 12597, 13717, 14658. Arbrisseau, fl. bleuàtres. Juillet-septembre. CG.

276. L. Harmsianus Glaz. n. sp.? in herb. Paris., Berol., Kew., Brux, ete. - Serra de Ourn Branco, dans le campo, Mrsis, n" 14658. Arbrisseau, f1. roses. Février-mars. C.

פ77. I. subglaucescens Hart. in Fl. Bras. XV, I, p. 283. - Lagoa 
de Araruama, pris de Cabo Frio, Rio-Jix., nos 10545, 10550, 11910. Arbrisseau, 11. lilas clair. Juillet-septembre. C.

278. Lonchocarpus floribundus Benth. Fl. Bros. XV, I, p. 284. Quinta de São Christovão, Rı-J cult., fl. violacées. Février-mars. R.

279. L. Spruceanus Benth. in Fl. Bras. XV, 1, p. 286. - Quinta de São Christovảo, cult., Rio-Jax., $n^{0} 11877$. Arbrisseau, fl. violacées. Janvier-février. R.

280. L. glabrescens Benth.; Fl. Brus. XV, I, p. 286. - Petropolis, au bord du Rio Piabanha, Rio-Jax, no 8409. Grand arbre, ll. roses. Décembre-janvier. C.

281. L. costatus Benth. in Fl. Bras. XV, I, p. 287. - Sources du Rio Manso, Mixis Geraes, $n^{0 s}$ 12598, 12599. Grand arbre, fl. violacées. Juin-juillet. C. Vulgo: Imbira de porco.

282. L. insignis Glaz. n. sp. in herb. Paris., Kew., Berol., etc. Quinta da Boa Vista, S. Christovão, Rı-Jax., $1^{\circ}$ 10555. Grand arbre du Ceará, cultivé. Février-mars. R.

283. L. Mocó Claz. n. sp.? in herb. Paris, Kew., Berol., Havn., etc. - Quinta da Boa Vista, S. Clıristovão, Rı-Jax., $1^{05}$ 9732, 10682. Arbrisseau cultivé, venu du Cearí, fl. jaunâtres. Mars-avril.

284. L. sarmentosus Glaz. n. sp.? in herb. Paris., Berol., liew., Brux., etc. - Marianna, dans le bois, près Ouro Preto, Mixus, $\mathrm{n}^{\circ} 12599$ l. Grande liane, fl. blanchâtres. Janvier-février. R.

28\%. L. cearensis Glaz. n. sp.? in herb. Paris., Kew., Berol., Brux., ete. - Quinta da Boa Vista, S. Christovãu, Rı-Jux., $1^{\circ} 9719$. Arbuste sarmenteux, venu du Ceará, ll. roses. Février-mars. R.

286. L. microphyllus Glaz. n. sp.? in herb. Paris., Kew., Berol., Brux., etc. - Serra da Mantiqueira, Minas, $1^{\circ}$ 10549. Arbrisseau, fl. roses. Aoùt-septembre. R.

287. Muellera moniliformis L.: Fl. Rrus. XV, 1, p. 290. - Reslinga de Copacabana, liı-.l M., $1^{\circ}$ 3928. Arbrisseau, 1l. roses. Septemhre-octobre. C.

288. Andira amazonum Mart. in Fl. Bras. XV, I, p. 992. - Quinta de Sàn Christovio, cult., Rio-Jax., n 13687 ॥. Arbrisseau, fl. rosées. Janvier-février. R. Vulgo : Fava de impigem.

989. A. stipulacea Benth.; Fl. Bras. XV, I, p. 992. - Engenho de lentro, liı-dan., 10 5819. Arbrisseau, fl. roses. C. Vulgo: Angelim.

290. A. frondosa Mart.; Fl. Bras. XV, I, p. 293 . - Serra do Conto, 
A.-F.-M. GLAZIOU LLSTE DES PLANTES DU BRESIL CENTRAL.

pris de Petropolis, Rio-JAx., $1^{\circ}$ 11899. Grand arhre, lit. roses, Juin-juillet. R. Vulgo : Angelim.

291. A. anthelmintica Benth.; Fl. Bros. XV, I, p. 2993. - Entre Gavea et Ligoa di Tijuca, Rio-Jıx., nos 6173, 10547, 10571. Arbrisseau, fi. roses. Juillet-aoùt. C. Vulgo : Angelim.

292. A. Pisonis Nart.; Fl. Bras. XV, I, p. 294. - Villa Nora, R10Jax., n 11897 ; Formaçĩo, près de Diamantina, Mrsas, no 19050. Arbrisseau, th. roses. Juin-juillet. C. Vulgo: Angelim.

993. A. fraxinifolia Benth.; Fl. Bras. XV, I, p. 294. - Morn Queimado, Tijuca, Rro-JAx., $n^{\circ}$ 2532; Itacolumy, près d'Ouro Preto, Mrsas, n ${ }^{\circ}$ 14670. Allrisseau, fl. rosées. Janvier-décembre. CC. Vulgo: Angelim.

394. A. parvifolia Benth.; Fl. Bras. XV, I, p. 29:3. - Villa Nova dans les sables, Rio-J Jav, $n^{\circ}$ 13684. Arbrisseau, fl. roses. C. Vulgo : Angelim.

29\%. A. micans Taub. n. sp. in lierb. Berol., etc. - Alto Hacahé de Nova Friburgo, Rro-Jus., n ${ }^{\circ}$ 20274. Grand arbre, fl. roses. JanvierPév rier. R. Vulgo : Angelim.

296. A. laurifolia Benth.; Fl. Bras. XV, 1, p. 297. - Entre Sãu Join d'El Rei et Aguas Santos, dans le campo, Mrsas, nos 10548, 15919, 16755; Nonte Alegre, Goyaz, no 20881. Plante naine, fl. roses. Octobrenorembre. CC.

297. Geoffroya superba Humb. B. et K.; Fl. Bras. XV, I, p. 300. São Fidelis, près Campos, Rio-JAx., no 16546. Arbrisseau, ll. lilas. Novembie-dérembre. li.

298. G. goyazensis Glaz. n. sp.? in herh. Paris., Berol., Kew., Brux, etc. - Ponso Alto, près Sobradinho, Goraz, n² 20878. Arbrisseau. 11. lilas. tont-septembre. C. Vulgo : Sucupira.

299. Dipteryx rosea Spruce in Fl. Bras. XV, I, p. 301. - Quinta de São Christovão, cult., Rio-Jax., nº 9751. Arbrisseau, fl. blanc rosé. Janvier-février. R.

300. D. alata Vogel; Fl. Bras. XV, I, p. 302. - Fazenda do Cipri, Goyaz, $n^{\circ}$ 21020. Frand arbre, ft. blanc rosé. Janvier-février. CC. Vulgo: Baru.

301. D. oppositifolia Willd.; Fl. Bras. XV, I, p. 303. -- Lagoa de Freitos, à Tres Vendas, Rio-Jax., no 9751 a. Grand arbre cultivé, fl. blanc rougeattres. Janvier-février. R.

302. D. nudipes Tul.? Fl. Bras. XV, I, p. 304. - Jard. Bot. da 
Lagoa de Freitos, cult., Rio-JAx., n ${ }^{\circ}$ 13685. Grand arbre, fl. violacées. Mai-juillet. R.

303. Pterodon emarginatus Vog.; Fl. Bras. XV, I, p. 305. - Rio dos Pedras, Mrxas Geraes, $1^{\circ}$ 19025. Très bel arbre, f1. roses. Avril. C. Vulgo: Páo Monjolo.

304. P. polygalaflorus Benth. in Fl. Bras. XV, 1, p. 30:3. - Porto do Rio Paracatu, Mrxis, n 20879 . Grand arbre, fl. lilas très odorantes. Aoilt-septembre. CC.

303. P. pubescens Benth. in Fl. Bras. XV, I, p. 306. - Entre Formos et Meia Ponte, Goraz, $n^{\circ}$ 20880. Grand arbre, fl. blanc rosé, très odorantes. C.

306. Etaballia guiancnsis Benth. in Hook., Journ. Bol. II, p. 99. - Quinta de São Christovão, cult., liı-Jar., no 13419. Arbuste, l'l. rougeâtres. Févier-mars. R.

307. Baphia ovalifolia Desv.; Amn. Sc. Nal. Sér. I, 9. - Quinta de São Christovão, cult., líu-JAx., no 18916. Arbuste, fl. blanches. Arrilmai. R.

308. Sophora tomentosa L.: Fl. Bres. XV, I, p. 314. - Restinga de Copacabana, près de la mer, et à llha Grande, Rro-Jax., $n^{\text {os }}$ 17, 1369, 8635. Arbuste, fl. jaunes. CC.

309. Castanospermum australe Cunn. et Fr. in Hook. Bot. Misc. I, p. 241. - Quinta de São Christovão, Rio-Jan., n 1040. Grand arbre cultivé, fl. jaunâtres. Février. R.

310. Ormosia nitida Vog.; Fl. Bras. XY, I, 1. 31:. - Entre Garea et Tijuca, Rı-Jıs., $n^{\text {os }}$ 14, 15. Grand arbre, fl. rousses. Janvier-mar's. CG. Vulgo: Otho de l'alo.

311. O. friburgensis Taub. n. sp. in herb. Paris., Berol., Kew., Brix.. ete. - Nova Friburgo, au hord de la rivière, Rro-Jax., no 19045. Grand arbre, 11. roses. Juin-juillet. C.

319. O. dasycarpa Jacks.; Fl. Brus. XV, I, 1. 316. - Alto Macahé de Nova Friburgo, liı-Jıx. nº 20275. Grand arbre, fl. rougeâtres. Marsavril. C. Vulgo: Angelim boi.

313. O. Escragnolliana Glaz. n. sp. in herb. Paris., Berol., etc. Floresta de Tijuca, liho-Jan., $n^{0}$ 11892. Grand arbre, fl. rousses. Marsavril. R.

314. O. fastigiata Tul.; Fl. Bras. XV, I, p. 319. - Serra do Inticionado, dans le bois, Hivis Geries, ${ }^{\circ}$ 11898. Grand arbre, fl. blanc rosé. Juillet-aotit. R. Vulgu : Muhungu bravo.

31\%. Diplotropis brasiliensis lienth. in FI. Brus. XV, I, p. 320. - 
A.-F.-M. GLAZIOU. - LISTE DES PlaNtes DU BRÉSIL CENTRAL. 153

Quinta de São Christovão, Riı-Jan., nº 13758. Arbre cultivé, fl. rosées. Févriel-mars. R.

316. D. Taubertiana Harms in Engler Botan. Jahrb. (1903), p. 26. - Entre Rio Manso et Arassuahy, Mixas, no 14668. Grand arbre, fl. brun rougeâtres. Septembre-octobre. C.

317. Bowdichia virgilioides Humb. B. et K.: Fl. Bras. XV, I, p. 31 2. - Entre Sambaitiba et Porto dos Caisos, Rio-Jas., $11^{03} 4790,11896$ : Mendonha, Misıs, $n^{0} 12601$; Iguas Claras, Goraz, n² 20877. Octobrenovembre. GC. Vulgo : Secupira.

318. Ateleia Glazioviana Baill. in Bull. Soc. Lim. P'aris I, p. 306. - Nova Friburgo, au Conego, Rı-Jın., nº 12565. Irbrisseau, f1. verdàtres. Février-mars. C..

319. Ferreirea spectabilis Fr. Allem.: Fl. Bros. XV, 1, p. 311.Guaxindiba, dans le bois, Rı-Jax., n ${ }^{0}$ 12602. Grand arbre, t1. jaunes. Septembre-octobre. R. Vulgo : Sepipira.

320. Myroxylon peruiferum L. fil.: Fl. Bras. XV, I, p. 310.Fazenda de Ibicaba, Sĩo Palco, n 12566 : Joord du Rio Preto, au Palmital, Govaz, nº 20885 u. Très grand arbre à beau boiš, fl. blanches. Irrilmai. C. Vulgo : Balsamo.

321. Myrocarpus frondosus Fr. Allem.; Fl. Brus. XV, II, p. 1.Petropolis, au Tingua et Nova Friburgo, liı-JAx., n ${ }^{\text {os }}$ 6516, 6837, 8446, 8449, 11906 et 11907. Tres grand arbre, fl. blanches. Mai-juin. C.C. Vulgo : Oleo pardo.

322. M. fastigiatus Fr. Allem.; Fl. Bras. XV, II, p. 3. - Praia Grande, au Iorro do Cavallão, Riı-Jıx., nº 5826. Grand arbre, fl. blanc jaunâtres. C. Vulgo : Oleo parlo, Craborahiba.

323. Sweetia lentiscifolia Spreng. ; Fl. Bras. XV, II, p. 4. - Santa Thereza, au Corcovado et à Jurujuba, Rio-Jıx., nos 803, 5853, 7581. Tres grand arbre, fl. blanches. Septembre-octobre. C.

324. S. fallax Taub. n. sp. in lıerb. Berol., etc. - Floresta da Tijuca, Rio-Jax., n ${ }^{\circ}$ 14618. Grancl arbre, fl. blanclıes. Septembre-octobre. R.

32:. S. dasycarpa Benth.: Fl. Brrs. XV, II, p. ̈. - Serra do Lenheiro et d'Ouro Branco, NIras, nos 10556, 10557, 10558, 13724 ; Solıradinho, à Canastrão, Goyız, n² 21021. Arbrisseau, fl. blanc jaunàtre. Janvier-mars. CC. Vulgo : Chapada, Unha d'Anta.

Var. glabrata in Fl. Bras. XV, II, p. 6. - Entre Arraial de Ouro Branco et Queluz, Mixus, $n^{\text {os }} 1263$, 14620, 17601. Arbrisseau, fl. blanc jaunàtre. Novembre-décembre. C. 
326. S. nitens Benth.; Fl. Bras. XV, II, p. 6. - Quinta de Sio Cluristovino, Ru-dıx, no 13762 . Arlre rultivé, fl. blanches. Marsarril. R.

327. Snectia elegans Benth.; Fl. Bres. XY, II, p. 6. - Campos da Bocaina Sĩo PAulo, $\mathbf{n}^{\circ}$ 13681. Arbrisseau, fl. blanc jaunâtre. Juilletseptemlire. C.

328. S. Glazioviana Harms in Engler Botan. Jahrb. (1903), p. 26. - Sabara, Mris Gerses, n 18207. Grand arlıe, 11. blanches. Janvierfévrier. C. Vulgo : Sobral.

329. S. macrostema Glaz. n. sp.? in herb. Paris., Berol., Kew., Brux., ets. - Valla Funda, au Sertio, Mıvıs, $n^{\circ}$ 19053. Arbrisseau tortueux à grosse écorce, fruits en mars. C.

330. Zollernia latifolia Benth. in F\%. Bras. XV, II, p. 9. - Petrojolis, à ltanaraty, Rio-dAx., nos 7583, 18205. Grand arbre, bon bois, fl. jaunâtres. Novembre-décembre. C. Vulgoo : Nocitaibr.

331. Z. falcata Nees.; Fl. Bras. XV, II, p. 9. - Corcovado, à Caixa d'Agua et à Lagoa do Peixe, Rio-JAx., $1^{\text {os }}$ 2557, 3941, 12605. Grand arbre, fl. blanc rosé. Novembre-décembre. C. Vulgo : Mocitaiba.

332. Z. ilicifolia Vog.; F\%. Bras. XV, II, 1). 10. - Bords du Rio Piabanha, à Petropolis, Rı-Jax., nos $2986,14616,11596$; Serra do Campanema, Mrxas, nos $12604,3730,15923$. Grand arbre, ll. blanc rosé. Octobre-novenbre. C. Vulgo : Nocitaiba.

333. Z. parvifolia Tauh. n. sp. in herb. Berol. - Alto Macahé de Nova Friburgo, Riı-Jax., $n^{\circ}$ 19054. Grand arbre, fl. rose pâle. Avrilmai. R.

33't. Exostyles 1'enusta Schott; Fl. Bras. XV, II, p. 11. - Restinga de Copacabana et Corcovado, Rio-J.ıv., $n^{\text {os }} 215,614,5851,5852$, $6185,6186,9410$. Arbrisseau, fl. rouge foncé. Juin-août. C.

33\%. Holocalyx Glaziovii Taub. 11. sp. in herl, Berol., Paris., etc. - Catas Nltas, Mixis Ger.es, no 14640. Arlore, fl. blanchàtres. Juinjuillet. R.

336. Swartia (Tounalea) triphy-lla Willd. : Fl. Bras. XV, II, p. 22. - Dans lntios, au Corcovado, Rı-Jیx., n 3930. Arbrisseau, ll. jaunes. Norembre-décembre, C.

337. S. (Tounatea) crocea Bentlı. Fl. Bras. XT, II, p. 23. - Paineiras, au Gorcovado, Rio-J.ı., nos 618, 7586. Arbre, 11. jaunes. Novemhre-dérembre. CC.

338. S. (Tounatea) elegans Schott; H. Bras. XV, II, p. 23. 


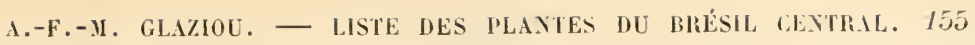
Petropolis, aux bords du Rio Piabanha, Rio-Jax., nos 616, 7585, 9414, 13732, 12606. Arbre, fl. jaunes. Novembre-décembre. C.C.

339. S. (Tounatea) Langsdorffii Raddi; Fl. Bras. IV, II, p. 24.Atalaia, à Praia Grande, Rı-J.x., nos 1037, 2547. Grand ariore, fl. l,lanches. Décembre--lanvier. CG. Vulgo : Jacaranda banana.

340. S. (Tounatea) multijuga Vog.; Fl. Bras. XV, II, p. 20. Ribeirão de Taquaruçú, Mıss, $n^{\circ}$ 19058. Arbrisseau, fl. Hanches. Avrilmai. C.

34. S. (Tounatea) Flemmingii Raddi; Fl. Bras. XV, II, p. 206. Corcorado, Gavea, Tijuca, Rı-Jıx., nos 1036, 2971, 6514, 10643, 10578, 10577, 19057. Grand arìre, f1. jaune pâle. Février-mars. CC. Vulgo : Jacaranda branco.

34.. S. (Tomatea) acutifolia Vog.: Fl. Bras. XV, II, p. 27.Bord du Rio Novo, au Pian, Maxss Gerses, n² 2548. Grand arlıe, ll. llane jaunâtre. Avril-mai. R.

343. S. (Tounatea) theiodora Taub. n. sp. in lierl. Berol., Paris, etc. Barranco do Rio Manso, Mrus Geraes, no 12607. Arbrisseau, fl. blanc jaunâtre. Juin-juillet. C.

34't. S. (Tounatea) Glazioviana Taub. n. sp. in herb. Berul., etc. - Restinga de Cabo Frio, Rı-Jıx., n 9415. Arbrisseau, 11. blanc jaunâtre. Mars-aviril. C.

340.. S. (T'ounatea) apetala haddi : Fl. Bras. XV, I1, p. 30. -- Sete Pontes, à Praia Grande, Rro-JAx., $n^{\text {os }} 8622$, 8623. Grand arbre, fl. blanc jaunàtre. Mar's-arril. C.

346. S. (Tounatea) rosea llart. in Fl. Bras. XY, II, p. 32. - Lagoa de Freitos, à Tres Vendas, Rio-J Ax., no 13770. Arlore cultivé, fl. rose pâle. Juin-juillet. R.

34T. S. (Tounatea) acuminata Willd.: Fl. Bras. XV, II, 1. 36. Quinta de Sào Christovão. Rın-JAx., n 13771. Grand arbre cultivé, fl. blanches. Hai-juin. R.

Var. puberula Taub. in herb. Berol., etc. - Campos de São Fidelis, dans le bois, Rı-J.r. $n^{\circ}$ 13771. Grand arlıre, fl. blanches. Févrielmars. R.

3'S. S. (Tounatea) alterna Benth.: Fl. Bras. XV. II, p. 39. - Sio Fidelis, près Campos, dans le, loris, lio-.las., no 9767. Grand arbre, 11. blanc rosé. Janvier-février. R. 


\section{CASALPINIÉES.}

349. Sclerolobium paniculatum Vog.; Fl. Bras. XV, II, p. 47. Campos da Bucaina, Sĩo PAlıo, $10^{\circ}$ 10644; Serla dos Pyreneus, Goyaz, $n^{0}$ 21024. Grand arbre, fl. jaunes à très houne odeur. Septembre. C. Vulgo : Cavaeiro.

3̋0. S. hypolencum Bentlı. in Fl. Bras. XV, II, p. 48. - Santa Quitaria, prìs de Caraça, Mlsas, $n^{0}$ 13760. Grand arbre, 11. jaunes. Janvier-février. R.

331. S. chysophyllum Papp.; Fl. Brus. XV, II, p. 49. - Nlo Macahé de Nova Friburgo, Rio-JAs., nos 13734, 19059. Grand arbre, 11. jaunes. Décembre-janvier. C. Vulgo : Cahenga.

30ّ. S. denudatum Vog.; Fl. Brus. XV, II, p. 49. - Paineiras, au Corcovaldo, Rio-Jax., $n^{\circ \mathrm{s}} 209,1570,13735$. Bel arbre, li. jaunes à odeur de Genêt. Septembre. CC.

333. S. Urbanianum Harms in Engler Botun. Jahrb. (1903), p. 23. - Rio do Ouro, près de l'eau, lio-Jax., $1^{\circ}$ 10683. Grand arbre, f1. jaunes. Aout-septembre. R.

394. S. Beaurepairei Harms, in Engler Bolan. Jahrb. (1903), p. 23. - Alto Macahé de Nova Friburgo, Lio-JAx., nos 18206, 19879, 20286. Grand arbre, fl. jaunes à tres bonne odeur. Novembre. C.

3\%̈. S. Pilgerianum Harms, in Engler Botmn. Jahrb. (1903), p. 24. - Petropolis, à Caclıambú, Rio-JAx., n 15933. Très grand arbre à 11. jaunes. Mar's-avilil. R.

3̈6. S.rugosum Mart.; F\%. Bras. XV, II, p. ̈̈0. - Nova Friburgo, Riı-Jıx., 11 0s 9408, 11910, 11911, 16757; São José dos Barreiros, Säo Paulo, n 18642. Grand arlre, 11. jaunes. Septembre-octobre. CC.

צั7. S. aureum Benth. in Fl. Bras. XV, II, p. 5̈0. - Entre Itajuru et Santa-Barbara, Mıvas, $10^{\circ 5} 12626,19056,20285$; entre Cianastrão et Macté, Goraz, $n^{\circ}$ 21023, 21025, 20285. Grand arbre, fl. jannes. (1)tobre-novembre. CG.

338. Diptychandra aurantiaca Tul.; Fl. Lims. XV, II, p. 92.- Quinta de Sâo Christovĩo, Rı-Jax., no $13686 a$. Mrbre cultivé, fl. blance jaunâtre. Juin-juillet. R.

389. D. glabra Renth.; Fl. Bras. XV, II, 1. 8̈2. - Campos da Bocaina, S̃̃o P’xzo, ॥ $^{\circ} 13735$ a. Arbrisseau, 11. rougeâtres. Juillet-septembre. Li. Vulgo : Páo de libro.

360. D. epunctata Tul.; Fl. Bras. XV, II, p. 52. - Serra do Caraça, 
A.-F.-M. GLAZIOU. - LISTE DES PLANTES DU BRÉSIL CENTRAL. 157

dans le campo, Mriss, nº 14619. Arbrisseau, t1. jaunâtres. Décembre-janvier. C.

361. Campsiandra laurifolia Bentlı.; Fl. Bras. XV, II, p. 54. Passeio Publico, Ro-JAx., $\mathrm{n}^{\text {os }}$ 9765, 13754. Grand arbre cultivé, fl. blane rosé. Juin-juillet. R. Vulg̈ : A capú.

362. Melanoxylon Braunia Schott; Fl. Bras. XV, II, p. 57. São Christovão, Rı-Jax., nos 1030, 10695. Grand arbre, hon bois de construetion, 11. jaunes. Février. C. Vulgo: Brauna.

363. Cenostiama macrophyllum Tul.; Fl. Bras. XV, II, p. 59. Nova Friburgo, au Conego, Rio-Jax., n 19060. Grand et bel arbre, fl. blanches. Septembre-octobre. R.

364. Phyllocarpus Riedelii Tul. ; Fl. Bras. XV, II, p. 62. - Bas de la Serra do Tingua, Rı-JAx., $1^{\circ} 6839 a$. Grand arbre, fl. jaunes. Aoùt-septembre. R.

363. Peltophorum Vogeliannm Benth.; Fl. Bras. XV, II, p. 62. — Floresta da Tijuca, Rio-IAx., nos 2551, 4789, 10693, 10694, 12610. Grand arbre, fl. jaunes. Février. CC. Vulgo : Solrazil.

366. Cæsalpinia Bondncella Roxl,.; Fl. Bras. XV. II, p. 6a.Restinga de Coparabana, Rı-Jax., $n^{\circ}$ 1038. Sarmenteux, 11. jaune pâle. Févriel-mars. CG. Vulgo : Julieriana.

367. C. acuminata n. sp.? Glaz. in herls. Paris., Berol., Kew., Brux., etc. - Quinta da Bua Vista, São Christovão, Rı-Jav., $n^{0} 8661$. Arluste sarmenteux, 11. hanc jaunattre, cultivé. Juillet-aoùt.

368. C. echinata Lamk; Fl. Bras. XV, II, p. 66. - Floresta de Tijuca, Rio-JAx., no 6839. Grand arbre, 17. jaunes. Octobre-novembre. R. Vulgo : Prio Brazil.

369. C. pulcherrima Swartz; Fl. Bras. XV, II, 1. 67. - Quinta de Sāo Glıristovão, Rn-Jıx, $n^{\circ}$ 6512. Arhuste cultivé, fl. orange. Marsjuillet. CC.

370. C. pyramidalis Tul.; Fl. Bras. XV, II, p. 68. - Sìo Fillelis, au Collegio, Rı-Jas., $\mathrm{n}^{\text {ss }} 9752$, 10645. Arbuste, fl. jaunes. Janvierfévrier. C. Vulgo : Catingueira.

371. C. ferrea Mart.; Fl. Bros. XV, II, p. 69. - Serra de Jacarepagua, Floresta da Tijuca, etc., Rı-J $\mathrm{J}_{\mathrm{Ax}}$., $\mathrm{n}^{\text {os }}$ 2555, 5847, 12609, 11904. Frand arbre, fl. jaunes. Janvier-mars. CG. Vulgo : P'io ferro.

372. C. peltophoroides Penth. in Fl. Bras. XV, II, p. 72. - Corcovado et Tijuca, lior-JAN., II ${ }^{09} 1032,3943,6187,6838,11905$; SantaBarbara, Mixis, no 14621. Grand arbre, 1\%. jaunes. Septembre-octolre. CC. Vulgo: Sepipiruna. 
373. Casalpinia sepiaria lioxb. in Hor. Beng., p. 32. - Quinta te sino Cluristovio, Ro-Jax., $n^{\text {os }} 2552,5850$. Arluste cultivé, fl. jaune pâle. Mai-juillet. C.

37' C. Juca Glaz. n. sp.? in lıerb. Paris., Berol., Kew., Havn., elc. - Serra de Itabapoana, Esprito Santo, $n^{\text {os }}$ 9760, 10646. Arbrisseau, 11. jaunes. Septembre-octohre. C. Vulgo: Juca.

375. Schizolobium excelsum Vog. : Fl. Brus. XV, II, p. 74. - São Christovão, Corcovado. Rio-Jav., $1^{\circ s} 1569,4994,13427$. Très grand arbre, fl. jaunes. Septembre-octobre. CC. Vulgo : Bacurubú, Caperoroca.

376. Moldenhauera floribunda Sclırad.; Fl. Bras. XV, II. p. 76. - Serra da Estrella, Bio-JAx.. nos 7582, 8662. Grand arbre, 11. jaunes. Novembre. C. Vulgo : Guaraçahy.

377. Parkinsonia aculeata L.; Fl. Brrs. XV, II, p. 78. - Passeio Publico, Rio-Juv., no 619. Petit arbre cultivé, 11. jaunes. Févrierinars. CC.

378. Martia excelsa Benth.; Fl. Bras. XV, II, 1. 79. - Quinta de

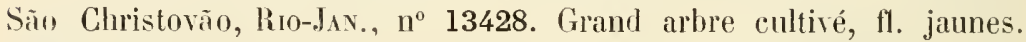
Janvier-février. R.

379. Diconynia paraensis Benth.; Fl. Bros. XY, II, p. 81. - Tres Vendas à Lagoa de Freitas, Rı-JAN., $n^{\circ} 7583 a$. Très grand arbre cultivé, fl. jaunes. Avril-mars. R.

380. Cassia Fistula; Fl. Bras. XV, II, p. 92. - Larangeiras, à Cosme Velho, Rio-Jax., $n^{\text {os }} 608,6511$. Arbrisseau cultivé, f1. james. Janvier-avril. CC.

381. C. grandis L.; Fl. Brus. XV, II, p. 93. - Passeio Puhlico, Rio-J $J_{A x}, n^{\circ}$ 1564. Grand arbre cultivé, 11. rouge orange. Septembreortobre. C. Vulgo : Mari-Mari, Geneuno.

382. C. ferrnginea Schrad.; Fl. Bras. XV, II, p. 94. - Floresta da Tijula, Rı-Jax., ${ }^{0 s} 4995,10696$; Carandalıy, Usxas, ${ }^{\text {os }}$ 10647, 13750, 14627. Grand arbre, fl. rouge brique. Novembre-janvier. CC. Vulgo : Coma-fistula.

383. C. affunis Benth. in Fl. Bras. XV, II, p. 98. - Lagoinla, au Corcovado, Ro-dax., $1^{0 s}$ 1033, 2981. Arluste, fl. jaunes. Janvier-mar's. CC. Vulgo : Fedegozo.

384. C. bacillaris L.; Fl. Bras. XV, II, p. 98. - Santa Quiteria, Minas Gerabs, $n^{0 s} 10687,12616$, 14636. Arbuste, fl. james. Octobrenovembre. CC. 
A.-F.-M. GLAZlOU. - LISTE DES PLANTES DU BRÉSIL CENTRAL. 159

38\%. C. quinquangulata Rich.; Fl. Bras. XV, II, p. 99. - São Sehastião, près l'ltabapoana, Rı-Jx., $1^{\circ \mathrm{s}}$ 9764, 10686. Arbuste, fl. jaunes. Février-mar's. CC.

386. C. chrysocarpa Desv.: Fl. liras. XV, II, p. 100. - Campos da Bocaina, Sĩo Paulo, no 10653. Arbuste, fl. jaunes. Septembre. C.

387. C. angulata Vog.: Fl. Bras. XV, II, p. 101. - Serra dos Orgãos, à Theresopolis, Rio-JAs., n 3939. Arbuste, fl. jaunes. Arrilmai. C.

385. C. pudibunda Mart. in Fl. Bras. XV, II, p. 102. - Petropolis, à Santo Antonio, Rro-JAx., n ${ }^{\circ}$ 7580. Alluste, fl. jaunes. Juillet-septembre. C.C.

389. C. speciosa Schrad.; Fl. Bras. XV, II, p. 102. - Campos de Caraça, Misas Genaes, ${ }^{08} 12612,13744$. Arbuste, fl. jaunes. Juinjuillet. C.C.

Var. nervosa Benth. in Fl. Bras. XV, 11, p. 103. - Entre Queluz ef Carandalyy, dans le campo, Mıxas, $n^{\circ} 12612$ . Arbuste, fl. jaunes. Juinjuillet. C.

390. C. rugosa Don.: Fl. Bras. XV, II, p. 103. - Entre Sitio et Barbacena, Misas, $n^{\circ \mathrm{s}} 12613,15935,19081$; Fazenda do Palmital, Gosaz, $\mathrm{n}^{\circ}$ 21005. Arbuste des campos, f1. jaunes. Juin-juillet. CC. Vulgo : Amendoim do campo.

391. C. Hoffmannseggii Mart. in Fl. Bras. XV, II, p. 104. Caraça, dans le campo, II ixas Gerses, $n^{\circ}$ 12618. Arbuste, fl. jaunes. Juin-juillet. C.

392. C. macranthera DC.: Fl. Bras. XV, II, p. 104. - Floresta da Tijuca, Rio-JAx., nos 1034, 4209. Arbuste, fl. jaunes. Arril-mai. C... Vulgo : Ipé branco.

393. C. splendida Vog.; Fl. Bras. XV, II, p. 105. - Serra de Caraça, llans le campo, Nixas Geraes, $n^{\circ 5}$ 10650, 13745. Arbuste, 11. jaunes. Mars-avril. C.

Var. angustifolia in Fl. Bras. XV, II, p. 105. - Ayuruoca el São Joàn d'El Rei, Mıxas, nº 9413, 16756; Ipanema, Sĩo Pallo, no 12608. Arbuste, 11. jaunes. C.C.

394. C. bicapsularis L.; Fl. Bras. XV, II, p. 106. - Serra dos Orgãos, à 'Theresopolis, Iiı-Jax., $n^{\circ}$ 1035; Diamantina et Ayuruoca. Vinas, $n^{\text {os }}$ 15940, 19063; Lagoa Formosa, Goraz, n $20963 a$. Arbuste, f1. jaunes. Janvier-mar's. CC.

39.. C. corymbosa Lamk.; Fl. Bras. XV, II, p. 107. - Entre 
Ayuruoca et Caxambù, Minas, $n^{\circ} 15940 a$. Arbuste fl. jaunes. Janvier. C.

396. Cassia lavigata Willd. ; Fl. Bras. XV, II, p. 108. - Restinga de Copacabana et Tijuca, Rio-JAx., $n^{\text {os }} 6869,8415,132,5848,28289$. Arluuste. fl. jaunes. CC.

397. C. c.xcelsa Schrall.; Fl. Bras. XV, II, p. 109. - Catas Altas, près de Caraça, Minas Geraes, ${ }^{\text {os }} 10648,12615$; Petropolis, Rio-Jan., $n^{\circ}$ 8413. Arbre, fl. jaunes. Janvier-février. C. Vulgo : Prio d'Ovelha.

398. C. oblongifolia Vog.; Fl. Brus. XV, Il, p. 110. - Sommet du Pico de Tijuca, $\mathrm{n}^{\circ}$ 605, 1459, 7597, et Petropolis, sur les rochers du Retiro, Rio-Jas., $n^{\text {os }} 8417,8664$. Arbuste, 11. jaunes. Janvier-mars. CG.

399. C. sulcata DC.; Fl. Bras. XV. II, p. 112. - Pé do Rio, près de Petropolis, Rio-Jax., nº 8663. Sous-frutescent, fl. jaunes. Févriermars. GC.

400. C. occidentalis L.; Fl. Bras. XV, II, p. 112. - Campos da Bocaina, Sĩo Pallo, $n^{\text {os }} 8415 a, 13747$. Sous-frutescent, fl. jaunes. Janvier-février C. Vulgo : Fedegosa ou Tamrocú.

401. C. Sophera L.; Fl. Bras. XV, II, p. 113, ohs. - Près d'Antonio Pereira, Mrxas. $n^{\circ}$ 13748. Sous-frutescent, fl. jaunes. Marsavril. C.

402. C. pentagonia Will.; Fl. Brus. XV, II, p. 114. - Près de Queluz, Mixas Geraes, $n^{0} 14633$ a. Sous-frutescent, f1. jaunes. Juinjuillet. C.

403. C. Tora L.; Fl. Bras. XV, 11, p. 115. - S. Christovão, RıJax., $n^{0} 3941$; Catas Altas, Hrisas Geraes, $n^{\circ}$ 13749. Sous-frutescent, fl. jaunes. Février-avril. C.

404. C. pilifera Vog.: Fl. Bras. XV, II, p. 115. - Campos da Bocaina, Sĩo PAulo, $\mathrm{n}^{\text {os }} 10657,14633$ ? Sous-frutescent, 11. jaunes. Février. C.

40:3. C. sericea Swartz; Fl. Bres. XY, II, p. 116. - Serra da Mlantiqueira, Msxas, $n^{0}$ 10655. Frutescent, fl. jaunes. R.

406. C. velutina Vog.; Fl. Bras. XV, II, p. 118. - Ificionado, dans le campo, Mixas, nos 10656, 13743; Santa Luzia, Goyaz, no 21007. Arbuste, f1. jaunes. Mars-mai. C.

407. G. gamaensis Glaz. n. sp.? in lıerb. Paris, Berol. Kew., Brux., ete. - Barre du Rio Gama, au bord du bois, Goyaz, n² 20943. Arbuste, fl. jaunes. Mai-juin. C. 
1.-F.-H. GlazloU, - LISTE DEs Plantes dU brésil Central. 161

408. Cassia appendiculata Vog.; Fl. Bras. XV, II, p. I19. - Restinga de Taipu, Rio-Jav., n ${ }^{\circ 5}$ 6182, 18208. Arbuste, fl. jaunes. Mars-avril. C.

409. C. Gardneri Benth. in Fl. Bras. XV, II, p. 120. - São João da Barra. près de Campos, Rio-Jix., $n^{\circ}$ 9750. Arbuste touffu, fl. jaunes. Janvier-février. R.

410. C. biflora L.; Fl. Bris. XV, II, p. 121. - Passage du Rio Paranahyha, Mrsas, $\mathrm{n}^{05}$ 20962, 20963. Arluste, l1. jaunes. Aont-septembre. C.

411. C. trachypus Mart. in F\%. Brus. XV, II, p. 122. - Quinta de São Christovĩo, Rro-Jax., no 10651. Arbuste cultivé, f1. jaunes. Janvier-mars. C.

412. C. açuruensis Benth. in Fl, Bras. XV, II, p. 122. - Rio Manso, dans le bois, Mrxas, nº 12611. Arluste, fl. jaunes. Mai-juin. C.

413. G. mollifolia Harms, n. sp. in lıerl. Paris, Berol.. Kew., Brux. - Entre le Rio Rajadinha et Vargem, Goviz, nos 20944, 20945. Albuste, fl. jaunes. Mai-juin. C.

414. C. multijuga Rich.; Fl. Bros. XV, II, p. 193. - Santa Theresa, au Corcovalo, $\mathrm{n}^{\circ:} 612,1051,10649$; Ouro Preto, Gandarela, Rio Manso, Mixas, $n^{\text {o` }} 13742,13746,13751,14625$. Grand arbuste, fl. jaunes. Janvier-mars. CC.

Var. lindelana in Fl. Bras. XY, II, p. I23. - Serra do Picu, Sĩo Pavlo, no 10649 a. Grand arluste, 11. jaunes. Avril-juillet.

419. C. reniformis G. Don; Fl. Bras. XT, II, p. 124. - Biribiry, près de Diamantina, Mris, $n^{0 s} 14628,19077$, 19079. Arbuste, ft. jaunes. Février-mars. C.

416. C. silvestris Vell.; Fl. Brus. XV, II, p. I2כ̈. - Gandarela, Caraça, Santa Luzia, etc., IIxıs, $n^{\circ 5} 2982,13741$, 14626, 20288. Arbuste, fl. jaunes. Janvier-février. CC.

417. G. petropolitana Glaz., n. sp.? in herb. Paris., Kew., Berol., Brux., ete. - Petropolis, entre les rochers, au Alto Serra, Rio-Jan., $n^{0}$ 10684. Arinuste, t1. jaunes. Avril-mai. R.

418. C. racemosa Nill.; Fl. Biras. XV, II, p. 126. - Entre Queimados et Rio do Ouro, liro-Jix., nos 9661,10688 . Arhuste, fl. jaunes. Février-mars. C.

419. G. pilicarpa Glaz., n. sp.? in herb. Paris., Berol., Kew., Brux., etc. - Serra do Caraça, Mhxas, $n^{0}$ 15939. Arluuste, fl. jaunes. Juilletaoùt. C. 
420. Cassia simea Lamk. Encycl. Bot., I, p. 618. - Passeio Publico, Rio-J $\mathrm{Jx}_{\mathrm{x}}, \mathrm{Il}^{0}$ 609. Grand arbre cultivé, 11. jaunes. Février-mars. R.

421. C. alata L.; Fl. Bras. XV, I, p. 26. - Juiz de Fora, Minas Geraes, $n^{\circ}$ 10685. Arluste, 11. jaunes. Janvier-février. CC.

429. C. aculeata Pohl in Fl. Bras. XV, II, p. 128. - Norro do Cioco, près de Campo. Rio-J.x., n ${ }^{\circ} 10688 \%$. Arbuste, fl. jaunes. Décembre-janvier. R.

423. C. Aponconita Aubl.; Fl. Bres. XV, II, 1. 129. - Corcovado, Tijuca, São Christovão, liı-Jıx., nos 611, 2538, 3940, 9762; Gandorela. Serra da Alegria, etc., Misas, $\mathrm{n}^{\text {os }}$ 12617, 14634, 14635. Petit arbre, 11. jaunes. Janvier-mar's. CG.

424. C. hispidula Vahıl; Fl. Bras. XV, II, p. 131. - Horro do Romĩo, à Sabara, Itabira do Campo, Nlıxas, $n^{\text {os }} 10654,10660,19104$; Morro do Lamarĩo, Gorız, nº 20983. Rampant. fl. jaunes. Avril-juin. CC.

42.). C. monticola Mart. in Fl. Bras. XV, II, p. 134. - Biribiry, près de Jiamantina, Mixas, $n^{\circ}$ 19106. Arbuste, fl. jaunes. Mars-avril. C.

426. C. andromedea Nart. in Fl. Bras. XV, II, p. 13\%. - Diamantina, Mrxas Ger.ess, $n^{\circ}$ 19102. Petit arbuste, fi. jaunes. Avril-mai. C.

427. G. oppositifolia Glaz., n. sp.? in herb. Paris, Berol., Kew., Brux., ete. - Serra dos Crystaes, dans le campo, Goyaz, $n^{\circ} 21006$. Plante naine, fl. jaunes. Août-septembre. R.

428. G. campicola Harms, n. sp. in herb. Berol., Kew., Paris., Genev, etc. - Santa Lioza, dans les cerrados, Goraz, n² 20999. Petit arbuste, f1. jaunes. Mars-atril. R.

429. C. scabra Polll in Fl. Liras. XV, II, p. 139. - Guariroba, dans Ir campo, Goyı, n 21003. Petit arluuste, fl. jaunes. Octobrenovembre. C.

430. C. linearifolia G. Don; Fl. Bras. XV, II, P. 137. - Entre Rajadinla et le Rio Torto, Goyaz, $n^{\circ}$ 20964. Arbuste du campo, fl. jaunes. Juin-juillet. R.

431. C. dentata Yogel; Fl. Bras. XV, II, p. 137. - Cipo, près de Congonhas da Serra, Nins, n 19097. Arbuste, fl. jaunes. Avril-mai. R.

432. C. cotinifolia G. Don; Fl. Bras. XV, Il, p. 138. - Rio Gama, dans le campo, Govaz, $n^{\circ}$ 20972; Fazendo do Cipo, Mlisas, $n^{\circ}$ 19100. Petit arluste, 11. jaunes. Juillet. CC.

433. C. Blancheti Bentlı.; Fl. Bras. XV, II, p. 138. - Biribiry, dans le campo, Nixus, $n^{\circ}$ 19098. Petit arbuste, fl. jaumes. Avril-nai. R.

134. C. Vauthieri Bentl. in Fl. Bras. XV, II, p. 138. - Rio das 
A.-F.-M. GLAZIOC. - LISTE DES PLIYTES DU BRESSIL CEYTRAL, 163 Pedras, dans le campo, Misas Geraes, n 19101. Petit arbuste, fl. jaunes. Avril-mai. C.

433. G. pachypoda Harms, n. sp. in herl, Paris, Berol., Kew., Genev., etc. - Chapadão Grande, entre Guariroba et fio Torto, Goraz, $n^{0}$ 20979. Arbuste à grosse érorre, fl. jaunes. Aoùt-septembre. C.

436. C. orbiculata Benth.; Fl. Bras. XV, II, p. 140. - Formação, près de Diantantina, Hwas, $\mathrm{n}^{\circ} 19099$; entre le Rio Tocantins et Os Porcos, Serra dlos Pyreneus, Bom Successo, Govaz, $11^{\text {os }} 20973,20974$, 20976, 20977. Arluste des cerrados, 11. jaunes. Juin-juillet. CC.

437. C. crenulata Benth.; Fl. Bras. XV, II, p. 140. - Entre Deia Ponte et Bernarlo Lobo, dans le rerrado, Goviz, n² 20997. Arbuste, 11. jaunes. Juillet. C.

138. G. lavradiiflora Harms, n. sp. in herb. Berol., Kew., ete. - Fazenda do Lamarão, dans le campo, Gor.1z, n² 20968. Plante étalée, tl. jaunes. Juin-juillet.

439. C. Clausseni Benth.; Fl. Brus. XV, It, p. 140. - Abbade, près de Heia Ponte, Morro das Lagos, Ponte Lavrala, Govas, $n^{0 s} 20969$, 20970, 20975. Arbuste, 11. jaunes. Loùt-septembre. CG.

440. C. setosa Vogel; Fl. Bras. XV, II, p. 141. - Fazenda de Natto Grande, Misss, $n^{\circ}$ 19074; Paranana, Cassu, Gorız, nos 21000 , 21001, 21002. Arbuste, ti. jaunes. Avril-mai. CC.

441. C. conferta Benth.; Fl. Brus. XV, I, p. 142. - Diamantina, à Formação, Mısas, no 19105: Buracão: dans le campo, Goviz, nº 20941. Petit arbuste, fl. jaunes. Avril-juin. C.

442. C. ochnacea Vog.; Fl. Bras. XY, II, p. 142. - Serra dos Cristaes, à Diamantina, Muxus Geraes, no $19160 a$. Arbuste, fl. jaunes. Avrilmai. R.

443. C. Lundii Benth. in Fl. Bros. XV, II, p. 143. - Fazenda de Taboquinha, dans le campo, Govaz, $n^{\circ}$ 20978. Petit arbuste, fl. jaunes. Mai-juin. Cli.

4'4. C. nummularicefolia Benth. in Fl. Bras. XV, II, p. 144. Mestre d'Armas, Goraz, nos 20981, 20996. Plante rampante, fl. jaunes. Octobre-novembre. C.

4 ‘.. C. planaltoana Harms, n. sp. in herb. Berol., Kew., Paris, Genev., etc. - Grande vallée de Chico Costa, dans le cerrado, Goraz, $n^{\circ}$ 20995. Frutescent, 11. jaunes. Octobre-novembre. C.

4'6. C. mollicaulis Harms, n. sp. in herb. Berol, Kew., Paris., Brux. - Capelinha de Santo Antonio, au Rio Descoberto, Goyaz, $n^{\circ}$ 20950. Frutescent, 11. jaunes. Octobre-novembre. C. 
4:7. Cassia pycnophylla Harms, n. sp. in herb. Berol., kew., Paris., Cienev., etc. - Serra dos Pyreneus, dans le campo, Govaz, n² 20953. Septemlne-octobre. C.

448. G. Benthamiana Harms, n. sp. in herb. Jerol. el Kew. ined. Chapadinha, dans le campo, Goraz, $n^{\circ}$ 20982. Plante italie, ti. jaunes. Septembre-octobre. C.

449. C. punctata Vog.; Fl. Bras. XV, II, p. 145. - Caraça, au campo de Fora, Nixas, no 14629. Petit arbuste, 11. jaunes. Janvierfévrier. C.

4\%0. C. lomatopoda Benth. in Fl. Bras. XV, II, p. 1'46. - Entre Morro hedondo et Hanoel João, dans le carascal, Gorız, $n^{\circ}$ 20966. Arbuste, fi. jaunes. Octobre-novembre. R.

431. C. lamprosperma Nart. in Fl. Bras. XV, II, P. 146, - Diamantina, au Morro dos Cristaes, Mixas, $n^{\circ} 19073$ Ariuste, fl, jaunes. Mars-arril. C.

4:02. C. ciliolata Benth. : Fl. Bras. XV, II, p. 146. - Paranana, dans le campo, Goraz, $n^{0 s}$ 20953, 20954, 20958; Serra do Cipo, Misas, $\mathrm{n}^{0}$ 19064. Plante naine, fi. jaunes. C.

4.93. G. adenopoda Harms, n. sp. in herb. Berol., Kew., Paris., Genev., etc. - l'iehoa, dans le campo, près de l'Espigòa, Govaz, no 20955. Frutescent, 11. jaunes. Octobre-novembre. R.

40ั\%. G. brachyblepharis Harms, n. sp. in herb. Berol. et Kew. ined. - Entre Hector et Lagedo, dans le campo, 'Goyaz, ${ }^{\circ}{ }^{0}$ 20949. Petit arluste, fl, jaunes. Janvier-février. C.

4.95. C. brachystachis Harms, 11. sp. in herb. Berol. - Campos do Rio Gama, Goraz, nº 20994. Petit arbuste, fl. jaune. Mai-juillet. C.

40\%6. C. pseudociliolata Glaz., n. sp.? in herb. Paris. Berol., Kew., Gener, etc. - Chapadào lo Veadeiros, dans le campo, Goraz, $n^{0} 20985$. Frutescent, 11. jaunes. Janvier. C.

4:57. C. filicifolia Mart. in F\%. Bras. XV, II. p. 148. - Vargem du Rio Paranána, dans le campo, Goraz, $n^{\circ}$ 20948. Petit arbuste, fl. jaunes. C.

498. G. microphylla Glaz., n. sp.? in lierb. Paris., Berol., Kew., Brux. - Guariroba, au Morro Cubatão, dans le campo, Gordz, nº 20960. Frutescent, fl. jaunes. Octubre. R.

4599. C.Pohliana Benth.: Fl. liras. XV, II, p. 149. - Ponte Alta, près des sources du liio Salgado, Goraz, $n^{\circ}$ 20959. Petit arluste, f1. jaunes. Septembre-octobre. C. 
A.-F.-川. GLAZIOU. L LISTE DES PLANTES DU BRÉSIL CEYTRAI. I65

460. C. polymorpha Glaz., n. sp. in herb. Paris., Berol., Kew., Brux., etc. - Cachaeira da Vargem Grande, dans le campo, Gordz, $n^{\circ} 20961$. Frutescent, sans fleurs en janvier.

461. C. laxiracemosa Harms, n. sp. in herb. Berol. et Kew. ined. - Parananá, dans le campo, Goraz, n²0986. Petit arbuste, fl. jaunes. Avril-mai. C.

462. C. dalbergiafolia Benth. in Fl. Bras. XY, II, p. 149. - Pres de Santa Luzia, Goraz, $n^{\circ}$ 20947. Arbuste, fl. james. Mars-arril. C.

463. C. debilis Vogel; Fl. Bras. XV, 1I, p. 149.- Pinheiro, près Diamantina, dans le campo, Mrsas, $n^{\circ}$ 19068. Frutescent, fl. jaunes. C.

464. G. hirsutissima Glaz., n. sp. in herb. Paris., Berol., Kew., Genev., etc. - Serra do Ificionado, près Caraça, dans le campo, Mrsas, $n^{0}$ 14639. Arbuste superbe, fleurs jaunes. Arril-mai.

46ว. C. ursina Mart. in Fl. Bras. XV, II. p. 1.̈l. - Biribiry, près de Diamantina, dans le campo, Mrsas Gerıes, n 19076. Arbuste, fl. jaunes. Mars-arril. C.

466. G. leucopilis Glaz., n. sp.? in herb. Paris., Berol., Kew., Genev. - Serra da Baliza, à Cachoeira da Vargem Grande, Goraz, $n^{0}$ 20998. Arbuste, fl. jaunes. Mars-avril. R.

467. C. paniculata Benth.; Fl. Bras. XV, II, p. 1ั33. - Sommet de la Serra dos Pyreneus, Goraz, n² 20965. Arbuste, f1. jaunes. Aoùt-septembre. C.

468. C. trachycarpa Vogel; Fl. Bras. XV, II, p. 1\%4. - Ayuruoca, dans le campo, Mrss, no 9412 a. Arbuste, f1. jaunes. Mai-juiı. C.

469. C. trachycarpoides Harms, n. sp.? in herb. Berol., Kew., ined. - Entre Rio Bananal et Rio Torto, dans le campo, Gorsz, nº 20956. Petit arbuste, fl. jaunes. Novembre. C.

470. C. cathartica Mart.; Fl. Bras. XV, II, p. Іӓ. - Entre Sitio et Barbacena, Morro de São Vicenti, etc. Mıss, nos 9412, 14630, 15937, 15938, 19065 ; entre Santa Maria et Pongo, Chico Lobo, Goraz, ${ }^{\text {os }} 20948$, 20952. Petit arbuste, fl. jaunes. Janvier-mars. CG.

471. C. diphylla L.; Fl. Bras. XV, II, p. 156. - Restinga de Gabo Frio, Rio-JAx., no 10659. Frutescent, 11. jaunes. C.

472. C. latistipula Benth.; Fl. Bras. XV, Il, p. 136. - Rio dos Couros et Mestre d'Armas, Goriz, n ${ }^{\text {os }}$ 20992, 20993. Frutescent, f1. jaunes. C.

473. C. uniflora Spreng.; Fl. Bras. XV, II, 1. 1:̈7. - Taipú, liestinga de Tijuca, etc. Rı-JAx,, ${ }^{\text {os }}$ 607, 1378, 6181, 10658; Biribiry, 
Pinlıeiro, Diamantiıa, ete., Mıxas, ${ }^{\text {os }}$ 1908, 19089, 19090, 19091, 19092, 19093; Serra dos Veadeiros, Goraz, $1^{\circ}$ 20991. Frutescent, fl. jaunes. CG.

474. Cassia Desyauxii Collarl,; Fl. Bras. XV, II, p. 157. - Restinga de .lana et de Tijuca, Rı-JAN., ${ }^{\circ{ }^{\circ s}} 8454,9756,14631$. Frutescent, f1. jaunes. CC.

47.. C. Langsdorffi Kunth; Fl. Bras. XV, II, p. 158. - Chapalão dos Veadeiros, dans les sables, Goraz, n 20990. Frutescent, 11. jaunes. Janvier-mars. CC.

476. C. tecta Vogel; FI. Brus. XV, II, p. 159. - Diamantina, au Curahulıo, Mrvas, $n^{\circ}$ 19095. Frutescent, fl. jaunes. Avril-mai. R.

477. C. malacophylla Vog.; Fl. Bras. XV, II, p. 159. - Piracicaba, S̃̃o Pallo, $n^{\circ} 15941$; Perpetua, près de Diamantina, Mı̀as, nº 19096. Frutescent, 1l. jaunes, Mars-avril. C.

478. C. curvifolia Vog.; Fl. Bras. XV, II, p. 160. - S. Sebastião, près đ'Itabapıana, Rı-JAx., $n^{\circ}$ 9763. Frutescent, ll. jaunes. Janvier-février. $\mathrm{R}$.

479. C. basifolia Vog.; Fl. Bras. XV, II, p. 161. - Entre Ciganos et As Brancos, Goraz, no 20987. Frutescent, fl. jaunes. Décembre-janvier. C.

480. C. rotundifolia Pers.; Fl. Brus. XV. II, p. 161. - Morro da Babylonia 't S. Christovão, hio-Jax., $n^{05}$ 4992, 5846; Santa Barbara, Mlinas, no 14637; Rio Descoberto, Goraz, n $n^{\circ}$ 20989. Rampant, 11. jaunes. Octolrr'sléermbre. CC.

481. C. Tagera L.; Fl. Bras. XV, II, p. 162. - Formosa la Imperatriz, Goraz, nº 20988. Rampant, ll. jaunes. Décembre-janvier.

482. C. repens L. : Fl. Bias. XV, II, p. 162. - Formaçĩo, près de Diamantina, Mrsas, no 19088 a. Rampant, fl. jaunes. Mars-avril. CC.

483. C. trichopoda Benth. in Fl. Bras. XV. II, p. 163. - Curalinho, près Diamantina, dans le campo, Mwas, n 19088 " bis. Frutescent rempant, fl. jaunes. Mars-avril. R.

48\%. C. supplex Mart. in Fl. Bras. XV, II, p. 163. - Campos de Caraça, Mısas, $n^{\circ}$ 12614. Frutescent, f1. jaunes. Janvier-février. C.

48̈̈. C. choriophylla Vog.; Fl. Bras. XV, II, p. 163. - Biribiry, près le Diamantina, Mrsas, $\mathrm{n}^{0}$ 19103. Frutescent, fl. jaumes. Marsavril. R.

486. G. bifoliola Glaz., n. sp.? in herb. Paris., Berol., Kew., 
A.-F.-.I. GLIZIOU, - LISTE DES PLANTES DU BIÉSIL, CENTRIL.

Genev, etc. - Ponte Alta, dans le campo, Goyaz, $n^{\circ} 21006 a$. Herhacé rampant, tl. jaunes. Octobre-novembre. R.

487. C. gygophylloides Taub., u. sp.? in herb. Berol. -- Entre Ilheos et Sitio, Mixas, $\mathrm{n}^{\circ}$ 12619. Arbuste fl. jaunes. Novembre-décembre. C.

488. C. atroglandulosa Taub., n. sp.? in herb. Berol. - Campos da Bocaina, São Paclo, nº 8414. Arbuste, fl. jaunes. Janvier. R.

489. C. bulbotricha Taub., n. sp. in herb. Berol. - Serra de Lenheiro, près de S. João d'El Rei, Mısas, nº 20270. Arbuste fl. jaunes. Juinjuillet. C.

490. G. chrysoclada Taub., n. sp. in herb. Berol. - Serra dos Orgãos, à Theresopolis, Rio-Jan., $\mathrm{n}^{0} 8416$. Arbuste, fl. jaunes. Décembrejanvier. C.

491. G. organensis Glaz., n. sp.? in herb. Paris., Berol., Kew., Brux., etc. - Serra do Orgàos, au Imbahy, Rio-Jax. $11^{\text {os }} 3721,3942$. Arbuste, fl. jaunes. Novembre-lécembre. C.

492. C. thyrsiflora Glaz., n. sp.? in herb. Paris., Berol., Kew., Brux., etc. - Santa Barbara, dans le campo, Mıxss, n 14632. Arbuste, fl. jaunes. Juin-juillet. C.

493. C. Glaziovii Taub., n. sp.? in herb. Berol. - Diamantina à Perpetua, Misas, $n^{\text {os }}$ 19076, 19067. Arbuste, f1. jaunes. Avril-mai. C.

494. C. vernicifolia Taub., n. sp.? in herb. Berol. - Biribiry, prés de Diamantina, Mıxıs, $n^{\circ s} 19070,19071$. Arluste, fl. jaunes. Marsavril. C.

498. C. subnitida Taub., n. sp. in herb. Berol. - Riacho das Veras, Misas Geraes, nº 19069. Arbuste, fl. jaunes. Mars-avril. R.

496. C. adenophylla Tauh., n. sp.? in herb Berol. - Pineiro, près de Diamantina, Mrsas, $\mathrm{n}^{\circ}$ 19066. Arluuste, fl. jaunes. Mars-arril. C.

497. C. chætoblepharis Harms, 11. sp.? in herb. Rerol., Kew., Paris., Genev., etc. - Chapalào de Porto Seguro, Goyaz, no 21004. Petit arbuste, 11. jaunes. Décembre-janvier. C.

498. C. elachistophylla Harms, n. sp.? in herb. Berol. - Pichoa, dans le campo, Goyaz, $n^{0}$ 20984. Arbuste, fl. jaunes. Septembre-octibre. h.

499. C. cæsia Taub., n. sp.? in herb. Berol. - Rio this Pedras, au Valú, Mıxas, $n^{\circ}$ 19070. Arbuste, f1. jaunes. Mai-juin. R.

500. C. macrocarpa Glaz., n. sp.? in herb. Paris., Berol., Kew., 
Brux, etr. - Birilir! entre les rochers, Mras, $1^{\circ}$ 19080, Grand arbuste, firuit ferrugineux. Mars. li.

:01. Cassia trichothyrsus Harms, 11. sp. in herb. Berol. - Haut te la Serra Dourada, Goviz, $n^{0}$ 20971. Arbuste, fl. jaunes. Août-septembie. CG.

502. C. trachyclada Harms, n. sp.? in herb. Berol. - Entre Santa Maria et Panca, Goraz, $n^{\circ}$ 29067. Arbuste. 11. jaunes. Aoùt-septembre. C.

503. C. goyazensis Taub. in Beitr. Fl. Centralbl., p. 435. - Cabeceiras do Rio Ganta, Govaz, $n^{0 s}$ 20946, 20959. Arbuste, 11. jaunes. Avrilmai. C.C.

504. C. Taubertiana Harms, n. sp. in herb. Berol. - Haut lle la Serra Dourada, dans le campo, Goxiz, $n^{\circ}$ 20957. Arlouste, 11. jaunes. Acrût-septembre. C.

50ว. C. Gilliesii Glaz., n. sp.? in herb. Paris., Berol, Kew., Genev., elc. - Santa Barbara, dans le campo, Mrsas, nº 14638. Arbuste, f1. jaunes. Juin-juillet.

506 . C. malachotricha Harms, n. sp. in herb. Berol. - Cabereiras do Rio Gama, Gorsz, $11^{\circ}$ 20942. Arbuste des bois, 11. jaunes. Mai-juillet. C.

507. C. tragacanthoides Mart. in Fl. Bras. XV, II, 1. 166. - Biribiry, pres de Diamantina, Mıxs, $n^{\circ}$ 19094. Petit arbuste des campos, t1. jaunes. Mars-avril. C.

5008. C. rotundata Vogel; Fl. Bras. XV, II, p. 167. - Biribiry, au Morro dlo Jlocuto, $\mathrm{n}^{\text {os }}$ 19085, 19087; Serra de Lenheiro, près de S. J. d’El Rei, Mlsas, $n^{\circ 0}$ 20268, 20269. Arluuste, f1. jaunes. Mars-mai. CC.

509. C. distichoclada Mart. in Fl. Bras. XV, II, p. 168. - Biribiry, entre les rochers, Mrxs, $n^{\circ}$ 19084. Petit arbuste, fl. jaunes. Marsavril. C.

310. C. potentilla Mart. in Fl. Bras. XV, II, p. 168. - Diamantina, à Formação, Vrxas, $n^{0 s}$ 20267, 19083. Petit arbuste, fl. jaunes. Arrilmai. C.

:11. C. flewuosa L.: Fl. Bras. XV, II, p. 169. - Restinga de Copacalıana, près tle la mer, Rı-Jix., $n^{0 s} 1377,3792$. Frutescent, fl. jaunes. Juin-juillet. CC.

:12. C. olesiphylla Vogel; Fl. Bras. XV, II, p. I69. - Diamantins, au Tombartor, Mixas, $n^{0 s} 8412$, 19082. Petit arbuste, fl. jaunes. Mars-avril. R.

313. C. parvistipula Benth.; Fl. Bras. XV, II, p. 170. - Barra du 
A.-F.-M. GLAZ1OU. - LISTE DES PLANTES DU BRÉSHL EENTRAL. 169

Rio Torto, dans le campo, Goyaz, $1^{\circ}$ 20980. Frutescent, tl. jaunes. Janvier-février. C.

o14. C. mucronata Spreng.; Fl. Lras. XV, II, p. 191. - Serra da Piedarle et Biribiry, Mrxas, $n^{\circ 5} 19072,19086,2087$. Frutescent, 11. jaunes. Janvier-mars. C.

515. C. chancecrista L.; Fl. Bias. XV, II, p. 172. - Morro da Babrlonia, près de Botafogo et Tijuca, Rı-JAx., $n^{0 s} 4993$, 10661. Sousfrutescent, fl. jaunes. Octobre-novembre. CG.

516. C. stenocarpa Vug.; Fl. Bras. XV, II, p. 173. - Entre Gavea et Lagoa de Tijuca, Rio-JAx., $n^{\circ 5} 6502,12621$. Sous-frutescent, f1. jaunes. Juin-juillet. C.

:17. C. patellaria DC.; Fl. Lras. XV, II, p. 174. - Corcovado, à Paineiras, Rio-Jar., nos 603, 12620. Sous-frutescent, fl. jaunes. Aouttseptemlire. CC.

:18. C. mimosoides L.; Fl. Brus. XV, II, p. 175. - Paratımirim, dans les pàturages, Rı-JAx., $n^{0}$ 10662. Herlacé, 1l. jaunes. Janvier-février. C.

\%19. Apuleia procox Mart.; Fl. Bras. XV, II, p. 177. - Corcovado, à Cova da Onça, Rio-Jà., nos 1568, 2543, 9409. Grand arbre, 11. blanches. Mars-arril. CC. Vulgo: Grapiapunhe.

:20. A. molaris Spruce in Fl. Bras. XY, II, p. 177. - Serra do Picu, Sĩo Pacto, nº 10663. Grand arbre, ft. hlanehes. Avril-mai. C.

521. Dialium divaricatum Vahl; Fl. Bras. XV, II, p. 178. - Sãu Sebastiāo da Barra, Rı-Jax., n 9769. Grand arbre, 11. blanchâtres. Janvier-férrier. C.

:202. Bauhinia smilacifolia Burch. in Fl. Bras. XV, II, p. 183. Serra da Estrella, Rio-Jax., nos 2554, 11912. Arbuste sarmenteux, fi. blanches. Mars-avril. C.

323. B. dubia Don: Fl. Bras. XV, II, p. 184. - São Sebastião da Barra, Rio-Jax., nº 10669. Arluste. fl. blanches. Janvier-février. R.

5224. B. holophylla Steuu.; Fl. Bras. XV, II, p. 18\%. - Serra dus Cristaes, près de Diamantina, Mrxas, $n^{\circ} 19061$ a. Arluuste, 11. blanches. Mars-avril. C.

:.9. B. longicuspis Spruce in Fl. Rras. XV, II, p. 185. - Sio Fillelis, dans le bois, Rı-Jax., $n^{0}$ 9758. Arbuste, f1. blanches. Janvier-février. li.

326. B. rufa Steud.; Fl. Bras. XY, II, p. 186. - Serra das Ver- 
tentes au Chaparlinha, Goxz, $n^{\circ 5} 21014,21015$; Diamantina, Mıxas, $1^{\circ}$ 19061. Arbuste, fl. blanc rosé. CG.

Var. cordata in Fl. Brels. XV, Il, p. 187. - Chapadinha, dans le cimpo, Goraz, no 21013. Arluste, fl. blanches. Octobre-novembre. C.

527. Bauhinia fusconervis Steud.; Fl. Bras. XV, II, 1. 188. Praia Grande, dans le bois, Rı-JAN., $n^{0} 2979$; Inficionalo, dans la forèt, Mhsss, $\mathrm{n}^{\circ}$ 13736. Arbrisseau, fl. hlanches. Février-mars. C.

528. B. Bongardi Steud.; Fl. Bras. XV, II, p. 189. - Fazenda do Palmital, dans la Capocira, Goyaz, $\mathrm{n}^{0} 21016$ «. Arbrisseau, fl. blanches. Septembre-octobre. R.

529. B. pulchella Benth. in Fl. Bras. XV, II, p. 190. - Barluacena, dans le campo, Hısas, $n^{\circ}$ 9746; Serra dos Cristaes, Goyaz, $n^{\circ} 21009 a$. Arbuste, 11. blanches, Décembre-janvier. R. Vulgo : Unha de boi.

:330. B. obtusata Vow.; Fl. Bres. XV, II, p. 190. - Petropolis, à Itamaraty, dans la forêt. Rio-J $\mathrm{JN}_{\mathrm{AN}}, \mathrm{n}^{0}$ 14622. Arbuste, fl. blanches. Septembre-octobre. C.

531. B. cuiabensis Steul.; Fl. Bras. XV, II, p. 191. - São Pallo, $n^{0 s}$ 10667, 10668 ; Carraça, au Campo de Fora, Mrsas, n 12623. Arbuste, f1. blanches. Juin-juillet. C.

592. B. longifolia Steud.; Fl. Bras. XV, II, p. 192. - Entre Queimados et le Rio d'Ouro, Rin-Jan., no 10692; Taquarucú, Mlsas Cieraes, $n^{0}$ 19062; Paranania, Gosaz, no 21017. Arbuste, 11. lilanches. Férriermiti, CC.

333. B. grandifolia Steud.: Fl. Bras. XV, II, p. 193. - Quinta de São Christovão, Rio-Jav., no 13752 . Arbuste cultivé, fl. blanches. Févriermars. R.

:34. B. curvula Benth. in Fl. Bras. XV, II, p. 194. - Lagoa Formosa, Goyaz, $n^{\circ}$ 21009. Arluste des rampos, fl. hlanches. Janvier-lëvilier. R.

53\%. B. pentandra Walp.; Fl. Bras. XV, II, p. 19:3. - Quiçanom, près de Lagoa Feia, Rio-Jax., nº 10665. Arbuste des bois, fl. blanches. Juillet-septembre. C.

ร36. B. platypetala Burch. in Fl. Bras. XV, II, p. 198. — São Fidelis, près de Cimpos, Rı-JAx., $1^{0}$ 9748. Arbuste des hois, f1. blanches. Janvier-mars. R.

337. B. forficata Link.; Fl. Bras. XV, II, p. 200. - Corcwado, Floresta da Tijuca, Sete Pontes, Ro-Jas., $n^{0 s} 617,6870,8411$. Arbuste, 11. blanches. Janvier-avril. CG. Vulgo: Unhu de vacca. 
3̈38. B. affunis Vogel; Fl. Brus., XY, II, p. 201. - São Clıristovão, dans la Capveira, Rio-Jan, $n^{\circ 5} 2980,12624$. Arbuste, fl, blanches. Novembre-décemlire. C.

339. B. Raddiana Bong.; Fl. Brus. XV, 11, p. 203. - Laranzeirus, à Cosme Velho, Corcovado, Tijuca, Riso-Jan., $\mathrm{n}^{0 \mathrm{~s}}$ 1144, 3720, 6513; Serra da Alewria, près de Caraça, Mrvas, $n^{\circ}$ 14623. Arbuste, 11. blanc rosé. Janvier-avril. CC.

5\%0. B. Langsdorffiana Bong.; Fl. Bras. XV, Il, p. 204. - Coreovalu, Tijuca, Rio Tapixeiro, Atalaia, etc., Ro-JAx., $1^{\circ 5}$ 2553, 3719, 4791, 6841, 10690, 10691; Santit Barlara, Misas, nos 13737, 14624. Grande et nrosse liane, 11. rousses. Mars-avril. CC. Vulgo : Cipo Escada.

๖41. B. flexuosa Moric.: Fl. Brts. XV, 11, p. 20马. - Entre Inficionado et Caraça, Mrsas Geraes, $n^{\text {os }} 12622,13739,13740$. Liane mince, il. blanches. Janvier-mai. C.

542. B. angulosa Vog.; Fl. Bras. XV. II, p. 207. - Serra do Commercio, en bas du Tingua, Rro-JAx., n 8665 . Grande liane, 1l. blanches. Juin-juillet. R.

543. B. rubiginosa Bong.; Fl. Bras. XV, II, 1. 207. - Quiçaman. près de Lagoa Feia, Rio-das., $n^{05}$ 10689, 13753; près de Meia Ponte, Goraz, $n^{\circ}$ 21019. Grande liane, fl. blanchâtres. Juillet-aoùt. C.

344 . B. splendens Humb., Bonpl. et Kunth.: Fl. Bras. XV, Il, p. 208. - Jacarépagua et Corcuvalo, Rı-JAx., ${ }^{0 s}$ 2978, 6184, 6842. Grande liane. C. Vulgo : Unha de boi.

Y4. B. lamprophylla Harms, n. sp.? inerl. in herl. Berol. - Serra dos Cristaes, Goraz, $1^{\circ}$ 21008. Petit arlsuste des campos, 11. blanthes. Août-septemlire. R.

ร46. B. depauperata Glaz., 11. sp.? in herb. Paris., Berol., Kew., Genev., etc. - Cabeceiras do hio Sant'Anna, dans le campo, Goyaz, no 21011. Frutescent, 11. blanches. Janvier. C.

马47. B. cumanensis Humb., Bonpl., Kunth.; Fl. Bras. XV, II, p. 212. - Angras dos Reis, près Jerumirim, Rio-Jax., n 10670. Arluuste sarmenteux, 11. rousses. Janvier-iévrier. R.

548. B. goyazensis Harms, n. sp.? ined. in herb. Berol. - Fazenda de Paranaúa, Goraz, $11^{\circ}$ 21012. Arbuste des campos. fl. blanches. Avrilmai. C.

รั49. B. Glaziovii Taub., n. sp.? ined. in herb. Berol. - Entre Caraça et Inficionado, dans le bois, Mhxis, $n^{\text {os }} 12625,13738$. Arbuste sarmenteux, ll. blanches. C. 
3̋0. Bauhinia viscidula Ilarms, n. sp.? ined. in herl. Berol. Entre Cocal et Encruzilhado, dans le campo, Goyaz, n ${ }^{05} 21010,21012 a$. Irbuste, li. blanches. Novembre-décembre. C.

¿̈31. B. malacotricta Harms, n. sp.? ined. in herl. Berul. - Chapadão dos Veadeirus, dans le campo, Goxaz, $n^{\circ} 21016$. Arluste, f1. blanches. Janvier-tévrier. R.

- 5.8.2. B. angularis Harms, n. sp.? ined. in herb. Berol. - Fazenda do Palmital, Goyaz, $n^{\circ}$ 21018. Grand arbuste, fl. blanches. Juin-juillet. C.

3ั33. Heterostemon mimosoides Desf.; Fl. Bras, XV, II, p. 316. Quinta de Sĩo Christovão, Rı-Jax., no 13757 . Arbre cultivé, fl. blanches. Février-mars. R.

3.. 4. Macrolobium multijugum Benth. in Fl. Brus. XIII, III, p. 222. - Lagoa de Freitos, à Tres Vendas, Rio-Jax., no 13759. Arbrisseau rultivé, fl, blanches. Février-ar ril. R.

5\%3. M. acaciafolium Benth. in Fl. Bras. XV, II, p. 224. - Quinta de Sĩo Christovão, Rio-Jax., $\mathbf{l}^{0}$ 14755. Grand arbre cultivé, f1. blanches. Mars-avril. R.

5̆6. Tamarindus indica L.; F\%, Bras. XV, II, p. 227. - Passeio Pullico. Rio-Jax., $n^{\circ}$ 2533. Grand arbre cultivé, fl. lılanc pâle. Janviermars. C. Vulgo: Tanarindeiro.

397. Tachigalia paniculata Aubl.; Fl. Bias. XV, II, p. 2028Lagoa de Freitos, au Jard. Bot., Riro-Jas., n 13751. Grand arbre cultivé, fl. jaunâtres. Juillet-septembre. R.

598. T. multijuga Benth. in Fl. Bras. XY, II, p. 2099. - Serra dos Orgãos, à Barreira, Rı-JAx., nos 2556, 11909. Très grand arbre, fl. jaunâtres. Février-mars. CC.

539. Peltogyne venosa lienth.; Fl. Bras. XV, II, p. 233 (Ols.). Matosinho, près de S. Juño d'El Rei, Mlsas, $n^{\circ}$ 16672. Grand arbre, l'. verdatres. Septembre-ortobre. R. Vulgo : Páo koxo.

560. P. discolor Vog.: Fl. Biras. XV, II, p. 233. - Santa Thereza, au Corcovarlo, Rio-Jan., nos $3943,7584,18204$. Grand arbre, fl. verdâtres. Nuvembre-décembre. CG. Vulgo : Guarabu, Pró roxo, Julahyrana.

:61. Hymenæa stilbocarpa Hayne; Fl. Bras. XV, II, p. 23\%. Floresta da Tijuria, Rı-Jax., n ${ }^{0 s}$ 5849, 9768, 10674, 10697, 11903. Grand arbre, fl. verdattres. Février-mars. C. Vulgo : Jatahy.

562. H. splendida Vogel; FI. Brus. XV, II, 1) 236. - Serra do 
Puris, Espintro Saxto, n 10674. Grand arbre, tl. blanchâtres. Norembredécembre. C. Vulgo : Jatobii.

๑63. H. stigonocarpa Mart.; Fl. Bras. XV, II, p. 236. - Entre Baependy et Cachambú, Misas, n⿳ 10673, Serra de Ouro liranco, Mixas, no 17600. Arbrisseau, th. blanchàtres. Norembre-tlécembre. Vulgo : Jatobri.

Var. pubescexs in Fl. Bras. XV, II, p. 237. - Serra de Ouro Branco, Mısas, no 17600. Arbrisseau, fl. blanchâtres. Décembre-janvier. C. Vulgo: Jatobí.

36'. H. Martiana Hayne; Fl. Biras. XV, II, 1. 2937. - Entre Jaragua et Bernardo Lobo, Goraz, $1^{0}$ 21022. Arbre superbe. Vulgo : Jatobí.

วั6อ̆. Crudya amazonica Spruce in Fl. Bras. XV, II, p. 238. Lagoa de Freitos, au Jard. Bot., Rı-JAx.. n 13763. Grand arbre cultivé, fl. blanchàtres. Février-mars. R.

¡66. Copaifera Langsdorffii Desf.: Fl. Bras. XV, II, p. 242.Floresta da Tijuca, Petropolis. Serra dos Orgãos, etc., Rio-Jas.. n ${ }^{0 s}$ 2541, 2985, 9411, 9754, 10675, 10677: Ilheus, près de Sitio, Mnas, $n^{\text {os }}$ 15924, 17603: Formosa et Layedo, Goraz, nºs 21027, 21028. Girand arbre, fl. rerdatres. Décembre-janvier, CC. Vulgo : Oleo de Copaiba.

Var. glabra in Fl. Bias. XV, II. p. 24ㄹ. - Queluz, dans le campo, Mrsis, $n^{0}$ 13729. Arbrisseau, fruit jaunatre. Mars-avril. C. Vulgo : Oleo de Copaiba.

:67. C. trapezifolia Hayne; Fl. Brus. XV, II, p. 243. - Alto Macahé de Nova Friluurgo, Rio-Jax. et Serra de Ilendanha, nos 2542 , 2984, 13727, 19055. Grand arbre, fl. verdatres. Février-mars. C. Vulwo: Ulen de Copuiba.

568. C. rigida Benth.: Fl. Bras. XV, II, p, 242. - Cachoeira do Campo et Carandahy, Mixss, $n^{\circ-10074, ~ 10676, ~ 14614 . ~ A r b r i s s e a u, ~ f 1 . ~}$ brunes. Janvier-février. C.

:69. C. elliptica Mart.; Fl. Bras. XV, II, p. 243. - Entre le hio Tocantins et Os Porcos, Goyaz, $n^{\circ}$ 21029. Petit arbuste, f1. brunes. Janvier-février. C.

370. C. Martii Hayne; Fl. Bres. XV, II, p. 244. - Quinta de São Christovio, Rio-Jax., $n^{\circ}$ 13728. Arbrisseau cultivé, fl. brunes. Janvierfévier. R.

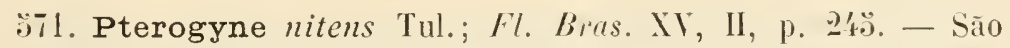
Christorão, Rio. Jax., $11^{\text {os }} 4792,8639,10678$; Jendanha. Mıss, nos 12627 , 21026. Grand arbre, fl. blanc jaunâtres. Janvier-février. CC. Vulgo : Arveira brabo, Cama de Vacca. 
วั72. Cynometra bauhinia folia Benth.: Fl. Bras. XV, II, p. 2246. - Quinta da Boa Vista, São Christovĩo, Ro-Jav., $1^{\circ}$ 3426. Arbrisseau rultivé, fl. blanches. Août. R.

373. G. Glaziovii Taub., n. sp.? ined. in lert. Berol. - Bord du Rio Novo, Mixas Geraes, $n^{03} 13725$, 14617. Arbrisseau des bois, fl. blanches. Déremlre-janvier. CC.

374. C. Spruceana Benth.; Fl. Bras. XV, II, p. 247. - Quinta de São Christovĩo, Rio-Jax., $n^{\circ}$ 13756. Grand arbre cultivé, fl. blanches. Juillet-août. R.

57.ั. Gonorrhachis marginata Taub., n. sp.? ined. in herb. Berol. - Serra da Babylonia, Misas Geraes, $n^{\circ}$ 13726. Arbre des forèts, fl. blanc jaunàtre. Janvier-avril. C.

576. Dimorphandra exaltata Schott; Fl. Bras. XV, II, p. 2:0. Tijuca, Gavea, Itha de Governador, Rio-JAs., 110s 610 , 2983, 3938, 7878. Grand arbre, fl. blanc jaunâtre. Novembre-décembre. CC.

577. D. mollis Benth.; Fl. Bras. XV, II, p. 292. - Capão, près de Sabara et Barbacena, Misus, $n^{0 s}$ 10679, 19111; Sobradinho, Goviz, $n^{\circ}$ 21032. Arlırisseau des cerrados, f1. jaunes. Novembre-décembre. Vulgo : Farinha, Fabeira.

578. D. Gardneriana Tul.: Fl. Bras. XV, II, p. 202. - Entre Cal\% Frio et Mataruna, dans le bois vierge, Ro-Jax., n ${ }^{\circ}$ 10681. Grand arbre, Il. blane jaunâtres. Juillet-août. C.

\section{Légummeuses (MIMOSÉES).}

579. Pentaclethra filamentosa Benth.; Fl. Bras. XV, II, p. 262. - Quinta de São Christovão, Rı-JAx., ${ }^{\circ \mathrm{S}}$ 9780, 13764. Grand arbre rultivé, fl. blanches. Juin-juillet. R. Vulgo : Paracauxi.

880. Parkia platycephala Benth.; Fl. Bres. XV, II, p. 26't. Quinta de São Christovão, Rı-Jax., nº 9770. Grand arbre cultivé, f1. rougeâtres. R. Vulgo : Faveira de beloque.

581. P. pendula Bentlı.; Fl. Bras. XV,II, p. 26.3. - Quinta de São Christovãu, Rı-Jın., $1^{\circ}$ 10603. (irand arbre cultivé, fl. blanches. Juinjuillet. Vulgo: Vesgueiro.

582. P. multijuga Benth.; Fl. Bras. XV, II, p. 26\%. - Quinta de Sĩo Christovio, Rio-Jax., no 2972. Grand arbre cultivé, fl. blanches. Janvier-février. R.

583. P. discolor Spruce in Fl. Bras. XY, II, 1) 267. - Quinta da 
A.-F.-Y. GLAZIOL, - LISTE DES ILANTES DE RRESHL CENTRAL.

175

Bod Vista, à São Christovão, Riı-JAx., $1^{\circ}$ 9776. Grand arbre cultivé, f1. blanc rosé. Février-mars. R.

כ8't. Entada polystachya D. C.; Fl. Bras. XV, II, p. 268. - Lagoa de Freitas, au Jard. Bot., Rio-JAx., nº 8660, 9759. Grande liane cultivée, fl. blanchàtres. Avril. R.

5ั8.. PJathymenia reticulata Benth.; Fl. Bras. XV, II, p. 270. Congonha do Campo, dans le bois, Mrxas, $n^{\circ}$ 12638. Fiand arbre, 11. jaunes. Janvier-février. C.

¿36. P. foliosa Benth.; Fl. Bras. XV, II, p. 27I. - Larangeiras, a Cosme Velho, Rio-Jax., nos 10610, 10621, 11939, 11940; Santa Luzia do Rio das Velhas, Misas, $n^{\circ}$ 20293. Grand arbre, fil. jaunes. Décembre. C. Vulgo : Vinhatico testa de boi.

ड87. Piptadenia latifolia Penth.; Fl. Bras. XV, II. p. 273. - Entre Gavea et Tijuca, Riı-JAx., n ${ }^{\circ}$ 3722. Arbuste sarmenteux, ll. jaunes. Avril-mai. C.

ö8s. P. laxa Benth.: Fl. Bras. XV, II, p. 274. - Carandahy, dans le bois, Mixas, $n^{\circ}$ 12646. Arbuste sarmenteux. fl. james. Juillet-août. C.

389. P. paniculata Benth. ; Fl. Bras. XV, II, p. 27̈.) - Larangeiros et Corcovalo, Rio-JAN., ${ }^{\text {os }}$ 5828, 8444, 11928. Grand arbre, fl. blanchâtres. Janvier-férrier. CC.

Var. inermis Schumm. herb. Berol. ined. - São José do Barreiro, Riı-Jax., $11^{\circ}$ 8443. Arbre, fl. blanchâtres. Février-mars. R.

390. P. nitida Benth.; Fl. Bras. XV, II, p. 276. - Colrovado et Gavea, Rio-Jix., $n^{\circ}$ 8452, 10597. Grand arbre, fl. jaunes, odorantes. Janvier-février. C.C.

591. P. contorta Benth.; Fl. Bras. XV, II, p. 276. - Corcovado. à Paineiras, Rio-J.ı.., $\mathrm{n}^{05}$ 114, 1567, 9404, 9405. Grand arbre, fl. jaunes. Septembre-octobre. CC.

992. P. foliosa Penth.; Fl. Bras. XV, II, p. 276. - Icarahy, à Praia Grande, Rı-Jax., nº 8421. Arbrisseau, fl. blanches. R.

393. P. macradenia Benth.: I7. Bras. XV, II, p. „2T. -- São José do Barreiro, Rio-Jax., $n^{\circ}$ 8442. Arbuste sarmenteux, fl. roses. Férriermars. C.

594. P. biuncifera Benth.; Fl. Bras. XV, II, p. 27T. - Morro do Cóco ou do Balıu, Rio-Jax., nº 10617. Arbrisseau, fl. blanc jaunàtre. Novembre-décembre. R.

¡93. P. rigida Benth. : Fl. Bras. XV, II, p. 278. - Serra da Estrella 
et de Gerecino, Rio-Jas., $1^{\circ *} 8440,11924$. Grand arbre, fl. blanchitres. Aoùt-septembre. C. Vulgo: Cabuim Angico.

396. Piptadenia trisperma Iienth.; Fl. Bras. XI, II, p. 278. liestinga de Copacabana, Rio-JAs., $\mathrm{n}^{\circ \mathrm{s}}$ 3931, 10593. Arbuste sarmenteux, fl. rouge pourpre. Février-mars. CC.

597. P. polyptera Benth. in Fl. Bire. XV, II, p. 279. - Sapopunba et Sĩo Christovão, Rio-Jax., $n^{05}$ 5829, 10594. Arluste sarmenteux, 11. rouge pourpre. Février-mar's. CC. Vulgo : Espinha roxa.

598. P. communis lienth.; Fl. Bras. XV, II, p. 279. - Corcovado, Petropolis, Lemos, ho-Jus, $n^{05} 630,5834,8448$, 10591. Arbrisseau, fl. jaune pàle. Février-avril. CG.

899. P. Blancheti Benth. in Fl. Biras. XV, II, p. 280, var. Glaziovii Taub. in herb. Berol. ined. - São Gonçalo do Rio Preto, Mras Ger.tes, $\mathrm{n}^{0}$ 12647. Arbrisseau, fl. jannâtres. Mars-avril. C.

600. P. Schwackei Glaz., n. sp, in herb. Paris., Berol., Kew., Brux., ete. - São João da Barra, près Campos, Rı-JAx., nº 9753. Arbrisseau, 11. blanches. Février-mars C.

601. P. incequalis Benth.; Fl. Bras. XV, II, p. 280. - Corcovado, à Caixa d'Igua, Rı-Jax., no 19110. Arbrisseau, fl. blanc jaunàtre. Novembre-décembre. C.

602. P. Schumannii Taub., n. sp. in. herb. Berol., Kew., Paris., Genev., etc. - Petropolis, à Itamaraty, Lio-J $\mathrm{J}_{\mathrm{A} .}$., $\mathrm{II}^{\circ}$ 13774. Grand arbre, fl. Wlanc jaunâtre. Novembre-décembre. C.

602. P. leptostachya Benth.; Fl. Bres. XV, II, p. 281. - Floresta de Tijuca, Corcovado, Petrupolis, Rio-Jav., $n^{05} 625$, 8441, 8443. Grand arbre, fl. jaune pàle. Janvier-février. CC. Vulgo : Cabuim vinlatico.

604. P. moniliformis Benth.; Fl. Rras. XV, 11, p. 281. - Serra de Cayanaa, près Natividade, Rio-Jax., $1^{0}$ 10612, 10613. Arbrisseau, fl. jaunàtres. Mlai-juin. R. Vulgo : Sáo carasco.

603. P. macrocarpa Benth.; Fl. Lras. XV, II, p. 28I. - São Cris-

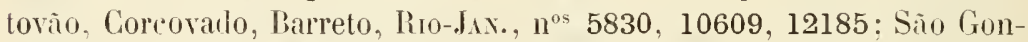
çalo do Rio Preto, Mıxıs, nos 12653 , 13684. Grand arbre, li. jaunes. Novembre-janvier. CG. Vulgo : Cabuim cascudo Angico.

606. P. colubrina Benth.; Fl. Bras. XV. II, p. 282. - Corcovado, Copacabana, Andarahy Grande, Jho-Jax., $1^{05}$ 79, 633, 5831, 10592, 10596. Grand arbre, fl. jaunes. Janvier-mars. CC. Vulgo : Cabuim.

607. P. perigrina Bentl.; Fl. Bras. XV, It. p. 28‥ - Sete Pontes, an Barreto, cultivé, Riı-JAN., $n^{\circ}$ 13429: Guariroha, Goraz, $n^{0}$ 21034, spont. Grand arbre, fl. jaunes. Septembre-novembre. C. 
I.-F.-I. GLAZ10U. - LISTE DES PLA.TES DU BRÉSIL CENTRAL.

608. P. falcata Benth.: Fl. Bras. XV, It, p. 283. - Norro Queimado, près de Tljuca, Rio-Jax., no 19110 a. Grand arbre, fl. jaunàtres. Févriel-mars. R.

609. P. Senæii Glaz., n. sp.? in herb. Paris., Berol., Kew., Brux. Caraca. au Curalinho dans le campo, Miss, nº 14650. Arbrisseau, fi. jaunàtres. Mars-arril. C.

610. P. Puiggrii Glaz., n. sp.? in herb. Paris,, Berol., Kew., Brux. - Itatiaia, dans le bois, Rio-Jax., no $5828 a$. Arbrisseau, fl. jaunâtres. Novembre-décembre. R.

611. P. flava Benth. in Trans. Limn. Soc. XXX (1873), p. 371.São Fidelis, près Campos, Iiı-J.s., nº 9773, 10679. Arbrisseau, fl. blanc jaunâtre. Février-mars. C.

612. Stryphnodendron Barbatimao Mart.; Fl. Bras. IV, II, p. 284. - Barbacena, Campos do Caraça, Mıxas. nos 10586, 14649: entre Guarirolıa et le Rio Torto, Goraz, $n^{\circ} 21030$. Arbrisseau. fl. violacées. Octobredécembre. CC. Vulgo : Barbatimao.

613. S. pumilum n. sp. in herb. Berol., ined. - Campos do Rio Gama, Goraz, n² 21031. Plante naine, fl. violacées. Norembre-décembre. C. Vulgo Barbatimao mindo.

614. S. polyphyllum Mart.; Fl. Bras. XV, II, p. 28:3. - Nora Friburgo, dans la forèt, Rı-Jax., n ${ }^{0}$ 12635; Morro de São Vicente, Mrxas Geraes, n $14649 a$. Grand arbre, fl. rouge pourpre. Janvier-février. C.

615. S. rotundifolium Mart.; Fl. Bras. XV, II, p. 28.. - São Goncalo do Rio Preto, Mısas, no 10611. Arbrisseau, fl. rougeâtres. Juinjuillet. C. Vulgo : Uavatimo.

616. Adenanthera Pavonina L.; Fl. Bras. XV, II, p. 288. - Quinta de São Cinristovão, Rı-JAN., nº 8420. Arbrisseau cultivé, ll. blanchâtres. Novembre-décembre. C.

617. Neptunia oleracea Lour.; Fl. Bras. XV, II, p. 290. - Entre Caraça et Inficionado, dans les bourbiers, Mixas, no 13775 a. Herbacé, fl. roses. Septembre-octobre. C.

618. N. plena Benth.; Fl. Irras. XV, II, p. 291. - Entre Carandahy et Queluz, dans les bourbiers, Minas, $n^{\circ}$ 12637, 13775. Herbacé, 11. roses. Juin-octobre. CC.

619. Desmanthus virgatus Willd.: Fl. Bras. XV, II, p. 293. Praia Granıle, au Morro do Cavallão, Rı-JAx., nº 5838, 10615, 19132. Sous-frutescent, fl. rouges. Aoùt-septembre. CC.

620. Mimosa Velloziana Mart.; Fl. Bras. XV, II, p. 304. - Pedre- 
gulho, à Sìo Christoviou, Rio-dax., $11^{\circ} 5841$. Frutescent, f1, roses. Avriljuin. CC. Vulgo: Maliciu.

621. Mimosa Sensitiva L. : Fl. Bras. XV, II, p. 30\%. - Petropolis, à Santos Antonio, lio-Jax., ${ }^{\circ 5}$ 5840, 7593: Ouro Preto, Mixas, no 13779. Frutescent, fl. roses. Mars-mai. C. Vulgo : Malicir.

6를. M. rixosa Nart.; Fl. Bras. XV, II, p. 30:. - Entre le Rio Torto et le Rio Bananal, dans le campo, Goraz, no 21069, 21070. Frutescent, f1. ruses Avril-mai. C. Vulgo : Malicia.

623. M. ursina Nart.; Fl. Brrs. XV, II, p. 310. - Araruama, près de Calo Frio, Rio-Jax., nº 9772. Frutescent, fl. rose pâle. Janvierfêvrier. î.

62'. M. trichocephala Penth. in Fl. Bras. XV, II, p. 319. - Campos da Bocaina, près de l'eau, SÄo Paulo, nº 8433 ". Frutescent, fl. roses. Janvier-mar's. R.

62.). M. ramosissima Benth. in Fl. Bras. XV, II, p. 312. - Campos da Bocaina, $\mathrm{SA}_{\mathrm{A}}$ Palco, $\mathrm{n}^{\circ}$ 10640. Arbuste, 11. jaunes. Septembreoctobre. C.

626. M. insidiosa Benth.; Fl. Bras. XV, II, p. 313. - Serra de São José d'El Rei, Mrxas, no 15927. Sous-frutescent, fl. roses. Norembredécembre. C.

627. M. dolens Vell.; Fl. Bras. XV, Il, p. 314. - Serra do Picú, dans le Campo, Cachoeira du Rio Parahỵba, Sĩo P.uvo, nºs 8432, 10590; Serra dos Cristaes, Goraz, nos 21077, 21079. Sous-frutescent, fi. roses. Janvier-avril. CC.

628. M. trachycephala Benth. in Fl. Brus. XV, H, p. $314 .-$ Campos da Bocaina, à la Cascatinha, SAo Pacıo, no 8433. Sous-frutesrent, fl. ruses. Janvier-mars. C.

629. M. polycarpa Kunth: Fl. Bras. XV, II, p. 315. - Nova Frilıurgo, près de l'eau, Rio-Jax., no 15928: Cachoeira d'Itiquira, Goraz, $n^{\circ}$ 21068. Arbuste, fl. roses. Février-mai. C.

630. M. Glaziovii Benth. in Fl. Bras. XY, II, p. 316. - Sommet de la Serra dos Orgãos, Rio-Jax., nos 3723,6191 . Arbuste, fl. jaunes. Aoùt-septembre. R.

631. M. pudica L.; Fl. Bras. XV, II, p. 316. - Pedregulho, à Sào Christovão, Rur-Jax., $n^{\circ}$ 626, 5844. Annuel, fl. roses. Février-avril. CC. Vulgo : Malicia.

632. M. procurrens Benth.; Fl. Bras. XV, II, p. 322. - Ponte Alta, dans le campo, Goraz, no 21042. Sous-frutescent, fl. roses. Septembreoctobre. C. 


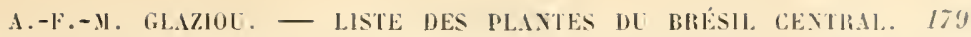

633. M. distans Benth.; Fl. Bras. XV, II, p. 32̈. - I'onte Alta, dans le campo, Goraz, $\mathrm{n}^{\circ} 21079 a$. Sous-frutescent, f1. roses. Octobrenovemlire. C.

634. M. multiplex Benth. : Fl. Bras. XV, II, p. 327. - Fazenda do Rio Preto, Rio-Jax., n ${ }^{0}$ 8653. Sous-frutescent. fl. rose palle. Octobrenovemble. C.

639. M. rigida Benth.; Fl. Bras. XV, II, p. 330. - Norro de Sĩo Vicente, Fazenda do Taquaral, IIsas, $n^{\text {os }} 7590,14651$; serra dos Pireneus. Goraz, n² 21074. Sous-frutescent, 11. roses. Juin-septemlre. GC.

636. M. conferta Benth. in Fl. Brus. XV, II, p. 331. - Fazenda da Boa Vista au Rio dos Couros, Goraz, n² 21057. Sous-frutescent, fl. roses. Janvier-mars. C.

637. M. acerba Benth.; Fl. Biras. XV, II, p. 392. - Gandarela, dans le campo, Mrxas, no $14652 a$. Sous-frutescent, f1. rose pâle. Juinjuillet. C.

638. M. eriophylla Benth.; Fl. Bras. XV, II, p. 332. - Pres du Burarão, dans le campo, Croraz, no 21080. Sous-firutescent, fl. roses. Septembre-octobre. CC.

639. M. pogocephala Benth.: Fl. Bras. IV, II. 11. 333. - Entre Gandarela et Palmital, Insas, $n^{0}$ 14652. Arbuste, fl. l'ose pâle. Juinjuillet. C.

640. M. microcarpa Benth. in Fl. Bras. X V, II, p. 333. - Itatiaia, Ayuruoca, campos do Caraca, Ifrss, $n^{\circ} 8652$, 14657, 15926. Aphuste des petits bois, fl. roses. Novembre-décembre. C.C.

641. M. Radula Benth.; Fl. Bras. XV, II, p. 33\%̈. - Entre Cabeceiras d» Rio Gama et Saia Velha, Goraz, n² 21078. Arbuste des campos, t1. roses. Mars-arril. C.

642. M. imbricata Benth.: Fl. Bras. XV, II, p. 336. - Fartura, près de Formosa, Goraz, n² 21081. Suus-frutescent, f1. bleues. Férriermars. CC.

643. M. lanata Benth.; Fl. Brus. XV, II, P. 338. - Campos da Boraina, sĩo Pallo, n 10641. Sous-frutescent, 11. jaunes. Septembreactobre. C.

64'. M. goyazensis Benth.: Fl. Bras. XV, II, p. 340. - Entre Rin Gama et le Rio Paranaúa, Goraz, no 21064. Sous-frutescent, 11. roses. Février-mars. C.

(44). M. Tremula Benth.: Fl. Birts. XV, II, 1. 340. - Serra da Bucrina, dans le campo, Sĩo PAtu, n 10641 a. Sous-fruteserent, fl. jaunes. Septembre-octolire. R. 
646. Mimosa setistipula Bentlı.; F\%. Bras. XV, II, 1. 340. - Fripuhy, pros d'Ourn Preto, Minas, $n^{0} 19126,20264$. Sous-frutescent, 11. rose pâle. Décombre-janvier. C.

697. M. neuroloma Benth. in Fl. Bras. XV, II, p. 341. - Entre Os Poreus et le Rio Tocantins, Govaz, n 21065. Frutescent, 11. roses. Janvier-fóvrier. C.

6.48. M. brevipes Benth.; Fl. Birts. XV, II, p. 341. - Tripuhy, près d'Ouro Preto, Dlinas, $11^{\circ} 20263$. Frutescent, 11. roses. Décembre-janvier. CG.

649. M. Regnellii Benth.; Fl. lirus. XV, II, p. 342. - Itatiaia, dans le rampo, Mixas, 8632 a. Arbuste, f1. rose paile. Novembre-tlécembre. C.

630. M. myriophylla Bong.; Fl. Bras. XV, II, p. 342. - Ayuruoca, dans le campo, Jısas, $11^{\circ}$ 15925. Arbuste, fl. jaune pâle. Janvier-février. CC.

681. M. millefoliata Scheele; Fl. Liras. XV, II, p. 344. - Petropolis, à Santo Intonio, Rı-JAx., no 8656, 8436. Frutescent, fl. roses. Arril-mai. C.

652. M. myriadena Benth. in Fl. Bras. XV, II, p. 344. - São João de Barra, près de Campos, hio-Jav., $n^{\circ}$ 9775. Frutescent, fl. roses. Janrier-février. C.

6.33. M. punctulata Spruce; Fl. Bras. XV, II. p. 345. - Collegio, près de Campos, Rio-Jav., $n^{\circ}$ 9771. Arbuste sarmenteux, fl. blanches. Janvier-février. C.

6̈̈4. M. rupestris Bentlı.; Fl. Bras. XV, II, p. 346. - Serra de Ouro Rranco, Mixas, $11^{\text {os }} 14653,17605$. Frutescent, fl, roses. Novembredécembre. CC:

63ั.. M. ciliata Spring.; Fl. Bres. XV, Il, p. 347. - Nto Macahé, au sommet de la Serra, Ro-JAx., $n^{\circ s} 19133,19134$. Arbuste rabougri, 11. jaunes. Lout-septembre. R.

6.66. M. involucrata Benth.: Fl. Bras. XV, II, p. 348. - Haut de la Serra do Ariro, Rio-JAx., $n^{\circ} 8431$ a. Bel arbuste, f1. jaunes. Janvierfévrier. li.

657. M. incana Benth.; Fl. Bras. XV, II, p. 348. - Campos da Bocaina, SÃo Pallo, no 8431; entre Sitio et Barbacena, Misas, nos 1058, 18203. Granl arbuste, f1. jaunes. Janvier-mars. CC.

6อั8. M. calothamnos Mart.; F\%. Bras. XY, II, p. 330. - Haut du Norro Cavado, Mısss, no $7592 a$. Grand arbuste, f1. james. Septembreoctobre. R. 
A.-F,-M. GLAZIOU. - LISTE DLS PLANTES DU BRESHL CENTRAL. ISI

6\%9. M. aurivilla Mart.; Fl. Bres. XV, II, p. 3̈̈l. - Caraça, dans le campo, $n^{\circ}$ 14656: Biribiry, Msss, $n^{\text {os }} 19129$, 19130. Arlouste, Il. jamnes. Janvier-mars. CC.

660. M. calodendron Mart.; Fl. Bras. XV, II. p. 3:9. - Fazenda do Taquaral, au Morro Cavado, Mrsas, nos 7591, 7592. Bel arbuste, 11. jaunes. Septembre-octobre. C..

661. M. furfuracea Benth.: Fl. Bras. XV, II, 1. 3\%3. - Entre Sitio et Barbacena, Mrss, nº 8430; Campos Bocaina, S̃̃o Palıo, $n^{\circ}$ 19125. Bel arbuste, ll. jaunes. Janvier-mars. CC.

662. M. cylindracea Benth.; Fl. Bras. XV, Il, p. 3̈̈4. - Biribiry, près de Diamantina, Mlnas, no $19129 a$. Arbuste, tl. jaunes. Mars-arril. R.

663. M. verrucosa Benth. : Fl. Bras. XV, II, p. 33̈. - Fazenda do Rio Preto, Mhnas, $n^{0}$ 8651; Quinta de S. Christovâo, cult.. n 13430. Arbrisseau, fi. jaunes. Novembre-décembre. C.

664. M. pteridifolia Benth. ; Fl. Brus. XV, II, p. 30̈\%. - Congonhas do Campo, Biriliry, Misas, ${ }^{0 s}$ 12643, 19119: Serra dos Cristaes, Govaz, $n^{o s} 21039,21040$. Arbuste, fl. roses. Septembre-octolre. CC.

663. M. Warmingii Benth. in Fl. Bras. XV, II, 1).3:6. - Congonhas do Campo dans le bois, Nixs, $n^{\circ}$ 13783. Grand arbre, 11. jaunes. Janvier-février. C.

666. M. seriacantha Benth.; Fl. Bias. XV, II, p. 3.57. - Serra do Picú, à Barreira, Mrsas, $n^{\circ}$ 10589. Arbuste sarmenteux, 11. jaunes. Avril-mai. R.

667. M. pithecolobioides Benth. in Fl. Bras. XV. II. 1. 337. S. Goncalo do Rio Preto et à Taboquinha, Mivas, $n^{\circ 5} 13786,19118$. Allouste, fl. jaunes. Février-mars. C.

668. M. acutistipula Benth.; Fl. Bras. XV. 11, 1. 308. - Cimpos da Bocaina, Sĩo Pılıo, $\mathrm{n}^{\text {os }}$ 10623, 10628, 10629. Albuste, t1. jaunes. Aoùt-septembre. R.

669. M. malacocentra Benth.; Fl. liras. XV, II, p. 360. - Praia Giande, au Barreto, Rio-Jax., nos 8655, 10630; Inticionado, Misas, no 13780. Arbrisseau, fl. blanches. Février-mars. CG. Vulgo : Espinho de cerca.

670. M. casalpiniafolia Benth. ; Fl. Bras. XV, II, 1. 360. - Jorro de Coco ou do Bahú, Rio-Jax., n" 10622. Alhuste sarmenteux, fl. blanches. Décembre-janvier. C.

671. M. extensa Benth.; Fl. Brus. XV, II, p. 361. - Ilto Macahe de Nova Friburgo, Rio-JAx., nos 10582, 11923, 18200. Arbuste sarmenteux, 11. blanches. Novembre-décenbre. CC. 
672. Mimosa Spruceana Benth. in Fl. Bras. XV, II, p. 362. - Q Quinta de Sãn Christorio, hio-Jax., $n^{0}$ 13765. Arbuste sarmenteux, ultivé, fll. blanehes. Févlier-mars. R.

673. M. obovata Benth.: Fl. Bras. XY, II, p. 363. - Pris le Corrego Secor, Ilsas, $11^{\text {os }}$ 10625, 19121. Arluste sarmenteux, fl. hlanches. Mars-avril. C.

67'. M. sepiaria Benth.; Fl. Bras. XV, II, p. 364. - Petropolis, a Quitandinha, $11^{\circ}$ 93, São Christovĩo et Tijuca, Liı-JAx., $n^{0 s} 5832$, 624, 10588. Arbrisseau, fl. Hlanches. CG. Vulgo : Espinho roxo.

67.). M. capillipes Renth. in Fl. Bras. XV, II, p. 371. - Serra da Baliza, Goraz, $1^{\circ}$ 21063. Pl. rampante, fl. roses. Janvier-février. C.

676. M. gracilis Benth.; Fl. Bras. XY, II, p. 372. - Corrego du Brejo, Goriz, n² 21058. Sous-frutescent, fl. roses. Novembre-décembre. C.

677. M. pancifolia Bentlı.; Fl. Bras. XV, II, p. 373. - Corrego do Brejo, entre Bananal et le Rio Torto. Goyaz, $1^{0^{8}}$ 21059, $21060,21061$. Sous-fiutesient, fl. roses. Novembre-décembre. CG.

678. M. phyllodinea Benth.; Fl. Bras. XV, II, p. 378. - Serra dos Cristaes, daus le campo, Goraz, n" 21055. Sous-frutescent, 11. roses. Septembre-oetolore. R.

679. M. somnians Humb. et Bumpl, : Fl. Bras. XV, II, 1. 373. Sommet du Borro das Velancias, Goyaz, $n^{\prime \prime} 10626,21053$. Frutescent, 11. roses. Norembre-décembre. R.

680. M. leptocanlis Benth. : Fl. Bras. XV, II, p. 375. - Os Porcos, près de Serra da Baliza, Goyaz, no 21062. Sous-frutescent, fl. roses. Janvier-février. C.

681. M. invisa Mart.; fil. Bras. XV, II, p. 379. - S. Christovão, Rio-Jax., no 5842 ; Santa Barbalia, Misas, nos 12641, 13776, 13778. Sousfrutescent, fl. roses. Février-mars. CC. Vulgo : Malicia.

682. M. adenocarpa Benth.; Fl. Bras. XY, II, p. 380. - Pedregulho, à S. Chrristorão, Rio-JAv., no 5839. Sous-frutescent, 11. roses. Mai-juin, CG. Vulgo : Valicia.

683. M. paludosa Benth. : Fl. Bras. XV, II, p. 381. - Comgonhas da Serra, Mixas, $n^{0 s} 10616,19123,19124$; entre Vargem et Rajadinha, dans les bourbiers. Goraz, $n^{0:}$ 21047, 21052. Arluste, 11. roses. Avril-mars. C.

68't. M. melanocarpa Benth. in Fl. Brus. XV, Il, p. 381. - Ponte Alta, à Cabeceira do liio Gama, Goysz, nos 21097, 21098, 21048; Sertăo, Mıxıs, $n^{\circ}$ 19125. Arbuste, ll. roses. Octobre-novembre. C.

683. M. asperata L.; Fl. Bras. XV, II, p. 381. - Barra do Pirahy, 
au hord du Rio Parahiba, Rı-Jax., nos 622, 5843. Arbuste, 11. roses. Janvier-février. CC.

686. M. cinerea Vell. : Fl. Bras. XV, II, p. 383. - Serra de Jacarepagua, Pı-JAx., n² 3932. Arhuste, f1. rose pàle. Janvier-mars. R.

687. M. adenotricha Benth.; Fl. Liras. IV, II, p. 38\%. - Serra dos Cristaes, près de Diamantina, Mras, $n^{\circ}$ 19128: entre As Brancas et Hector, Goyaz, $n^{0}$ 21102. Arbuste, fl. roses. Arril-mai. C.

688. M. vernicosa Bong. ; Fl. Brus. XV, II, p. 386. - Biribiry, près de Diamantina, Nixas, $11^{\circ}$ 29127; entre Paraizo et le Rio Tocantins, Goraz, no 21103. Arbustes, fl. roses. Janvier-mars. C.

689. M. setosa Bentlı. : Fl. Bras. XV. II, p. 386. - Abbade, prés de Meia Ponte, dans le campo, Goraz, n 21028. Petit arbuste, fl. roses. Aout-septembre. C.

690. M. Gartneri Benth.; Fl. Bras. XV, Il, p. 38T. - Entre Rajadinha et Paranaúa, dans le campo, Goraz, n² 21099. Petit arbuste. 11. roses. Janvier-févier. C.

691. M. mullipinna Bentlı. in Fl. Bras. XV, II, p. 338. - Pichoa. prés de Espigão, dans le campo, Goyaz, $n^{03}$ 21066, 21067, 21108. Petit arbuste. fl. roses. Septembre-octobre. C.

692. M. Lœseneriana Glaz., n. sp.? in Jerb. Paris., Berol.. Kew., Gener., etc. - Serra Dourada et Serra do Arruda, Goraz. nos 21050 , $2105 a$. Frutescent, 11. roses. Aoùt-septembre. C.

693. M. Clausseni Benth.: Fl. Bras. XV, II, p. 389. - Entre Rio 'Tol'tı et Rio Bananal, Goyaz, nos 21090, 21091, 21106. Arbuste, tl. l'oses. Mars-avil. C.

694. M. densa Benth.; Fl. Bras. XV, 11, p. 389. - Entre Ciganos et Is Brancas dans le cerralo, Goraz, $n^{\circ}$ 21107. Arbuste, f1. roses. Décembre. C.

69.. M. Dammeriana Glaz., n. sp. in herb. Paris., Berol., Kew., Brux., etc. - Matto Grosso, près Fazenda do Cipó. Mıx.s, nº 19136. Arbuste, fl. roses. Mar's-avilil. C.

696. M. pseudo-obovata Taul., n. s]. in herb. Berol., Kew., Paris., Genev., etc. - Guaximdeba, Rio-Jax., no 11934. Arbuste sarmenteux, 11. jaunes. Septembre-octubre. C.

697. M. brachystachya Taub., n. sp. in. herb. Berol. ined. S. Gonçalo do Rio Preto, Mrsas, n 12642. Arbuste sarmenteux, fl. roses. Mars-arril. C.

698. $M$. dryandroides Taub., 1. sp. in herb. Berol. ined. - Nova 
Friburgo, il Pedro do Conego, Rio-Jax., no 11922. Arbuste, fl. roses. Juinjuillet. R.

699. Mimosa adenophylla Taub., n. sp. in herl. Berol. ined. - S. Goncalo do Rio Preto, Mriss, $11^{\circ}$ 12645. Arbuste, fl. roses. Mars-ivril. C.

700. M. Crulsiana Glaz., ı. sp.? in herb. Paris., Berol., Kew., Brux., ete. - Rio Torto, au Pedro-Jorge, diuns les bourbiers, Goraz, $n^{\circ}$ 21046. Arbuste, fl. roses. Mai-juin. C.

701. M. Schwackeana Taub., л. sp. in herb. Berol., ined. Rudrigo Silva, au Calpão, Mrsas, $n^{0} 19120$. Petit arbuste, ll. roses. Avrilmai. C.

702. M. microphylla Glaz., n. sp.? in herb. Paris., Berol., Kew., Brux., ete. - Horro do Abbade, près Meia Ponte, Govaz, no 21056. Petit arbuste, fl. roses. Juillet-anût. CC.

703. $M$. arachnoides Taub., n. sp. in berb. Berol., ined. - Biribiry, près de Diamantina, Misas, $n^{0}$ 19131. Petit arbuste, fl. rouges. Marsavril. R.

704. M. lanuginosa Glaz.. 11. sp. in herb. Paris, lierol., Kew., Brux., etc. - Corrego do Brejo, dans le campo, Goyaz, ${ }^{\circ} 21082$. Frutescent, fl. bleues. Février-mars.

705. M. formosissima Taub. in Beitr. Flora Centralbr, p. 431. Entre Liborio et Ciganos, Goraz, $n^{\circ}$ 21092. Grand arbuste, fl. roses Novembre-décembre. C.

706. $M$. decorticans Harms, n. sp. in herb. Berol., Kew., Paris., Brux., etc. - Chapadão dos Veadeiros, Goyaz, $n^{0}$ 21089. Arbrisseau superbe, sans fleur en janvier. C.

707. M. tomentosa Taub, in Beitr. Flora Centralbr. p. 434. Cachoeira da Vargem Grande, Goya, n² 21087. Bel arhrisseau, 11. roses. Janvier-février. C.

708. M. albolanata Taub. in Beitr. Flora Centralbr. p. 433. Pichoa, près de Espigão, Goyaz, $1^{\circ} 21100$. Petit arbuste des campos, fl. roses. Septembre-octobre. C.

709. M. setosissima Taub. in Beitr. Flora Centralbr. p. 434. Albade, près de Nleia Ponte, Goyaz, $\mathrm{n}^{0} 21105$. Grand arbuste, fl. roses. Septembre-octobre. CG.

¡10. M. pyrenea Taub. in Beitr. Fl. Centralbr. p. 430. - Corumba, dans le campo, Goyaz, $n^{0}$ 21051. Arbuste, fi. roses. Septembre-octobre. C.

711. M. Urbaniana Glaz., n. sp. in herb. Paris., Berol., Kew., 
Genev, etc. - Cabeceiras do Rio Sant'Anna, dans le campo, Govaz, $n^{\circ}$ 21076. Frutescent, 11. roses. Janvier. R.

712. M. polydema Harms, n. sp. in herb. Berol., Kew., Paris., Brux., ete. - Ponte Alta, dans le campo, Goraz, n² 21095. Arbuste, fl. roses. Octolbre-novembre. $\mathrm{C}$.

713. M. pyrrhopila Harms, n. sp. in herb. Perol., Kew., Paris, Gener., etc. - Près du Rio dos Couros, dans le campo, Goraz, $n^{\circ}$ 21088. Arbuste splendide, haut de 2 à 3 mètres, tl. blane rosé. Juinjuillet. R.

714. M. dolichopoda Harms, n. sp. in her'). Berol., Kew., Paris., Brux., etc. -- Chiro Costa, dans le campo, Goyaz, $n^{\circ}$ 21093. Arbuste à tige simple, fi. roses. Octobre-novembre. C.

7l.. M. planaltoana Harms, n. sp. in herl. Rerol., Kew., Paris., Brux., etc. - Entre le Rio Tocantim et Fazenda do Paraizo, dans le rampo, Goraz, no 21045. Arbuste, fl. roses. Janvier-février. C.

7I6. M. reflexa Harms, n. sp. in herb. Berol., Kew., Paris., Gener., etr. - Guariroba, dans le campo, Goraz, n² 21044. Arbuste, f1. roses. Septembre-octobre. C.

717. M. brachycaulis Harms, n. sp. in herb. Berol., kew., Paris., Brux., etc. - Calpeceiras do Rio Gama, dans le campo, Goyaz, $n^{0} 21041$. Plante acaule, fl. roses. Vai-juin. C.

718. M. brevibractea Harms, n. sp. in herb. Berol., Kew., Paris., Brux, etc. - Entre Paranaúa et Retiro do Rio Torto, dans le cerrado, Guraz, n² 21096. Arbuste, fl. roses. Férrier-mars. C..

719. M. multispinoides Harms, n. sp. in herb. Berol., Kew., Paris., Genev., ete. - Lagoa Formoza, près de l'eau. Arbuste, fl. roses. Décembre-janvier. CC.

720. M. eriostachys Harms, n. sp.? in herb. Berol., Kew., Paris., Brux., etc. - Entre Jatolasinho et Lajedo, dans le campo, Goriz, $\mathbf{1}^{\circ}$ 21101. Frutescent, 11. roses. Janvier-février. CC.

721. M. affinis Harms, n. sp.? in herb. Berol., Kew., Paris.. Brux., ete. - Fazenda dos Porcos, dans le campo, Goraz, nº 21043. Arbuste, fl. roses. Décembre-janvier. C.

722. M. paryisensis Taub. Beitr. Fl. Centralbl. p. 430. - Près du Rio Tocantins, dans le campo, Goyaz, $n^{\circ} 21073$. Petit arbuste, fl. roses. Février-mars. C.

723. M. Harmsiana Glaz., n. sp.? in herl. Paris, Berol., Kew., Gener, etc. - Entre Chico Lobo et Cabeceiras do Rio Torto, dans le campo, Goraz, n² 21071. Frutescent, fl. roses. Novembre-décembre. C. 
7ำ. Mimosa pilifera Glaz., n. sp.? in herh. Paris., Berol., Kew., Brux., etc. - Sommet du Morro Canastra, dans le campo, Goyaz, ${ }^{0}$ 21072. Futescent, fl. rosées. Novembre-décembre. R.

7๖อ̆. M. Pseudo-radula Glaz., n. sp. ? in lierb. Paris., Berol., Kew., Brux., etc. - Entre Rajidinha et le Rio Jardim, dans le campo, Goyaz, $11^{0}$ 21075. Frutescent, fl, roses. Mai-juin. R.

726. Schrankia leptocarpa DC.; Fl. Bras. XV, II, p. 391. - Rio d'Ouro, Rio-J.x.. no 5839. Sous-frutescent, sarmenteux, 1l. roses. Févriermars 1872.

727. Leucæna glauca Benth. in Fl. Bras. XV, II, 1. 391. - São Christovão, Rito-Jı.., n 1498. Arbuste cultivé, 11. blanc jaunâtre. Varsjuillet. CG.

728. Acacia Farnesiana Willd.; Fl. Bras. XV, II, p. 394. - Quinta de São Christorão, Rro-dın., no $7588 a$. Arbuste cultivé, ll. jaunes. Juinjuillet. CC. Vulgo : Espongeira.

799. A. lacerans Benth.; Fl. Bras. XV, II, p. 396. - Sommet du Corcovado, Rio-Jix., n ${ }^{0 s} 628,5835$. Arbuste sarmenteux, fl. jaunes. Décembre-janvier. GG.

730. A. monacantha Willd.; Fl. liras. XV, II, p. 397. - Alegria, près de Caraça, Mrsas, ${ }^{\circ}$ 12644. Arbuste, fl. jaunes. Février-mars. C.

731. A. pteridifolia Bentlı.; Fl. Bras. XV, II, p. 398. - Praia Grande a Jurujuha, Corcovado, Rio-JAs., $n^{05}$ 632, 6840, 8439, 18201. Arbuste sarmenteux, fl. jaunes. Novembre-décembre. CC.

732. A grandistipula Benth.; Fl. lires. XV, II, p. 399. - Berco, São José dos Bareiros, Tijuea, Rı-Jas., $n^{0.5}$ 2123, 8438, 11936; Gamba, près d'Ouro Preto, Mivas, $11^{\circ:} 12649$, 13782. Arbuste sarmenteux, fl. blanc jaunâtre. Décembre-janvier. C.

733. A. Jurema Hart. Syst. Hat. Med. Fl. Bras., p. 53. - Paracatu, dans le cerrado, Mls.s, no 21033. Arbrisseau, fl. jaunes. Juin-juillet. C. Vulgo : Jurema.

734. A. Miersii Benth.; Fl. Bras. XV, 11, p. 400. - Cosme Velho, à Larangeiras, Rio-Jav., $\mathrm{n}^{\circ \mathrm{s}} 6189,6871$. Arbuste sarmenteux, fl. jaunes. Septembre-octobre. R.

733. A. pedicellata Benth.; Fl. Bras. XV. II, p. 401. - Fazenda da Limeira, au Tingua, Rio-Jıv., n 10583 . Arbuste sarmenteux, fl. jaunes odorantes. Aoùt-septembre. C. Vulgo : Aranhe de gutu.

736. A. recurva Benth.; Fl. Bras. XV, II, p. 402. - São José dos Barreiros, Rio-J.s., $n^{\circ}$ 8435. Arbuste sarmenteux, fl. jaunes. Janvierfévrier. C. 
A.-F.-M. GLAZIOU. - LISTE DES PLANTES DU BRÉSIl. CENTRAL.

737. A. adhoerens Benth.; Fl. Bres. XV, II, p. 402. - Petropolis, près de Quintandinha, Rı-Jax., no 10587: Ouro Preto, Mlsas, no ${ }^{\circ 3} 13781$, 19122. Arbuste sarmenteux, 11. jaunes. Févier-mars. C.

738. A. riparia Humb., Bonpl. et Kunth.; Fl. Brus. XV, II, p. 403. - São José dos Barreiros, Rio-Jıx., nº 8435 u. Arbuste sarmenteux, f1. jaunes. Janvier-février. C.

739. A. glomerosa Benth.: F\%. Bras. XV, II, p. 403. - Corcovado, Tijuca, Praia Grande, Rı-Jıx., nos 629. 5836. 10598; Santa Barbara, Itinas et Caraça, Mris, $n^{\text {os }}$ 10604, 10606, 10618. Grand arbre, fl. jaunes. Janvier-mars. GC. Vulgo : Camuré.

740. A. polyphylla DC.: F\%. Bras. XV, I, P. 404. - Petropolis, Rio-Jıx., nos 8658, 11926, 21049; Sĩo João da Chapada, Ilısas, nos 12651, 12652. Grand artre, t1. Llane jaunâtre. Dérembre-mars. CC.

741. A. paniculata Willd.: Fl. Bras. XV, II, p. 40\%. - Ypiranga, Pé do Rio, à Petropolis, Rio-Jıx, nos 10599, 10624, 12186. Arbuste sarmenteux, fl. jaunes. Norembre-(lécembre. CC.

742. A. longifolia Willd., Spec. Plant. IV, p. 10\%2. - Floresta de Tijuca, Rio-Jav., n $1^{0}$ 7588. Arbuste rultivé, fl. jaunes. Aoùt-septembre. C.

743. Colliandra Schwackeana Taub. in Legum. nov. vel nı. cogn., p. 2. - Quinta de São Christovĩo, Rı-Jax.. nº 13793. Arbuste cultivé, fl. blanc rosé. Janvier-février. R.

744. C. longipes Benth. in Fl. liras. XV, II, p. 410. - Serra do Inficionado, Mrsas, no 15929 a. PI. naine, fl. rouge pourpre. Janvierfévrier. C.

740. C. Harrisii Benth.; Fl. Bras. XY, II, p. 410. - Corcorado, à Lagoinha, Rio-Jas., nos 9403, 631; Caraça, Mrsas, no 15929. Arbuste, 11. rouges. C.

7'16. C. sessilis lienth.; Fl. Bras. XV, II, p. 414. - Araruama, près de Cabo Frio, Rio-Jix., no 10631. Arbuste, fl. rouge pourpre. Juinjuillet. C.

747. C. brevipes Benth.; Fl. Bras, XV, II, p. 4I6. - Juiz de Fora, Misas, nos 5787,19116 . Arbuste, fl. rouge pâle. Janvier-février. C. Vul(20): Handuruva.

748. C. surinamensis Benth.: Fl. Bras. XV, II, p. 417. - Quinta de Sãı Chritovão, Rio-Jıx., nº 9779. Arbuste cultivé, fl. rouges. Janvierfévrier. C.

749. C. virgata Benth.; Fl. Bras. XV, II, p. 417. - Entre Honjolo et Mestre d'Armas, Gornz, n² 21036 . Petit arbuste, f1. r'ouges. Novembredécembre. CG. 
7:0. Colliandra bracteosa Benth.; Fl. Bros. XV, II, p. 419. - Mar Dhespanlia au Cạado, Misas, $1^{\circ}$ 13787. Arbuste, it. rouge pourpre. Janvier'-mar's. C.

7ij1. C. mertensioides Benth.; Fl. Brets. XV, H, p. 419. - Caraça, près de la Cachoeira, Mnss, $n^{\circ}$ 14655. Arbuste, fl. roses. Juin-juillet. CG.

73.. C. fasciculata Benth.; Fl. Bras. XY, II, p. 420. - Diamantina, au Tombador, Mris, $n^{\circ}$ 19114. Arbuste, 11. louge pourpre. Nar'savril. C.

739. C. macrocephala Benth.; Fl. Bras. XV, II, p. 423. - Entre Fazenda de Lambary et Lagoa Formosa, Goraz, no. 21037, 21038; Fazenda do Cipo, Hixus, no 19115. Arbuste, fl. rouges. Janvier-février. CG.

7.34. C. foliosa Benth.; Fl. Bras. XV, II, p. 423. - Gavea, près de Pedra Bonita, Ro-Jax., no 3794 a. Arbuste des bois, 11. rose pâle. Septembre-octubre. P.

79.. C. Tyeediei Benth.; Fl. Bras. XV, II, p. 424. - Boa Vista, près du Rio Paralıylı, Rı-Jıx., nos 3794, 10608, 12633; Biribiry, au Moeoto, Mixas, no 19117. Arbuste, 1l. roses. Juin-juillet. C.

756. C. myriophylla Benth.: Fl. Bras. XV, II, p. 49.). - Caraça, près de la rivière, Mixis, $n^{\circ s} 10620$, 14648. Arbuste, 17. rose pâle. Juinjuillet. C.

7ö7. C. parviflora Benth.: Fl. Bras. XV, II, p. 427. - Près de Biriliry, dans le campo, Nixss, $n^{\circ} 19112$; Cachoeira d'Itiquira, Gorız, $n^{\circ}$ 21054. Arbuste, fl. brunes. Mars-mai. CC.

758. C. cinerea Taub. in Legum. nov. vel m. cogn., p. 3. - Serra de Caraesa, près de Alegria, Mixas, $n^{\circ}$ 12639. Arluste, fl, roses. Octubrenovembre. C.

7599. C. Glaziovii Taub., Legum. nov. vel m. cogn., 1. 4. - Serra do Campanema, llıxas, $n^{0}$ 12640. Arbuste du campo, f1. rouges. Mlaijuin. C.

760. C. Santosiana Glaz., n. sp.? in herb. Paris., Berol., Kew., Genev, etc. - Biribiry, près Diamantina, Mrxas, no 19113. Frutescent, 11. rouge pourpre. Février-mars. Vulgo : Gargarejo.

761. Albizzia Lebbeck Benth.; Fl. Bras. XV, II, p. 428. - Quinta de São Christovào, hıo-J Jn., no 620. Arbrisseau cultivé, fl. blanc jaunatre. Janvier-février. CC.

762. A. procera Benth. in Hook. Lond. Joum. But. IIl, p. 89. - 
1.-F.-1. GLAZ10U, - IISTE DES PLANTES DU BRÉSIL CENTRAL. 189

Quinta de Sãu Christovão, lio-JAx., nos 7877, 8422. Arbre cultivé, 11. blanches. Mars-avril. C.

763. Pithecolobium diversifolium Bentlı; Fl. Bras. IV, II, p. 432. - Serra da Leopoldina, Mıxs, $n^{\circ}$ 10635. Arbrisseau, fl. blanc jaunàtre. Novembre-décembre. C.

764. P. Avaremotemo Mart. : Fl. Bras. XV, II, p. '33..-Corcorado, aux Dons Irmãos, Rı-JAx.. n ${ }^{\text {ss }}$ 1566, 7589. Arbrisseau, fl. blanches. Septembre-actolse. CC.

7(6.). P. trapezifolium Benth.; Fl. Bras. XV, Il, p. 436. - Quinta de São Christorão, Rio-Jax., nos 9778,10632 . Arbrisseau cultivé, fl. lilas. Juin-juillet. R.

766. P. lusnrium Bentlı.: Fl. Bras. XV, II, p. 437. - Restinga de Tijuca et Palmeiras, Rio-Jax., nos 6188 , 1343. Arlurisspau, fl. blanches. Aoùt-septembre. CC.

767. P. Langsdorffi Benth. ; Fl. Rias. XV. II, p. 4.38. - Corcorado, Tijuca, Serra dos Orwāos, etc., Rio-JAn., nos 627, 2973, 2974, 6125 . 8654, 10634, 10662, 11927, 20992. Grand arbre, f1. blanches. Décembre-février. CC.

768. P. corymbosum Benth.: Fl. Bras. XY, II, 1). 440. - Lagoa de Freitus, au Jard. Bot., Rio-JAx., no 13766. Grand arbre, fl. blanchâtres. Févier-avril. R.

769. P. Saman Benth.; Fl. Bras. XV, Il, p. 441. - Quinta de São Christovino et Passeio Publico, Rio-Jax., nos 3515, 10601, 10633, 11925. Frand arbre, fl. jaunâtres. Novembre-décembre. C. Vulgo : Lordao de velho.

70. P. adiantifolium Benth.; Fl. Bras. XV, II, p. 444. - Lagnoa de Freitas, à Tres Yendos, Iiı-JAx., n 13793. Grand arbre rultivé, f1. blanches. Juin-juillet. Ii.

7T1. P. incuriale Benth.; Fl. Liras. XV, II, p. 445. - Yetropolis, à Santo Antonio. Rio-Jax., $n^{\circ} 5837$, 8447. Grand arbre, f1. blanc jannâtre. Janvier-mars. CC.

772. P. polycephalum Benth.: Fl. Bras. XV, II, p. 446. -- Coreovado, Serra da Estrella, Tijucit, Rı-JAx., nos $5833,8437,11933,12648$. Grand arlore, fl. jaunes. Janvier-férrier. C.C.

773. P. (Mimosa) terminale Vell.; Fl. Flum. vol. XI, tab. 30. Floresta?da Tijuca, Rio-JAs., nos 8451, 11929. Grand arbre, fl. jaunes. Mai-juin. CC.

774. P. divaricatum Benth.; Fl. Bras. XV, II, p. 448. - Quinta da 
lina Vista, Sàn Christovio, Rı-JAx., n 13767. Arbrisseau cultivé, 11. blanchàtres. Férrier-mars. Ri.

773. Pithecolobium cauliflorum Mart.; Fl. Bras. XV, II, p. Łö0.-Caraca, près des cours d'eau, Mıvas, 10 "s 12655 , 12792. Arbrisseau, fl. blanches. Juin-juillet. C.

776. P. tortum Hart.; Fl. Bras. XV, II, p. 433. - Cabo Frio, Imbitila, Campos, Rin-Jax.. n1 ${ }^{0 s} 11938,13636,18202$. Arbrisseau, fl. blanches, Aout-septembre. C. Vulgo: Jucaré.

777. P. dumosum Benth.; Fl. Bras. XV, II, p. 483. - Caraça et Serra da Alegria, dans le bois, Mixas Geraes, nos 10607, 1650, 13785. Arbrisseau, fl. jaunâtres. Aoùt-septembre. C. Vulgu : Sacalrapa.

778. P. parvifolium Benth.; Fl. Bras. XV, II, p. 4ö4. - Serra de Ouro Branco, Mixas Geraes, no 11937. Arlorisseau, fl. blanc jaunätre. Novembre-décembre. Vulgo : Jurema branca.

779. P. Glaziovii Bentlı. in Fl. Bras. XY, II, p. 45̆4. - Comovado, Tijuca. Sunta Cruz, Rı-Jax., n ${ }^{\text {os }} 1565,8630,8650,10595,11930,11931$, 11932 ; liio Novo, Nıxs, $n^{\text {os }} 14646,17609$. Grand arbre, fl. blanches. Septembre-octobre. CC. Vulgo: Vinhatico d'Espinhos.

780. P. Mathen'si Benth. in Hook. Lomd. Journ. Bot. III, p. 22029. Quinta da Boa Vista, Sào Christovão, Rı-JAx., nº 10607 u. Arbrisseau cultivé. fl. blanches. Juillet-aıǹt. R.

781. P. minarum Glaz., n. sp.? in herb. Paris., Berol., Kew., Brux., ete. - Sà Juse do Lagerlo, dans le campo, Hıxas, nos 13789, 13790. Grand arbre, fl. blanchâtres. Février-mars. C.

782. P. Schwackeii Gilaz., n. sp.? in herl. Paris., Berol., Kew., Brux., etc. - Itacolunıy, près Ouro Preto, Mixas, no 14654. Arlurisseau, fl. blanches. Février-mars. C.

783. P. Serronii Glaz, n. sp. in herb. Paris., Berol., Kew., Gener., etc. - Entre Gavea et Floresla da Tijuca, Rı-Jıs., $11^{\circ} 13772$. Très grand arbre, fl. blanchâtres. Janvier-l’évrier. C.

784. P. paraense Gliz., n. sp. in herb. Paris., Berol., Kew., Genev, etc. - Quninto de São Christovau, Ruo-Jan., nº 10680. Arbrisseau rultivé, fl. blanchâtres. Février-mars. R.

78\%. P. depauperatum Glaz., 11. sp. in herb. Paris., Berol., Kew., fenev, etc. - Cachoeira do Pao d'Arlho, Espirito Saxto, no 9777. Arbuste sarmenteux, fl. blanches. Avril-mai. Ri.

786. Enterolobium cllipticum Benth.; Fl. Bras. XV, II, p. 456. - Aldea de Ouro Branco, Hixis Genaes, $1^{\text {os }}$ 12654, 14647, 15934, 
A.-F.-M. GLAZIOU. - LISTE DES PLANTES DU BRÉSIL CENTRAL. 191

17608 a; Barro antarello, Govaz, $n^{0} 21035$. Arbrisseau. 11. blanc jaunâtre. Septembre-octobre. CC.

787. E. Timbouva Mart.; Fl. Bras. XV, II, p. 4气6. - Serra do Tincua, Floresta da Tijuca, Parahıba do Sul, Rio-Jux., nos 9406, 9407,

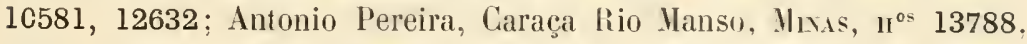
13791, 14645, 17607, 17608. Grand arbre, fl. jaune pàle. Novembre-décembre. CG. Vulgo: Timbo uva Tamboril, Vinhatico caballeiro.

788. E. Schomburgkii Benth. var. glazıovi in Fl. Bras. XV, II, p. 4อ̆8. - Corcovado, Tijuca, Larangeiros, Rio-lan., nos 626, 1143, 1494, 11935. Grand arbre, fl. jaunes. Octobre-novembre. CC. Vulgo : Cabu vinhatico.

789. Inga flagelliformis Malt.; Fl. Bras. XV, II, p. 466. - Cimminho do Macaco, Tijuca et Corcovado, Rro-Jax., n ${ }^{0 s}$ 4793, 6517, 10579. Arbre, fl. blanches. Anut-septembre. CC.

790. I. Sellowiana Benth.; Fl. Brus. XV, II, p. 467. - Alto Macahé de Nova Friburgo, Rio-Jax., no ${ }^{0}$ 3933. Arbrisseau, f1. blanches. Narsavril. C.

791. I. cordistipula llart.; Fl. Bras. XV, II, 1. 467. - Entre Gavea et Tijuca, Corcurado, Larangeiros. Riro-Jus., n ${ }^{\circ 5}$ 2977, 3936, 6518, 8426. Arbrisseau, fl. blanches. Juin-juillet. CG.

792. I. lentiscifolia Benth.; Fl. Bras. XV, II, p. 468. - Paratimirim, Rı-Jax., $n^{0}$ 19108. Arbrisseau, fl. blanches. Février-mars. R.

793. I. nutans Mart.; Fl. Bras. XV. II, p. 469. - Floresta de Tijuca et Corcovado, Rio-JAx., $\mathrm{n}^{\circ 5}$ 2549, 17604. Arbrisseau, fl. blanches. Janvier-février. C.

794. I. schinifolia Benth.; Fl. Brus. Xv, II, p. 469. - Près de Petropolis, Rı-Jax., no 11921. Arbrisseau, fl. hlanches. Février. C. Vulgo : Angelim pedire.

798. I. lanceafolia Benth. in Fl. Bras. XV, II. p. 469. - Petrupolis

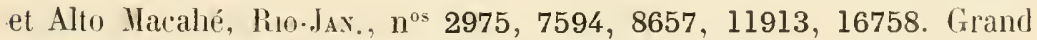
arbre, fl. blanches. Mai-juin. CC.

796. I. bullata Benth.: Fl. Bras. XV, II, p. 470. - Serra da Estrella, à Nandinca, Rio-Jax, $11^{\circ} 9400$. Très grand arbre, fl. blanches. Juilletaoùt. R.

Var. glabrescens in herb. Kew. - Serra do Tingua, au Rio d'Ouro, Røo-JAx., no 10580. Grand arbre, fl. blanches. Aoùt-septembre. C.

797. I. fagifolia Willd.; Fl. Bras. XV, II, p. 471. - Piratininga, Gavea, Corcovado et Tijuca, Rio-dax., nos 5825, 9774, 10600, 10636, 
12630; Serra dil Callaca: Mıxds, ${ }^{\circ 5}$ 14643, 14644. Arbrisseau, II. blanches. Novembre-alécenbre. CC. Vulgo: Inga feijuo.

798. Inga marginata Willd.; Fl. Bras. XV, II, p. 472. - Caminho do Hacaco. Parahyba do Sul, Floresta da Tijuca, Rio-Jax., nos 2550, 12631 , 15931. Arbre de petite taille, 1l. blanches. Janvier-février. CC.

799. I. cylindrica Nart.; Fl. Bras. XV, II, p. 473. - Rio Torto, près du campement, foraz, $n^{\circ}$ 21084. Grand arbre, f1. blanches. Mar'savril. C.

800. I. stipularis DC.; Fl. Bras. XV, II, p. 47.8. - Quinta de Sĩu Christovào. Rio-Jav., no 13769. Arbrisseau cultivé, fl. blanches. Janvierférrier. R.

801. 1. capitata Desv.; Fl. Bras. XV, II, p. 476. - Icarahy, à Praia Grande, Flıresta da Tijuca, Rio-Jax., nºs 4794, 8427, 11919. Arbrisseau, fr. blanches. Juin-aoùt. CG.

Var. tenuror in Fl. Bras. XY. II, p. 476. - Paineiras, au Corrovado, Rio-Jır., nos 615, 9401, 1380. Arlrisseau, fl. blanches. Août-septembre. C.

802. I. lenticellata Benth. in Fl. Bras. XV, II, p. 478. - Corcovado et Floresta de Tijuca, Rı--las., $n^{0 \star} 2122,4796,9402,11920$. Petit arbre, f1. blanches. Septenture-octolre. CC.

803. I. nobilis Willd.; Fl. Brras. XV, II, p. 478. - Rio Parahỵba, près de Campos, Rio-Jax., no 9784 . Arbre, fl. blanches. Janvier-février. C.

804. I. setifera DC.; Fl. Brus. XV, I, p. 481. - São Fidelis, at bord du Rio Parahyba, Rio-Jax.. no ${ }^{\circ} 9782$. Frand arbre, fl. blanches. Janvier-février, R.

80ั. I. maritima Benth.; Fl. Bras. XY, II, p. 483. - Restinga de Copacabana, Rio-Jav., nos 74, 1379. Arbrisseau, fl. blanches. Janviermars. CC.

806. I. Sal-manniana Benth.; Fl. Bras. XV, II, p. 484. - São Francisco de Paulo, Rio-Jax., n 10638. Arbrisseau, fl. blanches. Janvier-février. R.

807. I. ciliata Presl.; Fl. Bras. XV, II, 1). 484. - Petropolis, au Cachambú, Rio-Jax., nos 4797, 8429, 11917. Arbuste, f1. blanches. Septembre-octubre. C.

808. I. leptantha Benth.: Fl. Bras. XV. II, p. 485. - Serra da Babylonia, au Piau, Mrvas, $\mathbf{1}^{\circ}$ 19107. Arbrisseau, fl. blanches. Janvier-février. R. 
A.-F.-M. GLIZIOU. LISIL ULS PLANTES OU BIÉSIL CLNIIAL.

809. I. striata Benllı.; Fl. Bras. XV, II, 1. 48\%. - Illo Macahé de

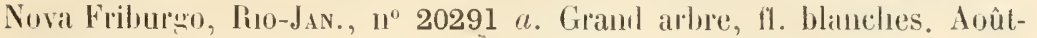
septembre. R.

810. I. macrophylla Ilumb), et Bonpl.; Fl. B'rus. XV, II, 1'. 490. Riu Manso, Mlsas Geraes, $n^{0}$ 13768. Grand arlue, 11. hlan'lıes. Janvierfévrier. R.

8I1. I. barbata Benth.; Fl. Bras. XV, II, p. 491. - Petropolis, Alto Marahé, elc., liı-JAN., $11{ }^{\text {os }} 3934,10584,13773,15930,16759$, 20290. Arlurisseau, fl. blanches. Janvier-février. CC.

SIJ. I. Guilleminiana Benth, ; Fl. Bras. XV, II, 1. 491. - Serra dos Orgãos, à Theresopolis, Riı-.lan., $1^{\circ}$ 11918. Glaud arbre, fl. blanches. Arril-mars. C.

813. I. vnlpina Mart.; Fl. Bres. XV, II, p. 492. - Serra d'Itabira do Campo, Caraça, Mrsas, nos 14641, 16760. Arbrisseau, fl. blanc rosé. Septembre-octobre. C.

Sl4. I. vera Willd.; Fl. Bros. XV, II, p. 194't. - Säo Fidelis, près de Campos, Rio-Jax., $\mathbf{u}^{\circ}$ 9785. Arbrisseatu, fl. blatlelues. danvier-février. R.

81:. I. uragensis Hooh. et Aru. ; Fl. Bras. XV, II, 1. 49:). - Entre Purto dis Caisis et Villa Novat, Rio-Jav., no 11915. Arlure, l1. blambes. Septembre-rctolse. C.

Slli. I. insignis Kunll, Fl. Bras., XV. II, І. 49:̈. - Laqua de

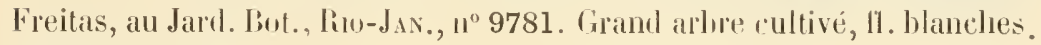
Février-mars. R.

817. I. affinis DC.; Fl. Brers. XV, II, P. 496. - Nova Frilurgo, au Chalet et à Petropolis, Rio-JAN. II ${ }^{\circ s} 8428,11914,12656,14642,20291$. Grand arbre, ll. blanclıes. Aoùt-septembre. CC.

81S. I. edulis Mart.; Fl. Brrs. XV, II, p. 497. - Serra da Bocaina, S. Pallo, $n^{\circ} 8423$; Lagoa do Peixe, Sete Pontes, Riro-Jax., $\mathbf{n}^{05} 8424,8425$, 12628. Grand arlıre, fl. blanches. Février-mar's. CG.

Var. parvifolia ill Fl. Brers. XV, II, p. 498. - Mllo Malcillé de Nuva Frilumgo, liı-Jax., $n^{0}$ 3935. Arbre, 1l. blanclies. Fivier-mars. C.

819. L. Luschnathiana lienth.; Fl. Bras. XV, 1, 1. 498.-- Lagoinha, au Corcovado, Rio-Jax., no 2976. Arbre, fl. blanches. Février-11ars. C.

820. I. ingoides Willd.; Fl. Bras. XV, II, 1. 499. - Entre Gerecino et liealengo, Rio-J.x., $1^{\circ}$ 11916. Grand arbre, ll. blanches. Août-septembre. C. 


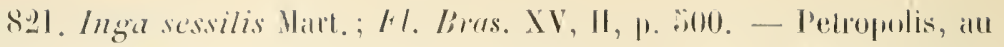

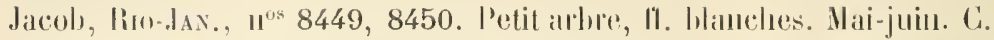

Var. vilzosa Bentlr. in lerh. Kew. - Serla da Bocaina, São Paulo,

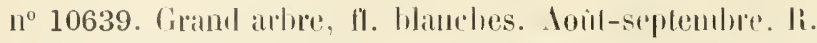

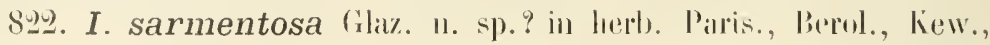
brux., ele. - Entre Lagoa do Peixe et Rio Bonito, Ro--lax., no 12629. Arlouste samenteus, li. blanches. Septembre-octolore. R.

829. I. purpurea Glaz. 11. sp." in herb. Paris., Berol., Kew., Gener. - Fazenta das Larangeirats, pres Cantagallo, Rio-Jax., n 15932. Arbrisseau, ll. rouge pourpre. Septenubre-octubre. Ri.

824. I. Poissoniana Glaz. 11. slo." in herl. Paris., Berol., Kew., Brux., ete. - lion Viga Lume, mes Moia Ponte, Goraz, $1^{\circ} 21082$. Grand arbre, ll. blanches. Anul-septembre. R.

8203. 1. ramiflora Steul.? in Flora (1843), p. 799. — Ouinta da Bua Visla, Sio Christovio, Rı-Jas., $1^{0}$ 9783. Arbrissean cultivé, ll. hlanelies. Avril-mai. li.

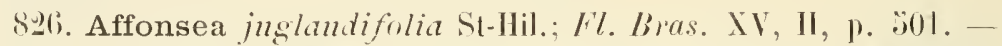
Andarahy firande, lim-das., $11^{\circ}$ 4795. Arbuste, 11. blanches. Anut-seplembre. Ri.

827. A. bullala Reull.: Fl. Bras. XV, II, 1. 502. - Santa Rosa, à Praia Grimble et à Alalaia, liı-JaN., II ${ }^{\circ 5} 3937,5827,9399$. Arlıuste, fl. blanches. Juin juillel. C.

Fann. 48. Rosacées.

I. Chrysobalanus Icaco I.; IFl. Bres. XIV, II, 1). 7. - Passeio Publico, Riı-.یx., $11^{\text {os }} 9716,10698$. Arbuste rullivé, ll. brunes, bon fruit. Février. R. Vulgo : Guajoni.

2. Licania heteromorpha Iienth.; Fl. Bras. XIV, II, p. 12. - Quinta

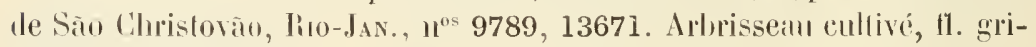
sâtrès. Mai-juiı. R.

2. L. rigida lienllı; Fl. Bros. XIV, II, 1. I2. - Sele Pontes, all Barreto, Ro-dax., "10 10700. Grand ardre, fl. blanchitres. Févier-mars. C. Vulgo: triti rica.

4. L. spicata Ilook. fil. in Fl. Bras. XIV, II, P. H6. - Villa Thereza, a Petropolis, Rio-d Ax., nos 8399, 11943, 19137. Cirmt arbre, fl. blanchatres. Janvier-lévirier. CiC. Vulgro: Milho cozido. 
¿. L. Kunthiana Hook. fil. in Fl. Bras. XIV, H, p. 16. - Larangeiras, au Cosme Velho, ho-dax., $1^{05}$ 738, 6519, 7603; Heia Ponte, Govaz,

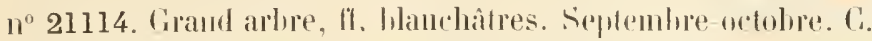

6. L. micrantha Miq. : FI. Rias. XIV. H, p. 18. --- Laqua de Freitas,

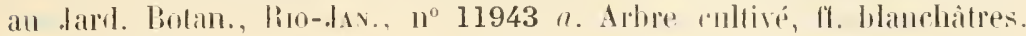
Mars-avil. R.

7. L. littoralis Warm. in Symb. ad H. Rras. 1, 1. 469. - Restinga de Tijuca, Rio-Jax., n 6168 . Mrbrisseau, fl. hanches. Septembre-octobre. C.

8. L. Glazioviana Warm. in Symb. ad R. Bras. I, p. 470. - Floresta da Tijuca, Rio-JAx., n² 2561. Arbrisseau, fl. Llanc verdàtre. Marsavilil. C.

9. L. gracilis Tanb. in Beibl. Bot. Jahrb. no 34, p. 8. - Entre Carandahy el Oneluz, Misas, ${ }^{\circ}$ 13800. Arbrisseau, ll. blante jamitre. Juinjuillet. R.

10. L. parriflora Bentlı.; Fl. Bros. XIV. II, p. 18. - Quinla da Boa Vista, Sĩo Ciluistovân. Rio-dan., no 10701. Arbrissuan cultice, fl. blanehatres. Avril-mai. R.

11. L. silvatica Glaz. n. sp.? in herh. Paris., lierol., Kew., Brux., etr. - Serra de Itahapoana, Esprhto Saxto, ${ }^{\circ}$ 10702. Arhrisseau, 11. lianchaties. Septembre. C. Vulgo : Oili silvestre.

12. Moquilea tomentosa Bentlı. : Fl. Bras. XIV, II, P. 21. - Restinga de Copacabana, Rio-Jas., ${ }^{\text {os }}$ 237, 1514, 7875, 10703. Grand arbre, 11. Blanches. Septembre-otetobre. CC. Vulgo : Oili da praia.

13. M. utilis Hook. fil. in Fl. Bras. XIV, II, P. 2.'t. - Corcovado of à Floresta da Tijuca, coté de Jacarepagua, Rin-JAs, n 1385 . Grand arbre, ll. hanchı̀tıes. Iuin-juillet. C. Vulgo : Oiti.

14 M. Turima Hook. f. in Fl. Bras. XIV, II, 1. 2:. - Heia Ponte et Serra dus Pyreneus, Goraz, $n^{\text {os }} 21114,21115$. Crand arbre, fl. blanches. Septembre-octobre. C.C. Yulqo: Mño de picäo.

1:.. M. bothynoply lla Mart. ; Fl. Bras. XIV, 11, p. 206. -.. São João da Chapada dans la forîl, Mnsas. n 14678. Grand arbre, li. blanches. Septembre-octubre. C.

I6. M. hmmilis Hook. f. in Fl. Bras. XIV, H, 1. 20. - Entre liio Binanal et lion Torto, lans le campo, Cioviz, nos 21113, 21116. Plante naine, fl. grisitles. Mai-juin. CG. Vulgu : Frnetn de Ema.

17. Parinarium Gardneri Howh. fil. in Fl. Bras. XIV, II |' "in. Cocaes, dans le rimpo et les rerralos, Miss, nos 14677, 15943. Arbisseau, fl. blinchothes. Jauvier-fivier. C. 
18. Parinarium brasiliensis Hook. fil. in FI. Brus. XIV, II, p. : 1. -

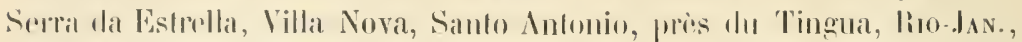
n"s 7602. 9391, 13796. liel arthre, f1. rousses. Novemlne-thesembre. CG.

19. P. Glaziovianum Warm. in Syml. 11. Mirs. II, p. 474. - Cosme Velho, it Larallgeiras, Corrovado, liın-.IN., $1^{\text {o* }} 752,2128,2560$. Cirand arbre, fl. rousses. danvier-didembre. C.

20. P. obtusifolium Hook. fil. in Fl. liras. XIV, II, P. 52. Fazenda dos Maracos, dins le campe, Gosnz, ${ }^{\circ} 21112$. Plante naine, fl. rousses. Ortobre-novembre. CG.

21. P. campestre Aubl., Fl. Guin. I, p. 514. - Araruama, près de Cabo frio, Ru-Jav., $n^{0}$ 10707. Arbrisseau rahougri, fl. rousses. Juinjuillet. R.

22. Hirtella hebeclada Horic.; Fl. Bras. XIV, II, p. 28. - Floresta da Tijuca, liı-Jan., nos 2127, 2559, 11942 ; Ouro Prelo, Mrvas, no 14682 ; Meia Ponte, Goraz, no 21110 . Arbrisseau, li. Tilas pầle. Novembre-décemlre. CG. Vulgo : Jacur.

23. H. Martiana Hooh. fil. in Fl. Bras. XIV, II, p. 29. - São Bartholomeu, Mınas, nos 12657, 14676. Arlurisseau, ll. hlanchâtres. Févriermars. C.

24. H. angustifolia Schott; Fl. Bras. XIV, II, p. 30. - Entre Porto dos Caixas et Simbaitilı, Rio-JAN., nos 11941, 12658. Arbrisseau, ft. violacées. Septembre-octolnre. C.

25. H. longifolia Benth.; Fl. Bras. XIV, II, p. 31. - São João da Barra, près de Campos, Rio-Jav., no 9786. Arbuste, ft. blanc jaunàtre. Février-mars. R.

26. H. floribunda Ch. et Schl.; Fl. Bras. XIV, II, 1. 32. - Serrinla de Santa Barbara, Minas Geraes, $1^{\circ}$ 19138. Arbuste, fl. violacées. Avril-mai. G.

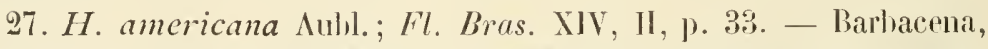
Ouro Preto, Caraca, Rio Nanso, etc., Minas, nos 9787, 10704, 10705, 14680, 14681, 15944; Heia Ponte, Gornz, n ${ }^{\circ} 21111$. Arluste, f1. blanc rosé. GG.

28. H. glandulosa Spreng.; Fl. Bras. XIV, II, p. 35̃. - Serra da Mantiqueira. à João Gomes, Minas, $n^{0}$ 10706; Meia Ponte, Goyaz, no 21110. Arbre, fl. blanchâtres. Aoùt-septembre. C.

29. H. ciliata Hart. et Zuc.; Fl. Bras. XIY, II, p. 36. - São Sebastião da Barra, liı-J Jan., no 10699. Arbuste, ll. rougeâtres. Novembredécembre. R. 
A.-F.-M. GLAZIOU. - LISTE DES PLANTES DE BRÉSIL CEYTRAL. '197

30. H. collina Sp. Moote, in Trams. Limn. Soc. IV, 3. P. 3iil. -

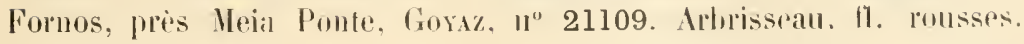
Aoît-septembre. li.

31. H. triandra Sw. : FI. Krors. XIV, II, 1. 37. - Jatareliagla et à

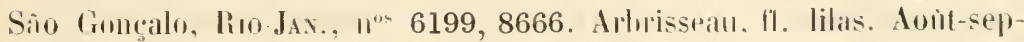
teinbre. C.

32. H. Glaziovii Taul. in Beibl. Bot. Juhrl., n 3't, 1. 8. - Sommet du Pico de Tijuca, liı-Jas., $u^{0}$ 4946. Arbuste. fl. violacées. Novembredécembre. C.

33. Couepia macrophylla Spr. in Fl. Bras. XIV, II, p. 41. - Sete Pontes, au Barreto, Rio-Jax., nos 1383, 4800, 18217. Arlme superbe cultivé, fl. blanches. Septembre-octolre. CG. Oili coroia.

34. C. bracteosa lienth.; Fl. Bras. XIV, II, 1. 40̈. - Oninta de Sĩo Chroistovão, Rio-Jas., nos 13797, 13799. Grand arlure cultivé. fl. blanches. Aont-septembre. R. Vulgo : Umari-rama.

3.. C. grandiflora Penth.; Fl. Bras. XIV, II, 11. 46. - Entre Santa Maria et Ponga, Govaz, $n^{\circ} 21117$. Arbre tortueux des campos, fl. blan lies. Aoùt-septembie. C.

36. C. Uiti Bentl.; Fl. Bras. XIV, II, 1). 17. - Serra do Funil, au Paranaua, Mrsas, no 19139. Amrisseau des campos, fl. blanches. Avrilmai. C. Vulgo : Oili.

37. C. ovatifolia Bentl.; Fl. Bras. XIV, II, J. 48. - Restinga de Copacabana, Guaratiba, ltipio, ete., Riı-JAx., nos 78, 751, 896, 1384, 2126, 6167, 7876 ef Alto Naralıs, $1^{\circ}$ 16761. Grand alse, f1. Hanches. Aoùt-septembre. CC. Vulğo : Frucla de coruja, Oili de praia.

38. C. paraensis Benth.; Fl. Bras. XIV, II, p. 48. - Qninta de Sino

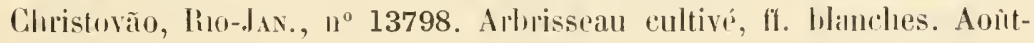
septenulore. R.

39. C. multiflora Benth. in /look. Jonrn. Bot. II, p. 21:3. - Quinta de Sĩo Christovãu, liı-Jax., nº 13433. Arbre cultivé, fl. blanches. Aoùtseptembre. R.

40. Prunus spharocarpa Sw.; Fl. Bras. XIV, II, p. :6. - Petropolis, Gavea, Sema do Tingua, ete., Riı-Jan., nus 1065, 1125, 1441, 2563, 7604, 8400 ; Parbarena, Congonlıs do Cimpoo, Mixas, ${ }^{\text {os }} 10709$, 14679, 15945; Santa Luzia, Goraz, $n^{\circ} 21118$. Petit arbre, fl. blanches. Juin-juillet. CC.

41. Quillaja brasiliensis Mart.; Fl. Bras. XIV, II, 1. 58. - Sera da Bocaina, au Bom Jilrlim, Sĩo PuUı, $11^{\circ \mathrm{S}}$ 14198, 19140. Arlurisseall, 11. Jrunes. Janvier-février. R. 
42. Rubus roscefolius Smillı; F1. Pros. XIV, 11, 1. 61. - Corco-

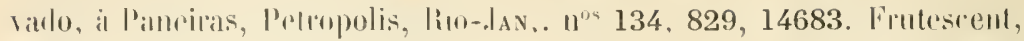
17. blanches. Firrier-atril. CC.

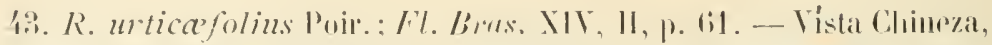
Coreovado. Morto da Biblylonia. Rio-dax., II"s 133, 830, 5000 h. Irbuste

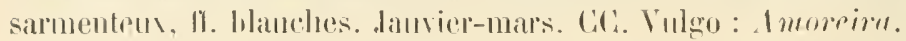

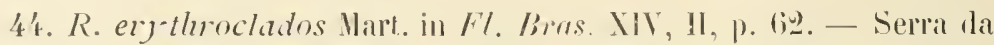

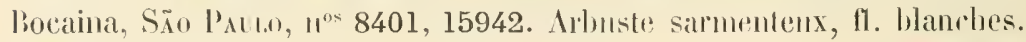
Janvier-fívrier. Ci.

4.. R. brasilicusis Mart.; Fl. Bras. XIV. II, p. 60. - Petropolis, à

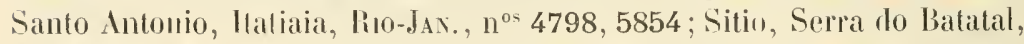
Rio Manso, Mrvas, $1^{\circ *} 8402,1468,14685$. Arlmste sirmenteux, tl. blanches. Janvier-mars. CG. Vulgo: A moreiru.

46. R. imperialis Cham. et Schlt.: FI. Bres. XIV, II, D. 64. Fazenta la Boraini, Sĩo Pacto, no $8402 a$. Alumste simmenteux, fl. lilanches. Féviler-mars. C.

47. Fragaria vesca 1..; Fl. Bros. XIV, II, P. 66. - Serra do Itatiaia, Rio-Jas, $1^{\circ 5} 4799,8671$. Herb. vivare, fl. blanches. Mai-jnillet. C. Vulgo : Muranga.

48. Agrimonia parviflora Lit.; Fl. Bras. XIV, II, p. 67. - Serra da Bocaina, Sĩo Patıo, 10 19141. Herb, vivace, ll. Manches. Janviermars. C.

49. Margyricarpus setosus liuiz. et Par.; Fl. Brus. XIV, II, p. 68. - Serra da Boraina, coté de la mer, Sĩo Pano, $1^{\circ}$ 19142. Frutesent, fl. blanc jauntître. Janviel-mar's. C.

:0. Eriobotrya japonica Lindl. in Trans. Limn. Soc. XIII, p. 109. - Quinta de Sĩo Christovão, Rio-Jan., $1^{\circ}$ 11944. Arhre fruitier cultivé, 11. Blanches. Mai-juin. GG. Vulgo: Ameixu do Japröo.

\section{Fan. 19 : Saxifragées.}

I. Escallonia Claussenii Niq.; Fl. Bras. XII, II, p. 19' - Areal do Ourn Brillon, Mivas, n" 14872. Arbuste, 11. roses. Novemlre-décemhire. C.

2. E. organensis Garln.; Fl. Bras. XIT, II, 1) 13... - Serras dos

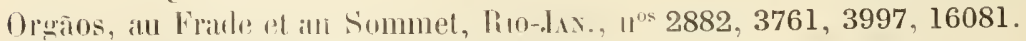

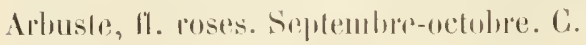

3. E. chlorophy-lla Cham. et Sehl.; Fl. Rras, XII, II, p. 133.-- 


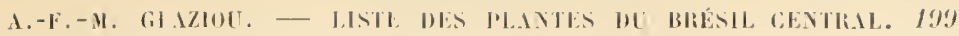

Campos da lioraina, Sïo PAtı, $11^{\circ} 8248$ a. Muste, M. rose pille. Janvier-fintier. C.

4. E. montevidensis Cllann. et Selıl. ; F\%. Riras. XIV, II, 1. 136. Nlto da Boa Vista de Nora Frihureo, Theresopolis, Itatiaia, liro-Jax., $11^{\circ 5}$. 2597, 4819, 6890, 8728, 19406. Irbuste, ll. Mauches. Janvier-mars. CiC.

5. E. vaccinioides St-llil.; Fl. Liras. XIV, II, 1. I3S. - Itatiaia, dans le rampo, lio-Jax, $11^{05} 6554,6555$. 8248. Irluste, fl. blanches. Janvier-mars. C.

6. E. Selloniana DC.; Fl. lims. XIV, II, 1. 139. - Campos da Bocaina, au Chapéo, S̃̃o I'Alto, os $^{\text {os }} 8249$, 19405. Arbuste, fl. blanc rosé. Janvier-février. CC.

7. E. floribunda IJumb. I. at K.; Fl. Brots. XIV, II, P. 14:3.Serra dos Orenos, à Theresopolis, pres du Nlu, Rio-J.x., I $^{\circ} 2894$. Irbuste, f1. hlanches. Anût-septembre. C.

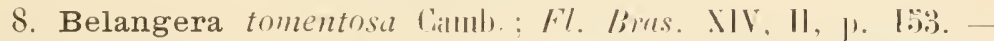

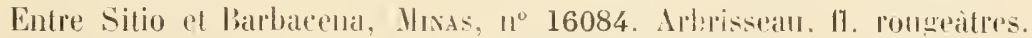
Novembre decembre. CL. Vulgo : Salgupira do malo.

9. B. glabra Camb.; Fl. lirres. XIV, II, p. lö't. - Piro d'Ttabira do

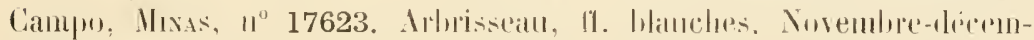
bre. C:

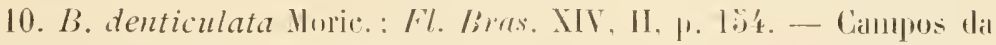

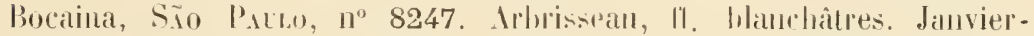
lévrier. C.

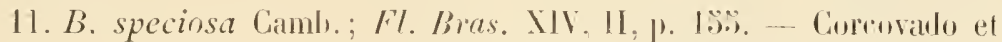

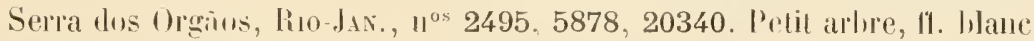
rougeatre. Février-mars. CG. Vulwo : Cedrilho.

12. B. hirta Gilaz. sl. n.? in herls. Berol., ined. - Corrego do Brejo, Govaz, $11^{\circ} 21119$ a. Grand arlore, 1l. hanchàtres. Mai-juin. CC. Vulgo: Rosa branca.

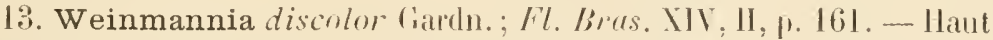

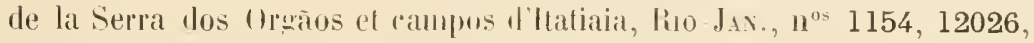
843, 14197, 6552, 16083. Mrluste, 11. Mlanches. Mai-juin. C.C.

14. W. paullinia folia l'ohl: FI. Brus. XIV, II, J. I6I. - Serra dil

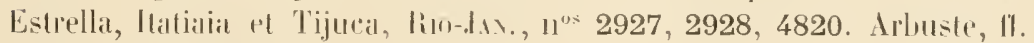
blanches. Noremblè-décembre. Ci:

1\%. W. organensis Gardn.; F\% lires. XIV, II, P. 162.-Cimpos la Bucaina, S̃̃o P'sulo, $11^{\text {os }} 8246,12027$; Serlal dos Orgĩos, Rio-Jax., $10^{\text {os }}$ 14870, 16082. Irbuste, fl. blanches. Mars-avril. C.C. 
16. Weinmannia hirta Sw.; Fl. Bras. XIV, II, p. 163. - Serma dos

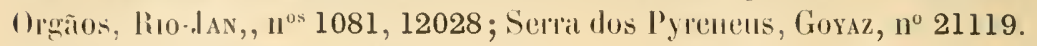
Arluste, lleurs blanches. Mars-avril. C.

Var. glabha Engler; Fl. Irrets. XIV, II, 1. 163. - Serra do Itatiaia, dans le 'ampo, Rı-JaN., $n^{\circ}$ 6553. Arbuste, fl. hlanches. Janvierfévrier. C.

17. W. goyazensis K. Sch., n. sp. in herb. Berol. et Kew. ined. Fazenda rlos Pyreneus, Goraz, $n^{0}$ 21119. Arbusle, ll. blanches. Aoutseptembre. G.

18. W. Intmilis Engl.; Fl. Bras. XIV, II, p. 163. - Serra dos Orgaios, au sommet, Rio-Jax., n"8 3998,14871 . Arluuste, fl. blanches. Mars-avril. C.

\section{Fan. :0 : Crassulacées.}

1. Tillæa pednncularis Sm.; Fl. Brrts. XIV, II, p. 380. - Entre Sitio et Barluacena, clans les bourbiers, Mısas, $n^{\circ} 10258$ a. Herbacé, fl. blanchâtres. Juin-juillet. R.

2. Bryophyllum calycinum Sal.; FI. Brus. XIV, II, p. 383. - Quinta

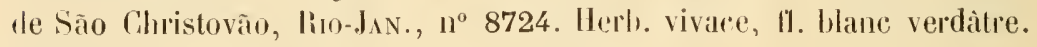
Iuillet-aout. CG. Vulgo : Folha da forluna.

3. Kalanchoe brasiliensis Gamb.; Fl. Brus. XIV, II, p. 381.Copacalıana, sur les rorhers, liı-J J.s., $n^{\circ} 3996$. Ilerb. vivare, fl. verdàtres. Octobre-décembre. CG. Vulgo: Sayão.

Juillet 1906 .

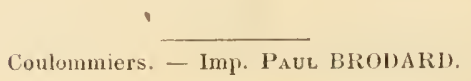




\section{TIRAGES A PART}

Le Conseil d'alministration, dans sa séance du 7 avril, a décidé que, dorénavant, il serait attribué graluitement, à tous les auteurs de communicalions originales qui en feront la demande en remettant leur manuscrit, 25 exemplaires en tirage à part, imprimés on même temps que le numéro, sans remaniement de texte ni remise en pages. Lorsque les auteurs feront exécuter un nombre plus grand de tirages à part, ou quils feront subir au texte des modifications qui doivent rester à leur charge, il leur sera tenu compte sur le tarif habituel d'une soinme de trois francs par feuille ou fragment de feuille, en représentation du prix dəs 20 exemplaires attribués à titre gratuit.

La présente mesure a reçu son application à partir du numéro contenant la séance d'avril.

\section{Tarif des tỉrages à part.}

Un tirage sous presse de 25 exemplaires est accordè gratuitement à Messieurs les Auteurs qui en feront la demandc en remettant leur manuscrit. - Les Auteurs qui préfèrent des tiragres à part avec rẻimposition, bẻnèticieront en compensation d'une réduction de 3 fr. sur les prix du tarif ci-dessous.

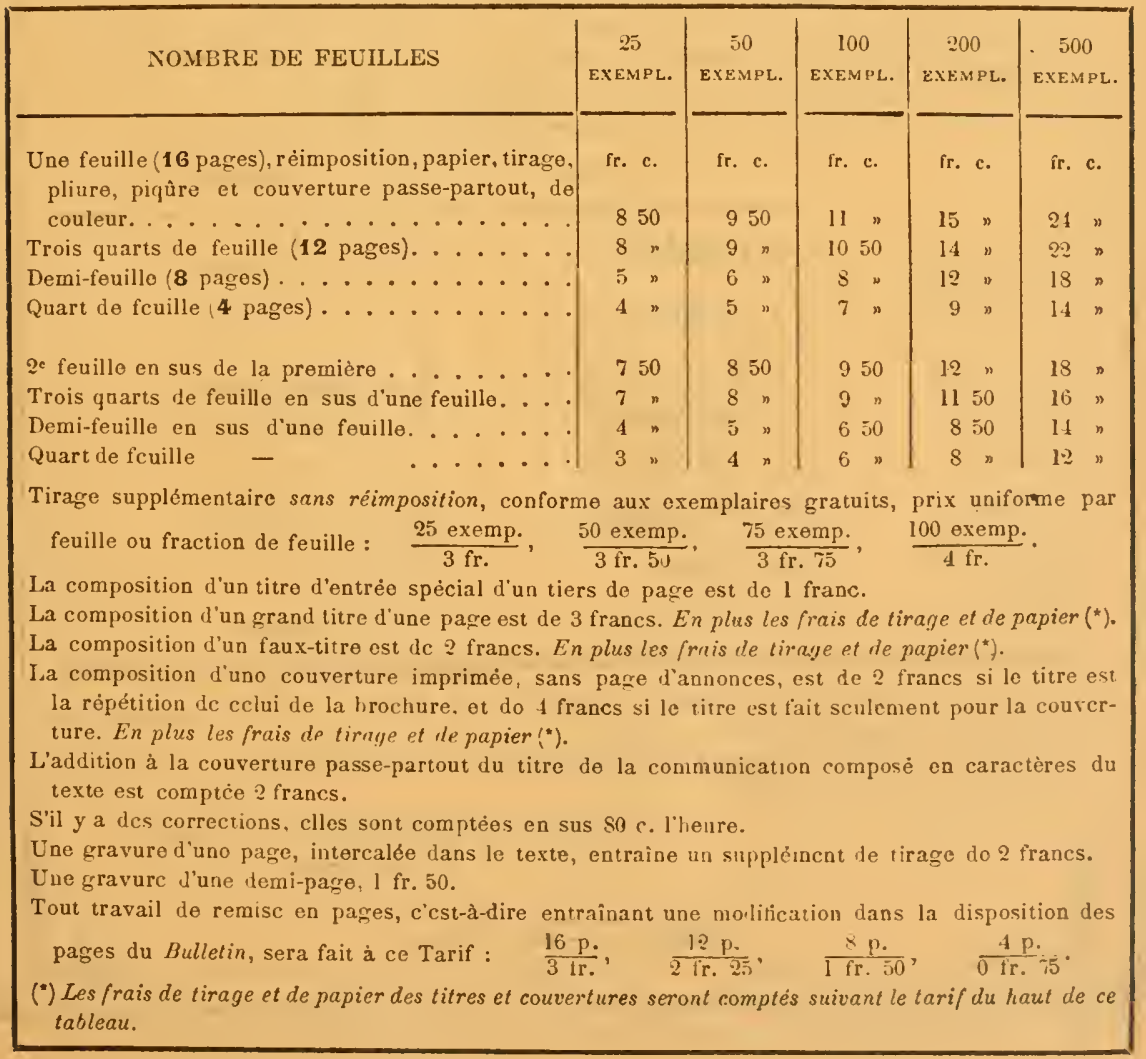




\section{AVIS IMPORTANTS relatifs à la Publication du BULLETIN}

1. - Les manuscrits, rẻligés ne varietur et lisiblement, doivent être dẻposés It jour mime vil sont faites les communications, faute de quoi leur impression est ajournèe sills que les auteurs puissent élever de réclamation a cel égard.

11. - si les manuscrits sont accompragnés de figures destinées à ètre insèrées dans le l’xte, celles-ci duivent être lessinèes a la plume et au trait, ou bien au crayun Wultí sur papier procedé, ou consister en bonnes pholographies, de maniere a en permettre la reproduction par les procedés zincograpliques. L'insertion de toute figure ne pouvant ètre reproduite que par des procedtes difrẻrents reste soumise à l'approbation de la Cominission du Bulletin.

III. - Les auteurs reçoivent une épreuve en pliacards el en double exemplaire de leurs communications, la correction des autres epreuves étant faite par le Secrétariat. Les corrections doivent etre retournées dans le délai maximum de trois jours all Secrétaire-rédacteur, faute de quoi la correction est faite d'office par le Secrétariat

IV. - Lorsque les manuscrits dépassent la longueur réglementaire de $\&$ pages el qu'ils ne comportent pas de question de priorite. ils peuvent être publiès sons la rubrique: Mémoires puliliess par la sisciété britanque de France. Ces Mémuires sont édités avec foute la célérité possible, malis sans garantie de date. Ils prennent place dans les volumes annuels a la suite des comnunications insérées aux séances ordinaires et sont fournis aux Membres de la Sociétė sans majoration de leur cotisation.

V. - Afin de perinettre l'établissement des convocations aux séances, MIM. Ies Auteurs sont instamment priés d'aviser le Secrétaire général huit jours à l'avance des communications qu'ils ont l'intention de présenter.

VI. -- En vue d'assurer l'unité typographique du Bulletin, le Conseil a arrêté le protocole ci-dessous, réglant les caracteres employés dans les descriptions et les listes de végétaıx. Il ne sera admis aucune lèrogation ä cette régle.

\begin{tabular}{|c|c|c|}
\hline & NOCVELLES & ANCIENNES \\
\hline Fa:HLLie. & 1. Labiées. & 2. Labiées. \\
\hline $\begin{array}{l}\text { SoUS-FAMLLE. } \\
\text { TRIBU. }\end{array}$ & 3. LAMIÉES. & 4. LAMIÉES. \\
\hline $\begin{array}{l}\text { Sous-Tribu. } \\
\text { GENRE. }\end{array}$ & $\begin{array}{l}\text { 5. Stachydeæ. } \\
\text { Sonchus. }\end{array}$ & $\begin{array}{l}\text { 6. Stachydeæ. } \\
\text { Sonchus. }\end{array}$ \\
\hline Section. & 7. Autalpinia. & 8. Autalpinia. \\
\hline EsPÉce. & 9. Communis. & 10. Communis. \\
\hline $\begin{array}{l}\text { Sous-Espèce. } \\
\text { VARIÉtÉ. }\end{array}$ & $\{$ 11. Pilosa. & 12. Pilosa. \\
\hline Fовме. & 13. Laciniata. & 14. Laciniata. \\
\hline
\end{tabular}

Tout ce qui concerne ladministration de Ia Sociète doit être adressé au Secrètaire gènéral à l'aılresse suivante:

3. Lutz, prolesseur agrégé à l'École supérieure de pharmacie, 4, avenue de l'observatoire, Paris $\left(\mathrm{Vl}^{\circ}\right)$.

Le Ses.rétrire-rédacteur, Gérant du Bulletin :

F. Gagnepals.

Goulommiers. - Imp. P. Brodard 


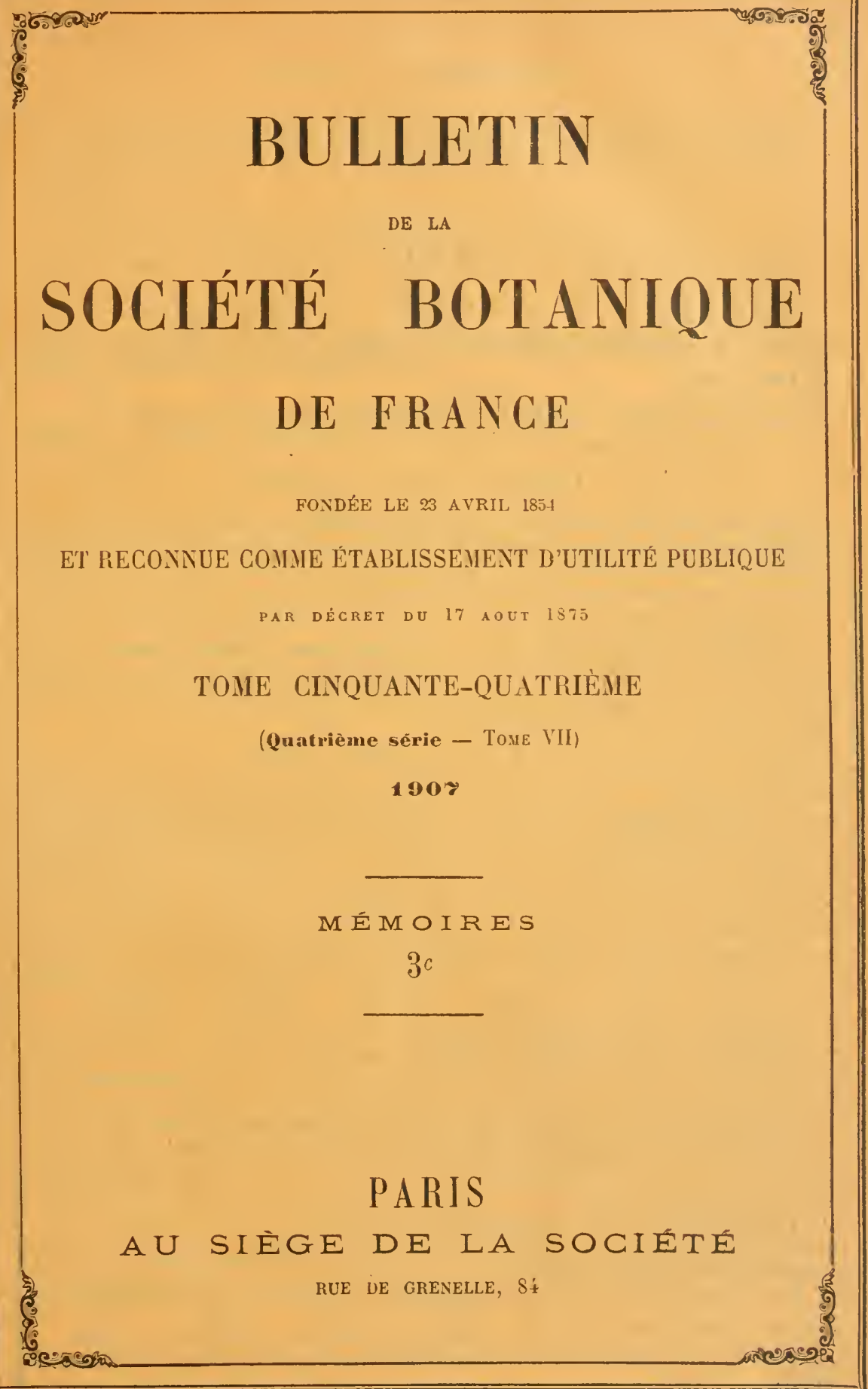

Le Bulletin de la Société botanique de France parait par livraisons mensuelles. Le Bon à tirer de ce numéro a été donné le 22 Février 1908. 


\section{A VIS}

\section{L'adresse de M. Fernand CAMUS, Secrétaire-rédacteur, est Villa des Gobelins, $\mathrm{n}^{\circ}$ 7, Paris, XIII ${ }^{\mathrm{e}}$.}

\section{Tarif des tirages à part.}

Un tirage sous presse de 25 exemplaires est accordè gratuitement à Messieurs les Auteurs qui en feront la demande en remettant leur manuserit. - Les Auteurs qui préferent des tirages à parı avec rẻimposition, bénéficieront en compensatiou d'une réduction de $3 \mathrm{fr}$. 60 sur les prix du tarif ci-dessous

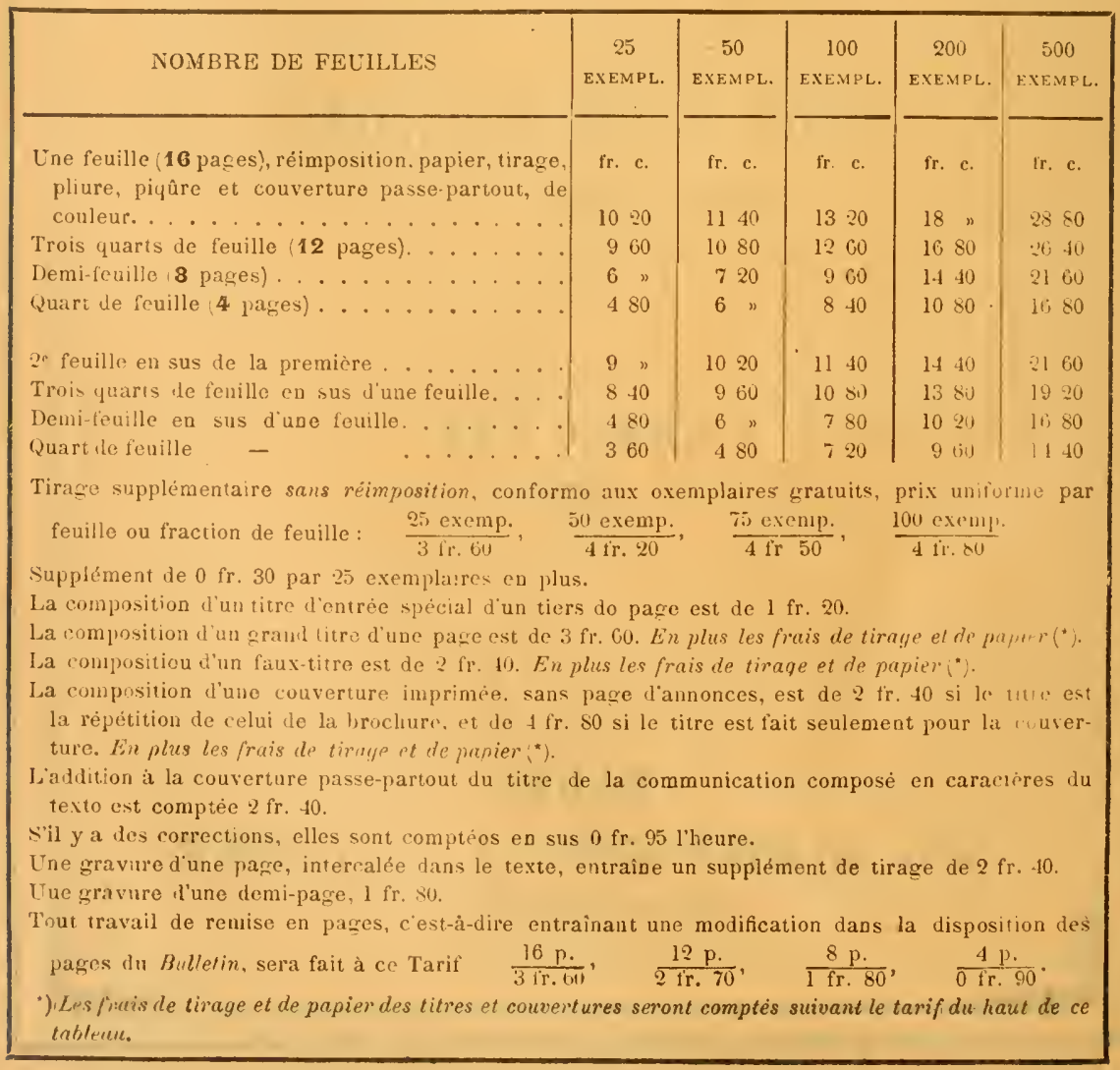




\section{Fam. מ̆1 : Droséracées.}

1. Drosera sessilifolia St-Hil.; Fl. Bras. XIV, II, p. 389. - Fazenda do Rio dos Indios, Goyaz, $n^{\circ} 21120$. Herbe virace, f1. rose foncé. Aoùtseptembre. CC.

2. Drosera tomentosa St-Hil.; Fl. Bras. XIV, II, p. 393. - Itacolumy, Mixas, $n^{\text {os }} 14482$, 18858. Herbe virace, fl. roses. Juin-juillet. GC.

3. D. communis St-Hil.; Fl. Bras. XIV, II, p. 394.- Nova Friburgo, Rio-Jax., nos $10257,15829,12429$; campos de Caraça, Mısas, nos 8262 , 14483. Herbe vivace, fl. roses. CC.

4. D. villosa St-Hil.; Fl. Bras. XIV, II, p. 393. - Serra dos Orgãos, Rio-Jax., $n^{\text {os }} 1605,3868$; Itacolumy, Mrsas, $n^{0} 14484$. Herbe vivace, f1. roses. Novembre-décembre. C.

כ. D. graminifolia St-Hil.; Fl. Bras. XIV, II, p. 396. - Serra do Caraça, à la Garapuça, Mıxas, n 14485 . Herbe vivace, fl. roses. Juinjuillet. R.

6. D. chrysolepis Taub. in Pl. nov. Glaz. IV, p. 50\%. - Serra do Cipo, Misas, $n^{\circ}$ 18857: entre Rio Torto et Paranana, Goyaz, nº 21121. Herbe vivace. fl. roses. Avril-mai. R.

\section{Fam. ¿2: Haloragées.}

1. Laurenbergia tetrandra Kanitz in Fl. Bras. XIII, II, p. 378. Entre Cabo Frio et São Pedro dos Indios, dans les bourbiers. Herbacé, 11. blanchàtres. Juillet. C.

2. Myriophyllum brasiliense Camb. : Fl. Bras. XIII, II, p. 380. Juiz de Fora, dans l'eau dormante, Misas, $1^{\circ} \mathbf{3 6 6 2}$. Herbe vivace, f1. blanches. Juin-juillet. CC.

3. M. proserpinacoides Gill.; Fl. Bras. XIII, II, p. 380. - Paratymirin, dans les bourbiers, Rro-J $J_{A N}$, $n^{\circ} 3662 a$. Herbe vivace, fl. blanches . Janvier-février. C.

4. Callitriche peploides Nutt. in Trans. Am. Phil. Soc., p. 140. Petropolis, à Santo Antonio, Rio-Jax., dans les bourbiers. Herbe virace. Aoùt-septembre. C.

๖. C. deflexa A. Br.; Fl. Bras., XIII, II, p. 13. - Petropolis et Tijuca, dans les hourbiers, Rio-JAx., $n^{\circ s} 3647,8077$. Herbe rampante, fl. blanc rosé. CC. 


\section{Fam. 53 : Rhizophoracées.}

1. Rhizophora Mangle L.; Fl. Bras. XII, II, p. 426. - Praia Grande, dans la boue de la mer, Rı-JaN., $n^{\text {os }} 1363,11585$. Arbrisseau, f1. verdâtres. Juin-août. CG. Vulgo : Mangue.

2. Cassipourea Spruceana Benth.; Fl. Bras. XII, II, p. 429. Quinta da Boa Vista, Rio-JaN., n 13812. Arbuste cultivé, fl. blanches. Mai-juin. R.

3. C. guianensis AubI.; Fl. Bras. XII, II, p. 429. - Quinta da Boa Vista, Rı-Jan., $\mathrm{n}^{\circ}$ 13813. Arbuste cultivé, fl. blanchâtres. Mai-juin. R.

\section{Fam. ๖ั4: Combrétacées.}

1. Terminalia Catappa L.; Fl. Bras. XIV, II, p. 83. - Passeio Publico, Rio-Jan., $n^{0}$ 1508. Grand arbre cultivé, fl. verdâtres. Juin-juillet. CC. Vulgo : Amendoeira, Capeo de sol.

2. T. australis Camb.; Fl. Bras. XIV, II, p. 85. - Passeio Pullico, Rı-Jan, $n^{\circ}$ 2910. Petit arbuste cultivé, f1. blanches. Octobre-novembre. C.

3. T. fagifolia Mart. et Zucc.; Fl. Bras. XIV, II, p. 86. - Entre Mestre d'Armas et Fartura, Goyaz, no 21124; Serra da Leopoldina, Misas, $\mathrm{n}^{\text {os }}$ 10712, 10720. Arbrisseau, fl. verdâtres. CG. Vulgo : Tingidor, Cascudo.

4. T. argentea Mart. et Zucc.; Fl. Bras. XIV, II, p. 86. - Santa Luzia do Rio das Velhas, Hısas, n²0294; Formosa, près de Lagoa Feia, Goyaz, n 21123. Grand arbre, f1. blanches. Novembre-décembre. CG. Vulgo : Capitao do mato.

э. T. jannariensis DC.; Fl. Bras. XIV, II, p. 89. - Coreovado, Petropolis, Nova Friburgo, Rio-JAx., nos 831, 1303, 2911, 8668, 20295. Grand arbre, fl. blanches. Novembre-janvier. CG. Vulgo : Merindiba.

6. T. brasiliensis Eichler in Fl. Bras. XIV, II, p. 91. - Villa Nova, São Gonçalo et Rio d'Ouro, Rı-JAN., nos 7606, 10721, 10726, 11946 ; Serra de Ouro Branco, Misas, $\mathrm{n}^{\mathrm{os}} 12660$, 14686. Grand arbre, f1. blanclies. Juillet-aoùt. CG. Vulgo : Merindiba.

7. T. glabrescens Mart.; Fl. Bras. XIV, II, p. 91. - Serra de Ouro Branco, Misas, nos 10711, 12661. Grand arlıre, fl. blanchâtres. Juilletaoùt. C. Vulgo : Sao de sangue.

8. T. acuminata EichI. in $\mathrm{Fl}$. Bras. XIV, II, p. 92. - Larangeiras 
A.-ト.-M. GLAZ1OU. - LISTE DES PLANTES DU BRESLL CENTRAL. 203

et Floresta de Tijuca, Rio-Jax., $n^{08} 6143,6521,11947$. Grand arbre, f1. blanchâtres. Novembre-décembre. C. Vulgo : Guarajuba.

9. T. rotundifolia Glaz. n. sp. in herb. Paris., Berol., Kew., Genev. - Biribiry, dans la forêt, Mısas, $n^{\circ}$ 19146. Grand arbre, sans fleurs en mars. Vulgo : Carvalho.

10. T. excelsa Glaz. n. sp. in herb. Paris., Berol., Kew., Brux. Biribiry, dans la forêt, près Diamantina, Mıxas, $n^{\circ}$ 19145. Très grand arbre, sans fleur en mars. C. Vulgo : Cabo de janlar.

11. T. debilis Glaz. n. sp. in herb. Paris., Berol., Kew., Genev. São Fidelis, près Campos. Rı-Jan., nº 10242. Arbıste, fleur's blanchâtres. Février-mars. R.

12. Buchenavia capitata Eichl.; Fl. Bras. XIV, II, p. 96. - Quinta de São Christovão et Passeio Publico, Rio-Jax., nos 10719, 10722, 10723, 10725, 13803. Arbrisseau cultivé, fl. verdâtres. Juin-juillet. C. Vulgo : Tanibuca.

13. B. macahensis Glaz. n. sp. in herb. Paris., Berol. - Alto لlacahé de Nova Friburgo, Rı-JAx., no ${ }^{18218}$. Grand arbre, fl. verdâtres. Juinjuillet. C. Vulgo : Merindiba.

1'4. B. tomentosa Eichl.; Fl. Bras. XIV, II, p. 97. - Biribiry, Nixas, $n^{\circ}$ 19144; entre Alegre et Ponte do Sevorino, Goyaz, $n^{\circ}$ 21125. Arbrisseau, f1. rousses. Octobre-novembre. G.

1.. B. gracilis Glaz. n. sp. in herb. Paris., Berol., Kew., Genev., etc. - Caminho do Macaco, près Boa Vista, Rio-JAx., nº 5855. Arbrisseau sans fleurs en décembre. C. Vulgo: Merindiba-rana.

16. B. fluminensis Glaz. n. sp. in herb. Paris.. Berol., Kew., Genev., etc. - Corcovado, à Paineiras, Rio-JAx., $1^{\circ} 6142$. Grand arbre, f1. verdàtres. Juin-juillet. C. Vulgo : Merindiba.

17. Conocarpus erecta L.; Fl. Bras. XIV, II, p. 101. - Entre Cabo Frio et Aldèa de São Pedro. Rio-Jax. nos 10022, 10724, 13130. Arbrisseau, fl. verdâtres. Septembre-octobre. C.

18. Laguncularia racemosa Girtn.; Fl. Bras. XIV, Il, p. 102. Praia Grande, au bord de la mer, Rio-Jar.; $11^{\circ}$ 10464. Arbrisseau, fl. verdàtres. Janvier-mars. CG. Vulgo : Mangue.

19. Combretum lanceolatum Pohl in Fl. Bras. XIV, II, p. 110. Serra dos Orcãos, à Theresopolis, Rio-Jax., n 8337 . Arbuste sarmenteux, fl. jaune orange. Aout-septembre. C.

20. C. Loeflingii Eichl. in Fl. Bras. XIV, II, p. 110. - Serra dos Orgãos, à Theresopolis, Gavea, Petropolis, Rı-JAr., nos 3949, 10727, 
11945 ; Inficionado, Minas, nos 12659 , 13805. Arbuste sarmenteux, fl. orangées. Août-septembre. CC.

21. Combretum Glaziovianum Taub. n. sp. in herb. Paris., BeroI., - Lagoa do Cambello, pres de Campos, Rio-Jan., no 10715. Arbuste sarmenteux, fl. jaune orange. Juin-juillet. C.

22. C. leprosum Mart.; Fl. Bras. XIV, II, 1. 112. - Restingra de Cabo Frio, Rio-JAx., n ${ }^{\text {os }} 9792,10714$. Arbuste sarmenteux, fl. jaunâtres. Juin-juillet. R. Vulgo : Cipoaba.

23. C. leptostachyum Mart.; Fl. Bras. XIV, II, p. 112. - Campos da Bocaina, dans Ie bois, São Pailo, $n^{\circ}$ 10710. Arbuste sarmenteux, $\mathrm{fl}$. rousses. Févier-mars. li.

24. C. Monetaria Mart.; Fl. Bras. XIV, II, p. 113. - Lagoa de Freitos, au Jard. Bot., Rro-JAx., nº 10713. Arbuste cultivé, fruit rougeâtre. Mai-juin. R.

23. C. parviflorum Eichl. in Fl. Bras. XIV, II. p. 114. - São Joāo da Chapada, Mixas Geraes, nº 9792. Arbuste sarmenteux, fl. jaunt̀tres. Décembre. R.

26. C. Jacquini Griseb. var. $\gamma$ mensiliensis Fl. Bras. XIV, II, p. 116. - Corcovado, Sajobemba, Restinga de Mana, etc., Rio-Jax., ${ }^{\text {os }}$ 3948, 7607, 8338, 8339, 10716. Arbuste samenteux, fl. orangées. Mai-juillet. CC.

- Forma ovatifolia $\mathrm{Fl}$. Bras. XIV, II, p. 116. - Belem el Queimados, Rio-JAx., nos 8669,10717 . Arbuste sarmenteux, fl. jaune orange. Mai-juin. C.

27. C. pisonioides Taub. in Beibl. Bol. Jahrb. XV, no 34, p. 10. Aldèa de Ouro Branco, Minas, n 10718. Arbrisseau, fl. blanc jaunâtre. Septembre-octobre. R.

28. C. discolor Taub. in Beibl. Bot. Jahrb. XV, n 34, p. 8. - Serra de Ouro Branco, Mınas, no $13805 a$. Arluuste, fl. blanc jaunâtre. Aoûtseptembre. C.

99. C. nitidum Spruce in Fl. Bras. XIV, II, p. 118. - Quinta de São Christovão, Rio-JAx., $n^{\circ}$ 13802. Arbuste sarmenteux cultivé, fl. blanchâtres. Mai-juin. R.

30. C. floccosum Eichl.; Fl. Bras. XIV, II, p. 119. - Biribiry, près de Diamantina, Mixas, $n^{\text {os }} 10478,19143$. Arbuste sarmenteux, fl. rousses. Mars-avril. C.

31. C. pyrenæum Glaz. n. sp. in herb. Paris., Berol., Kew., Brux. - Serra dos Pyreneus, dans le bois, Goraz, n² 21122. Arbuste sarmenteux, fl. jaunâtres. Juin-juillet. C. 
32. Thiloa glaucocarpa Eichl. in Fl. Bras. XIV, II, p. 103. - São João da Chapada, Mrxis Geraes, ${ }^{0 s} 13804,14687$. Arbuste sarmenteux, f1. jaunes. Novembre-décembre. C.

33. Sparattanthelium tupiniquinorum Nart.; Fl. Bras. V, II, p. 291. - Serra da Cayanna, dans le bois, Rio-Jax., $n^{0}$ 11456. Arbuste sarmenteux, fl. grisàtres. Aoùt-septembre. Vulgo : A rco de baril.

34. S. tupinambazzm Mart.; Fl. Bras, V, II, p. 292 - Entre Guaxindiba et Alcantara, Rio-JAN., no 12139. Arbuste sarmenteux, fruit blanchâtre. Septembre. C.

\section{Fam. รั : Myrtacées.}

1. Melaleuca ericifolia Sm.; Warm. Symb. Enum. Myrt. Fl. Bras., 1. อั. - Petropolis, Rio-Jav., nº 14848. Arbrisseau cultivé, f1. blanches. Août-septembre. C.

2. Feijoa Sellowiana Berg; Warm. Symb. Enum. Myrt. Fl. Bras., p. 187. - Quinta de São Christovão, Rı-JAx., n ${ }^{0 s}$ 6156, 7886. Arbuste cultivé, fl. roses. Aoùt-septembre. C. Vulgo : Araça do líio. Grande.

3. Britoa Selloniana Berg; Warm. Symb. Enum. Myrt. Fl. Bras., p. ¿. - Serra dos Orgãos, à Theresopolis, Rio-Jax., nos $9431,9432$. Arbuste, fl. blanches. Janvier-février. C.

4. B. acida Berg in Warm. Symb. Enum. Myrt. Fl. Bras, p. Э. - Passeio Publico, Rio-Jar., no 5871. Arbuste cultivé, fl. blanches. Janvier-février. R.

5. B. rugosa Berg in Warm. Symb. Enum. Myrt. Fl. Bras., p. 6. - Quinta de São Christovão, Rı-Jav., nº 6833. Arbrisseau cultivé, f1. Llanches. Octobre-novembre. CG. Vulgo : Guabiroba.

6. B. Gląioviana Kïrsk. in Warm. Symb. Enum. Myrt. Fl. Bras., p. 6. - Fazenda de Santa-Ciruz, Barreto, Berquó, etc., Rio-Jas., ${ }^{05} 4990$, 7873, 9246 et 9249. Arbrisseau, fl. blanches. Novembre-décembre. C. Vulgo : Arassaroba.

7. B. Kiærskowiana Glaz. 1l. sp.? in herb. Paris., Berol., Kew., Harn., etc. - Cabo Frio, Rio-JAx., $n^{\circ}$ 12734. Arbuste, fl. blanches. Septembre-octobre. R. Vulgo : Guabiroba.

8. Campomanesia laurifolia Gardn. in Warm. Symb. Enum. Myrt. Fl. Bras., p. 8. - Corcovado et Floresta da Tijuca, Rio-Jax., $\mathrm{n}^{\mathrm{os}} 2589,6153,7643$. Arbuste, f1. blanches. Novembre-décembre. C. Vulgo : Guabiroba. 
9. Camponanesia Guaviroba Kiærsk. in Warm. Symb. Enum. Myrt. Fl. Bras. p. 8. - Restinga de Cabo Frio, Rio-Jax., no 10822. Arbuste, ft. blanches. Juin-juillet. R.

10. C. maschalantha Kiærsk. in Warm. Symb. Enum. Myrt. Fl. Bras., p. 8. - Serra dos Orgãos, à Taboinha, Rı0-Jav., n ${ }^{\text {os }} 3003,3978$. Arbuste, fl. blanches. Novembre-décembre. C.

11. C. Fenzliana Berg (sub. Abbevillea) in Mart. Fl. Bras. XIV, I, p. '433. - Serra dos Orgãos, à Theresopolis, Rio-Jan., nº $9432 a$. Arbrisseau, fl. blanches. Janvier-février. R.

12. C. stictopetala Kiærsk. in Warm. Symb. Enum. Myrt. Fl. Bras., p. 8. - Serra dos Orgãos, Rı-Jax., $n^{\circ} 3975$. Arbuste, fl. blanches. Novembre-décembre. R.

13. C. itanarensis Kiærsk. in Warm. Symb. Enum. Myrt. Fl. Bras., p. 8. - Theresopolis, à Quebra Frascos, Rio-JAx., $11^{\circ} 12011$. Arbrisseau, fl. blanches. Janvier-février. G.

14. C. Cagaiteira Kiærsk. in Warm. Symb. Enum. Myrt. Fl. Bras., p. 12. - Praia Grande, au Barreto, Rro-JAx., $1^{\circ}$ 6159. Arbuste cultivé, fl. blanches. Septembre-octobre. R. Vulgo : Cagaiteira.

10. C. hirsuta Gardn. in Warm. Symb. Enum. Myrt. Fl. Bras., p. 13. - Petropolis, à Santo Antonio, Rio-Jav., $1^{\circ}$ 5870. Arbuste, fl. blanches. Février-nars, R.

16. C. fusca Berg in Fl. Bras. XIV, I, p. $44 \overline{4}$. - Serra de Ouro Preto, Misas, $n^{\circ} 14806$ a. Arbre, fl. blanches. Février-mar's. C.

17. C. corymbosa Berg in Warm. Symb. Enum. Myrt. Fl. Bras., p. 13. - Serra da Caraça et à Barbacena, Misas, $n^{\text {os }} 12730$, 13862, 16979. Arbuste, fl. blanches. Septembre-octobre. C.

18. C. Langsdorffii Berg in Warm. Symb. Enum. Myrt. Fl. Bras., p. 13. - Entre Sitio et Barbacena, Mlinas, n 13863. Arbuste, fl. blanches. Novembre-décembre. R.

19. C. prosthecesepala Kiærsk. in Warm. Symb. Enum. Myjrt. Fl. Bras., p. 13. - Rio Manso, MINas, $\mathrm{n}^{\circ}$ 13875. Arbuste, fl. hanches. Février-mars. C. Vulgo : Guabiroba.

20. C. reticulata Berg in Warm. Symb. Enum. Myrt. Fl. Bras., p. 14. - Chapadinha, dans le campo, Goraz, $\mathrm{n}^{\circ} 21172$ b. Arbuste, f1. blanches. Octobre-novembre. R. Vulgo : Guabiroba.

21. C. salviafolia Berg in Warm. Symb. Enum. Myrt. Fl. Bras., p. 14. - Barbacena, dans le campo, Misas, $n^{\circ} 16979$ a. Arbuste rabougri fl. blanches. Aoùt-septembre. R. Vulgo : Guabirobinha. 
A.-F,-H. GLAZIOU. - LISTE DES Plantes DU BRÉSIL CENTRAL. 207

22. C. Beaurepairiana Kiarsk. in Warm. Symb. Enum. Myrt. Fl. Bras., p. 15. - Sete Pontes, au Barreto, Rio-JAx., no 11980. Arbuste cultivé, fl. blanches. Janvier-février. R.

23. C. xanthocarpa Berg in Mart.; Fl. Bras. XIV, I, p. 4\%1.Campos da Bocaina, SÃo-Paulo, no 11980 «. Arbuste, fl. blanches. Septembre-octobre. C.

24. C. crenata Berg in Warm. Symb. Enum. Myrt. Fl. Bras., p. 16. - Campos da Bocaina, Sĩo-Paulo, nº 11993. Arbuste, fl. blanches. Janvier-février. C. Vulgo : Guabiroba.

2\%. C. Glazioviana Kiærsk. in Warm. Symb. Enum. Myrt. Fl. Bras., p. 16. - Serra da Mantiqueira, dans le bois, Misas, no 12729. Arbuste, fl. blanches. Novembre-décembre. C.

26. C. ovalifolia Berg. in Mart. Fl. Bras. XIV, I, p. 4.2. - Campos da Bocaina, SÃo-Paulo, no 11993 a. Arbuste, fl. blanches. Septembreoctobre. C.

27. C. carulea Berg in Mart. Fl. Bras. XIV, I, p. 40ั5. - Itacolumy, près Ouro Preto dans le campo, Mixas, no 14806. Arbuste, fl. blanches. Février-mars. C.

28. C. desertorum Berg in Mart. Fl. Bras. XIV, I, p. 4006 . Meia Ponte, dans le bois, Goraz, n² 21192. Arbuste, fl. blanches. Septembre-octobre. C.

29. Psidium Araça Raddi in Warm. Symb. Enum. Myrt. Fl. Bras., p. 2\%. - Petropolis, à Santo Antonio, Rio-Jax., n ${ }^{\text {os }} 10824$ et 12731. Arbrisseau. fl. blanches. Octobre-novembre. C. Vulgo : Araça.

30. P. Goyava Rarldi in Warm. Symb. Enum. Myrt. Fl. Bras., p. „ّ̈. - Floresta da Tynea, Rı-Jax.. nº 349. Arbrisseau, fl. blanches. Aoùt-octobre. CG. Vulgo : Goyava.

31. P. guineensis Swartz; Mart. Fl. Bras. XIV, I, 1. 397. Rio Gama, dans le campo, Goraz, no 21173. Petit arbuste, fl. blanches. Novembre-décembre. $\mathrm{R}$.

32. P. ovoideum Berg in Warm. Symb. Enum. Myrt. Fl. Bras., p. 26. - Colline d'Ipiranga, SÃo-PAulo, n 12715. Arbrisseau, fl. blanches. Avril-mai. C.

33. P. anthomega Vell.; Fl. Bras. XIV, I, p. 410. - Serra do Itatiaia, dans le bois, Rio-JAx., no 12731 a. Bel arbuste, fl. blancles. Juinjuillet. R.

34. P.striatulum DC.; Warm. Symb. Enum. Wyrt. Fl. Bras., p. 26. - São Fidelis, près Campos, Rio-Jas., nº 9835. Arbuste, fl. blanches. Janvier-février. R. 
3\%. Psidium microcarpum Camb.; Mart. Fl. Bras. XIV, 1, p. 403. - Serra do Picú, Mivas, $n^{0} 10871$ a. Arbuste, fl. blanches. Avril-mai. C. Vulgo: Araça do campo.

36. P. suffruticosum Berg in Warm. Symb. Enum. Myrt. Fl. Bras., p. 27. - Serra de São José d'El Rei, Mınas, nº 16972. Petit arbuste, f1. blanches. Septembre-octobre. C.

37. P. Warmingianum Kiærsk. in Warm. Symb. Enum. Myrl. Fl. Bras., p. 28. - Serra do Picú, dans le campo, Mıxas, ${ }^{\circ}$ 10781. Petit arbuste, fl. blanches. Mars-avril. R.

38. P. Cattleyanum Sab.; Warm. Symb. Enum. Myrt. Fl. Bras., p. 28. - Serra da Estrella, Rio-Jan., n ${ }^{\text {os }} 6887,16060$. Arbuste, fl. blanches. Janvier-novembre. C.

- Var. coriacea Kiærsk. in Warm. Symb. Enum. Myrt. Fl. Bras., p. 28. - Quinta de Sào Christovão, Rio-Jav., n ${ }^{\text {os }} 6538,20324$. Arbuste cultivé, fl. blanches. Aoùt-septembre. G. Vulgo : A raça.

39. P. grandifolizm DG. var. incanescens Berg in Warm. Symb. Enum. Myrt. Fl. Bras., p. 32. - Colline d'Ipiranga, dans le campo, São-Paulo, $n^{\circ}$ 16053. Arbuste, fl. blanches. Mars-avril. C.

40. P. argenteum Berg in Warm. Symb. Emum. Myrt. Fl. Bras., p. 29. - Rio Gama, dans le campo, Goyaz, $n^{\circ} 21171$. Arbuste, fl. blanches. Octobre-novembre. C.

41. P. Gardnerianum Berg in Fl. Bras. XIV, I, p. 389. - Cabo Frio, près São Pedro do Indios, Rio-Jax., n ${ }^{\circ}$ 10823. Arbuste, fl. blanches. Juillet-aoùt. C.

42. P. glaucescens Berg in Mart. Fl. Bras. XIV, I, p. 600. - Biribiry, près Diamantina, Mıxas, $n^{\circ} 19361$ a. Petit arbuste, fl. blanches. Mars-avril. R.

43. P. itanareense Berg in Warm. Symb. Enum. Myrt. Fl. Bras., p. 29. - Bocaina, dans le campo, São-Paulo, nº 11994. Novembredécembre. Arbuste, fl. blanches. C. Vulgo : Araça.

44. P. cupreum Berg in Fl. Bras. XIV, I, p. 393. - Nova Friburgo, à Pedra do Conego, Rio-Jan., nos 8711,16989 . Arbuste, fl. blanches. Septembre. C.

- Var. glabrata Kiærsk. in Warm. Symb. Enum. Myrt. Fl. Bras, p. 30. - Nova Friburgo, Rı-J Jax., n ${ }^{\circ}$ 17683, Octobre-novembre. C.

43. P. rufum DC.; Warm. Symb. Enum. Nyrt. Fl. Bras., p. 31. - São Julião, près Ouro Branco, Mısas, $n^{\circ}$ 18244. Arbuste, fl. blanches. Janvier-mars. R. 
46. P. Widgrenianum Berg; Warm. Symb. Enum. Nyrt. I.l. Bras., p. 31. - Nova Friburgo, au Suspiro, Rio-Jax., n ${ }^{o s} 13446,14845$. Arbuste, fl. blanches. Novembre-décembre. CC.

47. P. incanescens DC.; Warm. Symb. Enum. Nyrt. Fl. Bras., p. 32. - Serra da Bocaina, São-Paulo, $n^{0}$ 8385; Ponte Alta, Goyaz, $\mathrm{n}^{0}$ 21172. Petit arbuste, fl. blanches. Septembre-octobre. C. Vulgo : Araça de campo.

48. P. Glaziovianum Kixrsk. in Warm. Symb. Enum. Myrt. Fl. Bras., p. 33. - Serrado Inficionado, près Caraça, Mısas, nos 13861 , 13870. Arbuste, f1. blanches. Octobre-novembre. C.

49. Acca Glazioviana Kiærsk. in Warm. Symb. Enum. Wyrt. Fl. Bras., p. 115. - Atalaia, à Pria Grande, Rio-JAx., nos 4812, 8708. Arbrisseau, fl. blanches. Aoùt-septembre. R.

50. Myrtus (Blepharocalyx) acuminatus Berg in Fl. Bras. XIV, I, p. 426. - Alto Macahé de Nova Friburgo, Rı-J ${ }_{\Lambda N}$., $n^{0}$ 19354. Arbuste, f1. blanches. Septemhre-octobre. C.

51. M. Getheanus DC.; Warm. Symb. Enum. Nyrt. Fl. Bras., p. 18. - São Fidelis, près Campos, Rio-Jax., no 9844 . Arbuste, fl. blanches. Juillet-août. R.

52. M. (Bleph.) angustifolius Berg in Fl. Bras. XIV, I, p. 420. - Pinheiro, près Diamantina, Mrsıs, $1^{\circ}$ 19731. Arbuste, fl. blanches. Mars-avril. R.

วิ2. M. organensis Glaz. n. sp.? in herb. Paris., Berol., Kew., Brux., etc. - Serra dos Orgãos, Rio-Jax., nº 16995. Arbuste, fl. blanches. Mars-avril. C.

5.'. M. corynantha Kiærsk. in Warm. Symb. Enum. Myrt. Fl. Bras., p. 18. - Nova Friburgo, Rı--JAN., nos 12721, 13887, 13892 et 19352. Janvier-février. C.

5ั. M. stictophylla Kiærsk. in Warm. Symb. Enum. Myrt. Fl. Bras., p. 20. - Serril de Ouro Branco, Minas, $n^{\circ}$ 14841. Petit arbuste, fl. Hanches. Novembre-décembre. R.

56. M. tijucana Glaz. n. sp.? in herb. Paris, Berol., Kew., Brux. - Floresta da Tijucil et Corcovado, Rio-Jan., $n^{\text {os }}$ 656, 2594. Arbuste, fl. blanches. Juillet-aoùt. C.

כั7. M. Beaurepairiana Kiærsk. in Warm. Symb. Enum. Wyrt. Fl. Bras., p. 22. - Serra dos Orgãos, côté sud, Rı-Jan., nº 17661. Arbuste, f1. blanches. Mar's-avril. R.

38. M. tomentosus Glaz. n. sp.? in herb. Paris., Berol., Kew., 
Havin, etc. - Corrego do Brejo, dans le campo, Goyaz, n² 21178. Petit arbuste, 11. blanches, fruit vert comestible. Septembre-octobre. CG.

59. Myrtus Glazioviana Kiarsk. in Warm. Symb. Enum. Myrt. Fl. Bras., p. 23. - Caraça, chemin de Catas Altas, Mısas, $n^{\circ} 14805$. Arbuste, 11. blanches. Juin-juillet. R.

60. M. fulvescens Kiersk. in Warm. Symb. Emum. Myrt. Fl. Bras., p. 24. - Sao João d'El Rei, dans le bois, Mıxas, $1^{\circ} 16984$ a. Grand arbre, Mars-avril. R.

61. M. fulvescens lorma Glazioviana Kiprk. in Warm. Symb. Enum. Myrt. Fl. Bras., p. ㄴ4. - Nova Friburgo, Rio-JAx., n 17682. Arbrisseau, li. blanches. Norembre. R.

62. M. Pseudo-Caryophyllus Gomaz in Warm. Symb. Enum. Myrt. Fl. Bras., p. 24. - Barbacena et São João d'El Rei, Mısas, $n^{o s} 11976$, 14807, 16055 et 16984. Arbrisseau, fi. blanches. Janvier-avril. G. Vulgo : Chá de Louro.

63. Myrcia pinifolia Camb. in St.Hil. Fl. Bras. Merid., p. 333. - Guariroha, dans le campo, Goraz, n² 21127. Frutescent, fl. blanches. Juin-juillet. C.

64. M. linearifolia Camb. in St.-Hil. Fl. Bras. Merid., p. 334. Cabeceira do Rio das Pedras, Goyaz, n 21128 . Frutescent, fl. blanches. Juin-juillet. CG. Vulgo : Ratania.

63. M. gamæana Glaz. n. sp.? in herb. Paris., Berol., Kew., Havn., etc. - Cabeceiras do Rio Gama, au Riacho Foundo, Goraz, $n^{\circ}$ 21159. - Frutescent, f1. blanches. Octobre-novembre. C.

66. M. bracteata DC.; Warm. Symb. Enum. Myrt. Fl. Bras., p. Ø̈2. - São Fidelis, près de Campos, Rio-Jav., no 9845. Arbuste, f1. blanches. Février-mars. R.

67. M. capitata Berg; Warm. Symb. Enum. Myrt. Fl. Bras., p. 82. - Entre Chico Lobo et Cabeccira du lio Torto, Goyaz, nos 21152, 21153. Frutescent, fl. blanches. Novembre-décembre. C.

68. M. angustifolia Glaz. n. sp.? in herb. Paris., Berol., Kew., Brux., etc. - Entre Rajadinha et Rio Torto, Goraz, $1^{\circ} 21168$. Frutescent, fl. Jlanches. Juin-juillet. C.

69. M. Eriopus DC.; Warm. Symb. Enum. Hyrt. Fl. Bras, p. 59. - Petropolis et Serra dos Orgãos, Rı-JAx., $n^{05} 3012,6539,7633$ et 16971. Arbuste, f1. blanches. Juillet-aoùt. CC.

70. M. hispida Berg; Warm. Symb. Enum. Myrl. Fl. Bras., p. 52. - Petropolis, à Santo Antonio, Rio-Jax., n $n^{\circ} 8394$; Bareira do Veado, Goraz, n² 21186. Arbuste, fl. blanches. Septembre-octobre. C. 
A.-F.-M. GLAZIOU. - LISTE DES PLANTES DU BRÉSIL CENTRAL. 211

71. M. Vauthieriana Berg in Nart. Fl. Bras. XIV, I, p. 13̆4. Serra de Ouro Preto, Misas, $n^{\circ}$ 14844. Arbuste, fl. blanches. Juinjuillet. C.

72. M. hirsuta Berg in Warm. Symb. Enum. Myrt. Fl. Bras., p. 52. - Fazenda de Sant' Anna, Mrsas, n 3759. Arbuste, 11. blanches. Juillet-aoùt. R.

73. M. Augustana Kiærsk. in Warm. Symb. Emum. Myrt. Fl.Bras., p. 52. - Entre Magé et Piedade, Rio-Jax., n ${ }^{\circ}$ 3002. Arbuste, fl. blanches. Octobre-novembre. R.

7'. M. costata DC.; Warm. Symb. Enum. Myrt. Fl. Bras., p. "33. - Restinga de Calıo Frio, Rio-JAx., nos 2595, 10831. Arbuste, fl. blanches. Juin-juillet. C.

79. M. guyavifolia Berg forma grandifolia Kiærsk. in Warm. Symb. Enum. Myrt. Fl. Bras., p. 54. - Theresopolis et au Jacú, Rio-Jav., $n^{o s} 1582,6160,8396,12716$. Arluste, fl. blanches. Septembre-octobre. CG.

76. M. Langsdorffii Berg; Warm. Symb. Emm. Myrt. Fl. Bras., p. 54. - Petropolis et à Nova Frilırgo, Rı-Jax., nos 11988, 11990. Arbuste, fl. blanches. Septembre-octobre. C.

77. M. melanosticta Kiærsk. in Warm. Symb. Enum. Myrt. Fl. Bras., p. 5้4. - Restinga de Cabo Frio, Rio-Jax., no 10832. Arluste, f1. blanches. Juillet-aoùt. R.

78. M. huanocensis Berg var. Glazroviana Kiærsk. in Warm. Symb. Enum. Myrt. Fl. Bras., p. כัŏ. - Apialıy, dans la forèt, São-Paulo, $\mathrm{n}^{\circ} 16068$ a. Arbuste, t1. blanches. Septembre-octobre. R.

79. M. ovata Camb.; Warm. Symb. Enum. Myrt. Fl. Bras., p. $ّ 5$. — Fazenda de Piratininga, Rio-JAv., ${ }^{\circ \mathrm{s}}$ 1280, 8390. Arluste, fl. blanches. Juin-juillet. C.

80. M. recurvata Berg; Warm. Symb. Enum. Myrt. Fl. Bras., p. 5ั. - Copacabana et à Restinga de llaná, Rio-Jav., $n^{o s} 51,2133$, 7631, 7632. Arbuste, f1. blanches. Novembre-décembre. CG.

81. M. anceps Berg var. depauperata Kiærsk. in Warm. Symb. Enum. Myrt. Fl. Bras., p. 5̋6. - Restinga de Naná et à Magé, Rı-Jax., $\mathrm{n}^{\text {os }} 2875,8389$. Arbuste, f1. blanches. Aoùt-septembre. C.

82. M. communis Berg var. glabrata Berg: Warm. Symb. Enum. Myrt. Fl. Bras., p. 56 . - Jurujuha, à Praia Grande, Rio-Jax., nº 9434. Arbuste, f1. blanches. Avril-mai. R.

83. M. corcovadensis Berg; Warm. Symb. Enum. Myrt. Fl. Bras., p. 56. - Serra do Cioelho, près Rezende, Rı-J.s., n 8700. Arbuste, fl. blanches. Novembre-décembre. C. 
8'. Myrcia Doniana Berg; Warm. Symb. Enum. Wyrt. Fl. Bras., p. ¿̈6. - Caho Frio, Rio-JAN, $n^{\circ} 11984$. Arbuste, ll. blanches. Juinjuillet. C.

85. M. microphylla Berg; Warm. Symb. Enum. Myrt. Fl. Bres., p. ¿6. - Nova Friburgo à Peda do Conego, Rio-d.1x., n 17679. Petit arbuste, fl. blanches. Novembre-décembre. C.

86. M. negrensis Berg; Warm. Symb. Emum. Myrt. Fl. Bras., p. 56. - São Fidelis, près de Campos, Rı-Jas., nº 9838. Arbuste, fl. blanches. Janviel-février. R.

87. M. arrudæana Glaz. n. sp.? in herb. Paris, Berol., Kew., Brux, etc. - Serra do Arruda, près Ileia Ponte, Goyaz, nº 21167. Frutescent, ft. blanches. Juillet-aoùt. C.

88. M. meiapontensis Glaz. 11. sp.? in herb. Paris, Berol., Kew., Havn, etc. - Meia Ponte, au Morro do Frota, Goraz, n² 21166. Frutescent, fl. blanches. Août-septembre. C.

89. M. opaca var. angustifolia Berg: Warm. Symb. Enum. Myrt. Fl. Bras., p. 56. - Haut du Coreovado et à Nova Friburgo, Rio-Jax., $n^{\circ s} 1275,17680$. Arluste, fl. blanches. Octobre-novembre. C.

- Var. latifolia Berg; Warm. Symb. Enum. Myrt. Fl. Bras., p. 37. - Santa Theresa, au Corcorado, Rio-Jan., n ${ }^{\circ}$ 9442. Arbuste, fl. blanches. Octobre-novembre. C.

90. M. oxyacanthophylla Kiersk. in Warm. Symb. Enum. Myrt. Fl. Bras., p. 57. - Serra do Cioello, près Rezende, Rio-JAN., no 8701; Diamantina, Mrvas, $n^{\circ}$ 19362. Mars-avril. R.

91. M. Regnelliana Berw; Warm. Symb. Enum. Nyrt. Fl. Bras., p. 58. - Petropolis, au Mundemo, Rio-dax., n 10795. Arbuste, 11. blanches. Novembre-décembre. C.

- Var. robusta Berg.; Warm. Symb. Enum. Myrt. Fl. Bras., p. З8. - Serra da Mantiqueira, à João Ayres, Mısas, no 16058. Arbuste, fl. blanches. Décembre-janvier. C.

92. M. rostrata DC.; Warm. Symb Enum. Myrt. Fl. Bras, p. ๖ั8. - Corcovado et Floresta da Tijuca, Rio-JAx., nos 655, 1511, 1540, 9438, 10830. Arbuste, fl. blanches. Septembre-nctobre. CG.

93. M. sylyatica var. Kisers. in Warm. Symb. Enum. Vyrt. Fl. Bras., p. 59. - Itapemirim et à Serras dos Puris, Espinito S.nтo, nos 9840 , 9842, 9847, 13900. Arbuste, f1. blanches. Octobre-novembre. CG.

94. M. sparadosticta Kiærsk. in Warm. Symb. Enum. Myrt. Fl. 
A.-F,-M. Glaziou. - liste des plantes du BRÉSIL CeNTral.

Bres., p. 59. - Itapemirim, Esp. Saxto, $\mathrm{n}^{\circ 8}$ 9836, 18248? Arbuste, fl. blanches. Février-mar's. R.

93. M. itambensis Berg in Warm. Symb. Enum. Nyrt. Fl. Bras., p. 60. - Serra da Caraça, dans le campo, Mrsas, $n^{\circ}$ 14811. Arbuste, fl. blanches. Aoùt-septembre. C.

96. M. melanosepala Kirersk. in Warm, Symb. Enum. Myrt. Fl. Bras., p. 60. - Serra do Alto Macahé, Rio-Jav., nº 17668. Arbuste, fl. blanches. Octobre-novembre. R.

97. M. buxifolia Gardn. in Warm. Symb. Enum. Myrt. Fl. Bras., p. 61. - Serra dos Orgãos, Rio-Jax, n 16996. Arbuste, fl. blanches. Mars-avril. C.

98. M. mischophylla Kirrsk. in Warm. Symb. Enum. Myrt. Fl. Bras., p. 61. - Serra do Inficionado, près Caraça, Misas, ${ }^{0 s} 14808$, 19377. Arbuste, 11. blanches. F'évier-mars. C.

99. M. Sellowiana Berg; Warm. Symb. Enum. Myrt. Fl. Bras., p. ¿̈2. - Bemposta, près Valance, Rio-JAx., no 2129. Arbuste, fl. blanches. Septembre-octobre. R.

100. M. canescens Berg; Warm. Symb. Enum. Myrt. Fl. Bras., p. 63. - Rio Areas, dans le campo, Goyaz, $\mathrm{n}^{\circ} 21154$. Petit arbuste, fl. blanches. Septembre-octobre. C.

101. M. nivea Camb. in St-Hil. Fl. Bras. Merid. II, p. 238. Serra dos Crystaes, près Diamantina, Mıxs, $n^{\circ}$ 19373. Petit arbuste, fl. blanches. Avril-mai. R.

102. M. tomentosa Glaz. 11. sp.? in herb. Paris., Berol., Kew., Brux., etc. - Entre Olho d'Agua et Paranána, Goraz, 1² 21556. Frutescent, fl. blanches. Mai-juin. C.

103. M. cordifolia Berg; Warm. Symh. Enum. Myrt. Fl. Bras., p. 63. - Cabeceiras do Rio Gama, dans le campo, Goyaz, no 21155. Petit arbuste, fl. blanches. Juillet-aoùt. R.

104. M. Lasiantha DC.; Warm. Symb. Enum. Myrt. Fl. Bras., p. 63. - Morro do Frota, près Heia Ponte, Goyaz, $11^{0 s} 21160,21161$. Arbuste, fl. blanches. Aoùt-septemlire. C.

10.. M. sabaræensis Glaz. 11. sp.? in herh. Paris., Berol., Brux., Kew.. etc. - Sabara, an Morro do Ramão, Mısas, $n^{\circ}$ 20325. Arbuste, fl. blanches. Novembre-décembre. G.

106. M. lemosiana Glaz. n. sp.? in herb. Paris., Brux., Berol., Havn., Kew., etc. - Entre Porto do Lemos et Macaco, Goyaz, no 21193. Arbuste, fl. blanches. Aout-septembre. CG. 
107. Myrcia rigida Glaz. n. sp.? in herb. Paris., Berol., Kew., Brux., etc. - Entre Saia Velha et Santa Luzia, dans le cerrarlo, Havı., Goyaz, nº 21194. Arhrisseau, fl. blanches, Aoùt-septembre. C.

108. M. ferruginea Glaz. n. sp.? in herb. Paris., Berol., Brux., Kew., etc. - Bella Vista, au Barro Amarello, Goyaz, nº 21195. Arbrisseau, fl. blanches. Aoùt-septembre. C.

109. M. pilotantha Kixrsk. in Warm. Symb. Enum. Myrt. Fl. Bras., p. 64. - Petropolis, au Mlorro do Retiro. Rı-J Jan., $n^{05} 13881,16991$. Arbuste, fl. blanches. Janvier-février. C.

110. M. pulchra Berg in Warm. Symb. Enum. Myrt. Fl. Bras., p. 63. - Alto Macahé de Nova Frilurgo et à Petropolis, Rio-Jan., $n^{0}$ 17663. Arbuste, f1. blanches. Février-mars. C.

111. M. subcordata DC.; Warm. Symb. Enum. Myrt. Fl. Bras., p. 65̃. - Itacolumy, près Ouro Preto, dans le campo, Misas, nº 14829. Arbuste, fl. blanches. Férrier-mars. R.

112. M. bicolor Kiærsk. in Warm. Symb. Enum. Myrt. Fl. Bras., p. 68ั. - Floresta da Tijuca, Rio-Jav., no 10797. Très grand arbre, fl. blanches. Novembre-décembre. C.

113. M. Gardneriana Berg in Mart. Fl. Bras., XIV, I, p. 184. Restinga de Copacabana et de llaná, Rı-Jax., nos 7, 10, 62. Arbuste, f1. blanches. Janvier-février. CG.

114. M. plusiantha Kiærsk. in Warm. Symb. Enum. Myrt. Fl. Bras., 1) 66. - Alto Macahé de Nova Friburgo, Riso-Jax., n 16994. Arbrisseau, fl, blanches. Hars-arril. R.

115. M. pilodes Kixrsk, in Warm. Symb. Enum. Myrt. Fl. Bras., p. 67. - Serra do Lenheiro, dans le campo, Mixas, $1^{\circ}$ 16976. Arbrisseau, fl. blanches. Octobre-novembre. R.

116. M. atropunctata Kiærsk. 11. sp.? in Warm. Symb. Enum. Myrt. Fl. Bras., p. 68. - Restinga de Cabo Frio, Rio-Jav., n 11982. Arbuste, fl. blanches. Juin-juillet. R.

117. M. Kiærskowii Glaz. n. sp.? in herb. Paris., Berol., Kew., Brux, etc. - Près Santa Luzia, Goyaz, n² 21176. Arbuste, fl. blanches. Aoùt-septembre. C.

118. M. alloiota Kiarsk. in Warm. Symb. Enum. Myrt. Fl. Bras., p. 70. - Rio Manço, près Arassuahy, Mıxas, $n^{\circ}$ 13865. Arbrisseau, fl. blanches. Férrier-mars. C.

119. M. curatellifolia DC. var. grandifolia Berg in Warm. l. cit., p. 70. - Páo d'Alho, Espinito Santo, n 10837. Arluuste, fl. blanches. Janvier-février. R. 
A.-F.-M. GLAZIOU. - LISTE DES Plantes DU BRÉSIL CENTRAL. 215

120. M. longipes Kixrsk. in Warm. Symb. Enum. Myrt. Fl. Bras, p. 70. - Nova Friburgo, au Morro do Suspiro, Rı-JAx., $11^{\circ} 13447$; Serra do Lenheiro, Mıvas, nos 16975, 19356, 19357; Chapada da Bandeirinha, Goraz, $n^{\circ}$ 21174, 21175. Arbrisseau, f1. blanches très odorantes. Septembre-novembre. CC.

-- Forma obovata Berg; Warm. Symb. Enum. Myrt. Fl. Bras., p. 70. - Entre Ouro Preto et Marianna, Mlisas, ${ }^{0 s}$ 1387, 14846. Arbrisseau, fl. blanches odorantes. Octobre-novembre. C.

121. M. maranhanensis Kiarsk, in Warm. Symb. Enum. Mypt. Fl. Bras., p. 71. - Serra da Italapoana, Espmito Saxto, no 10839. Arbuste, f1. blanches. Aoùt-șeptembre. R.

129. M. membranacea Kiærsk, in Warm. Symb. Enum. Myrt. Fl. Bras., p. 71. - Campos da Bocaina, São-Paulo, nº 9834. Arluuste, f1. blanches. Janvier-février. R.

123. M. rosulans Kixrsk. in Warm. Syml. Enum. Myrt. Fl. Bras., p. T2. - Serra dos Orgãos, à Theresopolis, Rio-JÃx., nos 12732, 14814. Arbuste, f1. blanches. Février-mars. C.

124. M. spathulata Kixrsk. in Warm. Symb. Enum. Myrt. Fl. Bras., p. 72. - Petropolis, au Nlundemo, Rio-Jax., no 3006. Arbuste, f1. blanches. Octubre-novembre. R.

12.. M. hexasticha Kiærsk. in Warm. Symb. Enum. 1/yrt. Fl. Bras., p. 72. - Guaximdiba, dans les sables, Rio-Jax., $n^{0} 11975$. Arbrisseau, fl. blanches. Février-mars. R.

126. M. morroqueimadensis Kiprsk. in Warm. Symb. Enum. Myrt. Fl. Bras., p. 73. - Morro Queimado, près Tijura, Rio-Jax., $\mathrm{n}^{05} 6537,19363$. Arbuste. 11. Hanches. Aoùt-septembre. C.

127. M. pubiflora DC... var. Glazioviana Kiærsk. in Warm. Symb. Enum. Mypt. Fl. Bras., p. 74. - Morro do Coco ou do Bagy, Rio-Jan., $\mathrm{n}^{\circ}$ 10842. Arbuste, tl. blanches. Novenbre-décembre. R.

128. M. Laruotteana Camb.; Warm. Symb. Enum. Myrt. Fil. Bras., p. 74. - Nova Friburgo, Rio-JAN., $\mathrm{n}^{\text {os }}$ 11979, 13451, 16988; Itabira do Campo, Mnvs, $\mathrm{n}^{0 \mathrm{~s}}$ 16977, 16978. Arbuste, f1. blanclres. Septembre-octobre. CC.

129. M. rhodeosepala Kixrsh. in Warm. Symb. Enum. Myrt. Fl. Bras., p. 7\%. - Serra da Caraca, dans le campo, Mlasas, $n^{\circ \mathrm{s}} 13866$, 13867. Arluste, fl. blanches. Février-mars. R.

130. M. adpresse-pilosa Kixersk. in Warm. Symb. Enum. Myrt. Fl. Bras., p. ̄̌̈. - Norro do Coco ou do Bahú, R10-Jax., nº 10834. Janvierdécembre. Ii. 
131. Myrcia amblyphylla Kixrsk. in Warm. Symb. Enum. Myrt. Fl. Bras., p. 76. - Serra da Garaça, dans le campo, Minas, no 14831. Arbuste, fl, blanches. Février-mars. R.

132. M. calumbaënsis Kiersk. in Warm. Syml. Emum. Myrt. Wl. Bras., p. 77. - Alto do Norro da Gavea, Rio-Jax., n 8392. Arbuste, fl. blanches. Mai-juin. C.

133. M. Schwackeana Glaz. n. sp. in herl. Paris., Berol., Kew., Brux., Havn., elc. - São Fidelis, Rı-Jan., nº 9689. Arluste, f1. blanches. Janvier-février. R.

134. M. lateriflora Kiærsk. in Warm. Symb. Enum. Myrt. Fl. Bras., p. 77. - Serra de Nova Friburgo, à Cachoeila, Rı-JAn., nº 3979. Arbuste, fl. blanches. Février-mars. C.

130. M. leptoclada DC. var. Glazioviana Kiarsk. in Warm. Symb. Enum. Myrt. Fl. Bras., p. 78. - Corcovato et Floresta da Tijuca, RıJAN., $n^{\text {os }} 8710,9441$. Très grand arbre, fl. blanches. Aoùt-septembre. C.

136. M. Lundiana Kiærsk. in Warm. Symb. Emum. Myrt. Fl. Bras., p. 78. - Restingal de Copacabana, Rio-Jan., $11^{\circ}$ 5865. Arbuste, fl. blanches. Juin-juillet. R.

137. M. torta DC. val, glauca Berg; Warm. Symb. Enum. Nyrt. Fl. Bras., p. 79. - Barbacena, dans le campo, Hısas, ${ }^{\circ s} 12723,16075$; Rio Areis, Goyaz, n 21188. Arbuste, ll. blanches. Aoùt-septembre. C.

138. M. corumbensis Glaz. n. sp. in herb. Paris., Berul., Kew., Brux., etc. - Entre Corumba et As Estacas, Goynz, n 21190. Frutescent, fl. blanchies, très odorantes. Aoùt-septembre. C.

139. M. rorida Berg; Warm. Symb. Enum. Wiyrt. Fl. Bras., p. 79. - Guariroba, dans le campo, Goraz, $n^{0 \mathrm{~s}} 21162,21163$. Frutescent, fi. blanc-rose. Avùt-septembre. CC.

- Var. microphylla Glaz. in herb. Paris., Berol., Kew., Brux., etc. - Entre Serril dos Pyreneus et Corumba, Goyaz, nos 21137, 21164. Frutescent, fl. blanches. Aoùt-septembre. Ci.

140. M. corulescens Kirrsk, in Warm. Symb. Enum. Myrt. Fl. Bras., p. 79. -- Restinga de Cabo Frio, Rio-JAN., $n^{\circ}$ 12725. Arbuste, 11. blinches. Août-septembre. CG.

141. M. ramulosa DG.; Warm. Symb. Enum. Myrt. Fl. Bras., p. 184. - São Clıristorão, au Pedregulho, Rio-J.ñ., nos 2130, 3007. Arbuste, fl. blanches. Octobre-novembre. CG.

142. M. colpodes Kiærsk. in Warm. Symb. Enum. Wyrt. Fl. Bras., p. 80. - Praia Grande, au Morro da Viracão, Rı-Jax., $n^{\circ} 832$. Arbuste, fl. blanches. Mars-itril. R. 
A.-F.-M. GLAZIUU. - LISTE DES PLANTES DU BRÉSIL CENTRAL.

143. M. colosepala Kiærsk. in Warm. Symb. Enum. Myrt. Fl. Bras., p. 81. - Serla de Nova Friburgo, Rio-Jax., n 13893. Arbuste, fl. blanches. Décembre-janvier. C.

144. M. exsucca DC.; Warm. Symb. Emum. Myrt. Fl. Bras., p. 82. - Serra da Caraça, dans le campo, Misas, n 14810. Arbuste, fl. blanches. Décembre-janvier. C.

143. M. pallens DG.; Warm. Symb. Enum. Myrt. Fl. Bras., p. 83. - Serra de Itabapoana, Esr.-Santo, $1^{\circ}$ 11983. Arbuste, fl. blanclies. Septembre-octobre. C.

146. M. Hostmanniana Kiærsk. var. roвustion Berg.; Warm. Symb. Enum. Myrt. Fl. Bras., p. 83. - Itapenirim et à Pao d'Allı, EspiritoSanto, ${ }^{\text {os }}$ 13896, 13897, 13899. Arbuste, fl. blanches. Février-mar's. C.

147. M. grandiglandulosa Kiærsk. in Warm. Symb. Emum. Myrt. Fl. Bras., p. 83. - Santo Angelo, près Villa Nova, Rı-JAx., nº 13879. Arbuste, fl. blanches à odeur de miel. Octobre-novembre. C.

148. M. Kiærskowiana Glaz. 11. sp.? in herb. Paris., Havn., Berol., Brux., etc. - Lagoinha, près Santa-Luzia, Goyaz, n²1176. Arbrisseau, fl. blanches. Mars-avril. C.

149. M. multiflora DC.; Warm. Symb. Enum. Myrt. Fl. Bras., p. 84. - São Fidelis, près Campos, Rı-Jax., nº 9839. Arbuste, fl. blanches. Janvier-février. R.

150. M. ovalifolia Kirrsk. in Warm. Symb. Emum. Myrt. Fl. Bras., p. 84. - Fazenda de Santa-Cruz, Rio-JaN., nos 9430, 13880. Arbuste, 11. blanches. Novembre-décembre. C.

151. M. tenuivenosa Kiærsk, in Warm. Symb. Emum. Myrt. Fl. Bras., P. 84. - Petropolis et à Nova Friburgo, Rı-JAN., $11^{0 s} 3004,6540$, 11989, 17675. Arbuste, fl. blanches. Septembre-octobre. C.C.

15\%. M. chapadinhæana Glaz. n. sp.? in herb. Parris., Berol., Havn., Brux., etc. - Chapadinha, dans le campo, Goyaz, n² 21179. Frutescent, fl. blanches. Octobre-novembre. C.

153. M. marginata Berg. in Mart. Fl. Bras. XIV. I, p. 565ั. - Guralinho, près Diamantina, Mısas, no 19359. Frutescent, f1. blanclıes. Marsavril. R.

1ั4. M. siriacoana Glaz. 11. sp.? in herl, Paris., Berol., Havn., Kew., etc. - Entre As Lages et Siriaco, Goraz, $n^{0}$ 21148. Frutescent, fl. blanches. Aoùt-septembre. R.

13\%. M. daphnoides DG.; Warm. Syml. Enum. Myrt. Fl. Bras., p. 86. - Bella Vista, au Barro Vermelho, Goraz, $n^{\circ} 21149$. Frutescent, fl. blanclies. Septembre-octobre. C. 
Var. nervosa Kiwrsk. in herb. Havn., Berol., kew., Brux., etc. - Chapadinha, dans le campo, Goraz, $11^{\circ}$ 21169. Futescent, fl. blanches. Octohre-novembre. C.

156. Myrcia (Aulomyrcia) tortuosa Kimrsk.; Mart. Fl. Bras. XIV, I, p. 5838 . - Solıadino, à Puso Alta dans le Cerrado, Govaz, $1^{\circ} 21165$. Arbrisseau, fl. blanches. Aoùt-septembre. C.

15\%7. M. Rabeniana Kiærsk. in Warm. Symb. Enum. Myrt. Fl. Bras., 1. 86. - Rio Gama, au bord de la rivière, Gosaz, no 21142. Arbuste, fl. blanches. Novembre-décembre. C.

158. M. subrugosa Kiærsh. in Warm. Symb. Enum. Myrt. Fl. Bras., 1. 86. - Petropolis, à Itamaraty, Rı-JAx., $1^{\circ}$ 7642. Arbuste, fl. blanches. Octobre-novembre. C.

159. M. subverticillaris Kixrsk. in Warm. Symb. Enum. Wyrt. Fl. Bras., p. 88. - Congonhos do Campo, Nivas, $n^{\text {os }}$ 14538, 19376. Arlouste, fl. blanches. Juin-juillet. C.

160. M. bombycina Kiærsk. in Warm. Symb. Enum. Myrt. Fl. Bras., 1. 89. - Lagoa do Mestre d'Armos, Goyaz, nos 21144, 21189. Arlouste, fl. blanches. Norembre-décembre. C.

161. M. coriacea DC.; Warm. Symb. Enum. Myrt. Fl. Bras., p. 89. - São Fidelis, près Campos, Rio-Jan., nº 9833. Arluuste, fl. blanches. Janvier-février. R.

162. M. crassifolia Kiærsk. in Warm. Symb. Enum. Myrt. Fl. Bros., 1. 89. - Entre Sitio et Ilheos, Mrsas, no 16054. Arbrisseau, fl. blanches. Décembre-janvier. C.

163. M. obtecta Kiersk. in Warm. Symb. Enum. Myrt. Fl. Bras., p. 89. - Piro da Tijuca, Petropolis, Nova Friburgo, Rı-JAs., ${ }^{\text {os }} 4987$, 7630, 8383, 10794, 10798, 10799, 13448, 13449; Serra de São José d'El Rei, Barbacena, dans le cerrado, Mixas, $1^{\text {os }} 8699,10794,14837,16070$. Arbuste, fl. blanches. Novembre-décembre. CC.

164. M. amethystina Kiærsk. in Warm. Symb. Enum. Myrt. F\%. Bras., p. 90. - Arraial de Ouro Branco, Misas, nos 14836, 20326. Arbrisseau, fl. blanches. Novembre-décembre. C.

163. M. intermedia Kiærsk. in Warm. Symb. Enum. Myrl. Fl. Bras., p. 90. - Entre Cuba et Morrinhos, Goyaz, no 21187. Arbuste, fl. blanches. Aoùt-septenibre. R.

166. M. cymosopaniculata Kixrsh. in Warm. Symb. Emum. Myst. Fl. Bras., p. 90. - Corcovado, à Paineiras, Rio-Jax., n 11986. Très grand arbre, fl. blanclies. Aoùt-septembre. C. 
A.-F.-N. GLAZIOU. - LISTE DES PLAXTES DU BRÉSHL CEXTRAL. 219

167. M. diaphanosticta Kirs'sk. in Warm. Symb. Enum. Myrt. Fl. Bras., 1. 91. - Serra da Caraça, dans le campo, Mısas, nº 14812. Arlurisseau, fl. b]anches. Janvier-février. C.

168. M. fastigiata Kixrsk. in Warm. Symb. Emmm. Myrt. Fl. Bres., p. 92. - Floresta da Tijuca, Rı-JAx., nos 17669, 17677. Arbrisseau, fl. blanches. Anutt-septembre. C.

169. M. oblongata DC. in Warn. Symb. Enum. Myrl. Fl. Bras., p. 93. - Serra de Ouro Preto, Mlinas, $n^{\text {os }}$ 14838, 16973. Arbrisseau, f1. blanches. Septembre-octobre. C.

170. M. spharocarpa DC.; Warm. Symb. Enum. Myrt. Fl. Bras., p. 93. - Entre Sitio et Barbacena, Mis.se, $n^{\text {os }}$ 11977, 14200, 14835. Arbuste, fl. blanches. Novembre-décembre. C.

171. M. oreioeca Kimrsk. in Warm. Symb. Emum. Hyrt. Fl. Bras., p. 9'. - Serra da Estrella, Rio-Jax., no 6547. Arbrisseau, fl. blanches. Septembre-octobre. R.

172. M. cuprea Kiarsk. in Warm. Symb. Emum. Myrt. Fl. Bras., p. 9\%. - Paço Isabel, à Larangeiras, Rio-dax, $n^{\text {os }} 15421$, 16071. Arluste cultivé, fl. blanches. Juin-juillet. R.

173. M. rufipes D. C. var. pilantha Kiærsk. in Warm. Symb. Emum. Myrt. Fl. Bras., p. 9\%. - Serra da Caraça, dans la forèt, Misas, $n^{\circ s} 13877$, 16076, 20324 a. Arbuste, fl. blanches. Aout-septembre. C.

174. M. pubipetala Vliq.; Warm. Symb. Enum. Myrt. Fl. Bras., p. 9.. - Corcovado, Floresta da Tijuca et à Petropolis, Rı-Jas., $n^{\circ} 862$, 3000, 11992, 12002 et 16986. Arbrisseau, f1. blanches. Février-mar's. CG. Vulgo : Arara.

17\%. M. pyrrhopilodes Kiprsk. in Warm. Symb. Enum. Myrt. Fl. Bras., p. 96. - Serra de Sĩo José d'El Rei, Mixas, no 16067. Arhuste, fl. blanches. Novembre-décembre. R.

176. M. vestita DG. in Warm. siymb. Enum. Myrt. Fl. Bras., p. 97.

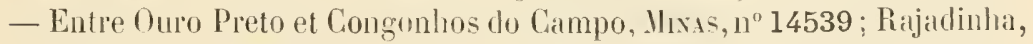
dans le campo, Goraz, ${ }^{\circ 5} 21150,21201$. Arbuste, fl. blanches. Févilermars. C.

- Vill. grandifolia Berg; Warm. Symb. Enum. Wypt. Fil. Birls., p. 97. - Chico Costa, dans le cerrado, Goraz, $1^{\circ}$ 21202. Albuste, fl. blanches. Octolsre-novembre. R.

177. M. Richardiana Kixrsk. in Warm. Symb. Enum. Myrt. Fl. Bras., p. 97. - Floresta da Tijuca, au Norro do Archer, Ro-Jax., $n^{\circ}$ 16062. Grand arbre, 11. blanches. Novembre-décembre. R. 
178. M. dermatophylla Kixrsk. in Warm. Symb. Enum. Nyrt. Fl. Brus., p. 97. - Restinga da Tijuca, près la mer, Rı-Jan., $\mathrm{Il}^{\circ} 885$. Arluste, fl. blanches. Novembre-décembre. C.

179. Miyrcia lenkeirensis Kixrsk. in Warm. Symb. Emum. Myrt. Fl. Bras., p. 98. - Serra dos Orgãos, Rı-Jan., $n^{\circ} 16040$; Caraca et Serra de Ouro Branco, Minas, ${ }^{\circ 5}$ 14820, 14840. Arbuste, fl. blanches. Décembre-janvier. C.

180. M. paracatuensis Kirrsk. in Warm. Symb. Enum. Myrt. Fl. Bras., p. 99. - Chapadinha et à Corrego do Brejo, Goyaz, nos 21133 , 21134, 21135, 21136. Frutescent, fl. blanches. Septembre-octobre. CC.

- Var. pumila Glaz. in herb. Paris., Berol., Kew., Havı., etc. Serra dos Crystaes et au Abbade, Goraz, $n^{\text {os }} 21131,21132$. Frutescent, 11. rosées. Septenbre-octobre. C.

181. M. stricta Kiærsh. in Warm. Symb. Enum. Myrt. Fl. Bras., p. 99. - Rio Corumba, dans le campo, Goraz, $\mathrm{n}^{\circ}$ 21126. Frutescent, fl. blanches. Aoùt-septembre. C.

I82. M. rhabdoides Kirersk. in Warm. Symb. Enum. Myrt. Fl. Bras., p. 99. - Alto Macahé de Nova Friburgo, Rıo-Jax., $1^{\text {os }} 1583$. 17660. Arbuste, fl. blanches. Mars-avril. R.

183. M. innovans Kiærsk. in Warm. Symb. Enum. Myrt. Fl. Bras., p. 100. - Petropolis au Alto do Inperador, Rio-JAv., $\mathrm{II}^{\circ}$ 12000. Arbrisseau, fl. blanches. Février-mars. C.

I84. M. Vittoriana Kiærsk. var. pratenigensis Kiærsk. in Warm. Symb. Enum. Myrt. Fl. Bras., p. 102. - Piratiniga, dans le bois vierge, Rı-Jax., nº 5872. Arbrisseau, fl. blanches. Novembre-décembre. R.

185. M. spectabilis DC.; Warm. Symb. Enum. Myrt. Fl. Bras., p. 101. - Floresta de Tijuca et à Petropolis, Rio-Jan., nos 2586, 12008. Arbrisseau, 11. blanches. Février-mars. C.

186. M. (Aulom.) Lingua Berg in Linnsea XXVII (185̈4), p. 77; Fl. Bras. XIV, I, p. 130. - Rodrigo Sylva ou Capão, près Ouro Preto, Ilısas, n" 19374 a. Frutescent, il. blanches. Novembre-décembre. C.

187. M. nitida Kixrsk. in Warm. Symb. Enum. Myrt. Fl. Bras., p. 102. - Corcovado et Floresta da Tijuca, Rio-JAx., $n^{05} 654,2585,3980$. A'brisseau, fl. blanches. Février-mars. CC.

188. M. brasiliensis Kixrsk. in Warm. Symb. Enum. Myrt. Fl. Bras., p. 102. - Haut du Coreovado et Petropolis, Rio-JAN., ${ }^{\circ s} 65$, 657, 2584, 3005, 20320. Arbuste, fl. blanches. Janvier-décembre. CC.

I89. M. tijucensis Kiærsk. in Warm. Symb. Enum. Myrt. Fl. Bras., 
1.-F.-M. GLAZIOU. - LISTE DES PLANTES DU BRÉSIL CENTRAL.

p. 102. - Floresta da Tijuca et à Jacarepagua, Rı-Jav., nos $3977,6886$. Arbuste, f1. blanches. Décembre-janvier. C.

190. M. Warmingiana Kiarsk. in Warm. Symb. Enum. Myrt. Fl. Bras., p. 104. - Alto Macahé de Nova Friburgo, Rio-Jax., u 17673. Arbuste, fl. blanches. Décembre-janvier. R.

191. M. crocea Kiarsk. in Warm. Symb. Enum. Myrt. Fl. Bras., p. $10 \%$. - Porto das Caixas, Morro da Babylonia, Serra da Estrelli, etc. Rio-J Ax., $\mathrm{n}^{\text {os }}$ 139, 1121, 1281, 2596, 4989, 7641 et 12003. Aririsseau, 11. blanches. Janvier-février. CC.

192. M. estrellensis Kiærsk. in Warm. Symb. Emmm. Wyrt. Fl. Brus., p. 107. - Alto Macahé et Serra da Estrella, Rio-Jas., ${ }^{05} 652$, 10780, 17670. Arbrisseau, fl. blanches. Mars-avril. C.

193. M. Hookeriana Kiarsk. in Warm. Symb. Enum. Myrt. Fl. Bras., p. 107. - Serra do Picú et à Nova Friburgo, Rı-Jan., nos 9433 , 19378. Arbuste, fl. blanches. Mars-avril.

194. M. (Gomidieza) amplexicaulis Berg in Mart. Fl. Bras. XIV, 1, p. 13. - Floresta da Tijuca, au Morro da Fazendo, Rio-Jas., no 4811. Arbrisseau, fl. blanches. Janvier-février. R.

195. M. reticulata Camb.; Warm. Symb. Emum. Myrt. Fl. Bros., p. 107. - Fazendo do Itatiaia, dlans le bois, Rio-Jas., nº 6546. Arbrisseau, fl. blanches. Janvier-février. R.

196. M. picuensis Kixrsk. in Warm. Symb. Enum. Myrt. Fl. Bras., p. 107. - Serra do Picú et à Sào José do Barreiro, liro-Jax., nos 8381 , 10782. Arbuste, fl. blanches. Février-mars. R.

197. M. Hartupegiana Kiærsk. in Warm. Symb. Enum. Myrt. Fl. Bras., p. 109. - Campos de Bocaina, S̃̃o-PAulo, n 8386 ; Agua Limpa, Gandarela, Mrsas, $n^{0}$ 14830; Alto Macahé et à Theresopolis, Rio-Jax., $n^{\circ}$ 17004. Arbuste, fl. blanclıes. Février-mars. C.

198. M. Decaisneana Glaz. n. sp. in herb. Paris., Berol., Kew., Genev., etc. - Entre Ciganos et As Brancas, dans le cerrado, Goraz, $n^{\circ}$ 21151. Frutescent, fl. blanches. Décembre-janvier. C.

199. M. douradensis Glaz. n. sp. in herb. Paris., Berol., Kew., Brux., etc. - Haut de la Serra Dourada, dans le campo à Otho d Agua, Goraz, n²1140. Frutescent, fl. blanches. Aout-septembre. li.

200. M. ilheosensis Kiarsk. in Warm. Symb. Enum. Myrt. Fl. Bras., 1. 109. - Restinga de Copacabana, Cabo Frio, da Gavea, RioJAx., $n^{\text {os }} 90,653,3981,5873$. 8705. Arbuste, fl. Hanches. Norembrejanvier. CC. 
401. Myrcia minensis Kixrsk. in Warm. Symb. Enum. Myrt. Fl. Bras., p. 110. - Norro Quimato, près de Tijuca, Rro-JAx., $1^{05} 2582$, 2999, 10792. Aljuste, 11. Jlanches. Janvier-février. C.

202. M. eriocalyx DC. var. Beyrichiana Kixrsk, in Warm. Symb. Enum. Myrt. Fl. Bras., p. 110. - Alto Nacahé de Nova Friburwo, RioJAN., $n^{\circ}$ 13890. Arbuste, fl. blanches. Février-mars. R.

- Form. brumea Berg; Warm. Syml. Enum. Myrt. Fl. Bras., p. 111. - Serra do Lenlıeiro, dans le campo, Misas, $1^{05}$ 14827, 17674. Alluste, fl. blanches. Janvier-février. C.

203. M. caraçana Glaz. n. sp. in herb. Paris., Berol., Kew., Ilavn., etc. - Caraça, au Morro da Carapuça, Mrsas, n² 14817. Petit arluste, fl. blanclres. Jnin-juillet. R.

204. M. Gaparoana Schw. nov. sp. in lrerb. Berol., Hawn., Kew., Brux., etc. - Guaviroba au Morro Cubatão, Goraz, no 21159. Frutescent, fl. blanches. Octobre-novembre. C.

205. M. virgata Camb. in Fl. Bros. merid. II, p. 320. - Jaragua. au Curalinho, Goyaz, $n^{\circ 5} 21184$ et 21170 . Frutescent, fl. blanches. Juilletatoùt. C..

206. M. Glazioviana Kixrsh. in Warm. Symb. Enum. Myrt. Fl. Brus., p. 111. - Serra do Alto Viacalıé de Nova Friburgo, Rro-Jax., $n^{\circ}$ 17005. Arbuste, fl. blanches. Février-mars. R.

- Var. villosa Kiærsk. in Warm. Symb. Enum. Myrt. Fl. Bras.,

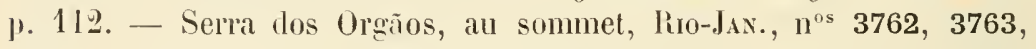
16999. Arbuste, 11. Blanches. Février-mars. C.

907. M. Kunthiana Kiærsk. var. Latifola Berg; Warm. Symb. Enum. Myrt. Fl. Bras., p. 113. - Serra de São José d'El Rei, Mrnas, $n^{\circ}$ 16072. Arbuste, fl. blanches. Décembre-janvier. C.

- Var. catissima Kiærsk. in Warm. Symb. Emum. Myrt. Fl. Bras., p. 113, - Serra dos Orgãos, au sommet, Rro-JAn., $n^{\text {os }} 3760,3983$, 16049. Arbuste, fł. blanches. Janvier-février. C.

- Var. microphyle Kixrsk. in Warm. Symb. Enum. Mypr. Fl. Bras., p. 113. - Serra dos Orøãos, còté de Petropolis, Rio-Jus, no 16998. Arbuste, fl. blanches. Février-mars. C.

208. M. Labordeana Glaz. n. sp.? in herb. Paris., Havn., Berol., Kew., ete. - Entre Porto de São Bartholomeu, et Serra dos Crystales, dans le campo, Goyaz, n² 21157. Frutescent, fl. blanches. Septembreoctolire. C.

209. M. tocantinensis Glaz. n. sp.? in herb. Paris., Berol, Kew. 
A.-F.- H. GLAZIOU. LISTE DES PLANTES DU BRÉSIL CENTRAL.

Brux., etc. - Entre le Rio Tocantins et Os Porcos, Goyz, $1^{\circ} 21158$. Frutescent, fl. blanches. Janvier-février. C.

210 M. Crulsiana Glaz. n. sp. in herb. Paris.. Berol., Kew., Brux, etc. - Entre Mestre d'Armes et Fartura, Govaz, n² 21139. Frutescent, fl. blanclies. Octobre-norembre. C.

211. M. ouropretoensis Kiærsk. in Warm. Symb. Emum. Myrl. Fl. Bras., p. 113. - Itacolumy, pres Ouro Preto, Misas, ${ }^{\circ}$ 14828. Arbuste, fl. blanches. Février-mars. R.

212. M. sessilifolia Kirersk. in Symb. Enum. Myrt. Fl. Bras., p. 115. - Serra de São João d'El Rei, Mixıs, nos 14824, 16068. Arluste, fl. blanches. Décembre-janvier. C.

213. M. Peckoltiana Glaz. 11. sp.? in herb. Paris., Berol., Kew., Brux., etc. - Alto Macahé de Nova Friburgo, Rio-Jax., no 18242. Arbrisseau, fl. blanches. Octobre-novembre. C.

21'4. M. Wittigiana Glaz. n. sp.? in herb. Paris., Berol., Kew., Brux., elc. - Nlto Nacahé de Nova Friburgo, Rio-Jan., nº 18241. Albrisseau, fl. blanches. Octobre-novembre. C.

21\%. M. diamantinensis Glaz. n. sp. ? in herb. Paris., Berol., kew., Gener., etc. - Serra dos Crystaes, près Diamantina, Mrsas, n 19360, 19361. Frutescent, f1. blanches. Arril-mai. C.

216. M. lanuginosa Berg in Fl. Bras. XIV, I, p. 20\%̈. - Serra Dourada dans le campo, Goysz, $n^{\circ}$ 21195. Arbuste, fl. blanches. Aoùtseptemlire. C.

217. M. depauperata Glaz. 11. sp.? in herł. Paris., Berol., Kew., Harn., Brux., etc. - Serra dos Crystaes, dans le Campo, Goraz, no 21129. Frutescent, fl. blanches. Septembre-octobre. R.

218. Marlieria Regeliana Berg; Warm. Symb. Enum. Myrt. Fl. Bras., p. 44. - Queimados, Jacarépagua, Corcovado, Rio-dAx., $n^{\circ \mathrm{s}}$ 10787, 10804 et 16059. Arbrisseau, fl. blanches. Décembre-janvier. CC.

219. M. grandifolia Berg; Warm. Symb. Enum. Myrt. Fl. Bras., p. 4't. - Corcovado, à Caixa I'Agua, Rı-JAx., nº 4813. Arbuste, fl. blanches. Octolsre-novembre. R.

220. M. verticillaris Berg in Nart. Fl. Bras. XIV, I, p. $538 .-$ Floresta da Tijuca, Rı-Jax., nº 10796. Arbuste, fl. blanches. Décembre. R.

221. M. spathulata Berg; Warm. Symb. Emum. Myrl. Fl. Bras., p. 45. - Corcovado et Floresta da Tijuca, Rio-JAN., $11^{\text {os }} 1277,6534,9423$, 9424, 9436, 17666. Arbrisseau, fl. blanches. Juin-juillet. CC. V'ulgo : Guapurunga. 
222. Marlieria Langsdorffii Berg; Symb. Enum. Myrt. Fl. Bras., p. 45. - Serra da Estrella, à Mandioca, Rio-Jan., nº 6161. Arbrisseau, f1. blanches. Novembre-tlécembre. C.

223. M. brachymischa Kiærsk. in Warm. Symb. Enum. Myrt. I l. Bras., p. 47. - Corcovado et Floresta da Tijuca, Rio-Jax., $n^{\text {os }} 6535$, 11985. Arluste, fl. blanches. Juin-aoùt. C.

2924. M. choriophylla Kiærsk. in Warm. Symb. Enum. Myrt. Fl. Bras., p. 47. - Restinga de Copacabana, Rio-Jav., $\mathrm{n}^{\circ}$ 8388. Arbuste, fl. blanches. Septembre-octobre. C.

225. M. Glazioniana Kiærsk. in Warm. Symb. Enum. Nyrt. Fl. Bras., p. 48. - Serra da Estrella, Rio-JAN., nº 11998. Arbrisseau, f1. blanches. Février-mars. R.

226. M. subacuminata Kiærsk. in Warm. Symb. Enum. Myrt. Fl. Bras., p. 50. - Alto Nacahé de Nova Friburgo, Rio-Jav., nº 17672. Arbrisseau, fl, blanches. Janvier-février. C.

227. M. Clausseniana Kiærsk. in Warm. Symb. Enum. Myrt. Fl. Bras., p. ̌̈1. - Serra de Itabira do Campo Vıras, n 16980. Arbrisseau, fl. blanches. Septembre-octobre. C.

228. M. racemosa Kixrsk, in Warm. Symb. Enum. Myrt. Fl. Bras., p. 51. - Corcovado et Serra do Alto llacahé, Rı-JAN., $n^{\text {os }}$ 2587, 8706, 11996, 16993, 17665. Arbrisseau, fi. blanches. Janvier-mars. CC.

229. M. sylvatica Kiærsk. in Warm. Symb. Enum. Nyrt. Fl. Bras., p. ̋̈1. - Alto Macahé de Nova Friburgo, Rı-Jax., n 17002. Arbrisseau, f1. blanches. Février-mars. C.

230. M. layigata Kiærsk. in Warm. Syml. Enum. Myrt. Fl. Bras., p. こ̌1. - Près Barbacena dans le Campo, Minas, no 14815. Arbuste, fl. blanches. Octobre-novembre. C.

- Var. Glazioviana K. in Warm. Symb. Enum. Myrt. Fl. Bras., p. - Serra de Nova Friburgo. Rio-Jav., $n^{\circ s} 13450,19368$. Arbuste, 11. blanches. Octobre-novembre. C.

231. Calyptranthes clusiifolia Berg; Warm. Symb. Enum. Wyrt. Fl. Bras., p. 3\%. - Ipiranga, dans le bois Sĩo Paclo, $n^{\circ s} 16056$, 16057. Arbrisseau, f1. blanches. Février-mars. C.

232. C. Glazioviana Kiærsk. in Warm. Symb. Enum. Myrt. Fl. Bras., p. 3ö. - Petropolis, au Retiro, Rı-JAx., nº 11991. Grand arbre, f1. blanches. Mars-avril. C. Vulgo : Canella de Vendo.

233. C. grandifolia DC.; Warm. Symb. Enum. Myrt. Fl. Bras., p. 37. - Petropolis, dans le bois vierge, Rio-JAs, $\mathrm{n}^{\circ}$ 1207. Grand arbre, fl. blanches. Mars-avril. C. Vulgo : Bacuruna. 
A.-F.-M. GLAZIOU. - LISTE DES PLANTES DU BRESIL CENTRAL. 225

234. C. Loranthifolia DC.; Warm. Symb. Enum. Myrt. Fl. Bras., p. 37. - Copacabana et à Sapopemba, Rio-JAx., $n^{\text {os }} 75,4809,10786$, 10788. Arbrisseau, f1. blanches. Février-mars. CG.

233. C. affinis Berg; Fl. Bras. XIV, I, p. 43. - Caxoeira do Rio dos Indios, Goraz, n 21177 . Arbrisseau, fl. blanches. Aoùt-septembre. C.

236. C. Widgreniana Berg; Warm. Symb. Enum. Myrt. Fl. Bras., p. 38. - Ipiranga, dans le bois, Sĩo Paclo, $n^{\text {os }} 16057 a, 16986 a$. Arbrisseau, fl. blanches. Février-mars. R.

237. C. strigipes Berg; Warm. Symb. Enum. Myrt. Fl. Bras., p. 38. - Corcovado, à Paineiras, Rio-Jax., nos 12005, 17007. Grand arbre, fl. blanches. Février-mars. C.

238. C. grandiflora Berg in Fl. Bras. XIV, I, p. 542. - Alto Nacahé de Nova Friburgo, Rio-JAx., n 18239. Arbrisseau, t1. blanches. Août-septembre.

239. C. bimarginata Berg in Mart. Fl. Bras. XIV, I, p. כ̌43. Morro da Urea, près Botafogo, Rı-Jax., nº 9831. Arbuste, fl. blanches. Septembre-octobre. R.

240. C. oboyata Kiærsk. in Warm. Symb. Enum. Miyrt. Fl. Bras., p. 38. - Alto Nacahé de Nova Friburgo, Rio-Jax., nos 16992, 17662. Arluste, fl. blanches. Février-mar's. C.

241. C. aromatica St-Hil.; Warm. Symb. Enum. Myrt. Fl. Bras., p. 40. - Rio do Ouro, près Caixa d'Agua, Rio-Jax., n 10789. Arbrisseau. fl. blanches. Février-mars. R.

242. C. lanceolata Berg; Warm. Symb. Enum. Mypt. Fl. Bras., p. 40. - Corcovado et Floresta da Tijuca, Rio-Jax., ${ }^{05} 868,899,2588$ et 6541. Arbrisseau f1. blanches. Janvier-février. CG.

243. C. maschalantha Berg; Warm. Symb. Enum. Myrt. Fl. Bras., p. 40. - Corcovado, à Lagoinha, Rio-Jax., $n^{\circ}$ 1279. Arbuste, fl. blanches. Avril-mai. C.

244. C. cordata Berg in Mart. Fl. Bras. XIV, I. p. 48. - Serra dos Orãos, Rio-Jax., no 3984 a. Arbuste, fl. blanches. Mars-avril. C.

2's. C. tuberculata Berg; Warm. Symb. Enum. Myrt. Fl. Bras., p. 30. - Praia do Harpoador, Rito-Jıx., $n^{0}$ 10783. Arbuste, f1. blanches. Mars-avril. C.

246. C. Warmingiana Kiærsk, in Warm. Symb. Enum. Myrt. Fl. Bras., p. 40. - Corcovado et à Floresta da Tijuca, Rio-Jax., ${ }^{0 s} 1273$, 6533, 9427 et 19875. Arbre, f1. blanches. Juillet-aoùt. CC.

247. C. angustifolia Kiærsk. in Warm. Symb. Enum. Myrt. Fl. 
Bras., p. 42. - Serra dos Orgãos, au sommet, Rio-Jax., $n^{\text {os }} 2869$, 3984,16997. Petit arbuste, fl, blanches. Aoùt-septembre. C.

948. Calyptranthes musciflora Berg; Warm. Symb. Enum. Myrt. Fl. Bras., p. 43. - Colline d'Ipiranga, Sĩo Paulo, nº 19366 a. Arbuste, fl. blanches. Août-septembre. R.

249. C. Langsdorffii Bern; Warm. Syml. Enum. Mypl. Fl. Bras., p. 43. - Corcovado, vieux chemin, Rio-JAx., $1^{\text {os }} 10793$, 14840 a. Arbuste, ft. blanches, Janvier-février. C.

-. Var. grandifolia Kixersh. in Warm. siymb. Enum. Mymt. Fl. Brus., p. 43. - Petropolis, au Morro do Cubicado, Rio-Jax, no 14840 a. Arbuste, fl. blanches. Jan vier-février. C.

- Var. macrophyle Kiarsh. in Warm. Symb. Enum. Myp. Fl. Bras., p. 43. - Serra dos Orgãos el Alto Macalıé, Rio-Jan., nos 17000, 17664, 18245. Arbuste, f1. blanches. Février-mars. CC.

250. Myrrhinium atropurpureum Schott; Warm. Symb. Enum. Myjrl. Fl. Bras., p. อ̈. - Restinga de Copacabana, au bord de la mer, Rio-Jas., n $^{\circ 5} 63,5864$ et 8391. Arbuste. f1. rouges. Mai-juin. CC.

בֵ1. Eugenia aromatica Baill, Warm. Symb. Enum. Myrl. Fl. Bras., p. 117. - Floresta da Tijuca, Rio-Jas., nos 659, 12720. Grand arbre cultivé, fl. l'ougeâtres. Novembre-décembre. C. Vulgo : Craveira da India.

20.9. E. pungens Berg; Warm. S'ymb. Enum. Myrt. Fl. Bras., 1. 117. - Seté Pontes, au Barreto, liro-Jax, nº 13445. Aibuste, f1. blanches. Septembre-octobre. C. V'ulgo : Guabijú.

253. E. acutata Miq.; Fl. Bras. XIV, I, p. 22.:. - Entre Mossamedes et Goyaz, dans le campo, Goraz, n² 21196 . Arbuste, ll. blanches. Aoùtseptembre. C.

25't. E. Uvalha Camb.; Symb. Enum. Hyrt. Fl. Bras., p. 117.Sete Pontes, au Barreto, Rio-Jav., nos 16158, 9422. Arbuste, fl. blanches. Septembre-octobre. L. Vulgo: Uvalha.

2.9. E. eurysepala Kiærsk. in Warm. Symb. Enum. Mypl. Fl. Bras., p. 117. - Petropolis, à Itamaraty, Rio-Jax,, no 12001. Grand arbre, fl. blanches. Février-mars. C. Vulgo : Bacumixa-branca.

956. E. stictosepala lirirsk. in Warm. Symb. Enum. Myrt. Fl. Bras., p. 119. - Nto Nacahé de Nova Friburgo, Rı-Jax., nos 17671 , 20321. Arbrisseau, f1. blanches. Janvier-février. C.

פ97. E. tenuifolia Berg; Warm. symb. Enum. Myrt. Fl. Bras., p. 120. - Floresta da Tijuca, Rio-Jav., $\mathbf{1}^{\circ} 3001$. Arbuste, fl. lilanches. Janvier-février. C. 
A.-F.-H. GLAZ1OU. - IISTE DES PLANTES DU BRÉSIL CEYTRAL. 22T

פ̈S. E. platyclada Berg; Mart. Fl. Bras. XIV, I. 1. 25̈7. - Guariroha, dams le campo, Gosaz, no 21203. Arbuste, fl. blanches. Septembreoctolse. R.

- Var. ovalis Berg Fl. Bras. XIV, I, p. 20̈7. - Entre Gavea et Tijuca, près de la mer, Rı-Jan., nº 3761. Arbuste, f1. blanches. Juilletaoùt. R.

- Var. cunenta Berg Fl. Bras. XIV, I, p. 2:8. - Niterohy, au Barreto, Rı-Jax, nos 8395, 9841 (?). Arbuste, 11. blanches. Juin-juillet. C.

2.9. E. Klotzschiana Berg; Warm. Symb. Emm. Myrl. Fl. Bras.. p. 120. - Entre Barbacend et Sitio, Mrsas, nos 3665, 10443, 15855, 16713, 21199. Arbuste, 11. blinches, beau fruit. Juin-juillet. CC. Yulgo : Pera ou Cabacinho do campo.

260. E. gracillima Kiarsk. in Warm. Symb. Enum. Myrt. Fl. Bras.,

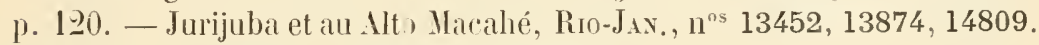
Arlouste, fl. blanches. Novembre-décembre. C.

261. E. angustifolia Glaz. n. sp.? in herb. Paris., Havn., Kew., Berol., etc. - Biribiry, au Morro do Mocoló, Misas, $n^{\circ}$ 19370. Arbuste sans fleurs en mars. R.

262. E. acutifolia Gla\%. n. sp. in lierb. Paris., Berol., Kew., Brux., etc. - Serra de Ouro Branco, Mixas, $n^{0}$ 14839. Frutescent, f1. blanches. Novembre-décembre. $\mathbf{R}$.

6․․ E. Sipolisii Glaz. n. sp.? in herb. Paris., Havn., Berol., Kew., ete. - Rio das Pedras, au Valú, Miss, no 19371 a. Arbuste, sans fleurs en avilil. C.

264. E. leptomischa Kisersk. in Warm. Symb. Enum. Myrt. Fl. Bras., p. 121. - Serro do Ificionado, près Caraga, Mrsas, $1^{0 s} 10840$, 14809. Arlıuste, fl. blanclıes. Juin-juillet. C.

263. E. Stephani Berg: Warm. Symb. Emum. Mym. Fl. Bras., p. 122. - Lio das Pedras, au Valú, Mıvas, no 19367. Arbuste, ll. blanches. Mars-avril. C.

266. E. arbutifolia Berg? in Nart. Fl. Bras. XIT, I, p1. 306-,3̈8. - Rio Parahyba, près Boa Vista et à Tijuca, Rio-JAx., nos 3009, 12718. Arbuste, fl. blanches. Aoùt-septembre. C.

- Var. pallida Berg; Warm. Symb. Enum. Wyrt. Fl. Bras., p. 122. - Diamantina, au Curalinho, Misss, n 19374. Arbuste, fl. blanches. Mar's-avril. C.

267. E. exechusa Berg; Warm. Symb. Enum. Myrt. Fl. Bras., p. 122. - Restingi de Cabo Frio, Rio-Jav., $n^{\circ}$ 10817. Arbuste, 11. blanches. Juin-juillet. R. 
268. Eugenia Kunthiana DC.; Warm. Symb. Enum. Myrt. Fl. Bras., p. 129. - Serra to Lenheiro, Mixas. $n^{05} 12009,16982$; Morrinhos el à Serra dos Pyreneus, Goyaz, $n^{0 s} 21145,21146,21185$. Arbuste, f1. blanches. CC.

969. E. decumbens Camb. in Fl. Bras. Merid. II, p. 330. - Serra dos Prreneus, diuns le campo, Goraz. n 21185 . Frutescent, ft. blanches. Aoùt-septembre. C.

270. E. parvula Glaz. n. sp.? in herb. Paris., Berol., Kew., Brux., ete. - Curalinho, près Diamantina, dans le campo aride, Mısas, I $^{0} 19358$. Frutescent, ft. blanclies. Avril-mai. C.

271. E. polyphylla Berg; Warı. Symb. Enum. Myrt. Fl. Bras., p. 124. - Serra do Lenheiro, près São Joño d'El Rei, Mixas, $n^{0 s} 14826$, 16985. Arbuste, 11. blanches. Ivril-mai. C.

272. E. pichoana Glaz. n. sp? in berb. Paris., Berol., Kew., Brux., etc. - Pichoá, dans le campo aride, Goyaz, $n^{\circ} 21141$. Frutescent, fl. blanches. Octubre-novembre. C.

273. E. pyrrhoclada Berg; Warm. Symb. Enum. Myrt. Fl. Bras., p. 125ั. - Restinga de Cabo Frio et à Campos, Rio-JAs., ${ }^{\text {ns }}$ 10807, 10814, 10815, 10816, 10829. Arbuste, fl. blanches. Juin-juillet. CC.

274. E. vaga Berg in Warm. Symb. Enum. Myrt. Fl. Bras., p. 195. - Itapemirim, Espikito Savto, $n^{\circ} 10810,10835$. Arbuste, fl. blanches. Février-mars. C.

פ75. E. linearifolia Berg; Warm. S!lmb. Enum. Myrt. Fl. Bras., p. 12อั. - São Joũo d'El Rei, Mısas, $11^{0 s} 14818$, 16983. Frutescent. fl. blanches. Avril-nirii. C.

276. E. brachysepala Kiarsk. in Warm. Symb. Enum. Myrt. Fl. Bras.. p. 125. - Araruama, Rio-Jav., n 9837. Arbuste, t1, blanches. Juin-juillet. R.

277. E. Nhanica Camb.; Mart. Fl. Bras. XIV, 1, p. 244. - São Fidelis, près Campos, Rı-Jan., $1^{\circ} 9832$. Petit arbuste, fl, blanclies. Janvier-février. R.

278. E. corcovadensis Kixrsk. in Warm. Symb. Enum. Myrt. Fl. Bras., p. 126. - Corcovado et Alto Nacahé, Rio-JAx., n ${ }^{o s}$ 1276, 19350. Arbrisseau, fl. blanches. Juillet-iout. C.

279. E. lepidota Berg? in Limma, XXVII (18\%4), p. 226. - Nto Micahé de Nora Friburgo, Rı-JAn., ${ }^{0}$ 19364. Arbrisseau, fl. blanches. Aoùt-septembre. C. Vulgo: Ubapeba minda.

280. E. flava Berg in Fl. Bras. XIV, I, p. 273. - Itapemirim, Espritro Santo, $n^{0} 10810$ a. Arbuste, fl. blanches. Février-mars. R. 
A. -F.- N. GLAZIOU. LISTE DES PLANTES DU BRÉSIL CENTRAL.

281. E. Glazioviana Kirrsk. in Warm. Symb. Emum. Fl. Bras., p. 128. - Corcovado à Paineiras, Rio-Jax., no 1278 (var. Parvifolia). Arbrissean, f1. blanclıes. Mai-juin. C.

- Var. macrophylla Kiærsk. n. sp. vel var. in Warm. Symb. Enum. Myrt. Fl. Bras., p. 129. - Serri da Mantiqueira, Mixas, n. 13864. Arbrisseau, 11. blanches. Juillet-aoùt. R.

- Vir. pauciflora Kiærsk. n. sj. vel var. in Warm. Symb. Enmm. Mypt. Fl. Bras., p. 129. - Barbacena, dams le campo, Mrxas, $n^{0 s} 10836$. 14816. Arbrisseau, 11. blanches. Mai-juin. Vulgo : Uvalha de Jatoba.

282. E. glomerata Spring in Warm. Symb. Emum. Myrt. Fl. Bras., p. 129. - Serra da Estrella, près Petropolis, Rio-Jax., nos 7639, 7640, 11999, 20322. Arbuste, fl. blanches. Février-mars. C.

283. E. sericea Berg; Warm. Symb. Enum. Myrt. Fl. Bras., p. 129. - Serra dos Or@ãus, Rio-Jax., n 9444. Arbrisseau, t1. blanches. Octobre-novembre. R.

284. E. excelsa Berg in Fl. Bras. XIV, I, p. 277. - Serra da Bocaina dans le bois, Sĩo Paulo, no $7639 a$. Arbrisseau, fl. blanches. Février-mars. C.

285. E. lanceolata Berg Fl. Bras. XIV, I, p. 276. - Serra da Estrella, à Nandioca, Rio-Jıx., $n^{\circ}$ 9437. Arbrisseau, t\}. blanchâtres. Juin-juillet. R.

286. E. subundulata Kirsk. in Warm. Symb. Enum. Myrt. Fl. Bras., p. 129. - Nova Friburgo, au Conego, Rio-JAx., nos 12722 , 17681. Arbrisseau, fl. blanches. Janvier-février. C.

287. E. bimarginata Berg; Warm. Symb. Enum. Myrt. Fl. Bras., p. 132 - Serra do Lenheiro, Barbacena, Jivas, ns 12713, 13873, 16981, 20318; Fizenda do Palmital Goraz, $n^{05}$ 21180, 21181. Arbuste, f1. fl. blanclıes. Juin-juillet. CG.

288. E. coriacea Gliz. n. sp.? in held. Paris., Berol., Brux., Kew., Havı., etc. - Rio Torto, dans le campo, Goraz, no 21182. Arbuste, fl. blanchess. Mai-juin. R.

289. E. dicrossa Berg in Mart. Fl. Bres. XIV, I, p. 291. - Serra de Itabapmana, Esurito Saxto, $11^{\circ}$ 10821. Arbuste, f1. Hanches. Awùtseptembre. $R$.

990. E. cachocirensis Berg vall. sessibifolia Kiaersk. in ITarm. Symb. Emum. Myrt. Fl. Bras., P. 192. - Serra de Nova Friburgo, à Cachoeira, Rio-Jax., no 13902. Arbuste, t1. blanches. Février-marls. R.

291. E. crassifolia Kiarsk. in Warm. Symb. Enum. Wyrt. Fl. 
Bras. p. 132. - Serra da Estrulla, près Petropolis, Rio-Jan., nn 8387. Arbuste, fl. blanches. Février-mars. C.

292. Eugenia Schwackeana Gliz. 11. sp.? in herh. Pirtis., Brol., kew., Brux., de. - Quinta da Boa Vista, Rio-JAx., nº 13901. Arbuste cultivé, fl. blanche's. Février-mars. R.

993. E. curvatopetiolata Kiarsk. in Warm. Symb. Enum. Myrt. Fl. Brres., p. 133. - Serra do Alto Macahé, Røo-Jax., $11^{\circ} 13889$. Arlusste, fl. blanches. Novembre-décembre. C.

994. E. cyclophylla Berg; Warm. Symb. Enum. Myrt. Fl. Bras, p. 13\%. - Aldéa de Sĩo Pedro, près Cailoo Frio, liıo-Jan., nos 10828, 11978. Arbuste, f1. blanches. Juillet-aoùt. C.

295. E. dodonaifolia Camb.; Warm. Symb. Enum. Myrt. Fl. Bros., p. 134. - Porto clas Cadials, dans les sables, Rio-Jas., $n^{0} 7640$ a. Arluste, fl. blanches. Févier-mars. R.

Q96. E. ellipsoidea Kirprsk. in Warm. Symb. Enum. Myrt. Fl. Bras. p. 134. - Serra da Mantiqueira, prìs João Ayros, Mlısas, $1^{\circ} 13878$. Arbuste, li. blanches. Anut-septembre. C.

297. E. glareosa Berg; Warm. Symb. Enum. Myrt. Fl. Bras., p. 118 . - Birihiry, près Diamantina, Misas, $n^{\circ}$ 19375. Arbuste, fl. blanches. Février-mars. R.

998. E. Magnifolia Kiærsk. in Warm. Symb. Enum. Mypl. Hl. bras. p. 136. - Scrra dos Orgãos, à Theresopolis, Rı-JAx., n. $17006 a$. Arbuste, fl. blanches. Févier-mars. R.

999. E. Pianhyensis Berg; Warm. Symb. Enum. Myrt. Fl. Bras. p. 137. - São Sehastiõo da Barra, Rio-Jax., $n^{08}$ 10819, 10820. Arbuste, 11. blanches. Juillet-aoit. C.

300. E. pluriflora DG.; Warm. Symb. Enum. Myrt. Fl. Bras., 1. 137. - Sâo Sebastiño da Barra, Rio-Jan, , 10 10806. Arbuste, tl. blanches. Juillet-ionit. R.

301. E. polycarpa Berg; Warm. Symb. Enmm. Myyrt. Fl. Bras., p. 137. - Ipanema, Sño Paulo, no 12714. Arbuste, fl. Blanches. Aritmai. CC.

302. E. robustorenosa Kiærsk, in Warm. Symb. Enum. Wyrt. Fl. Bras., 1. 137. - Serra da Estrella, à Mandioca, Rio-Jal, n. 3008 Arbuste, l'. blanches. Novembre-décembre. R.

303. E. rotundifolia Gasar. in Warm. Sigmb. Enmm. Myrt. Fl. Liras., p. 138. - Restingua de Copacabana et de Tijuca, Rio-JAx., $11^{\circ} 89$, 91, 4988 et 10784. Arbuste, f1. blanches. Février-mars. CG. Vulgo : Juboticabe de prain. 
A.-F.-H. GLAZIOL. - LISTE DES PLANTES DU BRÉSIL CENTRAL.

30'. E. sphenophylla Berg in Fl. Bras. XIV, I, p. 288. - Sorocaba dans le bois, São Paulo, no 12714 a. Arbrisseau, fl. blanches. Aoùtseptembre. C.

30今. E. debilis Glaz. n. sp.? in herb. Paris., Berol., Kew., Brux., etc. - São Christovão, Rio-JAx., n ${ }^{0}$ 18247. Arbuste, 11. blanches. Maijuiı. C.

306. E. spathulata Berg; Warm. Symb. Enum. Myrt. Fl. Bras., p. 138. - Carandahy, dans le campo, Mrsas, nos 12733, 14813. Arbuste, 11. blanches. Octobre-novembre. C.

307. E. compactiflora Spring; Warm. Symb. Enum. Myrt. Fl. Bras., p. 139. - Botafogo, au llorro da Babylonia, Rio-Jax., n. 75, 10785. Arbrisseau, f1. blanches. Mars-avril. C.

308. E. brevipedunculata Kirersh. in Warm. Symb. Enum. Myrt. Fl. Bras., p. 139. - Sapopemba, Rio-Jax., n' 8703. Arbuste, f1. blanches. Octobre-novembre. C.

309. E. friburgensis Glaz. n. sp.? in herb. Paris., llavn., Berol., Kew., Brux., etc. - Nova Friburgo, au Alto, Rio-JAx., $11^{\circ} 4815$. Arbuste, f1. blanches. Octohre-novembre. C.

310. E. distans Berg; Warm. Symb. Emum. Fl. Brus., p. 140. Fazenda do Taquaral, au Rio Preto, Mwas, no 7629. Arbrisseau, f1. blanches. Septembre-octobre. C.

311. E. pseudoverticilliflora Kiarsk. in Warm. Symb. Enum. Wyrt. Fl. Bras., p. 140. - Officinas, à Engenho Novo, Rio-Jax., nos 5869 , 10790. Arbuste, f1. blanches. Février-mai. C. Vulgo : Guaranhem do campo.

312. E. Villa-nove Kiarsk. in Warm. Symb. Emum. Myrt. Fl. Brecs., p. 141. - Entre Villa Nova et Porto das Caixas, Rio-JAx.. no 7636. Arbrisseau, 11. blanches. Mai-juin. C.

313. E. jurujubensis Kixrsk. in Warm. Symb. Emum. Myrt. Fl. Bras., p. 143. - Jurujuba, près de la mer, Rio-JAs., n 7638. Arbuste, 11. blanches. Novembre-décembre. R

31'4. E. magnifica Spring; Warm. Symb. Emum. Mypt. Fl. Bras., p. 143. - Corcovado, à Paineiras, Rro-JAx., nos 898, 2590, 12004. Irbrisseau, f1. blanches. Féviler-mars. C.

310̈. E. relutiniflora Kirrsk. in Warm. Symb. Emum. Myrt. Fl. Bras., p. 144. - Corcovado, à Lagoinha, Rio-Jıx., 1108 846, 10791, 16064. Grand arbre, f1. blanches. Janvier-février. C.

316. E. Sprengelii DC.; Warm. Symb. Enum. Myrt. Fl. Bras., 
p. 143̈. - Floresta da Tijuca et à Caho Frio, Rro-Jax., $\mathbf{n}^{08} 3010,8707$, 16063, 17676, 18243: Serra Dourada, Goyaz, $u^{0} 21130$ a. Pelit allbuste, fl. blanches. Septembre-octobre. CG.

317. Eugenia Hoffmannseggii Berg; Warm. Symb. Enum. Myrt. Fl. Bras., p. 14:̈. - São Fidelis, près Campos, Rı-Jav., $11^{0} 9846$. Arbuste, fl. hanches. lanvier-février. R.

318. E. oxyoentophylla Kïersk. in Warm. siymb. Nyrt. Fl. Bras., p. 14.5. - Fortaleza do Pico de Santa-Cruz, Rı-Jan., $n^{0}$ 6832. Arbuste, 11. blanches. Novembre-décembre. C.

319. E. velutina Berg; Warm. Šymb. Emum. Myrt. Fl. Bras., p. 146. - Petropolis, au Norin, Rı-J.s., $n^{\circ}$ 14843. Arbuste, fl. blanches. Novembre-décembre. C.

320. E. Gardneriana Berg; Warm. syml. Emum. Myrt. Fl. Bras., p. 147. - Floresta da Tijuca et à São Fidelis, R10-Jav., $\mathrm{n}^{0 \mathrm{~s}} 6885,10826$, 10827, 11987; Serra do Lenheiro, Juvas, ${ }^{\text {os }}$ 12728, 16974; Jaragua, au Corrego Fundo, Goyaz, n² 21197. Arbuste, ft. blanches. Janvier-mars. CG.

321. E. racemiflora Berg in Limna XXVII (18วั4), p. 232. Restinga de Cabo Frio, Rio-JaN., $n^{\circ}$ 10825. Arbuste, f1. blanches. Juinjuillet. $R$.

329. E. glandulosissima Kiærsk. in Warm. Symb. Enum. Myrt. Fl. Bras., p. 147. - Carandahy et à Resaquinha, Mısas, nos 12727, 13868 et 13869. Arbuste, 17. blanches. Juin-juillet. C.

323. E. christovana Kiærsk. in Warm. Symb. Enmm. Myrt. Fl. Bras., p. 148. - São Christovão, Rı-Jax., nº 6542. Arbuste cultivé, fl. blanches. Mars-avril. C, Vulgo : Ameix do Pare.

324. E. longiracemosa Kixrsh. in Warm. Symb. Emum. Myrt Fl. Bras., p. 149. - Itapemirim, Espintro Snsto, n 13898. Arbuste, fl. blanches. Septembre-octobre. R.

325. E. olivacea Berg; Warm. Symb. Enum. Myrt. Fl. Bras., p. 15ั1. - Entre Magé et Piedade, Rio-Jax, n n ${ }^{\text {os }} 863$, 1274, 3976, 7635. Arbuste, fl. blanches. Avril-mai. CG.

326. E. cambucarana Kiærsk. in Warm. s'ymb. Emum. Myrt. Fl. Bras., p. 151. - Caminho da Gavea, à Boa Vista, Rio-Jax., $\mathrm{H}^{\circ} 6536$. Arbuste, fl. blinches. Juillet-aoùt. C.

32-. E. paracalnana Berg; Warm. Siymb. Emum. Hyrt. Fl. Bras., p. 153. - Entre Cuba et Norinhos, Goraz, no 21143. Arbrisseau, fl. blanches. Aout-septembre. C.

328. E. excoriata Berg; Warm. Siyml. Enum. Myrt. Fl. Bras., 
p. 1533. - Corcovado, à Caixa d'Agua, Rı-Jax., no 2872. Arbrisseau, fl. blanches. Septembre-octobre. R.

399 E. Augustana Kixrsk. in Siymb. Enum. Myrt. Fl. Bras., p. 153. - Pico da Tijuca, au sommet, Rio-Jas., n 5868 . Arbuste, fl. blanches. Avril-mai. R.

330. E. diaphana Kiærsk. in Warm. Symb. Enum. Myrt. Fl. Bras., p. 1\%4. - Caho Frio, près du phare, Rio-Jav., $11^{\circ} 9425$. Arbuste, f1. blanches. Juillet-aoùt. R.

331. E. Michelii Lamk; Warm. Symb. Enum. Myrt. Fl. Bras., p. 15\%. - Restinga de Copacabana, Rio-JAN., no 8, 9439. Arbuste, fl. Blanches, fruit rouge. Aont-septembre. CC. Vulgo : Pilanguevia.

332. E. stenosepala Kiærsk. in Warm. Symb. Myrt. Fr. Bras., p. 15 . - Alto Nacahé de Nova Friburgo, Rio-Jax., nos 17678, 19355. Arbuste, f1. blanches. Septembre-octobre. C.

333. E. sulcata Spring var. iatifolia Berg; Warm. siymb. Enum. Myrt. Fl. Bras., p. 156. - Copacabana et à Nova Friburgo, liı-Jax., $\mathrm{n}^{\text {os }} 2131,8709,9443,9447,13453$. Arbuste, fl. blanches. Septembreoctobre. CC. Vulgo : Pilangui.

33'. E. subreticulata (nom. nov.); stenocalyx reliculatus Berg. in Mart. Fl. Bras., XIV, I, 1. 340. - Restinga de Copacaliana, Riro-Jan., $\mathrm{n}^{\circ}$ 84. Arbuste, f1. blanches. Janvier-février. G.

338. E. botequimensis Kiærsk. in Warm. Symb. Enum. Myrt. Fl. Bras., p. 1\%6. - Serra da Estrella, au Botequim. Rı-Jax., nº 8393. Arbuste, fl. blanches. Aout-septembre. C. Vulgo: Goiabeira do Vatto.

336. E. brasiliensis Lamk; Warm. Symb. Enum. Myrt. Bras., p. 1亏7. - Quinta da Boa Vista, à São Clıristovão, Rio-Jax., nos 1434, 10803, 10813. Arbre, f1. blanches, fruit noir. Octobre-novembre. CC. Vulgo: Cirumixama.

337. E. dolichophylla Kixrsk., in Warm. Symb. Enum. Myrt. Fl. Bras., p. 1:57. - Sete Pontes, au Barreto, Rio-JAN., n 6157. Arbuste, fl. blanches. Aoùt-septembre. R.

338. E. dysenterica DC.; Warm. Symb. Enum. Myrt. Fl. Bras., p. 158. - Patrocinio, Mwas, $n^{\circ}$ 13872; Paracatú, Goraz, $n^{\circ} 21198$. Arbrisseau, fl. blanches. Septembre-octobre. Vulgo : Cagueiteiro.

339. - E. hirta Berg in Nart. Fl. Bras., XIV, I, p. $574 .-$ Alto Marahé de Nova Friburgo, Rio-JAx., n ${ }^{0}$ 18238. Arluste, fl. blanches. Juin-juillet. R.

3\%0. E. gamæana Glaz. n. sp.? in herl. Paris., Berol., Kew., 
Brux., etc. - Rio Gama, dans le cerrado, Govaz, n² 21191. Arbrisseau, f1. blanches. Novembre-décembre. C.

341. Eugenia diantha Berg in Fl. Bras. XIV, 1, p. 2939. - Santa Barbara, dans le campo, Mrxas, $\mathrm{n}^{\circ}$ 13876. Arbuste, fl. blanches. Juilletaoutt. C. Vulgo: Pao de Bilos.

3ł‥ E. ligustrina Willd.; Warm. siymb. Enum. Myrt. Fl. Bras., p. 159. - Itahiapoana, Espirito Savto, $n^{\circ}$ 10818. Arbuste, fl. blanches. Septembre-octobre. C.

343. E. pulcherrima Kiarsk. in Warm. Symb. Enum. Myrl. Fl.

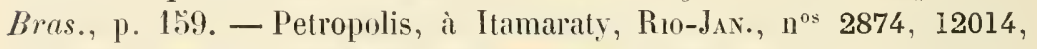
16065. Arbrisseau, fl. blanches. Septembre-octobre. C.

344. E. aggregata Kiærsk. in Warm. symb. Enum. Vypt. Fl. Bras., p. 162. - Caminho do Nacaco et Tijuca, Rio-Jیs., nº 9440. Grand arbre, f1. blanches, très odorantes. Octobre-novembre. C.

34. E. edulis Kiarsk. in Warm. Symb. Enum. Hyrt. Fl. Bras., p. 162. - Restinga de Copacabana, Rio-Jav., $n^{\circ s}$ 9, 92, 6831. Arbuste, fl. blanches. Septembre-octobre. C. Vulgo : P'itangâo.

346. E. Lundiana Kiærsk. in Warm, symb. Enum. Mypt. Fl. Bras., p. 162. - Alto Macahé de Nova Friburgo, Rı-Jan., nos 16987, 19353. Arbrisseau, il. blanches. Novembre-dérembre. C.

347. E. pallescens Kiarsk. in Warm. Symb. Enum. Mypt. Fl. Bras., p. 162. - Sete Pontes, au Barreto, Rio-Jax., nº 9446. Arbuste, ll. blanches. Aout-septembre. R.

348. E. santensis Kiarsk. in Warm. Symb. Enum. Myrt. Fl. Bras., p. 163. - Corcovado, à Gaixa d'Aguil, Piı-Jan., $1^{\circ \mathrm{s}} 1512$, 11997. Arbuste, fl. blanches. Janvier-février. C.

349. E. Luschnathiana Kiærsk.; Phyllocalyx Luschnathianus Berg. in Nart. Fl. Bras. XIV, I, p. 333. — Serra de Jacarejagua, lio-Jax.. $\mathrm{n}^{\circ \mathrm{s}} 220,10818 a$. Arbrisseau, fl. blanclies. Novembre-décembre. R.

330. E. acutiflora Kisersk. in Warm. Symb. Enum. Myrt. Fl. Bras., p. 164. - Alto Vacahé de Nova Friburgo, Rio-Jav., nos 1388, 13894. Arluste, fl. blanches. Janvier-février. R.

331. E. alpigena DC.; Warm. Symb. Emum. Myre. Fl. Bras., p. 1633. - Itatiaia et ì Serra dos Orgãos, au sommet, Rı-JAx., $1^{05} 6544$, 14834, 16050, 19366. Petit arbuste, f1. blanches. Janvier-février. CG.

330. E. brachymischa Kixrsk. in Warm. Symb. Emm. Myrt. Fl. Bras., p. 163. - Alto Macahé de Nova Frilıurgo, Rio-JAx.. nos 13891, 17003. Arbuste, fl. blanches. Février-mars. G. 
A,-F.-M. GLAZIOL. - I.ISTE 0ES PLANTES DU BRÉSIL CENTRAL. 235

33̈3. E. emarginata Glaz. n. sp.? in herb. Paris., Berol., Kew., Brux., etc. - Près Barbacena, dans le campo, Minas, n 14825. Arbuste, fl. blanches. Juillet-août. C.

3\%'t. E. Franciscensis Berg; Warm. Symb. Enum. Myrt. Fl. Bras., p. 166. - Près Barbacena, dans le campo, Minas, no 16066. Arbuste, fl. blanches. Décembre-janvier. C.

3อั. E. fuliginea Berg in Warm. Symb. Enum. Myrt. Fl. Bras., 1. 166. - Serra de São José d'El Rei, Mısas, n 14271. Arbuste, fl. blanches. Octobie-novembre. R.

33̈6. E. itatiaiensis Kiærsk. in Warm. Symb. Enum. Myrt. Fl. Bras., p. 166. - Itatiaia, près du Ribeirãs, Rio-Jax., no 6545. Petit arbuste, fl. blanches. Janvier-février. C.

30̈7. E. Miersiana Gardn.; Warm. symb. Enum. Myrt. Fl. Bras., p. 167. - Floresta da Tijuca et à Petropolis, Rio-Jax., n ${ }^{\text {s }}$ 1103, 2591, 6543. Arbuste, fl. blanches. Mars-avril. CC.

- Val. membranacea Berg; Warm. Symb., Enum. Myrt. Fl. Bras., p. 167. - Petropolis, à ltamaraty, Rı-JAx., $\mathrm{n}^{\circ}$ 8712. Arbuste, fl. blanches, Avili-mai. C.

3อง. E. macahensis Glaz. n. sp. in herb. Paris., Berol., Havn., Kew., Brux., etc. - Alto Macahé de Nova Friburgo, Rio-Jan., " ${ }^{\circ}$ 18249. Arluste, fl. blanches. Juin-juillet. R.

3อ̆\%. E. nana Ber@; Warm. Symb. Enum. Myrt. Fl. Bras., p. 167. - Campo da Bocaina, Sĩo Paulo, no 19369. Petit arbuste, fl. blanches. Janvier-février. C.

- Valr. robusta in herb. Paris., Belol., Kew., Havn., etc. - Campos da Bocaina, São Paulo, no 8382. Petit arbuste, fl. blanches. Féviermars. C.

360. E. Regnelliana Berg in Mart. Fl. Bras. XIV, I, p. 240̈.Selra da Lenheiro, dans le campo, Misas, nº 16985 a. Arbuste, ll. blanches. Avril-mai. C.

361. E. glaucescens Camb. in St. Hil. Fl. Bras. Merid. 11, p. 368. - Entre Rio Torto et Bananal, dans le campo, Goraz, n² 21147. Arbuste, fl. blanches. Mai-juin. C.

362. E. obtusiflora Kiærsk. in Warm. Symb. Enum. Myrt. Fl. Bras., \%. 168. - Floresta da Tijuca et à Nova Friburgo, Rio-Jar., $\mathrm{n}^{\circ 5} 5867,13885$. Arbuste, fl. blanches. Mars-avril. C.

363. E. pilotantha Kiærsk. in Warm. Symb. Enum. Myrt. Fl. Bras., 
p. 169. - Petropolis, à Itamaraty, R10-J $\mathrm{J}_{\mathrm{A}}$., $\mathrm{n}^{\circ}$ 16052. Arbuste, f1. blanches. Nar's-avril. G.

364. Eugenia seriatopedunculata Kiarsk. in Warm. Symb. Enum. Myrt. Fl. Bras., p. 170. - Itacolumy, près Ouro Preto, Misas, $11^{\text {os }}$ 14821, 19363 a. Arlorisseau, 11. Wlanches. Juin-juillet. R.

360. E. seriatoracemosa Kixrsh. in Warm. Symb. Enum. Nyrt. Fl. Bras., p. 151. - Serra dos Orgãos, còté de Petropolis, Rio-Jan., $11^{\circ}$ 17006. Arbuste, ft. blanches. Janvier-février. C.

366. E. sticheromischa kiærsk, in Warm. siymb. Enum. Myrt. Fl. Bras., p. 172. - Agua Limpa, à Gimdarela, Misas, n 14833. Arbuste, ll. blanches. Février-mars. C.

367. E. copacabanensis Kiærsk. in Warm. Symb. Enum. Myrt. Fl. Bras., p. 172. - Restinga de Copacabana, Rio Jax., $n^{0}$ 3982. Arbuste, fl. blanches. Février-mars. R.

368. E. xanthochloa Berg; Warm. Symb. Emum. Myrt. Fl. Bras., p. 173. - Ayuruoca, au Pico do Papagaio, Mwsas, $n^{\circ}$ 16073. Petit arbuste, 11. blanches. Janvier-février. C.

369. E. Jambos L.; Warm. Symb. Enum. Myrt. Fl. Bras., p. 173. - Passeio Publico et Quinta de São Christovão, Rio-Jan., ${ }^{0 s} 213,4808$. Arbrisseau cultivé, fl. blanches. Septembre-octobre. C. Vulgo : Jambeira.

370. E. samarangensis Berg in Nirt. Fl. Bras. XIV, I, p. 377; Jambosa samarangensis DC. - Quinta da Boa Vista, à S. Christovão, RroJan., $n^{0}$ 10802. Arbrisseau cultivé, fl. blanches. Septembre-octobre. R.

- Var. grandfola Berg in Mart. Fl. Liras. XIV, I, p. 377. - Lagoa de Freitas, à Tres Vendas, Rı-Jax., n0 8898. Arbrisseau cultivé, fl. blanches. Aoùt-septembre. R.

371. E. chnoosepala Kixisk. in Warm. Siymb. Enum. Myrt. Fl. Bras., p. 174. - Alto Macalié de Nova Friburgo, Rio-Jav., 10" 20319. Arbuste, fl. blanches. Juin-juillet. C.

- Var. angustralia Kixisk. in Warm. Symb. Enum. 1/yrt. Fl. Bras., p. 175. - Floresta da Tijuca, Rio-Jax., $1^{\text {os }} 2592,19351$. Arbuste, fl. blanches. Avril-mai. C.

- Var. ellaptica Kiærsk. in Warm. Symb. Enum. Myrt. Fl. Bras., p. 175. - Alto Macahé de Nova Friburgoo, Rı-Jav., nº 18246. Arbuste, fl. blanches. Février-mar's. C.

- Var. latifolia Kiærsk. in herb. Paris., Havn.. Berol., Brux., etc. Paiol, à Lagoa do Cercado, Mlısas, $n^{\circ}$ 21183. Arbuste, fl. blanches. Octobre-novembre. C. 


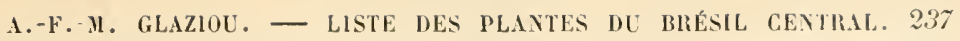

379. E. myriophy-lla Catsar.; Warm. Symb. Enum. Myrt. Fl. Bras., p. 173. - Morra da Carapuça, à Caraça, Mssas, n 14832. Petit arbuste, fl. blanches. Juin-juillet. C.

373. E. adenodes Kiiprsk. in Warm. Symb. Enum. Wypt. Fl. Bras., p. 176. - Serra dos Orgãos, à Theresopolis, Rio-Jax., $11^{0} 16990$. Arluste, fl. blanches. Février-mar's. R.

37't. E. psendodichasiantha Kiarsk, in Warm. symb. Emum. Myit. Fl. Bras., p. 177. - Alto Macalıé de Nova Friburgo, Rro-Jan., nº 13452. Arbuste, fl. blanches. Novembre-décembre. C.

37\%. E. Nettiana Kiærsk. in Warm. Symb. Enum. Myrt. Fl. Bras., p. 179. - Sĩo Fidelis, près Campos, Ro-Jax., n 9843. Arbrisseau. fl. blanches. Janvier-fëvrier. C.

376. E. plicatocostata (nom. nov.); Mypriaria plicatocostala Berg in Mart. Fl. Bras., XIV, I, p. 366. - Garea et Floresta da Tijuca, Rio-Jax., no 4810. Arbre cultivé, fl. blanches. Férrier-mars. CG. Yulgo : Cambuca.

37T. E. alegrensis Kiærsk. in Warm. Symb. Enum. Mypt. Fl. Bras., p. 180. - Sete Pontes, au Baretto, Rio-Jax., nos 11995, 13444. Arbuste cultivé, fl. blanches. Janvier-février. C. Vulgo: Cambuim do Paraguay.

378. E. biseriata Kiærsk. in Warm. Symb. Enum. Myrt. Fl. Bras., p. 180. - Serra dos Orgãos, à Theresopolis, Rı-Jax., $n^{\circ}$ s 2873, 4814, 19372. Arbuste, f1. blanches. Arril-mai. C.

379. E. Cabelludo Kixrsk. val. Glazioviana Kiaprsk. in Warm. syzmb. Enum. Mart. Fl. Bras., 11. 180. - Quinta da Boa Vista, à São Christovão, Rio-Jax., $1^{\text {os }} 1272,7634,18250$. Arbuste cultivé, 11. blanches. Juin-juillet. C.C. Vulgu: Cabelludo.

380. E. delicatula DC.; Warm. Symb. Enum. Mypl. HT. Lires., p. 180. - Restinga de Copracabana, Rio Parahyba et à Theresopolis, RuJAx., $n^{05} 64,8966,12712,12717$. Arbuste, t1. blanches. Mai-juin. CC.

381. E. grandiglandulosa Kirrsk. in Warm. symb. Enum. Myr. Fl. Bras., p. 181. - Itapemirim, Espinito-Saxto, no 13443. Arhuste, 11. blinches. Février-mar's. R.

382. E. Guaquica Kixrsk, in Warm. Symb. Enum. Myrt. Fl. Bras., p. 181. - Quinta da Boa Vista, à São Christovão, Rio-JAx., nos 1122. 18251. Arbuste cultivé, fl. Hanches. Juin-juillet. C. Vulg̈) : Gnenquica.

383. E. maranhensis Kiærsk. in Warm. Symb. Enm. Wyrt. Fl. Bras., 183. - Restinga de Saquarema, près Cabo Frio, Rio-Jax., $\mathrm{n}^{\text {os }} 10808$, 10809, 10811. Arbuste, f1. blanches. Juin-juillet. C. 
384. Eugenia Schitchiana Berg in Mart. Fl. Bras. XIV, I, p. 2008. - Faria, près Sabara, Mivas, $\mathbf{1}^{\circ}$ 18237. Arbuste, ll. blanches. Janvierfévrier. R.

38:. E. maschalantha Kixrsk. in Warnn. Siyml. Emem. Hyrl. Fl. Rras., p. 183. - Caraça, au Campo de Fori, Misas, n 14822. Arbuste, fi. blanches. Juin-juillet. C.

386. E. protracta Stend.; Warm. Syml. Ennm. Mypl. Fl. Bras., p. 18'́. - Sete Pontes, au Barreto, Rin-Jax., $1^{\circ}$ 13422. Arbuste cultivé, 11. Hanches. C. Vulgo : Cambuim de são l'oulo.

387. E. tenella DG.; Warm. Symb. Enum. Myrt. Fl. Bras., p. 18't. - Copacabana, Corcovado, Tijuca, Rio-Jav., nos 2132, 2583, 4991, 5866 ; Campos da Bucaina, São Paulo, ns 8384, 11981. Arbuste, fl. blanlches. Janvier-février. CG. Vulgo : Cambuim.

- Var. elciptica Berg; Warm. Symb. Enum. Myjt. Fl. Bras., p. 184. - Rego d'Agua, entre Ayurnoca et Caxambú, Mrsas, nº 16074. Arbuste, f1. Wanches. Janvier-février. C.

- Var. spathulata Berg; Warm. Sigml. Emm. Myrl. Fl. Bras., p. 184. - Magy das Cruzes, dans les bourbiers, Sĩo-Paulo, $\mathbf{n}^{\circ} 17667$. Arbuste, fl. blanches. Mars-avril. C.

- Var. Glazroviana Kiprsk. in Warm. Symb, Emm. Wyrt. Fl. Bras., p. 184. - Nova Friburgo, Rio-Jar., nº 1386. Arbuste, fl. blanches. Janvier-févier. C.

- Var. macrocarpa Kiærsk. in Warm. symb. Emum. Wyrt. Fl. Bras., 1. 184. - Serra dos Urgãos, coté de Petropolis, hio-Jax., no 17001. Arbuste, fl. blanches. Janvier-février. C.

388. E. cauliflora DC.; Warm. Symb. Enum. Myr. Fl. Bras., P. 185. - Petropolis, au Retiro, Rio-lav., n6 6155. Arbrisseau, fl. blanches. Janvier-février. (..

389. E. phitrantha Kiærsk. in Warm. Symb. Enum. Myrl. Fl. Bras., p. 18:. - Quinta da Boa Vista, à São Christovão, Rio-Jan., nos 9445, 16051, 20323. Arbrisseau cultivé, fl. blanches. Janvier-février. C. Vulgo : Jabolicaba branca.

390. E. Babesiana Kixrsk. in Warm. Symb. Enum. Myrl. Fl. Bias., p. 186. - Alto Nacahé de Nova Friburgo, Rio-JAN., n ${ }^{\text {ss }} 13882$, 18240. Arbrisseau, fl. blanches. Aoùt-septembre. R.

391. Calycorectes Pohlianus Kiærsk. in Warm. Symb. Enum. Myrt. Fl. Bras., p. 117. - Corcovado, à Lagoinlıa, Rio-Jas., no 9435. Arbrisseau, fl. blanchâtres. Juin-juillet. R. 
1.-F.-M. GLAZIOU. - LISTE DES PLANTES DU BRESIL CETTRAL. 239

392. Gustavia augusta L.; Mart. Fl. Bras. XIV, I, p. 469. - Quinta da Boa Vista, S. Christovão, Rio-J.s., n 139 b. Arbuste cultivé; 11. roses. Janvier-février. R. Vulg: Japuaranduba.

393. G. brasiliana DC.; Mart. Fl. Bras. XIV, I, p. 472. - Passeio Publicu. Rio-JAx., nº $139 a$. Arbuste cultivé, fl. roses. Janvier-février. R. Vulgu: Jandiparana.

39'. Couroupita crenulata Miers in John Miers On the Lecythid. V, p. 19õ. - Serra dı Tingua, Rı-Jax., n 13883. Grand arbre, fl. jaunes. Octobre-novembre. C. Vulgo : Sapucaia.

39:- Bertholletia excelsa Humb. et B.; Mart. Fl. Bras. XIV, I, p. 478. - Quinta da Boa Vista, S. Christovio, Rio-Jax., $n^{\circ} 658$ a. Grand arbre cultivé, fl. blanchâtres. Avril-mai. C. Vulgo : Castuneiro do Maranhĩo.

396. Lecythis Pisonis Camb.; Mart. Fl. Bras. XlY, I, p. 480. Serra da Estrella, à Mandioca, lino-JAs., nº 4816. Grand arbre, fl. lilas. Norembre-décembre. C. Vulgo : Sapucaia.

397. L. Pohlii Berg in Mart. Fl. Bras. XIV, I, p. 484. - Serra Estrella, Corcovado, Tijuca, Riı-JAN., $n^{0 s}$ 658, 6166, 8704, 13884. Grand arlıre, fl. lilas. Décembre-janvier. CG. Vulgo : Sipucaia.

398. L. angustifolia Endl.; Mart. Fl. Bras. XIV, I, p. 489. - Larangeira, au Cusme Velho et au Corcovado, Rio-JAx., $n^{\text {os }}$ 2592, 3985, 8398, 8492. Grand arbre, fl. lilas. Janvier-février. CC. Vulgo : Sapucaia.

399. L. (Chy-troma) chartacea Berg in Limnea, XXVII, p. 4000.Quinta da Bua Vista, à S. Clıristovĩo, Rí-Jas., $1^{\circ}$ 13895. Grand arbre cultivé, fl. jaunitres. R. Vulgo : Via-rana.

400. L. (Ch). retusa Spruce ex Berg in Fl. Br., XIV, I, p. 487. Patrocinio, dans le campo. Hisss, no 14847 . Arbre, fl. jaunatres. Janvielfévrier. G.

401. L. (Eschweilera) ovata Camb. in St-Hil. Fl. Br. M., II, p. 378. - Abbadia, Misas, no 14847. Arbrisseau, fl. jaunâtres. Janvierfévrier. C.

402. L. (E.) Luschnathii Berg in Fl. Bras., XIV, I, p. 499. Quinta da Boa Vista, à S. Cliristovão, Rio-JAn., nº 10841. Grand arbre cultivé, fl. lilas. Février-mars. R. Vulgo : Sapucniarana.

403. L. (Lecytropsis) rufescens Berg in Limnea, p. 432. - Hlo-

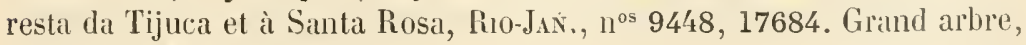
f1. Jamues. Mars-avril. G.

404. Couratari domestica Mart.; Fl. Bras. XIV, I, p. š10. - 
Floresta da Tijuca et Corcovado, Rio-Jav., n ${ }^{\text {os }} 6165,10801$. Très grand arbre, 11.? C. Vulgo : Jequitiba roxo.

40\%. Couratari estrellensis Raddi; Mart. Fl. Bras. XIV, I, p. $ّ 11$. - Petropolis, Rio Comorido, Tijuca, Rio-JAN., $n^{05} 6162,7644,8397$, 10800, 12012 et 12013, Arbre gigantesque, fl. blanchâtres. Janvierdécembre. Vulgo : Jequitiba.

406. C. legalis Nart.; Fl. Bras. XIV, I, p. S̈12. - Corcovado, Serra da Estrella, Rı-JAN., nos $6164,7645,12719$. Arbre géant, fl. blanchâtres. Janvier-février. CG. Vulgo: Jequetiba.

407. G. Glaziovii Taub. n.sp. in herb. Paris., Berol., Kew., Brux., etc. - Petropolis, à Quitandinha, Rio-JAx., n ${ }^{\circ}$ 17008, Arbre gigantesque, fl. blanchâtres. Février-mars, R.

\section{Fam. 56. - Mélastomacées.}

1. Eriocnema fulva Naud.?; Fl. Bras. XIV, III, p. 8. - Faria, près de Sabaras, dans les fissures des rochers, Mivas, $n^{\circ} 18230$. Presque acaule, fl. blanches. Janvier-février. R.

2. E. acaulis Triana; Fl. Bras. XIV, III, p. 9. - Ouro Preto sur les rochers, Minas, n 20309. Acaule, fl. blane rosé. Décembre-janvier. C.

3. Cambessedesia Eichleri Cogn. in Fl. Bras. XIV, III, p. 11. Serra da Caraça dans le campo, Minas, n 12708. Arbuste, fl. rose foncé. Février-mars. C.

4. C. Weddellii Naud.; Fl. Bras. XIV, III, p. 13. - Entre Barreira do Veado et Morro Redondo, Goraz, n² 21205. Plante naine, fl. rouge jaunâtre. Octubre-novembre. C.

5. C. latevenosa DC.; Fl. Bras. XIV, III, p. 14. - Diamantina, au Campo de Fora, Misas, n 19190. Arbuste, fl. rougeâtres. Mars-avril. C.

6. C. rugosa Cogn. in Fl. Bras. XIV, III, p. 14. - Entre Casa Branca et Ouro Preto, dans le campo, Mrsas, ${ }^{\text {os }} 14706$ et 18235. Arbuste, fl. jaunâtres. Février-mars. C.

7. C. arenaria Cogn. in Fl. Bras. XIV, IlI, p. I8. - Perpetua, près Diamantina, dans le campo, Minas, $n^{\circ}$ 19189. Arbuste, fl. jaunâtres. Avri-mai. R.

8. C. corymbosa IDC.; Fl. Bras. XIV, IIl, p. 16. - Diamantina, au Tombador, dans le campo, Minas, $n^{\circ}$ 19188. Arbuste, fl. jaunâtres. Avril-mai. R.

9. C. espora DG.; Fl. Bras. XIV, III, p. 17. - Mogy das Cruzes, 
A.-F.-M. Glaziou. - LISTE DEs Playtes DU BRÉsil Cextral. 241 dans le campo, São Padlo, nº 17501. Frutescent, f1. jaunes. Mars-avril. CC. Vulgo: Cinherinho do campo.

10. C. espora DC. var. chamedrifolia Cogn. in Fl. Bras. XIV, III, p. 17. - Colline d'Ipiranga, S̃̃o Padlo, nº 16041. Frutescent, fl. jaunes. Mar's arril. C. Vulgo : Cinherinho do campo.

11. C. ilicifolia Triana; Fl. Bras. XIV, III, p. 18. - Itatiaia, au Campo Feio, Ruo-Jax., no 8371. Frutescent, 11. james. Février-mar's. C.

- Var. genuina Cogn. in Fl. Bras. XIV, III, p. 18. - Morro Cavado et de S. Vicente, dans le campo, Mrvas, $n^{0 s} 7624$ 14709. Frutescent, fl. jannes. Juin-juillet. C.

12. C. adamantium DC. var. Najor Cogn. in Fl. Bras. XIV, III, p. 20. - Serra dos Viadeiros, au Morro do Salto entre les rochers, Goraz, nº 21204. Frutescent, rouge. Janvier-février. C.

- Var. minor Cogn. in Fl. Bras. XIV, IlI, p. 20. - Diamantina, au Tombador, dans le campo et à Ayuruoca, Mlisas, nos 9462 et 19187. Frutescent, fl. rouges. Mars-avril. C.

13. C. Hilariana DC. var. setosa Cogn. in Fl. Bras. XIV, III, p. 21. - Itacolumy, près Ouro Preto, Mcsas, $n^{\circ} 14707$ a. Frutescent, fl. rouges. Février-mars. C.

- Var. vulgaris Cogn. in Fl. Bras. XIV, III, p. 22. - Itacolumy, près Ouro Preto et à Diamantina, dans le campo, Mrras, $n^{05} 14707$ et 19186. Frutescent, f1. rouges. Mars-arril. CC.

- Var. genuina Cogn. in Fl. Bras. XIV, III, p. 22. - Rio Manso dans le campo, Mrxas, $n^{\text {os }} 12702$ et 14708. Frutescent, fl. rouge jaunàtre, Mai-juin. C.

- Var. bidentata Cogn. in Fl. Bras. XIV, III, p. 22. - São João d'El Rei, dans le campo, Mrras, $n^{\circ}$ 16040. Frutescent, fl. rougeâtres. Maijuin. C.

- Val. galioides Cogn. in Fl. Bras. XIV, III, p. 22. - Chapadão Ios Veadeiros, Goyaz, n² 21207. Frutescent, fl. jaunâtres. Décembrejanvier. R.

- Var. linearis Cogn. in Fl. Bras. XIY, III, p. 22. - Pico d'ltabira do campo, Mrsas, no 17525; Corrego do Brejo, à Chico Lobo, dans le campo, Goyaz, nº 21206. Frutescent, fl. rouges. Décembre-janvier. C.

14. C. setacea Cogn. in Fl. Bras. XIV, III, p. 23. - Chapadão dos Veadeiros, à Olhı d'Agua do Vente, Goraz, $11^{\circ} 21207$ a. Frutescent, f1. jaunâtres. Janvier-février. R.

13. Pyramia salviafolia Cham.; Fl. Bras. XIV, III, p. 24. - 
Formario, près Diamantina, dans le campo, Muvas, no 19191. Arbuste, 11. roses. Mars-arril. R.

16. Pyramia pityrophylla Clam.; Fl. Bras. XIV, III, p. 2:.Serra de Caraça, alu Norro da Carapuça, $11^{\circ} 14706$ et $a$; Diamantina, Serra dus Cristaes, Mtsas, no 19192. Arbuste, fl. blancluattres. Avril-mai. C.

17. Stenodon suberosus Naud.; Fl. Bras. XIV, III, p. 27. - Ghapadio da Serra das Divisoes ou do Urhano, Goraz, $n^{0 s} 21349,21350$ et 21351. Petit arbuste, fl. roses. Mai-juillet. C.

18. Chætostoma Glaziovii Cogn. var. pallida Cogn. in Fl. Bras., XIV, III, 1). 30. - Entre As Datas et Paranańa, Misas, $n^{\circ}$ 19193. Frutescent, fl. roses. avril-mai. G.

- Var. rubella in Fl. Brots. XIV, III, p. 30. - Haut de l'Itatiaia, dans le campo, Rio-Jav., ${ }^{0 s}$ 4803, 6526. Frutescent, fl. roses. Mai-juin. C.

19. C. Joanna Cogn. Suites au Prodr. VII, p. 28. - Serra do Lenheiro, près S. J. d'El Rei, Mrsas, nos 17504, 20302 et 20302 a. Frutescent, ft, jaunes. Janvier-juin. GC.

20. C. scoparia Gogn. in Engler Beitrag (I89:), p. 447. - Entre Rio dos Couros et le Rio Piçarão, Goraz, n² 21214. Frutescent, fl. ignorée. R.

21. C. Intenm Cogn. Suites au Prodr. VII. p. 28. - Serra do Leinheiro, jrès São João d'El Rei, Mnsas, ${ }^{\text {os }} 16769$ et 17502. Frutescent, fl. jaunes. G.

- Vall. quadrifaria Cogn. Suites au Prodr. VII, p. 29. - Serra do Lenheiro, près S. J. d'El Rei, Mısıs, $1^{\circ} 17503$. Frutescent, ll. jaunes. Janvier-février C.

22. G. aureum Glaz. n. sp.? in herb. Paris., Berol,, Kew., etc. - Entre Engenho de Souza et Porto do Rio São Bartholomeu, Goraz, $n^{0 s} 21208,21210$. Frutescent, fl. jaunes. Septembre-octubre. C.

23. G. gracile Glaz. n. sp.? in. herb. Paris., Berol., Kew., etc. Serra dos Crystaes, près Almocafre, Campos do Rio Rasgão, etc., Goraz, $n^{\circ}$ 21209. Frutescent, fl. roses. Aoùt-septembre. C.

24. G. debile Glaz. n. sp. in herb. Paris., Berol., Kew., Brux., etc. - Calueceiras do Rio Sambambaia et au Ponso do Barbatimão, Goyaz, $\mathrm{n}^{05} 21211,21212$. Frutescent, fl. blanches. Aoint-septembre. C.

25. C. pungens DG.; Fl. Bras. XIV, III, 13. 31. - Nagy das Cruzes, Sĩo Paulo, no 17505; Biribiry, près Diamantina, Minas, no 19194. Frutescent, fl. rouges. Mars-avril. CG.

- Var. pallidiflora Cogn. in Fl. Bras. XIV, III, p. 32. - Haut de 
1. F. -I. GLAZIOU. — LISTE DES PLANTES DU BRÉSIL CENTRAL. 243 la Serra da Piedade, Mlsas, $\mathbf{n}^{\circ}$ 14753. Frutescent, fl. blanclıes. Févriermars. C.

- Val. brachycarpa Cogn. in Fl. Brels. XIV, III, p. 32. - Campo do Ipiranga, Sĩo PAllo, nº 16044. Frutescent, fl. roses. Mars-avril. C.

26. C. Riedelianum Cogn. Fl. Bras. XIV, 1). 32. - Entre Dianıantina et Is Datas, dans le campo, Msis, $n^{\circ}$ 19203. Frutescent, fl. rouges. $\mathrm{R}$.

27. C. trauninense Cogn. Suites au Prodr. VII, p. 30. - Serra do Lenheiro, près de São João d'El Rei, Nıxas, nº 16769 a. Frutescent, f1. jaunes. Arril-mai. C.

28. C. fastigiatum Naud.; Fl. Bras. XIV, III, p. 33. - Ayuruoca, au Serro Frio, Mrsas, n 16045. Frutescent, fl. rouges. Janvier-férrier. R.

99. C. Petronianum Sald, et Cogn. in Fl. Bras. XIV, IV, p. ̋̈91. Haut de la Serra dos Orgãos, Rı-JAx., $n^{\circ s}$ 14752, 15961 et 16770 . Frutescent, fl. rouges. Janvier. C.

30. Microlicia loricata Naud.; Fl. Bras. XIV. III, p. 43. - Serra dos Crystaes, près J'Mmocalie, Goraz, n² 21285 a. Frutescent, fl. roses. Aoùt-septemhre. CC.

31. M. virgata Cogn. var. subpatens Pilger Botan. Jahrb. (1903, 1. 19. - Abbade et Serra dos Cirystaes, Goraz, nos 21282, 21286, 21287, 21288 et 21289. Frutescent, fl. Aoit-septembre. CG.

- Var. gracilss Pilger Bolan. Jahrb. (1903), p. 19. - Serra dos Crystaes, dans le campo, Goxaz, $n^{\circ}$ 21283, 21285 et 21290. Frutescent, f1. roses. toùt-septembre. CC.

-- Var. glabrescens Pilger Botan. Jahrb. (1903), 1). 19. Rio Torto et Rajarlinha, Gortz, n²1291. Frutescent, fl. roses. Juin-juillet. C.

- Var. angustrfola Pilger Kotan. Jahrb. (1903), p. 20. - Morro do Cubatão et Cabeceiras do Rio Gama, Goraz, n² 21284. Frutescent, fï. roses. Juillet-aunt. C.

32. M. viminalis Triana; Fl. Bras. XIV, III, p. 43. - Cabiceiras do Rio Gama, dans le campo, Gosaz, $n^{\text {os }} 21281$ et 21285 a. Frutescent, fl. roses. Janvier-février. C.

33. M. Warmingiana var. latrfolm Cogn. Fl. Bras. XIV, IV, p. 891. - Itacolumy, près Ouro Preto, dans le campo, Mixas, nº 14735. Frutescent, fl. roses. Févier-mars. R.

- Var. hirtella Cogn. Suites au Prodr. VII, p. 36. - Serra de Ouro Branco, dans le campo, Mrsas, $1^{\circ}$ 17508. Frutescent, f1. roses. Décembre. R. 
3'. Microlicia leuconeura Cogu. n. sp. in herb. Paris., Berol, Kin., ete. - Curalinlı, près Diamantina, daus le campo, Mısas, nº 19226. Frutescent. 11. roses. Avril-mai. R.

33. M. obtusifolia Cogn. n. sp. in herb. Paris., Berol., Kew., ete. - Serra dos Crystaes, pris de Diamantina, Mrvas, n 19206. Frulescent, fl. roses. Nars-avril. C.

- Var. mícrophylla Cogn. in herb. Paris, Berol., Kew., ete. Serra dos Cristaes, près Diamantina, Mixas, n 19207. Frutescent, f1. roses. Arril-mai. C.

36. M. melanostagma Pilger Botan. Jahtb. (I903), p. 18. - Cochoeira da Vargem Grande et Chapadão dos Veadeiros, Goyaz, nº 21230. Frutescent, fl. roses. Janvier-février. C.

37. M. goyazensis Pilger Botan. Jahrb. (1903), p. 17. - Serra do Aruda, Govaz, n² 21250. Frutescent, f1. roses. Juin-juillet. R.

38. M. parvula Glaz. n. sp.? in herl. Paris, Berol., Kow, ete. Morro do Salto, dans le campo pierreux, Govaz, $n^{0} 21218$. - Frutescent, fl. roses. Janvier-février. R.

39. M. Glazioviana Cogn. Fl. Bras. XIV, IV, p. 391. - Itacolumy, près Ouro Preto, entre les rochers, Mliss, nos 14731, 19123 a. Frutescent, fl. roses. Février-mars. C.

40. M. denudata Cogn. in Fl. Bras. XIV, III, p. S1. - Serra do Funel et à Diamantina Mhrss, $n^{\text {os }} 19200$ et 19201 . Frutescent, fl. roses. Mars-avril. G.

41. M. crenulata JG.; Fl. Bras. XIV, III, p. ॐ̆́t. - Itacolumy, près Ouro Preto, dans le campo, Minas, $n^{\circ}$ 14736. Frutescent, fl. roses. Février-mars. C.

42. M. Schreinerii Schw, in herb. Paris., Berol, Kew. Gener, etc. - Serra do Inficionado, près Caraça dans le campo, Minas, no 19216. Frutescent, fl. rose's. Mars-avril. R.

43. M. pseudoscoparia Cogn. in Fl. Bras. XIV, III, p. 60. - Vorm da Carajuça, Caraça el à Serro do Cipo, Mrsas, nos 14719 et 19217. Frụtescent, fl. roses. Juin-juillet. C.

44. M. multicaulis Mart.; Fl. Bras. XIV, III, p. 61. - Caraça, au Morro da Carapuça et à Serra do Cipo, Muxas, $1^{\circ} 14718$ et 19281. Frutescent, fl. roses. Février-avril. C.

43. M. linifolia Cham.; Fl. Bras, XIV, III, p. 62. - Serra do Cipo, au Morro dos Mangabeiros. Nixas, $n^{\circ} 19163$ a. Frutescent, fl. roses. Avril-mai R. 


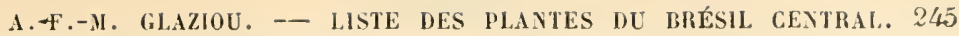

- Var. Naudinana Cogn. in Fl. Bras. XIY, 11I, p. 63. - Biribiry, près Diamantina, entre les rochers, Iliss, $n^{\circ} 19219$, Frutescent, fl. roses. Mars-avril. C.

46. M. isophylla DC.; Fl. Bras. XIV, III, p. 63. - Serra do Lenheiro, près de S. J. d'El Riei, Mixas, ${ }^{0 s} 15967,16775,21228$. Frutescent, f1, roses. Décembre-janvier C. Vulgo: Vassourinha do campo.

47. M. isophylla DC. var. latifolia in Fl. liras. XIV, III, p. 64.Campos Brejos, au Morro Cavado, $\mathrm{n}^{\circ}$ 7626,1475 . Ayuruoca et Serra do Lenheiro, Mras, $1^{0 \text { s }} 15966,16043,17510$ et 19199. Frutescent, f1. roses. Janvier-février. CC.

48. M. minutifolia Glaz. n. sp.? in herb. Paris., Berol., kew., ete. - Cachoeira da Vargem Grande, Goraz, n² 21229. Frutescent, sans fleurs. C.

49. M. arenariafolia DG.; Fl. Bras. XIT, III, p. 67. - Pico do Itacolumy, près Ouro Preto, Mixas, $n^{\text {os }} 834,14717$. Frutescent, fl. roses. Février-mars. C.

- Var. Riedeliana Cogn. in Fl. Bras. XIV, III, p. 68. - Serra de Caraça, dans le campo, Ilısas, $n^{\circ}$ 14716. Frutescent, fl. roses. Févriermars. R.

50. M. ericoides Don var. obtusa Cogn. in herb. Paris., Berol., Kew., etc. - Serra do Cipo, dans le campo, Hwas, n 19198. Plante naine, fl. roses. Avril-mai. R.

51. M. juniperina St.-Hil.; Fl. Bras. XIV, III, p. 69. - Serra do Cipo, dans le campo sablomeux, Mwas, $n^{0}$ 19197. Plante naine, fl. rose's. Mars-arril. R.

52. M. Martiana Berg; Fl. Bras. XIV, III, J. 69. - Pico d'Ttabira do Campo, entre les rochers, Mwsas, $n^{0 s} 16777,17509$, 19238. Frutescent, fl. roses. Août-septembre. C.

93. M. cuspidifolia Nart.; Fl. Brus. XIV, III, p. 72. - Perpetua, près Diamantina, dans Ie eampo, Mısas, $n^{\circ}$ 19227. Frutescent, fl. roses, Mars-avril. R.

öt. M. carnosula Naud.; Fl. Bras. XIV. III, p. T2..- Pinheiro, près Diamantina, dans le campo, Ilixas, $n^{\text {os }}$ 19209, 19211, 20307; Goraz, $1^{\circ}$ 21262. Frutescent, fl. roses. Mar's-avril. C.

53. M. paryifolia Naud; fil. Bras. XIV, III, p. 73. - Diamantina. à Formação, dans le campo, Mısds, nº 19212. Frulescent, 11. roses. Arrilmai. C.

366. M. doryphylla Naud.; Fl. Bras. XIV, III, p. 74. - Serra do 
Lenheiro, H’ès São Joâo d'El Riei, Misas, n’ 14726. Frutescint. f1. ruses. C.

- Val. puberula Cagn. in Fl. Bras. XIV, III, p. 75. - Serra do Lenheiro, près Sào Joĩo d'EI Rei, Mras, uns 14725, 15738, 15965 et 17512. Frutescent, fl. roses. Janvier-février. GC.

- Var. orata Cogn. in Fl. Bras. XIV, III. 1. T\%. - Entre Biribiry et Diamantina, Misas, $n^{\circ}$ 19214. Frutescent, 11. roses. Avril-mai. C.

- Var. glabra Cogn. Suites au J'rodr. VII, 11. 48. - Sĩo João d'El Riei, près du Rio das Mortes Pequenos, Misas, n 17511. Frutescent, fl. roses. Janvier-février. C.

Ӟ7. Microlicia myrtoidea Cham.; Fl. Bras. XIV, III, p. 76. - Itatiaia, au Campo Feio, Rio-Jax., $n^{\circ}$ 8372. Frutescent, fl. roses. Févier-mars. C.

58. M. formosa Chann.: Fl. Bras. XIV, III, 1) 77. - Serra do Cipo, dans le campo, Misas, n 19220. Frutescent, fl. loses. Avril-mai. C.

- Var. parvifolia Cogn. in litt. - Paranaúa, à Congonlos da Serra, Mrsas, $n^{\circ}$ 19241; Cachoeira do Rio Macaco, entre les rochers, Goyaz, $n^{\circ}$ 21227. Frutescent, fl. blanc rosé. C.

̋̊). M. albida Pilger Botan. Jahrb. (1903). Beibl. 79, p. 16. Cachoeira da Vargem Grande ou da Serra da Baliza, Goyaz, $1^{\circ} 21220$. Frutescent, 11. roses. Janvier-février. C.

60. M. crebropunctata Pilger Bolan. Jahrl). (1903), Beibl. 72, 1. 17. - Cachoeira da Vargem Firande ou da Serra da Baliza, Goraz, n²1224. Frutescent, fl. rose pâle. Janvier-février. R.

61. M. tetrasticha Cogn.? in Fl. Bras. XIV, III. p. 80. - Cachoeira da Vargem Grande, Gorä̈, $n^{\circ}$ 21213. Frutesrent, sans fl. en février. R.

62. M. amplexicaulis Cogn. in Fl. Bras. XIV, III, p. 82.- Biribiry, dans le rampo, près de Diamantina, Mixas, $n^{\circ}$ 19205. Frutescent, fl. roses. Février-mars. C.

63. M. viscosa Gogn. n. sp. in herb. Paris., Berol, Kew., etc. Biribiry, près Diamantina, dans le campo, Jıxas, n 19204. Frutescent, f1. roses. Février-mars. C.

64. M. cuneata Naud.; Fl. Bras. XIV, III, p. 87. - Biribiry, près Diamantina, Misas, $n^{\text {os }} 19208$ et 19210. Frutescent, fl. loses. Marsavril. C.

6ï. M. Burchelliana Cogn. in Fl. Bras. XIV, III, P. 88. - Abbade et Serra dos Vearleiros, Goraz, $11^{\circ} 21232$ et 21259 . Frutescent, ft. roses. Janvier-février. C.

66. M. serrulata Cham.; Fl. Bras. XIV, III, p. 89. - Pico do Ita 
A.-F.-M. GLAZIOU. - LISTE DES PIANTES DU BRÉSHL CENTRAL. 247 columy, prés de Ouro Preto, Misas, n 14734; Chajadão dos Veadeiros, Goraz, $n^{\text {os }} 21231$ et 21232. Frutescent, fl. roses. Janvier-février. C.

67. M. hirsutissima Naud. : Fl. Bras. XIV, 1. 90. - Serra dos Veadeiros, Rio Gama et de Corumba, Goraz, nos 21233, 21248, 21254, 21256, 21264 et 21275. Frutescent, f1. roses. Octohre-décembre. C.C.

68. M. vestita DC.; Fl. Bras. XIV, III, p. 91. - Chapadão dos Veadeiros, Goraz, $\mathrm{n}^{\circ \mathrm{s}}$ 21233, 21265. Frutescent, fl. roses. Janvierfévilitrí. R.

- Val. Garderr Cogn. in Fl. Bras. XIV, p. 92. - Formosa, près Meia Ponte, Goraz, n² 21257. Frutescent, fl. loses. Décembre-janvier. C.

69. M. acuminata Cogn. Suites au Prodr. VII, p. J3. - Serra de Ouro Branco, près de São Julião, Msxs, n 17507 . Frutescent, fl. roses. Décembre-janvier. R.

70. M. hirsuta Cogn. n. s]. in herb. Paris., Berol.. Kew. - Diamantina, Hrsas, $n^{\circ}$ 19232; Ponta Lavrada, Goyaz, $n^{\circ s} 21251,21265 a$. Frutescent, fl. roses. Juillet-aoìt. C.

7I. M. ramosa Pilger. Botan. Jahrb. (1903), 1) 18. - Cabeceiros do Rio Gama et Morro d" Abbade, Goraz, nºs 21221, 21225, 21226 et 21242. Frutescent, fl. ruse pourpré. Septembre-octobre. C.

72. M. Santosiana Glaz. n. sp.? in herb. Paris.. Berol., Kew., ete. - Biribiry, près Diamantina, entre les rochers, Mrsas, n 19196. Frutescent, fl. roses. Mars-arril. R.

73. M. leucantha Naud. var. purpunea Cogn. in Fl. Bras. XIV, IV, 1. 592. - Ouro Preto, au campo de São Sebastiño, Mrsas, $n^{\circ} 14720$ : Serras das Jivisoes ou do Ulbano, Goraz, n ${ }^{\circ s} 21243,21244$ et 21245. Frutescent, fl. roses. Novembre-décembre. CC.

74. M. helvola Triana; Fl. Bras. XIV, III, p. 96. - Bas de la Serra Dourada. aux borls des bois, Goraz, $n^{\circ \mathrm{s}} 21292,21293$ et 21294. Arbuste, f1. roses. CiC.

7\%. M. pruinosa Cogn. n. sp. in herb. Paris., Bur., Kew., Brux. - Pepetua, près Diamantina. Misas, $n^{\circ}$ 19246. Frutescent, fl. roses. Avril-mai. C.

76. M. ciliata Cogn. 1. sp. in herb. Paris., Berol, Kew., Brux. Diamantina, à Formacĩo, Mriss, $n^{\circ}$ 19245. Frutescent, fl. roses. Arrilmai. R.

77. M. rivularis Glaz. n. sl.? in herl, Paris., Berolin., Kew., ete. - Paracatú, près des ruisseaux, Minas, nos 21297, 21298. Arbuste, fl. roses. Mlai-juin. C. 
MEMOIRE 3 .

78. Microlicia euphorbioides Mart.; Fl. Bras. XIV, III, p. 97. Serra do Lenheiro, près São João d'El Rei, Mısas, nos 14750, 16776 et 17506. Arbuste, 11. blanches. Février-juin. CC.

- Var. parvifolia Cogn. in Fl. Bras. XIV, III, p. 98. - Biribiry, dans Ie campo, près Diamantina, Mınas, $\mathrm{n}^{\circ}$ 19223. Petit arbuste, fl. rosées. Mars-avril. R.

- Var. тоnantha Mart. Fl. Bras. XIV, III, p. 98. - Chemin de Sabara, près Ouro Preto, Hivas, $^{08}$ 9458, 14721,14739 et 14751 ; Cabeceiras do Rio Gama, Goyaz, nos 21255 et 21261 . Frutescent, fl. roses. Févriermars. CC.

- Var. oblongifolia Naudin in Ann. Sc. nat., ser. 3, III, p. 177. Carandahy, dans, Ie campo, Mrsas, $n^{\circ}$ 14751. Frutescent, f1. rosées. Mars-avril. C.

- Var. setosa Cogn. Fl. Bras. XIY, III, p. 98. Serra de Ouro Branco, près São Julião, Mıxas, no 18233. Arbuste, fl. roses. Mars-avriI. R.

- Var. brevifolia Cogn. in Fl. Bras. XIV, III, p. 98. - Serra de Sĩo José d'El Rei, dans le campo, MINas, $n^{\text {os }} 15964,21239$. Petit arbuste, fl. roses. Janvier-décembre. R.

79. M. sublævis Cogn. n. sp. in herb. Paris., Berol., Kew. etc. - Biribiry, près Diamantina, dans le campo, Mliss, no 19215. Frutescent, fl. roses. Mars-avril. C.

80. M. avicularis Nart.; Fl. Bras. XIV, III, p. 99. - Norro to Inficionarlo, pres Caraça, Mixas, $n^{\text {os }} 14727$ et 19221 . Frutescent, f1. roses. Juin-juillet. C.

- Var. subspathulata Cogn. Suiles au Prodr. VII, p. 61. - Rio das Pedras, dans le campo, Misas, $n^{\circ s} 14728$ et 19240 . Frutescent, fl. roses. Avril-mai. R.

81. M. hispidula Naud.; Fl. Bras. XIV, III, J. 100. - Sobradinho, dans le campo, Goyaz, nos 21263 et 21266 . Frutesrent, fl. roses. Novembre-décembre. C.

82. M. adenocalyx Cogn. n. sp. in herb. Paris., Berol., Kew., ete. - Biribiry, près Diamantina, Nıxas, $1^{\circ}$ 19202. Frutescent, fl. roses. Nars-avril. C.

83. M. polystemma Naud.; Fl. Bras. XIV, III, p. 102. - Bord du Rio Gama, dans le campo humide, Goysz, $\mathrm{n}^{\text {os }} 21249,21252,21260$. Frutescent, fl. roses. Janvier-février. CL.

84. M. graveolens DC.; Fl. Bras. XIV, III, p. 103. - Serra de Ouro Preto, au campo de S. Sebastião et à Diamantina, Mınas, $11^{\circ \mathrm{sS}} 14733$, 
A.-F.-M. GLAZIOU. - LISTE DES PLANTES DU BRÉSIL CENTRAL. 249 19222, 19230 et 19231. Frutescent, fl. roses. Février-avril. Vulgo : Coquinha.

- Var. Serngeana Triana; Fl. Bras. XIV, III, p. 104. - Campos do Rio Gama, Goyaz, $n^{09} 19229$, 21223, 21235, 21236, 21237, 21254, 21257, 21264 et 21273. Frutescent, fl. roses. Novembre-janvier. CC. Vulgo: Coquinho.

8̈. M. Cogniauxii Glaz. 11. sp. in herb. Paris., Berol., Kew., Brux., etc. - Perpetua, près Diamantina entre les rocllers, Mrvas, $n^{0}$ 19308. Frutescent, fl. d'un beau rose. Avril-mai. R.

86. M. Schwackeana Glaz. n. sp. in herh. Paris., Berol., Kew., Brux., etc. - Serra do Cipo, entre les rochers, Mrsas, n 19290. Frutescent, fl. roses. Mars-avril. R.

87. M. formosana Glaz. n. sp.? in herb. Paris., Berol., Kew., Brux., etc. - Formosa, dans les grottes sèches, lixıs, $1^{\circ} 19291$. Frutescent, fl. rose pâle. Mars-aviil. R.

88. M. macrophylla Naud.; Fl. Bras. XIV, III, p. 104. - Quartel do Biribiry, dans le campo, Mlsas, nº 19236. Frutescent, fl. roses. Marsavril. R.

- Var. congestifolia Cogn. in herl. Paris., Berol., Kew., etc. - Biribiry au Nocotó dans le campo. Mrsas, $n^{0}$ 19235. Frutescent, ll. roses. Mars-avril. R.

89. M. robusta Cogn. n. sp. in lierb. Paris., Berol., Kew., etc. Biribiry, près Diamantina, dans le campo, Mrsas, n 19237 . Frutescent, 11. roses. Mars-avril. C.

90. M. myrtifolia Naud. var. obtusifolia Cogn. in Fl. Bras. XIV, III, 1. 107. - Serra do Funil, au Rio Paraúna, Mısas, n ${ }^{\circ}$ 19224. Frutescent, f1. roses. Mars-avril. C.

91. M. rigida Cogn. n. sp. in herb. Paris., Berol., liew., ete. Biribiry, jrès Diamantina, dans le campo, Misas, n² 19225. Frutescent, f1. roses. C.

92. M. decussata Naud.; Fl. Bras. XIV, III. p. 108. - Sabara, au Morro da Gloria, Mrxas, $n^{0 s} 20305,21280$ b. Frutescent, fl. roses. Novembre-décembre. R.

93. M. fulva Cham.; Fl. Bras. XIV. III, p. 109. - Entre Sitio et Barluacena. Mrsis, $\mathrm{n}^{\text {os }}$ 9452, 10762, 12688, 14730, 16042, 16771, 19228 et 21280. Frutescent, fl. roses. Juin-septembre. CC.

- Var. Martialis Cogn. in Fl. Bras. XIV, IIl, p. 110. - Pico do Itacoluny, près Ouro Preto, Mssas, $n^{\circ}$ 14737, 16771, 16773 't 16774. Frutescent, f1. roses. Janvier-février. C. 
94. Microlicia cardiophora Naud.; Fl. Bras. XIV, III, I. 110. Diamantina, à Formação, Mıxas, $1^{\circ}$ 19213; Cabeceiras do Rio Gama, dans le campo, Goraz, $\mathbf{1}^{\circ}$ 21278. Frutescent, fl. roses. Avril-mai. C.

9\%. M. petiolulata Cogn. 13. sp. in herb. Paris., Berol., Kew., etc. - Biribiry, près Diamantina, dans le campo, Whsas, nº 19233. Frutescent, fl. roses. Mars-atril. C.

- Var. parvifolia in herb.. Paris., Berol., Kew., etc. - Birihiry, près Diamantina, dans le campo, Mlsas, $n^{\circ}$ 19234. Frutescent, fl. roses. Mars-avril. R.

96. M. cordata Cham.; Fl. Bras. XIV, III, p. 111. - Serra do Batal, dans le campo, Mıxas, $n^{\text {os }} 8361,14724$ et à Serra da Saramenha, près Ouro Preto, ${ }^{\circ}$ 20306. Frutescent, fl. roses. Avril-juin. C.

97. M. tomentella Naud.; Fl. Bras. XIV, III, p. 11ษ. - Perpetua, près Diamantina, Mivss, ${ }^{\circ} 19234 a$. Frutescent, ll. roses. Avril-mai. R.

98. M. fasciculata Nart.; Fl. Bras. XIV, III, p. 116. - Serra de Ouro Branco et à Santa Luzia, Minas, $n^{\text {os }} 14722,20304$; Cabeceiras do Rio Gama, Serinha, etc., Goraz, $n^{\text {os }} 21216$, 21217, 21219, 21222, 21267, 21268, 21269, 21270, 21271 et 21272. Frutescent, fl. roses. Aoùt-octobre. CG.

- Var. candida Glaz. in herb. Paris., Berol., Kew. - Barreira do Veado, Goyaz, n² 21246. Frutescent, fl. blanches. Septembre-octobre. R.

- Var. parvifolia Pilger in herb, Paris., Berol. - Rio Gama dans le campo, Goyaz, n² 21223. Frutescent, f1. roses. Novembre-décembre. C.

99. M. glandulifera Cugn. Suites au Prodr. VII, p. 69. - Serra do Lenheiro, près de São João d'El Rei, Mıxas, nº 16772. Frutescent, fl. roses. Mars-avril. R.

100. Trembleya pityoides Cliam.; Fl. Bras. XIV, III, p. 123. Perpetua, près Diamantina, dans le campo, Minas, nos 14746, 19239. Frutescent, f1. jaunes. Février-mars. C.

101. T. rosmarinoides DC.; Fl. Bras. XIV, III, p. 123. - Serra do Batatal ou de Capanema. Mrvas, $n^{\circ s} 14747$, 19242. Frutescent, fl. d'un beau jaune. Mar's-arril. $\mathrm{C}$.

102. T. calycina Cham.; Fl. Bras. XIV, III, p. 124. - Itacolumy, près Ouro Preto, Mhnas, $n^{0 s} 14745$, 18232. Arbuste, fl. roses. Juinjuillet. CG.

103. T. debilis Glaz. n. sp.? in lıerb. Paris., Berol., Kew., Brux., etc. - Fazenda da Boa Vista, près Morro do Salto, Goyaz, $n^{\circ}$ 21300. Arbuste, 1l. roses, blanches. Rare. 
A.-F.-M. GLAZIOU. - LISTE DES PLANTES DU BRÉSIL CENTRAL. 251

10'4. T. pentagona Naud.; Fl. Bras. XIV, III, p. 125. - Serra do Batatal ou de Capanema, Hisas. $1^{\circ}$ 14742. Arbuste, f1. roses. Juinjuillet. C.

108. T. tridentata Naud.; Fl. Bras. XIV, III, p. 126. - Serra do Caraça et do Lenheiro, Misas, $n^{\text {os }} 14743,16781$, 17513. Arbuste, f1. roses. Féviler-mars. C.

106. T. parviflora Cogn. var. vulgaris Cogn. in Fl. Bras. XIV, III, p. 128. - Petropolis et Serra dos Orgãos. Rıo-Jan., nos 8680,12704 , 16779; Rajadinha dans les bourbiers, Goraz, $\mathrm{n}^{0} 21300$ a. Arbuste, fl. blanc rosé. Mai-juin. CC.

- Var. Warmingri Cogn. in Fl. liras. XIV, III, p. IgS - Serra dos Orgãos, at Theresopolis, Rio-Jav., n 2579. Arbuste, fleurs blanc rosé. Mars-avril. G.

- Var. axgustrfolia Cogn. in Fl. Bras. Xiv, III, p. 128. - Serra de Ouro Prelo, Mixas, n 14744. Arhuste, fl. blanc rosé. Juin-juiltet. C.

- Var. parvifolia Cogn. in Fl. Bras. XIV, III, p. 129. - Serra do Leinhero, près São João d'El Rei, Mısas, nº 16780. Arbuste, fl. blanc rosé. Juin-juillet. C.

- Var. multaflora Cogn. in Fl. Bras. XIV, III, p. 129 - Ayuruoca, au Serro Frio, Mixas, ${ }^{\circ}$ 9454. Arbuste, fl. blanc rosé. Avril-mai. R.

- Var. heterophisla Cogn. in DC. Suiles au Prodr. VII, 1) Tö. Nova Friburgo, Rı--Jax., $n^{\circ}$ 16778. Arbuste, f1. blanches. Juin-juillet. C.

107. T. laniflora var. genuina Cogn. Fl. Bras. XIV, III, 1. 130. Campo de São Sebastião, près Ouro Preto, Mısas, $n^{\circ}$ 14741. Arbuste, fl. blanches. Février-mars. C.

- Var. grandifolia Cogn. Fl. Bras. XIV, III, p. 131. - Serta do Caraça, au Morro do Inficionado, Mıxas, $n^{\circ}$ 14740. Arbuste, il. blanches. Juin-juillet. C.

108. T. capitata Cognl. u. sp. in herl. Paris., Berol., Kew., Brux., rte. - Quartel do Biribiry, près Diamantina, Mras, ${ }^{0} 19305$. Arbuste, fl. roses. Mars-avril.

109. T. phlogiformis 1)C.; Fl. Lras. XIV, III, p. 131. - Entre Sitio et Parharena, dans le campo, Misas, $n^{\circ}$ 12705. Frutescent, fl. roses. Juin-juiltet. C.

- Var. geverna Gugn. in Fl. Brus. XIY, III, p. 132. - Ipiranga et campos da liocaina, São Paulo, $n^{08}$ 8376, 16047; Ayuruoca, Scrra de Ouro Preto, Minas, $11^{\circ 5}$ 9459, 14748; Corrego do Brejo, Goraz, $n^{0} 21301$. Frutescent, fl. roses. Février-avril. CG. 
- Var. villosa Cogn. Fl. Bras. XlV, III, p. 132. - Casa Branca, rstrata de Sabara, Misas, $n^{\circ}$ 14749. Frutescent, fl. roses. Février-mars. C.

- Var. latifolia Cugn. in Fl. Bras. XIV, III, p. 132. - Serra de Antonio Pereira, Mras, nº 19244. Frutescent, fl. roses. Mai-juin. R.

- Var. Qunquenervia Cogn. Fl. Bras. XIV, III, p. 132. - Formacão, près Diamantina, Mlsas, $\mathbf{1}^{\circ}$ 19304. Frutescent, fl. roses. Avril-mai. C.

- Var. microlicioldes Cogn. in DC. Suiles au Jrodr. VII, p. 78. Ipiranga, dans le campo, São Pavlo, $n^{\circ} 16046$; Chapadão dos Veadeiros, foyaz, n² 21299. Frutescent, fl. roses. Janvier-février. R.

- Var. parvifolia Cogn. XIV, Ill, p. 132. - Bento Rodrigues, près O)uro Preto, dans le campo, Mrsas, no 19243. Frutescent, fl. roses. Avrilmai.

110. Trembleya Santæ-Luziæ Glaz. n. sp. in herb. Paris., Kew., Brux., etc. - Santa Luzia, au bord des ruisseaux, Goyaz, $n^{0 s} 21301$ a, 21302. Arbuste, fl. blanches. Septembre-novembre. C. Les orpailleurs se servent des rameaux de cette plante pour retenir l'or.

111. Lavoisiera pulcherrima DC.; Fl. Bras. XIV, III, p. 138. llacolumy, près Ouro Preto, Ihsas, $n^{\circ}$ 14761. Arbuste, fl. roses. Février-mars. CC.

112. L. robusta Cogn. n. sp. in herb. Paris., Berol., Kew., ete. - Serra do Cipo, entre les rochers, Mixas, no 19210. Arbuste, f1. roses. Hars-avril. C.

113. L. macrocarpa Naud.; Fl. Bras. XIV, III, p. 139. - Serra do Cipo, entre les rochers, Mwas, $n^{\circ}$ 19271. Arbuste, fl. roses. Févriermars. C.

114. L. suberosa Cogn. in Taubert (Engl. Bot. Jahrb. XXI), p. 446. Chapadão dıs Veadeiros, dans les terrains pierreux, Goysz, $\mathbf{n}^{\circ} 21303$. Arbuste sans fl. en janvier.

115. L. cordata Cogn. n. sp. in herb. Paris., Berol., Kew., etc. Diamantina, à Formargão, Mısas, $n^{0}$ 19274. Arbuste, fl. blane rosé. ilars-avril. C..

116. L. patulifera Pilger. n. sp. in herb. Paris., Berol., Kew., Brux., etc. - Fazenda da Boa Vista, près Morro do Salto. Gorsz, n² 21309. Frutescent, fl, blanc rosé. Décemlıre. R.

117. L. punctata DC.; Fl. Bras. XIV, III, p. 140. - Caraça, au Morro da Carapuca, Mısas, $\mathbf{n}^{\circ}$ 14759. Arbuste, fl. roses. Arril-juin. C.

118. L. Riedeliana Cogn. in Fl. Bras. XlV, III, p. 141. - Caraça, 
1.-F.-M. GLAZIOU. - LISTE DES PLANTES DU BRÉSIL CENTRAL. 253 au bord des bois humides, Mixas, $\mathrm{n}^{\circ} 19275$ a. Albuste, 11. roses. Avriljuin. C.

119. L. grandiflora Naud.; Fl. Bras. XIV, III, p. 141. - Pres de Cocal, au bord des bois liumides, Goraz, no 21304, 21305, 21306. Arhuste, f1. roses. Janvier-férrier. C.

120. L. novemnervia Cogn. n. sp. in herh. Paris., Berol., Kew. - Serra do Cipó, au Rio Paraúna, Mrsis, nº 19273. Arbuste, fl. blancliàtres. Avil-mai. R.

121. L. alba DC.; Fl. Birs. XIV, III, p. 143. - Serra de Ouro Branco, entre les rochers, Mıvas, $n^{0}$ 14760. Arbuste, fl. blanches. Marsavril. CG.

Forma longifolia Cogn. in lierb. Paris., Berol., Kew., ete. - Serra do Cipó, au Rio Paraúna, Unss, nos 19272 et 19275. Adbuste, ll. blancles. Mars-arril. C.

122. L. rigida Cogn. in Fl. Bras. XIV, IH, p. L'1't. - Terra dos Crystaes, près Diamantina, Mrss, $n^{\circ}$ 19266. Arbuste, 11. roses. Marsavril. C.

123. L. crassifolia DC.; Fl. Bras. XIV, III, p. Ifli. - Serra dos Crrstaes, près Diamantina, Mrss, $n^{\circ}$ 19268. Aruste, fl. Poses. Marsavril. C.

- Var. parvifolia Cogn. in herb. Paris., Berol. Kew., etc. - Biribiry, au Mocotó, Mrss, no 19275 b. Arbuste, fl. roses. Mars-avril. R.

- Forma grandifolia Cogn. in herb. Paris., Berol., Kew., etc. Biribiry, près de Diamantina, Mras, n 19267. Arbuste, fl. roses. Marsavil. R.

124. L. caryophrllea Naud.: Fl. Bras. XIV, III, 1. 146. - Diamanłina, au Tombador, Mrxs, $1^{\circ}$ 19265. Arbuste, fl. roses. Mars-arril. li.

19:. L. confertiflora Naud. var. latifolia Cogn. in Fl. Pras. XIV, III, p. 147. - Biribiry, prés Diamantina, Mrxas, ${ }^{\circ}$ 19262. Arbuste, t1. poses. Mars-avil. C.

- Val. loxgrfolra Naut, in Fl. Bras. XIV. III, p. l任. - Biribiry, près biamantina, Mrrs, $n^{\circ}$ 19262. Arbuste. fl. roses. Mars-avril.

126. L. crassinervia Gogn. n. sp, in herb. Paris, Berol, hew., etc. - Serra do Arruda et au Morro do Abbale, Goraz, 11 ${ }^{\text {os }}$ 21307, 21303. Arbuste, fl. puses. Juillet-aoùt. R.

127. L. macorifera Naud.: Fl. Bras. XIV, III, p. 1'8. - Biribiry, près de Diamantina, Minas, $n^{\circ}$ 19264. Arbuste, 1l. roses. Mars-avril. Cli.

- Var. parvifolia Cugn. in herb. Paris., Berol., liew., etc. - 
Biribiry, près Diamantina, Minas, $1^{\circ}$ 19263, Arluste, fl. roses. Marsavril. C.

128. Lavoisiera glandulifera Naul.; Fl. Bras. XIV, III, p. 149. Serra de Caraça, au Campo de Fora, Mınas, $n^{\circ}$ 14758. Arbuste, fl. roses. Mai-juin. G.

- Var. brevifolia Cogn. in Fl. Bras. XIV. III, p. 149. - Serra do Cipó, près des rochers, Minas, n 19269. Arbuste, ll. roses. Mars-arril. C.

- Var. genuina Cogn. in Fl. Bras. XIV, III, p. 149. - Caraça, au Morro da Carapuça, Mlısas, $n^{\circ}$ 14757. Arbuste, fl. l'oses. Février'mars. C.

199. L. australis Naud.; Fl. Bras. XIV, III, p. Lŏ0. - Source du Rio Parahylıa, aux campos da Bocaina, Sĩo P’aclo, nº 8377. Frutescent, fl. roses. Janvier-février. C.

130. L. microphylla Cogn., n. sp. in herb, Paris., Berol., Kew., etc. - Formacão, près Diamantina, Mıvas, $n^{0} 19254$ a. Frutescent, fl. roses. Mars-avril. R.

131. L. parviflora Cogn., n. sp. in herb. Paris., Berol., Kew., etc. - Fazenda rlo Lamarão, dans les bourthiers, Goraz, nº 21319. Arbuste, fl. roses. Juin-juillet. C.

132. L. uliginosa Cogn. in DG. Suites au Prodr. VII, p. 88. - Itabira do Campo, en bas du Pico, Mısas, n 17514. Arbuste, ft. rose pàle. Décembre-janvier. C.

133. L. Selloana Cogn. in Fl. Bras. XIV, III, p. 152. - Serra dos Crystaes, près Diamantina, Mrvs, $\mathbf{1}^{\circ} 19268$ a. Arbuste, fl. roses. Avrilmai. R.

134. L. serrulata Cogn. in Fl. Brus. XIV, III, p. 133. - Serra dos Crystaes, près Diamantina, Mrsas, no 19259. Frutescent, fl. roses. Marsavril. C.

I33. L. Bergii Cogn. in Fl. Bras. XIV, III, p. 1.ّ't. - Serra de São José d'El Rei et à Rodrigo Silva, Mrras, no 1672, 19260; Abbade, pres de Meia Ponte, Bom Successo, Corrego do Brejo, etc., dans les bourbiers, Goyaz, $n^{\text {os }} 21314,21315,21316,21317$ et 21318. Arbuste, t1. roses. Avril-juin. CC.

136. L. rugulosa Cogn. n. sp. in herb. Paris., Berol., Kew., etc. - Guralinho, près Diamantina, Misus, $n^{\circ}$ 19252. Frutescent, fl. roses. Avril-mai. C.

137. L. compta DG.; Fl. Bras. XIV, III, p. I54. - Serra dos Orgãos, au sommet, Irio-Jax., no 15963. Frutescent, fl. roses. Février-mars. C.

- Var. rubrocincta Cogn. in Fl. Bras. XIV, III, p. 15.̈. - Serra dos 
A.-F.-M. GLAZIOU. - LISTE DES PLANTES DU BRÉsIL CENTRAL. 255

Orgaos, aul sommet, Rio-J $\mathrm{JN}_{\mathrm{N}}, \mathrm{n}^{\circ}$ 16783. Frutescent, fl. roses. Févriermars. C.

- Var. longiciliata Cogn. in herb. Paris., Berol., Kew.. etc. Riacho das Varas, dans le campo, Mrvas, no 19255. Frutescent, l'l. roses. Mars-avril. G.

138. L. phyllocalycina Cogn. in Fl. Bras. XIV, 111, p. 15̆6. - Rodrigo Silva, près Ouro Preto, Mrsas, n 19250 . Frutescent, fl. roses. Maijuin. C.

139. L. insignis DC. ; Fl. Bras. XIV, 1Il, p. 15้6. - Selra dos Or@ãos, au sommet pres du rancho, liro-JAx., $n^{0 s}$ 14754, 15962: Serra da Saramenha, près Ouro Preto, Mrsas, nos $19250 a$ et 20308. Frutescent, fl. roses. Janvier-février. CG.

140. L. Glazioviana Cogn. in Fl. Bras. XIT, I1], p. 1\%7. - Serra dos Orgãos, à Garrafão, Rio-JAx., nos 585, 2864, Aịuruoca, Minas, $n^{\text {os }} 4804$ et 9449. Frutescent, fl. roses. Avril-mai. C.

141. L. Francavilleana Cogn. in Fl. Bras. XIV, III, p. 108. - Rio das Pedras, à Mato Grosso, Mrxas, n 19256. Frutescent, f1. roses. Arrilmai. R.

142. L. Schwackeana Glaz. in Suites au Prodr. VII, p. 90. - Serra de São José del Rei, Minas, nº 16784. Frutestent, fl. roses. Juin-juillet. R.

143. L. cataphracta DC.; Fl. Bras. XIV, III, J. 1399. - Riacho das Varas, dans le campo humide, Hrsas, $n^{\circ}$ 19254. Frutescent, fl. roses. Mars-avril. C.

- Var. calycina Cogn. in herb. Paris. Berol., Kew., etc. - Riacho das Varas, dans le campo, Mıxas, $n^{0}$ 19259. Frutescent, fl. roses. Marsavril. C.

144. L. imbricata DG.; Fl. Bras. XIV, III, p. 139. - Itacolumy, près Ouro Preto, Mrsts, $n^{\text {os }} 14756,19251,21320$. Arbuste, fl. roses. Janvier-févier. CC.

- Var. subserrulata Cogn. in Fl. Bras. XIV, IV, p. 5̈9\%. - Serra de Caraça, Mrsas, $n^{\text {os }} 14755,19257$; Rasgão, jores de Corumba, Gosaz, $n^{0}$ 21313. Frutescent, fl. blanchâtres. Férrier-mars. C.

140ั. L. elegans Cogn. in Fl. Bras. XIV, III, p. 160. - Serra dos Orgĩos, au Frade, Rio-Jax., $n^{\circ}$ 3758. Frutescent, fl. rose pâle. Mai-juin. R.

146. L. dichotoma Ciogn. 11. sp. in herb. Paris., Berol., Kew., etc. - Biribiry, près de Diamantina, Mras, $n^{\circ}$ 19248. Frutescent, fl. roses. Avril-mai. C. 
147. Lavoisiera tetragona DG.; Fl. Bras. XIV, IHI, p. 162.-Diamantina, au Tombaldor, Minas, $1^{\circ}$ 19247. Frutescent, 1l. roses. Avril-mai. C.

148. L. dorifolia Cogn. n. sp. in herb. Paris., Berol., Kew, etc. - Serrar de Crystaes, près Diamantina, Mısas, $n^{\circ}$ 19249. Frutescent, f1. roses. Arril-mai. R.

I49. L. chancepitys Naud.; Fl. Bras. XIV, III, p. 163. - Diamantina, au Tombador, Mlsas, n 19195. Frutescent, fruits secs. Avril. C.

150. L. fragilis Cogn. n. sp. in herb. Paris., Berol., Kew, etc. - Serra dos Crystaes, entre les rochers, près Almocafre, Goyaz, $\mathrm{n}^{\circ}$ 21312. Arbuste, fl. blanc rosé. C.

131. L. quinquenervis Cogn. n. sp. in herb. Paris., Berol., Kew., etc. - Guariroba, au Mor’o do Cubatão, Goyaz, nos $12310,21311$. Arbuste, fl. roses. Octobre-novembre. R.

159. Rhynchanthera humilis Cogn. in DC. Suites au Prodr. VII, p. 98. - Mogy das Cruzes, S. Paulo, no 17517. Frutescent, fl. roses. Mars-avril. G.

153. Rh. gracilis Cogn. n. sp. in herl, Paris., Berol., Kew., etc. - Formaçao, près de Diamantina, Mlisas. $n^{\circ}$ 19289. Frutescent, fl. roses. Mars-avril. C.

- Var. glabrata Cogn. in herb. Paris., Rerol., Kew., etc. - Formação, près Diamintina, Minas, no $19289 a$. Frutescent, fl. roses. Marsavril. R.

1ั4. Rh. montana Glaz. n. sp. in herb. Paris, Berol., Kew., Brux., etc. - Entre Meia Ponte et Serra dos Pyreneus, dans le campo sec, Goraz, no 21325. Frutescent, fi. violacées. Juin-juillet. C.

155. Rh. parvifolia Glaz. n. sp. in herb. Paris., Berol., Kew., Brux., etc. - Rio Gama, au Colombiste, dans le campo, Goyaz, nº 21325. Frutescent, fi. violacées. Janvier-février. C.

156. Rh. stricta Cogn. in Fl. Bras. XIV, III, p. 168. - Mogy das Cruzes, dans les bourbiers, São Padro, $1^{\circ} 17517$ b. Frutescent, 11. violettes. Avril-mai. R.

157. Rh. ursina Naud.; Fl. Bras. XIV, III, p. 169. - Entre le Rio Indaya ef Bocaina, dans le campo humide, Nıvas, $n^{\circ} 21321$. Frutescent, fl. rose foncé. Octobre-novembre. C.

158. Rh. grandiflora DC.; Fl. Bras. XIV, III, p. 172. - Près de Santa Luzia, dans les bourbiers, Groraz, $n^{\circ} 21332 a$. Frutescent, fl. roses. Avril-mai. R.

1599. Rh. novemnervia DC.; Fl. Bras. XIV, III, p. 173. - São João 
A.-F.-M. GLAZIOL. - LISTE DES PLANTES DU BRESIL CENTRAK. 257 d'El Rei, dans les endroits humides, Mınas, ${ }^{0}$ 16786. Frutescent, fl. roses. Mars-avril. C.

160. Rh. cordata DC.: Fl. Bras. XIV, III, 1. 17\%. - Moro de São Vicente, dans le campo, Msas, $n^{\circ} 14765$ a. Frutescent, f1. violacées. Juinjuillet. $\mathrm{R}$.

- Var.genuina Cogn. in Fl. Bras. XIV, III, p. 176. - Ouro Preto, au campo de São João, Mıxıs, $n^{\circ s}$ 14766, 17515. Frutescent, ll. violacées. Févilier-mars. C.

161. Rh. limosa DC.; Fl. Bras. XIV, III, 1). I7T. -- Entre Sitio et Barbacena, Mısas, nos 12711, 14765 et 19297; Parauna, près de Cachoeirinlal, Goyaz, nos 21329 et 21330 . Frutescent, fl. roses. Juin-juillet, CC.

162. Rh. rostrata DC.; Fl. Bras. XIV, III, p. 178. - Pinlueiro, près Diamantina, Mrsas, $n^{\circ}$ 19303; Olho d"Igua Quente, près de Saia Vella Goys, $n^{\text {os }} 21331$ et 21332 . Frutescent, fl. violacées. Mars-avril. CC.

163. Rh. dichotoma DC.; Fl. Bias. XIV, III, p. 182. - Gavea et Rio do (Turo, dans les bourbiers, liro-Jax., n ${ }^{0 s} 565,1539,3755,10843$ et 16785. Frutescent, fl. violacées. Mai-juillet. CC.

164. Rh. mollis Glaz. п. sp. in herb. Paris., Berol., Kew., Brux., Genev, etc. - Valence dans le bois humide, Rı-JAx., no 2137. Frutescent, fl. violacées. Octobre-novembre. R.

163̈. R/t. hispida Naud.; Fl. Bras. XIV, III, 1). 186. - Estrada do Norte ou da Canastra, près de Goyaz, Gorız, n² 21328. Frutescent, fl. violacées. Juillet-aoùt. C.

166. Rh. Glazioviana Cogn.: Fl. Lrus. XIV, III, p. I89. - Itapemirim, dans les bourbiers, Esplrito SAxto, $n^{\circ}$ 9828. Frutescent, fl. ıiolacées. Févier-nuars. R.

167. Rh. goyazensis Glaz. n. sp. in herb. Paris., Berol., Kew, etc. - Iaut du Rio Paranaúa, près des rivieres, dans le campo, Goraz. $n^{0} 21328$ a. Frutescent, $\mathbf{f l}$. violettes. Arril-nai. R.

168. Siphanthera villosa Cogn. in Fl. Bras. XIV, III. p. 192. Itacolumy, près Ouro Preto, Mris, n² 14762. Herb., fl. roses. Janvierfévrier. C.

169. S. arenaria Cogll. in Fl. Brus. XIV, III, p. 193. - Srra do Batatal, près Capanema, Mıxs, $0^{\circ}$ 14764, 19281. Sous-fiutescent, fl. roses. Juin-juillet. C.

- Var. cordifolia Cogn. in DC. Suils au Prodr. VIl, 1. 113. Serra de Caraça, au campo de Fora, Mrsas, nº 14763. Sous-frutescent, f1. roses. Févricr-mars. C. 
170. Siphanthera capillaris Cogn. n. sp. in herb. Paris., Berol., Kew., ete. - Congonlaas da Serra, au Cipó, Minas, $1^{\circ}$ 19280. Herb., 11. roses. Mars-avril. R.

171. S. microphylla Cogn. n. sp. in herb. Paris., Berol., Kew., etc. - Biribiry, près Diamantina, dans le campo, Mıxıs, $n^{\circ} 19228$ l. Herb., fl. roses. Mars-avril. R.

172. S. Glazioviana Cogn. n. sp. in herb. Paris., Berol., Kew., ete. - Curalinho, près Diamantina, Mrsas, $n^{0}$ 19282. Suus-fiutescent, 11. roses. Avril-mai. C.

173. S. cordata Pohl; Fl. Bras. XIV, III, p. 196. - Diamantina, à Formação, Mrvas, $n^{0 s}$ 17516, 19278; entre Rio Torto et Rio Bananal, Goyaz, no 21333. Sous-frutescent, fl. rouges, Mars-avril. CG.

174. S.tenera Pohl; Fl. Bras. XIV, III, p. 199. - Curalinlı, près Dianıntina, Hıvas, nº 19279. Herb., fl. roses. Arril-mai. C.

17.े. Poteranthera pusilla Bong.; Fl. Bras. XIV, III, p. 202. Entre Colombista et Rio Bananal, Goraz, $\mathrm{n}^{0}$ 21436. Herb., fl. roses. Avril-mai. C.

176. P. gracillima Cogn. in DC. Suites au Prodr. VII, 1. 121. Entre Cabeceiras do Rio Gama et Riarho Funto, Goraz, $n^{0} 21344 b$. Herl, fl. roses. Avril-mai. R.

177. Acisanthera pulchella Cogn. in Fl. Bras. XIV, III, 1. 211. Pouzo Aito et à Passa Tres, Goyaz, $n^{\circ 5} 21340,21341,21342$. Herbacé, fl. roses. Juillet-auût. C.

178. A. inundata Triana; Fl. Bras. XIV, III, p. 213. - Tijuco dans les grands bourbiers, Goraz, $\mathrm{n}^{05}$ 21338, 21344. Herb., 11. roses. Juilletaouit. C.

179. A. fluitans Cogn. var. nova. densifolia Cogn. in herb. Paris, Brux., Berol., liew., etc. - Cabeceira do Rio do Brejo et entre Rio Torto et Paranaúa, au fond de l'eau, Goraz, $\mathrm{n}^{\text {os }} 21343,21345 a$. Herbacé, 11. roses. Mai-juin. C.

- Var. repens Cogn. in Fl. Bras. XIV, III, p. 2lä. - Pouso Alto, dans les bourbiers. Goraz, n 21339. Herb. fl. roses. Juillet-aoùt. G.

180. A. punctatissima Triana; Fl. Bras. XIV, III, p. 219. - São João del Rei. dans le campo, Mısas, $n^{0}$ 16810. Sous-frutescent, fl. roses. Juin-juillet. C.

181. A. variabilis Triana; Fl. Bras. XIV, III, p. 220 . - Entre Heia Ponte et Bernardo Lobo, Goraz, $n^{\circ}$ 21324. Sous-frutescent, 11. roses. Juinjuillet. C. 
A.-F.-H. GlazioU, - LISTE DEs PlaNtes dU BRÉSLL CENTRAL. 259

- Var. glabriuscula Coğh. in Fl. Bras. XIV, III, p. 222. - Piracicaba, dans le campo, São Paulo, n 1603. Sous-frutescent, fl. roses. Févriermars. R.

182. A. Glazioviana Cogn. in Fl. Bras. XIV, III, p. 223. - Selra do Picí, au Palmital, dans les bourbiers, Rı-Jan., no 10769. Sous-frutescent, fl. roses. Mars-avril. R.

183. A. alsinafolia Triana; Fl. Bras. XIV, III, p. 223. - Serra de Ouro Preto, dans le campo, Mıxas, $n^{\circ} 17517 a$. Sous-frutescent, fl. roses. Février-mars. C.

- Var. Glazroviana Cogut. in Fl. Bras. XIV, III, p. 2024. - Entre Sitio et Barbacena, Mıvıs, $n^{\circ}$ 10765. Sous-frutescent, fl. roses. Maijuin. C.

184. Nepsera aquatica Naud.: Fl. Bras. XIV, III, p. 231. - Itapemirim, dans les marécages, Esprito Sixto, I $^{\circ} 9804$. Fivutescent, fi. blanclıâtres. Février-mar's. C.

18\%. Desmoscelis villosa Naud. val. stachyordes Cogn. in $\mathrm{Fl}$. Bras. XIV, III. p. 234. - Biribiry dans le campo, Ninas, n 19277 a et à Cabeceiras do Rio Bananal, Goyaz, $n^{\circ}$ 21323. Frutescent, f1. roses. Mars-avril. C.

- Var. lrchnitones Cogn. in Fl. Bras. XIV, III, p. 234. - Jaragua, près du Ponso do Grego Fundo, Goraz, n 21322. Frutescent, fl. roses. Juillet-aoùt. C.

- Var. gracildma Cogn. in Fl. Bras. XIV, III, 1) 234. - Itapemirin, dans le bois, Espimito Sixto, $n^{\circ}$ 9807. Frutescent, fl. rosées. Févriermars. R.

186. Microlepis Mosenii Cogn. Val. acutrfolia Cogn. ill Fl. Bras. XIV, III, p. 936. - Entre Aỳuruoca et Cacliambú, Misas, n $17524 a$. Arbuste, fl. violacées. Janvier-février. C.

187. M. quaternifolia Cogn. in Fl. Bras. XIV, III, p. 236. - Ayuruoca, dans le bois, Mixas, $n^{\circ}$ 15970. Arbuste, fl. violacées. Janvierfévriel. C.

188. M. oleafolia Triana; Fl. Bras. XIV, III, p. 237. - Magy das Cruzes, dans les marécages, S̃̃o Paulo, n 17524 . Albuste, fl. violacées. Avril-mai. C.

189. Svitramia pulchra Cham.; Fl. Bras. XIV, III, p. 240. - Serra do Lenheiro. près São João d'El Rei, Hıv.s, no 16820. Mrbuste, fl. roses. Mars-avilil. $R$.

190. Macairea Mosenii Cogn., in Fl. Bras. XIV, III, P. 242. - 
Piraciralar, São Paulo, n 16039 ; Fazendia Amoreira, dans les capoes luunides, Goraz, no 21345. Arbuste, fl. roses à centre blanc. Férriermars. C.

191. Macairea sericea Gogn. in Fl. Bras. XIV, III, 1). 243. Entre Lage et Curumba, au bord du bois et dans le campo, Goraz, пi̊ 21346 a. Arurisseau, fl. rosies. Juillet-aunt. C.

192. M. adenostemon DC.; Fl. Bras. XIV, III, p. 244. - Près de Rio Manso, dans le campo, Mixas, ${ }^{\text {os }}$ 12709, 13843, 16038, 16787 et 21346. Arluuste, 11. roses. Juillet-ioùt. CC.

193. M. foveolata Cogn., in Fl. Brus. IV, p. $593 \%$ - Pao d'Alho, Esprirto Sayto, $1^{0}$ 9806. Arbuste, 11. rougeâtres. Mai-juin. R.

194. Pterolepis trichotoma Cogn. in Fl. Bras. XIV, III, 1). 261. São Jıão da Barra, près de Campos, Lío-Jas., ${ }^{05}$ 9829, 11936. Sousfrutescent, fl. roses. Février-mars. C.

193. Pt. Glaziovii Pilger Lotan Jahrb. (1903) Beibl. 72, p. 16. Cachoeira de Paranaía, dans le canpo, Goraz, nº 21355. Frutescent, f1. louses. Mai-juin. C.

196. Pt. caraçana Glaz. n. sp. in herb. Paris., Berol., Kew., Brux, etc. - Serra do Carara, au rampo de Fora, Msxs, nº $14762 a$. Sous-frutescent, fl, violacées. Janvier-février. R.

197. Pt. paludosa Cogn. in Fl. Bras. XIV, III, p. 272. - As Estacas et au Purity Vermelho, Goyaz, $n^{\text {os }}$ 21347, 21348. Sous-frutescent, fl. roses. Avril-nai. C.

198. Pt. maritima Cogn. in Fl. Bras. XIV, III, 1. 273. - Guaratiba, près de la mer, Rıo-JAx., no 6148 a. Sous-frutescent, fl. roses. Ioùt-septembre. R.

199. Pt. glomerata Niq.; Fl. Bras. XIV, III, p. 274. - Restinga de Copacabana, dans les endroits humides, Ro-JAx., $n^{05} 2134$, 8567. Sousfrutescent, lit. roses. Juin-aoùt. CG.

- Var. lovglfolia Cogn. in Fl. Bras. XIV, III, p. 275. - Varianna, près Ouro Preto, dans les maréraces, Mixas, $n^{\circ}$ 13842. Solis-frutescent, fl. roses. actobre-novembre. C.

- Var. angustifolia Cogn. in Fl: Bras. XIV, III, p. 273. - Entre Ouro Preto et Marianna, Mrsas, $\mathrm{n}^{\circ} 12706$; près de Jaragua au bord des ruisseaux, Goraz, nos 21347 et 21348. Sous-frutescent, 11. roses. Avril-juiı. C.

- Var. micropiylla Cogn. in Fl. Bras. XIV, III, p. 27̈. - Bas de la vallie de Jacarepagua, Rı-Jax., $n^{\circ}$ 6148. Sous-frutescent, fit. roses. Aoùtseptembre. C. 
1.-F.-M. GLAZIOU. - LISTE DES PLANTES DU BRÉSIL CENTRAL. 260

- Var. Glazionir Cogn. in Fl. Bras. XIV, III, p. 276. - Illa do Governador, Rio-JAx., $10^{\circ}$ 7885. Sous-frutescent, 11. roses. C.

- Var. Saldaxhei Cogn. in Fl. Bras. XIV, III, 11. 276. - Restinga de Coparabana, dans le sable humide, Rio-Jax., n 11965. Sous-frutescent, 11. roses. Juillet-aoùt. C.

200. Pt. filiformis Triana: Fl. Bras. XlV, III, j. 279. - Entre Rio Bananal et Rio Torto, dans les fissures des rochers, Govaz, nº 21336. Presque acaule, fl. rosées. Mars-avril. C.

201. Pt. exigna Cogn., in DC. Suiles au Prodr. VII, p. 188. - Serra Meloncias, dans les fissures des rucleers, Goraz, $n^{0} 21336$ ॥. Herbacé, fl. roses. Mars-avril. R.

202. Pt. perpusilla Cogn. in F\%. Bras. XIV, III, 1. 280. - Corregu do Brejo, aux bords des rivières, Gorız, n² 21337 . Herbacé, tl. blanclatatres. Nars-avril. C.

203. Pt. repanda Triana; Fl. liras. XIV, III, p. 281. - Serra de Lenheiro, près São João del Rei, Mwas, ${ }^{\text {os }} 17516 a$, 12694. Sous-fiutescent, 11. roses. Juillet-roùt. C.

204. Pt.alpestris Triana var. n. hispida Cogn. in herl. Paris., Berol., Kew., etc. - Biriluiry, près Diamantina, Mrss, nº 19276. Frutescent, fl. roses. Mars-avril. C.

- Var. nor. hirsutior Cogn. in herb. Paris., Berol., Kew., ete. Biribiry, pris Diamantina, Mnss, $n^{\circ}$ 19277. Frutescent, fl. roses. Marsavril. C.

9030. Tibouchina camescens Cogn. in Fl. Bras. XIV, III, p. 298. - Nova Friburgo, dans le bois, Rio-Jax., nos 11962,15987 et 16801. Arbrisseau, f1. rose violacée. Janvier-février. CC.

206. T. arborea Cogn. in Fl. Bras. XIV, III, p. 299. - Quitandinha, près Petropolis, Rio-Jax., $n^{05}$ 6881, 15993. 15994 et 15995; Serra da Mantiquerra, Mrsas, n ${ }^{\circ}$ 15996. Allorisseau, fl. rose violacé. Décembrefévrier. C.

207. T. mutabilis Cogn. in Fl. Liras. XIV, III, p. 300. - Serra de Manbuca, près Paraty, Rio-JAx., n" 6881 a. Arbrisseau, f1. rose violacé. Décembre-janvier. C.

208. T. pulchra Gugn. in Fl. Bras. XIV, III, p. 301. - Minrunca, dans le bois vierge, Mrsas, $n^{\circ}$ 9455. Arbrisseau, fl. rose violacé. Malrsarril. C.

209. T. Petroniana Cugn. et Sald. in Fl. Bias. XIV, IV, p. ".98. Alto da Serra de Nova Filuurgo. Rio-JAx., n 15997. Arburssau. fl. rose violacé. Mars-arril. C. 
210. Tibouchina Saldanhai Cogn. in Fl. Bras. XIY, III, p. 302.

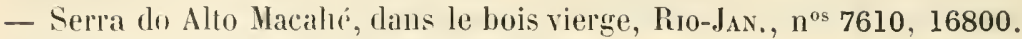
Arbrisseall, f1. rose violacé. Mars-avril. C.

211. T. Raddiana Cogn. in Fl. Bras. XIV, III, 1. 303. - Serio Frio da Ayuruoca, lans le bois, Mivas, no $9455 a$. Arbrisseau, fl. rose violace. Mars-avril. C.

212. T. Imperatoris Sald. et Cogn. in Fl. Bras. XlV, IV. 1. 598. - Sommet de la Serra do Alto Macalıé, Rio-Jan., nº 15982. Arbuste, f1. roses. Juillet-aoùt. R.

- Var. nov. parvifolia Sald. et Cogn. in Fl. Bras. XIV, IV, ґ. 599. - Ayuruoca, au Serro Frio dans le bois, Misas, no 15983. Arbuste, f1. violaeres. Juillet-aoùt. R.

213. T. Sellowiana Cogn. in Fl. Bras. XIV, III, p. 304. - Colline d'lpiranga, aux bords des bois, SÃo-PAL'Lo, nº 12692. Arluuste, fl. violettes. Avril-mai. C.

- Var. вrevifolia Cogn. Fl. Bras. XIV, III, p. 30"̈. - Mogy das Cruzes, dans le bois, São-Paulo, no 17518. Arbuste, fl. violettes. Avrilmai. C.

214. T. organensis Cogn. in Fl. Bras. XIV, III, p. 308. - Serra dos Orgãos, dans le bois vierge, lio-JAx., n 3969 a. Arbrisseau, f1. violettes. Mars-avril. G.

215. T. semidecandra Cogn. in Fl. Bras. XIV, III, p. 309. - Theresoprolis, au Inbuhy, Rio-Jas., $11^{08}$ 9458, 10774 et 15984. Arbrisseau, 11. violettes. Har's-avril. CC.

216. T. Schvackei Cogn. in DC. Suites au Prodr. VII, p. 906. Alto Macahé de Nova Friburgo, Rı-Jax., n ${ }^{0}$ 16802. Arluuste, fl. violettes. Décembre-janvier. R.

217. T. floribunda Cogn. in Fl. Bras., XIV, III, 1. 312. - Nova Friburgo, au Pico da Saude ou do Suspiro, Rio-Jax., $11^{\text {os }} 587$ et 12685. Arbuste, fl. roses. Août-septembre. C.

218. T. Weddellii Cogn. var. angustifolia in Fl. Bras. XIV, III, p. 312. - Cachambú, près de Petropolis, dans le bois, Rro-Jax, $11^{\circ 8} 7611$ et 15981. Arbuste, fl. violettes. Janvier. C.

- Var. parvifolia in lrerb. Paris, Berol., kew., etc. - Entre Biribiry ef Iiamantina, Misas, no 19302. Arbuste, fl. violacées. Avril-mai. $\mathrm{R}$.

219. T. nervulosa Cugn. in Fl. Bras. XIV, IlI, p. 315. - Serra dos 
A.-F.-M. GLAZIOU. - LISTE DES PJANTES DU BRÉSIL CENTRAL. 263 Orgãos, au Frade, Rıo-Jan., $1^{\circ}$ 3974. Arhuste, fl. violettes. Mars-arril. C.

Val. glabrata Cogn. in DC. Suites au Prol. V'II, p. 209. - Alto Macahé de Nova Friburgo, Rio-Jax., n 16794. Arbuste, 11. violettes. Mals-avril. C.

- Var. ovata Cogn. loc. cit. 1). 209. - Alto Macahé de Nova Friburgo, Rro-Jax., no $16794 a$. Arbuste, fl. violettes. Mars-avril. C.

2ュ0. T. aspericaulis Cogn. Suites au Prodr. VH, 1\%. 209. - Serra dos Orgàos, còté de Petropolis, Rı-JAv., n 16795. Albuste, fl. violettes. Mars-avil. C.

291. T. alba Cogn. in DC. Suites au Prodr. VII, p. 210. - Alto Macalié de Nova Friburgoo, Rı-Jax., nº 16805. Arbuste, Il. blanches. Janvier-février. R.

22u. T. Gardneriana Cogn. in Fl. Bras. XIV, III, p. 319. - Serra dos Orgaios, a Theresopolis, Rio-Jıx, nos 2866, 3968, 16806, 16807, 17521 ; Serra dos Crystaes, près Dianantina, Ilsss. $n^{\circ}$ 19298. Arbuste, fl. violettes. Février-mars. CG.

- Var. pilosa Glaz. in lerb. Paris., Berol., Kew., - Serra dos Crystaes, pres Diamantina, Mısıs, n 19298. Arbuste, fl. violettes. Marsavril. C.

223. T. pallida Cogn. in Fl. Bras. XIV, III, p. 316. - Pico do Andarahy Grande ou da Tijuca, Rı-JAs., n ${ }^{0 s} 1090$ et 8356. Petit arbuste, fl. violettes. Mar's-arril. R.

224. T. ovata Cogn. in DC. Suites an Prorlr. VII, 1. 211. - Alto Macahé de Nova Friburgo, Rio-Jas, n 16803. Albuste, fl. violettes. Décenbre-janvier. R.

22쿠. T. Fothergilla Gogn. in Fl. Bras. XIV, 111, p. 320. - Serra da Estrella, à Mandioca, Rio-JAn., $1^{\circ} 9457$ a. Arluuste, fl. violettes. Marsavril. C.

226. T. Moricandiana Baill.; Fl. Bras. XIV, III, p. 321. - Corcovado, a Paineiras. Tijuca, Alto da Serra de Nova Friburgo, Rı-J.x., $n^{\circ s}$ 566, 1086, 9457 et 15979. Arbuste, f1. violettes. Mars-avril. CC.

- Var. parvifolia Cogn. ill Fl. Brres. XIV, HI, p. 32y. - Serra dos Orgãos et à Petropolis, Rio-Jax., nos 9456 et 15978. Arbuste, fl. violettes. Mars-avil. C.

207. T. trichopoda Baill.; Fl. Bras. XIV, III, p. 221. - Entre Villa Nova et Porto das Caixas, dans les bourbiers, Rı-Jax., $11^{\circ}$ 7609. Alluste, fl. violettes. Janvier-lévrier. CC. 
2028. Tibouchina Glazioviana Cognt. in Fl. Bras. XIV, III, p. 325. - Campos da Bocaina, São Pacio, $1{ }^{0}$ 11954. Arluuste, f1. violettes. toùt-septembre. C.

2ᄈ99. T. multiceps Cogn. in Fl. Bras. XIV, III, p. 3206. - Mogy das Cruzes et à Agua Branca, São Paclo, nos 15980 et 17520. Arluste, t1. violettes. Février-avril, C.

30. T. pilosa Cogn. in Fl. Bras. XIV, IV, p. 600. - Ipanema, dans le bois, São Paclo, no 15977. Arluste, fl. violettes. Mars-avril. R.

2931. T. Martiusiana Cogn. in Fl. Bras. XIV, III, 1. 327. - Petropolis, Rio-Jax., nos 8357, 12689; Serra de Ouro Preto, Hixas, $n^{\text {os }} 14798$ et 19299. Arluuste, fl. violettes. Février-mars. G.

232. T. frigidula Cogn. in Fl. Bras. XIV, III, p. 328. - Serra da Bocaina, à Vacea Cahio, São Pacto, $n^{\circ} 8378$ et 8379. Petit arbuste, f1violettes. Février-mars. C.

233. T. villosissima Cogn. in Fl. Bras. XIV, Ill, p. 330. - Serra do Lenheiro, près São Joño d'El Rei, Diamantina et au Pico d'Itabira do Campo, Mixas, $\mathrm{n}^{0 \mathrm{~s}} 16789,16791,19293$. Petif arlouste, fl. violettes, Marsavril. G.

- Var. petrolaris Coggn. in Fl. Bras. XIV, III, p. 331. - Pico d'Itabira do Campo, Mlsas, $n^{\circ} 17524$ a. Petit arbuste, fl. violettes. Décembre. R.

234. T. decemcostata Cogn. in Fl. Bras. XIV, III, p. 33I. - Serra de Caraça, au Campo de Fora, Misas, $n^{\circ}$ 14795. Petit arbuste, fl. roses. Mai-juin. C.

293. T. lævicaulis Cogn. n. sp. in herb. Paris, Berol., Kew., etc. - Vallée du Rio Torto, dans le campo, Goyaz. n² 21374. Arbuste, f. violettes. Mai-juin. C.

236. T. adenostemon Cogn. in Fl, Bras. XIV, III, p. 332. - Entre Inficionado et Caraca, dans le campo, Mixas, $1^{\circ}$ 12710. Arbuste, fl. violettes. Juillet-aouit. C.

- Var. paucisetulosa Cogn. in herb. Paris., Berol., Kew., etc. Curalinho, pris Diamantina, Mnse, 11" 19295. Arbuste, fl. violettes. Avril-mai. R.

237. T. multiflora Coen. in Fl. lros. XIV, III, p. 333. - São João d'El Rei, Muss, nos $14796,15974,16790$; Serra dos Orgãos, Rı$\mathrm{J}_{\mathrm{AN}}$, $\mathrm{n}^{0 \mathrm{~s}} 15973$ et 16793. Arbuste, fl. violettes. Mlars-arril. CC.

298. T. grandifolia Cogn. in Fl. Bras. XIV, III, 1. 333. - Serra 
A.-F.-31. GLAZIOT, - J.ISTE DES HLATTES DC BRÉSHL CENTRAL. 265 dia Babylonia, au Ciagado, Misis, $11^{\circ \mathrm{s}} 164$ et 8965. Arbuste, fi. violettes. Mills-ilvil, R.

- Var. obtusifolia Cogn. in Fl. Bras. XlY, ill p. 336. - Serra da IBabylonia, au Cagado, Mls.s, n² 2569; Entre Gavea et Tijuca, près la mer, Rio-Jax., n 10777. Arluuste, 11. vinlettes. Décembre-janvier. R.

239. T. heteromalla Cogn. in Fl. Bias. IN, III, J. 336. - CopaCabana, a Pedra dos Calıritos, Rio-JAx., n 16792: Serrinlıa, jres Santa Barluara, Mixas. n 19292. Arbuste, fl. violettes. Mai-juin. C.

240. T. Candolleana Cogn. in Fl. Bras. XIV, III, p. 339. - Sio João del Rei, au bord de la rivière, MlNas, nos 16496. 17232: loord du Rio Corumba, Goraz, nos 21372 et 22373 . Grand arbuste, fl. violettes. Aout-septembre, CC.

241. T. gramulosa Cogn. in Fl. Bras. XIV, III, p. 340. - Floresta da Tijura, Santa Ciruz, etc., Rio-dis., nos 567, 10776 et 15992. Arbrisseau, fl. violettes. Janvier-avril. CC. Vulgo : Flor de Ourresma.

242. T. estrellensis Cugn. in Fl. Bras. XIV, III, p. 342. - Serra da Estrella, pres Petropolis, Rio-Jax., nos 15988 et 15989. Arbrisseau, fl. violettes. Mars-avil. CC. Vulgo : Flor de Ouaresma.

243. T. albescens Cogn. in herb. Paris., Berol., Kew., etc. Fazenda dos Veadeiros, Goyaz, no 21376. Arbuste, fl. violettes. Janviel-févier. R.

244. T. trinervia Cogn. n. sp. in herb. Paris., Berol., Kew., etc. - Serra do Funil, au Rio Paranaúa, Nisas, n 19301. Albuste, fl. violettes. Nars-avril. R.

240̆. T. fissinervia Cogn. in Fl. Bras. XIV, III, p. 343. - Petropolis, aux borks du Rio Pyabanha. Rı-Jax., nos 15985. 15986; Ilheos, Mıse, $n^{\circ}$ 17582. Arbrisseau, fl. violettes. Février-mar's. C..

姺6. T. stenocarpa Cogn. in Fl. Bras. XIV, III, p. 34t. 一 Piracicalıa, dans le campu, Sĩo Patıo, nos 2993, 15990: Sĩo João d'El Rei, Misas, $n^{\text {os }}$ 16797, 16799: Santa Luzia, Goraz, $n^{05} 21370$ ef 21371. Arbrisseau, fl. violettes. Arril-mai. CG.

- Var. lateola Cogn. in Fl. Brols. XIV, III, p. 3集, - São João d'El Ripi, Mısas, n 16798. Arbrisseau, fl. violettes. Mai-juin. G.

24T. T. Martialis Cogn. in Fl. Buas. XIV, 1I!, p. 346. - Campos da Bocaina, Sĩo Patio, nos 8362, 8368; Novil Friburero, a Pedra do

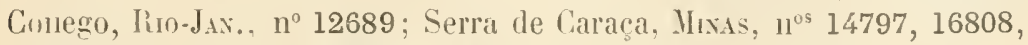
19300. Arbuste, 11. violettes. Février-malls. C.C.

248. T. Chamissoana Cogn. in Fl. Brus. XIV, III, 1) 319. - Cam- 
pos da Bocaina, à Vacca Cahio, São P’avlo, $11^{\circ}$ 8374. Arbuste, fl. roses, mars-avril. C.

249. Tibouchina tuberculata Glaz. n. sp.? in herl. Paris., Berol., Kew., Brux., etc. - Serra dos Pyreneus, entre les rochers, Goyaz, $\mathrm{n}^{\circ}$ 21354. Frutescent, f1. violettes. Juin-juillet. R.

25̈0. T. macrorrhiza Cogn. n. sp. in herb. Paris., Berol., Kew., Brux., etc. - Sommet de la Serra Dourada, entre les rochers, Goyaz, $n^{\circ}$ 21353. Frutescent, f1. violettes, Juillet-août. R.

251. T. ursina Cogn. in Fl. Bras. XIV, III, p. 351. - Serra dos Crystaes, près Diamantina, Mısas, $n^{0} 19293 a$. Arbuste, 11. violettes. Avrilmai, R.

252. T. Langsdorffiana Baill. var. chartacea Cogn. in Fl. Bras. XIY, III, p. 3388. - Lagoa de Freitas et au Corcovado, Rio-JAn., $n^{\circ 8} 2993$ et 15991. Arbuste, fl. violettes. Décembre-janvier. C.

253. T. holosericea Baill.; Fl. Bras. XIV, III, p. 353. - Restinga de Copacabana, dans les sables, Rı-Jax., $\mathrm{n}^{\circ} 1$; près de Diamantina, Minas, $n^{\circ}$ 19294. Petit arbuste. 1l. violettes. Mars-avril. R.

20\%4. T. paulensis Cogn. in DC. Suites au Prodr. VII, p. 229. Mogy das Cruzes, dans le campo, Sĩo Paclo, n 17523 . Petit arbuste, fl. violettes. Avril-mai. R.

20\%. T. Claussenii Cogn. in Fl. Bras. XIV, III, p. 310. - Faria, près Sabara, Mısas, $n^{\circ}$ 18231. Arbuste, f1. violettes. Janvier-février. R.

256. T. Gaudichaudiana Baill.; Fl. Bras. XIV, III, p. 360. Entre Gavea et Tijuca, Magi et Piedade, Santa Cruz et Serra da Estrella, Rio-Jan., $n^{\text {os }} 592,3960,15975$ et 15976. Arbuste, f1. violettes. Décembre-janvier. CC.

257. T. Maximiliana Baill.; Fl. Bras. XIV, III, p. 362. - Serra de Caraça, dans le campo, Mrnas, $n^{\circ} 14797$ a. Arbuste, fl. violettes. Févriermars. R.

258. T. corymbosa Cogn. in Fl. Bras. XIV, III, p. 363. - Floresta da Tijuca, Rio-Jan., nos 568 et 3962. Arbuste, fl. violettes. Janvier-février. C.

פ999. T. dendroides Cogn. in Fl. Bras. XIV, III, p. 369. - Itacolumy, près Ouro Preto, Mınas, $n^{\circ}$ 14800. Arbuste fl. violettes. Maijuin. R.

260. T. Eichleri Cogn. in Fl. Bras. XIV, III, p. 370. - Campos da Bocaina, au Bom Jarlim, São PACzo, nº 8359. Arbuste, fl. violettes. Janvier. R. 
A.-F.-M. GLaziou. - LISTE DES Plates DU BRÉsil CeNtral. 26J

261. T. cardinalis Cogn. in Fl. Bras. XIV, III, p. 371. - Biribiry, près Diamantina, dans le campo, llinas, $n^{0}$ 19296. Petit arbuste, fl. violettes. Mars-avril. C.

262. T. hirsuta Cogn. in Fl. Bras. XIV, IV, p. 601. - Itacolumy et Serra de Ouro Preto, Mrsas, $1^{\text {os }} 14793$ et 14801 . Arbuste, t1. violettes. Février-mars. C.

263. T. aspera Aubl.; Fl. Bras. XIV, III, p. 374. - Itabapoana, pris Retiro, Rro-Jan., $n^{\circ}$ 9824. Petit arbuste, f1. violettes. Juin-juillet. $\mathrm{R}$.

264. T. cordifolia Cogn. in Fl. Bras. XIV, III, p. 393. - Ayuruoca, au Pico do Papagaio, Misas, $n^{\circ}$ 9460. Frutescent, fl. violettes. Avrilmai. C.

26อั. T. papyerifera Cogn. in Fl. Bras. XIV, III. p. 378. - Serra Dourada, cliemin du Gurgulho, Goyaz, n² 21352. Arbuste sans fleurs en aoùt. C.

266. T. pogonanthera Cogn. in F7. Bras. XIV. III, p. 381. - Riacho Fundo, sur les buttes de Cupim, Goyaz, nos 21375 et $21375 a$. Arbuste, f1. violettes. Juillet-aunt. C.

267. T. nigricans Cogn. n. sp. in herb. Paris., Berol., Kew., etc. - Fazenda dos Macacos, au Morro dos Crystaes, Gordz, n² 21360. Frutescent, fl. violettes. Septembre-octobre. C.

268. T. goyazensis Cogn. n. sp. in herb. Paris., Berol., Kew., etr. - Entre Fartura et Rajadinha, dans le campo, Goyaz, ${ }^{\text {os }} 21360$, 21367, 21368 et 21369. Frutescent, fl. violettes. Févriel-mars. CC.

269. T. agopogon Cogn. in Fl. Bras. XIV, III, p. 383. - Chapadão dos Veadeiros, à Boa Vista, Govaz, $n^{\text {os }} 21359$ et 21363 . Frutescent, fl. violettes. Janvier-février. C.

270. T. cyanea Cogn. 11. sp. in herb. Paris., Berol., Kew., etc. - Entre Fazenda da Boa Vista et Rio dos Couros, Goraz, no 21362. Frutescent, fl. violettes. Janvier-férrier. R.

271. T. major Cogn. n. sp. in herb. Paris., Berol., Kew., ete. Entre Engenlo et Jatobá, dans le canıpo, Goraz, nos 21358 et 21361. Frutesrent, fl. roses. Janvier-février. C.

279. T. gracilis Cogn. in Fl. Bras. XIV, III, p. 386. - Sambaitiha et Caminho dus llararos, Rio-JAx., $n^{\circ 5}$ 2573, 11960 ; Campo da Bocaina. Sĩo Paclo, $n^{0 s} 8380$ et 10764 . Frutesernt fl. roses. Aocit-octobre. Cí.

- Var. graclelima Cogil. in Fl. Virle. XIV, III, p. 387. - Colline

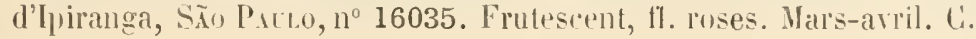


- Var. fraterna Cogn. in Fl. Bras. XIY, III. p. 387. - Pris d'As Brancas, dans les campos limmides, Goraz, $n^{\circ} 21357$. Frutescent, fl. roses. Janvier-février. R.

- Var. vulgaris Cogil. in Fl. Bras. XIV, III, p. 387. - Entre liio Bananal et Rio Torto, Goraz, n² 21356. Frutescent, 11. roses. Févier-mars. C.

- Var. strigrlosa Cogn. in Fl. Bres. XN, III, p. 387. - Corrego do Brejo, Goraz, no 21364. Frutescent, fl. roses. Mar's-arril. C.

273. Tibouchina hieracioides Cogn. in Fl. Bros. XIT, MI, p. 389. - Campos da Rocaina, au Sobrado, São Paulo, no 8370. Frutescent, fl. violettes. Janvier-février. C.

274. T. minor Cogn. in Fl. Brols. XIV, III, p. 390. - Campos da Bocaina, au Sobrado, São PALlo, no 8369. Frutescent, fl, violettes. Janvier-février. R.

270̈. T. Benthamiana Cogn, in Fl. Lras. XIV, III, p. 391. - Serra la Estrella et Serra dos Orgãos, Rıo-J৯x, nos 1093 et 1192. Arbuste, fl. violettes. Mai-juin. C.

- Var. punicea Cogn. in DG. Suites au Prodr. VII, p. 247. - Alto Nacahé de Nova Friburgo, Rio-Jax., no 16788. Arluuste, lt. violettes. Arril-mai. C.

276. T. cordifolia Cogn. in Fl. Bras. XIV, III, p. 393. - Ayurunca et à Engenlia da Serra, Nisas, nos 9460 et 10770. Arbuste, fl. violettes, Avril-mai, R.

277. T. axillaris Cogn. in Fl. Bras. XIV, III, p. 396. - Petropolis, jrès Cascatinha, Rio-Jav., no 11971. Arbuste fl. violettes, Avril-mai. R.

278. T. angustifolia Cogn. in Fl. Bras. XIV, III, p. 396. - Diamantina au Tombador, Hisas, no 19170. Arbuste, arec fruits. Avril. R.

279. T. clidemioides Cogn. in Fl. Bras. XIV, III, p. 398. - Ayurunca, au Pico do Papagaio, Mıxas, nos 9460 a. Arbuste, f1. violettes. Mars-avril. R.

280. T. debilis Cogn. in Fl. Brus. XIV, III. p. 401. - Serra da Estrella, au Alto. Rio-dAr., no 15969 a. Frutescent, fl. roses. Nar'sarril. C.

281. T. rupestris Cogn. in DG. Suites au Prodr. VII, P. 1176. Serra do Lenheiro, près São Jocio d'El Rei, Hıxas, no 16809 a. Frutescent, 11. violettes. Juin-juillet. C.

282. T. cerastifolia Cogn. in Fl. Bres. NIV. III, p. 403. - Serra da Estrella, à Mamminha, Rio-Jan. no 15969. Arbuste, fl. roses. Févriermars. G. 
283. T. herbacea Cogn. in Fl. Bras. XIY, III, p. 408. - São João d'El Rei, dans les bas-fonds Lumides, Misas, nos 1096, 16809; Santa Luzia, Gorsz, 11² 21327. Arbuste, fl. roses. Avril-juin. C.

y84. T. sebastianopolitana Cogn. in Fl. Biras. XIY, III, p. 409. Petropolis, à Guitandinha, Rı-Jax. no 11970.Arbuste, 11. roses. Maijuill. C.

- Var. hirsuta Cogn. in Fl. Bras. XIV, IlI, p. '410. - Aleg ia et Barbacina, dans le bois, Mlixas, $n^{\text {as }} 8964$ et 13841. Arhuste, fl. roses. Janvier-février. C.

- Var. meueliava Cogn. in Fl. Bros. XIV, ill, p.410. - Serra de Ouro Preto, dans le campo, Mixus, $n^{\circ}$ 12707. Arbuste, fl. roses. Juin-juillet. C.

285. T. Urbanii Cogn. in Fl. Bras. XIV, IV, p. 602. - Ayuruora au Pico do Papagaio, Misas, no 16034. Frutescent, ll. roses. Janvieifévrier. R.

286. T. clinopodifolia Cogn. in Fl. Bras. XIV, III, p. 411. - Serra do Commercio, au bord du chemin, Rio-Jax., n ${ }^{\circ} 8697$. Frutescent, t1. roses. Juin-juillet, C.

287. T. Itatiaice Cogn. in F\%. Bras. XIT, IIT, p. 414. - Itatiaia, dans le campo, près des rochers, Riro-Jax., $n^{\circ}$ 6529. Ar'juste, fl. roses. Janvier-février. C.

288. T. microphylla Cogn. in DG. Suites au Prodr. VII, p. ㄲi. - Serra do Caparáo, dans le campo, Mrsas ( $n^{05} 6472,6722$, Schwacke), $\mathrm{n}^{0} 15972$ a. Petit arbuste fl. Ulanchies. Hars-arril. C.

289. T. minutiflora Cogn. in Fl. Bras. XIV, III, p. 41:. - Campos da Bocaina, à Vacca Cahio, S̃̃o Paulo, $1^{\circ}$ 8366. Arhuste, fl, rose pâle. Janvier-février, C.

990. T. cinerea Cogn. in Fl. Bras. XIV, III, p. 416. - Campos da Bocainri, au Sobrado, São Paulo, $n^{\circ}$ 8367. Arbuste. f1. rose pâle. Janvier-février. C.

- Var. parvifolia Cogn. in herb. Paris., Kew., Berol., etc. - Nogy das Cruzes, Sĩo Paulo, nº 19306. Arbuste. f1. roses. Mars-avril.

991. T. hospita Cogn. var. albiflora Cogn. in Fl. Bras. XIV, III, p. 418. - Serra dos Orgãos, au Frade, Rio-Jas., nos 2865, 3971, 14799, 15972, 16804. Arbuste, f1. blanches. Janvier-février. CG.

- Var. minor Cogn. in Fl. Bras. NIT, IiI, p. 418 . - Ayuruoca, au Serro Frio, Hixas, $n^{\text {os }} 4805,6531$ et 15971. Arbuste, fl. blanchàtres. Janvier-lévrier. C.

292. Comolia ovalifolia Triana; Fl. Bras. XIV. III, p. 428. - 
Campo de Sâo Joâo près Ouro Preto, Mlsas, nº 14772 a. Frutescent, fr. roses. Mai-juin. R.

293. Comolia sessilis Triana; Fl. Bras. XIV, III, p. 430. - Serra de Ouro Branco, dans le campo, Mivas, $n^{\text {os }} 14790,14791$ et 16811 . Frutescent, fl. roses. Octobre-novembre. C.

294. C. violacea Triana; Hl. Bras. XIV, III, p. 431. - Serra de Ouro Branco, dans le campo, llısas, $n^{\circ} 14790 a$. Frutescent, fl. violettes. Novembre-décembre. R.

995. C. tetraquetra Cogn. in Fl. Bras. XIY, IV, p. 603. - Serra de Ouro Branco, Misas, nos 14792 et 19288. Frutescent, fl. roses. Avriljuilı. C.

996. C. stenodon Triana var. suborbicularis Cogn. in herb. Paris., Berol., kew., Brux., Gener., etc. - Biribiry, près Dianantina, Mısas, $n^{0}$ 19287. Frutescent, fl. violettes. Mars-avil.

297. C. lanceaflora Triana; Fl. Bras. XIV, III, p. 434. - Entre Cachamba et Ayuruoca, à Rego d'Agua, Mixss, nº 16037. Frutescent, fl. roses. Janvier-février. C.

298. C. Sertularia Triana; Fl. Bras. XIV, III, p. 43.\%. - Serra do Lenheiro et à Itacolumy, Hrys, $n^{\text {os }} 14710,15968$ et 17526. Petit arluuste, 凡1. violettes. Janvier-février. CC.

- Var. nana Cogn. in herb. Paris., Berol. Kew., etc. - Serra do Cipo, près Congonlas da Serra, Mixas, $1^{\text {os }} 19284$ et 19286. Frutescent, fl. violettes. Avril-mai. R.

999. Fritzschia integrifolia Ch. et Sch.; Fl. Bras. XIV, III, p. 437. - Perpetua, pres Diamantina, Msas, $n^{\circ} 19221$ b. Frutescent, fí violacées. Mars-avril. R.

300. F. anisostemon Triana; Fl. Bras. XIV, III, p. 439. - Diamaniñả, au Curalinlro, Mrsas, $n^{0} 19221$ a. Frutescent, fl. roses. Avril-mai. R.

301. F. recubans Glaz. 11. sp.? in herb. Paris., Berul., Kew., Genev, etc. - Itatiaia, côté nord, dans le campo humide, Mrsas, nº 8695. Frutescent, fl. blanchâtres. Novembre.

302. Marcetia excoriata DG. var. villosi Cogn. in Fl. Bras. XIV, III, p. 14t. - Serra dı Cipo, près de Congonhas da Serra, Mrsas, $n^{\circ}$ 19309. Frutescent, fl. roses. Avril-mai. C.

303. M. cordigera DC.; Fl. Bras. XIV, III, p. 4彷. - Serra de Ouro Preto, dans le campo, Misas, $n^{0 s} 14714$ et 14723 . Frutescent, f1. roses. Juin-juillet. C.

304. M. taxifolia DC.; Fl. Bras. XIV, III, p 446. - Serra de 
Ouro Preto, dans le campo, Mtsas, $n^{0 s} 14713,19313$; Nova Friburgo, au vieux chemin, Rı-JAx., $n^{\text {os }} 1344$ et 16814. Frutescent, 11. blanches. Mai-juin. CG.

- Var. glandulosa Cogn. in Fl. Bras. XIV, III, p. 44.T. - Quartel do Biribiry, près Diamantina, Mrxas, $n^{\circ} 19314$. Frutescent, fl. roses. Marsarril. G.

- Var. decumbens Cogn. in Fl. Bras. XIV, III, p. 447. - Serra dos Crystaes, près Diamantina, Mıxas, ${ }^{0 s} 19317$ et 19318. Frutescent, f1. rosées. Avril-mai. C.

- Var. pubescens Cogn. in Fl. Bras. XIV, III, p. 447. - Restinga da Tijuca et à Pedra dos Cabritos, liso-Jax., nos 6149 et 16813 ; entre Diamantina et As Dattas, Mlsas, nos 19312 et 19321 . Frutescent, fl. r'oses. Avril-mai. C.

- Var. glabrescens Cogn. in Fl. Bras. XIY, III, p. 447. - Entre Barbacena et Carandahy, dans le campo, Minas, n² 12703. Frutescent, fl. r’oses. Juin-juillet. C.

305े. M. disticha Cogn. in Fl. Bras. XIV, III, p. 447. - Itacolumy. près Ouro Preto, Mrivas, nos 14711 et 14712 . Frutescent, f1. blanches Juin-juillet. G.

306. M. Glazioviana Cogn. in Fl. Bras. XIV, III, p. 449. - Restinga de Cabo Frio, dans le sable, Riro-Jax., nos 8686 et 12686 . Frutescent, fl. roses. Septembre. C.

307. M. hirsuta Cogn. in Fl. Bras. XIV, III, 1.40̈1. - Diamantina, au Tombador, Misas, $n^{\circ}$ 19316. Frutescent, fl. rosées. Mars-avril. R.

308. M. cinerea Triana; Fl. Bras. XIV, III, p. 'ł2. - Restinga da Tijuca, Rı-Jax., no 6149 a. Frutescent, f1. rosées. Septembre-octobre. R.

309. M. fastigiata Cogn. in Fl. Bras. XIV, III, p. 40.2. - Serra de Sĩo José d'El Rei, Mixas, $n^{0 s} 16812,20301$ et à Paracatú, dans les vieilles mines, $n^{\circ}$ 21215. Frutescent, fl. blanches. Juin-juillet. C.

- Var. imbricata Cogn. in Fl. Bras. XIV, IlI, p. 4:̈3. - Serra do Lenheiro, près São João d'El Rei, Mıxas, nº 20300. Frutescent, fl. blanches. Mai-juin. R.

310. M. tenuifolia DC.; Fl. Bras. XIV, III, p. 4,33. - Restinga de Cabo Frio, dans le sable, Río-Jan., nº 332 ; Serra dos Crystaes et do Cipo, Mrxis, $n^{\text {os }} 19310$ et 19315 . Frutescent, fl. roses. Janvier-février. C.

- Forma purpurascens Cogn. in herb. Paris., Berol., kiew., etc. - 
Biribiry, près Diamantina, Mnsas, $11^{\circ}$ 1931l. Frutescent. fl. roses. Hars. C.

311. Marcetia denndata Nand.; Fl. Brus. XIV, III, P. 4:34.Serra de Ouro P'reto, Mivas, $11^{\circ} 19319$ a. Frutesent. Ml. roses. Mai-juin. R.

312. M. trichocalycina DC. Leste Cogniaux in lill. - Poha de Amolar, près Ouro Preto, Musas, ${ }^{\circ s} 14732$ et 19319. Frutescent, ll. roses. Janvier-février. R.

313. M. acerosa DC.; Fl. Bras. XIV, 1II, p. 43ั. - Entre Diamantina et As Dattas, lans les sables, Mlıss, nos 19320, 19885 et 19223. Frutescent, fl. roses. Mars-avril. C.

314. Aciotis paludosa Triana; Fl. Brus. XIV, Ill, p. 466. - Entre Gavea et Tijuca, dans les fossés, hio-JAx., $n^{\text {os }} 569,2570$ et 6151 . Herbacé, fl. blanchâtres. Janvier-février. CC.

315. A. circeafolia Triana; Fl. Brus. XIV, III, p. 472. - Campos de São Fidelis, dans les bourluier's, Rio-Jax., $n^{0}$ 9822. Herbacé, fl. blanclıâtres. Janvier-février. C.

316. A. acutiflor a Triana; Fl. Brus. XIV, III, p. 4i6. - ltapemirim, Espirito Saxto, no $2570 a$. Frutescent, fl. blanc rosé. Juin-juillet. C.

317. A. dysophylla Triana; Fl. Bras. XIV, III, p. 478. - São Fidelis, près de Campos, dans les bourbiers, Rio-Jav., $n^{0}$ 9877. Herbacé, fl. blanchâtres. Janvier-février. G.

318. Huberia ovalifolia DC.; Fl. Bras. XIV, IV, p. 7. - Floresta de Tijuca et Copacalsana, Rio-JAx., $n^{05}$ 97, 574, 1271, 5862, 13835, 17527. Arbuste, fl. blanches. Janvier-lécembre. CG. Vulgo : Mangue do Nallo.

- Var. robusta Glaz. in herb. Paris.. Berol., Kew., Brux., ete. - Rio Manso, dans le campo, Mixas, $n^{0}$ 13835. Arbuste, fruits roux. Janvier. C.

- Var. parvifiora Cogn. in lill. - Floresta da Tijuca, Rio-Jav., $n^{\circ}$ 18229. Arbuste, Il. blanches. Février-mar's. C. Vulg. : Mangue do Watto.

319. H. Glazioviana Cogn. in DC. Monogr. Phan. VII, p. 409. Alto Nacahé de Nova Friburgo, Rio-Jav., $n^{\circ}$ 16816. Arbuste, f1. blanc rosé. Février-mars. C.

320. H. glabrata Cogn. in DC. Monogr. Phan. VII, p. 409. - Alto Nacahé de Nova Frilsurgo, Rı-JAx., n 16815. Arbuste, fl. blanches. Février-mars. R.

321. H. minor Cogn. in DC. Monogr. Phan. VII, p. 409. - Alto Macahé de Nova Friburgo, Rı-JAN., nº 16818. Arbuste, fl. blanches. Févriermars. C. 
1.-F.-M. GLAZIOC. - LISTE DES PLANTES DU BRÉSL CEYTRAL. 273

32). H. triplinervis Cogn. in T) Monogr. Mhan. VII. 1. 410. Alto Macahé de Nova Friburgo, lio-JAx., $11^{\circ}$ 16969. Arbuste, ll. blanches. Irril-mai. R.

323. H. parvifolia Cogn. in DC. Monogr. Mhren. VII, P. 410. Nlto Macahé de Nova Friburgo, Rio-JAx., nos 16817, 17528. Arbuste. 11. blanches. Décembre-janrier. R.

32'. H. semiserrata DC.; FI. Bras. XV, IV, 1. 9. - Campo da Boraina, à Tacca Cahio, SÃo PAuzo, n 8375. Anbuste, (1. blanches. Févier. R.

32\%. Bisglaziovia behminides Cogn. in DC. Monogr. Jhan. WII, p. 412. - Serra do Alto Macalú, Rio-Jdx., nos 1828, 16821, 16970. Petit arbuste, f1. roses. Mai-juin. C.

326. Benevidesia organensis Sald. et Cogn. Fl. Bras. XV, IV, p. 60:). - Serra dos Orgĩos, sur les grands rochers, Rı-JAx, nos 16027 , 16819, 17529. Petit arbuste, fl. blanc rosé. Férrier-mars. Ci.

327. Behuria insignis Cham. in DC. Monogr. Phan. VII, p. 413. - Campos da Bocaina, Sĩo PAulo, n 7625 a. Petit arbuste, ll. roses. Février-mars. R.

328. B. parvifolia Cogn. in DC. Monogr. Phan. VII. p. 413. Yorm Cavado, près du Rancho, Mısas Geraes, n 7625. Petit arbuste, fl. roses. Août-septemire. R.

329. B. Monrei Cogn. in DC. Jonogr. Phan. VII, p. 414. - Sommet cle la Serra dos Orgãos, Rı-JAx., nos 16821 a, 17563 b. Petit arbuste, 11. roses. Février-mars. R.

330. B. coryembosa Cogn. in Fl. Bras. XIV, IV, p. 13. - Serra dos Orgãos, à Pedra do Sino, Rı-JAx., n 3970. Arbuste, f1. blanc rosé. Avril-mai. C.

- Var. grandfolia Gogn. in DG. Monogr. Phan. VII, p. 4\%. - Serra dos Orgàos, còté de Petropolis, Rio-Jax., no 17563. Arbuste, fl. blanc l’osé. Ilars-avril. C.

331. B. Glazioviana Gogn. in IC. Monogr. Phru. VI, p. '́1:̈.Serra do Alto Macahé, Rio-Jav., n 17563 a. Arbuste, Il. blanc rosé. Févier-mars. R.

332. B. cordifolia Gogn. in DC. Monogr. Phan. VII, 1. 41ว. — Pedra de José Sineiro, a la Tijuca, R10-JAs., nº 6884. Arbuste, fl. blanc rosé. Janvier. H.

333. B. glutinosa Cogn. in Fl. Bius. XIV, IV, p. 14. - Itacohumy, près Ouro Preto, Misas Geiues, nº 14794. Arbuste, 11. blanc rosé. Féviermars. C. 
33'. Meriania pergamentacea Cogn. in DC. Vomogr. I/ean. VII, 1. 432. - - Petropolis et Serra de Nova Friburgo, liı-Jax., nos 13859 , 16822. Arbuste, 11. blanches. Janvier-février. C.

33.. M. glabra Triana; Fl. Bras. XIV, IV, p. 26. - Corcovalo, à Paineiras, Rio-Jax., $11^{05} 1089$, 2991, 8351. Arbuste, fl. blanches. Févriernars. C.

336. M. Claussenii Triana; Fl. Bras. XIV, IV, p. „̄i. - Serra dos Orgioss à Vargem, Rio-Jax., nos 11953, 16874. Arbuste, 11. blanches. Janvier-février. R.

387. M. paniculata Triana; Fl. Bras. XIV, IV, p. 28. -- Petropolis, au Horin et à Itamaraty, Rino-JAx., nos 1753, 10759, 11964, 16033. Arbuste, ll. blanches. Juillet-Août. CG. Vulg. Arapoca branca.

338. M. Glazioviana Cogn. in Fl. Bras. XIV, IV, p. 30. - Serra do Ariro, près Angra dos Reis, Rio-JAn., $1^{\circ} 2571$. Arbuste, fl. blanches. Maijuin. R.

339. M. dentata Cogn. in DC. Monogr. Phan. VII, p. 13\%. - Alto Hacahé de Nova Friburgo et à Theresopolis, Ro-Jax., n 17531. Arbuste, fl. blanches. Juillet-aoùt. C.

3ł0. M. Sipolisii Glaz. et Gogn. in DC. Monogr. Phan. Vll, p. 1182. - Biribiry, entre les rochers, Mrsas Geraes, nº 19307. Arbuste, lil. blanc rosé, odorantes. Février-mars. C.

341. Calyptrella cucullata Triana; Fl. Bras. XIV, IV, p. 44. Quinta de São Christovão. Rio-JAx., $n^{\circ} 16533 a$. Arbuste cultivé, fl. blanchâtres. Février. R.

342. Bertolonia nymphaifolia Raddi; Fl. Bras. XIV, IV, p. $气 0$. - Serra da Estrella et Alto Nacahé, au bord des ruisseaux, Rio-Jax., $\mathrm{n}^{\circ 8} 1092,14804,19343$. Pl. naine, fl. blanches. Janvier-février. CC.

343. B. sanguinea Sald. et Cogn. in Fl. Bras. XIV, IV, p. "̈1.Alto Hacahé de Nova Friburgo, Rio-Jav., nº 19344 a. Pl. naine, fl. blanches. Nurembre. $\mathrm{R}$.

34t'. B. leužeana DC.; Fl. Bras. XIV, IV, p. 5̆4. - Floresta da Tijuca et Alto Ilacahé, Rio-JAx., nos 2572, 19344. Pl. naine, 11. blanches. Novembre-décembre. C.

340ั. B. Mosenii Cogn. in Fl. Bras. XIV, IV, p. วั. - Floresta da Tijuca, dans les endroits humides, Rio-Jar., $\mathbf{n}^{05}$ 2995, 6147. Pl. naine, fl. blanches. Décembre. C.

346. B. acuminata Gardn.; Fl. Bras. XlY, $\mathrm{N}$, p. 36. - Alto Macahé de Nova Friburgo, Ro-Jıx, no 19344 b. Petite plante, fi. blanches. Novembre. $\mathrm{l}$. 
A.-F.-II. GLAZIOL - LISTE DES PLAITES DE BRESIL CEMTRAL. 275

347. Salpinga margaritacea Triana: Fl. Bras. IIV, IV, p. 1;2.Serra do Var, à Palmeiras. Rro-Jas., n 8687. Pl. naine, 11. blanches. Septembre. C.

3 is. Leandra fectinata Cogn. in Fl. Bras. XIV. IV. p. Ts. - Alto da Serra de Fora Friburgo. Rio-Jax., n n 3964. 6528. 16002 c. Arbuste, 11. blanches. Mars-mai. C.

249. L. attenuata Cogn. in DC. Monogr. Phan. VII. p. 617. - Serra do Alto Hacabé, Puo-Jas.. n 16826. Arbuste. hl. Hanches. Janvierfëvrier. R.

35. L. amplexicaulis DC. : Fl. Bras. IIV. IT. p. 79. - Serra do Alto Macahé. Rij-Jas., no 16825. Arbuste. fl. blanches. Décembre-janvier. C.

3.i. L. longisty-la Cogn. in DC. Monogr. Phan. YII. p. 617.Serra da E-trella. au Botejuim, Fio-Jar., n 2994. Arbuste, t1. blanches. Décembre. R.

3. 2. L. Faulina UC. ; Fl. Eras. IIT, IV. p. O1. - Cabeveiras du Rio Turto, dan= les copies. Goraz, n² 21411. Arbuste, t1. rougeàtres. Vorem. ble. C.

39. L. umbellata DC.: Fl. Bras. IV, IV. p. S.. - Barra do Pirahy. Serra do Mar, Puo-Jas., n 2135 a. Arbuste, fl. blanchảtres. Février. R.

3ist. L. melastomoides Raddi: Fl. Bras. XIT. IV. P. St. - Picu de Andarahy. à Tijuca, Rı-Jıs., no 151 a. Arbuste, ti. blanchàtres. Fèriermar-. R.

- Var. losigrala Cogn. in Fl. Bias. NIV. IV, p. S.. - Nora Friburzo. au Conezo. Rio-Jax., nos 13849. 16823. Arbuste, t1. blaniliatres. Arril-mai $\dot{L}$.

3\%. L. Glaqioniana Cozn. in Fl. Bras. IV, IV. p. \&6. - Serra dos Orgãos. à Theresopolis, Rio-JAx.. n $n^{i s} 7616,16824$. Arbuste. tĩ. Wlanchà tres. Janvier-févier. C.

3.̈b. L. scabra DC.: Fl. Bras. XlT. IV. p. Sb. - Curcovadu. Tijuca. ete., Puo-Jas.. no: 151, 594, 5861: Serra de Caraça. São Juão dEI Rei. Mris Geraes, $n^{0 s} 14767,16032$. Arbuste. tl. blanchátres. Janvierfeivier. CL.

3̈. L. dubia DC.; Fl. Bras. XIV. IV, p. 89. - Ouebra Frasco. à Theresopolis, Rı-JAx.. n ${ }^{05}$ 596. 16860. 19347. Arbuste. 11. Jlanchatres. Janvier-février. C.

3⿻x. L. hirta liaddi: Fl. Bras. XIV. IV. p. 91. _ Serra do Alto Maıahé, Rio-Jas., n 16859. Arbuste, fl. Hlancliatres. Janvier-février. C. 
3.9. Leandra xanthostachra Cogn. in Fl. Bras. XIV, IV. 1. 93.

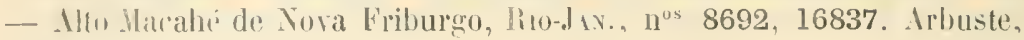
fl. Hanchitres, Octolse. C.

360. L. nianga formis Gogn. in F\%, Brms. XIT, IV, p. 93. - Petropolis, à Quitamlinha, Rio-J.1x., $11^{\circ}$ 16836. Arbuste, fl. hlanchâtres. (Jctobre-novembre. C.

361. L. xantholasia Cogn. in Fl. Bras. XIV, IV, p. 94. - NovaFriburgo, an Conego, Rio-dav., $11^{\circ}$ 16838. Arbuste, fl. blanchâtres. flicembre. C.

369. L. Gardneriana Cogn. in Fl. Bras. XIV, IV, 1. 9\%. - Theresopolis, a Quebra Frasco, Ru-JAN., n 8692 a. Arbuste, fl. blanchatres. Février-mars. C.

363. L. echinata Cogn. in DC. Monogr. Phan. VII, p. 626. - Serra do Picú, près Boa Vista, Rı-JAx, no 16002. Arbuste, fl. blanchâtres. Mai. R.

364. L. douradensis Glaz., n. sp.? in herb. Paris., Berol., Kew., Brux., etc. - Serra Dourada, à Yossamedes, dans le bois, Goyaz. ${ }^{\circ}$ 21410 a. Arbuste, il. blanchatres. Aoùt-septembre. R.

363. L. Nianga Cogn. in Fl. Bras. XlV, IV, p. 96. - Corcovado, Tijnca et Petropulis, Rio-Jax., nos $156,11966,16834,16835$. Arhuste, 11. violacées. Févier-mars. CG. Vulgo : Pixirica.

- Var. ovata Cogn. in Fl. Bros. XIV, IV, p. 97. - Coreovado, à Lagoinha, Rio-Jan., $n^{\circ}$ 8683. Arbuste, fl violacées. Aoùt-septembre. CG. Vulgo: Pixirica.

366. L. cordifolia Cogn. in F\%. Bras. XIV, IV, p. 98. - Ttatiaia, dans le bois, Rıo-Jav., nº $8683 a$. Arbuste, fl. rousses. Janvier-février. C.

367. L. foveolata Cogn. in Fl. Bras. XIV, IV, p. 100. - São João d'El Rei, Minus Geracs, nos 16841, 16852; Serra dos Orgãos, Riu-Jan., ${ }^{1{ }^{09}} 16839,16840$. Arbuste, fl. violacées. Janvier-avril. CG.

368. L. polychata Cogn. in DC. Ilonogr. Phan. VII, p. IIS b. - Serra de Ouro Preto, Mlixas Geraes, $n^{\circ}$ 18226. Petit arbuste, li. blanchâtres. Juin-juillet. R.

369. L. oligochata Cogn. in Fl. Bras. XIV, IV, p. 101. - Serra de Ouro Preto, Mrvas Genaes, $n^{\circ}$ 19325. Arbuste, 11. blanchâtres. Avrilmai. C.

370. L. cancellata Cogn. in Fl. Bras. XIV, IV, p. I03. - Entre Inficionado et Caraça, Mlivas Geraes, nº 13839. Arluuste, fl. blan chàtres. Juillet-aoùt. C. 
A.-F.-I. GLAZIOC. - LASTE IES PLAMTES DU BHESII, CENIIAL.

371. L. flavescens Gogn. in W(. Honogr. Phon. VII, p. 6.21. - Petropolis, alı Cachaminí, Ro-Jix., $1^{0} 16767$ a. Arluste, 11. blanchaitres. Mai-juill. H.

372. L. australis Cogn. in Fl. Bras. XIV, IT, p. 10\%. - Norro das Araras, à Theresopolis. Kun-Jin., $1^{\circ} 18226$ ". Irisuste, fl. blanthitres. Janvier. C.

373. L. multisetosa Cogn. in J)C. Monogr. Phan. VII, p. 632.Ser'a do Nlto Nacalié, Rro-Jax., no 16828. Arbuste, fl. blanchitres. Septemire-octobre. C.

374. L. purpurascens 10C.; Fl. Bras. XIV, IV, J. 110. - Serra dos Orgãos, Petropolis el Nova Friburgo, Riro-Jax., nos 2138, 6524, 16856. Arbuste. fl. blanchâtres. Septembre-ortubre. CC.

- Var. Claussenn Cogn. in F\%. Bras. XIV, IT, p. 111. - Pelrupolis, à Itamaraty, Rio-Jix., $n^{\circ} 6524 a$. Arimste, fl. rousses. Septembre-octobre. C.

37.). L. tetraquetra Cogn. in Fl. Bras. XIV, IV, p. 112. - Serra da Estrella, pres Petropolis, Rro-JAs, n ${ }^{\circ}$ 10768. Arluste, fl. blanclatres. Halsarilil. Ir.

376. L. tetragona Cogn. in DC. Vomngr. Phan. VH, 1. 63.). - Nto Macahé de Nova Friburgo, Rı-dıx., n 16872. Arhuste, Il. lilanchâtres. Septembre-sctolre. R.

37T. L. dasytricha Cogn. in Fl. Bras. XV, 1V. p. 113. - Gavea, Corcovado, Tijuca, ete., Rio-Jas., $\mathrm{I}^{0 \mathrm{~s}}$ 572, 573, 1094, 16869, 16870. Arluste, fl. blanchâtres. doùt-septrinbre. CC.

378. L. alterninervia Cogn. in Fl. Bras. XIV, IV, p. 11\%. - Theresopolis, au Alto, Rio-Jix., $1^{\circ}$ 16871. Arluste, fl. blanchàtres. Janvierfóvriel. C.

379. L. Schenckii Cogn. in DC. Suites au Prodr. VII, p. 636. -

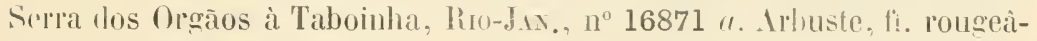
tres. Janvier-février. R.

380. L. Regnellii Cogn. in Fl. Bras. XIV, IV, 1) 116. - Serra da Mantipueira, à Mão Gomez, Hras Geraes, $10^{\circ}$ 15999. Aluuste, fl. blanchàtres. Novembre. C.

381. L. sublanata Cogn. in F\%. Bras. XIV, IV, 1. 118. - Petropolis et Nlto Nacalı́, Rı-J.ı.. $1^{0 s}$ 16830, 16831, 16832, 16833. Mrluste, fl. blanchâtres. Janvier-févirer. CC.

382. L. confusa Cogn. in Fl. Bras. MIT, IV, p. 119. - Serril do Alto Matahe, Rio-Jax, nº 16829. Arhuste, H. ilanchitres. Janvier-fivrier. C.

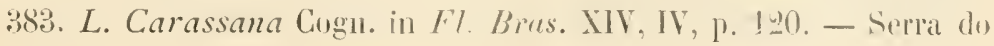




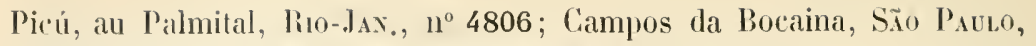
$n^{\text {os }} 10771,10844$. Arbuste, 11. blanchâtres, Avril-juin. C.

- Var. estrellensis Cogn. in Fl. Bras. XIV, IV, p. 120. - Tijuca et Quitandinha, à Petropolis, Rı-JAx., nos 2578 , 15998. Arbuste, f1. hlanclıttres. Février-mars. C.

38'. Leandra xanthocoma Cogn. in Fl. Bras. XIV, IV, p. 124. Nora Friburgo, au Conego, dans le bois, liı-JAx., $11^{\circ}$ 16827. Arbuste, fl. blanchàtres. Décembre. C.

383. L. eriocalyx Cogn. in DC. Monogr. Mhan. VII, J. 642. Alto Macalı́ de Nova Friburgo, Rı-Jas., nos 16854, 16858 a. Arbuste, fl. blanchâtres. Janvier. R.

386. L. laxa Cogn. in DC. Monogr. Phan. VII, p. 642. - Alto Macalıé de Nova Friburgo, Rí-JAx., $n^{0}$ 16853. Arbuste, fl.hlanchâtres. OCtobre. R.

387. L. mollis Cogn. in Fl. Bras. XंI, IV, p. 126. - Serra do Alto Macahé, Rı-JAx., $\mathrm{n}^{\mathrm{os}} 3965$, 16862. Arhuste, ll. blanchâtres. Février. mars. C.

388. L. strigilliflora Cogn. in Fl. Bras. XIV, IV, p. 126. - Corcovarlo, à Lagoinha dos Porcos, Rio-.las., $n^{0 \mathrm{~s}} 562$, 1268, 8685. Arbuste, fl. blanchâtres. Janvier-février. C.

389. L. atroviridis Gogn. in DG. Monogr. Phan. V1l, p. 644.Serra do Alto Macahé, liı-JAv., nº 16914. Arhuste, fl. blanchattres. Marsavril. R.

390. L. aptera Cogn. in Fl. Bras. XIV, IV, p. 127. - São dos Barreiros, São Paulo, $n^{\circ} 16002 a$. Arbuste, fl. blanchâtres. Marsarril. R.

39I. L. ionopogon Cogn. in Fl. Bras. XIV, IV, p. 129. - Floresta da Tijuca, Riı-Jax., nº 572 a. Arbuste, fl, hlanchâtres. Mai-juin. C.

392. L. sylyatica Cogn. in Fl. Bras. XIV. IV, p. 131. - São Joào d'El Rei et Ayuruoca, Mivas Geraes, nos 16024, 16848. Petit arbuste, ll. blanchâtıes. Mars-avril. C.

393. L. polystachya Cogn. in Fl. Bras. XI, I, p. 132. -- Serra de Ouro Branco, dans le campo, Jixas Geraes, $n^{\circ} 14786 a$. Petit arbusle, fl. blanchattres. Octobre-novemlre. C.

394. L. rigida Cogn. in Fl. Bras. XIV, IV, p. 134. - Ser'ra de Ouro Branco, dans le campo, Mrsas Geraes, nº 14786. Petit arbuste, fl. Dlanchâtres. Novembre. C.

393\%. L. oblongifolia Cogn. in DC. Monogr. Phan. VII, p. (349. - 
A.-F.- ॥. GLAZIOU. - LISTE DES PLANTES DU BRÉSIL CENTRAL.

Serra de São José d'El Rei, Muvas Geraes, nº 16847. Arbuste, fl. blanchàtres. C.

396. L. lacunosa Cogn. iı Fl. Bras. XIV, IV, p. 138. - Serra de Itabira do Campo, Mrsas, $n^{\circ}$ 16845. Arbuste, 11. rousses. Aonil-septembre. G.

397. L. erostrata Cogn. in Fl. Bias. XIV, IV, p. 139. - Barbacena et Itabira do Campo, Mrxas Geraes, $11^{05} 8364,16958,17568$. Petit arbuste, f1. blanchàtres. Septembre-octobre. CG.

- Var. minor Cogn. in Fl. Bras. XIY, IV, p. 140. - Sabara, au Morro do Ramão, Minas Geraes, nº 20317. Petit arbuste, fl. blanchàtres. Novembre. C.

398. L. Eichlerii Cogn. in Fl. Bras. XIV, IV, p. 1 't0. - Itatiaia, dans le campo, Rio-JAN., n ${ }^{05} 6532,8694$. Petit arbuste, 11. blanchlâtres. Janvier-février. C.

399. L. simplicicaulis Cogn. in Fl. Bras. XIV, IV, p. 141. - Serra de Ouro Branco, dans le campo, Mrsas, n 14787 . Plante naine, fl. blanchâtres. Novembre. R.

400. L. nana Cogn. n. sp. in herb. Paris., Berol.. Bruxell. etc. - Rodrigo Silva (Capão), près Ouro Preto, Mivas Geraes, in 19323. Plante naine, fl. blanchâtres. Avril-mai. R.

401. L. pachyrrhiza Cogn. n. sp. in herb. Paris., Berol. et Bruxell. - Rodrigo Silva (Capão), près Ouro Preto, Mrsas Geraes, no 19322. Plante naine, sans fleurs. R.

409. L. aurea Cogn. in Fl. Bras. XIV, IV, p. 142. - Barbacena, Caraça, Itabira do Campo, Serra do Lenheiro, Mryas Geraes, $11^{05} 10761$, 12697, 14788, 16844, 16849, 16851, 16855; Nova Friburgo, au Morro do Suspiro, Rio-JAx., $n^{\circ}$ 16843. Arbuste, fl. blanclıatres. Juin-juillet. CC.

- Var. glabrata Cogn. in litı. el herb. Paris., Berol. - Sabara, au Norro do Ramão, Misa Geraes, nos 20315, 20316. Irbuste, 11. rougeâtres. Octobre-norembre. C.

403. L. acuminata Cogn. in Fl. Bras. XIV, IV, p. 143. - Serra dos Orgĩus, Rı-Jax., $n^{\circ}$ 6152. Arbuste, 11. blanchitres. Septembre-octobre. li.

404. L. coriacea Cogn. in DC. Monogr. Phan. VIl, p. 6.9. - Sào João d'El Riei, dans le campo, Mrxas Griages, nº 16846. Arbuste, fl. blanchitres. R.

40:3. L. pennipilis Cogn. in Fl. Bras. XIV. IV, p. L'4. - Serra de São José d'El Rei, Mlivas Gelaes, $11^{\circ}$ 16865. Arbuste, fl. blanthitres. C. 
406. Irandra lancifolia Cogn. in fil. Brus. XIV. W. 1). 14:3. Serra de Siio Josi d El liei, Mixis Giliats, $1^{\circ}$ 16858. Arhuste, ll. mugeritres. Juin-juillet. R.

- Vall. latifola Gogn. in Fl. Bras, XIV. IV, p. 146. - Noval Friburou à Pedra do Conego, Rio-Jan., 110s 16842, 16857. 18225. Aluuste, 11. rougecties. Juillet. C.

407. L. aspera Cogn. in DC. Monogr. Mhan. XII, p. 6ёе. - Alto

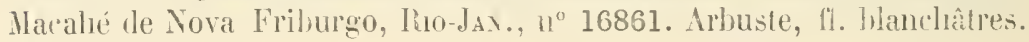
Janvier-février. C.

408. L. linearifolia Cogn. in FI. bras. XIV, IV, P. 149. - Petropolis, au Rio Itamaraty, Rio-Jax., $n^{\circ}$ 14776. Petit arbuste, fl. rougeñtres. C.

409. L. parrifolia Cogn. in Fl. Bras. XIV, IV. p. 150. - Serra de Onro Preto, Mnas Geraes, no 19324 a. Petit arbuste, fl. rougeâtres. Mai. R.

110. L. Intea Cogn. in Fl. Pras. XIV, IV, p. 131. - Floresta de Tijuca, au Pico do Papaqaio, Rio-Jix., nos 2135, 16001. Arluste, f1. blanchâtres. Novemlıre-décembre. C.

- Var. glabriuscula Cogn. in Fl. Brels. XIT, IV, p. 10ّ2. - Haut du Corcovado, Rio-Jas., $n^{\text {os }} 4942,7620,10779$. Arbuste, fl. Mlanchâtres. Octobre-novembre. C.

411. L. tomentosa Cogn. in DC. Monogr. Phan. VII, p.661. - Serra dos Oroãos, au Frade, Rio-JAN., nos 3757, 16899. Arluste, fl. blanchâtres. Octobre-novembre. C.

- Var. major Cogn. in DC. Monogr. Phan. VII, p. 661. - Petropolis, au Norro da Carangola, Rio-JAx., n ${ }^{\circ} 13845 a$. Arbuste, 11. blanchâtres. Décembre. Ii.

412. L. sulfurea Cogn. in Fl. Bras. XIV, IY, 1). 153. - Itatiaia et à Petropolis, Rio-Jan., nos 4802, 16941. Arluuste, fl. blanchàtres. Avriljuin. C.

113. L. circumscissa Cogn. in Fl. Bras. XIV, IV, p. 134. - Ayuruoca, au Pico do Papagaio et à Serra do Picú, Mrias Geraes, nos 9461 , 10772. Arbuste, fl. blanchâtres. Avril-mai. C.

41'. L. dentata Cogn. in DC. Monogr. Phan. VII, 1.662. - Theresopolis, au Morro das Araras, Rı-Jax., n 16938. Arbrisseau, fl. blanchâtres. Janvier-février. C.

415้. L. velutina Cogn. in Fl. Bras. XIV, IY, p. 15\%. - Serra do Orgãos, au Frade, Rı-JAN., $1^{\circ}$ 3972. Arbuste, ll. blanchâtres. Marsavril. C. 
A.-F.-M. GLAZIOU. L LISTE DES PLANTES DU BRESIL CENTRAL.

416. L. quinquedentata Cogn. in Fl. Bras. XIV, IV, p. 15̈6. - Petropolis à Cachambú, Rio-Jax., n ${ }^{\circ}$ 16900. Arbrisseau, fl. blanchâtres. Novembie. C.

- Var. depalperata Cogn. in Fl. Bras. XIT, IY, p. 157. - Serra do Tingua, au sommet et au Alto Macahé, Rio-Jax., nos 8696, 16940. Arbrisseau, fl. blanchâtres. Mars-avril. C.

417. L. quinquenodis Cogn. in Fl. Bras. XIV, IV, p. I5T. - Alto Nacahé de Nova Friburgo, Riro-Jas., nos 16924, 16942; Gandarela, Irsas, $n^{\circ}$ 14775. Arbrissean, fl. blanches. Janvier-férrier. C.

418. L. vesiculosa Cogn. in Fl. Lras. XIV, IV, p. 18̈8. - Serra do Itatiaia, près Campo Bello, Rio-Jax, $n^{\circ}$ 6527. Arbuste, fl. blanchâtres. Janvier-février. C.

419. L. Grayana Cogn. in DC. Monogr. Phan. VII, p. 66.3. - Itacolumy, près Ouro Preto, Caraça, Mrxas Geraes, ${ }^{0 s}$ 14772, 16007; Theresopolis, à Serra das Araras et Serra do Picú, Rio-Jax., $n^{03}$ 10773, 16939. Arbrisseau, fl. blanchâtres. Janvier-mars. CC.

420. L. Saldanhari Cogn. in DC. Monogr. I'han. VII, p. 666.Petropolis, à Caclıambú, dans le bois vierge, Rro-Jax., $1^{\circ}$ 16893. Arbuste, fl. blanchâtres. Novembre. R.

421. L. Trauninensis Cogn. in DC. Monogr. Phan. VII, p. 666. Alto Macahé de Nova Friburğo, Rio-Jar., n 16894 . Arbuste, fl. blanchâtres. Décembre. C.

- Var. masor Cogn. in DC. Monogi. Phan. VII, p. 666. - Nlo Ilacalsé de Nova Friburgo, Rio-Jax, $n^{\circ}$ 17538. Arbuste, fl. blanchâtres. Septembre. C.

4929. L. barbinery'is Cogn. in Fl. lirus. XIV, IV, p. 10ั9. - Serra dos Orçaos, au Imbui, Rı-JAx., $\mathrm{n}^{\circ-3}$ 3756, 16962. Arbuste, fl. blanı hàtres. Mai. C.

423. L. neurotricha Cogn. in Fil. Liras. XIV, IV, p. 160. - Serra dos Orgios et Alto Macahé, Rio-Jax. nos 8376,16008 , 16923. Arbrisseau, fl. blanchâtres. Janvier-février. C.

42y. L. acutiflora Comn. in Fl. Bras. XIV, IN, p. 162. - Petropolis, au Morro da Carangola et ì Serra do Alto Hacahé, Rio-fax, $11^{05} 13847,16925.16926$. Arbuste. f1. blancles. Décenture. CC.

- Var. grandfolin Cogn. in Fl. Bras. XIV, IV, p. 162. - Yova Fribureo et Surra dos Orgios, Riro-Jax.. $11^{0}$ 13855. Arbuste, fl. blanches. Janrier-février. C.

420. L. gracilis Cogn. in Fl. Bras. XIV. IV, p. 163. - Serra dos 
Orgĩos, près Cachambú el ì Nova Friburgo, au Morro do Suspiro, hio$J_{A x}, n^{0 \times} 16004,16901,16920$. Arbusle, fl. blanchàtres. Novembre-décembre. C.

- Var. Glazioviana Cogn. in DC. Monogr. Phan. VII, p. 669. - Alto Macahé de Nova Friburgo, Rio-JAN., $n^{\circ}$ 17533. Arbuste, fl. blanchàtres. Septembre. R.

4⒍ Leandra Riedeliana Cogn. in Fl. Bras. XIV, IV, p. 16' - Petropolis au sommet du Morro do Retiro et à Nova Friburgo, liı-dan., $n^{\circ s}$ 13846, 16919. Arluste, fl, blanchâtres. Décembre-janvier. C.

427. L. adenothrix Cogn. in Fl. Bras. XIV, IV, p. 163. - Sĩo Julião, dans lp hois, Mlinas Geraes, $n^{\circ}$ 17567. Arbuste, fl. blanchâtres. Décembre. R.

428. L. cordigera Cogn. in Fl. Bras. XIV, IV, p. 166. - Campos da Bocaina, São Paulo, $n^{0} 11610$. Petit arbuste, fl. blanchâtres. Septembre. R.

429. L. pallida Cogn. in Fl. Bras. XIV, IV, p. 167. - Itatiaia, dans le campo, Rio-JAx., nº 8693. Petil arbuste, fl. blanchâtres. Novembre. R.

-- Var. brevifolia Cogn. in Fl. Bras. XIV, II, p. 167. - Serta dos Orgãos, au sommet, lío-J $\mathrm{J}_{\mathrm{Ax}}, \mathrm{n}^{\circ}$ 3959. Petit arbuste, fl. blanchàtres. Décembre. R.

430. L. fluminensis Cogn. in Fl. Bras. XIV, IV, p. 169. - Serra do Ouro Branco, Mixas Geraes, no 14785. Arbuste, fl. blanchâtres. Norembre. C.

- Var. latifolia Cogn. in Fl. Bras. XIV, IV, p. 170. - Serra do Ouro Branco, chemin de Deos Livre, Minas Geraes, n 14784. Arbuste, fl. blanchâtres. Novembre. C.

431. L. glabrata Cogn. in Fl. Bras. XIV, IV, p. 172. -.- Pico de Itabira do Campo, Mixas.Geraes, $n^{\circ}$ 17537. Arbuste, fl. blanchâtres. Décembre. C.

432. L. sessiliflora Cogn. in DC. Monogr. Phan. VII, p. 674. Gandarela, daus le bois, Mixas Geraes, $n^{\circ}$ 14774. Arbuste, fl. blanchâtres. Février. R.

433. L. Itatiaice Cogn. in Fl. Bras. XIV, IV, p. 173. - Itatiaia, dans le campo et it Isabeloca, Serra dos Orgãos, Rı-JAx., $1^{\text {os }} 5858,16867 b$. Petit arbuste, fl. blanchâtres. Juin-juillet. C.

434. L. catharinensis Cogn. in DC. Suiles au Prodr. VII, p. 1188. - Itatiaia et Serra dos Orgãos, dans le bois, Rio-dan., no 8693 a. Arluste, fl. rougeâtres. Novembre-décembre. R. 
1.-F.-11. GLAZIOU. - LISTE DES PLANTES DU BRÉSIL CENTRAL. 2\$3

130. L. debilis Cogn. in Fl. Brus. NIV, WV, p. 174. - Petropolis, à Cachambir, Rı-Jax., $n^{\circ}$ 16866. Petit arbuste, f1. blanchâtres. Novembredécembre. C.

- Var. brevifolia Cogn. in Fl. Bras. XiV, IV, p. 17\%. - Ranedo do Iorm Gavado, Mivas Geraes, no 7623 ; Petropolis, al Cachambú, Ruo-Jay., $n^{0}$ 16867. Petit arbuste, fl. blanchâttres. Septembre-octıbre. C.

436. L. mutans Cogn. in DC. Monogr. Mhan. VII, p. 676. - Altn Máahé de Nova Friburgo, Rı-JAx., nº 16915. Arbuste, t1. blanchàtres. Janvier-février. C.

437. L. sphacerocarpa Cogn. in DC. Vonogr. Phan. VIl, p. 676. Serra do Alto Nacahé, Rio-JAx., nos 16916, 17555. Arbrisseau, f1. blanchàtres. Décembre. G.

438. L. lavigata Cogn. in Fl. Bras. XIV, IV, p. 177. - Alto Nacahé de Nova Friburgo, Rio-Jay, $11^{\text {os }} 13439,16868$. 17534. Arbrisseau, fl. blanchàtres. Octobre-novembre. CG.

439. L. Brackemridgei Cogn. in Fl. Bras. XIV, IV, p. 179. - Corcovalo, à Paineiras, lho-Jav., I $^{\circ}$ 7621. Arbrisseau, fl. blanchàtres. Gctobre. C.

440. L. rubida Cogn. in DC. Monogr. Phan. VII, p. 679. - Peiropolis, à Itamaraty, Rı-JaN., $n^{\circ}$ 16953. Arbuste, fl. rougeâtres. Octobrenovembre. R.

441. L. multiplimervis Cogn. in Fl. Bras. XIV, IV, p. I80. - Tijuca, Petropolis et Alto Macahé, Rro-JAN., $\mathrm{n}^{\circ \mathrm{s}} 584,1577,16873,17532$. Arluste, fl. rougeâtres. Septembre-octolıre. CC.

442. L. longisetosa Cugn. in Fl. Bras. XIV, IV, p. 181. - Serra do Coelho, dans le bois, près Rezende, Rio-Jax., no 8691. Arbuste, fl. rouneàtres. R.

443. L. Schmackei Gogn. in DC., Monogr. Mhan. VII, p. 681. Nlto Nacahé de Nova Friburgo, Rio-Jax., n 17535. Arbuste, fl. rougeâtres. Octobre. R.

44.4. L. breviflora Cogn. in Fl. Bras. XV, IV, p. 182. - Serra do Alto Nacahé et Serrá dos Orgãos, Rio-JAx., nos 6882, 13853, 13857, 16889, 16963. Arbuste, fl. blanchâtres. Janvier-mars. CG.

4,ï. L. membranifolia Gogn. in DC. Monogr. Phan. VII, p. 68?. - Alto Nacahé de Nova Friburgo, Ru-Jax., $11^{\circ}$ 17536. Arbuste, fl. blanchâtres. Octobre. R.

- Var. parviflora Gogn. in lill. et herb. Paris, et Berol. - Serra Nova Friburgo, Rio-Jax., no 19341 a. Arbuste. fl. blanchâtres. Décembre. R. 
44ti. Leandra aristigera Cogn. in Fl. Bras. XIV, IV, 1. 18..- São Joâo da Barra, dans le bois, Rio-dxx., nº 9812 . Arbuste, fl. rougeâtres. Février. R.

4'7. L. hirtella Cogn. in Fl. Brus. XIT, IV, p. 187. - Norro Queimalo, près du Alto et à Nova Frilurgo, Rio-Jax., $n^{05} 586$, 16961. Petit arbuste, 11. blanchâtres. Aoùt-septembre. C'.

4'8. L. atrata Cogn. in Fl. Bras. XIV, IV, p. 189. - Serra do Mar, à Rodeio, Rio-ıax., no 8688, Albusle, fl. blanchâtres. Janvier. C.

449. L. dendroides Cogn. Fl. Bras. XIV, IV, p. 190. - Pien de Itabira do Campo, Mixas Gelraes. n 17566 . Petit arbuste, fl. blanchâtres, Décembre. CC.

- Var. parvifolta Gogn. in Fl. Bras. XIV, IV, p. 191. - Serra de Ouro Branco, Minas Geraes, $n^{0 s} 14783,17566$ a. Petit arluuste, fl. blanchâtres. Novembre. C.

40.0. L. solenifera Cogn. in Fl. Bras. XIV, IV, p. 191. - Itabapoana, près S. Sebastião, Rio-Jax., no $9812 a$. Arbuste, fl. blancluatres. Février-1nars. R.

4..1. S. reversa Cogn. in Fl. Bras. XIV, IV, p. 198. - Serra de Jararepragua, Campo Grande et à Tijuca, Rı-JAx., $n^{\text {os }}$ 149, 591, 19346 b. Arbuste, f1. rougeâtres. Décembre-janvier'. C.

409. L. rufescens Cogn. in Fl. Bras. XIV, IV, p. 204. - Itabapoana, près S. Sebastião, Rio-Jax., no 9810. Arbuste, fl. rougeâtres. Févier. R.

433. Miconia Jucunda Triana; FI. Brus. XIV, IV, p. 2ㄱ․ - Raizda Serra da Estrella, Rio-Jax., no 570 a. Arbuste, fl. blanches. Févriermars. C.

40.4. M. staminea DC.; Fl. Liras. XIV, IV, p. 230. - Gavea. Praia Grande, Villa Nova, Rı-Jan., $n^{05} 333,570,13848$ : Ponte Grante, Sĩo Paclo, $11^{\circ} 16015$. Arbuste, fl. blanches. Janvier-nnvembre. CG.

43\%. M. Langsdorffii Cogn. in Fl. Bres. XIV, IV, p. 232. - Nogy das ciruzes, Sĩo Paclo, no 17546 u. Arbuste, fl. blanches. Févriermars. C.

4ï6. M. holosericea Triana; Fl. Bras. XIV, IV, p. 236. - Restinga de Mana, Riro-Jax., nos 576, 8353, 9820 et à Petropolis no 10767. Arhuste. fl. blanches. Avril-mai. CC.

4:T. M. macrophy-lla Triana; Fl. bras. XIT, IT, p. 239. - Piedade, Ariro, Andayassu, Rio-Jix., nos 9821, 17544, 19337. Grand arbuste, fl. blanches. Décembre-janvier. CC. 


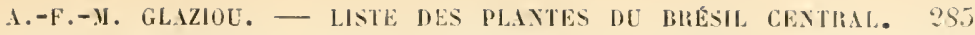

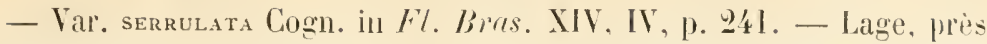
Hector, Govaz, no 21393 a. Grand arbuste, sans fleurs en juillet.

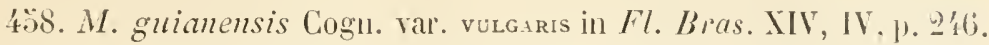
- Restinga de Copacabana, Tijuea, Gavea. Rio-J.ix., $11^{\text {os }}$ 153, 162, 599, 9823. Grand arbuste, 11. blauches. Septembre-octobre. CC.

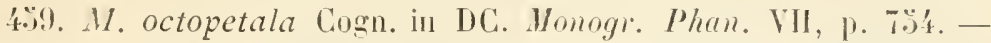
Alto .lacahé de Nova Friburgo, Rı-Jıx., nos 16876, 16967, 18222, 20311. Grand arbuste, ll, blanches. Mai-juin. CC.

460. M. atrata Wawra; Fl. Bires. XIV, IV, p. 9:38. - Corrovado et Floresta da Tijuca, Rio-Jax., $11^{\text {os }} 2574$, 8355. Arbuste. 11. rougeàtres. Février. C.

461. M. robnstissima Cogn. in Fl. Bras. XIV, IV, p. 611; 1/. robusta Ciogn. Lor. cit., p. 270 non p. 611 . - Nova Friburgo et Theresopolis, Rio-Jax., I1 ${ }^{\text {s }} 8689$, 16888. Grand arbuste, li. blanchâtres. Juillet-août. C

46ュ. M. organensis Gardn.; Fl. Bras. XIV, IV, p. „281. - Serra dos

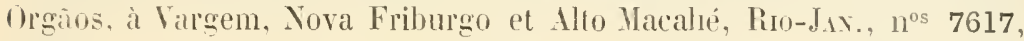
7618, 16009, 16907, 17546. Arbuste, f1. blanches. Janvier-novembre. C.C.

463. M. Warmingii Cogn. in Fl. Birts. XIV, IV, p. 28:- Sìo José de Mitosinho, Mrvas Geraes, $n^{\circ}$ 21393. Arhuste, fl. hanches. Septembre-octubre. C.

46\%. M. scorpioides Schlt.: Fl. Brus. XW, IN, p. 283. - Fazenta do Solnal, près du Rio Parahıba, Rro-Jix, no $12690 a$. Arbuste, fl. blanchàtres. Septembre-octobre. L.

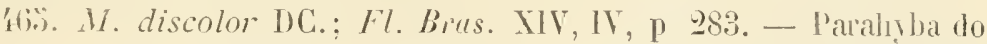
Sul, à Solıral, Ro-Jix, $1^{\circ}$ 12690: Serrinha, à Santa Larbara, Mrves Gerses, $n^{\circ} 19331$ \%. Arbuste, fi. blanche's. Aoùt-septembre. C.

466. M. herpetica DC.; Fl. Brus. XIV, IV, 1. 286. - Carandahy, dans le campo, Hris lieraes, $11^{\circ} 13836$. Petit arbuste, fl. blanches. Juin juillet. C.

407. M. pennipilis Cog̣. in Fl. Bras. XIV, IV, p. „257. - Itacolumy, près Guro Preto, Mlxas Geraes, no 14769. Arbuste, 11. bliuches. Juinjuillet. (i.

46s. M. albicans Triana Fl. Bras. XIV, IV, p. 288. - Magé, Pria

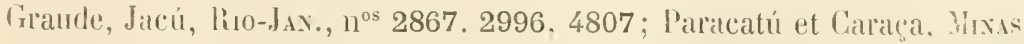
Cieraes, $11^{\text {os }} 19338$ a, 21388. Arbuste, ll. blanches. Juin-septembre. CC.

469. M. cinerea Cogn. in Fl. Bras. XIV, IV, p. 290. - Eutre Sambaitiha et Collegio, Rio-Jas., no 11974. Arbuste, t1. Banches. Otobrenovenubre. C. 
470. Miconia macrothyrsa Benth.; Fl. Bras. XIV, IV, 1. 290. Entre Queluz el Carandahy, dans le campro, Mnxas Geraes, $1^{0} 13837$; Congonhas da Serra, n 19333; Horro Canastra, Ribeirio do Inferno, Govaz $\mathrm{n}^{\text {os }}$ 21386, 21387. Arbuste, fl. bianches. Juin-septembre. CG.

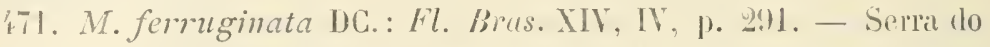
Palmital, près Alegria et Serra do Leinheiro, Nivas Geraes, $n^{0 s} 14771$, 16030, 16875. Arbrisseau, fl. blanches. Févier-arril. CC.

4T. M. fallax DC.; Fl. Bras. XIV, IV, p. 293. - São João d'El Rei, Mnvas Geraes, nº 16962 a. Arbuste, 11. Blanches. Mai-juin. R.

473. M. stenostachya DC.; Fl. Bres. XIV, IV, p. 29'4. - Antonio Pereiro, Serrinha de Sanla Barbara, Serra do Leinheiro, Mnas Geraes, $\mathrm{n}^{05}$ 12598, 16905, 19331; Rio Areios el Pouzo do Barbatimāo, Goraz, $\mathrm{n}^{0 \mathrm{~s}} 21390,21391,21392$. Arbuste, fl. blanches. Mai-juin. CC.

47'. M. argyrophylla DC.; Fl. Bras. XIV, IV, p, 296. - Serra do Inficionado, près Caraça, Mıxas Geraes. $1^{\circ}$ 13827. Arbuste, fl. blanches. Février. R.

47ั. M. heliotropioides Triana; Fl. Bras. XIV, IV, p. 297. - Formosa, dans le campo, Goyaz, n 21399. Arbuste, fl. blanches. Décembre-janvier. R.

476. M. Glazioviana Cogn. in Fl. Bras. XIV, IV, p. 301. - Serra do Alto Nacahé, dans le bois vierge, Rio-Jax., nos 13850, 16936, 19328. Arbuste, fl. blanchâtres. Arril-juin. C.

477. M. polyandra Gardn.; Fl. Bras. XIV, IV, p. 302. - Petropolis, à Villa Thereza, Rio-Jas., $n^{\circ s} 8363,12180,16006$ et au Alto Macahé, $n^{\circ 5} 16012$, 20310. Arbrisseau, f1. blanchàtres. Février-mar's. CC.

478. M. pulchra Cogn. in DC. Monogr. Phan. VII, p. 79:. - Florest. da Tijuca, Rio-Jax., $1^{\circ}$ 17541. Grand arbuste, fl. blanchâtres. Juinjuillet. R.

479. M. calvescens DC. ; Fl. Bras. XIV, IY, p. 307. - Gavea, Corcorado, Rio d'Ouro, Rro-dax, $1^{\circ 5} 583,1124,1576,16390,17547$; Bento Rodrigues, Mhxas Geraes, $n^{\circ} 19334$; entre Taboquinha et Taquaril, Goraz $\mathbf{n}^{\circ}$ 21398. Arbuste, f1. blanches. Arril-juin. CC.

480. M. Chamissois Naud.; Fl. Bras. XIT, IV, p. 309. - Ipanema, dans les bourbiers, Sĩo Paclo, $1^{\text {os }} 12693,13838$; São Juão d'El liei, Mlinas Geraes, $n^{0 s}$ 16029, 16891 ; Fazenda do Amoreira, dans les buurbiers, Govaz, $n^{\circ}$ 21401. Grand arbuste, fl. blanches. Juin-aont. CC.

481. M. elegans Cogn. in Fl. Brets. XIV, IV, p. 312. - Serra de São João d'El Rei et do Lenheiro, aux bords des ruisseaux, Mixas GeraEs, 
A.-F.-M, GLAZIOC. - LISTE DES PLATTES DC BRESIL CENTRAL. 2ST nos 14768, 16028, 16892, 20312; Lage, Goraz, no 21400. Arbrisseau, 11. blanches. Juin-juillet. C.C.

482. M. prasina UC.; Fl. Bias. XIV, IV, p. 316. - Restinga de Nana, Corcovado, Gavea, Angra dos Reis, Rio-JAx., $1^{\text {os }}$ 161, 558, 1269, 8456, 9813, 17539, 17545. Alrisseau, 11. blanches. Mars-juin. GC.

- Var. collina Triana; Fl. Bras. XN, IV, p. 317. - Serla da Estrella, Rir-Jax., n 1091. Arbrisseau, ff. blanches. Arril-mai. R.

483. M. engenioides Triana; Fl. Bras. MIT, IV, p. 32ュ. — Ponta do Perdiclo, près de Cabo Frio, Rio-Jax., no 8457 a. Arbuste, fi. blanches. Décembre. R.

48'. M. Matthoe Triana; Fl. Bras. XIV, IV, p. 32\%. - Guariroba, au bord de la rivière, Goyaz, $n^{\circ} 21400 a$. Arbuste, fl. blanchàtres. Juillet. R.

485. M. ibaguensis Triana; $\mathrm{Fl}$. Bras. XIV, IV, p. 331. - Entre Sambaitiba et Collegio, Balem, Igussú. Riı-JAx.. nos 8681, 8698, 11961, 19327: S. I. J'El Rei, Mras Geraes, $1^{\circ}$ 16864; Rio Areios et Serra Dourada, Goraz, nos 21377, 21378, 21379. Arbuste, fl. blanchâtres. Aoùtseptembre. CG.

486. M. nervosa Triana; Fl. Bras. XIV. IV. p. 336. - Ponta do Perdido, près Cabo Frio, liı-Jax., nº 9811 . Arbuste, fl. rougeàtres. Novembre-décembre.

487. M. pseudo-nervosa Cogn. in Fl. Bras. XIT, IV, p. 337. -- Rio Jardim, dans le bois. Yeia Ponte, Iona Barbara, etc., Gorı, nos 21380 , 21381, 21382, 21383. Arbuste, fl. blanchitres. Janvier-aoùt. CC.

488. M. ceramicarpa Cogn. in Fl. Bras. MIV, IV, p. 338. - São Vicente de Paula, près de Cabo Frio. Rro-Jax., nos 9809, 9825. Arbuste, f1. blanchâtres. C.

489. M. alata DC.: Fl. Bras. XIV, IV, p. 340. - São Vicente de Paula, près le Cabo Frio, Rio-Jax., nos 9830 , 13832. Arbuste, fl. blanchàtres. Janvier-l'évrier. C.

490. M. Schivackiei Cogn. Fl. Bras. XIV, IV, p. 342. - Quinta da Boa Vista, Rio-Jax., nº 13825. (Namaos teste Schwache). Arbuste cultivé, 11. rougeâtres. Février-mars. R.

491. M. rubiginosa DG.; Fl. Brus. XIV, IV, p. 3’3. - Serra do

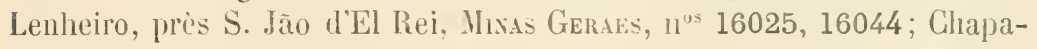
dão dos Veadeiros, Goraz, $n^{\circ}$ 21395. Arbuste, fl. blanchaitres. Janviurdécembre. C.

492. M. Burchellii Triana; Fl. Bras. XIV, IV, p. 849. - Norro do 
Frota, près de Meia Ponte, Goraz, ${ }^{\circ}$ 21393. Arluuste, 11. blanchatres. Septembre. C.

- Var. glabrata Cogn. in lill. et in herl. Paris. et Berol. - Rio das Pedras, Minas Geraes, no 19330. Arbuste, 11. blanchitles. Avril-mai. C.

493. Miconia Pohliana Cogn. in F\%. Bras. XIV, IV, p. 349.Chapadão central do Rio Torto, Goyaz, n² 21304. Grand arbuste, fl. blanches. Arril-mai. C.

494. M. fasciculata Gardn.: Fl. Bras. XIV, IV, p. 3:4. - Floresta da Tijuca, Corcovado, Serra de Jacarépagua, Rı-JAx., nos 159, 563, 564, 571, 581, 582, 6150. Grand arluste, fl. blanchâtres. Février-mars. CG.

495. M. Rabenii Cogn. in DC. Monogr. Mhan. VII, p. 832. - Alto Macahé de Nova Friburgo, Rio-Jan., nº 17561 a. Grand arbuste, fl. blanchâtres. R.

496. M. Maximonicziana Cogn.; Fl. Bras. XIV, IV, p. 3“̈̆. Itabira do Campo, Minas Geraes, $n^{0}$ 17543. Grand arbuste, fl. blanchâtres. Janvier-décembre. C.

497. M. revoluta Miq.; Fl. Bras. XIV, IV, p. 358. - Serra do Lenheiro, près de S. J. d'El Rei, Mras Genaes, no 16045 a. Arbuste, ll. blanchâtres. Octobre. R.

498. M. pepericarpa DC.; Fl. Bras. XIV, IV, p. 3999. - Serra do Lenheiro, près de São João d'El Rei, Mhxas Geraes, nos 16026, 16045; Taboleira Grande, dans le cerrado, Govaz, n² 21402. Arbuste, fl. blanchâtres. Octobre-novembre. CG.

499. M. Petroniana Cogn. et Sald.; Fl. Bras. XIV, IV. p. (il3. Serra dos Orgãos, à Theresopolis et au Alto Macahé, liı-Jax., nos 1581, 9463, 16011. Grand arbuste, li. blanchâtres. Février-mars. C.

300. M. corallina Spreng.; Fl. Bras. XIV, IV, p. 363. - Serra do Picú, coté de São Paulo et Serra de Ouro Branco, Mhas Geraes, $n^{\text {os }}$ 10775, 14770. Ariouste, fi. blanchâtres. Novembre-décembre. C.

5001. M. Augustii Cogn. in DC. Monoyr. Phan. VII, p. 833.Serra do Alto Macahé, Rio-Jix., n 16895. Grand arbuste, fl. blanchâtres. Décembre. C.

ö02. M. gilua Cogn. in DC. Monogr. Phan. VII, p. 836. - Alto Macahé de Nova Friburgo, Rı-JAx., n 16897. Grand arbuste, fl. blanchâtres. Décembre. R.

503. M. racemifera Triana; Fl. Bras. XIV, IV, p. 366. - Juiz de Fora, Mrwas Geraes, $n^{0}$ 7612. Arluuste, 11. blanchâtres. Décembre-janvier. $\mathrm{C}$. 
А.-F.-M. GLAZIOU. - LISTE DES PLANTES DU BRÉSIL CEXTRAL. 289

504. M. altissima Cogn. in DC. Monogr. Phan. VII, p. 837. Alto Macahé de Nova Friburgo, liı-Jix, $1^{\circ}$ 16909. Grand arbre, fl. blanclies. Décembre. G.

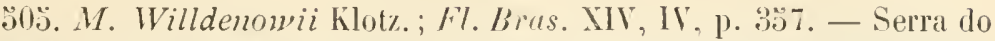
Alto Nacahé, Pro-J.x., nos $13851,16904,16906$. Grand arluste, fl. blanchâtres. Janvier-décembıre. C.

5006. M. argyraxa Cogn. in DC. Monogr. P'han. VII, p. 838. Alto Macahé de Nova Friburgo, Riro-JAx., $11^{\circ}$ 16905. Arluste, 11. blanches. Décembre. C.

307. M. chartacea Triana; Fl. Bras. XIV, IV, p. 369. - Petropolis, au Retiro, Rio-Jax., $1^{\text {os }}$ 12181, 13436, 13838, 13844, 16014, 16879. Arbuste, fl. blanchàtres. Janvier-décembre. CG.

- Var. Mrqueliana Cogn. in Fl. Brus. XIV, IV, p. 369. - Serra do Lenheiro et Serra de Santa Barbara, Mrsas Genass, nos 6879, 16886 , 16887, 19335. Grand arbuste, fl. blanchâtres. Octobre-novembre. CC.

- Var. longrfolra Cogn. in bC. Monogr. Phan. VII, p. 838. - Alto Hacahé de Nova Friburgo, Rio-Jax., $n^{0}$ 16884. Arluuste f1. llanchàtres. Décembre. R.

- Var. erevifolia Cogn. in DC. Monogr. Phan. VII, p. 839. - Alto Macahé de Nova Friburgo, lỉo-Jas., nº 1881. Arłuste, ll. blanchâtres. Décembre. C.

- Var. angustrfola Cogn. in DC. Monogr. Phan. VII, 1. 839. - Alto da Serra de Nova Friburgo, ho-JAs., n 16880. Arbuste, fl. blanchàtres. Décembre. C.

¿̈08. M. budlejoides Triana; Fl. Bires. XIV, IV, 1. 370. - Serra dos Or@ãos, Pelropolis, Alto Macahé de Nova Friburgo, liso-Ji., $n^{\text {os }} 8354,11963,17549,17550,17551,17552$. Arbuste, ll. blanchâtı'es. Septembre-novenbre. Ci.

509. M. brumea UC.: Fl. Bras., XT, W. p. 371 . _ Serra dos Orgãos, ¿ Theresofolis, Rıo-JAx., n ${ }^{05}$ 284, 1578, 1579, 1580, 3963; Serrinla de Santa liabara, Mrssis Genses, $11^{\circ}$ 19336. Grand arbuste, 1\%. blanchatres. Janvier-avril. C.

:30. M. divaricata Gardn.; Fl. Bors. XIV, IV, P. 370. - Mlto Macahé de Nova Friburgo, Rí-Jix., nos 16882, 16883, 16885. Arbuste fl. blanchâtres. Janvier-ılécenulıe. CiC.

:ill. M. angustifolia Cugn. in Fl. Brus. XIV, IV, 1. 613. - Serra dos Orgãos, à Theresopolis et à Cachambú, près de Petropolis, lino-Jax., 11 ${ }^{\text {*s }} 16877,16878$. Arluste, 11, blanchitres. Janvier-février. C. 


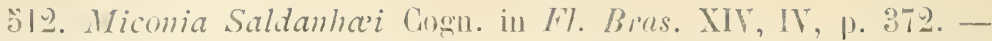
Theresopolis, au Imbui et Petropolis, Rou-Jix., nos 7613, 9464, 13852, 18896. Cirand anduste, fl. blanchâtres. Jans ier-fivier. L.

- Var. granderlora Cogn. in Monogi. Phan. VII, p. 841. - Alto Macalé de Nora Friburgo, hio-dax., no 17561. Grand arbuste, fi. blanchâtres. bécembre. R.

513. M. oblongifolia Cogn.; DC. Monogr. Phan. VII, 1) 8.1. Nora Friburgo, au Morro do Suspiro, Rio-Jav., $10^{0}$ 13437. Arluste, fl. l,lanchistres. Novemlıre. C.

5̆14. M. formosa Cogn. in DC. Monogr. Phan. VII, p. 842. - Serra do Alto Hacahé, Rio-Jax., no 16911. Arbre, ll. blanches. Janvier-décemlre. Ci.

- Var. angustriola Gogn. in DC. Monogr. Phan. VII, 1. 842. Floresta da Tijuca, Rio-Jax., $n^{\text {os }} 16910$, 17557. Arbrisseau, fl. blanches. Octobre-novembre. C.

313. M. oyalifolia Cogn. in DC. Monogr. Phan. VII, p. 842. - Alto Macahé de Nova Friburgo, Rıo-JAx., $11^{\circ}$ 16908. Grand arbuste, fl. blanches. Mars-avril. C.

כ̈16. M. albo rufescens Naud.; F\%. Lros. XIV, IV, p. 36̈. - Serra do Mar, à Rodeio, Rio-Jax., no 12699; Biribiry, près Diamantina, Mixas, $n^{\circ}$ 19332: entre Morro Reilondo et Wanoel Joâo, dans le carascal, Goraz, $11^{\circ}$ 21389. Arbuste, fl. blanches. Février-mars.

s17. M. setoso ciliata Cogn. in DG. Wonogr. Phan. VIl, p. 843. Petropolis, à Villa Theresa, Rio-Jax., no 16934. Arbuste, l'. blanches, Février-mars, C.

318. M. Waltherii Naud.; Fl. Bras. XIV, IV, p. 361. - Floresta da Tijuca, Rıo-Jax., 11² 2577. Arbuste, fi. blanchâttres. Avril-mai. R.

- Var. Sardanhar Cogn. Fl. Bras. XIV, IV, p. 362. - Floresta da Tijuca, Run-J৯x., nº 11969. Arluste, fl. blanchâtres. Avril-mai. C.

519. M. Eichlerii Cogn. in F\%. Bras. XIV, IV, p. 36\%. - Petropolis et Serra dos Orgãos, Rı-JAv., 11 ${ }^{\text {os }} 5860,8679,14777,16013,16966$. Arbuste, fl. blanchàtres. Mars-mai. CG.

520. M. pseudo-Eichlerii Cogn. in Monogr. Phan. VII, p. S4'. Alto Nacahé de Nova Friburgo, Rio-JAx., $1^{\circ}$ 16935. Grand arbuste, fl. blanchatres. Janvier. C.

521. M. eriantha Cogn. in DG. Monogr. Phan. VII, p. 843. Petropolis, à Cachambú, Rio-Jax., $n^{0}$ 16863. Arbuste, l1. blanchàtres. Novemlıre. C. 
A.-F.-U. GLAZLOL. - LISTE DES MLATTES UL BLESIL CEYTRAL.

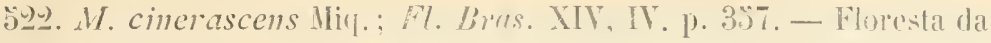
Tijuca et au Col'covalo, lìro-d.x., n n 152, 580, 597. 3961, 17562. irlouste, fl. blanches. Noventire-lécentore. LC.

323. M. psendo-Petroniana Cozn. in DC. Vonogr. Whan. VII, p. 8't6. - Nova Friburgo, au Conego. Riu-J.x., $11^{\circ}$ 16898. Trand arbuste, 11. blanchàtres. Décembre. R.

¿204. M. paulensis Naud. in Fl. Birs. NT, IV, p. 336. - Serra do Alto Marahé, al sommet, Rı-১Ax., n 17562 . Arbuste, fl. blan'hes. bécemble. R.

5̈.ّ. M. brasiliensis Triana; Fl. Bras. XTV, IV, 1) 3\%2. - Colcovado et Floresta da Tijuca, Rio-Jax., nos 1270, 7628, 8457. Arbuste, fl. blanches. Mai-juillet. C.

526. M. subvernicosa Cogn. in Fl. Bras. XIV, IV, p. 37' - Floresta da Tijuca et au Alto Macahé de Nova Frilıurgo, Rio-Jax., nos 590 , 16937, 18220. Albuste, f1. Hanches. Novembre. C.

927. M. longicuspis Cogn. in DC. Monogr. Phan. VII, p. 8.31.Nito Hacahé de Nova Friburgo, Rio-dav., n 16916. Arbuste, fl. blanchàtres. Mars-avril. R.

528. M. depauperata Garhn.: Fl. Bias. XIV, IV, p. 37\%. - Petropolis, Serra rlos Orgaos et Alto Nacalıé, lio-JAx., n ${ }^{05} 6878,8678,13854$, 16917, 18221. Arbuste, fl. llanches. Avril-mars. C.C.

929. M. petropolitana Cown. in Fl. Bras. XIV, IV, p. 613.Petropolis, à Itamaraty, Rio-Jax., $n^{\circ}$ 16021. Arbuste, fl. Hanches. Septembre. R.

:30. M. paniculata Naud.; 17. Bias. XIV, IV, p. 377. - Ilto da Serra de Nova Friburgo, $11^{\circ 5} 16913,16968$. Arbuste, fl. blanches. Arrilmai. C.

331. M. tristis Spring: Fl. Bras. XIV, IV, p. 378. - Corcovado, Floresta de Tijuca, Horro do Cavallio, Rio-Jix., nos 561, 877, 1123 , 1267, 2580, 11968, 17540. Arbuste, 1l. Hanches. Mai-juin. Vulgo : Jacatirio pequeno.

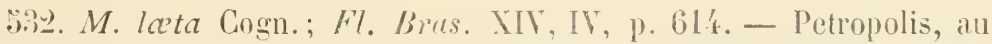
Morro Cubicado et à Serra dos Orogãos, lino-jAx., nos 16927, 16928. Arbuste, f1. blanches. Juin-juillet. C..

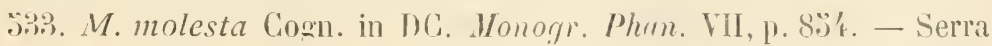
do Nlo Vacahé, Rio-Jax., $1^{\text {os }}$ 16937, 17542, 18224. Arbrisseau, fl. blanches. Janvier-février. C.

9.74. M. Candolleana Triana; Fl. Bras. XIV, IV, p. 382. - Barreira 
dos Orgios, Serta da Estrella et à Cabo lírio, Rio-Jax., nos 600, 5863, 7614, 12687. Arbre, ll. blanches. Janvier-mars. Vulgo : Jacutirão.

- Var. angustriola Cogn. in Fl. Mrus. XIV, IV, p. 383. - Floresta (lat Tijuca, Alto Nacalıé, Gavea, Rio-Jax., ${ }^{\text {os }} 2136,7615,17560$. Nibre, 11. blanches. Décembre-mars. CG. Vulgo : Jacatirão.

338. Miconia ligustroides Naud.; Fl. Bras. XIV, IV, p. 383. Barbacena, Ouro Preto, Queluz, dans le campo, Minas Geraes, $11^{0 \mathrm{~s}} 10763$, 11958, 16018, 16019; Campo do Y priranga, São Pavlo, nos 12701, 16020. Arbuste, fl. blanches. Janvier-mars. CC.

- Var. cordifolia Cogn. Fl. Bras. XIV, IV, p. 384. - Serra do Lenheiro, près S. J. d'El Rei, et Serra de Sâo José, Mrus Geraes, nos 12700, 16017; entre Morro Redondo et Barreiro do Veado, Goraz, $1^{\circ}$ 21385. Arbuste, f1. blanches. C.

536. M. minutiflora DC.; Fl. Bras. XIV, IV, p. 384. - Cantagallo, à Larangeira, Ro-Jax, $n^{\circ 5} 4923,11957$; Santa Luzia do Rio das Velhas, Minas Gemas, $n^{o s} 13436,13828$; Diamantima, $n^{o s} 19340$ a, 19341. Artrisseau, fl. blanches. Févier. C. Vulgo Jacalirão.

:37. M. lyypoleuca Triana; Fl. Brus. XIV, IV, p. 390. - Serra de Ouro Preto, Minas Geraes, no 19338. Arbuste, fl. blanches. Avril-mai. C.

:38. M. tentaculifera Naud.; Fl. Bras. XIV, IV, p. 392. - Campo de São João, près Ouro Preto, Mixas Geraes, n 19339. Arbuste, fl. blanches. Avril-mai. C.

839. M. uroplyylla DC.; Fl. Brus. XIV, IV, p. 393. - Sĩo Niguel do Barreiro, Alto Macahé, liı-JAx., $\mathrm{n}^{03}$ 8365, 17554; Itabira lo Campo, Mixis Geraes, no 16930. Arbuste, fl. blanches. Aoùt-septembre. CG.

¿40. M. Trianai Cogn. in Fl. Bras. XIV, IV, p. 39'. - Serra de São José d'El Rei, Mrxas Geraes, $u^{\circ}$ 16931. Arbuste, fl. blanches. Septembre octobre. C.

¿44. M. Reguellii Cogn.? in Fl. Brus. XIV, IV, p. 396. - Serra de Itabiro to Campo, daus le bois, Mivas, no 16929. Arbuste, fl. rousses. Septembre. C.

542. M. latecrenata Naud. : Fl. Bras. XY, IV, p. 397. - Corcovado, Tijura, Campo Grande, Sapopenloa, Serra da Estrella, etc., Rıo-Jas., $n^{0 \approx} 154,559,560,1087,1266,2575,2990,6525,8358,16933,16965$. buste, fl. blanches. Mai-aout. CG.

ว43. M. rigidiuscula Cogn.; Fl. Bras. XIV, IV, p. 398. - Floresta di Tijuca, liro-dAx., nos 593, 2576, 5859, 11967, 16003. Grand arluste, Ar fl. blanches. Avril-mai. C. 
A.-F.-M. GLAZIOU. - LISTE DES PlaNtes dU BRÉSLl CENTRAL.

̋̌44. M. hymenonervia Cogn.; Fl. Bras. XIY, IV, p. 399. - Petropolis, au Retiro, Rio-JAx., $n^{\circ}$ 1088. Arhuste, fl. blanches. Mars-avril. R.

543. M. Sellowiana Naud. in Fl. Bros. XIV, IV, p. 500. - Itatiaia,

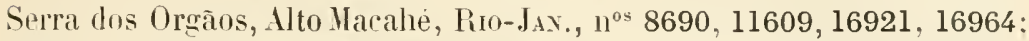
Serra de São José d'El Rei, Mrxas Gikrass, $1^{\circ}$ 16922. Grand arbuste, fl. blanches. Septembre-décembre. CC.

- Var. quintuplinervis Cogn. in DG. Monogr. Mhan. VII, p. 863. Alto Nacahé de Nova Friburgo, Rio-. dax., n 17553. Grand arbuste, fl. blanches. Septembre. C.

346. M. pusilliflora Triana; H. Bras. XIV, IV, p. 102. - Tijuca, Theresopolis et Nova Friburgo, Ruo-Jax., ${ }^{\text {os }}$ 163, 3967, 16010; Sitio de Barbacena, Mixas Geraes, ${ }^{\circ 5}$ 1095, 10766. Arbrisseau, 11. blanches. Mars-arril. C.

- Var. intermedia Cogn. in Fl. Bras. XIV, IV, p. 403. - Restinga de IIana, dans les sables, Rio-Jax., $n^{\text {os }} 8458,8459$. Arbuste, f1. blanches. Juin-juillet. C.

Ӟ47. M. pileata DC.; Fl. Bras. XIV, IY, p. 407. - Barreto, près de Nacahé et au Brejo de Imburu, Rio-Jax., nos 9826, 11955. Arbuste, fl. rougeitres. Juin-juillet. R.

348. M. ciliata DC.; Fl. Bras. XIY, IY, p. 408. - Vargem do Cupim, au bord du Rio Pizarĩo, Goraz, n 21384. Petit arhuste, fl. rougec̀tres. Janvier-février. $\mathrm{R}$.

:49. M. racemosa DC.: Fl. Bres. XIY, IV, p. 410. - Nangaratiba, près de Santa-Cruz, Rio-Jax., $n^{0 s}$ 150, 9808. Arbuste, fl. blanchâtres. Septembre. C.

\%ัu. M. paradoxa Triana: Fl. Bras. XIV, IV, p. 4H. - Dianantina, entre les rochers, Mıvas, $n^{\circ}$ 19326. Petit arluuste, fl. blanchâtres. Mars-avril. C.

\%.). M. penduliflora Cogn. in Fl. Bras. XlY, IV, p. 41't. - Petropolis. all sommet du Horro do Lietiro, Serra do Alto Macahé, Theresopolis, Ro-Jax., $11^{0 s} 588,2992,8677$. 13845, 16902, 17559. Arbuste, fl. blanches. Janvier-mars. CiC.

:30. M. cyathanthera Triana: Fl. Líras. XIV, IV, p. 417. - Serra do Palnital, Caraça, Ayuruoca et Serra de S. José d'El Rei, Mıxas Ganaes, $n^{0 \mathrm{~s}} 14779,16022,16946$. Petit arbuste, fl. blanches. Janvier-mai. C..

.933. M. dichroa Cogn. in UG. Monogr. Phan. Vll, p. 1192. - N1to Maralue dr Nova Friburgo, Rio-JAx.. no 18223. Arhuste, fl. Hanchàtres. Juillet. R. 
58̈4. Miconia conferta Cognt. in Fl. Lims. X1T, IT, p. 116. - Firenda

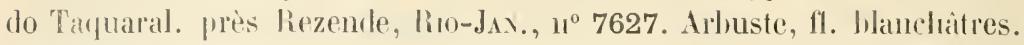
Aoùt-septembre. C.

93\%. M. inconspicua Miq. : Fl. Bres. XIT, IV. p. 4li;. - Corcovado, à Panciras, Ro-J.1.., nos 155, 575, 2909. Arluste, fi. blanches. Septembre-nctubre. C.

-- Var. lancelata Cogn. in Fl. Brus. XIV, IV, p. 415. - Floresta da Tijuca, au Baracĩo et au Alto Nacahé, lio-Jax., $11^{05}$ 10778, 17556. Arbuste, fl. hlanclies. Septembre-novembre. C.

5ั6. M. thecenalls var. paludosa Cogn. Fl. Bras. XIV, IV, p. $420 .-$ Petropolis. a Santo Antonio, Rio-Jax., nº 13856. Arbuste, fl. blanches. Janvier-mars. C.

- Var. glazloriana Cogn. in Fl. Bras. XIV, IV, p. 421. - Serra da Estrella, près de Petropolis et Serra dos Orgãos, Rı-dax., n ${ }^{\circ 5} 3958,7619$. Arbuste. fl. blanches. Décembre. C.

- Var. vulgaris Cogn. in Fl. Brels. XIV, IN, p. 伍1. - Itacoluny, Serra do Lenheiro et de São José d'El liei. Minas Geraes, nos 11973, 14773, 16016, 16912. Arbuste, ft. blanches. Décembre-janvier. CG.

5ั57. M. hivtella var. ovata Cogn. Hi. Bras. XIV, IV, p. 423. - Pouzo do Cigano, au bord du ruisseau, Goraz, n 21397. Arluste, 11. blanches. Dérembre. C.

5้8. M. gigantea Cogn. in DC. Monogr. Phan. VH, p. 937. Ariro, au Toca da Onça, Riso-JAN., nº 17548. Grand arbre, sans fleurs, en mars.

5.9. Pleiochiton crassifolium Naud.; Fl. Bras. XIV, IV, p. 425. - Petropolis, au Iorro Cubiçado, Rio-dax., $1^{\circ}$ 10760. Epiphyte, fi. rouges. Juin-juillet. C.

560. P setulosum Cogn. in Fl. bras. XIV, IV, p. 426. - Corcovado et Alto Macahé de Nova Friluurgo, Ruo-Jan., $n^{\circ}$ 589, 18234. Epiphyte. li. rouges. C.

561. P. parvifolium Cogn. in DC. Monogr. I'han. VII, p. 949. Alto Macalı́ de Nova Friburgo, Rio-JAx., $n^{\circ}$ 16947, 20314. Epiphyte, fl. rouges. Févier-n1ars. C.

56气. P. Glaziovianun Cogn. in Fl. Bras. XIV, IV, p. 426. - Serra da Estrella, Rı-JAx., nos 2998, 16031. Epiphyte, l1. rouges. Octobre-novembre. C.

563. P. micranthum Cogn. in DG. Monogr. Phan. VII, p. 950. Alto Nacahé de Nova Friburgo, Ro-JAn., nº $16947 a$. Epiphyte, fl. rouges. Décentbre. R. 
A.-F.-y. GLAZIOU. - LISTE des plaves de BRÉSIL CENTRAL.

¿6'. P. ebracteatum Triana; Fl. Bras. XIV, IV, P. 427. - Serra da Estrella, à Gruta Funda, Rı-Jax., $1^{\circ}$ 14778. Epiplyyte, fi. rouges. Aoûtseptembre. R.

¡6. Heterotrichum octonum DC. var. brasiliensis Cogn. in $\mathrm{Fl}$. Bras. XIV, IV, p. 429. - Alto Macahé de Nova Friburgo, Rio-Jas., $n^{0}$ 19342: Fazenda do Palnital, dans le bois, Goyaz, $n^{\circ}$ 21408. Arbuste, f1. blanchâtres. Mai-juin. C.

366. Tococa formicaria Mart. ; Fl. Bras. XIV, IV, p. 439. - Ponso do Cuba, prìs de l'eau et au Rasã̃o, Goraz, nos 21403, 21404. Arbuste, fl. blanc rosé. doùt-septembre. CC.

- Var. didyophysa Cogn. in Fl. Bras. XIV, IV, p. 440. - Rio Vaga Lume, près Hea Ponte, dans le bois, Govaz, n 21403. Arbuste, fl. blanc rosé. doût-septembre. C.

- Var. Gardneri Cogn. in Fl. Bras. XIV. IV, p. 440. - Entre Meia Ponte et Bernardo Lobo, Goraz, n² 21403 bis. Arbuste, fl. blanc rosé. Juillet-aouit. C.

o67. T. aristata Benth.; Fl. Bras. XIV, IV, p. 442. - Manguinhos, dans le bois humide, Rio-.dAx., n ${ }^{\circ}$ 9827. Arbuste, f1. Jlanches. Janvierfévrier. C.

气68. T. bullifera Mart.; $F l$. Bras. XIV, IV, p. 447. - Nanguinhos, dans le bois, Rio-JAx., $n^{\circ}$ 9815. Arbuste, fl. blanchâtres. Févriermars. C.

369. T. longisepala Cogn. in Fl. Bras. XIV, IV, p. 449. - Quinta de Sao Christovão, Rio-JAn., nº 13831. Arbuste cultivé, fl. blanches. Janvier-février. R.

¿70. Maieta gnianensis Aubl. : Fl. Bras. XIV, IV, p. 463. - Quinta de São Christovão, Rı-JAn., $n^{\circ}$ 8918. Arbuste cultivé, fl. blanchâtres. Janvier. R.

:TI. Clidemia tiliafolia DC.; Fl. Bras. XIV, IV, p. 472. - Chapadinlı, dans le campo, Govaz, n² 21407. Arbuste, fl. blanchâtres. Septembre-octobre. C.

Ӟ72. C. hirta D. Don: Fl. Bras. XIV, IV, p. 473. - Botafogo, Corcovado, Tijuca, Rio-Jix., $\mathrm{n}^{\text {os }} 157,9819,12695$, 16956. Arbuste, fl. rougeàtres. Juin-juillet. CC. Vulgo Pixirica.

373. C. blepharodes DC.; Fl. Bras. XIV, IV, 1) 479. - Itatiaia, dans le bois vierge, Riı-JAx., $11^{\circ}$ 6530. Epiphyte, fl. rougeâtres. Janvierfévrier. C.

รั̆4. C. parasitica 0. Berg: Fl. Bras. XIV, IV, p. 480. - Serra do 
Conto, près de Petropolis et au Retiro, Rio-JAx., $n^{0 s}$ 2997, 14802. Epiplıyte, il. rougeâtres. Mar's-avril. C.

573. Clidemia neglecta D. Don; Fl. Bras. XIV, IV, p. 483. - Corcovado, Coparabana, Ariro, Rø-JAx, nos 9451, 16957, 17264 ; Serrinha, Minas, nº 19346; Serra Negra, au Pouzo de J. Ignacio, Goyaz, nº 21409. Arbuste, fl. rougeâtres. Octobre-novembre. CC. Vulgo Pixirica.

576. C. spicata DG.; Fl. Bras. XIV, IV, p. 485. - Serra dos Orgãos et de Nova Friburgo, Rio-JAx., $11^{0 s} 6880,9814,15696,13840$. Arbuste, 11. rougeàtres. Janvier-février. C.

577. C. bullosa Cogn. in Fl. Bras. XW, IV, p. 490. - Angra dos Rios, dans la cipacira, Rio-JAx., $n^{0}$ 17565. Arbuste, f1. rougeâtres. Mars-avril. G.

878. C. rubra Mart.; Fl. Bras. XIV, IV, p. 499. - Serra do Lenheiro, près S. J. d'El Rei, Mnus Ger ues, no 16959 ; Morro do Frota, Goyaz, $n^{0} 21411$ a. Petit arbuste des campos, fl. rougeatres. Mars-avril. C.

- Var. microphylla Naud.; Fl. Bras. XIV, IV, p. 500. - Morro dos Crystaes, près Diamantina, Mixas Geraes, no $19346 d$. Petit arbuste des campus, fl. rougeâtres. R.

579. C. aphanantha Sag. in DC. Monogr. Phan. V'll, p. 1006. Carandahy, flans le bois, Mixas Genaes, $n^{\circ}$ 13834. Arluuste, fl. rougeàtres. Mai-juin. R.

580. C. capillipes Cogn.; Fl. Bras. XIV, IV, p. 509. - Entre Queluz et Carandahy, dans le campo, Mixas Geraes, $1^{\circ}$ 13826. Arbuste, fl. blanchittes. Hai-juin. C.

58 . Bellucia dichotoma Cogn.: F\%. Bras. XIV, IV. p. :314. Quinta de San Christovio, Rio-JAx., nº 9816. Arbuste cultivé, fl. blanclâtres. Fìr rier-nars. C.

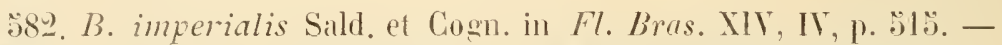
Manaos, Amazosis (legit Srlwache), $n^{\circ}$ 13830. Arbre, fl. blanchattres. Avril-mai. C.

583. Henriettea Glazioviana Cogn. in Fl. Bras. XIT, IT, p. 332. - Restinga de Maná, Rio-Jax., $11^{\circ} 8460$. Grand arbuste, fl. blanchîtres. Nai-juin. C.

- Var. verreculosa Cogn. in Fl. Bres. XIV, IT, p. 339 . -- liestinga de Maní, Ru-dax., 10 8352. Grand arbuste, fi. blanchitres. Juillet-aoùt. C.

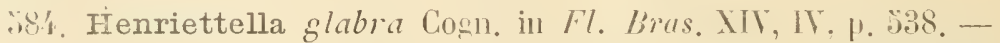
Nova Frilumeo, dans la forit, Ruo-J arbuste, ll. blanc rosé. Janvier-février. CC. 


\section{HEHOIRES PUBLIES}

1. Chrıst. Fougères de la Chine, 69 p. (mai 1905), terminé.

2. Terracciavo. Gagea du nord de l'Afrique, 26 p. (nov. 190อั), terminé.

3. Glazıou. Plantes du Brésil central, 112 p. (nov. 1905̃), à suivre.

千. Finet el Gagnepain. Flore de l'Asie orientale. 5 '́ p.; 8 pl. (I-VIII) distribuées avec la table de 190د (mars 1906), à suivre.

5. Lignier. Anatomie des Renonculacées, 38 p. (juin 1906), terminé.

3b. Graziou. Plantes du Brésil central. p. $113-200$ (juil. 1906), à suivre.

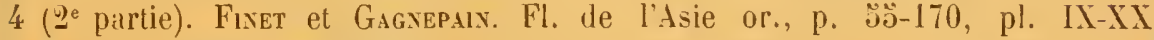
(déc. 1906), à suivre.

6. Pеrrot et Gérard. Anatomie du tissu ligneux dans ses rapports avec la diagnose des bois, 43 p.; 6 pl. (juin 1907), terminé.

7. Pitaro. Muscinées des îles Canaries, 44 p. (juin 1907), terminé.

8. Chevalier. Novitates florie africanie (1 ${ }^{\mathrm{re}}$ partie), p. 1-30 (anùt 1907), à suivre.

9. Finet. Orchidées africaines de !a tribu des Sarcanthées, 63 p.; 12 pl. (nov* 1907), terminé.

10. Fuche. Monocotylédones arborescentes ou frutescentes de France, d'Algérie ou de Tunisie, 26 p.; 1 pl. (aoùt 1907), terminé.

11. P. GuÉrin. Études sur les Diptérocarpées.

3c. Grazıou. Plantes du Brésil central, p. $201-996$ (février 1908), à suivre.

12. Hue (abbé). Lichens Tarbelliens. - Pour paraitre en 1908.

13. 0. Lignier. Le fruit des Benneltitées et l'ascendance des Angiospermes.Pour paraitre en 1908. 


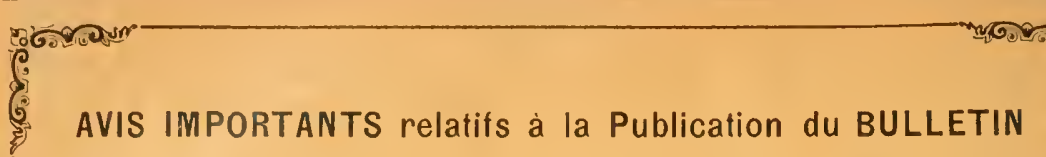

1. - Les manuscrits, rẻdigès ne varietur et lisiblement, doivent être dẻposés le jour même où sont faites les communications, faute de quoi leur impression est ajournée sans que les auteurs puissent élever de réclamation à cet égard.

11. - Si les manuscrits sont accompagnés de figures destinées á ĉtre insèrẻes dans le texte, celles-ci doivent être dessinées á la plume et au trait, ou bien au crayon Wolff sur papier procėdé, ou consister en bonnes photographies, de manière á en permettre la reproduction par les procèdés zincographiques. L'insertion dc toute figure ne pouvant être reproduite que par des procèles diffèrents reste soumise à l'approbation de la Commission du Bulletin.

111. - Les auteurs recoivent une épreuve en placards et en double exemplaire de leurs communications, la correction des autres épreuves étant faite par le Secrètariat. Les corrections doivent être retournées dans le délai maximum de trois jours au Secrétaire-rédacteur, faute de quoi la correction est faite d'office par le Secrétariat.

IV. - Lorsque les manuscrits dépassent la longueur réglementaire de 8 pages et quils ne comportent pas de question de priorité. ils peuvent être publiés sous la rubrique : Mémoires publiés par la Société botanique de France. Ces Mémoires sont éditès avec toutc la célérité possible, mais sans garantie de date. Ils prennent place dans les volumes annuels à la suite des communications insérées aux séances ordinaires et sont fournis aux Nembres de la Société sans majoration de leur cotisation.

V. - Afin de permcttre l'établissement des convocations aux séances, MM. les Auteurs sont instamment priés d'aviser le Secrétaire général huit jours á l'avance des communications qu'ils ont l'intention de présenter.

Vl. -- En vue d'assurer l'unité typographique du Bulletin, le Conseil a arrêtẻ le-protocole ci-dessous, rẻglant les caracteres employés dans les descriptions ou citations de végétaux. Il ne sera admis aucune dèrogation à cette règle.

\begin{tabular}{|c|c|c|}
\hline & NOUVELLES & ANGIENNES \\
\hline Famille. & 1. LE்GUMINEUSES. & 2. LÉGUMINEUSES. \\
\hline $\begin{array}{l}\text { Sous-Familie. } \\
\text { Tribu. }\end{array}$ & 3. Papilionacées. & 4. Papilionacées. \\
\hline Genre. & 5. MEDICAGO. & 6. Medicago. \\
\hline Espéce. & 7. Cylindracea. & 8. Cylindracea. \\
\hline VARIÉté. & 9. Laciniata. & 10. Laciniata. \\
\hline
\end{tabular}

Tout ce qui concerne ladministration de la Sociẻté doit être adressé au Secrétairc gẻnẻral à l’arlresse suivante :

11. Lutz, professeur agrégé à l'École supérieure de pharmacie, 4, avenue de l'Observatoire, Paris $\left(\mathrm{Vl}^{\mathrm{e}}\right)$.

Le Secrétaire-rédacteur, Gérant du Bulletin :

F. Camus.

Coulommiers,-- Imp. PAUL BRODARD. 
Par suite d'une erreur de l'imprimerie, le fascicule $3 d$ du Menorre Glaziou a été distribué incomplet. Il y manque les feuilles 20 et 21 qui forment le contenu du présent fascirule destiné à prendre plare en lête de colıi récemment publir.

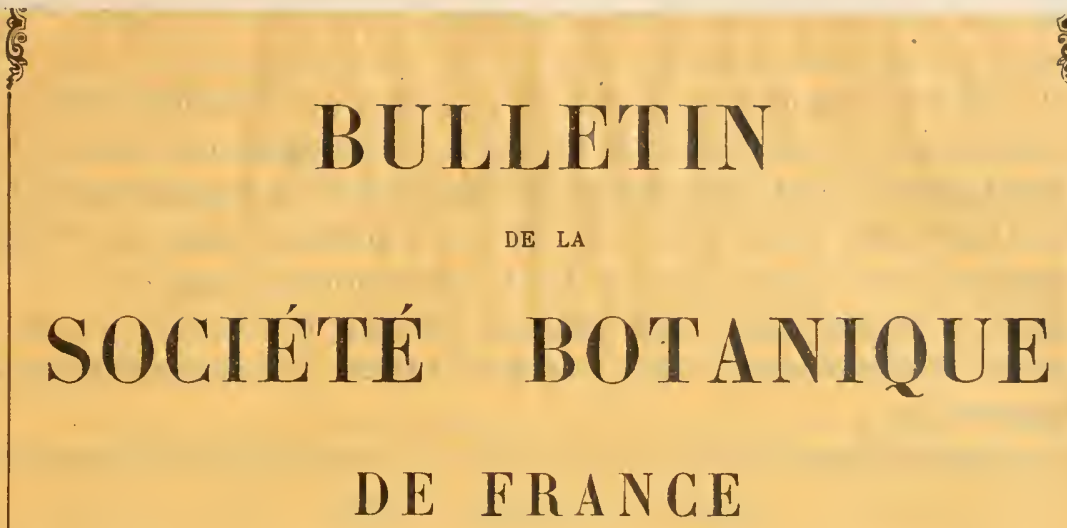

FONDÉE LE 23 AVRIL 1854

ET RECONNUE COMME ÉTABLISSEMENT D'UTILITÉ PUBLIQUE

PAR DÉCRET DU 17 AOUT 1875

TOME CINQUANTE-SIXIÈME

(Quatrième série - Tомe IX)

1909

ME MOIRES

$3 d$ 


\section{AVIS IMPORTANT}

Par suite de l'augmentation croissante du nombre des communications et de sa répereussion sur les finances de la Société, la Commission du Bulletin croit devoir rappeler à nos Confrères que le Règlement limite la longueur des manuscrits à huit pages d'impression par séance et à quarante pages pour l'année entière, au delà desquelles l'auteur doit sa collaboration pécuniaire.

Dans un intérêt commun, la Commission prie donc très instamment MI. les Auteurs de condenser le plus possible le texte des Notes destinées à l'impression.

\section{Tarif des tirages à part.}

Un tiragre sous presse de 25 exemplaires est accordè gratuitement à Mlessieurs les Auteurs qui en feront la demande en remeltant leur manuscrit. - Les Auteurs qui préfèrent des tirages à parı avec réimposition, bénélicieront en compensation d'une réduction de $3 \mathrm{fr}$. $60 \mathrm{sur}$ les prix du tarif ci-dessous

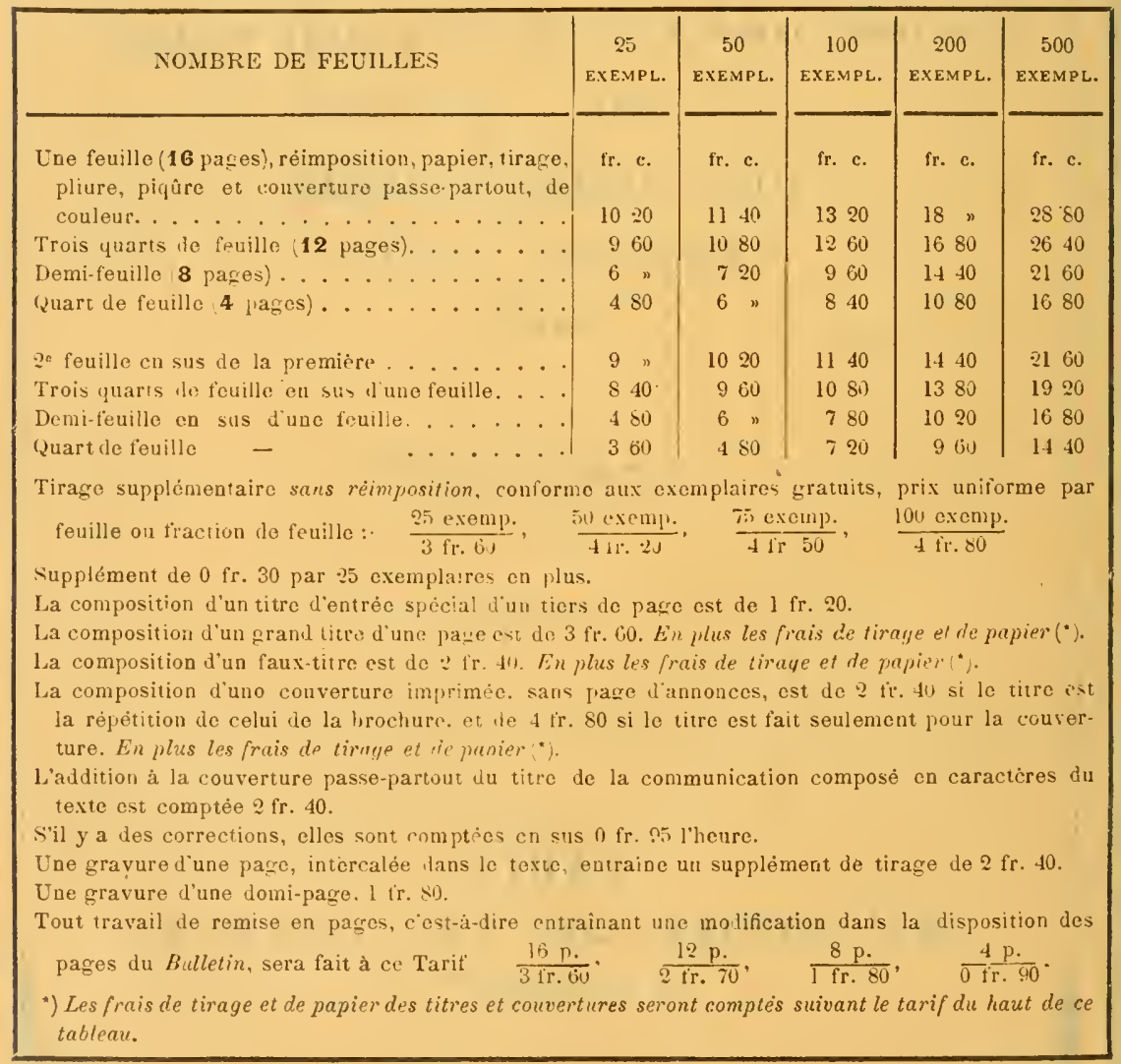




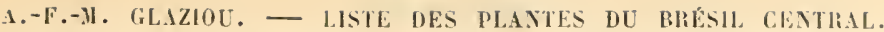

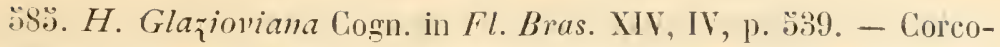
vado, à Paineiras près de l'eau, Rro-Jax., n 8684 . Grand arbuste, fl. blanc rosé. Janvier-février. C.

¿86. Ossæa angustifolia Triana; Fl. Bras. XIV, IV, p. 万̈42. Corcovado, à Caixa d'Ag̣ua. Piı-Jax., n ${ }^{\circ} 577$. Petit arbuste, fl. rougeâtres. Février-mars. C.

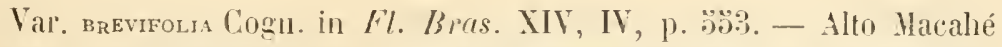
de Tova Friburgo, Rio-Jıx., nos 6883, 16949. Arbuste, 11. rougeàtres. Février-mars. C.

O87. O. brachystachya Triana; Fl. Bras. IV, IV, p. 543. - Caminho do Hacaco, Tijuca, Nlto Macahé de Nova Friburgo, Rı-Jax., nos $9450,16948,16950$. Pelit arbuste, f1. rougeâtres. Septembre-octobre. CC.

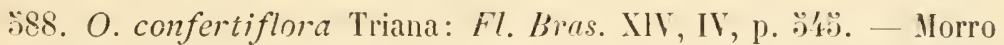
Queimado, au vieux chemin et au Corcovado, Rı-JAx., nos 16951, 16952, 16954, 16955. Petit arbuste, f1. rougreâtres. Octobre-décembre. C.

i89. 0. Gogniauxii Glaz. n. sp. in herb. Paris., Bruxell. et Berol., ined. - Serrinha de Santa Barbara, Misas Geraes, n 19324. Arbuste, fl. blanclıâtres. Arril-mai. R.

990. O. amygdaloides Triana var. ambigut Cogn. in Fl. Bras. XIV, IV, р. ॐ̆ 4 . - Petropolis, a Itamaraty, Rio-JAx., no 8682. Petit arbuste, fl. rougeâtres. Septemlıre-octobre. Ri.

:91. O. marginata Triana; Fl. Pras. XIV, IV, p. כ̌48. - Floresta da Tijuca, Rı-Jar., $n^{\circ}$ 158. Petit arbuste, fl. rougeâtres. Févrierniars. C.

992. O. congestiflora Cogn. in Fl. Bras. XIV, IV, p. \%̈3. - Serra do llhéos, près de Sitio, Jinas Geraes, nos 14789, 16023, 17569; Seria dos Cristaes, dans le campo, Goraz, no 21411 b. Petit arbuste, fl. blanchàtres. Janvier. C.

¡93. O. coriacea Triana; Fl. Bros. XIY, IV, p. 3̈3̈. - Serra de Ouro Branco et au Pico de Itabira do Campo, Misas Geraes, nos 14780 , 17570. Petit arbuste, f1. blanches. Novembre-décembre. C.

¿94. O. cimamomifolia Triana: $1 \%$. Bras. XIV, IV, p. :3̈4. - Serra de Ouro Branco, dans le campo, Hivas Geraes, no 14782. Petit arbuste, f1. blanches. Novembre-décembre. C.

:9\%. O. enphorbioides Triana: Fl. Bras. NIV, IV, p. כ̈̈̌. - Caraça, au Campo de Fora, Mixas Geraes, $n^{\circ 3}$ 14781, 19341 b. Petit arbuste, fl. blanches. Juillet. C. 
896. Myriaspora egensis DC.; Fl. Bras. XIV, IV, p. :587. - Quinta do Boa Vista, a Sĩo Christovão, Rio-JAx, $1^{\circ}$ 13833. Arbuste cultivé, 11. blanchitres. Avril-mai. R.

597. Mouriria Doriana Sald. in Fl. Bras. XIV, IV, 1. 572. - Allo Macallé de Nova Friburgo, R10-JAx., no 11959 a. Grand arbuste, fl. blanches. Janvier. R.

:98. M. Chamissoana Cogn. in Fl. Bras. XIV, IV, p. :73. - Petropolis. au bort du Rio Piabanha, Rı-Jax., $n^{\circ s}$ 14803, 18236. Grand arbre, il. blanches. Novenbre-décembre. C.

599. M. guianensis Aubl.; Fl. Brus. XIV, IV, 1. 574. - Quinta de Sào Christovão, Rı-JAN., no 11959. Arbuste eultivé, fl. blanches. Janvier-février. R.

600. M. Glazioviana Cogn. in Fl. Brus. XIV, IV, p. 580. - Praia Grande, à Jurujuba, Rio-JAx., $\mathrm{n}^{0 \mathrm{~s}} 6830,19349$. Arbre, fl. blanches. Octobre-novembre. C.

601. M. arborea Gardn.; Fl. Bras. XIV, IV, p. 587. - Petropolis, all Alto, Rio-Jax., $n^{\text {os }} 8702,13441$. Arbre, fl. blanches. Novembre-décembre. C.

602. M. Petroniana Cogn. et Sall. in Fl. Bras. XIV, IV, p. "̈88. Serra do Alto Vacahé dans le bois vierge, Rio-Jax., $n^{\circ}$ 13860. Grand arbre, tl. blanches. Novembre-décembre. C.

603. M. Pusa Gardn.; Fl. Bras. XIV, IV, p. 583. - hio das Pedras, dans les sables, Mixis Geraes, $n^{\circ}$ 19348. Arbrisseau, fl. r'oses, bon fruit, Avril-mai. C. Vulgo Mandabussa.

\section{Fam. 5i. - Lythracées.}

1. Rotala ramosior Kohue in Fl. Bras. Xll, II, p. 194. - Pmiz de Fora, dans les bourbiers, Mısas Geraes, no 3661 , Herb. fl. rose pâle. Juillet-aoùt. C.

פ. Heimia salicifolia Link et Otto; Fl. Bras. XIII, II, p. 202. P'iratymirim, près de la mer, Rio-Jas., $n^{\circ}$ 19165. Arbuste, fl. blanc jaunâtre. Janvier-février. C.

3. H. myrtifolia Ch. et Schlt.; Fl. Bras. XIIl, II, p. 202. - PiriIymirim, près de la mel', Rio-Jas., 4 janvier 1893, $1^{\circ}$ 19164. Arbuste, 11. blanchattres. C.

4. Ammania latifolia L.; Fl. Bras. XI1I, 11, p. 2066. - Piratininga, près du lac, Rı-Jax., nº 8340. Herbacé, fl. blanc jaunâtre. Juin-juillet. C.C. 
1.-K.-M. GLAZIOU. - LISTE DES PLANTES DC BRESIL CENTRAL.

3. A. arenaria H. B. K.; Fl. Brus. XIII, II, p. 206. - Lagoa de Tijuca, dans le sable humide, Rio-Jax., 10753. Herbacé, f1. blanchâtres. Vars-arril. R.

6. Cuphea fruticosa Spreng.; Fl. Bras. XIII, II, p. 249. - Nova Friburgo, Serra da Estrella, liı-JAx., nos 1157, 2989, 11951, 12682; Rio Taboca, Goraz, $n^{\circ} 21430$. Sous-frutescent, fleurs violettes. Novembredécembre. CC.

7. C. racemosa Spreg. in Engler P'flans. IV, p. I04. - Petropolis, au Alto da Imperatriz, Rio-Jax., ${ }^{\text {os }} 339,11952$. Sous-firutescent, fleurs violettes. Février-mars. CG.

Yar. tropica Cilı. et Schlt.; Fl. Bras. XIII, II, p. 2'3. - Engenho Novo, Rio-Jax., $n^{0}$ 10749. Sous-frut., fl. violet pâle. Novembre-décembre. C.

8. C. origanifolia Ch. et Schlt.; Fl. Bras. XIII, II, p. 249. Paralymirin, au pied de la Serra, Rı-JAx., n $19165 a$. Herb., fl. blanchâtres. Janvier-février. CG.

9. C. Iongiflora kiolne in Flora Bras. XIII, II, p. 246. - Campos da Bocaina, S. P.ucuo, no 8350 . Herbacé, fleur's violettes. Février-mar's. G.

10. C. repens Kohne in Fl. Bras. XIII, II, p. 2כัı. - Rio Gama, dans le marécage, Goraz, n 21435 . Herbe ramp., fl. violet pâle. Norembre. C.

I1. C. calophylla Cham. et Schlt.; Fl. Bras. XIII, II, p. 292. lio Itamaraty, sur les rochers, près de Petropolis, Rio-Jan., n ${ }^{\circ} 14698$; Itabira do Campo, Mhras Geraes, $n^{\circ}$ 16768. Frutese., fl. violacées. Maijuin. C.

12. C. mesostemon Kohne in Fl. Bras. XIII, II, p. 252. - Serra do Picú, près de Boa Vista, Rio-Jax., nº 12677 a. Sous-frut., ll. lilas. Juillet-aoùt. R.

13. C. Balsamona Cham. et Schlt.; Fl. Bras. XIII, II, p. 20ั. Corcovado et Tijuca, Rio-JAx., $n^{\circ 5} 243,340$. Sous-frut., f1. violacées. Asut-septembre. CC.

1'. C. aperta liohne in Fl. Bras. XIII, Il, p. 2ّ66. - Tijuca, Jacarepagua, Gavea, Riso-JAx., $1^{\text {os }} 341,6144,6523$. Sous-fiut., t1. violet pàle. Janvier-férrier. CC.

1̈. C. campestris Mart. in Fl. Bras. XIII, II, p. ¿6̈. - Cabo Frio, Rio-JAx, $n^{\circ}$ 10755. Herb., f1. lilas, duillet-avril. R.

16. C. strigulosa II. B. K.; Flora Bras. XIII, II, p. 257. - Barbacena, dans les bois, Mrxas, 12681. Ilerbacé, fleur's violettes. Juinjuillet. 
17. Cuphea ingrata Cham. et Schlt.; Fl. Bras. XIII, II, p. 2:8. Rio Paralịba, entre les pierres, Rio-Jav., $11^{\text {os }}$ 1597, 12677. Sous-frut.. f1. lilas. Juin-juillet. C.

18. C. thymoides Cham. et Schlt.; Fl. Bras. XIII, II, p. 260 . Ayuruoca, $\mathrm{n}^{\text {ns }} 10752$, 15954, 15955, et Serra do Lenheiro, Minas Geiraes, $\mathrm{n}^{\mathrm{os}} 15958,16767$. Sous-frut., fl. lilas rosé. Janvier-février. C.

19. C. polymorpha St. Hil.; Fl. Bras. XIIt, II, p. 26으. - Ipiranga et Mlogy das Cruz, Sĩo Pauro, $\mathrm{n}^{0 s}$ 15956, 10751, 17616. Sous-frut., fl. lilas. Février-mars. Ci.

20. C. reticulata Kohme in Fl. Bras. XIII, II, p. 27̈. - Biribury, au Mocotó, Mrxas Grnaes, no 19177. Sous-frut., fl. violacées. Mar'savril. C.

21. C. pseudericoides Kohne in Engl. Bot. Jahrb. XIII (1897), Beibl., p. 2't. - Biribiry, près Diamantina, Mrsas Geraes, $n^{\text {o. }} 19180$, $19183 a$. Sous-firut., fl. lilas. Mars-avril. C.

22. C. disperma Kwhne in Fl. Bras. XIII. II, p. 278. - Perpetua, près Diamantina, Minas Geraes, $n^{05} 19179$, 19181. Sous-frut., fl. rouges. Mars-avril. G.

23. C. acicularis Kolne in Engl. Bot. Jahrb. (1897), loc, cit, p. 22. - Guariroba, au Nlorro do Cubatão, Goraz, nº 21433. Sous-frut., fl. roses. Octohre-novembre. R.

24. C. linarioides Cham. et Schlt.; Fl. kres. XIII, II, p. 281. Chapadão de Porto Seguro, Goraz, $10^{0 s}$ 21429, 21434 a. Sous-frut., fl. rouges. Novembre-décembre. C.

25. C. Spermacoce St. Hil.; Fl. Bras. XIII, II, p. 272. - Rio Bananal, dans le c'ampo, Goraz, ${ }^{08} 21431,21434$. Sous-frut., fl. blanthâtres. Avril-mars. C.

26. C. remotifolia Kohne in Engl. Bot. Jahrb. (1897), loc. cit.. p. 느. - Rio Rasgão, lans le campo, Goraz, $n^{\circ} 21431$ a. Sous-frut., ll. violacées. Aoùt-septembre. R.

27. C. Crulsiana Kohne in Engl. Bol. Jahr. (1897), loc. cil., p. 23. - Serra dos Veadeiros, dans le canpo humide, Goraz, nº 21432. - Sous-frut., il. purpurines. R.

28. C. sperguloides St. Hil.; Fl. Bras. XIII, II, p. 278. - Curilinho, près Diamatina, Misas Geraes, $n^{0}$ 19183. Sous-frut., fl. rougeâtres. Avril-mai. G.

29. C. antisyphilitica H. B. K.; Fl. Bras. XIII, II, p. ㅛs.:- - 
A.-F-.y. GLAZIOL. - LISTE DES PLANTLS DU BRÉSIL CEXTRAL.

Carandahy, dans le campo, Minas Geraes, $n^{\circ}$ 13821. Frutescent, fl. louges. Juin-juillet. R.

31. C. patula St. Hil.; Fl. Bras. XIII, II, p. 286. - Entre Barreira et Valafunda, Misas Geraes, $n^{\circ}$ 19178. Sous-frut., fl. loose pâle. Marsavril. R.

31. C. Radula kwhne in Fl. Bras. XIII, II, p. 287. - Curalinho, près Liamantina, Mtras, $n^{\circ} 19176$; Mestre d'Armas, Goraz, $n^{\circ} 21428$. Frutescent, fl. rouges. Avril-mai. C.

32. C. glauca Pohl in Floru Bras. XIII, II, p. 288. - Mestre d'Almas, dans le campo, Goyaz, $1^{\circ} 21428$. Sous-frutescent, fleur's violacées. Novembre. C.

33. C. reflexifolia Kohne in Engl. Bot. Jahrb. (1897), loc. cit., p. 24. - Burity Vermelho, dans le marécage, Goraz, $n^{0}$ 21427. Frutescent, fl. rougeàtres. Juin-juillet. C.

3'. C. ericoides Chan. et Schlt.; Fl. Bras. XIII, II, p. 291. Entre As Datas et Diamantina, dans le campo, Mcras Geraes, $11^{0 \mathrm{~s}} 9798$, 19182. Sous-frut., fl. roses. Mars-avril. C.

Var. jumiperifolia St. Hil.; Fl. Brus. XIII, II, p. 2991. - Serra do Lenheiro, près São Joño d'El hei. Mıxas, $n^{\circ}$ 15957. Frutesc., fl. roses. Janvier-décembre. C.

33. C. flava Spreng.; Fl. Bras. XIII, II, p. 293. - Restinga de Tijuca et de Cabo Frio, Rio-J $J_{A N}, n^{\circ s} 6145,12678$. Frutesc., f1. jaunes. Septembre-octobre. r.

36. C. circceoides Smith; Fl. Bras. XIII, II, p. 29:. - Entre Infi('ionado et Caraça, dans le bois, Minas Geraes, $n^{\text {os }}$ 10756, 12679. Herbacé, fl. violettes. Juillet-août. C.

37. C. Glaziovii Kiohne in Engler Pflanz. IV, p. 159. - Serra da Bocaina dans le campo, Sĩo Pacto, $n^{\circ}$ 18219. Sous-frutescent, fleurs rouges. Février-mar's. R.

38. C. Melvilla LindI.; Fl. Bras. XII, II, p. 300. - Aldeia de Ouro Branco, dans les bourbiers, Mixas Geraes, $n^{\circ}$ 12683; Rio de Janeiro, cult., $11^{\circ}$ 9800; Chico Lobo, Goraz, $n^{\circ} 21435$ a. Frutesc., 11. rouges. Maí-aoùt. C.

39. C. micropetala H. B. K.: Fl. Bras. XIII, Il, p. 232. - Quintit de São Christovão, cult., Rı-Jar., no 10748. Frutesc., fl. jaunâtres. Mar's-avril. C.

10. C. grandiflora Pohl in Fl. Bras. Xlli, II, p. 308. - Campo 
Grande, près Mendanha, Rio-Jax., $u^{n}$ 10757. Frutescent, fl. jantuitres. Juin-juillet. R.

41. Cuphea hybogynea Kiolne in Engl. Bol. Jahrl. (18!17), loc. vil.. 1. 27. - Bandeirinha, près Diamantinil, Minas Gerafs, ${ }^{\circ} 19183$ ". Frutescent, fl. rouges. Mars-arril. R.

42. C. pubiflora Benth.; Fl. Bras. XIII, II, p. 237. - Sinta Luzia to Rio das Velhas, Muxas Geraes, $n^{0}$ 13820. Sous-fiut., fl. violet foncé. Aoùt-septembre. R.

43. Pleurophora anomala Kolne in Fl. Bras. XIII, II, p. 307. Itabapoana, aux endroits humides, Rro-JAr., $n^{\circ}$ 9799; Catas Altas aux hords des ruisseaux, Mlivas Geraes, $11^{\text {os }} 10754$, 12680, 12684, 13435, 13819. Frutescent, f1. jaunes. Mai-juin. CC.

44. Diplusodon virgatus Polı; Fl. Bras. XIII, II, p. 314. - Ipanema, dans le bois, São Paulo, $n^{\text {os }} 9420,10750,12674$; Sabara et Ouro Preto, Minas Geraes, 13818, 14701, Santa Luzia, Goyaz, nº 21421. Arbuste, fl. blanches. Février-mars. CC.

45. D. oblongus Pohl; Fl. Bras. XIII, II, p. 315. - Cachoeira da Vargem Grande, Goxaz, n² 21548. Arbuste, f1. roses. Janvier-février. R.

46. D. ramosissimus Poll var. decrpens Kohne in Engl. Bol. Jahrl. (1897), loc. cit., p. 30. - Paranaua, dans le campo, Goraz, $n^{\circ} 21414$. Arbuste, fl. roses. Arril-mai. C.

47. D. buxifolints DC.; Fl. Bras. XIII, II, p. 317. - Rio Pizarĩo, dans le campo, Goraz, n $21548 a$. Arbuste, fl. roses. Janvier-février. C.

48. D. Glaziovii Kæhne in Engl. Bol. Jahrb. .1897), p. 32. - Biribiry, près Diamantina, Mrasas Geraes, 110 19174. Arbuste, fl. roses. Février-mars. C.

49. D. marginatus Pohl; Fl. Bras. XllI, II, p. 320. - Entre Guariroba et Siriaco, dans le campo, Goraz, $n^{\circ} 21420$. Petit arbuste, fl. bleuâtres. Juillet-aoùt. CC.

50. D. rotundifolins DC.; Fl. Bras. XIII, II, p. 321. - Riocho das Varas, dans le campo, Mrisas Geraes, $n^{\circ}$ 19l66. Arbuste, fl. roses. Mar'savril. C.

51. D. sordidus Kolme in Engl. Bot. Jahrb. (1897), loc. cit., p.31. - Cachoeira da Vargem Grande, dans le campo, Goraz, n² 21426. Arbuste, fl, roses. Janvier-février. C.

52. D. glancescens DC.; Fl. Bras. XIII, II, p. 322. - Rio das Pedras, dans la Serri, Mrivas Geraes, $n^{\circ}$ 19168. Arbuste, 11. l'oses. Arrilmai. C. 
1.-F.-H. GLAZIOT. - LISTE DES PLANTES DL BRESIL CENTRAL.

53. D. orbicularis liochne in Fl. Bras. XIII, II, p. 322. - Serra do ('ipo, dans le campo, Mrxas Geraes, $11^{\circ}$ 19167. Arbuste, fl. roses. Marsavril. C.

:34. D. helianthemifolius DB.; Fl. Bras. XIII, II, J. 32ö. - Mendanha, dans le campo, Minas Geraes, nos $14700 a$, 19169. Arbuste, fl. roses. Février-mar's. C.

Var. pemphordes (DG).; Fl. Bras. XIII, II, p. 32:3. - Heudanha, dans le campo, Mixas, $1^{\circ}$ 12675. Arbuste, fleurs roses. Janvier-lévrier. C.

53. D. hexander DG.; Fl. Bras. XII, III, p. 32/. - Morro dos Gristaes, près Diamantina, Misas Geraes, nº 19171. Arluste, fl. roses. Mars-avril. C.

Var. angustrfolıus DC.; $F l$. Bras. XIII, II, p. 32̈. - Biriliry, aı Mocotó, Minas Geraes, $n^{\circ 5}$ 19172, 19175. Arbuste, fl. roses. Mars-avril. R.

56. D. humilis Kœhne in Engl. Bot. Jahrb. (1897), loc. cit., p. 33. - Corrego do Brejo, dans le campo, Goraz, $n^{0}$ 21423. Petit arbuste, fl. roses. Avril-mai. C.

57. D. hirsutus DG.; Fl. Bras. XIII, II, p. 327. - Haut de la Serra de Gandarela, Mrisas Geraes, nº 14699. Arbuste, f1. roses. Juin-juillet. G.

58. D. nigricans Kohne in Engl. Bot. Jaheb. (1897), p. 34. - Chapadon dos Veadeiros, Goraz, $11^{\circ} 21425$. Arbuste, 11. roses. Janvierfévrier. R.

39. D. villosus Pohı; Fl. Bras. XIII, II, p. 327. - Entre Formosa et Lagoa Feiá, Goraz, $n^{03}$ 21418, 21419. Arbuste, 11. roses. Férriermars. C.

60. D. lanceolatus Pohl; Fl. Bras. XIII, II, p. 329. - Rio Paranaua, dans le campo, Goyaz, n² 21414 a. Arbuste, fi. roses. Avril-mai. R.

61. D. paniculatus Koehne in Engl. Bot. Jahrl. (1897), loc. cil., p. 30. - Cabeceira do Rio Sambambaia, Gosaz, $n^{\circ}$ 21416. Arbuste, fl. roses. Août-septembre. R.

6も. D. strigosus Pohl; Fl. Bras. XIII, II, p. 331. - Entre Lage et Corumba, dans le campo, Goraz, $1^{\circ}$ 21413. Arbuste, fl. roses. Juilletaoût. C.

63. D. retroimbricatus Kohne in Engl. B'ol. Jahrb. (I897), loc. cil. p. 34. - Formosa, dans le campo, Goraz, $n^{\circ} 21417$. Arbuste, fl. roses. Novembre-décembre. $\mathbf{R}$.

64. D. villosissimus Pohl; Fl. Bras. XIII, II, p. 331. - Serra dos Ilheos, Mrnas Gerdes, $11^{\circ}$ 17617. Arlouste, f1. roses. Janvier-février. C. 
63. Diplusodon Crulsianus Kæehne in Engl. Bot. Jalub. (1897), p. 33. - Entre Rio Torto et Rio Bananal, dans le campo, Goraz, no 21415. Arbuste, fl. roses. Mai-juin. C.

66. D. microphyllus Pohl; Fl. Bras. XIII, II, p. 339. - Serra de Ouro Preto, Mrnas Geraes, nº 14700. Arbuste, 11. roses. Mai-juin. C.

67. D. pulchellus Kohne in Engl. Bot. Jahrb. (1897), loc. cit., p. 32. - Serra do Cipó, Misas Geraes, n 19173; Corrego do Brejo, dans le campo Goyaz, n² 21422. Petit arbuste, fl. roses. Février-mars. C.

68. D. rosmarinifolius St. Hil.: Fl. Bras. XIII, II, p. 339. - Calleceiras do Rio Gama, Goyaz, $\mathrm{n}^{\circ}$ 21424. Arbuste, fl. roses. OctobreNovembre. C.

69. Physocalymma scaberrimum Pohl; Fl. Bras. XIII, II, p. 343. - Entre Bemardo Lobo et Jaragua, dans les bois et les campos, Goraz, $n^{\circ}$ 21412. Grand arbre, fl. roses. Juillet-septembre. CG. Vulg. Nó ou Grão de porco, Pão rosa.

Var. angustifolum Spruce in Flora Bras. XII, II, p. 343. - Rio Manso, dans le bois el le campo, Misas, $n^{\circ} 13824$. Grand arbre, fleurs roses. Juillet-aoùt. C.

70. P. floridum Pohl in Plant. Bras. Vol. I, p. 100. - Mendanha, dans le campo, Mrvas, $n^{0}$ 9796. Petit arbre, fleurs roses. Juin-juillet. R. Vulgo : Pr̃o liosa.

71. Lafoensia Vandelliana DG.; Fl. Bras. XIll, II, p. $348 .-$ Taipú, dans les marais, Rio-JAx., $n^{\circ}$ 1361. Arbrisseau, fl. verdâtres. Mai-Juin. C.

72. L. Pacari St. Hil.; Fl. Bras. XIII, II, 1. 349. - Petropolis, au Retiro, dans la forêt, Rı-Jan., n 5857; Gandarela, Minas Geraes, $n^{\circ}$ 14702. Arbrisseau, fl. jaunàtres. Mars-arril. CG. Vulg. Pacari.

Var. petrolata Klotsch in Fl. Bras. XIII, II, p. 349. - Barbacena, dans le campo et le bois, Mixas Geraes, no 14702 a. Arbrisseau, fl. vert jaunâtre. CG. Vulgo Pacari.

73. L. replicata Pohl; Ft. Bras. XIII, II, p. 352. - São Vicente de Paulo, daus le bois, Rio-Jan, $n^{\circ}$ 10758. Arbre fl. jaune verdatre. Juinjuillet. R.

74. L. glyptocarpa Koelme in Flora Bras. XIII, II, p. 383. - Corcovado, à Paineiras, Rio-Jan., nos 9421 , 15960. Grand arbre, fleurs verdâtres. Juillet-aoùt. C. Vulgo : Lomo de São Paulo.

75. L. densiflora Pohl in Flora Bras. XIII, II, p. 33̈4. - Entre Barlacena el Queluz, dans le campo, Misas, $\mathrm{n}^{\circ} 12676$; entre Jatoba- 
sinho et As Brancas, Goraz, no 21412 a. Arbuste, fleurs ruse verdatte. doùt-septembre. CC. Vulgo: l'acari.

76. Lagerstrœmia speciosa Pers. in Engler Pflans. IV: p. 261. Passeio Publico, Rı-Jax., nº 9418. Arbre cultivé, ll. roses. Norembredécembre. CG.

77. L. indica L. in Syst. veget. ed. X, p. 1076. - Quinta de São Christorão, Rio-Jax., nº 9419. Arbuste cultivé, fl. roses. Janvier-février. C..

Fant. 5s. - Onagrariées.

1. Jussiæa tomentosa Camb.; Flora Bras. XIII, II, p. 150. - Entre Urucuia et Taboca, Goraz, $n^{\circ}$ 21438. Sous-frutescent, fleurs jaunes. Juin-juillet. R.

פ. J. Laruotteana Camb.; Fl. Bras. XIII, II, p. 150. - Ouro Pretı, près Jlarianna, Mıxas Geraes, $n^{\circ}$ 12668. Sous-frutesc., ll. jaunes. Juinjuillet. C.

3. J. elegans Camb.; Fl. Bras. XIII, II, p. 151. - Petropolis et environs, dans les endroits humides, Rio-Jas, $\mathrm{n}^{\text {os }} 242,688,8345,8674$. Sous-frutese., fl. jaunes. Avril-mai. CG.

4. J. peruviana L.; Fl. Bras. XIII, II, p. 1öl. - Petropolis, au Retiro, Rio-Jax., no 8675; Ouro Preto, Mrinas Geraes, no 19161. Frutescent, fleurs jaunes. Mars-avril. C.

๖. J. anastomosans DG.; Fl. Bras. XIII, II, p. 133. - Campo de São João, près de Ouro Preto, Minas Geraes, $n^{\circ}$ 14705. Arbrisseau, f1. jaunes. Janvier-février. R.

6. J. myrtifolia Camb.; Fl. Bras. XIII, II, p. 15้4. - Entre Sitio et Barbacena, dans Ie bourbier, Misas Geraes, nº $10746 a$. Frutescent, fl. jaunes. Maii-juin. R.

7. J. sericea Camb.; Fl. Bras. XIII, II, p. 154. - Cachambú, près de Baependy dans les bourbiers, Minas Geraes, nos 10747, 15951, 15952. Sous-frutesc., fl. jaunes. Janvier-février. CC.

8. J. nervosa Poir.; Fl. Bras. XIII, II, p. 15̌ò. - Villa Nova, R1o$J_{A x}, n^{\circ} 11950$; Barbacena et environs, Misas Geraes, $n^{0 s} 10746,12671$, 13816, 14704, 15953, 19162; Corrego do Brejo, Gosaz, 21439. Frutescent, fl. jaunes. Nars-avril. CC.

9. J. longifolia DC.; Fl. Bras. XIII, II, p. 136. - Floresta de Tijuca, Rio-Jax., no 2988; São João d'El Rei, Mlixas Geraes, nº 15950. Sousfrutesc., fl. jaunes. C. 
10. Jussian Burchellii Hich.; Fl. Bres. XIII, II, p. 168. - Entr" Sitio et Babbacena, Misas Geras, no 15949. Arbuste, 11. jaunes. Janvierfisiver. R.

11. J. sedoides II. B. K.; Fl. Bras. XIII, II, p. 1:88. - Purto we Jequitiba, dans le lac, Mnvas Gerazs, $n^{\circ \mathrm{s}} 13814$, 19163. Herbacé, fleurs jaunes. Mars-avril. C.

12. J. inclinata L. P.: Fl. Bras. XIII, II, p. 159. - Campos de Caraça, dans l'eau, Mrvas Gerues, $n^{\circ}$ 13815. Herbacé, H. jaunes. Aoùtoctobre. C.

13. J. Potamogeton Burch.; Fl. Bras. XIII, II, p. 159. - Varianna, près Ouro Preto, dans les bourbiers, Minas Geraes, $n^{\circ} 12673$. Herb. fl. jaunes. Juillet-octobre. CC.

14. J. decurrens DC.; Fl. Bras. XIII, II, p. 160. - São João da Barra, près Campos, Ro-Jax., nº 9795. Herb. 11. jaunes. Févriermars. C.

15. J. erecta L.; Fl. Bras. XIII, II, p. 160. - Intonio Pereira, dans les bourbiers, Mivas Geraes, $n^{\circ} 12672$. Herbacé, 11. jaunes. Mai-juillet. C.

16. J. goyazensis Glaz. n. sp. in herb. Paris., Berol., Kew., Genev., etc. - Tijuca, dans les bourbiers, Goyaz, nº 21442. Herbacé, fleurs jaunes. Aout-septembre. R.

17. J. pilosa H. B. K.; Fl. Bras. XIII, p. II, p. 164. - Entre Fornos et Meia Ponte, dans les bourbiers, Govaz, ${ }^{\text {os }} 21440,21441$. Herb. fl. jaunes. Aoùt-septembre. C.

18. J. repens L.; Fl. Bras. XIII, II, p. 166. - São Francisro de Paula, sur l'eau, Rı-JAx. nº 10742 . Herbacé, fl. jaunes. Janvier-février. C.

19. J. suffruticosa L.; Fl. Bras. XIII, II, p. 169. - São Christovão et Petropolis, dans les bourbiers, Rio-Jax., $n^{09}$ 689, 5403, 6710, 8346, 8347. Sous-frut., Il. jaunes. Juillet-octobre. CG.

Forma glabra Fl. Bras. XIII, II, p. 170. - Petropolis, Rio-Jan., $\mathrm{n}^{\circ}$ 10743. Sous-frut., fleurs jaunes. Août-septembre. C.

90. J. octonervia Lamk; Fl. Bras. XIII, II, p. 170. - São Christovão et Petropolis, dans les bourbiers, Rı-JAN., n ${ }^{03} 687,8673,10744$, 10745 ; Carandahy, mème station, Mrsas, $1^{0 s} 12669$, 12670, 13817. Herb. fl. jaunes. Mlai-septembre. CC.

21. Fuchsia integrifolia Camb.: Fl. Bras. XIII, II, p. 174. Petropolis, dans la forèt, à Itamaraty, Rı-JAx., ${ }^{\circ s} 3733,8676$. Frutesrent, sarmenteux, fl. rouges. Mars-mai. CC.

22. F. montana Camb.; Fl. Bras. XIII, II, p. 178. - Ilaut de l'Ita- 
tiaia, dans le bois, $1^{\text {os }} 4801,6522,15948$, et à Nova Friburgo, Rı-Jax., $n^{\circ}$ 12667. Frutesc., fl. louges. Janvier-mars. C.

23. F. pubescens Camb.; Fl. Bras. XIII, II, p. 176. - Itacolumy, prés douro Preto, Mrsis Geliass, nº 14703. Frutescent, fl. rouges. Janvier-mars.

24. F. Glazioviana Taub. in Engl. Bol. Jahrb. (1892), p. 10. Alto Macalıé de Nova Friburgo. dans la forèt, Riı-Jax., $1^{\circ}$ 17614. Frutescent, fl. rouges. Juillet-Août. C.

93. Enothera mollissima L.; Fl. Bras. XIII, II, P. TT. - Petropolis, it Villa Thereza. Rio-Jax., $n^{\circ} 8344$. Herb. fl. jaunes. Janvierfévirier. C.

26. OE. Glazioviana Mich. in Fl. Bras. XIII, II, p. 178. - Floresta de Tijuca, près des ruisseaux, Rı-JAx., nº 2568, 8343. Herlo. fl. jaunes. Février-mars. CC.

27. CE. rosea dit. in Horl. Kew. I, p. 3. - Petropolis, au bord des chemins, Rio-JAx., nos 8342,17615 . Herb. fl. roses. Janvier-mai. CC.

\section{Fam. 59. - Samydacées.}

1. Casearia oblongifolia Camb.: Flora Bras. XIII, I, P. 463.Tijuca, Corcovado, Santa Cruz, Gravea, etc. Rro-lax., nos 2101, 2565, 7515, 7516, 10250. Arbrisseau, fleurs blanchâtres. Janviel-mars. CC.

2. C. parvifolia Willd.: Fl. Bras. XIII, I, p. 467. - Paineiras, au Corcovado, Rio-Jax., $n^{\circ}$ 6198. Grand arbre, fl. blanchâtres. Septembreoctobre. C.

3. C. lasiophylla EichI. in Fl. Bras. XIII, I, p. 468. - Floresta de Tijuca, Rio-Jax., $7^{\circ} 2896$ a. Arbuste, fl. blanchàtres. Février-mars. C.

4. C. pauciflora Camb.; Fl. Bras. XIII, I, p. 471. - Corcovado, Tijuca, Praia Grande, au Barreto, Rio-JAx., n ${ }^{\text {os }}$ 2564, 2711, 6200, 8565. Arbuste, f1. blanchàtres. Février-mars. CC. Vulg. : Naria Pedreda.

5. C. microphylla Eichl. in Fl. Bras. XIII, I, p. 47' - Cabo Frio, Riro-Jax., $n^{\circ}$ 10245; Quartel de Biribiry, Mıxas Geraes, nº 18853. Arbuste, 11. blanchâtres. Mars-aviil. C.

6. G. ferruginea Briq. in herb. Paris., Berolin., ined. - Entre Sitio of Barbacena, dans le campo, Mıxas Geraes, $n^{0}$ 13529. Mrisseau $f 1$. blanchàtres. Décembre-Janvier. C.

7. C. Cambessedesii Eichl. in Fl. Bras. XIII, 1, p. 475. - Petropolis, à Santo Antonio, Rio-JAx., $n^{\circ} 2896,8266,8267$. Arlıriss., f1. Blanchâtres. Septembre-octobre. CC. 
8. C. brasiliensis Eichl. in Fl. Buas. XIII, I, p. 477. - Corcovalo, Tijuca, Gavea, Rio-Jan., nos 845, 848, 2562, 8567. Arbriss., ll. lilanrhàtres. Octolrr-Novembre. CG.

9. C. grandiflora St. Ilil.; Fl. Bress. XIII, I, p. 479. - Horro lo Coco ou do Bahù et près d'Itabapoana, Pio-Jax., n ${ }^{\circ}$ 9613, 9615, 10244, 13525. Arbriss., fl. blanchâtres. Décembre-Janvier. C. Vulgo : Cascaria .

Var. oвтusifolia Eichl. in $\mathrm{Fl}$. Bras. XIII, I, 1. 479. - Entre Alexandre et As Antas, dans le campo, Goraz, $n^{\circ} 21443,21444$. Petit arbuste, fl. blanches. Aout-octobre. CC.

10. C. incequilatera Camb.; Fl. Bras. XIII, I, p. 480. - Corcovado, Nova Frihurgo, etc., Rio-J $\mathrm{Jx}_{\mathrm{x}}, \mathrm{n}^{\text {os }} 4205,6866$, 8566. Arbriss., fl. blanchâtres. Janvier-mars. CC.

11. C. sylvestris Swartz; Fl. Bras. XIII, I, p. 481. - Gavea, Cor* covado, Itapuca, Rio-J $J_{A x}, n^{\text {os }} 1111,1389,3645,5804,6469,10246$, 12421 ; Fazenda de Sant'Anna, Minas Geraes, ${ }^{\text {os }} 3644,13527$. Arbriss., fl. blanchâtres. Juillet-août. CG. Vulg. : Pão de Lagato.

- Forma Lingua (Camb.); Fl. Bras. XIII, I, p. 482. - Inficionado, dans le bois, Mnxas Geraes, $n^{05} 12421$, 13528. Arbriss., fl. blane jaunâtre. Juillet-août. C. Vulg. : Folha de Tiú.

- Var. campestris Eichl. in Fl. Bras. Xlit, I, p. 482. - Antonio Pereira, dins le bois, Minas Gieraes, $n^{0 s} 13526,14479,10249$. Arbriss., fl. blanchâtres. Octobre-décembre. Vulg. : Päo de Lagasta, Folha de Tiú.

12. C. Glaziovii Briq. n. sp. in herb. Paris., Berolin. ined.? - Alto Macahé de Nova Friburgo, dans la forèt, Rıo-Jax., $n^{0 s}$ 133404, 18852. Arbriss., fl. blanchâtres. Novembre-décembre. C.

13. C. Selloana Eichl. in Fl. Bras. XIII, I, p. 483. - Praia de Maria Angí, Rio-Jan., no 8268. Arbriss., fl. blanchâtres. Septembre. R.

14. C. javitensis H. B. K.; Fl. Bras. XIII, I, p. 484. - São João da Chaparla, dans le campo, Misus, $\mathrm{n}^{0}$ 14480. Arbriss., fl. blanchâtres. Aoùt-novembre. R.

15. C. densiflora Benth.; Fl. Bras. XIII, I, p. 488. - Serra do Inficionado, dans le campo, Mivas Geraes, no 13530. Arbuste, fl. blanchâtres. Octobre. C.

16. C. Commersoniana Camb.; Fl. Bras. XIII, I, p. 487. - Corcovado, Gavea, Serra da Estrella, Rio-JAx., $1^{05} 1507,1510,2907,8564$, 10243. Arbuste, ll. blanchâtres. Aoùt-septembre. CC.

17. Banara parviflora Benth.; Fl. Bras. XIII, I, p. 498. - Serra 
A.-F.-Y! GLAZIOU. - LISTE DES PLANTES DU BRĹSIL CENTRAL.

da Estrella, Rio-J.s., $n^{0 s} 6087$, 7513. Arbriss., fl. jaunes. Janvierfévier. CC.

18. B. brasiliensis Benth.; Fl. Bras. XIII, I, p. 499. - Lagoinha, au Corcovado. Rio-Jax., nos 2920, 2921, 10253. Arbriss., fl. jaunes. Février-mars. C.C.

19. B. Vello ii Gardn.: Fl. Bras. XIII, I, 1. 5000. - Fazenda de Sant'Anna, près de Juiz de Fora, Mrsas Geraes, no 7514. Arbriss., f1. jaunes. Janvier-févier. C.

20. B. guianensis Aubl.; Fl. Bras. XIII, I, p. 500. - Quinta de São Christovĩo, Liı-JАx., $1^{\circ}$ 10248. Arbrisseau cultivé, 11. jaunes. Marsavril. R.

2i. Abatia tomentosa Mart. in Fl. Bras. XIII, I, p. 509. - Tripuhy, près d'ouro Preto, Mras Geraes, n² 20253. Frutesc., 11. jaunes. Janvier-décenbre. C.

22. A. americana Eichl. in Fl. Bras. XIII, I, p. J̈10. - Serra dos Orgãos, all sommet, Rio-JAx., $n^{\circ s} 2889$, 3999. Frutesc., fl. jaunâtres. Aoùt-septembre. R.

23. A. microphylla, Taub. in Engler Bol. Jahrb. XV (1892, Beibl., p. 11. - Pedra do Conego, à Nova Friburgo, Rio-J.1x., no 12179. Frutesc., fl. jaunes. Mai-j uin. R.

24. Homalium densiflom Benth.; Flora Bras. XIII, I, p. 506. Lagoa de Feitas, à Tres Vendas, Rı-JAx., n 13523 a. Arbrisseau cultivé, fleurs blanchâtres. Janvier-février. R.

9.0. H. pedicellatum Benth.; Fl. Bras. XIII, I, p. :008. - Quinta de São Christovão, Rı-Jas., $n^{\circ}$ 13523. Arbrisseau cultivé, fl. blanchâtres. Février-mars. P.

\section{Fam. 60. - Loasacées.}

I. Sclerothrix fasciculata Presl; Flora Bras. XIII, III, p. 204. Conceição, près Lagoa Cambello, Riı-Jax., $n^{0}$ 10876. Herbacé, fleur's jaunâtres. Février-mars. Ii.

2. Loasa parviflora Schrad.; Fl. Bras. XIII, III, P. 209. - Corcovado, Jurujuba, sur les rochers, Rio-JAx., nos 193, 8317, 12025, 14856. Herb., 11. blanc-jaunàtre. Janvier-mars. CC. Vulg̨o. : Cansancão.

3. Blumenbachia urens Url. in Fl. Bras. XIII, III, p. 213.

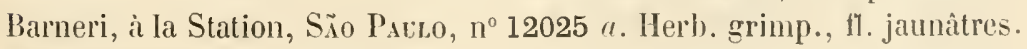
Mars-arril. R. 
1. B/umenbachic aspera Urb. in Fl. Bras. XIII, III, 1. 221.-Bords de Lagoa de Cambello, lio-JAx., $1^{0}$ 10875. Herb., fl. jauntitres. Févier-mal's. R.

\section{Fam. 61. - Turneracées.}

1. Piriqueta sidifolia Lrb. val. genurna in Fl. Br. XIIII, III, 1. 92. - Sino Juĩo da Barra, près Campos dans les capoeiros, Rio-Jan., $1{ }^{\circ} 9853$. Sous-frutescent, fleurs jaunes. Mars-avril. C.

- Var. multiflora in Fl. Bras. XIII, III, p. 92. - Serra da Mantiqueira, à João Gomos, Mısis, ${ }^{\text {os }} 10884,10885,19310$. Frutese., ll. jaune pàle. Septembre-octobre. C.

- Var. ignatil ill Fl. Bras. XIII, III, p. 92. - Fazenda da Cava, près du Morro da Canastra, Goyaz, no 21459. Frutesc., fl. jaune pâle. Norembre décembre.

2. P. viscosa (iriseb.; Fl. Bras. XIII, III, p. 99. - Jurujuba, près de la mer, Rio-Jax., n ${ }^{0}$ 6854. Herh., ll. blanchâtres. Novembre-décembre. C.

3. P. aurea Unb. in Fl. Bras. XIII, III, p. 100. - Campos da Bocaina, dans les endroits pierreux, S. Paulo, n" 5515 a. Sous-frutesc., 11. jaunes. Février. C.

4. P. nitida Urb. in Fl. Bras. XIII, III, p. 101. - Serrinha de Santa Barbari, Mryas feraes, $n^{\circ} 19395$ a. Sous-frutese., fl. jaunes. Mai. R.

ร. P. cistoides Mley.; Fl. Bras. XIII, III, p. 104. - Entre Mambucaba el Serra do Frade, Rro-Jax., no 13915 b. Herb., fl. jaunes. AvrilIlai. R.

6. Turnera serrata Vell.; Fl. Bras. XIII, III, p. 116. - Corcovado, à Caixa d'Agua et à Larongeiras, Rı-Jax., nos 192, 226, 1340, 3751. Frutesc., [1. jannes. Arril-mai. CG.

- Var. Schwacker. - Petropolis, dans le bois, a Itamalraty, Rio-Jan., $11^{\circ} 14857$; Hogy das Cruzes, S⿱艹 Avril-mai. li.

7. T. Glaziovii Urb. in Flora Bras. XIII, III, p. 117. - Serra de Itabajoana, Espritro-Saxto, $n^{\text {os }} 9852,9857$. Frutescent, fleurs jaunes. Novembre-décembre. R.

8. T. brasiliensis Willd.; Fl. Bras. XIII, III, p. 118. - Rio-Janeiro, cultiré, $11^{\circ} 9854$ : près de Jaragua, dans le bois, Goyaz, $11^{\circ} 21445$. Arbuste, fl. jaunes. Juillet-aoùt. C.

9. T. acuta Willd.; Flora Bras. XIII, III, p. 120. - Serra da Mantiqueira, Mıxas, $n^{\circ} 13915$. Frutescent, fleurs jaumes. Janvier-février. R. 


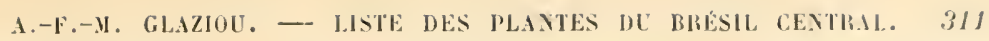

10. T. dolichostigma Uib.? in Flora Bras. XIlI, III, ए. 128. Biribiry, près Dianantina dans le campo, Mras, $n^{\circ}$ 19389. Sous-frutesrent, fleurs jaunes. Mars-avril. C.

11. T. Hilaireana Lrb. var. laxceolata in Fl. Bras. XlII, III, p. 130. - Ilabira do Campo, Mris Geraes, nos 17014, 18259; Mestre d'Armas, Goraz, n² 21452, 21453. Sous-fritesc., 11. jaunes. Septembre-novembre. CG.

- Vill. oblongrfolia in Fl. Bras. XIII, III, p. 131. - Curalinho, Misas Geraes, $1^{\circ} 19390 a$. Serra dos Veadeiros, Goraz, $1{ }^{\circ}$ 21454. Sous-frutesc., f1. jaunes. Janvier-février. C.

- Var. mnor Urb. in Fl. Br. XIlI, III, 1\% 131. - Entre Sitio et Barbacena dans le campo, Miras, $1^{0}$ 9617, 9618. Sous-frutescent, fleur's jaunes. Février-mars. C.

12. T. Crulsii Uib. in Engl. Bot. Jahrb. XXY (1898), Beibl., 1. 6. Entre Cihico Costa et Cabeceiras do Rio Torto, Goyaz, n² 21448. Herb. vivace, fl. d'un beau jaune. Octobre-norembre. C.

13. T. foliosa Urb. in Engl. Bot. Jahrl. (1898), loc. cil., p. ॐ.- Entre Burity Vermelho et Vargem daus le campo pierreux, Goraz, $n^{0}$ 21450. Frutesc. ll. jaunes. Juin-juillet, C.

1't. T. tenuicaulis Urb. in Engl. Bot. Juhrb. (1898), loc. cit., p. †. - Serra dos Cristaes, dans le campo pierreux, Goyaz, n² 21447. Frutescent, fl. jaunes. Septembre. R.

15. T. melanorrhiza Úrb. in Engl. Bot. Jahrb. (1898), loc. cit., p. 7. - Serra dos Pyreneus, dans le campo, Goraz, $n^{\circ}$ 21449. Frutescent, 11. jaunes. Septembre-octobre. R.

16. T. subnuda Urb. in Engl. Bot. Jahrb. (1898), loc. cit., p. \&. - Entro Sirraco et Guariroba, dans le campo pierreux, Goraz, $1^{\circ} 21446$. Frutescent, 11. jaunes. Aoùt-septembre. C.

17. T. pinifolia Cann.; Fl. Bras. XIII. III, p. 134. - Cacloeira do Abbade, dans le campo, Goraz, $n^{\circ} 21460$. Frutescent, 11. jaunes. Aouttseptembre. $\mathrm{C}$.

18. T. genistoides Camb.; Fl. Bras. XIII, III, p. 133̈. - Diamantilla, au Tombador, Mrsis Geraes, no 19391. Frutest., fl. jaunâtles. Marsarril. C.

19. T. armata Urb. n. sp. in herb. Paris., Perol. ined. - Hacacos, an Ilorno dos Cristaes, Goraz, $1^{\circ} 21451$. Frutesc., fl. jaunes. Octobrenovembre. $\mathbf{C}_{\text {. }}$.

20. 7'. melochioides Camb.; Fl. Bras. XIII, III, 1). 136. - Horro 
do Coco ou do Bahı́, Rino-Jav., $11^{\text {os }} 10299$, 10879. Frutescent, fl. jaumes. Décembre.

- Var. oblongholia in Fl. Bras. XIII, III, p. 137. - São Fidelis, près de campos, lio-Jax., $1^{\circ 5}$ 9649, 9656. Frutescent, ll. jaunes. Janvierfévrier. C.

21. Turnera opifera Nart.; Flora liras. XIII, III, p. 138. - Gandarela, dans le bois, Misis, $1^{\circ}$ 13913. Sous-frutescent, fleurs jaunes. Juin-juillet. C.

2y. T. lamiifolia Camb.; Fl. Bras. XIII, III, p. 139. - Entre Nexandre et $\Lambda$ s Antas, dans les campos, Goyaz, $n^{0}$ 21458. Frutescent, fi. jaunes. Juillet-août. CG.

23. T. discolor Urb. in lerb. Paris., Berol. ined. - Curalinho, pris Diamantina, Misas Geraes, nº 19396. Frutescent, ll. jaunes. Mars-avril. R.

24. T. incana Camb.; Fl. Bras. XIII, III, p. 140. - Cabeceiros du Rio St-Anna, près Cavalcante, Goyaz, $\mathrm{n}^{\text {os }} 21456,21457$. Petit arbuste, fl. blanches. Janvier-mars. C.

23. T. longiflora Camb.; Fl. Bras. XIII, III, p. 141. - Rio Areas, dans le campo, Goraz, $n^{\circ}$ 21455. Frutescent, fi. rouge pourpre. Septembre-octobre. CC.

26. T. odorata Tich.; Fl. Bras. XIII, III, p. 143. - São Joũo da Barra, près Italıapoana, Rı-Jax., $n^{0 s} 9646,9855,10880$. Frutesc., 11. jaunes. Février-mars. C.

27. T. Eichleriana Urb. 11. sp. in herb. Paris., Perol., Kew., Brux., etc. - Serro do Caraça, dans les bois, Minas, $n^{\circ} 13915 a$. Sous-frutesc., fleurs jaunes. Octobre-novembre. C.

28. T. anmularis Urb. in Fl. Bras. XIII, III, p. 144. - Jurujuba, près de la mer, Rio-Jan., no 6812 . Frutesc., ll. jaunes. Novembre-dérembre. C.

29. T. hebepetala Uıb. in Fl. Bras. XIII, III, p. J4T. - São Fidelis, près de Campos, Run-JAN., $n^{0}$ 9802. Petit arbuste, fl. blanchâtres. Février-mars. R.

30. 7. calyptrocarpa Urb. in Fl. Bras. XIII, III, p. 148. - Serra da Mantiqueira, Mras Geraes, $n^{\circ}$ 10877. Frutese., fl. jaunes. Aoùt-septembre. C.

31. T. chamadryfolia Camb.; Fl. IBras. XIII, III, p. 149. - Fazenda do Morro Azul, dans le bois, São Paulo, $11^{\circ} 12743$; Caraça, Mrxas Gemaes, $1^{\circ} 13914$. Frutesc., fl. jaunes. Hars-avril. C.

32. T. capitata Camb.; Fl. Bras. XIII, III, p. 133. - Itabira do 
A.-F.-M. GLAZIOC. - LISTE IDS PDLATES DU BRÉSIL CEYTRAL.

Campo, dans le bois, Mlixas Giries, $n^{n s}$ 17621, 18260. Frutesc., 17. jaunes. Décembre. C.

33. T. dichotoma Gardn.; Fl. Bras. XIII. III, p. 156. - Biribiry, près Diamantina, Noxas Geraes, nos 18338, 19395. Petit arbuste. I1. blanchatres. CG.

- Var. stenophyeta Urb. in herb. Paris., Berol. - Biribiry, près Dianantina, dans le campo, Mhxas Geraes, $1^{n}$ 19393. Frulescent, 11. blanchâtres. Mars avril. C..

34. T. revoluta Urlo. n. sp. in herh. Paris., Berolin. ined.? - Serra da Mangabeira, dans le eampo, llixas Geraes, $n^{\circ}$ 19392. Frutesc., fl. jaunâtres. Avril-mai. R.

3. T. Schwackeana Urb. n. sp. in herl. Paris., Berolin. ined.? - Serra da Mangabeira, dans le campo, Mlixas Gerses, n 19394. Frutesc., fi. blanchâtres. Arril-mai. C.

36. T. ulmifolia L. var. cuneıforms Urb. in Fl. Bras. XIII, III, p. Lö9. - Restinga de Copacabana, Rio-JAx. $11^{05} 35,3812,5515$ b, 10878, 10882. Frutescent, fl. jaunes. Juillet-septembre. CC.

37. Dilkea Glaziovii Mast. n. sp. in herl. Lond. et Berol. ined.? Lagoa dos Peixes, dans le bois, près Cabo Frio, Rı-Jax., nº 12741. Arluste sarment., fl. Llanclies. Septembre-octobre. R.

\section{Fam. 62. - Passifloracées.}

1. Passiflora Mansoi Mast. in Fl. Bres. XIII, I, 1. 579. - Corcovado, au Caminho do Enforcado et à Tlieresopolis, Riı-Jax., II" 3993, 6089, 14852. Sarment., fl. blanchâtres. Septembre-octobre. C.

๖. P. platystyla Mast. n. sp. in herb. Paris., Kew. et Berol. ined.? - Nora Friburgo, au Suspiro, liro-Jax., $n^{\circ}$ 13454. Sarment., fl. Llanches. Novembre. C.

3. P. costata Mast. in Fl. Bras. XIII, I, p. :73. - Quintas de São Christovão, cultiv., Rin-IAx, $n^{0} 13912 a$. Sarment., fl. blanc jaunâtre. septembre-octobre. R.

4. P. elliptica Gardn.; Fl. Bras. XIII, I, 1. 574. - Larangeiras. Rio-Jax., $n^{\circ}$ 18258. Sarment., fl. blanches. Novembre-décembre. C.

¿. P. rhaminifolia Mast. in Fl. Bras. XIII, I, p. 578̈. - Floresta de Tijuca, Pedra do Archer, Riro-Jax., $11^{\circ}$ 17620. Sament., M. blanches. Février. (..

6. P. oyalis Vell.; Fl. Bras. XIII, I, 1. fog2 (Telrastylis monlum 
Barb. Rodr.). - Gavea et Vista Chinez, Rio-JAN., $n^{\text {os }} 7859$, 14854. Sillment., fl. rose pâle. Août-septembre. C.

7. Passiflora suberosa L.; Fl. Bras. XIII, I, 1. 878 . - Serra do Tingua, Rı-Jax., 5875 a. Sarment., fl. olivâtres. Juillet-aonit. C.

- Var. hederacea Mast. in Fl. Bras. XIII. I, p. 579. - Pedregullia, dans le bois, Rro-JAx., $n^{\text {os }} 5875,21461$. Petite liane, fl. verdâtres. Juinjuillet. C. Vulg. : Maracuja mirim.

8. P. villosa Vell.; Fl. Bras. XIII, I, p. こ̌81. - Sete Pontes, au Barreto, dans les haies, Nova Friburgo, mème station, Rı--JAx., $n^{08} 4818$, 18255, 20334. Petite liane, fl. verdàtres. CG.

9. P. fatida L.; Fl. Bras. XIII, I, p. 582. - Praia Grande, au

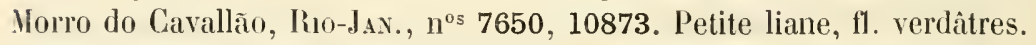
Aoùt-septemlire. C.

10. P. capsularis L.; Fl. Bras. XIII, I, p. こ\$9. - Floresta da Tijuca et Corcovalo, Rio-JAx., $\mathrm{n}^{\text {os }} 3990,10871$. Petite liane, fl. violacées. Novembre-décembre. C. Vulg. : Maracuja minda.

11. P. organensis Gardn.; Fl. Bras. XIII, I, p. 890. - Alto Hacalıé de Nova Friburgo, liı-Jax., $n^{0}$ 18254. Petite liane, fl. violacées. Octobre-Novembre. C.

12. P. Maximiliana Bory; Fl. Bras. XIII, I, p. :92 (P. cabelensis Barb. Rodr.). - Sorra da Mantiqueira, Mixas Geraes, no 10871 a. Petite liane, hl. blanchâtres. Septembre. R.

13. P. poroplyzlla Vell. in Fl. Flum. vol. IX, tab. 82. - Restinga de Cabo Frio, Rio-JAx., $1^{\circ}$ 12742. Petite liane, 11. verdâtres. Septembreoctobre. C.

14. P. alata Ait.; Fl. Bras. XIII, I, p. 896. — Campos, au Collegio et à Tijuca, Riro-Jax., nº 6549. Grande liane, fl. bleu rosé.. Février-mars. CG. Vulg. : Naracuja.

13. P. Miersii Mast. in Fl. Bras. XIII, I, p. 599. - Serra do Tingua, au Rio d'Ouro, Rı-dax., $11^{\circ} 6551$ a. Petite liane, ft. violacées. Mai-juin. R.

16. P. glandulosa Cav.; Fl. Bras. XIII, I, p. 600 (Tacsonia coccinea Barb. Rodr.) - Quinta de Sào Clıristovão, Ruo-Jav., $11^{\circ} 10874$. Grande Iiane cultirée, fl. rosées. Juillet-aoùt. R.

17. P. subrotunda Mart. in Fl. Bras. XIII, I, p. 601 (Passiflora Barbosae Barb. Rodr.). - Restinga de Cabo Frio, Rio-JAN., no 10872. Petite liane, h. blanches. Juin-juillet. R.

18. P. Jilekii Wawra; Fl. Bras. XIII, I, p. 602. - Floresta de 
A.-F.-M. GLAZIOC. - LISTE DES PLANTES DU BLÉSH. CENTRAL.

Tijuca et Gavea, Rro-JAx., $n^{\text {os }} 3020$, 6551. Liane, fl. violacées. Décembre. C.

19. P. laurifolia L.; Fl. Bras. XIII, I, p. 603. - Praia de Coplacabana, Rio-Jax., nº 3991. Liane, fl. blanches. Septembre-octobre. C.

20. P. mucronata Lamk; Flora Lras. XIII, I, p. J̈63. - Larangeiras, au Cosme Velho, Rio-J.x., no 3655 a. liane, lleurs roses. Mai-juin. R.

21. P. odontophylla Harms. n. sp. in herl., Paris., Berol. ined.? - Alto Macahé de Nova Friburogo, Ruo-Jax., $11^{\circ}$ 20333. Liane, roses. Janvier-février. R.

22. P. speciosa Gardn.; fl. Bras. XIII, I, p. 606. - Serra dos Orgños, à Theresopolis, Ru-JAx., $1^{\circ}$ 1598. Liane, fl. rouges. Septembreoctobre. C.

23. P. quadriglandulosa Rodr.; Fl. Bras. XIII, I, p. 607. - Quinta de São Christovão, Rı-Jax., nos 9851, 13912 b. Liane cultivée, t1. rouges. Juin-juillet. R.

24. P. edulis Sims; Fl. Bras. XIII, I, p. 609 (l’. picroderma Barl). Rodr.). - Gavea et Nova Friburgo, Rio-dix., nos 3019, 17013. Grande liane, fl. bleuâtres. Juillet août. C. Yulgo: Marajuca.

2\%. P. tetraden Vell.; Fl. Bras. XIII, I, p. 611. - Coreovado, it Lagoinha et à Nova Friburgo, Rı-Jax., $n^{\text {os }} 6604,6700,18257$. Liane, 17. blanchâtres. Mars-avril.

26. P. violacea Vell.; Fl. Bras. XIII, 1, p. 612. - Petropolis, it Santo Antonio et à Nora Friburgo, Rio-Jax, nos 8721, 18256. Liane, f1. bleues. Mars-arril. C. Vulg. : Maracuja.

27. P. antethystina Mik.; Fl. Bras. XIII, I, p. 613. - Gavea et Pico de Tijuca, Ruo-JAx., $n^{\circ 5} 6550,7649$. Liane, 11. violacées. Janvier-mars. C.

28. P. carulea L.; Fl. Bras. XIII, I, p. 617. - Entre Carandaliy et Queluz, dans le bois, Mras Geries, $1^{\circ}$ 12740. Grande liane, 11. bleues. Juillet-aout. C. Vulgo: Maracuja.

29. P. setacea DC.; Fl. Bras. XII, I, p. 618. - Gavea, dans le hois, chez Frei Custodio, Rio-Jar., no ${ }^{1538 . ~ G r a n d e ~ l i a n e, ~ f ! . ~ b l a n c h a ̂ t r e s . ~ S e p-~}$ tembre-octobre. R.

30. P. racemosa Brot.; Fl. Bras. XIII, I, p. 618. - Corcorado, Tijuca, Serra da Estrella, Rio-dax., $\mathrm{n}^{\circ \mathrm{s}} 3655,3992,8269$. Liane, fl. roses. Hai-juillet. CG.

31. P. Raddiana DG.; Fl. Bras. XIII, I, 1. 619. - Gorcovado et Andarahy Grande, Rio-Jax., $n^{0} 3018$, 13912. Liane, Il. roses. Janvierfévrier. C. 
32. Passiflorasyliestris Vell.; Fl. Bras. XIII, I, p. 620. - Restinga de Copocabana, Rir-JAx., $1^{\circ}$ 14853. Liane, fil. blanchattres. Mars-avril. C.

33. Carica quercifolia Solms in Fl. Bras. XIII, III, 1. 178. Passeio Publico, liı-Jax., $n^{\circ}$ 5876. Arbuste cultivé, fl. blanc jaunâtre. Septembre-octobre. C. Vulg. : Mamoeirinho.

34. C. platanifolia Solms? in Fl. Bras. XIII, III, p. 182. - Bords du Rio Manso, dans le bois, Hoxas Geraes, $n^{\circ}$ 14855. Arbuste, fl. jaunâtres. Férrier. R.

39. C. Papaya L.; Fl. Bras. XIII, III, p. 188. - Quinta de São Cilıristovão, Rio-Jax., $1^{0}$ 5877. Arbuste cultivé, fl. jaunàtres. Avril-mai. CG. Vulgo: Nameeiro.

36. Jaracatia dodecaphylla DC.; Fl. Bras. XIII, III, p. 190. Corcovado, à Paineiras, Rio-Jax., $11^{\circ} 6090$. Grand arbre, fl. blanchatres. Novembre. CG. Vulgo : Jaracalia.

37. J. spinosa A. DC.; Fl. Bras. XIII, III, p. 191. - Quinta dle Sảo Christovão, Rı-Jux., no 6090 a. Grand arbre cultivé, fl. blanc-jaunàtre. Décembre. R. Vulgo: Jaracatia.

\section{Fam. 63. - Cucurbitacées.}

1. Lagenaria vulgaris Ser.; Fl. Bras. VI, IV, p. 8. - Hiturmna, près Oliveira, dans le campo, Howas Geraes, nos $19382 a$, 20332. Sarment., fl. blanches. Juin-juillet. C.

2. Lufĩa cegyptiaca Nill.; Fl. Bras. VI, IV, p. 10. - Quinta de São Christovão, Rio-Jav., $1^{\circ}$ 6548. Sarnent., ann., cult., fl. jaunes. Avriljuin. Vulgo: Bucha de Paulista. C.

3. L. operculata Cogn. in Fl. Bras. VI, IV, p. 12. - São João da Barra, Rio-das., $n^{\text {os }} 9849$, 19388 b. Liane herbacée, fl. blanchâtres. Février-mars. C.

4. Sphærosicyos sphcericus Cogn.; Suites au Prodr. Vol. III, 1. 466. - Praia Grande, au Barreto et à Sete Pontes, dans les haies, Rio-Jan., n ${ }^{\text {os }} 6888$, 18911, 19382, 20331, 21466. Sarment., Il. blanches. Septembre-octobre. C.

כ. Momordica Charantia L.; Fl. Bras. VI, IV, p. 1't. - Larangeiras, au Cosme Velho, Rı-Jan., nº 3017. Sarment., ann., 11. jaunatres. Février-avril. CG. Vulg. Melũo de Säo Caelano.

6. Cucumis Anguria L.; Fl. Bras. VI, IV, p. 16. - Quinta de São Christovão, Rı-JAN., nº 10859. Sarment.: ann., fl. jaunes. Janvierlërrier. CG. Vulg. : Machicho. 
A.-F.-N. GLA7IOU. - LISTE DES PLANTES DU BRESIL CEXTRAL.

317

7. Citrullus 1'ulgaris Schrad.: Fl. Bras. VI, IV, p. 19. - Quinta de São Christovão, Rio-Jax.. nos 10852, 10853. Herb., ann., sarment., cult. Janvier-mars. CG. Vulg. : Melancia.

8. Cucurbita moschata Duch.; Fl. Bras. VI, IV, p. 21. - Oliveira, près des cultures, Maxas Geraes, nº 20332 a. Herb. sarment., ann., fl. jaunes. Avril-juin. C.

9. Sicana odorifera Naud.; Flora Bras. VI, IV, p. 22. - Quinta da Boa Vista, Rio-JAx., $11^{0}$ 10845. Grimpant, fleur's jaunes. Aoùt-septembre. C.

10. Melancium campestre Naud.; Fl. Bras. VI, I, p. 23. - Enlre Ipanema et Sorocaba, São PAULo, $n^{0 s}$ 12738, 16078. Sarment., fl. jaunes. Arril-mai. CC. Vulgo : Melancia do campo.

11. Melothria Cucumis Vell.; Fl. Bras. VI, IV, p. 25. - Petropolis, près Cachambú, dans le bois, Rı-Jıx., $\mathrm{n}^{0}$ 10854. Liane, 11. blanchàtres. Nars-avril. C.

12. M. fluminensis Gardn.; Fl. Bras. VI, IV, p. 27. - Petropolis, au Jací et à São Christovão, Rı-Jan., n ${ }^{0} 3656,10863$. Liane, fl. blanchâtres. Octobre-décenbre. CC. Vulg. : Abobrinha do matto.

13. M. hirsuta Cogn. in Fl. Bras. VI, IV, p. 28. - Corrego Secco, dans le bois, Mixas Geraes, $n^{\circ} 19384$ a. Liane, fl. jaunitres. Marsarril. C.

14. Wilbrandia verticillata Cugn. in Fl. Bras. VI, IV, p. 30. Gavea, Tijuca, Jacarepagua, etc., Rio-Jax., $n^{\text {os }}$ 2581, 3013, 3014, 10856, 10857. Liane, f1. verdàtres. Nurembre-décembre. CG. Yulg. : Tayzuya.

13. W. Glaziovii Cogn. in litt. et in herb. Paris., Berol. ined.? Andaralı̣ Grande, dans le bois, Rio-Jas., n 12019. Liane, fl. verdâtıes. Novembre. R.

16. W. hibiscoides Nanso; Fl. Bras. VI, IV, p. 31. - Entre Gavea et Tijuca, Rio-Jax., $n^{\circ} 10866$; Fazenda do Paraizo, Goyaz, $n^{0} 21465$. Liane, fl. verdâtres. Décembre-janvier. C. Vulgo: Tayuya, Abobrinha do mallo.

- Var. latrloba Cogn. in Fl. Brets. VI, IV, p. 32. - Sũo Juliño, dans le bois, Mrsas Geraes, $1^{\circ}$ 17619. Liane, f1. verdattres. Décembre-janvier. C. Vulg. : T'ayuya, Abobrinha do mallo.

17. Ir. longibracteata Cogn.; Fl. Bras. VI, IV, p. 32. - Fazenda de Santa Cruz, au Cercadinho, et à Barreira do Orgãos, Rı-Jav., 3016, 10858, 12015. Liane, 11. verdâtres. Février-mars. C.

18. Apodanthera argentea Cogn. in Fl. Bras. VI, IV, p. 37. - 
Serra dos Orgoãs el all Alto Macalé de Nova Friburgo, Riı-Jax., $11^{\text {os }} 1614,17619$ b., 18253. Liane, fl. blanchâtres. Octobre. C.

- Var. angustrfola Cogll. in Fl. Bros. VI, IV, [1. 37. - Itatiaia, dans le hois, Rio-Jan., $1^{\text {os }}$ 4817, 8714, 9466; Carara, Minas Geraes, 14850. Liane, fl. blanchitres. Juin-juillet. CC.

19. Apodanthera smilacina Cogn.; Fl. Bras. Vl, IV, p. 38. Petropolis et Nova Friburgo, Rio-Jas., $n^{\text {os }} 8713$, 17009, 20327. Liane, f1. rerdittres. Mars-iviril. C.

20. A. Glaziovii Cogn. 11. sp. in litt. et in herb. Paris., Bruxel. inéd.? - São Christovão, Rio-dan., $1^{\circ}$ 20328. Liane, fl. verdâtres cultivées. Décembre. R. Vulgo : Cabeca de negro.

21. Anguria Warmingiana Cogn.; Fl. Bras. VI, IV, p. 43.Petropolis, à Santo Antonio, Rro-dan., nos 10864, 16080, 19387 b. Liane, f1. orangées. Décembre. C.

22. A. umbrosa Kuntlı; Fl. Bras. VI, IV, p. 43. - Curalinlı, près Diamantina, Mrnas Geraes, $n^{0}$ 19386. Liane, fl. verdatres. Avril-mai. R.

23. Gurania villosa Cogn.; Fl. Bras. VI, IV, p. 46. - Fazenta da Limeira, près Ciantagallo, Rio-JAN., $n^{\circ}$ 10869. Liane, sans fleur en aout. R.

24. G. Paulista Gogn.; Fl. Bras. VI, IV, p. 47. - Diamantiua, ì Formacão, Minas Geraes, no 19387 a. Liane, fl. orangées. Avril-mai. R.

23. G. ovata Cogn.; Fl. Bras. VI, IV, p. 48. - Floresta de Tijuca, Rı-JAN., nº 1445. Liane, fll. orangées. Janvier-f’évrier. L.

26. G. multiflora Cogn.; Fl. Bras. VI, IV, p. 49. - Alto Macahé de Nova Friburgo, Rio-Jan., nos 18252, 21463. Grande Liane, fl. rouges. Juin-juillet. C.

- Var. longipedunculata Cogn. in herh. Paris., Berol., Kew., Brux., etc. - Entre Gapelinha de Santo Antonio et Rio Ponte Alta, Goraz, $1{ }^{\circ} 21464$. Grimpant, fleurs rouges. Octolre. R.

27. G. spinulosa Gogn.; Fl. Bras. VI, IV, p. 53. - Serra da Estrella à Mandioca, Rı-Jav., n 14849. Grande liane, 11. rouges. Janvier-mars. C.

28. G. subumbellata Cogn.; Fl. Bras. IV, VI, p. ̈̈6. - Petrupolis et Floresta de Tijuca, Rıo-Jav., nos 8715,10868 , 12024. Grande liane, fi. rouges. Février-mars. C.

29. G. pseudo-spinulosa Ciogn.; Fl. Bras. VI, IV, p. 37. - Serra da Estrella, près Hamminha, Rı-JAN., no 3015. Grande liane, 11. rouges. Novembre-décembre. R.

30. G. velutina Cogn.; Fl. Bras. VI,.IV, p. 58. - Corcovado, à Paineiras, Rio-JAx., no 12020. Grande liane. 
31. G. cissoides Cogn ; Fl. Bras. VI, IV, p. 62. - Carandahỵ, dans le hois, Mrisas Geraes, n 13903 a. Grande liane, M. rouges. Juin-juillet. R.

32. Helmontia leptantha Cogn.; Fl. Bras. VI, IV, p. 64. - Serra de Caraça, près Alegria. Mixas Geraes, nº 13903 b. Liane, fl. verdâtres. Octobre. R.

33. Cayaponia Cabocla Mart.; Fl. Bras. VI, IV, p. 73. - Petropolis et Alto Macahé de Nova Friburgo, dans le bois, Rı-Jax., nos 6889, 8717, 19384. Liane, fi. lılanc jaunâtre. Janvier-février. CG. Vulg. : Purga de Cabodo.

34. C. Glaziovii Cogn.; Fl. Bras. VI, IV, p. 74. - Petropolis, Fazenda Ingleza, Rı-Jan., nos 12021, 12022; Juiz de Fora, Mlixas Geraes, $\mathrm{n}^{\circ}$ 7646. Liane, fl. blanchàtres. Février-mars. CG.

33. C. fluminensis Cogn.; Fl. Bras. VI, IV, p. 76. - Serra de Caraça, dans le bois, Minas Geraes, n 13905. Liane, fl. verdâtres. Septembre-octobre. C.

36. C. pilosa Cogn. Fl. Bras. VI, IV, p. 7.. - Petropolis et Alto Macalé de Nova Friburgo, Rı-JAx., nos 8716, 17011, 19383, 19385. Liane, fl. Jlanchàtres. Février-mars. CC. Vulgo: Abobrinha do matto.

37. C. Almeideana Cogn. n. sp. in litt. et in herb. Paris., Berol. ined.? - Cantagallo, ì Larangeiras, Rio-JAN., n 16079. Liane, fl. verdàtres. Septembre-octohre. C. Vulgo: Abobra d'anta.

38. C. palmata Cogn. Suites au Prodr. Vol. III, p. 749. - Petropolis, au Cachambú, Rı-J JAx., no 12023. Liane, fl. verdâtres. Févriermars. C.

39. C. pentaphylla Cogn. Suites au Prodr. Vol. III, p. 760. - Paineiras, au Corcovalo, Rı-JAN., $n^{0}$ 10862. Liane, fl. verdâtres. Janvierfévrier. C.

40. C. ternata Cogn.; Fl. Bras. VI, IV, p. 79. - Petropolis, à Itamaraty et à Cachambú, Rı-JAx., n ${ }^{\text {os }} 8998,13908,13909,13910$. Liane, fl. verdàtres. Janvier-février. CG.

41. C. pedata Cogn.; Fl. Bras. VI, IV, p. 80. - Corcovado, à Paineiras, Rı-JAx., $1^{\circ}$ 10861. Liane, fl. blanchâtres. Janvier-février. C. Vulg. : Cereja de purga.

42. C. villosissima Cogn.; Fl. Bras. VI, IV, p. 81. - Serra dos Orgãos, à Theresopolis, Rı-JAN., $\mathrm{I}^{\text {os }} 3989$, 10865, 17618. Liane, fl. blanchâtres. Janvier-décembre. CC.

43. Trianosperma Tayuya Vart.; Fl. Bras. VI, IV, p. 8̈̈. - Corcovado, Tijuca, Gavea, Rı-Jax., nos $3657,10847,10848$; Caraça, Mıxas 
Genses, $n^{\text {os }}$ 12736, 13903. Liane, fl. verdattres. Juillet-octobre. CG. Vulgo: Abobrinha do matto.

4. Trianosperma Martiana Cign.; Fl. liras. V1, IV, p. 87. Restinga de Tijuca et a Petropolis, Rı-Jan., $n^{9 *}$ 10849, 10851, 10855; Sinta Luzia, Mlivas, $n^{05}$ 13904, 20330. Liane, fl. verditres. Janvier-avril. CC. Vulgo: Abobrinha dinla.

40. T. floribunda Cogn. in Fl. Brus. VI, IV, p. 88. - Nora Friburgo, au Conego, Rio-Jav., $n^{\circ}$ 12737. Liane, f1. verditres. Septembreootobre. C.

46. T. trilobala Cogn. in Fl. Bras. VI, IV, p. 89. - Chemin du Nacaco à la Tijuca, Rıo-JAx., $11^{\circ}$ 10860. Liane, ll. verdâtres. Janvierfévrier. C..

47. T. diversifolia Cogn. in Fl. Bras. VI, IV, p. 92. - Petropolis, à Quitandinha, Rı-JAx., $n^{05} 10846$, 12017. Liane, fl. verdatres. Mar'smai. C.

- Var, subintegrifolia Cogin. in Fl. Bras. Vi, IV. p. 93. - Nova Friburgo, Rio-JAN., $n^{0} 12737$ a. Liane, fl. verdàtres. Septembre. C.

48. Perianthopodus Espelina Manso; Fl. Bras. VI, IV, p. 95. Carhocira do Campo, Mrinas Geraes, nos 17619 a, 20329; Guariroba, dans le campo, Goraz, n² 21462. Liane, fl. verdâtres. Octobre-décembre. CC.

49. P. longifolia Cogn. Suites au Prodr. Vol. III, p. 796. Theresopolis, dans le bois, Rio-Jan., $n^{\circ}$ 12016. Grande liane sans fleurs en mars.

O0. Echinocystis muricata Cogn.; Fl. Bras. VI, IV, p. 98. lianeri, dans les haies, Sĩo PAclo, n $n^{0}$ 12739. Liane, fl. jaunâtres. Avrilmai. C.

51. Elaterium amą̧onicum Cogn.; Fl. Bras. VI, IV, p. 100. Campos, aux bords du Rio Parahyba, Rio-Jas., no 19387. Liane, fl. blanchâtres. Février. R.

59. Cyclanthera elegans Cogn.; Fl. Bras. VI, IV, 1. 102. - Petropolis, au Palre Correa, dans les liaies et ì Santo Antonio, Rı-JAx., $1^{\text {os }} 5874,8488,8719$. Liane, f1. jaunatres. Mars-avril. CC.

53. C. quinquelobata Cogn.: Fl. Bras. VI, IV, p. 104. - Serra dos Orgãos, à Theresopolis, Rio-Jax., II $^{\circ}$ 12018. Liane, f1. jaunâtres. Marsavril. C.

5̆4. C. brasiliensis Cogn.; Fl. Bras. V1, IV, p. 10氵. - Petropolis, au Padre Correa, Rı-Jan., $n^{\circ}$ 3987. Liane, fl. blanches. Mars-avril. R.

5\%. C. Eichleri Cognı.; Fl. Bras. VI, IV, p. 106. - Serra de José 
Vaz, près Rezende, Rio-. Ix., n 7648. Liane, fl. blanches. Septembre. li.

56. Sicyos polyacanthos Cogn. in Fl. Bras. VI, IV, p. 107. Biribiry, près Diamantina, Mixas Gelaes, $n^{\circ} 19381$ a. Liane, fl. blanchatres. Avril-mai. C. Vulg. : P’é de mico.

57. S. fusiformis Cogn. in Fl. Bras. VI, IV, p. 108. - Serra da Babylonia, près Juiz de Fora, Mınas Geraes, n 7647. Liane, fl. blanches. Janvier-février. C.

58. S. Glaziovii Cogn. n. sp. in litt. et in herb. Paris., Bruxell. Diamantina, dans les haies, Mıxas Geraes, nº 19381. Liane, fl. blanches. Avril-mai. C.

59. Sechium edule Swartz; Fl. Bras. VI, IV, 1) 111. - Tijuca el Săo Christovão, Rı-Jıx., nº 10867. Liane cultivée, 11. blanches. Décembre-janvier. CG. Vulgo: Chuchu.

60. Sicydium monospermum Cogn.; Fl. Bras. VI, IV, 1. 114.Serra da Bica, près Cascadura, Rio-JAs., no 17012, Liane, fl. verdâtres. Novembre-décembre. C. Vulg. : Relogio.

61. Alsomitra brasiliensis Cogn. in Fl. Bras. VI, IV, p. 113. - Restinga de Cabo Frio, Rio-Jax., nos 10071, 10412. Liane lign., fl. blanchitres. Juillet-aoùt. C.

62. Feuillea trilobata L.; Fl. Bras. V1, IV, p. 117. - Serra dos Orgãos et Nlto Macahé, Rio-JAN., nos 8720 , 9850, 17010. Liane, fl. jaunàtres. Mai-juin. C.

- Val. tomentosa Gardn., Fl. Bras. VI, IV, p. 118. - Pelropulis. a Itamaraty: Gavea, Rio d'Ouro, Rio-JAx., nos 1344, 3986, 9465, 10850 , 14851. Liane, fl. jauntitles. Mars-mai. CC.

- Var. Glaziovii Cogn. in litı. et in lıerl. Paris., Bruxell. ined.? Serra do Inficionado, près Caraça, Mivas Geraes, nº 13906. Liane, 11. jaunitles. Septembre-octobre. C.

63. F. albiflora Cogn.; Fl. Bras. VI, IV, p. 118. - Perpetua, mès Diamantina, Mras Geraes, n ${ }^{\circ}$ 19388. Liane, f1. blanchitres. Mars-aviil. R.

64. F. deltoidea Cogn.; Fl. Bras. VI, IV, p. 119. - Nova Friburga, dans la forêt, Rio-Jan., $n^{0^{s}} 11848$, 13907. Liane, f1. blanchâtres. Octolire. R.

63. Anisosperma Passiflora Nanso; H. Bras. VI, IV, p. 120. Serra do Pirú, au Palmital et au Nto Macahé, Rı-JAx., nos 10870, 20335. Liane, 11. verdâtres. Mars-avril. C. Vulgo : Maracuja de periquito, Jabota, Castunha de Bugre. 


\section{Fam. 64. - Bégoniacées.}

1. Begonia cucullata Willd.; Fl. Bras. IV, I, p. 341. - Marianna, dans les bourbiers, Minas Geraes, ${ }^{o s}$ 14234, 15387. Herb., fl. roses. Janvier-février. C.

2. B. semperflorens Link et 0tto; Fl. Bras. IV, I, 1. 342. - Serra da Estrella, sur les rochers humides, Rio-Jas., no $14234 a$. Herb., fl. roses. Janvier-février. C.

3. B. hirtella Link: Fl. Bras. IV, I, p. 34'4. - Corcovarlo, sur les rochers humides, Rio-Jax., no 9573. Herb., fl. roses. Août-septembre. GC. Vulgo: Herva de saracura.

4. B. macroptera Klutı.; Fl. Bras. IV, I, p. 34. - Pelropolis, au Retiro, dans le bois, Rio-dav., n 11492 a. Hetb., fl. roses. Mars-avril. C.

э. B. uliginosa Klotz.; Hl. Bras. IV, I, p. 347. - Antonio Pereira, dans les bourbiers, Mrxas Geraes, $n^{0}$ 16324. Herb., fl. roses. Janviermars. C.

6. B. paulensis A. DC.; Fl. Bras. IV, I, p. 330 . - Serra da Estrella, sur les rochers, à Mandioca, lín-Jan., nº 3099. Herlo, fl. roses. Févíieravril. C.

7. B. populnea Schott; Fl. Bras. IV, I, p, 30̈3. - Serra da Estrella, sur les vieux arbres et les rochers, Rio-JAx., n ${ }^{\circ}$ 14232. Frutescent, fl. roses. Juillet-aoùt. C.

8. B. maculata Raddi; Fl. Bras. IV, I, p. 3\%4. - Alto Hacahé de Nova Friburgo, sur les arbres et sur les rochers, Rio-JAx., $n^{\circ} 17204$. Frutescent, fl. roses. Octobre-novembre. C.

9. B. sanguinea Raddi: $F l$. Bras. IV, I, p. 337. - Serra da Estrella, sur les rochers, Rio-dax., $n^{\circ s} 6671,11493$, 11495. Herb., fl. roses. Janvier-mars. CC.

10. B. Riedelii A. DC.; Fl. Bras. IV, I, p. 338. - Alto Hacahé de Nova Friburgo, sur les rochers, Rio-JAx., nº 18469. Frutescent, f1. roses. Janvier-février. R.

11. B. angularis Raddi; Fl. Bras. IV, I, p. 358. - Petropolis, à Itanaraty, sur les vieux arbres et sur les rochers, Rio-Jax., no 11494. Frulescent, fl. roses. Mars-avril. C.

12. B. ansulata Vell.; Fl. Bras. IV, I, p. 359. - Petropolis, au Palatinato, Riro-Jax., $n^{\text {os }} 8914,11492$. Frutescent, fl. roses. Avril-mai. C.

13. B. Fischeri Otto et Dietr.; Fl. Bras. IV, I, p. 360. - Floresta 
de Tijuca, pres des ruisseaux, Rio-Jax., nº 6092. Frutescent, fl. roses. Octobre-novembre. $C_{i}$.

14. B. coccinea Hook.; Fl. Bras. IV, I, p. 360. - Corcovado, ì Paineiras, sur les rochers, Rio-JAs., n 4187, 4970. Frutescent, f1. roses. Septembre-octobre. C.

1\%. B. Epibaterium Mart. in Fl. Bras. IV, I, p. 362. - Collegio, près de Campos, dans le bois humide, Rio-Jx., nº 6094 a. Frutescent, f1. roses pâles. Octobre. R.

16. B. hispida Scholt; Fl. Bras. IV, I, p. 364. - Corcovado, Petropolis, Alto Macahé, dans les bois, près des ruisseaux, Rio-Jax., n ${ }^{\text {os }} 8915$. 17205, 19822. Frutescent, fl. roses, Janvier-mars. CC.

17. B. paleata A. DC.; Fl. Bras. IV, 1, p. 36'. - Petropolis, Nova Friburgo, dans les forèts humides, Rio-Jax., no 11497. Frutescent, fl. roses. Janvier-mars. CC.

18. B. convolvnlacea A. DC. in Fl. Bras. IV, I, p. 367. - Corcovado, à Lagoinha, et à Tijuca, Rı-Jax., n ${ }^{\text {s }} 9574,11491,12148$. Frutescent, f1. roses. Juin-septembre. L.

19. B. longipes Hook.; Fl. Brus. IV, I. p. 368. - Jurujuba, sur les rochers, près de la mer, Rio-Jax., no 8270 . Herb., fl. roses. Octobrenurembre. C.

20. B. vitifolia Schott; Fl. Bras. IV, I, p. 369. - Serra da Estrella, près Petropolis, Rio-J৯s., n ${ }^{\circ} 11490$. Frutescent, fl. roses. Mars-arril, C.

21. B. muricata Scheidw.: Fl. Bras. IV, I, p. 373. - Itatiaia. dans le bois, Rro-Jax., n 6093 a. Frutescent, fl. roses. Mai-juin. R.

22. B. luxurians Scheidw.; Fl. Bras. IV, I, p. 373. - Petropolis, a Itamaraty, Rio-JAx., $n^{\circ}$ 13167. Frutescent, fl. roses. Janvier-mars. C.

23. B. heracleifolia Ch. et Sch. in Limnxa V (1830), p. 603. - Cantagallo, à Larangeiros, Rio-Jax., no 15389. Frutescent, fl. roses. Loùtseplembre. C.

24. B. digitata Raddi; Fl. Bras. IV, I, p. 37'4. - Serra dos Orgãos, au Imbui, Rro-Jax., n 6093. Frutescent, f1. roses. Octobre-noremlre. C.

23. B. lobata Schott: Fl. Rras. IV, I, p. 37̈̈. - Petropolis et Nora Filutirgo, sur les rochers, Rio-JAx., ${ }^{0 s} 6672,8917,11487,11498$, 12145. Frutescent, fl. roses. Jarvier-mars. CG.

26. B. tomentosa Schott; Fl. Bras. VI, I, p. 376. - Corcovado, à Panciras, sur les rochers, Rio-JAx, no ${ }^{\circ} 1496$. Frutescent, I1. roses. Janvier, $R$.

27. - B. rigida Regel; Fl. Bras. IV, I, p. 376. - Corcovado, Serra 
dia Estrella, Nlto Macalıé, sur les rochers, Rio-Jax., $10^{\text {os }}$ 12146, 13166. 16326, 17206. Frutescent, 11. roses. Janvier-décembre. C.

28. Begonia acetosa Vell.? in Fl. Flum. X, tab. 50. - Alto Macalıé de Nova Friburgo, sur les rochers, Rı-Jax., $n^{\circ} 19822 a$. Herb., fl. roses. toùt-Septembre. C.

99. B. fruticosa 1. DC. in Fl. Bras. IV, 1, 1. 377. - Corcorado, au ruisseau Carioca, Ru-Jax., $1^{0}$ 6094. Frulescent, 11. roses. Févriermars. C.

30. B. arborescens Raddi; Fl. Bras. N, I, p. 378. - Lagoinha, an Corcovado, Rio-Jax., $n^{0 s} 3098$, 8916. Frutescent. 11. roses. Févriermars. CC.

31. B. petropolitana Glaz. 11. sp. in herl. Paris., Berol., Kew., Brux., etr. - Petropolis, dans les buis et les jardins, Rio-Jax., $n^{\circ} 16323$. Sous-firutescent, fleurs roses. Mai-juin. C.

32. B. Hookeriana Gardn.; Fl. Bras. IV, 1, p. 379. - Serra do Nar, it Palmeiras, Rio-Jax., $\mathrm{n}^{0}$ 8918. Frutescent, fl. roses. Janviermars. C.

33. B. bidentata Raddi; Fl. Bras. 1V, 1, p. 380. - Fl. de Tijuca, près des ruisseaux, Rio-Jav., $\mathrm{n}^{\text {os }} 6091,11488,13165,14235$. Frutescent, i1. roses. Novembre-décentore. C.

34. B. herbacea Vell.; Fl. Bras. IV, 1, p. 382. - Serra da Estrella, près Petropolis, sur les rochers lıumides, liı-JAx., $n^{\text {กs }} 12147,16325$. Herlo, ir. roses. Mai-juillet. C.

33. B. attenuata A. DC. in Fl. Bras. 1Y, I, p. 383. - Petropolis et Alto Macahé, sur les rochers humides, Rio-Jax., $n^{\text {os }} 14236$, 19821. Herb., 11. roses. Janvier-décembre. C.

36. B. macahensis Glaz. n. sp. in herb. Paris., Berol., Kew. Brux., etc. - Nlto Macahé, sur les arbres, Rı-Jax., n 19823. Frutescent, fleurs roses, Juin-juillet. R.

37. B. integerrima Spreng.; Fl. Bras. IV, 1, 1. 383. - Alto de Nova Friburgo, sur les troncs l'arbres, Rio-Jax., n 17202. Frutescent, f1. roses. Aoùt-septembre. R.

38. B. Mereniana Walp.; Fl. Bras. IV, 1, p. 383. - Petropolis, à Itamaraty, sur les arbres, Rio-Jax, $1^{\circ}$ 11489. Herb.. 11. roses. Marsavril. R. 


\section{Fam. (3̈. - Caclacées. ${ }^{1}$}

1. Melocactus violaceus Pfeiff.; Fl. Brus. IV, II, p. ․34. - Restinga de Taipuí, dans le sable, Rio-Jax., $n^{\circ}$. Fl. roses. Nuvembredécembre. C. Vulg. : Cabeça de frade.

2. Echinocactus placentiformis K. Sch.; Fl. Bras. IV, II, Ir. 2'ff. - Biriliry, près Diamantina, sur les rochers, Mrsas Geliats, $1^{\circ}$. Fl. roses. Octobre-novembre. C.

3. Cereus microspharicus $\mathrm{K}$. Sch. in Fl. Bras. IV, II, p. 197. Copacabana, sur les rochers, Rı-Jax, no $n^{0}$. Fl. Blanc jaunâtre. Yorembre-décembre. C.

4. C. parvilus K. Sch. in Fl. Brus. IV, II, p. 197. - Praia te Fora, sur les rochers, près la mer, Rio-Jas., $n^{0} \quad$. Fl. blanche. Décembrejanvier. C.

3. C. obtusangulus K. Sch. in Fl. Bras. IV, II, p. 198. - Petropolis, sur les arbres et sur les rocher's, lino-Jax., $n^{0}$. Fl. blanches. Janvier-février. C.

6. C. melanurus K. Sch. in Fl. Brus. IV, II, p. 200. - Serra in Lenheiro, Muxs Gerues, sur les nids de termites, $\mathbf{1}^{\circ}$. Fl. jaunes. Novembre-décembre. C.

7. C. Glaziovii K. Sch. in Fl. Bras. IV, II, p. 200. - Pien d'ltabira do Campo, sur les rochers, Misas Geraes, $n^{n}$. Fl. jaunes. Décembre-janvier. C.

8. C. macrogonus S.-Dych; Fl. Bras. IV, II, p. 201. - Restinga de Copacabana, dans le sable, Rio-Jas., $n^{\circ}$. Fl. blanches. Férriermal's. CG. Vulg. : Cardo.

9. C. Hildmannianus K. Seh. in fil. Bras. IV, It, p. 200. - Queluz, dans les haies, Mixas Geraes, $\mathbf{1}^{\circ}$. Fl. blanches. Octobre-nurembre. CC. Vulg. : Manducaru.

10. C. Pitajaja DC.; Fl. Bras. IV, II, p. 208. - Copacabana, sur les rocher's, Rio-JAx, $n^{\circ} 18268$ a. Fl. blane jaunàtre. Février-mar's. CG.

11. C. triangularis Haw.; F\%. Bras. IV, II, p. 208. - Gavea, près la mer, sur les rochers, Rio-JAx., $1^{\circ}$. Restinga de Copacabana, dans le sable, Rı-Jax., $\mathbf{n}^{\circ} \quad$. Pl. grasse, ll. blanches. Aoùt-septemlıre. Janvier-février. CG. Vulg. : Cardo.

1. Les espèces de la famille de Cactacées portant ici les numéros diordre 1 a 9,11 à $1 \%$ et 26 ne sont pas représentées dans l'herbier de liL.tzlot. Nous nous sommes borné à transcrire les fiches de ces espèces telles que Guzııu les avait établies. (Note de lit Rédaction.) 
12. Cephalocereus Melocactus K. Sch. in Fl. Bras. IV, II, p. 215.

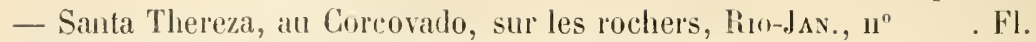
blanc jaunâtre. Nar's-avril. CG.

13. Epiphyllum Russelianum Hook.; Fl. Bras. IV, II, 1). 2218. Serra dos Orgãos, sur les vieux arlres, lio-J.s, $n^{\circ}$. Fl. rosées. Janvier-mars. C.

14. E. Phyllanthus Haw.; Fl. Bras. IV, II, p. 219. - Serra dos Orgãos, sur les vieux arbres, Rio-Jax., $n^{\circ} \quad$. Fl. blanches. DécembreJanvier. C.

15. E. acuminatum $\mathrm{K}$. Sch. in Fl. Bras. IV, II. p. 2222. - Serra dos Orgãos, sur les vieux arbres, Rio-Jav., $n^{0}$. Fl. llanches. Février-mars. C.

16. Rhipsalis Lindbergiana K. Sch. in Fl. Bras. IV, II, p. 271. São Christovão, sur les vieux arbres, Rio-JAx., ${ }^{\circ}$ 18263. Fl. blanches. Aoùt-septembre. CC.

17. R. grandiflora Haw.; Fl. Bras. IV, II, p. 273. - Floresta de Tijuca, sur les vieux arbres, Rı-JAx., $n^{\circ}$ 14869; Serra da Piedade, Minas Geraes, $1^{0}$ 20338. Fl. lilanches. Janvier-mars. C.

18. R. teres Steud.; Fl. Bras. IV, II, 1). 274. - Corcovado, sur les arbres et sur les rochers, Rio-Jin., $1^{\text {os }} 10888,20337$. Fl. Hanches. Novembre-décentre. C.

19. R. penduliflora N. E. Brown.; Fl. Bras. IV, II, p. 276. - Alto Macahé de Nova Friburgo, sur les vieux arlıes, Rı-Jax., $n^{0 s} 18262$, 18264. Fl. blanclies. Octobre-110 rembre. C.

20. R. mesembrianthemoides İaw.; Fl. Bras. IV, II, p. 276. - Floresta de Tijuca, sur les vieux arlres et les rochers, Ro-Jax., n 18265. blanches. Juillet-août. G.

21. R. cribrata Ruempl.; Fl. Bras. IV, II, p. 277. - Larangeiras, au Cosme Vellı, sur les vieux arlores, Rio-JaN., $n^{\circ}$ 18261. Fl. blanches. El. Juin-juillet. C.

22. R. macahensis Glaz. sp. nov. in herb. Paris., Berol., Kew., Brux. - Alto Macahé sur les arbres et les rochers, liı-Jax., $\mathrm{n}^{0} 18262$. Fl. . Janvier-février. C.

23. R. Neves-Armondii K. Sch. in Fil. Bras. IN, II, p. 28'́Corcovado, à Paineiras, sur les vieux arbres, Rio-J $\mathrm{JN}_{\mathrm{N}}, \mathrm{n}^{\circ}$ 14868. Fl. blanclıes. Janvier-février. C.

24. R. squamulosa K. Sch. in Fl. Bras. IV, II, p. 280. - Serra da Estrella, sur les vieux arbres et les rochers, Rio-Jav., $1^{\circ}$ 13916. Fl. blanc rosé. Septembre. R. 
9.j. R. macropogon K. Sch. in Fl. Bras. IV, II, 1). 282. - Petropolis, au Retiro, sur les vieux arbres, Rio-Jax., $n^{\circ}$ 14863. Fl. blanc rosé. Février-mars. C.

26. R. trigona Pfeiff.; Fl. Bras. IV, II, p. 283. - Serra dos Orwios, au Garafar, sur les vieux arbres et les rochers, Ro-jan., no . Hil. blanches. Juillet. C.

27. R. pachyptera Pfeiff.: Fl. Bras. IV, II, p. 292. - Petropolis, au Alto do Imperador, sur les vieux arbres, Rı-JAx., nº 14862. Fl. blanches. Juin-juillet. C.

28. R. rhombea Pfeiff.; Fl. Bras. IV, II, p. 294. - Floresta de Tijuca, sur les vieux arbres et les rochers, Rio-JAx., nos $14859,14860$. Fl. blanches. Juin-juillet. CC.

29. R. Regnellii Lindb.; Fl. Bras. IV, II, p. 290. - Serra do Tingua, sur les vieux arbres, Rı-Jax, $n^{\text {os }} 14860$ a, 14861, Juin-juillet. Fl. blanclies. C.

30. Hariota salicornioides DC. ; Fl. Bras. IV, II, p. 264. - Coreovado, sur les arbres et sur les rocliers, Rio-JAN., $1^{\text {os }} 1161,18266$. Fl. blanches. Février-mars. CC.

31. Zygocactus truncatus K. S.lı.; Fl. Bras. IV, II, p. 224.Serra dos Orỡos, sur les vieux arbres, Rı-Jax., $n^{0} 3775$. Fl. rose foncé. Mars-avril. C.

92. Opuntia brasiliensis Haw.; Fl. Bras. IV, II, P. 304. - Serra de Jacarépagua, Riı-JAx., $n^{\circ}$ 14866. Arboresc., 11. jaunes. Juin-juillet. CC. Vulg. : L'rumbeba.

33. O. monacantha Haw.; Fl. Bras. IV, II, p. 30:. - Restinga de Copacabana, dans le sable, Rio-JAv., nº 14867. Fl. jaunâtres. Juin-juillet. CC. Vulgo: Urumbeba, Palmalona.

34. O. inamona K. Sch. in Fl. Bras. IV, II, p. 306. - Serra dos Ilheos, près Sitio, sur les rochers, Mixas Geraes, no 14864. Fl. blanc jaunâtre. Décembre. R.

3ə̈. O. rubescens S.-Dyck; Fl. Bras. IV, II, p. 306. - Serra de São José, entre les rochers, Mtxas Geraes, $n^{\circ}$ 14865. Fi. blanc jaunâtre. Décembre. C.

36. Peireskia Bleo DC.; Fl. Bras. IV, II, p. 311. - Caminho do Leme, à Botafogo. dans la rocaille, Rio-Jas., no 18268. Mrbuste, fl. roses. Octobre-novembre. CC. YuIg. : Ora pro nobis.

37. P. aculeata Plum.; Fl. Bras. IV, II, p. 312. - Morro da Viracão, à Praia Grande, dans la rocaille, Ríı-Jax., n 18267. Arbuste, 1 1. roses. CC. Vulg. : Ora pro nobis. 
Fam. 66. - Ficoidées.

1. Sesuvium Portulacastrum L.; Fl. Bras. XIV, II, p. 310. Riestinga de Copacanana, dans le sable humide, Ro-J Jx., $\mathrm{n}^{0 \mathrm{~s}} 3994$, 8245, 19402. Herb., fl. roses. Octobre-novembre. C.

2. Mollugo verticillata L.: Fl. Bras. XIV, II, p. 240. - Restinga de Copacabana au bord de la mer, Petropolis et à Theresopolis, dans les sables humides, Rio-Jav., $n^{03}$ 1259, 1602, 10886, 10887, 12437. Herb., fl. blanches. Mars-juin. CG.

3. Glinus radiatus Rohrb. in Fl. Bras. XIV, II, p. 238. - Porto do Rio Paracatú, Abbadia, etc., Mlxas Geraes, 11424, 13487, 21963, 21964. Herb., fl. blanches. Aout-septembre. GG.

\section{Fam. 67. - Ombellifères.}

1. Hydrocotyle umbellata L. var. INTERMEdia Urb. in Fl. Bras. XI, I, 1. 270. - Corcovado, à Paineiras et dans les chemins, Rio-Jax., $n^{0 s} 355,873,4002$. Herlacé, fleurs blanches. Janvier-février. CC.

2. H. quinqueloba Ruiz et P.; Fl. Bras. XI, I, p. 274. - Petropolis, au Retiro, dans le bois, Rro-Jan., $n^{0} 13917$. Herb., fl. blanches. Aoùt-septembre. C. Vulgo: Acaricoba.

— Var. macror hrlea Urb. in Fl. Bras. XI, I, p. 273̈. - Petropolis, à Santo Antonio, dans le bois, Rin-Jax., $\mathrm{n}^{\text {os }} 874,7651$. Herb., fl. blanches. Juillet-aoùt. C.

- Var. asterias Urb. in Fl. Bras. XI, I, p. ע74. - Serra da Piedade, Mixas, 20341. Herbacé, fleurs blanclies. Novembre-décembre. C.

3. H. barbarossa Cham.; Fl. Bras. XI, I, p. 277. - Petropolis, à Santo Antonio, dans le bois, Rio-JAx., $11^{\circ} 7652$. Herb., f1. blanches. Juillet-aoùt. C.

4. H. leucocephala Cham.; Fl. Bras. XI, 1, p. 278. - Gavea, dans le bois humide, Rio-JAx., nos 3778, 13918. Herl., f1. blanches. Septembre-octobre. CG.

ร. H. hirta R. Br.; F\%. Bras. XI, I, p. 노1, - Carandahy, dans le campo humide, Misas Geraes, $n^{0} 13918$ a. Herb., fl. blanches. Maijuin. R.

6. H. hirsuta Sw. var. exigua Uib. ill Fl. Bras. XI, I, p. 282. Entre Gavea et Tijuca, dans le chemin, Rı-Jax., n ${ }^{\circ} 873 a$. Herb., 11. blanches. Aont. C. 


\section{MENHOIRES PUBLIESS}

1. Cunist, Fougères de la Chine, 69 p. (mai 190o̊), terminé.

2. Terracciavo, Gagea du nord de l'Afrique, 26 p. (nov. 190\%), terminé.

3. Glaziou, Plantes du Brésil central, 112 p. (nor. 190る̆), a suivre.

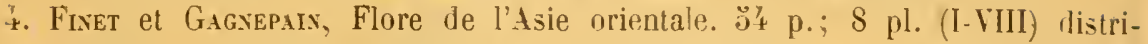
buées arec la table de 190: (mar's 1906), di suivre.

ॐ. Ligner, Anatomie des Renonculacées. 38 p. (juin 1906). terminè.

3b. Guzzou, Plantes du Brésil central. p. 113-200 (juil. 1906), à suirre.

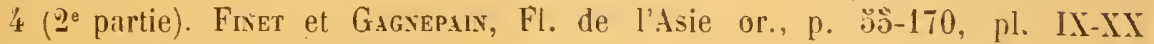
(déc. 1906), à suivre.

6. Perrot et Gérard, Anatomie du tissu ligneux dans ses rapports avec la diagrnose des bois, 43 p.; 6 pl. (juin 1907), terminé.

7. Pitard, Muscinées des iles Canaries, 44 p. (juin 1907), terminé.

8. Chevalier, Novitates floræ africunx (1 ${ }^{\text {re }}$ partie), pp. 1-30 (août 1907), à suivre.

9. Fixet, Orchidées africaines de la tribu des Sarcanthées, 63 p.; 12 pl. (nov. 1907), terminé.

10. Furche, Monocotylédones arborescentes ou frutescentes de France, d'Algérie ou de Tunisie, 26 p.; 1 pl. (aoùt 1907), terminé.

11. P. Guérux, Etudes sur les Diptérocarpées, 93 p. (décembre 1907), terminé.

3c. Glazıov, Plantes du Brésil central, pp. 201-296 (février 1908), à suivre.

12. Hce (abbé), Lichens Tarbelliens, 19 p. (avril 1908), terminé.

13. 0. Lugnier, Le fruit des Bennettitées et l'ascendance des Angiospermes, 17 p. (avril 1908), terminé.

8b. Chevalier, Novitates floræ a fricanæ (2e partie), lpp. 31-109 (aoùt 1908), da suivre.

14. Palrs (Général), Florule bryologique de la Guinée française, (novembre 1908).

3d. Glaziou, Plantes du Brésil central, pp. 297=392 (juin 1909), à suivre. 


\section{AVIS IMPORTANTS relatifs à la Publication du BULLETIN}

I. - Les manuscrits, rédigés ne varietur et lisiblement, doivent être déposés le jour même oil sont faites les communications, faute le quoi leur impressiun est ajournce sans que les auteurs puissent élever de réclamation a cet égard.

II. - Si les manuscrits sont accompagnés de figures destinées à ètre insérćes dans le texté, celles-ci doivent ètre dessinees a la plum: et au trait, ou bien au craron Wolff sur papier procéde, ou consister en bunnes photographies, de maniere a en permettre la reproduction par les procedes zincographicues. L'insertion de toute lizure ne pouvant ètre reproduile que par des procedes dill'erents reste soumise a l'approbation de la Comuission du Bulletin.

111. - Les auteurs recoivent une épreuve en placards et en louble exemplaire de leurs communications, la correction des autres epreuves etant faite par le secretariat. Les corrections doivent être retournées daus le delai maximun de trois jours an Secretaire-redacteur, faute de quoi la correction est faite d'oftice par le Secrétariat.

IV. - Lorsque les manuscrits dépassent la longueur réglementaire de 8 pages et qu'ils ne comportent pas de question de priorité. ils peuvent être publiés sous la rubrique: Mémoires publiés par la Sociélé britanique de France. Ces Mémoires sont édités avec toute la célérité possible, mais sans garantie de date. Ils prennent place tlans les volumes annuels a la suite des comnunications insèrées aux séances orlinaires et sont fournis aux Membres de la Sociéte sans majoration le leur cotisation.

V. - Afin de permettre l'établissement des convocations aux séances, WI. les Auteurs sont inslamment pries d'aviser le Secretaire général huit jours a l'avance les communitions qu'ils ont l'intention le présenter.

VI. -- En vue d'assurer l'unite typographique du Bulletin, le Conseil a arrêté le protocole ci-lessous, réglant les caractères emplorés dans les descriptions ou citations de végétaux. Il ne sera admis aucune dèrogation à cette régle.

\begin{tabular}{|c|c|c|}
\hline & NOUVELLES & ANCIENNES \\
\hline FAMille. & 1. LÉGUMINEUSES. & 2. LEGGUMINEUSES. \\
\hline $\begin{array}{l}\text { SoUs-FaMiLle. } \\
\text { Trine. }\end{array}$ & 3. Papilionacées. & 4. Papilionacées. \\
\hline GENRE. & 5. MEDICAGO. & 6. Medicago. \\
\hline EspÉce. & 7. Cylindracea. & 8. Cylindracea. \\
\hline VARIÉTÉ. & 9. Laciniata. & 10. Laciniata. \\
\hline
\end{tabular}

Tout ce qui concerne l'alministration de l'a Société doit être adressé au Secrétaire général à l'adresse suivante:

II. Lutz. professeur agrègé à l'École supérieure de pharmacie, 4, avenue de l'observatoire, Paris $\left(\mathrm{Vl}^{\mathbf{e}}\right)$.

Le Secrétaire-rédacteur, Gérant du Bulletin :

F. Cayus.

Coulommiers.- Imp. PAUL BROIDARD. 


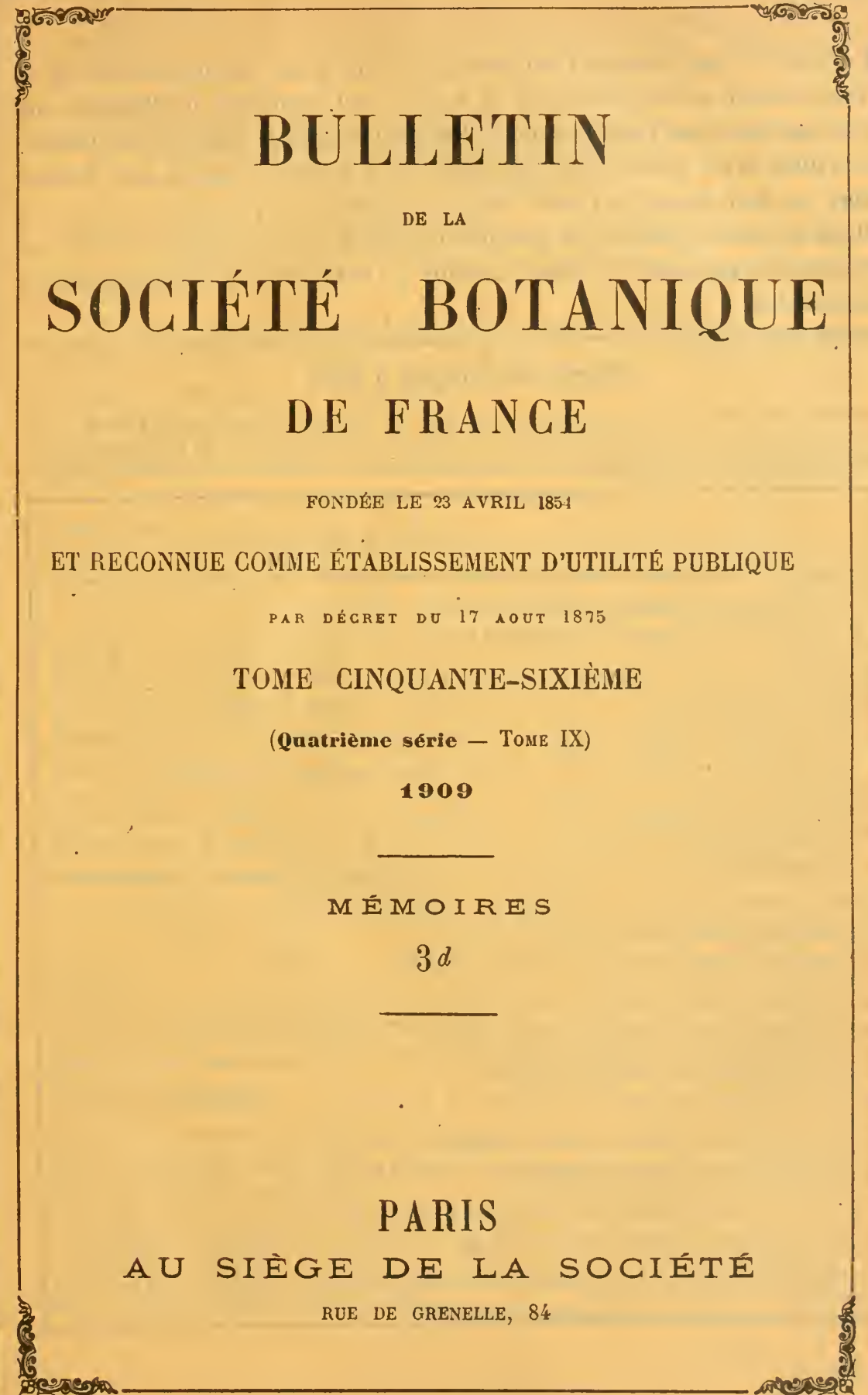

Le Bulletin de la Société botanique de France paraît par livraisons mensuelles. Le Bon à tirer de ce numéro a été donné le 20 juin 1909. 


\section{AVIS IMPORTANT}

Par suite de l'augmentation croissante du nombre des communications et de sa répercussion sur les finances de la Société, la Commission du Bulletin croit devoir lappeler à nos Confrères que le Règlement limite la longueur des manuscrits à huit pages d'impression par séance et à quarante pages pour l'année entière, au delà desquelles l'auteur doit sa collaboration pécuniaire.

Dans un intérêt commun, la Commission prie donc très instamment MM. les Auteurs de condenser le plus possible le texte des Notes destinées à l'impression.

\section{Tarif des tirages à part.}

Un tiragre sous presse de 25 exemplaires est accordé gratuitement à Messieurs les Auteurs qui en feront la demande en remettant leur manuscrit. - Les Auteurs qui préfërent des tirages à parı avec róimposition, bẻnèticieront en compensarion d'une réduction de $3 \mathrm{fr} 60$ sur les prix du tarif ci-dessous

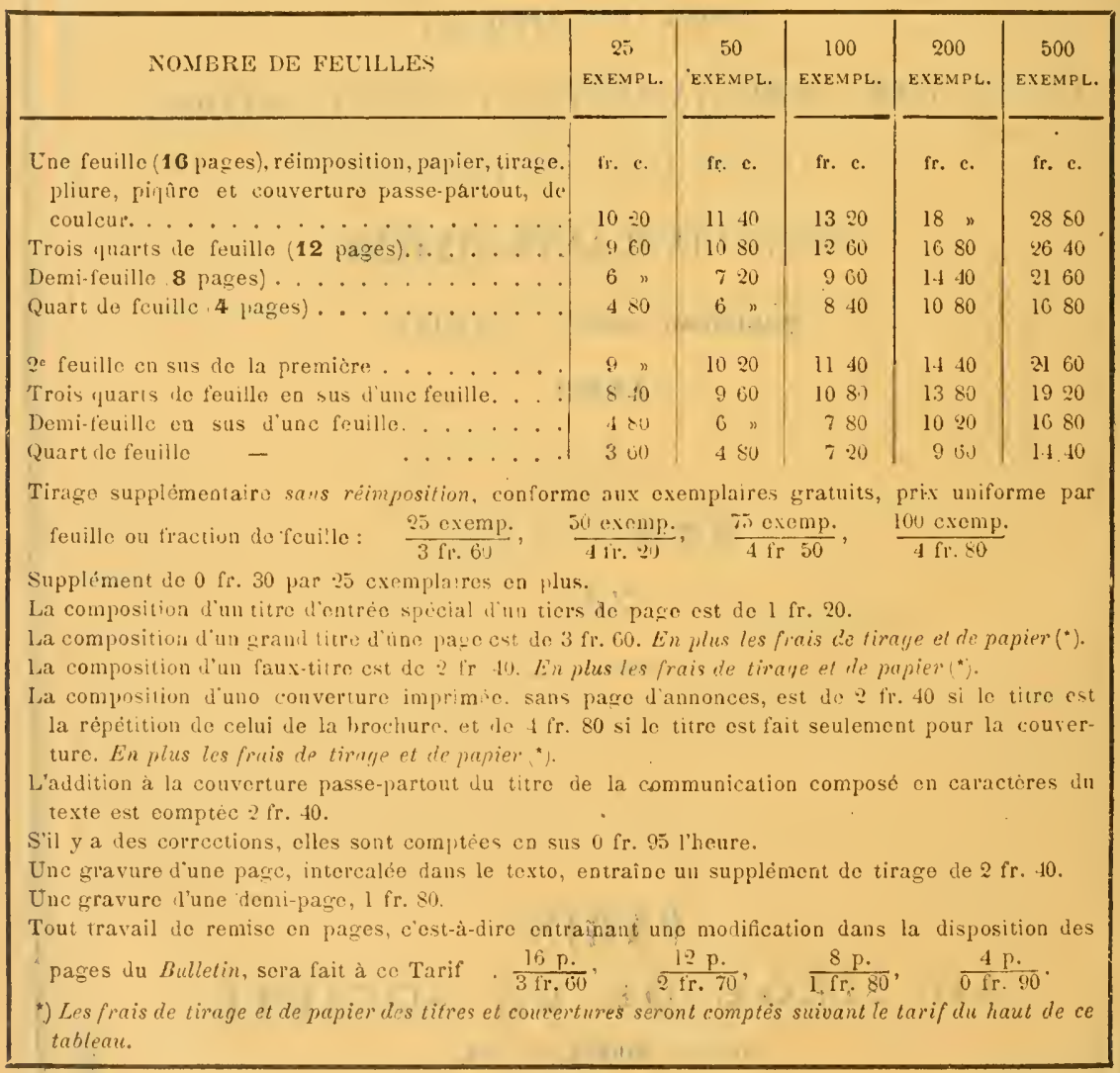


7. Centellia asiatica Urb. in Fl. Bras. XI, I, p. 287. - Serra de Jacarepagua, dans le chemin, Rı-JAx., no $3778 a$. Herb., fl. blanches. Février-mars. C.

8. Klotzschia brasiliensis Chanı.; Fl. Bras. XI, I, P. 29\%.Serra de São José d'El Rei et Serra de Caraça, M.sas Geraes, nos 14879 , 16105. Sous-frut., f1. blanchâtres. Décembre. C.

9. K. rhizophylla Urb. in Engler Botun. Jahrb. XXIII (1893), Beibl., p. 508. - Serra do Sepó. Misas Geraes. $n^{\circ}$ 19409. Viv., fl. blanchàtres. Mars-avril. G.

10. K. Glaziovii Urb. in Engler Botan. Jahrb. XXV 1898), Beibl. 60, p. 12. - Serra do Cabelludo, près Meio Ponte, Goraz, $11^{\circ} 21477$. Sousfrut., f1. blanchâtres. Septembre. C.

11. Eryngium fretidum L.; Fl. Bras. XI, I, p. 301. - Quinta de São Christovão, Rı-Jax., no 17626 . Herb., fl. blanchàtres. Septembre. C. Vulg.: Coentro da colonia.

12. E. ebracteatum Lank; Fl. Bras. XI, I, p. 306. - Lit du Rio Parahyba, à Boa Vista, Rı-Jix., nos 10892, 12746 : entre Sitio et Barbacena, dans le campo, nos 13919, 13920; São João d'El Rei, Minas Geraes, nos 16092, 16101, 16102: Rio São Bartloloneu, Goraz, nos 21471, 21472. Sous-frut., fll violacées. Aoùt-novembre. CG.

13. E. aloifolium Mart. in Fl. Bras. XI, I, 1. 309. - Campos da Bocaina, près des ruisseaux, Sĩo Paulo, $1^{0 s} 8238,16088,16089$. Sousfrut., fl. blanchàtres. Janvier-février. CC.

14. E. Serra Cham.; Fl. Bras. XI, 1, p. 310. - Entre Sitio et João Ayres, dans les bourbiers, Mixas Gernes, $n^{\text {os }} 10891,16098$. Herb., 11. blanchàtres. Novembre-décembre. C.

15.. E. elegans Cilam.; Fl. Bras. XI, 1, p. 311. - Gandarela, dans le campo, Mrxas Gerats, $n^{\circ}$ 14874. Herb., fl. blanchâtres. Févriermars. C.

16. E. floribundum Ciliam.; Fl. Bras. XI, I, p. 312. - Près de Queluz, dans les bourbiers, Misas fier.es, n" 16087. Herb., fl. blanchàtres. Janvier-décembre. C.

- Var. angustifolicm Úrb. in Fl. Bras. XI, I, p. 313. - Rancho do Marçal, près São João d'El Rei et à Garandalỵ, dans les bourbiers, Misas, $\mathrm{n}^{\text {os }}$ 14878, 16099. Herb., f1. blanchâtres. Janvier-mars. C.

17. E. Decaisneanum Urb.; Fl. Bras. X1, I, p. 316. - Barlacena et Ressaquinha, près des ruisseaux, Mrxas Geraes, $n^{\text {os. }} 12029,12030$, 12744, 12745, 16103. Herb., ti. blanchàtres. Juin-juillet. CC. 
18. Eryngium pandanifolium Cham.; Fl. Bras. XI, I, p. 317. Campos de Caraça, près des ruisseaux, Minas Geraes, nos 14873,14883 , 16104. Herb., 17. violacées. Janvier-février. C.

19. E. farinosum Glaz. n. sp. in herb. Paris., Berol. ined. - Bas de la Serra dos Pyreneus, dans le campo, Goyaz, $11^{\text {os }} 21467,21468$. Herl), f1. blanchâtres. Septembre. C.

20. E. Sanguisorba Cham.; Fl. Bras. XI, I, p. 319. - Pasto do Pires, près Faria, Mixas Geraes, $n^{\text {os }} 18270,20342$. Herb., fl. blanchâtres. Janvier-février. C.

21. E. marginatum Pohl in Fl. Bras. XI, I, p. 321. - Sitio, à Ilheos, Minas, $1^{\circ} 16096$; Fazenda dos llacacos, dans le campo, Goyaz, $\mathrm{n}^{\circ}$ 21469. Herlı., 11. blanchâtres. Octobre. R.

22. E. Kœlmeanum Url.; Fl. Bras. XI, I, p. 323. - Campos da Bocaina, São Paclo, no 8237 ; Ayuruoca, Minas Geraes, nº 16090. Herb., f1. blanchâtres. Février-mars. C.

23. E. goyazense Urb. in Engler Botan. Jarhb. XXV (1898), Beibl. 60, p. 13. - Cabeceira do Rio Santa Anna, Goyaz, no 21474. Herb., fl. blanchâtres. Janvier-février. R.

24. E. hemispharicum Urb. in Fl. Bras. Xl, I, p. 324. - Entre Sitio et Ilheos, dans le campo sec, Ninas Geraes, $n^{\circ}$ 16095; Capelinha de Santo Antonio, Goyaz, $\mathrm{n}^{\circ}$ 21470. Herb., fl. blanchàtres. Décembre. C.

25. E. Glaziovianum Urb. in Fl. Bras. XI, I, p. 325. - Itatiaia, dans le campo, Rı-Jan., n 4837. Herb., fl. blanchâtres. Juin-juillet. R.

26. E. fluminense Urb. in Fl. Bras. XI, I, p. 3џ6. - Serra dos Orgaos, au Frade et au Pico da Sandade à Nova Friburgo. Rıo-Jan., $\mathrm{n}^{\text {os }} 2839,6603,12748,13455,17627$. Herb., fl. blanchâtres. Juinseptembre. CC.

27. E. paniculatum Cav.; Fl. Bras. XI, I, p. 32T. - Itatiaia, au Campo do Silverio, Serra dos Orgãos, Rio-Jas., n ${ }^{\circ s} 4836,6578,12747$, 16086; Serra de São José d'El Rei, Mivas Geraes, $n^{\circ}$ 16100. Herb., f1. blanchàtres. Décembre-février. CG.

Forma Junior Urb. in herb. Paris, Berol., Kew. - Entre Sitio et Ilheos, dans le campo sec, Mivas, $n^{\circ} 16097$. Herbacé, fleurs blanchâtres. Janvierfévrier. C.

28. E. Goulartii Glaz. et Urb. in Engler Botan. Jarhb. (1898), loc. cit. p. 14. - Serra dos Orgãos, près de Isabeloca, Rı-JAN., nº 16085. Herb., fl. bleues. Janvier-février. C.

29. E. camporum Gl. n. sp. in herb. Paris., Berol., Kew., Brux., 
etc. - Entre Ilheos et Sitio, dans le campo sec, Minas, 11 16097 Herbacé, fleurs blanchâtres. Janvier-décembre. C.

30. E. Pristis Cham.; Fl. Bras. XI, I, p. 331. - Ayuruoca, Barbacena, Serra dos Vertentes, Minas Geraes, ${ }^{05} 550,10893,16091$; Serra dos Pyreneus, Goraz, nº 21473. Herb., fl. blanchâtres. Janvier-mars. GG.

31. E. canaliculatum Cham.; Fl. Bras. XI, I, p, 332. - Campos da Bocaina, Serra do Picú, São Paulo, nos 8240, 10890; Morro do Pires, Serra do Palmital et do Lenheiro, Mrsas Gemaes, $n^{05}$ 14875, 17625, 18269. Herb., fl. blanchâtres. Janvier-avril. CG.

32. E. scirpinum Cham.; Fl. Bras. XI, I, p. 333. - Norro das Melancias, au Rio Paranaua, Goyaz, ${ }^{\circ}$ 21476. Herb., fl. blanchâtres. Novembre. C.

33. E. junceum Cham.; Fl. Brus. Xl, I, p. 334. - Campo do Ypiranga, Sĩo Pallo, $n^{\circ}$ 16094; Serra do Lenheiro, Mrxas Geraes, $n^{\circ}$ 17016; Serra do Arruda, près Meia Ponte, Goraz, nº 21475. Herb., f1. blanchàtres. Juin-septembre. CC.

3'. E. erosum Urb. in Engler Botan. Jarhb. (1898), loc. cit., p. 14. - Serra do Batatal, Mixas Geraes, $n^{\circ}$ 14876. Herb., f1. blanchâtres. Juinjuillet. R.

33. E. Pohlianum Url, in Fl. Bras. XI, I, p. 336. - Serra de Caraça, au Palmital et à Cachambú, Mıxas Gertes, no ${ }^{\text {os }}$ 14877, 16093. Herb., fl. blanchâtres. Janviẹr-février. R.

36. Conium maculatum L.; Fl. Bras. XI, I, p. 339. - Ouro Preto et à Diamantina, Mixas Geraes, $n^{\text {os }}$ 19408, 20343. Sous-frut., fl. verdàtres. Janvier-mars. C.

37. Apium australe Du P.-Th.; Fl. Bras. XI, I, p. 340. - Gavea, près de la mer, Rio-Jas., $n^{\circ} 4001$; Ouro Preto, dans les chemins, Mixas Geraes, $1^{\circ}$ 20344. Hell., fl. verdâtres. Février-mars. G.

38. A. Ammi Urban in Fl. Bras. XI, I, p. 34l. - Floresta de Tijuca Gavea, dans les chemins, liı-JAx., ${ }^{\text {os }}$ 875, 6072; Itabira do Campo, Miras Geraes, n 17624. Herb., fl. verdâtres. Octobre-décembre. CG.

39. Ammi Visnaga Lank; Fl. Bras. XI, I, p. 344. - Piracicaba, champ inculte, São l'aulo, $\mathrm{I}^{\circ}$ 19407. Herb. ann., fl. hlanchâtres. Juinjuillet. C.

40. Fœniculum capillaceum Gilib.; Fl. Bras. XI, I, p. $3 \%$ Quinta de São Christovão, cultivé, Rio-Jax., $11^{\circ} 6072 a$. Herb. viv., fl. rerdâtres. Octobre-novembre. C. Vulg. : Funcho, Aniz.

41. Crantzia brasiliensis Glaz. n. sp. in herb. Paris, Berol., Kew., 
Gener. - Entre Ouro Preto et Mariamua, dans les bourbiers, Musas, $n^{0}$ 18510. Herbacé, Meurs jantitres. Juin-juillet. G.

\section{Fam. 68. - Araliacées.}

1. Aralia ferruginea Glaz. n. sp. in herb. Paris., Berol., Kew., Genev., ete. - Rio Santo Antonio, en bas de la Serra do Tingua, Rı-Jax., $n^{\circ}$ 9467. Arbisseau sans lleur en octobre. R.

2. A. fluminensis Glaz. n. sp. in herh. Paris., Berol., Kew., Genev., etc. - Engenho Novo et à Imbetilıa dans les sables, Rı--Jas., nos 6559 , 1895, $109416 a$. Arbrisseau sans fleur en octobre et en décembre. C.

3. Panax samoense A. Gray in Botan. U. St. Exped. 1, 717. - Quinta da Boa Vista, Rı-JAx., $\mathrm{n}^{\circ} 13922 a$. Arbuste cultivé, fleurs blanchâtres. Juillet-aout.

3 bis. Fatsia papyrifera Dene. et Pl. in Rev. Hortic. (18\%'), p. 103. - Nova Friburgo dans les jardins, Rio-JAx., n 7854 a. Arbuste cultivé, fleurs blanchâtres. Novenbre-décembre. C.

4. Didymopanax longepetiolatum E. March. in Fl. Bras. XI, I, p. 234. - Corcovado, à Cova da Onça, Rio-Jax., $11^{\text {os }} 1495,19415$. Grand arbre, fl. blanchâtres. Février-mars. C.

ว. D. lucumoides Dene et Pl.; Fl. Bras. XI, I, p. 233̈. - Itabira do Campo, Movas Genaes, $n^{0}$ 17020. Arbriss., fl. blanchâtres. Aoùt-septembre. C.

6. D. acuminatum E. March. n. sp. in herb. Paris, Bruxell. et Berol. ined. - Alto Nacahé de Nova Frihurgo, Rı-Jan., nos 19414, 17017 Arbrisseau, fl. hanchâtres. Janvier-février. R.

7. D. macrocarpum Seem.; Fl. Bras. XI, 1, 1. 237. - Serra Dourada, Goyaz, n ${ }^{\text {os }}$ 21480, 21481; Diamantina, Mlivas Geraes, nos 13922, 19412. Arbrisseau, fl. Wanchàtres. Juillet-aoùt. CG. Vulg. : Mandioca braen.

8. D. vinosum E. Warch. in Fl. Bras. XI, I, 1. 238. - Itatiaia of Serra dos Orgãos, Río-Jas., nos 10894, 17019; Ipanema, Sĩo Pacto, $n^{\text {os }}$ 12751, 13921; Diamantina, à Formação, Mıìas Geraes, no 19411. Arbriss., fl. blanchàtres. Juin-aoùt. GC.

9. D. anomalum Taub. in Engler Botan. Jahrb. (1893), p. 3̈1. Floresta da Tijuca, liı-JAN, no 12031. Grand arbre, f1. blanchàtres. Octobre-novembre. R.

10. D. falcatum E. March. 11. sp. in herb. Paris., Bruxell., et Berol. ined. - Petropolis, au Morro do Cubicado, Rio-Jax., n ${ }^{\circ}$ 17018. Grand arbre, fl. hlanchâtres. Juir-juillet. R. 
11. D. Morototoni Dene et Pl. ; Fl. Bras. XI, I, p. 240. - Corcovado, Cava da Onça, Rı-Jan., $n^{\text {os }} 1496$, 6557; Paracatú, Mtsas Geraes, $n^{\circ}$ 21479. Grand arbre, fl. blanchâtres. Janvier-mars. CG. Vulg. : Prio são José, Páo caixeta.

12. D. angustissimum E. March. in Fl. Bras. XI, I, p. 241. - Serra da Estrella, au Botequim, Rio-J $\mathrm{J}_{\mathrm{A} .}$, $\mathrm{n}^{0 \mathrm{~s}}$ 6558, 20345. Grand arbre, f1. blanchâtres. Mars-avril. C.

13. D. cordatum Taub. in Engler Botan. Juhrb. (1893), p. 509. Biribiry, Serra do Mlocotó, Mlinas Geraes, no 19413. Arbriss., 11. blanchâtres. Mars-avril. R.

1't. D. Glaziovii Taub. in Engler Botan. Jahrb. (1893), p. 5̋10. Serra do Cipo, dans le campo, Mlsas Geraes, $n^{\circ}$ 19410. Arbuste, fl. blanchâtres. Avril-mai. C.

1\%. D. calvum Dene; Fl. Bras. XI, I, p. 242. - Tijuca, au Pico do Papagaio, Rio-JAx., n $20345 a$. Grand arbre, fl. hlanchâtres. Décembre. R.

16. Gilibertia heterophylla E. Iarch.; Fl. Bras. XI, I, p. $246 .-$ Entre Corcovado et Tijuca, au llorro Queimado, Rio-JAs., $n^{\text {os }} 3021$, 5879, 12749, 19416. Arbuste, fl. blanchâtres. Mars-avril. C.

17. G. Langsdorffii E. Marcl. in Flora Bras. XI, I, p. 248. - Petropolis, au Morin, Rio-Jax., nos 13924,17021 et 17022 . Arbrisseau, fleurs verdâtres. Mars-avril. C.

18. G. cuneata E. March. in Fl. Bras. XI, I, p. 20̈0. - Congonhas do Campo et Rio Manso, Mixas Geraes, $n^{o s} 12750,13923,14880$. Arbriss., fl. blanchâtres. Juin-juillet. CG.

- Var. abbreviata E. March. in $\mathrm{Fl}$. Bras. XI, I, p. 250. - Petropolis, vieux chemins de Iinas, Rıo-Jav., ${ }^{\text {os }} 7653$, 8241; Cassu, près Uberaba, Mixas Geiraes, no 21453. Arbrisseau, f1. blanchattres. Juillet-septembre. C

19. G. affinis E. March. in $F l$. Bras. XI, I, p. 2o้1. - Entre Vargem et Rajadinha, au bord du bois, Goysz, n 21482 . Arbriss., f1. blanchâtres. Juin-juillet. C.

20. Oreopanax capitatum Dene et PI.; Fl. Bras. XI, I, p. 2อั3. Serra dla Estrella, près des rochers, Rio-JAx., $n^{0 \leqslant} 1025$, 5880. Arbrisseau, fl. blanchâtres. Août-septembre. C.

21. O. fulvum E. March. in Fl. Bras. XI, I, p. Qg:4. - Serra dos Orgãos, côté de Petropolis, près Santo Antonio, Rio-Jan., $n^{\circ} 7654$. Grand arbre, 11. blanchâtres. Juin-juillet. C. 


\section{Fam. 69: Cornacées.}

1. Griselinia ruscifolia var. Iтатіana Taub. in Engler Botan. Jahrb. XVI (1892), p. 392. - Itatiaia, entre les rochers, Rio-dax., $13^{\text {s }} 3650$, 3651; Itacolumy, Mixas, $1^{\text {os }}$ 14881, 18184: Alto Macihé et Serra dos Orgĩos, Riı-JaN., nos 4928, 6696, 12752, 13482, 17235 et 19417. Arhuste, ll. verititres. Ioùt-septembre. C.

\section{GAMOPÉTALES}

Fam. 70: Caprifoliacées.

1. Sambucus australis Ch. et Schlt.; Fl. Bras. VI, IV, p. 336. Petropolis, Rro-Jax., $\mathrm{u}^{\mathrm{os}}$ 16130, 17644. Arbrisseau cultivé, fl. blanches. Septembre-octobre. CC. Vulg. : Sabugneiro.

\section{Fam. 7l: Rubiacées.}

1. Cephalanthus glabratus K. Sch.; Fl. Bras. VI, VI, p. 128. Quinta da Boa Vista, Rio-JAx., n ${ }^{\circ}$ 12044. Arbuste cultivé, fl. blanchàtres. Novembre-décembre. R.

2. Cinchona officinalis L.; Fl. Bras. V1, VI, 1. 141. - Serra dos Orgãos, à Barreira de Sto Antonio, Ri-JAs., nos 7682, 17027, 17028. Arhrisseau cultivé, fl. rosées. Février-mars. R.

3. C. carabayensis Wedd.; Fl. Bras., VI, VI, P. 141. - Serra dos Or@ãos, a Barreira do Riø Soberbo, Rı-Jax., nos 8733, 14940. Arbrisseau cultivé, fl. blanches. Mai-juin. R.

4. C. succirubra Pav.; Triana Les Quinquinas, p. (6\%. - Serra dos Or@ãos à Barreira do Rio Soberbo, Rı-Jax., nos 7681, $1702617027 a$. Arbrisseau cultivé, t1. losées. Janvier-février. R.

5. Remijia amazonica K. Sch., Fl. Bous. VI, VI, p. 153. - Quinta da Boa Vista, Rı-Jì., nos 9885, 13937. Arbrisseau fl. Hanchâtres. Février-mars. R.

6. R. Roraime K. Sch.; Fl. Bras. VI, VI, p. 154. - Passeio Publico, Rı-JAx., nº 13462. Arbrisseau cultivé, fl. blancliâtres. Janvier-février. $\mathrm{R}$.

7. R. ferruginea DC.; Fl. Bras. VI, VI, p. 15̆. - Entre Morro de S. Vicente et Casa Branca, Mrnas, nos 12768, 12769, 13964, 14936. Arbuste, fl. blanchâtres. Janvier-février. CC. Yulg. : Muina do Campo.

8. Sickingia Glaziovii K. Sclı., Fl. Bras. VI, Vl, 1. 22077. - Serla 
da Estrella pres Mandioca, Rio-Jax., $n^{\text {os }} 12785$, 14938. Grand arbre, f1. blanchàtres. Novembre-décembre. C.

9. S. Oliveri K. Sch., Fl. Bras. VI, VI, p. 231 Pinckneya erubescens Fr. All. et Sald.). - Serra da Estrella près des rivières, Rio-Jax., $n^{\text {os }} 1100,2105,9479,14939$. Arbrisseau, f1. verdâtres. Décembre-janvier CC. Vulg. : Arariba.

10. S. viridiflora K. Seh.; Fl. Bras. VI, VI, p. 232) (Pinclimeya viridiflora Fr. All. et Sald.). - Corcovado, Tijuca, Serra do Estrella, Rio-JAx., $\mathrm{n}^{\circ \mathrm{s}} 713,4017,4826,12786$. Grand arbre, fl. verdâtres. Janvierdécenibre. CC. VuIg. : Arariba branca.

11. S. rubra K. Sch.; Fl. Bras. VI, VI, [). 233 (Pinckneya rubescens Fr. All.). - Serra la Estrella, Rıo-JAx., nos 691, 12585 a. Grand arbre, fl. verdâtres. Mars-avril. R. Vulg. : Arariba vermelho.

12. Ladenbergia hexandra Kl. ; Fl. Bras. VI, VI, 1. 144. - Restinga de Mauá et Petropolis, Rio-Jax., nos 147, 2103, 16129. Arbrisseau, fl. blanches. Octobre-novembre. C. Vulg. : Quina.

13. L. Lambertiana Klotz.; Fl. Bras. VI, VI, p. 147. - Quinta da Boa Vista, Rio-Jax., no 13947. Arbrisseau cultivé, fl. blanchâtres. Novembre-décembre. R. Vulg. : Quina.

14. Manettia gracilis Cham. et Schlt.; Fl. Bras. VI, VI, 1. 170. Serra do Picú, Rio-J.x., nos 10909, 17060. Petite liane, f1. roses. Avrilmai. C.

1i). M. ignita K. Sch.; Fl. Bras. VI, VI, P. I70. - São Julião, Ouro Preto, ele., Mrsas, $n^{\text {os }} 12773$, 12774, 18295. Liane, fl. rouges. Maijuillet. C.C. Vulg. : Poejo do mullo.

16. M. pubescens Cham. et Schlt.; Fl. Bras. VI, VI, p. 172. - Gandarela, Mrsas, nos 14913, 17630. Liane, f1. rouge pourpre. Févier-mars. C.

17. M. pedunculata K. Sch.; Fl. Bras. VI, VI, p. 173. - São Julião, Mıxas n 19435 . Liane, fl. rouges. Août-septembre. R.

18. M. luteo-rubra Benth.; Fl. Bras. VI, VI, p. 174. - Fazenda do Cipó, prés Ribeirão, Mris, $n^{\circ}$ 19434. Liane, fl. jaunes et rouges. Avrilmai. C.

19. M. racemosa Ruiz et Pav.; Fl. Bras. VI, VI, p. 176. - Serra dos Orgãos, à São Luiz, Rı-JAx., nos 3750, 10907 ; entre Sitio et Barbacena, Misas, ${ }^{\text {os }}$ 13966, 13967. Liane, fl. blanchâtres. Avril-mai. CC.

20. M. congesta K. Sch.; Fl. Bras. VI, VI, p. 177. - Serra Estrella, près Petropolis, Rio-Jav., $1^{\text {os }} 10905,10908$. Liane, f1. blanches. Marsarril. C. 
2I. Manettia Beyrichiana K. Sch., Fl. Bras. VI, VI, p. 181. - Alto Macalé de Nova Friburgo, Rio-Jav., $n^{\circ}$ 17061. Liane, 11. roses. Avriln11ai. C.

29. M. parvula K. Sil. n. sp. in herb. Paris., Berol., Kew., Gener., cte. - Serra do Alto Ilacahé, Rio-Jax., no 18294. Liane, f1. blanches. Février-mars. R.

23. M. mitis K. Sch.; Fl. Bras. VI, VI, p. I85. - Piratininga, près la mer, Rio-JAN., nº 6569. Liane, fl. blanchâtres. Mars-arril. C.

- Var. fimbriata. Fl. Bras. VI, VI, p. 185. - Floresta da Tijuca, RioJax., no 3022. Liane, fl. blanchâtres. Janvier-février. C.

- Var. Glazioviana, Fl. Bras VI, VI, p. I85̈. - Petropolis, à Quitandinha, Rio-Jax., $1^{\text {os }}$ 1101, 9476. Liane, f1. roses. Décembre-janvier. C.

24. Hindsia longiflora Benth.; Fl. Bras. VI, VI, p. 163. - Pedra do Conego, à Nova Friburgo, Rio-Jav., nos 12784, 13955, 14933 et 20351. Arbuste, fl. hleues. Février-arril. CC.

25. H. violacea Benth.; Fl. Bras. VI, VI, p. 164. - Serra do Alto Macahé, Rı-Jax., $n^{05}$ 4024, 17056. Arbuste, f1. bleues. Mar's-avril. C.

26. H. glabra K. Sch., Fl. Bras. Vl, VI, p. 16\%. - Itatiaia, dans le campo, Rio-Jan., nº 4834. Arbuste, fl. blenes. Juin-juillet. R.

27. H. breviflora K. Sch., Fl. Bras. VI, VI, p. 168. - Serra dos O)rãos, au sommet, Rio-Jax., no 2893. Arbuste, 11. bleues. Aoùt-septembre. R.

28. H. phyllocalyx K. Sch., Fl. Bras. VI, VI, p. 166. - Petropolis, au Morro da Bandeira, Rı-JAx., nos 882, 17049. Arbuste, f1. bleues. Mai-juin. R.

29. Alseis floribunda Schott; Fl. Bras. VI, VI, p. 188. - Corcovado et Petropolis, Rio-JAx, $n^{\circ 5} 3033,6038$, 8748. Arbuste, fl. hlanches. Octobre-novembre. C.

30. A. involucrata K. Sch.; Fl. Bias. VI, VI, p. 1889. - Horro da Callão et au Corcovado, Riı-JAN., $n^{\text {s }} 750,5883$, 13970. Arbuste, f1. blanches. Août-septembre. C.

31. Calycophyllum Sprnceamm Hook. f.; Fl. Bras. VI, VI, p. 191. - Quinta da Boa Vista, Rı-Jan., no 9886. Arbuste cultivé, f1. jaunàtres. Janvier-février. R.

32. Hillia Saldanhai K. Sch., Fl. Bras. VI, VI, p. 201. -- Nova Friburgo, entre les lochers, Rio-JAx., $n^{\circ}$ 12790. Arbuste, fl. blanches. Juin-juillet. R.

33. H. illustris K. Sch.; Fl. Bras. Vl, VI, p. 202. - Serra da 
A.-F.-y. GLAZJOU. - LISTE DES PLAXTES DU BRÉSIL CENTRAL.

Estrella, sur les rochers, près des ruisseaux, Rı-Jav., n $12790 a$. Arbuste, fl. blanches. R.

3'. H. parasitica Jacy. ; F. Bras. VI, VI, p. 203. - Serra do Alto Macahé, sur les rieux arbres et les rochers. Rio-JAx., $\mathrm{n}^{\text {os }} 6568,13943$. Arbuste, f1. blanches. Janvier-février. C.

30. Ferdinandusia speciosa Pohl; Fl. Bras. VI, V1, p. 207. Baixo da Serra los Pyreneos, Goysz, $n^{\circ}$ 21523. Arbuste, f1. rouges. Septembre-octobre. C.

36. F. elliptica Pohl; Fl. Bras. VI, VI, p. 207. - Sobradinho et Ilonjolo, Goraz, n² 21524. Arbrisseau, fl. rouges. Octobre-novembre. C.

37. F. rudgeoides Hook. f.; Fl. Bras. VI, VI, p. 210. - Passeio Publico, Rı-Jas., no 9883. Arbuste cultivé, ll. rouges. Février-mars. R.

38. Molopanthera panniculata Turcz. : Fl. Bras. VI, VI, 1. 199. - Cattas Altas, dans le bois, Mısas, n ${ }^{0 s} 13974,13975$, 14892. Arbrisseau, 11. blanclies. Avril-mai. C.

- Val. scabrida Ki. Sch. in Warm. Symb., p. 918. - Taquaruçu, dans le bois, Mtxas, $n^{\circ}$ 19438. Arbrisseau. Avril-mai. C.

39. Coutarea hexandra K. Sch.; Fl. Bras. VI, VI, p. 196. - Alegria, près Caraça, Hıss, $n^{\text {os }} 12770,14934$. Arbrisseau, fl. roses. Octobre-novembre. C.

- Var. fluminexsis K. Selı., Fl. Bras. VI, VI, p. 197. - Corcovado, Petropolis, Alto Vacahé, Rio-JAx., n ${ }^{\text {os }}$ 710, 4015, 8736, 10937, 13942 et 18304. Arbre, f1. blanches. Février-mars. CC.

- Var. gracilis K. Sch. in herb. Paris., Berol., Kew., etc. - Serra de Crubixaes, Rio-Jax., $n^{\circ}$ 10938. Arbuste, f1. blanchâtres. Septembrevetobre. R. Vulg. : Ouina-Quina branco.

- Var. pubescens K. Sch.; Fl. Bras. VI, VI, p. 198. - Campos da Bocaina, Sĩo-Paulo, no 10937 a. Arbre, fl. roses. Féviel-mars. C.

40. Rustia angustifolia K. Sch., Fl. Bras. VI, VI, p. „262.-Serra da Estrella, près Handioca, Rio-J An., $n^{\circ}$ 12038, 14937. Arbuste, fl. rouges. Arüt-septembre. R.

41. R. formosa Klotz.; Fl. Bras. VI, VI, ए. 262. - Corcorado et Serra da Estrella, Fio-JAx., nos 148, 1098, 2607, 6564. Grand arbre, fl. blanclıes. Janvier-férier. C.

42. R. Mosenii K. Sch. n. sp. in herb. Paris., Berol., hew., Havn., etc. - Meia Ponte, au Rio Vasa Lume, Govaz, n² 21548 a. Grand arbre, 11. blanches. Août-septembre. Ii.

43. R. gracilis K. Sch., Fl. Bras. VI, VI. p. 263. - Serra dos 
Orgrios, Alto Macahé, Rio-Jav., nos 6039, 12036, 14893, 18306, 19437. Grand arbre, ll. blane rosé. CC.

'1'. Pogonopus tubulosus K. Sch.; Fl. Bras. VI. VI, p. 260̈.Pirsseio Publico, Rro-Jav., no 18305. Arluste cultivé, fl. roses. FévrierIIIars. C.

43. Warscewiczia coccinea Klotz.; Fl. Brus. VI, VI, p. 216. Luninta da loa Vista, Rro-Jan., $\mathrm{n}^{\circ \mathrm{s}} 9863$, 13938. Arbre cultivé, f1. rouges. Janvier-février. R.

46. Bathysa Nicholsonii K. Sch., Fl. Bras. VI, VI, p. 236. - Serra da Estrella, près Petropolis, Rio-J $\mathrm{J}_{\mathrm{AN}}, \mathrm{n}^{\text {os }}$ 10902, 13949. Arbrisseau, 11. blinchâtres. Aoùt-septembre. C. Vulgo Bapebucù.

47. B. Senæii Glaz. n. sp. in herl. Paris., Berol., Kew., Havn., etc. - Faria, près Sabara, Mrxas, $n^{0}$ 18307. Grand arbre, fl. blanches. Janvier-fëvrier. R.

48. B. cuspidata Hook. f.; Fl. Bres. VI, VI, p. 237 . - Petropolis, alu Alto do Imperador, Ruo-J $\mathrm{J}_{\mathrm{x}}, \mathrm{n}^{\mathrm{0s}}$ 6567, 17055. Arbuste, fl. blanches. Février-mars. C. Vulg. : Ouina do malto.

49. B. gymnocarpa K. Sch., Fl. Bras. VI, VI, p. 238. -.- Corcovado, Jacarepagua, Tijuca, Rı-JAx., ${ }^{0 s}$ 285, 707, 10914. Arbuste, fl. blanches. Décembre-janvier. C.

50 . B. australis Hook.; Fl. Bras. VI, VI, p. 239. - Petropolis et au Alto Hacahé, Rro-Jav., n 6541, 7685, 8741, 13950, 20364. Arbuste, 11. blanches. Décembre-janvier. CC. Vulg. : Luina do matlo.

51. B. Mendonçcei K. Sch.; Fl. Brets. VI, VI, p. Ð39. - Serra da Estrella, Rı-Jax , $1^{0}$ 7677. Arbuste, 11. blanches. Novembre-décembre. C.

52. B. stipulata Presl; Fl. Brus. VI, VI, p. 2'40. - Corcovado, Tijuca, Petropolis, liro-Jas., $n^{o s} 694,703,3030,3031,13958,17629$, 20365. Arbre, f1. blanches. Octobre-novembre. CC.

53. Sipanea pratensis Aubl.; Fl. Bras. VI, VI, p. 249. -- Santa Luzia do Rio das Velhas, Mixas, n 20358 ; Retiro do Bananal, Goyaz, $\mathrm{n}^{\circ}$ 21519. Herbacé, ll. roses. Janvier-février. C.

- Var. тrichantha (Miq.); Fl. Brols. VI, VI, p. 2马̈0. - São Joũo da Barra, Rir-JAN., $1^{\circ} 9887$. Herbacé, fl. roses. Janvier-février. R.

54. Limnosipanea Spruceana Hook, ; Fl. Bras. VI, VI, p. 283. São João da Barra, dans les bourbiers, Rı-Jas., nº 9887 a. Herbacé, ft. roses. Janvier-février. C.

:ï. L. erythraoides K. Sch.; Fl. Bias. VI, VI, p. $2: 33$. - Ponte 
A.-F,-M. GLAZIOU. - LISTE DES PLANTES DU BRÉSH CENTRAL.

Lavrada, dans les bourbiers, Goyaz, $I^{0} 21692$. Herbacé, fl. roses. Aoûtseptembre. C.

56. Oldenlandia thesiifolia K. Sch.; Fl. Brets. VI, VI, p. 269. Copacabana, Gavea, Nova Friburgo, etc., Rio-J Jax., $1^{03}$ 26, 2601, 3817, 8160, 8732, 8894 et 17174. Herhacé, f1. blanc rosé. CC.

37. O. cormbosa L.; Fl. Bras. VI, VI, p. ¿̨I. - Restinga de Cabo Frio, Rı-Jax., nº 10952. Herbacé, fl. blanches. Juin-juillet. C.

58. Isertia coccinea Vahl var. hypoleuca K. Sch., Fl. Bras. VI, VI, p. 866. - Quinta da Boa Vista, Rio-Jax., $n^{\circ}$ 9880. Arbrissealu cultivé, fl. rouges. Norenbre-décembre. R.

วั9. I. longifolia K. Sch.; Fl. Bius. VI, VI, 1. 288. - Quinta da Boa Vista, Rro-Jax., nº 9902. Arbrisseau cultivé, 11. rouges. Décembrejauvier. R.

60. Schradera polycephala DC.; Fl. Bras. VI, VI, p. 29̋̈. Quinta da Boa Vista, Rro-JAx., n 13936 a. Arbuste cultivé, fl. blanclâtres. Février-mars. R.

61. S. Riedeliana, Glaz. n. sp.? in herb. Paris., Berol. Kew., Genev, etc. - Passeio Publico, Rro-Jax., nº 10935. Arbuste cultivé, fl. blanchàtres. Janvier-férrier. R. Vulgo Canella de Veado.

62. Hippotis brevipes Spr. ms.; Fl. Bras. VI, VI. p. 298. - Passeio Pulblico, Rio-Jar., $n^{\circ}$ 9906. Arbuste cullivé, f1. rousses. Novembre-décembre. R.

63. Sabicea cana Hook. f. : Fl. Lirus. VI, VI, p. 30د. - Caraça, dans le campo, llisas, nº 14912. Frutescent, fl. blanches. Janvier-férrier. C.

64. S. cinerea Aubl.: Fl. Bras. VI, VI, p. 30د̆. - Corcovado, à Paineiras, Rı-JAv., nos 714, 8740. Arbuste sarmenteux, 11. blanchitres. Janvier-février. C.

65. S. aspera Aubl. var. rotundifolia K. Sch. in herb. Paris., Berol., Kew., etc. - Quartel do Biribiry, près Diamantina, Mrsas, nº 19420 a. Arbuste sarmenteux, fl. blanchâtres. Férrier-mars. R.

- Var. scandens K. Sch., Fl. Bras. VI, VI, p. 307. - Diamantina dans le bois, au Tombador, Mrsis, no 19435 a. Sarmenteux, fl. blanchitres. Mars-avril. C.

66. Coccocypselum pedunculare Ch. et Schl.; Fl. Bras. VI, VI, p. 312. - Itacolumy, près Ouro Preto, Hısas, $\mathbf{1 1}^{\circ}$ 18293. Herbacé, fl. bleues. Juin-juillet. C.

67. G. rotundifolium Glaz. n. sp. in herb. Paris., Berol., Kew., 
Havn, etc. - Itatiaia, daus le campo humide, Rıo-JAN., II $^{\circ}$ 4832. Ilerbacé, 11. bleues. Juin-juillet. R.

68. Coccocy pselum Condalia Pers.: Fl.Bras. VI, VI, p. 313. - Serra dos Orgãos et au Pico da Tijuca, Río-Jax., nos 8156, 8744, 14906, 17030. Herbacé, fl. hlenes. Février-mars. CG.

69. C. guianense K. Sch.; Fl. Bras, VI, VI, p. 31马. - São João da Barra, près Campos, Rı-JAx., nº 9905. Herlacé, fl. bleues. Janvier-février. C.

70. C. pulchellum Cham.; $\mathrm{Fl}$. Bras. VI, VI, p. 313̈. - Itatiaia, dans le bois, liı-Jax., no 8744 a. Herbacé, l1. hleues. Janvier-février. C.

71. C. canescens Willd.; Fl. Bras. VI, VI, p. 316. - Petropolis, à Itanaraty, Rio-JAx., nos $3029,8157,18291$; Tripuhy; près Ouro Preto, Mixas, $11^{\circ}$ 20348. Herbacé, f1. bleues. Décembre-janvier. C.

72. C. erythrocephalum Cham. et Schl.; Fl. Bras. VI, VI, p. 317. Serra de Ouro Preto, Mriss, no 18292 . Herbacé, fl. bleues. Juin-juillet. R.

73. Lipostoma prostratum K. Sch., Fl. Bras. V1, VI, 1. 273. Corcovado, à Caixa d’Agua, Rio-Jav., n ${ }^{\circ s} 693,7672,12787$. Herbacé, 11. bleues. Septembre-octolure. C.

74. L. capitatum Don; Fl. Bras. VI, VI, p. 276. - Copacabana et Cabo Frio, Rio-Jav., nos 38, 12788; Cattas Altas, Mlsas, $n^{\text {os }} 13961$, 14907. Herbacé, 11. bleues. C.

75. Framelia patens Jacr.; fil. Bras. VI, VI, p. 32I. - Passeio Publico, Rı-Jux., no 706. Arbuste cultivé, fl. rouges. Sejtembre-octobre. CC.

76. Hoffmannia Peckii K. Sch, var. Selloana K. Schum., Fl. Bras. VI, VI, p. 327. - Corcovado, au I'uisseau Carioca, Rı-JAx., $11^{05} 6193$, 6775. Arbuste, fl. jaunàtres. Octobre-novembre. CC.

77. Bertiera guianensis Aubl.; Fl. Bras. VI, VI, p. 324. - Passeio Publico, Rio-JAv., n ${ }^{\circ}$ 9888. Arbuste cultivé, fl. blanches. Novemblıre-décembre. R.

78. Sommera sabiceoides K. Sch., Fl. Bras. VI, VI, p. 300. - Itabapoana, dans le bois, Espikito-Savto, nº 9890. Arbuste, ll. blanchâtres. Février-mars. R.

79. Stachyarrhena spicata Hook. f. ; Fl. Bras. VI, VI, j. 369. Passeio Publico, Rio-Jax., no $12767 a$. Arbuste cultivé, 11. blanchâtres. Nars-avril. R.

80. S. penduliflora K. Sch., Fl. Bras. VI, VI, p. 370. - Quinta da 
A.-F.-Y. GLAZIOU. - LISTE DES PLANTES DU BRÉSIL CEMTRAL.

Boa Vista, Rio-Jax., no 12767. Arbuste cultivé, f1. blanchâtres. Janvierfévrier. R.

81. Alibertia concolor K. Sch.; Fl. Bras. VI, VI, p. 388. - Serra da Cantareira, Sĩo Paclo, nos 10931,12782 , 16120. Arbuste, f1. blanches. Mars-avril.

82. A. vaccinioides K. Sch., Fl. Bras. VI, VI, p. 389. - Serra de Sào José d'El Rei, Mrsas, n 16121. Arbuste, fl. blanches. Novembre-décembre. R.

83. A. elliptica K. Sch.; Fl. Bras. VI, II, p. 389. - Congonhas do Campo, Itabira, Queluz, Mrsas, $n^{\text {os }}$ 13970, 14914, 17046, 20354 et 2356. Arbuste, f1. blanches. Juin-juillet. C. .

84. A. humilis K. Sch.?, Fl. Bras. VI, VI, p. 391. - São Fidelis, près Campos, Rro-Jax., no ${ }^{\circ}$ 9865. Petit arbuste, f1. blanches. Janvier-févirier. R.

85. A. rigida K. Sch.; Fl. Bras. VI, VI, p. 391. - Capelinha de S. Antonio, Goraz, $n^{\circ}$ 21491. Arbuste, f1. blanches. Juin-juillet. R.

86. A. longiflora K. Sch.: Fl. Bras. VI, VI, p. 412. - Serra dos Orõãos, Rio-Jax., nos 17034, 20357. Arbuste, fl. blanches. Mar's-avril. C.

87. A obtusa K. Sch, ; Fl. Bras. VI, VI, p. 393. - Restinga de Cabo Frio, Rio-Jax., nos 10945, 10960 ; Serra de Ouro Branco, Vıxas, n 14915. Arbuste, fl. blanches. Octobre-novembre. C.

88. A. myrciifolia K. Sch.: Fl. Bras. VI, VI, p. 393. - Abbade, près Meia Ponte, Goyaz, n $^{\circ}$ 21490. Arbrisseau, fl. blanches. Aoùt-septembre. C. Vulg. : Fructa de cachorro.

89. A. sessilis K. Sch.; Fl. Bras. VI, VI, p. 39\%.-- Birbacena, dans le campo, Mrsas, $n^{\circ}$ 12766. Arbuste, f1. blanches. Juillet-aoùt. R.

90. Melanopsidium nigrum Cels; Fl. Bras. VI, V, p. 372. Guaximdiba, Maria, Jurujuba, Rio-JAx., $\mathrm{n}^{\text {os }}$ 2104, 6826, 6827, 7667, 12040. Octobre-novembre. Arbuste, fl. blanches. CC.

91. Thieleodoxa lanceolata Cham.; Fl. Bras. VI, VI, p. 381. Quinta da Boa Vista, Rio-Jax., nos 10930, 13936. Rio dos Couros, Goraz, n² 21489. Arbuste cultivé, f1. blanches. Janvier-férrier. C.

92. Amajoua guianensis Aubl.; Fl. Bras. VI, VI, p. 33̆8. - Passeio Publico, Rı-Jax., n 9866. Arbuste cultivé, fl. blanches. Mai-juin. R.

- Var. brasiliaxa K. Scli., Fl. Bras. VI, VI, p. 35̆9. - Corcovado et Nova Friburgo, Rio-Jax., $\mathrm{n}^{\circ}$ 2605, 12039, 17045. Arbre, f1. blanches. Novembre-décembre. C. 
- Var. confertiflora K. Scli, Fl. Bras. VI, VI, p. 30̈9. - Santa Luzia do Rio das Vellıos, Mivas, $11^{\circ}$ 20355. Arbuste, fl. blanches. Norembre-décembre. C.

93. Duroia saccifera Hooh. f.; Fl. Bras. VI, VI, p. 36». - Quinta da Boa Vista, Rın-Jav., $n^{\circ} 8743 a$. Arbuste cultivé, fl. blanchâtres. Févriermars. R.

94. Basanacantha Annc K. Sch., Fl. Bras. VI, VI, p. 374. - Rezende, dans le bois, Rı-Jax., $n^{\circ}$ 8751. Arluste, fl. blanches, à très bonne odeur. Octobre-novembre. R. Vulg. : (inina dos pobres.

95. B. calycina K. Sch. : Fl. Bras. VI, VI, p. 375. - São Christovão, au Pedregulho, Rio-JAN., nº 18309. Arluste, fl. blanches. Août-septembre. C.

96. B. minutiflora Glaz. n. sp.? in leerb. Paris., Berol., Kew., Brux., etc. - Norro da Babylonia, à Botafogo, Rı-Jav., n $^{\circ}$ 18311. Arbuste, fl. blanches. Mars-avril. R.

97. B. spinosa K. Sch. var. polyantha K. Sch., Fl. Bras. VI, VI, p. 377. - Corcovado, à Paineiras, Rio-Jas., $1^{\circ s} 1519$, 12759. Arbuste, fl. blanches, tout-septembre. C.

- Var. ferox K. Sch., Fl. Bras. VI, VI, p. 378. - Corcovado, Jurujuba, Alto Nacahé, Rio-Jan., nos 6829,8752 , 17038. Arbrisseau, fl. blanches. Octobre-novembre. CG.

98. Posoqueria palustris Mart. ?; Fl. Bras. VI, VI, p. 337. - Passeio Publico, Rı-Jax., $n^{\circ} 4018$. Arbuste cultivé, fl. blanches. Novembredécembre. R.

99. P. macropus Mart.; Fl. Bras. VI, VI, p. 336. - Pico da Tijuca, Nova Friburgo, Rı-JAN., $n^{05} 219$, 4833. Arbuste, fl. blanches très odorantes. Novembre-décemlı'e. C. Vulg. : Bacupry.

100. P. latifolia Rom. et Sihult.; Fl. Bras. VI, VI, p. 338. - Ilha do Governador, Sambaitiba, Rio-Jax., ${ }^{0 s} 6897,8745,12041$; Carandahy, Muxas, $11^{\circ}$ 16124. Arbuste, fl. blanches odorantes. Octobre-novembre. CG. Vulg. : Bacupry.

101. P. acutifolia Vart.; Fl. Bras. VI, VI, p. 340 (Posoqueria culantha Barb.). - Serra dos Orgãos, au Imbui, Rı--JAN., $n^{0 \mathrm{~s}}$ 1603, 12042 : Itacolunny, près Ouro Preto, Mivas, $n^{\circ}$ 14917. Arbuste, fl. blanthes. Septembre-octobre. C. Vulg. : Bacupry mindo.

102. Tocoyena formosa K. Sch.; Fl. Bras. VI, VI, p. 347. - Areal de Ouro Branco, São João d'El Rei, ete., Mıxas. nos $13965,14916$. 17042; Calpelinlıa de Santo Antonio, Goraz, n 21484. Arluste, fl. verdàtres. Octobre-novembre. GG. 
- Var. petropolitana Glaz. in herb. Paris., Berol., Kew., Gener., Harn., etc. - Petropolis, Rı-JAv., nº 16123. Arbuste, fl. jaunâtres. Férier-mars. C.

103. T. stipulacea K. Sclı. n. sp. in lıerb. Paris., Berol., Kew., Brux., etc. - Entre Macacos et Chico Costa, Goxaz, $1^{\circ}$ 21485. Petit arbuste, fl. jaunes. Septembre-octobre. R.

104. T. brasiliensis Mart.; Fl. Bras. VI, VI, p. 348. - Corcovado, à Paineiras, Rio-JAx., $\mathbf{n}^{\circ}$ 10919. Arbre, fl. blanchâtres. Novembre-décembre. R.

105. T. Selloana K. Sch.; Fl. Bras. VI, VI, p. 349. - Serra do Alto Macalé, Rı-JAx., $\mathrm{n}^{\text {os }}$ 13461, 17043, 17044, 18308. Arbuste, f1. jaunes. Novembre-décembre. CC.

106. T. bullata Vlart.; Fl. Bras. VI, VI, p. 349. - Copacabana et Boa Vista, Rı-Jıx., $n^{\text {os }} 83,2606$. Arbuste, f1. jaunes. Norembre-décembre. C.

107. Ucriana longifolia Spreng.; Fl. Bras. VI, VI, p. 242. - Floresta da Tijuca, Serra da Estrella, Rio-Jan., II $^{\text {os }}$ 9471, 14935; Meia Ponte, près des ruisseaux, Goyaz, $\mathrm{n}^{\text {os }} 21521,21522$. Arbuste, f1. rouges. Aoùtseptembre. C.

108. Genipa americana L.; Fl. Bras. VI, VI, p. 331. - Quinta da Roa Vista, Rio-Jan., $n^{\text {os }} 6828,8743,10928,10929$ et 12760. Grand arbre, fl. blanches. Décembre-janvier. CC. Vulg. : Jenipapeiro.

109. Retiniphyllum truncatum Müll. Arg., Fl. Br(ts. VI, V, p. 11. - Quinta da Boa Vista, Rio-Jas., no 9870 a. Arluuste cultivé, fl. blanchâtres. Février-mars. R.

110. Guettarda platyphylla Müll. Ars.: Fl. Bras. Vl, V, p. 16. Corcovado, à Santa Thereza, Rı-JAx., nº 4021. Arlırisseau, f1. blanches. Novembre-dérembre. C.

111. G. platypoda DC.; Fl. Brus. VI, V, P, 20. - Serra de Itabapoana, Espirito Savto, n 9899. Arbuste, fl. blanclies. Août-septembre. C.

112. G. viburnoides Cham, et Schlt.; Fl. Bras. VI, V, 1. 17. - Imbitiba, près Macahé, Rro-JAx., nos 19439, 19940; São Julião, Barbacena, Serra da Piedade, etc., Misas, ${ }^{0 s}$ 10939, 12758, 13971, 14911, 17642; Lapa et Chico Lobo, Govaz, $n^{\text {s }} 20355,21534$. Arbrisseau, f1. blanches. Octobre-novembre. CC.

- Var. genura Müll. Arg.; Fl. Bras. VI, V, p. 18. - Floresta da Tijuca, Rro-Jax., no 712. Arbrisseau, f1. blanches. Octobre-novembre. R.

- Var. rhombifolia Müll. Arg., Fl. Bras. VI, V, p. 18. - Floresta 
da Tijuca, Rro-Jax, no $n^{\circ} 71$. Arbrisseau, f1. blanches. Octobre-novimbre. R.

113. Guettarda uruguensis Ch. et Scht.; Fl. Bras. VI, V, p. 26. Serra dlo Ouro Branen et au Racho do Vlarcal, Mixas, $n^{\text {os }} 14909,17039$, 20353. Arbuste, fl. blanches très odorantes. Octolne-novemlre. C.

- Var. grandifolia Müll. Arg. in herb. Paris., Berol., Kew., Genev., etc. - Serra do Ouro Branro, Mrsas, $n^{\circ}$ 14910. Arbuste, fl. blanches. Octobre-novembre. R. Vulg. : Veludinka.

11\%. Machaonia brasiliensis Cham. et Schl.: Fl. Bras. V1, V1, p. 101. - Serra da Italoapona, Esp. Savтo, $n^{\circ} 9898$. Arbuste, septemloreoctobre. C.

115. Chomelia transiens Müll. Arg., Fl. Bras. V1, V, p. 4:37. São João da Barra, Rı-JAx., $1^{05} 9867$, 10940. Arbuste, fl. blanchâtres. Février-mars. C.

116. C. minutiflora Glaz. n. sp. in herb. Paris., Berol., Kew, Gener., Brux., etc. - Fazenda do Rio Preto, Mrsas., nº 8749. Arbuste, fl. blanchâtres. Novembre-décembre. C.

117. G. gracilis K. Sch. n. sp. in herb. Paris., Berol., Kew., Brux., Gener., etc. - Riacho das Varas, Mrvas., $n^{0}$ 19441. Arbuste, fl. blanchitres. Févier-mars. C.

118. C. obtusa Cham. et Schlt.; Fl. Bras. V1, V, p. 32. - Sĩo Julião, Mrvas, $n^{0 s} 18310$, 19443; bord du Rio Tocantins, Goraz, $n^{\circ} 21492$. Arluste, fl. blanchâtres. Janvier-février. C.

119. C. occidentalis Müll. Arg.; Fl. Bras. V1, V, p. 33. - Entre Nestre d'Armas et Formosa, Goraz, $n^{0}$ 21493. Arbuste, f1. blanches. Novembre-décembre. C.

120. C. pedunculosa Benth.; Fl. Brus. V1, V, p. 3ว. - Congonhas do Campo, Mras, nº $17040 a$. Arbuste, fl. blanches. Mai-juin. C.

121. C. brasiliana A. Rich.; Fl. Bras. VI, V, p. 36. - Corcovado

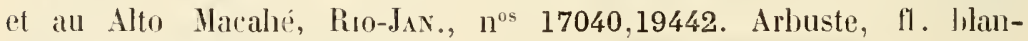
châtres. Octobre-novembre. C.

122. C. ribesioides Benth; Fl. Bras. VI, V, p. 40. - Morro Redondo et à Serra dos Pyreneos, Goraz, ${ }^{\text {os }}$ 21525, 21526. Petit arbuste, fl. blanches. Septembre-octubre. CC.

123. Malanea bahiensis Müll. Arg̣.; Fl. Bras. V1, V, p. 44. - Reslinga de Nauá, Rı-Jax., $1^{\circ}$ 8165. Arbuste, ll. blanches. Avril-mai. R.

194. M. spicata Müll. Arg. n. sp. in herb. Paris, Berol., New., 
Brux., Gener., etc. - Restinga de Mauá, Rio-Jax., II $^{\circ}$ 8166. Arbuste, f1. blanchitres. Janvier-février. R.

12\%. M. gabrielensis Vüll. Arg.; Fl. Brus. VI, V, p. 43. - Cabo Frio, Rı-Jav., nos 9884 et 13932 . Arbuste, fl. blanches. Juin-juillet. C.

126. Chiococca nitida Benth. var. anazonica Mïll. Arg.; Fl. Bras. VI, V, p. 50 . - Cabo Frio, Rio-Jas., nos 9870 et 10942. Arbuste, fl. blanches. Juin-juillet. R.

127. Ch. brachiata var. вıғовмs Müll. Arg.; Fl. Bras. VI, V. p. כ2. Itapemirim, Espirito Saxto., $1^{\circ}$ 10943. Arbuste, fi. blanchattres. Janvierfévrier. R.

- Var. dessifolia Mïll. Arg.; Fl. Bras. VI, V, p. 53. - Gavea au bord de lat mer, Rıo-Jax., $n^{0}$ 6563. Arbuste, 11. blanches. Mars-avril. C. Vulg. : Cainca.

- Var. acutrfolia Müll. Arg., Fl. bras., VI, V, 1. 53. - Restinga de Copacabana, Rio-Jax., $n^{\circ 5}$ 6, 3034. Arbuste, ll. blanches. Févriermars. C.

- Var. tenuifolia Müll. Arg. in herb. Paris., Berol., Kew., Genev., Havn., ete. - Itapemirin, Esp. Saxto, nº 10941. Arbuste, ll. blanchâtres. Janvier-février. C.

- Var. racenosa Vell.; Fl. Bras. VI, V, p. J'4. - Restinga de Cabo Frio, Rio-Jax., nº 9864. Arbuste, f1. blanches. Juin-juillet. C.

- Valr. laygeolata Mlïll. Arg., Fl. Bras. VI. V, p. כ̆4. - Itabira do Cimpo, Mrvas, no 17643: Varzea do Rio Torto, Goraz, no 21488. Arbuste, 11. blanchâtres. Décembre-janvier. C.

128. Salzmannia nitida IOC.; Fl. Bras. VI, V, p. 36 . - Restinga de Cibo Frio, Rin-Jax., no $10942 a$. Arbuste, fl. blanchâtres. Décembrejanvier. R.

129. Ixora heterodoxa Miül. Arg., Fl. Bras. VI, V, p. 67. - Floresta da Tijuca, Rı-JAx., ${ }^{0} 6154$. Arbuste. 11. blanchâtres. Novembrelécembre. C.

130. I. dimorphophrlla Vüll. Arg.; Fl. Bras. VI, V, p. 67. Morro Queimado, Ri-Jax., nos 705 et 8742 . Arluste, f1. blanchâtres. Janvier-février. C. .

131. I. membranacea Müll. Arq.; Fl. Bras. VI, V, p. 458. - Itapemirim, Esplitto SANto, no 10947. Arbuste, 11. blanches. Février-mars. C. Vulg. : Urapebr.

132. I. truncata Nüll. Arg., Fl. Bras. VI, V, p. 459. - Araruma, Rio-J $\mathrm{Jx}_{\text {. }} \mathrm{n}^{03}$ 10933, 10934. Arbrisseau, fl. blanchàtres. Juin-juillet. C. 
133. Ixora Gardneriana Benth.; Fl. Bras. VI, V, p. 69. - Serra da Estrella, Rio-JAx., ne 705 a. Arbuste, fl. blanches. Novembre-décembre. R.

134. I. venulosa Benth.: Fl. Bras. VI, V, p. 70. - Morro da Babylonia, Rio-JAn., nos 18296 et 19878. Arbuste, fr. blanches. Novembredécembre. C.

135. I. Warmingii Müll. Arg.; Fl. Bras. VI, V, p. 73. - Nova Friburgo, Rio-Jın., nos 1593, 17041. Grand arbre, fl. blanches. Octobrenovembre. C.

136. I. syringaflora Vüll. Arg.; Fl. liras. VI, V, p. 73. - Petropolis et Nova Friburgo, Rio-JAx., nos 13959,17628 . Grand arbre, fl. blanches. Novembre-décembre. C.

137. I. Glaziovii Müll. Arg., Fl. Bras. VI, V, p. 460. - Serra da Bica, près Cascadura, Rio-J $\mathrm{Jx}_{\mathrm{N}}, \mathrm{n}^{\circ}$ 10932. Arbrisseau, 11. blanchâtres. Janvier-février. R.

138. I. brevifolia Benth. ; Fl. Bras. VI, V, p. 74. - Alto Vlacahé de Nova Friburgo, Rio-Jax., n ${ }^{0} 17041$ a. Arbuste, fl. blanclies. Mar'savril.

139. Pavetta angustifolia Rom. in Schult., Syst. III, p. 173. Lagoa de Freitas, au Jard. Bot., Rio-JAx., n 16126 . Arbuste cultivé, fl. blanches. Janvier-février. C.

140. Coffea arabica L.; Fl. Bras. VI, V, p. 76. - Andarahy Grande, Rio-JAx., $1^{05} 221,7669$. Arbuste cultivé, f1. blanches. Aoùtseptembre. CG. Vulg. : Cafeciro.

141. Coussarea meridionalis Müll. Arg.; Fl. Bras. VI, V, p. S3̈. - Corcovado, Tijuca, Serra da Estrella, Rio-Jax., $1^{\text {os }} 702,1265,2608$, 2612, 16113 et 17633. Arbrisseau, fl. blanches. Aoùt-octobre. CC.

142. C. porophylla Nüll. Arg,; Fl. Bras. VI, V, p. 86. - Alto da Serra de Nova Friburgo, Rio-Jax., no 17052. Arbrisseau, fl. blanches. Novembre-décembre. C.

143. C. contracta Vïll. Arg.; Fl. Bras. VI, V, p. 92. - Floresta da Tijuca, Rio-JAx., $n^{\circ} 1263$ a. Arbuste. Mars-arril. C.

144. C. speciosa K. Sch. n. sp. in herb. Paris., Berol., Kew., Havn., etc. - Alto Macahé de Nova Frihurgo, Rio-Jax., nº 17051. Arbuste, fl. blanches. Décembre-janvier. R.

145. C. verticillata var. gr.abra Müll. Arg.; Fl. Bras. Vl, V, p. 94. - Norro Queimado, chemin du Vlacaco, Rio-JAx., nos 2610, 10912. Arbuste, fl. blanchâtres. Janvier-février. R.

146. C. hydrangeafolia Benth.; Fl. Bras. VI, V, p. 9'. - Sania 
Luzia do Rio das Velhas, Misas, $n^{\circ}$ 20363. Arbuste, f1. blanches. Norembre-décembre. C.

1'47. C. comifolia Benth. et Hook; H. Brus. VI, V, p. 9\%. - Serra dos Orgãos, Rio-JAx., n 10927. Arbuste, 11. blanches. Avil-mai. R.

148. C. nodosa Mïll. Arg.; Fl. Bras. VI, V, p. 96. - Corcovado à Paineiras, Rio-JAN., ${ }^{\text {os }}$ 1263, 1518, 4827 et 20366. Arbuste, fl. blanches. Septembre-octobre. C.

149. C. capitata Benth. et H.; Fl. Bras. VI, V, p. 98. - Jurujuba, près la mer, Rio-dax., $n^{\circ}$ 6822. Arhuste, 11. blanches. Novembre-décembre. R.

I:0. C. graciliflora Benth.; Fl. Bras. VI, V, p. 101. - Floresta da Tijuca et au Corcovado, Rio-Jav., $n^{05}$ 1262, 2604 et 10915. Arbuste, fl. blanches. Norembre-décembre. C.

1:i. C. triflora Nüll. Arọ.; Fl. Bras. V1, V, p. 102. - Nto Macahé, dans le bois vierge, Rio-Jax., Il $^{\circ}$ 20361. Arbuste, fl. blewes. Marsavril. C.

152. C. viridis Müll. Arg., Fl. Bras. VI, V. p. 104. - Entre Villa Nova et Porto das Caixas, Rı-Jax., $\mathrm{n}^{\circ}$ 7686. Arbuste, fl. blanches, fiuits noirs. Févier-mars. R.

I0̈3. Faramea urophylla Nüll. Arg.; Fl. Bras. VI, V, p. 108.Serra do Alto Macahé, Rı-Jax., nº 19447. Arbuste, fl. bleues. Arrilmai. R.

IOั4. F. Eichleri Ilïll. Arg., Fl. Bras. VI, V, p. 109. - Versant de Copacabana, au Berco, Rio-DE-JAx., n 4027; Mercès do Arassuahy, Mrss, $n^{\circ}$ 14895. Arbuste, fl. bleues. Mars-avril. C.

Io้อ̆. F. pachyantha Müll. Arg.; Fl. Bras. Vl, V, p. 119. - Serra da Estrella, Rio-JAx., n ${ }^{0}$ 6041. Arbuste, f1. blenes. Novembre-décembre. C.

Iö. F. Saldanhæi Glaz. n. sp. in herl. Paris., Berol., Kew., etc. - Restinga de Cabo Frio, Rio-Jax., nos 10948, 10949. Arlouste, fl. bleu pâle. Mars-avril. C.

157. $\boldsymbol{F}$. dichotoma K. Sch. n. sp. in herb. Paris., Berol., Kew., Havir, etc. - Nlto Macahé et Serra dos Orgãos, Rı-JAx., $n^{0 s} 3032$, 3653, 18299, 17050. Arbuste, 11. bleues. CC.

I̋\&. F. Gagnepainiana Glaz. n. sp. in herb. Paris., Berol., Kew., Genev., etc. — Serra dos Orgāos; Rı-JAs., nº 17047. Arbuste, fl. bleues Aoùt-septembre. C.

1ö9. F. salicifolia Presl; Fl. Bras. VI, V, p. 119. - Nlto Macahé 
et a Serra dos Orginos, Rio-Jax., $n^{\text {os }} 13952,16116$ et 19445. Arluste, 11. bleues. Novembre-décembre. C.

160. Faramea micrantha Müll. Arw.; Fl. Bras. VI, V, p. 126. Nova Frilurgo, Rı-Jan., $n^{\circ}$ 6561. Arbuste, fl. bleues. Janvier-février. li.

161. F. aristata Müll. Arg., Fl. Bras. VI, V, p. 460. — Fazenda de Sanla Cruz, Rro-Jan., nos 9475 et 13992 a. Arbuste, ll. blenâtres. Décembre-janvier. C.

162. F. megalophylla Mïll. Arg.; Fl. Bras. VI, V, p. 129. - Serra do Nar à Palmeiras, Rı-Jan., $n^{\text {os }} 4822,8735$ et 9869. Arbuste. f1. bleuâtres. Octobre-novembre. C.

163. F. longifolia Benth., Fl. Bras. VI, V, p. 132. - Araruama près Cabo Frio, Rro-JAx., $n^{\circ} 16117$ a. Arbuste, Il. bleuâtres. Juin-juillet. R.

164. F. Martiana Müll. Arg.; Fl. Bras. VI, V, p. 134. - Santa Anna, près Cantagallı, Rio-Jax., $n^{0}$ 16117. Arluste, fl. bleues. Septembre-octobre. C.

168. F. marginata Vart.; Fl. Bras. VI, V, p. 134. - Larangeiras près Cantagallo, Rio-Jax., no 16117. Arbuste, fl. bleues. Octobrenovembre. R.

166. F. Warmingiana Müll. Arg.; Fl. Bras. VI, V, p. 13\%. - Entre Sitio et Barbacena, Minas, n" 14896. Arbuste, 17. Jleues. Juillet-aont. C.

167. F. platypoda Viill. Arg.; Fl. Bras. VI, V, p. 136. - Itaboapoana, Espirito Saxto, $n^{\circ} 10951$; Indaya près Porto da Bandeira, Goraz, $\mathrm{n}^{n}$ 21536. Arbuste, fl. bleues. Octolire-novembre. C.

168. F. Glaziovii Müll. Arg.; Fl. Bras. VI, V, p. 139. - Serra da Estrella près Petropolis, Rio-Jax., n 3023 . Arbụste, fl. bleues. Févriermars. R.

169. F. cyanea Müll. Arg.; Fl. Bras. VI, V, p. 142. - Serra da Murilieca, Esp. Saxto, no 12761 a; Alto Nacahé, Rio-Jax., $1^{\circ} 17634$. Arbuste, fl. blenes. Octobre-novembre. C.

170. F. hyacinthina Nart.; Fl. Bras. VI. V. p. 113. - Barbacena dans le bois, Mrnas, ${ }^{\text {os }} 12761$ et 13972. Arbuste, fl. bleues. Octobrenovembre. C.

171. F. latifolia DC.; Fl. Bras. VI, V. p. 14ö. - Floresta da Tijuca, Rio-Jax., $n^{\text {os }} 698,12043$; Serra d'Ouro Branco, Mınas, ${ }^{05} 14897$ et 14898. Arbuste, fl. bleues. Octobre-novembre. C.

172. F. Nettoana Müll. Arg., Fl. Bras. VI, V, p. 147. - Alto da Gavea, Rı-JAN., no 8153. Arbuste, t1. bleues. Mai-juin. R. 
A.-F.-M. GLAZIOU. - LISIE DES PLANTES DU BRÉSIL CENTRAL.

173. F. fallax Müll. Arg., Fl. Bras. VI, V, p. 14T. - Serra de Jacarepagua, Rio-JAx., $11^{\circ}$ 852. Arbuste, fl. bleues. Septembre-octobre. R.

174. F. Lutzeana Glaz. n. sp. in lierb. Paris., Berol., Kew., Gener., etc. - Alto Macahé dans le bois vierge, Rı-Jan., nº 17054. Arbuste, fl. bleues. Novembre-décembre. C.

173. F. occidentalis Müll. Arg.; Fl. Bras. VI, V, p. 149. - Serra da Estrella, Rı-JAs., $n^{\circ}$ 13957. Arbuste, f1. bleues. Novembre-décembre. C.

176. F. nitida Müll. Arg.; Fl. Bras. VI, V, p. 15̈l. - São João da Barra, Rio-JAx., n 9868. Arbuste, f1. bleues. Janvier-février. R.

17i. F. cordifolia Glaz., 11. sp. in herb. Paris., Berol., Kew., ete. Ilorro do Coco, Rı-JAx., $1^{\circ} 9868$ a. Arbuste, fl. bleues. Janvier-févier. R.

178. F. xanthina Müll. Arg.; Fl. Bras. VI, V, p. 461. - Serra de Itaboapoana, Espimito SAnto, $\mathbf{n}^{\circ}$ 10950. Arbuste, fl. bleues. Août-septembre. C.

179. F. filamentosa Müll. Arg.; Fl. Bras. VI, V, p. 136. - Serra da Estrella près Petropolis, Rı-JAx, $n^{\circ}$ 3035. Petit arbuste, fl. bleuâtres. Mars-arril. G.

180. F. rivularis Gardn.; Fl. Bras. VI, V, p. 157, -- Corcovado, à Paineiras, Rio-J J ., $\mathrm{n}^{\text {os }} 3026,12034,13956$. Arbrisseau, 11. bleues. Novembre-décembre. CC.

181. F. anisocalyx Prepp. et Endl. Nova Gen. et species, III, 28. Quinta da Boa Vista, Rı-JAx., n" 9873. Arlouste cultivé, 11. roses. Marsavril. R.

182. Psychotria Sprucei Müll. Arg., Fl. Bras. VI, V, p. 226. - Itapemirim, Espirito $\mathrm{S}_{\text {axto, }} \mathrm{n}^{\mathrm{os}}$ 9874, 9878. Arluuste, fl. jaunes. Férrier-mars. C.

183. Ps. rigida Willd. var. hrrtella Müll. Arg., Fl. Bras. VI, V, 1. 230. - Serra de Ouro Preto, au Falcão, Misas, $n^{\circ} 19448$. Arbuste, 11. jaunes. Mars-avril. R.

- Var. intermedia Mull. Arg., Fl. Bras. VI, V, p. 230. - Campos de Pyraciraba, S. Pacto, $11^{\circ} 16114$ a. Arbuste, t1. jaunes. Février-mars. C. Vulgo Gritadeira.

- Var. strepess Müll. Arg., Fl. Bras. VI, V, p. 230. - Serra de Ouro Branco. Mixas, n 12765; Sobradinho, Govaz, $n^{\circ}$ 21528. Arbuste f1. jaunes. Octobre-novembre. C. Vulg. : Parabio.

- Var. gexurna Müll. Arg., Fl. Bras. Vi, V, p. 230. - Barneri, 
S. Pallo, 11" 10959: Sĩo Joĩo d'El Rei, Minas, $1^{\circ}$ 16114. Normbredécembre. CC. Vulg. : Griladeira.

I84. Psychotria medica Mlïll. Arg.; Fl. Bras. VI, V, p. 232. Serra de S. Pedro, dans le cerrado, Goxaz, $11^{\text {os }} 21531$, 21532. Petil arbuste, fl. jaunâtres. Décembre-janvier. C.

185. Ps. verticillata Müll. Arg.; Fl. Bras. VI, V, p. 233. - Serra las Mraras à Theresopolis, Rio-dax., n 17032; Caraça dans le bois, Minas. $n^{05} 14890,14891$. Arbuste, fl. jaunes. Férrier-mar's. C.

186. Ps. tabacifolia Müll. Arg.; Fl. Bras. VI, V, p. 2936. - Fazenda de Sant Anna, Mixas, n 2603. Arbuste, f1. jaunes. Mars-arril. C. Vulg.: Herva de Bato.

187. Ps. longepedunculata Nüll. Arg.; Fl. Bras. VI, V, 1. 237. Petropolis, à Correios, Rio-Jax., $n^{\circ 5} 2600,5887$. Arbuste, 11. jaunes. Mars-arril. C. Vulg. : Herva de Bato.

188. Ps. ampla Müll. Arg., Fl. Bras. VI, V, p. 462. - Serra do Conto près Petropolis. Rio-JAN., nos 3036 , 10958. Arluste, 11. jaunes. Mars-arril. C.

189. Ps. rudgeoides llüll. Arg., Fl. Bras. VI, V, p. 463. - Fazenda do Rio Preto, dans le bois, Mrxas, $1^{\circ 5}$ 8747. Arbuste, 11. jaunes. Novembre-décembre. li.

190. Ps. subcrocea Müll. Arg.; Fl. Bras. VI, V, p. 244t. - Belem, Rı-JAx., $n^{\circ}$ 4823; Rio Bananal, Goyaz, $n^{\circ}$ 21544. Arbuste, fl. jaunes. Oetohre-novembre. CC. Vulg. : Herva venenosa.

191. PS. Crulsiana Glaz. n. sp. in herb. Paris., Berol., Kew., Brun., ete. - Capelinha de S. Antonio, Goraz, $n^{\circ}$ 21533. Arbuste, fl. jaunes. Décembre-janrier. R.

192. Ps. coriacea Glaz. 11. sp. in herb. Paris., Berol., Kerw., Brux., etc. - Serra das Araras près Theresopolis, Rio-Jax., n' 17033. Arbuste, 11. jaunes. Janvier-février. R.

193. Ps. Maregravii Spreng.; Fl. Bras. VI, V, p. 2900. - Serra dos Orgãos, Rıo-Jax., nos 9889, 13948; Intieionado, près Caraça, Mısas., $\mathrm{n}^{\circ}$ 14889. Arluuste, 11. jaunes. Décembre-janvier. C. Vulss. : Heréa de Bato.

- Var. pubescens Mïll. Arg.; Fl. Bras. Vi, V, p. 2̈̈1. - Serra dos Orgãos, à Theresopolis, Rı-Jıx, $n^{\text {os }} 12763,12764$; Chico Costa, dans le bois, Goyaz, $n^{\circ}$ 21545. Arbuste, 11. jaunes. Octobre-norembre. C. Vulg. : Herva venenosa.

194. Ps. platypodina Miill. Arg., Fl. Bras. VI, V. p, 463. - Serra 
do Mar, à Palmeiras, Rio-JAx., nº 8739. Arbuste, f1. jaunes. Janvierfévrier. R.

19.3. Ps. subaneo-fusca Müll. Arg., Fl. Bras. VI, V, p. 464. Serra da Estrella, à Mandioca, Rio-lax., nº 10954. Arbuste, fl. jaunes. Mars-arril. R.

196. Ps. stenoclada Müll.; Fl. Bras. VI, V, p. 2כั4. - São João da Barra, Rio-J $J_{A x}$, no 9894. Arbuste, f1. jaunes. Février-mars. R.

197. Ps. xanthophy-lla Miull. Arw.; Fl. Bras. VI, V, p. 20\%. - Morrinhos dans le campo, Govaz, $n^{0 s} 21529,21530$. Petit arbuste, f1. jaunes. Septembre-octobre. C.

198. Ps. fulgens .lüll. Arg., Fl. Brus. VI, V, p. 2כ̈ . - Petropolis au Morin. Rio-Jax., n 10917. Arbuste, 1l. blanchâtres. Février-mars. R.

199. Ps. Schlechtendaliana Müll. Arg., Fl. Bras. VI, V, p. Ðอ9. Itapemirin, Espintro Sisto, $n^{0}$ 10957. Arbuste, 11. jaunâtres. Févriermars. R.

200. Ps. limbata Benth. n. sp. in herb. Paris., Berol., Kew.. Gener.. etc. - Paó d'Atho, dans le bois, Esp. Sasto, nº 13934. Arbuste, f1. roses. Avril-mai. R.

201. Ps. Glaziovii IIüll. Arg., Fl. Bras. VI, V, p. 667. - Serra do Conto, près Petropolis, Rı-Jax., n ${ }^{\circ}$ 3037. Arbrisseau, 11. bleu pâle. Mars-avril. C.

202. Ps. patentinervia Vill. Arg.; Fl. Bras. VI, V, p. 274. - Floresta da Tijuca, Rio-Jas., $n^{\circ}$ 699. Arbuste, fl. bleu pâle. Mars-avril. C.

203. Ps. pallens Gardn.; Fl. Bras. VI, V, p. 274. - Serra do Alto Macahé, Riı-Jax., $11^{\circ}$ 4023. Arbuste, fl. bleu pâle. Ilars-awril.

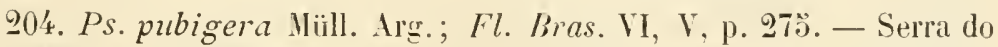
Alto Maralıé et à Tijuca, Rio-Jax., nos 704, 1261, 4022. Arbuste, fl. bleu pâle. Hars-avril. C.

200̈. Ps. clavipes Müll. Arg., Fl. Bras. VI, V, p. 464. - Itamaraty près Petropolis, Rı-JAx., no 8734. Arbuste, fl. bleu pâle. Févriermars. C.

206. Ps. macahensis Glaz. n. sp. in hert. Paris, Berol., Kew., Gener., etc. - Alto Ilarahé, Rio-Jax., nº 17635. Arbuste, 1l. blanc jaunâtre. Février-mars. C.

207. Ps. nemorosa Gardn.; Fl. Bras. VI, V, p. 278. - Serra do Alto Macahé, Rio-Jax., nos $13944,13950,16165$ et 18297. Arbuste, fl. bleues. Févirier-mars. C.C.

208. Ps. leiocarpa Cham. et Schlt.; Fl. Bras. VI, V, p. 280. - Serra 
da Estrella à Mandioca, Rio-J $\mathrm{J}_{\mathrm{A}}, \mathrm{n}^{\circ}$ 8161. Arbuste, 11. bleues. Mars. avril R.

- Var. genuina Müll. Arg., Fl. Bras. VI, V, p. 281 . - Floresta da Tijuca, Ro-Jas, n ${ }^{0}$ 696. Petit arbuste, 11. bleues. Janvier-lévrier. C.

209. Psychotria tenuinervis Mïll. Arg.; Fl. Bras. VI, V, p. 282. - Corcovado, à Paineiras, Pio-Jan,, $n^{\circ}$ 4830; Itacolumy, Mlsas, $n^{\circ}$ 14901. Arbuste, 11. bleues. Février-mars. C.

210. Ps. nitidula Ch. et Schlt.; Fl. Bras. VI, V, p. 288ั. - Jurujuba près la mer, Rı-JAx., $\mathrm{n}^{\circ \mathrm{s}} 697,6823,6824$ et 18302. Arbuste, fl. bleues. Novembre-décembre. CC.

211. Ps. diplospharica Müll. Arg.; Fl. Bras. VI, V, p. 460̈. - Sĩo Sebastião près Campos, Rı-J Jav., no 10955. Arbuste, f1. bleues. Févriermars. R.

212. Ps. brachygyne Nüll. Arg. ; Fl. Bras. VI, 1, p. 287. - Horro da Gavea, Rio-J $\mathrm{JN}_{\mathrm{N}}, \mathrm{n}^{0}$ 4028. Petit arbuste, fl. blanches. Janvier-février. R.

213. Ps. sessiliflora Glaz. n. sp. in herl. Paris, Berol., kew., Brux., etc. - Alto Macahé, Rio-JAx., n 18300. Arbuste, 11. blanchãtres. Août-septembre. C.

214. Ps. cuspidata Willd. var. vulgatior Willd.; Fl. Bras. VI, V, p. 288. - Entre Villa Nova et Porto das Caixas, Rı-JAv, nos 7688, 19444. Arbuste, fl. blanches. Février-mars. C.

215. Ps. flexuosa Willd.; Fl. Bras. VI, V, p. 293. - Serra dos Orgãos, Rio-Jax., nos 10956, 13953. Arbuste, fl. blanchâtres. Avrilmai. C.

216. Ps. cujabensis Schlt.; Fl. Bras. VI, V, p. 296. - Rio Bananal, dans le bois, Goraz, n² 21544. Arbuste, fl. jaunes. Octobre-novembre. C. Vulg. : Herva venenosa.

217. Ps. mamillaris Hüll. Arg. ; Fl. Bras. VI, V, p. 299. - Entre Villa Nova et Porto das Caixas, Rio-Jax., $\mathrm{n}^{\circ}$ 7687. Arbuste, fl. blanchâtres. Février-mars. C.

218. Ps. brevicollis Müll. Arg.; Fl. Bras. VI, V, p. 298. - Gandarela dans le bois, Minas, no $14903 a$. Arbuste, fl. blanches. Févriermars. C.

219. Ps. subundulata Benth; Fl. Bras. VI, V, p. 302. - Serra Itabapoana, Esp. SAxto, nº 9892.10955 a. Arbuste, f1. blanchâtres. Févriermars. C.

220. Ps. malaneoides Müll. Arg var. glabrescens Müll. Arg. : $F$. 
A.-F.-H. GLAZIOL. - I.ISTE DES PLINTES DU BRESHL CEYTRAI.

Bras. VI, V, p. 306. - Petropolis, a Quintandinha, Rı-JAx., $\mathrm{n}^{0 \mathrm{~s}} 7683$, 9477. Arbuste, t1. blanches. Janvier-février. C.

220 bis. Ps. forsteromioides Müll. Arg. - Fazenda de l'Itatiaia, $\mathrm{n}^{\circ} 6566$.

221. Ps. chlorotica Vüll. Arg.; Fl. Bras. VI, V, p. 310. - Inficionado, Mrsas, $n^{\text {os }} 10918,12762$, 14899; Lagoa Feia, dans le bois, Goraz, $\mathrm{n}^{\circ 5} 21542$ et 21543 . Arbuste, fl. blanches. Décembre-janvier. CC. Vulg. : Herva cafecira cenenosa.

2202. Ps. Langsdorffiana Müll. Arg.; Fl. Bras. VI, V, p. $316 .-$ Alto Jacahé, Rio-JAx., $n^{\circ}$ 20362. Arbuste, 11. blanches. Mars-avril. C.

223. Ps. bracteata DC.; Fl. Bras. VI, V, p. 312. - São João da Barra près Campos, Rio-Jax., $n^{\circ}$ 9869. Arbuste, 11. blanches. Févriermars. R.

2214. Ps. rhodoleuca Vïll. Arg.; Fl. Bras. VI, V, p. 314. - Serra do Ariro. São Pallo, no 9935 a. Arbuste, fi. blanches. Janvier-février. R.

225. Ps. spathicalyx Viill. Arg.; Fl. Bras. VI, V, p. 319. - Theresopolis, près Vargem, Rı-Jux., $n^{0}$ 12035. Arbuste, fl. bleues. Marsavril. C.

2926. Ps. venulosa Mlüll. Arg. ; Fl. Bras. VI, V, p. 294. - Quinta da Boa Vista, Rio-Jax., nos 9891,13933 . Arluuste cultivé, fl. blanc jaunâtre. Avril-mai. R.

227. Ps. biattemuata Müll. Arg.; Fl. Bras. V1, V, p. 468. - Serra do Mar à Palmeiras, Rro-JAx., $n^{0}$ 8737. Arbuste, 11. jaunâtres. Janvierfévrier. R.

228. Ps. barbiflora DC.; Fl. Bras. VI, V, p. 329. - Restinga de Mauá, Rı-JAx., $1^{05} 30$, 18301. Arbuste, 11. jaunâtres. Octobre-norembre. C.

- Var. minor Müll. Arg. in Warm. Symb., p. 910. - Santa Luzia do Rio das Velhas, Mrsas, nos 10936, 20360, 21538. Petit arbuste, fl. jaunâtres. Novembre-décembre. CG. Vulg. : Herva de rato.

2999. Ps. Ipecacuanha Müll. Arg.; Fl. Bras. VI, V, p. 341. - Jacarepagua, Rıo-JAx.. n ${ }^{05}$ 708, 2609. Sous-frutescent, fl. blanchâtres. Févriermars. C. Vulg. : Ipecacuanha.

230. Ps. pleiocephala Vïll. Arg.; Fl. Bras. VI, V. p. 3'6. - Natividade, Mrsas, no 14918. Arbuste, fl. blanches. Février-mars. C.

231. Ps. triantha Müll. Arg.; Fl. Bras. Vì, V, p. 349. - Serra Estrella, à Handioca, Rı-JAx., $11^{\text {os }} 9879$, 16122. Arbuste, 1l. blanchâtres. Février-mars. C.

239. Ps. hastisepala Müll. Arg.; Fl. Bras. VI, V, p. 330, - Serra 
do Nito Nacahé, Rio-JAx., II $^{\text {s }} 13930,21537 a$. Arbuste, 11. blanchitres. Novembre-dícembre. C.

233. Psychotria pilosa Glaz. n. sp. in herl. Paris, Berol., Kew., Gencr, etc. - Lagoa Feia, dans le bois, Goraz, n² 21539. Sous-frutescent. 11. blanchâtres. Novembre-décembre. C. Vulg. : Klerva ecnenosa.

234. Ps. xanthocephala Miill. Arg., Fl. Bras. VI, V, p. 3̈l. - Lagoa Feia, dans les hois près Formosa, Goyaz, $11^{\circ}$ 21540. Petit arbuste, 11. blanchitres. C. Vulg. : Ierva venenosa.

230. Ps. Hervinha Glaz. n. sp. in herl. Paris., Berol., Kew., Gener, etc. - Bords du Rio Gama, dans le bois, Goraz, no 21541. Petit arbuste, fl. blanchâtres. Octobre-novembre. C. Vulg. : Hervinha (très vénéneuse).

236. Ps. stachyodes Benth.; Fl. Bras. VI, V, 1. 3̈33. - Nova Friburgo, au Suspiro, Rio-JAN., no 13460. Arluuste, fl. blanchâtres. Octobrenovembre, C.

237. Ps. purpurascens Vüll. Arg. Fl. Bras. VI, V, p. 354. - Serra dos Orgaos, Rio-Jax., nos 2884, 4163, 8746, 10913. Sous-frutescent, 1 . rosées. Décembre-janvier. GC.

238. Ps. longipes Müll. Arg., Fl. Bras. VI, V, p. 334. - Nora Friburgo, Tijuca, Corcovado, etc., Rio-JAs., nos 695, 6037, 13940, 17637. Arbuste, fl. blanchâtres. Novembre-décembre. CC.

239. Ps. hancornicefolia Benth; Fl. Bras. VI, V, p. 335. - Serra do Alto Nacahé, Rio-J Jx., $n^{0}$ 17636. Arbuste, 11. blanches. Novembredécembre. C.

240. Ps. velutipes Müll. Arg.; Fl. Bras. VI, V, 1. 336. - Petropolis, à Cachambí, Rio-Jax., ${ }^{\circ}$ 7678. Arbuste, fl. blanchâtres. Norembredécembre. C.

241. Ps. janeirensis Müll .Arg. : Fl. Bras. VI, V, p. 357. - Restinga de Mauá, Rio-Jax., no 7676. Arluste, 11. blanchâtres. Octobre-novemlre. R.

249. Ps. sessilis Vell. : Fl. Bras. VI, V. p. 358. - Serra do Alto Macahé, Rı--Jax., $n^{0}$ 13458. Arbuste. 1l. blanches. Novembre-décembre. $\mathrm{R}$.

- Var. genursa Miill. Arg. ; Fl. Bras. VI, V, p. 3\%8. - Petropolis, à Cachambú, Rro-Jax., no 8155. Arbuste, 11 . blanches. Novembre-técembre. C.

2'43. Ps. megapontica Miill. Arg., Fl. Bras. VI, V, p. 361. - Bords 
A.-F.-M. GLAZIOL. - LISTE DES PLAYTES DU BRESH CEYTHAL. 355 du Rio Tocantins, Goraz, no 21537. Arluste. 11. blanclıes. Janvierférrier. C. Vulg. : Herva venenosa.

24'. Ps. ruelliafolia Miill. Arg.; Fl. Bras. VI. V, 1. 36'. - Nova Friburgo et à Petropolis, Rio-dax., nos 8159, 13459. Arbuste, 11. rougeâtres. Octobre-novemlıre. C.

2年. Ps. uberabana Miill. Aro., Fl. Bras. VI. V, p. 371. - Curainlıo, dans le bois, Goriz. nos $19444 a$, 21527; Cachoeira do Campo, llisas, n 9901. Sous-frutescent, fl. rouges. Aoùt-septentibre. C.

246. Ps. colorata Müll. Arg.; F. Bras. VI, V, p. 372. - Entre Inficionado et Caraca, Mlsas, nos 9895 . 13931. Sous-frutescent, 11. rougeâtres. Juillet-août. R.

2't7. Ps, terminalis Vell.; Fl. Bras. Vl, V, 1. 379. - Floresta da Tijuca, Rı-Jax., n 12037, Arbuste. fl. blanches. Juin-juillet. C.

248. Ps. Gardneriana Miill. Arg., Fl. Bras. VI, V, p. 379. - Corcovado. Tijuca, etc., Rio-Jax., nos 701, 3025. 3027. Arbuste, fl. blanchâtres. Mars-arril. CC.

249. Ps. estrellana Miill. Arg.; Fl. Bras. VI. V, 1. 282. - Serra do Alto Macahé, Rio-Jax., nos 10910. 18298. Arbuste, fl. blancliâtres. Novembre-décembre. C.

9:30. Mapouria chionantha Müll. Ars.; Fl. Bras. VI, V, 11. 38T.liio Gama dans le bois, Goraz, $n^{\text {os }}$ 10953, 21547. Arbuste, fl. blanches. Novembre-décembre. C. Vulg. : Herva venenosa.

2.)1. M. odoratissima Glaz. n. sp.? in herb. Paris., Berol., ȟri., Gener., etc. - Alexandre, au hord du l'uisseau, Goraz, n 21547 a. Arluuste, fl. blanches à trìs bonne odrur. Août-septembre. C.

20̈2. M. alba Müll. Aro.; Fl. Bras. VI, V, p. 393. - Corcovarlo, Floresta da Tijuca, Rio-dAx., nos 5, 700, 1264, 9882 et 10946. Arluste, fl. blanches. Février-mars. CC. Vulg. : Pao Pretinho.

23̈3. M. Martiana Müll. Argr.; Fl. Bras. VI, V, p. 39'4. - Floresta da Tijuca, Rio-Jax., no $700 a$. Arbuste, fl. blanches. Février-mars. R.

9̈3'. M. corjombifera Müll. Arg. ; Fl. Bras. VI, V, p. 396. - Itacolumy, près Ouro Preto, Msas, no 14905 ; bas du lío Gama, dans le bois. Gorız, $n^{\circ}$ 21546. Arbuste, fl. blanches. Novemlıre-décembre. CC. Vulg. : Herva venenosa.

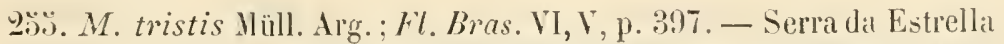
près Petropolis, Rio-JAx., non 14904, 17638. Arluste, fl. Blanches. Maijuilı. C.

2:36. M. niveobarbata Müll. Are., Fl. Bras. V1, V, 1. 401. - Serra 
da Babylonia, Mrsas, no 7684. Arhuste, fl. blanches. Janvier-février. C.

¿3̆7. Mapouria formosa Müll. Arg.; Hl. Bras. VI, V, 1. 406. - Corcovado, à Paineiras, Rio-Jan., no 17048. Arbuste, fl. blanches. Aoùt-septembre. C.

238. M. cephalantha Müll. Ar世.; Fl. Bras. VI, V, p. 41 I. - Restinga de Nauá, Rio-Jan., $n^{\circ} 7679$ a. Alluuste, fl. hlanches. Novembre-décembre. R.

๑ڤ9. M. depauperata Müll. Arg., Fl. Bras. VI, V, 1). 466, - Res. tinga de Cabo Frio, Mıxas, $n^{\circ}$ 10944. Arbuste, fl. hlapclıes. Juiı-juillet. C.

260. M. a’mulans Müll. À.; Fl. Bras. V1, V, 1. 417.--Restinga de Mauá, Rı-JAx., nos 7679, 9875, 16119. Arbusle, 11. blanches. Novembredécembre. C.

261. M. umbelluligera val. brevipes Müll. Arg., Fl. Bras. VI, V, p. 467. - Serra do Mar, à Rodeio, Rı-JAs., no 8738. Artıuste, fl. blanches. Janvier-février. C.

202. M. cymuligera Müll. Arg.; Fl. Bras. VI, V, p. 419. - Petropolis, au Vorin, Rio-Jax., $n^{0}$ 13951. Arbuste, fl. blanches. Janvier-février. C.

263. Rudgea nobilis Nüll. Arg., Fl. Bras. VI, V, p. 172. - Serra dos Oronãos, Rio-Jax., $n^{\circ}$ 6040. Arbrisseau, 11. blanchâtres. Septembreoctobre. C.

264. R. macrophylla Benth.; Fl. Bras. VI. V, p. 176. - Corcovado, à Paineiras, Rio-Jax., nº 4825. Arbuste, fl. blanches. Octobre-novembre. C.

263. R. Gomeziana Müll. Arg., Fl. Bras. VI, V, p. 177. - Restinga de Mauá, Riı-Jas., nº 7668. Arbuste, fl. blanchâtres. Octobre-novembre. R.

266. R. subcordata Müll. Arg., Fl. Bras. VI, V, p. 178. - Entre Tijuca et Jacarepagua, Rio-Jax., $n^{\text {os }} 4824,8154$. Arbuste, fl. blanches. Juillet-aoùt. C.

267. R. lanceolata Benth.: Fl. Bras. VI, V, p. 180. - Floresta da Tijuca, Rı-JAx, $n^{\circ} 8154 a$. Albuste, fl. blanches. Mai-juin. R.

268. R. erioloba Benth.; Fl. Bras. VI, V, p. 182. - Bas de la Serra Dourala, Govaz, $n^{\circ}$ 21535. Arbuste, fl. blanches. Octobre-novembre. C.

269. R. irregularis Müll. Arg.; Fl. Bras. VI, V, p. 184.- Diamantina dans le bois, Misas, $n^{\circ} 19448 a$. Arhuste, fl. blanches. Mars-avril. R.

270. R. eriantha Benth.: Fl. Bras. VI, V, p. 186. - Larangeiras et Corcovado, Rio-JAx., $n^{\circ s} 1517,4828$, 7673. Albuste, fl. blanches. Oclobrenovembre. G. Vuln. : Fructa de Jacaré.

27I. R. coriacea K. Sch. n. sp. in Ierb. Paris., Berol., Kew., 
Brux., ete. - Cosme Velho, à Larangeiras, Rio-Jax., n 19446. Arbuste, fi. blanches. Oetobre-novembre. C.

272. R. Langsdorffii Müll. Arg., Fl. Bras. VI, V, p. 191. - Corcovado, à Paineiras, Rı-Jas , $1^{\circ}$ 7674. Arbrisseau, 11. blanches. Aoùt-septembre. C.

273. R. clavipes Bentlı.: Fl. Bras. VI, V, 1. 192. - Jurujuba près de la mer, Rio-Jax., $11^{\circ} 6825$ a. Arbuste, fl. blanches. Novembredécembre. R.

274. R. Martiana Nïll. Arg.; Fl. Bras. VI, V, p. 197. - Sete

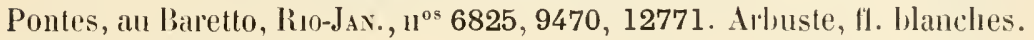
Octobre-novembre. CC.

273. R. corniculata Benth.; Fl. Bras. VI, V, p. 199. - Nova Friburgo, au Conego, Rio-Jax., $\mathbf{n}^{\circ \mathrm{s}} 4016,13457$, 17053. Arbuste, fl. blanches. Noventbre-décembre. C.

976. R. Poissonii Glaz. n. sp.? in herb. Paris., Berol., Kew., Genev., etc. - Pico do Itacolumy, Mras, n 14900. Arluste, 11. blanclies. Févier-mars. C.

27T. R. parvifolia Müll. Arg.; Fl. Bras. VI, V, p. 201. - Petropolis, à Itamaraty, Rio-Jax., $n^{0 s} 14894,14902$. Arbuste, 1l. blanches. Févriermars. C.C.

278. R. decipiens Müll. Arg. ; Fl. Bras. VI, V, p. 202. - Morro da Gavea, Rro-JAx., nº 692. Petit arbuste, fl. blanches. Mai-juin, R.

279. R. insignis Vü̈ll. Ar., Fl. Bras. VI. V, p. 203. - Nova Friburgo, au Alto, Rí-JAx., $n^{\text {os }} 6896,13941,13954$. Arbuste, fl. Hlanclaâtres. Janvier-rlécembre. C.

280. R. viburnoides Benth.; Fl. Bras. VI, V, p. 20't. - Sĩo Joiio d'El Rei, Mixas, no 17037 ; Fazenda dos Vacacos, Goraz, n² 21487. Arhuste, f1. blanches... (.

281. R. lacerostipula K. Sch. n. sp.? in herb. Paris., Berol., Kew., Havn., etc. - Rio Tocantins, au passage, Goraz, n 21486. Arbuste, 11. blanches. Janvier-février. C.

282. R. gardenioides Müll. Arg. Fl. Bras. VI, V. 1. 206. - Serra do Picu, près Barreira, liı-Jax., nº $19446 a$. Arluste, ll. blanches. Aoùtseptembre. R.

283. R. vellerea Hüll. Arg., Fl. Bras. VI, V, 11. 208. - Sera Estrella, à Mandioca, Rro-Jax., nos 1097, 8158. Arbrisseau, 11. blanchâtres. Septembre-octobre. C.

284. R. tinguana Müll. Alg.; Fl. Bras. VI, V, p. 210. - Canta- 
gilllo, a Larangeiras, Rio-Jav., $n^{0}$ 16118. Arbuste, f1. blinches. Octolrenovembre. C.

283. Rudgea ovalis Müll. Arg., Fl. Bras. VI, V, p. 462. - Restinga de Cabo Frio, Rio-Jas., nº 9478. Arbuste, fl. blanches. Avüt-septemlıre, R.

286. R. cyanosperma Hüll. Aro.; Fl. Bras. VI, V, p. 211. - Corcovado, à Lagoinha, Rio-Jax., $11^{\circ}$ 3024. Arbuste, fl. blanches. Férriermars. C.

287. R. Uleana Glaz. 11. sp.? in herb. Paris., Berol., Kew.; Genev., etc. - Serra do Picú près Iiarreira, Rro-Jan.. nº 10911 a. Arluste, t1. blanches. Février-mars. C.

288. R. conocarpa Müll. Arg.; Fl. Bras. VI, V, p. 212. - Sapopemba, Rio-dan., no 10911. Arbuste, fl. blanches. Janvier-février. C.

289. R. Glaziovii Mlüll. Arg., Fl. Bras. VI, V, p. 217. - Corcovado, Rio-Jıx., no 2096, 6560. Arbuste, fl. blanches. Aoutt-septembre. C.

990. R. villosa Benth. 11. sp.? in herb. Paris., Kew., Berol., Genev., etc. - Serra dos Purys, Espinito Saxto, no 9893. Arbuste, 11. blanchâtres. Loùt-septembre. R.

991. Declieuxia cordigera Nart. et Z.; Fl. Bras. VI, V, p. 433. Ayuruoci, dans le campo, Mrsss, no 9473 . Frutescent, fl. bleues. Marsavril. C.

- Var. genuina Müll, Arg.; ; Fl. Brus. VI, V, p. 434. - Cabeceiras do Rio Bananal, dans le campo, Goraz. no $21503 a$. Frutescent, fl. bleues. Mars-avril. C.

- Var. floribunda K. Sch. var. nov. in herb. Paris., etc. - Biriliry, près Diamantina, Mıvas, $n^{\circ 5} 19450,19451$. Frutescent, fl. bleues. Mars-avril. C.

992. D. amplexicaulis K. Sch. n. sp.? in herb. Paris., Berol., kew., Genev., etc. - Entre Barreira Grande et Valla Funda, Misas, $n^{\circ}$ 19449. Frutescent, li. bleues, Hars-avril. C.

993. D. origanoides Zucc., Fl. Brrs. VI, V, p. 439̈. - Riacho Fundo, dans le campo, Misas, $1^{\circ} 19453$. Frutescent, fl. bleues. Févriermars. R.

294. D. glauca Mart.; Fl. Bress. VI, V, p. 438. - Corrego Secco, dans le campo, Mıxas, $1^{\circ}$ 19454. Frutescent, fl. bleues. Février-mars. C.

295. D. divergentiflora DC.: Fl. Bras. VI, V, p. 4 1 I. - Itacolumy près Ouro Preto, Nisis, $1^{\circ} 14199$; Eutre Lambary et Formosa, Goraz, $n^{\circ}$ 21494. Frutescent, fl. bleues. Janvier-février. C.

296. D. anceps K. Sch. n. sp.? in herb. Paris., Berol, Kew., Ge- 
A.-F.-.H. GLAZIOU. - LISTE DES PLANTES DU BHESH. CEYHAL.

nev., etc. - Entre Lagoa do Piquiero et Buraco da Onça, . Mısıs, $1^{0} 21500$. Frutescent, fl. blanches. Septembre-octobre. R.

997. D. chiococcoides Nüll. Argg.; Fl. Bras. VI, V, p. 4'1. - Norro do Pires près Sabara, Nwas, $n^{\circ}$ 18303; Barra do Rio Torto. dans le campo, Goyz, $\mathrm{n}^{\text {os }} 21496,21497,21498,21499$. Frutescent, 11. bleues. Janvier-mars. CC.

- Var. lucida Müll. Arg. ; Fl. Pries. VI, V, p. 443. - Pedra do Coneggo près Nova Friburgo, Rio-JAx., $\mathrm{n}^{\circ}$ 12783; Corrego do Brejo, dans le campo. Goraz, n² 21495. Frutescent, fl. blanches. CC.

- Var. peberulexta Müll. Arg., Fl. Bras. VI, V, p. 444. - Santa Luzia do Rio dos Velhos, Mswas, $n^{0 s} 19452,20359$. Frutescent, fl. bleu pâle. Novembre-décembre. C.

¿98. D. sclerophylla Vüll. Arg., Fl. Brus. VI, V, p. '67. - Campos da Bocaina, S. Paclo, no 8162 . Frutescent, fl. bleues. Janvier-février. C.

299. D. dasyphylla K. Sch. n. sp.? in herb. Paris., Berol., Kew., Brux., etc. - Entre Rio Tocantins ef Os Porcos, Goyaz, $n^{\circ}$ 21502. Frutescent, fl. blanches. Janvier-février. C.

300. D. polygaloides Zuce.; Fl. Bras. VI, V, p. 446. - Caraça, dans le campo, Mrsts, $n^{0}$ 14929. Frutescent, fl. bleues. Mars-avril. C.

301. D. Selloana Müll. Arg.; Fl. Bras. VI, V, p. 4ł'̇. - Caraça, an Morro da Carapuça. Mrsas, ${ }^{\circ}$ 14927, 19456 a. Frutescent, tl. bleues. Mai-juin. CC.

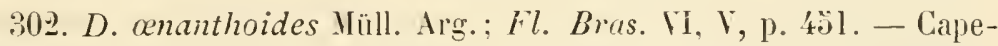
linla de Santo Antonio, Goraz, $n^{\circ}$ 21501. Frutescrnt, 1l. bleues. Septembre-octolre $\mathrm{C}$.

- Var. genuina Müll. Arg.; Fl. Bras. VI, V, p. 40̈2. - Ayuruoca, au Serro Frio, Mrsas, nos 9474,16115 . Frutescent, 11. bleues. Janvier-février.

- Var. loxgrfolia Mïll. Arg.; Fl. Brols. Vl, V, p. 4302. - Caraça, dans le campo, Mısas, $n^{\circ}$ 14928. Frutescent, 1l. bleues. Janvier-févier. C.

303. D. spergulifolia Mart., $\mathrm{Fl}$. Bras. VI, V, p. 40̈2. - Pinheiro près Biribiry, dans le campo, Hrss, $n^{\circ s} 19455$, 19456. Frutescent, f1. bleues. Février-mars. C.

304. D. frankenioides K. Sch. n. sp.? in herb. Paris.. Berol., Kew., Genev., etc. - Serra dos Cristaes près Diamantina, Vıxis, nos 19116 , 19457. Frutescent, fl. bleues. Avril-mai. R.

30 3̆. D. aspalathoides Müll. Arg.; Fl. Bras. VI, V, p. 45ั3. - Caheceiras do Rio Torto, dans le campo, Goyaz, $n^{\circ}$ 21503. Frutescent, f1. bleues. Norembre-décembre. C. 
306. Declieuxia Schwackei K. Sch. n. sp.? in herb. Paris., Berol., Kew., Brux, etr. - Biribiry pris Diamantina, dans le campo, Mısas, $n^{\circ}$ 19717. Lintescent, 11. blenes. Mars-ivril. C.

307. D. ericoides Glaz. n. sp.? in herb. Paris., Berol., Kew., Genev., etc. - Bords du Riacho las Varats, Mtsas, $11^{\circ}$ 19458. Frutescent, 11. bleues. Mars-avril. R.

308. D. muscosa St. Hil., Fl. Bras. VI, V, p. 45\%. - Bandeirinha près Diamantina, Nasas, $n^{\circ}$ 19459. Plante très petite, 11. bleues. Avrilmai. R.

309. Congdonia carulea Müll. Arg.; Fl. liras. VI, V, p. 456 . Serra dos Orgãos, au sommet, Rı-J AN., $^{\text {os }} 3754,14908,17029,17632$. Frutescent, 11. bleues. Juillet-aoùt. R.

310. Pæderia Gardneri Hook.; Fl. Bras., VI, VI, p. 6. - Restinga de Cabo Frio, Rı-Jav., no 13935. Arbuste, f1. blanches, Octobre-septembre. R.

311. Diodia polymorpha Ch. et Schlt. var. microphylla Ch. et Sehlt., Fl. Bras. VI, VI, p. 12. - Serra da Babylonia, Mlısas, nos 7670 , 7671 ; Petropolis, dans les chemins, $n^{\circ}$ 17059; Santa Luzia, aux bords des bois, Goraz, $1^{\circ}$ 21520. Frutescent, 11. blanches. Aoùt-septembre. GC.

- Var. anthospernoides K. Sclı, Fl. Bras. VI, VI, 1. 12. - Caraça, dans les bourbiers, Mrxis, $n^{0 s}$ 14926, 16110. Frutescent, fl. blanches. Juin-juillet. CC. Vulgo: Vassirunha.

- Var. floribunda K. Sch., Fl. Bras. VI, VI, p. 13. - Petropolis, au Retiro, Rı-Jav., $11^{\circ}$ 3028. Frutescent, fl. blanches. Septembreoctobre. C.

312. D. paradoxa Cham.; Fl. Brus. VI, VI, p. 13. - Nova Friburgo, au Conego dans le loois, Rio-Jan., $n^{\circ} 18282$ a. Herbacé, n. blanchex. Juin-juillet. C.

313. D. alata Nees et Mart.; Fl. Brus. VI, VI, p. 1't. - Restinga da Tijuca, Rı-JAx., nº 6043 a. Herbacé, fleurs blanches. Octobre-norembre. R.

314. D. saponariffolia K. Sch., Fl. Bras. VI, VI, p. 16. - Ilha do Governador, Rı-Jan., no 17035 . Herbacé, ll. blanclıes. Novembre-décembre. C.

315. D. gymnocephala K. Sch., Fl. Bras. VI, VI, p. 16. - Serra da Estrella, Rio-JAN., $11^{\circ} 10926$ a. Frutescent, fleurs blanches. Juilletsoùt, C.

316. D. rosmarinifolia Pohl; Fl. Bras. VI, VI, p. 18. - Fazenda do 
Morro Azul, S. Paulo, $\mathrm{n}^{\text {os }} 12779,13969$. Herbace, 17. blanches. Arrilmai. C.

317. D. prostrata Sw.; Fl. Bras. VI, VI. p. 19. - Sao Juĩo da Barra, Rı-JAx., no 9872 . Herbacé, fl. blanches. Févriel-mars. IR.

318. D. conferta DC. : Fl. Bras. VI, V1, p. 19. - Serma da Caraça, Mrxas, no 13939. Herbacé, fl. blanches. Octobre-novembre. C.

319. D. setigera DC.; Fl. Bras. YI, V1, p. 20. - Serra da Mantiquiera, Misas, no 10923. Herbacé, fl. blanches. Aoùt-septembre. R.

320. D. rigida Ch. et Schlt.; Fl. Bras. VI, VI, p. 21. - Restinga dil Tijuea, Rio-Jax., no 6043; Congonhas do Campo et Serra do Lenheiro, Mriss, nos 10921. 16109, 18287 et 17631. Frutescent, fl. blanches. Maiaoùt. CC.

321. D. hyssopifolia Ch. et Schlt. Fi. Bras. VI, VI. p. 23. - Restinga de Copacaliana, Rio-JAs., n ${ }^{\circ}$ 9876. Herbacé, fl. blanches. Féviernal's. R.

322. D. Radula Ch. et Scinlt.; Fl. Bras. VI, VI, 1. 2:3. - Restinga de Copacabana et Nova Friburon, Rio-JAx., nos 23, 18278, 18282. Herbacé, fl. blanches. Oetobre-novembre. C.

323. D. microcarpa K. Sch. n. sp.? in herb. Paris., Genev., etc. - Nora Friburgo, dans le bois. Riro-Jax., nº 18283. Herbacé, fl. blanches. Novembre-décembre. C.

324. Hemidiodia ocimifolia K. Sch.; Fl. Bras. VI, VI, p. 29.-Floresta da Tijuca et Corcorado, Rio-JAx., $1^{\circ \mathrm{s}} 9897,10926$ et 18273. Helbacé, f1. blanches. Aout-septembre. CC.

323. Spermacoce tenuior L., Fl. Bras. VI, VI, p. 34. - Itabapoana, prés de la mer, Esp.-Sixto, no 9920. Herbacé, fl. blanches. Févriermars. R.

326. Borreria lavis Griseb.; Fl. Bras. VI, VI, p. 43. - Marianna, près Ouro Preto, Mısas, no 12777. Herbacé, fl. blanches. Juin-juillet. C.

327. B. capitata DC.; Fl. Bras. VI, VI, p. 44. - Restinga de Copacabana, Rio-Jas., $n^{03} 31,8750,18277$, Petropolis, $n^{\text {os }} 17239,17240$; Serra do Lenheiro, Mrrss, no 20346. Frutescent, fl. blanclıes. Mai-juin. CG. Vulgo: Vassurinha.

328. B. tenuis DG. ; Fl. Bras. VI, VI, p. 40̈. - Campos pres la mer, Rio-Jix., n? 9871 . Mars. R.

329. B. eryngioides Ch. et Schlt.; Fl. Bras. VI, VI, V. 4T. - São Christovão, Rro-Jax., nos 18281, 19421 ; Mestre d'Amas, Goraz, no 21513. Herbace, fl. blanches. Mai-juillet. CC. 
330. Borreria simplicicaulis K. Sch. n. sp.? in herh. Paris., Berol., Kew, Genev., ete. - Fazenda do Cipó, près Itiquira, Misas, n² 21514. Herbacé, 11. blanches. Mars-arril, C.

331. B. ocimoides DC.; Fl. Bras. VI, VI, p. 48. - Calo Frio, Rio$\mathrm{J}_{\mathrm{AN}}, \mathrm{n}^{\circ}$ 10925. Herbacé, 11. blanches. Juin-juillet. R.

332. B. verticillata Ney.; F!. Bras. VI, VI, p. 49. - Entre Gavea et Tijuca, Rio-JAN., n ${ }^{\text {os }} 3752,4981$; Petropolis et au Corcovado, $n^{\text {os }} 17057$, 17058, 18279, 18280; Faria près Sabara, Mrnas, $1^{\circ}$ 18284. Frutescent, f1. blanches. Janvier-mai. CG.

333. B. argentea Cham.; Fl. Bras. VI, VI, p. 51. - Piracicaba, dans le campo, S. Pavlo, $n^{\text {os }} 12884,16108$. Herbacé, f1. blanches. Févriermars. C.

334. B. scabiosoides Ch. et Schlct.; Fl. Bras. VI, VI, p. 54. - Restinga de Nauá, Rı-JAN., nos 6042, 9896; Lagoa Feia, près Santa Luzia, Govaz, no 21518. Herbacé, fl. blanches. Octobre-novembre. C.

335. B. cupularis JC.; Fl. Bras. VI, VI, p. 52. - Itapemirim, EspIпито Saxto, no 10916. Herbacé, fl. blanehes. Février-mars. C.

336. B. tenella Cham. et Schlct.; Fl. Bras. VI, VI, p. 54. - Floresta da Tijuca, Rio-JAx., nos 32, 205, 19426 a, 21505. Herbacé, f1. blanches. GC.

- Var. genuina K. Sch., Fl. Bras. VI, VI, p. 5̋. - Campos da Bocaina, S. Paulo, $\mathrm{n}^{\text {os }} 8163,9900,10904$; entre Barbacena et Sitio, Minas, $\mathrm{n}^{\text {os }}$ 12776, 14922. Herbacé, fl. blanches. Novembre-décembre. CC.

- Var. corracea K. Sch.; Fl. Brols. VI, VI, p. こّ̋, et in Warming. Symb. p. 916. - Ayurunca, S. Paulo, nos 9472,18288 . Herbacé, fl. blanches. A vril-mai. C.

- Var. macrocephala Glaz. in herb. Paris., Berol.. Kew., Genev., etc. - Campos da Bocaina, São Paulo, nº 8143. Herbacé, fl. blanches. Janvier-févirier. $\mathrm{R}$.

- Var. platyphylla K. Sch., Fl. Bras. VI, VI, p. $5 \%$. - Diamantina, Minas, $n^{\circ} 19426$; Pouso Alto, aux sources du Rio Santa Anna, Goyaz, $n^{\circ}$ 21516. Herbacé, fl. blanches, Janvier-février. C.

- Var. tenera K. Sch. var. nov. in herb. Paris., Berol, Kew., etc. São Julião, Hsxas. no 18286; Rio Torto, Goyaz, no 21512. Herbacé, fl. blanches. Mars-avril. G.

- Var. pumila K. Sch. n. var. in herb. Paris., Berol., Kew., etc. Cachoeira da Vargem Grande, Goyaz, $n^{0 s} 21509$, 21510. Herbacé, fl. blanches. Janvier-février. C. 
A.-F.-M. GLAzIOU. - LISTE DES PlaNtes DU BRÉSIL CENTRAL.

- Var. suaveolexs K. Sch., Fl. Bras. VI, VI, p. 56. - Serra da Piedade, Mivas, $n^{03} 19423,20347$. Herbacé, fl. błanches. Novembre-décembre. C.

337. B. brachystemonoides Ch. et Schlt.; Fl. Bras. V1, V1, p. $37 .-$ Biribiry, près Diamantina, Mrxas, ${ }^{\circ} 19425$; source du Rio Torto, Goraz, $n^{0 \times} 21506,21507$. Frutescent, f1. blanches. Novembre-décembre. C.

338. B. Poaya DC.; Fl. Bras, VI, VI, p. :8. - Serra de Ouro Branco, Hisas, ${ }^{\text {os }} 16128,17036,18285$. Herbacé, fl. bleues. Hars-mai. C.

- Var. gevurna K. Sch., Fl. Bras. VI, V1, p. อ̈9. - Serra dos Orgaos, au sommet, Rio-JAx., $\mathbf{n}^{03} 3753,14920$. Herbacé, fl, blanches. Mar'savril. R.

- Var. nervosa K. Sch. Fl. Bras. VI, VI, p. 59. - Campos la Bocaina, S̃̃o Paulo, $n^{0}$ 14921; Rasgão, près Corumba, dans le campo, Goyaz, $\mathrm{n}^{\circ}$ 21508. Herbacé, fl. bleues. Septembre-octobre. C.

339. B. latifolia K. Sch.; Fl. Bras. V1, V1, p. 61. - Serra da Itabapoana, Esp. Savto, nos 10924,18277 a. Herbacé, 1l. blanchâtres. Septembre-octobre. R.

340. B. cymosa Ch. et Schlt.; Fl. Bras. VI, VI, p. 64. - Floresta da Tijuca, Rio-JAx., $1^{0 s} 5885,5886$. Herbacé, fleurs blanches. Nai-juin. C.

341. B. eupatorioides Ch. Schlt.; Fl. Bras. VI, VI, p. 66. - Fazenda do Mlorro Azul, S. Paulo, $\mathrm{n}^{\circ}$ 12781. Herbacé, fl. blanches. Avrilmai. C.

342. B. angustifolia Ch. et Schlt.; Fl. Bras. VI, VI, p. 67. - Campos da Bocaina, Süo-Pauro, $\mathrm{n}^{0}$ 8164; entre Sitio et Barbacena, Mrvas, $\mathrm{n}^{\text {os }} 14924,14925,16107,17640$ et 19424. Herbacé, fl. blanches. Norembre-décembre. CG.

343. B. valerianoides Ch. et Schlt.; Fl. Bras. VI, VI, p. 70. Campos da Bocaina, Sïo-Pauro, $\mathrm{n}^{0 \mathrm{~s}}$ 10903, 12780; Congonhas do Campo, Mras, nos 14925 a 18290 . Herbacé, f1. blanches. Avril-juin. CG.

344. Schwendenera tetrapy xis K. Sch.; Fl. Bras. VI, VI, p. 98. - Nambucaba, Rio-Jıx., no 191 a. Herlacé, fl. llanchâtres. Févriermars. R.

34\%. Psyllocarpus asparagoides 11. et Z.; Fl. Bras. VI, VI, p. 31. - Curalinho, près Diamantina, Mrsas, nos 14930 , 19430. Frutescent, 11. bleues. Mars-avril. C.

346. Ps. phyllocephalus K. Sch.n. sp. in herb. Paris., Berol., Kew., Brux., etc. - Guralinho, près Diamantina, Mrsas, $11^{\circ} 19429$; entre Paranauá et le Rio Torto. Gorız, $n^{\circ} 21504$. Frutescent, fl. bleues. Férriermars. C. 
34. Psy-llocarpus laricioides M. et\%. ; Fl. Bras. VI, VI, p. 32. - DiaInantina, au Tombadol et à Caraça, Minas, $11^{05} 8470$, 14931, 14932, 17641, 19431, 19432, 19432 a, 20350. Frutescent, fl. bleues. Janvier-mars. CC.

348. Endlichera umbellata K. Sch.; Fl. Bras. VI, VI, p. 38. Floresta da Tijuca, Corcovado, Rio-JAx., nos 145, 1102, 1502, 7867; entre Inficionado et Caraça, Mısas, $n^{0 s} 12772,13962$. Herlacé, volulile, fi. blanches. Juin-octubre. CC.

349. Mitracarpus microphyllus Glaz. n. sp.? in herb. Paris., Berol., Kew., Brux., ete. - Paracatu, près du Porto, Mixas, no 21511. Frutescent, li. blanchâtres. Septemlre-octobre. R.

330. M. Lhotzkyanus Cham.; Fl. Bras. VI, VI, p. 80. - Restinga de Copacabana, Rio-JAx., $n^{\text {os }} 2106$, 4025. Herbacé, fl. blanches. Octolurenovembre. C.

381. M. frigidus K. Sch.; Flora Bras. VI, VI, p. 81. - Cabo Frio et Copacabana dans les sables, Rio-JAx., nos 12789, 18275. Herbacé, f1. blanchâtres. Septembre-actobre. C.

392. Var. Humboldtanus K. Sch.; Fl. Bras. VI, VI, p. 82. - Serra da Ouro Preto, Mixas, nos 18289, 19422. Frutescent, fl. Blanchîtres. Arrilmai. GC.

3:33. M. hirtus DC. ; Fl. Bras. VI, VI, p. 84. - Caraça dans le campo, Mrsas, $n^{\circ}$ 12775. Herbacé, fl. blanches. Juillet-aoùt. C.

3̋ั4. - Var. remotiflorus K. Sch. Fl. Bras. VI, VI, p. 85. - Restinga da Tijuca, Rio-Jax., no 10920; Soya Velha, Goraz, nº 21515. Herbacé, fl. blanches. Mars-avril. C.

3ä5. Richardsonia grandiflora Ch. et Schlet.; Fl. Bras. VI, VI, p. 93. - Alegre, près Caraça, Mıxas, $n^{\circ}$ 12778. Herbacé, fl. blanches. Juin-juillet. C.

3506. R. brasiliensis Gomez; Fl. Bras. VI, VI, p. 94. - Restinga de Copacabana, Rio-Jax., nos $191,709,3790,5884$; Faria, près Sabara, Ilris, $n^{\text {os }} 18274$, 18276. Septembre-octobre. CC. Vulg. : Picao du Prino, Soraya branca.

5ii. R. rosea St. Hil.; Fl. Brus. VI, VI, p. 98. - Itatiaia, daus le campo, Rio-JAx., nº 5884 a. Herbacé, fl. blanchâtres. Juin-juillet. R.

3ə̌8. Perama hirsuta Aubl.; Fl. Bras. VI, VI, p. 89. - Serra de Itabapoana, Esp. SAxro, nos 9805, 10922; Biribiry, près Diamantina, Mıxas, $n^{\circ} 19420$. Herbacé, fl. blanches. Février-mars. C.

33̈9. P. vellerea K. Sch. n. sp. in herb. Paris., Berol., Kew., Brux., etc. - Serra do Cipó, Mısas, nos 19462,19463 . Frutescent, fleurs rosées. Avril-mai. R. 
A.-F.-M. GLAZIOU. - LISTE DES PLANTES DU bRÉLL CENTRAL.

360. Staelia capitata K. Sch., Fl. Bras. V1, VI, p. 72. - Corrego do Brejo, Goraz, nos 19463 a, 21517. Herbacé, fleurs blanches. Févriermars. G.

361. Relbunium atherodes K. Sch.; Fl. Bras. VI, VI, p. I07. Fazenda de Santa Gruz, Rio-Jas., nº 19427, Frutescent, f1. blanches. Aoùt-septembre. C.

362. R. hirtum K. Sclı.; Fl. Bras. VI, VI, p. I0t. - Serra da Piedade et Ilheos, Mixıs, $\mathrm{n}^{\text {os }} 16112$, 20349. Sous-frutescent, f1. blanchâtres. Janvier-février. CC.

363. R. diffusum K. Sch.; Fl. Bras. VI, VI, p. 111. - Serra de Ouro Preto, Mixas, $n^{\circ} 16111$. Herbacé, fl. blanches. Novembre-décembre. GC.

364. R. hypocarpum Hemsl.; Fl. Bras. VI, VI, p. 112. - Carandahy, dans les bois, Misas, no 13946. Herbacé, f1. blanclies. Janvierférrier. C.

365. R. Sellowianum K. Sch.; Fl. Bras. VI, VY, p. 11\%. - Itatiaia et au Pico d'Itacolumy, Misas, $n^{\text {ss }} 6562$, 14919. Herbacé, f1. blanches. Février-mar's. C.

366. R. vaillantioides K. Sch.; Fl. Bras. VI, VI, p. 115. - Itatiaia et au Morro Jaragua, $\mathrm{S}_{\mathrm{A} O} \mathrm{P}_{\mathrm{Au}} \mathrm{L}, \mathrm{n}^{\text {os }} 4831$, 19428. Herbacé, fl. blanches. Avril-juin. C.

367. B. diphyllum K. Sch., Fl. Bras. VI, VI, p. 117. - Campos da Bocaina, au Garaffão, SÃo Pavıo, nº 11604. Herbacé, fl. blanches. Aoùtseptembre. R.

368. Schenckia Blumenaviensis K. Sch., Fl. Bras. VI, VI, p. 247. - Itatiaia, dans le bois, Rio-Jax., no 4834 a. Frutescent, 11. rosées. Juinjuillet. R.

\section{Fam. i2: Valérianées.}

I. Valeriana scandens L.; Fl. Bras. VI, IV, p. 343. - Nova Friburgo, dans le bois, Rı-JAx., no 12791 . Herbacé, volubile, f1. blanchâtres. Mai-juin. C.

- Var. Candolleana Müll. Arg.; Fl. Bras. VI, IV, p. 344. - Floresta da Tijuca, Rı-JAx., n ${ }^{\text {os }} 6694,12792$. Herbacé, volubile, fl. blanchâtres. Aoùt-septembre. $\mathbf{R}$.

2. Valerianopsis organensis Müll. Arg. A.; Fl. Bras. VI, IV, p. 3'18. - Itacolumy, près Ouro Preto, IIxis, no 14923. Sous-frutescent, 11. blanclıes. Février-mars. C. 
3. Valerianopsis Glaziovii Taul,. in Engler Bot. Jahrb. XV (1893), Beibl. 38, p. 10. - Itatiaia, dans le campo, Ro-JAN., I1 ${ }^{0 s} 4847,6576$. Sous-frutescent, fl. blanches. Janvier-février. C.

\section{Fam. 73: Calycérées.}

1. Boopis bupleuroides Müll. Arg.; Fl. Bras. VI, IV, p. 339. Itatiaia, dans les campos Brajos, Rı-J $\mathrm{J}_{A N}$., $1^{\circ \mathrm{s}} 6586$, 16215. Herbacé, 17. blancles. Janvier-'évrier. C.

2. Acicarpha spathulata R. Br.; Flora Bras. VI, IV, 3306 . - Restinga de Copracabana, Rio-Jas., $n^{\text {os }} 60,3681,18341$. Sous-frutescent, fl. Hamchâtres. Septembre-octobre. CC.

\section{Fam. 74: Composées.}

1. Sparganophorus Vaillantii Grantz; Fl. Bras. VI, II, p. Ћ. Carandahy. dans les bourbiers, Mısas, no 12802 Sous-frutescent, f1. violacées. Juin-juillet. C.

2. Centratherum punctatum Cass.; Fl. Bras. VI, II, p. 11. Fazenda da Stationa, Rio-Jax., $n^{\circ}$ 4864, 5904. Sous-frutescent, fl. blanches. Juin-juillet. C.

3. C. brachylepis Sch. Bip.; Fl. Bras. VI, II, p. 12. - Barbacena, dans le campo, Minas, $n^{\circ}$ 14013. Sous-frutescent, fl. blanchâtres. Juin-juillet. C.

4. Vanillosmopsis erythropappa Sch. Bip. : Fl. Bras. VI, II, p. 14. - Tijuca, Corcovado Petropolis, etc., Rio-Jax., $n^{03}$ 166, 1416, 8115, 8783, 11045: Campos da Bocaina, S. Pavlo, nº 8126: Serra da Caraça, Barbacena, Carandahy, Mıvas, nos $11070,11108,12853,14958$ et 19564. Arbrisseau, fl. blanc rosé. Aoùt-septembre CG. Puo Candeia et Camara.

5. V. polycephala Sch. Bip.; Fl. Bras. VI, II, p. 1. 13. - Serra de Ouro Preto, Mıxas, $n^{\circ}$ 12811. Arbrisseau, 11. blane rosé. Juillet-aoùt. R.

6. V. capitata Sch. Bip.; Fl. Bras. VI, II, p. 15. - Pinheiro, près Diamantina, Mısas, no 19563. Arbuste, fl. blanchâtres. Février-mars. C.

7. Gorceixia decurrens Bak. in Journ. of Bot. (1882) p. 225. Antonio Sereira, dans le bois, Mıxas, nos 12803 , 14026. Arbuste, ll. blanchâtres. Février-mar's. C.

8. Albertinia brasiliensis Spreng.; Fl. Bras. VI, II, p. 17. Floresta da Tijuca et au Corcovado, Rio-JAx., $n^{\text {os }} 552,1485,4045$. Arbuste, f1. jaunâtres. Juillet-aoùt. C. 
A.-F.-Y. GLA7LOE. - LISTE DES PLANTES DU BRESIL CENTRAL.

9. Alcantara Isabellæ Glaz. nov. g. et n. sp.? in leerb. Paris., Berol., Kew., Genev., Brux., etc. - Serra da Baliza, entre les rochers à Vargem Grande, Goyaz, n 21668 . Arbuste de 2 ì 3 m. o fl. roses. Janvier-février. R.

10. A. Petroana Glaz. sp. n.? in. herh. Paris., Berol., Kew., Genev., etc. - Chapadão dos Veadeiros, entre les rochers, Goyaz, $n^{\circ}$ 21667. Arbuste de 2 à 3 m., fl. roses. Janvier-février. R.

11. Vernonia pedunculata DC.; Fl. Bras. VI, II, 1). 20. - Serra da Caraça, aux bords des bois. Misas, $n^{\circ}$ 14973. Arbrisseau, fl. roses. Janvier-février. C.

I2. V. oppositifolia Less.; Fl. Bras. VI, II, p. 21. - Tijuca, Corcovado, Serra dos Orgãos, Tingua, Rı-Jax., nos 167, 1399, 1486, 8782, 9481, 13988 et 16210. Arbrisseau, f1. blanches. Janvier-juillet. CG.

13. V. puberula Less.; Fl. Bras. VI, II, p. 22. - Alto Macahé et Petropolis, Rio-JAn., n ${ }^{\text {os }} 3042,17072$. Grand arbre, f1. blanches. Octobrenovembre. C.

14. V. diffusa Less.; Fl. Bras. VI, II, p. 22. - Serra dos Orgãos, Rio-JAx., nos 2840, 9497, 12057. Grand arbre, fl. blanches. Septembreoctobre. C. Vulgo : Pao C'andeia.

- Var. approximata Bah.; Fl. Bras. VI, II, p. 23. - Entre São José dos Cerreiros et Formosa, Rio-Jax., n 11104. Grand arbre, f1. blanches. Aoùt-septembre. R.

- Var. dilatata Glaz. var. nov. in herb. Paris., Kew., Berol., etc. Serra dos Orgãus, à Theresopolis, Rı-Jax., n 9498 . Grand arbre, fl. blanches. Octobre-novembre. $\mathrm{R}$.

10๊. V. discolor Less.; Fl Bras. VI, II, p. 23. - Serra dos Orgãos et Corcovado, Rio-JAx., $n^{\circ s} 180,1616,6027$. Grand arbre, f1. blanches Aoùt-septembre. G. Vulg. : Pao candeia.

- Var. robusta Bak. var. n. in herb. Paris., Kew., Berol., etc. Itacolumy, près Ouro Preto, Misas, nos 15041 , 18334. Grand arbre, fl. blanches. Juin-juillet. C.

- Var. parvifolia Bak. var. n. in. herb. Paris., kew., Berol., etc. Alto Macahé et Nova Friburgo, Rio-JAN., n ${ }^{\circ 5}$ 2634, 13463, 17652, 19566. Grand arbre, fl. blanches. Octobre-novembre. C.

I6. V. serrata Less.; Fl. Bras. VI, II, p. 24. - Corcovado et Floresta da Tijuca, Rio-Jax., $n^{\text {os }} 1425,5890,8505$. Sous-frutescent, fl. blanches, Juin-juillet. CC.

17. V. condensata Bak. in Journ. Bot. XIII (1875), p. 202. Lagoa de Freitas, à Tres Vendas, Rio-JAx., n ${ }^{\text {os }} 3700$, 7705. Sous-frutes- 
cont, 11. blanchitres. Juin-juillet. Vulg. : Carurú, Arumin, Liurú, cultivé (originaire d’Afritjue).

18. Termonia crotonoides Sch. Bip. : Fl. Bras. VI, II, 1. 2'4. - Serra de Ouro Preto, Mrsas, nos 14951, 19560. Arhuste, fl. roses. Février-mars. CC.

19. V. Iychnophoroides Glaz, n. sp.? in herh. Paris., Kew., Berol., Genev., Brux., etc. - Cachoeira de Vargem Grande, Goraz, $n^{0}$ 21594. Frutescent, fl. blanchâtres. Juin-juillet.

20. Y. megapotamica Spreng.: Fl. Bras. VI, II, p. 27. - Itacolumy, pres Ouro Preto, Mlixas, $1^{\text {os }} 8120,11039,14992$; entre Valu et Paranauá dans le campo, Goraz, no 21620 . Herbacé, fl. blanches. Févriermars. C.C.

- Var. argentina Hieron., in herls. Paris., Berol., etc. - Santa Luzia dans les campos sees, Goraz, n ${ }^{\circ}$ 21621. Herbacé, fi. violettes. Mars-avril. C.

2I. V. tragicefolia DC.: Fl. Bras. VII, II, 1) 28. - Barbacena, dans le campo, Mxas, $n^{0}$ 14993. Herbacé, fl. lilas. Novemhre-décembre. C.

22. V. araneosa Bak.; Fl. Brus. V1, II, P. 32. - Rio dos Couros, dans le campo, Goraz, n² 21633. Sous-frutescent, fl. blanches. Juilletaonit. C.

23. I. dura Mart: Fl. Bras. VI, II, p. 33. - Serra dos Cristaes près Diamantina, Mıxas, $n^{\circ}$ 19524; entre Rio Torto et Paranauá, Goyaz, $n^{\circ} 21633 a$. Sous-frutescent, 1\%. violettes. Avril-llai. C.

24. V. Poissoniana Glaz. n. sp.? in herb. Paris., Kew., Berol., Gener., etc. - Cabeceiras do Rio Sant'Anna, Goraz, no 21659. Sousfrutescent, fl. blanchâtres. Janvier-férrier R.

2อ้. V. eriolepis Gardn.; Fl. Bras. VI, II, p. 34. — Jocio Pereira, Misas, $n^{\text {os }}$ 14023, 16145. Sous-fiutescent, fl. violetles. Juin-jnillet. C.

26. V. onopordioides Bak.; Fl. Bras. VI, II, p. 36. - Serra dos Ciristaes, près Diamantina, Misas, $1^{\circ}$ 19505. Sous-fiutescent, fl. violettes. Avril-mai. R.

27. V. bardanoi des Less.; Fl. Bras. VI, II, p. 36. - Santa Luzia dans les cerrados, Goraz, $n^{0}$ 21628; Morro do Pires, près Sabara, Mrvas, $\mathrm{n}^{\text {as }} 14986,18328,18329$. Sous-frutescent, fl. violâtres. Février-mars. CC.

28. V. pjenostachya DC.; Fl. Bras. VI, II, p. 37. - Formação près Diamantina, Mrvas, $1^{\circ} 14990$, 19504. Frutescent, f1. violettes. Marsavril. C.

29. V. rosea Mart.; Fl. Bras. VI, II, p. 38. - Barbacena ef Serra de Ouro Branco, Mivas, $1^{\circ s} 14988$, 14989. Frutescent, fl. roses. Octobrenovembre. CC. 
A.-F.-M. GLAZJOL. - LISTE DES PLANTES DU BRESHL CENTIAL.

30. V. argyrophylla Less.; Fl. Bras. V1, II, 1. 39. - Ipanema, dans le campo, S. Paulo no 12890: Barbacena, Misas, nº 14987: Fazenda do Paraizo, au passage du Rio Tocantins, Goraz, $11^{\circ}$ 21627. Frutescent, f1. violettes Janvier-mai. CG.

31. V. Urbaniana Glaz. n. sp.? in herb. Paris,, Berol., Kew., Brux.. etc. - Ponte Alta, dans le campo, Goyaz, $n^{\circ} 21660$. Frutescent, 11. riolettes. Octobre-novembre. R.

32. V. macrophylla Less.; Fl. Bras. VI, II, p. 40. - Petropolis, à Santo Antonio, Rio-Jax., $n^{\circ s} 8117,8482$, Frutescent, fl. blanchâtres. Nai-juin. C.

33. V. Glazioviana Bak., Fl. Bras. VI, II, p. 41. - Serra dus Orgĩos, au sommet, Rio-Jax., $1^{\text {os }} 2843,4062,16153,17650$. Frutescent, 11. blane jaunâtre. Férrier-mars. C.

34. V. coriacea Less.; Fl. Bras. VI, II, 1. 43. - Sâo Julião dans Ie campo, Hras, no 18327. Sous-frutescent, fl. lilas. Férrier-mars. R.

30. V. buddleiafolia Vart.; Fl. Bras. VI. II, p. 43. - Entre Joào Ayres et Sitio, Mnss, $n^{0 s} 1644,19490$ b.; Paranauá. dans le campo, Goraz, $n^{\text {os }} 21625$ a, 21630. Sous-frutescent, fl. roses. Férrier-mars. C.

36. V. flavescens Glaz. n. sp.? in. herb. Paris., Berol, kew, etc. - Serra do Cabelludo, près Meia Ponte, Goraz, $1^{\circ}$ 21631. Arluste. f1. roses. Aoùt-septembre. C.

37. V. adenophylla Mart.; Fl. Bras. VI, II, p. 47. - São João d'El Rei, Uisas, no 17081. Sous-frutescent, fl. lilas. Octolre-norembre. C.

38. I. cephalotes DC. : Fl. Bras. VI, II, p. 47. - Barbacena, Mrss, $n^{\circ}$ 15093; Entre Chapadinha et Guariralıa, Govaz, $n^{\circ}$ 21577. Herbacé, f1. lilas. Septembre-octobre. C.

39. V. robusta Gla\%. 11. sp.? in lıerb. Paris., Berol., Kew., etc. Entre Palmital et Amoreira, dans le cerrado, Goraz, n 21626. Arbuste, 11. violacées. Juin-juillet. C.

40. I. desertorum Yart.: Fl. Lras. VI, II, p. 48. - Serra de Ouro Preto, Hrxas, $n^{\circ}$ 15089; Rileirão de Caldas et à Tijuca, Goraz, $n^{\circ s} 21581,21582$. Herbacé, 11. lilas. Août-septembre. CC.

41. V. Sicechas Mart.? Fl. Bras. VI. II, p. 49. - Serra do Lenheiro, près S. João d'El Rei, Mrys, $n^{\circ}$ 17063. Sous-frutescent, fl. blancliätres. Vars-arril. R.

42. V. brevifolia Less.? in Limnixa IV (1899), p. 28:3. - Serra dos Cristaes, près Diamantina, Mriss, $11^{\circ} 19491$ a. Sous-frutescent, f1. Ilanchâtres. Mars-arril. R. 
43. Vernonia psilophylla DC.; Hl. Bras. VI, II, P. 49. - Campos da Bocaina, São Pauto, $n^{\circ} 8136$; Serra do Lenheiro, Mısas, nos $19090 a$, 19506, 19536. Sous-frutescent, 11. lilas. Février-mars. C.

44. V. rosmarinifolia Less.; Fl. Bras. VI, II, p. :50. - Chapadão dos Veadeiros, à Vargen Grande, Goyaz, $\mathrm{n}^{\circ}$ 21605. Sous-frutescent, f1. lilıs. Janvier-février. C.

43. V. paulensis Glaz. n. sp.? in herb. Paris., Berol., Kew., Genev., etc. - Campos da Bocaina, S. Pavlo, no 8133. Petit arbuste, f1. lilas. Janvier-février. G.

46. V. solitaria Glaz. n. sp.? in herb. Paris., Berol., Kew., Genev., etc. - Chapadão dos Veadeiros, ì Vargem Grande, Goraz, $n^{\circ}$ 21604. Sous-frutescent, f1. lilas. Juin-juillet. R .

47. V. linearifolia Less.; Fl. Bras. VI, II, p. 51. - Barbacena, dans le campo, Mrsas, $n^{\circ}$ 14984. Sous-frutescent, fl. lilas. Novembredécembre. R.

48. V. erythrophylla DC.: Fl. Bras. VI, II, p. :2. - Rio Gama, dans le campo, Goyaz, no 21576 . Sous-frutescent, fl. roses. Octobrenovembre. C.

49. V. simplex Less.; Fl. Bras. VI, II, p. Зั2. - Serra do Lenheiro près São João d'El Rei, Mısas, nos 17071, 20375. Herbacé, fl. lilas. Juinjuillet. CG.

ॐ0. V. psilostachya DC.; Fl. Bras. VI, II, p. こ33. - Cabeceiras do Rio Gama, dans le campo, Goraz, $1^{\circ} 21643$. Herbacé, fl. blanchâtres. Octobre-novembre. C.

51. V. alpestris Bak.; Fl. Bras. VI, II, p. 53. - Biribiry, entre les rochers, Minas, $n^{\circ}$ 19547, 19548. Subacaule, fl. blanchâtres. Marsavril. C.

- Var. angustifolia Bak. var. n. in herb. Paris., Kew. Berol., Brux., ete. - Entre Biribiry et Diamantina, Mısıs, $n^{0}$ 19545. Subacaule, fl. blanchàtres. Mar's-avril. C.

52. V. Gagnepainiana Glaz. n. sp.? in herb. Paris., Kew., Berol. - Diamantina, à Formação, Mrsas, n ${ }^{\circ}$ 19546. Acaule, fl. blanchâtres. Avril-mai. R.

כัง. V. barbata Less.; Fl. Bras. VI, II. p. 57. - Entre São Vicente et S. Bartholomeu, Mrinas, ${ }^{0}$ 14991. Sous-firutescent, fl. blanches. Juinjuillet. C.

34. V. oligactoides Less.; Fl. Bras. VI, II, p. 58. - Ipanema, dans le campo, S. Pauıo, $n^{0}$ 12896. Frutescent, 11. blanches. Avril-mai. G. 
A.-F-.M. GLAZIUL. L LISTE DES PLANTES IU BRESIL CEXTRAL.

5้. V. velutina Glaz. n. sp.? in lıerb. Paris., Berol., Kew., Genev., etc. - Cabeceiras do Rio Sant'Anna près du Pouso Alto, Goraz, n² 21632. Arbuste, fl. violacées. Janvier-février. C.

วั6. V. arenaria Mart.; Fl. Bras. VI, I, I. 6I. - Campos da Rocaina. S. Paulo, nº 9914. Sous-frutescent, f1. blanches. Férrier-mars. R.

วั7. V. grisea Bak.; Fl. Bras. VI, II, p. 61. - Caraça, dans le campo, Mixas, $n^{0}$ 15066. Frutescent, fl. blanc jaunatre. Juin-juillet. C.

58. V. chalybaea Mart.: Fl. Bras. Vi, II, p. 62. - Formação, près Diamantina et Queluz, Misas, $n^{0 s}$ 10975, 19502. Frutescent, f1. blanchâtres. Aoùt-septembre.

59. V. syncephala Sch. Bip.; Fl. Bras. VI, II, p. 6't. - Entre Sitio et João Aỹres, Mısas, nº 11066. Frutescent, fl. blanchâtres. Juin-juillet. C.

60. V. muricata DC.; Fl. Bras. VI. II, p. 63̈. - Serra Mantiqueira, Mısas, $\mathrm{n}^{0} 15066$ a. Frutescent, fl. blanchâtres. Juin-juillet. R.

61. V. adamantium Gardn.; Fl. Bras. VI, II, p. 66. - Petropolis, au Horro Cubiçado, Rı-Jax., $n^{\circ}$ 11046. Frutescent, fl. lilas. Juinjuillet. C.

62. V. Warmingiana Bak.; Fl. Bras. VI, II, p. 68. - Santa Luzia do Rio das Velhas, Mrras, $n^{\circ}$ 20383. Sous-frutescent, fl. blanchâtres. Octobre-novembre. C.

63. V. echitifolia Mart.; Fl. Bras. VI, II, p. 7I. - Barbacena, Mivas, no 16186 ; Corrego do Brejo, Goyaz, no 21622 . Frutescent, tl. blanchàtres. Février-mars C.

64. V. Salzmanni DC.; Fl. Bras. VI, II, p. 73. - Serra da Estrella et Pedra do Conego, Rı-Jax., nos 6612 , 12052. Frutescent, 11. blanches. Juin-juillet. C.

63. V. fruticulosa Mart. : Fl. Bras. VI, II, p. 72. - Congonlas do Campo, Miss, $11^{\circ}$ 15067; Santa Luzia, Goyaz, nº 21623. Frutescent, 11. Llanches. Mar's-avril. C.

66. V. Miersiana Gardn. in Hook. Lond. Joum. Bot. IV, p. 11\%. Petropolis et Nova Friburgo, Rio-JAx., Il ${ }^{\text {os }} 5914,12827,14022$. Frutescent, fl. blanchâtres. Mars-avril. CG. Vulg. : Herva Imperial.

67. I. mucronifolia DC.; Fl. Bras. VI, II, p. 74. - Fazenda do Morro Azul., S. Paulo, nº 12828. Sous-frutescent, fl. blanchâtres. Arrilmai. C.

68. V. obtusifolia Less.; Fl. Bras. VI, II, p. 74. - Floresta da Tijuca, Rı-JAx., nº 1397. Frutescent, f1. blanclıes. Mai-juin. R. 
(99. Vernonia linearis Spreng.; Fl. Bras. VI, 11, p. 7\%े. - Serra do Picu, dans le campo, Mıvas, no 9910. Sous-frutescent, blanc rosé. Arril-mai. C.

70. V. Senæii Gliz. 11. sp.? in. herb. Paris., Berol., Kew., Genev., ete. - Serrai do Batatal on do Capanema, Mlsas, $\mathrm{n}^{\circ}$ 14985. Sous-frutescent, 11. blanc jaunâtre. Février-mars. C.

71. V. Nettoana Giaz. n. sp.? in herb. Paris, Berol., Kew., Brux., etc. - Congonhas do Campo, Mrsas, $11^{\circ}$ 14981. Frutescent, f1. lilas. Juin-juillet. R.

72. V. glabrata Less.; Fl. Bras. VI, II, p. 76. - Nova Friburgo, Rio-Jax., $n^{\text {os }} 12858$, 12860; Ipanema dans le campo, S. Paduo, $n^{\circ 5} 1165,12895$. Frutescent, fl. violettes. Avril-Mlai. C.

73. V. Gustodiana Glaz. sp. n.? in herb. Paris., Brux., ete. Gavea, na Chacara Custodio, Rro-Jav., n ${ }^{\circ}$ 1131. Sous-frutescent, fl. lilas. Janvier-février. C.

7's. V. lacunosa Mart.; Fl. Bras. VI, II, p. 77. - Ayuruoca et Barbacena, dans le campo, llixss, ${ }^{05}$ 9496, 14938. Sous-fi'utescent, 11. blanchâtres. Nuvembre-janvier. C.

73. V. tomentella Nlart.; Fl. Bras. VI, II, p. 79. - Campos da Bocaina, S. Pavio, $\mathbf{n}^{\text {s }} 8131,8132$. Sous-frutescent, fl. violàtres. Janvierfévrier. C.

76. V. gracilis H. B. K.; Fl. Bras. VI, II, p. 81. - Sorocaba, dans le campo, S. Pat lo, nº 12829. Sous-frutescent, fl. blanchàtres. Avril-mai. C.

77. V. varronicefolia DC.; Fl. Bras. VI, II, p. 82. - Sĩo Paulo, $1^{\text {os }}$ 12888, 12891, 12892; Ribeirão de Taquaruçú, Hinas, $n^{\text {os }} 19501$, 19503. Frutescent, fl. blanchàtres. Avril-mai. CG.

78. V. elegans Gardn.; Fl. Bras. VI, II, p. 82. - Ipanema, dans le campo, S. Paulo, nos 12894,19500 . Sous-frutescent, fl. violâtres. Marsavril. C.

79. T. brevipetiolata Sch. Bip.; Fl. Bras. VI, II, p. 85. - Norro de São Vicente, Misas, n 14024. Sous-frutescent, fl. lilas. Février-mars. C.

80. V. obtusata Less.; Fl. Bras. VI, II, p. 87. - Ipanema, S. Paulo, $n^{\circ}$ 12821; Morro de Sío Vicente, Mrsas, $n^{\circ}$ 14982. Sous-frutescent, fl. blanchâtres. Avril-juin. C.

81. I. obscura Less.; Fl. Bras. VI, II, p. 89. - Entre Ipanema et Sorocaba, S. Paulo, no $12888 a$. Frutescent. fl. lilas. Avril-mars. R.

82. I. Zuccariniana Mart.; Fl. Bras. VI, II, p. 89. - Burity 
A.-F.-M. GLAZIOU. - LISTE DES PLAXTES DU BRESIL CENTRAL. 373 Vermelho, Goraz, $n^{\circ}$ 21629. Sous-frutescent, fl. blanchâtres. Juinjuillet. R.

83. V. obovata Less.; Fl. Bras. VI, II, p. 91. - Campos da Bocaina, S. Paclo, $n^{\text {os }} 8144,12810$. - Entre Barbacena et Sitio, Mısas, nos 15091 , 15092 ; Pichoa, au Espigĩo, Goraz, nºs 21586, 21587. Herbacé, fl. blanchâtres. Octobre-novembre. CC.

8'. V. sylvestris Glaz. n. sp.? in herb. Paris., Berol., Kew.. Gener., ete. - Alto Nacahé et Petropolis, dans les bois, Rio-JAr., $\mathrm{n}^{\text {os }} 13987,17103$. Sous-frutescent, fl. blanches. Avril-mai. R.

8.. V. sulcata Glaz. sp. n.? in herb. Paris., lierol., Kew.. Genev, etc. - Ponte Alta, dans le campo, Goraz, $n^{\circ}$ 21583. Herbacé, f1. llanchàtres. Aoùt-septembre. C.

86. V. fluminensis Glaz. n. sp.? in herb. Paris., Berol., Kew., Gener., etc. - Pico de Santa Cruz, Rio-Jax., no 8114. Herbacé, f1. blanches. Avril-mai. R.

87. V. secunda Sch. Bip.; Fl. Bras. VI, II, p. 93. - Corrego do Brejo, dans le campo, Goraz, n" 21634. Sous-frutescent, fl. violacées. Juin-juillet. C.

88. V. flexuosa Sims; Fl. Bras. V1, II, p. 93. - Entre Aldea de São Pedro dos Indios et Rio Bonito, Rio-Jax., nos 12850, 12887, 19528. Herbacé, t1. lilas. Septembre-octobre. C.

89. V. depauperata Glaz. 11. sp.? in herb. Paris., Brux., ete. Ponte Alta, dans le campo, Goyaz, $n^{\circ} 21585$. Herbacé, fl. lilas. Septembreoctolire. R.

90. I'. cognata Less.; Fl. Bras. VI, II, p. 94. - Entre Ipanema et Sorocaba, S. Pacto, nº $12887 a$. Sous-frutescent, fl. blanchâtres. Arrilmai. C.

91. V. ignobilis Less.; Fl. Bras. VI. II, p. 96. - Entre Barbatimão et le Rio Sào Marcos, Govaz, $11^{\circ} 21580$. Herbacé, fl. blanches. Aoùtseptembre, R.

92. V. geminata Less : Fl. Bras. VI, II, p. 97. - Corcovado et Floresta da Tijuca, Rio-JAs, $n^{\circ} 1410,1411,5895$. Sous-frutescent, fl. blanchàtres. Juin-juillet. CC. Vulg. : Herva Imperial.

93. V. ehreticefolia Benth.; Fl. Bras. VI, II, p. 98. - Alto Macahé, dans le bois, Rio-JAx., no 17099. Frutescent, fl. blanches. Avril-mai. IR.

94. V. scabra Pers.; Fl. Bras. VI, II, p. 100. - Serra da Cantareira, S. Paulo, no 12822,12834 b. Frutescent, f1. blanchattres. Nar'savril. 
98̈. Ternonia scorpinides Pers.; Fl. Bras. VI, II, p. 101. - Corcovalo, Floresta da Tijura, Serra da Estrella, R10-JAx., $1^{\text {os }} 184,1134$, $1423,1479,1480,6613,8481$; Serra de Ouro Preto et Marianna, Misas, $11^{\text {os }}$ 12824, 12832, 14020 et 14021. Sous-frutescent, f1. blancliàtres. Juin-aoùt. CC.

96. V. ferruginea Less.; Fl. Bras. VI, II, p. 102. - Uheraba, dans 'le campo, Minas, $11^{\circ}$ 21607. Arbuste, 11. blanches. Avril-mai. CB.

- Var. polycephala Bak.; $\mathrm{Fl}$. Br. VI, II, p. 102. - Serra das Vertentes, près Oliveira, Misas, $\mathrm{n}^{\text {os }} 14031$, 20374. Arbuste, fl. blanches. Mai-juin. C.

- Var. pedicellaris Bak.; Fl. Br. VI, II, p. 103. - Morro de São Vicente, Mivas, $n^{\circ}$ 14030. Arbuste, fl. Hanches. Mars-avril. C.

97. V. densiflora Gardn.; Fl. Bras. VI, II, p. 104. - Serra dos Orgãos, Rio-Jax., $n^{\circ}$ 1051. Arbuste, t1. blanches. Janvier-lévrier. C.

98. V. Westiniana Less.; Fl. Bras. VI, II, p. 104. - Entre Ayres et Sitio, $\mathrm{n}^{\text {os }} 11020,11067$, et près des fossiles, Misas, $n^{0} 15063$; entre Ipanema et Sorocaba, S. PActo, $n^{\circ}$ 12893. Frutescent, f1. roses. Févriermars. C.

99. V. Itatiaiæ Glaz. n. sp.? in herb. Paris., Berol., Kew., Genev., etc. --- Itatiaia, dans le campo, Rio-JAx., no 5893. Frutescent, fl. jaunâtres. Juin-juillel. Ci.

100. V. Beyrichii Less.: Fl. Bras. VI, II, p. 104. - Gavea, S. Christovão. Rio-Jas., nos $165,1052,1053,5908,11015$. Frutescent, fl, roses. Mars-avril. CC. Vulg. : Alecrim da Praia, Assu., Peixe et Salsa da Praia.

101. V. missionis Gardn.; Fl. Bras. VI, II, 1. 106. - Entre João Ayres et Sitio, Mrsas, $1^{0}$ 12834. Frutescent, f1. blanches. Juin-juillet. G.

102. V. Mariana Vart.; Fl. Bras. VI, II, p. 107. - Gandarela, dans le bois pris des fossiles, Minas, $11^{\circ}$ 15062. Arbuste, fl. blanchâtres. Février-mars. C.

103. V. polyanthes Less.; Fl. Bras. VI, II, p. 107. - Gavea, Corcovado, Serra da Estrella, Rio-Jav., ${ }^{\circ \text { os }} 1054,1401,11012$; Serra da Mantiqueira, Mixas, $n^{\text {os }} 11068$, 12833. Frutescent, fl. rose pâle. Juinjuillet. C.

- Var. tijucana Glaz. var. n. in herb. Paris., Berol., Kew., Gener., Havn, etc. - Floresta da Tijuca et Pedra Bonita, Rı-JAx., ${ }^{0 s} 4868$, 11043. Frutescent, fl. blanches. Juin-juillet. C.

104. V. macahensis Glaz. n. sp.? in herb. Paris., Gener., et:. 
A.-F.-M. GLAZIOU. - LISTE DES PLATTES DU BRÉSIL CENTRAL.

- Serra do Alto Macahé, Rio-Jax., n 17098. Sous-frutescent, f1, blanches. Mars-avril.

10อั. V. virgulata Mart.; Fl. Bras. VI, II, p. 109. - Norro de São Vicente, Mrsas, $n^{\circ}$ 15102; Fazenda de Dona Barlıara. à Serrinha, Goyaz, $\mathrm{n}^{\circ} 21600$. Frutescent, fl. violacées. Août-septembre. C.

106. V. stricta Gardn., Fl. Bras. V1, II, p. 110. - São João d'El Rey, Mras, no 17089. Sous-frutescent, f1, roses. Juin-juillet. C.

107. V. holoseric ea Mart.; Fl. Bras. VI, II, p. 110. - Serra do Caraça, Mıxds, $n^{\text {os }} 12825,13996$. Sous-frutescent, fl. rosées. Octobrenovembre. C.

108. V. schwenkiafolia Mart.; Fl. Bras. V1, 11, p. 111. - Serra do Lenheiro et Caraça, au Campo de Fora, Mrsas, nos 15103, 17090, 19523 et 20373. Sous-frulescent. f1. roses. Mai-juin. CG.

109. V. compacta Gardn.; Fl. Bras. V1, II, p. 112. - Barbacena, dans le campo, Misas, $\mathrm{n}^{0 \mathrm{~s}} 15009,20382$. Arbuste. f1. blanches. Juilletaoùt. G.

110. V. frutescens Glaz. II. sp. in herb. Paris., Berol., Kew., Brux., etc. - Serra dos Pyreneos, Goyaz, n² 21593. Frutescent, fl. jaunâtres. Juin-juillet. C.

111. V. cuneifolia Gardn. Hl. Bras. V1, 1I, p. 113. - Rio Torto, dans le campo, Goyaz, $n^{0}$ 21638. Arbuste, f1. blanches. Juin-juillet. GG.

112. V. viscidula Less.; Fl. Bras. V1, II, p. 113 - Serra do Palmital, Mixas, n 15060. Frutescent, 11. rosées. Juin-juillet. R.

113. V. nitidula Less.; Fl. Bras. VI, I1, p. 113. - Norro Jaragua, S. Paclo, nos 20382 et 20382 a. Arbuste. 11. jaunâtres. Avril-mai. R.

114. V. lucida Less.; Fl. Bras. V1, 11, p. 11\%. - Serra do Batatal ou da Capanema, Misas, no 15061. Frutescenl, f1. blancluâtres. Juinjuillet. C.

113̈. V. laxa Gardn.; Fl. Bras. VI, I1, p. 116. - Serra do Caraça, au Campo de Fora, Mixas, $n^{\text {os }} 12826,13997,16187$. Frutescent. fl. bianches. Juin-juillet. C.

116. V. mucronulata Less.; Fl. Bras. VI, II, p. 116. - Congonhas do Campo, Barbacena, Hixas, $\mathrm{n}^{\text {os }} 11074,15087$; marécage du Rio Gama, Goyaz, n² 21638. Frutescent, fl. blanchâtres. Mai-juin. CG.

117. Piptocarpha pirifolia Bak, Fl. Bras. VI, II, p. 120. - Corcovado et Petropolis, Rio-Jas., $\mathrm{n}^{\text {os }} 177,1618,7727,15038$. Arbuste sarmenteux, fl. blanches. Aoùt-septembre. CG.

118. P. lucida Benn.; Fl. Bras. VI, II, p. 121. - Morro do Corcovado, 
Rio-Jax., 10.s 178, 1418. Arbuste sarmenteux, fl. blanches. Anit-septembre. C.

119. Piptocarpha oblonga Bak. Fl. Bras. VI, II, p. I21. - Di'11polis, at Cachambiu, Rio-dax., $n^{\text {os }}$ 7694, 12059. Arbuste sarmenteux, fl. blanches. Anot-septembre. C.

- Var. ovalifolia Bak., Fl. Br. VI, II, p. 122. - Floresta da Tijuca. Rio-JAx., ${ }^{0 s} 179$, 15040. Arbuste sarmenteux, t1. lilanches. Septemhre-octobre. C.

120. P. axillaris Bak., Fl. Brus. VI, II, p. 122. - Entre Sitio et Joao Ayres, Mıxas, no 11071. Arbrisseau, fl. blanches. Mai-juin. G.

- Var. minor Bak., Fl. Br. VI, II, p. 123. - Brancho do Morro Cavado, Mrsas, $n^{\circ}$ 7720. Arbrisseau, fl. hlanches. Aout-septembre. C.

121. P. tomentosa Bak. n. sp. in herb. Paris., Berol., Kew., Gener., etc. - Fazenda do Rio Preto et au Morro Cavado, Musas, n ${ }^{08} 7719,8774$. Arbrisseau, fl. blanches. Octobre-novembre.

122. P. pannosa Bak. 11. sp. in herb. Paris., Berol., Kew., Genev., etc. - Petropolis, à Cachambú, Rio-JAx., n 7695. Grand arbre, fl. blanches. Novembre-décembre. R.

123. P. macropoda Bak.; Fl. Bras. VI, II, 1. 123. - Serra dos Orgãos, Ruo-JAx., $\mathrm{n}^{\text {os }} 1617,3690,816,17062,19567$. Grand arbre, 11. hlanches. Février-mai. CG.

- Var. acutifolia Bak. in litt. et in herb. Paris, kew. - Corcovado et Petropolis, Rı-JAx., nos 1417, 12058. Très grand arbre, fl. hlancbes. Août-septembre. C. Vulg. : Canella branca.

- Valr. crassifolia Bak.; Fl. Br. VI, II, p. 123. - Corcovado, à Paineiras, Riro-Jiv., nos 1551, 1455. Grand arbre, fl. blanches. Aout-septembre. C.

- Var. graziovi Bak.; Fl. Bras. VI, H, p. 123. - Petropolis et Nova Friburgo, Ro-Jan., no 1615 , 15037. Grand arbre, fl. blanches. Aoûtseptembre. C.

124. P. organensis Glaz. n. sp.? in herb. Paris., Berol., Kew., Gener, ete. - Serra dos Orgãos, au sommet, liı-Jムx., nº 16211. Arbrisseau, fl. blanches. Janvier-février. R.

125\%. P. rotundifolia Bah.: Fl. Bras. VI, II, p. 12\%. - Ipanema, près la mine de fer, S. Paclo, ${ }^{\circ s}$ 10997, 10999, 12897; Areal da Serra de Ouro Branco, Misas, $n^{\circ} 15039$; Formosa, dans les cerrados, Goyaz, $\mathrm{n}^{\circ}$ 21662. Arbrisseau, tl. blanches. Novembre-décembre. CG.

126. P. umbellulata Bak.; Fl. Bras. VI, II, p. 126. - Entre Belem 
el Rio do Ouro, Rio-Jax., nos $8760,11090,12799$. Arbuste sarmenteux, 11. blanches. Juillet-août. C.

127. - P. quadrangularis Bak. ; Fl. Brus. V1. II p. I28. - Theresopolis, à São Luiz, Rro-Jux., n² 2841. Arbuste sarmentenx, fl. blanches. Septembre-octobre. R.

128. P. Bakeriana Glaz. n. sp. in herh. Paris., Berol., Kew., Genev, etc. - Fazenda to Rio Preto, Mrsas, n 8770. Grand aluuste sarmenteux, f1. blanches. Novembie-décembre. R.

129. P. notata Bak.; Fl. Bras. VI, Il, 1. I29. - Serra da Bocano, S. Pacio, $n^{0}$ 11107. Arbuste sarmenteux, 11. blanches. Aout-septembre. C.

130. P. Luntiana Bak.; Fl. Bras. VI, II. P. 130. - Copacabana, Rio-JAx., $n^{\circ}$ 4046. Arbuste sarmenteux, fl. blanches. Aout-septembre. R.

131. Stilpnopappus pratensis Mart.: Fl. Brus. VI, II, P. 136.Serra da Itabapoana, Esp. S.xto, n 10966. Herbacé, fl. blanches. Aontseptembre. R.

132. - S. ferrugineus Bak.; Fl. Brus. V1, II, p. 138. - Chapadão central, entre Rio Gama et Rio Bananal, Goyaz, no 21666. Arbuste, 11. jaunâtres. Mai-juin. R.

133. St. Allemaovii G1. n. sp.? in herl. Paris., Berol., Kew., Gener., etc. - Serra da Itabapoana, Esp. SArro, $n^{\circ}$ 10965. Herbace, 11. blanches. Aoùt-septembre. R.

13'. St. speciosus Bak.; Fl. Bras. Vl, Il, 1. 138. - Morro do Frota, pris Meia Ponte, Gorı, no 21676 a. Arbuste, fl. jaunâtres. Aoùtseptemble. $R$.

133. Piptolepis leptospermoides Sch. Bip.; Fl. Bras. V1, II, p. 142. Entre Sopa et Diamantina, Mrsas, $n^{\circ}$ 19550. Pelit arbuste, fl. blanchàtres. Mars-avil. C.

136. P. imbricata Seh. lip. : Fl. Bras. VI. II, p. 143. - Serra do Cipo, dans le campo, Misas, no 19551. Petit arbuste, fl. blanchâtres. Mars-avril. C.

137. P. ericoides Sılı. Bip.; Fl. Bras. VI, II, p. I't3. - Itacoluny, près Ouro Preto, Misas, nos 14969, 14980. Petit arluuste, 11. jaunâtres. Février-mars. C.

138. P. buxoides Sch. Bip.; Fl. Bres. VI, Il, p. 143. - Tombador près Diamantina, Mrsas, $n^{\circ}$ 19552. Petit arluste, fl. blanchitres. Avrilmai. C.

139. P. Schwackeana Glaz. n. sp.? in herb. Paris., Berol., Kew. 
Genev., etc. - Pico d'Ital,ira do Campo, Mlixas, $1^{05} 17658,19565$. Arbuste, 11. roses. Novembre-décenibre. C.

140. Piptolepis Gardneri Bak.? Fl. Iras. VI, II, p. 1'44. - Biribiry, près Diamantina, Mnsa, $\mathbf{n}^{\circ}$ 19491. Petit arbuste, fl. jauntitres. Mars-avril. G.

141. Proteopsis argentea Nart. el Zuce. ; Fl. Bras. VI, II, p. 146. - Biribiry près Diamantina, Mıxas, $n^{\circ}$ 19544. Sous-frutescent, fl. Dlanches. Février-mars. R.

142. P. Sellozyii Sch. Bip.; Fl. Bras. VI, II, p. 146. - Carãça, entre les rocliers, Mivas, $n^{\circ}$ 14974. Sous-frutescent. fl. roses. Février-mars. G.

143. Sipolisia lanuginosa Glaz. in Hooker Icon. Plant. pl. 2281. - São Gonçalo près Biribiry, Mrsas, $n^{\circ}$ 19470. Frutescent, fl. blanc rosé. Mars-aviil. R.

144. Haplostephium Passerina Mart.; Fl. Bras. VI, Il, p. 149. - Serra do Lenheiro, dans le campo, Mhsas, nos 14963, 16158, 17094. Petit arbuste, fl. lilas. Février-mars. CG.

145. H. ramosissimum Sch. Bip.; Fl. Bras. VI, II, p. 149. Diamantina, au Curalinho, Mrsas, $n^{\text {os }} 14962$, 19484. Petit arluste, 11. lilas. Février-mars. C.

146. Lychnophora rosmarinifolia Viart.; Fl. Bras. VI, II, p. 152. - Formação près Diamantina. Mrvas, n 19480 . Arbuste, fl. violettes. Avril-mai. C.

147. L. uniflora Sch. Bip.; Fl. Bras. VI. Il. p, 1:8. - Diamantina, au Curalinlıo. Minas, $n^{\circ}$ 19487. Arbuste, fl. violettes. Avril-mai. C.

148. L. reticulata Gardn.; Fl. Bras. VI, II. p. 183. - Serra de Ouro Branco. Mhras, ${ }^{o s}$ 14968, 19483. Arbusie, fl. lilas. Avril-mai. C.

1'49. L. ericoides Mart.; Fl. Bras. VI. II. p. 13̆4. - Entre Biribiry et Diamantina, Hisaz, $\mathrm{n}^{\text {os }}$ 19477. 19477 a; Serra Bourada, près Ollıo d'Agua, Goyaz, nos 21652, 21653, 21655. Arbuste, fl. lilas. Aoùt-septembre. CC. Vulgo : Arnica.

Var. leucopholis Glaz. in lierb. Paris., Berol., Kew., Genev., etc. Cabeceiras do Rio Gama, au Colombisto, Goyaz, $n^{\circ}$ 21654. Arbuste, f1. lilas. Mai-juin. CG. Vulgo : Arnica.

150. L. Urbaniana Glaz. n. sp.? in herb. Paris,, Berol., Kew., Genev.. etc. - Serra do Inficionado. près Caraça, Mısas, nº 14028. Arbuste, f1. lilas. Février-mar's. R.

15̆1. L. brunioides Mart.; Fl. Bras. VI, Il, p. 15̆4. - Serra do Palmital et à Itabira do Campo. Misas, $n^{n s}$ 14966, 17093, 17647, 20384. Arbuste, f1. lilas. Juin-juillet. CG. Vulgo: Arnica. 
A.-F.-H. GLAZIOU. LISTE DES PLANTES DU BRESIL CENTRA.

- Var. affinis Bak.; Fl. Bras. VI, II, p. 15̆3ั. - Entre Barreiro do Veado et Morro Redondo. Goraz, ${ }^{0}$ 21651. Arbuste, 11. lilas. Septembre-octobre. C.

152. L. trichocarpha Spr.; Fl. Bras. V1, Il, 1. I:3̈. - Caraç, au Norro Calrapuça, Mrsas, $n^{\text {os }}$ 14964. Arbuste, fl. lilas. Février-mars. C. Vulgo : Arnica.

- Var. robusta Glaz. n. var. in herb. Paris., Berol., Kew., Genev., Brux., ete. - Curalinho près Diamantina. Mrsas, n 19486. Arbuste. f1. lilas. Mars-avril. C.

15้3. L. villosissima Vart.; Fl. Bras. VI, II, p. 15̋6. - Biribiry, près Diamantina dans le campo, Mısas, ${ }^{0 s} 17093$ e, 19475. Arluste, il. lilas. Mars-avril. C.

154. L. Blanchetii Sch. Bip.: Fl. Bras. VI, II, p. 136. - Serra do Cipo, dans le campo. Mixas, ${ }^{\text {os }} 19432$, 19485. Arbuste, fl. lilas. Irrilnıai. C.

1\%:. L. staavioides Mart.; Fl. Bras. VI, II, p. 1:57. - Serra de Ouro Branco, Misas, nos 14967, $17093 a, b, 19479$; Cliapadão dos Veadeiros. Goyaz nos 21656, 21657, 21658. Arbuste, fl. lilas. Janvier-février. C.

1.36. L. staavioides var. microphylla Bak. n. var. in herb. Paris., lierol., Kew. Havı., eic. - Serra dos Ciristaes, près Diamantina, Mrsas, ${ }^{o s} 19488,19489$. Arbuste, fl. lilas. Arril-mai. C.

157. L. unicaulis Glaz. n. sp. in herb. Paris., Berol., Kew., Genev., etc. - Baudeirinha près Diamantina, Mrsas, n 19478. Grand arbuste, tl. lilas. Avril-mai. R.

1:38. L. Gorceixii Glaz, sp. n.? in herb. Paris., Berul., Kew, Gener., etc. - Près Diamantina lans le campo pierreux, Misas, $n^{\circ}$ 19481. Arbuste, fl. lilas. Avril-mai. R.

159. L. tomentosa Sch. B.; Fl. Bras. VI, II, p. 15̈7. - Diamantina, Perpetua, Tombador dans le campo, Mixas, $n^{\text {os }}$ 19471, 19472. 19473 et 19474. Arbuste, fl. lilas. Avril-juin. CG.

160. L. salicifolia Mart; Fl. Bras. VI, II, p. 159. - Pinheiro près Diamantina, Mıxas, $1^{\text {os }} 19469$, 19476. Arbuste, fl. lilas. Mars-arril. R.

161. L. Martiana Gardn.; Fl. Bras. VI, II, p. 159. - Perpetua pres. Diamantina, Mixss, ${ }^{\text {os }} 19466$, 19467, 19468. Arbuste, fl. lilas. Marsavril. C.

162. Lychnophoriopsis heterotheca Sclı. Bip.? Fl. Brus. VI, II, p. 147. - Serra das Vertentes près Oliveira. Misas, $1^{\circ}$ 20372. Frutescent, fl. roses. Juin-juillet. R. 
163. Lychnophoriopsis macrocephala Gl. n. sp. ? in lıerb. Paris., Berol., Kew., Gener., etc. - Entre Banreira Grande et Valla Funda, dans le campo, Mrvas, $n^{\circ}$ 19465. Frutescent, f1. violaccées. Mars-avril. R.

16' '. Eremanthus incants Less.; F'l. Brus. VI, II, p. 161. - Caraça près la Cachoeira, Mrws, $11^{0 s} 14055$ 14056. Arbrisseau, 17. Wlanches. Juin-Juillet, CG. Vulgo: Pao candeia.

165. E. Schwackei Glaz. n. sp.? in herh. Paris., Berol., kew., Gener. etc. - Biribiry près Diamantina, entre les rochers, Misas, $\mathrm{n}^{\circ}$ 19562. Arbuste, fi. lilas, Mars-avril. R.

166. E. glomerulatus Less.; Fl. Bras. VI. I1, p. 162. - Serra do Palmital, Misas, $n^{\text {os }}$ 9492, 14953, 14954; entre Rio Torto et Paranana, Goraz, n² 21665. Arbrisseau, fl. blanchâtres. Mai-juillet. C.

167. E. stellatus Sch. Bip. in Pollichia (1861), ). 164. - Fazenda de Dona Barbara à Sobradinho, Govaz, $n^{\circ}$ 21664. Arbuste. 11. blanchâtres. Juillet-août. C.

168. E. goyazensis Suh. Bip , Fl. lBras. VI, II, p. 163. - Fazenda de Rajadinha, au Valú, Goxaz, n² 21669. Arluste, 11. blanches. Févriermars. R.

169. E. mollis Sch. Bip.; Fl. Bras. VI, II, p. 164. - Entre Formosa et Lagoa Feia, Goraz, $n^{\circ}$ 21670. Arbuste, 11. blanches. Janvierfévrier. C.

170. E. exsuccus Bak.; Fl. Bras. VI. II, p. 166. - Entre Paranatú et Rajadinha, dans le campo, Govaz, $n^{0 s} 21674,21675$. Sous-frutescent, 11. bleues. Juin-juillet. CG.

171. E. spharocephalus Bak. Fl. Bras. VI, II, p. 167. - Fazenda do Cipo, à Maita Grande, Mısas, $n^{0 s}$ 15045, 19549; Fazenda Bolivia. Govaz, $\mathrm{n}^{\circ}$ 21671. Sous-fruteseent, f1. Iilas. Avril-mai. CG. Vulgo : Chapeu de Couro.

172. E. plantaginifolins Bah.; Fl. Bras. VI, II, p. 168. - Serra do Lenheiro, dans le campo, Mısas, ${ }^{05}$ 7710, 15049, 17087; Pichoa près Espigão, Goyaz, $n^{0}$ 21589. Herbacé, fl. lilas. Septembre-octobre. C.

173. E. Harmsianus Taub. in Beitr. Fl. Bras. centr., p. 43̆4. Morro do Froto, près Meia Ponte, Goraz, $n^{\circ}$ 21646. Herbacé vivace, f1. roses. Aoùt-septenibre. C.

174. E. Labordeii Gl. n. sp.? in herb. Paris., Berol., Kew., Genev., etc. - Ponte Alta, dans le campo pierreux, Goraz, nº 21675. Herlracé, fl. rouges. Aoùt-septembre. C.

17\%. E. scapigerus Bak.; Flora Bras. VI, II, p. I68. - Barbaeena, 
Mrvas, $n^{0 s}$ 15046, 17088: entre Lage et Corumba, daus le campo, Goraz,

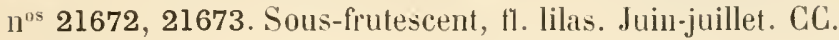

176. E. purpurens Bak. in Hooker Icon. Jlant. III (189'1), pl. 22982. - Serra do Cipó près Congonhas da Serra, Yixas, nº 19464. Acaule, fl. rouges. Avril-mai. R.

177. Pithecoseris pacourinoides Mart.; Fl. Bras. VI, I, p. 1'48.Serra do Inficionado, Mıvas, $n^{\circ} 12812$, 14032. Sous-frutescent, fl. roses. Juin-juillet.

- Var. capitata Glaz. in. lıerb. Paris., Berol., Kew., Genev., Haun., etc. - Caraça entre les pierres, Mlısa, nos 10998, 14032. Sousfrutescent, fl. blanchàtres. Juillet-aoùt. R.

178. Soaresia velutina Sclı. Bip.; Fl. Brus. V1, II, p. 1\%0. - Entre Guara et Corrego do Brejo dans le campo, Goyaz, $11^{\text {os }} 19490 a, 21661$. Sous-frutescent, fl. rosées. Mars-arril. C.

179. Chronopappus bifrons DC.; Fl. Bras. VI, II, p. 171.Serra do Caraça et à Biribiry près Diamantina, Mrsas, nos $14952,19561$. Arbuste, fl. violettes. Février-mars. R.

180. Elephantopus scaber L.; Fl. Bras. V1. II, p. 173. - Floresta da Tijuca, Rı-JAx., ${ }^{\circ 5} 9913,10968,13984$. Sous-frutescent, fl. blanchîtres. Février-mars. CC.

181. E. hirtiflorns DC.; Fl. Bras. VI, II, p. I73. - Itapemirim, daus le bois, Ess. Saxto, n 10967. Herbacé, f1. blanches. Janvier-février. Ii.

182. E. riparius Gardn.; Fl. Bras. VI, II, p. 174. - Moro de São Vicente, Mixas, $n^{o s}$ 15105, 16146. Herbacé, f1. violacées. Janvierf'érrier. C.

183. E. micropappus Less.; Fl. Bras. VI, II, p. 17't. - Eminencia do Ipiranga, S. PAclo, $n^{0 \mathrm{~s}} 16151,19529$. Herbacé, fl. rougeâtres. Férriermars. C.

184. E. elongatus Gardn.; Fl. Bras. VI, II, p. 17̈. - Correcro do Brejo, près du campement, Goxaz, $n^{\circ} 21584$. Herbacé, tl, violacées. Maijuill. R.

18\%. E. angustifolius Sw.: Fl. Bras. VI, II, p. 176. - Corcovado, à Paineiras, liı-JAx., n ${ }^{\circ}$ 547. Herhacé, fl. blanchàtres, Mars-arril. C.

186. E. biflorus Sch. Bip.; Fl. Bras. VI, II, \%. 177. - Congonhas do Campo, Mıxas, n 15104. Herbacé, fl. blanches. Juin-juillet. C.

IS7. Rolandra argentea Rotth. : Fl. Bras. VI, II, 1) 178. - Serra da Itahapuana, Esp. Sisтo, n 10963. Sous-frutescent, fl. blanchitres. R.

188. Ophyrosporus pachychata Bak. : Fl. Bras. VI, II, p. 187. - 
Mariamna, près Ouro Preto, Mixas, ${ }^{05}{ }^{\text {14 }}$ 14018, 14019. Sous-frutescent, 11. jamnâtres. Juin-juillet. G.

189. Ophyrosporus Freyreissii Bak.; Fl. Bress. VI, II, p. 188. Nova Friburgo, Rio-J JN., $\mathrm{n}^{\circ}$ 15158; Gandarela prìs des plantes fossiles, dans le bois, Mısas, $n^{\circ}$ 15156. Sous-frutescent, f7. blanches. Juin-juillet. C.

190. O. Reynellii Bak.; Fl. Brus. V1, I1, p. 188. - Serra do Pieñ, au Palmital, Ro-Jav, n 14019 a. Sous-frutescent, 11. blanchâtres. R.

191. Adenostemma viscosum Forst.; Fl. Biras. VI, II, p. 18\%. Nova Friburgo, dans le bois, Rı-Jax., $n^{\circ} 4052$; Verıtania, Hısas, $n^{\circ} 16179$. Herbacé, fl, blanchâtres. Mars-avril. C.

692. Alomia Armani Bik., Hl. Bras. VI, Il, p. 191. - Cabeceiras do Rio Gama, au Colombista, Goyaz, n 21579. Sous-frutescent, f1. roses. Mai-juin. R.

193. A. polyphylla Baker, Fl. Bras. VI, II, p. 191. - Barbacena, Minas, $\mathrm{I}^{0}$ 15086; Petropolis, au Retiro, Rio-Jax., $1^{\circ}$ 17102. Sous-frutescent, fl. blanches. Mai-juin. $\mathrm{C}$.

194. A. cinerea Benth.; Fl. Bras. VI, II, p. 191. - São Joño d'El Rei, dans le campo, Msxas, $n^{\text {os }} 11069,17074$. Sous-frutescent, fl. blanchâtres. Avril-mai. CG.

198. A. fastigiata Benth.; Fl. Bras. VI, II, p. 192. - Serra do Inficionado, dans le campo, Mixas, $n^{\circ}$ 12798. Sous-frutescent, fl. blanchâtres. Juin-juillet. C.

196. Planaltoa salviifolia Taub. in Beitr. Flora centr. Brasil. (189:3), p. 40̈4. - Serra do Arruda, près Neia Ponte, Goyaz, $n^{\circ} .21618$. Sous-frutescent, 11. violacées. Juin-juillet. C

197. Ageratum conyzoides L.; Fl. Bras. Vl, II, p. 194. - Corcovado, Floresta da Tijuca, Rı--Jan., nos 170, 224, 8754; Ouro Preto, Mlisas, $n^{0}$ 14034. Herbacé, fl. blanchâtres. Juin-juillet. CG. Vulgo: Herva de Sйо Joйo.

198. A. serratum Glaz. n. sp. in herb. Paris., Berol., Kew., Gener., etc. - Pao d'Alho, Espirito Santo, no 10980. Herbacé, fl. blanchâtres. Nai-juin. R.

199. A. longifolium Benth.; Fl. Bras. VI, II, p. 197. - Aldea de São Pedro do Indios près Cabo Frio, Rı-Jax., nº 11000 . Sous-frutescent, fi. blanchâtres. Juin-juillet. R .

200. Sievia camporum Bak., Fl. Bras. VI, II, p. 202. - Itatiaia, dans le campo, Rı-JAN., $n^{\circ} 6575 a$. Sous-frutescent, fl. roses. Janvierfévrier. C. 
201. S. organensis Gardn.; Fl. Bras. VI, II, p. 203. - Itatiaia et à Serri dos Orgãos, Rio-JAx., $n^{\circ s} 3687,6575$. Sous-frutescent, fl. roses. Avril-mai. C.

202. S. pauciradiata Bak. n. sp. in herl. Paris., Berol., Kew., Gener., etc. - Serra do Picú dans le campo, Mrsas, $1^{\circ} 11025$. Sousfrutescent, fl. roses. Arril-mai. C.

203. S. decussata Baker; Fl. Brus. VI, II, p. 203. - Ipiranga, dans le campo, S. Paulo, $11^{\circ} 1277$ u. Sous-frutescent, fl. roses. Mars-arril. R.

204. S. Riedelii Sch. Bip.; Fl. Bros. VI. II, 1. 204. - Araial de Ouro Branco, Misas, $n^{\circ}$ 15095. Sous-flutescent, ft. roses. Juin-juillet. C.

203. S. collina Gardn. ; Fl. Bras. VI, II, p. 206. - Carandahy, lans le campo, Mrxas, ${ }^{\circ s} 12877,15096$. Sous-frutescent, fl. roses. Févriermars. C.

206. S. Veronica DC.; Fl. Bras. VI, II, p. 210. - Eutre Sitio et Barbacena, Mixas, $n^{0 s} 9493,11089,12874$. Sous-frutescent, fl. roses. Mai-juiı. C.

207. Trichogonia villosa Sch. B.; Fl. Bras. VI, II, p. 213. - São João d'El Rei, Mıxas, nos 15083, 16184 et 19520. Sous-fiutescent, 11. roses. Décemlnre-janvier. CG.

208. T. hirtiflora Sch. B.; Fl. Bras. VI, II, p. 214.-Itacolumy près Ouro Preto, Mras, $1^{\circ}$ 15151. Sous-frutescent, f1. roses. Janvierfévrier. C.

209. Symphyopappus cuneatus Sell. Bip.; Fl. Bras. VI, II, p. 367. - Serra S. José d'El Rei, Itacolumy, Ilheos, etc., Minas, $n^{\text {os }} 11016$. 14972, 16182, 16200, 17654 et 17655. Frutescent, f1. roses. Janvierfévier. CG.

210. S. reticulatus Bak.; Fl. Bras. VI, II, p. 367. - Itatiaia, Serra do Caraça, Biribiry. Mrsas, $n^{0 s} 6598,14971,19498$, 19499. Frutescent, fl. roses. Janvier-février. C.

211. S. polystachyus Bak.; Fl. Bras. VI, Il, p.368. - Itatiaia, Nova Friburgo, Rio-JAx., $n^{08} 539,6596,13990,16132,16133$; Juiz de Fora, Serra do Ouro Branco, Mris, ${ }^{\circ s} 7696,8139,14009$, 18332. Fruteseent, f1. blanclıatres. Janvier-mars. CG.

212. Eupatorium conyzoides Vilıl; Fl. Bras. VI, II, p. 277. Floresta da Tijuca, Corcovado, Rio-Jax., no ${ }^{o s}$ 1484, 5913, 8758 et 14010. Sous-frutescent, fl. bleues. Aoùt-septembre. CG.

- Var. Maximilian Bak., Fl. Br. VI, II, p. 277. - Entre Gavea et 
Roa Vista, Ro-Jax., $11^{0 \mathrm{~s}} 1046,5910,12796$. Sous-frutescent, fl. lleues. Mai-juin. C.

213. Eupatorium porphyrolepis Bah., Fl. Bras., VI, II, p. 280. Itatiaia, dans le campo, Rio-Jax., $\mathbf{1}^{\circ} 5913 a$. Sous-frutescent, fl. bleues. Juin-juillet. R.

214. E. multiflosculosum DG.; Fl. Bras. VI, II, p. 280. - Fazendi dos Porros, près Vargem Grande, Goraz, $n^{\circ s} 21601,21602$. Sous-frutescent, 11. blanchâtres. Janvier-février. C.

215. E. squalidun DC. : Fl. Bras. V1, II, p. 281. - Alto da Serra do Picú, dans le campo, et à Iponema, S. Paulo, ${ }^{\text {os }} 11021$, 12901, 12903, 12904; Gandarela, Vıxas, nº 15141. Sous-firutescent, fl. bleuâtres. Avril-mai. CC.

216. E. robustum Glaz. n. sp.? in herb. Paris., Berol., Kew., Genev., etc. - Entre Vicente Pires et Rio Guara, dans le campo, Goyaz, $n^{0}$ 21612. Frutescent, f1. jaunes à très bonne odeur. Mars-avril. C.

217. E. polyanthum Sch. Bip., Fl. Bras. V1, Il, p. 283. - Campos da Bocaina, S. Paulo, $n^{0}$ 8124. Sous-frutescent, f1. violettes. Janvierfévrier. C.

218. E. lavigatum Lank; Fl. Bras. VI, II, p. 286. - Floresta da Tijuca, Rio-JAN., $\mathrm{I}^{0 \mathrm{~s}} 1045,4048,11007$; entre Barlacena et Ilheos, Mısas, $\mathrm{n}^{\text {os }}$ 11062, 15142; Corrego do Brejo, Goraz, $n^{\circ} 21610$. Frutescent, f1. bleues. Mai-juin. CG.

219. E. angulicaule Sch. Bip. in Fl. Bras. V1, II, p. 287. - Serra da Mantiqueira, à l'entrée du campo, Mısas, $n^{\circ}$ 16188. Arbrisseau, fl. lilas pâle. Février'-mars. R.

220. E. tectum Gardn.; Fl. Bras, VI, II, p. 288. - Serra dos Orgãos et à Petropolis, Rio-Jax.. nos 3689,11009 . Frutescent, fl. lilas. Marsmai. C.

221. E. ivafolium L.; Fl. Bras. V1, II, p. 290. - Campos da Bocaina, au bom Jardim, S. PAulo, $1^{\circ} 8121$ a. Sous-frutescent, 11. bleuâtres. Février-mars. R.

222. E. xylorhi zum Sch. Bip., Fl. Bras. VI, II, p. 292. - Haut de la Serra do Picú, Mıxas, no 11022 a. Sous-frutescent, fl. lilas. Avril-mai. C.

223. E. bartsicefoliun DG.; Fl. Bras. VI, II, 1. 294. - Campos da Bocaina, S. Paulo, no 8121. Sous-frutescent, fl. lilas. Février-mars. C. 224. E. pedale Sih. Bip. in Fl. Bras. VI, II, p. 298. - Colline d'Ipiranga, S. Paulo, $n^{\circ 5} 15145,16136,16137$; Serra do Picú, dans le campo, Mısas, $11^{0}$ 11022. Sous-frutescent, l1. lilas. Avril-mai. C. 
A.-F.-M. GLAZIOU. - LASTE DES PlaNTES DU BRESH CENTRL. 355

293. E. paucidentatum Sclı. Bip., Fl. Bras, VI, II, 1. 297. Campos da Bocaina, au Sobrado, S. PAulo, n 8123 a. Sous-frutescent. f1. bleuâtres. Février-mars. R.

2206. E. toziciafolium DC.; Fl. Bras. VI, II, p. 297. - Campos da Bocaina, au Sobrado, S. Paulo, $1^{\text {ss }} 8123$, 11018. Sous-frutescent, f1. lilas. Février-mars. C.

227. E. Taunayanum Glaz. n. sp.? in herb. Paris., Berol., Kew., Genev, etc. - Floresta da Tijuca, pres Corcatimba, Rio-Jax., nº 11002. Frutescent, t1. roses. Octobre-novembre. R.

228. E. roseum Gardn. ; Fl. Bras. VI, II, p. 298. - Corcovado et à Serra dos Orgĩos, Rio-Jax., nos 3688, 4042, 4049, 15133, 16131. Sousfrutescent, t1. rose pàle. Janvicr-mai. CG.

229. $\boldsymbol{E}$. firmum Glaz. 11. sp.? in herb. Paris, Berol.. Kew., Genev., etc. - Fazenda do Taquaral, dans le campo, Inss, n 7713. Frutescent, blanchattres. Aoùt-septembre. R.

230. E. horminoides Bak.; Fl. Bras. VI, II, p. 300. - Serra do Caraca Mrsas, ${ }^{\circ}$ s 12902,15140 ; Ayurnoca, au Serro Frio, Mlsas, $n^{0}$ 9487. Sous-frutescent, f1. bleus. Juin- juillet. C.

- Var. calanocephalum Bak. : Fl. Br. VI, II, [). 300. - Serra Dourada dans le campo, Goraz, $n^{0}$ 21611. Sous-frutescent, f1. lilas. Aoùtseptembre. C.

231. E. Vauthieranum DC.; Fl. Bras. VI, II, p. 304. - Nova Friburgo et Petropolis et Serra dos Orgãos, Rı-Jan.. nos 544, 3697. 3698, 4862, 6606, 11014, 16134; Serra de la Bocaina, S. PAulo, n’ 11102. Sous-frutescent, 11. roses. Aoutt-septembre. CC.

232. - Var. ramosissmum Bah.; Fl. Br. VI, II, p. 304. - Petropolis, à Itamaraty; Rı-JAx., $u^{0}$ 15159. Sous-frutescent, 11. blanches. Juinjuillet. R.

333. E. Tranninense Glaz. sp. n. in herb. Paris., Berol., Kew., Genev, etc. - Alto Maralie de Nova Friburgo, Ro-Jax., nos 17651, 18339. Sous-frutescent, fl. blanchâtres. Janvier-février. R.

234. E. Vitalba DC. ; Fl. Bras. VI, II, 1). 308̈. - Campo Grande, Rio-Jax., no 12062 ; Serra de Ouro Preto, Minas, nos 14012, 15148. Sousfrutescerit, ft. blanchàtres. Juillet-aout. C.

233̆. E. cinereum Bak. in Journ. of. Bot., XX (1882, p. 226. Entre Inficionado et Caraça, Misas, n 12816. Sous-frutescent, fl. blanchâtres. Juin-juillet. R.

236. E. sordescens IC.; Fl. Bras. VI, II, p. 306. - Floresta da 
Tijuci, Villa Nova, liı-Jax., ${ }^{0 *} 1482,1483,6614,12063$; Norro do Jaragua, S o Pat to, no 12908. Frutescent, 11. blanchîtres. Mai-juillet. CG.

937. Eupatorium guadalupense Spreng.; Fl. Iras. VI, II, p. 307. Eutre Lagoa de Freitas et Boa Vista, Rı-Jax., nº 3800. Herbaré, fl. bleues. Septembre-sctobre. C.

238. E. amphidictyum DC.; Fl. Bras. VI, II, p. 309. - Alto da Serra do Batatal, Mrsas, nº 15054 . Herbacé, 11. Hanchatatres. Mai-juin. C.

239. E. pandurifolium Bak.. Fl. Bras. VI, II. p. 310. - Congonhas do Campo, Mrsas, $n^{\circ} 15100$ a; Serra Dourada, près Rio dos Indios, Goraz, no 21591. Frutescent, fl. roses. Aoutt-septembre. C.

240. E. itacolumiense Sch. Bip., Fl. Bras. VI, II, p. 310. Itacolumy, près Ouro Preto, Mrsas, $\mathrm{n}^{\text {os }} 15050$, 18331. Sous-frutescent, f1. roses. Mai-juin. C.

2'1. E. amy gdalinum Lamk; Fl. Bras. VI, II, p. 312. - Itabira do Campo et à Cunceição, Mrsas, ${ }^{0 s} 13998,15069,17073$. Sous-frutescent, fl. roses. Juillet-aoùt. CC.

242. E. angustissimum Spreng.; Fl. Bras. VI, II, p. 32马. - Serra de Ouro Branco, Itabira do Campo, etc., Hivas, n ${ }^{\text {ss }}$ 14975, 17066, 17067. Arbuste, fl. jaunâtres. Octobre-novembre. CC.

2'43. E. goyazense Glaz. n. sp.? in herb., Paris., Berol., Kew., Genev., etc. - Entre As Lages et Sicario, dans le campo, Goraz, $n^{0}$ 21590. Frutescent, f1. rose tendre. Juillet-aouit. R.

244. E. serrulatum DC.: Fl. Bres. VI, II, p. 316. - Norrinhos, dans le campo, Goraz, n $21590 a$. Frutescent, f1. blanches. Juillet-aoùt.

240. E. spharocephalum Sch. Bip.; Fl. Bras. VI, II, p. 317. Fazenda do Cipó, à Matta Grande, Mrss, $n^{0}$ 19542. Frutescent, f1. violacées. Avril-mai. C.

246. E. orgyale DC.; Fl. Bras. VI, II, p. 318. - Copacabana, au Morro de S. João, Rio-J $\mathrm{Ax}$, $\mathrm{n}^{0}$ 4055. Frutescent, fl. blanchàtres. Décembre-janvier. R.

247. E. stevicefolium DG; Fl. Bras. VI, II, p. 318. - Itatiaia, entre les rochers dans le campo, Rio-J $\mathrm{J}_{\mathrm{Ax}}, \mathrm{n}^{\text {os }} 5891,6572,12905$. Sous-frutescent, fl. jaunâtres. Janvier-février. C.

-- Var. Itatiaiæ Glaz. n. var. in herl. Paris., Berol., Kew., ete. -Itatiaia, au Campo Feio, Rio-Jax., ${ }^{\circ}$ 6579. Sous-frutescent, fl. rosées. Janvier-février. C.

248. E. monardifolium Walp.; Fl. Bras. VI, II, p. 320. - Entre 
Marianna et Antonio Pereira, Mrsas, no 15146. Frutescent, f1. blanchatres. Mars-avril. C.

249. E. pinnatifidum DC.; Fl. Bras. VI, II. p. 320. - Serra da Contareira, São Paulo, no 19509 a. Frutescent, fl. urangées. Avril-mai. R.

20\%0. E. dendroides Spreng. ; Fl. Bras. VI, II. p. 321. - Casa Branca près Sabara, Mixas, $1^{0 \mathrm{~s}}$ 15116, 16181; Rio Bananal, dims les bourbiers, Govaz, nº 21640. Frutescent, 11. blanchâtres. Janvier-férrier. CC.

- Var. xreophrleoddes Bah.; Fl. Br. VI, II, 1. 322. - Arassuahy, dans les bourbiers, Mws $n^{0 \leq} 15147,19509,19510$. Frutescent, fl. blanchâtres. Mars-avril. C.

2öI. E. serratum Spreng.; Fl. Bras. VI, II, p. 328. - Petropolis. ¿ Santo Antonio, Rio-JAx., n ${ }^{\circ}$ 16193. Sous-frutescent, fl. blanchâtres. Avril-mai. R.

- Var. alpestrts Bak.; Fl. Bras. VI, II, p. 3ㄹ․ - Gandarela, dans le bois près des plantes fossiles, Mixas, $1^{\text {os }} 15134$, 15157. Frutescent, fl. rosées. Févier-mars. C.

ע32. E. intermedium DC.; Fl. Bras. VI, II, P. 328. - Itatiaia, dans le campo, Rio-JAx., n" 6599, 12900. Frutescent, fl. blanc-rosé. Janvierfévrier. C.

2353. E. Gaudichaudianum DC.; Fl. Bras. VI, II, p. 329. - Serra do Picú, ete., Rio-Jax., nos 1049, 4058, 8138, 11019 et 16189. Frutescent, fl. roses. Janvier-mars. CC.

בัצ' E. anethifolium DC.; VI, II, p. 330. - Morro Cavado, près Serra Negra, Mixas, no 7714. Sous-frutescent, fl. blanchâtres. Aout-septęmbre. R.

Q3.5. E. coriaceum Scheele; Fl. Bras. VI, II, p. 331. - Entre Sitio et Barbacena, Misas, $n^{\circ} 11082$. Frutescent, fl. blanchattres. Juin-juillet. C.

Q36. E. velutinum Gardn.; Fl. Bras. VI, II, p. 32'. — Morro Cavadu. dans le bois, Mivas, no 7714 a. Frutescent, 11. blanehâtres. Août-septembre. R.

20ั7. E. pallescens DG; Fl. Bras. VI. II, p. 324. - Parahyba do Sul, Ruo-Jas., nos 2618, 1043; Santa Barbara, Mıss, no 1951l. Frutescent, fl. blanchâtres. Avril-mai. C.

עus. E. angustissimum Spreng.; Fl. Bras. VI, II, 1. 32\%. - Serra d'Ouro Branco, S. Jose l'El Rei, Itabira do Campo, Misis, n's 14975 , 17066, 17067. Arluuste.

- Var. goyazense Glaz. in lierl. Paris., Berol., Kew., ete. - Vargem 
de Chico Costa, Goyaz, no 21615. Arbuste, n. blanc jaunâtre. Septembreoctobre. R.

959. Enpatorium halimifolium DC; Fl. Bras. VI, II, p. 326. Serra do Palmital. Niras, nos 15097, 16142, 17657; As Brancas, Gora\%, $n^{\circ}$ 21617. Frutescent, fl. violacćes. Janvier-février. CC. Vulgo : Losna.

260. E. gnidioides DC; Fl. Bras. VI, II, p. 327. - Colline d'Ipiranga, dans le campo. S. Pıuıo, $1^{\circ}$ 16143. Frutescent, fl. blanchâtres. Novembre-décembre. C.

261. E. bupleurifolium I)C.; Fl. Bras. VI, II, p. 332. - Itatiaia, dans le bois, Ro-Jax., $n^{n} 8772$; entre Ouro Preto et Quelioz, Misas, $n^{\text {os }}$ 15132; Agua Branca, S. P'iulo, n" 16191. Frutescent, fl. rosées. Janvier-mars. C.

- Var. cinifolius Bak.; Fl. Bras. VI, II, p. 332. - Serra da Cantareira, S. PALlo, n 16192. Frutescent, fl. roses. Janvier-février. C.

262. E. oblongifolinm Bak.; Fl. Bras. VI, II, p. 333. - Ipanema. dans le campo, S. Paulo, $n^{\circ}$ 12876. Frutescent, fl. blanclies. Mars-avril. R.

263. E. vernoniopsis S.l. Bip.; Fl. Bras. VI, II, p. 334. - Ipanema dans le campo, S. Paulo, n 12875. Sous-frutescent, f1. blancliâtres. Mars-avril. C.

264. E. stachyophyllnm Spr.; Fl. Bras. VI. II, p. 337. - Serra de São José d'El Rei, Misas, $n^{\circ}$ 15090, 17078; entre As Bracas et Os Ciganos, Goyaz, $n^{0 s} 21635,21636,21637$. Sous-frutestent, f1. bleues? Janvier-février? C?.

26.5. E. snbalternifolim DC., Prodr. Syst. Wat. V, p. 152.Serra de Ouro Branco, Mrsas, $n^{\circ}$ 15082. Sous-frutescent, fl. blanchàtres. Octobre-novembre. C.

266. E. dentatum Gardn.; Fl. Bras. VI, II, p. 337. - Ponte Alta, dans le campo, Goraz, no 21640 a. Sous-frutescent, fl. blanchattes. Octobre-novembre. R.

267. E. pinnatipartitnm Sch. Bip.; Fl. Bras. VI, II, p. 338. Serra do Picú, Ians le campo, Mras, $n^{0} 11035$ a. Sous-frutescent, fl. blanc jaunâtre. Hars-avril. C.

268. E. bracteatum Gardn.; Fl. Bras. VI, II, p. 338. - Itabira do Campo, Mivas, $1^{\circ}$ 15070, 17068. Frutescent, f1. blanchâtres. Septembreoctobre. C.

269. E. trigonmm Gardn.; Kl. Bras. VI, II, p. 339. - Aguas Santas, 
près S. José, Minas, $1^{\circ} 17077$ : Chico Costa, Goraz, n² 21639 a. Sousfrutescent, fl. blanches. Septemlsre-octolse. C.

270. E. dictyophyllnm IOC. ; Fl. Bress. VI, II. p. 340. - Norro de S. Vicente. Wixs, $1^{\circ} 15155$; entre Corumba et As Lages, Goraz, $n^{\text {os }}$ 21639, 21641. 21642. Sous-firutescent, ll. blanchâtres très odorantes. Août-septembre. CC.

27l. E. capillare Bak.; Fl. Bras. II, II, p. P4l. - Pinheiro et

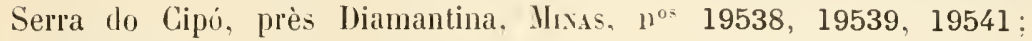
Plateau central, près Corrego do Brejo, Gortz, $11^{\circ} 21609$. Herbaré, fl. bleues. CC.

272. E. Fileinioides H. B. K. : Fl. Bras. VI, II, p. 342. - Itatiaia et prés Barbacena, Alto do Lamando do Rio das Velhas, Mrsas, nos 4863,11088 , 2379 : entre Ipanema et Sorocaba, Camp de Ipiranga, SÄo PALıo, $n^{\circ} 4863$, 16190. Herbacé, f1.bleues. C..

273. E. urticifolium L.; Fl. Bras. VI, II, 1. 343. - Abbade, près Meia Ponte, Goraz, nº 21608 . Herbacé, fl. bleu pâle. Aont-sejtembre. C.

„74. E. decumbens liak.; Fl. Bras. VI, II, p. 344. - Itacolumy et Serra do Picú, Mrss, $n^{\circ} 8125,11024,15143$. Herluacé, f1. violettes. Février-mars. C.

97ò. E. macrophyllmm L.; Fl. Bras. VI, II. p. 34\%. - Araruoma, près Cabo Frio, Rio-Jax., nº 878. Sous-firutescent, fl. blanchàtres. Janvier-fivinier. $R$.

276. E. ianthinmm Hemsl. in Biol. centr. Am. Bot. II, p. 96. Passeio Pulılico el Villa Nova, Rio-Jax., $n^{0 s} 541$, 1534. Sous-frutescent, fl. roses, cultivé. Loùt-septembre. R.

27T. E. pirifolium DC.; I7. Bras. VI, II, p. 346. - Serra dos Oræãos, Rio-Jax., $n^{\circ}$ 2846. Sarmenteux, fl. blanchâtres. Août-septembre. $R$.

278. E. rufesiens Lund; Fl. Bras. VI, II, p. 348. - Nova Friburgo. près du Alto, Rio-Jax., $n^{\circ}$ 12848. Frutescent. fl. roses. Aoüt-septembre. R.

279. E. hebecladum DC.; Fl. Bras. VI. II, p. 348. - Itacolumy, prés Ouro Preto, Misas, $\mathrm{n}^{0 s}$ 8135, 15152, 20369. Sous-frutescent, f1. blanchâtres. Décembre-janvier. C.

280. E. consanguineum DC. ; Fl. Brus. VI, II, p. 30̈0. - Corcovarlo et Floresta da Tijuca, Rio-J.x., nos 181, 183, 1426, 8484. Sous-frutescent, fl. bleu pâle. Juin-juillet. CG.

28I. E. rupestre Gardn.; Fl. Bras. VI, II. p. 349. - Itapemirim, 
E.pirıto S.nto, no 10977. Sous-frutescent, fl. blenâtres. Janvier-février. R.

482. Eupatorium conglobatum DC.; Fl. Bras. VI, II, p. 3850. Itapemirim, Espuntro Santo, $n^{\circ}$ 10978. Sous-frutescent, f1. bleuatres. Janvier-février. R.

283. E. lave DG.; Fl. Brets. VI, II, p. 33̈2. - Norro da Babylonia, a Botafogo, lito-Jax., $\mathrm{n}^{\text {os }} 879,10979,11001,11008$. Frutescent, 11. hanchîtres. Février. CG.

284. E. Adamantium Gardn.; Fl. Bras VI, II, p. 330. - Alto Macahé de Nova Friburgo, Rio-Jan., $n^{o s} 2857,14015,18312$; Serra de Ouro Preto, Mixas, $n^{\text {os }}$ 15068, 15128. Frutescent, f1. blanchâtres. Janvier-février. CG.

- Var. minor Bak. v. nov. in herb. Paris., Berol., Kew., etc. -- Inficionado, près Caraça, Mrsas, $n^{\circ}$ 12823. Frutescent, 11. rosées. Juin-juillet. G.

283. E. orbiculatum DC.; Fl. Bras. VI, II, 1. 3933. - Serra do Caraca, dans le campo, Hixas, $n^{\circ} 12910 a$. Frutescent, 11. roses. Marsavril. C.

286. E. baccharifolium Gardn.; Fl. Bras. VI, II, p. 383. - Serra dlos Orgĩos, au sommet, R10-JAv., ${ }^{\text {os }} 4056$, 15064, 16208. Arbuste, 11. blanchâtres. Mars-avril. Exhale une excellente odeur de vanille. C.

287. E. megacephalum Mart.; Fl. Bras. VI, II, p. 30̈4. - Campos do Pící, à Engenho da Serra, Mıvas, $n^{\text {os }} 11035,19519$; Quinta da Boa Vista, Rio-Jax., nos 548, 2616, 4032; Neia Ponte, Goraz, n² 21575. Herlacé, tl. pourpres. Novembre-décembre. CG.

288. E. purpurascens Sch. Bip.; Fl. Bras. VI, II, p. 386. Campos da Bocaina, S. Paulo, $n^{\circ}$ 8144. Herbacé, ll. rougè pourpre. Janvier-février. C.

289. E. angulosum Glaz. n. sp.? in herb. Paris., Berol., Kew., Gener., etr. - Chico Lobo, dans le campo, Goraz, n² 21578. Herbacé, 1h. roses. Juin-juillet. R.

990. E. Glaziovii Bak.; Fl. Bras. VI, II, p. 357. - Santo Amaro, dans les bourbiers, S̃̃O PacLo, $1^{\text {os }} 2617,12907$. Herbacé, 11. roses. Avril mai. R.

291. E. chlorolepis Bah.; Fl. Bras. VI, II, p. 357. - Entre Ipanema et Sorocaba, Sĩo Paulo, nos 12910, 16152; Rio Gama, dans le campo, Goraz, $1^{\circ} 21574$. Herlıa'é, 11. roses. Février-mars. C.

292. E. parvulum Glaz. n. sp.? in herb. Paris., Berol., Kew., Genev., etc. - Entre Ouro Preto et Queluz, Misas, n 15150. Herbacé. fl. roses. Février-mars. R.

993. E. macrocephalum Less.; Fl. Bras. VI, II, p. 358. - Campos 
da Bocaina, S. Paulo, $\mathrm{n}^{0 \mathrm{~s}} 8122,19519$ a. Herbacé, t1. roses. Janvielfévrier. C.

294. E. ballotafolium H. B. K.; Fl. Bras. V1, II, p. 360. - Serra dos Orgĩos, Rio-Jax., no 2852; entre Inficionado et Caraça, Mrxas, no 12797. Sous-frutescent, 11. roses. Juin-juillet. C.

295. E. organense Gardn.; Fl. Brus. VI, II, p. 361. - Serra dos Orgãos et à Petropolis, Rı-Jıx., n ns 4063, 15085, 17092 et 17100. Sousfrutescent, 11. roses. Mars-avril. C.

- Var. maximum Bak. var. nov. in herb. Paris., Berol., Kew., ete. Morro do Carangolo, au Retiro, Rio-JAx., nos 13989, 13991. Sous-flutescent, 11. blanchâtres. Novenbre-décembre. ir.

- Var. junius Bak. var. nov. in lıerb. Paris., Berol., Kew., ete. Itacolumy et Serra do Picú, Mivas, $n^{\circ}$ 11017, 15153. Sous-frutescent, fl. blanchâtres. Mars-avril. C.

996. E. apiculatum Gardn.; Fl.Bras. VI, II, J. 361. - Restinga de Copacabana, Rı-J Ax. $^{\circ 5}$ 99, 1407, 1408, 2094. Sous-frutescent, l1. roses. Juin-juillet. C.

997. E. betonicaforme Bak.; Fl. Bras. YI, I1, p. 362. - Fizenda Santa Gruz, Ilha Grande, Rı-JAn., $1^{\text {os }}$ 7883, 9486, 12906; Ganlarela, Minas, $n^{0}$ 15154. Sous-frutescent, fl. rosées. Février-mars. CC. Vulgo: Matapala.

298. E. palustre Bak.; Fl. Bras. VI, II, p. 363. - Agua Limpa, à Gandarela, Mixas, $n^{\circ}$ 12909, 15149. Sous-frutescent, 11. rosées. Férriermars. C.

999. Mikania microphylla Sch. Bip.; Fl. Bras. VI, II, p. 219. Itacolumy, près Ouro Preto, Mrsas, n 15144. Herluacé, 11. hlanches. Février-mars. C.

300. M. officinalis Mart.; Fl. Bras. VI, II, P. 22.1. - Ipanena pris la mine de f'er, S. Piulo, $n^{\circ}$ 16135. Herbacé, f1. blanchâtres. Férriermars. CG. Vulgo : Coracão de Jesus.

30I. M. reticulata Gardn.; Fl. Bras. VI, II, P. 223. - Serra do Palmital et à Caraça, Mrsas, $n^{0 s} 15117,15118,19513$ et 19514. Sous-firltescent, fl. jaunâtres. Février-mai. C.C.

302. M. nummularia DC.; Fl. Bras. VI, II, p. 223. - Itatiaia, Serra do Picú, Itabira do Campo, Mrvas, n 4854, 6574, 11032, 11083 et 17079. Sous-frutescent, fl. jamâtres. Avril-mai. CG.

303. M. sessilifolia DC.; Fl. Bras. VI, II, p. 22z̈. - Caraça, Serra 
do Picú, S. Joño d’El Rẹi, Mrsas, nos 11031, 12886, 15121, 15122, 15124, 17076, et 19515. Sons-frutescent, 11. blanchittres. Mars-juiı. CG.

- Valr. regneld Bak. Fl. Br. VI, II, p. 226. - Alto da Serra do Batatil, ou do Calranema, Mısıs, $11^{\circ}$ 15126. Sons-frutescent, fl. jaunâtres. Juin-juillet. C.

304. Mikania leiolana DC.; Fl. Bras. VI, II, p. 227. - Serra do Caragra dans le campo, Nivas $11^{\circ}$ 15123. Sous-frutescent, 11. jaunatres. Juin-juillet. C.

30:3. M. myriocephala DC.; Fl. Bras. VI, II, p. 230. - Petropolis et Gavea, Rio-Jan., $1^{\text {os }} 1403,6607,7856,11013$. Volubile, f1. jaunattres. Mars-avril. CG.

306. M. buddleiafolia DC.; Fl. Bras. VI, II. p. ㅆ31. - Fazenda do Taquaral, Mısas, $1^{0} 7721$ : Petropolis, au Retiro, Rio-Jav., nº 13976. Volubile, It. blanchittres. Aont-septembre. C.

307. M. estrellensis Bak., Fl. Bras. VI, II, p. 231. - Serra da Estrella, à Maudioca, Rı-JAN., nº 6607 a. Volubile, fl. jaunâtres. Aoûtseptembre. R.

308. M. Lindbergii Bak., Fl. Bras. VI, II, p. 232. - Fazenda do Taquaral, Mixas, $1^{\circ} 7721 a$. Volubile, fl. blanchâtres. Août-septembre. R.

309. M. erioclada DC.; Fl. Bras. VI, II, 1) 233. - Parahyba do Sul, Rio-Jan., $n^{o s} 1404,12862$. Volubile, fl. blanches. Septembre-oetobre. C.

310. M. pilosa Bak., Fl. Bras. V1, II, p. 234. - Entre Carandahy et Queluz, Misas, $n^{0}$ 18313. Volubile, fl. Blanches. Juillet-aoùt. C.

311. M. Lasiandre DC.; Fl. Bras. VI, II, p. 236. - Petropolis, au Murin, Rio-JAx, no 9483. Grosse liane, 11. blanchâtres. Janvier-février. R.

312. M. anara Willd.; Fl. Bras. VI, II, p. 237. - São João da Bara,

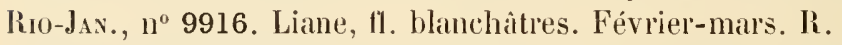

313. M. smilacina DC.; Fl. Brus. VI, Il, p. 298. - Entre Nacaen et Lage, Goraz, n² 21644 a. Liane, f1. Dlanches. Juin-juillet. R.

314. M. bracteosa DG.; Fl. Brus. VI, II, p. 239. - Restinga de Mauá, Rı-Jıx., no 8419 a. Volubile, fl. blanches. Juin-juillet. R.

313. M. pachylepis Sch. Bip., Fl. Bras. VI, II, P. 239. - Alto Macalıé dle Nova Friburgo, Rı-JAx., n 13978. Grosse liane, fl. blanches. Novembre-dérembre. C.

316. M. lavis DG.; Fl. Bras. VI, II, 1. 240. - Corcovado, Tingua, Naud, Rio-JAx., nos $6611,8471,11092,12863,13977$; Barbacena et à Caraça, Mısas, $\mathrm{n}^{\circ}$ 15129, Volubile, l1. blanchâtres. Juillet-aoùt. CC. 


\section{MÉMOIRES PUBLIÉS}

1. Christ, Fougères de la Chine, 69 p. (mai 190อั), terminé.

2. Terracciavo, Gagea du nord de l'Afrique, 26 p. (nov. 1905), termine.

3. Grazrou, Plantes du Brésil central, 1122 p.. (nov. 190气), à suivre.

千. Finet el Gagnepain, Flore de l'Asie orientale, 5 ' p. ; 8 pl. (I-VIII) distribuées avec la table de 190ð (mars 1906), à suivre.

כ. Ligiver, Anatomie des Renonculacées, 38 p. (juin 1906), terminé.

3b. Guazıou, Plantes du Brésil central, p. 113-200 (juil. 1906), à suivre.

4 (2e partie). Finet et Gagnepain, Fl. de l'Asie or., p. こัวั-170, pl. IX-XX (déc. 1906), à suivre.

6. Perrot et Gérard, Anatomie du tissu ligneux dans ses rapports avec la diagnose des bois, 43 p.; 6 pl. (juin 1907), terminé.

7. Prtard, Nuscinées des îles Canaries, 44 p. (juin 1907), terminé.

8. Chevalier, Novitates floræ africanie (1 ${ }^{\text {re }}$ partie), pp. 1-30 (aoùt 1907), à suivre.

9. Finet, Orchidées africaines de la tribu des Sarcanthées, 6马 p.; 12 pl. (nov. 1907), terminé.

10. Furche, Monocotylédones arborescentes ou frutescentes de France, d’Algérie ou de Tunisie, 26 p.; 1 pl. (août 1907), terminé.

11. P. Guéris, Études sur les Diptérocarpées, 93 p. (décembre 1907), terminé.

3c. Glazrou, Plantes du Brésil central, pp. 201-296 (février 1908), à suivre.

12. Húe (abbé), Lichens Tarbelliens, 19 p. (avril 1908), terminé.

13. 0. Lignier, Le fruit des Bennettitées et l'ascendance des Angiospermes, 17 p. (avril 1908), termine.

8b. Chevalier, Novitates floræ africanæ (2e partie), pp. 31-109 (août 1908), à suive.

14. Paris (Général), Fłorule bryologique de la Guinée française, (novembre 1908).

3d. Glazıou, Plantes du Brésil central, pp. 297-392 (juin 1909), à suivre, 


\section{AVIS IMPORTANTS relatifs à la Publication du BULLETIN}

I. - Les manuscrits, rédigés ne varietuv et lisiblement, doivent ètre déposés le joul même où sont faites les communications, faute de quoi leur impression est ajournée sans que les auteurs puissent élever de réclamation à cet égard.

Il. - Si les manuscrits sont accompagnès de figures destinées à ètre insérées dans le texte, celles-ci doivent être dessinées à la plume et au trail, ou bien au crayon Wolf sur papier procédé, ou consister en bonnes photographies, de manière à en pernuttre la reproduction par les procédés zincographiques. L'insertion de toute ligure ne pouvant ètre reproduile que par des procédés différents reste soumise a l'approbation de la Conmission du Bulletin.

111. - Les auteurs reçoivent une épreuve en placards et en double exemplaire de leurs communications, la correction les autres épreuves etant faite par le Secrétariat. Les corrections doivent ètre retournées dans le delai maximum de trois jours au Secrétaire-rédacteur, faute de quoi la correction est faite d'office par le Secrétariat.

IV. - Lorsque les manuscrits dépassent la longueur réglementaire de 8 pages et qu'ils ne comportent pas de question de priorité, ils peuvent être publies sous la rubrique: Mémoires puliés par la Suciélé botanique de france. Ces Mèmoires sont éclités avec toute la célérité possilıle, mais sans garantie de date. Ils prennent place dans les volumes annuels a la suite des communications insérées aux séances ordinaires et sont fournis aux Membres de la Société sans majoration le leur cotisation.

V. - Atin de permettre l'établissement des convocations aux séances, MM. les Auteurs sont instamment priés d'aviser le Secretaire général huit jours à l'avance des communications qu'ils ont l'intention le présenter.

VI. -- En vue d'assurer l'unité typographique du Bulletin, le Conseil a arrêté le protocole ci-dessous, reglant les caraclères employés dans les descriptions ou citations de végétaux. Il ne sera admis aucune dérogation à cette règle.

\begin{tabular}{|c|c|c|}
\hline & NOUVELLES & ANCIENNES \\
\hline FaMiLLE. & 1. LEEGUMINEUSES. & 2. LEGGUMINEUSES. \\
\hline $\begin{array}{l}\text { Sous-Famlle. } \\
\text { Tribu. }\end{array}$ & 3. Papilionacées. & 4. Papilionacées. \\
\hline Genre. & 5. MEDICAGO. & 6. Medicago. \\
\hline ESPÈCE. & 7. Cylindracea. & 8. Cylindracea. \\
\hline VARIÉTÉ. & 9. Laciniata. & 10. Laciniata. \\
\hline
\end{tabular}

Tout ce qui concerne ladministration de la Société doit être adressé au Secrétaire général à l'adresse suivante :

M. Lutz, professeur agrégé à l'École supérieure de pharmacie, 4, arenue de l'Observatoire, Paris (VI $)$.

Le Secrétaire-rédacteur, Gérant du Bulletin:

F. Casues.

Coulommiers. - Imp. PAUL BRODARD. 


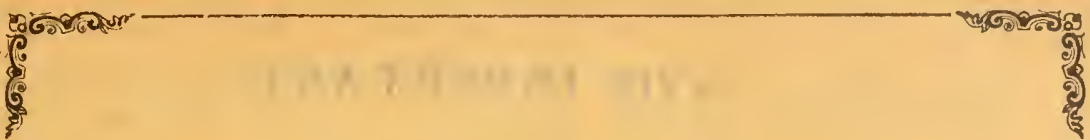

\section{BULLETIN}

DE LA

\section{SOCIÉTÉ \\ BOTANIQUE}

\section{DE FRANGE}

FONDEE LE 23 AVRIL 185-1

ET RECONNUE GOMME ÉTABLISSEMENT D'UTILITÉ PUBLIQUE

PAR DÉCRET DU 17 AOUT 1875

\section{TOME CINQUANTE-SEPTIÈME}

(Quatrième série - Tome $\mathrm{X}$ )

1910

M E MOIRES

$3 e$

\section{PARIS}

AU SIEGE DE LA SOCIÉTE RUE DE GRENELLE, S4

Le Bulletin de la Societé botanique de France paraît par livraisons mensuelles. Le Bon à tirer de ce numéro a été donné le 21 férrier 1910. 


\section{AVIS IMPORTANT}

Par suite de l'augmentation croissante du nombre des communications et de sa répercussion sur les finances de la Société, la Commission du Bulletin croit devoir rappeler à nos Confrères que le Règlement limite la longueur des manuscrits à huit pages d'impression par séance et à quarante pages pour l'année entière, au delà desquelles l'auteur doit sa collaboration pécuiniaire.

Dans un intérêt commun, la Commission prie donc très instämment MM. les Auteurs. de condenser le plus possible le texte des Notes destinées à l'impression.

\section{Tarif des tirages à part.}

Un tirage sous presse do 25 exemplaires est aecordé gratuitement à Messieurs les Auteurs qui en feront la demande en remettant leur manuscrit. - Les Auteurs qui préférent des tirages à parı avec réimposition, bénéfieieront en compensation d'une réduction de $3 \mathrm{fr}$. 60 sur les prix du tarif ci-dessous

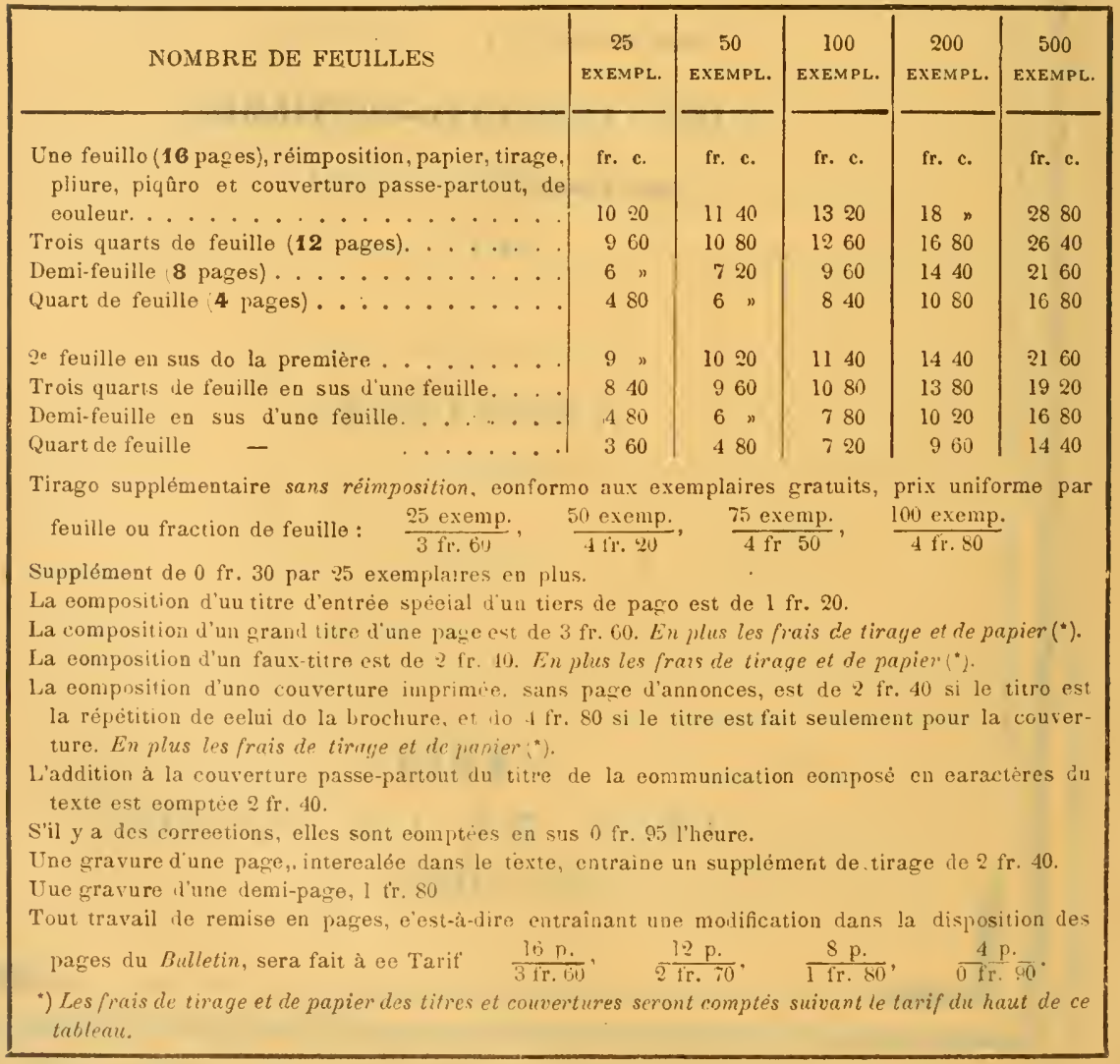


317. M. confertissima Sch. Bip. in Fl. Bras. VI, II, p. 242.-Restinga de Mauá, Rio-Jı., $n^{\circ} 8479$ a. Volubile, fl. Blanches. Juinjuillet. R.

318. M. retifolia Sch. Bip. in Fl. Bras. V1, I1, p. 242. - Serra de Inficionado, près Caraça, Musas, $n^{\circ}$ 14011. Sous-frutescent, fl. blanchâtres. Aout-septembre. li.

319. M. elliptica DC.; Fl. Bras. 11, II, p. 243. Petropolis, au Morro Cubieado, Rio-Jax., nº 11048. Volubile, fl. blanchâtres. Juin-juillet. C.

320. M. obtusata DG.; Fl. Bras. 11, I1, p. 243. - Nova Friburgo, a Pella do Conego, Rio-Jax., nos 8490, 12849; São João d'El Rei, Itacolumy, Caraça, Misas, nos $15101,17075,19512$. Sous frutescent, f1. blanrliatres. CG.

321. M. nitidula Bak. in Fl. Bras. V1, II, p. 243. - Itacolumy, près Ouro Preto, Mlivas, ${ }^{\circ}{ }^{\text {s }}$ 14008, 15130. Souss-frutescent, fl. blanchàtres. Juin-juillet. C.

320. M. hispida Gardn.; Fl. Bras. VI, II, p. 244. - São Sebastião, au Retiro, Rio-Jax., $n^{\circ}$ 4950. Volubile, fl. blanches. Mai-juin. R.

323. M. glomerata Spreng.; Fl. Bras. VI, II, p. 2450. - Rio Trapixeiro, Pedra Bonita, Belem, Rio-Jax., nos 11091,12865 , 12873. Volubile, f1. blanchâtres. Aoùt-septembre. C.

3노. M. vitifolia DC.; Fl. Bras. VI, II, p. 246. - Petropolis, au Morro da Bandeira, Rio-JAx., no 13979. Grosse liane, f1. blanches, Avrilmai. R.

3… M. biformis DC.; Fl. Bras. VI, II, p. 246. - Petropolis, Restinga de Yauá, Ignassu. Rio-Jıx., nos 8480, 8781, 13980. Volubile, 11. Blanchàtres. Janvier-février. C.

326. M. triangularis Bak. : Fl. Bras. VI, II, p. 246. - Petropolis, dans le vieux chemin, kio-Jax., $n^{\circ}$ 6609, 12871. Volubile, 11. blanchâtres. Juin-juillet. C.

327. M. chlorolepis Bak. in F\%. Bras. VI, II, p. 247. - Alto llacahé de Nova Friburgo, Rio-Jax., nos 12869 , 17097. Volubile, f1. blanches. Juin-juillet. C.

328. M. Ramiziana Glaz. n. sp. in lerb. Paris., Berol., Kew., Gener., etc. — Petropolis, à Quitandinha, R10-Jax., nº 12048. Volubile, fl. jaunattres. Juin-juillet. C.

329. M. scandens Willd.; Fl. Bras. VI, II, p. 248. - Gavea, Copacabana, Jacarepagua, Rio-Jax., nos $1041,1402,1406$, 11029. Volubile, 11. blanches. Mars-avril. CG. Vulg. : Guaco. 
- Var. umbelifera Bah.; Fl. Br. VI, II, p. 299. - Entre Queluz et Garrandahy, Mixas, $1^{05} 12819,12867$. Volubile, ll. blanches. Juin-juillet. CC. Vuls. : Guuco.

- Var. crnanchiolia Bak.; Fl. Br. VI, II, p. 249. - Floresta da Tijuca, à Soledade, Ru-Jax., nº 10972. Liane, ll. blanches. Février-mar's. G. Vulg. : Guaco.

330. Mikania testudinaria DC.; Fl. Bras. VI, II, p. 231. - Restingà de Mauá, Rro-Jax., nº 8111 . Volubile, fl. jaunàtres. Avril-mai. C.

331. M. Glaziovii Bak, Fl. Bras. VI, Il, p. 2:1. - Nto do Itatiaia, dans le bois, Rio-Jax., $n^{\circ}$ 4856. Volubile, f1. jaunâtres. Juin-juillet. C.

332. M. microcephala DG. in Fl. Bras. VI, II, p. 292. - Serra do Picú, au Palmital, Rı-JAx., no $10972 a$. Volubile, ll. jaunâtres. Mar'savril. G.

333. M. cordifolia Willd.; Fl. Bras. VI, II, p. 253. - Petropolis, Praia Grande, Rro-JAx., $n^{\circ 8} 8753,10970,10971,12051$. Volubile, fl. jaunâtres. Juin-juillet. GG.

- Var. unbrosa Bak. in Fl. Br. VI, II, p. 254. - Serra clo Picú, Sìo Christovão, Rio-Jax., $11^{\text {5s }} 7706,11030,12864$. Volubile, fl. jaunâtres. Avril-juillet. CG.

- Var. carnosula Bak.; Fl. Br. VI, II, p. 2:4. - Entre Joño Ayre et Sitio, Muxas, nos 12818,12820 . Volubile, f1. jaunâtres. Juin-juillet. C.

334. M. Lundiana DC.; Fl. Bras. VI, II, p. 268. - Corcovado et Floresta da Tijuca, Rio-Jav., $n^{03}$ 175, 1400, 1405, 1414, 1421. Volubile, fl. blanchâtres. Juin-juillet. CG.

33\%. M. deflexa Gardn. in Hooker Lond. Journ. V, p. 482. - Nova riburgo et Corcovado, Rio-Jan., nos 1487, 12050. Volubile, 11. jaunâtres. Juin-juillet. R.

336. M. hemispharica Sch. Bip.; Fl. Bras. VI, II, p. 2:4. - Petropolis, au Palatinato, Rı-Jax., no 8753 a. Volubile, fl. jaunâtres. Maijuin. R.

338. M. salvia folia Gardn.; Fl. Bras. VI, II, p. Цəัวั. - Cantagallo, à Larangeiras, Rro-JAx., $n^{\circ}$ 12872. Liane, fl. blanchâtres. Juin-julllet. G.

339. M. microdonta DC.; Fl. Bras. VI, II, p. 20ั0. - Serra do Tingua et Petropolis, Rı-Jan., $n^{\circ s} 8147,8780$. Volubile, fl. jaunâtres. Mai-juin. C.

340. M. Banisterice DG.; Fl. Bras. VI, II, p. ¿ə̌6. - Campos da Bocaina, S. Padzo, $n^{0} 11100$. Volubile, fl. jaunâtres. Août-septembre. C. 341. M. Argyreia DC. ; Fl. Bras. VI, II, p. 20̈7. - Serra da Estrella, 


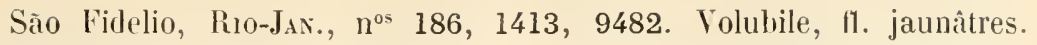
Février-mars. C.

342. M. vismiafolia UC.; Fl. Bras. VI, II, p. 2̆̈. - Serra d'Itabira do Campo, Mrsas, n 17080. Volubile, f1. blanchâtres. Aoùt-septembre. C.

343. M. setigera Sch. Bij). in Fl. Bras. VI, I1, p. 2259.-Petropolis, au Alto do Imperador, Rio-JAx., n 11010 . Volubile, f1. blanchâtres. Mars-avril. R.

344. M. microlepis Bak. in Fl. Bras. VI, II, p. 209. - Entre São José do Barreiro et Formosa, Rı-Jas., nº 11096. Volubile, f1. blanchâtres. Septembre-octolore. C.

345. M. conferta Gardn.; Fl. Bras. VI, II, p. 260. - Corcovado, Floresta da Tijuca, Taquaral, Rio-Jax., nos 1415, 5909, 7722. Grosse liane, fi. blanchâtres. Juillet-septembre. C.

- Var. bicolor Bak. var. n. in herb. Paris., Kew., Berol., etc. - Nova Friburgo, au Conego, Rin-Jax., n 12868. Grosse liane, fl. blanchàtres. Juin-juillet. R.

346. M. hirsutissima DC. ; Fl. Bras. VI, II, p. 260. - Sera dos Orgãos, Colcovado, Boa Vista, etc., Rio-Jas., nos 1412, 4060, 4061, 11093, 11097, 12866. Liane, f1. blanchàtres. Juillet-aoìt. CC.

- Var. Martiana Bak.; Fl. Bras. VI, II, p. 261. - Serra da Estrella, près Petropolis, Rı-Jax., $n^{\text {os }}$ 6608, 12817. Volubile, f1. blanchâtres. toùt-septembre. C.

347. M. lanuginosa DC.; Fl. Bras. VI, II, p. 261.-Campos da Bocaina, dans le bois, S. PduLo, nos 3043 , 8137. Volubile, fl. blanchâtres. Février-mars. R.

348. M. apiifolia DC.; Fl. Bras. V1, II, P. 262. - Floresta da Tijuca et Serra da Estrella, Rio-JAx., n ${ }^{\text {os }} 4053,8761,12047,12049$, 12870. Volubile, 11. blanches. Avril-mai. CG.

349. M. psilostachya DC.; Fl. Bras. VI, II, p. 263. - Araruama, Rı-JAx., nº 10969; Fazenda da Vargem, au Rio Jardim, Goyaz, nº 21644. Volubile, f1. blanches. Juin-juillet. C.

35̆0. M. nigricans Gardn.; Fl. Bias. VI, II, p. 267. - Restinga de Taipu, Jurujuba, Gavea, Rio-JAx., nos 14020, 6604, 8113. Vulubile, f1. jaunâtres. Mars-avilil. C.

331. M. thyrsoidea Bak. in Fl. Bras. V', Il, p. 267. - Nova Friburgo, au Alto, Rio-JAx., no 12050 a. Volubile, t1. blanches. Juinjuillet. R.

30̈2. M. ligustrifolia DC.: Fl. Bras. VI, II, p. 270. - Tripuhỵ, 
pres Oulo Preto, Mixas, no 15129 a, 20368. Volubile, fl. blanches. Norembre-dicembre. C.

3is. Kanimia oblongifolia Bak.; Fl. Bras. VI, I1, p. 369. - Entre Barbarena et Sitio, Serra de Ouro Preto, Ayuruoca, Minas, n ${ }^{08} 15127$, 16140, 16141. Sous-fiutescent, l1. jaunatres. Mai-juin. C.

334 . K. gracilis Bak. in Fl. Bras. VI, II, p. 371. - Norro do Inficionalo, pris Caraça, Mrsas, $1^{\circ}$ 15120. Sous-frutescent, f1. jaunâtres. Maijuin. R.

3ïi. Brickellia pinifolia A. Gray; Fl. Bras. VI, II, p. 372. Entre São Vicente ef S. Bartholomeu, Mnss, $n^{\text {os }} 14027$, 14976; entre Alexandre et As Antas, Goraz, n² 21616. Frutescent, 11. blanches. Juinaouit. C.

336. Leucopsis scaposa Bak.; Fl. Bras. VI, III, P. 6. - Serra de Onro Branco, Ayuruoca, Barbacena, Misas, nos 7711, 9489, 11016. 15072; Ipiranga, S. PAulo, nos 16177, 16178. Acaule, 11. blanches. Marsarril. CC. Vulg. : Quebra Frasco.

3.7. L. gnaphaliodes Bak. in Fl. Bras. VI, III, p. 8. - Serra Frio, près Ayuruoca, Mrsas, no $9489 a$. Herbacé, fl. blanchàtres. Mars-avril. R.

3̋̈8. L. Tweediei Bak.; Fl. Bras. VI, III, p. 9. - Carandahy, dans les hourhiers, João Aỵres, Caclıambú, etc., Mixas, $n^{\circ s} 11052,14016$, 15034, 15084, 18316, 16173; Rio Jataba, Goyaz, nº 21596. Herbacé, f1. jaunes. Janvier-mars. C.C.

3อ̆9. Solidago microglossa DC.; Fl. Bras. VI, III, p. 10. - Entre Ipanema et Sorocaba, S. Paulo, $n^{\text {os }} 11081,12899,16156$. Herbacé vivace, fl. jaunes. Mars-avril. C.

360. Egletes viscosa Less.; Fl. Bras. VI, III, p. 20. - Serra do Picí, au Paulo, Rio-Jax., no 10981. Herbacé, 1). jaunes. Nars-avril. C. Vulg. : Marcella do certao.

361. Aster divaricatus Torr. et Gr.; Fl. Bras. VI, III, p. 21. - Corcovado, à Sta Theresa, Riro-Jax., nº 7692. Sous-frutescent, fl. jaunes. Norembre-décembre. C.

362. Sommerfeltia spinulosa Less.; Fl. Bras. VI, III, p. 26. Restinga de Caloo Frio, Rro-Jav., no 19521. Frutescent, fl. blanches. Novembre-décembre. C.

363. Podocoma hirsuta Bak. in Fl. Bras. VI, III, p. 15. - Serra da Mantiqueira, près Joâo Ayres, Mıxs, nº 11081. Sous-frutescent, f1. jaunes. Juin-juillet. R.

361. P. bellidifolia Bak. in Fl. Bras. VI, III, P. 16. - Serra dos 
A.-F.-M. GLAZIOU. - LISTE JES PLANTES DU BRÉSIL CEXTRAL.

Orgĩos, à Pedra do Sino, Rio-Jax., no 8766 a. Herhacé, 11. jaunâtres. Septembre-octobre. R.

36\%. Erigeron maximus Link; Fl. Bras. VI, III, p. 28. - Serra dos Orgãos, à Pedra do Sino et à Serra da Estrella, Rio-Jax., nos 1048 , 8746. Herh., f1. blanches. Octobre-novembre. C.

- Var. palustris Bak. Fl. Bras. VI, III, p. 28. - Serra dos Orgãos, cooté de Petropolis, Rio-Jax, n 16166. Entre Sitio et Joño Ayres, dans les hourbiers, Mixas, ${ }^{0 s} 11050,15079,16167$. Herb., fl. blanches. Janvierfévirier. CC.

- Var. minor Bak. in Fl. Bras. VI, III, p. 28. - Itatiaia, aux Campos Brejos, Rro-Jax., $1^{\circ s}$ 6583, 4866. Herb., 11. blanches. Mai-juin. C

366. E. bonariensis L.; Fl. Bras. VI, III, p. 30. - Corcovado et S. Chıristovão, Rı-JAx., $n^{0 \leq}$ 189, 543, 7689, 7690. Herb., 11. blanchâtres. Dérembre-janvier. CG.

- Var. major Bah. in herl. Paris., Berol., Kew., etc. - Nova Fri burgo, au Conego, Rio-Jax., no 12847 ; entre Ouro Preto et Nirianna, dans les bourbiers, Misis, $1^{\text {os }} 14017,15065$. Herb., il. blanchàtres. Janvier-février. C.

367. E. linifolizus Willd.; Fl. Bras. VI, III, p. 3I. - Floresta da Tijuca, Rı-JAN., $n^{0 s} 542,549$. Herb., fl. jaunes. Janvier-février. C.

368. Conyza triplinervia L. ; Fl. Bras. VI, III, p. 33. - Congonhas do Campo, Mras, $1^{\circ}$ 1508. Frutescent, t1. blanches. Mai-juin. C.

369. C. arguta Less.; Fl. Bras. VI, III, p. 33. - Rio Manso, Mlixas, no 14003. Sous-frutescent, fl. blanches. Février-mar's. C.

370. C. rivularis Gardn.; Fl. Bras. VI, III, p. 34. - Sema dos Orgãos, aux bords des rivières, Rio-JAx., $n^{\circ} 1619$. Herb., fl. blanchàtres. Septembre-octobre. C.

371. C. notobelliastrum Griseb.; Fl. Bras. VI, III, p. 34. - Serra da Estrella, à Mandioca, Rio-JAN., $n^{\circ} 2621$ a. Herb., fl. blanches. Novenbre-décembre. C.

372. C. chilensis Spreng.; Fl. Bras. VI, III, p. 33̈. - Floresta da Tijuca, S. Christorão, Serra dia Estrella, Rio-Jax., n ${ }^{05} 350,2621,7693$, 8756. Herh., 11. jaunâtres. Décembre-janvier. CG.

373. Baccharis stenocephala Bak. in Fl. Bras. VI, III, p. 39. Entre Sorocaba et Ipanema, Sĩo Pacto, $n^{\circ}$ 16198. Frutescent, 11. jaunes Novembre-décembre. C.

374. B. fastigiata Bak. in Fl. Bras. VI, III, p. 39. - Serra de Ouro Branco, Misas, n ${ }^{\text {os }} 12911,18325$. Frutescent, fl. jaunàtres. Mars-avril. C. 
37i. Baccharis microcephala DC.; Fl. Bras. VI, III, p. 40. - Eutre João Ayres et Sitio, Caranlahy, Mıxas, $1^{0 s} 11079,15021$. Sous-lirutescent, 11. jannes, Mai-juin. C.

376. B. xylophylla Bak. in herl, Paris., Berol., Kew., Genev., etc. - Eutre Ouru Preto et Queluz, Muxas, $n^{\text {os }} 15004$, 16203. Frutescent, fl. blanchı̂tres. Janvier-mar's. R.

377. B. genistelloides Pers.; Fl. Bras. VI, III, p. 40. - Serra dos Orgãos, Nova Friburgo, Rio-Jax, $n^{\text {os }}$ 2629, 4037, Serra de Ouro Preto, Casil Branca, Mıxas, $1^{\text {s. }}$ 12835, 13994, 15018 et 15019. Février-juin. CC. Vulg. : Carqueja.

- Var. вrachystachys Bak. in Fl. Br. Vi, III, p. 4l. - Campos da Bocaina, au Sobrado, São Paulo, no 11095. Sous-frutescent, fl. james. Août-septembre. C. Vulg. : Carqueja.

- Var. cremdrica Bak. in Fl. Bras. Vl, III, p. 41. - Nova Frilurgo, au Suspiro, Rio-JAx., n ${ }^{0}$ 12854. Sous-frutescent, fl. jaunes. Aoùt-septembre. R.

378. B. Glaziovii Bak. in Fl. Bras. VI, 11I, p. 44. - ltatiaia, dans le

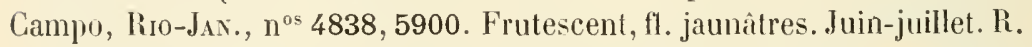

379. B. gracilis DC.; Fl. Bras. VI, III. p. 4̧. - Serra das Divisoes ou do Urbano, Goyaz, $n^{\circ}$ 21595. Sous-frutescent, fl. blanches. Aoùtseptembre. C.

380. B. aphylla DG.; Fl. Bras. VI, III, p. 40̆. - Campos da Bocaina, à Vacca Cahio, S. Patco, no 8141: Serra da Saromenia, Mutuca et Barbacena, Mıxas, $n^{05} 7709,16199,20371$. Sous-frutescent, f1. jaunâtres. Janvier-février. C.

381. B. polygona Bak. in Fl. Bras. VI, III, p. 46. - Entre Sitio et Barbacena, Misas, $11^{\circ}$ 15020. Sous-frutescent, fl. blanches. Novembredécembre. li.

382. B. ochracea Spreng.; Fl. Bras. VI, III, 1) 47. - Quartel do Biribiry, près Diamantina, Mısas, $n^{\circ}$ 19507. Arbuste, fl. blanc jaunàtre. Varsavril. $R$.

383. B. artemisioides H. et A.; $\mathrm{Fl}$. Bras. VI, III, p. 47. - Serra da Cantalreira, S. Padlo, $n^{\circ} 16196 a$. Arbuste, fl. jaunes. Février-mars. R.

384. B. discolor Bak. in Fl. Bras. VI, III, p. 48. - Itatiaia, dans le campo, Rio-JAx., nº 4850. Arbuste, fl. blanches. Juin-juillet. C.

385. B. erioclada DC. ; Fl. Bras. VI, III, p. 48. - Entre Sĩo BarthoIomeu et Ouro Preto, Barbacena, Itatiaia, Mrxas, ${ }^{\text {os }} 5902$, 6591, 11075, 
15011: Serra da Cantareira, Sĩo Pacto, n 16196. Arbuste, fl. blanchàtres. Juin-juillet. CC.

386. B. tarchonanthoides DC.; Fl. Bras. V1, III, p. 49. - Fazenda do Taquaral, Itabira to Campo, Serra da Bocaina, etc., Mtsas, ${ }^{\text {os }} 7715$, 7716, 8773, 11113, 17069. Arbuste, ll. Hanchâtres. Septembre-octobre. CC. Vulg. : Carasco do campo.

- Var. integrela Balk. in Fl. Br. VI, III, p. 00 . - Fazenda do Taquaral, Mrsas, $n^{0}$ 7717. Arbuste, f1. jaunatres. Septembre. C.

- Var. albifolia Glaz. var. nor. in herlo. Paris., Berol., Kew., etc. Serra do Cipó, Mrsas, $n^{\circ}$ 19553. Arbuste, fl. Jlanc jaunàtre. Avril-mai. R.

387. B. helichrysoides DC.; Fl. Bras. VI, III, p. 31. - Campo Bello, Rio-Jax., $n^{05} 6595,15098$. Frutescent, fi. blanches. Janvierfévrier. C.

- Var. leucopappa Bak. in Fl. Br. VI, III, 1. :̈1. - Haut de l'Itatiaia, dans le campo, Rio-JAx., $n^{o s}$ 4852, 5901, 6594. Arbuste, fl. blanches. Juin-iuiliet. C.

388. B. gnaphalioides Spreng.; Fl. Bras. VI, III, p. ॐ̈1. - Riacho das Varas, Mixas, $n^{0}$ 19522. Sous-frutescent, fl. blanches. Février-mars. C.

389. B. elaragnoides Steud.; Fl. Bras. VI, III, p. 33. - Serra da Estrella, Rino-JAx., nos 540, 1050; Gandarela, dans le bois, près des plantes fossiles, Mris, nos 15006, 15007. Arbuste, f1. blanches. Férrier-mars. C.

390. B. calvescens DG.; Fl. Bras. VI, III. p. วั3. - Cachoeira do Campo, Itatiaia, entre Sitio et Barbacena, Ilsıs, ${ }^{\text {os }} 2628$, 4849, 11084 , 11085, 14014, 15012. Frutescent, fl. llanches. Juin-juillet. CC.

391. B. lychnophora Gardn.; Fl. Bras. VI, III, p. 34. - Serra da Caraça, entre les rochers, Mlsas, $n^{05} 15052$, 18333. Arbuste, fl. blanchâtres. Juin-juillet. C.

392. B. juncea Desf.: Fl. Bras. VI, III, p. ̋̈6. - Serra do Ouro Branco, Mıxas, $n^{\circ} 15023$. Sous-frutescent, fl. jaunâtres Novembre-décembre. C.

393. B. coridifolia DG.; Fl. Bras. VI, III, p. 5̆. - Parapanema, dans le campo, S. Paclo, et à Ipanema, $n^{05}$ 12917, 16195. Sous-frutescent, fl. jaunatres. Arril-juin. C. Vulg. : Mio-mio.

394. B. erigeroides DC.: Fl. Bras. VI. III, p. 38 . - Serra do Ouro Pranco, Mrsas, no 15024. Sous-frutescent, f1. jaunes. Novembre-décembre. C.

39:. B. serrulata Pers.; Fl. Bras. VI, III, p. :38. - Campos da Bocaina, S̈̈0 PALto, no 11063 . Sous-frutescent, fl. blanches. Juin-juillet. C. 
- Var. Pingraza Bak. in Fl. in Br. VI, III, p. 59. - Serra do Mar, a Palmeira et a hodeio, Rio-JAN., $n^{\text {os }} 8763,11064,13465$. Sous-frutescent, 11. !hanches. Janvier-février. C.

396. Baccharis microdonta DG.; Fl. Bras. VI, III, p. 59. - Serra to Lenheiro, près São Joño d'El Rei, Mrsas, nº 17064. Frutescent, fl. blanchâtres. Mars-avril. R.

397. B. semiserrata DC.; Fl. Brus. VI, III, p. 60. - Petropolis, a Santo Antonio, Rio-Jax., $n^{\circ} 11005$. Frutescent, fl. jaunâtres. Novembredécembre. C.

398. B. ligustrina DC.; Fl. Bras. VI, IIl, ए. 60. - Serra dos Orgãos, à Theresopolis, Rı-Jax., $1^{\circ}$ 2847; Campos da Bocaina, Sĩo Pallo, $1^{\text {os }} 11112$, 11114. Frutescent, ll. blanchatres. Septembre-octolre. CC.

399. B. glutinosa Pers.; Fl. Bras. VI, Ill, p. 61. - São João d'El Rei, dans le lit des rivières, Mtras, $n^{0}$ 17065. Frutescent, fl. jaunattres. Mars- avril. C.

400. B. rufescens Spreng.; Fl. Bras. VI, III, 1. 63. - Serra do Lenheiro, dans le campo, Mnsas, $n^{\circ} 17069 a$. Frutescent, fl. blanchâtres. Mar's-avril. R.

- Var. tenufolia Bak.; Fl. Br. VI, III, p. 63. - Floresta da Tijuca et Corcovado, lío-Jax., $n^{\circ s} 208,351,555$; Horro de Sĩo Vicente et Cachoeira do Campo, Insas, nos 12912, 15010, 20370. Frutescent, fl. blanchâtres. Juin-juillet. CC.

- Var. pedalis Bak. in Fl. Bras. VI, IlI, p. 64. - Entre Ipanema et Sorocaba, Sĩo Paulo, no 12915. Frutescent, fl. blanchâtres. Mlar's-avril. R.

- Var. leptocephala Bak. in Fl. Bras. VI, III, p. 6't. - Paramapanema, São Patio, $11^{\circ}$ 16197. Frutescent, 11. blanchâtres. Mars-avril. Ri.

401. B. sebastianopolitana Bak. in Fl. Bras. VI, III, p. 65. - Serra do Ariro, Rı-JAs., n 2627. Frutescent, fl. blanchàtres. Mai-juin. C.

402. B. sessiliflora Vahl; Fl. Bras. VI, III, p. 63. - Itatiaia, dans le campo, Rio-JAx., $n^{\text {os }} 4845,4846$, 5892, Frutescent, fl. Wanchitres. Juin-juillet. C.

403. B. fluminensis Glaz. sp. n.? in herb. Paris., Kew., Genev., etc. - Morro da Babylonia, à Botafogo, Rı-JAx., n ${ }^{\circ} 11006$. Frutescent, fl. blanc jaunâtre. Février-mar's. R.

404. B. recurvata Gardn.; Fl. Bras. VI, III, p. 66. - Boa Vista, près du Rio Parahyba, Rio-J $\mathrm{JN}_{\text {. }}, \mathrm{n}^{0}$ 12857. Frutescent, fl. blanchâtres. Juinjuillet. C.

403̈. B. capraricefolia DC.; Fl. Bras. VI, III, p. 66. - Serra do 
Ariro, dans Ie bois, Rio-JAx., $11^{\circ}$ 2626. Frutescent. fl. jaunitres. Maijuin. C.

406. B. platensis Spr.: Fl. Bras. VI, III, p. 67. - Itatiaia, au Campo do Silverio, Mnsas, n 6589 . Frutescent, t1. jaunattres. Janvier-février. R.

407. B. megapotamica Spr. ; Fl. Bras. VI, III, p. 68. - Itatiaia, au Campo do Silverio et à Barbacena, Nıss, $n^{0 \mathrm{~s}} 6589$, 11073; Serra dos Orgãos, Rı-JAN., nos 4057, 16209. Frutescent, fl. blauc jaunâtre. Févriermars. CC.

408. B. polyphylla Gardn.; Fl. Bras. VI, III, p. 69. - Diamantina, aı Tombador, Misas, $n^{\circ}$ 19492. Frutescent, fl. blanchâtres. Mar's-arril. C.

409. B. minutiflora Mart.; Fl. Bras. VI, III, p. 69. - Serra do Caraca et do Cipó, Mixas, nos 14977, 14978, 14979, 19495. Frutescent, fl. jaulnàtres. Février-avril. C.C.

410. B. microthamna Sch. Bip.: Fl. Bras. VI, III, p. 70. - Alto da Serra dos Orgãos, Rio-Jax., nº 16204. Frutescent, tl. blanchâtres. Janvierfévrier. R.

411. B. dracunculifolia DC.; Fl. Bras. VI, III, P. TI. - Barneri, Säo Paulo, n 12913; Gandarela, dans le bois près des plantes fossiles et ¿ Taquarussu, Mısı, nos 15005, 19493. Frutescent, fl. blancliâtres. Janvier-avil. CG.

412. B. trinervis Pers.; Fl. Bras. VI. III, p. 73. - Restinga de Copacabana, Tijuca, Corcovado, Rio-JAx., nos 171, 173, 532, 1409; Serra dit Mantiquera, Carandahy, Misas, $n^{0 s} 1042$, 10974, 15099, 15100. Frutescent, fit. blanchâtres. Septenbre-octobre. CC.

- Val. cinerea Bak.; Fl. Br. VI, III. p. T3. - Petropolis, dans les capociras, Rio-JAs., nos 2625,12830 . Frutescent, fl. blanchattres. Harsavril. C.

- Var. riexioides Bak.; Fl. Bres. VI, III, p. 73. - Corcovado, ì Paineiras, Rio-Jax., nos 539, 553. Frutescent, fl. blanchâtres. Mars-arril. C.

413. B. Regnellii Sch. Bip.; Fl. Bras. VI, III, p. T4. - Fazenta do Taquaral, Mixas, n ${ }^{0}$ 7718. Frutescent, fl. jaunatres. Septembre-octohre. C.

414. B. organensis Bak. in Fl. Bras. VI, III, p. 74. - Serra los Orgãos, au sommet, Rí-Jas., nos 2849. 4038, 6034. Frutescent, fl. blanchâtres. Octobre-novembre. C.

41:3. B. Lundii DC.; Fl. Brus. VI, III, p. T̈. - Serra dos Orgãos et Nova Friburgo, Rio-Jax., n ${ }^{\text {os }} 6035$, 12851; Santa Luzia do Rio das Velhas, Mlivas, $n^{\text {os }} 12831$, 14002. Frutescent, fl. blanchâtles. Aoùtseptembie. C. 
416. Baccharis oxyodonta [DG.; 1\%. Bras. VI, III, P. 76. - Serra dos Orgãos, à Theresopolis, Ro-dax., $1^{0 s} 7699$, 12046. Frutescent, fl. banches. Nars-juillet. C.

- Var. punctulata Bah.; Ml. Mr. VI, III, p. 77. - Itatiaia, dams le campo, Rio-Jax., $11^{\circ}$ 5894. Frutescent, t1. blanchâtres. Juillet-aoùt. C.

417. B. Dutaillyana Fraz. n. sp.? in herb. Paris., Berol., Kew., etc. Campos da Bocaina, São Pavio, ${ }^{\circ} 11110$. Frutescent, fl. Hanchitres. Septembre-octubre. R.

418. B. anomala DC.: Fl. Bras. V1, III, p. 77. - Serra da Mantiqueira, Mixas, no $16202 a$. Frutescent, fl. jaunâtres. Novembre-décembre. R.

419. B. Schultaii Bak. in Fl. Bras. VI, III, p. 78. - Serra da Mantiqueira et do Picú, Mlxas, nos 11034, 13992, 16202. Frutescent, ft. blancjaunatre. Décembre-janvier. C. Vulg. : Tingongo do Campo.

420. B. macrodonta DC.; Fl. Bras. V1, III, p. 78. - Serra do Lenheiro près S. João d'EI Rei, Mısas, n 17653 . Frutescent, fl. blanchâtres. Décemlıre-janvier. C.

421. B. camporun DC.; Fl. Bras. VI, III, p. 80. - Serra da Mantiqueira, à João Gomez, Mxas, $1^{\circ} 17645$. Sous-frutescent, fl. blanchàtres. Février-mars. R.

Var. integrifolia Bak. in Fl. Bras. Vi, III, p. 80. - Bords tu Rio Manso, dans le campo, Ilixis, $n^{\circ 5} 12836,14025$, 18326. Sous-frutescent, 11. blanchâtres. Juillet-aoùt. C.

429. B. maxima Bak. in Fl. Bras. VI, III, p. 80. - Itatiaia, dans le campo, Rio-JAx., $n^{\circ s} 4860,15099 a$. Sous-frutescent, f1. blanc-jaunattre. Mai-juin. C.

493. B. stylosa Gardn. in Fl. Bras. VI, III, p. 81. - Serra dos Orgaios, au sommet, Rio-Jax, $n^{0 s} 2848,3686,4039,16207$. Frutescent, fl. llanchàtres. Dérembre-janvier. C.

424. B. vernonioides DC.; 11. Bras. VI, III, p. 81. - Floresta da Tijuca et Corcovado, Rio-JAN., ${ }^{05}$ 2613, 7703, 7704, 11042; Serra do Picú et Ouro Preto, Mlinas, nos 11023 , 15119. Frutescent, ll. jaunàtres. Juin-juillet. CG.

420.j. B. brachylanoides DG.; Fl. Bras. VI, III, p. 81. - Picó do Papagaio, Tijuca, Corcovado, Gavea, ete., Rio-JAs., n ${ }^{\text {os }} 168,1396,1427$, 2845, 3798, 6610, 8118, 11047. Frutescent, 11. blanchuatres. Juinjuillet. CC.

- Var. parvifolia Bak. in herb. Paris., Berol., Kew., etc. - Campos da Bocaina, au Sobrado, São Paclo, nos 2615, 11111 ; Serra do Palmital 
et Ouro, Preto, Misas, $1^{0}$ 15088. Frutescent, f1. J)lanchâtres. Aoùtseptembre. C.

426. B. cassinafolia DC.; Fl. Bras. VI, III, P. 8ב. - Corcovado, Tingua, Engenlo Vello, Vorro do Cubiçado à Petropolis, Rio-Jax., $n^{\text {os }} 538,554,1419,4859,5907,11044$. Frutescent, fl. blanchâtres. Juinjuillet. CC.

- Var. Riedelii Bak. in herh. Paris., Berol., Kew., etc. - Floresta da Tijuca, Serra do Tingua, Rı-Jax., nos $531,8776,8777,8778$. Frutesrent, fl. blanchatres. Juin-juillet. CC.

427. B. coriacea Glaz. n. sp.? in herl, Paris., Berol,, Kew., Genev, etc. - Itatiaia, dans le campo Rangel, Msas, nos 4844, 8771. Frutescent, fl. blancliâtres. Juin-juillet. R.

428. B. orgyalis ICC. : Fl. Bras. VI, III, p. 8\%. - Serra dos Orgãos et Floresta da Tijuca, Rio-JAx., $1^{\text {os }}$ 1481, 3696, 6032. Frutescent, t1. blanchâtres. Août-septembre. C.

429. B. axillaris DC.; Fl. Bras. VI, III, p. 87. - Serra do Cipó, dans le campo, Mısas, $n^{\circ}$ 19496. Frutescent, fl. blanches. Mars-avril. R.

430. B. incisa Hook. et Amn.; Fl. Bras. VI, III, p. 87. - Bamery, près Ia station, S. PAlıo, n 12914. Frutescent, fl. blanches. Mars-avril. C.

- Var. pentata Rak. in Fl. Bras. VI, III, p. 88. - Serra do Cipó, prís Congonlias da Serra et à Caraça, au Morro Carapuca, Mrsas, n ${ }^{\text {os }} 15017$, 19494. Frutescent, fl. blanches. Mar's-avril. C.

431. B. micropoda Bak, in Fl. Bras. VI, III, p. 88. - Serra de Ouro Preto, Mras, $n^{0}$ 15003. Frutescent, fl. blanches. Février-mars. R.

432. B. ciliata Gardn. ; Fl. Bras. VI, III, p. 89. - Serra dos Orgĩos, au Morro Comprido et au Frade, Rio-JAx., nos 3694, 3695, 4040, 4041, 6036 et 16206. Frutescent, fl. blanchâtres. Décembre-janvier. CG.

433. B. illinita DC.; Fl. Bras. VI, III, ). 91. - Entre Ilheos et Sitio de Barbacena, Mıxas, nº 16201. Frutescent, fl. blanc-jaunâtre. Décembrejanvier. C.

43'. B. Vauthieri DC.; Fl. Bras. VI, III, p. 92. - Caraça, au Morro do Inficionado, Mwas, $n^{\text {os }}$ 12837, 15014. Frutescent, fl. blanchàtres. Juin-juillet. C.

433. B. humilis Sclı. Bip. in Fl. Bras. VI, IIl, p. 92. - Serra dos Veadeiros, dans le campo pierreux, Goraz, $\mathrm{n}^{\circ}$ 21606. Acaule, vivace, 11. blanchattres. Janvier-février. C.

436. B. vaccinioides Gardn:; Fl. Bras. VI, III, p. 92. - Serra dos Orgãos, à Perlra do Sino et à Itatiaia, liıo-JAs., nos $3693,4848,5905$, 6033 et 16205. Frutescent, f1. blanchâtres. Juin-juillet. C.C. 
437. Baccharis myriocephala Bak. in Fl. Bres. VI, III, p. 93. Campos da Bocaina, S. Palto, $\mathbf{n}^{\circ}$ 8130. Frutescent. fl. jaunitres. fésrier-mars. R.

438. B. halimimorpha DG.; Fl. Brers. VI, III, p. 94. - Entre Inficionado et Caraça, daus le campo, Hısas, $n^{\text {os }} 12838$, 19877. Frutescent, f1. blanchâtres. Juin-juillet. C.

439. B. retusa DG.; Fl. Bras. V1, III, p. 9'. - Petropolis, à Santo Antonio, Rio-Jax., $n^{\text {os }}$ 6597, 7700; Serra do Picú, dans le campo, Mtsas, $n^{0 \varsigma} 11033,11080$, Serra do Batatal $n^{\circ s} 14996,14997,14999$, Serra de Ourn Preto, Mrsas, nos 15002,18323 . Frutescent, fl. blanchâtres. Juinaoùt. CC.

440. B. ramosissima Gardn. in Hook. Lond. Journ. Bot. VII, p. 84. - Itatiaia, dans le campo, Rio-Jas., n 4839. Frutescent, fl. hlanchâtres. Juin-juillet. I.

441. B. truncata Gardn.; Fl. Bras. VI, III, p. 9ò. - Perpetua, près Diamantina, Mnas, nº 19497. Frutescent, f1. blanches. Mars-avriI. C.

- Var. microphylla Glaz. in herb. Paris., Berol., Kew, etc. - Biribiry, au Nocotó près Diamantina, Mrsas, $n^{\circ}$ 19508. Frutescent, fl. hlanches. Mars-arril. R.

442. B. brevifolia DC.; Fl. Bras. VI, III, p. 98. - Entre Ayurunca et Cachambú, Misas, $n^{0 s} 15013,16194$. Frutescent, fl. blanches. Janvierfévrier $\mathrm{C}$.

443. B. tridentata Vahl; Fl. Bras. VI, III, p. 97. - Itatiaia, dans le rampo, Rio-JAN., $n^{\text {os }} 4853,9488,11076$; S. Bartholomeu, Mixas, $n^{0 s} 15015,15016$. Frutescent, fl. blanchitres. Juin-juillet. CG.

444. B. Salzmanni DC.; Fl. Bras. VI, III, p. 97. - Campos da Bocaina, S. Paclo, no 11109; Serra do Caraça, Misas, no 14994. Frutescent, fi. blanchâtres. Mai-juin. CG.

44\%. B. rotundifolia Spreng; Fl. Bras. VI, III, p. 98. - Ipanema, dans le campo, S. Pavlo, $\mathbf{I}^{\circ}$ 12916. Frutescent, fl. blanchaitres. Marsavril. C.

446. B. subcapitata Gardn.; Fl. Bras. VI, III, p. 98. - Serra do Palmital, près S. Bartholømeu, Mrxis, $n^{\circ} 15013$ a. Frutescent, fl. blancjaunàtre. Juin-juillet. C.

4́7. B. platypoda DC.; Fl. Bras. VI, III, p. 99. - Serra dos Orgãos et Petropolis, Rio-Jav., ${ }^{\circ{ }^{\circ}} 3683,11011,11041$, 12054; Serra de Ouro Preto, Misas, nos 14998, 18324. Frutescent, fi. jaunâtres. Juinjuillet. CC.

4'18. B. Clausseni Bak. in Fl. Bras VI, III, p. 99. - Itacolumy près 
A.-F-.y. GLAZIOL. - LISTE DES PLAMTES DU BRÉSIL CEXTR.AL.

Ouro Preto, Mıss, nos $15000,15001,15060,18322$. Frutescent, f1. blanches. Juin-juillet. CC.

449. B. reticularia DC.; Fl. Bras. VI, III, 1. 100. - Petropolis, à Santo Antonio, Rio-Jax., no 7701 ; Congonhas do Campo, Mıras, nº 14995. Frutescent, fl. blanchâtres. Juin-juillet. C.

- Var. polmeura Sch. Pip. ex Bah. Fl. Brols. VI, III, p. 100. - Entre Fazenda do Tayuaral et Rezende, Petropolis à S. Antonio, Rio-Jax.,

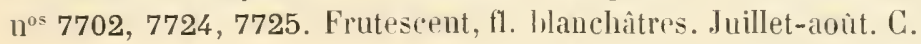

400. Heterothalamus brunioides Less.; Fl. Bras. VI, III, p. 18. - Entre Inficionado et Caraça, Mrsss, $1^{\circ}$ 12045. Frutescent, 11. jaunâtres. Juin-juillet. R.

401. H. psiadioides Less.; Fl. Bras. VI, III, p. 19. - Arraial do Ouro Branco, Vıxas, n $^{0} 18322$ a. Frutescent, fl. blanchàtres. Seplembreoctobre. R.

4ว̈2. Pluchea Quitoc DC. : Fl. Bras. VI, III, p. 106. - São Christovão, Corcovadı, Tijuca, Pio-JAx., nos $537,1132,6820,12815$. Frutescent, fl. IIanches. Anùt-octobre. C.C. Vulg. : Quitoc.

433. P. oblongifolia DC.; Fl. Bras. VI, III, p. 107. - llha do Governador, Corcovado, Tijuca, etc., Rio-JAx., nos 1135, 1136, 2619 , 7884, 8112, 12843, 15109 et 16139. Sous-frutescent, 11. Hlanchàtres. CG.

兮年. Pterocaulon virgatum DC.; Fl. Bras. VI, III, p. 110. Pedregulho, à São Clıristorão, Rio-Jax., no 5916. Sous-frutescent, f1. blanchatres. Mars-arril. C.

- Var. capitatum var. nor. ex Bak. in lıelb. Paris., Ker., Berol., etc. - Ipanema, près de la mine de fer. S. Pavlo, nos 12814, 12879 ; Matta Grande, au Rio das Pedras, Mras, n 19530. Sous-frutescent, fl. blan(-hâtres. Août-septembre. C.

4ij.. P. polystachymm DC.: Fl. Bras. V1, III, p. 111. - Entre Caraça et Gandarela, Mrss, $n^{\text {os }} 1044,15110,16154$. Sous-frutescent, 11. blanclıatres. Février-mars. C.

4.66. Oligandra lycopodioides Less.; Fl. Bras. VI, III, 1) 126. Cimpo da Bocaina, à Vacca Cahio, S. Pacıo, nos 8140, 11115, 14970: Itatiaia, aux Campos Brejos, Riro-JAx., nos 7726, 11038. Herb., fl. blan. ches. Arril-juin. GG.

47. Chionolæna lychnophorioides Sch. B.; IF. Bras. VI, III, p. 128. - Itacolum! près Ouro Preto, n 14960, et Serra da Caraça, au Morro da Carapuç, Mrsas, no 14160 a. Frutescent, fl. Hanches. Févriermars. CC. Vulg. : Ainica. 
43̈8. Chionolana arbuscula DC.; Fl. Bras. VI, III, P. 129. - Serra lo Caraça, au Ciampo de Fora, Mıxas, $n^{\text {cs }} 11036,11459$. Frutescent, fl. blanches. Févier-mars. R.

- Var. hololeuca ex Bak. in herh. Paris., Perol., Kew., etc. - Serra Io Itatiaia, entre les rochers, Rio-Jav., $n^{0 s} 4843,4842,6593,8768$. Frutescent, fl. blanches. Janvier-février. C. Vulg. : Amica.

4:9. Ch. innovans Wawr.? in Itin. Princ. S. Caburgi, p. 30. Itatiaia, sur les rochers, hio-Jan., $n^{\text {os }} 5899,6592,7723$. Frutescent, fl. blanches. Nai-juillet. C. Vulg. : Arnica.

460. Ch. Wittigiana Pak. in Fl. Bras. VI. III, p. 199. - Itatiaia, entre les rochers, liro-Jax., ${ }^{o s} 5896,6590$. Frutescent, fl. blanches. Janvier-février. R. Vulg. : Arnica.

461. Ch. glomerata Bak. in Fl. Bras. VI, III, p. 130. - Serra do Itatiaia, entre les rochers, Rro-Jav., $n^{\circ} 4851$. Frutescent, fl. blanches. Maijuin. R. Vulg. : Arnica.

462. Ch. Glaziovii Bak. in F'l. Bras. VI, III, p. 130. - Serra de Pirapitinga, $2120 \mathrm{~m}$. d'altitude, Mixas, $n^{0} 8769$. Fitescent, fl. blanches. Novembre-décembre. C.

463. Ch. Isabellow Bak. in Fl. Bras. VI, III, p. 130. - Itatiaia, entre les rochers à $2420 \% \mathrm{~m}$. d'altitude, Rio-Jav., ${ }^{\circ}{ }^{\circ} 4840,6601$. Frutescent, fl. blanchâtres. Juin-juillet. R.

463 bis. Ch. phylicoides Bak.; Fl. Bras. VI, III, 1) 131. - Haut des Orgues, Petropolis, Rio-Jax., nos 2854, 3692, 6602, 14961, 16157. Frutescent, ft. blanches. Juillet-septembre. C.

464. Ch. latifolia Bak.; Fl. Bras. VI, III, p. 132. - Serra do Itatiaia, dans les rocher's, Riro.JAx., nos 4841, 5903, 6600. Frutescent, fl. blanches. Juillet-aoùt. C.

465. Chevreulia acuminata Less.; Fl. Bras. VI, III, p. 119. Corcovado, à Paineiras, Riı-Jav., $n^{0 s} 2858,15111$. Herl., fl. blanches. Septembre-octobre. CG.

466. Facelis apiculata Cass.; Fl. Brs. VI, III, p. 118. - Entre Gavea et Tijuca, Rio-Jan., $n^{\circ} 2620$. Herb., fl. blanches. Novembredécembre. C.

467. Achyrocline satureioides DG. var. Vargasiana Bak.; Fl. Bras. VI, III, p. 115. - Itatiaia, dans le campo; Gavea, Rio-Jan., n ${ }^{\text {os }} 169,1424$, 5897, 5898, 6570, 6605. Herl., ft. jaunes. Janvier-avril. GG. Vulg. : Marcella.

468. A. alata DC.; Fl. Bras. VI, III, p. 117. - Entre Rio Manso et 
1.-F.-II. GLAZIOU. - LISTE DES PLAYTES DU BRÉSIL CENTRAL.

Mendanha, Mıxıs, n 12809. Herb., fl. jaunes. Juin-juillet. C. Vulg. : Varcella.

- Var. Vauthieriana Bak.; Fl. Br. Fl. Bros. VI, III, 1. 117. - Serra dos Orgãos, Riı-Jax., $n^{\circ}$ 3685. Herb., 11. jaunes. Mai-juin. C. Vulg. : Marcella.

469. Gnaphalium cleeiranthifolium Lamh; Fl. Bras. VI, III, p. 1292. - Serra dos Orgãos, à Theresopolis, Rio-Jas., nos 182, 1621, 4835, 6585. Herb., fl. blanches. Septembre-ortobre. CG. Vulg. : Marcella.

- Var. Gaudichaudianum Bak.; Fl. Bras. VI, III, p. 123. - Floresta da Tijuca, Pico de Santa Cruz, Riı-J.s., $n^{0 s} 533,2622,6819,6898$. Herb., 11. jaunitres. Janvier-février. CC. Vulğ. : Marcella.

170. G. indicum L.; Fl. Bras. VI, III, p. 123. - Entre Marianna et Antonio Pereira, dans les bourbiers, Hixss, $n^{\circ 5}$ 13993, 15112 ; Jacarepagua, Rı-Jax., $n^{\text {os }}$ 172, 6615. Herlı, fl. blanches. Juin-juillet. C.

471. G. purpureum L.; Fl. Bras. VI, III, p. 124. - Carandahy, dans le campo humide, Mixss, $n^{05} 12885,15113$. Herb., 11. blanehitres. Marsaviil. G.

- Var. filagineun Bak.; Fl. Bras. VI, III, p. 12't. - Congonhas do Campo, Mıxas, no 16155. Herb., ll. blanchàtres. Juin-juillet. R.

- Var. spicatum Bak. : Fl. Krus. VI, III, p. 124. - Campos da Bucaina, à Vacca Gahio, S. Paulo, $\mathrm{n}^{0 \mathrm{~s}} 4857,6584,8134$. Herb., 11. blanclaatres. Janvier-février. C.

- Var. stachyoffolium Bak.; Fl. Pras. VI, III, p. 12;. - Itatiaia, en haut des campos, Rı-JAs., no 4857 a. Herb., l'. blanchitres. Juinjuillet. C.

472. Lucilia acutifolia Cass. var. virescexs Sch. Mip. ex liaker. Serra da Bocaina, au Sobrado, São Palzo, nº 8129 a. Herb., fl. lilanches. Décembre-janvier. R.

473. Lucilia nitens Less. : Fl. Bras. VI, IIl, p. 113. - Cumpos da Bocaina, au Bom Jardin, SÃo PAvlo, nº 8129 b. Herb., fl. blanc-jaunâtre. Février-mar's. li.

474. L. Jamesoni Bah. in Fl. Bras. VI, III, p. 113. - Campos do Corrego do Brejo, Goraz, $1^{\circ}$ 21592. Herlı., fl. blanchatres. Mars-avril. C.

475. L. Lundii Bak. in Fl. Bias. VI, III, p. I 13.-Campos da Bocána, SÄo Paclo, no 8142 a. Herl., f1. blanchàtres. Décenulıre-janvier. R.

476. L. linearifolia Bak. in Fl. Bıas. VI, III, P. II'4. - Campos de Bocaina, au Sobrado, Sĩo Pauıo, no 8142. Herlı, 11. Hlanc-jannitre. Janvier-février. C. 
47. Lucilia fermginea Bah. in Fl. Bras. p. 114. - Ilheos, près de Sitio, Mhxas, no 17646 a. Herb., ll. blanchattres. Janvier-février. C.

178. L. squarrosa Bak. Fl. Bras. VI, III, p. 114. - Campos da Burainil, à Vacca-Gallio, São Paulo, no 8129; Ilheos. Minas, $n^{\circ} 17646$. Herb., fl. blanchâtres. Janvier-féviler. C.

479. L. glomerata Bak. in Fl. Bras. VI, III, 1. 114. - Campos da liocaina, au Subrado, S. PArlo, $11^{\circ} 8142$ a. Herb., fl. rosées. Janvierfövier. R.

480. Stenocline chioncea DG.; Fl. Bras. VI, III, p. 127. - Nova Friburgo, au Suspiro, Rio-Jax., $n^{\circ}$ 12852; Ouro Preto et Gandarela, Mixas, nos 15114, 15115. Herb., fl. blanches. Mai-juin. CG. Vulg. : Varcella.

481. Lagascea mollis Car.; Fl. Bras. VI, III, p. 141. - Norro do Coco ou do Bahú, Espirito Santo, $n^{\circ}$ 10987. Herb., fl. blanchâtres. Norembre-récembre. Ir.

482. Elvira biflora DC.; Fl. Bras. VI, III, p. 142. - Norro do Coco ou do Bahú, Esplito Saxto, $n^{\circ}$ 10986. Herb., fi. blanchattres. Novembredécemlıre. C.

483. Riencourtia oblongifolia Gardn.; Fl. Bras, VI, III, p. 14y. Morro da Gloria près Sabara, Minas, no 18426 ; Formosa dans le cerrado, Gorız, n² 21565. Herb., fl. Jlanches. Janvier-février. C.

484. $R$. angustifolia Glaz. n. sp.? in herb. Paris., Berol., Kew., Gener., etc. - Cachoeira da Vargem Grande, Goynz, nº 21564. Herlo., f1. blanchattres. Janvier-févirier. C.

48.). Clibadium rotundifolinm DC.; Fl. Bras. VI, III, p. 152. Entre Queimado et Rio d'Oura, Santa Cruz, Rio-JAN., n1 ${ }^{\text {os }}$ 9484, 9485 ; Itabira do Campo, Mixas, nos 12878, 17656. Frutescent, ft. blanchâtres. Novembre-décembre. CG.

486. Cl. erosum DG.; in Prodr. Syst. Nat. V, p. 56. - Piralininga, dans les bourbiers, Esp. SANTO, nos 9908, 9918. Frutescent, ff. blanches. Novembre-décembre. R.

487. Ichthyothere linearis Bak.; Fl. Bras. VI, III, p. 15̈4. - Ponte Alta, près rie la cascade, Goraz, $n^{\circ} 21571$. Herb., fl. blanchâtres. Aoùtseptembre. li.

488. I. angustifolia Glaz. 11. sp.? in herl. Paris., Berol., Kew., Genev., etc. - Guabiroba, au Morro Cubatão, Goraz, no 21572. Herh., fl. jaunâtres. G.

489. I. Cunabi Nart.; Fl. Bras. VI, III, p. 18̈4. - Serra dos Purys, 
A. -F.-M. G.LAZIOL. LISTE DES

PLANTES DU BRÉSIL CEYTRAL.

Espirito SAnto, $11^{0 s} 9917,10994$; Faria, près Sabara, Mixas, no 18314. Ilerł., th. blanchàtres. Janvier-février. C. Vulg. : Cunambi.

490. 1. latifolia Bak.; Fl. Bras. VI, III. p. Iö. — Guabiroba, dans le campo, Gorsz, $11^{\circ}$ 21647. Herb., 11. banchitres. Octubre-novembre. C.

491. I. hirsuta Gardn.; Fl. Bras. VI, III, 1) 1\%6. - Eutre Ciganos et As Brancas, Goraz, $n^{\circ} 21649$, Herb., fl. blanchàtres. C.

492. I. rufa Gardn.; Fl. Bras., p. 1\%̈6. - Arraial de Ouro Branco, Mris, $\mathrm{n}^{\circ}$ 17659. Herb., fl. blanchàtres. Novembre-décembre. R.

493. I. suffruticosa Gardn.; Fl. Bras. VI, III, P. Iรั. — Chapadão dos Veadeiros ou de Porto Seguro, Goraz, no 21648. Herb., fl. blanchâtres. Janvier-fívrier. C.

494. I. dubia Glaz. n. sp.? in herb. Paris., BeroI., Kew., Gener., etc. - Entre Rajadinha et Paranauna dans Ie campo, Goraz, $1^{0} 21561$. Herb., 7. Blanchâtres. Janvier-février. C.

495. I. integrifolia Bak. ; Fl. Bras. VI, III, P. 157.- Ponte AIta, dans le campo, Goraz, n² 21571 a. Herb., fl. Jlanchâtres. Aoùt-septembre. R.

496. I. agrestis Bak. in Fl. Bras. VI, III, p. 157. - Ponte Alta, dans la Serra do Urbano ou das Divisues, Goraz, $n^{\circ}$ 21573. Herb., f1. blanchàtres. Août-septembre. C.

497. Acanthospermum xanthioides DC.: Fl. Bras. VI, 1II, p. 162. - Copacabana, São Clıristovão, Berco, Rio-Jax., $1^{0 s} 59,119,5919$, 13999: Serra dos Vertentes uu do Lrbano, Goraz, no 21594 «. Herl., 11. blanchâtres. Janvier-férrier. CG. Yulg. : Picäo da Praia, Carapicho.

498. A. hispidum DC.; Fl. Bras. VI, III. 1. 163. - Gavea et Sio Christovão, Riı-Jরx., $11^{\text {os }} 3682$, 13983. Herb., fl. blanchâtres. Avriljuin. CC.

499. Ambrosia polystachya DC.; Fl. Bras. VI, III, p. 149. - Bord du Rio Parahyba, près Desengono et Petropolis, Rı-Jax., 5917, 12187. Sous-frutescent, fl. blanchàtres. Norembre-décembre. CC.

500. A artemisiafoliı L.; Fl. Bras. YI, III, p. 1̋0. - Corcovado et S. Christovio, Rio-J.х., I $^{\text {कs }}$ 546, 4031. Sous-frutescent, fl. blanchâtres. Novembre-décembre. C.

¿01. Polymnia Siegesbeclia IC.; Fl. Bras. VI, III, 1). 10̈8.Corcurado, à Paineiras, Rio-JAx.. nos 4044, 15071. Herb., f1. jatmes. Novembre-décembre. CC.

:02. P. macroscypha Bak. in Fl. Bras. VI, III, P. 13̈8. - Floresta da Tijnca, Rı-Jas., nº 4044 a. Herh., fl. james. Janvier-févier. R.

ə03. P. corcovadensis Glaz. n. sp.? in herb. Paris., Berol., liew. 
Gener., etr. - Corcovaldo, près dur ruissean Carioca, Ro-Jan., nº 5918. Herlb., 11. jaunitres. Janvier-férrier. C.

30.'. Polymnia Bakeriana Glaz. 11. sp.? in Lerl, Paris., Berol., hew., Gener., ete. - Fazenda de Sauta Gruz et Sĩo Christorão, RioJas., $1^{\text {os }} 6029$, 7691. Herl), 11. roses. Octobre-novembre. C.

$30 \%$. Baltimora recta L.; Fl. Bres. VI, III, p. 16\%. - Morro do Inficimado près Caraça, Mısas, $n^{\circ}$ 12793. Herb., fl. jaunes. Mai-août. C.

506. Melampodium divaricatum DG.; Fl. Bras. VI, III, p. 160. - Fazenda do Morro Azul, Sĩo Paulo, no 12794. Herb., fl. jaunes. Avrilmai. C.

507. M. paniculatum Gardn.; Fl. Bras. VI, III, p. 161. - Carandahy, dans les broussailles Lumides, Mivas, 14036. Herb., fl. jaunes. Mars-avril. R.

5008. Xanthium strumarium L. var. вrasilicum Bak.; Fl. Bras. VI. III, p. 147. - Carhanbú, près des fontaines, Mixas, nº 16213. Herb., f1. blanchàtres. Décembre-janvier. C.

509. X. orientale L.; Fl. Bras. VI, III, p. I47. - Cachambú, près des fontaines, Mnsas, n" 16212. Herb., fl. blanchâtres. Décembre-janvier. C.

310. X. spinosum L.; Fl. Bras. VI, III, p. 148. - Cabo Frio, près de la mer, Rı-Jax., nos 12918,12919 ; entre Ipanema et Sorocaba, S̃̃oPacto, n 16214. Herb., fl. blanchàtres. Janvier-avril. CC.

511. Jægeria hirta Less.; Fl. Bras. VI, III, p. 167. - Serra do Picú, au Palmital, Rı-Jav., $n^{\circ} 11026$. Herb., fl. blanches. Mar's-avril. C.

¿LI․ Enhydra Anagallis Gardn.; Fl. Bras. VI, III, p. 169. - São Christorão, dans les bourbier's, Rı-JAx., n ${ }^{0}$ 4982. Herb., li. blanchâtres. Octobre-novembre. G.

513. E. sessilis DC.; Fl. Bras. VI, III, p. 169. - Restinga de Mauki, dans les sables humides, Rı-Jax., nº 8152. Herb., ll. blanches. Juillet-aoùt. C.

514. Eclipta alba Hassk.; Fl. Bras. V1, III, p. 170. - Corcovado, Tijuca, Gavea, etc., Rio-Jav., nos 185. 187, 2623, 4050, 495114001. Herb., fl. blanches. Octubre-décembre. CC. Vulg. : Herva Botäo.

815\%. Wulffia stenoglossa DC.: Fl. Bras. VI, III, p. 173. - Petropolis, à Santo Antonio, Ruo-Jav., n ${ }^{05} 3041$, 9907, 10988. Sous-frutescent, Il. jaunes. CG.

:16. II. longifolia Gardn. in Hooker Lond. Journ. Bot. VII, p. 292. - Entre Garea et Boa Vista, Rio-Jax., nos 8762, 11003 . Sous-frutescent, 1. jaunes. Novembre-décembre. C. 
A.-F.-M. GLAZIOU. - LISTE DES PLANTES DE BRÉSIL CENTRAL. 411

817. Blainvillea rhomboidea Cass.; Fl. Bras. VI, III, p. 17̈. Entre Gavea et Boa Vista, Ro-Jax., nos 29, 534, 5906. Herb., 11. blanchâtres. Juin-juillet. C.

518. Wedelia paludosa DC.; Fl. Bras. VI, III, p. 180. - Gavea, dans les fossés et les bourbiers, hı-JAx., nº 557. Herb. fl. jaunes. Janviermar's. CC.

519. W. puberula DC.; Fl. Bras. VI, III, p. 183. - Eutre Cachambú et Ayuruoca, Nhras, $n^{\circ} 16162 a$. Sous-fiutescent, t1. jaunâtres. Janvierfévrier. C.

320. W. macrodonta DC.; Fl. Bras. VI, III, p. 184. - Ipiranga, au bord du Riu Parahyba, Rio-Jax., no 16161. Sous-frutescent, fl. jaunes. Avril-mai. C.

5221. W. subvelutina DC.; Fl. Bras. VI, III, p. 184. - Petropolis, à Santo Antonio, Rio-IAx., $\mathrm{n}^{\prime 15}$ 5915, 1i 057. Sous-frutescent, fl. jaunes. Férrier-mars. C.

522. W. villosa Gardn, ; Fl. Bras. VI, III, p. 186. - Paó d'Alho, Espinito Saxto, nos 10989, 10990. Sous-fítescent, fl. jaunes. Avril-mai. C.

523. Eleutheranthera ruderalis Sch. Bip.; Fl. Bras. VI, III, p. 209. - São Fidelis, près Campos, Rio-Jax., no 9919. Herbacé, fl. blanchitres. Janvier-février. CG.

52 '. Aspilia linearifolia Bak, in Fl. Bras. VI, III, p. I92. - Serra do Ouro Branco, Mrvas, $n^{\text {os }} 15074,19533$. Herb., fl. jaunes. Novembredécembre. C.

89.). A. Warmingii Bak. in Fl. Bras. VI, III, p. I92. - Guabiruba, dans le campo, Goraz, n 21549. Herb., 11. jaunes, Octobre-norembre. R.

826. A. foliacea Bak.; Fl. Bras. VI, III, p. 193. - Serra do Uuro Branco, Mivas, $n^{\circ}$ 15076; Abhade, près Mleia Ponte, Goyaz, no 21553. IIerb., Il. jaunes. Septembre-octobre. CC.

527. A. Burchellii Bak.: Fl. Bras. VI, III, p. 194. - Chapadinha, près Alagulos, Goys, n' 21561. Herb., fl. jaunes. Octobre-novembre. C.

828. A. buphthalmiflora Griseb. var. angustifom (UC.): Fl. Bras. VI, VII. p. 19\%. - Riacho das Varas, dans le campo, Mssas, $n^{\text {os }}$ 19534, 19535. Herb, , 11, jaunes. Février-mars. G.

529. A. Martii Bak. in Fl. Bras. VI, III, p. 19\%. - Cabeceiras do Rio Gama, au Colombista, Goraz, $1^{\circ} 21560$. Herh., f1. jaumes. Mai-juin. C.

530. A. reflexa Bak.; Fl. Bras. VI, III, p. 196. - Campos da Bocaina, S. Paulo, I $^{\circ} 8483$; Morro da Gloria, près Sabara, Mixas, $n^{\circ} 18318$. Herl., fl. jaunes. Janvier-février. C. 
:331. Aspilia Riedelii Bak, in Fl. Bras. VI, III, p. 196. - Serra dos Purys, Esp. Saxto, 1 $^{\circ}$ 10992. Herb., fl. jaunes. Septembre-octobre. R.

782. A. gracilis Bak.; Fl. Bres. V1, HI, 1. 198. - Serra da Caraça, Mras, nos 12804 , 14004. Herb., ll. jannes. Octubre-norembre. C.

:33. A. Malinvaudii Glaz. n. sp.? in herb. Paris., Berol., Kew., Gener., etc. - Serra da Itahapoana, Esp. Saxto, no 10991. Herb., fl. jaunes. Septembre-octobre. R.

334. A. floribunda Bak, Fl. Bras. VI, III, p. 198. - Serra da Caraça, dans le campo, Misas, $n^{03} 12805,14005$, Sous-frutescent, 11. james. Octobre-novembre. C.

53\%. A. reticulata Bak. in Fl. Bras. VI, III, p. 202. - Itacohumy, près Ouro Preto, Mlısas, $n^{\circ} 15081$ a. Frutescent, fl. jannes. Juin-juillet. R.

336. A. fiuticosa Bak.; Fl. Bras. VI, III, p. 204. - Serra do Caraça, au Morro Carapuça, Mıxas, $n^{\text {os }} 15081,16176$. Frutescent, f1. jaunes. Jaurier-février. C.

ว37. Oyedæa rotundifolia Bak.; Fl. Bras. VI, III, p. 208. - Rego d'Agua, entre Cachambú et Ayuruoca, Mısas, nº 16162. Sous-frutescent, fl. jaunes. Janvier-février. C.

838. Viguiera nonneafolia Bak. in Fl. Bras. VI, III, p. 222. - Entre Sitio et Barbacena, dans le bois, Misas, $n^{\circ} 16165 a$. Sous-frutescent, fl. jaunes. Novembre-décembre. C.

539. V. pilosa Bak., Fl. Bras. VI, III, p. 223. - Entre Illheos et Sitio, Mivas, $11^{\text {os }} 15080,16165$. Sous-frutescent, f1. jaunes. Novembredécembre. C.

340. I'. dissitifolia Bak.; Fl. Bras. V1, III, p. 29:3. - Barbacena, Carandahy, Mixas, nos 12806, 14006, 15077. Sous-frutescent, fl. jaunes. Novembre-décembre. CC.

341. V. oblongifolia Gardn.; Fl. Bras. V1, III, p. 229:. - Serra do Caraça, dans le campo, Mıras, $n^{\circ} 16170$; Entre Rio dos Couros et le Rio Piçario, Goraz, ${ }^{\circ s} 21552,21563$. Sous-frutescent, 11. jaunâtres. Octobreseptembre. GC. Vulg. : Hal-mequer.

“42. V. glaucescens Glaz. n. sp.? in hert. Paris., Berol., Kew., Genev., etc. - Serra da Baliza, entre les pierres, Goraz, $n^{0}$ 21562. Sousfrutescent, jaunâtres. Janvier-février. C.

343. V. robusta Gardn.; Fl. Bras. VI, III, p. 227. - Serra do Picú, dans te campo. Niras, $n^{09} 9490,11027,12880,17084$. Sous-frutescent, f1. jaunes. Mars-avril. CG.

亏年. V. angustifolia Glaz. 11. sp.? in herb. Paris., Berol., Kew., 
Gener., etc. - Corrego do Brejo, au campement, Goraz, n²1603. Sousfrutescent, fl. roses, Février-mars. R.

540ั. V. platyphylla Bak.; Fl. Bras. VI, III, p. 227. - Entre Cocal et As Brancas, Goyaz, nos 21550, 21551. Sous-frutescent, 11. jaunes. Janvier-févirier. C.

"̈46. V. wedelioides Bak., n. sp. in herb. Paris., Berol., Kew., Genev., etc. - Pedra do Conego, à Nuva Friburgo, Rı-Jax., nº 12845. Frutescent, fl. jaunes. Février-mars. R.

54 7. V. discolor Bak. in $\mathrm{Fl}$. Brols. VI, III, p. 228. - Petropolis, à Santo Antonio, Rro-Jax., $n^{\circ} 5915$ a. Sous-frutescent, fl. jaunes. Nlarsavril. R.

๖'4. V. macrantha Glaz. n. sp.? in herb. Paris., Berol., Kew., Genev., etc. - Chapadinha de Guariroba, dans le campo, Goraz, $\mathrm{n}^{\circ}$ 21556. Sous-frutescent, f1. jaunes. Septembre-octobre. CC.

549. Verbesina glabrata Hook. et Arn.; Fl. Bras. VI, III, p. 211. - Serra dos Orgãos et Petropolis, Rio-Jan., nos 4059, 3038, 12846 , 16164. Frutescent, fl. jaunes. Mars-avril. GG.

550. V. Clausseni Sch. Bip.; Fl. Bras. VI, III, p. 212. - Entre Ilheos et Sitio, dans le bois, Mrsas, $n^{\circ}$ 16169. Frutescent, fl. jaunes. Novembre-décembre. C.

551. V. bipinnatifida Bak. in Fl. Bras. VI, III, p. 213. - Aldeia de Ouro Branco, Mrxas, $n^{\circ}$ 15036. Sous-frutescent, fl. blanches. Novembredécembre. G.

592. V. diversifolia DG.; $\mathrm{Fl}$. Bras. VI, III, p. 213. - Alto do Morro Azul, S. Pauro, $\mathrm{n}^{\text {os }}$ 10995, 12898. Sous-frutescent, fl. jaunâtres. Marsavril. C.

353. V. subcordata DC.; Fl. Bras. VI, III, p. 213. - Serra dos Orgãos, à Theresopolis, Rio-JAx., $n^{0} 4059$ a. Sous-frutescent, fl. jaunes. Mars-avril. R,

5̆54. V. sordescens DC. var. semiserrata Bak. in Fl. Bras. VI, III, p. 214. - Piracicaba, dans le bois, S. Pavlo, $n^{\circ}$ 16168. Sous-frutescent, f1. jaunes. Janvier-février. C.

5ั5. V. Arnottii Bak.: Fl. Bras. VI, III, p. $215 \%$ - Serra do Picú, à Engenho da Serra, Mrsas, nos 1047,11040 . Sous-frutescent, fl. jaunâtres. Mars-avril. C.

5ั56. V. australis Bak.; Fl. Bras. VI, III, p. 213̆. -- Gabo Frio, au bord des bois, Rio-JAx., n 12855. Herb., fl. jaunes. Aoùt-septembre. C.

כวั7. Spilanthes Acmella L. var. uliginosa Bak.; Fl. Bras. VI, III, 
p. 232. - Nova Frilurgo, dans les lossés et les bourloiers, Pio-Jan., $1^{\circ \mathrm{s}} 5920$, 12795. Herl., ll. jannes. Janvier-mars. C.

- Var. oleracea Bak. : Fl. Bras. VI, I1, p. 239. - Serra da Mantiqueira, Mras, nº 10993. Herb., fl. jaunatres. Septembre-octobre. C.

Jïs. Svilanthes urens Jacy.; Fl. Bras. VI, III, p. 233. - Serra da Baliza, Goxız, $1^{\circ}$ 21568. Herh., fl. jaunâtres. Hécembre-janvier. C.

339). S. armicoides DG. var. macropoda Bak.; Fl. Bills. VI, III, p. 234. - Entre Sitio et Barbacena, Mrxas, no 15073; Morro dos Cristaes, Goraz, no 21567. Herb, ,1. jaunes. Octobre-novembre. C.

560. S. stolonifera DC. var. pusilua Bak; Fl. Bras. VI. III, p. 933. - Chapadão dos Veadeiros, Goxw, n²1569. Herb., fl. jaunâtres. Janvier-févier. R.

361. Trichospira menthoides H. H. K.; Fl. Bras. VI, II, 1. 935. - Rio Manso, près Arassualy, Mrss, nº 13985. Herb., fl. blanches. duillet-awit. C.

562. Cosmos caudatus H. B. K. ; Fl. Bras. VI, III, p. 242. - Floresta da Tijuca, Rio-dAn., nos 12813, 12844; Cogonlas do Campo, Minas, $n^{0 s}$ 14007, 15033. Herl., ll. roses. Arril-juin. CC.

503. Bidens pilosus L. ; Fl. Bras. V1, III, P. 244. - Entre Lagoa de Froilas et Gavea. Rio-Jan, nos 4034, 8755. Herb., fl. roses. Juillet-aoùt. C.C.

564. B. rubifolius H. B. K.; Fl. Bras. N, HI, p. Q40.- Ipanena, près de la mine de fer, SAO Paulo, no 12881. Frutescent, li. jaunes. Mars-arril. C.

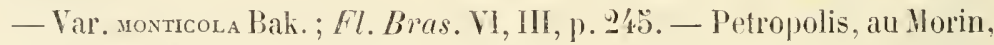
dans le bois, Rio-J.1x., n² 2624. Frutescent, fl. jaunes. Mars-avil. C.

563. B. Gardneri Bak. in Fl. Bras. VI, III, p. 246. - Morro do Pires, près Sabará, Mınas, no $18315 a$. Herl), fl. jaunes. Janvier-février. C.

566. B. graveolens Mart.; Fl. Bras. VI, III, p. 248. - Morro do Pires, près Sabara, Misas, no 18315 ; Corrego do Brejo, Goyaz, no 21588. Herb., fl. verdâtres. Décembre-janvier. C.

367. B. flagellaris Bak. in Fl. Bras. VI, 11I, 1. 248. - Riribiry, près Diamantina, Mrsas, $n^{\circ}$ 19525. Hełh., Il. jaunâtres. Mars-avril. R.

368. Isostigma microcephalum Bak.; Fl. Bras. VI, III, p. 239. Cassú, entre les rochers, Mrxas, n² 21557 . Herb., ll. jaunes. Juillet-aoùt. C.

569. I. pencedanifolium Less.; Fl. Bras. V1, II, p. 2\$1. - Entre Rio Parapeba et Porto do Zephrerino, Goraz, no $21569 a$; entre Piedade 
et Sta Luzia do Rio das Velhas, Mixas, nº 20381 . Herb. vivace, ff. violettes. Norrmbre-décembre. C.

„70. Chrysanthellum procumbens Rich. . Fl. Bras. VI, III, p. 238. - Campos da Bocaina, au Bom Jardim, São Paclo, no 10976. Herb., ft. blanchàtres. Fésrier-mars. C. Vulg. : Assaré.

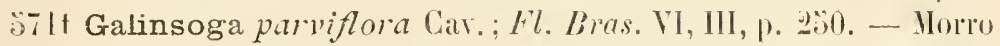
da Babytunia, à Botafogo, Rio-Jax., $1^{\circ}$ 190. Herh., ft. blanchâtres. Févriel-mars. C.

372. Calea lemmatioides Sch. Bip. in Fl. Bras. VI, III, P. 292. Itacolumy, près Ouro Preto. Mixas, no 15139. Frutescent, tl. jaumes. Janviel-février. C.

:73. C. petropolitana Glaz. 1. sj.? in herb.. Paris., Berol., Kew., Gener, ete. - Petropolis, au Norin. sur les roches et au Nto Nacahr. RioJAx., $n^{\text {os }} 13986,17101,18317$. Futesent, fl. jaunes. Janvier-mars. CG.

j7'. C. rotundifolia Bak.; Fl. Bras. VI, III, p. 233. - Cachoeira do Campo, Mrss, no 15138; Rio Parama, Gosaz, n² 21613. Frutescent, f1. jaunes. Arril-mai. C.

37. C. nitida Less. ; Fl. Bras. VI, III, p. 25ั3. - Serra do Caraca, dans le campo, Mivas, $u^{\text {os }}$ 15136, 15137. Frutescent, 11. james. Janvirlfévier. C.

:76. G. floribunda Bal. n. sp.? in herb. Paris., Berol., Kew.. Genev., etc. - Biribiry, près Diannantina, Mrxas, no 19543. Frutescent. ll. jaunes. Mars-avril. C.

:77. C. lantanoides Gardin.; Fl. Bras. VI, III, p. 294. - Serra dos Pyreneos et Vicente Pires, Goraz, no 21614. Sous-fintescent, ll. jaunes. Aout-septembre. C.

ร78. C. hymenolepis Pak. in Fl. Bras. VI, III, P. 2.̈8. - Pres Santa Luzia, dans le campo, Gorä, n² 21558. Sous-fruteseont, 11. jaunes. Marsarril. C.

\%79. C. mrrtifolia Bak.; Fl. Bras. VI, III, 1. 260. - Entre Sitio et Joãu Ayres, Mıxas, no 11054. Sous-fiutescent. fl. jaures. Mali-juin. C.

¿s0. C. phyllolepis Bak. in Fl. Bras. VI, III, 1. 260. - Iynnocil, au Pico do Papagaio, Msxas, $n^{\circ}$ 16163. Frutescent, fl. jaunes. Janvierliviler. C.

¿81. C. hispida Bak.; Fl. Bras. VI, III, p. 261. - Selra Frio, pres Ayurnoca, Muxas, $n^{\circ} 16163$ u. Frutescent, fl. jaunes. Jamvier-férrier. R. 3̈82. C. pinnatifida Less.; Fl. Bras. VI, III, P. „263. - Corcovado, à 
Paineiras, Rio-JAN., no 6028. Sarmenteux, fl. jaunes. Octobre-septembre. C.

583. Calea multiplinervia Less.; Fl. Bras. VI, III, p. 264. - Serra do Lenleiro, Misas, $11^{\circ}$ 17082; Pichoa, dans les campos, Goyaz, $1^{\circ} 21551$. Herb., fl. jaunes. Septembre-octobre. R.

584. C. Clausseniana Bak. in Fl. Bras. VI, III, p. 260̈. - Serra de ()uro Branco et Serra do Lenheiro, près S. João d'El Rei, Mixas, $n^{\text {os }} 15075,17083$. Herb., fl. jaunes. Octobre-novembre. C.

585. C. cuneifolia DC.; Fl. Bras. VI, III, p. 266. - Chico Costa, pres Lagoinha, dans le cerrado, Goraz, $n^{0}$ 21554. Herb., fl. jaunes. Octobre-novembre. C.

586. C. cymosa Less.; Fl. Bras. VI, III, p. 267. - Retiro do Rio Torto, près Paranauna, Goyaz, no 21559. Herb., ft. jaunes. Février-mars. C.

387. C. platy-lepis Sch. Bip.; Fl. Bras. VI, III, p. 267. - Pichoa dans le campo, près Espigão, Goyaz, nº 21650 a. Herl., fl. jaunes. Octobre-novembre. R.

588. Geissopappus gentianoides Bak., Rl. Bras. VI, III, p. 279. Chapadinlıa do Ipiranga, S. Paulo, $\mathrm{n}^{\circ}$ 16149. Herb., fl. roses. Janvierfévrier. C.

589. Porophyllum ruderale Cass.; Fl. Bras. VI, III, p. 282. Entre Vista Chineza et Tijuea, Rio-JAx., $11^{0 s} 556,11004$. Herb., fl. verdâtres. Novembre-décembre. C.

590. P. lanceolatum Bentlı.; Fl. Bras. VI, III, p. 282. - Rodrigo Silva, au Capĩo, Mrsas, $n^{\circ}$ 19527. Herb., ft. verdâtres. Avril-mai. C.

591. P. prenanthoides DC.; Fl. Bras. VI, III, p. 283. - Cabeceiras do Rio Bananal, Goraz, 11" 21599. Herlı, fl. verdâtres. Mai-juin. C.

592. P. Martii Bak.; Fl. Bras. VI, III, p. 284. - Biribiry, près Diamantina, Mınas, $n^{0}$ 19526. Herb., fl. verdattres. Mars-avril. C. Vulg. : Catingr.de Urubur.

ร93. P. lineare DC.; Fl. Brus. VI, III, p. ŁSəั. - Serra do Palmital, Mıxas, $n^{\circ}$ 15030; Corrego do Brejo, au Chapadão central, Gờz, $\mathrm{n}^{0}$ 21598. Herl., fl. verdâtres. Mai-juin. C.

594. Tagetes minuta L.; Fl. Bras. VI, III, p. 273. - Serra dos Orgãos, à Theresopolis, Rio-Jav., ${ }^{0 s} 1622,8146,14000$; Fazenda do Parauna, Goraz, n 21597. Herb., fi. blanc jaunâtre. Févirier-mai. Exlıale une très bonne odeur. CG.

598. Flaveria repanda Lag.; Fl. Bras. VI, III, p. 270. - Ilha de Paqueta, Rıo-JAn., n ${ }^{\circ} 60$ a. Herb., fl. blanchâtres. Février-mars R.. 
A.-F,-M. GLAZIOU. - LISTE DES PLAXTES DU BRÉSIL CENTRAL.

896. Pectis decumbens Bak.; Fl. Brus. VI, III, p. 286. - Săo Fidelis, près Campos, Rı-Jax.. no 9912. Herb., fl. blanchattres, Janvier-févilier. R.

597. P. rubiacea Bak. in Fl. Bras. VI, III, p. 2287. - Cabo Frio, près São Pedro dos Indios, Rio-Jan., $n^{\circ}$ 12807; Nacacos, à Serra dos Crislaes, Goraz, $1^{0}$ 21570. Herb., 11. blanchâtres. Août-septembre. C.

5998. P. apocephala Bak. in Fl. Bres. VI, III, p. 288. - Valta Funda et au passage du Rio Parauna, Mrsas, $n^{0 s} 12808$, 19532. Herb., fl. blanchâtres. Mars-avril. C.

599. P. oligocephala Bak.; Fl. Bras. VI, III, p. 289. - Entre Araruama et Cabo Frio, Rio-Jax., nos 9915, 10964. Herb., fl. blanchàtres. Aviril-mai. C.

600. Erechthites hieracifolia Rafin. ; Fl. Bras. VI, III, p. 298. Copacabana, Corcovado, Tijuca, Rio-Jas., $n^{0 s} 174,225,4033,4043$, 4047, 8759, 10962. Herb., fl. blanches. Novembre-décembre. CC. Vulg. : Carurú.

601. E. valeriancefolia DC.; Fl. Bras. VI, III, p. 300. - Quinta da Boa Vista, à S. Christovão, Rio-Jan., no 8759 a. Herb., fl. roses. Aoùtseptembre. C. Vulg. : Cairurú.

602. Emilia sagittata DC.; Fl. Bras. VI, III, p. 297. - Corcovado, à Caixa d'Agua, Rio-JAv., nº 535. Herls., fl. roses. Juin-juillet. C.

603. Senecio goyazensis Gardn.; Fl. Bras. VI, III, p. 302. - Serra dos Orgãos, au sommet, Rio-Jav., n 16174. Herb., fl. jaunes. Janviermars. C.

604. S. Pohlii Sch. Bip.: Fl. Bras. VI, III, p. 303. - Itacolumy, près Ouro Preto, São João d'El Rei, Mı̀as, nos 12861, 15057, 17091. Herb., f1. roses. Janvier-mars. CC.

608. S. grandis Gardn. Fl. Bras. VI, IIII, p. 304. - Serra dos Orgãos et Itatiaia, Rı-Jax., n ${ }^{\circ 5} 6581,7728,18340$. Herb., fl. jaunes. Juin-juillet. C.

606. S. imbricatus Gardn.; Fl. Bras. VI, III, p. 304. - Serra do Ouro Branco, Mixas, ${ }^{\circ}$ 15031. Frutescent, fl. jaunes. Novembre-décembre. C.

607. S. trixoides Gardı.; Fl. Bras. VI, III, p. 305. - Arraial de Ouro Branco, Mlsas, no 15032 . Frutescent, fl. jaunâtres. Juin-juillet. C.

608. S. ranentaceus Bak. in Fl. Bras. VI, III, p. 308̈. - Serra dos Orgãos, an Frade, Rı-Jax., n's 2855, 2856. Sous-frutescent, fl. jaunàtres. Aoüt-septembre. C. 
(it). Senecio Glaziovii Bak. in Fl. Bras. VI. III, p. 305. - Morro Cavado, pries Serra Negra, Misas, 11" 7707; Campos da Bocaina, dans le bois, S. l'tulo, n" 11105. Albrisseau, fl. blanchîtres. Aont-septembre. C.

610. S. leptoschizzs liong.; Fl. Bras. VI, III, p. 306. - Ayuruoca, an Pieo do Papagaio, Mrsas, no 16147. Herh., fl. james. Janvier-mars. li.

611. S. dunctornm Gardn.; Fl. Bras. VI, III, p. 308. - Serra do Batatal ou do Capanema, Mixas, n" 15047, 19516, 19517. Sous-fiutescent, Il. jaunes. Mai-juin. C.

612. S. pulcher Hook. et Arn.: Fl. Bras. VI, III, p. 310. - Serra dos ()rgĩos, dans les bourbiers, Rio-Jav., n 17085 . Herb., fl. roses. Octobrenorembre. G.

613. S. colpodes Bong.; Fl. Bras. VI, III, p. 311. - Itacolumy et Caraça, au Morro da Carapuça, Mrsa, $n^{\prime \prime s} 15048,15049$, 18330. Herb., fl. jaunes. Juin-juillet. C.

614. S. vernonioides Sch. Bip. in Fl. Bras. VI, III, p. 312. - Entre Sitio et Barbacena, Misas, n" 11055. Herb., fl. jaunes. Juin-juillet. C.

613. S. hastatus Bong.; Fl. Bras. VI, III, I. 314. - Itatiaia, au Campo do Silverio, Ruo-Jax., n"s 4865, 6571. Herb., ff. jaunes. Hai-juin. C.

616. S. icoglossus DG.; Fl. Bras. VI, III, p. 316. - Itatiaia, aux Campos Bejos, Rio-Jux., n's 7708, 8767; Campos da Bocaina et a

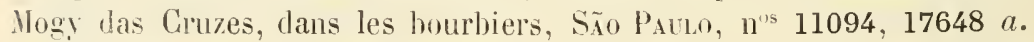
Herh., fl. blanches. Juin-septembre. CG.

617. S. cuncifolins Gardn.; Ft. Bras. VI, III, p. 317. - Serra dos Drgion, au sommet, Rı-JAx., II's 4051, 15055, 16180. Sous-frutescent. ft. jaunàtres. Décembre-janvier. C.

618. S. cllipticus DC.; Fl. Bras. VI, III, p. 318. - Serra dos Orgins, au Frade, Ruo-Jax., u" 2850 ; Serra da Bocaina, dans le hois, S. Parlo, n"s 11028. 11103 . Albuste sarmenteux, 11. jaunes. Aoûtseptembre. C:

619. S. pellucidinervis Sch. Bip. in Fl. Bras. VI, III, p. $319 .-$ Serra da Bocaina, dans le bois, S. Palto, n" 11106; Itacolumy près Ouro Preto. Misas, $n^{\circ}$ 15051. Arbuste sarmenteux, fl. jamnes. Octobreseptembre. C.

620. S. organensis Casar.; Fl. Bras. VI, III, p. 320. - Serra dos Orgaios; do Alto Jlacahé, do Tingua et Pico da Tijuea, Rio-Jax., $n^{\prime \prime s} 1454.3684,4858,8775,17231$ et 19518. Sous-frutescent, fl. jaunes. Juin-aoùt. CG. 
A.-F.-M. GLAZ10T. - LISTE DES PLINTES DU BRÉSIL CEXTRA.

6ㄹ. S. adamantinus Bong.; Fl. Bras. VI, III, p. 320. - Itatiaia. lans le campo, Rio-Jix, n's 4855, 6587, 16183. Sous-frutescent, fl. jaunâtres. Janvier-mars. C.

622. S. stigophlebius Bak. in $\mathrm{Fl}$. Bras. VI, III, p. 321. - Itatiaia, dans le campo, Rio-Jax.. n" 4867. Herb., fl. hrunes. Juin-juillet. R.

623. S. erisithalifolius Sch. Bip. in Fl. Bres. VI, III, p. 321. - Sitio de Barbacena, dans les bourbiers, Mrsas. n" 11049. Herb.. fl. blanches. Mai-juin. C.

624. S. brasiliensis Less.: Fl. Bras. VI, III, p. 322. - Serra dos Orerios, à Theresopolis, Rio-Jax., n's 1620, 2851, 8765: Campos da Bocaina, S. Parlo, n" 11099. Sous-frutescent, fl. jaunes. Septembreoctobre. CG.

620̈. S. paucijugus Bak. Fl. Bras. VI, III, p. 323. - Sitio de Barbacena, Mixas, 1" 11053. Herl., fl. jaunes. Mai-juin. C.

6⒍ S. pinnatus Poir.; Fl. Bras. VI, III, p. 3⒊ - Serra dos Orqios, à Theresopolis, Ruo-Jav., $n^{0}$ 15056. Herb., fl. jaunes. Juin-juillet. R.

627. Schlechtendalia luzulafolia Less.; $\mathrm{Fl}$. Bras. VI, III, p. 341. — Entre Ouro Preto et Rodrigo Silva, an Capão, Mıxas, no 19490. Herb., fl. jaunàtres. Mai-juin. R.

628. Arctium minus Schk. : Fl. Bras. VI, III, p. 326. - Petropolis, a Santo Antonio, Rio-JAx., n's 2095, 7698. Sous-flutescent, fll. blanchâtres, Juillet-åoùt. C.

639. Barnadesia rosea Lindl.; Fl. Bras. VI, III, p. 364. - Entre Sitio et Joĩo Ayres et près de Queluz, Itrsas, nos 11058, $14942,18337$. Arbuste, fil. roses. Juin-juillet. C.

630. Mutisia speciosa Hook.; Fl. Bras. VI, III, p. 366. - Flor'esta da Tijuca, Gavea, Rio-Jax., ${ }^{15}$ 4054, 13981, 16185. Liane herbacée, 11. rouges. Aout-septembre. C.

631. M. campanulata Less.; Fl. Bras. VI, III, p. 367. - Entre Sitio et João Arres, Gandarela, Misas, $n^{\prime s}$ 11056, 14950. Liane herbaceee, 11. rouges. Juin-juillet. C.

632. Chuquiraga cryptocephala Bak. Fl. Bras. VI, III, p. $33 \%$. Nova Friburgo, à Pedra do Suspiro, Rio-JAx., n" 12841. Arbuste, fl. rosées. Aoùt-septembre. C.

633. Ch. reticulata DG.; Fl. Bras. VI, IH, p. 33̈6. - Serra da Mangabeira, Mrsss, $n^{1 / 5}$ 18336, 19569, 19570. Arluste, lt. jaunâtres. Arrilmai. C. 
634. Chuquiraga lanosa Glaz. n. sp. in herb. Paris., Berol., Kew, Genev., etc. - Serra do Cipo, dans le campo, Misas, n" 19571, Arbuste, 17. jaunattres. Mars-avril. R.

63:. Ch. trichophylla Bak. in Fl. Bras. VI, III, p. 3̈̈6. - Serra do Caraça, dans le campo, Nisas, $n^{\circ}$ 16159. Arbuste, fl. jaunâtres. Juinjuillet. C.

636. Ch. macrocephala Bak. in Fl. Bras. VI, III, p. 339. - Serra do Caraça, au Campo de Fora, Misas, $n^{\circ s} 14945,14946$. Arbuste, f1. blanchâtres. Juin-juillet. C.

637. Ch. Sprengeliana Bak. in Fl. Bras. VI, III, p. 3ä7. -- Serra da Caraça et de São José d'El Rei, nos 10982, 14029, 14943, 14944, 17096; entre Manoel João et Ponte do Abacté, dans le carascal, MlNas, ${ }^{08} 21679$ et 21680. Arbuste, 11. blanchâtres. Juin-octobre. CC.

638. Ch. Regnellii Bak.; Fl. Bras. VI, III, p. 339. - Morro de São Vicente, Misas, $n^{0} 14944 a$. Arbuste sarmenteux, fl. blanchâtres. Juinjuillet. R.

639. Ch. leptacantha Bak.; Fl. Bras. VI, III, p. 360. - Alto da Serra dos Orgãos, Rıo-Jan., nos $3691,16160,17095$. Arbuste, f1, rosées. Maijuin. C.

640. Ch. orthacantha Bak.; Fl. Bras. Vl, III, p. 360. - Copacabana, entre les rochers, Rı-JAv., $\mathrm{n}^{i s}$ 1398, 5912. Arbuste, ft. rosées. Juinjuillet. R.

6ł1. Ch. tomentosa Bak.; Fl. Bras. VI, III, p. 360. - Nova Friburgo, au Suspiro, Rıo-Jav., n ${ }^{\circ}$ 12056; Cassú près Uberala et au passage du Rio Parnahyba, Mivas, $n^{\text {os }} 21677,21678$. Arbuste sarmenteux, 1l. jaunàtres. Août-septembre. C.

642. Ch. vagans Bak.; Fl. Bras. VI, III, p. 361. - Petropolis, à Santo Antonio, Rio-Jax., n 7697; Entre Sitio et Barbacena, Gandarela dans le bois, près des fossiles, Mixas, $\mathrm{n}^{\circ} 11055,14947$. Arbuste sarmenteux, fl. blanchâtres. Juin-juillet. C.

643. Ch. spinescens Bak. n. sp. in herb. Paris., Kew., Brux., etc. - Nova Friburgo, au Conego, Rio-J.J., $1^{\circ}$ 12055. Grand arbre, fl. blanchâtres. Juin-juillet. R.

644. Ch. glabra Bak.; Fl. Bras. VI, III, p. 363. - Corcovado et à Petropolis, Rio-Jax., n ${ }^{\circ s} 2630,2631,3040,5911$; Serra to Picú, à Barreira, Mıxas, $n^{\text {os }} 12859$, 14948. Arbuste, fl. blanchâtres. Juin-juillet. C.

640̆. Wunderlichia Glaz̃iovii Bak.; Fl. Bias. VI, III, p. 343. - 
1.-F.-M. GLAZ10U. - LISTE DES ILANTES DU BRÉSIL CENTRAL.

Pedra do Conego, à Nova Friburgo, Rio-Jas., nos 12060, 12842. Frutescent, 11. jaunitres. Juin-juillet. R.

646. W. crulsiana Taub. in Beitr. Fl. central, st Goyaz, p. 450. Cachoeira da Vargem Grande, Govaz, no 21681. Arbuste de 2 à $3 \mathrm{~m}$. de hauteur, fl. jaunâtres. Janvier-février. R.

647. W. mirabilis Ried. in Fl. Bras. VI, III, p. 343. - Serra do Caraça, près la Cachoeira, Mivas, no 14941. Arbrisseau de 3 à :3 m. de hauteur, tl. blanchâtres. Juin-juillet. R.

648. W. tomentosa Claz. n. sp. ? in herb. Paris., Berol., Kew., Genev., etc. - Serra da Baloza entre les rochers, Goraz, $n^{\text {os }} 21682$, $21683,21684,21685$. Arbuste de 2 à $3 \mathrm{~m}$. de hauteur, fl. blanc jaunâtre. Août-septembre. CC.

649. W. Senæii Glaz. n. sp. ? in herl. Paris., Berol., Kew., Genev., etc. - Curalinho près Diamantina, entre les rochers, Misas, 11" 19568. Arbuste de 1 à 2 m., fl. jaunâtres. Août-septembre. R.

650. Gochnatia rotundifolia Less.; Fl. Bras. VI, III, p. 349. Nova Friburgo, à Pedro do Suspiro, Rio-JAx., nº 12061. Arbuste, 11. jaunâtres. Juin-juillet. R.

68̈1. Moquinia racemosa DC.; Fl. Bras. VI, III, p. 344. - Itacolumy, près Ouro Preto et Caraça, Mısas, $1^{\prime \prime s}$ 15043, 18335. Arbuste, f1. jaunâtres. Juin-juillet. R.

652. M. polymorpha DG.; Fl. Bras. VI, III, p. 345. - Serra do Lenheiro près S. João d'El Rei, Hısas, n" 12840. Arbuste, fl. blanchâtres. Février-mars. C.

653. M. lanuginosa Bak. in Fl. Bras. VI, IIl, p. 345. - Norro de S. Vicente, près S. Bartholomeu, n 15044, et Caraça, Hısas, no 19557. Arbuste, fl. blanchâtres. Avril-juin. C.

634. M. paniculata DC.; Fl. Bras. VI, III, p. 346. - Nova Friburgo, à Pedra do Conego, Rio-Jav., n ${ }^{\text {ns }} 11072$, 12053; Campos da Bocaina, vieux chemin de Mambucaba, S. Paulo, n" 11098. Arbuste, fl. blanchâtres. Juin-juillet. Vulg. : C'amará.

69.. M. velutina Bong.; Fl. Bras. VI, III, p. 346. - Corcovado, à Santa Theresa, Rio-JAx., un $^{\text {os }} 55 \mathrm{i}$, 3039. Arbrisseau, fl. blanchàtres. Janvier-février. GG. Vulg. : Camarí.

6ə̃6. M. cratensis Gardn.; Hl. Bras. VI, III, p. 347. - Rodrigo Silva, au Capão près Ouro Preto, Iıras, $n^{\circ}$ 19558. Arbuste, fl. blanchittres. Avril-mai. C.

6357. M. coriacea Glaz. n. sp., in herh. Paris., Berol., Kew., 
Genev., etc. - Haut du Norro Redondo, Goraz, n" 21663. Arbuste, fl blanchatres. Septenthre-octobre. R.

68̈8. Moquinia lucida Bak.; Fl. Bras. Vl, III, p. 347. - Fazenda do Horro Azul, S̃̃o Paulo, H" 12839. Arbuste, fl. blanchâtres. Mars-avril. C.

689. M. Gardneri Bak. in Fl. Bras. VI, III, p. 348. - Entre Rio Manso et Arassuahy, Mivas, n" 13995. Arbuste, ll. blanchàtres. Juin-juillet. C.

660. M. glaucescens Glaz. n. sp., in herb., Paris., Berol., Kew., Genev., etc. - Serra do Funil, au Cesario, Mrsas, n" 19559. Arbuste, 11. blanchâtres. Avril-mai. C.

661. Seris amplexifolia Gardn.; Fl. Bras. VI, III, p. 353. - Biribiry, au Nocoti, Mlsas, n" 19556. Sous-frutescent, ll. blanchâtres. Marsavril. G.

- Var. vaginata Bak.; Fl. Bras. VI, III, p. 30̈4. - Aldeia de Capanema, daus le campo, Misas, $n^{\circ}$ 15042. Sous-frutescent, li. blanchâtres. Janvier-février. C.

662. S. polyphylla Bak. in Fl. Bras. VI, III, p. 3ัّ̋4. - Tombador, près Diannantina, Mısas, II" 19555. Sous-frutescent, fl. blanchàtres. Harsavril. G.

663. Stifftia chrysantha Mik.; Fl. Bras. VI, III, p. 3äl. - Corcovado et Floresta da Tijuca, Rio-JAN., n" 1130. Arluuste, fl. jaunes. Janvier-mars. GG. Vulg. : Pincel.

664. S. parviflora Don; Fl. Bras. VI, III, p. 332. - Ponte do Rio Abaeté dans le bois, Mlıxas, $n^{\circ}$ 21676. Arbuste, fl. jaunâtres. Septembreoctobre. R.

665. Trichocline incana Cass.; Fl. Bras. VI, III, p. 371. - Collina do Ipirango, S. Pauto, $n^{\circ} 16175$. Herb. acaule, fl. jaunes. Févriermars. R.

666. T. macrocephala Less.; Fl. Bras. VI, III, p. 371. - Entre Ipanema et Sorocaba, dans le campo, S. Paulo, $n^{\circ} 16175$ a. Herb. acaule, fl. jaunes. Février-mar's. R.

667. T. heterophylla Less.; Fl. Bras. VI, III, p. 372. - Entre Queluz el Ouro Preto, dans le campo, Hinas, ${ }^{\circ}$ 18319. Herb. acaule, fi. jaunes. Juin-juillet. R.

668. T. polymorpha Bak.: Fl. Bras. VI, III, p. 373. - Campos da IBocaina, S. Pawlo, 11" 8145; Serra Piedade, Serra da Caraça et Itacolumy, Mlısas, $\mathrm{n}^{\text {us }} 15058,15059,19554,20380$. Herb. vivace, 11. jaunàtres. Janvier-févirier. CC.

669. T. araneosa Bak. in Fl. Bras. VI, III, p. 374. - Serra do 
A.-F.-H, GLAZIOU. LISTE DES PLANTES DU BRÉSH CENTRAL.

Batatal ou do Capanema, Mtxas, $\mathrm{n}^{\prime \prime 5}$ 15027, 20378. Herb. acaule, 11. roses. Juin-aoùt. C.

670. T. Martii Bak. in Fl. Bras, VI, III, p. 375. - Caraca, Caminlo da Capelina et au Morro do Inficionato, Nixas, n ${ }^{15}$ 15028, $15028 a$, 15029. Herb. acaule, fl. jaunâtres. C. Vulg. : Isgneira.

671. T. cordata Bak. n. sp. in herl., Paris, Berul., Kew., Gen., ete. - Alto Macahé de Nova Friburgo, Rio-Jav., $n^{3 \$} 17104,18320$. Herb. vivace, fl. blanches. C.

672. T. denticulata Bak. in Fl. Bras. VI, III, p. 375. - Alto dil Serra do Orgãos, source du Rio Soberbo et Serra do Tingua, Ro-JAv., $\mathrm{n}^{\mathrm{s}} 6031,8779$, 16171. Herio. acaule, fl. blanches. Janvier-mar's. C.

673. T. nervosa Less.; Fl. Bras. VI, III, p. 376. - Campos do Bocaina, dans les touffes de grosses Cypéracées, S. Pawlo, n" 8119. Herb., fl. jaunes. Janvier-février. li.

674. Chaptalia mutans Hemsl.; Fl. Bras. VI, III, p. 37̈. - Petropolis et Nova Friburgo, Rı-Jax., $n^{118}$ 13982, 15026. Acaule vivace, fl. blanches. Juillet-aoùt. C.

67\%. Ch. integrifolia Bak,; Fl. Bras. VI, III, p. 377. - Serra de Ouro Branco et Santa Luzia do Rio das Velhas, Misas, $11^{\text {ss }} 15025$, 16148, 20377. Acaule vivace, fl, blanches. Juin-juillet. C.

676. Ch. piloselloides Bak.; Fl. Bras, VI, III, p. 378. - Silio de Barbacena, dans le campo et Morro Cavado près Serra Negra, Mtras, $\mathrm{n}^{\mathrm{ns}} \mathbf{7 7 1 2}, 11060,18321$. Acaule vivace, ft. blanches. Nai-juin. C.

677. Ch. exscapa Bak..; Fl. Bras. VI, III, p. 379. -- Itatiaia, aux Agulhas Negras, entre les rochers sur le versant du Rio Petro, Mtras, n" 6580 a. Acaule vivace, II. jaunâtres. Janvier-février. R.

678. Perezia cubataensis Less.; Fl. Bras. VIII, 1. 38I. - Itatiaia, au Campo do Silveirio, Rı-Jax., n" 6580. Herb., li. blenes, Janvierfévrier. R.

679. Trixis mollissima D. Don; Fl. Bras. VI, III, p. 38:. - Serta da Bocaina, dans le bois, S. Pavbo, n" 11101. Sous-frutescent, 11. blanchàtres. Septembre-octobre. C.

680. T. divaricata Spreng.; Fl. Bras. VI, III, p. 38' Frio, Corcovado, Tijuca, etc., Rio-Jıx., n"15 8757, 12800, 12856, 15035. Sous-frutescent, II. jaunâtres. Aoùt-septembre. CG. Exhale l'odeur de la pêche.

681. T. glaberrima Less.; Fl. Bras, VI, III. p. 386. - Casa Brantal, 
Mixas, in" 15106; Pirariralra, S. Pacto, no 16150. Sous-frulesrent, 11. jammes. Fivrier-mars. C.

682. Trivis verbasciformis Less.; Fl. Bras. VI, III, p. 387. - Ayu-

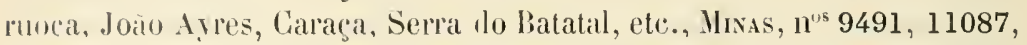
15107, 15108, 19531. Sous-frutescent, 11. jaunes. Février-juin. CC. Plante à bonne odeur.

683. T. spicata Gardn.; Fl. Bras. VI, III, p. 388. - Rodrigo Silvil, an Capaio, Mrxas, n" 19531 a. Sous-frutescent, 11. blanches. Mai-juin. R.

684. T. glutinosa D. Don; Fl. liras. VI, III, p. 388. - Entre Horro de S. Vicente et S. Bartholomeu, Mrsas, II" 15053. Sous-frutescent, tl. jaunes. Juin-juillet. C.

685. T. Vauthieri DG.; Fl. Bras. VI, III, p. 389. - Fazenda do Horto Azul, São Paclo, no 12801. Sous-frutescent, fl. jaunes. C.

686. T. Bonmanii Bak. Fl. Bras. VI, III, p. 390. - Serra dos Orgĩos, au Frade, R10-Jax., n 2844. Sous-fitutescent, Il. jaunes. Aøùtseptembre. R.

687. T. Lessingii DG.; Fl. Bras. VI, III, p. 390. - Serra dos Orgãos, à Theresopolis, Rio-Jax., n" 17086; Tripuhy, près Ouro Preto, Minas, n" 20385. Herlo. fl. jaunes. Janvier-février. C.

688. T. Glaziovii Bak. in Fl. Bras. VI, III, p. 391. - Itatiaia, au Campo Feio, Rı-Jax., $1^{\prime s} 4861$, 6582. Herb., f1. jaune orange. Janviermars. C.

689. T. pimnatifida Less.; Fl. Bras. VI, III, p. 391. - Serra dos Orgàos, au sommet, R10-JAx., n' 2853; entre Sitio et Joĩo Ayres, dans les bourluiers, Mixas, $n^{0} 11051$. Herb., fl. blanches. Juin-aout. C.

690. Jungia floribunda Less.; Fl. Bras. VI, III, p. 393. - Haut de la Serra da Mantiqueira, près João Ayres, Mısas, $n^{\circ} 11086 a$. Sous-frutescent, t1. blanchâtres. Juin-juillet. C.

- Var. affinis Bak.; F\%. Bres. VI, III, p. 393. - Entre Barbacena et Sitio, Mıxas, no 11086. Sous-frutescent, fl. blanchâtres. Mai-juin. C.

691. Hypochœris Gardneri Bak.; Fl. Bras. VI, III, p. 331. Campos dia Bocaina, S. Paclo, n's 8127, 12882; Serra dos Orgãos, dans les bourbiers, Rio-Jax., nos 4036, 6577, 16172. Herb., 11. jaunes. Janvier-mars. CG.

692. H. brasiliensis Grisel.; Fl. Bras. VI, III, p. 333. - Quinta da Boa Vista, ì S. Christorão, Rio-Jax., no 8764. Herb. vivace, fl. blanchâtres. Septembre-octobre. C.

693. Hieracium Commersonii Nonn.; Fl. Bras. VI, III, p. 337. - 
Campos de Barbacena, Mlsas, n" 15078. Herb., ft. jaunes. Novembredécembre. R.

69'. Taraxacum officinale Hall.; DC. Prodr. VII, p. 143. - Petropolis, dans les chemins, Rio-JAx., n" 17648. Herb, vivace, fl. jaunes. Janvier-mai. CC.

69\%. Sonchus oleraceus L.; Fl. Bras. VI, III, p. 38\%. - Corcorado et Tijuca, Ruo-Jax., n 3799 . Herb., fi. jaunâtres. Octobre-septembre. C.

$$
\text { Fam. 7.. - Goodeniacées. }
$$

1. Scævola Plumieri Valıl; DC. Prodr. Syst. Nat. VII, 1. 306. - Restingal de Copacabana, llans les sahles au bord de la mer, Rio-Jav., $n^{\circ}$ 17106. Sous-frutescent, fl. blanches, fruit noir. Aoùt-octobre. CC.

\section{Fam. 76. - Lobéliacées.}

1. Centropogon Chamissonianus Kan.; Fl. Bras. VI, IV, p. 133. - Serra do Picu et Nova Friburgo, Rro-Jax., n ${ }^{\circ} 11116$. Sous-frutescent, 11. blanchâtres. Avril-juin. C.

9. C. surinamensis Presl; Fl. Bras. VI, IV, p. 134. - Quinta da Boa Vista, à S. Christorão, Rio-JAx., nos 3044, 5923. Sous-frutescent, f1. rouges. Mai-juillet, cultivé. C.

3. Siphocampylus longepedunculatus Pohl; Fl. Bras. VI, IV, p. 1'́t. - Alto Ilacahé de Nova Friburgo, Rio-Jan., no 4064. Herbacé, fl. roses. Janvier-mars. R.

4. S. Warmingii Kanitz in Fl. Bras. VI, IV, p. 148. - Ponte Alta, prìs des cours d'eau, Govaz, $n^{\circ}$ 21688. Herbacé, fl. rouges. Octobre-septembre. C.

3. S. Eichleri Kanitz in Fl. Bras. VI, IV, p. 148. - Rasgão, près du Rio Corumba, Goyaz, $n^{0}$ 21687. Herbacé, fl. rouges. Octobre-septembre. C.

6. S. imbricatus Don: Fl. Bres. VI, IV, p. 149. - Caraça, au Campo de Fora. Mrxas, nº 15161. Herbacé, fl. rougeâtres. Juin-juillet. C.

7. S. verticillatus Don; Fl. Bras. VI, IV, p. 1:00. - Caraça et entre Sitio et Barbacena, dans les bourbiers, Mis.ss, $n^{\text {os }} 8149$, 11120, 16217, 16218 et 16219. Herbacé, fl, rougeǹtres. lanvier-juin. CC. Vulg. : Jaratataca. Exhale une odeur repoussante.

8. S. duploserratus Pohl; Fl. Bras. VI, IV, p. 13̈1. - Serra da Mantiqueira, près João Ayres, Mrxas, nos 11119 , 14039. Herbalcé, fl. rosés. Juin-juillet. C. 
9. Siphocampylus Westintanns Pohl; Fl. Bras. VI, IV, p. 152. Itatiaia, entre les rocher's, Rio-Jax., $n^{\text {os }}$ 4869, 6616, 9499; Ouro Preto, Mıxas, $n^{\text {ns }} 15163$, 16216. Herhacé, fl. roses. Février-juin. CC.

10. S. macropodus Don; Fl. Brras. VI, IV, p. I:3Q2. - Serra de Ouro Preto et João Ayres, Mixas, $n^{o s} 11118,11122$, 15164, 18342. Herbacé, fl, rouges. Avril-juin. CC.

11. S. corymbiferus Pohl; Fl. Bras. VI, IV, p. 184. - Serra dos Orgĩos, au Frade, Rio-Jan., $\mathrm{n}^{0 s} 3711,15155$. Ilerbacé, fl. roses. Aoùtseptemlire. C.

19. S. convolunlacens Don: Fl. Bras. VI, IV, p. 146. - Petropolis, au Alto do Imperador, Rio-Jax., n $4869 a$. Volubile, fi. roses. Févriermars. R.

13. Isotoma longiflora Presl; Fl. Bras. VI, IV, p. 156. - São Christovão, sur les vieux murs, Rı-JAx., $1^{\circ} 12922$. Herbacé, fl. blanches. Janvier-mars. R.

14. Lobelia aquatica Cham.: Fl. Bras. VI, IV, p. 137. - Barbacena, dans les hourbiers, MIsas, $n^{05} 11121$, 18343: Tijuco, dans les pâturages humides, Goyaz, $\mathrm{n}^{0}$ 21689. Herbacé, ft. bleues. Aoùt-septembre. C.

15. L. Erimus L.; DC. Prodr. VIII, p. 370. - Copacabana et lierquó, Rı-JAx., nos 5922, 18344. Herbacé, ft. bleues. Octobre-novembre. C.

16. L. nummularioides Cham.; Fl. Bras. VI, IV, p. 138, - Carandahỵ, dans les bourbiers, Mrsas, $n^{0} 13488 a$. Herbacé, fl. lilas pâle. Juinjuillet. C.

17. L. xalapensis II. B. K.; Fl. Bras. VI, IV, p. 139. - Carandahy, dans le campo humide, Misas, $n^{\circ}$ 13488. Herbacé, fl. jaunâtres. Juinjuillet. R.

18. L. camporum Pohl; Fl. Bras. VI, IV, p. I39. - Campos da Bocaina, à Vacca Cahio, Sĩo Pallo, nos $6617,8150,15162$. Herbacé, f1. lilas. Février-mars, CC.

19. L. Cliffortiana Willd.; DC. Prodr. VII, p. 372. - Caraça, au Campo Feio, Mlsas, $n^{0}$ 14040. Herbacé, ft. blanchâtres. Septembreoctobre. C.

20. Haynaldia exaltata Kanitz; Fl. Bres. VI, IV, p. 141. - Entre Sitio et Barbacena, dans Ies bourbier's. Mısas, no 11117 . Herbacé, fl. vioIeltes. Juin-juillet. C.

21. H. Hilaiveana Kanitz in Fl. Bras. VI, IV, p. 143. - Campos da Bocaina, au Sobrado, São Padlo, $n^{0}$ 8148. Herbacé, fl. lilas. Janviermars. R. Vulg. : Gomeira de soldado. 
22. H. organensis Kanitz; Fl. Bras. VI, IV, p. 143. - Serra dos Orgãos et Nora Fríburgo, au Picó da Saude ou do Suspiro, Rio-Jax., $n^{\text {os }} 8744,12920,14038$. Herbacé, fl. violettes. Mai-juillet. C.

23. H. thapsoidea Kanit, Fl. Bres. VI, IV, p. 14't. - Serra da Estrella et de Nova Friburgo, Rio-Jax., nos 2632, 12921, 14037, 17105. Herbacé, fl. violettes. Janvier-mai. CC.

\section{Fam. iт. - Campanulacées.}

1. Cephalostigma bahiense A. DC.; Fl. Bras. VI, IV, p. 181. Campos da Bocaina, S. Paulo, $n^{\circ} 11607$ a. Herbacé, fl. blanchâtres. Aoùt-septembre. R.

2. Wahlenbergia brasiliensis Cham.; F'l. Bras. VI, IV, p. 183. Campos da Bocaina, au Sobrado, Säo Paclo, $n^{05} 8151,11607,16220$, 16700. Sous-fi'utescent, f1. lilas. Aoùt-septembre. C.

3. W. linarioides A. DG.; Fl. Bras. VI, IV, p. 183. - Sĩo João d'El Rei, Mrras, n 17576. Sous-f'utescent, fl. blanches. Janvier'-mars. C.

4. Sphenoclea zeylanica Giertn.; Fl. Bras. VI, IV, p. 185. Morro do Coco, Espirito Santo, $n^{\circ s}$ 10023, 11439. Sous-frutescent, f1. blanchàtres. Décembre-janvier. R.

\section{Fam. 78. - Vacciniacées.}

1. Gaylussacia brasiliensis Meissn.; Fl. Bras. VII, p. 129. Pico da Tijuca, Serra dos Orgãos, Cabo Frio, etc., Rio-Jas., nos 2881, 6071, 6622, 11125, 12924. Arluste, f1. rouges. Octobre-novembre. CC.

- Val. myrtifolia Meissn.; Fl. Bras. VII, p. 130. - Theresopolis, au Alto da Boa Vista, Rio-Jax., $n^{\circ}$ 8785. Arbuste. fl. rouges. Septembreoctobre. C.

- Var. oblongifolia Meissil.; Fl. Bras. VII, p. 131. - São João del Rei, Rio Preto, Caraça, Biribiry, ete., Mrsas, nos $8788,15178,17112$, 17116, 19575, 20389. Arbuste, fl. rouges pourpres. Juin-novembre. CG.

2. G. Vitis-idaca (Mart.) Meissn. in Fl. Bras. VII, p. 134. - Serra das Araras, près Theresopolis, Rio-JAx., no 17111. Frutescent, 17. roses. Janvier-février. IR.

3. G. densa Cham.; Fl. Bras. VII, p. 133̈. - Serra do Alto Nacahé et Pico da Tijuca, Rio-Jax., nos 881, 7731, 14043. Frutescent, 11. rouges. Norembre-décembre. C.

4. G. fasciculata Gardn.; Fl. Bras. VII, p. 136. - Serra dos Orgãos 
et Itatialia, R10-JAr, $n^{\text {os }} 4873,16228$. Frutescent, fl, rouges. Janvierfévier. C.

¿. Gaylussacia parvifolia Gardn.; Fl. Bras. V1I, p. 136. - Serra dos Orgãos, au Frade, Rio-Jan., $n^{0}$ 4069. Frutescent, 11. rouges. Norembre-décembre. R.

6. G. salicifolia Cham. et Schl.; Fl. Bras. VIl, p. 136. - Serra do Cipó ef Itacolumy, près Ouro Preto, Mixas, $\mathrm{n}^{\text {os }} 18346$ a, 19573, 19574, 20391. Arbuste, f1. rouges. Avril-mai. C.

7. G. pruinosa Loesen. in Flora, LXXII (1889), p. 77. - Serra dos Orgios, au sommet, Rio-Jax., $1^{0} 17118$. Frutescent, fl. rouge pourpre. Norembre-décembre. C.

8. G. cinerea Taub. in Engler Bot. Jahrb. (1893), XVII, b̈11. Serra do Cipó, dans le campo, Mlisas, $n^{0 s}$ 19576, 19578. Frutescent, ll. blanchâtres. Avril-mai, C.

9. G. decipiens Clıam.; Fl. Bras. VII, p. 139. - Campos da Bocaina, S. Paclo, et Serra te Ouro Branco, Míras, $n^{\text {os }} 8234,11127,15177,15180$. Frutescent, 11. rouges. Férrier-mars. C.

10. G. amœna Clım.; Fl. Bras. VII, p. 140. -- Serra dos Orgãos et litio Preto, dans le campo, Rio-JAx., $n^{\text {os }} 8789$, 16229. Frutescent, fi. blanches. C.

11. G. rugosa Cham, et Schl.; Fl. Bras. VII, p. 140. - Campos da Bocaina, Säo PAdro, $n^{0}$ 11126. Frutescent, fl. rouges. Septembreoctobre. R.

12. G. virgata (Mart.) in Fl. Bras. VII, p. 141. - Biribiry, au Mocotó, près Diamantina. Mrwas, $n^{\circ}$ 19580. Frutescent, fl. rouges. Mars-avril. C.

13. G. reticulata (llart.) in Fl. Bras. VII, p. 142. - Serra de Ouro Preto et près Diamantina, Misas, $n^{0 s} 15179,19589$. Frutescent, f1. rouges. Mars-avril. C.

14. G. Pseudo-Gaultheria Cham. et Schl.; Fl. Bras. VII, p. 142. - Campos da Bocaina, à Vacca Cahio, Sao Paulo, nos 12182, 13466. Frutescent, fl, rouges. Janvier-février. C.

13. G. pallida Cham.; Fl. Bras. VII, p. 143. - Gandarela, près des plantes fossiles, Mıvas, $n^{\circ} 15175$. Frutescent, fl. rouges. Janvier-février. R.

16. G. canescens Meissn. in Fl. Bras. Vll, p. 143. - Serra dos Orgĩos, au sommet, Rio-JAx., $1^{05}$ 16227, 17114, 17115. Arbuste, fl. blanches. Octobre-novembre. C.

17. G. Chamissonis Meissn. in Fl. Bras. VII, p. 144. - Itatiaia, entre les rochers, Rio Jax., nos 5925, 6625; Serra da Piedade, Mrnas, nº 20394. Frutescent, fl. blanches. Novembre-décembre. C. 
A.-F.-Y. GLAZIOU. - LISTE DES PLANTES DU BRÉSIL CENTRAL.

18. G. hispida (DC.); Meissn. in Fl. Bras. VII, p. 140ั. - Serra dos Orgĩos, au sonmet, Rio-JAx., ${ }^{05} 3737,3738,6070$; Serras de S. José d'El Rei et da Piedade, Mix.s, $n^{\text {os }} 17113,20393$. Frutescent, fl. blanches. Octobre-novembre. C.

- Var. glabrescens. Fl. Brus. VII, p. 1 ' 6 . - Itatiaia, entre les rocher's. Rio-Jax., $1^{\circ}$ 6623; Itacolumy, près Uuro Preto et Serra Piedade, Mrxas, $n^{05}$ 15176, 18346, 20392. Frutescent, fl. blanches. Décembre-janvier. C.

19. G. pinifolia Cham.: Fl. Bras. VII, p. 14́t. - Itacolumy, près Ouro Preto, Misas, $n^{\text {os }} 15174,18345$. Frutescent, fl. roses. Janvierfévrier. C.

20. G. nctosperma Gardu.; Fl. Bres. VlI, p. 147. - Itatiaia, au Rio Preto, Mrxas, $n^{0} 8786$. Frutescent, fl. roses. Novemlre-dlécembre. R.

\section{Fam. 79. - Ericacées.}

1. Pernettya myrtilloides Meissn.; Fl. Bras. VII, p. 149. - Serrd da Piedade, près la chapelle, entre les pierres, Misas, no 20395. Frutescent, fl. blanches. Norembre-décembre. R.

2. Gaultheria Glaziovii ex Warm. n. sp.? in herb. Paris., Berol., Genev., etc. - Itatiaia, dans le campo entre les rochers, Rı-JAx., $n^{\circ 5} 4872$. 6626. Frutescent, fl. r'oses. Janvier-février. R.

3. G. ferruginea Cham. et Schl.; Fl. Bras. Vil, p. 131. - Serra dos Or@̃os. à Theresopolis, Rı-Jıx., nos 1594, 4871; Pedra de Amolar, près Ouro Preto, Misas, $n^{0 s} 13467,15169$. Arbuste, fl. ronges. Octobrenovembre. CG.

4. G. elliptica Cham.; Fl. Bras. VII, p. 152. - Serra dos Orgĩos, au Garrafão, Rio-. Ax., nos 3049, 4874. Frutescent, fl. rougeàtres. Octobreseptembre. C.

3. G. organensis Meissn. in Fl. Bras. VII, p. 133. - Serra dos Orgĩos, sur les rochers, Rio-Jax., no 17117. Frutescent, fl. rouges. Norembredécembre. R.

6. G. Roraima Klotz in Fl. Bras. VII, p. 153. - Pedra de Amolar, près Ouro Preto, Mrxas, no 13464. Frutescent, t1. rougeàtres. Octobrenovembre. R.

T. Leucothoe (A garista) stenophylla Loesen. in Flora od. Allgem. Bot. Zeit. (1889), p. 78. - Serra dos Orgãos, près des cours d'ean, Rı$J_{A x}, n^{0}$ 16232. Grand arbuste, fl. blanehes. Janvier-février. C.

8. L. (Agarista) minensis Glaz. n. sp.? in herb. Paris., Berol., 
Kew., Genev, etc. - Biribiry, au Mocoto, près Diamantina, Mıxas, $n^{\circ}$ 19572. Arbuste, f1. rouges. Mars-avril. R.

9. Leucothoe (Agar.) ericoides Taub. in Engler Bot. Jahrb., XVII, (1893), p. 812 (sul) Ayarista). - Serra dos Cristaes, près Diamantina, Mixas, nº 19577. Arbuste, fl. banchâtres. Janvier-février. R.

10. L. (Agarista) angustissima Glaz. n. sp.? in herlı. Paris. Pinheiro, Misas, ll 19582. Arbuste en fruit en mars.

11. L. multiflora DC.; Fl. Bras. VII, p. 159. - Itatiaia, dans le Campo Feio. Rı-JAs., no 6620 a. Arbuste, fl. rouges. Janvier-février. R.

- Var. eucaliptordes Meissn.: Fl. Bras. VII, p. 15̋. - Diamantina, au Tombador, Mıxas, nº 19581. Arbuste. f1. blanchâtres. Janvier-mar's. G.

12. L. ambigua Neissn. in Fl. Bras. VII, p. 15̆6. - Pedra do Conego, à Nova Friburgo, Rı-JAN., $n^{0}$ 12927. Arbuste, fl. rouges. Août-septembre. R.

- Var. glabra Meissn. in Fl. Bras. VII, p. 156. - Corumba, aux bords de la rivière, Goyaz, no 21691. Grand arbuste, f1. rouges. Juilletaoùt. C.

- Var. peduncularis Meissn. in Fl. Bras. VII, p. 156. - Italira do Campo, Mrsas, n 17107. Arbuste, fl. blanc rosé. Octobre-septembre. C.

- Var. congrfolia Mleissn. in Fl. Bras. VII, p. 156. - Meia Ponte, près du Rio das Almas, Goyaz, $n^{\circ}$ 21690. Arbuste, f1. rouges. Août-septembre. C.

- Var. parvifolia Meissn. in Fl. Bras. VII, p. 156. - Tijuca, au Morro Queimado, Rı-J $\mathrm{J}_{\mathrm{A}}, \mathrm{n}^{\text {os }} 3048,6620,6621$. Arbuste, 11. rouges. Août-septembre. CG.

13. L. oleifolia DC.: Fl. Bras. VII, p. 157. - Bords du Rio das Velhas, près Itabira do Campo, Mıxas, $n^{\text {os }} 15171,17108$. Grand arbuste, fl. rouges. Août-septembre. C.

14. L. crassifolia DC.; Fl. Bras. VII, p. 1588. - Serra do Palmital, près São Bartolomeu, dans le campo, Mıxas, n 15172. Petit arbuste, fl. rouges. Mai-juin. R.

15. L. revoluta DC.; Fl. Bras. VII, p. 160. - Restinga de Caho Frio, Rıo-J $\mathrm{JN}_{\mathrm{AN}}, \mathrm{n}^{\text {os }} 12925,12926$. Arbuste, f1. rouges. Octobre-septembre. C.

16. L. pulclira DG.; Fl. Bras. VII, p. 161. - Serra da Piedade, dans le campo, Mivas, n 20390 . Arbuste, fl. rouges. Octobre-novembre. R.

17. L. subrotunda DG.; Fl. Bras. VII, p. 161. - Serra do Lenheiro, 
A.-F,-I. GLAZIOU. - LISTE DES PLANTES DU BRÉSH CENTIAL.

près S. Joño d’El Rei, Hısas, no 17110. Arbuste, fl. rouges. Oetubrenovembre. R.

18. L. cordifolia Meissn. in Fl. Lirus. VII, p. 162. - Serra da Bocaina, ¿ Vacea Cahio, São Paclo, nos 8235, 8236; Serra José d'El Rei et Ouro Preto, Misas, nos 11599, 15173, 17109. Arbuste, fl. rouges. Févriermars. CC.

19. L. chlorantha DC.; Fl. Bras. VII, p. 169. - Serra dos Orgãos, au sommet, Rı-JAx., $n^{\circ}$ 16231. Arbuste, fl. blanches. Janvier-février. C.

20. L. organeusis Gardn.; Fl. Bras. VII, p. 163. - Serra dos Orgĩos, all sommet, Rio-Jan., n"s 2878, 3736, 15170, 16230 et 17119. Arbuste, f1. verdâtres. Norembre-décembre. CC.

21. L. intermedia Meissn. in Fl. Bras. VII, p. 163. - Itatiaia, au Rio Preto dans le campo, Mras, ${ }^{03} 4870,6624,8787$. Arbuste, fl. rouges. Novembre-décembre. C.

29. L. hispidula Meissn.; Fl. Bras. VII, p. 164. - Corumba, dans le campo, Gornz, nº 21691. Arbuste, f1. rouges. Août-septembre. C.

23. Clethra brasiliensis Cham.; Fl. Bras. VII, p. 167. - Serra dos Orgĩos, à Theresopolis, Rio-Jax., nos 3739, 16226. Arbrisseau, fl. blanc jaunatre. Dérembre-janvier. CC.

294. C. lavigata Meissn.; Fl. Bras. VII, p. 168. - Floresta da Tijuca, Corcorado et Petropolis, Ruo-JAx., 11 ${ }^{\text {os }}$ 748, 749, 4070, 7802, 16224, 16225. Arbrisseau, f1. blanc jaunâtre. Novembre-décembre. CC. Vulg. : Peroba brava.

\section{Fam. 80. - Plumbaginées.}

1. Statice brasiliensis Boiss.; Fl. Bras. VI, IV, p. 16'. - Restingal de Cabo Frio, près de la mer, Rro-J.s., $1^{0 s} 8896,13111$. Herbacé, 11. bleves. Aoùt-septembre. C.

Q. Plumbago scandens L.; Fl. Bras. VI, IV, p. 168̈. - Restinga de Copacabana, près de la mer, Rı-JAx., nos 1336, 5973 ; Inficionado, dans le campo, Mras, nos 13110, 14196. Frutescent, fl. bleuâtres. Mai-juin. C. Vulg. : Erva lonca. Passe pour ètre vénéneux.

\section{Fig. 81. - Primulacées.}

1. Anagallis arvensis L.; Fl. Bras. X, 261. - Restinga de Copa('abana, Iho-Jar.. nº 37. Herbacé, 11. roses. Février-mars. C.

2. A. tenclla L.; Fl. Bras. X, p. 262. - Itatiaia, dans le campo humide, côté du Rio Preto, Mıxas, nos 6705, 8895; Serra dos Orgãos, au 
sommet, Ru-Jax., nos 16299 , 17175. Herbacé, li. blanc rosé. Janviermars. CC.

3. Anagallis alternifolia Car.; Fl. Bras. X, p. 263. - Alto Hacahé de Nova Friburgo, pres de la riviere, Rio-Jan, nº 14190 a. Herbacé, ll. blanchitres. Décembre-janvier. C.

4. Centunculus pentandrus R. Br.; Fl. Bros. X, p. 264. - Entre Sitio et Barlacena, dans le campo humide, Mrsas, $n^{\circ}$ 11396; Serra do Alto Jlacahé, Piı-Jax., $n^{\circ}$ 14190. Herbacé, ll. blanchâtres. Décembrejanvier. C.

๖. Samolus subnudicaulis St. Hil.; Fl. Bras. X, p. 266. - Aruruoca, au Serro Frio, Minas, no 16299. Herlacé, fl. roses. Décembrejanvier. R.

\section{Fam. 82. - Myrsinacea.}

1. Rapanea Glazioviana . Mez in Pflanzenreich IV, p. 378. - Serra dos Orgãos, au Frade, Rio-JAx., $1^{\text {os }} 3640,6067,15190,17122$. Petit arbuste, li. rousses. Octobre-novenbre. C.

2. R. Schnackeana Mez in Pflanzenreich IV, p. 379. - Serra de Ouro Preto, dans le bois, Mrsas, $n^{0 \mathrm{~s}} 5928$, 15192. Arbrisseau, fl. rousses. Juin-juillet. C. Vulg. Capororoca.

3. R. villicaulis Mez. in Pflanzenreich IV, p. 379. - Entre Sitio et Barbacena, Minas, $n^{\circ} 11138$. Arbrisseau, f1. rousses. Juin-juillet. P.

4. R. ferruginea Mlez; Pflanzenreich IV, p. 381. Floresta da Tijuca, Corcovado, ete., Rio-Jax., $n^{\text {os }} 815,1026,1297,12065$. Arbrisseau, fl. rousses. Avril-juillet. CG. Vulg. : Capororoca.

5. R. paulensis Hez in Pflanzenreich IV, p. 38\%. - Floresta da Tijuca. Rio-Jav., nº 137. Arbrisseau, fl. rousses. Mai-juin. C. Vulg. : Capororoca.

6. R. Löfgrenii Hez in Pflanzenreich IT, p. 382. - Campo Bello. près du Rio Parahyba, Rio-JAx., no 5927 a. Arbrisseau, fl. rousses. Juin-juillet. C.

7. R. congesta Schw. mss.; Mez in Pflanzenreich IV, p. 383. Petropolis, au Norro Carangola, Rio-JAN., $\mathrm{n}^{\circ}$ 14044; Itacolumy, près Ouro Preto, Minas, no 15188. Petit arbuste, fl. rousses. Janvier-février. C.

8. R. villosissima llez; Pflanzenreirh IV, p. 383. - Campos da Botaina, S. Paulo, no 11139. Petit arbuste, 11. rousses. Février-mars. C.

9. R. parvula Hez in Pflanzenr. IV, p. 384. - Serra da Estrella, près Petropolis, Rı0-J Ax., nos 7739, 12067. Arbrisseau, fl. brunes. Janviermars. C. Vulg. : Mangue rosa. 
A.-F.-N. GLAZIOL. - LISTE LES PLANTES DL BRÉSIL CEXTRAL.

10. R. Gardneriana Vez; Pflanzenı. IV, p. 384. - Serra do Nito Macahé, Rio-Jas., no 19598. Arbrisseau, 11. rousses. Férrier-mar's. C.

11. R. umbellata Mez in Pflanzeni. IV. p. 384. - Corcorado, à Paineiras, Ro-Jax., no 11137. Arbrisseau, f1. rousses. Juin-juillet. C.

- Val. major Miq.; Fl. Bras. I, p. 3II. - Petropolis, à Santu Antonio el à Nora Friburgo, Rio-lAx.. nos 817, 5927, 7735, 7736, 11581 , 12066, 15193. Arbrisseau, 11. lousses. Juillet-septembre. CC. Yulg. : Capororoca.

12. R. lineata Mez in Pflanzenreich IV, p. 38\%. - Itatiaia, au Rio Preto, Mrsas, $n^{\circ}$ 8792; Alto Nacahé de Nova Friburgu, Rio-Jı., $n^{\circ s}$ 18347, 17690. Arbrisseau, 11. blanchàtres. Mars-arril. C. V'ulg. : Capororoca.

13. R. acuminata Nez in Pflanzenr. IV, p. 386. - Itatiaia, dans le bois, Rio-JAx., $11^{\circ}$ 4876. Arbrisseau, fl. rousses. Juin-juillet. R.

14. R. venosa Mez: Pflanzenr. IV, p. 386. - Floresta da Tijuca et Corcovado, Rio-Jıг, nos 736, 1294, 1296, 5926, 7737. Arbrisseau, fl. blanchàtıes. Мai-juin. CG.

10. R. lancifolia Mez; Pflanzenr. IV, p. 38T. - Sera dos Orgãos, Santo Antonio, près Petropolis, Nova Friburoo, Rio-JAx., nos 3638, 4072 , 7734, 11580, 15191 et 17123. Arbrisseau, fl. rousses. Mai-juillet. CC.

16. R. emarginella Mez; Planzenr. IV, p. 38s. - Serra dos Cristaes, près Diamantina, Mris, $n^{\circ}$ 19590. Arbuste, fl. rousses. Marsavril. R.

17. R. parvifolia Mez; Pflanzenr. IV, p. 389. - Ilha do Govelnador et Itapuca, Rio-Jsx., nº 8791. Arbuste, f1. brunes. Noremiredécembre. R.

18. R. oblonga Polıl; Pflanzent. IV, p. 189. - Restinga de Mauí et Floresta da Tijuca, Rio-J.x.. $n^{0 s}$ 75, 7738, 8220, 1I136. Arbrisseau, 11. blanchàtıes. Mai-juin. CC.

19. R. leuconeura Mez; Pfanzemreich IV, p. 389. - Serra de Alto Macahé, Riı-Jax., n 1298; Congonhas do Campo et Barlacena, Mrsas, $n^{\text {os }}$ 15194, 16236. Arbrisseau. fl. blanchâtres. Juin-juillet. C. Vulg.. : Caproroca.

20. R. ovalifolia Nez; Pflanzeneich IV, p. 391. - Nova Friburgo, au Conego, Rio-Jıx., n² 4072 a. Arbrisseau, f1. rousses. Janvier-mars. $R$.

2I. R. guyanensis Aubl.; Pflanzenreich IV, p. 392. - Restinga de Copacabana, Praia de Maria Angú, Rio-jix., nos 105, 1295 ; Sío Jocio d'El Rei, Mrxs, nos 15186, 16238, 17687; entre Paracatú et Serra 
dos Ciristaes, Gork\%, $n^{\circ}$ 21693. Mrbrisseau, fl. roses. Décenbre-février. C.C.

22. Rapanea glaucorubens Nez in P'llanzemeich IV, P. 394. - Restinga de Cabo Frio, lino-Jax., no 12929. Arbrissean, ll. rousses. Aoǹtseptembre. C.

23. R. la'tevirens Hez in Planzenreich IV, p. 39̋̈. - Petropolis, au Retiro, Rı-Jax., ${ }^{\circ}$ 19589. Arbrisseau, fl. rousses. Mars-avil.C. Vulg. : Caporoginha.

24. Cybianthus cuneifolius Mart.; Fl. Bras. X, p. 293. - Floresta da Tijuca et Corcovado, liro-J As., nos 842, 6632. Arbrisseau, f1. verdâtres. Octobre-novembre. C.

2:. C. angustifolius A. DC.; Fl. Bras. X, p. 294. - Serra dos Orgãos, à Bareira do Soberbo, Ruo-Jax., $n^{\circ \mathrm{s}} 1155,2877,11130$. Arbuste, fl. verdâtres. Lout-septembre. C.

26. C. nitidus Miq. in Fl. Bras. X, p. 295̆. - São Sebastiõo da Barla, Rio-Jax., $n^{\circ}$ 11131. Arbrisseau, fll. verdâtres. Janvier-février. R.

27. C. Schmackeanus Nez in Pflanzenreich IV, p. 22'. - Biribiry, près Diamantina, Mras, ${ }^{\circ}$ 19591. Arbuste, fl. brunes. Janvier-février. C.

28. C. densicomus Mart. in Fl. Bras. X, p. 293. - Itatiaia, dans le bois, hio-JAx., nº 6632 a. Arbuste, fl. brunes. Juin-juillet. R.

29. C. coriaceus Mart.; Fl. Bras. X, p. 29̋. - Petropolis, au Morro da Carangola, Rro-JAs., $n^{\text {os }} 14048$, 17120. Arbrisseau, fl. rousses. Novembre-décembre.-C.

30. C. Glaziovii Mez in Pflanzenreich 1V, p. 227. - Floresta da Tijuca et Serra dos Orgaos, Rio-Jas., n’s 895, 17121. Arbrisseau, f1. rousses. Avril-juillet. C.

31. C. detergens Mart.; Fl. Bras. X, p. 296. - Ouro Preto, Barbarena, Santa Luzia do Rio das Velhas, Mısas, $1^{\text {os }} 11134,12931,15184$, 20398 ; Ponte Alta, dans le campo, Goraz, $1^{\circ}$ 21694. Arbrisseau, fl. blanclıâtres. Juillet-octobre. C.C.

32. C. subspicatus Bentl. in Fl. Bras. X, p. 296. - São Sebastiĩo da Barra, Rı-JAx., nº 11135. Arbrisseau, fl. blanchâtres. Février-mars. R.

33. C. Boissieri A. DC.; Fl. Bras. X, p. 297. - Entre le Rio Paraopeba (Porto do Zeferino) et Porto Feliz, dans le cerrado, Goraz, no 21695. Arbrisseau, 11. jaunâtres. Octobre-novembre. R.

34. C. gracillimus Mez in P'flanzenreich IV, D. 224. - Serra do Couto, près Petropolis, Rro-Jax., n² 2961. Arbuste, ll. blanchâtres. Février-mars. R. 
A.-F.-M. GLAZIOU. - LISTE DES PLANTES DU BRÉLIL CENTRAL.

35. Weigeltia Gardneri A. DC. in Prodr. VIII, p. 115. - Alegre, près du ruisseau et Rio Uruhú, dans le cerrado, Gorız, nos 21696 , 21697. Arbuste, fl. blanchâtres. Octobre-norembre. C.

36. W. Glaziovii Mez in Pflanzemeich IV, p. 289. - Morro do Coco ou do Balı́, dans la capacira, Espirito-Saxto, n 11133 . Arbuste, f1. jaunàtres. Férrier-nars. C.

37. Conomorpha peruviana A. DC. in Pflanzenreich IV, p. 202. - Restinga de Mauá, Alto Macahé, Petrojolis, Rı-Jax., nos 8221, 14047, 17688, 17689. Arbrisseau, fl. blanchâtres. Avril-mai. CC.

38. Ardisia semicrenata Hart.; Fl. Bras. X, 1. 283. - Campos da Bocaina, dans le bois, Sä́ Paulo, $n^{\circ} 11132$. Arbuste, fl. blanchâtres. Février-mars. C.

39. Stylogyne ambigua Nez in P/lanzenreich IV, p. 266. - Limeira, au Fazenda do Morro Azul, São Paulo, no 12930. Arbuste, fl. orange. Mars-avril. C.

40. St. lavigata Nez in Pflanzenreich IV, p. 266. - Corcovado, à Paineiras, Rio-JAx., nos 1529, 15185. Arbuste, fl. blanc rougeatre. Aoùt-septembre. C.

41. St. cauliflora Mart. et 11 ; Mez in Pfanzenreich IV, 1. 276. Itapemirim, dans le bois, Espinito Sixto, $n^{\circ}$ 9921. Arbuste, fl. blanchâtres. Février-mars. R.

42. St. depauperata Mez in I/lanzenreich IV, p. 277. - Floresta da Tijuca, Serra da Estrella, Corcovado, Rio-JAx., nos 735, 4073, 6631, 14046. Arbuste, f1. blanchâtres. Novembre-décembre. C.

43. Clavija parviflora Benth? ex Traill in herb. Kewensi. - Quinta da Boa Vista, à S. Christovão, Rı-Jan., nº 8222 a. Arbuste cultivé, f1. blanchâtres. Aont-septembre. Ii.

4'4. C. Riedeliana Regel in Gartenflora (18:9), p. 245. - Praia Grande, à Jurujuba, près la mer, Rio-JAN., n ${ }^{0 s}$ 5929, 8222. Petit arluste. 11. jaunâtres. Aoît-septembre. C.

4.厃. G. Procopeana Glaz. n. sp.? in herb. Paris., Kew., Perol., Gener., etc. - Serra da Babylonia, près Juiz de Fora, Mıxas, n 3637. Arbuste sans fleur. En juillet. C.

46. Jacquinia brasiliensis Mez. in Engler Pflanz. IV, p. 3̈ (Théuphrastées). - Nldeia de São Pedro dos Indios, près Cabo Frio, Rio-JAx.. $\mathrm{n}^{\circ \mathrm{s}} 11140$, 12933. Arbrisseau, f1. blanchâtres, fruit jaune. Janvier-mars. C. Vulg. : Saputi Quiaba. 


\section{Fam. 83. - Sapolacées.}

1. Ecclinusa floribunda Pierre n. sp. in lerb. Mus. Paris., Berol., Kew., Gener, ete. - Nacacos, dans le campo pierreux, lio-Jax., n²1707. Plante naine, 11. rousses. Septembre-octobre. C.

2. E. ramiflora Mart. in Floru, 1838, p. 177. - Corcovado, à Paineiras, Rio-Jix., $n^{\text {os }}$ 4962, 6634, 7742, 20400. Grand arbre, fl. rousses. Octobre-novembre. CC. Vulg. : Guapeba, Aci.

3. E. costata Pierre, Notes Bol. Sapol., p. 56. - Restinga de Mauá, dans le sable, Rı-Jan,, nos 7744, 18352. Arbrisseau, fl. rousses. Octobre-novembre. CG. Vulg. : Gurtpéba.

4. E. Glaziovii Pierre, Notes Botaniques Supot., p. 56. - Itaborahy, dans les bois, Rio-Jax., nos 7743, 8229. Grand arbre, fl. rousses. Novembre-décembre. C. Vulg. : Gnapéba.

๖. Passaveria lanceolata Mart. et Eichl. (Ecclimusa) in Fl. Bras. VII, ґ. 86. - Itapemirim, Espirito Saxto, nº 11154. Arbuste, fl. jaunâtres. Février-mars. R.

6. Chrysophyllum januariense Eicht. in Warm. Symb. ad Fl. Bras., p. 250 . - Cosme Velho, à Larangeiras, Rio-Jan., nos 1055 , 2558. Grand arbre, fl. rousses. Janvier-février. C.

7. Ch. flexuosum Mart.; Fl. Bras. VII, p. 91. - Petropolis, Floresta da Tijuca, Corcovado, etc., Rio-JAx., nos 793, 1355, 2566, 17124, 19596. Grand arbre, fl. rousses. Mai-juillet. CC. Vulg. : Guaranhem.

8. Ch. elegans Raunk. in Warm. symb. ad Fl. Bras., p. 871. Entre Queimado et Rio d'Ouro, Rio-Jas., $n^{\text {os }}$ 9501, 11582. Petit ariore, ff. rousses. Février-mar's. C.

9. Ch. Cainito L.: Fl. Bras. VII, p. 94. - Quinta da Boa Vista, à S. Christovão, Rı-Jan., $n^{0}$ 7887. Arbrisseau cultivé, fl. rousses. Janviermats. C.

10. Ch. tomentosum Fr. Aflem. in Comm. Scient., p. 69, t. 20.-Quinta da Boa Vista, S. Christovĩo, Rı-Jax., no 11146 . Arbuste cultivé, li. rousses. Février-!nars. R.

11. Ch. monopyrenum Sw. var. microphylum Fl. Bras. VII, 1. 96. - Restinga de Cabo Frio, Rio-JAs., n ${ }^{0 s} 11147$, 11148. Arbuste. fl. rousses. Juin-juillet. C.

12. Ch. glycyphloum (Cassar.) ex Fr. Allem. in Comm. Scient. p. 60, Lab. 17. - Serra da Mendanha, près Campo Grande, Rio-JAN., n 19595. Grand arbre, Il. rousses. Octolire-novembre. C. Vulg. : Guaranhem. 
1.-F.-M. GLAZIOU. L LISTE DFS PLAYTES DE BRÉSIL CENTPAL.

13. Ch. Persicastrum Eichl. in Warm. symb. ad Fl. Bras., p. Lö6; Chr. cearense Fr. Allem. - São Pedro dos Indios, près Cabo Frio, Rio-JAx., nos 11143,11144 . Juin-juillet. C. Vulg. : Oiti brabo.

14. Ch. ebenacenm Mart. in Herb. Fl. Bras., 176 et in Warm. Symb. ad. Fl. Bras., 1. 25\%. - Petropolis, à Santo Antonio, Rı-Jax., nos 5930 , 8793. Arbuste, f1. rousses. Février-mars. C.

- Var. coxgrfoliur Mart. in Herb. Fl. Bras., p. 176. - Sete Pontes, au Baretto, Rio-J.s., n 8226. Arbuste, fl. rousses. Juin-juillet. C.

- Var. tomentosum Mart. in Herb. Fl. Bras., p. I76. - Bord du Rio Parahyba, Rı-Jax., nos 5930 a, 12936. Arbuste, fl. rousses. Juinjuillet. C.

1\%. Ch. maytenoides Hart.; Fl. Bras. VII, p. 101. - Entre Carandahy et Orueluz, llixas, $n^{\circ}$ 12069, 14054. Arbuste, fl. rousses. Juinjuillet. C.

16. Lucuma Bonplandii H. B. K.?; Fl. Bras. VII, p. 64. - Sete Pontes, au Barreto, Rı-JAx., nº 18355. Arbrisseau cultivé, sans fl. ni fruit. En juin.

17. L. meruocana F. Allem. in Commis. Scientif., p. ว̆̈. - Quinta de São Christorão, Rı-JAx., nos $11141,11145,11156$. Arbrisseau cultivé, fl. brunes, Janvier-férrier. C. Vulg. : Miú branco ou Maria preta.

1S. L. montana Fr. Nlem. in Commis. Scientific., p. ö3, t. 1'4. Quinta da Boa Vista, S. Christorão. Rı-JAx., nos 11153, 12073. Arbre, fl. rousses. Arril-mai. C.

19. L. minutiflora Fr. Allem. in Commis. Scientific., p. ت̈, t. 1'4. - Quinta da lioa Vista, S. Christovão, Rio-Jas., nos 11155, 12070, 2041. Arbrisseau cultiré, f1. rousses. Janvier-février. C.

20. L. marginata Ilart. et Eichl.; Fl. Bras. VIl, p. 67. - Praia de Piratininga et Gavea, près de la mer. Rio-Jax., nos 1292, 8227. Arbrisseau, fl. verdàtres. Juin-juillet. C.

21. L. Casaretti A. DC. ; Fl. Bras. VII, p. 69. - Restinga de Copacabana, de Mauá et de Tijuca, Rı-JAs., nos 4074, 6068, 6635. Aribrisseau, fl. verdâtres. Janvier-février. C.

22. L. Rivicoa Grertn.; Fl. Bras. VII, p. 71. - Sete l'ontes, au Baretto, Rio-Jax., n ${ }^{\text {os }} 11142,14051$ b, 14053. Arbrisseau cultivé, fl. rousses. Férrier-mars. C. Vulg. : Viti-tetuba.

23. L. procera Mart.; Fl. Bras. V'II, P. T2. - Entre Vista Chineza et Tijuca, Rio-JAx., n 12935 a. Grand arbre, fl. rousses. Mars-arril. C. Vulg. : Massaranduba bravo. 
- Var. cusprdata Miq. in Wilm. s'ymb., 1. 20'. - Floresta da Tijuca et all Corcovado, Rio-IAN., $n^{\circ 5} 210,17694$. Très grand arlore. C. Vulg. : Massarunduba.

24. Lucuma Glazioviana Pierre 11. sp.? in herb. Mus. Paris., Berol., Kew., Gener., ete. - Cova da Onça, au Corcovado et ì Tijuca, hio-dAx., $n^{0 s} 762,3050,8228$. Très grand arbre, fl. rousses. Octobrenovembre. C. Vulg. : Massaranduba.

23. L. rubicunda Pierre? in herl. Mus. Paris., Berol., Kew., Genev., etc. - Serra da Bica et Rio Tapixeiro, Rı-JAx., nos 753, 6716, 12938, 14057, 15198. Bel et grand arbre, fl. rousses. Janvier-février. C.

26. L. subcærulea Pierre in herb. Mus. Paris., Berul., Kew., Genev., etc. - Serra dos Cristaes, dans le campo, Goyaz, nº 21708. Frutescent, fl. rousses. Septembre-octobre. R.

27. L. nitida Pierre n. sp.? in herb. Mus. Paris., Berol., Kew., Gener., etc. - Entre Fornos et Meia Ponte, Goyaz, n² 21702. Grand arbre, 11. rousses. Septemlre-octohre. C.

28. L. torta A. DC. ; Fl. Bras. VII, p. 74. - Entre Inficionado et Caraęa, dans le campo, près Diamantina, Misas, nos 12937, 15197, 19607; Maria Panga, Goraz, no 21703. Arbrisseau, fl. rousses. Août-septembre. CG. Vulg. : Curiola.

99. L. dentata Pierre n. sp.? in herb. Nus. Paris, Kew., Berol. Gener., etc. - Rio Vaga Fogo, près Neia Ponte, Goraz, n² 21701. Très gr'and arbre, fl. verdâtres. Loùt-septembre. C.

30. L. minutiflora Pierre n. sp.? in herb. Mus. Paris., Kew., Berol., Genev., etc. - Bella Vista, au Barro Vermelho, Goyaz, n² 21700. Grand arbre, fl. roses. Aoùt-septembre. C.

31. L. ramiflora A. IC.; Fl. Bras. VII, p. 70े. - Entre Barreitas et Melancias et à Taboquinha, Nisss, $n^{08}$ 19603, 19608, 19609; Area, près Neia Ponte, Goinz, ${ }^{05}$ 21705, 21706. Grand arbre, fl. rousses. Juinjuillet. $\mathrm{CC}$.

- Var. lanceolata Pierre in herb. Mus. Paris., Berol., Kew., Genev, etc. - Area, dans le campo, Goraz, $n^{\circ}$ 21704. Arbrisseau, fl. rousses. Septembre-octobre. R.

32. L. catocladantha Eichl. in Warm. Symb. ad Fl. Bras. centr., 1. 2:30. - Serra de Antonio Pereira, près Ouro Preto, Misas, $n^{\circ} 16240$. Arbrisseau, fl. blanchâtres. Aoùt-septembre. G.

33. L. Gardneriana 1. DG.; Fl. Bras. VII, p. 76. - Arassuahy et au Tombador, près Diamantina, Mlsas, nos $14057 a, 15195,19600$. Arbrisseatu, fl. rousses. Janvier-férrier. C. 
A.-F.-M. GLAZIOU. - LISTE DES PLANTES DU BRÉSII. CENTRAL.

34. L. psammophila A. DC.: Fl. Bras. VII, p. 76. - Fazenda de Santa-Cruz et Copacabana, Rı-JıN., $1^{\text {os }}$ 87, 4961, 9502, 11152, 19602. Arbre, fl. rousses. Novembre-décembre. CC. Vulg. : Bapebussú et Oiti-bá.

3̋̈. L. nitida A. DC.; Fl. Bras. VII, p. 77. - Plaia do Harpoador, à Gaveá, Rio-Jax., no 18351. Arbrisseau, f1. rousses. Octobre-norembre. G.

36. L. Caimito A. DC.: Fl. Bras. VII, p. 79. - Paco Isabel, à Larangeiras, Rı-Jan., $n^{0} 11162$. Arbrisseau cultivé, f1. rousses. Févriermars. CC. Vulg. : Abieiro.

37. L. laurifolia A. DC. : Fl. Bras. V1I, p. 80. - Serra da Estrella, près Petropolis et Tijuca, Rio-Jax., nos 759, 760, 2635, 11583. Grand arbre, f:. brunes. Aoùt-septemlı'e. CC. Vulg. : Tapinhoa amarello.

- Var. reticulata A. DC. in herb. Ilus. Paris., Kew., Berol., Genev., etc. - Restinga de Maui, Rio-Jax., nos 77, 8232 et 18357 b. Arbrisseau, fi. rousses. Aout-septembre. C.

38. L. Beaurepairei Raunk. in Warm Symb. ad Fl. Bras. centr., p. 869. - Sete Pontes, au Baretto, Rio-Jav., nos 16241, 19599. Arbuste, fl. blanchàtres. Janvier-févirier. R. Vulg. : Batatá.

39. L. elegans Glaz. n. sp.? in herb. Paris., Berol., Kew., Genev., etc. - Estrada de Cachambú, à Petropolis, Rio-J $\mathrm{J}_{\mathrm{N}}, \mathrm{n}^{0} 17692$. Grand et bel arbre, sans fl. en octobre et décembre. C.

40. L. Moseniana Glaz. n. sp.? in herb. Paris., Berol., Kew., Gener., etc. - Floresta da Tijuca, Rio-Jax., no 12935 a. Grand arbre, 11. rousses. Nuvembre-rlécembre. R.

41. L. parviflora Benth. in Fl. Bras. VII, p. 81. - Restinga de Cabo Frio, Rio-Jax., $1^{\circ}$ 11149, 11150. Arbrisseau, fl. rousses. Juillet-septembre. CC. Vulg. : Bacomixa et Pitomba de leite.

4․․ L. macahensis Glaz. n. sp.? in herb. Paris., Berol., Kew., Genev, etc. - Serı do Alto Macahé, Rio-Jax., nº 18353. Arbrisseau, fl. rousses, Janvier-février. R.

43. L. petropolitana Glaz. II. sp.? in herb. Paris., Berol., Kew., Gener., etc. - Petropolis, Estrada de Cachambú, Rı-Jav., nos 8225 , 17693. Arbrisseau sans fl. en octobre et en décembre. C.

44. L. Sellonii A. DC.; Fl, Bras. VII, p. 84. - Santa Barbara, dans le bois, Mixas, nº 19604. Arbuste, fl. lousses. Janvier-mar's. C.

4.. L. neriifolia Hook. et Am.; Fl. Bras. VII, p. 85. - Serra dos Orgãos et liio d'Ouro, Rı-Jax., $11^{05} 2924,8900,11196$. Arbuste, fl. hlanchâtres. Aoùt-septemlıre. C. 
40. Pradosia glycyphloca Liais in Climal. Geolog. du Brésil, p. (ili.) - Praia Grande, à learahy, Rı--das., $1^{\text {os }} 6835,8467,20403$. Grand arbre. 11. brunes. Juin-octobre. C. Vulg. : Jamminha de porco, Bacuri.

'T. Martiusella imperialis Pierre in Noles Bolaniques Sapol., p. 66. - Serra da Estrellal ef de Nova Friburgo, Rio-Jas., ${ }^{\text {os }} 6633$, $7745,8230,11163$ et 20402. Frand arbre, fl. blanchâtres. Novembredécemlire. C.

48. Sapota Achras Vill.; Flora Bras. VII, p. 58. - Quinta da Boa Vista, S. Christorão, Rı-Jan., $1^{\circ}$ 12072. Arbrisseau cultivé, fl. rousses. Norembre-décembre. CC. Vulg. : Saputi.

49. S. gonocarpa Nart. et Eichl. in Fl. Bras. VII, p. 60. Menulanha et Pinheiro, près Diamantina, Mısas, $n^{\text {os }} 8223 a$, 19610. Arbrisseau, fl. blanchàtres. Janvier-mar's.

:0. Sideroxylon venulosum Mart. et Eichl. in Fl. Bras. VII, p. ̋2. - Calo Frio, dans le bois, Rio-Jax., $\mathrm{n}^{\circ} 14050$ a. Grand arbre, 11. rousses. Loût-septembre. R.

¿1. S. parvifolium Raunk, in Wäm. Symb Flor. Bras., p. 4. S. João Baptista, dans le campo, Mıxas, $n^{\circ}$ 15196. Arbuste, fl. rousses. Août-septembre. C.

32. S. Saldanhæi Glaz. n. sp. in herb. Paris., Perol., Kew., Gener., ete. - Cosme Velhlo, à Larangeiras, Rio-dax., $n^{\circ}$ 18348. Grand arbre, fl. rousses. Juin-juillet. R.

อั3. S. Eichlerii Pierre n. sp. in herb. Paris., Berol., Kew., Gener., etc. - São Pedro dos Indios, près Cabo Frio, Rı-Jav., nº 12068. Arbrisseau, 11. rousses. Aoùt-septembre. R.

5̆4. S. cuspidatum DC.; Fl. Brus. VII, p. כ̌s. - Corcovado, à Paineiras, Rio-JAx., $n^{\text {os }} 9505$, 19598. Grand arbre, fl. rousses. Juinjuillet. C.

3\%. S. cyrtobotryum Mart. in Fl. Bras. VII, P. 37. - Quinta da Boa Vista, S. Christovão, Rı-JAx., nº 14050. Arbrisseau cultivé, fl. blanchâtres. Mai-juin. R.

56. S. elegans DG.; Fl. Bras. VII, p. 54. - Passeio Publico, RuJAx., $n^{\circ} 14050 a$. Arbrisseau cultivé, fl. brunes. Norembre-décembre. R.

57. Bumelia Sartorum Mart.; Fl. Bras. VII, p. 46. - S. Christovão, près la mer, Rio-J $\mathrm{JN}_{\mathrm{N}}, \mathrm{n}^{\text {os }} 11159,11160,18349,18350,19606$. Arbrisseau, fl. blanchâtres. Aoùt-septembre. CC. Vulg. : Rompe gibão.

:8. B. obtusifolia R. et S.; Fl. Bras. VII, p. 47. - Alto Macahé et 
A.-F.-M. GLAZIOC. - LASTE dEs PlaNTES dU BRÉsll CENTRAL.

Cabo Frio, Rı-Jax., $1^{\text {os }}$ 2901, 12934, 19605. Arbrisseau, fl. blanchâtres. Septembre-octobre. C.

- Var. buxifolia in herb. Paris., Berol., Kew., ete. - Maruin, à Praia Grande, Riı-Jax., n 4075. - Arbrisseau, fl. blanchầtres. Aoùtseptembre. R.

99. Micropholis Glazioviana Pierre in Urb. Symb. Antill. V, p. 1⒏8. - Restinga de Mauá, dans les sables, Rı-Jan., $1^{\text {os }} 8224,8466$. Arbrisseau, 11. rousses. Juin-juillet. C.

60. M. Gardneriana Pierre in Urb. Symb. Antill. V, p. 128. Caminlıo do Macaco, entre Lagoa de Fretas et Tijuca, Rı-Jax, nos 7741, 9504. Très grand arbre, fl. rousses. Octobre-novenubre. C. Vulg. : Bacomixa.

61. M. linoneura Pierre in Urb. Symb. Antill. V, p. 129. - Quinta da Boa Vistal, S. Christorão, Rı-JAx., $n^{\circ}$ 14051. Arbrisseau eullivé, fl. rousses. Juin-juillet. R.

62. Micropholis cuneata Pierre in herb. Ius. Paris., Kew., Berol., Genev, ete. - Petropolis et Alto Macahé, Riro-Jax., nº 14056. Très graud arbre, fl. rousses. Janvier-février. R.

63. M. grandifolia Pierre n. sp.? in herb. Hus. Paris., Kew., Berol., Genev., etc. - Guariroba, aux bords des rivières; Goyaz, n 21698 . Grand arbre, fl. rousses. Octohre-novembre. C.

6'. M. compta Pierre n. sp. in lierb. Hus. Paris., Kew., Berol,, Gener.. etc. - Alto llacalıé de Nova Frilourgo, Rı-Jax., nº 17691. Grand arbre. 11. rousses. Février-mars. R.

6ว̆. M. rigida Pierre n. sp. in herb. Mus. Paris., Kew., Berol., Gener., etc. - Guariroba, près des rivières, Goraz, $n^{0}$ 21699. Grand arbre, tl. rousses. Novembre-décembre. R.

66. Fibrocentrum Glaziovianum Pierre n. sp. in herb. Nus. Paris., Kew., Berol., Gener., etc. - Serra dos Orgãos et Alto Macalıé, Rio-J $J_{A x}, n^{\circ s} 8223,18354,19597$. Grand arbre, fl. rousses. Octobrenovembre. C.

67. Mimusops elata F. Allem.; Fl. Bras. VII, p. 42. - Serrä da Estrella, près Petropolis, Rio-Jan., $n^{0 s} 11151,12071$. Grand et bel arbre, 11. rousses. Mars-mai. C. Vulg. : Vassaranduba.

6S. M. triflora F. Altem. in Commis. Scientific., p. 50, t. 13. Quinta da Boa Vista, S. Christovão, Rio-Jax., no 11157. Arbrissean cultivé, fl. rousses. Aout-septembre. Ri.

69. M. Salimanni 1. DC.; Fl. Bras. VII, p. 43. - Quinta da Boa 
Vista, ‥ Cilıistovito, Riı-JAx., 11 11158. Arbrisseau cultivé, ll. rousses. Aoirt-septembre. (i. Vulg. : Massarandubu.

70. Mimusops zufula Miq. ?; Fl. Bras. VII, p. 44. - Quinta da Bua Vista, S. Clinistovio, Rı-Jax., no 1293 a. Arbrisseau cultivé, fl. rousses. Septemlre-octobre. C. Vulg. : Massanraduba.

71. M. subsericea Mart.; Fl. Bras. VII, p. 414. - Copacabana. Gavea, Floresta da Tijuca, Rio-JAx., nos 45, 1293, 1547, 3781. Arbrissean, II. rousses. Aout-septembre. CC.

- Var. Massaranduba Pierre in herb. Mus. Paris. - Imbetiba, près de la mer, Rı-JAx., nº 18357 a. Arbrisseau, fl. rousses. Aoùt-septembre. C. Vulg. : Massaranduba.

- Var. acuminata Pierre in lierb. Mus. Paris. - Sete Pontes, au Barreto, Kio-JAN., nos 9503, 18357. Arbrisseau cultivé, fl. rousses. Aoùtseptembre. R. Vulg. : Massiranduba da Bahia.

72. M. Elengi L. Sp. Plant., p. 349. - Quinta da Boa Vista, S. Christorão, Rio-Jan., no 16242. Arbrisseau cultivé, 11. rousses. Févriermars. C.

73. M. floribunda Mart.; Fl. Bras. VII, p. 19. - Restinga de Cabo Frio, près de la mer, Rio-Jax., nos 757, 19593. Arbrisseau, fl. rousses. Aotit-septembre. C. Vulg. Massaranduba da Praia.

74. M. coriacea Niri. : Fl. Bras. VII, p. 44. - Passeio Publico, RioJan., $n^{0} 11161$. Arbuste cultivé, fl. rousses. Janvier-février. C. Vulg. : Abricú.

79. Imbricaria Thouarsii H. Baill. in herb. Mus. Paris. - Lagoa Rodrigo de Freitas, au Jard. Bot., Ro-Jax., ñ 18356. Arbrisseau cultivé, sans fleur en avril. R.

76. Podoluma Glaziovii H. Baill. in herb. Mus. Paris., Kew., Berol., Gener., etc. - Caminho do Hacaco, à Vista Chineza, Rı-Jas., nos 128 , 12935, 16239. Grand arbre, fl. rousses. Novembre-décembre. R.

\section{Fam. 84. - Ebénacées.}

1. Diospyros sericea DC.; Fl. Bras. VII, p. 3. - Barbacena, Queluz, Serra do Cipó, Wixas, $11^{\text {os }}$ 9606, 9616, 10227, 14058, 18849, Abbade, près Meia Ponte, Goraz, no 21710. Arbrisseau, f1. rousses. Juillet-septembre. CG.

2. D. hispida A. DC.; Fl. Bras. VII, p. 4. - Estrada vella do Porto de Jequitiba, Mınas, $11^{\circ}$ 20407. Arbrisseau, fl. rousses. Novembredécenbre. C. 
1.-F,-I. GLAZ1OU. - LISTE DES PLANTES DU BRÉsil CENTRAL.

3. D. minensis Glaz. n. sp.? in herb. Paris., Berol., Kew., Gener., etc. - Entre Sitio et Barbacena, Mras, n 14052. Arbrisseau, fl. et fruits rerdatres. Norembre-décembre. C.

4. D. velutina Hiern in Trans. Camb. Phil. Soc. XII (1873), p. 200. Entre São Pedro dos Indios et Araruama, Rio-Jav., no 11172. Arbrisseau, fl. verdâtres. Juin-juillet. Vulg. : Araça linga. C.

Э. D. brasiliensis Mart. in Fl. Bras. VII, p. ั.. - Petropolis, à Santo Antonio, Ru-Jax., nos 7748 , 11164. Arbrisseau, fl. rousses. Juilletseptembre. C.

6. D. Burchellii Hiern in Journ. of Bot. XII (1874), p. 240. Arraial de Ouro Branco, Serra do Lenfleiro, Misss, $1^{05}$ 15199, 17128; Serra dos Pyreneos, Goyaz, $1^{\circ}$ 21709. Arlurisseau, fl. rousses. Octobrenovembre. C.

7. D. Ebchum Kien. in Phys. Salsk. Hand., 1, p. 176. - Serra de N. Friburgo, à Boca do Matto, Rio-JAx., nos 7746, 16243. Arlore, f1. verdàtres. Novembre. R.

8. D. Sapota Roxb. Hort. Beng., 40 : Fl. Ind. II, p. 53ò. - Quinta da Boa Vista, S. Christorão, Rio-JAx., n 7747. Arbre cultivé, fl. rerdâtres. Septembre-octobre. C.

9. D. Embryopteris Pers. in Rheede Hort. Malab. III, p. 41. Quinta da Boa Vista, S. Christovão, Rı-JAx., $11^{\circ} 7747$ a. Arbrisseau cultivé, ll. verdàtres. Septembre-octobre. R.

10. D. discolor Willd. Species Plant. IV, p. H08. - Passeio Publico, Rro-JAx., nos 1560,1561 . Grand arbre cultivé, fl. blanchâtres. toût-septembre. C.

11. Macreightia obovata Iart. Fl. Bras. VII, p. 9. - Serra de Ouro Branco, dans le campo, Mrxas, $\mathrm{n}^{\circ \mathrm{s}} 11173,15200$; Imbetiba, près Nacahé, Rio-JAx., $11^{\circ}$ 19613. Arbuste, fl. rousses. Novembre-tlécembre. CG.

\section{Fam. 8.. - Styracacées.}

1. Symplocos insignis Brand in Pflanz., p. 27- - Serra do Picú, au Palmital, Minas, no 11597. Arbrisseau, fl. blanchattres. Mars-avril. C.

2. S. phacoclados DG.; Fl. Bras. VII, p. 32. - Rodrigo Silva, au Capão près Ouro Preto, Mısas, n 18984. Arbuste, fl. blanches. Avrilmai. C.

3. S. vermucosa Br. in I'llanzenreich, p. 297. - Rodrigo Silva, au Capão près Ouro Preto, Muxis, no $18984 a$. Arbrisseau fl. blanches. Mar'sarril. C. 
4. Symplocos celastrinea Mart. Fl. Bras. VII, p. 31. - Itacolumy, près Ouro Preto. Misas, $n^{\circ}$ 18195. Arbuste, 1l. blanches. Avril-mai. C. Vulg: Congonha.

".. S. dasyphylla Br. in Pflanzenreich, p. 27. - Serra dos Orgàos et Morro Cubiçado, près Petropolis, Rio-Jan., $n^{\text {os }} 10483$, 16745. Arbuste, 11. blanclıes. Novembre-décembre Ci.

6. S. tetrandra Mart.; Fl. Bras. Vll, p. 33. - Alto Macahé et Nova Friburgo, Rio-Jav., ${ }^{0 s}$ 17236, 19619. Arbrisseau, fl. blanches. Mai-juillet. C.

7. S. firondosa Br. in Pflanzenreich, p. 28. - Concevado, Lagoninha dos Porcos, Rio-JAN., nº 1282. Arbre, fl. blanches. Juin-juillet. R.

8. S. variabilis Mart. in Fl. Bras. Vll, p. 30. - Corcovado, Petropolis, Magé, Alto Nacahé, etc., Rı-JAx., nos 6669, 6809, 8574, 11596, 15204, 18196, 18358, 19621 ; Guariroba, Goyaz, n² 21712. Arbrisseau, f1. blanclies. Avril-ınai. CC.

9. S. rhamnifolia A. DC. Fl. Bras. VII, p. 32. - Chapadño dos Veadeiros ou de Porto Seguro. Goraz, no 21711. Arbrisseau torlueux, fl. blanches. Janvier-février. C. Vulg. : Congonha.

10. S. lanceoluta A. DC. Fl. Bras. VII, 29. - Entre Sĩo Vicente et Sĩo Bartholomeu, dans le campo, Misas, $n^{05}$ 14528, 16246. Arbuste, fi. blanches. Juin-juillet. C. Vulg. : Congonha.

- Var. integerima Mart. in Fl. Bras. ViI, p. 30. - Itatiaia et Fazenda do Taquaral, Mınas, $1^{05}$ 6588, 7577; Campos da Bocaina, S. Paulo, $n^{\circ}$ 11168. Arbuste, fl. blanches. Aout-septembre. C.

- Var. angustifolia an. sp. nova? in herb. Paris., kew., Berol., Genev. Brux., etc. - Serra dos Cristaes près Diamantina, Mıxas, $\mathrm{n}^{\circ}$ 19620. Arbuste, f1. verdàtres. Avril-mai. R.

11. S. Itatiaia Wawr. in I'flanzenreich, p. 29. - Serra dos Orgãos, au Frade, Rio-J $\mathrm{JN}_{\mathrm{A}}$, $\mathrm{n}^{\text {s }}$ 3731, 6195. Arluste, f1. blanches. Octobrenovembre. C.

12. S. revoluta A. DC.; Fl. Bras. VII, p. 31. - Itacolumy, près Ouro Preto, Misas, $n^{\circ} 18195$ a. Arlurisseau, fl. blanches. Juin-juillet. C.

13. S. commutata Br. in P/lanzenreich, p. 82. - Cãraça, au Morro do Inficionado, Misas, $n^{\circ}$ 15205. Grand arbre, fl. blanches. Juin-juillet. C.

14. S. distans Br. in Plansenreich, p. 82. - Caraça, au Campo de Fora, Misas, $n^{\circ}$ 14060. Arbrisseau, fl. lilanclies. Octobre-novembre. C.

1.. S. agrota Brand in I'flanzenreich, p. 71. - Nova Friburgo, Floresta da Tijuca et Petropolis, Rro-Jas., nos $15203,17129,17696$. Arbrisseau, fl. rousses. Octobre-novembre. CC. 
A.-F.-M. GLAZIOU. - LiSTE dEs plantes dU BRÉsIl CeNTRAL.

16. S. altissima Brand in Pflansenreich, p. Tl. - Alto Nacalıé de Nova Friburgo, Rio-JAN., $1{ }^{\circ 5} 18347$ a et 19618. Grand arbre, fl. rousses. Octohre-novembre. C.

17. S. ascendens Br. in Pflanzenreich, p. 71. - Alto Macahé de Nova Friburgo, Rio-Jav., $\mathrm{n}^{\circ}$ 20212. Grand arbre, fl. rousses. Octobre-novembre. C.

18. S. falcata Brand in Pflanzenreich, p. 71. - Serra do Alto Wacahé, Rro-Jax., $\mathrm{n}^{\circ}$ 17473. Grand arbre, 11. rousses, Octobre-novembre. R.

19. S. densiflora Br. in Pflanzenreich, p. 71. - Rancho do Morro Gavado, Misas, $11^{\circ}$ 7769. Arbre, fl. rousses. Septenbre-octobre. G.

- Var. minor Brand in Pflanzenreich, p. 71. - Haut Itatiaia, dans le bois, Rio-Jan., nos 6695,11167 . Arbre, fl. rousses. Janvier-février. C.

20. S. tenuifolia Br. in Pflanzenreich, p. 71. - Alto da Serra dos Orgãos, Rı-J Jas., n ${ }^{\circ} 3731$ a. Arbrisseau, fl. rousses. Mai-juin. R.

21. S. corymboclados Br. in Pflansenreich, 72. - Alto Nacahé de Nova Friburgo, Rio-Jan., $\mathrm{n}^{0}$ 18359. Arbre, fl. blanchâtres. Septembreoctobre. G.

22. S. organensis Br. in Pflanzenreich, p. 72. - Alto da Serra dos Orgĩos, Rio-J Jav., nos 3641, 6023, 15202, 17130. Arbuste, fl. blanches. Octobre-novembre. C.

23. S. Glaziovii Brand in Pflanzenreich, p. 73. - Serra do Alto Macahé, Rio-Jav., nº 13469. Arbuste, fl. rousses. Octobre-novembre. C.

24. S. angulata Brand in Pflanzenreich, p. 73. - Morro do Inficionado à Caraça, Nrvas, $1^{\circ}$ 15189. Petit arbuste, fl. blanchâtres. Juinjuillet. R.

23. S. hirtella Brand in Pflanzenreich, p. 78. - Alto Macahé de Nova Friburgo, Rio-JAN., no 11169. Arbrisseau, fl. rousses. Novembredécembre, R.

26. S. Sellowiana Brand in Pflanzenreich, p. 81. - Cachoeira do Campo, Mrsas, n² 20404 a. Arbrisseau, fl. rousses. Novembre-décembre. C.

27. S. pubescens Klotzsch var. нuмn.rs Brand Pflanzenreich, p. 84. Entre Sitio et Barbacena, Cachoeira do Campo, Misas, nos 16244, 20404; Lagoa do Mestre d'Armas, Goyaz, n 21714. Arbrisseau, 11. blanchâtres. Décembre-janvier. CG.

28. S. laxiflora Benth.; Pflanzenreich, p. 8ə̌. - Floresta da 


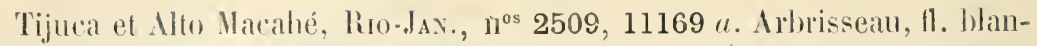
ches. Hécembre-janvier. C.

29. S;-mplocos fallax Brand in Pflanzenteich, p. S6. - Sĩo lïlelis, près Campos, Rio-Jar., $11^{03}$ 10473, 11170. Arhuste, fo. rousses. JanvierPévrier. R.

30. S. nitens Bentlı. Fl. Bras. VIl, 24. - Serras do Lenheiro et da Piedade, Misas, nos 15206, 16245, 20405; Fazenda dos Pyreneus, Goraz, n²1713. Grand arbre, fl. blanches. Aout-septembre. GG.

31. Styrax glabratum Spr.; Fl. Bras. VII, p. 187. - Campos da Bocaina, dans le bois, Säo-Pauro, $n^{\circ} 11166$ a. Arbrisseau, fl. blanches. Aoùt-septembre. R.

32. S. leprosum Hook et Arn.; Fl. Bras. VII, p. 188. - Campos da Bocaina, S. Paclo, no 11166 : Biribiry près Diamantina, Mhas, $n^{\text {os }}$ 19617, 19617 a. Arbrisseau, fl. Blanches. Mars-avril. C.

33. S. varians Stend.; Fl. Bras. VI, p. 189. - Cumpos da Bocaina, S. Paulo, $1^{\circ} 11171$; Serra de Ouro Branco, Mrasas, $n^{\circ}$ 15210. Arbrisseau, 11. Wanches. Septembre-octobre. C. Vulg. : Pao Santo.

34. S. Gardnerianum DC.; Fl. Bras. VII, 1) 189. - Chico Lobo, près des rivières, Goyaz, $n^{\circ}$ 21715. Grand arbre, fl. blanches. Octobrenovembre. C.

35. St. camporum Pohl; Fl. Bras. VII, p. 190. - São Fidelis, près Campos, Rion-Jas., no 10069; Caraça, dans le Campo, Jisas, no 14059 a. Grand albre, ft. blanches. Janvier-févier. C.

36. St. urophyllum Gilg n. sp. in herb. Paris., Berol., kew., etc. Santa Luzia do Rio dos Velhas, Mixas, $n^{0}$ 20406. Grand arbre. 11. blanches. Octobre-novembre. R.

37. St. acuminatum Pohl; Fl. Bras. VII, p. 190. - Floresta da Tijuca, Rio-Jax., nos 3784,7768 . Grand arbre, fl. blanches. Septembreoctobre. C.

35. St. neryosum A. DC.; Fl. Bras. VII, p. 191. - Serra do Lenheiro, Minas, $n^{\text {os }} 17126,19616 a, 21717$. Grand arbre, fl. blanches. Marsavril. C.

39. St. parvifolium Pohl; Fl. Bras. VII, p. 192. - Alegria, près Garaça, Mıvıs, nos 15208, 19616. Arhrisseau, Il. blanches. Juin-juillet. C.

40. St. punctatum A. DC. Fl. Bras. VII, p. 192. - Entre Sĩo Vicente et Sĩo Bartholonıeu, Mıvas, $1^{\circ}$ 15207. Arbrisseau, fl. blanches. Juin-juillet. C.

41. St. barbarossa Gilg n. sp. in herb. Paris., Berol., Kew., 
Gener, ete. - Entre Sourdo et Heia Ponte, Govaz, ${ }^{\circ}$ 21716. Arlorisseau, fl. blanches. Juin-juillet. C.

42. St. ambigmum Seub. in Fl. Bras. VII, p. 192. - Carara, au Campo de Fora, Mrss, $11^{\circ}$ 15209. Arbre, fl. blanclies. Juin-juillet. R.

43. St. Pohlii A. DG.; Fl. Bras. VIl, p. 193. - Fazenda de Cachambi, pres Petropolis, Rio-JAx., nos 5931, 7767. Grand arbre, fl. hanches. Norembre-décemlre. C.

44. St. Martii Seul. in Fl. Bras. VII, 1. 191. - Serra dos Orgĩos, par Cachambu, Ro-Jıx, nos 16147,17127 . Grand arbre, fl. blanches. Janvier-mars. CG.

- Var. gracinus Wam. in Symb. p. 466. - Alto da Pedra Bonita, Rı-dix, $n^{\text {os }}$ 2678, 3051. Arbrissean, ft. blanches. Frivrier-mars. C.

43. Pamphilia anreu Mart. Fl. Bras. VII, p. 18\%. - Perpetua, pres Diamantina. Mixas, $10^{0 s} 19614$, 19615. Arbuste, th. Blanches. Marsarril.

46. P. styracifolia DC.; Fl. Bras. VII, p. 186. - Serra ditabira do Canpo, Mixss, n 17125. Arbrisseau, fl. Banches. Août-septembre. C.

47. Diclidanthera lanrifolia Mart. Fl. Bras. VII, p. 12. - Floresta da Tijuca, Morro da Viraça, Gavea, entre Queimado et Rio douro. R1o-Jix., n! $123,819,7801,9923,11165$. Arbuste rougeâtre. Loùtseptembre. CC.

\section{Tim 86. - Oléacées.}

1. Jasminum pubescens Willd. : Fl. Bras. VI, I, ן. 3I\%). - Duinta da Bua Vista, S. Christovio, Rro-dxx., $n^{0} 11584$. Arbuste cultiré, fl. blanches, Juin-juillet. C.

2. J. azoricum L.; Fl. Bras. VI, 1, 1. 318̈. - Engenho Novo, RoJax., $1^{\circ}$ 4877. Arbuste sarmenteux cultivé, lit. blanches. Octobre-norembre. C. Vulg. : Jasmin.

3. J. humile L. SP.Pl., p. 9. - Passeio Publico, Ru-Jır., $11^{0} 11585$. Irbuste cultivé, fl. jaunes. Juin-jnillet. (c. Vulg. : Jasmin.

4. Nyctanthes Arbor-tristis L.; Fl. Biras. VI, I, p. 317. - Passirio Publico, Ro-Jax., no 5932. Arbuste cultivé, fl. banches. Arril-mai. C.

8. Ininociera crassifolia Ilart.; Fl. Bras. VI, I, P. 307. - Nlto Macahé de Nova Friburgo, Ruo-dıx, $1^{\circ} 18360$; Serra de Cabelleiro, Govaz, no 20821. Arbuste, fl. blanches. Juillet-seplembre. C.

6. L. Glaziovii Gilg in Engler Botun. Jarhb. XXI (159s). Beihl, 
p. 33. - Serra dos Pyreneos et Cassú, Goraz, $11^{\text {os }} 20822,20822$ a. Arluste, fl. blanches. Aoùt-septembre. R.

7. Linociera ferruginea Gilg in Engler Botan. Jahrl. loc. cit., p. 33. - Biribiry, près Diamantina, Mıvas, ${ }^{\circ}$ 20214. Arbuste, fl. blanchattres. Février-mar's. R.

8. S. arborea Eichl. in Fl. Bras. VI, I, p. 308. - Serra da Rocaina, S. Paulo, $n^{\circ}$ 12074. Arbrisseau, fl. blanches. Février-mar's. C. Vulg. : Limeira.

9. L. mandiocana Glaz. 11. sp.? in herb. Paris., Berol., Kew., Gener., etc. - Serra da Estrella, à Mandioca, Rı-JAx., $n^{\circ} 13567$. Grand arbre, f1. blanchâtres. Janvier-février. R.

10. Tessarandra fluminensis Niers: Fl. Bras. Vl, I, p. 30\%.Morro do Flemengo, à Botafogo, Rio-JAx., $\mathrm{n}^{0.3}$ 3677, 4162, 4932. Arbuste, fi. blanches. Avril-mai. C.

11. Ligustrum japonicum Maxim. in Bull. Acad. Petersb. XIX (1874), p. 270. - Petropolis, dans les jardins, Rio-JAN., $n^{\circ} 11588$. Arbuste cultivé, f1. blanches. Janvier-février. G.

\section{Fam. 87. - Apocynacées.}

1. Allamanda cathartica L.; Fl. Bras. VI, I, p. i0. - Quinta da Boa Vista, S. Christorão, Rı-JAx., no 12945 a. Arbuste cultivé, ft. jannes. Février-avril. C. Vulg. : Purga de 4 patacas.

2. A. Schottii Pohl; Fl. Bras. VI, I, p. 13. - Passeio Publico, Rio-Jas., no 1018. Arluuste cultivé, Il. jaunes. Février-mars. CC.

3. A. puberula A.DC.; Fl. Bras. VI, I, p. 14. - Quinta da Boa Vista, à S. Christovĩo, Rı-JAx., n ${ }^{\circ}$ 12945. Arbuste cultivé, fl. jaunes. Février-mars. C.

4. A. angustifolia Pohl; Fl. Bras. VI, I, p. 13̈. - Serra da Baliza, dans le campo, Goraz, no 21734. Arbuste, f1. jaunes. Janvier-mars. R.

5. Hancornia speciosa Müll. Arg. Fl. Bras. VI, I, p. 24. - Aldeia de S. Pedro do Indios, près Caho Frio, Rio-Jav., nis 11186,12956 ; S. João d'El Rei, Minas, $1^{\circ}$ 12947. Arbrisseau, fl. blanches. Marsavril. CG. Vulg. : Mangabeira.

- Var. pubescess. Müll. Arg. in Fl. Bras. VI, I, p. Q:. - Guariroba, au Morro Cubatĩo, Goyaz, n 21735. Arbrisseau, fl, blanches. Septembre-octobre. C. Vulg. : Nangabeira.

6. $\boldsymbol{H}$. fluminensis Glaz. n. sp.? in herb. Paris., Berol., kew., 
Genev., etc. - Restinga de Cabo Frio, près de la mer, Rio-Jıx., $\mathrm{n}^{\circ}$ 12946. Arbuste, fl. blanc jaunâtre. C.

7. Couma utilis Müll. Arg. in Fl. Bras. VI, I, p. 19. - Quinta da Boa Vista, à S. Christovão, Rı-Jax., nos 14081, 19629. Arbre cultivé, 11. blanches. Avril-mai. R. Vulg. : Sorva.

8. Ambelania macrophylla Miill. Arg. in Fl. Bras. VI. I, p. 18. Quinta da Boa Vista, São Cbristovĩo, Rio-JAs., no 14078. Arlrisseau cultivé, fl. blanches. Janvier-février. R. Vulg. : Pepino do malto.

9. A. camporum Glaz. n. sp.? in herb. Paris., Berol., Kew., Genev., etc. - Entre Barbacena et Queluz, dans le campo, Misas, $n^{\circ}$ 15222. Frutescent, Il. jaunàtres. Octobre-novembre. C.

10. Zschokkea gracilis Miill. Arg. in Fl. Bras. Vl, I, p. 2I. Passeio Publico, Rio-IAx., $\mathrm{n}^{0}$ 14079. Arbrisseau cultivé, fl. jaunes. Juin-juillet. R. Vulg. : Jacataca.

11. Z. arborescens Müll. Arg. in Fl. Bras. VI, I, p. 22. - Quinta da Boa Vista, S. Clıristovão, Rı-Jax., nº 14083. Arbrisseau cultivé, 11. verdîtres. Mai-juin. R. Vulg. : Apui.

12. Rauwolfia Blanchetii A. DC.; Fl. Bras. VI, I, p. 30. - Itapemirim, Esprito Santo, $n^{\circ}$ 11183. Arbuste, f1. blanchâtres. Févilermars.

13. R. paucifolia A. DC.; Fl. Bras. VI, I, 31. - Serra de Itabapoana, Espmito Santo, $\mathrm{n}^{\circ}$ 11182. Arbuste, fl. blanches. Septembreoctolse. R.

14. R. affinis Müll. Arg. in Fl. Bras. VI, I, p. 3't. - Serra dos Orgãos, Corcovado, Floresta da Tijuca, liı--l木x., $1^{\circ-} 639,2915,6045$, 7751. Arbrisseau, 11. blanches. Septembre-octobre. C.

1̋. Thevetia neriffolia Juss.; Fl. Bras. VI, I, p. 26. - Entre Cabo Frio et Aldeia de São Pedro dos Indios, Rio Jax., nos 12958, 18361. Arbrisseau, fl. jaunâtres. Aoùt-septembre C.

16. Condylocarpon Raunolfia A. DG.; Fl. Bras. VI, I, p. 64. Gavea, Pétropolis, Nova Friburgo, Rı-Jav., nos 7758, 7866, 15223 ; Abacté dans le bois, Goraz, n 21730. Irbuste sarmenteux, fl. jaunâtres. Septembre-octobre. CC.

17. C. isthmicum A. DC.: Fl. Bras. VI, I, p. 67. - Larangeiras, au Cosme Velho, Rio-Jax., $n^{0 s} 4081,13470$. Albuste sarmenteux, 17. blanchâtres. Novembre-décembre. C.

18. C. glabrum Nüll. Arg. in Fl. Bras. VI, I, p. 66. - Lagoa Rodrigo de Freitas, Rı-Jax., $n^{\circ}$ 16251. I1. blanchàtres. Norembre-décembre. C. 


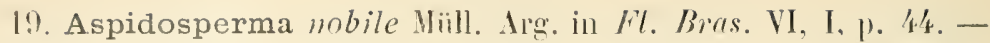
Entre Rernardo Lobo et Jaragua; Goras, n² 21742. Arbrissean, tl. jaunattres. Juin-juillet. C.

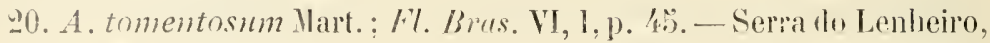

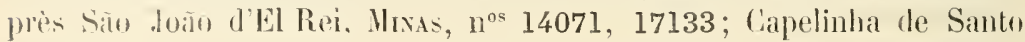
Antonio, an Rio Descoberto, Goraz, $n^{0}$ 21738. Arbrissean, H. hlanches. Octobre-novembre. C.

21. A. dasycarpon DC.; Fl. Bros. VI, I. p. 40. - Entre Alexandre et As Antas, Goras, $n^{\circ}$ 21740. Arbrisseau, fl. blanches. Août-septembre. C.

2.2. A. platyply llum Müll. Arg.; Fl. Bros. VI. I, p. 46. - Entre Diviza et Ponte Lavrada, Goras, $1^{\circ} 21741$. Arbre torkeux, fl. blanches. Aoùt-septembre. C.

23. A. Gardner; Vüll. Arg. in Fl. liras. VI, I, p. 47. - Entre Porto do Rio Paracató et Piqueiro, Misas, no 21739. Arbrisseau, fl. blanches. Juillet-aout. R.

24. A. camporum Miill. Arg. in Fl. Bras. VI, I, 49. -- Serra de Ouro branco, Misas, ${ }^{\circ}$ 12040. Arbrisseau, 11. Blanchâtres. Novembredécembre. C.

23. A. melanocaly $x$ Miill. Arg. in Fl. Bras. VI, I, :2. - Serra do Alto Macahé. Jiı-Jax., $1^{0}$ 20414. Grand arbre, fl. jaunâtres. Févriermars. C. Vulg. : Pequia Assu.

46. A. ingratum K. Schum. in Engler Bolan. Jahrb. XXX (1901), Beibl. p. 30. - Serra do Alto Macahé, Ro-Jav., $11^{\text {os }}$ 17131, 17697, 18366. Grand arbre, hi. rousses. Novenbre-técembre. C.

Q-i. A. pirifolinm Mart.; Fl. Bras. VI, I, p. 53. - S. Fidelis, près Campos, Ru-Jax., no 11184. Arbrisseat, fl. blanches. Février-mars. C.

28. A. cylindrocarpon Müll. Arg.; Fl. Bras. VI, 1, p. :̈4. Alleia de Săo Pedro dos Indios, Ro-JAx., no 12952. Grand arbre, 11. blanchâtres. Aoùt-septembre. C. Vulg. : P'eroba branca.

29. A. lagoense Hüll. Arg. in Warm. siymb. ad fl. Bras., p. 102. Entre Sitio et Barbacena, Hinas, $n^{0}$ 12948. Grand arbre, fl. blanchàtres. Novembre-décembre. C. Vulg. : P'eroba.

30. A. ramiflorum Viill. Arg. in Fl. Bras. V1, I, p. 53. - Entre Lagoa de Freitas et Paineiras, Rio-Jas., nos 6636, 9509, 17132. Grand arbre, It. blanchâtres. Juin-juillet. C. Vulg. : Pequia doce.

31. A. parvifolimn A. DC.; Fl. Bras. W, I, p. 57. - Serra da Estrella el Campo Grande, Rio-Jax, $n^{\circ 5}$ 1066, 12075. Grand arbre, tl. rousses. Aout-septembre. C. Vulg. : Pequin. 
32. A. polyneuron Mïll. Arg. in Fl. Brus. VI, I, p. 5T. - Floresta da Tijuca, Rio-Jax., n 11189. Grand arbre, fl. blanchâtres. Norembredécembre. C. Vulg. : Meroba.

3i. A. olivaceum Miill. Arg. in Fl. Bras. VI, I, p. :37. - Serra dos Ureios, Ato Macahé, etc., Rio-Jax., $11^{05}$ 636, 637, 1586, 2923, 4079, 18364, 19630. Arbrisseau, 11. blanchâtres. Novembre-décembre. CC. Vulg. : Pequia.

34. A. dispermum Hïll. Arg. in Fl. Bras. VI, I, p. 60. - Peinheiro, près Diamantina. Mrss, no 19631. Grand arbre, fl. blanchàtres. Févriermars.

3.). A. piricollum Müll. Areg. in Fl. Bras. VI. I, כ̊. - Copacabana et liestingua da Tijuca, Rio-dax., nos 94, 5000, 5933. Arbrisseau, fl. blanchâtres. Norembre-rlécenbre. C. Vulg. : Pequia.

- Var. obovatum Müll. Irg. in Fl. Bras. VI, I, p. ös. - Larangeiras, au Cosma Vellıo, Rio-.lax., ${ }^{\circ}{ }^{\circ}$ 18365. Arbrisseau, fl. blanchâtres. Yoventhre-décembre. C. Vulg. : Pequia.

36. A. argenteum Müll. Arg. in Warns. Symb. ad Fl. Bras., p. 10'. - Serra do Caraca, Mixas, no 15211. Arbrisseau, fl. blancluâtres. Février-mars. C.

37. A. eburnezm Fr. Allem. in Trab. da socied. Telloziana, p. 37. Floresta da Tijuca, Rio-Jax., $n^{0 s} 638$, 6046, 12076. Grand arbre. fl. lianchâtres. Octubre-norembre. C. Vulg̣. : Pequia marfun.

38. A. Lhotzianum Hüll. Arg. var. parvifolrum Taub. in Engler Bot. Jahrb. - Restinga de Caho Frio. R10-JAx., nº 11185. Arhrisseau, 11. jaunatres. Juin-juillet. C. Vulg. : P'ereira branca.

39. A. anomalum Müll. Arg. in Fl. Bras. YI, I, 1. Ril. - Espirito Santo, dans le bois, Mixas, n ${ }^{0}$ 14084. Arbrisseau, fl. blanchâtres. Janvierférrier. C. Vulg. : I'equia de folha larga.

40. Vinea rosea L.; Fl. Bras. VI, 1, p. 69. - Restinga de Cabo Frio, près do la mer, Rio-JAx., nº 13471. Sous-frutescent, ll. roses. Aoùtseptembre C.

11. Plumeria bracteata A. DC.; Fl. Rras. VI, I, P. 36. - Serra dos Verientes, pres Oliveira, Mins, no 14069. Arbuste, 1l. blanches. Juillet-aout. C.

42. PI. cuspidata Glaz. n. sp.? in lierb. Paris., Kew., Perol., Genev., etc. - Serra dos Yertentes, près Oliveira, linas, $n^{\circ} 14070$. Arbuste, fl. blanclıes. Juin-juillet. R.

43. Pl. speciosa Müll. Alg. in Fl. Bras. VI, I, "p. 36. - Serra dos 
l'urys, Espinito Saxto, $1^{0}$ 11175. Arbuste, fl. blanches. Septembreoctobre. Ci.

4'. Plumeria fallax Muill. Arg. in Fl. Bras. VI, I, 1. 38. - São João da Bàra, liı-Jax., n" 9939. Arbrisseau, fl. blanches. Avril-mai. C.

40̈. Pl. Warmingii Nliill. Arg. in Symb. ad Fl. Bras. centr. P. 1, p. ๖. - Serra de Ouro Branco, Mıxas, $1^{\circ}$ 19628. Arbrissean, ll. blanclies. Nirembre-décembre. C.

46. Pl. abovata Miill. Arg. in Fl. Bras. VI, I, p. 40. - Rio Paranaua, dans le campo, Gorsz, $1^{\circ}$ 21736. Arbuste, fl. blanches. Juillet-septembre. C. Vulg. : Tiborno.

47. Pl. floribunda Vüll. Arg. in Fl. Bras, VI, I, 1. 40. - Morro do Coco ou do Balıu, Espirito Saxto, nos 9938,9938 a. Arbuste, fl. blanches. Septembre-octohre. R.

48. Pl. lancifolia Mïll. Arg. in Fl. Bras. VI, I, p. 41. - Corcovado, à Caixa d'Agua, Rio-Jav., nos 640, 20409. Arbuste, fl. blanches. Octobrenovembre. C.

49. Pl. loranthifolia Müll. Arg. in Fl. Bras. VI, I, p. 42. - Itapemirim, Espikito Saxto, $n^{0}$ 9937. Arbrisseau, fl. blanches. Férriermars. R.

50. Tabernæmontana ovalifolia Glaz. sp. n.? in herb. Paris., Berol., Kew., Genev., etc. - Gandarela, dans le bois, $H_{\text {Lxas, }}{ }^{\circ} 14081 a$. Arbrisseau, fl. blanches très odorantes. Janvier-février. R.

5I. T. submollis Hart. in Fl. Bras. VI, I, p. 70. - Quinta da Boa Vista, S. Chıristovão, Rho-JAN., no 14077. Arbuste cultivé, fl. blanches. Février-mars. R.

52. T. Riedelii Vüll. Arg. in Fl. Bras. VI, I, p. 72. - Passeio Publico, Rı-Jas., $\mathrm{n}^{\text {os }}$ 7749, 8167. Arbuste eultivé, f1. blanchâtres. Marsmai. C.

53. T. angulata Nart. in Fl. Bras. Vl, I, p. 72. - Entre Cabo Frio et Araruoma, Riı-Jan., nº 9936. Arbuste, f1. blanches. Février-mar's.

54. T. oblongifolia A. DC.; Fl. Bras. VI, I, p. 74. - Vauả et Villa Nova, Rio-Jax., nos 7750,14068 . Arbuste, fl. blanches. Septembreoclobre. C C.

כั. T. rupicola Benth.; Fl. Bras. VI, I, p. 74. - Serra da Itabapoana. Esprituto SAxto, $11^{\circ}$ 14076. Arhuste, t1. blanches. Férrier-mars. C.

こ̈6. T. lacta Mart.; Fl. Bras. VI, I, 1. 79. - Corcovado, Floresta da Tijuca, Serra da Estrella, etc., Rı-Jax., nos $231,1610,4078,8797$, 9933, 12950, 15213. Arbre, fl. blanches. Oetobre-novembre. CG. 
A.-F.-M. GLAZIOU. - LISTlE des plaNtes dU BRÉsil CENTRAL.

37. T. affin is llüll. Arg. in Fl. Bras. VI, I, p. 83. - Entre Gavea et Bora Vista, Rio-Jax., $\mathrm{n}^{\text {os }} 3052$, 3053. Arluuste. fl. blanches. Ortobrenovembre. C.

58. T. fallax Nü̈ll. Arg. in Fl. Bras. VI, I, p. 84. - Riacho Fundo, dans le campo, Goyaz, $n^{0}$ 21737. Frutescent, fl. blanches. Octobrenorembre. C.

:9. T. nervosa Glaz. n. sp.? in herb. Paris., Berol., Kew., Genev., etc. - Arassuahy, dans le campo, Mrxas, $n^{\circ}$ 15212. Arbrisseau, 11. blanches. Octobre-novembre. R.

60. Geissospermum Vellozii Fr. Allem.; Fl. Bras. VI, 1. p. 90. Floresta da Tijuca, Rıo-JAx., $\mathrm{n}^{0 \mathrm{~s}} 1473,3724,5935$. Grand arbre, f1. blanchâtres. Janvier-févier. C. Vulg. : Páo Pereira.

61. Malouetia virescens R. Spr.; Fl. Bras. VI, I, p. 92. - Serra dos Purys, Espirito Savo, no 1585 a. Arbrisseau, fl. blanchâtres. Aoûtseptemlire. R.

62. M. furfuracea R. Spr.; Fl. Bras. VI, I, p. 93. - São Sebastiño da Barra, Rio-JAv., $n^{0}$ 14082. Arbrisseau, f1. blanches. Mars-avril. C.

63. M. lanceolata Vüll. Arg. in Fl. Bras. VI, I. p. 93. - Fazenda de Santa Cruz et Gavea. Rı-JAx., $n^{0 s} 1585,5934,9511$. Arbrisseau, fl. blanches. Octobre-novembre. C.

6'. M. Martii لü̈ll. Arg. in Fl. Bras. VI, I, p. 94. - Cascadura, dans le bois, Rı-JAn., $n^{\circ}$ 4077. Arbrisseau, fl. blanches. Norembredécembre. C.

6ə̃. Prestonia calycina Müll. Arg. in $\mathrm{Fl}$. Bras. VI, I, p. 162. Praia Grande, au Morro do Cavallão et à Gavea, Rı-JAx., n ${ }^{05}$ 7761, 18363. Grande liane, fl. jaunes. Novembre-décembre. C. Vulg. : Cipo carneiro.

66. P. hirsuta Nüll. Arg. in Fl. Bras. VI, I, p. 162. - Petropolis, à Santo Antonio, Rı-Jax., no 8173 . Grande liane, f1. jaunes. Févriermars. R.

67. P. tomentosa R. Br.; Fl. Bras. VI, I, 163. - Petropolis, à la Nosella, Rio-Jax., nos 12077,12944 . Grande lime, f1. jaunes. Férriermars. C.

68. P. lutescens Müll. Arg. in Fl. Bras. VI, I, p. 16't. - Itha do Gorernador, Rı-JAx., no 8800 ; Melancias, Mlsas, $n^{\circ}$ 19625. Liane, fl. jaunes. Norembre-décembre. R.

69. Hæmadictyon acutifolium Benth. : Fl. Bras. VI. I, p. 167. Itãipú, près la mer, liı-Jax., $n^{\circ}$ 9925. Liane, fl. jaunes. Janvierfévrier. R. 
70. Hamadictyon membranaceum Mïll. Arg. in Fl. Bras. VI, I,

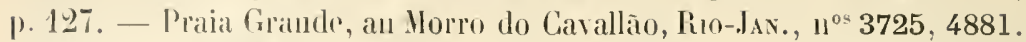
Liane, f1. jamnes. Nai-juin. C.

7I. H. Gaudichaudii A. 1)C.; Fl. Liras. VI, 1, p. 168. - Lilgoa Rodrigo de Freitas, Ro-J dx., no 12954 . Liane, fl. jaunes. Février-mars. C. Vulg. : Cipo carneiro.

79. H. asperum Mïll. Arg.; Fl. Bras. VI, I, p. 169. - Santa Luzia do Río das Vellias, au Alto do Tamandoa, Nixas, $\mathrm{n}^{0 \mathrm{~s}}$ 12943, 14072, 20412. Liane, fl. jaunes. Novembre-décembre. C.

73. H. megalagrion Müll. Arg.; Fl. Bras. VI, I, p. I70. - Serra ‘los Orgãos, à Theresopolis, Rı-JAx., n ${ }^{\circ}$ 4085. Grosse liane, f1. jaunâtres. Novembre-décembre. R.

74. Forsteronia refracta Nüll. Arg. in Fl. Bras. VI, I, p. 97. Nova Friburgo, Floresta da Tijuca, Bemposta, Rio-JAx., nos 2091,4080 , $6902,7756,14066$. Arbuste sarmenteux, fl. blanches. Décembre-janvier. CG.

7\%. F. pilosa Müll. Arg.; Fl. Bras. VI, I, p. 99. - São Christovão ef Praia Grande, Rı-Jax., $n^{\circ}$ 3056. Arbuste, 11. blanchàtres. Décembrejanvier. C.

76. F. acutifolia Müll. Arg. in Fl. Bras. VI, I, p. 99. - Praia Grande, i Jurujuba, Rio-Jax., $\mathrm{n}^{\circ}$ 6818. Arbuste sarmenteux, fl. blanchâtres. Novembre-decembre. C.

77. F. minutiflora Vüll. Arg. in Fl. Bras. VI, I, p. 99. - Serra da Estrella, sur les arbres, Rio-JAx., n ${ }^{\circ}$ 15457. Longue liane, 11. blanclies. Décembre-janvier. R.

78. F. rufa Vüll. Arg. in Fl. Bras. VI, I, p. 100. - Serra dos Orgàos, sur les rochers, Rio-Jax., nos 5939, 6905, 8799, 14065, 14067. Arbuste sarmenteux, fl. rousses. Janvier-février. CG.

79. F. Sellon ii Müll. Arg. in Fl. Bras. VI, I, p. 101. - Larangeiras, au Cosme Vellı, Rı-JAx., n ${ }^{\circ}$ 7532. Arbuste sarmenteux, fl. blanchâtres. Septembre-octolire. R.

80. F. brasiliensis A. DC.; Fl. Bras. VI, I, p. 10\%. - Copacabana, Villa Nova, Ruo-Jax., $n^{\text {os }} 4206,11176,14062$; Abaeté, au Porto das Andorinhas, au Rio S. Francisen, Mixas, n² 21729. Grande liane, fl. blanches. Octobre-novembre. C.

81. F. pubescens A. DC.; Fl. Bras. VI, I, p. 104. - Villa Nova et Alto Nacalıé, Rı-Jıs., $n^{\text {os }} 11178,14064,17138$. Arbuste sarmenteux, 11. blanchâtres. Octobre-novembre. C. 
A.-F.-M. GLAZiod. - LISTE des plattes dU Biésil CENTIAL.

89. F. multinervia A. DC.; Fl. Bras. VI, I, p. 104. - Caminho dos Haracos, entre Lagoa de Freitas et Vista Chineza, Rio-Jax., $1^{\circ 5} 2507$, 7757. Arbuste sarmenteux, fl. rousses. Norembre-décembre. C.

83. F. thyrsoidea Vüll. Ar.; Fl. Bras. VI, I, p. 103̈. - Restinga de Copacalinia, Rio-Jax., $11^{\circ}$ 4092. Arbuste sarmenteux, fl. binchâtres. Février-mars. R.

8'. F. laurifolia A. DC.; Fl. Brees. VI, p. 106. - São Jıão da

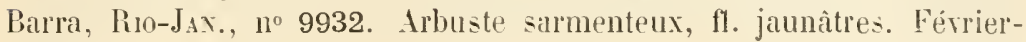
mars. R.

83. Nerium Oleander L. Sp. Pl. p. 209 rar. - Passeio Publico, R10- Jax., $n^{0}$ 1613. Arbuste cultivé, îl. blanches. Novembre-décembre. CC.

86. Secondatia densiflora A. DC.; Fl. Bras. VI, I, p. 108. Santa Luzia do Rio das Velhas, au Porto do Jequitiba, Mrsas, nos 11179 , 20408. Grande liane, fl. blanches très odorantes. Octolure-norembre. C.

87. S. floribunda A. DC. : Fl. Bras. VI, I, p. 109. - Entre Lagoa do Cereado et São Jose de Matosinho, Mixas, no 21720 , Arluste sarmenteux, fl. blanches. Octobre-novembre. C.

88. S. foliosa A. DC.; Fl. Bres, VI, I, p. 109. - Serra da Estrella, au Botequim, Ro-Jax., n 12941. Haute liane. fi. blanches. Avril-mai. C.

89. S. arborea Müll. Arẹ.; Fl. Bras. VI, I, p. 110. - S. Jod̀o da Barra, Rı-Jax., nº 9934. Arbuste, fl. blanches. Février-mars. R.

90. Odontadenia gracilis K. Sch. n. sp.? in herb. Paris., Berol, Kew., Genev., etc. - Alto Nacahé de Nova Friburgo, Rı-dax., $n^{0}$ 20416. Petite liane, nl. blanches. F'́vrier-mars. R.

91. 0. goyazensis Glaz. n. sp.? in hert. Paris., Berol., Kew., Gener., etc. - Corrego do Brejo, dans le bois, Goraz, n² 21718. Grande liane, fl. jaunes. Mars-avril. IR.

92. Anisolobus hebecarpus Vüll. Arg. in Fl. Bras. VI, I, p. III. Rio dos Indios, près Serra Dourada, Goraz, n 21727. Arbuste, fl. roses. Aoùt-septembre. C.

- Var. тomentosus Müll. Arg. in Fl. Lras. VI, I, p. 112. - Biribiry, près Diamantina el Caraça, Hısss, $n^{0=} 14073,14074,14075$. 15220, 19623. Belle liane, f1. roses. Hilrs-arril. CG.

92. A. lancifolius K. Sch. n. sp.? in herb., Paris., Berol., Kew., Gener., etr. - Pé da Serra de Ouro Branco, Muxas, $n^{\circ}$ 15221. Liane, il. roses. Nurembre-décembre. R.

9'. Stipecoma peltigera Müll. Arg.; Fl. Bras. VI, I, p. 176. Biribiry: au Mocotó près Diamantina, Mhsss, $1^{\circ}$ 19622. Volubile, fl. blanc rosé. Mars-avril. C. 
9\%. Echites circinalis Swarl\%: Fl. Bras. VI, I, p. 134. - Laranweiras, au Cosme Vello et al Marica, Rio-Jax., $1^{\text {os }}$ 4091, 11177. Volubile, fl. jannes. Janvier-févier. C.

46. E. coalita Vellozo; Fl. Bras. VI, I, p. 15\%. - Floresla da Tijuca, Fazenda do Palmital, Gavea, Jacarépagua, Rio-Jas., $\mathrm{I}^{\text {os }} 3055$, 4090, 11191, 12940, 21719. Liane, fl. jannes. Janvier-décenbre. GC.

97. E. Martii Miill. Arg.; Fl. Bras. VI, I, p. 15\%. - Floresta da Tijuca, Gave, Rio-JAx, $11^{\text {os }} 3058$, 3059, 5940, 7865. Liane. fl. jaunes. Janvier-février. C.

98. E. varia Stadelm. Fl. Bras. V1, 1, p. 1857. - Restinga de Copacabana, Rı-JAx., ${ }^{05}$ 634, 4089. Liane, fl. james. Janvier-février. C.

99. E. violacea Vellozo; Fl. Bras. VI, I, p. 158. - Entre Queluz et Barbacena, Misas, ${ }^{\text {os }} 11181,12942$, 14075. Liane, fl. rouge pourpre. Juin-juillet. C.

100. E. lutea Vellozo; Fl. Bras. VI, I, p. 159. - Entre Lagoa do Peixe el le Rio Bonito, près Queimado, Rio-J JN., nos 4882, 11194, 12957. Liane, fl. jaunes. Aoùl-septembre. C.

I01. E. peltata Vellozo; Fl. Bras. VI, I, p. 139. - Serra da Estrella, Tijuca, Gavea, Rı-JAx., ${ }^{05} 3726$, 4879, 7753, 9927; Vargem de Clico Costa, Goraz, $n^{\circ}$ 21728. Grande liane, fl. james. Octobrenovembre. CC. Vulg. : Cipú Capador.

102. E. macrocalyx Niull. Arg. in Fl. Bras. VI, I, p. 160. - Entre

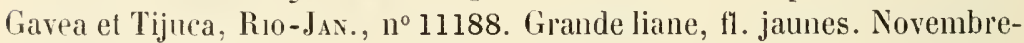
décembre. $R$.

103. Mesechites sulphurea Müll. Arg. Fl. Bras. VI, I, p. 151.Biribiry près Diamantina, Mixas, $n^{0}$ 19624. Volubile, fl. jaunâtres. Marsavril. li.

104. Laseguea erecta Nïll. Arg.; Fl. Bras. VI, I, p. 133. Campos da Bucaina, S. Paulo, $n^{\circ} 16249$; Chico Costa, près du campement, Goraz, $11^{\circ} 21752$ a. Frutescent, fl. rousses. Janvier-février: C.

10\%. Rhodocalyx rotundifolius Vüll. Arg.; Fl. Bras. VI, I, 1. 173. - Serra do Lenlıeiro, près Sào João d'El Rei, Misas, nos 12951 , 17137 ; Rio Gama, dlans le campo, Goraz, no 21726. Sous-frutescent, 11. rouge pourpre. Octobre-novembre. GC.

106. Macrosiphonia Velame Müll. Arg.; Fl. Bras. VI, I, p. 138. Ayuruoca et Serra do Palmital, Misas, nos 9507, 15214; Chico Lobo, dans le campo, Govaz, no 21731. Sous-frutescent, fl. blanches. Févriermars. C. 
107. M. Martii Müll. Arg.; Fl. Bras. VI, I, p. 138. - Vorro Canastro, près Hestre d'Armas, Goraz, no 21732. Sous-frutescent, fl. blanches. Décembre-janvier. C.

108. M. longiflora Vüll. Arg.; Fl. Bras. VI, I, p. 140. - Entre Rio Gama et Rio Paranauk, Govaz, n 21733. Sous-frutescent, fl. blanches. Novembre-dúcembre. R.

109. Dipladenia polymorpha Müil. Arg.; Fl. Bras. VI, I, p. 121. - Serro Frio da Ayuruoca, Misas, $1^{\circ 5}$ 15218, 15219, 16250. Sous-frutescent, 11. roses. Norembre-décembre. C.

- Var. tenutfolia Müll. Arg. in Fl. Bras, Vl, I, 1. 121. - Serra do Lenheiro, près S. Joîo d'El Rei, Mixas, no 17136. Sous-frutescent, fl. roses. Septembre-octobre. R.

110. D. Myrioply-llam Taul. in Engler Bolan. Jahrb. XXI, 448. - hego do Chico Loho, dans le terrain ferrugineux, Goyaz, $n^{05} 21721$, 21722, 21723. Herlacé à gros bulbes, fl. roses. Novembre-décembre. C.

111. D. acicularis K. Sch. n. sp.? in herb., Paris., Berol., Kew., Genev, etc. - Entre Rio Torto et Sobradinho, dans le campo, Goyaz, no 21722 u. Herbacé, bullieux, fl. ruses. Janvier-février. R.

112. D. spigeliaflora Müll. Arg.; Fl. Bras. VI, I, 122. - Entre Sitio et Barbacena, Mıxas, $11^{\circ}$ 15216; Rio Gama, dans le campo, Goyaz, n" 21725. Sous-1̂́utescent, fl, roses. Novembre-décembre. C.

113. D. xanthostoma Hüll. Arg.; Fl. Bras. VI, I, p. 123. - Serra de Ouro Branco, Mlixas, $n^{0} 15217$ a. Sous-frutescent, tl. roses. Novembredécembre. R.

114. D. gentianoides Nüll. Arg.; Fl. Bras. VI, I, P. 124. - Entre Sitio et Barbacena, dans le campo, Mıxas, no $15215 a$. Sous-frutescent, 11. roses. Ortol,re-novemlre. R.

11:. D. illustris MülI. Arg.; Fl. Bras. VI, I, p. 19\%. - Serra de Ouro Branco, dans le rampo, Minas, $n^{\circ}$ 15217. Sous-frutescent, fl. roses. Octohre-novembre. C.

- Var. tomentosa Müll. Arg. Fl. Bras. VI, I, p. 129ั. - Aguas Santas, dans le campo, Misas, $1^{\circ}$ 17134. Ponte Alta, au Chapadão do Gama, Goxiz, n² 21724. Sous-frutescent, 11. roses. Octobre-novembre. GC. Vulg. : Jalapa et Bora do campo.

116. D. venulosa Müll. Arg. in Fl. Bras. VI, I, p. 126. - Serra de S. José d'El Rei, Mıv.s, $n^{\circ} 17134$ a. Frutescent, fl. roses. Octobrenovembre. R.

117. D. atroviolacea Hüll. Arg.; Fl. Bras. VI, I, p. 127. - Floresta 
da Tijuca, Pico do Papagaio, liı-JAN., nos 635,2090 , 3054. Volubile, 11. violettes. Novembre-décembre. C.

118. Dipladenia Sellonii Müll. Arg. in Fl. Bras. VI, I, 1. 12S. Itaniaraly, près Petropolis et au Morro da Carangola, Ro-JAx., nos 6638 , 8803, 14062 ; Itacolumy, près Ouro Preto, Mnsas, ${ }^{\text {ns }}$ 15215, 17135. Frutescent, fl. rusées. Février-mars. Ci.

119. D. ayuruocana Glaz. n. sp.? in herl. Paris., Berol., Kew., Genev., etc. - Serro Frio da Ayuruoca, Mlsas, no 9510. Frutescent, fl. llanchâtres. Janvier-février. R.

120. D. splendens A. DC.; Fl Rras. Vl, I, p. 130. - Itamaraty près Petropolis, Rio-Jax., no 9512 . Grande liane, fl. roses. Novembredécembre. C.

121. D. fragrans A. DC. Fl. Bras. VI, I, p. 130. - Tijuca, Restinga de llauá et Cachoeira, ho-JAN., $\mathrm{n}^{05}$ 4086, 7755, 11187. Grande liane, fl. roses. Novembre-décembre. CC.

122. D. urophylla Hook.; Fl. Bras. VI, I, p. I31. - Serra dos Orgãos, à Theresopolis, Rio-Jax., $1^{\text {os }} 11190,14061,19627$. Arbuste sarmenteux, fl. roses. Janvier-février. C.

- Var. erecta Glaz. n. var. in herb. Paris., Kew. - Nova Friburgo, au sommet de Pedıa do Conego, Rio-Jax., n ${ }^{\circ}$ 12955. Arbuste, fl. hlanches. Février-mars. R.

123. D. crassinoda A. DC. Fl. Bras. VI, I, p. 132. - Morro da Gavea, au sommet, Rro-JAx., $n^{0 s} 5943,8171$. Arbuste, fl. roses. Juinjuillet. C.

124. Amblyanthera funiformis Müll. Arg.; Fl. Bras. VI, I, p. 144. - Restinga de Copacabana et Picó de Santa Cruz, Rio-Jav., nos 4088, 7754, 8170. Volubile, 11. roses. Février-mars. C.

- Var. microphylla Müll. Arg.; Fl. Br., VI, I, p. 144. - Serra do Alto llacahé, Rio-JAv., $n^{08}$ 17698, 20415. Volubile, li. jaunes. Novembredécembre. C.

125. A. versicolor Müll. Arg.; Fl. Bras. VI, I, p. 146. - Rio do Ouro, Rio-Jan., no 11180 ; lio Gama, dans le campo, Goyaz, $n^{\circ} 21728 a$. Volubile, ft. blanches. Juillet-aoùt. C.

126. A. hispida Müll. Arg.; Fl. Bras. VI, I, p. 147. - Entre Rio do Ouro et Queimado, Rıo-JAx., ${ }^{\circ}$ 11195: entre Piedade et Santa Luzia do Rio das Vellıas, Mınas, $\mathbf{n}^{\circ}$ 20410. Volubile, fl. jaunes. Août-septembre. C.

127. A. fluminensis Müll. Arg.; Fl. Br. V. I, p. 148. - Entre Cabo 
Frio et São Pedro dos Indios et près llagé, Rı-Jan., nos 8796, 9931. Volubile, fi. jaunes. Mai-juin. C.

128. Rhabdadenia Pohlii Müll. Arg.; Fl. Bras. VI, I, p. 174. Eutre Magé et Piedade, Rı-Jax., $n^{\text {os }} 4082,5941$; Serra da Mantiqueira, près Joĩo Ayres, Minas, $n^{\circ}$ 16248. Volubile, fl. roses. Décembre-janvier. C.

\section{Fam. 88. - Asclépiadacées.}

1. Astephanus Gardnerii Fourn. in Fl. Bras. VI, IV, p. 199.Biribiry, près Diamantina, Mrvas, $n^{\circ}$ 19644. Liane, fl. blanches. Mar'savril. $\mathbf{R}$.

2. Hemipogon acerosus Dene; Fl. Bras. VI, IV, p. 198. - Santa Luzia do Rio dos Vellas, Mrvas, $n^{\circ} 20411$; Mestre d'Armas, Govaz, $n^{\circ}$ 21750. Sous-frutescent, fl. verdâtres. Novembre-técembre. C.

3. H. abietoides Fourn. in Fl. Bras. VI, IT, p. 196. - Serra d'Itibira do Campo, Mrxas, ${ }^{o s} 15235$, 19636. Sous-frutescent, fl. verdatres. Octobre-novembre. C.

4. H. setaceus Dene; Fl. Bras. VI, IV, p. 197. - Mestre d'Armas, Goyaz, no $21750 a$. Sous-frutescent, fl. verdâtres. Novembre-décembre. R.

5. H. luteus Fourn.; Fl. Bras. VI, IV, p. 197. - Serra de Santa Rita, Goyaz, $n^{0}$ 21749. Sous-frutescent, fl. blanchâtres. Juillet-août. Ci.

6. Fischeria acuminata Dcne; Fl. Bras. VI, IV, p. 298. - Juiz de Fora, dans le bois, Mixas, $n^{\circ}$ 7752. Grande liane, fl. blanchâtres. Janvierfévrier. C.

7. F. Warmingii Fourn. in Fl. Bras. VI, IV, p. 299. - Parahyba, dans le bois, Mıxas, $n^{\circ} 7752 a$. Grande liane, fl. jaunàtres. Janvierfévrier. R.

8. F. Martiana Dene; Fl. Bras. VI. IV, p. 300. - Larangeiras, à Cantagallo, Rio-Jax., $\mathrm{n}^{\circ}$ 16252. Grande liane, f1. blanchitres. Octobrenovembre. $\mathrm{R}$.

9. Araujia sericifera Brot.; Fl. Bras. VI, IV, p. 292. - Nova Friburgo, tlans les jardins, Rio-Jav., $n^{\circ}$ 6637. Sous-frutescent, fl. blanchâtres. Février-mars. C.

10. A. hortorum Fouru. in Fl. Bras. VI, IV, p. 993. - Quinta da Boa Vista, S. Christovão, Rro-Jax., $1^{\circ}$ 5938. Sous-frutescent, fl. blanchâtres, cultivé. Février-mars. C. 
11. Schubertia grandiflora Virl. ot Z.; Fl. Brras. VI, IV, P. 299. - Corcovado, ż Lagoinha, Rio-Jas, n ${ }^{0 s} 3057,11174$. Grande liane, 11. Hantılies. Juin-juillet. C.

12. Oxypetalum pallidum Fou'n. in Fl. Bras. VI, IV, 1. 999. Entre lio d'(luro el Queimado, Rio-Jas., $1{ }^{\text {os }} 4084,8801$. Liane, f1. blanches. Octobre-novembre. C.

13. O. umbellatum Gardn.; $\mathrm{Fl}$. Bras. VI, IV, p. 259. - Floresta da Tiju'a, Rı-JAx., n 4878. Liane, fl. blanches. Novembre-dérembre. R.

14. O. villosum Fourm. in Fl. Bras. VI, IV, p. 269. - Serra do Picu, dans le campo, Mrsas, no 7759 a. Liane, 11. Mlanches. Décembre-janvier. R.

15. O. Glaziovianum Loes. n. sp. in herb. Paris., Berol., Kew., Gener., etc. - Serra dos Orgãos, au sommet, Rio-JAN., nos 15226 , 17700, 17143. Liane, fl. blanchàtres. Janvier-février. G.

16. O. pannosum Dene; Fl. Bras. VI, IV, p. 266. - Ayuruoca, Minas, $n^{\circ}$ 16256. Griande liane, fl. blanchâtres. Janvier-février. C.

17. O. lanatum Dene; Fl. Bras. VI, IV, p. 266. - Serra dos ()rgãos, au Rio Soberbo, Rio-JAx., $n^{\circ \varsigma} 4093,7759,16253$. Grande liane, fl. hlanchâtres. Janvier-férrier. GG.

18. O. Banksii R. et S.; Fl. Bras. VI, IV, p. 268. - Restinga de Copacabana, Rı-Jan., $n^{0}$ 44. Volubile, fl. verdâtres. Janvier-février. C.

19. O. riparium H. B. K.; Fl. Bras. VI, IV, p. 269. - Entre Lagoa de Freitas et Vista Chineza, Rio-JAN., nº 4096. Liane, fl, verdàtres. Marsavril. G.

20. O. pedicellatum Dene; Fl. Bras. VI, IV, p. 269. - Petropolis, au Palatinato, Rı-J $J_{A N}$, $n^{\circ} 8795$. Grande liane, fl. verdâtres. Avrilmai. C.

21. O. Wightiannm H. et A.; Fl. Bras. VI, IV; P. 270. — Serra de Ouro Preto, Misas, n 14090. Liane, fl. verdâtres. Juin-juillet. C.

29. O. arachnoideum Fourn. in Fl. Bras VI, IV, p. 272. - Entre Sitio et Barbacena, dans le bois, Minas, $n^{\circ} 14091$. Grande liane, fl. blanchâtres. Novembre-décembre. C.

23. O. appendiculatum Nart. et Z.; F7. Bras. VI, IV, P. 273. Serra do Cipó et d'Ouro Preto, Mixas, nos 19643, 20413. Liane, ll. verdâtres. Novembre-décembre. C.

24. O. lutescens Fourn. in Fl. Bras. VI, IV, p. 273. - Alto Macahé Ite Nova Friburgo, Ikio-Jan., $n^{\text {os }} 6903$, 17699. Liane, fl. verdattres. Décembre-janvier. C. 
23. O. Schottii Fourn. in Fl. Bras. VI, IV, p. 273. - Petropolis, a Santo Antonio, Rio-Jax., no 7760. Liane, fl. rerdâtres. Juin-juillet. R.

26. O. subhirtellum Miq.; Fl. Bras. VI, IV, p. 274. - Serra de Alto Macalıé, Riı-Jax, nº 6903 a. Liane, fi. verdàtres. Décembre-janvier. C.

27. O. campestre Dcne; Fl. Bras. VI, IV, p. 27\%. - Serra do Lenheiro, près São João d'El Rei, Mısıs, n 17147. Sous-frutescent, fl. verdâtres. Mars-avril. C.

28. O. erectzm Mart. et Z. : Fl. Bras. VI, IV, p. 2̈̈̆. - Serra do Batatal ou de Capanema, Mrsas, $n^{\circ}$ 15237; Morro do Salto, Goyaz, n² 21751. Sous-fiutescent, ll. jaunâtres. Décembre-janvier. CC.

29. O. strictım Mart. et Z.: Fl. Bras. VI, IV, p. Đ76. - São João d'El Rei. entre les rochers, Mixas, $n^{0}$ 17701. Sous-frutescent, fl. rerdittres. Mars-avril. C.

30. O. patulum Fourn.; Fl. Bras. VI, IV, p. 278. - Ayuruoca, au Serro Frio, Mrxas, $n^{\circ}$ 16257. Volubile, fl. blanchâtres. Décembre-janvier. $\mathrm{C}$.

31. O. foliosmm Mart. et \%.; Fl. Bras. VI, IV, p. 278. - Sitio de Barbacena et Caraça, Mrsas, $n^{\circ s}$ 15236, 16255. Sous-frutescent. 11. rousses. Janvier-février. C.

32. O. capitatum Mart. et 7.; Fl. Bras. V1, IV, p. 280. - Aguas Santas, près Serra de são José d'El Rei, Mısa, no 17I43 a. Sous-frutescent, fi. blanchatres. Septembre-octohire. R.

33. O. Martii Fourn. in Fl. Bras. VI, IV, 1). 280. - Capelinha de Santo Antonio, au Rio Descoberto et Ponso do Ribeirão, Goraz, ${ }^{\text {os }} 21752$, 21753. Sous-frutescent, fl. blancliàtres. Septembre-octubre. C.

3't Calostigma Gnilleminianum Dene; $F l$. Bras. VI, VI, p. ¿28ö. - Alto Macahé de Nova Friburgo, Rio-Jax., n 16364. Liane, fl. Jlanchàtres. Janvier-février. R.

3\%. C. Burchelli Fourn. in Fl. Bras. VI, IV, p. 286. - Serra de Ouro Preto. dans le bois, Mrsas, $\mathrm{n}^{\circ} 20413$ a. Liane, ll. blancliàtres. Décembre-janvier. Ií.

36. C. Glaziovii Foum. in Fl. Bras. VI, IV, p. 286. - Nova Friburgo, au Alto da Boa Vista, Rio-JAx., n 14087. Liane, 11. blanchâtres. Janvier-février. C.

37. C. glabrum Dene; Fl. Bras. VI, IV, p. 286. - Serra do Lenleiro, près Säo Joào d'El Rei, Mıxas, no 17144. Liane, fl. blanchâtres. Mars-avril. li. 
38. Bustelma Warmingii Fuurn. in Fl. Bras. VI, IV, p. 288. Entre Queluz et Ouro Preto, Mıxas, $1^{\circ}$ 15227. Liane, ll. Hanchàtres. Janvier-février. C.

39. Asclepias curassavica L.; Fl. Bras. VI, IV, p. 199. - Floresta da Tijuca, Corcovado, Rio-Jax., $n^{\circ s} 232,3803,12960$. Sous-frutescent, 11. jaunâtres. Janvier-avril. CC. Vulı̣. : Official da sala.

40. A. candida Vellozo; Fl. Bras. VI, IV, p. 200. - Guariroba, dans le campo humide, Goraz, $n^{\circ}$ 21746. Sous-frutescent, f1. blanches à très bonne odeur. Octobre-novembre. C.

41. A. bracteolata Fourn. in Fl. Bras. VI, IV, p. 200. - Ayuruoca, Mixas, $n^{\circ}$ 16254; Corrego do Brejo, dans le campo, Goyaz, no 21745. Sous-frutescent, fl. blanchâtres. Février-mars. C.

42. Gompholobus brasiliensis Fourn. in Fl. Bras. VI, IV, p. 203. - Petropolis, au Retiro, Rı-JAax.. $n^{\circ}$ 6706; Santa Luzia, Goyaz, $11^{\circ} 21757$ a. Sous-frutescent, fl. blanches; cultivé. Aoùt-septembre. Vulg. : l'aina de seda.

43. Metastelma venosum I)ne; Fl. Bras. VI, IV, p. 207. - Entre Barbacena et Queluz, Mixss, no 9508 a. Petite liane, fl. blanches. Juinjuillet. C.

44. M. tomentosum Dene; Fl. Bras. IV, IV, p. 208. - Tijuca, au Morro Queimado et à Petropolis, Rio-Jav., $n^{\circ \text { s }}$ 4094, 9508. Liane, fl. blanchattres. Mars-avril. C.

45. M. obscurum Fourn, in Fl. Bras. VI, IV, p. 208. - Congonhas do Campo, Mısas, no 15230. Volubile, f1. blanchâtres. Mars-avril. R.

46. M. bracteolatum Fourn. in Fl. Bras. VI, IV, p. 209. - Pão d'Alho, Espirito SAxto, no ${ }^{11201 . ~ V o l u h i l e, ~ f 1 . ~ b l a n c h a ̀ t r e s . ~ J a n v i e r-~}$ mars. R.

47. M. Hilarianum Fourn. in Fl. Bras. VI, IV, p. 209. - Serra da Mantiqueira, MInas, $1^{\circ} 11212$. Volubile, fl. blanchâtres. Aoùt-septembre. C.

48. M. urceolatum Fourn. in Fl. Bras. VI, IV, p. 210. - Corcovado, à Paneiras, Rio-Jax., $n^{0} 11192$. Volubile, fl. jaunâtres. Décembrejanvier. C.

49. Glaziostelma ovalifolizm Fourn. in Fl. Bras. VI, IV, p. 227. Campos, près São Fidelis, Rı-JAx., nº 9924. Volubile, fl. blanchâtres. Janvier-février. R.

50. Tassadia Sprucei Fourn. in Fl. Bras. VI, IV, p. 229. - São Fidelis, près Campos, Rı-J $J_{A N}$, $n^{\circ} 9924 a$. Volubile, t1. blanches. Janvier-février. R. 
51. T. comosa Fourn. in Fl. Bras. VI, IV, p. 2299. - Restinga de Mauá, Rio-Jax., $11^{0}$ 18367. Arbuste sarmenteux, fl. rousses. Novembredécembre. C.

5๊2. Blepharodus pallidus Dene; Fl. Bras. VI, IV, p. 30\%.Serra de Ouro Branco, Mrsas, $n^{\circ} 15225 a$. Liane, fl. blanches. Novemlredécembre. R.

83. Bl. diffusus Dene: Fl. Bras. VI, IN, p. 303. - Ouro Preto et Serral de Ouro Branco, Mrxas, nos 11207, 15225, 19641. Liane, fl. blanchâtres. Mai-juin. C.

วั4. Bl. asterion Fourn.; Fl. Bras. VI, IV, p. 307. - Nova Frilurgo, au Conego, Rio-Jax., $11^{\circ}$ 14086. Liane, fl, blanchâtres. Janvier-février. C.

5... Ditassa taxifolia Dene in DC. Prodr. VIII, p. 578. - Rio das Pedras, au Valú, Mrsis, $n^{\circ} 14085$, 19632. Sous-frutescent, fl. blanc jaunâtre. Arril-mai. C. Vulg. : Leiteira brava.

36. D. decussata Mart. et Z.; Fl. Bras. VI, IV, p. 237. - Serra do Caraça et Morro do Pires, près de Faria, Mrsas, $n^{\text {os }} 15233$, 18368, 19634. Sous-frutescent, fl. blanchâtres. Janvier-février. CC.

:T. D. passerinoides Mart. et Z.; Fl. Bras. VI, IV, p. 238. - Cabeceiras do Rio sta Anna, au Chapadão dos Veadeiros, Goyaz, no 21748. Sous-frutescent, fl. blanchâtres. Janvier-mar's. C.

58. D. virgata Fouru.: Fl. Bras. VI, IV, p. 238. - Serra de S. José d'El Riei, Mrras, $11^{\text {os }} 16259,17142$; Cabeceiras do Corrego do Brejo, Goraz, nº 21747. Sous-frutescent, Il. blanchattres. Arril-mai. C.

39. D. hemipogonoides Fourn. in Fl. Bras. VI, IV, p. 238. - Cipí, au Rio das Pedras, Mrxas, $n^{\circ}$ 19637. Sous-frutescent, fl. rousses. Marsavril. C.

60. D. acerosa Mart. et Z.; Fl. Bras. VI, IV, p. 39. - Serra de Ouro Preto, à S. Sebastião, Mrsas, $1^{\text {os }}$ 15232, 19635. Sous-frutescent, fl. blanchâtres. Janvier-février. C.

61. D. ericoides Dene; Fl. Bras. VI, IV, p. 239. -- Serra do Lenheiro et de S. José d'El Rei, Mrxas, $11^{\text {os }} 11210$, 15231, 16260, 17146. Sous-firutescent, fl. rousses. Décembre-jantier. CC.

62. D. Micromeria Dene; Fl. Bras. VI, IV, p. 240. - Biribiry et Tombador, près Diamantina, Urvas, $n^{0 *} 19638$, 19639, 19640. Sousfrutescent, l1. rousses. Mars-avril. C.

63. D. imbricata Fourn. in Fl. Bras. VI, IV, p. 240. - Serra dos Orgios, au Frade, Rio-Jas., nos $3728,14093,17140$. Liane, fl. blanches. Nai-juin. Ci. 
fił. Ditassa montana Drme; Fl. Bres. VI, IV, 1. 240. - Alto Hakahe de Noval Friluurgo, Rio-Jax., $1^{05} 4087,17161$. Liane, fl. blanches. Marsarril. C.

6ii. D. nitida Fourn. in Fl. Bras. VI, IV, p. 241. - Alto Vlaralse de Nova Friburow, Rio-JAx., nos 11193,17139 . Liane, fl. blanches. Janvierfévier. C.

66. D. obcordata Mart. et Z.; Fl. Bras. VI, IV, p. 2̌t3. - Tomhador, prés Diamantina, Mıvas, $n^{\circ}$ 19642. Liane, fl. blanclies. Mar'savril. li.

67. D. retusa Nart. et Z.; Fl. Bras. VI, IV, p. 243. - Serra do Lenheiro, près S. doño d'El Rei, Maxas, no 17145. Liane, fl. blanches. Mars-arril. C.

68. D. umbellata Dene: Fl. Bras. VI. IV. p. 244. - Restingil de Copacabana, Rio-IAv., $n^{\circ 3}$ 43, 2092, 17702. Liane. fl. blanches. Novembre-décembre. C.

69. D. rufescens Dene: Fl. Bras. VI, IV, p. 24:. - Serra dos (Jrgãos, à Tahoinlıa, Rio-JAN., no 4095 a. Liane, ll. blanchıâtres. Arrilmai. R.

70. D. lanceolata Dene; Fl. Bras. VI, IV, p. 24:3. - Pedra dos Cabritos, à Coparabana, Rio-Jax., no 854. Liane, 11. blanches. Mar'savril. C.

71. D. ramosa Fourn. in Fl. Bras. VI, IV, p. 246. - Morro do Coes wu do Bahí, Rio-JAx., no 11202. Liane, fl. blanches. Septembre-nctobre. R.

79. D. Guilleminiana Dene: Fl. Bras. VI, IN, H. 246. - Larangeira, au Cosme Velho, $n^{\circ}$ 4095. Liane, fl. blanchàtres. Mar's-arril. C.

73. D. aristata lienth. in $\mathrm{Fl}$. Bras. VI, IV, p. 247 . - Restinga de Cabo Frio, Ro-JAx., nº 9926. Liane, fl. blanchàtres. Janvier-février. R.

74. D. Glaziovii Fourn. in Fl. Bras. V1, IV, p. 2900. - Campos da Bocaina, S. PAdLo, nº 11200. Liane, 11. Blanchàtres. Septembre-tuctobre. R.

79. D. anomala Mart.; Fl. Bres. VI, IV, p. 280. - Pico do Andarahı̣ Grande, à Tijuca, Rı-Jax., $n^{\circ s}$ 1017, 2687. Liane, fl. blanchâttres. Janvier-février. C.

76. D. hastata Dene; Fl. Bras. VI, IV, p. 2:1. - Campos da Bocaina, S. Paulo, $\mathrm{n}^{\text {os }} 9930,11197$. Liane, f1. blanches. Févriermars. C.

77. D. preccincta Fourn. in Fl. Bras. VI. IV, p. 2933. - Serra de Mambucaba, S. Paulo, $n^{0}$ 9928, 11199. Liane, fl. blanches. Févriermars. C. 
A. $-r^{2},-M$. GLAZIOU. LISTE DES PLAYTES DU BRESIL CENTRAL.

78. D. lavvis Mart. et Z.; Fl. Brus. VI, IV, J. 20ั4. - Ayuluoca. au Serro Frio et au Pico d'Itacolumy, Mrsas, $n^{0 \mathrm{~s}} 15229$, 16258. Liane, 11. blanches. Jamvier-février. C.

79. D. grandiflora Fourn. in Fl. Brus. VI, IV, p. 20\%. - Picú da fortaleza de Santa Cruz, Rio-Jan., nº 5942. Liane, fl. blanchâtres. Aoûtseptembre. C.

S0. Melinia Glaziovii Fourn.; Fl. Kras. VI, VI. p. „89. - Itatiaia. entre les rochers, à $2300 \mathrm{~m}$. d'altitude, Ruo-JAx., n ${ }^{\circ 3} 6639$, 8802. Liane. fl. verdâtres. Décembre-janvier. $R$.

81. M. Urbaniana K. Sclı, in Engler Botan. Jahrb. XXV, Beilıl. IX. - Vargen do Rio Paranaú, au Chico Costa. Govaz, no 21743. Liane, fl. bianchâtres. Norembre-décembre. C.

82. Kerbera Eichleri Fourn. in Fl. Bras. VI, IV, p. 290. - Cabo Frio, au Morro do Telegrapho, Rı-JAs., n 11211 ; Serra de Ouro Preto, dans le bois, Mrsıs, n 14089. Liane, fl. blanchâtres. Mars-avril. C. Vulı̣.: Braro forte.

83. Orthosia Eichleri Fourn. in Fl. Bras. VI, IV, p. 22z. - Petropolis, au Altu do Implerador, liso-Jax., n 8174 . Volubile, 11. blanc jaunaitre. Avril-mai. C.

84. O. congesta Dene; Fl. Bras. VI, IV, p. 222. - Selra dos Orgãos, à S. Luiz, Riı-Jax., n ${ }^{\circ}$ 2688. Volubile, f1. blanches. Arrilmai. C.

8\%. Amphistelma ferruginenm Foum.; Fl. Bras. VI, IV, p. 런. Picó da Tijuca, au sommet, Rio-Jax., n ${ }^{0}$ 4083. Volubile, fl. rousses. Norembre-slécenbre. R.

86. A. parviflorum Fourn. in Fl. Bras. VI, IV, 1. 224. - Nova Friburgo, au Alto da Boa Vista, Rio-JAx., nº 6904. Volubile, fl. blanthes. Janvier-février. C.

87. A. Riedelii Fourn. in Fl. Bras. VI, IV, p. 223. - Corcovarlo, à Lagoinhas dos Porcos, Rio-Jax., n 11203. Volubile, fl. blanches. Marsavril. R.

88. A. aphyllum Fourn.; Hl. Bras. VI, IV, p. 225. - Floresta da Tijuca, Taipú, Engenho Velho, etc., Rio-JAx., $1^{\text {os }}$ 788, 1021, 1350 , 1466, 5936, 6701 et 11602. Volubile, 11. blanches. Мai-juin. CC.

89. A. melanthum Fourn.; Fl. Bras. 'V], IV, p. 226. - Haut du Picó da Tijuca, Rio-Jis., $n^{\circ}$ 5937. Volubile, t1. rousses. Mai-juin. C.

90. Amphidetes quinquedentatus Fourn. in Fl. Bras. VI, IV, 1. 213. - Restinga da Tijuca, Rio-Jax., no 11206. Volubile, fl. blanchatres. Novembre-décembre. R. 
91. Amphidetes laciniatus Fourn. in Fl. Bras. VI, V, 1. 214. -

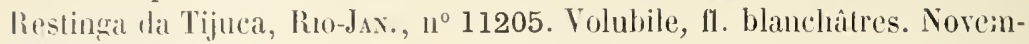
bre-decembre. C.

!). Peplonia niti.la Dene; Fl. Bras. VI, IV, 1. 236. - Gavea et Jurujuba, Rio-Jax., nos 6640,8169 . Vohulile, fl. blanchattres. Marsavril. C.

13. Sarcostemma pallidum Fourn. in Fl. Bras. VI, IV, p. 2393.Barbacena. dans les bois, Mixas, $n^{0}$ 14092. Volubile, 11. blanclies. Novembre-décenbre. C.

9'. S. pedunculatum Foum. in Fl. Bras. VI, IV, p. 235. - Sete Pontes, au Baretto, Rı-JAx., no 8168. Volubile, fl. blanches. Marsavril. C.

93. S. Glaziovii K. Sch. in Engler Botan. Jahrb. XXV (1898), Beibl., p. 19. - Guariroba, dans le bois. Goyaz, no 21744 . Volubile, ll. blanches. Juin-juillet. C.

96. Phæostemma Riedelii Fourn. in Fl. Bras. VI, IV, p. 311. Alto Hacahé de Nova Friburgo, Rio-Jax., nos 18362. 19626. Grande liane. fl. verdattes. Octobre-novembre. G.

97. Ph. Glaziovii Fourn. in Fl. Bras. VI. IV. p. 312. - Serra dos Orgãus, à São Luiz, Rı-Jax., no 1584. Grande liane, fl. verdâtres. Octobre-novembre. R.

98. Gonolobus Glaziovii Fourn. in Fl. Bras. VI. IV, p. 315. Petropolis ì Fazenda Ingleza, Rio-JAx., no 8798 . Volubile, it. verdattres. Décembre-janvier. C.

99. G. viridiflorns R. et S.; Fl. Bras. VI, IV, p. 316. - Entre Araruama et Cabo Frio. Rı-Jıx, n ${ }^{\circ}$ 11208. Volubile, fl. blanchàtres. Juin-juillet. R.

100. Cœlostelma refractum Fourn.; Fl. Bras. VI, IV, p. 320. Serra da Babylonia, dans le bois, Iıxas, $n^{\circ} 3727$. Volubile, fl. verdàtres. Juin-juillet. R.

101. Exolobus grandiflorus Fourn. in Fl. Bras. VI, IV, p. 319. Serra da Mantiqueira, à João Gomez. Mrxas, $1^{\circ}$ 11209. Liane, fl. brunes. Décembre-janvier. C.

102. Peckoltia pedalis Fourn. in Fl. Bras. VI, IV, p. 310. - Serra da Caraça, dans les bourluiers, Misas, $n^{0 s}$ 14088, 15228. Frutescent, fl. verdâtres. Juin-juillet. C.

103. Ibatia quinquelobata Fourn. in Fl. Bras. VI, IV, p. 308. Restinga de Copacabana, Rio-Jax., no 11204. Liane, f1. blanchattes. Juin-juillet. R . 
A. F.-M. GLAZIOU, - LISTE DES PLAYTES DU BRÉSIL CENTRAL.

I04. I. Selloana Fourn. in Fl. Bras. II, IV, p. 389. - Guariroba, dans le campo. Goyaz, no 21756. Sous-frutescent, fl, jaunitres. Octobrenovembre. R.

10\%. I. lanosa Fourn. in Fl. Bras. VI, IV, p. 309. - Formosa da Inperatriz. dans le campo, Goraz, $n^{\circ}$ 21757. Sous-frutescent, 11. jaunàtres. Novembre-décembre, C.

106. Jobinia hernandifolia Fourn. in Fl. Bras. NI, IV, p. 327. Serra de Ouro Branco, au Cesario, Mrsas, $n^{\circ} 15225$ a. Liane, fl. blanchâtres. Uctobre-novembre. R.

107. J. Lindbergii Fourn. in $\mathrm{Fl}$. Bras. VI, IV, p. 3џ̄. - Nova Friburgo, Rio-JAv., $n^{\circ}$ 18369. Liane. Novembre.

108. Barjonia racemosa Dcne; Fl. Bras. VI, IV, P. 208.. - Biribiry, près Diamantina, Mısas, nº $19633 a$. Sous-frutescent. 11. verdàtres. Mars-avril. R.

109. B. linearis Dcne; Fl. Bras. VI, IV, p. 20\%̆. - Campos da Bocaina, S. Pavlo, n 8172: Fazenda do Rio Jardim, Goraz, no 21755. Sous-frutescent, fl, verdâtres. Arril-juin. R.

110. B. triangularis K. Sch. n. sp, in herb. Paris., Berol., Kew., Gener., etc. - Caraça, dans le campo, Mrsas, $n^{\circ}$ 15234; Guariroba, au Norro Cubatĩo, Goraz, $n^{\circ}$ 21754. Sous-frutescent, f1. verdàtres. Juinjuillet. Plante rénéneuse.

111. B. platyphylla K. Sch. in Engler Botan. Jarhb. XXX (190I), Beibl., p. 3I. - Perpetua, près Diamantina, Mrsas, $n^{\circ}$ 19633. Sous-frutescent, 11. rerditres. Arril-mai. C.

II2. Marsdenia macrophylla Fourn.; Fl. Bras. VI, IY, p. 32I. Barra do Pirahy, Sussuga, près Campo, Rio-Jdx., 10s 7762, 15224, $19626 a$. Grande liane, fl. brunes. Octobre-novembre. C.

113. M. mollissima Fourn. in Fl, Bras. VI, IV, p. 322. - Parahyba do Sul, Rio-Jax., nos 12959, 21756 a. Grande liane, fl. brunes. Septembre-octobre. C.

114. M. brasiliensis Dcne? Fl. Bras. VI, IV, p. 323. - Barra do Pirahy à Ipiranga, Rro-Jar., n 7763. Grande liane, fl. brunes. Détembre-janvier. C. Vulg. : Ciipo seda.

1[\%. M. loniceroides Fourn. in Fl. Bras. VI, IV, p. 323. - Forteresse du Picó de Santa Cruz, Gavea et Suspiro de N. Friburgo, Rio$J_{\text {A. }}, \mathrm{n}^{\text {os }}$ 12953, 13472. Frutescent, 11. oranges. Mars-avril. C.

116. Stephanotella Glaziovii Fourn. in Fl. Bras. VI, IV, p. 326. Quinta da Boa Vista, S. Christorão, Rı-J̦x., nº 8804. Liane cultirée, 11. verdatres. Mai-juin. C. Vulg. : Jasmim verde. 


\section{1'an. 89. - Loganiacées.}

1. Spigelia Lundiana DC.; Fl. Bras. VI, I, p. 295. - Serra la Piedade, dans le campo, Mrxas, $n^{\text {os }} 14102,20418$. Sous-fruteserent, 11. ronges. Octobre-novembre. C.

„. S. Olfersiana Ch. et Schl.; 1\%. Bras. VI, I, 1). 29ö. - Serra de São José l'El Rei. MIxas, nos 14101, 16262. Sous-frutescent. fl. rougeâtres. C.

3. S. Sellowiana Ch. et Schl. : Fl. Bras. VI, I, 1. 2.36. - Serra da Piedade, dans le campo, Mrsas, no 20417. Sous-frutescent, 11. rouges. Novembre-décemlire. C.

4. S. Glaziovii Taub. n. sp. in hell. Paris., Berol., Kew.. Genev., etr. - Serra Estrella, près Petropolis à Grutta Funda, fío-Jan., no 14099. Sous-firutescent, fi. roses. Novembre-décembre. C.

¿. S. spartioides Cín. et Schlt.; Fl. Bras. V, I, p. 207. - Itacolumy, près Ouro Preto, Misas, no 15240. Sous-frutescent. fl. rougeàtres. Janvier-férrier. C.

6. S. Schlechtendaliana Mart.: Fl. Bras. VI, 1, p. 2:8. - Serra de Ouro Branco. dans le campo, Mlsxs, $n^{\circ}$ 15241. Sous-frutescent, fl. roses. Février-mars. C.

7. S. Martiana Clıam.; H. Bras. VI, I, p. 20̈8. - Corrego do Brejo, au campement, Goyaz, no 21758. Sous-frutescent, f1. roses. Mars-avril. C.

8. S. scabra Ch. et Schl. var. angustata Prog. Fl. Bras., VI, I, p. 261. - Restinga da Tijuca, dans les bombiers. Rı-Jax., n ${ }^{\circ} 160$. Sous-frutescent, fl. rougeàtres. Juin-juillet. C.

9. S. Humboldtiana Ch. et Schl.; Fl. Bras. VI, I, 1. „61. - Serra dos Orgĩus, par Cachambú, Rir-Jas, n 16261. Sous-frutescent, fl. roses. Décembre-janvier. C.

10. S. anthelmia L.; Fl. bras. VI, I, p. \$62. - Alto llacahé de Nova Friburgo, Rio-Jax., nos 4026, 14098, 19647. Herbacé, fl. roses. Février-mars. G.

11. S. tetraptera Taub. n. sp. in herl. Paris., Berol., Kew., Genev., ete. - Morro da Carangola, près Petropolis. Rio-Jas., n 14100. Sous-frutescent, fl. roses. Norembre-décembre. C.

12. Mitreola paniculata Wall.; Fl. Bras. VI, I, p. ¿66. - Taipú, près de la mer, Rio-Jax., ${ }^{\text {os }} 13963,18371$. Sous-frutescent, fl. blanchìtres. Mars-avril. C. 
A.-F.-M. GLAZTOL. - LISTE DES PLANTES DL BRÉSIL CEYTRAL.

13. M. petiolata Torr. et Gr.; Fl. Bras. IV, I, 1. 266. - Serra da Mantiqueira, à Joũo Gomez, Msxas, no 13968. Sous-firutescent, f1. blanchâtres. Septembre-uctubre. C.

1'. Buddleia brachiata Ch. et Schlt.; Fl. Bras. VIII, I, p. 281. Itatiaia, au bord des bois, Rio-Jax., $n^{0} 5971$ a. Arbuste. f1. rousses. Juin-juillet. C.

1\%. B. brasiliensis Jacl.; Fl. Brus. VIIl, I, p. 282. - Serra dos Orgãos, à Theresopolis, Rio-dAx., $n^{\circ} 1107$. Sous-frutescent, 11. rousse's. Jannier-février. C. Vulg. : Calca de Velho.

- Var. Glazioviana Gilg in herb. Paris., Berol., Kew., Genev., etc. - Monte Alegre, Goraz, no 21759. Sous frutescent, Il. rousses. Juinjuillet. C. Vulg. : Calca de Velho.

16. B. elegans Ch. et Schlt.: Fl. Bras. VIII, I, p. 284. - Itabira do Lampo, au bord du Fio das Velhas, Mrsas, $n^{\circ} 17171$. Arbuste, fl. rousses. doùt-sejtembre. C.

17. B. speciosissima Taub. in Engler, Botan. Jahrb. XIII (1893), lieibl., p. ડัI3. - Serra de Pirapitinga, à l'Itatiaia, Rio-Jax., nos 40926, 5971, 6662 et 8891. Arbuste fl. rousses. Décenlire-janvier, C.C.

18. B. grandiflora Ch. et Schlt.; Fl. Bras. VIII, I, p. 28\%. - Santa Luzia do Rio das Velhas, Mrxas, $n^{\circ}$ 19648. Arbuste, fl. rousses. Tovembre-décembre. C.

19. B. Glazioviana Taub. in Engler Botan. Jahrb. (1893). 1) כ̋14. - Camipo da Bocaina, au bord des bois, Rio-JAx., no 11398. Arbuste, fl. rousses. Septembre-octolre. R.

20. B. thyrsoidea Lamk? Fl. Bias. VIII, p. 286. - ltatiaia, dans le Campo Feio, Rio-Jax., no 5971 a. Arbuste, fl. rousses. Juin-juillet, R.

21. B. madagascariensis Lamk Encyclop. Method. vol. I, p. วั13. - Passeio Publico. Rio-Jax., $n^{\circ}$ 1537. Arbuste cultivé, fl. rougeâtres. Aoùt-septembre. CC.

22. Antonia ovata Pohl var. grabra Müll. Arog. in Fl. Bras. VI, I, р. 203. - Meia Ponte, dans les broussailles, Goyaz, nos 19646, 21760. Arbuste, 11. blanches. Septembre-octobre. C.

- Var. prlosa Müll. Arg.; Fl. Bras. VI, I. p. 9o3. — Caraça, dans le Campo de Fora, Mrsas, ${ }^{\circ}$ 14097. Arbuste, f1. blanches. Juin-juillet. C.

23. Strychnos triplinervia Mart.; Fl. Bras. VI, I, p. 272. - Serra dos Orgãos, Pico de Santa, São Christovão, elc., Rı-Jax.. n ${ }^{\circ}$ 5944, 9520, 9521, 17148. Arbuste, 11. blanches. Aoùt-septembre. CC. Vuls. : Cipó Cruzeiro. 
24. Strychnos Pseudo-Quina St. Ilil.; Fl. Rras. 11, 1, 1. 2)73. Serra de Ouro Branco, dans le campo, Muxas, $1^{\text {os }} 14094$, 15238; entre As Brancas ef Os Ciganos, Govxz, $n^{\circ} 21761$. Arbrisseau, fl. blanchâtres. Décembre-janvier. CC. Vulg. : Quina de periquito.

25. S. Gardneri 1. DC.; Fl. Bras. VI, I, 279. - Jacarepagua, Rio d'Ourn, Corcovado, Rio-Jax., $\mathrm{n}^{0 \mathrm{~s}} 6817,9519$. 12961. Arbuste sarmenteux, 11. blanches. Décembre-janvier. CC.

26. S. Glaziovii Gilg in Engler Botan. Jahth. XXV (1898), Beibl., p. 36. - Alto Mlacahé de Nova Friburgo, Ruo-Jan., 10 $^{\circ}$ 18370. Arbuste, f1. Llanchâtres. Décembre-janvier. R.

27. S. smilacina Benth.; Fl. Bras. VI, I, p. 274. - Rio d'Ouro et Corcovado, Rio-Jan., nos 9513, 9518. Arbuste, fl. blanchâtres. Janvierfévrier. C.

28. S. Jobertiana Baill. in Adansonia, XII, 1879, p. 367. - São Sebastião da Bura et cultivé, Rio-J $\mathrm{J}_{\mathrm{Ax}}$, $\mathrm{n}^{\text {os }} 9514$, 9941. Arbuste sarmenteux, fl. blanchâtres. Novembre-décembre. C.

29. S. Rouhamon Bentlı.; Fl. Bras. VI, I, p. 276. - Itabapoana, Espirito Santo, no 9944. Arbuste sarmenteux, fl. blanchâtres. Janvierfévrier. R.

30. S. oblonga Gilg in Engler Botan. Jahrb. (1898), p. 37. - Serra do Lenheiro, près São João d'El Rei, Mıxas, nos 14095 , 19645. Albuste sarmenteux, fl. blanchâtres. Septembre-octobre. C.

31. S. cordifolia Gilg n. sp. in Engler Botan. Jakrb. XXV (1898), Beibl., p. 38. - Itabapoana, Espirito Sasto, nos 14096 et 19645 a. Arbuste sarmenteux, fl. blanchâtres. Janvier-févirier. C..

32. S. depauperata Baill. in Adansonia, XII, 1879, p. 372. - Sete Pontes, au Baretto, Rio-JAx., n ${ }^{\circ}$ 9516, 9945. Arbuste sarmenteux, fl. blanchâtres. Janvier-féviter. C.

33. S. brevifolia Spruce; Fl. Bras. VI, I, p. 277. - Quinta da Boa Vista, S. Christovão, Rio-Jax., no 11213. Arbuste cultivé, fl. blanchâtres. Décembre-janvier. R.

34. S. rubiginosa A. DG.; Fl. Bras. VI, I, p. 277. - Sĩo Christovĩo, au Morro do Telegrapho. Rio-Jax, n² 4883. Arbuste, fl. rousses. Noveubre-décembre. C.

38. S. Castelnci Wedd.; Fl. Bras. VI, I, p. 278. - Quinta da Boa Vista, S. Christovĩo, Rio-JAN., $n^{0}$ 9517. Arbuste sarmenteux, fl, blanchâtres. Janvier-mars. Ii. 
A.-F.-M. GLAZIOU. - LISTE DES PLANTES DU RRESIL CENTRAL.

36. S. Martii Progel; Fl. Bras. VI, I, p. 279. - Serra da Bocaina, S. Pavlo, $n^{0 s} 9522,9940$. Arbuste sarmenteux, 11. blanchàtres. Févriermars. C.

37. S. calophylla Gilg in Engler Botan. Jahrb. XXV (1898), Beibl., p. 37. - Ayuruoca, dans le campo, Mrsas, no 15239, Arbuste, f1. blanches. Septembre-octobre. C.

38. S. albiflora Prog.; Fl. Brus. VI, I, p. 279. - Entre Cabo Frio et Aldeia de S. Pedro dos Indios, Rio-Jan., $n^{\circ}$ 4097. Arbuste sarmenteux, fl. blanchàtres. Septembre-octobre. C.

39. S. breviflora A. 1D.; Fl. brus. VI, I, p. 281. - Serra de Jacarepagua et Corcovado, Rio-JAx., $n^{\circ \mathrm{s}}$ 2966, 3785, 4884. Arbuste, f1. blanches. Novembre-décembre. C.

40. S. brasiliensis Nart.; Fl. Bras. VI, I, p. 281. - Serra dos Orgiios, à Theresopolis, Rı-Jan., nos 869, 6047. Arbuste, ft. blanches. Octobre-novembre. C.

41. S. Medeola Sagot; Fl. Bras. VI, I, p. 282. - São Franeisco de Paulo, Rio-Jax., $n^{0}$ 9943. Arbuste sarmenteux, fl. blanches. Janvierfévrier. R.

\section{Fam. 90. - Gentianacées.}

1. Voyria uniflora Lamk; Fl. Bras. VI, I, p. 220. - Nlto Nacahé, dans Ia forêt vierge el au Corcovado, Rio-J.s., nos 6641, 18374, 19649. Herbacé, fl. jaunes. Janvier-février. C.

2. V. flavescens Gris.; Fl. Bras. VI, I, p. 2204. - Corcovado, it Paineiras, Rı-Jax., nº 6641 a. Herbacé, fl. jaunes. Janvier-février. R.

3. Hockinia montana Gardn.: Fl. Bres. VI, I, p. 227. - Alto Macahé et Serra dos Orgĩos, Rı-JAN., $1{ }^{\circ s} 4065,4885,6899,16265$, 17150. Sous-frutescent, f1. bleues. Janvier-avril. CG.

4. Schuebleria stricta Mart.; Fl. Bras. VI, 1, p. 2I:̈. - Serra da Caraça et Biribiry près Diamantina, Mıras, $n^{\text {os }} 15245$, 19654; Lagoa Formosa, près Meia Ponte, Goraz, no 21764. Herbacé, t1. bleues. CG.

5. S. patula Nart.; Fl. Bras. VI, I, p. 217. - Sera do Cipó, près Congonhas da Serra, Mısas, $n^{\circ}$ 19656. Herbacé, 11. bleuàtres. Marsavril. C.

6. S. pusilla Hart.: Fl. Bras. VI, I, p. 217. - Itacolumy, près Ouro Preto et Diamantina, Misas, ${ }^{0 s} 15244,19655$. Herbace, n1. roses. Janvierfévrier. C. 
7. Schuebleria tenella Nlart.; Fl. Bras. VI, p. 217. - Cinalinho pris I)iamantina, Mrsas, no 19657; Lagoa Fornosa, dans le campo, Goraz, n 21763. Herbacé, li. roses. Décembre-janvier. C.

S. S. tenuifolia Don; Fl. Bras. VI, I, p. 218. - Itatiaia, dans le Camper Feio, Rio-Jax., $1^{\text {os }} 8175$, 9949; Tombador près Diamantina, Muxas, nº 19657 a. Herbacé, fl. roses. Janvier-février. C.

9. Erythræa Centaurium Pers. Syn. Plant., I, p. 283. - Itatiaia, daus le campo près du Brancho, Rio-Jax., $\mathbf{n}^{\circ}$ 6642. - Herbacé, fi. roses. Janrier-février. C.

10. Zygostigma australe Gris.: Fl. Brus. VI, I, p. 209. - Campos da Bocaina, au Bom Jardim, Sĩo Paulo, n0 9946. Herbacé, fl. roses. Janvier-février. C.

11. Dejanira erubescens Ch. et Schl.; Fl. Bras. VI, I, p. 201.Biribiry, dans le campo près Diamantina, Mrsas, $1^{\circ}$ 19651. Sous-frutescent, ft. blanc rosé. C.

- Var. pallescens Prog. Fl. Bras. VI, I, p. 201. - Rajalinha dans le campo, Goraz, n² 21770. Sous-frutescent, fl. blanches. Vulg.: Centorea ou Boca de colra. CC.

12. D. nerrosa Ch. el Schl.; Fl. Bras. VI, I, p. 202. - Serra de Ouro Braneo, près São Julião, Hıxas, nos 12963 , 18373; Fazenda da Bolivia, dans le campo, Goraz, $n^{\circ}$ 21771. Sous-fiutescent, fl. roses. Nai-juin. CG.

- Var. folrosa Griseb, Fl. Lras. VI, I, p. 202. - Congonhas do Campo et Sĩo Joño d'El Rei, Nhsas, nos 15251, 17149; Corrego do Brejo, sur la colline, Goraz, $n^{\circ}$ 21772. Suus-frutescent, fl. loses. Avriljuin. CG.

13. Schultesia subcrenata K1.; Fl. Bras. VI, I, p. 20อั. - Quarte do Biribiry, près Diamantina, Mıxas, $n^{\circ} 19653 a$. Mars-avril. CG.

14. S. gracilis Mart.; Fl. Bras. VI, I, p. 206. - Entre Inficionado et Caraça, dans le !ourbier, Mınas, $1^{\text {os }} 12962$, 19653; Cabeceiras to Rio Gama, Goyaz, $1^{\circ}$ 21766. Herbacé, fl. bleues. Mai-juillet. C.

15. S. stenophy-lla llart.; Fl. Bras. VI, I, p. 206. - Restinga de Copacalsana et Cabo Frio, dans les endroits humides, Rio-Jan, , ${ }^{0.5} 1256$, 6242 a: Barbacena, dans le campo, Mıvas, $n^{\circ s} 9947,11214$ et 19652. Herbaré, f1. roses. Juin-juillet. CC.

16. S. Benthamiana Kl.; Fl. Brrss. VI, I, p. 209. - Sĩo Fidelis, près Campos, Ro-Jax., $1^{\circ}$ 9948. Herbacé, fl. blanchâtres. Janvierf'évrier. R. 
A.-F.-M. GLAZIOU. LISTE DES PLANTLS DU BRESIL CENTRAL.

17. Coutoubea spicata Aubl.; Fl. Bras. VI, I, p. 210. - Sĩo Fidelis, près Campos, Riro-JAN., nº 9801 . Suus-frutescent, fl. jaunes. Janvier-février. C.

18. Prepusa connata Gardn.; Fl. Bras. VI, I, p. 243. - Alto Nacahé de Nuva Friburgo, Rio-Jax., $1^{\circ 5} 3813,18372,17238$. Herbacé, f1. bleu foncé. Mai-juin. C.

19. Pr. Hookeriana Gardn.; Fl. Bras. VI, I, p. 24'. - Serra dos Orginos, au sommet, Rio-Jax., $n^{\text {os }} 3814,4099,15242,16263$. Herbacé, f1. blanchâtres. Mars-avril. C.

20. Lisianthus amplissimus Mart.; Fl. Bras. VI, I, p. 232. -

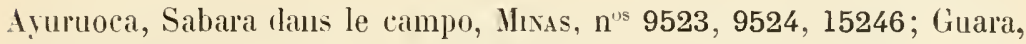
près Vicente Pires, Goraz, ${ }^{\circ s} 21768,21769$. Herbacé, fl. bleues. Févrierarril. GG.

21. L. speciosus Cham.; Fl. Bras. VI, I, p. 233. - Serra do Palmita, dans le campo, Misas, $n^{\circ}$ 15250. Herbacé, fl, rouges. Juin-juillet. C.

22. L. pendulus Mart.; Fl. Bras. VI, I, p. 233. - Serra do Batatal ou do Capanema, dans le campo, Misas, $1^{\circ}$ 15248. Herbacé, 11. rouges. Juin-juillet. C.

23. L. pulcherrimus Mart.; Fl. Bras. VI, I, p. 234. - Serra do Palmital et Serra da Piedade, dans le canpo, Mixas, nos $15249,15247 a$. Herbacé, fl. rouges. Février-mars. C.

24. L. elegans Wart.; Fl. Brus. VI, I, p. 234. - Campos da Bocaina, Sĩo Paclo, no 8477. Herbacé, fl. bleues. Férrier-mars. C.

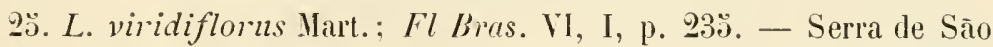
José d'El Rei, Mswas, n $^{\circ}$ 17703; Brejo do Rio Pananal, Goraz, ${ }^{\circ} 21767$. Herbacé, fl. verdâtres. Février-mars. C.

26. L. cartulescens Aubl.; Fil. Bras. VI, I, p. 236. - Source du Rio Alagado, à Ponte Alta, dans le campo, Goyaz, n² 21765 . Herbacé, fl. blanchâtres. Octobre-novembre. R.

27. L. nliginosus Gris.; Fl. Bras . VI, I, p. 237. - Marianna, près Ouro Preto, Mrxas, no 14103. Herbacé, fi. bleuâtres. Octobre-novembre. C.

⒏ L. arborens Spr.; Fl. Bras. VI, I, p. 240. - Sĩo João da Barra, près Campos, Rro-Jax., no 9950. Sous-frutescent, fl. r'oses. Janvierfévrier. C.

99. L. brevifolizls Gris.; Fl. Bras. VI, I, p. 240. - Campos di Bocaina, S. Paclo, n" 8477 a. Herbacé, fl. rosées. Février-mars. R.

30. L. Martii Gris.; Fl. Bras. VI, I, p. 241. - Cachambu, près Baependy, Misas, no 16264. Herbacé, fl. rosées. Janvier-mars. C. 
31. Macrocarpæa Glaz̧iovii Gilg in Engler lBol. Jahrb. XXIl (1897),

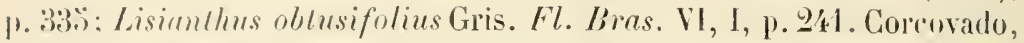
a P'aineiras, fho-Jax., $n^{0 *} 900$ et 4939. Sous-frutescent, fl. verdâtres. Aoùt-septembrr. C.

32. Symphyllophyton caprifolioides Gilg in Engler Bot. Jahrl. XXY (1898), Beib., p. 13. - Morro das Lages, entre les rucher's, Goyaz, 11" 21773. Sous-frutescent. Juin-juillet. R.

33. Senæa carulea Taub. in Engler Bot. Jahrb. XVII, 1893, p. "̈.ð. - Biribiry, près Diantantina, Mıxas, n" 19739. Sous-frutescent, 11. hleues. Férrier-mars. R.

39. Iimnanthemum Humboldtianum Gris.; Fl. Bras. VI, I, p. 2'33. - Copateabana, dans l'eau stagnante, Rio-Jav., $1^{\circ} 4270$; Carendahy, Mrsas, n² 14104; Lagoa Feia près Formosa, Goyaz, n' 21762. Herbacé, 1l. jaunes. Bécembre-janvier. CC.

\section{Fam. 91. - Hydrophyllacées.}

1. Wigandia urens Choisy; Fl. Bras. VII, p. 398. - Passeio Publico. Rro-Jax., $n^{\circ}$ 1533. Sous-frutescent, fl. blanches, Aoùt-septembre, cultivé. C.

9. Hydrolea spinosa L.; Fl. Bras. VI, I, p. 394. - Entre João Ayres et Sitio et Marimna, près Ouro Preto, Misas, $n^{03} 11280,13041$, 13042, 14146. Sous-fiutescent, fl. bleues. CC.

- Var. inermis Spr. in Fl. Bras. VII, p. 39ð. - Serra do Lenheiro près S. Joũo d'El Rei, Mıvas, $1^{\circ}$ 17155. Sous-frutescent, 11. bleues. Mars-arril. G.

\section{Fim. 92. - Borraginacées.}

1. Cordia excelsa A. DC.; Fl. Bras. VIII, I, p. 4. - Barbacena, dans Ia forêt, Misss, $n^{\text {os }} 14145$, 15276. Grand arbre, fl. blanches. Octobre-novembre. C. Vulg. : Louro.

2. C. alliodora Cham.; Fl. Bres. VIII, I, p. '́. - Petropolis, it Santo Antonio, Rio-JAx., no 8475. Grand arbre, fl. blanches. Marsavril. C.

3. C. hypolenca A. J).: Fl. Brus. VIII, I, P. 5. - Corcovado, Tijuca, Serra dus Orgãos, Ruo-Jax., ${ }^{0 s} 1105,6855,16278$. Grand arbre, f1. blanches. Mars-avril. CC. Vulg. : Louro pardo.

4. C. Chamissoniana Steud.; Fl. Bras. VIII, 1, p. ̋̈. - Entre 
Carandahy et Queluz, dans les bois, Mrsis., n" $11282,14143,14144$. Grand arbre, fl. blanches. Octolre-norembre. CC. Vulg. : Frei Jorg.

3. C. cujabensis llot et Lhans.; Fl. Bras. VIII, I, p. ॐ. - Serra Duurada, caminho do Guurguho. Goraz, $n^{0}$ 21782. Arbrisseall, fl. blanches. Aout-septembre. C.

6. C. Nettoana Taub. in Engler Bot. Jahrb. XV (1893), p. 11. Cabo Frio, dans les bois, Rio-JAx., $n^{\circ} 11283$. Arbrisseau, fl. blanches. Juin-juillet. R.

7. C. superba Cham.; Fl. Bras. VIII, I, p. 6. - Passeio Publico, Rio-JAx, $n^{\circ}$ 745. Arbuste cultivé, fl. blanches. Décembre-janvier. CC.

- Var. cunzata Fresen. in Fl. Bras. VIII, I, p. 7. - Cabo Frio, dans les bois, Rio-Jax., n 11281. Arbuste, t1. blanches. Juin-juillet. R.

- Var. elliptica Cham.; Fl. Bras. VIII, I, p. i. - Sete Pontes, au Baretto, Rıo-Jax, $n^{\circ}$ 6051. Arbuste cultivé, fl. blanches. Septembreoctobre. C. Vulg. : Juruté.

8. C. atrofusca Taub. in Engler Bot. Jahrb. XV (1893), p. 19. Sete Pontes, au Baretto, Rio-Jax., $n^{\circ}$ 12087. Arhuste cultivé, fl. blanches. Septembre-octubre. Vulg. : Clara d'ovo. R.

9. C. glabra Cham.; Fl. Bras. VIII, I, P. 8. - Floresta da Tijuca, Rio-JAx., nos 1106, 3065. Arbrisseau, fl. blanches. Février-mars. CG. Vulg. : Louro batata.

10. C. intermedia Fres. in Fl. Bras.; VIII, I, p. 8. - Floresta da Tijuca, Corcovado, Rio-Jix., $\mathrm{n}^{\text {os }} 8822,9979,13035$. Arbuste, f1. blanches. Janvier-février. C. Vulg. : Clara d'ovo.

11. C. piauhiensis Fres. in Fl. Bras. VIII, I, p. 9. - Quinta da Boa Vista, São Christovão, Rı-Jax., no 11284. Arbuste cultivé, fl. blanches. Mlars-avril. R.

12. C. mucronata Fres. in $\mathrm{Fl}$. Bras. VIII, I, p. 9. - Floresta da Tijuca et Corcovado, Rio-Jax., n ${ }^{05}$ 744, 5951, 6052, 7778. Arluste, fl. blanches. Janvier-février. CG.

13. C. candida Vell. Fl. Flum. vol. II, p. 93. - Entre Jerecino et Realengo, Rio-Jגх. n ${ }^{\circ}$ 12088. Arbuste, fl. blanches. Aoùt-septembre. C.

I4. C. grandifolia A. DC.; Fl. Bras. VIII, I, p. 10. - Corcovado et Tijuca, Iro-JAx, $1^{\text {os }} 146,1505,6050$; João Gomez, Mrsas, $1^{\circ *} 14141$, 15274. Arbuste. tl. blanches. Aont-septembre. CC.

Ið. C. magnoliafolia Cham ; Fl. Bras. VII, I, p. 12. - Floresta do Tijuca et Petropolis, Riro-Jax., ${ }^{\text {os }}{ }^{835}, 1057,5952,7780$. Arbrisseau, f1. blanches. Févier-juillet. CG. 
16. Cordia sylvestris Fres, in Fl. Bras. VIII, I, p. 12. - Cascadura, dans le buis, Rio-Jax., nº 4148. Arbrisseau, ll. blanclies. Novenıbredécembre. C.

17. C.ochnacea DC.; Fl. Bras. VIII, I, p. 13. - Morro da Babylonia, il Rotafogo, Rio-Jan., n ${ }^{05} 4149,18383$. Arbrisseau, 1l. blanclies. Février-mars. C..

18. G. estrellensis Glaz. 11. slı.? in herb. Paris., Berol., Kew., Genev., etc. - Serra da Estrella, R10-J $\mathrm{Jx}_{\mathrm{x}}, \mathrm{n}^{\circ}$ 1073. Arbuste, f1, blanches. Décembre-janvier. R.

19. C. salicifolia Cham.; Fl. Bras. VIII, 1, p. 14. - Valança, à Santa Theresa, Rio-J $\mathrm{J}_{\mathrm{X}}, \mathrm{n}^{\circ}$ 2093. Arbrisseau, fl. blanches. Septembreoctobre. R.

20. C. Glaziovii Taub. in Engler Bot. Jahrb. XV (1893), Beibl., p. 14. - Alto Nacahé de Nova Friburgo, Rio-Jav., n 18384. Arbrisseau, fl. blanches. Octobre-novembre. C.

21. C. bicolor A. DC.? Prodr. IX, p. 48\%. - Quinta da Boa Vista, S. Christovão, Rio-Jar., nº 11290. Arbrisseau cultivé, fl. blanches. Maijuin. R.

22. C. leptocaula Fres. in Fl. Bras. VIII, I, p. 14. - Itatiaia, dans le boís, SÃo Pavlo, $1^{\circ} 7780 a$. Arbuste, fl. blanches. Janvier-février. R.

23. C. Sellowiana Cham.; Fl. Bras. VIII, I, p. 14. - Entre Queluz et Ouro Preto, Minas, $n^{\text {os }} 11289$, 14135. Arbrisseau, f1. blanches. Novembre-décembre. C.

24. C. platyphylla Steud.; Fl. Bras. VIII, 1, p. 15. - Serra dos Orgãos, à Theresopolis, Rıo-Jax., n ${ }^{\circ s}$ 2862, 2863, 5950. Arbrisseau, fl. blanches. Mars-avril. C.

25. C. obscura Cham.; Fl. Bras. VIII, I, p. 15. - Nova Friburgo,

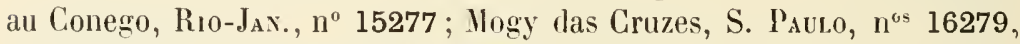
17712. Arbre, fl. blanches. Mars-avril. C.

26. C. hebecarpa DC.; Fl. Bras. VIII, I, p. 16. - Araruama près S. Pedro dos Indios, Rio-Jan., no 11286. Arbuste, f1. blanches. Juilletaoùt. R.

27. C. umbraculifera DG.; Fl. Bras. VIII, I, p. 16. - Passeio Publico, Rio-J $\mathrm{Jx}_{\mathrm{x}}, \mathrm{n}^{\circ}$ 5949. Arbrisseau cultivé, fl. blanches. Avril-mai. C. Vulg. : Guarda sol.

28. C. tetrandra Aubl.; Hist. des Pl. de la Guiane Fr. I, p. 222. Quinta da Boa Vista, Sĩo Christovão, Rio-Jav., nº 9534. Arbre cultivé, 11. blanches. Août-septembre. C. Vulg.. : Parapora. 
A.-F.-M. GlazioU. - LISTE dEs PlaNtes dU BRÉSIL CENTRAL.

99. C. nodosa Lamk; Fl. Bras. VIII, I, p. 16. - Quinta da Boa Vista, S. Christovão, Rio-Jax., n ${ }^{\circ}$ 9980. Arbrisseau cultivé, fl. blanches. Janvier-février. R.

30. C. multispicata Cham.; Fl. Bras. VIII, I, p. 17. - Entre Carandihy et Ouro Preto, Misis, ${ }^{\text {os }} 9978$, 13036; Formosa, dans les cerrados, Goyaz, $1^{\circ} 21781$. Arbuste, f1. blanches. Juin-juillet. C.

3I. C. curassavica Rem. et Selı.; Fl. Bras. VIII, I, p. 18. Copacabana et S. Christovão, 'dans les sables, Rı-JAx., nos 22, 4963. Arbuste, fl. blanches. Mars-avril. CG. Vulg. : Erva baliera.

32. C.discolor Cham.; Fl. Bras. VIII, I, p. 20. - Floresta da Tijuca et Corcovado, Rio-Jax., $\mathrm{n}^{00}$ 206, 746. Arbuste, f1. blanches. Janvierfévrier. C.

33. C. hermanniafolia Cham.; Fl. Bras. VIII, I, p. 20. - Morro da Babylonia, à Botafogo, Rı-JAv., n ${ }^{93}$ 4964, 7777. Arbuste, f1. blanches. Décembre-janvier. C.

3'. C. Salzmanni DC.; Fl. Bras. VIII, I, p. 20. - Serra de Ouro Preto, Mrsas, nº 14142. Arbuste, fl. blanches. Février-mars. C.

3\%. C. lapensis Warm. Symb. ad Fl. Bras. centr., p. 9. - Serra dos Orgãos, à Theresopolis, Rio-Jav., n ${ }^{\circ}$ 6053. Arbuste, fl. blanches. Octobre-novembre. C.

36. C. Caput-Medusa Taub. in Engler Bot. Jahrb. XV (1893), Beibl., p. 1̈̈. - Gandarela, dans le bois près des plantes fossiles, Misas, $\mathrm{n}^{0}$ 15273. Arbuste, f1. blanches. Juin-juillet. C.

37. C. globosa H.B.K. in Nova Gen. et Sp. III, p. 76. - Serra da Mantiqueira, à João Gomez, Mrsas, $n^{\circ}$ 13037. Arbuste, fl. blanches. Avril-mai. C.

38. C. patens H.B.K.; Fl. Bras. VIII, I, p. 21. - Bords du Rio Parahyba, à Boa Vista, Rio-Jax., $n^{\circ}$ 13038. Arbuste, fl. blanches. Juinjuillet CC.

39. C. calocephala Cham.; Fl. Bras. VIII, I, p. 24. - Entre Chico Lobo et les sources du Rio Torto, dans le campo, Goraz, $n^{\circ} 21780$. Petit arbuste, fl. blanclies. Octobre-novembre. R.

40. C. leucomalla Taub. in Engler Bot. Jahrb. XV (1893), Beibl., p. 14. - Larangeiras dans le bois, Rio J J $\mathrm{Jx}_{\text {. }}, \mathrm{n}^{\circ}$ 4146. Arbuste, fl. blanches. Novembre-décembre. R.

41. C. sessilifolia Cham.; Fl. Bras. VIII, I, p. 24. - Entre Chico Lobo et les sources du Rio Torto, Goraz, $n^{0} 21779$. Petit arbuste, fl. blanches. Novembre-décembre. R. 
42. Patagonula americana L.: F\%. Lras. VIII, I, 1. 27. - Serra do

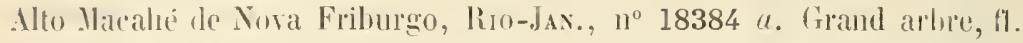
blatchathes. Novembre-dicembre.

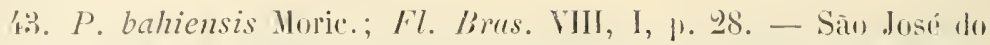
Chapadio, Mrsas, $11^{\circ}$ 15275. Grand arbre, fl. handers. Deremulorejanvier. C.

44. P. Glazioviana Mez in Engler Bot. Jahrb. XII (1890), p. I H. Nova Friburgo, au Alto da Boa Vista, Rio-JAx., no 13476. Frand arlure, f1. blanches. Octobre-novembre. C.

4.). Auxemma Glazioniana Taub. in Engler Bot. Jahrb. XV (1893), Beilı., p. I1. - Entre Araruana et Rio Bonitı, Rro-Jav., nos 11285 , 11287 , 11288. Grand arbre, fl. blanches. Juin-juillet. C.

4t. Rhabdia lycioides Nart.; Fl. Bras. VIII. I, p. is. - Itapemirim, Espirito Saxto, $n^{0}$ 11198. Arbuste, fl. blanchattres. Févilermars. R.

47. Tournefortia hirsutissima L.; Fl. Bras. VIII, I, 1) 49. Comeovado et Morro do Flemengo. Rro-Jax, $n^{0 s} 1343$, 3675. Mai-juin. CC.

48. T. levigata Lank; Fl. Bras. VIII, 1. p. 49. - Serra dos Orgãos, Jacarepagua, Rezende, Gavea, Rı-Jux., nos 3880, 4891, 7779 et 11294. Frutescent, 17. bleuâtres. Septembre-octobre. CG.

49. T. breviflora DC.; Fl. Bras. VIII, I, p. כั0. - Corcovado. à Caixa d'Agua, Rio-Jax., no 19682. Arbuste sarmenteux, fl. brunes. Janvierfévier. C.

30. T. elegans Cham.; Fl. Bros. VIII, I, p. :0. - Petropolis, a Itamaraty et à Santo Antonio, Rio-JAN., $n^{\circ 5} 8474,14136$. Frutescent, fl. hrunes. Janvier-mars. C.

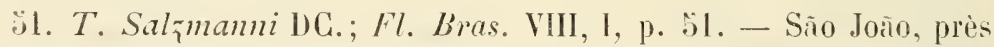
Campos, Riro-JAx.; no 9981. Frutescent, fl. blanchâtres. Février-mar's. R.

52. T. floribunda H.B.K.; Fl. Bras. VIII, I, p. 51. - Corcovado, au Bons Irmãos, Rio-Jıx., nos 188, 11295; Frutescent sarmenteux. fl. brunes. Février-mars. C.

5ั3. T. Pohlii Fres.; Fl. Bras. VIII, I, p. 52. - Nhea de Ouro Branco, Minas, n 15271. Frutescent, il. blanches. Octobre-norembre. C.

:̌4. T. rubicunda Salzm. Fl. Bras. VIII, I, p. בั4. - Petrupolis, chemin de Cachambú, Rıo-Jax., n 16277. Arbuste, fl. rousses. Juilletaoùt. C.

5ร. T. salicifolia DG.; Fl. Bras. VIII, I, p. ら6. — Sĩ̃o Joño da 
A.-F.-H. GLAZIOL. - LISTE DES PLAYTES HE BRESHL CENTRAL.

Barra, pris Campos, Ro-Jax., nº 11293. Sous-títescent, 1l. blanchâtres. Juin-juillet. R.

36. Heliotropium curassaricum L.: Fl. Bras. Vlll, I, p. 31. Sìo Vicente. dans les hourbiers. S. Paclo, n 19681. Herbacé, Il. bleutres. Férrier-mars. C.

57. H. minarum Glaz. n. sp.? in herb. Paris., Berol., hew., Gener., etc. - Entre Sitio et Barbacena, dans le bois, Mrsts, no 15272. Sous-frutescent, 11. blanc jaunàtre. C.

88. Heliophytum monostachyn DC.; Fl. Bras. V1lI, I, 1) 4ti. Calou Frio, dans les loroussailles près du phare, lino-dax., $n^{\circ} 13040$ : Sete Lagoas, Mıxas, $n^{\circ} 14140$. Sous-frutescent, fl. Wanchâtres. Aoùtseptembre. C.

59. H. phrllicoides DG.; Fl. Bras. VII, p. 46. - Serra do Cubatìo, s. Patro, no 19681 a. Frutescent, fl. blanches. Février-mars. R.

60. H. indicum DC.; Fl. Liras. VIII, I, p. 48. - Cachoeira do Cimpo, au bord lu chemin, Mrsas, $n^{\circ s} 14138,14139$. Sous-frutescent, fl. blanchâtres. Juin-juillèt. C.

61. H. persicarieefolizm DG.; Fl. Bras. VIII, 1, p. 4.7. - Sibara, dans le ehemin, Misas, $n^{\circ}$ 20425. Sous-frutescent. il. blanches. Octolrenovembre. C.

62. Schleidenia paradoxa DC. : Fl. Bras. VIII, 1. p. 38. - Entre

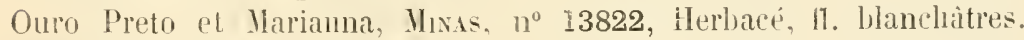
Aont-septemlre. CC.

63. S. parciflora DC. : Fl. Bras. VIII, I, p. 34. - Biribiry, près Diamantina, dans te campo, Mixss, $n^{\circ}$ 19679. Sous-frutescent, t1. blanchattres. Mars-arril. C.

6'. S. linifolia DG.; Fl. Bras. VIII, I, p. 36. - Cabo Frio, daus les broussailles et Santa Luzia, dans le campo, Mlwas, no 9975, 20424. Sous-frutescent, fl. blanches. Octobre-norembre. C.

63. S. polypinylla Fres.; Fl. Bras. VIIl, I, 1. 36. - Caho Frio, dans les broussailles, Rio-Jas., nos 11291, 13039. Sous-frutescent, f1. blanchatres. Aoùt-septemibre. C.

60. S. bahiensis Fres.; Fl. Bras. VIII, I, p. 37. - Restinga de Cabo Frio dans le sahhe, Rio-dax., $11^{\circ} 8823$. Sous-frutescent, fl. llanchitres. Octobre-novembre. C.

67. S. hispida Fres.; Fl. Bras. VIII, 1, p. 37. - Valla Funda, dans ic caupo, Hixss, $1^{\circ}$ 19678; entre Palmital et Amoreria, Gorsz. $\mathrm{n}^{\circ}=21774$, 21775. Sous-frutescent, fl. jaunes. Juin-juillet. C. 
68. Schleidenia salicoides lires.; Fl. Bras. VIII, I, p. 38. Cachoeira do Campo et Biribiry, près Diamantina, dans le campo, Mıxas, $11^{0 s} 13034,19680,19869$. Sous-frutescent, fl. blanches. Mars-avril. CC.

69. S. Clausseni Fres.; Fl. Bras. VIII, I, p. 38. - Serra dos Vertentes, près doliveira. Misas, nos 13033, 20423; Cabeceiras do Rio Sant'Anna, Goyaz, nos 21776, 21777. Frutescent, ll. blanchâtres. Décemlire-janvier. CC.

70. S. filiformis Fres.; Fl. Bras. VIII, I, p. 40. - Rio Parahybà à Rocha Leĩo, Rı-J $J_{A x}, n^{o s} 2117,8110,13061$. Sous-frutescent, fl. blanches. Janvier-février. C.

71. S. longepetiolata Fres. in Fl. Bras. VIII, I, p. 42. -- Entre Sitio et Barbacena, dans le campo, Misas, $n^{0} 11292$. Sous-fiutescent, fl. blanchâtres. Février-mars R.

72. S. inundata Fres.; Fl. Bras. VIII, I, p. 43. - Sete Lagoas, dans les bourbiers, Minas, ${ }^{08}$ 13032, 14137; Barra da Lagoa Feia, Goyaz, $\mathrm{n}^{\circ}$ 21778. Sous-frutescent, 11. blanchàtres. Juin-juillet. C.

73. Cyphomattia lanata Boiss. Fl. Orient. IV, p. 272. - Itatiaia, dans le campo, Rio-JAx., no 8731. Herbacé, fl. blanches. Janvierfévrier. R.

73. Thaumatocaryum Hilarii H. Baill. in Bull. Soc. Linn. II (1890), p. 839. - Diamantina, au Curalinho, Mıss, no 19682 a. Herbacé, fl. blanches. Mars-avril. R.

75. Echium plantagineum L.; Fl. Bras. VIII, I, p. 60. - Itatiaia, dans le campo humide, Rı-Jax., no 8731 a. Herbacé, fl. bleues. Janvier-février. R.

Fan. 93. - Convolvulacées.

1. Ipomœa Bona-Nox L.: Fl. Bras. VII, p. 21:3. - Entre Garea et Tijuca, dans les haies, Rio-JAN., $n^{0}$ 4134; Sete Lagoas, dans la forêt, Minas, $n^{\circ}$ 14130. Grande liane, fl. blanches. Septembre-octobre. C.

2. I. Quamoclit L. : Fl. Bras. VII, p. 2I7. - Quinta da Boa Vista, à S. Christovio, Rı-JAN., $11^{\circ}$ 13030. Liane cultivée, l1. rouges. Janvierfévrier. CC.

3. I. hederifolia L.; Fl. Bras. VII, p. 2IS. - Quinta da Boil Vista, à São Christovão, Rio-Jav., nos 1329 , 4888. Liane cultivée, fl. rouges. Mai-juillet. CC.

4. I. coccinea L.; Fl. Bras. VII, p. 218. - Apiahıy et près Lagoa 
Santa, Mrsas, $n^{0 s} 13003,13004,14128$. Voluhile, fl. rouges. Févriermars. C. Vulg. : Getirina.

๖. I. purpurea L. ; Fl. Bras VII, p. 223. - São Christovio, au Pedregulho, Rı-JAx., $n^{\circ}$ 3786. Volubile, fl. roses. Septembre-octobre. C.

6. I. Learii Paxt.; Fl. Bras. VII, p. 224. - Carandahy, dans les forêts, Mixas, $n^{\circ} 13003 a$. Volubile, fl. roses. Juin-juillet. C.

7. I. acuminata Romn. et Sch.; Fl. Bras. VII, p. 2226. - Sitio, près Birbacena, au bord des chemins, Mixis, $n^{0 \mathrm{~s}} 13001,13002$. Volubile, t1. roses. Juin-juillet. C.

8. I. cissoides Griseb.; Fl. Bras. VII, p. 229. - Floresta da Tijuca et Jacarepagua, Rı-Jax., $n^{\text {os }} 4889$, 14129. Volubile, fl. rose pâle. Nlaijuin. C.

9. I. fistulosa Mart.; Fl. Bras. VII, p. 239. - Aldea de São Perlro dos Indios, pres Cabo Frio, Rio-Jax.. no 8820. Frutescent, f1. roses. Juin-juillet. C. Vulg. Maravilha.

10. I. albiflora Moric.; Fl. Bras. VII, p. 230. - Santa Luzia do Rio dos Velhas et Itabira do Campo. Hiss, $n^{0 s} 17154,20421 a$. Herb. vivace, fl. hlanches. Novembre-décembre. C.

11. I. virgata Meissn. var. subspicata Meissn.; Fl. Bras. VII, p. 241. - Sabara, dans le campo, Misas, no $21785 a$. Sous-frutescent, t1. blanclıes. Novembre-décembre. R.

- Var. verbasciformis Meissn.; Fl. Bras. VII, p. 241. - Sabara, dans le campo, Mivas, $n^{\circ} 21788$ a. Sous-frutescent, fl. roses. Novembredécembre. C.

- Val. angusta Meissn.; Fl. Bras. VII, p. 241. - Paracatí, dans le campo, Mivas, $\mathrm{n}^{\circ}$ 21788. Herbacé vivace, $\mathrm{n}$. bleu rosé. Aoùt-septembre. C.

12. I. hirsutissima Gardn.: Fl. Bras. YII, p. 2妩- - Guariroba, dans le campo pierreux, Goraz, $n^{\circ} 21790$. Herbacé vivace, fl. roses. Octubre-norembie. C.

- Var. repens Glaz.? in herb. Paris., Berol., Kew., ete. - Sitio de Chico Lobo, dans le campo, Gosaz, no 21791. Rampant, 11. roses. Novembre-décembre. C.

13. I. aurifolia Damm. in Engler Bol. Juhrb. XXIII (1897), Beibl., 1. 39. - Rasgão, près Corumba, dans le campo, Govaz, no 21789. Ilerbacé, 11. roses. Septembre-octobre. C.

14. I. decipiens Damm. in Engler Botan. Jahrb. (1897), p. 40. Engenhos do Campo, dans la forèt, Mists, nos 13010, 13011. Grande liane, fl. rouge vif. Mars-avill. C. 
1ii. Ipomea villosa Veissn. Fl. Bras. VII, p. 244. - Colline d'Iparanga, S. Pauro, $1^{0}$ 16275: entre Rajalinha el Paranaúa, dans le campo, Go:nz, nº 21785. Sous-frutescent, ll. rougge pourpre. Février-mar's. C.

16. I. hrpoleuca Taul, in Engler Botan. Jahrb. XXI (1896i), p. 449. - Pords dir Rio des Couros, dans le campo, Govaz, $11^{\circ} 21786$ a. Souslintescent, fl. rouges. Janvier-février. R.

17. I. clegans Meissn.; Fl. Bras. VII, 1) 243. - Fazenda de Sĩo Bento. dans le campo, Goraz, $n^{\circ} 21786$. Sous-frutescent, il. ruses. Janvier-frivier. R.

18. I. tomentosa Pohl; Fl. Bras. VIl, p. 243. - Murro de Sãu Vicente, Sìo João d'El Rei, Mrxs, $11^{\circ}$ 15269, 17708, 17709; Chapadio dus Veadeiros, Govaz, $n^{\circ}$ 21787. Sous-frutescent, fl. blanches. Janvierfévrier. CC.

19. I. argrereia Meissn.; Fl. Bras. VII, p. 246. - Entre Fazenda dos Veadeiros et S. Bento, dans le eampo, Goyaz, no 21784. Sous-fíutescent, it. roses. Janvier-février. C.

20. I. cephalantha Damm. in Engler Bolan. Jahrb. (i897), p. 39. Biriliry, pres Diamantina, dans le campo, Hivas, no 19670 . Sous-frutescent, 11. Bleuâtres. Mars-avril. C.

21. I. angulata Mart.: Fl. Bras. VII, p. 248. - Alto da Serra de Silo Petro, dans les pâturages, Goraz, no $21783 a$. Sous-frutescent, fl. Hanc rosé. Novembre--lécembre. G.

- Var. linearis Meissn. in Fl. Bras. VII, p. 248. - Entre Rio Torto ot Rio Bananal, Goraz, $1^{\circ}$ 21783. Sous-fiutestent, fl. blanches. Marsavril. C.

23. I. angustifolia Clı.; Fl. Bras. VII, 1. 249. - Serra do Lenheiro, dans le campo, Mixas, $n^{\circ s} 17710$, 19671. Sous-frutescent, fl. roses. Décembre-janvier.

24. I. pinifolia Meissn. in Fl. Bras. VII, p. 2:0. - Norro to Salto, dans la serra de Saio José, Goraz, $n^{\circ}$ 21793. Sous-frutescent, 11. roses. Novembre-décembre. C.

20. 1. ericoides Mleissn. in Fl. Bras. VII, p. 20\%1. - Fazenda de Sio Bento, dans le campo sal)lonneux, Govaz, $n^{\circ}$ 21792. Sous-frutescent, 11. roses. Janvier-février. CC.

26. I. aturensis G. Don, Fl. Bras. VII, p. 2̈31. - Serra Canastra, Macacos, dans le canpo pierreux, Goraz, $n^{\circ}$ 21794. Herb. rivace, 11. Ulanches. Décembre-janvier. CC.

27. I. polymorpha Riedel; Fl. Bras. VII. p. 2:2. - Diamantina, au Tumbador, Minas, $n^{\circ} 19671$ a. Sarmenteux, f1. roses. Mars-avril. R. 
28. I. procumbens Mart.; Fl. Bras. VIl, p. 233. - Fazenda da Bocaina, dans le bois, Sĩo Paulo, $n^{\circ}$ 8189. Liane, 13. blane rosé. lanvierfévrier. C.

29. I. procurrens Ueissn. Fl. Lras. VII, 1. 29:4. - Itatiaia, dans le Campo Feio, Rro-Jax., $1^{\circ} 4889$ a. Sarmenterx, 11. roses. Juin-juillet. R.

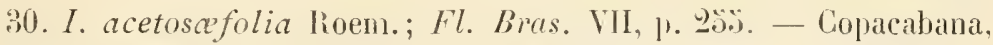

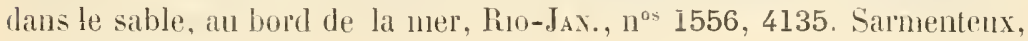
fl. blanches. Septembre-octobre. CG.

- Var. longifolia Glaz. in herb. Berol., kew., etc. - Restinga de Cabo Frio, dlans le sable au bord de la ner, Rio-Jax., no 9977. Samenteux, fl. blanclies. Août-septembre. C.

31. I. Pes-caprce Sweet; Fl. Bras. VII. p. 29.60. - Restinga de Copacabana, près de la mer, Rio-Jav., $11^{\text {os }} 101$, 4140. Sarmenteux, li. roses. Février-mars. CG.

32. I. tubata Nees.; Fl. Bras. VII, p. בos8. - Riheirĩo, à Taquaruçú, dans le bois, Misss, n 19672. Grande liane, fl. rouge pourpre. Ilai-juin. C.

32. I. Martii Meissn. in Fl. Brus. VII, p. 2:88. - Ribeirĩo, à Taquaruçú, dans le bois, Mriss, $1^{\circ \mathrm{s}} 11259$, 19673. Grande liane, 11. rouge pourpre. Hai-juin. C:

34. I. calycina Meissn. Fl. Bras. VII, p. 260. - São Sebastiāo de Itabapoana. Rio-JAx., no 11269 a. Haute liane, fl. jannattres. Juinjuillet. R.

3ö. I. astrichota Damm. in Engler Bot. Jahrb. (1897), 1. 40. Serra da Mantiqueira, dans le hois, Mrvas, $n^{\circ}$ 13008. Grande liane, fl. rouges. Février'mar's. C.

36. I. capparoides Choisy; Fl. Bras. VIl, p. 262. - Entre Lagoa de Freitas et Garea, dans le bois et les haies. Piı-Jax., $11^{\circ} 4139$. Grande liane, fl. rouge pourpre. Férier-mars. C.

37. I. floribunda Vorie.: Fl. Bras. VII, p. 262. - Gandarela, dans le bois, Mıxas, $n^{\text {os }}$ 13025, 14132. Liane, fl. blanchâtres. Juin-juillet. C.

38. I. calyptrata Damm. in Engler Bot. Juhrh. 1897), p. 40. Arassuahy, daus le bois, likis, no 15265 . Haute liane, ll. ronge foncé. Février-mars. R.

39. I. umbellata Heyer; Fl. Bras. VII, p. 263. - Serra dos Orgios. à Theresopolis, Rı-JAx, n 4887; Mattosinho, près Lagoa Santa, Mıxıs, $\mathrm{n}^{\circ}$ 14133. Liane, 11. blanc rosé. Juin-juillet. C.

40. I. batatoides Choisy; Fl. Pras. VII, p. 26ö. - Caixa d'Agua, au 
Corcovado, Rio-dax., nos 8819. 13029. Liane, 17. blanches. Févriermars. C.

- Var. tomentosa Glaz.? in herb. Paris., Berol., Kew., Genev., Havn., etr. - Serra dos Orgĩos, à Theresopolis, Rı-Jav., ${ }^{\circ} 4143$. liane, li. rouges. Nars-avril. C.

41. Ipomaa Regnellii Meissn. in Fl. Bras. VII, p. 266. - Floresta da Tijuea, Rı-Jan., nº 13029 a. Liane, fl. blanches. Février-mars. R.

42. I. fastigiata Sweet; Fl. Bras. VII, p. 267. - Larangeira, au Cosme Velho, Rı-JAN., $n^{\circ}$ 4890; Serra do Lenheiro, près S. Joĩo d'El Rei, Mısas, $n^{\text {os }} 13005,13006$. Liane, 11. roses. Juin-juillet. C.

- Var. pauciflora Siveet; $F l$. Bras. VII, p. 267. - Lagoa de Freitas et Gavea, R10-Jax., $1^{0 s} 4133,4137,4141$. Liane, 1l. roses. Févriermars. C..

43. I. Peckolti Heissn. in Fl. Bras. VII, p. 268. - Restinga de Copacabana, Rio-JAx., n ${ }^{0}$ 5791. Liane, fl. roses. Octobre-novembre. R.

4. I. syringafolia Neissn. in Fl. Bras. VII, p. 270. - Nova Friburgo, dans la forêt, Rıo-Jan., $n^{\circ 5} 4136,18382$, fl. blanchâtres. Janviermars.

45. I. Selloi Meissn. in Fl. Bras. VII, p. 271. - Restinga de Cabo Frio, dans les broussailles, Rı-Jas., $\mathbf{n}^{\circ} 11269$. Volubile, fl. blanchâtres. Juin-juillet. R.

46. I. Gipo-colla Glaz.n. sp. in herb. Berol., Kew., Paris., Havn., etc. - Juiz de Fora, dans les bois, Mnsas, no 8821 a. Grande liane, f1. blanchâtres. Mars-avril. R. Vulg. : Cipó colla.

47. I. goyazensis Gardn.; Fl. Bras. VII, p. 273. - Floresta da Tijuca et Pahmeiras, dans le bois vierge, Rio-Jax., $n^{\text {os }} 8190,8821$. Très haute liane, fl. rouges. Mars-avril. C.

48. I. triloba L.; Fl. Bras. VII, 1. 277. - Serra da Mantiqueira, près João Ayres, dans le bois, Irsas, $n^{\circ} 13021 a$. Liane, fl. roses. Juinjuillet. C.

49. I. digitata L.; Fl. Bras. VII, p. 278. - Entre Cabo Frio et Araruama, dans le bois, Rı-Jax., $\mathrm{n}^{\circ} 11262$. Grande liane, fl. roses. Juinjuillet. R.

50. 1. dichotoma Choisy; Fl. Bras. VII, p. 281. - Serra de Nantiqueira, près Juão Ayres, Mıxas, no 13021 . Volubile, f1. rose pâle. Juinjuillet. C.

51. I. Batatas Lamk; Fl. Bras. VII, p. 282. - Quinta da Boa Vista, 
A.-F,-M. GLAZ10L. - LISTE DES PIANTES DC BRESIL CENTRAL.

S. Clhristovão, Rı-JAx., n 4132. Herbacé vivace, cultivé, fl. roses. CC. Vulg. : Batata doce.

32. I. sinuata Ortega; Fl. Bras. VII, p. 284. - Gavea, dans les bois et les haies, Rı-JAx., nº 4138. Liane, fl. blanches. Janvier-février. C.

33. I. Gla iovii Damm. in Engler Kot. Jahrb. (1897), p. 40. - Piratiniıga, au bord de la mer, Rio-Jax., n 15267. Grande liane, fl. jaunes. Janvier-février. CC.

ت̈. I. pentaphylla Jacq.; Fl. Bras. YII, p. 287. - Entre Gavea et Tijuca, dans les haies, Rio-JAx.. n ${ }^{\text {os }} 7882$, 11264; Arassuahy, dans le bois, Mras, $n^{0}$ 13026. Volubile, fl. blanchâtres. Mai-juin. C.

3̈.). I. glabra Choisy; Fl. Bras. VII, p. 287. - Serra dos Orgãos et Petropolis, dans les bois, Rio-Jas., nos 1150, 4144, 13124, 14134. Haute liane, 11. blanc jaunâtre. Avril-mai. CG.

ว̆6. I. stipulacea Jacq.; Fl. Bras. VII, p. 288. - São Christovĩo,

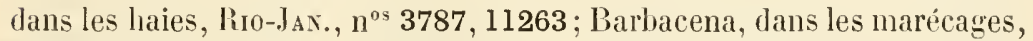
Misas, ${ }^{0 s} 13020$, 13028. Volubile, fl. roses. Juin-juillet. C.

รั7. Operculina Convolvulns Manso; Fl. Bras. VIi, p. 211. - Ilha do Governador, Rio-Jax., $11^{0} 7881$; Sete Lagoas, dans le bois, Misas, $n^{0}$ 14131. Grande liane, 11. jaunes. Février-mars. C. Vulg. : Jalapinha ou Balala.

38. O. altissima Meissn.; Fl. Bras. VII, p. 213. - Oueimado, dans le bois, Rı-JAn., nº 11258. Haute liane, fl. jaunes. Février-mars. C.

ॐ9. Aniseia cernua Moric.; Fl. Bras. VII, p. 319. - Sitio de Barbacena, daus les bourbiers, Mixas, $n^{0}$ 13022. Liane, f1. banches. Maijuin. C.

60. A. nitens Choisy; Fl. Bras. VII, p. 321. - Entre Sitio et Barbacena, sur les arbustes du campo, Misas, $n^{\circ}$ 13023. Liane, f1. blanc jaunàtre. Juin-juillet. C.

61. A. syringifolia Damm. in Engl. Bot. Jahrb. (1897), p. 38. Floresta da Tijuca, Rio-Jax., n 8191. Grande liane, 1 . jaunàtres. Marsavril. C.

62. A. gracillima Ciloisy; Fl. Bras. VII, p. 322. - Sĩo Sebastião, près Campos, liso-Jax., no 9970. Sous-frutescent, fl. blanches. Févriermars. R.

63. Calystegia Glaziovii Damm. in Engler. Bot. Jahrb. (1897), p. 11. - Pres Queluz, dans la forèt, Misas, n 13009. Grande liane, fl. blanches. Mars-avril. C.

64. C. discolor Damm. in Engler Bot. Jahrb. (I897), p. 42. - 
Ayuruoca, dans la forèt vierge, Mrsas, no 11260. Grande liane, fl. violettes. Aont-septembre. R.

63. Jacquemontia confusa Heissı.; Fl. Brus. VII, p. 294. - Serra da Mantiqueiral, daus le bois, Mrisas, $n^{\circ}$ 13018. Sous-frutescent. fl. bleu pile. Juin-juillet. CC.

66. J. velutina Choisy; Fl. Bras. VII, p. 294. - Entre Sitio et Barbacena, dans les bois, Mivas, $n^{\circ}$ 13027. Arbuste sarmenteux, fl. blanches. Juin-juillet. CG.

67. J. menispermoides Choisy; Fl. Bres. VII, p. 298. - Corcovado, it Caixa d'Igua, Rio-JAx., nº 690. Sarmenteux, fl. bleues. Janvier-mars. C.

68. J. Martii Choisy; Fl. Bras. VII, p. 298. - Floresta da Tijuca, à Soledad, lino-Jax., nos 334, 4130. Volubile, 11. bleu pâle. Janvierfévrier. C.

69. J. erecta Choisy; Fl. Bras. VII, p. 298. - Entre Sitio et Barbacena, dans les petits bois, Misas, $n^{\text {os }} 1307,15264$. Volubile, il. bleuâtres. Janvier-février. C.

70. J. hirsuta Choisy: Fl. Bras. VII, p. 298. - Entre Sitio et Barbacena, dans le campo, Mrsas, $n^{\circ} 13007$ a. Sous-frutescent, 11. blanchàtres. Juin-juillet. R.

71. J. grandiflora Vleissn.: Fl. Bras. VIl, p. 300. - Paraopeba, près Barbacena, dans le bois, Mnvas, $n^{\circ} 13027$ a. Volubile, f1. blanchâtres. Juin-juillet. R.

72. J. capitellata Chois!; Fl. Bras. VII, p. 301. - Chapadão dos Veadeiros, dans le campo, Goyaz, $n^{0} 21796 a$. Sous-frutescent, fl. blanches. Janvier-février. R.

73. J. eriocephala Choisy; Fl. Bras. VII, p. 303. - Petropolis, à Santo Antonio, Rio-Jax., n ${ }^{\circ}$ 5947; Rio Manso, dans les bois humides, Mrnas, no 15266. Liane, fl. jaunâtres. Aoùt-septembre. C.

74. J. grandifolia Damm. in Engler Bot. Jahrb. (1897), p. 41.São Christovão, à Pedregulho, Ruo-Jax., no 11257 . Volubile, f1. roses. Février-mars. C.

7\%. J. serrata Vleissn.; Fl. Bras. Vil, p. 304. - Norro da Urea, à Botafogo, Rio-Jax., $n^{\circ}$ 11266. Volubile, fl. hanchattres. Mars-avril. C.

76. J. rufovelutina Meissn. in Fl. Bras. VII, p. 30̋̈. - Campos da Bocaina, S. Pauto, $11^{\circ} 12167$ a. Sous-frutescent, it. blanchàtres. Aoùtseptembre. R.

77. J. rufa Dammer in Engler Bot. Jahrb. (1897), p. '1. - Guara, 
1.-F.-I. GLAZIOU. - LISTE DES PLAXTES DU BLESIL CEYTRAL.

près Vicente Pires, daus le campo, Goyaz, n² 21796. Sous-frutescent, 11. blanchàtres. Février-mars. C.

78. J. evolvuloides Meissn. in Fl. Bras. VII, p. 307. - Campos da Bocaina, S. PAuro, $1^{\circ}$ 11267. Sous-frutescent, tl. blanchàtres. Loùt-septemble. R.

79. Convolvulus nodiflorus Desl.; Fl. Bras. VII, 1. 310. - Serra da Vlambucaha, Sĩo Paúo, $n^{\circ}$ 11268. Samenteux, fl. blanchâtres. Aoùt-septembre. R.

80. C. hirsutiflorus Damm. in Engler Bot. Jahro. (1897), p. 41. Praia Grande, à Jurujuba, Rio-Jax., no 8188. Liane, 11. blanches. Uarsavril. C.

81. C. Ottonis Meissn.; Fl. Bras. VII, p, 311. - Ayuruoca, dans le bois, Mıxs, no 11260 a. Volubile, tl. blanches. Août-septembre. C.

82. C. Hermannia L'Herit.?; Fl. Bras. VII, p. 312. - Diamantina, à Formaçio et au Rio Manso, Mlsas, nos 13017, 19668. Liane, fl. bleuâtres. Mars-avril. C.

83. Evolvulus pterocaulon Moric; Fl. Bras. VII, p. 333. - Pão d'Alho, Espirito SAxto, no 9968; Parauna, chez Cesario, Mixas, no 19674. Sous-frutescent, fl. blanches. Mars-avril. CC.

84. E. pterygophyllus Mart.; Fl. Brts. VII, p. 333. - Entre les sources du Rio Torto et Sobradinho. Goraz, no 21798. Sous-frutescent, fl. bleues. Noremlre-décembre. C.

8\%. E. hypocrateriflorus Damm. in Engler Bot. Jahrb. (1897), 1. 37. - Entre Fazenda da Boa Vista et Rio dos Couros, Goraz, $1^{\circ} 21803$. Sous-frutescent, fl. bleues. Janvier-férrier. C.

86. E. Chamcepitys Mart. val. cæsprtosus Meissn.; Fl. Bras. VIl, p. 333. - Entre Fazenda Bolivia et Herculano Lobo, Goyaz, n 21795. Frutescent, fl. bleues. Octobre-norembre. C.

87. E. glomeratus Nees et Mart. in Fl. Bras. VII, p. 33\%. - Inficionado, dans le campo, pres Caraç, Mrsas, n's 11275, 13016. Sous-frutescent, 11. bleues. Novembre-décembre. C.

- Var. excrescexs Meissu. in Fl. Bras. VII, p. 336. - Restinga de Lopacabana, Rio-Jix., u $^{\circ} 8186 a$. Sous-fiutescent, fl. bleues. Juillet aoùt. C.

- Val. oвtusus Meissn. in Fl. Bras. VII, p. 336. - Pedra dos Cabritos, à Copacabana, Rı-Jıx., nos 8186 , 12086. Sous-frutesıent, f1. bleues. Juin-juillet. CC.

88. E. Martii Meissn.; Fl. Bras. VII, 1. 337. - Morro de Sio Vicente, Misas, no 15270. Sous-frutescent, tl. bleues. Févier-mars. R. 
89. Evolvulus liramerioides Nart.; Fl. Bras. VII, p. 338. - Serra da Piedade, dans le campo, Mixas, $\mathbf{n}^{\circ}$ 20421. Sous-frutescent, fl. bleues. Novembre-lécembre. C.

90. E. Glaz̧iovii Damm. in Engler Bot. Jahrb. (1897), 1. 37. Serra dos Cristaes, près Diamantina, Misas, $n^{\circ}$ 19675. Frutescent, fl. bleues. Mars-avril. C.

91. E. echioides Moric.; Fl, Bras. VII, p. 338. - Ayurnoca, au Pico do Papagaio, dans le campo, Mrxas, $\mathrm{r}^{\circ}$ 16276. Sous-frutescent, fl. bleuâtres. Janvier-février. C.

92. E. goyazensis Damm. in Engler Bot. Jahrb. (1897), p. 37. Barra du kio Torto et Fazenda da Amoreira, Goraz, no 21802. Sousfrutescent, fl. bleues. Février-mar's. C.

93. E. fuscus Meissn.; Fl. Bras. VII, p. 339. - Fazenda dos Porcos, au bord du Rio Pizarão, Goraz, $n^{\circ}$ 21800. Sous-frutescent, fl. blanches. Janvier-février. C.

- Var. villosus Damm. in herb. Paris., Berol., Kew., Brux., etc. Fazenda do Lambary, près Lagoa Formosa, Govaz, $n^{\circ}$ 21801. Sous-frutescent, fl. blanches. Janvier-février. C.

94. E. phyllanthoides Moric.; Fl. Bras. VlI, p. 339. - Morro de São Vicente, dans le campo, Mras, $n^{\text {os }} 11272,13015$, 15268. Arbuste, 11. blanches. Janvier-février. C.

98. E. graminifolius Damm. in Engler Botan. Jahrb. (1897), p. 38. - Restinga de Cabo Frio, Rı-Jax., nº 11265. Sous-firutescent, 11. bleuttres. Mai-juin. R.

96. E. gypsophiloides Moric, Fl. Bras. VII, p. 340. - Cabo Frio, au Morro do Phare, Rio-JAx., $1^{\circ s} 9972,11271$. Sous-frutescent, f1. bleuâtres. Mai-juin.

97. E. elegans Moric. var. capillaceus Meissn. in Fl. Bras. VII, p. 341. - Serra de Ouro Branco, Misas, no 17711 . Sous-frutescent, fl. blanclıes. Janvier-férrier. C.

98. E. filipes Mart.; Fl. Bras. VII, p. 342. - Praia Grande, au Morro do Cavellào, Rio-Jax., nº 6813 a. Herbacé, fl. bleuâtres. Novembredécembre. R.

99. E. romarinifolius Danm. in Engler Bot. Jahrb. (1897), p. 38. - Congonhas do Campo, Mrss, $n^{\circ}$ 13014. Sous-frutescent, fl. bleu pàle. Janvier-mars. C.

100. E. alsinoides L.; Fl. Bras. VII, p. 343. - Pico de Santa Cruz, à Praia Grande, Rro-Jax., ${ }^{\prime s}$ 5948, 6813, 9973; Serra de Ouro Banco, 


\section{MENOIRES PUBLIÉS}

1. Christ, Fougères de la Chine, 69 p. (mai 190ð), terminë.

2. Terracciavo, Gagea du nord de l'Afrique, 26 p. (nov. 1905), terminè.

3. Glaziod, Plantes du Brésil central, 112 p. (nov. 1903), à suivere.

ษ. Finet el Gagnepain, Flore de l'Asie orientale, ăł p.; 8 pl. (I-VIII) distribuées avec la table de $190 \Xi$ (mars 1906), à suivre.

ร. Lignier, Anatomie des Renonculacées, 38 p. (juin 1906), terminé. 3b. Glaziou, Plantes du Brésil central. p. 113 -200 (juil. 1906), à suivre.

4 (2 partie). Finer et Gagnepan, Fl. de l'Asie or, p. כૅă-170, pl. 1X-XX (déc. 1906), à suiore.

6. Perrot et Gérard, Inatomie du tissu ligneux dans ses rapports avec la diagnose des bois, 43 p.; 6 pl. (juin 1907), terminé.

7. Pitard, Muscinées les illes Canaries, 44 p. (juin 1907), terminé.

8. Chevalier, Novitates floræ africanæ ( $1^{\mathrm{re}}$ partie), pp. 1-30 (aoùt 1907), à suivre.

9. Finet, Orchidées africaines de la tribu des Sarcanthées, $6 \unlhd$ p.; 12 pl. (nov. 1907), terminé.

10. Fuche, Monocotrlédones arborescentes ou frutescentes de France, d'Algŕrie ou de Tunisie, $₫ 6 \mathrm{p}, ; 1 \mathrm{pl}$. (août 1907), terminé.

11. P. Guérrs, Études sur les Diptérocarpées, 93 p. (décembre 1907), terminé.

3c. Grazıov, Plantes du Brésil central, pp. 201-296 (février 1908), à suivre.

12. Hue (abbé), Liclens Tarbelliens, 19 p. (avfil 1908), terminé.

13. O. Lignier, Le fruit des Bennettitées et l'ascendance des Angiospermes, 17 p. (avril 1903), terminé.

8b. Chevalier, Noritates floræ africanæ (2e partie), pp. 31-109 (aoùt 1908), at suive.

14. Paris (Général) Florule bryologique de la Guinée française, 66 p. (novembre 1908), terminé

3d. Graziou, Plantes du Brésil central, pp. 297-392 (juin 1909), à suivre.

1ร. Laubr, Nouvelb méthode technique pour l'éturle paléophytologique des formations sédirrentaires anciennes, 110 p. (janvier 1910), terminé.

16. Díbaro, Reche'ches sur le genre Palaquium, 24p. (décembre 1909), lerminé. 3e. Gudziou, Plantss du Brésil central, pp. 393-488 (mars 1910, à suivere. 


\section{AVIS IMPORTANTS relatifs à la Publication du BULLETIN}

1. - Les manuscrits, rédigés ne varietur et lisiblement, doivent être déposés le jour mime ou sont faites les communications, faute de quoi leur impression est ajournee sans que les auteurs puissent élever de réclamation à cet égard.

I1. - Si les manuscrits sont accompagnes de figures destinées à c̀tre insérées daus le texte, celles-ci doivent être dessinees a la plume et au trait, ou lien au crayon Wolli sur papier procédé, ou consister en bonnes photographies, de maniere a en permette la reproduction par les procédés zincographiquies. L'insertion de tonte ligure ne pouvant ètre reprodnite que par des procédés diflèrents reste soumise a l'approbation de la Comuinission du Bulletin.

11I. - Les auteurs reçoivent une épreuve en placards et en double exemplaire de leurs communications, la correction des autres epreuves etant faite par le secretariat. Les currectious doivent ètre retournées dans le delai maximum de trois jours au secretaire-rédacteur, faute de quoi la currection est laite d'office par le Secrètariat.

IV. - Lorsque les manuscrits dépassent la longueur réglementaíre de 8 pages et qu'ils ne comportent pas de question de priorite, ils peuvent êtré publiés sous la rubrique: Mémoires puhliés par la soriété britunique de France. Ces. Mémoires sont édités avec toute la célérité possible, mais sans garantie de date. lls prennent place dans les volumes annuels a la suite des comnunications insérées aux séances ordinaires et sont fournis aux Membres de la Société sans. majoration de leur cotisation.

V. - Afin de permettre l'établissement des convocations aux séances, MM. les dnteurs sont instamment priés d'aviser le Secrétai"e général huit jours a l'arance des communications qu'ils ont l'intention de présenter.

VI. -- En vue d'assurer l'unité typographique du Bulietin, le Conseil a arrêté le protocole ci-tlessous, réglant les caractères employés dans les tescriptions ou citations de végétaux. Il ne sera admis aucune dèrogaticn à cette règle.

FAMILLE.

Sovs-Fanili.

Tribu.

GENRE.

EsPéce.

Y'ARIÉTÉ.
NOUVELLES

1. LÉGUMINEUSES.

3. Papilionacées.

5. MEDICAGO.

7. Cylindracea.

9. Laciniata
A NGIENNES

2. LEGUMINEUSES.

4. Prpilionacées.

6. Midicago.

8. Cyindracea.

10. Løiniata.

Tout ce qui concrine l'administration de la Société doit être adressé au Serrètaire gènéral a l'adresse suivante:

11. Lutz, professeur agrégé á l’École supérieure de phırmacie, 4, avenue de l'Observatoire, Paris $\left(\mathrm{VI}^{\mathrm{e}}\right)$.

Le Secrétaire-rédacteur, Géiant du Bulletin:

F. Canos.

Coulommiers.- Imp. PAUL BRODARD. 


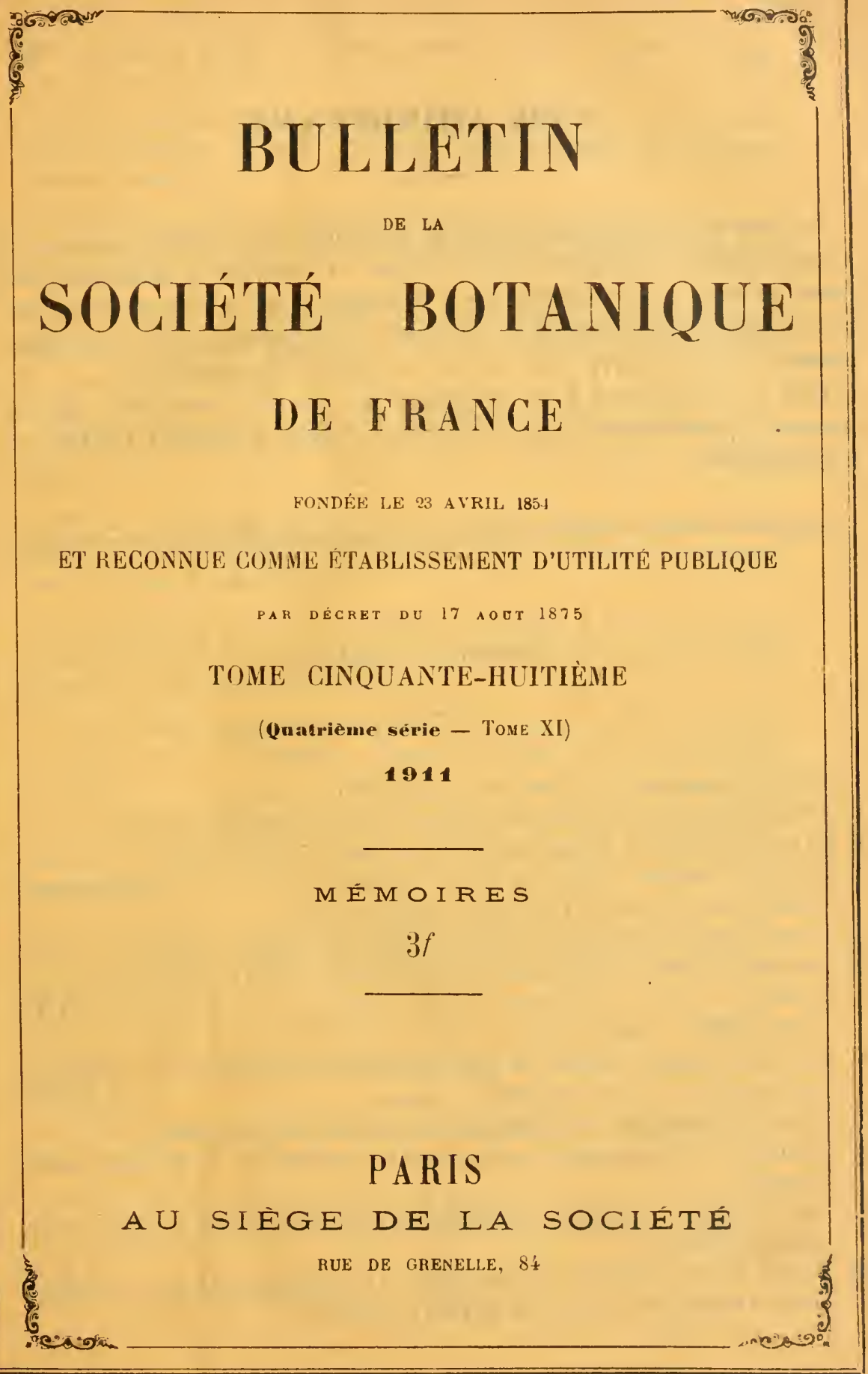

Le Bulletin de la Societe botanique de France paraît par livraisons mensuelles. Le Bon à tirer de ce numèro a été donné le 6 décembre 1911. 


\section{AVIS IMPORTANT}

Par suite de l'augmentatiou croissante du nombre des communications et de sa répercussion sur les finances de la Société, la Commission du Bulletin croit devoir rappeler à nos Confrères que le Règlement limite la longueur des manuscrits à huit pages d'impr'ession par séance et à quarante pages pour l'année entière, au delà desquelles l'auteur doit sa collaboration pécuniaire.

Dans un intérêt commun, la Commission prie donc très instamment M.M. les Auteurs de condenser le plus possible le texte des Notes destinées à l'impression.

\section{MEMOIRES PUBLIES}

1. Christ, Fougères de la Chine, 69 p. (mai 1905), terminé.

2. Terracciano, Gagea du nord de l'Afrique, 26 p. (nor. 1905), leminé.

3. Glaziou, Plantes du Brésil central, 112 p. (nov. 190.5), à suivre.

4. Finet el Gagnepain, Flore de l'Asie orientale. ö́ p.; 8 pl. (I-VIII) distribućes avec la table de 1905 (mars 1906), à suivre.

๑. Lignier, Anatomie des Renouculacées, 38 p. (juin 1906). terminé.

3b. Glaziou, Plantes du Brésil central, p. 113-200(juil. 1906), à suivre.

4 (2e partie). Finet et Gagnepan, Fl. de l’Asie or., p. כૅ-170, pl. IX-XX (déc. 1906), à suivre.

6. Pernor el Gérard, Anatomie du tissu ligneux dans ses rapports avec la diagnose des bois, 43 p.; 6 pl. (juin 1907), terminé.

7. Prtard, Muscinées des îles Canaries, 44 p. (juin 1907), terminé.

8. Chevalier, Noritales flore africunæe (1 partie), pp. 1-30 août 1907), a suivre.

9. Frnet, Orchilées africaines de la tribu des Sarcanthées, 6. p.; 12 pl. (nov. 1907), terminé.

10. Fliche, Monocotylédones arborescentes ou frutescentes de France, d'Algárié ou de Tunisie, 26 p.; 1 pl. (août 1907), terminé. 
dans le campo, Mrisas, $1^{0 s} 11273,13013$ et 17711. Herbacé, fl. blanc rosé. Janvier-mar's. CC.

101. E. pusillus Choisy; Fl. Bras. VII, p. 346. - Fazenda de Santa Cruz et Imbitiba, Rio-Jan., $\mathrm{n}^{05}$ 4967, 6055. Herbacé, fl. blanches. Octobre-novembre. G.

102. E. tenuis Mart.; Fl. Bras. VII, p. 346. - Aldea da Serra de Ouro Branco, dans le bois, Mixas, $n^{\circ} 14126$. Sous-frutescent, fl. blanches. Janvier-février. G.

103. E. frankenioides Horic.; Fl. Bras. VIl, p. 348. - Formosa, dans le campo, entre les rochers, Goyaz, $n^{\circ}$ 21806. Sous-fiutescent, fl. bleues. Janvier-février. C.

104. E. villosus R. et Pav.? - Sĩo Fidelis, entre les pierres, RioJax., $n^{\circ}$ 9974; Cachoeira do Campo, Visas, $n^{05} 1127,624020$. Décembrejanvier.

10ə.. E. chapadensis Glaz. n. sp. in herb. Paris., Berol., Kew., Genev, etc. - Chapadão dos Veadeiros, Govaz, $n^{\circ}$ 21804. Sous-firutescent, fl. bleues. Janvier-février. C.

106. E. nummularius L.; Fl. Bras. VII, p. 349. - São Christovâo, a Pedregulho, Corcovado, etc., Rio-Jax., nos 3064, 11277, 13019, 17153. Herbacé, fl. blanches. Janvier-mars. CG.

107. E. macroblepharis Mart.; Fl. Bras. VII, p. 30̈0. - Cachoeira do Campo, Mrxas, $n^{\circ} 20420$ a. Herbacé, fl. blanches. Décembre-janvier. R.

108. E. canescens Meissn. in Fl. Bras. VII, p. 350. - Campos da Bocaina, au Bom Jardim, S. Pauıo, no 8187. Herbacé, fl. bleues. Janvier-février. C.

109. E. incanus Pers.; Fl. Bras. VII, p. 30ั2. - Guara, près Vicente Pires, dans le campo, Goyaz, $n^{\circ}$ 21805. Sous-frutescent, f1. bleues. Février-mar's. C.

110. E. holosericeus H.B.K.; Fl. Bras. VII, p. 392. - Serra da Italuapoana, Esp. Surto, no 11270. Herbacé, f1. blanches. Seplembreoctolne. R.

111. E. sericeus Swartz; Fl. Bras. VII, p. 3033. - Carandahy, dans le campo, Mıxas, n 13475 . Herbacé, fl. blanches. Juin-juillet. C.

112. E. argyreus Choisy; DG. Prodr. IX, p. 44T. - Formosa, entre les pierres, Goraz, no 21806 a. Frutescent, fl. bleuâtres. Févriermars. R.

113. E. latifolius Ker-Gawl in Bot. Reg.; Fl. Bras. VII, p. 334. - 
Lalrangeiras w Copacabana, Rin-Jas., nos $1311,4147,11274$. Frutescent. 11. blanches. Décombre-janvier. C.

114. Evolvulus passerinoides Meissn. in Fl. Bras. VII, p. 39̈3̈. Chapadio dos Veadeiros, près Otho d'Agnua do Vente, Goraz, nº 21804. Frutescent, il. bleues. Février-mars. C.

110̈. E. Maximiliani Mart.; Fl. Bras. VII, p. 3306. - Restinga da Tijuca et Mlorro dos Cabritos, Rio-JAs., $\mathrm{n}^{\text {os }}$ 606, 6054. Frutescent, 11. blanches. Septembre-octobre. C.

116. $\boldsymbol{E}$. erectus Glaz. n. sp.? in herb. Paris., Berol., Kew., Gener., etc. - Diamantina, à Formaçĩo, NIsas, n 19669. Frutescent, it. bleues. Mlars-avril.

117. Breweria venulosa Meissn. in Fl. Bras. VII, p. 326. - Serra de Itabapoana, Espmito Santo, $1^{\circ}$ 9976. Liane. fl. blanches. Aoùt-septembre. C.

118. B. Langsdorffii Meissn. in Fl. Bras. VII, p. 32̈. - Norro da Babylonia, à Botafogo, Rio-Jax., no 18381. Liane, 11. blanches. Vévriermars. CC.

119. B. Burchellii Choisy; Fl. Bras. VII, p. 326. - Larangeiras, au Cosme Velho, Rio-Jan., n 4142; Liio Manso, Minas, $n^{\circ}$ 14127. Liane, 11. blanches. Mars-avril. C.

120. Prevostea ferruginea Choisy; Fl. Bras. VII, p. 323. - Sĩo Francisco de Paulo, près Manguinhas, Rı-JAs., $11^{\circ} 9976$ a. Liane, 11. blanchâtres. Janvier-férrier. R.

121. P. umbellata Choisy; Fl. Bros., VII, p. 324. - Corcovado, it Santa Theresa, Rio-JAx., $1^{\circ}$ 4131. Liane, f1. blanches. Novembredécembre. C.

122. P. spherocephala Damm. in Engler Bot. Jahrb. XXIII (1897), Reibl. $n^{0} 57$, 1. 37. - Serra Douradi, au sommet, Goyaz, $n^{\circ} 21797$. Sousfrutescent, fl. bleues. Aoùt-septembre. C.

123. P. capitata Damm. in Engler But. Jahrb. XXIII (1897), Beibl. $n^{\circ} 57$, p. 36. - Fazenda da Boa Vista, près Morro do Salto, Goraz, $n^{0}$ 21799. Sous-frutescent, f1. bleues. Janvier-février. R.

124. Dichondra macrocalyx Meissn. in Fl. Bras. VII, 1. 33̈8. Campos da Bocaina, S. Paulo, $n^{\circ} 8187$ a. Herbacé, fl. blanchâtres. Janvier-férrier. R.

123. D. sericea Sw.; Fl. Bras. VII, p. 3399. - Campos da Bucaina, S. Paulo, $n^{\circ} 8187$ b. Ilerbacé, n. blanches. Janvier-février. R.

126. Cuscuta americana L.; Fl. Bras. VII, p. 376. - Serra Dou- 
radą. it Otho d'Agua et à Taboca, Goyaz, $n^{\text {os }} 21809$, 21810. Volubile, f1. jaunes. Toute l'année. C. Vulg. : Cipó chumbo.

127. C. platy loba Prog. in Fl. Bras. V11, p. 381. - Serra da Baliza, près Fazenda dos Porcos, Goyaz, $n^{\circ}$ 21808. Volubile, 11. jaunes. Toute l'année. C. Vulg. Cipó chumbo.

128. G. tenuicaulis Glaz. n. sp.? in herb. Paris., Berol., Kew., Gener, etc. - Diamantina, au Tombador, Misas, $n^{\circ}$ 19676. Volubile, sur Myrtacée's, fl. jaunes. Toute l'année. C. Vulg. : Cipó chumbo.

129. C. corniculata var. spharocyma Engelm.; Fl. Iras. VII, p. 382. - Serra dos Pyreneus, près Meia Ponte, Goraz, $n^{\circ} 21811$. Sur Myrtacées, fl. jaunes. Toute l'année. C.

130. C. racemosa Mart.; Fl. Bras. VII, p. 383. - Floresta da Tijuca, Corcovado, Gavea, etc.; Rio-Jav., $n^{\text {os }} 335,11279$; Diamantina et Santa Luzia do Rio das Velhas, Mwsas, $1^{\circ 5}$ 19677, 20422. Volubile, f1. jaunes. Toute l'année. CC. Vulg. : Cipó chumbo.

\section{Fam. 94. - Solanacées.}

1. Lycopersicum esculentum Mill.; Fl. Bras. X, p. 126. - Quinta de Sãn Christovão, Rio-Jav., $n^{0}$ 12098. Herbacé, fl. blanches, cultivé. Septembre-octobre. CG.

2. Solanum tuberosum L.; Fl. Bras. X, p. 12. - Alto Vlacahé de N. Friburgo, Rio-JAv., $11^{\circ} 14185$ a. Herbacé, fl. bleuâtres, cultivé. Juillet-septembre. CG. Vulg. : Ingleza.

3. S. amplexicaule Sendt.; Fl. Bras. X, p. 14. - Gandarela, dans la forèt, Mixas, $n^{\circ}$ 15304; Nova Friburgo, au Conego dans le bois, Rio-Jax., no 18409. Sarmenteux, 11. bleues. Juillet-septembre. C.

- Var. pubescens Glaz. var. nov. in herb. Paris., Berol., Kew., ete. - Nova Friburgo, dans le bois, au Conego, Rro-J $\mathrm{Jx}_{\text {. }}, 1^{\circ} 18409$ a. Sarmenteux, fl. bleues. Septembre-octobre. R.

4. S. nigrum L.; Fl. Bras. X, p. 16. - Floresta da Tijuca, Theresopolis, Rio-Jax., nos 6061, 13092, 14185. Herbacée f1. blanches. Févriermai. CG. Vulæ. : Herva moira.

- Var. aspergilliflorum Dum.; Fl. Bras. X, p. 16. - Grandarela, dans le bois près des plantes fossiles, Hinas, $n^{\circ}$ 15310. Herbacé, fl. blanches. lévrier-mars. c.

5. S. odoriferum Vell.; Fl. Bras. X, p. 49. - Petropolis et Alto Macahé, Rı-JAN., nos 14176,18407 . Sarmenteux, blanches. Novembredécembre. C. 
6. Solamum jasminoides Paxt.; DG. Prodr. Syst. nat. VIII, p. 82. - Sant'Amna dos Topos, Rio-J J.v., nos 8192,8844 . Sarmenteux, fl. bleues. Février-mars. R.

7. S. prunifolium Willd.; Fl. Bras. X, p. 15. - Serra de Ouro Preto, Mrnas, $n^{\circ}$ 19730. Arbuste, fl. blanches. Février-mars, G.

8. S. Gardneri Sendt. in Fl. Bras. X, p. 69. - Floresta da Tijuca, sous les grands arbres, Rio-Jan., $n^{0}$ 8201. Arbuste, fl. blauchâtres. Juin-juillet. C.

9. S. Convolvulus Sendt. in Fl. Bras. X, p. 48. - Petropolis, à Santo Antonio, Rio-JAN., $\mathrm{n}^{\circ} 8885 a$. Sarmenteux, fl. bleuâtres. Avrilmai. C.

10. S. flaccidum Vell.; Fl. Bras. X, p. 48. - Petropolis et Nova Friburgo, lio-Jan., ${ }^{0 s} 8855,12100$. Arbuste sarmenteux, fl. blanchâtres. Avril-juillet. C.

11. S. amygdalifolinm Steud. Fl. Bras. X, p. 51. - Campos, près São Fidelis, Rı-JAx., nº 13087. Sarmenteux, f1. bleuâtres. Janvierfévrier. R.

12. S. ramulosum Sendt. in Fl. Bras. X, p. 45. - Fazenda do Rio Preto, Minas, $n^{\circ} 8868$ a. Arbuste, fl. blanches. Novembre-décembre. C.

13. S. eyonymoides Sendt. in Fl. Bras. X, p. 24. - Serra dos Orgãos, près Theresopolis, Rio-J $\mathrm{JN}_{\mathrm{AN}}, \mathrm{n}^{\text {os }} 8199,8856$. Arbuste, fl. blanches. Avril-mai. C.

14. S. Itatiaiæ Glaz. n. sp.? in herb. Paris., Berol., Kew., Genev., ete. - Serra da Itiaiaia, dans le campo, Misas, no 8867. Herbacé, fl. blanches. Novembre-décembre. C.

15. S. tetricum Dun, in DG. Prodr. Syst. nal. XIII, 208. - Corcovado, à Paineiras, Rio-JAx., $1^{\circ}$ 8881. Arbuste, 11. blanches. JanvierFévrier. G.

16. S. asperum Vahl; Fl. Bras. X, p. 39. - Fazenda de Mendanla, près Campo Grande, S. José dos Barreiros, Rio-Jan., nos 8849 , 8868, 11390, 12101. Arluuste, fl. blanches. Août-septembre. C.

17. S. Radula Vahl; DC. Prodr. Syst. nat. XIII, p. 107. Corcovado et Floresta da Tijuca, Rio-JAN., $n^{0 s} 1513,8882,11362$, 14181. Arbuste, 11. blanches. Janvier-Hars. CC. Vulg. : Amor do Cinkão.

18. S. citrifolium Willd.; Fl. Bras. X, p. 4'4. - Serra de Nova Friburgo, Rio-Jax., nº 2661 a. Arbuste, fi. blanches. Mai-juillet. C.

19. S. cinnamomeum Sendt. in Fl. Bras. X, p. 44. - Petropolis, à 
A.-F.-II. GLAZIOU. - LISTE DES PLANTES DU BRÉsil CEXTRAL.

Cascatinlı, Rı-JAx., $\mathrm{n}^{\circ \mathrm{s}}$ 2662, 12105, 17722. Arbrisseau, fl. blanches. Arril-mai. CG.

20. S. leucodendron Sendt. in Fl. Bras. X, p. 43. - Serra dos Orgĩos et Petropolis, Rı-JAY., n ${ }^{0 s} 2661,9554$ et 9555. Arbrisseau, fl. blanclies. Janvier-mars. C.

21. S. rufescens Sendt. in Fl. Bras. X, p. 39. - Fazenda da Cachoeira et Petropolis, Rio-JAx., $\mathrm{n}^{\text {os }} 8197,11373,11380$. Arbrisseau, fl. blanches. Février-mars. C.

- Var. glabrescens Sendt. in Fl. Bras. X, p. 39. - Serra do Picú, au Paulo, Rio-Jax., nos 9999, 11380. Arbrisseau, fl. blanches. Avril-mai. C.

— Var. virescens Hiern in Warm. Symb. p. 645. - Nova Friburgo, au Alto da Boa Vista, Rio-JaN., nos 5966, 18405. Arbrisseau, fl. blanches. Octobre-novembre. R.

22. S. Sipolisii Glaz. n. sp.? in herb. Paris., Berol., Kew., Genev., etc. - Entre Inficionado et Caraça, dans le campo, Mrsas, $n^{0}$ 13098. Sous-frutescent, fl. blanches. Juin-juillet. C.

23. S. Lantana Sendt. in Fl. Bras. X, p. 36. - Serra do Picú, au Paulo, Rio-JAx., $\mathrm{n}^{\circ} 11383$ a. Arbuste, f1. blanches. Mars-avril. R.

24. S. verbascifolizm L.; DC. Prodr. XIII, p. 114. - Serra do Picú, au Palmital, Rı-JAN., $n^{\text {os }} 892,10003$, 11369. Frutescent, f1. blanches. Avril-mai. G.

20̈. S. auriculatum Ait.; Fl. Bras. X, p. 40. - Corcovado et entre Belem et Queimado, Rio-JAx., $n^{\text {os }} 199,8851,8859$. Grand arbuste, $\mathrm{fl}$. blanches. Décembre-janvier. CG.

- Var. angustrfolium Sendt. in Fl. Bras. X, p. 41. - Andarahy Grande, Rio-JAx., n ${ }^{0}$ 13094. Arbuste, fi. blanches. Juin-juillet. R.

26. S. granuloso-leprosum Dun. in DC. Prodr. XIII, p. 113̆. Aldea de Ouro Branco, Mlixas, $\mathrm{n}^{\circ}$ 13095. Arbuste, fl. blanches. Juinjuillet. C.

27. S. Martii Sendt. in Fl. Bras. X, p. 41. - Serra do Mar, à Palmeiras et au Corcovado, Rio-JAN., $n^{0 s} 1332,6056,8874$. Frutescent, fl. blanches. Aoùt-septembre. C.

28. S. cladotrichum Vand.; DG. Prodr. XIII, p. 118. - Fazenda do Rio Preto et Itabira do Campo, Mısas, nos 8863 , 17721. Frutescent, fl. rousses. Norembre. C.

29. S. concinmum Schott; Fl. Bras. X, p. 36. - Fazenda da Cachoeira, Ayuruoca, et au Rio Preto, Mixas, ${ }^{\text {os }} 4899,9547,8864$. Frutescent, f1. blanches. Avril-juin. C. 
30. Solanum clathratum Sendt. in Fil. Brts. X, p. 3\%. - Ayuruoca, près de la rivière, Mtexas, $11^{\circ} 5947$ a. Frutescent, fl. blanches. Mars-avril. R.

31. S. gracillimum Sendt. in H l. Bras. X, p. 36. - Serra do Pié, a Engenlo da Serra, Mixas, $1^{\circ} 11381$ a. Arbuste, fl. blanches. Mar'savril. C.

32. S. megalochiton Mart.; Fl. Bras. X, p. 28. - Floresta da Tijuca et Petropolis, Rio-Jax., $n^{0 s}$ 1497, 8886, 8887. Frutescent, 11. lılanchấtres. Juillet-août. C.

33. S. didymum Dun.; DC. Irodr. XIII, p. 19.9. - Entre Mestre d'Armas et Formosa, Goraz, n 21816. Frutescent, fl. blanclies. Janvierdécembre. C.

34. S. gnaphalocarpum Vell.; Fl. Bras. X, p. 27. - Floresta da Tijuca et Corcovado, Rio-Jas., $n^{0 s} 11381,12107$. Arbuste, fl. blanc jaunâtre. Aoùt-septembre. C.

3.. S. Vellozianum Dun.; Fl. Bras. X, p. 43. - Serra da Estrella et Corcovado, Rio-JAv., $n^{\text {os }} 1331,8873$. Frutescent, fl. blanclies. Maijuin. C.

36. S. cernuım Vell.; Fl. Bras. X, p. 42. - Serra da Estrella et Theresopolis, lio-JAN., ${ }^{0 s}$ 1077, 6658, 8194 et 8852. Grand arbuste, fl. blanches. Janvier-juillet. CC. Vulg. : Panacea et Mäo de mono.

37. S. bullatum Vell.; Fl. Bras. X, p. 42. - Serra do Coellho, près Rezende, dans les bois, Rio-JAN., ${ }^{0 s} 6657,8860$. Arbuste, f1. blanches. Décembre-ianvier. C.

38. S. Surtzianum R. et S.; Fl. Bras. X, p. 30. - Serra da Estrella et Villa Nova, Rio-Jav., $n^{\text {os }} 7790,8472,8875,11377$. Arbuste, fl. blanches. Mars-mai. CC.

39. S. Schwackeii Glaz. n. sp.? in lıerb, Paris., Berol., Kew., Brux., etc. - Entre São Pedro dos Indios et Cabo Frio, dans le bois, Rio-JAx., $n^{\circ} 11377$ a. Arbuste, fl. blanches. Juin-juillet. R.

40. S. decorticans Sendt. in Flor. Bras. X, p. 47. - Petropolis, a Cachambú, Riro-Jax., no 15300. Sarmenteux, 11. blanches. Avril-mai. G.

41. S. argenteum Dun.; Fl. Bras. X, p. 29. - Floresta da Tijucal et Corcovado, Rio-Jan., $n^{\circ s} 102,8843$. Arbuste, f1. blanches. Novembredécembre. C.

42. S. undulatum Dum. in DC. Prodr. XIII, p. 138. - Floresta da Tijuca et Sete Pontes, Rio-JAN., nos 238, 7874, 8862, 11836. Arbrisseau, fl. blanches. Octobre-novembre. CG. Vulg. : Coerana.

43. S. apodum Dun. in DC. Prodr. XIII, p. 139. - Petropolis, au 
A.-F-.Y. GLAZIOU. - LISTE DES PLAYTES DU BRÉSIL CEYTRAL.

lietiro dans le bois. Rio-Jan., nº 893, 3076. Arbuste, 11. Jlanches. Octobrenovembre. C.

44. S. brevifolinm H. B. K.; DG. Prodr. XIII, p. 139. - Floresta da Tijuca, au Pico, Rio-Jax., nº 11368. Arbuste, f1. Blanches. Janvierfévrier. R.

40̈. S. incequale Vell.; Fl. Rras. X, p. 2̈. - Serra do Mar, à Palmeiras, Ruo-Jax., $n^{0} 8878$ a. Arbuste, fl. blanches. Janvier-mar's. R.

46. S. caruleum Vell.; Fl. Bras. X, p. 21. - Petropolis, au Morin et à Rodeie, Rio-Jay., n"s 8878, 11376, 15305. Arbuste, 11. blanches. Mars-avril. C.

47. S. intermedium Sendt. in Fl. Bras. X, p. 22. - Serra do Tingua, Rio-Jix., $n^{\circ} 11360$. Arbuste, f1. blanches. Janvier-avril. R.

48. S. laxiflorum Sendt. in Fl. Bras. X, p. 21. - Serra do Har, it Palmeiras, Rio-J Ax., n ${ }^{\circ} 8853$ a. Arluste, fl. blanches. Janvier-mars. C.

49. S. micranthum Willd.; Fl. Bras. X, p. 19. - Petropolis, entre Fazenda Ingleza et Alto da Imperatriz, Rio-Jax., nº 12102. Arbuste, f1. blanclies. Février-mars. R.

30. S. nudzum Kiunth; Fl. Bras. X, p. 19. - Petropolis, à Quitandinhra, Rio-JAx., ${ }^{\circ}$ 3078. Arbuste, f1. blanches. Octubre-novembre. R.

81. S. Warmingii Hiern.; in Warm. Symb. ad Fl. Bras, p. 6气0, Alto Maccalıé de N. Friburgo, Rio-Jax., no 17721 a. Arbuste, f1. blanches. Septembre-octobre. R.

5ั2. S. glomuliflorum Sendt.; Fl. Bras. X, p. 24. - Fazenda de Santa Cruz et Belem, Rio-Jav., ${ }^{05}{ }^{\text {10 }}$ 1076, 11391. Arbuste, ft. blanches. Aoûtseptembre. C.

53. S. acuminatum Ruiz et P.; IC. Prodr. XIII, p. 146. Gavea et Floresta da Tijuca, Rio-Jar., nos $3075,9998,10004$. Noventbredécembre. C.

34. S. Caavurana Vell.; Fl. Bras. X, p. 20. - Floresta da Tijuca et Corcovado, Rio-JAx., nos 890, 2140, 8853, 11361. Arlırisseau, fl. blanches. Octobre-novembre. CC. Vulg. : Coerana.

כ̈.. S. Capsicastrum Link; Fl. Brnas. X, p. 33. - Entre Ilheos et São Joño d'El Rei, Mıxas, nos $8869,11370,16297$. Sous-frutescent, fl. blanches. Novembre-décembre. C.

3̋6. S. corniculatum Hiern in Warm. Symb. ad F\%. Bras, p. 6ə̈1. - Entre Gavea et la Tijuca, Rio-Jax., $n^{\circ}$ 1078. Arbuste, 11. bleues. Juillet-aoùt. R.

37. S. isodynamum Sendt. in Fl. Bras. X, p. 33. - Fazenda do Rio 
Preto, Hixas, $n^{\circ} 8869$ a. Frutescent, fl. blanches. Novembre-décembre. R.

58. Solanum Pseudocapsicum L.; Fl. Bras. X, p. 32. - Fazenda de Sinta Cruz, Rio-Jax., no ${ }^{\circ}$ 9551. Frutescent, fl. blanches. Norembredécenbre. C.

39. S. capsicoides Mart.; Fl. Bras. X, p. 34. - Restinga de Copacabana, Rio-Jan., $n^{\circ}$ 2139. Frutescent, fl. blanches. Octobrenovembre. C.

60. S. Ramizii Glaz. n. sp.? in herb. Paris., Berol., Kew., Genev., etc. - Collegio, près São Fidelis, Rio-Jax., nº 10001. Frutescent, fl. blanches. Janvier-février. R.

61. S. paludosum Moric.; Fl. Bras. X, p. 92. - Sete Pontes, au Baretto, Rio-Jax., no 5962. Frutescent, fl. bleuâtres. Juin-juillet. R. Yulg. : Jubeba.

62. S. insidiosum Vart.; Fl. Bras. X, p. 90. - Corcovado, à Paineras et à Petropolis, Rio-Jax., nos 2639, 8195, 8884. Frutescent, fl. blanches. Décembre-janvier. C. Vulg. : Jubcba.

63. S. Saldanhæi Glaz. n. sp.? in herb. Paris., Berol., Kew., Gener., etc. - Caminho do Nacaco, entre Lagoa de Freitas et Tijuca, Rio-JAN., no 10002 . Frutescent, fl. blanches. Octobre-novembre. C.

64. S. pjenanthemum Vart.; Fl. Brts. X, p. 89. - Entre Sitio et Barbacena, dans le campo, Minas, $n^{\circ}$ 13093. Frutescent, fl. blanches. Décembre-janvier. C.

68. S. decompositiflorum Sendt. in Fl. Bras. X, p. 88. - Jacarepagua et Floresta da Tijuca, Kro-Jav., ${ }^{\circ s} 2660$, 3776. Frutescent, fl. blanches. Mars-mai. C.

66. S. Glazionii Hiern. in Warm. Symb. ad Fl. Bras., p. 6ö3. Fazenda de Santa Cruz, Rio-JAx., $n^{\text {os }} 6059$, 9552, 11364. Frutescent, 11. blanchâtres. Novembre-décembre. C.

67. S. decorum Sendt. in Fl. Bras. X, p. 83. - Serra dos Orgãos et Petropolis, Rio-Jan., $\mathrm{n}^{0 \mathrm{~s}}$ 3077, 11379, 13479; Campos da Bocaina, S. Paclo, ${ }^{\circ s} 11378,11388,17723$. Frutescent, ll. blanchâtres. Févriermars. C..

- Var. angustifolium Glaz. n. var. in herh. Paris., Berol., Kew., Genev., ete. - Petropolis, à Cachambú, Rio-Jan., $\mathrm{n}^{\text {os }} 8196,15298$. Frutescent, fl. blanchâtres. Septembre-octobre. C.

68. S. podotrichum Taub. n. sp.? in herb. Paris., Berol., Kew., Genev., etc. - Itatiaia, dans le bois, Rio-Jax., $n^{\circ} 4915$. Frutescent, sans fleur en juin. C. 
69. S. schizandrum Sendt. in Fl. Bras. X, p. 83. - Petropolis et Nova Friburgo, dans les bois, Rio-Jax., $n^{\text {os }} 10000,12104$, 18406. Sarmenteux, fl. bleues. Octobre-novembre. C.

70. S. ochroneuron Link; Fl. Bras. X, p. 10\%. - Corcovado, à Paineras, liı-JAN., $\mathrm{n}^{\circ}$ 12103. Arbuste sarmenteux, l1. blanches. Aoûtseptembre. C.

71. S. alatum Dunal in DC. Prodr. XIII, p. 23\%. - Corcovado, à Paineiras, liı-Jax., $n^{\text {os }}$ 9556, 18408. Sarmenteux, ll. blanches. Aoùtseptembre. C.

- Var. microphyllum Glaz. n. var. in herb. Paris., Berol., Kew., Genev., Haun., etc. - Serra do Mar, à Palmeiras, dans la forêt, Rio$\mathrm{J}_{\mathrm{Ax}}$, $\mathrm{I1}^{\circ}$ 8883. Sarmenteux, fl. blanches. Décembre. R.

72. S. Juciri Mart.; Fl. Bras. X, p. 110. - Entre Gavea Boa Vista et a Cantagallo, Rio-JAx., ${ }^{\text {os }}$ 1333, 16294. Sarmenteux, fl. blanches. Novembre-décembre. C.

- Var. inermis Glaz. nov. v. in herb. Paris., Berol.. Kew., etc. Fazenda de Boa Esperança près Cantagallo et Serra da Estrella, Rı-Jax., $n^{\circ} 16294 a$. Sarmenteux, sans fl. en février et en octobre. R.

73. S. argillicolum Dun. in DC. Prodr. Syst. nat. XIII, p. 236. São José do Barreiro, Rı-Jan., ${ }^{\circ}$ 11366. Frutescent, fl. blanches. Août-septembre. R.

74. S. acerosum Sendt. in Fl. Bras. X, p. 61. - Belem, dans les bourbiers et Petropolis, R10-JAx., nos 8850 , 8876. Frutescent, fl. blanclies. Aoùt-octobre. C.

75. S. platanifolizum Hook. var. Lagoense Hiem in Warm. Symb. ad Fl. Bras. centr., p. 65̈7. - Alto da Boa Vista de Nova Friburgo, Rio-JAx., $n^{\circ}$ 6907. Frutescent, fl. blanches. Décembre-janvier. C.

76. S. aculeatissimum Jacq.; Fl. Bras. X, p. 599. - Sũo Christavao,

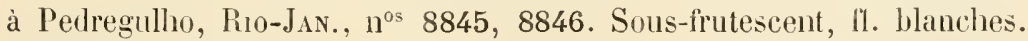
Septembre-octobre. C.

77. S. spectabile Stend.; Fl. Bras. X, p. 64. - Sĩo Christovĩo à Pedregulho, Rio-Jas., $n^{\circ} 8846$ a. Frutescent, fl. blanclıs. Aoùt-septembre. C.

78. S. incarceratum Ruiz. et P.; Fl. Bras. X, p. 57. - Nova Friburgo, au Conego, Rio-JAx., ${ }^{\circ}$ 13088. Sous-frutescent, fl. blanches. Février-mars. C.

79. S. mammosum Dun. in DG. Prodr. XIII, p. פ⿹้0. - Illa do Goveruador et chenin dos Macacos, près Lagoa de Freitas, Rı-Jas., 
$11^{\text {os }} 5964,8857,8879,13082$. Sous-frutescent, 11. Hanches, Décembrejanvier. CG.

80. Solanum demerarense Dun. in DC. Prodr. XIII, p. 257. Campos, près Sio Fidelis, Rio-Jax., $n^{0}$ 9997. Sous-frutescent, fl. Hlanches. Janvier-février. R.

81. S. robustum Wendl.; Fl. Bras. X, p. 72. - Serra da Estrella, a Mondioca, Rio-J $\Lambda x ., n^{\circ} 8842$. Frutescent, f1. blanches. Octobre-novembre. GC.

82. S. toryum Sw. rar. bbasiliense Senlln. in. Fl. Bras, X, p. 96. Serra da Cantareira, S. Paulo, nos 13085, 16295; Congonhas do Campo. dans les bois, Minas, $n^{\circ}$ 15303. Frutescent, fl. blanches. Avril-juin. CG.

- Var. lanuginosum Sendtn. in. Fl. Bras. X, p. 96 . - Serra de Ouro Preto, Misas, $n^{0}$ 14179. Frutescent, f1, blanches. Mai-juin. C.

83. S. tabacifolium Salzm. in DC. I'rodr. XIII, p. 261. - Serra da Mantiqueila, dans le bois, Mıxas, $n^{\circ} 16296$; Fazenda do Palmital, Goraz, no 21814 a. Frutescent, fl. blanches. Juin-juillet. C. Vulg. : Fumo bravo.

84. S. piluliferum Dun. in DG. Prodr. XIII, p. 268. - Corcovado et Petropolis, Rio-JAx., $n^{\circ s} 888,9553,11382$. Frutescent, fl. blanches. Janvier-nars. C.

- Var. densiflorum Dun. in DC. Prodr. XIII, p. 268. - Serra do Mlar, à Rodeio et à Palmeras, Rio-Jan., no 8847. Frutescent, fl. blanches. Aoùt-septembre. C.

83. S. curvispinum Dun. in DG. Prodr. XIII, p. 260ั. - Floresta da Tijura et au Horro da Viraçĩo à Praia Grande, Rio-Jav., nos 11367 , 11374, 18410. Frutescent, 11. blanches. Mars-avril. CG.

86. S. pelliceum Sendt. in Fl.Bras. X, p. 82. - Serra de Ouro Preto, Mivas, $n^{\circ}$ 15302. Frutescent, fl. blanches. Janvier-février. C.

87. S. paniculatum L.; Fl. Bras. X, p. 80. - Corcovado, Serra do Mar et Palmeiras, Rio-Jan., $n^{0 s}$ 198, 4900, 8861, 13099; Fazenda do Palmital, dans la capoeira, Goyaz, $n^{\circ} 21814$. Frutescent, fl. blanches. Octobrenovembre. CG. Vulg. : Jurubeba.

88. S. formosanum Glaz. n. sp.? in herb. Paris., Berol., Kew., Brux., ete. - Formosa, dans le cerrado, Goraz, no 21816 a. Frutescent, fl. blanches. Novembre-décembre. R.

89. S. velleum Swartz; Fl. Bras. X, p. 81. - Nova Friburgo, au Suspiro et à Barra do Pirahy, Rio-Jan.. nos $8858,12099,17167$. Frutescent, f1. bleues. Octobre-novembre. CG.

90. S. cyananthlum var. subatum Dun. in DG. Prodr. XIII, p. 316. - 
Serra dos Puris et cultivé au Passeio Publico, Rı-Jax., no 11363. Frutescent, n. bleues. Novembre-décembre. R.

91. S. crinitum Lam? in DG. Prodr. XIII, p. 316. - Chico Costa, dans le campo, Goraz, no 21813. Arbrisseau, f1, bleues. Septembreoctobre. CG. Vulg. : Lobeira ou Fructa de Lobo.

92. S. maroniense Poit.; DG. Prodr. XIII, p. 318. - Floresta da TTijuca, Corcovado, Rio-JAx., nos 3777, 5960, 8866, 8888, 9548. Frutescent, fl. bleues. Aoùt-septembre. CG.

93. S. hexandrum Vell. : Fl. Bras. X, p. 71. - Serra do Jar, à Palmeiras, Rro-Jâ., nº 8848. Frutescent, 11. bleues. Août-septembre. C.

94. S. sisymbrifolinm Lank; Fl. Bras. X, p. 76. - Floresta da Tijuca et Engenha Vello, Rio-Jas., $n^{\circ \mathrm{s}}$ 1079, 5965. Sous-frutescent, f1. blanches. Mai-juillet. C. Vulg. : Joá.

- Var. heracletfolium. Sendt. in Fl. Bras. X, p. 76. - Sete Pontes, au Baretto, Rio-Jax., no 8198. Sous-frutescent, f1. blanches. Décembrejanvier. C. Vulg. : Joá.

90ั. S. sublentum Hiern in Warm. Symb. ad Fl. Bras., p. 659. Serra do Caraça, dans le hois, Misas, $n^{\circ}$ 15301. Sous-frutescent, fl. bleues. Janvier-février. G.

96. S. macrocalyx Dun. in DG. Prodr. XIII, p. 337. - Entre Ipanema et Sorocaba, Sĩo Pavlo, no 13086. Arbrisseau, fl. bleues. Mar'savril. G. Vulg. : Lobolobo.

97. S. lycocarpum St.-Hil.; DC. Prodr. XIII, p. 338. - Serra de Ouro Branco, dans le campo, Mrsas, $n^{0 s} 6656,13100,14180$. Arbrisseau, 11. bleues. Novembre-décembre. CG. Vulg. : Fructa de Lobo et Berinjela.

98. S. subumbellatum Vell.; Fl. Bras. X, p. :4. - Barbacena et São Julião, Mrisas, $n^{\text {os }} 15299,18401$; Mestre d'Armas, dans le campo, Goyaz, n² 21815. Sous-frutescent, fl. blanches. Novembre-décembre. C.

99. S. variabile Mart.; Fl. Bras. X, p. 79. - Entre Barbacena et João Ayres, dans le bois, Mısas, no 15299 a. Frutescent, fl. blanches. Novembre-décembre. R.

100. S. fastigiatum Willd.; Fl. Bras. X, p. 77. - Nova Friburgo, au Conego, Rio-Jav., no 12099 a. Sous-frutescent, fl. blanches. Octobrenovembre. C.

101. S. asterophorum Mart. var. томentosus Sendt. in Fl. Bras. X, 97. - Corcovado, à Painecras, Rio-Jiv., $n^{08} 8880,12106$. Sarmenteux, fl. blanches. Décembre-janvier. R.

102. S. Melongena L.; Fl. Bras. X, p. 77. - Quinta da Boa Vista, 
S. Christovĩo, Rio-Jux., no 5964 a. Sous-frutescent, fl. blanches, cultivé. Juin-juillet. G. Vulg. : Beringela.

103. Gyphomandra calycina Sentt.; Fl. Bras. X, p. 11\%. - Nova Friburgo et Petropolis, dans le bois, Rio-JAN., n ${ }^{\text {os }} 3079,12096,18404$; Campo da Bocaina, SÃo PAulo, $1^{\circ}$ 11387. Frutescent, f1. blanchâtres. Septembre-octobre. C.

104. C. floribunda Duı. in DG. Prodr. X111, p. 390. - Corcovado, à Lagoinha dos Porcos, Rı-Jix., nº 16293. Frutescent, ll. blanchâtres. Octobre-novembre. $\mathbf{R}$.

10\%. C. fragrans Sendt.; Fl. Bras. X, p. 116. - Petropolis, à tamaraty, Riı-JAv., $n^{\circ}$ 3080. Frutescent, fl. blanchâtres. Septembre. uctobre. C.

106. C. sciadosty-lis Sendt.; Fl. Bras. X, p. 117. - Serra da Bocaina, dans le bois, S. PAclo, $n^{\circ} 11387$ a. Frutescent, f1. blanchàtres. Août-septembre. R.

107. C. betacea Sendt.; Fl. Bras. X, 1. 119. - Petropolis, a Cachambú, dans la forêt, Rio-J $\mathrm{JN}_{\mathrm{N}}, \mathrm{n}^{\circ}$ 7789. Sous-frutescent, fl. blanchâtres. Aoùt-septembre. C.

108. C. divaricata Sendt.; Fl. Bras. X, p. 118. - Serra do Coelho et Nova Friburgo, all Conego, Rio-JAx., $1^{\text {os } 8870, ~ 13084 . ~ S o u s-f r u t e s-~}$ cent, fil. blanchâtres. Octobre-novembre. C.

109. C. Fraxinella Sendt. in Fl. Bras. X, p. 122. - São Christovĩo et Engenho Velho, Rio-JAN., n ${ }^{\circ}$ 12097. Sous-frutescent, fl. blanchâtres. Aout-septembre. C.

110. C. ciliata Dun. in DC. Prodr. X111, p. 401. - Nova Friburgo, au Alto, dans le bois, Rio-JAx., n 18403. Sous-frutescent, fl. jaunâtres. Octobre-novembre. C.

111. Plysalis viscosa L. ; Fl. Bras. X, p. 129. - Barbacena, dans les rocas, Nixas, $n^{\circ}$ 14182. Herbacé, ll. jaunes. Aoùt-septembre. C.

112. Ph. angulata L.; Fl. Bras. X, p. 130. - Quinta da Boa Vista, à S. Christorão, Riı-Jax., $n^{\circ} 4169$, 13091. Herbacé, fl. jaunes. Aoûtseptembre. C.

113. Athenæa picta Sendt.; Fl. Bras. X, p. 134. - Floresta da Tijuca et N. Friburgo, Río-JAN., $n^{\circ} \mathbf{2 0 0}, 8200,17166$. Sous-frutescent, fl. blauchâtres. Juin-juillet. CC.

114. A. Martiana Sendt. in Fl. Bras. X. p. 136. - Bord du Rio Nora, Mris, $n^{\circ}$ 2663. Frutescent, fl. rousses. Mar's-arril. C.

11\%. A. hirsuta Sendt. in Fl. Bras. X, p. 137. - Alto Macahé de 
A.-F.-M. GLAZIOU. - LISTE DES PLAXTES DU BRÉSIL CEXTRAL.

N. Friburgo, dans le bois vierge, Rı-JAN., $\mathrm{n}^{03} 8871,14178$. Sous-frutescent, fl. rousses. Novembre-décembre. C.

116. A. anonacea Sendt. in Fl. Bras. X, p.137. - Serra dos Orgãos, à Theresopolis, Rı-JAx, $n^{\circ}$ 2859. Sous-frutescent, 11. rousses. Aoùtseptembre. C.

117. Bassovia sylvatica Aubl.; DC. Prodr. Syst.nat. XIII, p. 40\%. - Nova Friburgo, dans le bois au Conego, Rı-Jax., n' 1085. Arbuste, f1. blanches. Juillet-septembre. R.

118. B. glomuliflora Dun. in DC. Prodr. Syst. nat. XIII, p. 405. Caminho do Nacaco et à Nova Frilıurgo, Rio-Jas., nos 9549 , 14177. Frutescent, fl. blanchàtres. Septembre-octobre. C.

119. B. lucida Dun. in DC. Prodr. Syst. nat., XIII, p. 406. - Entre Gavea et Floresta da Tijuca, Rio-JAx., nº 889. Frutescent, li. blanchâtres. Novembre-décembre. C.

120. B. fasciculata Dun. in DC. Prodr. Syst. nat. XIII, 1) 408. Floresta da Tijuca, Rı-Jax., nº 8854. Arbuste, f1. blanches. Novembredécembre. C. Vulg. : Pimenta do matto.

121. B. crassiflora Dun. in DC. Prodr. XIII, p. 409. - Petropolis, à Cachambú, Rio-Jax., no 15308. Arbrisseau, f1. blanc jaunâtre. Juinjuillet. C.

122. Capsicum frutescens Willd.; Fl. Bras. X, p. 142. - Quinta da Boa Vista, à S. Christovão, Rı-JAx., $\mathrm{n}^{\circ}$ 18402. Sous-frutescent, fl. blanches, cultivé. Norembre-décembre. CG. Vulg. : Pimentinhe.

123. C. campylopodium Sendt. in Fl. Bras. X, p. 144. - Floresta da Tijuca, Petropolis, Rio-Jas., $n^{\text {os }} 4168,8872,11385$, 12108. Herbacé, f1. blanches. Janvier-février. CG.

124. C. microcarpon DC.; Fl. Bras. X, p. 146. - São Christovao, dans les roças, Rio-Jas., $n^{\circ}$ 8841. Sous-frutescent, t1. blanches. Aoùtseptembre. C. Vulg. : Pimenta pombinha.

129. C. baccatum L.; Fl. Bras. X, p. 146. - Floresta dia Tijuca, Rio-Jax., nº 3074. Sous-frutescent, fl. blanches. Norembre-décembre. C.

126. Brachistus oblongifolizs Miers; DC. Prodr. Syst. nat. XIII, p. 688. - Floresta da Tijuca et Petropolis, Rio-dax, nos 6062, 8877. Frutescent, fl. blanchàtres. Décembre-janvier. C.

127. Acnistus Miersi Dunal in DG. Prodr. XIII, p. 497. - Gavea et Floresta da Tijuca, Rı-Jav., nos 5961, 13090, 15307. Frutescent, f1. blanches. Aoùt-septenbre. CC.

128. A. cestroides Miers; DG. Prodr. Syst. nat. XIII, p. 500.- 
Serra da Mantiqueira, à Joũo Gmmes, Mrsas, n 13097. Frutescent, 11. blinchattres. Octobre-novembre. R.

129. Iochroma tubulosum Renth.; DC. I'rodr. XIII, p. 490. Campo da Acclanacĩo, cultivé, Rio-Jar., $11^{\circ}$ 11375. Sous-frutescent, ft. bleues. Juin-juillet. G.

130 Nicandra physaloides Garrtn.; Fl. Bras. X, p. 128. - Botafogo, caminho do Lem., Rio-Jax., $\mathbf{1}^{\circ}$ 4901. Herbacé, 1l. bleues. Juilletaloùt. C.

131. Grabowskia Schlechtendalii Sendt.; DG. Prodr. XIII, p. 20. - Quinta da Boa Vista, S. Christovão, lío-JAx., n ${ }^{0}$ 11363. Arbuste cultivé, f1. blanchâtres. Décembre-janvier. R.

132. Lycium ciliatum Schlecht. ; Fl. Bras. X, p. 153. - Qninta da Boa Vista, S. Christovão, Rı-Jax., no 13486. Arbuste cultivé, fl. blanches. Juin-juillet, R.

133. Solandra viridiflora Sims; Fl. Bras. X, 159. - Corcovado et au Alto Vacahé, Riı-Jax., $\mathrm{n}^{0 \mathrm{~s}} 12109$, 18411. Arbuste, fl. verdâtres. Juin-juillet. C.

13'. S. longipes Sendt. in Fl. Bras. X, p. 159. - Floresta da Tijuca, entre les roclies, Rio-JAx., $n^{\circ} 12109$ a. Frutescent, fl. blanc jaunâtre. Novembre-décembre. Ii.

133. Datura arborea L.; Fl. Bras. X, p. 162. - Quinta da Boa Vista, à Săo Christovĩo, Rio-JAx., $n^{\circ}$ 6715. Arbuste cultivé, fl. blanches. Octobre-novembre. C.

136. D. Metel L. ; Fl. Bras. X, p. 162. - Campo da Acclamaçĩo, Rı-Jan., $n^{0}$ 11384. Sous-frutescent, fl. blanches, cultivé. Décembrejanvier. C.

197. D. fastuosa L.; Fl. Bras. X, p. 162. - João Ayres, dans les bourbiers, Mixas., n ${ }^{\circ}$ 14183. Sous-frutescent, f1. violettes. Juin-juillet. G.

138. D. Stramonium L.; Fl. Bras. X, p. 163. - Quinta da Boa Vista, à São Ghristoviou, liıo-Jan., nos 6060 , 14184. Herbacé, fl. blanches. Octobre-novembre. CG. Vulg. : Figueira do inferno.

139. Cestrum coriaceum Niers; Fl. Bras. X, p. 2226. - Cataguaz, dans le bois vierge, Mris, $n^{0}$ 11357. Arbuste, f1. verdattres. Aoutseptembre. C.

140. C. intermedium Sendt. in Fl. Bras. X, p. 221. - Campos do Iío Preto, dans le bois, Minas, no $7791 a$. Arbuste, fl. verdâtres. Aoùtseptembre. R.

141. C. corymbosum Schlt.; Fl. Bras. X, p. 222. - Campos da 
Bocaina, près de la source du liio Parahyba, S. PAtlo, ${ }^{\text {os }} 7791,8193$. Arbuste, fl. verdâtres. Août-septembre. CC.

142. C. subpulverulentum Mart.; Fl. Bras. X, p. 211. - Morro Queimado, près Tijuca, Rio-Jax., nº 203. Arbuste, fl. verdâtres. Octobrenovembre. R.

143. C. Schlechendalii Don; Fl. Bras. X, p. 212. - Fazenda da Serra dos Pyreneos, Goraz, $n^{\circ}$ 21819. Arbuste, fl. verdatres. Aoùtseptembre. C.

144. C. lavigatum Schl.; Fl. Bras. X, p. 216. - Floresta da Tijuca et Corcorado, Rio-Jav., nos 9550, 1139; Cataguan, au Rio Pomba, Mlınas, $n^{\text {os }} 11358,11359$. Arbuste, t'. verdâtres. Vars-avril. CG. Vulg. : Coerana.

143. C. axillare Vell.; Warm. Symb. ad Fl. Bras, p. 670. - Restinga de Capacabana et Jacarepagua, lio-Jax., no 5963. Arbuste, fl. verdàtres. Mar's-arril. C.

146. C. bracteatum Link et Otto.; Fl. Bras. X, p. 217. - Serra dos Orgãos et Petropolis, Rı-Jax., n ${ }^{\text {os }} 6057,11371$. Arbuste, fl. jaunàtres. Juillet-septembre. C.

147. C. anictum Schlecht.; Warm. Symb, ad Fl. Bras., 671. Floresta da Tijuca, lì-Jax., $n^{0}$ 1458. Sous-frutescent, f1. blanchâtres. Aoùt-septembre. C.

1'48. - Var. organense Dun. in DC. Prodr., p. 64́4. - Serra dos Orgãos, à Theresopolis, Rio-JAx., $1^{\circ}$ 6058. Sous-frutescent, fl. blanrhattres. Septembre-octobre C.

149. C. Sellovianum Sendt. in Fl. Bras. X, p. 219. - Floresta da Tijuca, Rı-Jax., $1^{\circ} 337$ a. Arbuste, fl. jaunâtres. Septembre-octobre. R.

150. C. pedicellatum Sendt. in Fl. Bras. X, p. 224. - Barro Amarello, au Ribeirĩo de Caldas, Govaz, $1^{0 s} 21817,21818$. Arbuste, fl. verdàtres. Oetobre-norembre. C.

131. C. velutinum Hiem in Warm. Symb. ad Fl. Bras., p. 692. Petropolis, à Itamaraly, Rio-J.x., $\mathrm{n}^{\circ}$ 15309. Arbuste, f1. blanchàtres. Mai-juin. C.

152. C. calycinum Willı; Fl. Bras. X, p. ㄴl1. - Petropolis à Itamaraty, près de la rivière, liro-Jıx., no $15309 a$. Arbuste, fl. blanchìtres. Nars-avril. R.

1.39. C. Sendtuerianum Mart. in Fl. Bras. X, p. 210̈. - Santa lsabel. dans le bois, Mnsas, no 11359 a. Frutescent, fl. verdâtres. Arril-mai. C.

1\%). C. fasciculiflorum Taub. in Engler Bot. Jahrb. XY, (1893), 
Beibl. 38, n. 17. - Santa Isabel, dans le bois, Mrxas, no 11359. Mrutescent. f1. verdattres. Avril-mai. R.

13\%. Cestrum viminale Sendt. in Fl. Bras. X, p. 220. - Corcovado, à Paineiras, Rio-J $\mathrm{Jx}_{\text {. }}, \mathrm{n}^{\circ}$ 337. Arbuste, f1. blanchâtres. Octobre-norembre. C.

136. Sessea Regnellii Taub. in Engler Botan. Jahrb. XV, (1893), Beibl. 38, p. 18. - Santa Barhara, dans le bois, Mrsas, n 19729. Frutescent, f1. rousses. Mai-juin. C.

157. Metternichia principis Mik.; Hl. Bras. X, p. 227. - Corcovado et Larangeiras, Rı-JaN., $n^{\text {os }} 336,1080,14175$. Arbrisseau, fl. blanches. Décembre-janvier. C.

158. Nicotiana Tabacum L.; Fl. Bras. X, p. 166. - Onuinta da Boa Vista, São Christovão, Rı-Jax., $n^{0}$ 5517. Herhacé, fl. roses, cultivé. Janvier-février. CC. Vulg. : Fumo.

- Var. goyanum Glaz. nov. v. in herh. Paris., Berol., Kew., Gener., etc. Corrego do Brejo, Goyaz, no 21812. Herbacé, f1. blanchâtres. Aoûtseptembre, cultivé CG. Vulg. : Fumo goyano.

159. N. glauca Grah.; Fl. Bras. X, p. 170. - Quinta da Boa Vista, ¿ Sĩo Christovĩo, Rio-Jan., $\mathrm{n}^{\circ \mathrm{s}} 239$, 8473. Frutescent, fl. verdâtres. Juin-juillet. C.

160. N. Langsdorffii Weinm.; Fl. Bras. X, p. 169. - Entre Sitio et Joĩo Ayres, dans les endroits humides, Mnsas, $\mathrm{n}^{\circ} 11372$. Herbacé, fl. blanchâtres. Juin-juillet. C.

161. N. acutiflora St. Hil.; Fl. Bras. X, p. 168. - Floresta da Tijuca, Rı-Jax., $\mathrm{n}^{\circ}$ 4999. Herbacé, fl. blanchâtres. Novembre-décembre. G.

162. N. angustifolia Ruiz et Pavon.; Fl. Bras. X, p. 167. - Itatiaia, dans le campo et Nova Friburgo, Rio-JAx., $n^{\text {os }} 6655$, 13083. Herbacé, fl. blanchâtres. Janvier-février.

163. Petunia violacea Lindl.; Fl. Bras. X, p. 172. - Serra do Picú, dans le campo, Mıxas, no 17720 a. Herbacé, fl. violettes. Marsavril. R.

164. P. ledifolia Sendt. in Fl. Bras. X, p. 176. - Itahira do Campo, MINas, u$^{0}$ 17720. Herhacé, fl. violettes. Décembre-janvier. CG.

1(i⿱艹). Nierembergia graveolens St.-Hil.; Fl. Bras. X, p. 178. Bessaruinha, dans le campo, Mıvas, $n^{\circ}$ 19731. Sous-frutescent, fl. jaunt̀tres. Avril-mai. R.

166. N. rivularis Miers; Fl. Bras. X, p. 198. - Itatiaia, au campo Silverio, Rı-Jas., no 4901 a. Herbacé, fl. blanches. Juin-juillet. C. 
167. N. rigida lliers: Fl. Bras. X, p. 199. - Uhatula, dans le campo, S. Pacto, no 4969 a. Herbacé, fl. jaunâtres. R.

168. N. gracilis Hook.; Fl. Bras. X, p. 200. - Itatiaia, dans le ‘ampo, Rio-Jav., nº 4969. Sous-frutescent, 1i. blanchaitres. Juin-juillet. C.

169. Browallia demissa L.; Fl. Bras. VIII, I, p. 2öt. - Nova Friburgo, au Coneqo, Rio-Jax., n 17172. Sous-frutescent, f1. blenes. toùt-septembre. C.

170. Brunfelsia macrophylla Benth.; Fl. Bras. VIII, I, p. 20:6. - Floresta da Tijuca, Rio-Jax., n $n^{0}$ 11393. Arbuste, fl. violettes. Aontseptembre. R.

171. Br. hydrangeaformis Pentlı.; Fl, Bras. VIII, I, 236. Petropulis, au Morin, dans le bois vierge et à Nova Friburgo, Rro-Jav., $n^{\text {os }} 4904,9558,11392,14173,14174$. Arbuste fl. violettes. Aout-septembre, CG.

- Var. glabriuscula Schmidt; Fl. Bras. VIII, I, p. 20̈6. - Entre Tijuca et Jacarepagua, Rio-Jav., $n^{0 s} 811,8471$. Arluste, fl. violettes. Janvier-février. C.

172. Br. pauciflora Benth.; H7. Bras. VIII, I, p. 28\%. - Atto Macahé de Nova Friburgo, Rio-Jav., $n^{0 s} 811,17168$. Arbuste, 11. lilas. Octobre-novembre. C.

173. Br. obovata Benth.; Fl. Bras. VIII, I, p. 20̈8. - Entre Nietheroy et Piratininga, Rı-JAx., nº 5970. Arbuste, ft. lilas. Décembre. janvier. R.

174. Br. ramosissima Schm.; Fl. Bras. VIII, I, p. 2599. - Nova Friburgo, Corcovado et Petropolis, Rio-JAx., nos 812, 5969, 13478, 14171, 17170. Arbuste, t1. violettes. Décembre-janvier. CG. Vulg. : Manaca.

- Var. laxiflora Schim.; Fl. Bras. ViII, I, p. 260. - Alto Macahé de Nova Friburgo, Rro. Jax., n ${ }^{0}$ 6908. Arbuste, fl. violettes. Janvierfévrier. C. Vulg. : Manaca.

- Var. confertiflora Schm.; Fl. Bras. Vili, I, p. 260. - Serra dos Orgãos, Rio-Jas., nos 15312, 17169. Arbuste, fl. violettes. Novembredécembre. C.

- Var. parcifolia Schm.; Fl. Bras. VIII, I, p. 260. - Petropolis et Alto Naciahé, Rı-J J $\mathrm{Ax}_{\text {. }} 11^{\text {os }} 11394,11395,11400,14172$. Arlouste, 11. violettes. Janvier-mar's. C. Vulg. : Manaca.

175. Br. Hopeana Benth.; Fl. Bras. VIII, I, p. 261. - Serra do Palmital, dans le campo, et cultivé au Passeio Publico, Rio-Jav., 
$11^{\text {os }} 357,11319,12110,15311$. Arbuste, fl. violettes. Novembredecembre. C. Vulg. : Manaca.

176. Bronfelsia sylvicola Taub. in Engler Botan. Jahrb. XXI 189.;, p. '450. - Entre Rio das Pedras et Corrego do Brejo, Goraz, $n^{0}$ 21820. Arbuste, Il. violettes. Sept embre-octobre. R.

177. Schwenkia divaricata Benth.; Fl. Bras. VIII, I, p. 248. Caminho do Hacaco et Jurujuba, Rio-Jax., $n^{\text {os }} 5967$, 8889. Herbacé, Ill. jaunàtres. Décembre-janvier. C.

178. Sch. mollissima Nees et Mart.; Fl. Bras. VIII, I, p. 250. Itacolumy, près Ouro Preto, Mrsas, $n^{\text {os }}$ i 1404, 15959. Herbacé, fl. blanchâtres. Février'mar's. C.

179. Sch. americana L.; Fl. Bras. VIII, I, p. 281. - Entre Cabo Frio et S. Pedro dos Indios, Rio-Jax., no 11128 . Herbacé, fl. blanchàtres. Juin-juillet. C.

180. Sch. hirta Klotz.; Fl. Bras. VIII, I, p. 250. - Carandahy, dans le campo humide, líras, $n^{\circ}$ 15306. Herbacé, fl. blanchàtres. Décembre-janvier. C.

181. Sch. fasciculata Benth.; Fl. Bras. VIII, I, p. 2502. - Forteresse du Pico de Santa Cruz, Riro. Jan., $1{ }^{\text {os }} 5886$, 8349. Sous-frutescent, fl. violettes. Aout-septembre. R.

182. Sch. curyiflora Benth.; Fl. Bras. VIII, I, p. 263. - Entre Carandahy et Ouro Preto, dans le campo, Mrsas, $n^{\circ} 15306$ a. Sousfiutescent, fl. jaunâtres. Février-mars. R.

\section{Fam. 93. - Scrofulariacées.}

1. Heteranthia decipiens N. et Nart.; DC. Prodr. X, p. 201. Entre Carandahy et Ouro Preto, dans le campo, Moxas, $n^{\text {os }} 13823,154$. Sous-lirutescent, ft. blanchàtres. Mai-juin. C.

2. Verbascum blattarioides Lamk; Fl. Bras. VIII, I, p. 238. Quinta da Boa Vista, à S. Christorão, Rio-Jas., $n^{\circ}$ 6063. Herbacé, 11. jaunes. Septembre-octobre. C.

3. Calceolaria mexicana Benth.; DC. Prodr. Syst.nat. X, p. 20\%. Quinta da Boa Vista, à Sĩo Christovao, sur les vieux murs. Riı-Jax., $n^{\circ}$ 2891. Herbacé, ll. jaunes. Juillet-aoùt. C.

4. Alonsoa inciscefolia R. et P.; Fl. Bras. VIII, I, p. 246. - Entre Mataruna et Rio Bonito, Rio-JAN., n 10005. Herbacé, fl. bleuâtres. Février. R. 
今. Angelonia procumbens N. et $\mathrm{Il}$; Fl. Bras. VIII, I, p. 240. Nova Friburgo, à Pedra do Conego, Rio-Jax., nos 11401, 13109. Frutescent, fl. bleues. Mars-avril. C.

6. A. arguta Benth.; Fl. Bras. VIII, I, p. 241. - Itapemirim, EspIniто S.мто, $1^{\circ}$ 10007. Herbacé, t1. bleues. Janvier-lévrier. C.

7. A.pubescens Benth; Fl. Bras. VIII, I, p. 241. - Entre Cabo Frio et S. Pedro dos Indios, Rio-Jax., $n^{\circ} 11406$. Herbacé, th. bleues. Aoûtseptembre. R.

8. A. goyarensis Benth.; Fl. Bras. VIII, I, p. 242. - Entre Rio Paranauá et Clıico Lobo, dans le campo, Goraz, n 21823 . Sous-fruteseent, fl. bleues. Novembre-décembre. C.

9. A. Blanchetii Benth.; Fl. Bras. VIII, I, p. 242. - Entre Barbacena et João Ayres, dans le campo, Mısas, $n^{\circ} 11405$. Herbacé, ft. bleues. Décembre-janvier. R.

10. A. eriostachys Benth.; Fl. Bras. VIII, I, p. 243. - Biribiry, près Diamantina, Mras, $n^{\circ}$ 19741. Sous-frutescent, fl. bleues. Mars-avril. C.

11. A. tomentosa Horic.; Fl. Bras. VIII, I, p. 244. - Curalinho, près Diamantina, dans le campo humide, Mixas, $n^{0}$ 19740. Sous-frutesrent, fl. bleues. Mars-avril. C.

19. A. Gardneri Hook.; Fl. Bras. VIII, I, p. 245. - Quinta da Boa Vista, à S. Christovão, Rio-Jax., $\mathbf{n}^{0 s} 1339,6811$. Herhacé, fl. bleues, cultivé. Octobre-novembre. C.

13. A. cornigera Hook.; Fl. Bras. VIII, I, p. 246. - Itapemirim, Esprrito Santo, n 10009. Herbacé, fl. bleues. Janvier-février. R.

14. Beyrichia ocimoides Ch. et Schlt.; Fl. Bras. VIII, I, p. 289, Copacabana, dans les bourl,iers, fio-Jan., $n^{\circ 5} 39,4170,4175,7794$. Herbacé, fl. blanchâtres. Février-mai. CC.

15. Tetraulacium veronicaforme Turcz.; Fl. Bras. VIII, I, p. 319. - Morro do Coco ou do Bahú, Rio-Jav., nos 11307, 11411; Diamantina, ¿u Tombador, Mixas, ${ }^{\circ}$ 19744. Herbacé, fl. blanc jaunâtre. Nlars-avril. C.

16. Stemodia foliosa Benth.; Fl. Bras. VIII, I, p. 297. - Entre Pomba et Catagnaz, dans le bois, Misas, $1^{0 s}$ 13105, 14188. Herbacé, 11. bleues. Mai-juin. C.

17. St. parviflora Ait.; Fl. Bras. VIII, I, 299. - Entre Gavea et la Tijuca, Rio-JAx., n 3713 a. Herbacé, fl. blanchâtres. Mar's-avril. C.

18. St. trifoliata Richb.; Fl. Bras. VIII, I, p. 297. - Floresta da Tijuca et Corcovado, Rio-Jax., nos 1151, 3712. Sous-l'rutescent, f1. bleues. Avril-mai. C. 
19. Stemodia durantifolia Sw.; Fl. Bros. VIII, I, I. 300. - Ressaquinha, dans les bourbiers, $n^{\text {os }} 11407,13106,14191$ et Porto do Rio Parałaltí, Ilıxas, $1^{\circ}$ 21826. Herbacé, fl. bleues. Juin-juiltet. CG.

20. St. stricta Cham. et Schlt.; Fl. Bras. VIII, I, p. 302. - Ressaquinha, dans les bourbiers, Mısas, no 13107 . Herbacé, fl. Hanchâtres. Juin-juillet. R.

21. Conobea scoparioides Bentlı.; Fl. Bras. VIII, I, 1. 29'4. Entre Queluz et Ouro Preto, Mixas, $n^{05} 11413,13108$, 14189. Sous-frutescent, fl. blanches. Juin-juillet. CC.

22. Herpetes chancedrioides H.B.K. var, maropayla Schm. Fl. Brus. VIII, I, p. 304. - Ouro Preto, dans le campo humide, Minas, $n^{\circ} 20430$; Barra da Lagoa Feia, prís Formosa, Goyaz, nº 21828. Herbacé, 11. jaunes. Décembre-janvier. C.

23. H. tenelia Cham.; Fl. Bras. VIII, I, p. 30\%. - Ouro Preto, dans les endroits lıumides, Nwas, $\mathrm{n}^{\circ} 20430 a$. Herbacé, fl. jaunàtres. Novembre-décembre.

24. H. gratioloides Benth.; Fl. Bras. VIII, I, p. 307. - Restinga de Cabo Frio, Rı-JAN., no 11409. IIerbacé, fl. jaunattres. Juillet-septembre. R.

2.. H. Salzmanni Bentlı.; Fl. Bras. VIII, 1, p. 312. - Gavea, prìs de la mer, dans les bourbiers, Rı-JAx., $1^{\circ} 4029$ a. Herhacé, fl. Wlanchâtres. Février-111ars. C.

26. H. lanigera Ch. et Schlt. : Fl. Bras. VIII, I, p. 313. - Restinga de Copacahana, dans les endroits humides, Rio-Jax., n ${ }^{\circ 5} 1260,4171$. Herbacé, fl. blanchâtres. Juin-juillet. C.

27. H. bacopoides Bentl,; Fl. Bras. VIII, I, p. 316. - Entre Cabo Frio et Sào Pedro dos Indios, Rı-Jan., $1^{\circ} 11410$. Herbacé, 11. blanc jaunâtre. Juin-juillet. C.

28. H. Monnieria H. B. K.; Fl. Bras. VIII, I, p. 316 . - São Christovão, dans les endroits humides, et Gavea, Rı-JAv., $1^{\text {os }} 4029,8893$, 11403. Herbacé, f1. blanches. Février-mars. CG.

29. Ildefonsia bibracteata Gardn.; Fl. Bras. VIIl, I, p. 298. - Serra da Bica, près Cascadura, Rı-J $\mathrm{Jx}_{\text {. }}, \mathrm{n}^{\circ \mathrm{s}} 9546,17173$. Herbacé, fl. bleues. Août-septembre. C.

30. Gratiola peruviana L.; Fl. Bras. VIII, I, p. 292. - Villa Nova, dans les sables, Rı-Jax., nº 7794 a. Herbacé, fl. roses. Mai-juin. R.

31. Torenia parviflora Hamilt.; Fl. Bras. VIII, I, p. 322. — Quinta da Boa Vista, à S. Christovão, Rı-J Jav., n 4174. Herbalcé, fl. violettes. Norembre-décembre. C. 
A.-F.-M. GLAZIOU. - LISIE DES PLAYTES DU BRÉSIL CEYTIAL.

32. Vandellia crustacea Benth.; Fl. Bras. VIII, I, p. 319. - Itatiaia, au Campo-Feio, Rio-JAs.; n 4029 a. Herbacé, fl. blanches. Juinjuillet. R.

33. V. diffusa L. ; Fl. Bras. VIII, I, p. 320. - Entre Belem et Queimado, dans les bourbiers, Rı-Jax., $n^{0}$ 8890. Herbacé, f1. blanches. Octolsre-novembre. C.

34. Micranthemum orbiculatum Michx; Fl. Iras. VIII, I, p. 287. Porto da Estrella à Ignassú, Riı-Jan., nos 3154,3713 . Herbacé, fl. roses. Mars-mai. CC.

3\%. Scoparia dulcis L.; Fl. Bras. VIII, I, p. 264. - Restinga de Copacabana, Rio-Jxx., nos 11, 4173; Diamantina, Misas, no 11412 . Herbacé, f1. blanches. Janvier-mars. CC. Vulg. : Vassurinha, Tupixaba.

36. Sc. flav'a Cham. et Schit.; Fl. Bras. VIII, I, p. 26气. - Biribiry, au Mocotó dans le campo, Mixas, $n^{\circ}$ 19733. Ilerbacé, f1. blanclıâtres. Février-mars. C.

- Valr. pinvatifida Schm.; Fl. Br. VIII, I, p. 266. - Campos da Bocaina, au Bom Jardim, São Pallo, no 11412 a. Herbacé, 11. blanchâtres. Février-mars. C.

37. Capraria biflora L. ; Fl. Bras. VIII, I, p. 293. - Serra d'Itaboapoana, Esp. SAxto, nos 10082. 11408; Biribiry, prés Diamantina, Minas, $n^{\circ}$ 19734. Sous-frutescent, fl. blanches. Février-mars. C. Vulg. : Balsaminha.

38. Veronica peregrina I.; Fl. Bras. VIII, I, 263. - Vargem do Iiribiry, dans les bourbiers, Mıvıs, $n^{\circ}$ 19732. Herbacé, fl. blanchâtres. Février-mars. C.

39. V. serpyllifolia L. Syst. vegetab. I, p. 72. - Piribiry, dans les bourbiers, près Diamantina, Mrsus, $\mathrm{n}^{\circ} 19332 a$. Herbacé, fl. blanchâtres. Février-mars. R.

40. Escobedia scabrifolia Ruiz et P.; Fl. Bras. VIII, I, p. 269. Cachambú et Gandarela, Mıvas, $\mathrm{n}^{03}$ 15321, 16306; entre Jatobasinhı et As Brancas, dans le campo, Goyaz, $n^{\circ s} 21821$; 21822. Herbacé, fl. blanches. Novembre-décemlıre. CG.

41. Physocalyx major Mart.; Fl. Bras. VIII, I. p. 271. - Caraça, au Campo de Fora, Mrsis, $n^{\circ}$ 15243. Sous-frutescent, fl. urangées. Févriermars. C.

42. Ph. aurantiacus Pohl.; Fl. Bras. VIII, I, p. 271. - Diamantina, au Tombador, dans le campo, Mısas, $n^{\circ}$ 19650. Sous-frutescent, fl. orangées. Avril-mai. R.

43. Ph. dentatus Glaz. n. sp.? in herb. Paris., Berol., Kew., 


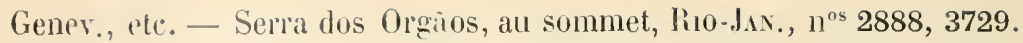
sous-frutescent, 11. orangées. Août-septembre. R.

4'. Alectra brasiliensis Benth.; Fl. Bras. VIII, I, p. 273. - Copacabana, Río-Jan., n 3810; Corrego do Brejo, près des rivieres, Goynz, $n^{\circ}$ 21824. Herbacé, 1l. orangées. Avril-mai. C.

4̋̈. Buchnera elongata Swartz; Fl. Bras. VIIII, I, p. 327. Guariroba, dans le campo, Goyaz, $11^{\circ} 21888$. Herbacé, li. bleues. Uctobrenovembre. C.

46. B. lobelioides Cham. et Sehlt.; Fl. Bras. VIII, I, p. 327. Guariroba dans le campo, Goyaz, $1^{\circ} 19742$ a. Ilerbacé, fl. bleues. Octobre-novembre. R.

4T. B. palustris Spr. F'l. Bras. VIII, I, 1. 32\%. - Diamantina, à Perpetua, Mivas, n 19742; Guariroba, Govaz, $n^{0}$ 21887. Herbacé, f1. bleues. Octobre-novembre. C.

48. B. rosea H. B. K.; Fl. Bras. VIII, I, p. 328. - Mogy das Cruzes, Sĩo Paclo, $n^{\circ} 15320,16301,17717$; Perpetua, près de Diamantina Mınas, $n^{\circ}$ 19743. Herbacé, fl. rosées. Mars-avril. C.

- Var: congesta Schm. Fl. Br. VIII, I, p. 328. - Paranauí près des grandes cascades, dans les broussailles, Mixas, $1^{\circ}$ 21889. Fl. bleues. Juin-juillet. C.

49. B. juncea Cham. et Schlt.; Fl. Bras. Vill, I, p. 329. - Mogy das Cruzes, São Paulo, n 17718. Herbacé, 11. bleues. Mars-avril. C.

50. Esterhazya splendida Mik.; Fl. Bras. VIII, I, p. 27\%. - Serra dos Orgĩos, Itatiaia, etc., Rı-JAx., n ${ }^{\text {os }} 4903,8469,7792,15318$; entre Capanema et Caraca, Nisas, $n^{\text {os }} 15316,15317$, 19737. Sous-frutescent, fl. roses. Juin-juillet. CG.

5̈l. E. macrodonta Cham. et Schlt; Fl. Bras. VIII, 1, p. 276. Alto da Serra de Ouro Branco, Mrxas, $n^{\circ s} 15315$, 16303. Sous-lirutescent, f1. roses. Décembre-janvier. C.

52. Gerardia brachyphylla Cham. et Sehlt; Fl. Bras. VIII, I, p. 278. - Biribiry, près Diamantina, Mras, $n^{\circ}$ 19738. Sous-frutescent, fi. roses. Avril-mai. C.

53. G. linarioides Cham. et Schlt. var. ramosissıma Selımidt. in Fl;

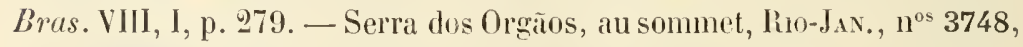
4172, 16302. Sous-frutescent, ll. roses. Décembre-janvier. C.

54. G. angustifolia Mart.; Fl. Bras. VIII, I, p. 279. - Serra do Cipo, près Congonlas, Misas, $n^{\circ}$ 19736. Sous-fiutescent, fl. roses. Avrilmai. C. 
3\%. G. pedunculata Benth. in Hook. Comp. bot. Mag. I (183.). Campo de São Fidelis, Rı-JAx., n ${ }^{0}$ 10011. Sous-frutescent, Janvierfévrier. R.

56. G. communis Cham. et Sehlt; Fl. Bras. VIII, I, p. ㅇ80. - Gavea et Sacco da Jurujuba, Rio-Jav., $n^{\circ \text { s }}$ 2658, 5945. Décembre-janvier. C.

57. Castilleja communis Benth.; Fl. Bras. VIII, I, p. 323. - Nora Friburgo, dans les endroits humides, Rı-JAx.; $11^{\circ}$ 19735. Herbacé, 11. rouges. Septembre-octobre. C.

:38. Velloziella dracocephaloides Baill. in Bull. Soc. Linn. de Paris $\left(\mathrm{n}^{\circ} 90\right)$, 1. TI\%. - Fazenda do Taquaral, aux Campos Brejos, Mrxas, $n^{\text {os }}$ 7795, 8892; Alto Nacahé de Nova Friburgo, Rio-Jax., $n^{\text {os }} 12967$, 20432. Sarmenteux, fl. orangées. Aoùt-septembre. C.

\section{Fam. 96. - Utriculariacées.}

1. Utricularia foliosa L.; Fl. Bras. X, p. 237. - Cabo Frio, dans l'eau stagnante, Rio.JAx., no 10088. 12928, 13468, 16234. Aquatique, Il. james. Aoùt-septembre. CG.

2. U. oligosperma St-Hill.; Fl. Bras. X, p. 237. - Mogy das Ciruzes, dans l'eau stagnante, S. Paclo, no 17685; Lagoa Feia, près Formosa, Goraz, no 21829. Aquatique, 11. jaunes. Aoùt-septembre. C.

3. U. longirostris Ell.; Fl. Bras. X, p. 238. - Fazenda de Sant Anna, pres Juiz de Fora, sur les rochers humides, Mrras, $n^{0 s}$ 2887, 3663. Ilerbacé, fl. jaunes. Juin-juillet. C.

4. U. palatina G. Web. in Fl. Bras. X, p. 239 . - Nogy das Cruzes, dans l'eau stagnante, S. Pavbo, $n^{\circ} 17585$ a. Aquatique, fl. jaunes. Mars-avril. C.

ö. U. Salzmanni St-Hil.; Fl. Bras. X, p. 239. - Marianna, près Duro Preto, dans l'eau stagnante, Mcras, $n^{0}$ 16235. Aquatique, 11. jaunes, Juin-juillet, C.

6. U. longifolia Gardn.; Fl. Bras. X, p. 241. - Corcorado et Alto Macahé, Rı-JAx., $1{ }^{\text {os }} 1156,1535,4152,7733$; Entre Nendanha et le Rio Manso, sur les rochers mouillés, Mlsas, nos 14045,15181 . Herbacé. 11. violettes. Septembre-octobre. GC.

7. U. nclumbifolia Gardn.; Fl. Bras. X, 1. 24.9. - Serra dos Orgañs et Alto Ilacahé, entre les feuilles des grandes Broméliacées terrestres, Rio-Jax., $n^{0}$ 6900. Herbacé, fl. violettes. Janvier-février. R.

8. U. geminiloba Benj.; in Fl. Bras. X, p. 242. - Serra dlos Orgãos 
et Piro da Tijuril, sur les rochers mouillés, Rio-Jav., $10^{05} 1604,4151$, 4154, 6628, 11129 . Herbacé, fl. violettes. Novembre-dérembre. CG.

9. Utricularia amethystina St-Hil.; Fl. Bras. X, p. 249. - Itacolumy, pres Ouro Preto, Itatiaia, dans les bourbiers, Mtsas, $n^{\circ 5} 6629$, 15182, 19871. Herhacé, fl. lilas. Janvier-février. C.

10. U. Gomezii DC.; Fl. Bras. X, p. 244. - Serra dos Orgĩos et Corcovado, sur les rochers mouillés, Rio-Jax, $n^{o s} 4153,6627,7732$. Herbacé, fl. lilas. Aoùt-septemhre. C.

11. U. anomala St-Hil.; Fl. Bras. X, p. 244. - Itatiaia, sur les rochers mouillés, Rio-Jax., no 6630 a. Herhacé, fl. lilas. C.

12. U. neottioides St-Hil.; Fl. Bras. X, p. 2\%. - Mlogy das Cruzes lans les bourbiers, S. PAulo, $n^{\text {os }} 15183,17686$. Herhacé, fl. blanches. Janvier-février. C.

13. U. Glazioviana Warm. in herb. Paris., Berol., Kew., Gener., etc. - Cabeceiras do Rio Gama, dans l'eau courante, Gorsz, $n^{\circ 5} 21830,21831$. Herbacé, fl. blanches. Mar's-avril. C.

14. U. reniformis St-Hil.; Fl. Bras. X, p. 247. - Serra dos Orgãos, entre les feuilles des grandes Bromeliacées terrestres, Rio-Jan., $n^{05} 2886$, 6630. Herlacé, fl. violettes. Septembre-octolre. C.

15. U. nervosa Web.; Fl. Bras. X, 1. 247. - Itatiaia, aux Campos Brejos, dans les bourbiers, Riı-JAx., nº 6630 b. Herbacé, fl. violacées. Janvier-février. R.

16. U. Lundii DC.; Fl. Bras. X, p. 249. - Campos da Bocaina, à la source du Rio Parahyla, dans l'eau, S. Pavto, $n^{\text {os }} 8218$, 20396. Herbacé, fl. violettes. Février-mars. C.

17. Genlisea ornata Hart.; Fl. Bras. X, p. 29̋2. - Serra dos Orgãos, au Campo das Antas, dans les bourbiers, Rio-Jav., n ${ }^{\circ s} 4150,8219$, 16233. Herbacé, f1. jaunes. Décembre-janvier. C.

18. G. violacea St-Hil. ; Fl. Bras. X, p. 20̆4. - Campos da Bocaina, au Bom Jardim, dans les bourbiers, S. Paulo, $n^{0} 8218$. Herbacé, fl. lilas. Février-mar's. C.

\section{Fam. 97. - Gesnéracées.}

1. Gloxinia attenuata Hanst.; Fl. Bras. V1ll, I, p. 349. - Tripuly, dans le bois sur les rochers, Mixas, $n^{0}$ 15168. Herbacé, fl. bleues. Janvier-février. C.

2. G. sarmentiana Gardn.; Fl. Bras. VIII, I, p. 350. - Corcovado, 
à Paineiras, sur les rochers, liıo-Jıx., nº 19584. Herbacé, fl. verdâtres. Novembre-décembre. C.

3. Dolichodeira tubiflora Hanst.; Fl. Bras. VIII, I, p. 384. Campos da Bocaina, sur les vieux arbres, Säo Patlo, $n^{\circ}$ 4067. Herlocé, 11. blanches. Décembre-janvier. R.

4. Houttea caulescens Glaz. n. sp.? in Iterl, Paris., Berol., Kew., Genev., etc. - Alto da Pedra, Gavea, sur les rochers, Rio-Jax., $n^{\circ} 8215$. Herlacé, n. roses. Juin-juillet. R.

ร. H. leptopus Hanst.; Fl. Bras. VIII, I, p. 393. - Serra dos Orgãos, sur les arbres et les rochers, Rı-Jas., $n^{\circ} 3773$. Herbacé, f1. roses. Mai-juillet. C.

6. Codonophora prasinata Lindl.: Fl. Bras. VIII, I, p. 39\%. Ouro Preto, au Campo de S. Joño, Mnss, $n^{\circ}$ 15166. Herbacé, f1. verdàtres. Février-mars. C.

7. C. Selloana Hanst.; Fl. Bras. VIII, I, p. 296. - Larangeiras, au Cosme Velho, sur les rochers, Rio-Jax., nº 8217. Herbacé, fl. verdàtres. Janvier-férrier. C.

8. Gesnera allagophylla Nlart.; Fl. Bras. VIII, I, p. 35\%.. - Itatiaia, Rio-Jax., nº 6618; Campos da Bocaina, S. Pavlo, $1^{\circ} 8214$; Ayuruoca, Serra do Picú, Sabara au Morro do Pires, Mrxas, ete., $n^{\text {os }} 11124,15167$, 16232, 18380; entre Jatoluasinho et As Brancas, dans le campo, Goyaz, $11^{\circ}$ 21833. Herbacé, fl. rouges. Janvier-mar's. CG.

9. G. tribracteata Ott. et Diet.; Fl. Bras. VIII, I, p. 33̈6. - Cimpos da Bociina, au Solrado, S. PAclo, nº 6618 a. Herbacé, fl. rouges. Janvier-février. R.

10. G. pilosa Glaz. n. sp.? in herb. Paris., Berol., Kew., Gener., etc. - Serra da Baliza, dans le campo, Goraz, n² 21835. Herbacé, fl. rouges. Janvier-février. Ii.

11. G. tuberosa Mart.; Fl. Bras. VIII, I, p. З3̈т. - Ouro Preto, sur les rochers, Mlivas, $n^{\circ}$ 20387. Presque acaule, 11. rouges. Norembredécembre. C.

12. G. rupicola Nart.; Fl. Bras. VIII, I, p. 358. - Serra da Piedade, sur les rochers près de la chapelle, Mrxas, $n^{0}$ 20388. Herbacé, 11. rouges. Novembre-décembre. C.

13. G. maculata Nart.; Fl. Bras. VIII, I, p. 361. - Alto do Imperador, près Pelropolis, sur les vieux arbres, Rio-Jax., $n^{\circ} 3047$ a. Bulbeux, f1. rouge jaunàtre. Juin-juillet. R.

14. G. polyantha DC.: Fl. Bras. VIII, I, p. 363. - Serra da Estrella, 
sur les rochers dans la forét, Ru-Jax., $n^{\circ} 16223$ b. Bulbeux, fl. rouges. Janvier-février. R.

13. Gesnera discolor Lindl.; Fl. Bras. VllI, I, p. 363. - Allo Macallé de Nova Friburgo, sur les vieux arbres, Rı-Jax., $n^{\circ} 3047$. Bullenx, 11. ronges. Arril-mai. C.

16. G. aggregata Lindl.; Fl. Bras. VIII, I, p. 366. - Copacabana

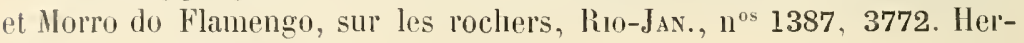
bacé, fl. rouges. Mai-juin. C.

17. G. pendulina Lindl.; Fl. Bras. VIII, I, p. 367. - Floresta da Tijuca, sur le rocher, Rı-Jan., $n^{\circ} 12064$ a. Herbacé, fll. rouges. Juinjuillet. C.

18. G. fruticulosa Glaz. n. sp.? in herb. Paris., Berol., Kew., Genev., etc. - Alto Nacahé de Nova Friburgo, sur les vieux arbres et les rochers, Rio-Jax., no 17707. Herbacé, ll. rouges. Décembre-janvier. R.

19. G. Sceptrum Mart.; Fl. Bras. VIII, I, p. 370. - Serra dos Orgãos, au Frade, Rı-JAN., n ${ }^{\text {os }} 5924$, 12064, 16221, 16223; Carandalıy, Hixas, $11^{\circ} 16223$ a; Cabeceiras do Rio Santa Anna, daus le campo, Goraz, $n^{\circ}$ 21834. Herbacé, fl. rouges. Janvier-mars. C..

20. G. bulbosa Gawl; Fl. Bras. VIII, I, 1). 379. - Serra da Estrella, sur les rochers et les vieux arbres, Rio-Jax., nº 14041, fl. rouges. Aoûtseptembre. C.

21. G. magnifica Ott. et Diet.; Fl. Bras. VIII, I, p. 380. - Copacabana, sur les lochers dans le bois, Iilo-Jas., no 7730. Herbacé, fl. rouges. Mai-juillet. C.

22. G. lateritia Lindl,; $\mathrm{Fl}$. Bras. VIII, I, p. 382. - Restinga da Tijuca, a Ponte do Marisco sur les rochers et Nova Friburgo, au Conego, Rı-Jax., ${ }^{o s} 3774,11123$, 12923. Herbacé, fl. rouges. Février-mars. R.

23. G. Cooperi Pax.; Fl. Bras. VIII, I, p. 383. - Campos da Bocaina, sur les rochers du Rio Mambucaba, S. PAlıo, no 11590. Herbacé, fl. rouges. Septembre-octobre. R.

24. Ligeria pusilla Hanst.; Fl. Bras. VIII, I, p. 386. - Belem, sur les rochers humides, Rio-J Ax., $n^{0} 4066$ a. Herbacé, fl. violettes. Févliermars. R.

23. L. speciosa Dcne; Fl. Bras. VIII, I, p. 389. - Gavea, sur les rochers près de la mer. Rı-JAx., nº 4066. Bulbeux, ll. violettes. Févriermars. C.

26. Episcia reptans Marl.; Fl. Bras. VIII, I, p. 401. - Serra do Jerecino, sur les arbres, Rı-Jax., n² 2636. Herbacé, fl. rouges. Févriermars. R. 
27. Alloplectus sparsiflortus Mart.; $\mathrm{Fl}$. Bras. VIIl, I, 1. 406.Fazenda do Rio Preto, sur les rochers, Mrsas, $n^{\circ} 8817$. Sous-frutescent, fl. rouges. Novembre-décembre. R.

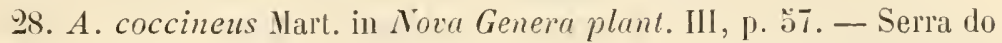
Mar, à Palmeiras, Rio-JAx., no 8816 . Herbacé, fl. rouges. Septembreoctobre. C.

99. A. tomentosus Glaz. n. sp.? in herb. Paris., Berol., Kew., Genev, etr. - Alto Vacahé de Nova Friburgo, dans le bois viercee, Rio-JAN., no 20386. Sous-frutescent, f1. rouges. Juin-juillet. R.

30. Columnea sanguinea Hanst. in Linnaa, XXXIY (1863̈), p. 384. - Páo d'Alho, sur les rochers et les vieux arbres, Espinito Saxto, $n^{\circ} 11591$. Herbacé, fl. blanchàtres. Arril-mai. R.

31. Nematanthus longipes DC.; Fl. Bras. VIII, I, 1. 41' resta da Tijuca, sur les vieux arbres, Biro-Jax., $1^{\circ}$ 8504. Herbacé, fl. rouges. Mai-juin. C.

32. Hypocyrta strigillosa Nart.; Fl. Bras. VIII, I, p. 410.Petropolis, dans le bois, au Retiro. Rio-JAx., nos 8216,15446 a. Sousfrutescent, f1. rouges. Octobre-novembre. C.

33. H. villosa Houk. et A.; Fl. Bras. VIII, I, p. 412. - Floresta da Tijuca, au Bico do Papagaio, Rı-JAx., nº 3045. Sous-frutescent, f1. rouges. Novembre-décembre. C.

34. Codonanthe Hookeri Lem.; Fl. Bras. VIII, I, p. 417. Floresta da Tijuca, sur les vieux arbres et les rochers, Rio-JAx, $11^{\circ} 4941$, Herbacé rampant, fl. rouges. Juin-juillet. C.

3ò. Napeanthus brasiliensis Gardn. in Hooker Lond. Journ. II, p. 13. - Serra do Mar, à Rodeio et au Alto Vlacahé de Nova Friburgo, Rio-JAx, $\mathrm{n}^{\circ}$ 1075, 8835, 18412, 19745. Herbacé, fl. blanches. Décenbrejanvier. CC.

36. Anetanthus gracilis Hiern in Warm. Symb. ad. Fl. Bras., p. 699. - Faria, près Sabara, sur les rochers, Mixas, $n^{\text {os }} 18413,20431$. Herbacé, fl. violacées. Novembre-décembre. C.

37. A. pusillus Glaz. n. sp.? in herb. Paris, Berol., Kew., Genev., etc. - Alto Macahé de Nuva Friburgo, sur les vieux arbres. Rio-Jax., nº 19586. Herbacé, 11. violettes. Janvier-février. R.

38. Besleria umbrosa Mart.; Fl. Eras. VIII, I, p. 397. - Serra da Estrella, à Vlandioca, sur les rochers, Rio-JAx., $11^{\text {os }} 7797$, 14042. Herbacé, fl. blanchâtres. Aoùt-septembre. C.

39. B. Riedeliana Hanst. in Fl. Bras. VIII, I, p. 399. - Floresta da 
Tijuca et Serra do Caello, près liezende, Rio-Jas., $\mathrm{n}^{\text {os }} 3046,6066,8818$. Herlacé, It. blanchtatres. Novembre-décembre. CG.

40. Besleria cuneata Gardn.; Fl. Bras. VIII, I, p. 400. - Corcovalo, au ruisseau Carroca, Rio-dax., ñ 7729 . Herbacé, f1. blinchâtres. Octolire-novembre. C.

41. B. Symphytum Kl. et Hanst? in Fl. Bras. VIII, I, p. 399. Serra dos Orgãos, dans le bois vierge, Rıo-Jan., $n^{\circ}$ 19585. Herbacé, f1. jaunitres. Février-mar's. C.

\section{Fam. 98. - Bignoniacées.}

1. Tynanthus labiatus Niers; Fl. Bras. VIII, II, p. 193. - Cattas Altas, dans le bois, Mixas, $n^{0}$ 14108. Arbuste sarmenteux, fl. jaunâtres. Janvier-février. C.

2. T. laxiflorus Miers; Fl. Bras. VIII, II, p. 193. - Pio d'Alho, dans le bois, Espritro SAvTo, $n^{0} 19664 a$. Arbuste sarmenteux, fl. blanc rosé. Mai-juillet. R.

3. T. fasciculatus Miers; Fl. Bras. VIII. II, p. 194. - Perpetua, près Diamantina, Minas, $1^{\circ}$ 19664; Campo da Bocaina, S. Paulo, $n^{0} 4692 a$. Arbuste samenteux, fl. blanc jaunâtre. Avril-mai. C. Vulg. : Cipó cravo.

4. T. cognatus Miers; Fl. Bras. VIII, II, p. 19̋. - Caminho do Macaco, Gavea, Floresta da Tijuca, Rı-JAv., $11^{\circ \mathrm{s}}$ 2638, 4692, 4709, 4719. Arbuste sarmenteux, fl. lilas. Février-mar's. CG.

5. T. elegans Niers; Fl. Bras. VIII, II, p. 196. - Corcovado et Fazenda do Sobral près Parahyba do Sul, Rio-JAx, $n^{\circ}$ 4124, 4683, 12973. Arbuste sarmenteux, fl. lilas. Août-septembre. C. Vulg. : Cipó cravo.

6. Arrabidæa Agnus-castus DC.; Fl. Bras. VIII, II, p. 22. - Restinga de Copacahana, Rio-J $\mathrm{J}_{\mathrm{AN}}, \mathrm{n}^{\circ \mathrm{s}} 2640,4113$. Arbuste sarmenteux, fl. lilas. Février-mar's. C. Vulg. : Cipó Rego.

- Var. Salzmanni Schum. et Bur.; Fl. Bras. VIII, II, p. 24. - Restinga de Copacaloana, dans les sables, Rio-Jan., $\mathrm{n}^{\text {os }} 4695,11223$. Arbuste sarmenteux, fl. lilas. Mars-avril. C. Vulg. : Cipó Rego.

7. A. subverticillata Bur. et K. Sch.; Fl. Bras. VIII, II, p. 2\%. Serra dos Orgĩos, à Theresopolis, Rı-Jan., $1^{\circ}$ 11230. Arbuste sarmenteux, fl, violettes. Janvier-février. R.

8. A. fagoides Bur.; Fl. Bras. VIII, II, p. 26. - Itacolumy, près 
A.-F.-M. GLAZIOU. - LISTE DES PLANTES DU BRLSIL CENTHAL.

Ouro Preto dans le bois, Mixas, nos 12996 a, 14107. Arbuste sarmenteux, fl. roses odoramtes. Mai-juin. C.

9. A. Chica Verl. valr. acutifolia Bur.; Fl. Bras. VIII, II, p. 32. Quinta da Boa Vista, S. Ghristovão, Rio-dAx., I $^{\circ} 11227$ a. Arbuste sapmenteux, 11. roses, cultivé. Février-mars. R.

10. A. florida DG.; Fl. Bras. VIII, II, p. 33. - Serra da Itabapoana, Espirito Saxto, $1^{\circ 8} 9955,11227$. Arbuste sarmenteux, fi. lilas. Septembre-octobre. C.

11. A. coningata Mart.; Fl. Bras. VIII, II, p. 3't. - Copacabana. Gavea, Caminho do Nacaco, Tijuca, Rio-Jav., nos 50, 2637, 2639, 4109. 4110, 4111, 4690. Arbuste sarmenteux, 11. violettes. Février-mars. CG.

12. A. chironeura l3ur. sp. nov. in herb. Mus. Paris. - Fluresta da Tijuca, Caminho da Taquara, Rio-JAN., n ${ }^{\circ}$ 4707. Arbuste sarmenteux, f1. roses. Janvier-février. R.

13. A. corymbifera Bur.; Fl. Bras. VIII, II, p. 36. - Copacabana, Floresta da Tijuca, Serra de Jacarepagna, Rı-JAx., $n^{0 s} 4116$, 4708, $4712,11220,12994$. Arbuste sarmenteux, fl. violettes. Décembre-janvier. CG.

14. A. platyplylla Bur. et K. Schum. var. acuminata Bur.; F'l. Bras. VIII, II, p. 39. - Villa Nova, près Porto das Caixas et Petropolis, Ro-

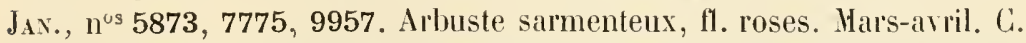

- Var. induta Bur.; Fl. Bras. VIII, II, p. 39. - Entre João Ayres et Barbacena, dans le bois, Mivas, ${ }^{\circ} 12992$, Arbuste sarmenteux, fi. roses. Jänvier-février. C.

- Var. firma Bur. : Fl. Bras. VIII, II, p. 40. - Ipanema, dans le bois, S. Patlo, $n^{\circ} 12970$; entre Sitio et Barbacena, Mixas, $n^{0}$ 16272. Arbuste sarmenteux, fl. d'un beau rose. Janvier-février. C.

- Var. sтricta Bur. el K. Sclı.; Fl. Bras. VIII. II, p. 41. - Ponte Alta, dans le campo, Goraz, $n^{\circ}$ 21853. Apbuste sarmenteux, fl. roses. Aoutseptembre. R.

15. A. celastroides Bur.; F'l Bras. VIII, II, p. 42. - Serra d'Ouro I'reto, dans le bois, Uriss, $n^{\circ} 14110$. Arbuste, Il. violettes. Janvierfévrier. C.

16. A. mollis Bur.; Fl. Bras. VIII, II, p. 46. - Quinta da Boa Vista, S. Christovĩo, Rio-Jax., $\mathrm{n}^{\circ} 14124$ a. Arbuste sarmenteux, cultivé, fl. violettes. Janvier-février. R.

17. A. multiflora Bur. et K. Sch.; Fl. Bras. VIII, II, p. 47. - Serra d'Ouro Preto, dans le bois, Mivis, $n^{o s} 12997,14114$. Arbuste sarmenteux, 11. lilas. Février-mars. C. 
18. Arrabidara rotundata Bur.; Fl. Bras. VIII, II, p. 48. - Serra da ltabapoana, dans le bois, Espritro SAxto, $n^{\circ} 11214$. Arbuste sarmenteux, t1. violettes. Octobre-novembre. R.

19. 4. dispar Bur.; Fl. Bras. VII, II, p. 33. - Calı Frio, press du plıare, Rı-JAx., no 11226. Arbuste sarmenteux, fl. roses. Juillet-août. R.

20 A. parviflora Bur. et K. Schum. var. Guaziovir Bur. et Sch.; Fl.

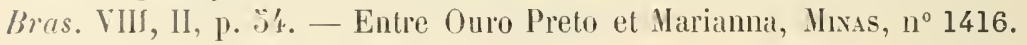
Arluste, f1. rose paile. Février-mar's. C.

21. A. Blanchetii DC.; Fl. Bras. VIII, II, p. 96. - Fazenda Imperial de Santa Cruz et Cabo Frio, Riro-J $J_{A N}$, $n^{05} 4723,11229,11251$. Arbuste sarmenteux, fl. lilas. Férrier-mars. C.

29. A. subexserta Bur. et K. Sch.; Fl. Bras. VIII, II, p. 59. - Arraial da Serra de Ouro Branco, Mrsas, ${ }^{\circ}$ 12996. Arbuste sarmenteux, fl. lilas. Mars-avril. C.

23. A. subincana DC.; Fl. Bras. VIII, II, p. 61. - Restinga de Copacabana, dans les sabies, Rı-JAx., $n^{\circ \mathrm{s}}$ 2107, 4112, 4958. Arbuste sarmenteux, $\mathrm{fl}$. violettes. Octobre-novembre. C.

24. A. craterophora Bur. var. acutifolia DC.; Fl. Bras. VIII, II, p. 6 i. - Paranaúa, dans le campo, Goraz, n² 21861. Arbuste sarmenteux, 11. roses. Février-mars. R.

20ั. A. triplinervia Baill.; Fl. Bras. VIII, II, p. 67. - Petropolis, à Santo Antonio, Rio-Jax., nos 5784, 8211; Santa Luzia, au bord des rivières, Goraz, $\mathrm{n}^{\circ}$ 21856. Arbuste sarmenteux, f1. blanches. Marsarril. GG.

26. A. ateramnantha Pur. et K. Schum; Fl. Bras, VIII, II, p. 68. Itapemirim, dans le bois, Espirito $\mathrm{S}_{\mathrm{Axt}}, \mathrm{n}^{\circ} 11228$. Arbuste sarmenteux, 11. roses. Févier-mars. R.

97. A. puberula Bur.; Fl. Bras. VIII, II, p. 71. - Cachoeira do campo, au bord des bois, Mixas, ${ }^{\circ s} 12995,14112$. Arbuste sarmenteux, ft. roses. Octolse-novembre. C.

28. A. lasiantha Bur. et K. Sch.; Fl. Brets. VIII, II, p. 71. - Caraça, dans le campo, Mhras, $\mathrm{n}^{\circ}$ 15264. Arbuste sarmenteux, fl. rousses. Juinjuillet.

49. A. pulchella Bur.; Fl. Bras. VIII, II, p. 73. - Catas Altas, dans le bois et les campos, Mixis, $n^{\circ} 14114 a$. Arbuste sarmenteux, fl. roses. Juin-juillet. R.

30. Fridericia speciosa Mart.; Fl. Bras. VIII, II, p. 293. - Corcovado, à Paineiras. Tijuca, Petropolis, Riı-JAs., nos 646, 2641, 4685, 
A.-F.-M. GLiziou. - Liste des Playtes du BRÉsil Cextral.

4701, 4720. 16274. Arbuste sarmenteux, fl. rouges. Décembre-janvier. CG.

31. Lundia obliqua Sonder; Fl. Bras. VIII, II, p. 240. - Campos da Bocaina, S. Patco, no 8810 a. Arbuste sarmenteux, fl. rose pâle. Aoùt-septembre. R.

32. L. longa DC.; Fl. Bras. VIII, II, 1. 2241. - Nova Friburgo et Petropolis, Rio-Jax., $1^{\circ s} 1083,4107,6643,8810$. Arbuste sarmenteux, f1. blanches. Février-mars. C.

33. L. nitidula A. DC. var. virginalis Bur. et Schum.; Fl. Bras. VIII, II, p. 2'43. - Serra dos Orgaos, à Theresopolis, Ruo-Jax., nos 4103, 4711, 6602; São João Baptista, Mıxas, $n^{\text {os }} 12993$, 15260. Haute liane, fl. blanc rose. Décembre-janvier. CG.

34. L. cordata DC.; Fl. Bras. VIII, II, p. 2'43. - Restinga de Mauá, Taipú, Praia Grande, Rio-JAx., nos 1444, 3770, 4716, 4724, 8210. Arbuste sarmenteux, fl. rouges. Février-avril. CG.

- Var. macrophylla Glaz. nov. v. in herb., Paris, Berol., Kew., Brux., etc. - Vista Chineza, Rio Comprido et Corcovado, Rio-Jıx., $\mathrm{n}^{\text {os }} 4704,4714,8809$. Arbuste sarmenteux, sans tl. Janvier-février. C.

3.. Petastoma samydoides Hiers; Fl. Bras. VIII. II, p. 78. Sauta Luzia do Rio das Velhas. dans le campo. Mrxas, $\mathrm{n}^{\text {os }}$ 16266, $20452 a$. Arbuste sarmenteux, fl. blanchàtres. Aoùt-septembre. C.

36. P. discocalyx Bur. et Sch.: Fl. Bras. VIII, II, p. 80. - Serra d'Ouro Preto, dans le bois, Mixas, $n^{\circ}$ 14111. Aibuste sarmenteux, f1. roses. Février-mars. C.

37. P. Leucopogon Bur.; Fl. Bras. VIII, II, p. 81. - Mata Gavallos et Gavea, Rı-Jax., n ${ }^{0 s}$ 642, 4117; Santa Luzia, près du pont, Goraz, $n^{0}$ 21857. Arbuste sarmenteux, fl. rouge pourpre. Mars-avril. C.

38. P. formosum Bur.; Fl. Bras. VIII, II, p. 83. - Ayuruoca, dans le bois. Mrsas, $\mathbf{I}^{\circ}$ 9526. Arbuste sarmenteux, fl. violet foncé. Marsavril. C.

39. Bignonia exoleta Vell.; Fl. Bras. VIII, II, p. 283. - Quinta, S. Christovio, Tijuca à la Pedra Bonita, Rio-JAx., n ${ }^{\text {os }} 3063,4687,4694$. Février-juillet.

40. Stizophyllum perforatum Viers; Fl. Bras. VIII, II, P. 220. - Campo Rello près du Rio Paralıyba et Nova Friburgo, Rio-Jav., ${ }^{\text {os }}{ }^{\circ 646}$, 13473. Arbuste sarmenteux, 11. rouge pâle. Décembre-janvier. C.

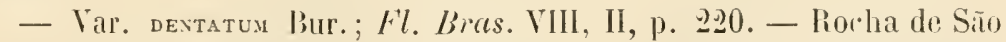
Joĩo et Floresta da Tijuca, Rio-Jıs., ${ }^{\text {os }}{ }^{4128,}$ 4684, 4686, 11216, 11233. Longue liane, fl. roses. Octobre-novembre. C. 
41. Cremastus lachnans Bur.; Fl. Bras. VIIl, II, 11. 21:). - Páo d'Alho, Esprato Saxto, $1^{\circ}$ 9954; Fayenda Vargem, au Rio Jardim, Gorız, $1^{\circ}$ 21858. Arbuste sarmenteux, li. rougetitres. Juin-juillet. R.

42. Cr. Sceptrum Bur. et Schum; Fil. Bras. Vill, 11, p. 巳It. Biribiry pres Dianantiua, Hrss, $\mathbf{u}^{\circ}$ 19661. Arbuste sarmenteux, ll. rouge foncé. Février-mars. C.

- Var. catifolius Bur. et Sch.; Fl. Bras. VIII, II, p. 216. - Formosa, dans le campo, Goraz, $n^{\circ} 21863$ a. Arbuste sarmenteux, 11. rouge pourpre. Février-mars. R.

- Var. angustifolius DG.; Fl. Bras. Vili, II, p. 217. - Santa Barbara, dans le bois, Hwas, $1^{\circ}$ 12998, 21863. Arbuste sarmenteux, fl. rougeâtres. Septembre-octobre. C.

43. Cr. pulcher Bur.; Fl. Bras. VIII, II, p. 217. Rio das Pedras, au Valu, Mısas, $n^{\circ}$ 19662. Arbuste sarmenteux, f1. rouge pourpre. Marsavril. C.

44. Pyrostegia venusta Miers; Fl. Bras. VIII, II, p. 292. - Juiz de Fora, Barbacena, dans le bois, Mixas, $n^{05}$ 1478, 4696, 12976, 13000. Haute liane, f1. jaunes. Juin-août. GC. Vulg. : Cipó São João.

40. P. cinerea Bur.; Fl. Bras. VIII, II, 1. 233. - Quinta da Boa Vista, à S. Christovão, Rıo-JaN., $\mathrm{n}^{0 \mathrm{~s}} 14124$, 19666. Arbuste sarmenteux, 11. roses, cultivé. Février-mars. R.

46. Paragonia pyramidata Bur.; Fl. Bras. VIII, II, p. 182. Serra dos Orgãos, à Theresopolis, près des rivières, Rio JAs., $11^{\text {os }} 4102$, 4702, 4737, 6064, 6702, 9958, 12084, 12986. Arbuste sarmenteux, 11. violettes. Janvier-mars. CC.

- Var. eleiptica Bur.; Fl. Bras. Vili, II, p. 182. - Serra de Jacarepagua, Fazenda de Sobral près Parahıba do Sul, Rio-dan., $11^{\text {os }} 4108$, 6720, 12971, 15259; Ponso de Cuba, Goxaz, $1^{\circ}$ 21860. Arbuste sarmenteux, fl. roses. Aout-septembre. C.

47. Pleonotoma variabile Miers. var. Castelnæi Bur. var. nor.? in herb. Glaziou (Paris). - Loc. non désignée, nº 9952.

48. Pl. jasminifolinm Miers; Fl. Bras. VI, III, p. 277. -- Loc. non désignée, $n^{\circ} 9963$.

49. Pl. tetraqnetrum Bur.; Fl. Bras. VIII, II, 1. 278. - Entre Jose Vaz et Rezende $n^{\circ} 7772$; entre Lagoa do Peixe et Rio Bonito, $n^{\circ}$ 12975, Rio-Jax. Fl. rouge pâle, gorge jaunâtre. Septembre. C.

50. Macfadyena uncinata DC.; Fl. Bras. VIII, II, p. 29I. - Nova Friburgo, au Chalet, Rio-Jux., $1^{\circ}$ 13474. Novembre.

๖1. M. mollis Seem.; Fl. Bras. VIII, II, p. 293. - Alto Macahé, lino-JAN., no 18377. Fl. jaunes. Janvier. 
82. Dolichandra cynanchoites Cham.; Fl. Bras. VIII, II, p. 302. Rio de Janeiro, cultivé, $1^{\circ}$ 15261: Janvier.

33. Phryganocydia corymbosa Bur.; Fl. Bras. VIII, II, p. 2249. Floresta da Tijuca, São Christovão au Pedregullo, Corcovado à Paineiras, Rro-Jax., : ${ }^{\text {os }} 644,1475,4118,4717,9225$. Arìuste sarmenteux, fi. rose pâle. Janvier-mar's. C.

̈’́. Melloa populifolia Bur.: Fl. Bras. VIII, II, p. 2903. - Serra do Picú, Rio-Jax., nos 11219, 12987, 12988, 12989. Avril-novembre.

3\%. Saldanhæa lateriflora Bur.; Fl. Bras. VIII, II, p. 29.2. Santa Luzia do Rio das Velhas, Mras, n 15258 . Arbuste sarmenteux, f1. violettes. Juin-juillet. C.

̈6. S. bracteata Bur. et K. Schum; Fl. Bras. VIII, II, p. 293. - Entre Sĩo Pedro dos Indios et Calıo Frio. Rio-JAx., nº 9956. Arbuste sarmenleux, fl. roses. Septembre-octobre. R.

37. S. heterocaly $x$ Bur. et K. Schum; Fl. Bras. VilI, II, p. 2马\%. Carandahy, dans la plaine, Mrsas, $n^{\circ}$ 14109. Arbuste, fl. violacées. Septembre-octobre. C.

58. S. myriantha Bur.; Fl. Bras. VIII, II, p. 29\%. - Bords du Rio Areias, dans le bois, foyaz, no 21859. Arbuste sarmenteux, fl. roses. Octobre-novembre. C.

- Var. pubescexs Bur.; Fl. Bras. VIII, II, p. בֶ̆Э. - Fazenda da Serra Vermelha, près Cantagallo, Rio-JAx., nº 16270. Arbuste sarmenteux, fi. roses. Octobre-novembre. C.

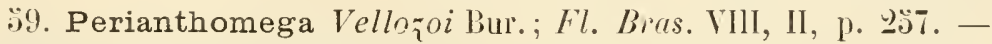
Loc. non désignée, $\mathrm{n}^{\circ} 11246$.

60. Mansoa difficilis Bur. et Sch.; Fl. Bras. VIII, II, p. 201. Serra do Picú, au Paulo et au Palmital, Serra da Estrella, Rio-Jax., $n^{\text {os }} 1082,11252,12968,12990,15252$. Arbuste sarmenteux, fl. violettes. Arril-mai. CG.

61. M. Glaziovii Bur. et Sch.; Fl. Bras. VIII, II, p. 203. - Serra de Ouro Preto, Mrsas, nos 12991,14120 . Arbuste sarmenteux, fl. violacées. Juin-juillet. C.

62. Cuspidaria pterocarpa DC. : Fl. Bras. VIII, II, p. 157. Floresta da Tijuca, S. Christovĩo, Belem. Serra de Jacarepagna, RioJix., $11^{\text {os }} 645,3769,4693,6719,8811,9528,11222,11225$. Arbuste sarmenteux, fl. roses. Octobre-norembre. CG.

63. C. erubescens Bur. var. subtruxcata DC.; Fl. Bras. VIII, II, p. 159. - Arraial dia Serra do Ouro Branco, Misas, n 14106. Arbuste sarmenteux, fl. violettes. Aoùt-septembre. R. 
6\%. Adenocalymma flanum Mart.; Fl. Bras. VIII, II, 1. 87. Fazendia do Sobral, clans la forêt, Mrsas, $n^{0} 12970$ b. Grand arbuste, n. jaunes. Septembre-octobre. R.

6ij. A. comosmm DC. var. acutissmum Bur. et K. Sch.; Fl. Bras. VIII, II, p. 89. - Caminho do Hacaco et Floresta da Tijuca, Rio-Jan, $\mathrm{u}^{\circ \mathrm{s}} 4126$, 4127, 4722; Queluz, Misas, nos 14115 , 15255. Arbuste, f1. jaunes. Aoùtseptembre.

- Var. lancelatum Bur. et K. Sch.; Fl. Bras. ViII, II, p. 90. - Icarahy, près Boa Viagem à Praia Grande, Rro-Jan., no 4736. Arbuste sarmenteux, fl. jaunes. Août-septembre. C.

66. A. bracteatum DC.; Fl. Bras. VIII, II, p. 90. - Floresta da Tijuca et Corcovarlo, Rı-JAx., $n^{\circ 5}$ 1443, 5780, 11217; Fazenda do Morro Azul. S̃̃o Patlo, $n^{\circ}$ 12969. Arbuste sarmenteux, fl. jaunes. Aoùt-septembre. CG.

- Valr. macradenum Bur.; Fl. Bras. Vili, II, p. 91. - Corcovado, à Paineiras, Rı-Jax., $n^{0 s} 4681$, 15253. Arbuste sarmenteux, fl. jaumes. Août-septembre. Vulg. : Cipó branco. C.

67. A. bullatum Bur.; Fl. Bras. VIII, II, p. 92. - Serra do Caelho, à losé Vaz près Rezende, Rio-dax., n 7771. Arbuste sarmenteux, fl. jaunes. Août-septembre. R.

68. A. marginatnm DC.; Fl. Brus. VIII, II, p. 92. - Restinga da Tijuca, à Ponte do Marisco et à Gavea, Rıo-Jav., nos 4121, 4721, 11250; Páo d'Alho, Espirito Santo, $1^{0 s} 9961,14105 u$. Arhuste sarmenteux, f1. jaunes. Janvier-février. C.

69. A. tephrinocalyx Bur.; Fl. Bras. VIII, II, p. 95. - Floresta da Tijuca et Horro Queimado, Rio-Jax., $\mathrm{n}^{\text {os }} 8815$, 9527. Arbuste, 11. jaunes. Juin-juillet. $\mathrm{R}$.

70. A. hypostictum Bur. et K. Sch.; Fl. liras. VIII, II, p. 99. Arassuahy, dans le bois, Misas, $n^{\circ} 15257$. Arbuste sarmenteux, fl. jaumes. Janvier-février. R.

71. A. longiracemosum Nart.; Fl. Bras. VIII, Il, p. 102. - Serra da Estrella et Floresta da Tijuca, Rı-Jav., nos 1152, 4122, 4710, 6644 et 12082. Arbuste sarmenteux, ft. jaunes. Janvier-février. CG.

72. A. grandifolizm Mart.; Fl. Bras. VIII, II, p. 106. - Serra do Tingua, au Rio Santo Antonio, Rio-JaN., $1^{\circ}$ 11256. Arbuste, fl. jaunes. Aoùt-septembre. R.

73. A. foreolatum Bur.; Fl. Bras. VIII, II, p. 109. - Entre Cabo Frio et São P'edro dos Indios, Rio-Jax., no 9960. Arbuste sarmenteux, fl. jaunes. Juin-juillet. R. 
7'. A. alliaceum Vier's; Fl. Bras. VIII, II, p. I11. - Aldea de São Pedro dos Indios et Copacabana, Rio-JAx., nos 4726, 12974. Arbuste sarmenteux, 11. rose pâle. Décembre-janvier. C. Vulg. : Cipó d'Alho.

7.). A. lavigatum Bur. et K. Sch.; Fl. Bras. VIII, II, p. 113. - Rio Douro, en bas du Tingua, Rio-Jax., $n^{\circ}$ 9529. Arbuste sarmenteux, fl. violettes. superbes. Octobre-novembre. C.

76. A. asperulum Bur. et K. Sch.; Fl. Bras. VIII, II, p. 113. - Serra dos Purys, Espirito Saxto, ${ }^{05} 9959,11218,11231$. Arbuste sarmenteux, fi. jaunes. Novembre-décembre. C.

77. A. splendens Bur. et K. Sch. in Fl. Bras. VIII, II, p. 115. Cosme Vellıo, à Larangeiras, Rio-JAx., nos 2644, 4106, 4718. Arbuste sarmenteux, f1. lilas. Février-mars. C.

78. A. gracile Bur. n. sp. in herb. Mus. Paris. - Rio Comprido, Larangeiras, au Cosme Velho, Rio-JAx., $n^{08} 649$, 4715. Liane, fl. jaunes. Février-mars. C.

79. Memora nodosa Miers; Fl. Bras. VIII, II, p. 2:9. - Entre Lage et Curumba, au bord des bois, Goyaz, n 21864. Fl. jaunes. Juilletaoût.

80. M. acutiloba Bur. n. sp. in herb. Mus. Par. - Loc. non désign., $n^{\circ} 11232$.

81. M. fulgens Bur.; Fl. Bras. VIII, II, p. 260. - Santa Anna dos Tocos, route de la Gavea, Riı-Jdx., $11^{0 s} 2642$, 8208. Février-mar's.

- Var. elongata Bur.; Fl. Bras. VIII, II, p. 261. - Loc. non désignn., nº 9967.

82. M. glaberrina K. Schum.; Fl. Bras. VIII, II, p. 262. - Barbacena, au Sitio dans les pâturages, Ouro Branco, à S. Juliño, Mıvas, $n^{\text {os }} 14117,16271$. Fl. jaunes. Janvier-mars.

83. M. magnifica Bur.; Fl. Bras. VIII, II, p. 268 . - Loc. non désignée, nº 9966.

8't. M. axillaris Bur. et K. Schum.; Fl. Bras. VIII, II, p. פ770. Fazenda da Cava, $n^{\circ} 21862$.

8\%. - M. pubescens I. Sch.; Fl. Bras. VIII, II, p. 279. Entre Barreiro Grande et Valla Funde, dans les campos, $n^{\circ} 19658$. FI. jaunes. llars.

- Var. Riedelir Bur. et K. Sch. in Fl. Bras. VIII, II, p. 273. - Entre Morro Redondo et João Nanoel, dans Ie carrascal, $11^{\circ} 21865$. Octobre.

S6. Anemopægma Hilarianum Bur. et K. Sch., Fl. Brus. VIII, II, p. 124. - Petropolis, au Retiro, Rio-JAN., $n^{08}$ 4105, 8207. Longue liane, fl. verdâtres. Mars-avril. R. 
87. Anemopagma pachyphylla liur. et Silt. II. sp. in Fl. Bras. Vllı, 1I, p. 120 - Entre São José dos Barreiros et Formosil, S. Paulo, no 11592. Arbuste sarmenteux, fl. jaunes. Aout-septembre. C.

88. A. lave 1. DC.; Fl. Bras. VIII, II, p. 127. - Entre sitio et Barbarelła, dans le campo, llovas, $n^{0 s} 11235,11237$, 19660. Arbuste sarmenteux, fl. jaunes. Mars-avril. C.

89. A. Chaimberlaynii Bur. et K. Sih., Fl. Bras. VIII, II. p. I98. Serra dos Orgãos et Campo Bello, Rio-Jan.. n ${ }^{05} 4123,4129,4738$, 19660 a. Arbuste sarmenteux, fl. jaunes. Juin-juillet. CG.

- Var. вrachybotrys DG.; : Fl. Bras. Vili, II, p. 198. - Nlto Jacahé de Nova Friburgo, Petropolis, Corcovado, Rio-JAx., n ${ }^{o s} 4682,5781$, 9962, 11215, 12083. Arlıuste sarmenteux, fl. jaunes. Février-mar's. CC.

90. A. gracile Bur. et K. Sch. in Fl. Bras. VIII, II, p. 132. - Nova Friburgo, au Alto da Boa Vista, Rio-J $\mathrm{JN}_{\mathrm{A}}, \mathrm{n}^{\circ}$ 12999. Arbuste sarmenteux, ft. jaunes. Février-mars. R.

91. A. subundulatum Bur. et K. Selı.; Fl. Bras. VIII, II. p. 133. Serra do Tingua, au Rio Douro, Rio-Jax., n 12080. Arbuste sarmenteux, 11. jaunes. Novembre-décembre. R.

92. A. prostratum DC.; Fl. Bras. VIII, II, p. 138̈. - Alto Vlacahé de Nova Frilurgo, Rio-Jax., ${ }^{0 s} 11236$, 17151. Arbuste sarmenteux, fl. jaunes. Novembre-décembre. Ci.

93. A. Nettoanum Glaz. n. sp. in herb. Mus. Par., Flum. - São João Baptista da Gloria. Muxas, no 1208 a. Arbuste sarmenteux, fl. jaunes. Novembre-décembre. $R$.

94. A. glaucum Mart.; Fl. Brus. VIII, II, p. 138. - Serra do Ouro Branco, à Sin Juliño, Mlsas, no 18378 a. Arbuste, fl. verdìtres. Vlarsavril. R.

95. A. goyazense K. Schum. in Fl. Bras. VIIl, II, p. 407. - Fazenda da Bolivia, dans Ie campo, Goyaz, $n^{\circ}$ 21846. Arbuste, fl. jaunes. Juinjuillet. C.

96. A. mirandum A. DC. var. verticillatum Bur.; Fl. Bras. VIIl, Il, p. 141. - Entre Corrego Secco et Porto do Jequiliba, Mivas, $1^{\circ} 19659$; Pichoí, au Epigão, Goyaz, no ${ }^{\circ}$ 21844. Petit arbuste, fl. jaunes. Octobrenovembre. C. Vulg. : Catuaba.

- Var. glabrum DC.; Fl. Bras. VIII, Il, p. 14l. - Morro de Cachaubú, Mrxas, no 16267. Petit arbuste, 11. jaunes. Janvier-férrier. C. Vulg. : Caluaba.

- Var. puber DC.; Fl. Bras. VIII, II, p. 141. - Serra dos Pyreneos, près Meia Ponte, Goraz, $\mathrm{n}^{\circ}$ 21845. Arbuste, fl. jaunes. Septembreoctobre. R. 
97. Distictis Mansoana Bur.; Fl. Bras. VIII, II, p. 173. - Morro da Gloria près Saluara, Serra dos Vertentes, Mrsas, nos 18376, 20419; Paranauá et Macicos, Goyz, $n^{\text {os }} 21854,21855$. Arluste sarmenteux, 11. blanı jaunâtre. Janvier-mars. CC.

98. D. crassa Bur. et K. Sch.; Fl. Bras. VIII, II, p. 177. - Bento Rodrigues, prẻs Ouro Preto, Mixas, $1^{\circ}$ 1418. Arbuste sarmenteux, fl. blanchâtres. Février-mars. C.

99. D stipularis Mart. sp. 11.? in herb. Mus. Paris. - Belem, dans les bourbiers, Rio-JAx., $\mathrm{n}^{\circ} 8812$. Haute liane, 11. violet foncé. Septembre-octohre. C.

100. D. Glaziovii Bur. et K. Sch.; Fl. Bras. VIII, II, p. 180. - Alto Macahé de Nova Friburgo, Ro--Jax., $n^{\circ}$ 17705. Arbuste sarmenteux, fl. jaunàtres. Mars-arril.

101. D. racemosa Bur. et K. Schum.; Fl. Bras. VIII, II, p. 179. Morro da Gloria, près Sabara, Misas, $\mathrm{n}^{\circ} 18376 a$. Arbuste sarmenteux, 11. jaunâtres. Janvier-février. R.

102. Pithecoctenium cordifolium Mart.; Fl. Bras. VIII, II, p. 164. - Serra dos Orgãos, à Teresopolis, Rio-JAx., nos 11253, 12972. Arbuste sarmenteux. fl. jaunes. Janvier-février. C.

103. P. dolichoides K. Sch.; Fl. Bras. VIII, II, p. 16\%. - Alto Nacahé de Nova Friburgo, Rio-Jax., $n^{\circ}$ 18375. Arbuste sarmenteux, 11. jaune pàle. C.

104. P. cynanchoides DC.; Fl. Bras. VIII, II, p. 166. - Sete Pontes, au Baretto, dans les haies, Rio-JAx., $n^{\text {os }} 4104$, 5946. Longue liane, Il. blanches. Septembre-octobre. C.

108. P. echinatum K. Sch.; Fl. Bras. VIII, II, p. 168. - Entre Villa Nova et Porto das Caixas, Corcovado et Gavea, Rio-JAx., n ${ }^{\text {os }} 647$, 4689, 6648, 7773, 7774. Arbuste sarmenteux, fl. jaunes. Janviermars. CC.

106. P. botryoides DC.; Fl. Bras. VIII, II, p. 169. - Inficionado, dans le bois, Minas, no 14113 . Arbuste sarmenteux, 11. jaunes. Octobrenovembre. C.

107. P. scabriusculum Mart. var. мaсranthum Bur. et K. Sch.; Fl. Bras. VIII, II, p. 1ЪI. - Andarahy Grande, Rı-JAx., nº 7776. Arbuste sarmenteux, 11. jaunâtres. Juin-juillet. R.

108. Clytostoma costatum Bur. et K. Sch. in Fl. Bras. VIII, II, p. 13\%. - Jurujuba, Naxambomba, Parahybuna, Rio-JAN., $\mathrm{n}^{\text {os }} 849$, $2.08,6815,8813,11221$. Arbuste sarmenteux, fl. violettes. Octobrenovembre. CG. 
109. Clytostoma punctatum Bur. in herb. Mus. Paris. - São Bartholomeu, dalls le campo, Misas, no 15256. Arbuste sarmenteux, 11. violettes. Novembre-décembre. R.

$110 \mathrm{Cl}$. noterophilum Bur. et K. Sch.; Fl. Bras. VIII, II, p. $1533 .-$ Fazenda de Santa Cruz, Belem et Botafogo, Rıo-Jav., $1^{0 s}$ 4691, 6065, $8811 b, 11234$. Haute liane, fl. violettes. Octobre-novembre. C.

111. Haplolophium bracteatum Cham.; Fl. liras. VIII, II, p. 173. - Petropolis, estrada de Cachambú, Rio-JAx., nos 7774, 8209. Arbuste sarmenteux, fl. jaunâtres. Janvier-février.

112. Glaziovia bauhinioides Bur.; Fl. Bras. VIII, II, p. 228. Floresta da Tijuca et Gavea, sur les vieux arbres et les rochers, Rı-JAN., $11^{0 s}$ 651, 4688, 12078. Arbuste sarmenteux, fl. lilas. Mars-avril. C. Vulg. : Quatro patacas.

113. Amphilophium Glaziovii Bur.; F'l. Bras. VIII, II, 1. 209. Petropolis, à Santo Antonio, Rı-JAv., $n^{0}$ 5782. Arbuste sarmenteux, f1. rousses. Mars-avril. R.

114. A. paniculatum H. B. K.; Fl. Bras. VIII, II, p. 211. Quinta da Boa Vista, à São Christovão. Riı-Jar., nº 16273 a. Arbuste sarmenteux, ll. rougeâtres, cultivé. Avril-mai. R.

11\%. A. Vauthieri DG.; Fl. Bras. VIII, II, p. 213. - Restinga de Coparahana, São Christovão à Pedregulho, Rı-JAx., $\mathbf{n}^{\text {os }} 4725$, 12079, 16273. Arbuste sarmenteux, 11. orangées. Décembre-janvier. C.

116. Callichlamys latifolia K. Schum.; Fl. Bras. VIII, II, p. 226. - Petropolis, Floresta da Tijuca, Serra dos Orgãos, Rıo-JAv., nos 4703 , 4728, 7872, 8206, 8814, 12085, 1405, 16269, 17704. Grosse liane, f1. jaunes. Janvier-février. CG. Vulg. : Cipó caboclo.

117. Sparattosperma vernicosum Bur. et K. Schum.; Fl. Bras. VIII, II, p. 359. - Floresta da Tijuca, Ro-JAN., $n^{05} 648,4731$. Grand arbre, 11. lianches. Décembre-janvier. C. Vulg. : Cinco chagas.

118. Sp. ellipticum Bur. et K. Schum; Fl. Bras. VIII, II, p. 362. Surdo, dans les bourbier's entre les Mauritia, Goraz, n² 21843. Arbrisseau, fl. blanches. Aoút-septembre. R.

119. Tabebuia cassinzoides DG.; Fl. Bras. VIII, II, p. 309. Gavea, dans les bourbiers, Rı-JAN., $n^{\circ s}$ 1544, 4732. Arbrisseau, 11. blanches. Aoùt-septembre. CG. Vulg. : P'io tamanco.

120. T. obtusifolia Bur.; Fl. Bras. VIII, II, p. 310. - Floresta da Tijuca, Rio-Jax., $n^{o s} 1477,4698,4733$. Arbrisseau, fl. blanc vergâtre. Juin-juillet. C. Vulg. : Tabebuia.

12I. Cybistax antisyphilitica Nart.; Fl. Bras. V'III, II, p. 356. 
- Corcovado el Praia Grande, Rio-J.n., nos 850, 1084, 4115. Arbuste, 11. verdâtres. Février-mars. CG. Vulg. : Cinco folhas.

122. Zeyhera montana Mart.; Fl. Bras. VIII, 1, p. 3.3. - Ayuruoca et Cillandahy, Mínas, nos 9531, 12966, 14123, 15263; Norro do Frota, Goyz, n² 21847. Arbuste, 1l. jaune pâle. Août-septembre. CG.

123. Z. tuberculosa Bur.; Fl. Bras. VIII, II, p. 334. - Petropolis, à Santo Antonio, Rio-Jax., $n^{\text {os }} 5788,11247$; Patrocinio, dans le campo. Misas, $n^{\circ}$ 12979. Grand arbre, fl. blanc cendré. Décembre-janvier. C. Vulg. : Ipé branco, Buxo de boi.

12'. Tecoma mollis H. B. K. Nova genera et sp. III. T. 14'. Passeio Publico, Rio-Jax., no 2643 a. Arbrisseau cultivé, fl. jaumes. Mars-avril. $\mathrm{K}$.

123. T. odontodisius Bur. et K. Sch.; Fl. Bras. VII, II, p. 320. Floresta da Tijuca, Rio-JAn., nº 7770. Arbrisseau, f1. roses. Aoûtseptembre. $\mathbf{C}$.

126. T. papyrophloios K. Sch., fil. Bras. VIII, II, P. $411 .-$ Corrego do Brejo, dans le bois, Goraz, no 21840 . Grand arbre, 11. blanches. Février-mars. C. Vulg. : Taipoca.

127. T. Ipe Mart.; Fl. Bras. VIII. II, p. 321. Pico do Andarahy Grande, hiro-Jax., $n^{\text {os }} 3061$, 4743, 4697. Arbrisseau. 1. roses. Juinjuillet. CC. Vulg. : Ipé mirim.

128. T. dentata Bur. et K. Schum.; Fl. Bras. VIli, II, 3. 323. Lagoa de Freitas el Corcovado, Rio-Jax., nos 2496, 8806, 12081. Albrisseau, 11. jaunes. Janvier-février. C.

129. T. heptaphylla Mart.; Fl. Bras. VIII, II. p. 323. - Haut du Corcovalo, Rio-Jan., $n^{\circ}$ 1446. Arbrisseau, fl. roses. Juin-juillet. R.

130. T. longiflora Bur. et K. Schum. : Fl. Bras. VIII, II, p. 324. Floresta da Tijuca, Rı-JAx.. n ${ }^{\text {os }} 4120,11243$. Grand arbre, 11. jaunes. Novembre-décembre. CG. Vulg. Ipé et l'áo d’areo.

131. T. alba Cham.; Fl. Bras. VIII, II, p. 327. - Nova Friburgo, Rio-Jan., no 12964. Grand arbre, fl. jaunes. CC. Norembre-décembre. Vulg. : Ipé.

- Var. subdenudata Bul.; Fl. Bras. VIII, II, 1. 327. - Selra dos Orgĩos, Rio-Jax., $n^{\text {os }}$ 1575, 8213. Grand arbre, fl. jaunes. Aoùt-septembre. C. Vulg. : Ipé.

132. T. araliacea DC.; Fl. Bras. VIII, II, p. 328. - Norro da Viuva, à liotafogo, Rio-JAx; nos 5787, 8807; Serlal de Ouro Preto, Hixas, $1^{\circ}$ 14121; entre Estacas et Jaragua, Goyaz, $n^{\circ} 21842$. Grand arbre, ft. jaunes. Aout-septembre. CG. Vulg. : Ipenna. 
133. Tecoma ochracea Cham.; VIII, II, p. 330. - Entre Sitio et Barbacena, Mnas, nos 9965, 11244, 12983; Serra Dourada, Goraz,

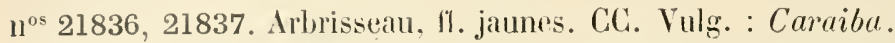

13\%. T. Caraiba Hari.; Fl. Bras. VIII, II, p. 331. - Rio Nanso, dans le campo, Mswas, $1^{05} 12984,12985$. 19665; Cassu, pris Uberalta. dans le cerrato, $n^{0}$ 21839. Arbre tortueux, ll. jaunes. Aoùt-septembre. CG. Vulg, : Caraiba.

135. T. impetiginosa Mart.; Fl. Bras. VIII, II, 334. - Près de Lagoa Santa, Mrsas, no 12980. Arbre, ll. violacées. Juin-juillet. CC. Vulg. : P'áo d'arco et P'áo cachorro.

- Var. lepidor Bur. Fl. Bras. VIII, II, p. 33't. - Gavea et São Gonçalo, Rı-JAN., $n^{05} 3060,4740,4741,8808,11240,11241.11242$; Morro Vermelho, Misas, ${ }^{\circ}$ 12981. Grand arbre, fl. violacees. Juinaoût. CG. Vulg. : Taipoca.

136. T. adenoplyylla K. Schum.; Fl. Bras. VIII, II, p. 412. -Fazenda do Palmital, Goyaz, no 21841. Grand arbre, fl. roses. Juinjuillet. C. Vulg. : P'áo d'arco.

137. T. umbellata Sond.; Fl. Bras. VIII, II. p. 333. - Entre Queimado et Rio Douro, Rio-Jan., no 11255. Arbre, fl. jaunes. Aouitseptembre. C.

- Var. lancelata Bur. et K. Sch. in Fl. Bras. VIII, II, p. 338. Serra da Estrella, à Mandioca, Rıo-JAx., nº 9533. Arbrisseau, fl. jaunes. Août-septembre. Vulg. : Ipé.

138. T. pedicellala Bur. et K. Sch.; Fl. Bras. VIII, II, p. 336. Corcovado, au Silvestre, Rio-JAx., no 1476. Arbuste, f1. jamnes. Aoùtseptembre. CC. Vulg. : Ipé tabaco.

139. T. Catinga Bur. et K. Sch. in Fl. Bras. VIII, II, p. 337. Morro Vermelho, Mlsas, $n^{\circ}$ 12982. Arbre, il. jaunes. Septembreoctobre. CC. Vulg. : Catinga.

140. T. chrysotricha Nart.; Fl. Bras. VIII, II, p. 338. - Serra dos Orgãos, à Theresopolis, Rı-Jas., nos 4730 , 9532. Arbuste, fl jaunes. Septembre-octobre. CG. Vulg. : Ipé tabaco.

141. T. petropolitana Glaz. n. sp. in herb. Paris., Berol., Kew., Brux., etc. - Petropolis, au Nlorin entre les rochers et au Mlorro da Viuva, Rıo-Jas., $n^{\text {os }} 3771,4734,11254$. Arbuste, f1. jaunes. Aoùtseptembre. C.

142. Stenolobium stans Seem.; Fl. Bras. VIII, II, p. 314. Quinta da Boa Vista, à São Christovão, Rho-Jax., $n^{\text {os }} 2643,4729$. Arbrisseau cultivé, fl. jaunes. Février-mars. C 
143. Jacaranda micrantha Gham.; Fl. Bras. VIII, II, p. 368. Petropolis, au Major Gorrea. Rio-Jan.. n ${ }^{\text {os }}$ 2648, 5786. Arbrisseau, 11. violettes. Mars-avril. C. Vulg. : Caroba.

144. J. micrantha Cham.; Fl. Bras. VIII, II, p. 368. - Petropolis, au Padre Correa, Rro-Jax., no 11248. Arbrisseau, fl. violettes. Janvierfévrier. Vulg.. : Caroba. C.

1'ö. J.tomentosa R. Br.; Fl. Bras. VIII, II. p. 370. - Restinga de Copacabana, Rı-Jax. $n^{\text {os }} 244,650,4114$. Arbuste, f1. violettes. Février-mars. G. Vulg. : Caroba minda.

146. J. rufa Manso; Fl. Bras. VIII, II. p. 371. - Biribiry, près Diamantina, Mrxas, $n^{\circ}$ 19667; Fazenda de Rajadinha, Goyaz, $n^{\circ} 21852$. Arbuste, fl, violettes. Janvier-février. R.

147. J. corcovadensis Glaz. n. sp.? in herb. Paris., Berol., Kew., Gener., etc. - Corcovado, à Paineiras, Rio-Jav., no 4739. Arlbre, fi. bleues. Octobre-novembre. R.

148. J. puberula Cham.; Fl. Bras. VIII, II, p. 376. - Belem, Magé, Tijuca et Serra dos Orgãos, Rro-Jax., nos 1574, 8805, 9530 , 16268. Arbuste, 1l. viulettes. Novembre-décembre. CG. Vulg. : Caroba minda.

149. J. semiserrata Cham.; Fl. Bras. VIII, II, p. 376. - Campos da Bucaina. S. Pavlo. no 8212; Agua Limpa. près Gandarela. Misas. $\mathrm{n}^{\circ}$ 15262. Arbrisseau, fl. violettes. Janvier-février. CC. Vulg. : Carobinha.

130. J. heteroptila Bur. et K. Schum. in Fl. Bras. VIII, II, p. 378. - Campos da Bocaina, S. Padlo. n 11239. Arbrisseau, fl. violettes. Janvier-févíer. R. Vulg. : Caroba.

131. J. simplicifolia Bur. et K. Sch. Fl. Bres. VIII, II, p. 414. Fazenda do Palmital, dans le campo, Goraz, $n^{\circ}$ 21848. Arbuste, fl. violet pâle. Juin-jnillet. R.

152. J. paucifoliata Mart.: Fl. Bras. VIII, II, p. 379. - Entre Barreira Grande et Valla Funda, Nivas, n 19663. Arbuste, fl. blane violacé. Mars-avril. $R$.

153. J. Caroba DC.; Fl. Bras. VlII, II, p. 380. — São Joño d'El Riei, Mixas, $\mathrm{n}^{\circ \mathrm{s}}$ 2647, 12978, 17152, 17706. Arbuste. 17. violettes. Octobre-novembre. CC. Vulg. : Caroba.

1:34. J. IJlei Bur. et K. Sch.; Fl. Bras. VIII, II, p. 383. - Fazenda dos Hacacos, Goraz, nor 21850, 21851. Arbuste, fl. violettes. C. Vulg. : Carobinha do campo.

15\%. J. cuspidifolia Mart.; Fl. Bras. VIII, II, p. 38s. - Arbre du 
Rio Grande do Sul, cultivé au Passeio Pullico, Rio-Jax., n $^{0}$ 4735. Arbre, 11. violettes. Nuvembre-décembre. R.

156. Jacaranda brasiliana Pers.; Fl. Bras. VIII, II, p. 389. Rio Itambem, dans le bois, Hinas, $n^{0 s} 11240,12965,12977,14122$, 21849. Arbrisseau, fl. bleues. Août-septembre. CG.

1:̈. J. decurrens Cham.; Fl. Bras. VIII, II, p. 309. - Caethé, dans le campo, Minas, $n^{\circ} 12977$ a. Arbrisseau, fl. violettes. Janvierfévrier. R. Vulg. : Caroha.

158. Setilobus bracteatus Baill.; Fl. Bras. VIII, II. p. 207. Duas Pontes, dans le bois, Mrxas, $11^{\text {os }} 12968$ a. 14119. Arbuste sarmenteux, fi. roses. Mai-juin. C.

159. Hanburyophyton xanthinum Bur. in Warning Symb. ad Fl. Bras., p. 1226. - Pico da Fortaleza de Santa Cruz, Botafogo et Rio Camprido, Rio-Jax., $n^{\circ \$}$ 2646, 4119, 4705, 4706, 4713, 6647, 6814. Superbe liane, fl. orange. Novembre-décembre. GC.

160. Martinella obovata Bur. et K. Sch.; Fl. Bras. VIII, II, p. 161. Quinta da Boa Vista, à S. Christovão, Rio-Jax.. n ${ }^{\circ}$ 14125. Grośse liane, fl. rougeâtres, cultivé. Aoùt-septembre. R.

161. Neojobertia Candolleana Bur. et K. Schum.; Fl. Bras. VIII, II, p. 2997. - Cachoeira, Espirito Santo, $n^{\circ s}$ 9953, 11238. Septembre.

162. Parabignonia Maximiliani Bur.; Fl. Bras. VIII, II, p. 304. - Jacú, ronte de Theresopolis, Rio-Jax., nº 4742. Septembre.

\section{Fanı. 99. Pédalinées.}

1. Martynia diandra Lamk; Encycl. Botan. II, p. 112. - Passeio Publico, Rın-Jax., no6649. Herbacé ann., cultivé, fl. roses. Avril-mai. C'.

\section{Fam. 100. Acanthacées.}

1. Thunbergia alata Bojer; Bot. Mag. t. 2991. - Praia Grande, dans les haies, Rio-JAx., $n^{\circ}$ 3808. Grimpant, 11. jaunes et blanches. Janvier-mars. CC.

9. Mendozia puberula Mart.; Fl. Bras. IX, p. 10. - Serra dos Orgăos, à Theresopolis, Rı-Jax., n 4020; Caraça, dans le bois, Misas, $n^{\circ}$ 15289. Grimpant, fl. blanchâtres. Décembre-janvier. C.

3) 3. M. mollis Lind. in Engler Bot. Jahrb. XXY (1898), Reibl. 60, p. 44. 
A.-F.-M. GLAZIOU. - LISTE DES PLANTES DU BRÉSH CENTRIL.

- Serra do Caraça, près Alegria, dans le bois, Mısas, $n^{0}$ 16292. Grimpant, fl. blanc jaunâtie. Juin-juillet. R.

4. M. Velloziana Mart.: Fl. Bras. IX, p. 11. - Entre Gavea et Tijuca, dans le bois, Rı-Jax., 4019, 7868. Grimpant, tl. blanc rosé. Aoùt-septembre. C.

๖ั. Elytraria tridentata Vahl; Fl. Irras. IX, p. 13. - Gomera. Rıo-Jax., $n^{0}$ 11351. Arassualı̣, dans l'humus des forêts, Mıvas, $n^{0} 13075,14167$. Frutescent, fl. bleues. Mai-juin. C.

6. Nelsonia Pohlii Nees; Fl. Bras. IX, p. 15. - Flıresta da Tijuca, près de la Cascade, Rio-Jar., n ${ }^{\circ}$ 9995. Sous-frutescent, f1. blanrhıttres. Juin-juillet. R.

7. Staurogyne ericoides Lind. in Engler Bot. Jahrb. XXV (1898), Beibl. 60, p. 4'́ - Alegria, au bord de l'eau. Misas, $1^{\circ}$ 15295. Frutescent, 11. jaunes. Juin-juillet R.

8. Ebermaiera mandioccana Nees in Fl. Bras. IX, p. 10̈. - Coreo vado, à Paineiras, Rı-Jax., $n^{0}$ 3806. Sous-frutescent, fl. jaune pâle. Aoùt-septembre. C.

9. E. brachiata Hiern in Warm. Symb. ad. Fl. Bras. p. 67ö. Petropolis, dans le bois vierge au Retiro, Rıo-Jas., nos $3070,15291$. Sous-frutescent, fl. jaunes. Mars-avril. C.

10. E. macahensis Glaz. n. sp.? in lierb. Paris., Berol., Kew., Genev, etc. - Alto Nacalıé de Nova Frilurgo, dans le bois vierge, Rio-J Jav., nº 19746. Herbacé, fl. jaunâtres. Août-septembre. C.

1I. Hygrophila conferta Nees in Fl. Bras. IX, p. 21. - Imbitiha, près des ruisseaux. lino-Jax., $n^{\circ}$ 11348; Rio Paranauí, Goraz, nº 20653. Sous-frutescent, fi. blanchâtres. Mars-atril. CG.

12. H. costata Nees; Fl. Bras. IX, p. 22. - Petropolis, dans les fossés, Rio-lax., $11^{\circ} 2650$; Caraça, dans les bourbiers, Mixas, $11^{05} 13074$, 14170. Sous-frutescent, fl. blanciritres. Octobre-novembre. C.

13. Otacanthus coruleus Lindl. in van Houtte Fl. des Serres et

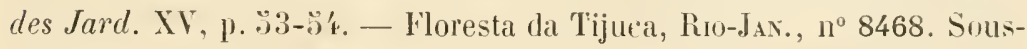
frutescent, fl. bleues. Mai-juin. C.

1'. Dipteracanthus Schauerianus Nees; Fl. Bras. 1X, p. 29. Floresta da Tijuca et Serra da Estrelli, Rio-Jax., n1 ${ }^{\text {os }} 8202$, 9544, 11342. Suns-frutesceut, li. bleues. Aoùt-septembre. GG.

13. D. dissitifolius Nees in Fl. Bras. IX, 1. 33. - Serra do Ouro Branco, dans le campo, Mrxas, ${ }^{0}$ 15296. Herbacé, fl. bleues. Novembre-décembre. R. 
16. Dipteracanthus brachysiphon Nees in Fil. Bras. IX, p. 34. Serra da Estrella, à Mandioca, Rio-Jav., no 8202, a. Herbace, H. bleues. Aoùt-septembre. R.

17. 1). Puri Ners in Fl. Brrs. IX, p. 30̈. - Campos da Bocaina, au Bum Jardin, S. Pstı, no 9544 a. Sous-frutescent, fl. bleues. Féviernlal's. C.

18. D. vinciformis Nees in $\mathrm{Fl}$. Bras. IX, p. 36. - Campos da Bocaina, dans le bois. S. Paclo, no $9992 a$. Sous-frutescent, fl. rougeattres. Aoùt-septembre. C.

19. D. macranthus Nees in Fl. Bras. IX, p. 37. - Serra d'Ouro Preto, au bord des bois, Misas, $1^{\text {os }} 3703,15296$ a. Sous-frutescent, 11. roses. Juin-juillet. C.

20. D. humilis Nees in Fl. Bras. IX, p. 39. - Nova Friburgo, RioJax., $n^{\circ} 19725$ a.; Entre Pouso do Ribeirão et Porto do Rio Paracatú, dans le campo. Mivas, $n^{\circ}$ 21874. Herbace, fl. blanches. Août-septembre. C.

21. D. geminiflorus Nees; Fl. Bras. IX, p. 40. - Campos da Bocaina, au Sobrado, S. Paulo, nº 9992 . Herbacé, f1. bleu pâle. Juinjuillet. C.

22. D. porrigens Nees in Fl. Bras. IX, p. 41. - Floresta da Tijuca, Rio-JAx., $\mathrm{H}^{\circ}$ 13077. Herhacé, fl. bleuàtres. Aoùt-septembre. C.

23. D. viscidnlns Nees; Fl. Bras. IX. p. 43. - Congonlas do Campo, Mixas, $n^{0}$ 13078. Sous-frutescent, f1. blanchâtres. Août-sept. C.

24. Stephanophysum longifolinm Pohl; Fl. Bras. IX, p. 30 . Floresta da Tijuca, Rio-Jas., $\mathrm{n}^{\circ}$ 4164. Sous-frutescent, fl. rouges. Octobre-novembre. CG.

29. Ruellia ochrolenca Itart. in Fl. Bras. IX, p. 56. - São Fidelis, près Campos, Rio-J $\mathrm{JN}_{\text {. }}, \mathrm{n}^{\text {os }}$ 11352, 11354. Sous-frutescent, tl. rouges. Novembre-janvier. C.

26. $\boldsymbol{R}$. bracteiflora Glaz. n. sp.? in herb. Paris., Berol., Kew., Brux., etc. - Juiz de Fora, dans le bois, Minas, $n^{\circ}$ 11349. Sous-frutescent, fl. rouges. Juin-juillet. K.

27. $\boldsymbol{R}$. subsessilis Lind. n. sp. in herb. Paris., Berol., Kew., Genev., etc. Quinta da Boa Vista, São Christovão, Rıo-Jax., nº 18396. Sous-frutescent, cultivé, fl. rouges. Mars-avril. C.

28. $\boldsymbol{R}$. villosa Lindau n. sp.? in herb. Paris., Berol., Kew., Genev.. et. - Nova Friburgo, dans les bourbiers, Rı-JAx., $n^{\circ} 13081$. Sous-frutescent, 11. rouges. Juin-juillet. C. 
29. R. eriocalyx Glaz. n. sp.? in herb, Paris., Herol., hew., Bıux, ete. - Entre As Intas et Pedro Gardinha, dans le campo, Goraz, $11^{\circ} 21877$ a. Herhacé, 11. blenes. Aoùt-septembre. CC. Vulg. : Flor do fogo.

30. R. trachyphylla Lind. in Engler Bot. Jahrb. XXV (1898), Beibl. 60, p. 46. - Vargem do Rio Corumba, Goriz, $11^{\circ 5} 21872,21875$. Herbacé, 11. bleues. Aoùt-septembre. R.

31. R. simplicicaulis Glaz. n. sp.? in herh, Paris., Berol., Kew., Brux., etc. - Rio Areias, dans le campo, Goyz, $1^{\circ} 21878$. Herbacé, fl. bleues. Septembre-octolre. C.

32. R. goyazensis lind. in Engler Bot. Jahrb. XXY (1898), Beibl. 60, p. 狩. - Morro de Prota, près Meia Ponte, Goraz, n 21879. Frutescent, fl. bleues. Août-seytembre. C.

33. R. hapalotricha Lind. in Engler Bot. Jahrb., XXV (1898), Beibl. 60, p. 4'. - Cabeceira do Rio Gama, Govaz, nº 21882. Sous-frutescent, fl. bleues. Mai-juin. C.

34. R. glanduloso-punctata Lind. n. sp.? in herb. Paris., Berol., Kew.. Brux., etc. - Entre Paraizo et le Rio Tocantins, dans le campo, Goyaz, nos 21880, 21881. Sous-frutescent, fl. blenes. Janvielfévrier. C.

3\%. R. asperula Lind. n. sp.? in herb., Paris., Berol., Kew., Brux., etc. - Entre le lío Torto et le Rio Parauna, dans le campo, Goxaz, no 21883. Sous-frutescent, fl. bleues. Mai-juin. C.

36. R. adenostachya Lind. in Engler Bot. Jahrb. XXV 1898), Beibl. 60, p. 4\%. - Estrado Norte, près Goyaz, tans le bois, Goyaz, no 21883, a. Sous-frutescent, f1. bleut's. Juillet-aoùt. C.

37. R. rubiginosa Lind. 11. sp.? in herb. Paris., Berol., Kew., Genev., ete. - Caraça, daus le campo de Fora. Misus, n 15294. Sousfrutescent, 11. rouges. Févriel-mars. C.

38. R. Herbstii Hiern in Warm. Symb. ad Fl. Bras. centr., p. 681. - Quinta da Boa Vista, S. Christovão, Rı-Jax., no 1453. Sous-frutescent, cultivé, 11. roses. Aoùt-septembre. CG.

39. R. adenocaly $x$ Lind. in Engler Bot. Jahrb. XXY (1898), Beibl. 60, p. 46. - Entre Guariroba et Siriaco, dans le campo. Goya, $11^{\circ}$ 21886. Sous-frutescent, tl. rouges. Juin-juillet. CC.

40. R. eurycodon Lind. in Engler, Bot. Jahrb. XXV (1898), Beibl. 60, p. 47. - Entre Forquilhas ef Fumos, dans le bois, Goraz, nº 21868. Sous-frutescent, fl. jaune pâle. Aoùt-septembre. C.

41. Arrhostoxylon acutangulum Nees; Fl. Bras. IX, p. ̈8. - 
Sermat da Estrellia, dans le bois, Ru-Jax., $1^{\circ}$ 3069. Sous-frutescent, ll. roses, Mars-atril. C.

4‥ Arrhostoxy-lon subsessile Nees in Fl. Bras. IX, p. ":8. - Alto Marahé de Nora Friburgo, Rio-J.s., $n^{\circ}$ 18397. Sous frutescent, f1. rouges. Juin-juillet. C.

43. A. formosum Nees; Fl. Bras. IX, p. 62. - Arraial de Ouro Branco. Mrsis, $1^{\circ}$ 15997. Herbacé, ll. rouges. Novembre-lécembre. CC.

' '. Eranthemum detruncatum Nees; Fl. Bras. IX, 1) 156. Morro da Gavea, dans le bois, Rio-Jan., nº 4896. Frutescent, fl. blanchâtres. Août-septembre. R.

4. E. heterophyllum Nees in Fl. Bras. IX, p. 158. - Petropolis, au Correios, Rio-Jan., no 8203. Sous-frutescent. f1. bleu rosé. Aoút-septembre. R.

46. Dædalacanthus nervosus And. in Journ. Linn. Soc. IX (1867), p. 487. - Cantagallo, à Larangeiras, et au Passeio Publico, Rio-Jan., $\mathrm{n}^{08} 8839,8959$. Sous-firutescent, fl. bleues. Avril-mai. CC.

47. Lophostachys floribunda Pohl; Fl. Bras. IX, p. 67. - Biribiry, près Diamantina, dans le bois, Misas, $\mathrm{n}^{\circ} 19727 a$. Sous-frutescent, fl. rouges. Mars-avril. C.

48. L. montana Mart. in Fl. Bras. IX. p. 68. - Biribiry, près Diamantina, Mrsas, n 19727; Vargem do Rio Torto, dans le campo, Goyaz, $n^{0}$ 21867. Sous-frutescent, fl. bleu rosé. Février-mars. CC.

49. Teliostachya alopecuroidea Nees; Fl. Bras. IX, p. 72. Arassuahy et Cirraça, dans les bourliers, Mrvas, $11^{\text {os }} 13072$, 14169. Herbacé, fl. jaunâtres. Novembre-janvier. C.

50. Chamæranthemum Beyrichii Nees in Fl. Bras. IX, p. 15ั. Serra do Mar, à Palmeiras, Rio-Jax., nos 2654, 8834, 18399. Herbacé, fl. bleu pàle. Septembre-octobre. C.

51. Aphelandra squarrosa Nees in Fl. Bras. IX, p. 89. - Alto Nacahé de Nova Friburgo, Rio-Jav., nos 4166, 4894. Sous-frutescent, fl. jaunes. Mars-avril. C.

32. A. lutea Nees in DC. Prodr. XI, P. 300. - Serra d'Estrella, près Petropolis, Rio-JAx., nos 3071,15293 . Sous-frutescent, fl. jaunes. Février-mars. C.

- Var, angustifolia Glaz. var. nov. in herb. Paris., Berol. - Alto Macalıé, Rio-Jax., n² 4165. Sous-frutescent, f1. jaunes. Mars-avril. R.

53. A. Liboniana Linden ex Hook. Bot. Mag. З゙463. - Indaiassú, dans les bas-fonds et Petropolis, Rio-Jax., nos 11345, 14170 a, 19726. Sous-frutescenl, fl. jaunes. Décembre-mars. C. 
34. A. ornala And. in Journ. Bot. II. (186'4), p. 289. - Petropolis, à Gruta Funda, hio-Jax., no 9993. Sous-frutescent, jaunes. Septembreoctolse. R.

รั. A. rigida Glaz. n. sp.? in herb. Paris., Berol., Kew., Brux., ete. - Alto Nacahé de Vova Friburgo, Rı-Jav., nº 18400. Sous-frutescent, f1. orangées. Juin-juillet. R.

56. A. acutifolia Nees in DC. Prodr. XI, p. 299. - Serra da Estrella. près Petropolis, Rio-JAx., n" 9994. Sous-frutescent, f1. bleuâtres. Septembre-octobre. R.

57. A. pubescens Glaz. n. sp.? in herh. Paris., Berol., Kew., Genev., etc. - Floresta da Tijuca, Rio-JAN., n" 11346. Sous-frutescent, fl. jaunàtres. Mai-juin. R.

58. Strobilorhachis prismatica Nees; Fl. Bras. IX, p. 84. - Cor'covado, près du ruisseau Carioca, Rı-JAx, $n^{\text {us }}$ 2653. 8837. Sous-frutescent, fl. jaunes. Janvier-février. C.

59. Geissomeria cincimnata Nees.; Fl. Bras. IX. p. 81. - Petropolis, dans te bois à Itamaraty, Rio-Jax., $n^{0}$ 12093. Sous-frutescent, fl. rouges. Mai-juin. Ci.

60. G. longiflora Lindl.; Fl. Bras. IX, p. 81. - Corcovado, à Paineiras, Rio-JAx., 11 ${ }^{\text {os }}$ 1010. 3073. Sous-frutescent, fl. roses. Mars-avril. C.

61. G. pubescens Nees in Fl. Bras. IX, p. 89. - Floresta da Tijuca, Rio-Jax., $11^{0} 12093 a$. Sous-frutescent, 11. roses. Mars-avril. R.

62. Stenandrium trinerve Nees in $\mathrm{Fl}$. Bras. IX., p. 7 var. Fazenda diı Cova. jrès Morro Canastra, Goraz, nº 21873. Acaule, vivace, fl. roses. Novenbre-décembre. R.

62. St, Polhlii Nees in Fl. Bras. IX, p. 7.3. - Campos do Rio Goma, au Colombista, Goraz, no 21877. Acaule, vivace, f1. roses. Norembrelécembre. C.

64. St. Riedelianum Nees; Fl. Bras. IX, p. 7̈̈. - Congonhas do Campo, Mras, $n^{\circ}$ 13079. Acaule, vivace, fl. roses. Aoùt-septembre. CC.

60̈. Stenostephanus lobeliaformis Nees in Fl. Bras. IX, 1, 92. Alto Nacahé de Nova Friburgo, Riro-Jav., $n^{\circ}$ 18398. Sous-frutescent, f1. rouges. Mai-juin. C.

66. Heinzelia ovalis Nees in Fl. Bras. IX, p. 15̆4. - Itatiaia, dans le bois, Rio-Jax.. n 8204 a. Sous-frutescent, fl. blançhâtres. Octobrenovembre. li.

67. Justicia Gendarussa Burm.; flora Ind., p. 10 (1768). - Passeio Publico, Rio-Jax., $n^{\circ}$ 1011. Sous-frutescent. cultivé, ll. blanchaatres. Janvier-mars. CG. 
68. Justicia Gilliesii Peulh. et Hook. Genera P'lant. 11, p. 1109. Arassualy, dans le hois, Maras, $n^{0} 14168$ a. Sous-frutescent salmenteux. fl. blanchàtres. Marrs-avril. R.

69. J. glischrantha Lind. in Engler Bot. Jahrb. XXV (1898). Beibl. 60, p. 49. - Estrada Norte ou da Canastra, Goraz, $n^{0} 21885$ a. Sousfrutescent, 11. rose pâle. Aonit-septembre. R.

70. J. Wittigiana Glaz. 11. sp.? in herb. Paris., Berol., Kew., Gener.. etc. - Itapemirim, dans le bois, Esp. Saxto, $n^{\circ} 8840$. Sousfrutescent, 11. roses. Juin-juillet. C.

71. J. sarothroides Lind. in Engler Botan. Jahrb. XXV (1898), Beibl. $n^{\circ}$ 60, p. 30 . - Capelinha de Santo Antonio, près du Rio Descolerto, Govaz, n² 21866. Sous-frutescent, f1. bleues. Juin-juillet.

72. J. Glaziovii Lind. in Bull. Herb. Boiss. III (189.3). - Serra do Caraça, dans le bois, Mrsas, $n^{\circ}$ 13073. Sous-frutescent, fl. rouges. Juinjuillet. C.

73. J. capitata Glaz. n. sp.? in herb. Paris., Berol., Kew., Genev., etc. - Serra dos Orgãos, an Imbui, Rio-JAr., n ${ }^{\circ} 11356$ a. Sousfrutescent, 11. roses. Arril-mai. C.

74. J. pycnophylla Lind. in Engler Bolan. Jahrb. XXY (1898), Beibl. no 60, p. 49. - Formosa, dans le campo, Goraz, $\mathrm{n}^{\circ} 21870$. Herbacé, virace, fl. violettes Novembre-décembre. C.

73. J. chrysotrichoma Pohl in DC. Prodr. Xl, p. 408. - Chapadão de Porto Seguro, Goraz, $n^{0 s} 21884,21885$. Sous-frutescent, fl. bleues. Novembre-décembre. C.

76. Beloperone diclipteroides Nees in Fl. Bras. IX, p. 136. Alto Macahé et Serra do Picú, R10 Jas., n"s 2655, 7796, 11343, 20429. Sous-firutescent, 11. violarées. Août-septembre. CG.

77. B. Selloviana Nees; Fl. Bras. 1X, p. 136. - Floresta da Tijuca. R10-Jax., $n^{\circ} 3072 a$. Sous-frutescent, fl. roses. Janvier-février. R.

78. B. microstachya Nees in Fl. Bras. IX, p. 137. - Floresta da Tijuca ef Corcovado, Rio-J $J_{\mathrm{AN}}, \mathrm{n}^{0 \mathrm{~s}} 8204,12095$. Sous-frutescent, fl. roses. Janvier-lévrier. C.

79. B. plumbaginifolia Nees; Fl. Bras. IX, p. 139. - Corcovado et Floresta da Tijuca, Rio-Jan., $n^{\text {vs }} 2656,3072$. Sous-frutescent, fl. roses. Février-mars. C.

80. B. monticola Nees in Fl. Bras. IX, p. 142. - Caraça, près du collège. Mrxas, no 15293 a. Sous-frutescent, fl. rouges. Février-mars. R.

81. B. hirsuta Nees in Fl. Bras. IX, p. 143. - Serra d'Itabira do Campo, Mwas, $n^{\circ}$ 17l64, Sous-frutescent, fl. rouges. Aoùt-septembre. C. 
82. B. organensis Gla\%. n. sp.? in herł. Paris., Berol., Kew., Genev., etc. - Serra dos Orgãos, au Frade. Rho-Jax., $1^{\circ}$ 3701. Sousfrutescent, fl. rouges. Mai-juin. R.

83. B. involucrata Nees et Mart.; Fl. Bras. IX, p. 143. - Nova Friburgo, au Alto, Rio-Jav., $\mathrm{n}^{\circ}$ 19724. Sous-frutescent, fl. roses. Octobre-novembre. R.

84. Adhatoda cydonicefolia Nees in Fl. Bras. IX, p. 148. - Floresta da Tijuca, Rio-JAx., $1^{\text {os }} 2657,8205$. Sous-frutescent, fl. bleu pâle. Juin-juillet. C.

85. Rhytiglossa oblonga Nees in Fl. Bras. IX, p. 124. - Caraça, dans le bois liumide, Mlxas, $n^{\circ}$ 13071. Herlacé vivace, fl. rose pâle. Novembre-décembre. C.

86. Rh. dasyclados Mart. in Fl. Bras. IX, p. 126. - Dezengano, près du Rio Parahyba, Rio-JAN., nos 11350,11350 a. Sous-frutescent. fl. roses Juin-juillet. C.

87. Rh. divergens Nees in $\mathrm{Fl}$. Bras. IX, p. 128. - Imbitiba, près de la mer, Rio-JAs., $\mathrm{n}^{\circ}$ 9996. Sous-frutescent, fl. blanches. Mars-avril. R.

88. Rh. pectoralis Nees; Fl. Bras. IX, p. 128. - Lagoa Rodrigo de Freitas, Rio-Jax., $n^{\circ}$ 4898. Herbacé, Il. violacées. Août-septembre. CG. Vulg. : Trevo do Pará.

89. Leptostachya comata Nees; DG. Prodr. XI, 1. 381. - Serra do Caraça, dans le bois, Mixas, $\mathrm{n}^{\circ}$ 15290. Sous-frutescent, fl. violacées. Février-mars. C.

90. L. lucida Nees in Fl. Bras. IX, p. 149. - Restinga de Copacabana. Rio-Jsx, no 3805. Sous-frutescent, 11. roses. Août-septembre. C.

91. Amphiscopia Beyrichii Nees; Fl. Bras. IX. p. 130. - Corcovado, Caminho do Enforcado, Rio-Jix., nos 1557, 3807. Sous-frutescent, fl. Hlanchâtres. Aoùt-septembre. CG.

92. Jacobinia Neesiana Lind. in Engler et Prantl. Nat. Pfl. IV, 36. - Serra do Tingua, Rı-Jav., $n^{\circ} 8838$. Sous-frutescent, fl. rouges. Juin-juillet. R.

93. J. lancifolia Glaz. n. sp.? in herb. Paris., Berol., kew., Brux., etc. - Serra da Babylonia, Misas, nº 3704. Sous-frutescent, fl. rouges. Juin-juillet. C.

9'. J. nervosa Lind. n. sp.? in herb. Paris., Berol., Kew., Genev., ete. - Nto Macahe de Nova Friburgo, Rio-Jı,, nº 17165. Sous-frutescent, 11. rouges. Arril-mai. R.

9\%. J. æquilabris Lind. n. sp.? in herh. Paris., Berol., Kew., 
Genev., etc. - Florestit da Tijuca, Rı-Jan., $n^{\circ}$ 11347. Sous-frutescent, 11. 1'ouges. Mai-juillet. C.

96. Jacobinia sarmentosa Gla\%. n. sp.? in herb. Paris., Berol., hew., Gener., etc. - Petropolis, au Morin, Rı-Jan., $1^{\circ}$ 9543. Sousfrutescent sarmenteux, fl. rouges. Novembre-décembre. C.

97. J. velutina Lind. 1. sp.? in lierb. Paris., Rerol., Kew., Cienev., etc. - Arassuahỵ, dans le bois, Mrsas, 11" 13076. Sous-frutescent, fl, rouges. Mai-juillet. CC.

98. J. breviloba Lind., n. sp.? in leerb. Paris., Berol., Kew., Gener, ete. - Biribiry, près Diamantina, Mrsas, nº 19728. Sous-frutescent, fl. rouges. Nars-avril. C.

99. J. Gląiovii Hiern in Warm. Symb. ad. Fl. Bras., p. 691. Itatiaia, dans le bois, Rio-Jax., $n^{\circ}$ 4895. Sous-frutescent, fl. rouges. Juin-juillet. R.

100. Sericographis polita Nees in Fl. Bras. IX, p. 109. - Nova Frilurgo et Petropolis, Rio-Jax., $n^{0 s}$ 12094, 13080. Sons-frutescent, fl. rouges. Mai-juin. CG.

- Var. unbrosa Nees in lil. Bras. IX, p. 109. - Serra dos Orgĩos, iu Prade, Rı-Jıx., n ${ }^{0}$ 3702. Sous-frutesrent, fl. rouges. Mars-avril. C.

101. S. pauciflora Nees in Fl. Bras. IX, p. 110. - Petropolis, au bord du Rio Itamaraty, Rio-Jax., $\mathrm{n}^{\text {os }} 11341,15292$ Sous-frutescent, $\mathbb{1}$. rouges. Juin-juillet. C.

102. S. Clausseniana Nees in F\%. Bras. IX, p. 111. - Alto Nacahé de Nova Friburgo, Rio-Jav., n"s 17719, 19880. Sous-frutescenf', fl. rouges. Juillet-aoùt. C.

103. Thyrsacanthus barlerioides Nees; Fl. Bras. IX, p. 97. Itatiaia, dans le bois, Rio-Jax., $n^{\circ}$ 6659. Sous-frutescent, fl. rouges. Janvier-lévrier. C.

104. Pachystachys Biedeliana Nees; Fl. Bras. IX, p. 99. Guinta de S. Clıristovão. Rio-JAx., $n^{0}$ 1492. Sous-frutescent cultivé, fl. roses. Mars-avril. C.

100ั. Cyrtanthera magnifica Nees; Fl. Bras. IX, p. 100. - Itatiaia. dans le buis, Rı-JAN., n 6659 u. Sous-frutescent, 11. rouges. Juinjuillet. C.

106. C. Pohliana var. velutina Nees in Fl. Bras. IX, p. 101. Passein Pullico, Rıo-Jax., n" 1492 a. Sous-frutescent, fl. rouges. Marsavril $C$.

107. C. picuensis Glaz. n. sp.? in herl. Paris., Berol., Kew., 
A.-F.-M. GLAZIOU. - LISTE DES PLANTES DU BRESIL CENTRAL.

Genev., etc. - Serra do Picú, au Paulo, Rro-Jan., no 11344. Sous-frutescent, fl. rouges. Avril-mai. R.

108. Schaueria virginea Nees iu Fl. Bras. IX. p. 105. - Floresta da Tijuca, Rio-Jav., $11^{\text {os }} 222,9545$. Sous-frutescent, f1. jaunes. Avrilmai. C.

109. S. calycotricha Nees; Fl. Bras. IX, p. 103. - Entre Gavea et Tijuca, Rio-dax., $n^{0}$ 4897. Sous-frutescent, f1. jaumes. Aoùt-septembre. C.

110. Dicliptera mucronifolia Nees in Fl. Bras. IX, p. 161. Serrà dos Orgãos, à Tabuinha, Rro-Jan., no il355. Sous-frutescent, fl. bleu pàle. Mars-arril. C.

111. D. fluminensis Glaz. n. sp.? in herb. Paris., Berol., Kew., Genev., etc. - Floresta da Tijuca, en bas du Pico, Rio-Jax., no 11353. Sous-frutescent, fl. blanchàtres. Mai-juin. R.

112. D. squarrosa Nees in Fl. Bras. IX, p. 161. - Serra da Babylonia, Mrvas, $\mathrm{n}^{0}$ 3705. Sous-frutescent, 11. roses. Juin-juillet. C.

113. D. Pohliana Nees in Fl. Bras. IX, p. 162. - Serra dos Orgãos, à Theresopolis, Riro-J $J_{A x}, n^{\circ} 11355 a$. Sous-firutescent, fl. blanchàtres. Vars-arril. C.

114. Poikilacanthus phyllocalyx Lint. in Engler Bot. Jahrb., XXV (1898), Beibl. 60, p. 48. - Entre As Brancas et Cocal, dans le campo, Goyaz, $\mathrm{n}^{0}$ 21876. Herbacé, f1. blenes. Janvier-février. C.

115. P. oncodes Lind. in Engler Bot. Jarb. XXV (1898). Beibl. $n^{\circ}$ 60, p. 48. - Fazenda da Boa Vista, daus le campo, Goyaz, no 21869. Herłacé, Il. lilas. Janvier-février. R.

116. Anisanthus brasiliensis Lind. n. sp.? in hert. Paris., Berol., Kew., Genev., etc. - Serra do Caraça, dans le bois, Mnnas, $n^{\circ}$ 15288. Sous-frutescent, fl. rouges. Novembre-décembre. C.

117. Dichazothece cylindracea Lind. in Engler Bot. Jahrb. XXV (1898). Beibl., $n^{\circ}$ 60, p. 4i. - Serra do Mar, à Palmeiras, Rı-JAv., $11^{\circ}$ 8960. Sous-frutescent, fl. blanchâtres. Aoùt-septembre. C.

\section{Fam. 10. - Verbénacées.}

1. Lantana brasiliensis Link; Fl. Bras. IX, p. 203. - Serra dos ()rgatus, à Theresopolis, Rio-Jar., $n^{\circ} 11332,12092,16291$. Arbuste, fl. blanches. Févricr-mars. CC.

2. L. nivea Vent.; Fl. IBras. IX, p. 20\%. - Sapopemha, Rio-Jax, n" 8829. Arbuste, fl. blanches. Octobre-novembre. C. 
3. Lantana Camara L.; Fl. Bras. IX, p. 29.). - Floresta da Tijuca, Rı-JAx., $11^{\circ}$ 8828, 14156. Arluste, fl. blanches. Octobre-novenbre. G.

4. L. tilicefolia Sehauer in F\%, Bras. IX, p. 287. - Nova Friburgo, au Alto, Riı-JAs, II" 13068. Arbuste, fl. llane l'osé. Mai-juin. C.

5. L. Riedeliana Schauer in Fl. Bras. IX, 1. 258. - Serra dos

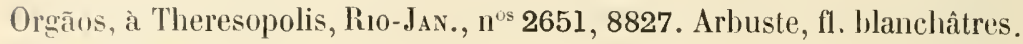
Février-mars. C.

6. L. Sellonicina Link et Otto, Fl. Bras. IX, p. 261. - Serra das Divisies, dans le campo près Ponte Alta, Goxaz, no 21802. Fruticuleux, 17. roses. C. Vulg. : Flôr do fogo.

7. L. lilacina Desf.; Fl. Bras. X, p. 261. - Corcovado et Floresta da Tijuca, Rio-JAN., n ${ }^{\text {us }} 111,8826$. Arbuste, fl. lilas. Novembredécembre. G.

8. L. trifolia L.; Fl. Bras. IX, p. 264. - Entre Queluz et Carandahy, Mrnas, $n^{\circ}$ 13069. Arbuste, fl. blanc rosé. Juin-juillet. R.

9. L. canescens H. B. K.; Fl. Bras. IX, p. 26\%. - Serra d'Ouro Preto, dans le bois, Minas, $\mathrm{n}^{0 \mathrm{~s}} 13070,14158$. Arbuste, fl. lilas. Aoûtseptembre. C.

10. Lippia lycioides Steud.; Fl. Bras. IX, p. 222. - Parahybuna, près de la rivière, Minas, $n^{0} 2118$ a. Arbuste, fl. llanchàtres. Octobrenovembre. $R$.

11. L. urticoides Steud,; Fl. Bras, IX, p. 222. - Parahybuna et Barbacena, Mivas, n"s 2118, 11329, 13067. Arbuste, f1. blanchàtres. Janvier-mars. CG. Vulg. : Camará.

12. L. Glazioviana Loes n. sp.? in herb. Paris, Berol., Kew, Brux., etc. - Biribiry, près Diamantina, entre les rochers, VIras, no 19170 ; Serra dos Veadeiros, Goyaz, $n^{\circ}$ 21918. Frutescent, fl. roses. Janvierfévrier. Plante à très bonne odeur. CG.

13. L. origanoides H. B. K.; Fl. Bras. IX, p. 224. - Ipanena dans le bois, S. Paulo, no 16286 a. Arbuste, fl. blanchâtres. Janvier-février. R.

14. L. salvicefolia Cham.; Fl. Bras, IX, p. 2刃ュّ. - Serra de Ouro Preto, au Campo de São Juão, Mınas, $n^{\circ}$ 15335; Ipiranga, Sĩo Paulo, $n^{\circ}$ 16286. Arbuste, fl. blanchâtres. Février-mars. C.

13. L. velutina Schauer in Fl. Bras. IX, p. 225. - Curimatahy, dans le bois, Misas, nº 14157. Frutescent, fi. lilas. Mai-juin. C. Vulg.. : Camará.

16. L. microphylla Cham.; Fl. Bras. IX, p. 228. - Nova Friburgo, aul Suspiro, Rio-J J . $n^{0 s}$ 1306\%, 13477; Itabira do Campo et Biribiry, Misas, $n^{\text {os }} 14155$, 19708. Frutescent, fl. lilas. Janvier-mars. GG. 
17. L. graveolens II. B. K. in Nova gen. et sp. II, p. 267. - Serra dos Purys, Espirito Santo, $n^{\circ}$ 9987. Frutescent, fl. blanchâtres. Septembre-octobre. R.

18. L, Martiana Schauer in Fl. Bras. IX, p. 2299. 一 Sĩo Julião do Ouro branco, Mısis, n 18390 . Frutescent, 11. blanchatres. Juin-juillet. C.

19. L. sericea Cham.; Fl. Bras. IX, p. 229. - Serra do Palmital, au Morro de S. Vicente, Mixas, $1^{05} 15331$, 21914. Sous-frutescent, fl. blanc jatunitre. Juin-juillet. C.

20. L. stachyoides Cham.; Fl. Bras. IX, p. 230. — Sĩo Gonçalo, dans le campo, Mixas, $n^{\circ} 15336$ a. Sous-frutescent, fl. blanc jaunâtre. Mai-juiı. C.

21. L. Chamissonis D. Dietr.; Fl. Bras. IX, p. 232. - São Gonçalo, dans le bois, Mlsas, $n^{\circ}$ 15336. Sous-frutescent, fl. roses. Avril-mai. CC.

22. L. aristata Schauer in Fl. Bras. IX, p. 232. - Floresta da Tijuca, Rio-Jax., $n^{\circ}$ 4998. Sous-frutescent, fl. lilas. Octobre-novembre. C.

23. L. turnerafolia Cham.; Fl. Bras. IX, p. 233. - Serra dos Pyreneos, près Meia Ponte, Goyaz, $n^{\circ}$ 21890. Herbacé vivace, fl. lilas. Octobre-septembre. C.

24. L. Psendo-Thea Schauer; Fl. Bras. IX, p. 234. - Biribiry, près . Diamantina, Nıss, no 19709. Arbuste, fl. verdâtres. Mars-avril. G. Vulg.: Chí de pedestre.

23. L. pumila Cham.; Fl. Bras. IX, p. 234. - Itatiaia. dans le Campo Feio, Rio-Jav., nº 8833. Herbacé, fl. lilas. Novembre-décembre. C.

26. L. geminata H. B. K. ; Fl. Bras. IX, p. 233. - Rio Manso, près Mlendanlı, Mrxas, ${ }^{\text {os }} 11330,11331,14159,21899$ a. Frutescent, f1. blanc rosé. Juin-juillet. CC. Vulg. : Herva cidreva.

27. L. asperifolia Rich.; Fl. Brels. IX, p. 236. - Antonio Pereira, près Ouro Preto, Mrsas, $1^{\circ}$ 14154. Arbuste, fl. lilas. Aoút-septembre. C

28. L. betulafolia H. B. K.; Fl. Bras. IX, p. 237. - Rio Hanso, près Mendanha, Mrsas, $n^{\circ} 11335$. Herbacé, fl. jaunàtres. Juin-juillet. C.

49. L. reptans H. B. K.; Fl. Bras. IX, p. 337. - Collegio, près Campos, Rio-Jav., nos 13065,13066 , 13464. Herbacé, fl. blanc jaunàtre. Janvier-férrier. CG.

30. L. bocainiensis Glaz. n. sp.? in hert. Paris., Berol., kew., IIaun., etc. - Camjos da Bocaina, au Sobrado, S. Paulo, no 11340. Frutescent, fl, lilas. Aoùt-septembre. C.

31. L. microcephala Cham.; Fl. Bras. IX, p. 240. - Entre Manoel 
Joâu et Ponte do lio Alaeté, dans le carrascal, Goraz, $11^{\circ} 21898$. Frutescent. fl. litas. Octobre-novembre. C.

32. Lippia hermannioides Cham.; Fl. Bras. 1X, p. 241. - Serra do Carara, à luflcionarlo, Mısas, $n^{08} 15330,19706,19707$. Arbuste, fl. blanches. Février-mars. CC.

33. L. iodophylla Schaner; Fl. Bras. IX, p. 2'1. -- Serra dos Orgĩos, au sommet, liro-J $J_{A N}$, $n^{\text {os }} 3707$, 4158, 9542, 16287. Arbuste, f1. violettes. Janvier-février. CG.

34. L. vernonioides Cham.; Fl. Bras. IX, p. 243. - Serra do Lenheiro, près São Joâo d'El Rei, Minas, $11^{\circ} 17161$ a. Arbuste, fl. lilas pâle. Octobre-novembre. B.

33̈. L. oxycuemis Schauer in Fl. Bras. IX, p. 244. - Fazenda do Paranauá, dans le campo, Goraz, no 21899. Frutescent, fl. roses. Maijuin. C.

36. L. corymbosa Cham.; Fl. Bras. IX, p. 24:3. - Itabira do Campo et Pinheiro, près Diamantina, Misas, $1^{\text {os }} 17713,19713$, 19714 ; Fazenda da Bua Vista, Goraz, n 21895. Frutescent, fl. roses. Janvier-mars. CG. Vulg. : Chá de pedestre.

37. L. rotundifolia Cham.; Fl. Bras. IX, p. 243̈. - Serra do Lenheiro, MINAS, $\mathrm{n}^{\text {os }} 15333,17160,17161,19715$. Frutescent, fl. roses. Octobre-novembre. CG.

38. L. lacumosa Mart. ot Schauer; Fl. Bras. IX, p. உ46 - - Bords du Rio Gama, Goyaz, nos 21896, 21897. Frutescent, fl. Jlanc rosé. Juinjuillet. C.

39. L. lasiocalycina Cham.; Fl. Bras. IX, p. 247. - Entre Piquieiro et Buraco da Onça, dans le cerrado Mıxas, no 21915 . Fiutescent, f1. roses. Septembre-octobre. C.

40. L. lupulina Cham.; Fl. Bras. IX, p. 247. - Ayuruoca, dans le campo, Minas, $n^{\circ}$ 9536; Corrego do Brejo près du campement, Goyaz, $\mathrm{n}^{\circ \mathrm{s}} 21891,21902$. Frutescent, f1. roses. Mars-avil. CG.

41. L. florida Cham, Fl. Bras. IX, p. 249. - Serra do Palmital, prìs Sào Bartholomeu, Misas, $n^{\circ}$ 15337. Frutescent, l'. roses. Juinjuillet. R.

42. L. diamantinensis Glaz. n. sp.? in herb. Paris., Berol., Kew., Brux., etc. - Curalinho, près Diamantina, dins le campo, Minas, $n^{0}$ 19712. Frutescent, fl. roses. Mars-avril. R.

43. L. heder a folia Mart. et Schaner; Fl. Bras. IX, p. 9:0. - Curalinho, près Diamantina, Mısas, $1^{\circ \mathrm{s}} 16285$, 19711. Frutescent, fl. roses. Avrilmars. C. 
4'. Bouchea Pseudogervao Cham.; Fl. Bras. IX, p. 19\%. - Serra da Baby lonia, Mısas, nº 7786. Sous-frutescent, 11. bleues. Janrier-Pévrier. C. Vulg. : Gereão de folha larga.

4.9. B. lowtevirens Schauer; Fl. Bras. IX, p. 196. - Caminho do Lemo, à Botafogo, Rio-Jav., $\mathrm{n}^{\circ}$ 18392. Sous-frutescent, fl. bleues. Septembre-octobre. C.

46. B. agrestis Schauer et Mart.; Fl. Bras. IX, p. 197. - Serra do Caraça, dans le bois et le campo, Misas, nos 13061, 14161. Sous-frutescent, fi. bleues. Janvier-février. C.

47. Stachytarpheta dichotoma Vahl: Fl. Bras. IX, p. 199. Corcorado et Floresta da Tijuca, Rio-JAx., 1105 809, 4997, 7787, 11327. Sous-frutescent, fl. bleues. Janvier-mars. CC. Vulg. : Gervão.

48. St. elatior Schrader; Fl. Bras. IX, p. 203. - Congonhas do Campo, Mısas, nos $3678,9986,13062$. Sous-frutescent, 11. bleues. Juinjuillet C. Vulg. : Herva Santa.

49. St. sanguinea Schauer et Mart.? Fl. Bras. IX, p. 204. - Serra da Itabapoana, Espirito Sa.sto, no 11326 . Sous-frutescent, fl. bleues. Septembre-octobre. R.

วั0. St. canescens H. B. K.; Fl. Bras. IX, p. 200̈. - Restinga de Cabo Frio, Rio-Jax., no 13054. Sous-frutescent, fl. bleues. Octobre-septembre. R.

¿i. St. bicolor Hook. in Botan. Magaz. tabl. 5088 . - Serra da Itabapoana, Espinito Savio, $n^{0}$ 11325. Sous-frutescent, !1. bleues. Septembre-octobre. R.

3̈. St. scaberrima Cham.; Fl. Bras. IX, p. 207. - Itacolumy, pris Oaro Preto, Misas, $1^{\circ}$ 16290. Sous-fiutescent, f1. bleues. Juin-juillet. C.

ว̈3. St. mutabilis Vahl in Enum. P'ant. I, p. פo8. - Congonhas do Campo, Mısas, no 13063. Sous-frutescent, f1. bleues, Juin-juillet. C.

34. St. gesnerioides Cham.; Fl. Bras. IX, p. 207. - Corrego do Prejo, dans le campo, Goraz, $n^{0} 21894$. Frutescent, ft. bleues. Févriermars. C.

7̈. St. Chamissonis Walp.; Fl. Bras. IX, p. 209. - Chico Costa, dans le campo, Goyaz, $1^{\circ}$ 21909. Sous-frutescent, hl. orangées. Octobrenovembre. C.

56. St. reticulata Mart.; Fl. Bras. IX, p. 209. - Serra do Lenheirn et Biribiry, près I)iamantina, Mıxas, $n^{\circ} 17714 a$, 19719. Sous-firutescent, 11. bleues. Avril-mai. R.

57. St. glabra Cham.; Fl. Rras. IX, p. 211. - Serra d'Ouro Preto et 
Biribiry, Mnss. $n^{1 / 5} 15328,19720,19721$. Frutescent, fl. oleues. FévrierInars. C.

58. Stachytarpheta rhomboidalis Schauer; Fl. Bras. IX, p. 212. - Chapadao dos Veadeiros ou de Porto Seguro, Govaz, no 21908. Sousfrutescent, f1. bleu rosé. Janvier-f'évrier. G.

59. St. pachystachya Mart. mss. Schauer; Fl. Bras. IX, p. 214. Entre Barreiros et Melancias, Misas, $n^{\circ}$ 19718. Sous-frutescent, fl. bleues. Mars-avril. C.

60. St. prostrata Glaz. 11. sp.? in herb. Paris., Berol., Kew., Gener., etc. - Cabeceiras to Rio Sant' Anna, dans le campo lumide, Goxaz, n² 21893. Herbacé, fl. blanches. Janvier-février. C.

61. St. commutata Schauer; Fl. Bras. IX. p. 216. - Pico d'Itacolumy, près Ouro Preto, Minas, no 15329. Frutescent, fl. bleues. Févriermars. C.

62. St. villosa Schaner; Fl. Bras. IX, p. 216. - Entre Sobradinho et Lagoa do Hestre d'Armas, Goraz, ${ }^{\text {os }}$ 21906, 21907. Frutescent, f1. rouge brique. Norembre-décembre. GC.

63. St. Glazioviana Loes. n. sp. in herb. Paris., Berol., Kew., Brux., etc. - Serra de Sĩo Joaquim, au Morro do Salto, Goraz, $\mathrm{n}^{\circ}$ 21905. Sous-frutescent, fl. noires. Janvier-février. G.

64. St. caraçana Glaz. n. sp.? in herb. Paris., Berol., Kew., Genev., etc. - Serra do Caraça, Mlısas, nº 15332. Frutescent, li. violettes. Juin-juillet. G.

6ə̃. St. sericea Loes n. sp.? in herb. Paris., Berol., Kew., Brux., etc. - Entre Engenho et Jatolı, dans le campo, Goyaz, ${ }^{\text {os }} 21903,21904$. Frutescent, fl. violettes. Janvier-février. C.

66. Verbena phlogiflora Cham.; Fl. Bras. IX, p. 182. - Entre Ilheos et Sitio, dans le campo, Mrsas, $11^{\circ}$ 16289. Herbacé, 11. bleues. Novembre-décembre. G.

67. V. hirta Spreng.; Fl. Bras. IX, p. 186. - Itatiaia, dans le campo, Rio-Jan., ${ }^{\text {os }} 5955,6654,8183,16288$. Herbacé, fl. roses. Janvier-février. CC.

68. V.perennis Wooton? in Bull. Torr. Bot. Club. (1898), p. 262. - Jaragua, dans le campo, S. Paulo, $n^{0} 17716$ a. Herbacé, ft. blanches. Août-septembre. C.

69. V. intermedia Gill. et Hook.; Fl. Bras. IX, p. 188. - Petropolis, au bord des chemins, Rio-J $\rfloor_{\Lambda}$., $\mathrm{n}^{0} 14162 a$. Sous-frutescent, 11. bleu pâle. Novembre-décembre. C.

70. V. bonariensis Linn.; Fl. Bras. IX, p. 189. - Caminho do 
Lemo, à Botafogo, Rio-Jax., nos 356,6048 . Sous-firutescent, fl. bleu pâle. Octobre-novembre. C.

7I. V. littoralis H. B. K.; Fl. Bras. IX. p. 189. - Petropolis, au bord des chemins, Rio-Jax., $n^{\circ}$ 14162. Sous-frutescent, fi. bleu pâle. Novembre-décembre. C. Vulg. : do pai Caetano.

72. V. ephedroides Cham.; Fl. Bras. IX, p. 191. - Mogy das Cruzes, S. Paulo, $n^{\circ}$ 17716. Sous-frutescent, f1. bleues. Mar's-arril. G.

73. V. filicaulis Schauer; Fl. Bras. IX, p. 192. - Entre Barbacena et Sitio, dans le campo, Mrsas, $\mathrm{n}^{0}$ 18391. Herbacé, fl. roses. Janvierfévrier. C.

74. V. erinoides Lamk; Fl. Bras. IX, p. 194. - Campos da Bocaina, S. Paclo, nº 8183 a. Herbacé, fl. bleuâtres. Février-mars. R.

7.. Amazonia lasiocaulos Mart. et Schauer; Fl. Bras. IX, p. 293. Itapemirim, au borl des bois, Espirito SAvto, nos 10012, 11336. Sous-frutescent, fl. et bractées rouges. Février-mars. R.

76. Casselia chamcedryfolia Cham.; $\mathrm{Fl}$. Bras. IX, p. 175. Queluz, dans le hois, Mrsas, $n^{0}$ 13060. Petit arbuste, ft. bleues. Octobrenovembre. C.

77. Petrea subserrata Cham.; Fl. Bras. IX, p. 279. - Sapopemba, dans le bois, Rio-Jax., nos 2652, 4957. Arbuste sarmenteux, fl. bleues. C. Vulg. : Tocu de viuva.

78. P. Martiana Schauer in Fl. Bras. IX, p. 276. - São Gonçalo, près Diamantina, Mivas, ${ }^{\circ}$ 15324. Arbuste sarmenteux, fl. bleues. Septembre-octobre. C. Vulg. : Toca de viuva.

79. P. insignis Schauer in Fl. Bras. IX, p. 276. - Quinta de Sĩo Christovĩo; Rio-J $\mathrm{Ax}_{\text {. }}, \mathrm{n}^{\circ}$ 14166. Arbuste sarmenteix, f1. violettes, cultivé. Juin-juillet. R.

80. Citharexylon barbinerve Cliam.; Fl. Bras. IX, p. 267. Campos da Bocaina, dans le bois, S. Paclo, ${ }^{0 s}$ 9540, 11318. Arbre, fl. blanches. Novembre-décembre. CG.

81. C. latum Hien in Warm. Symh. ad Fl. Bras. centr., p. 710. Desterro, près Barbacena dans le bois. Mrsas, $n^{\circ}$ 11245. Arbrisseau, fl. blanches. Juin-juillet. R.

82. C. solanaceum Cham.; Fl. Irras. IX, p. 268. - Nova Friburgo, dans le bois, au Conego, Rio-J ches très odorantes. Novembre-décembre. C.

83. G. Ramizii Glaz.n. sp.? in herb. Paris., Berol., Kew., Genev., etc. - Itamaraty pres Petropolis et Tijuca, Rio-Jax., $n^{\text {os }} 4929,15327$. Arbuste épiphyte, sur les arbres et les rochers, 11. blanches. Mars-avril. C. 
84. Citharexylon myrianthum Cham.; Fl. Bras. 1X, p. 269. Entre Sitio et Barbacena, dans le bois, Mısas, $\mathrm{n}^{\text {os }}$ 13058, 13059. Arbrisseau, fl. blanclies. Janvier-fívrier. C.

83. C. quadrangulare Jacq. in Enum. Plant. Car.; p. 26. - Quinta da Boa Vista, liı-JAx., $11^{\text {os }} 9989,1$ J328. Grand arbre cultivé, fl. blanches. Février-mars. R.

86. Duranta Plumieri Jacq.; Fl. Bras. IX, p. 27I. - Campos da Bocaina, dans le hois. S. Paulo, $\mathrm{n}^{05} 810,810$ a, cultive au Passeio Publico. Arbuste, fl. bleues. Octobre-novembre. CG.

87. Ægiphila Lhotskyana Cham.; Fl. Bras. IX, p. 279. - Piro d'Alho, Espiuto Santo . no 11334. Arbrisseau. fl. blanchàtres. Mai-juin. C.

88. E. tomentosa Cham.; Fl. Bras. IX, p. 280. - Cachoeira do Campo, Nisas, $n^{\text {os }} 14164 a$; 20428: Campos da Bocaina, S. Paulo, $n^{\circ}$ 8184; Rio Bananal, dans le campo, Goyaz, $n^{\circ}$ 21917. Arbuste, f1. blanclıâtres. Novembre-décembre. CC.

89. E. villosa Vahl Eclog. Amer. I, p. 16. - Entre Queluz et Carandahr, dans le campo, Mrsas, $n^{\circ}$ 13056. Arluste, ll. blanchatres. Novembre-décembre. R.

90. E. Sellowiana Chım.; Fl. Bras. IX, p. 281. - Alto Nacahé de Nora Friluurgo, Rio-JAv., no 14164 . Arbuste, fl. blanc jaunâtre. Janvierfévrier. C.

91. E. arborescens Vahl; Fl. Bras. IX, p. 281. - Serra dos Orgãos et Corcorado, Rio-Jax., $n^{\text {os }} 808$, 5956. Arbrisseau, fl. blanc jaunattre. Hars-avril. G. Vulg. : Carindiba.

92.' E. fluminensis Vell.; Fl. Bras. IX, p. 283. - Gavea et Corcorado, Rio-JAx., $n^{\text {os }} 806,3067$. Arbuste, f1. blanc jaunatre. Novembredécembre. C.

93. E. triantha Schauer; Fl. Bras. IX, p. 283. - Alto Nacahé de Nova Friburgo, Rio-Jav., ${ }^{08}{ }^{14165}, 15325,17714$. Artrisseau, fl. blanchâtres. Novemlıre-décembre. CC.

94. E. mediterranea Vell.; Fl. Bras. IX, p. 385. - Entre Belem et Rio Douro, Rin-Jax., nos 1546, 11337. Arbuste, 11. blane jaunâtre. Aoùtseptembre. C.

9\%. E. Luschnathi Schauer; Fl. Bras. IX, p. 28\%. - Corcovado, au Sylvestre, Riro-Jax., $n^{0 s}$ 865, 8832; Serra d'Ouro Preto, Misas, $n^{0}$ 15326. Arbrisseau, t1. blanc jaunâtre. Juin-juillet. C.

96. A. ferruginea Glaz. n. sp. ? in herb. Paris., Rerol., Genev., etc. Serra dos Purys, Espristo Saxto, no 11333. Arbuste, f1. rousses. Octobrenovembre. R. 
A.-F.-M. GLAZIOU. - LISTE DES PlaNTES DC BRÉsIL CENTRAL.

97. E. cuspidata Ilart.; Fl. Bras. IX, p. 287. - Corcovado, à Paineiras, Pio-J Ax., nos $^{\circ 07}$, 8831. Arbuste, f1. blanchàtres. Juillet-Auùt. C. Vulg. : Caferana.

98. E. obducta Vell.; Fl. Bras. IX, 1. 289. - Floresta da Tijuca et Alto Macahé de Nova Friburgo, Rio-JAx., nos 1498, 3068, 4160, 4161, $6652,11338,11339,18394,19722$. Arbuste, fl. blanc rosé. Septembreoctobre. CG.

99. Vitex Gardneriana Schauer.; Fl. Bras. IX. p. 296. - Serra da Itabapoana, Espirito Santo, $n^{\circ} 11322$. Arbrisseau, f1. violettes. Aoûtseptembre. C.

100. V. discolor Glaz. n. sp.? in herb. Paris., Berol., Kew., Brux. Serrinha de Santa Barbara, Mıxas, $n^{0}$ 19723. Arbrisseau, fl. bleues. Maijuin. R.

101. V. cymosa Bertero; fl. Bras. IX, p. 296. - Sapopemba et Tijuca, Rı-JAx., ${ }^{0 s} 3066,3679,4159,8830$. Arbrisseau, fl. lilas. Octobre-novembre. CG.

102. V. multinervis Schauer; Fl. Bras., IX, p. 297. - Itatiaia, dans le bois et le campo, Rio-Jax., $\mathrm{n}^{\text {os }} 4159 a, 11320$ - Arhrisseau, fl. lilas pâle. Juin-juillet. C.

103. V. montevidensis Cham,; Fl. Bras. IX, p. 297. - Serra do Inficionado, dans le bois, Minas, $n^{\text {os }} 13057,14160$. Arbrisseau, f1. violettes. C.

104. V. Sellonviana Cham.; Fl. Bras. IX, p. 298. - Santo Antonio, près Petropolis, Rio-JAx., nos 5957, 11319. Arbrisseau, fl. bleues. Marsarril. C. Vulg. : Ipé braco, Maminha de cadella.

108. V. polygama Cham.; F\% Bras. IX, p. 300. - Restinga de Mauá, Serra dos Orgãos, Rio-Jax., nos $3680,5958,5959,6049,7788$, 11321, 14344. Arbrisseau, 11. violettes. Août-septembre. CC.

106. V. triflora Vahl; Fl. Bras. IX, p. 301. - Quinta da Boa Vista, Rio-J $\mathrm{JN}_{\mathrm{N}}, \mathrm{n}^{0} 15165 a$. Arbrisseau cultivé, fl. blanchâtres. Fẻvrier-mars. R.

107. Clerodendron squamatum Vahl in Symb. Bot. II, p. T4. Quinta da Boa Vista, Rio-J.s., n ${ }^{\text {os }}$ 9541, 17163. Arbuste cultivé, fl. roses. Octobre-novembre. C.

108. Cl. fallax Lindl.?: DC. Prodrom. IX, p. 666. - Quinta dit Boa Vista, Rio-Jav., n ${ }^{\circ}$ 3809. Arbuste cultivé, f1. rose pâle. Août-septembre. C.

109. Cl. Siphonanthus Ait. in Hort. Keuensis. II, IV; p. $630 .-$ Quinta da Boa Vista, Rı-JAx., nº 8185. Sous-frutescent, cultivé, fl. blanc rosé. R. 
110. Clerodendron nereifolium Wall. in Calal., n ${ }^{\circ}$ 1789. - Quinta da Boa Vista, Rı-JAx., no 14163. Arbuste sarmenteux, cultivé, fl. blanc rosé. Octohre-novembre. CG.

111. Cl. glabrum Vleyer?; DC. Prodr. XI, p. 661. - Quinta di Boa Vista, Rio-J $J_{A} ., n^{o s} 6653$. Arbuste cultivé, 11. roses. Novembredécembre. R.

112. Avicennia tomentosa Jacq.; Fl. Bras. IX, p. 308. - Praia Grande, dans les bourbiers, près de la mer, Rio-Jav., $n^{0 s}$ 1362, 11317. Arbrisseau, 1l. blanchâtres. CC. Vulg. : Siriba, Mangue.

113. A. africana P. Beauv.?; Fl. Bras. IX. p. 305. - Itapemirim, près de la mer, Espirito Savro, no 11323. Arbrisseau, fl. blanchâtres. Février-mars. C. Vulg. : Javamataia.

114. A. nitida Jacq.: Fl. Bras. IX, p. 304. — Itapemirim, près de la mer, Espintro SAvтo, $n^{\circ 3} 4925,9988,11324$. Arbrisseau, fl. blanchâtres. Janvier-février. C. Vulg. : Canóa.

\section{Fam. 102. - Labiées.}

1. Ocimum gratissimum L.; Fl. Bras. VIII, 1, p. 71. - Serra da Mantiqueira, Mivas, $n^{\text {os }} 7784$, 13101. Sous-frutescent, 11. blanchâtres. Aout-septembre. C.

2. O. Sellonvii Benth.; Fl. Bras. VIII, I, p. 72. - Sĩo Fidelis, près Campos, Rio-J $\mathbf{J N}_{\mathrm{Ax}}, \mathrm{n}^{\circ}$ 10013. Sous-firutescent, fl. blanchàtres. Janvierfévrier. C.

3. O. carnosum Link et Otto; Fl. Bras. VIII, I, p. 73. - Bas Itatiaia, près Campo Bello, Rio-Jav., $\mathrm{n}^{0} 7784 a$. Sous-frutescent, fl. blanchâtres. Janvier-février. C.

4. O. micranthum Willd.; Fl. Bras. VIII, I, p. 74. - Alto do Tamandoa, près Santa Luzia do Rio das Velhos, Mıvas, nos $18385,20427$. Sous-frutescent, fl. blanthâttres. Novembre-janvier. C.

Э. Peltodon pusillus Pohl; Fl. Bras. VIII, I, p. To. - Rasgão, près Gorumba dans le campo, Goyaz, $1^{\circ} \mathbf{2 2 0 7 7}$. Herbacé, fl. blanchâtres. Août-septembre. GC.

6. P. radicans Pohl; Fl. Bras. VIII, I, p. 77. - Abbade, près Heia Ponte dans le campo, Goraz, $\mathrm{n}^{\circ} 21940$ b. Herbacé; 1l. rosées. Août-septembre. R.

7. Marsypianthes hyptoides Mart.; Fl. Bras. VIII, I, p. 78. - Cabo Frio et Copacabana, Rio-JAN., $n^{0 s} 8503,11302,11303,13044$. Herbacé, fl. blanc rosé. GG. 
8. M. Chamadrys Otto Kuntze in Rev. Gen.(1891), 5̈24. - Abbade, press Vleia Ponte et Serra dos Veadeiros, Goyaz, $n^{\text {os }} 21940,21940$ a. Ilerbacé, fl. rose pâle. Aoùt-septembre. R.

9. Hyptis virgata Benth.; Fl. Bras. VIII, I, p. 81. - Serra de São José d'El Rei, dans le campo, Mrvas, $\mathrm{n}^{\circ}$ 17156. Herbacé vivace, 11. violacées. Octobre-novembre. C.

10. H. interrupta Pohl; Fl. Bras. VIII, I, p. 81 var. subglabrata Briq. - Entre Ponte Lavada et Cuba, Goxaz, n² 21929. Herbacé, f1. jaunàtre. Août-septembre. C.

11. H. platanifolia Mart.: Fl. Bras. VIII, I, p. 83. - Entre Ouro Preto et Marianna, Mixas, $\mathbf{n}^{\circ}$ 15281. Herbacé, fi. lilas. Janvier-février. C.

12. H. spicigera Lamk; Fl. Bras. VIII, I, p. 83. - Serra d'Ouro Preto, dans Ie campo, Misas, $\mathrm{n}^{0 \mathrm{~s}} 11305,14194$. Herbacé, fl. jaunâtres. Février-mars. C.

13. H. nudicaulis Benth.; Fl. Bras. VIII, I, p. 8't. - Caraça, dans le Campo de Fora. ilsxas, $n^{\circ} 15334$ a. Herbacé, fl. brunes. Juin-juillet. C.

14. H. sericea Benth.; Fl. Bras. VIII, I, p. 8əั. - Ipanema, dans Ie campo, S. Paclo, no 13051 . Herbacé, fl. brunes. Mars-arril. C.

15. H. Sideritis Vlart.; Fl. Bras. VIII, I, p. 86. - Horro do Coco ou do Bahú, Rı-Jax., nos 9982,11304 . Herbacé, fl. blane rosé. Octobrenorembre. C.

16. H. elliptica Briq. in Ann. Cons. Jard. Bot. Gen. (1898), p. 341. Piracicaba, dans le campo, S. Patlo, no 16384 ; Mestre d'Armas, Goraz, n² 21938. Herbacé, 11. blanc rosé. Décembre-janvier. C.

17. H. subviolacea Briq. in Am. Conserv. Jard. Bol. Gen, 2229. Entre Barbacena et Sitio, dans le campo, Mixas, $n^{\circ}$ 15283, Herbacé, f1. blanc rosé. Octobre-norembre. C.

18. H. recurvata Poit.; Fl. Bras. VIII, I, p. 87. - Petropolis, au Jacob, Rio-Jax., no 8180. Herluacé, f1. blanc-rosé. Mai-juin. C.

19. H. paludosa St-Hil.; Fl. Bras. VIII, 1, p. 88. - Villa Nova, Rı-Jax., $1^{0 \mathrm{~s}}$ 7783, 12089; Caraça, dans Ie campo, Mlısas, $n^{\circ} 15334$. Herlacé, fl. thane jaunàtre. Juin-juillet. C.

20. H. microphylla Pohl; Fl. Bras. VIII, I, P. 88. - Fazenda de Santa Cruz, Rıo-Jax., $n^{\circ}$ 9535. Herbacé, f1. blanc-rosé. Notembredécembre. CG.

21. H. camporum Benth.; Fl. Bras. VIII, I, p. 90. - Chapadio dos Veadeiros ou de Porto Seguro, Goraz, $n^{0}$ 21946. Sous-frutescent, fl. blanchâtres. Norembre-décembre. C. Vulg. : Chá de principe. 
22. Hyptis longipes St-Hil.; Fl. Bras. VIII, I, p. 90. - Entre Rio Torto et Paranauá, Goyaz, $1^{\circ}$ 21901. Sous-frutescent, 11. roses. Nai-juin. C.

23. H. incisa St-Hil.; Fl. Bras. VIII, I, p. 93. - Formosa, dans le campo sablonneux, Goyaz, $\mathrm{n}^{\circ}$ 21947. Sous-frutescent, sans fleur en décembre. R. Vulg. : Chà de principe.

2't. H. peduncularis Benth.; Fl. Bras. VIII, I, p. 93. Fazenda Amoreira, dans le campo, Gornz, $n^{0}$ 21900. Sous-frutescent, fl. roses. Juinjuillet. C.

25. H. rugosa Benth.; Fl. Bras. VIII, I, p. 93. - Entre Barbacena et Sitio, dauns le campo, Misas, ${ }^{0 s}$ 11313, 14151. Sous-frutescent, fl. roses. Juin-juillet. GC.

26. H. pubescens Glaz. n. sp.? in herb. Paris., Berol., Kew., Genev., etc. - Barro Amarello, au Ribeirão de Calıas, dans le campo, Goraz, $n^{\circ}$ 21954. Sous-frutescent, fl. roses. Aoùt-septembre. C.

27. H. minensis Glaz. n. sp? in herb. Paris., Berol., Kew., Genev., ete. - Biribiry, près Diamantina, Mısas, no 19704. Sous-frutescent, fl. roses. Mars-avril. C.

28. H. lippioides Pohl: Fl. Bras. VIII, I, p. 94. - Campos da Bocaina, S. Pacto, $11^{05} 7782,8178,13046$; Chapadào dos Veadeiros, Goraz, $n^{\text {os }} 21943,21945,21955$ a. Sous-frutescent, li. bleues. Aouit-septembre. Ci.

29. H. plumosa Benth.; Fl. Bras. VIII, I, p. 93. - Saia Vello, près Santa Luzia, dans le campo. Goyaz, $\mathrm{n}^{\circ}$ 21955. Sous-frutescent, 11. bleues. Nars-avril. C.

30. H. nervosa Pohl ; Fl. Bras. VIII, I, p. 96. - Itabira do Campo, Mixas, no 17162. Sous-frutescent, ll. blanchâtres. Août-septembre. C.

31. H. mollissima Benth.; Fl. Bras. VIII, I, 1. 97. - Serra do Cipo, dans le campo, Mısas, no 15282. Sous-frutescent, fl. bleues. Mars-avril. C.

32. H. crinita Bentl.; Fl. Bras. VIII, I, p. 98. - Curvello, dans le campo, Mıxas, $1^{08} 14149$, 14150, 15285; Fazenda de Dona Barbara, à Sobradinho, Goraz, nº 21936. Frutescent. fl. blanchâtres. Juin-juillet. CG.

33. H. eriophylla Pohl; Fl. Bras. VIII, I, 1. 100. - Entre Fazenda da Vargem et Lamarão. Goyaz, $n^{\circ} 21935$. Frutescent, fl. blanchîtres. Janvier-février- C.

34. H. penceides Taub. in Engl. Bot. Jahrb. XXI (1896), p. 430. - Cachoeira da Vargem Grande, Goraz, nos 21624, 21625. Arbuste, fl. blanchâtres. 
3๖. H. ditassoides Mart.; Fl. Bras. VIII, I, p. 100. - Serra do Cijo, dans le campo, Miss, $1^{\text {ss }}$ 19693, 19694. Sous-fiutescent, fl. violettes. Arril-mai. C.

36. H. obtecta Benth.; Flora Biras. VIII, I, p. 101. Chapadão dos Veadeiros ou de Porto Seguro, Goraz, n² 21949. Sous-frutescent, f1. blanchâtres. Janvier-férrier. R.

37. H. subnuda Briq. in Ann. Conserv. Jard. Bot. Gen. (1898), 231. - Campos da Bocaina, S. Paclo, $1^{\ominus}$ 11308. Sous-frutescent, 11. lilas. Septembre-octobre. C.

38. H. passerina Nart.; Fl. Bras. VIII, I, p. 101. - Quartel do Biribiry, près Diamantiıa, Mlıxs, 1" $^{\prime \prime}$ 18395, 19689. Frutescent, fl. blanches. Février-mars. C.

39. H. lanuginosa Glaz. n. sp. ? - Serra da Baliza, dans le campo, Govaz, $1^{\circ}$ 21910. Frutescent, 11. blanchâtres. Janvier-février. R.

40. H. Sellowi Benth.; Fl. Bras. VIII, I, p. 102. - Serra do Lenheiro, près São João d'El Rei, .lısas, nos 16300 , 17159; Cabeceiras do Río Gama, dans le campo, Goyaz, no 21911. Frutescent, 11. blanches. Novembre-décembre. CC.

41. H. velutina Pohl; Fl. Bras VIII, I, p. 102. - Corrego do Brejo, près du campement dans le campo. Goraz, $n^{\circ}$ 21953. Sous-frutescent, t1. bleues. Mai-juin. CC.

- Var. origanoides Benth; Fl. Bras. VIII, I, p. 103. - Serra dos Cristaes près Diamantina, Mrsts, $n^{\circ s} 19690,19691$. Sous-frutescent, f. blanchàtres. Mai-juin. C.

42. H. crenata Pohl; Fl. liras. VIII, I, P. 106. Cabeceiras do Rio Gama, au Colombista dans le campo. Guraz, $n^{08} 11297,21952$. Sousfrutescent, fl. bleues. Arril-mai. C.

43. H. dilatata Benth.: Fl. Bras. VIII, I, p. 107. - Serra dos Purys, dans le campo, Esprirto Savto, $1^{0 s} 9654$, 9911. Sous-frutescent, fl. lilas. Août-septembre. C.

4'4. H. Schwackei Glaz. n. sp.? in herb. Paris., Berol., Kew., Brux.. etc. - Diamantina, au Tombador, dans le campo, Mrsas, $\mathbf{n}^{\circ} 19688$. Sous-frutescent, fl. lilas. Avril-mai. C.

4:. H. cordifolia Gla\% n. sp.? in leerb. Paris., Berol., Kew., Brux., etc. - Biribiry, au Mocotó prés Diamantina, Mıxds, nos 19702, 19703. Sous-frutesent, fl. violettes. Mars-arril. C.

46. H. asteroides St-ilil.: Fl. Bires. VIII, I, p. 107. - Serra do Arruda, pris Meia Ponte, Goraz, 21948. Sous-firutescent, l1. violettes. Juin-juillet. C. 
47. Hyptis capitata Jaeq.; Fl. Bras. VIII, I, p. 109. - Sâo João da Barra, prís Campos, Rio-Jax., no 8824, 11. lilas. Février-mars. C.

48. H. brevipes Poit.; Fl. Bras. VIII, I, p. 109. - Entre Sĩo Paulo et Barneri, au bord du chemin, S. Pauso, n's 13045, 13053; Congonhas do Campo, Mixas, no 14148. Herbacé, fl. lilas. Mai-juin. CG.

49. H. lappulacea Vart.; Fl. Bras. VIII, 1, p. 111. - Itatiaia, dans le camp̧o, Rro-J Ax., no $^{\circ} 5953$ a. Herbacé. fl. blanchâtres. Octolıre-novenbre. C.

80. H. monticola Mart.; Fl. Bras. VIII, I, 1. 112. - Pedra do Conego, près Nova Friburgo, Rio-Jan., no 12091 ; Itacolumy, Mlnas, $11^{\circ s} 15346$, 15286. Frutescent, fl. roses. Juin-juillet. CC.

51. H. albicans Glaz. n. sp.? in herb. Paris., Berol., Kew., Brux., etc. - Flazendos Macacos, à Chico Lobo, Goyaz, no 21912. Frutescent, fl. blanchâtres. Octobre-novembre. C.

5\%. H. caspitosa St-Hil.; Fl. Bras. VIII, I, p. 111. - Entre Ipanema et Sorocaba, S. Paulo, no 13050. Frutescent, f1. lilas. Mars-avril. C.

ร3. H. rotundifolia Benth.: Fl. Bras. VIII, I, p. 113. - Morro do Inficionado, près Caraça, et Itacolumy, Mıvas, $n^{\circ 3} 15348,15349,18386$, 19692. Frutescent, fl. roses. Juin-juillet. CC.

54. H. Crulsii Glaz. n. sp. in herb. Paris. - Entre les sources du Rio Torto et le Sobradinho, dans les jâturages sablonneux, Goyaz, $\mathrm{n}^{\circ}$ 21950. Frutescent, fl. lilas. Norembre.

5ว. H. Cissonii Glaz. n. sp.? in herb. Paris., Berol., Kew., Brux., etc. - Gapelinha de Santo Antonio, au Rio Descoberto, Goraz, $n^{0}$ 21913. Frutescent, f1. violacées. Octobre-novembre. R.

:6. H. insignis Glaz. n. sp.? in herb. Paris., Berol., Kew., Brux., etc. - Cachoeira da Vargem Grande, Goraz, n 21925. Frutescent, sans fi. en janvier. C.

57. H. complicata St-Hil.; Fl. Bras. VIII, I, p. 113. - Serra da Piedade, dans le campo, Iinas, $n^{\circ}$ 20426. Frutescent, fl. violettes. Novenibre-décembre. C.

58. H. linarioides Pohl; Fl. Bras. VIII, I, p. 114. — Campa Bocaina au Bom Jardim, S. PAvlo, n ${ }^{\circ} 11311$; Bento liodrigues, pres Ouro Preto, Mixas, $1^{\circ}$ 19696. Herbacé, fl. lilas. Mai-juin. C.

59. H. densifolia Pohl; Fl. Bras. VIII, I, p. 114. - Ponte Alta, daus le campo, Goraz, n² 21939. Herbacé, fl. violacées. Aoùt-septembre. C.

60. H. sinuata Pohl; Fl. Bras. VIII, I, p. 116. - Morro de São Vicente, près Ouro Preto, Misas, no 15345 a. Herbacé, ft. roses. Juinjuillet. C. 
A.-F゙.-M. GLAZIOU. - LISTE DES PLANTES DE BRÉsIL CENTRAL.

61. H. imbricata Polll; Fl. Bras. IIII, I, p. 118. - Serra dos Pụeneos, près Meia Ponte, Goraz, n' 21948 . Herbacé, fl. roses. Aoùtseptemlire. h.

62. H. acutifolia Glaz. n. sp.? in herb. Paris., Brux., Berol., Kew, etc. - As Brancas, dans le campo, Goyaz, no 21944 a. Sousfrutescent, ft. roses. Décembre-janvier. R.

63. H. quadrangularis Glaz. 11. sp.? in herb. Berol., Kew., Paris., Brux., etc. - Serra da Baliza, dans le campo, Govaz, nº 21944. Sousfrutescent, 11. roses. Janvier-février. R.

64. H. atrorubens Poit.; Fl. Bras. VIII, I, p. 118. - São Fidelis, près Campos, Rio-JAx., n 9990. Suus-frutescent, fl. roses. Janvierfévrier. C.

65. H. Lantancefolia Poit.; Fl. Bras. VIII, I, p. 119. - Corcovado, à Paineiras, Pio-Jax., nos 4156, 5953. Herbacé, f1. lilas. Mai-juin. C.

66. H. alutacea Pohl; Fl. Bras. VIII, I, p. 120. — Serra de São Pedro, au sommet, près Formosa, Goraz, n² 21337. Herbacé, f1. blanchàtres. Novembre-décembre. C.

- Var. microphylla Glaz. v. nor.? in herb. Paris., Berol., Kew., Gener., etc. - Serra do Lenheiro, dans le campo, Misas, no 17157. Herbacé, fl. rosées. Octubre-novembre.

67. H. conferta Pohl; Fl. Br. VIII, I, p. 121. - Abhade, près Neia Ponte, dans le campo, Goraz, $n^{\circ}$ 21951. Sous-frutescent, f1. blanches. Aoùt-septembre. C.

68. H. villosa Pohl val. neticulata Pohl? Fl. Bras. VIII, I, p. 123. Sitio do Buracĩo, dans le Campo, Goraz, n² 21930. Herbacé, f1. bleues. Août-septembre. C.

69. H. lutescens Pohl; Fl. Bras., VIII, I. p. 123. - Campos da Bocaina, au Solbado, S. Paclo, $n^{\circ} 11312$, 15345. Sous-frutescent, 11. jaunâtres, Juin-juillet. CC.

70. H. rubiginosa Benth.; Fl. Bras. VIII, I. p. 123. - Morro de S. Vicente, dans le campo, Miras, $\mathrm{n}^{\text {os }}$ 13102, 14152, 14153, 15346; Chico Lobo, à Taboquinha, Goraz, $n^{0}$ 21941. Frutescent, f1. blanches. Juin-juillet. CC.

71. H. homalophylla Pohl ; Fl. Bras.VIII, I, p. 126. - Jundiahy, dans le cainpo, S. Pavlo, $n^{\circ}$ 13052, 16282; Itacolumy, près Ouro Prelo, Mrsas, $11^{0}$ 15284. Suus-frutescent, fl. blanchâtres. Mars-avril. G.

72. H. halimifolia Mart.; Fl. Bras. VIII, I, p. 126. - Entre le Hio Tocantins et Os Porcos, Goraz, n 21934. Sous-frutescent, 11. lilas. Janvier-lévrier. C. 
73. Hyptis duplicato-dentata Pohl in Warm. Symb. ad Fl. Bras., p. 66. - Entre Taboquinha et Taquar!, Govaz, $1^{\circ}$ 21928. Sous-lintescent, l1. Blanı'lâtres. Juin-juillet. C.

74. H. vestita Benth.: Fl. Bras. VIII, I, 1) 128. - Jundiahy, dians le campo, S. l'aclo, no 13052. Sous-frutescent, fl. jaunatres. Mal'sarril. C.

- Var. duplicato-dentata Benth.; Fl. Bras. Vill, I, 1. 128. - Parapanema, dans le campo, S. Patlo, no 16283. Sous-frutescent, fl. blanchâtres. Juin-juillet. C.

7.. H. obvallata Spreng.; Fl. Bras. VIII, I, 1. 129. - Entre Barhacena et Barroso, dans le campo, Minas, $11^{\circ} 11315$ a. Sous-frutescent, II. blanchâtres. Juin-juillet. R.

76. H. carpinifolia Benth.; Fl. Bras. VIII, I, P. 130. - Nova Friburgo, Rio-Jan., $n^{\circ}$ 12090; Entre Ipanema et Sorocaba, S. Pavto, $n^{\circ \mathrm{si}}$ 11315, 13049, 14147; Serra Dourada, chemin du Gurgulho, Govaz, $n^{\circ}$ 21931. Sous-frutescent, fi. violettes. Aoùt-septembre. CC.

77. H. subrotunda Pohl ; Fl. Bras. VIII, I, p. 131. - Gabeceiras do Rio Guara lans Ie campo, Goyaz, $n^{\circ} 21932$. Frutescent, II. violettes. Mai-juin. C.

78. H. muricata Schott; Fl. Bras. VIII, I, p. 133.- - Petropolis, à Santo Antonio, Rio-J $\mathrm{JN}_{\mathrm{N}}, \mathrm{n}^{\circ}$ 8476. Sous-frutescent, fl. lilas. Mai-juin. C.

79. H. glomerata Mart.; Fl. Bras. VIII, I, P. I33. - Restinga de Copacabana, Rı-Jav., $1^{\circ} 3811$; Congonhas to Campo, Mlsas, $n^{\circ} 14187$, 15322. Sous-frutescent, fl. Llanchâtres. Juin-juillet. C.

80. H. dubia Pohl; Fl. Bras. VIII, I, p. 135. - Pindamunhanga, dans le campo, S. Pauto, $n^{\circ} 14186$ a. Herbacé, ll. violacées. Octobrenovembre. R.

81. H. spicata Poit.; Fl. Bras. VIII, I, p. 133. - Engenho Velho et Villa Nova, dans le bois, Rı-JAx., ${ }^{\circ{ }^{\circ}} 5968,9984,7785,14186$. Herbacé, 11. violettes. Mai-juin. CC.

82. H. communis St.-Hil.; Fl. Bras. VIII, I, p. I37. - Campos da Bocaina, dans les bourbiers, S. Pauto, ${ }^{\text {os }} 8177,11310$. Herbace, f1. roses. Juin-juillet. C.

83. H. racemulosa Hart.; Fl. Bras. VIII, I, p. 137. - Campos da Bocaina, S. PAulo, nº 9984 a. Herbacé, hl. violettes. Février-mars. R.

84. H. macrotera Briq. in Ann. Conserv. Jard. Bot. Geniv. (I898), p. 210. - Entre Barbacena et Sitio, dans le campo, Minas, n 11314. Sous-frutescent, ll. jaunâtres. Juin-juillet. C.

85. H. singularis Glaz. n. sp.? in lıerb. Paris., Berol., Kew., 
Gener., etc. - Serra da Mantiqueira, à Joân Ayres, Mıxas, nº 11300. Sous-frutescent, f1. blanchittres. Juin-juillet. Ri.

86. H. umbrosa Salzm.; Fl. Brols. YIII, 1, p. 138. - Petropolis, à Santo Antonio, Rı-Jax., $11^{\circ} 8181$. Herbacé, H. blanchàtres. Hai-juin. C.

87. H. suaveolens Poit.; Fl. Bres. VIII, I, p. I39. - Petropolis, ¿ Santo Intonio, dans le bois, Rio-Jax., $11^{\circ}$ 6906, 8182; Conceiçio, dans le bois. Mtuss, $1^{\text {s }} 13043,14193$. Sous-firutescent, ll. rongeâtres. Maijuin. CG.

88. H. pectinata Poit.; Fl. Bras. VIII, I, 1) I40. - Serra do Caraça, dans le bois, Misas, $1^{\circ}$ 14192. Sous-frutescent, fi. violacées. Octobre-novembre. C.

89. H. Clanssenii Benth.; Fl. Bras. VIII, I, 1. 1't' - Caraeg, dans le campo, Mıxas, $n^{0} 15286$; Corrego do Brejo, a Chico Lobo, Goyaz, n² 21942. Frutescent, t1. blanches. Mars-avril. C.

90. H. membranacea Bentlı.; Fl. Bras. VIII, I, p. 140̈. - Nova Friburgo et Petropolis, Rio-JAx., $n^{\text {os }} 3706,8179$, 13055, 15340. Bel arbuste, fl. lilas. Loùt-septembre. CG.

91. H. macrotricha Briq. in Ann. Conserv. Jard. Bot. Gen. (1898), p. 195. - Carandaly, dans le campo, Hisas, $n^{\circ}$ 13104. Frutescent, tł. lilas, Juin-juillet. C.

92. H. lencophy-lla Polıl Fl. Bras. VIII, I, p. I46. - Rio dis Pedras, laus le campo, Mrsas, n 19705. Arbuste, fl. violettes. Mars-avril. R.

93. H. scabra Benth, Fl. Bras. VIII, I, p. 146. - Congonhas do Campo et Queluz, Nixas, $n^{\text {os }} 13103,15338,15239$. Arbuste, fl. lilas. Juin-juillet. C.

94. H. cana Pohl; Fl. Bras. VIII, I, p. 147. - Entre Honte Alegre et Joào Lobo, dans le campo, Goraz, $n^{\circ}$ 21916. Arbuste, ti. violettes. toût-septembre. C.

93. H. densiflora Pohl; Fl. Bras. VIII, I, p. 149. - Barra do Torto, aux bords des bois, Govaz, $n^{\circ}$ 21919. Sous-frutescent, fl. roses. Maijuin. C.

90. H. irregularis Renth.; Fl. Bras. VIII, I, p. 13̈2. - Corrego do Brejo, au campement, Goraz, $n^{0}$ 21920. Sous-frutescent, fl. bleuattres. Mai-juin. C. Vulg. : Barrigudinha.

97. H. Salzmanni Benth.; Fl. Bras. VIII, I, p. 15\%. - Pinheiro, prís Diamantina dans le campo, Mixas, $1^{\circ} 11298$, 19686. Sous-frutescent, il. roses. Mars-avril. C. Vulg. : Barrigudinha.

98. H. Gląiovii Bri甲. in Bull. IIerb. Boiss. (1894), p. 716. 
Campos da Bocaina, prés Sĩo José dos Bareiros, S. Paulo, no 13047. Sous-fiutescent, fl. rouges. Aout-septembre. C. Vulg. : Barrigudinha.

99. Hyptis coccinea Mart.; Fl. Bras. VIII, I, j. 1:4. - Serra do Palmital, au sommet dans le campo, Mrsas, $n^{\circ}$ 15314. Frutescent, f1. rouges. duin-juillet. C.

I00. H. reticulata Mart. var. congrfora Mart. Fl. Bras, VIII, I, 1. 13วั. - Perpetua, près Diamantina, n 19687. Frutescent, 11. rouges. Avril-mai. R.

10I. H. glauca St-Hil.; Fl. Bras. VIII, I. p. 15\%. - Belle vallée de

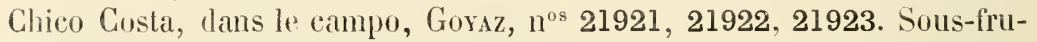
tescent, fl. rouges. Octobre-novembre. GC.

102. H. paniculata Benth.; Fl. Bras. VIII, I, P. 1\%3. - Entre le passage du Rio Indaya et Bocaina, Goyaz, n² 21957. Sous-frutescent, fl. roses. Octolie-novembre. $\mathrm{R}$.

103. H. caly-cina Pohl; Fl. Bras. VIII, I, p. 156. - Fazenda da Tahoquinha, à Lage, dans le campo, Govaz, no 21924. Sous-frutescent, 11. rouges. Plante tries odorante. Juin-juillet. C.

104. Eriope polyphylla Mart.; Fl. Bras. VIII, I. p. 159. - Curalinho, près Diamantina, Vıvas, $n^{\circ}$ 19684. Sous-frutescent, fl. blanclies. Avril-mai. R.

103. E. crassipes Benth.; Fl. Bras. VIII, I, p. 160. - Rio das Pedras, au Valu, dans le campo. Mrsas, $n^{\circ}$ 19685. Herbacé, fl. blanches. Avrilmai. CC.

106. E. macrostachya Mart.; Fl. Bras. VIII, I, p. 162. - Petropolis, à ltamaraty, Rro-JAx., nos 7793, 15433; Chico Costa, an bord des bois, Goraz, n² 21825. Sous-frutescent, f1. bleues. Auût-septembre. C.

- Var. hypoleuca Benth. in DC. Prodr. XII, 143. - Caraça, caminho da Charara, Mıxas, no 15342. Sous-frutescent, fl. bleues. Juin-juillet. R.

- Var. vilzosa Benth., loc. cit. - Piracinunga. dans le bois, São Patlo, nos 11306,15341 . Sous-frutescent, ll. lilas. Mai-juin. C.

107. E. chamædrifolia Taub. n. sp.? in herb. Paris., Berol., Kew ., Brux., ete. - Arassuahy, dans le campo, Minas, n 15313. Herbacé, fl. violettes. Novembre-décembre. C.

108. Cunila incisa Benth.; Fl. Bras. VIII, I, p. 16\%. - Curalinho, près Dianantina, Msas, $n^{\circ} 19707$ a. Frutescent, 11. blanchâtres. Avrilmai. R.

109. C. galioides Benth. var. mispida Benth in Fl. Bras. VIII, I, p. 167. - Itatiaia, au hord des ruisseaux, Rı-Jas., $n^{\circ} 4893$. Sousfrutescent, fl. violettes. Juin-juillet. CG. Vulg. : Poaya do brejo. 
110. C. stricta Benth. ; Fl. Bras. VIII, I, p. 168. - Itatiaia, au Campo do Silverio, Rro-Jan., no 11301 . Herbacé, fl. lilas. Février-mar's. C.

111. Hedeoma multiflora Benth.; Fl. Bras. VIII, I. 1. 170. - Biribirł, au Nocotó, près Diamantina, Mrsas, $n^{\circ}$ 19184. Sous-frutescent, fl. blanchâtres. Mars-avril. R.

112. H. Glazioyii Briq. in Ann. Conserv. Jard. Bot. Gen., p. 183 . - Itatiaia, au hord des ruisseaux, Rin-JAx,, no 6651. Sous-frutescent, fl. lilas. Janvier-férrier. G.

113. H. Schwackeana Glaz. n. sp.? in herb. Paris., Berol., Kew., Brux.. ele. - Tombador, près Diamantina, Msxs, n 19695. Frutescent, fl. lilas. Avril-mai. C.

114. Keithia nitida Benth.; Fl. Bras. VIII, I, p. 172. - Serra tos Orgãos, Rio-Jux., nos 4157, 6660; Pico do Papagaio, près Ayuruoca, Hinas, nos 9538, 16298. Février. C. Vulg. Poejo do brejo.

113. K. minima Schm.; Fl. Bras. VIII, I, p. 173. - Perpetua, près

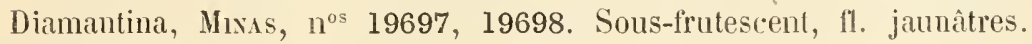
Avril-mai. C.

116. K. coccinea Benth.; Fl. Bras. VIII, I, p. 173. - Jatiaia, dans le Campo Feio, Rio-Jax., nos 4902, 6663. Herbacé, l'l. rouges. Janvierfévrier. C.

117. K. villosa Benth.; Fl. Bras. VIII, I, p. 173. - Entre Ayuruoca et Chambú, Mıxas, nº 16305. Herbacé, fl. blanchâtres. Janviel-février. C.

- Var. glabriuscula Benth.; Fl. Bras. VIII, 1, p. 174. - Pedra de Amolar, pres Ouro Preto, Mrvas, $n^{\circ s}$ 9537, 18416. Herbacé, 1l. blanchâtres. Mars-avril. C.

118. K. denudata Benilı.; Fl. Bras. VIII, I, p. 174. - Congonhas do Campo. Serra do Lenheiro, Ayuruoca, etc., Mixas, nos 9539, 15319, 16304. 17158; entre Amoreira et Bolivia, dans le campo, Goyaz, nos 21956, 21956 a. Herbacé, 1l. blanchâtres. Juin-juillet. CC. Vulğ. : Poejo do Campo.

119. Glechon spathulata Bentlı.; Fl. Bras. IIII, I, 1. 17\%. - Serra de Ouro Branco, à São Julião, Misıs, no 18389 a. Frutescent, fl. blanchâtres. Mars-avril. R.

120. Gl. thymoides Spreng.; Fl. Bras. VIII, I, 1. 176. - Guralinho, près Diamantima, Mıvas, $n^{\circ}$ 19700. Frutescent, fl. blanchâtres. Avrilmars. C.

121. Gl. origanifolia Benth.; Fl. Bras. VIII, I, p. 177. - Serra de Ouro Branco, à São Juliao, Mıxas, $n^{0}$ 18389, Herbacé, fl. blanchâtres. Mars-atvil. R. 
12.2. Glechon squarrosa Benth.; Fl. Bras. VIII, I, p. 177. - Barra do liio Torto, dans les bourbiers, Goyaz, $n^{\circ} 21933$. Frutescent, ll. bleues. Mar's-il ril. C.

123. Gl. ciliata Benth.; Fl. Bras. VIII, I, p. 178. - Abbade, près Heia Ponte, dans le campo, Goraz, no $21933 a$. Herluacé, fl. blanchâtres. Aoùt-septembre. C.

12'. Sphacela speciosa St-Hil.; Fl. Bras. VIII, I, p. 198. - Itatiaia, dans le campo, Rio-Jax., nos 5972, 6661; Serra do Picú, Ayuruoca, Mivas, nos 9557, 11397. Bel arbuste, fl. roses. Janvier-février. CG.

12\%. Salvia uliginosa Benth.; Fl. Bras. VIII, I. p. 180. - Petropolis, au Norin dans le bois, Rio-Jax., n ${ }^{0} 15280$ a. Sous-frutescent, fl. rougeâtres. Mar's-avril. R.

126. S. arenaria St.-Hil.; Fl. Bros. VIII, I, p. ISI. - Serra dos Orgãos, versant de Petropolis. Rio-Jax., nos 8825, 15280, 16281. Sousfrutescent, fl. violettes. Janvier-févirier. C.C.

127. S. montana Gardn.; Fl. Bras. VIII, I, p. 182. - Serra dos Orgãos. au Ibuhỵ, Rro-Jax., ${ }^{\text {os }}$ 2890, 3709, 37010. Sous-frutescent, fl. rouges. Août-septembre. C.

128. S. secunda Bentlı.; Fl. Bras. VIII, I, p. 182. - Serra do Picú, au Paulo, Rio-Jan., no 16316 a. Sous-frutescent, fl. rouges. Mars-avril. C.

129. S. confertiflora Pohl; Fl. Bras. VIII, I, p. 183. - Petropolis. dans le bois, au Retiro, Ru-Jax., no 2649. Sous-frutescent, fl. rouges. Février-mar's. C.

130. S. rigida Benth.; Fl. Bras. VIII, I, p. 186. - Près d'Ipanema. dans les paiturages. S. Paulo, $n^{\circ}$ 13048. Sous-frutescent, fl. bleu céleste, Mars-avril.

131. S. brevipes Benth.: Fl. Bres. VIII, I, p. 187. - Serra de Ouro Branco, à São Juliĩo, Misas, no 18388 a. Sous-frutescent, fl. lilas. Mar'savril. $R$.

132. S. tomentella Pohl; Fl. Bras. VIII, I, p. 188. - Cachoeira do Rasgio, près Corumba, Goraz, n 21926. Sous-frutescent, fl. blanches. Aoùt-septembre. C.

133. S. asperifolia Benth.: Fl. Bras. VIII, I, p. 188. - Rancho da Marçal, près Sĩo Joâo d'El Rei, Mıxas, n 18388; Rio da Gama, As Brancas, dans le campo, Goraz, $\mathbf{1}^{\circ}$ 21927. Sous-frutescent, fl. rouges. Décembre-janvier. C.

13'. S. balaustina Pohl: Fl. Bras. VIII, I, p. 189. - Gandarela, dans le bois près des plantes fossiles, Misas, $n^{0}$ 15278. Sous-frutescent, fl. rouges. Juin-juillet. C. 
133. S. Mariana Mart.; Fl. Bras. VIII, I, p. 190. - Sitio, près Barbacena, dans le bois, Mtr.ss, $\mathbf{1}^{\circ}$ 11309. Sous-frutescent, fl. rouges. Juinjuillet. C.

136. S. salicifolia Polıl; Fl. Bras. VIlI, I, p 191. - Ouro Preto, à São Gonçalo dans le bois, Mtxas, $1^{\circ s} 15279,20427$ a. Sous-frutescent, f1. rouges. Février-mars. C.

137. S. Sellowiana Benth.; Fl. Bras. VIII, I, p. 1!12. - Serra do Picú, au Palmital, Rio-Jıv., no 11316. Sous-frutescent, fl. roses. Avrilmai. C.

138. S. splendens Sellow; Fl. Bras. VIII, I, p. 192. - Serra do Mar, au Frechal et cultivé, Rı-JAx., n ${ }^{\circ} 5954$. Sous-frutescent, fl. rouges. Janvier-mars. CC.

139. S. Benthamiana Gardn.; Fl. Bras. VIII, I, p. I93. - Alto Nlacahé de Nova Frihurgo et Serra dos Orgitos, Rio-JAx., nos 3708,4155 , 17233, 18387. Sous-frutescent. 11. rouges. Mai-juin. CC.

I40. S. corrulea lienth.; Fl. Bras. VIIl, I, p. I94. - Itatiaia, dans le bois pres Campo Bello, Rro-Jax., ${ }^{\text {os }} 4892$, 6650. Sous-frtitescent, fl. bleu rosé. Janvier-février. C.

141. S. coccinea Linn.; Fl. Bras. VIII, I, p. 196. - Quinta da Boa Vista, à Sĩo Christovão, liı-JAx., n 4966 Sous-frutescent, cultivé. Oetobre-novembre. C.

142. Scutellaria tubiflora Bentl.; Fl. Bras. VIII, I, p. 201. - Nova Friburgo, dans le bois, Rı-Jax., nº 14195. Herbacé, fl . rose-pâle. Janvierfévrier. R.

143. Sc. rumicifolia Kth; Fl. Bras. VIII, I, p. 203. - Riacho das Varas, dans le campo, Hovas, $n^{\circ} 19701$. Herbacé, fl. blanchâtres. Mar'sarril. C.

14'. Stachys arvensis I.; Fl. Bras. VIII, I, p. I97. - Restinga de Copacabana, Rio-Jax., $n^{0}$ 353. Herbacé, f1. Jlanchâtres. Juin-juillet. C.

145. Leonurus sibiricus L.; Fl. Bras. VIII, I, p. 196. - Floresta da Tijuca, Rro-JAx, , II 1488. Sous-frutescent, fl. roses. Juiliet-septembre. CG.

146. Leucas martinicensis R. Br.; Fl. Bras. VIll, I, p. 200. - Coreovado, à Paineiras, Rıo-J $\mathrm{JN}_{\mathrm{N}}, \mathrm{n}^{\circ}$ 1489. Herlıacé, f1. blanchâtres. Maijuin. C.

147. Leonotis nepetifolia R. Br.; Fl. Bras. VIII, I, p. 200. Caminho do Leme, à Botafogo, Rio-Jav., nos 354, 1490. Sous-frutescent, 11. rouges. Aoùt-septembre. CG. Vulg. : Cordào de frade.

148. Teucrium cubense L.; Fi. Bras. VIII, I, p. 203. - Congonhas do Campo, Mısas, $n^{\circ} 19701$ a. Sous-frutescent, fl. jaunâtres. Avril-mai. R . 
149. Teucrium inflatum Sw.; Fl. Bras. VIII, I, 1). 20)' - Mangaratiba, près de la mer, Rı-JAN., no 18415 . Sous-frutescent, 11. jaunâtres. Septembre-octubre. C.

\section{Fan. 103. - Plantaginées.}

1. Plantago major L.; Fl. Bras. VI, IV, p. 169. - Floresta da Tijuca et Siu Christovioo, Rı-JAx., n ${ }^{\circ}$ 7799, 12111. Herbacé, fl. blanchatres. Octohre-novembre. CC. Vulg. : Tanchagem.

2. Pl. coriacea Cham. et Schl.; Fl. Bras. VI, IV, p. 170. - Riacho das Varas, dans le campo, Mixas, $n^{\circ}$ 19748. Herbacé vivace, fl. blanchâtres. Avril-mai. R.

3. Pl. Decaisnei Burn.? in herb. Paris., Berol., Kew., Brux., etc. Itatiaia, au Tijuca près de la source du Rio Preto, Mıvas, $n^{\circ} 8897$. Herbacé vivace, fl. blanchâtres. Octobre-novembre. C.

4. Pl. Guilleminiana Dene; Fl. Bras. VI, IV, p. 17I. - Floresta da Tijuea et Corcovado, Rio-JAv., ${ }^{\text {os }} 3764,4940,7798$. Herb. vivace, fl. blanchâtres. Novembre-décembre. CC. Vulg. : Tanchagem.

5. Pl. tomentosa Lamk; Fl. Bras. VI, IV, p. 172. - Serra dos Orgãos, au sommet, Rı-JAx., $n^{\circ}$ 16360. Herhacé vivace, fl. blanchâtres. Janvierfévrier. R.

6. Pl. lanceolata L. Spec. Plant., 113. - Petropolis, au bord des chemins, Rı-J J ${ }_{\Lambda N}, n^{\circ}$ 15323. Herbacé vivace, fl. blanchâtres. Octobrenovembre. C.

\section{APÉTALES}

Fam. 104. - Nyctaginées.

1. Mirabilis divaricata Lowe; Fl. Bras. XIV, II, p. 3.50. - Santa Thereza, au Corcovado, Rio-JAx., $n^{\circ}$ 18417. Herbacé vivace, cultivé, fl. roses. Août-septembre. CC. Vulg. : Maravilha.

2. M. dichotoma L.; Fl. Pras. XIY. II, p. 33̈0. - Quinta da Boa Vista. São Christovĩo, Rio-Jav., $1^{\circ} 18417$ a. Herbacé vivace, cultivé, fl. roses, Juin-juillet. CC. Vulg. : Maravilha.

3. Boerhaavia paniculata Rich.; Fl. Bras. XIX. II, p. 369. - Floresta da Tijuca et Corcovado, Rı-Jax., $n^{\circ s} 4178,13113$. Herbacé, fl. roses. Octobre-novembre. CC. Vulg. : Herva tostão.

4. B. erecta L.; $F l$. Bras. XIV, II, p. 370. - Floresta da Tijuca et 
A.-F.-Y. GL.IZIOU. - LISTE DES PLANTES DU BRÉSIL CEMTRAL.

S. Christovĩo, Rio-Jax., nº 9961. Herbacé, fl. roses. Janvier-février. CC. Vulg. : Herva tostäı.

̈. Bougainvillea spectabilis Willd.; Fl. Bras. XIV, II, P. 350.mbitiba, pres de la mer, Corcovado. Pur-J.x., nos 131, 3804, 12113, 18421. Arbuste sarmenteux, 11. roses. Aoùt-septembre. C'C.

6. B. glabra Choisy; Fl. Bras. XIV, II, p. 3̈̈l. - ltamaraty, près Petropolis, Rio-Jax., $n^{\text {os }} 11417,13112$. Arbuste sarmenteux, f1. roses. Norembre-janvier C.

7. B. arborea Glaz. n. sp.? in herb., Paris., Berol., kew.. Gener., etc. - Nova Friburgo et Alto Macahé, Rio-Jax., 11² 2664, 4177, 12112. Grand arbre sans épines, ll. roses. Miai-juillet. C.

8. Pisonia aculeata L.; Fl. Bras. XIV, II, p. 3\%4. - Paralipba do Sul et Alto Nacahé, liı-dax., nos $8962,13114,19749$. Arbrissieau, 11. brunes. Septembre-uctobre. C. Vulg. : Tapaciribr.

9. P. Pacurero H. B. K.; Fl. Bras. XIV, II, p. 3\%̈. - Serra dos Oræãos, au Garrafĩo. Rio-JAx., nos 11414,11416 . Arbrisseau, fl. blunes. Septembre-octobre. C.

10. P. nigricans Sw. var. oblonga Choisy in DC. I'rodr. XIII, II, p. 4'43. Serra do Picú, au Palmital, Rio-Jax., nº 18419. Arbrisseau, fi. liruntes. tout-septembre. R.

11. P. Olfersiana Link, Otlo et Kl.; Fl. Bras. XIV, II, p. 3\%..Floresta da Tijuca et Serra do Tingua, Rio-JAx., n ${ }^{03} 2666,8090,9560$. Arbrisseau, fl. brunes. Ortobre-novembre. C.

12. P. minor Choisy; Fl. Bras. XIV, II, p. 3:6. - Floresta da Tijuca et aı Berquó, Rio-Jax, nos 754, 3081, 4965. Arbrisseau. fl. brunes. Octobre-novembre. C.

13. P. nitida Mart. in Fl. Bras. XIV, II, p. 3\%6. - Petropolis, au Retiro, Rịo-JAx., $11^{\circ}$ 3083. Arbre, fl. blanchatres. Octobre-novembre. R.

- Var. parvifola liart. in Fl. Bras. XIY, II, 1. 3̈̈̈. - Serra da Estrella et Floresta da Tijuca, Ro-Jax., n 3082. Arbrisseatu, f1. blanchatres. Octobre-novembre. C.

14. P. acuminata Mart. in Fl. Bras. XIY, II, p. \$ั̈. - Alo Macahe et Corcovado, Rio-Jax.. n ${ }^{\circ 5} 1358,2665,18418$. Arbrisseau, 11. brunes. Octolore-novembre. C.

1\%. P. humilis Glaz. 11. sp.? in lıerb. Paris., Berol., Kew., Genev., etc. - Furfuilha, aus Fornos, dans le cerrado, Goraz, ${ }^{\circ}$ 21960. Plante naine, fl. verdatres. Aoùt-septembre. R.

16. P. graciliflora Mart. in Fl. Bras. XIV, II, p. 3\%8. - Entre 
Sitio el Illeeos, dans le campo, Musas, $1^{0}$ 11415, Arbuste, fl. rousses. Septembre-ortobre. C.

- Var. suberrugenosa Mart. in Fl. Bras. XIV, II, p. 3\%8. - Macacos, an Horro dos Cristaes, Goyaz, n" 21958. Arbrissealu, ll. brunes. Octobrenovembre. C.

17. Pisonia Cafferiana Casar.; Fl. Bras. XIY, II, p. 3388. - Corcovado, à Paineiras, Rı-Jax., $\mathbf{u}^{04} 755,1359$. Arbrisseau, ll. brunes. Juin-juillet. C.

18. P. campestris Netto: Fl. Bras. XIV. II, 339. - Piracicaba, dans le campo, Säo Paduo, no 16307. Arbuste, fl. brunes. Février-mars. R.

19. P. subcordata Sw. Fl. Bras. XIV, II, p. 361. - Restinga the Copacabima, Rio-Jax., $11^{05} 4,1360,4176$. Arbuste, fl. brunés. Janvierfévrier. CG.

20. P. obtusata Sw.; Fl. Bras. XIV, II, p. 361. - Entre Mlagé et Barreira do Rio Soberbo, Rio-JAN., $1{ }^{\circ}$ 2897. Arbuste, ll. lorunes. Septembre-octusie. C.

21. P. psammophila Nart. in Fl. Bras. XIV, II, p. 362. - Fazenda de Santa Cruz, Rin-Jax., $n^{\circ}$ 6146. Arbrisseau, fl. brunes. Octobrenovembre. C.

22. P. hirsuta Choisy; Fl. Bras. XIV, II, p. 363. - Morro do Inficionado, près Caraça, et Serra da Piedade, Hıxas, $1^{08} 15351$, 20433. Arbuste, f1. rousses. Juillet-aont. C.

23. P. tomentosa Cilsar.; Fl. Bras. XIV, II, p. 363. - Serra do Lenheiro, près São João d'El Rei, Mıvas, nos 15350, 17176; Chapadinha, Goyaz, nº 21959. Arbre, ll. brunes. Oetobre-novembre. CG. Vulg. : Páo juden et Prio de lepra.

2'. Neea theifora Oersted; Fl. Bras. XIV, II, p. 36\%. - Santa Luzia do Rio das Velhas, dans le campo, Mrvas, n² 20434. Arbuste, fl. brunes. Novembre-décentbre. C. Vulg. : Caparos.

25. N. rufula Mart. in Fl. Bras. XIV, II, p. 368. - Corcovado, à Paineiras, Rı-JAx., nos $1110,6664,6665$. Arbrisseau, fl. brunes. Marsavril. C.

26. N. Glaziovii Heimerl 11. sp.? in herb. Paris., Berol., Kew., Haun., ete. - Fazenda da Limeira, au pied du Tingua, Rı-Jax., $\mathrm{n}^{\circ}$ 9559. Arluste, ll. rousses. Octobre-novembre. R.

27. Reichenbachia caniflora Mart.; Fl. Bras. XIV, II, p. 372. Morro da Viração, à Piratininga, Rı-Jax., $n^{\text {os }} 3749,13115,18420$. Arhuste sarmenteus, fl. verdatres. Hars-avril. C.

98. Ramizia brasiliensis Glaz. apud Baill. in Bullet. Sociélé Linr. de Puris (1887), p. 697. - Entre São Vicente et S. Barllolomeu, Mhas, 
110s 14221, 15385: Larangeiras, pres Cantagallo, Rı-JAx, n n 16320. Grand arbre, fl. verdâtres. Hars-arril. C.

99. Andradæa floribunda F. All. : Fl. Bras. XIV, II, p. 3T1. Alto Macahé de Nova Fribur@o, liso-Jax., n ${ }^{0} 13115$ a. Grand arbre. f1. blanclàtres. Mars-avril. R. Vulg. : Tapaciriba. Marmelada, Cabello de neyro.

\section{Fam. 10ä. - Illécébracées.}

1. Acanthonychia ramosissima Rohrb. in Fl. Bras. XIV, II, P. 2̇?.?. - Angra dos Reis, près de la mer, Rio-Jax., nº 19399. Herbacé, fl. blanchâtres. Aoùt-septembre. C.

2. Paronychia camphorosmoides Camb. in Fl. Bras. XIV, II, p. Zül. - Serra da Pierlade, dans le campo, Mrss, n²0336. Herbacé, f1. blanchatres. Norembre-décembre. C.

3. P. chilensis DC.; Fl. Bras. XIV, II, 1. 202. - Curalinho, près Diamantina, Mrxs, no 19400. Herbacé, f1. blanchâtres. Avril-mai. C.

4. P. brasiliana DC.; Fl. Bras. XIV, II, 1. 2033. - Piracicaba, dans le campo, São Paulo, nos 16357, 19398. Herbacé, fl. blanchâtres. Marsavril. C.

̋̈. Polycarpon depressum Rohrb.? in Fl. Bras. XIV, II, p. 20̈7. Barra da Lagoa Feia, près Formosa, Goraz, nos 21961, 21962. Herbacé, fl. blanclıes. Novenbre-décembre. CC.

\section{Fam. 106. - Amarantacées.}

1. Celosia grandifolia Moq.: Fl. Bras. V, 1, p. 244. - Floresta da Tijuca, Pio-JAx.. n ${ }^{\circ}$ 6096. Sous-frutescent, 11. blanchàtres. Octobrenovembre. C.

2. C. longifolia Mart.; Fl. Bras. V, I, p. 29̈. - Serra do Mar, à Palmeiras et à Rodeio. Riı-Jix., no 8903. Sous-frutescent, fl. blanchàtres. Septembre-octobre. C.

3. Chamissoa altissima H. B. K. ; Fl. Bras. V, I, P. 242. - Petropolis, à Itamaraty, Rio-JAx, ${ }^{\text {os }} 2667,8902$; Ipanema, clans le bois, S. Paulo, nos 11423. 13120. Sous-frutescent, fl. blanc jaunâtre. Marsavril. C.C.

4. Ch. Maximiliani Mart.; Fl. Bras. V, I, p. 242. - Floresta da Tijuca et Curcovado, Riso-Jax., nos 871,11419 . Sous-frutescent, h. blanchâtres. Janvier-férrier. C. 
3. Chamissoa acuminala Viart.; Fl. Bras. V, I, P. 243. - Corcoviado, à Paineiras, Rio-Jar., $11^{\circ}$ 3084. Sous-frutescent, ll. blanchattres. Nlars-avril. C.

6. Amarantus flaulus L.; Fl. Bres. V, I, p. 238. - Fazenda do Horro Azul, dans la capoeira, S. Padro, $n^{\circ} 13121$ a. Herbace, fl. blanc jaunàtre. Mai-juin. C. Vulg. : Carurú do mallo.

7. A. chlorostaclyys Willd.; Fl. Bras. V, I, p. 239. - Quinta da Boa Vista, à Sĩo Christovĩo, Rio-JAn., $1^{\circ 8} 6012$, 13121. Herbacé, fl. blanchàtres. Octobre-novembre. GC. Vulg. : Carurú.

8. A. spinosus L. ; Fl. Bras. V, I, p. 239. - Entre Araruama et Cabo Frio, Rio-Jax., nº 11422. Herbacé, fl. blanchàtres. Février-mar's. R.

9. A. Blitum Iloq.; Fl. Bras. V, I, p. 240. - Oninta da Boa Vista, São Christovĩo, Rio-Jax., nº 6011. Herbacé, fl. blanchâtres. Octobrenovembre. CG. Vulg. : Carurú.

10. Telanthera pliiloxeroides Mor.; Fl. Brus. V, I, p. 169. - Restinga de Copacabana, Rio-JAx., $n^{\circ}$ 741: Rio Manso, dans les plaines humides, Mnas, no 14202. Herbacé, fl. Blanches. Juin-juillet. C.

11. T. proclonga Noq. : Fl. Bras. V, I, p. 170. - Praia de Sepitiba, près Santa Cruz, Rio-Jax., no 9562. Herbacé sarmenteux, fl. blanc jannâtre. Novembre-décembre. C.

12. T. maritima Hoq.; Fl. Bras. V, I, p. 170. - Praia do Arpoador, près de la mer, Rio-Jax., $1^{\circ}$ 1394. Herbacé sarmenteux, fl. Hanchâtres. llars-avril. G.

13. T. polygonoides Moq.; Fl. Brus. Fazenda de Santa Cruz, Rı$J_{A x}, n^{\circ} 8486$. Herbacé sarmenteux, fl. blanches. Mai-juin. CG.

- Var. radicans Moq., Fl. Bras. V, I, p. 173. - Sant'Amna dos Ferros, dans le bois, Mrxas, $n^{0 s} 11429,11432,13118$. Herbacé sarmenteux, fl. blanches. Mars-avril. C.

14. T. Regelii Seub. in Fl. Bras. V, 1, p. 117. - Morro Cavalo, à la Fazenda do Taquaral, Misas, $n^{\circ} 7805$. Herbacé sarmenteux, fl. blanches. Août-septembre. C.

13. T. rufa lloq.; Fl. Bras. V, 1, p. 177. - Fazenda lo Taquaral, dans le bois, Nixas, no 10014 a. Herbacé, ft. Blanc jaunâtre. Aoùt-septembre. R.

16. T. brasiliana Hoq.; Fl. Bras. V, I, p. 180. - Floresta da Tijuca, près du Pico, Rio-Jax., nº 1422. Herhacé, fl. blanclıes. Ilai-juin. C.

17. T. Moquini Webb. ; Fl. Bras. V, I, p. 180. - Serra da Estrella, à Hamminha, Rı-Jax., $n^{\circ}$ 10014. Herbacé, fl. blanches. Septembreoctobre. C. 
A.-F.-M. GLAZIUU, - LISTE DES PLANTES DU BRESIL CEXTRAL.

18. T. dentata Vlog.; Fl. Bias. V, I, p. 181. - Serra do Picú, près de Barreira, liı-JAx., nº 11418 . Sous-frutescent, fl. blanc jaunâtre. Arrilmai. C.

19. Alternanthera achyrantha R. Br.; Fl. Bras. V, I, p. 184. Fazenda de Santa Ciruz, Rio-JAx., $n^{0} 8088$. Herbacé, fl. blancliâtres. Nars-avril. CC.

- Val. ceraxtha Moq. Fl. Bras. V, I, p. 183. - Dianantina au Tumbador, dans le campo, Mısas, $n^{\circ}$ 19753. Herlbacé, fl. blanclıâtres. Marsavril. R.

20. A. sessilis R. Br.: Fl. Bras. V, I, p. 184. - Quinta da Boa Vista, à Sĩo Christoväo, Rio-Jax.. $1^{0 \mathrm{~s}} 3791,5974$. Herbacé, fl. blanches. Juinjuillet. CC.

21. A. paronychioides St-Hil.; Fl. Bras. Y, I, 1. IS̈. - São Vicente de Paulo, près Cabo Frio, Rio-Jax., nº 1395. Herbacé, fl. blanches. Février'mal's. C.

2.2. A. Bastosiana Glaz. 1. sp.? in herl. Paris., Berol., Kew., Gener., elı. - Serra de Sĩo José d'El Rei, dans le campo, Mixas, $11^{\text {os }}$ 16308. 19756. Herbacé, fll. blanches. Décembre-janvier. C.

23. A. pinheirensis Glaz. n. sp.? in herb. Paris., Berol., Kew., Gener., elc. - Pinheiro, près Dianantina, dans le campo, Mrras, no 19755. Herbacé. fl. blanchâtres. Avril-mai. C.

2'4. A. aphy Ia Glaz. n. sp. ? in herb. Paris., Berol., Kew., Brux., ete. - Serra das Cristaes, près Diantantina, Mrsas, $n^{\circ}$ 19754. Sous-flutescent, 11. blanchîtres. Mars-avril. R.

9.3. Gomphrena glauca Moq.; Fl. Bras. V, I, p. 190. - Boa Vista all bord du lio Parahyba, et Serra do Picú. Rıo-Jas., nos 13119, 13122 , 14201. Sous-frutescent, fl. blanches. Juin-juillet. C.

26. G. paniculata Mror.: Fl. Bras. V, I, p. 191. - Sĩo Goncalo,

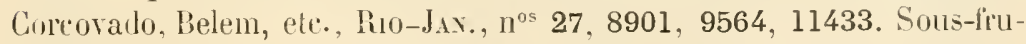
tescent, ft. blanches. Aoit-septembre. CC.

27. G. ericutha Mor.: Fl. Bras. V, I, 1. 192. - Serra da E-trella, Rio-Jax.. no 9563; São Joào Baptista, dans le bois. Mrsus, $11^{\text {os }} 13116$, 13117. Sous-frutescent, fl. blanchâtres. Juin-juillet. C.

98. G. pulverulenta IInq. ; Fl. Bras. V, I. p. 193. - Petropolis, à Sallo Antonio, dans le bois, Rio-JAx., nos 1393, 7804. Sous-firutescent. fl. blane jaunatıe. Jnin-juillet. C.

29. G. denudata Mor.; Fl. Bras. V, I, 1. 19:). - Cabeceiras do liio Gama, au Coloulbista, Goriz, $u^{\circ}$ 21970. Herbacé, fl. blanches. Septembreoctobre. C. 
30. Gomphrena grisea Lopr. in Englel Bolan. Jahrt. XXX (1901),

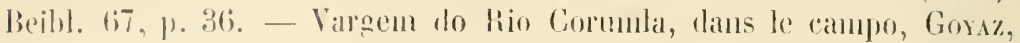

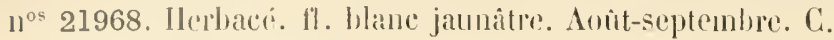

31. G. tuberosa Mn+. ; Fl. IBras. V, I, p. 19:3. - Collina do Ypiranga, S. Pat lo, no 16309 a. Herbacé, fl. buanches. Février-mar's. Ri.

32. G. jubata Mor.; fl. Bras. V, I, p. 196. - Ribeirão de Caldas, au Pouso Nlexandre, Goraz, n² 21967. Herbacé, fl. blanches. Juillet-septembre. C.

39. G. Jelutina Mlor. ; FI. Bras. V, I, p. 197. - Serra do Batatal ou do Capanema, Mrsus, no 15353 a. Herbacé, f1. blanchâtres. Juin-juillet. R.

34. G. cinerea Noy. in DC. Prodr. XIII, II, p. 390. - Nacacos, à Chico Custa, dans le campo, Goyaz, $n^{\circ}$ 21969. Herlacé, fl. blanchâtres. Octobre-nevembre. C.

33. G. lanata Poir. var.: F\%, Bras. V, I, 1. 197. - Campos da Bocaina, à Vacca Cahio, São Paclo, $n^{\circ}$ 10018. Herlacé, fl. blanches. Mars-avril. R.

36. G. gnaphalioides Vahı; Fl. Bras. V, I. p. 198. - Ouro Branco, à São Julião, Mrxas, $n^{\circ}$ 18424. Herbacé. M. blanches. Hars-avril. C.

37. G. vaga Hart.; Fl. Bras. V. I, p. 203. - Restinga de Copacabana. Rio-Jax., $1^{\circ}$ 5790. Sous-frutescent, fl. blanchàtres. Juin-juillet. C.

38. G. holosericea Hoq.; Fl. Bras. Y, I, p. 204. - Copacabana et Corcovado, Rio-Jav., nº 28. Sous-frutescent. fl, blane jaunatre. Févriermars. G. Vulg. : Sedinha.

39. G. elegans Mart.; Fl. Bras. V, I, p. 200̈. - Pinheiro, près Yuiranga, São Patlo, $n^{0 s} 11430,16309$. Herbacé, fl. blanches. Féviermars. C.

40. G. rudis Moq.; Fl. Bras. V, I. p. 206 . - D'Ouro Preto à Congonlas, Mıxas, $n^{\circ} 15352$. Herbacé vivace. Juin.

41. G. chloromalla Lopr. in Engler Bot. Jahrb. XXX (1901), Beibl. 67, p. 36. - Entre OHho d'Agua do Vente et Cocal, no Chapadão rlos Veadeiros, Goraz, $n^{\circ}$ 21972. Sous-frutescent, bulbeux. Octol)renovembre. C. Vulg. : Infahlivel.

42. G. scapigera Mart.; Fl. Bras. Y. I, p. 211. - Serra do Batatal ou do Capanema, $M_{\mathrm{Ivas}}, \mathrm{n}^{\text {os }} 15353,18425,19750$. Herbacé, f1. blanchâtres. Juin-juillet. C.

43. G. agrestis Mart.; Fl. Bras. V, I, p. 219. - Serra do Lenlieiro, près S. João d'El Rei, Mivas, $n^{\text {os }} 17207,17208,19751,20436$. Herbacé, 11. Jlanchâtres. Mars-avril. G. 
1.-F.-M. GLAZIOU. - LISTE DES PLAYTES DL IBRESL CENTRAL.

4́. G. rigidula Glaz.n. sp.? in lert, Paris.. Berol.. Kew., Genev, etc. - Entre Barbacena et liesicca, dans le campo, Mtsas, no 10016. Herbacé. fl. lolanc jaunàtre. Juin-juillet. C.

43. G. Riedelii Seub. in Fl. Bras. V. 1, P. 2Iㄹ. - Serra Dourada, près le Rio do Indios, Gomaz, $n^{\circ} 21973$. Herbacé bulbeux. fl. blanshes. Aoùt-septembre. C.

46. G. depauperata Glaz. sp. n.? in herb. Paris., Berol.. Kew., Genev, efle. - Serra dos Purys, Espinito Sayto, nos 10017 , 11428. Herbacé. fl. blanc jaunâtre. Octobre-norembre. C.

47. G. erincalyx Lopr. in Engler Lot. Jahro. XXX 1901), Beibl. 67, p. 37. - Entre Fazenda Bolivia et Herrulano Lobo. dans le campo, Goyaz, $n^{0}$ 21974. Bulbeux virace, f1. blanchâtres. Juin-juillet. CG. Vulgr.: Ifalhivel.

48. G. virgata Mart.; Fl. Bras. V, 1, p. 219. - Rio Gama, dans le rampo. Goyaz, ${ }^{\text {os }} 21971$. Virace bulbeux, fl. jaunattres. Octobre-novembre. C. Vulg. : Ifalhivel.

49. G. officinalis Mart.; Fl. Bras. V, I, p. 213. - Serra do Lenheiro et Ilheos, dans le campo, Mrsas, nos 16310,17749 . Herbacé virace, 11. orangées. Janvier-décembre. CC. Yulg. : Paratudo, Perpetua.

̈0. G. macrocephala St-Hil.; Fl. Bias. V, I. p. 214. - Entre Ipanema et Sormaba, dans le campo. S. Pacto, $1^{\circ} 16310$ a. Herbacé, 11. urangées. Juin-juillet. C. Vulg. : Paraludo, Ruiz do P'adie Salemo.

ว̈L. G. aurea Lopr. in Engter Bot. fuhrb. XXX (1901), Beibl. 67, p. 37. - Serra dos Vertentes, Mlsas, $n^{0} 20435$; Entre Pedro Sardinha et As Antas, dans le campo, Goraz, $\mathbf{1}^{\circ} 21966$. Herbace virace, fl. jaunes. Aoüt-septembre. C.

:20. G. leucocephala Mart.; Fl. Bras. V. I, p. 22I7. - Páo d'Alho, dans le campo, Espiruto Sixto, ${ }^{05} 10020,11431$. Herbacé, fl. blanches. Mai-juin. C.

58. G. celosioides Mart.; Fl. Bras. V, I, p. 218. - Piio d'Alho, dans le campo, Esproto Saxto, no 11425 . Herbacé, fl. blanches. Juin-juillet. C.

ớt. G. aquatica Glaz. n. sp.? in herb. Paris., Berol.. Kew., Gener.. etc. - Entre João et Sitio, dans les grands hourbiers. Misas, $11^{\text {os }} 10021$. Herbacé, fl. blanches. Juin-juillet. li.

כั. Iresine vermicularis Mor.; Hl. Bras. V. I, p. 22ב马. - Entre Lagoa Rorlnigro de Freitas et la mer, Rio-Jax., ${ }^{05}{ }^{\circ}$ 11426, 18422, 18422 «. Herbacé sarmenteux. f1. blanches. Juin-juillet. CG.

:6. I. polymorpha Nart.; Fl. Bras. V, I, p. 22206. - Serra da Itaba- 
poana. dans le rimpo, Espirito $S_{A N T}$, $n^{o s} 11420,11421$. Sous-frutescent, ft. blanc jaunàtre. Février-mars. C.

37. I. diffusa Hunl. et Bonpl.; Fl. Bras. V, I, p. 227. - Serra da Estrella, pres Petropolis, Rio-Jas., no 4953. Sous-frutescent, il. blanches. Février-mar's. Ci.

58. I. spiculigera Seub. in Fl. Bras. V, 1, p. 228. - Serra dos Orgaîs, an Rio Soberbo, dins le bois, Rio-JAN., $n^{0} 1601$. Sous-frutescent, fl. blanches. Octobre-novembre. R.

59. 1. Herbstii llook.; Fl. Bras. V, I, p. 228. - Petropolis, à Quitaudinha, Rio-dax., $1^{\circ}$ 18423. Sous-firutescent, cultivé, fl. blane jaunâtre. Juin-juillet. C.

\section{Fam. 107. - Chénopodiacées.}

1. Chenopodium murale L.; Fl. Bras. V, I, p. 144. - Colline de Copacabana, entre les pierres, Rı-Jax., nº 4179. Herbacé, fl. verdâtres. Octobre-novembre. GG. Vulg. : Herva de Santa Maria.

2. Ch. ambrosioides L.; Fl. Bras. V, I, p. 149. - Tijuca, dans Ies capoeiras, Rio-Jar., ${ }^{0 s} 3085$, 9566. Herbacé, fl. verdâtres. Octobrenovembre. CC. Vulg. : Herva de Santa Maria.

3. Ch. spathulatum Siel.; Fl. Bras. V, I, p. 146. - Entre Aldea de Sĩo Pedro et Lagoa do Peixe, Rio-dax., no 13124. Sous-frutescent, fl. blanchâtres. Septemlre-octobre. CC.

4. Ch. retusum Juss.; Fl. Bras. V, 1, p. 148. - Restinga de Cabo Frio, près de la mer, Rio-Jax., no 11435 . Herbacé, 11. verdâtres. Aoùtseptembre. R.

5. Obione montevidensis Moq.; Fl. Bras. V, 1, p. 154. - Sitio, près Barbacena, Mrnas, $n^{\circ} 11436$; Restinga de Cabo Frio, Rio-Jan., $\mathrm{n}^{\circ}$ 13123. Herbacé, fl. blanc jaunitre. Juillet-septembre. C.

6. Salicornia Gandichandiana Moq.; Fl. Bras. V, I, p. $156 .-$ Plaia de Maria Angú et Cabo Frio, Rio-Jax., no 8086 . Herbacé, fl. verdittres. Aonit-septembre. C.

7. Basella rubra L.; Species Plant., p. 272. - Quinta da Boa Vista, São Christovão, Rı-Jax., no 12183. Liane herbacée, fl. roseśs. cultivée. Juin-juillet. C.

8. Boussingaultia baselloides. H. B. K. Nova gen. et sp. VII, p. 196. - Serra de José Vaz et Pico de Santa Cruz, Rio-Jav., ${ }^{o s}$ 6996, 8008. Liane herbacée, fl. blanches. Mars-avril. C. 
Fam. 108. - Phytolaccacées.

1. Rivina humilis L.; Fl. Bras. XIV, II, p. 336. - Restinga de Copacabana, Rio-JAx., n' ${ }^{\circ 5} 3908,13128$. Sous-frutescent, 11. rougeâtres. Aoùt-septembre. C.

2. Mohlana nemoralis Nart.; $\mathrm{Fl}$. Bras. XIV, 11, p. 388. - Fazenda de Santa Cruz, Rio-Jav., $n^{o s} 9565,11437$. Sous-frutescent, fl. blanc jaunàtre. Novembre-décembre. G.

3. Petiveria alliacea L.; Fl. Bras. XlV, II, p. 332. - Floresta da Tijuca, Rio-JAx., $n^{o s}$ 10025, 13129. Sous-frutescent, 11. blanchâtres. Octobre-novembre. C. Vulg. : I'ipi.

4. P. hexaglochin Fisch. et Mey.; Fl. Bras. XIV, II, p. 333. Serra da Estrella, près Petropolis, Rio-J AN., $^{\circ}$ 4180. Sous-frutescent, fl. blane jaunâtre. Férrier-mar's. C. Vulg. : Pipi.

๖. Microtea maypurensis Don; Fl. Bras. XIV, II, p. 339. - Curimatahy, dans le campo, Mrisas, $n^{\text {os }} 11440,15355$. Herbacé, fl. blanches. Janvier-février. C.

6. M. paniculata Hoq. ; Fl. Bras. XIV, II, p. 340. - Serra de São José d'El Rei, Minas, ${ }^{\circ s}$ 4947, 16311. Herbacé, fl. blanc jaunâtre. Novembre-décembre. G.

7. M. glochidata Hoq.; Fl. Bras. XIV, II, p. 340. - Curimatahy, dans le bois, Mıvas, $n^{\circ} 13127$. Herbacé, fl. blanches. Janvier-février. C.

8. M. tenuifolia Noq.; Fl. Bras. XIV, II, p. 3ł1. - Serra dos Vertentes, près Oliveira, Mrsas, ${ }^{o s}$ 17748, 20437. Herbacé, fl. blanches. Juin-juillet. C.

9. Seguiera Langsdorffii Moq.; Fl. Bras. XIV, II, p. 329. - Alto Nacahé et Petropolis, Rio-JAx., $n^{0 s} 3864,5729$, 8259. Arlıuste, fl. blanchâtres. Janvier-février. C. Vulg. : Limäo do Matto.

10. S. americana L.; Fl. Bras. XIV, II, p. 330. - Curimatahy, dans les bois, Minas, $n^{\circ}$ 13]26. Arbre, fl. blinches. Février-mars. G.

11. S. floribunda Benth.; Fl. Bras. XIV, Il, p. 330. - Rio, Passeio Publico, Rio-Jax., $n^{\circ}$ 5730; Fazenda Cachoeira et Juiz de Forá, Mixas, $n^{0 s} 2488,8260,11438$. Arbuste, fl. blanc jaunâtre. Férrier-mars. CG.

12. Gallesia Gorazema Hoq.; Fl. Bras. XlV, II, p. 331. - Fazenda de Sant' Anna, près Juiz de Forá, Misas, nos 3671 , 13125; Copacabana, liı-Jax., n 4753. Grand arbre, fl. blanchàtres. GC. Vulg. : Báo d'Atho.

13. Pircunia dioica Moq.; Fl. Bras. XIV, II, p. 341. - Rio Grande 
et rultivé au Passeio Publico, Rho-dAx., 110 1612. Grand arbre, ll. blanrhes, fruit noir. Anùt-septembre. G. Vulg. : Umbú.

14. Phytolacea thyrsiflora Fenzl; Fl. Bras. XIV, II, p. 343. Quinta da Boa Vista, São Christovĩo, Rı-JAx, 110 1612 a. Herbacé, ll. blanc jaunâtre, cultivé. Juillet-anùt. C.

13. Ph. decandra L.; Fl. Rras. XIV, II, p. 343. - Serra dos Orgĩos, Rio-Jav., $1^{\circ}$ 6095; Rio Manso, dans le bois, Misas, no 15354. Sous-frutescent, fl. blanc jaunâtre. Octobre-novembre. CG.

16. Agdestis clematidea Moc. et Sessé in DC. Syst. Nat. I, p. 343 (1818). - Praia Grande, à Icaralıy, Rio-Jav., nº 12114. Liane herbacée, 11. blanches, cultivée. Janvier-février. R.

\section{Fan. 109. - Polygonacées.}

1. Rumex obtusifolius Linn.?: Fl. Bras. V, I, p. 9. - Serra dos Orgãos, à Theresopolis, Rı-Jax., no 13131 a. Herbacé, fl. llanehlâtres. Juin-juillet. R.

2. R. pulcher L. \%; Fl. Bras. V, I, p. 8. - Gavea et Tijuca, dans les terrains incultes, Rı-JaN., $\mathrm{n}^{0} 1019 a$. Herbacé vivare, fl. verdittres. Janvier-février. C.

3. R. crispus L.; Fl. Bras. V, I, p. 10. - Jacarepagua, dans les boulbiers, Rio-Jax., nos 1019, 13131. Herlacé vivace, fl. blanchâtres. Juin-juillet. CC.

4. Polygonum dinspyrifolinm Cham. et Schl.; Fl. Bras. V, I, p. 12. - Tripuly, prís Ouro Preto, Misas, $n^{\circ}$ 20440. Herbacé vivace, Il. rousses. Novembre-décembre. C.

¿. P. hispidum H. B. K.; Fl. Brus. V. I, p. 12. - Congonhas do Campo, dans les bourbiers, Mıvas, ${ }^{0 s} 13132,14222$. Herbacé vivace, fl. rousses. Mars-avril. CG.

6. P. spectabile Vart.: Fl. Bras. V, I, p, 13. - Serrád dos Oręâos, à Barreio do Solverbo, Riı-JAx., $11^{05} 4905,5975,11448$, 19757. Herbacé vivace, fl. rousses. Novembre-décembre. CG. Vulg. : Hera do Bicho.

7. P. acuminatum H. B. K. : Fl. Bras. V, I, p. 14. - Juiz de Fora, dans les terrains incultes, Mriss, $n^{\circ}$ 2668; Rasgão, près Corumbi, Goyaz, $n^{\circ}$ 21975. Herloacé vivace, ll. rousses. Norembre-décembre. C.

8. P. acre H. B. K.; Fl. Bras. V. 1, p. 18. - Entre Ouro Proto et Marianna, Mrvıs, nos 11449 , 13133. Herbacé vivace, fl. rousses. Maijuin. C. 
9. P. hydropiperoides Hichx; Fl. Bras. V, I, p. 17. - Restinga de Mauá, dans les bourbiers, Rı-Jav., nº 740 . Herbacé vivace, fl. blanchâtres. Février-mars. R.

10. P. Meisnerianum Cham. et Schl.; Fl. Bras. V, I, p. 19. Guaratingueta, dans les buurbiers, Säo Paulo, no $11449 a$. Herbacé vivace, f1. rousses. Hars-avril. R.

11. Muehlenbeckia sagittifolia Meisn.; Fl. Bras. V, I, p. 4\%. Angra dos Reis, dans les broussailles, Rio-Jax., no 11444 a. Petite liane, fl. blanchâtres. Juin-juillet. R.

19. Coccoloba crescenticefolia Cham.; Fl. Bras. V, I, p. 26. Haut du Corcovalo et Tijuca, Rio-Jax., nos 143, 1382, 6013. Grosse liane, fl. blanc jaunâtre. Aoùt-septembre. C.

13. C. douradensis Glaz. n. sp.? in lıerb. Paris., Berol., Kew., Brux., ete. - Serra Dourada, dans le bois, Goraz, $n^{\circ}$ 21978. Arbuste sarmenteux, fl. blanthes. Aoùt-septembre. C.

14. C. polystachya Wedd. var. glabra Lind. in Engl. Bot. Jahrb. XIII (1890), 1. 133; Fl. Bras. I, I, p. 133. - Uva, en bas de la Serra Dourada, dans le bois, Goyaz, $n^{\text {os }} 21980,21980$ a. Arbuste sarmentenx, t1. blanc jaunâtre. Aoùt-septembre. C.

-- Var. pubescens Lindau in Engler Bot. Jahrh. XIII (1890), 1. 133. Curvello, dans le bois, Misas, $n^{\circ} 11447$. Arbuste sarmenteux, 11. blanc jaunàtre. Août-septembre. C. Yulg. : Caucassú.

15. C. latifolia Lamk; Fl. Bras. V, I, p. 43. - Restinga de Cabo Frio, dans les petits bois, Rio-JAs., $n^{\text {os }} 11446$, 19768. Arbuste sarmenteux, fl. blane jaunditre. Février-mars. C.

16. C. acrostichoides Cham.; Fl. Bros. V, I, p. 33. - Caraça, au Morro Carapuça, dans les petits lıois, Mixas, $n^{0 s} 15356,19765$. Arbuste, 11. blanches. Juin-juillet. C.

17. G. Senæi Lindau n. sp. in herb. Paris., Berol., Kew., Gener., ete. - Rio dos Pedras, au Valu, Mıxas, $1^{\text {os }} 19762,19763$. Arluste sarmenteux, fl. blanchâtres. Avril-mai. C.

18. C. Glaziovii Lind. in Engler Bot. Jahrb. XIII (I890), p. I63. Serra da Estrella, près Petropolis, Rı-Jax., nos 3087, 8089. Arbuste sarmenteux, fl. blanc jaunattre. Janvier-férrier. C.

19. C. crlindrostachya Lind. in Engler Bot. Jahrb. XIll (I890, p. 163. - Serra da Mantiqueira, à João Gomez, Mixas, no 13135. Arbuste sarmenteux, fi. blanc jaunâtre. Février-mars. R.

20. C. declinata Mart.; Fl. Bras. V, I, p. 29. - Cosme Velho, à 
Larangeiras, Rı-JAN., $11^{\circ}$ 3089. Arbuste sarmenteux, fl. blanchâtres. Novembre-décembre. C.

21. Coccoloba ocreolata Wedd.; Fl. Bras. V, I, p. 40. - Serra dos Orgãos, à Theresopolis, Rı-Jav., $\mathrm{n}^{\text {os }} 3088$, 18428. Arbuste sarmenteux, fl. blanc jaunâtre. Juin-juillet. C.

22). C. fastigiata Meisn. in $\mathrm{Fl}$. Bras. V, I, p. 34. - Realengo, près Sapopemba, Rio-Jan., $\mathrm{n}^{\circ \mathrm{s}} 7888,11441$. Arbuste sarmenteux, fl. blanc jaunâtre. Février-mars. C.

23. C. parvifolia Schott; Engler Bol. Jahrb. XIII (1890), p. 175ั. Restinga de Cabo Frio, près de la mer, Rio-Jav., n 19766 . Arbuste sarmenteux, fl. blanc jaunâtre. Novembre-décembre. C.

24. C. grandiflora Iind. in Engler Bot. Jahrb. XIII (1890), p. 175. - Alto Macahé de Nova Friburgo, Rio-JAs., nos 14217, 20439. Arbuste sarmenteux, fl. blanches. Février-mars. C.

25. C. salicifolia Wedd.; Fl. Bras. V, I, p. 204. - Larangeiras et Lagoinha, au Corcovado, Rю-JAN., ${ }^{\text {os }} 3086,3090$. Arbuste sarmenteux, fl. blanchâtres. Janvier-février. C.

26. C. peltata Schott; Fl. Bras. V, I, p. 39. - Corcovado, au Sylvestre, Rı-JAN., $n^{\circ}$ 144. Grande liane, fl. hlanchâtres. Février-mars. R.

27. C. sticticaulis Wedl.; Fl. Bras. V, I, p. 28. - Faria, près Sabara, dans le bois, Minas, $\mathrm{n}^{\text {os }} 18427,21979$. Arbuste sarmenteux, fl. lanc jaunâtre. Janvier-février. C.

28. C. lavis Casar. in Fl. Bras. V, I, p. 41. - Restinga d'Itapemi$\therefore$, Espirito Santo, $\mathrm{n}^{0} 11445$. Arbuste sarmenteux, fl. blanc jaunâtre. Février-mars.

29. C. laxiflora Lind. in Engler Bot. Jahrb. XIII (1890), p. 191. Restinga d'Itapemirim, Espirito Santo, $n^{\circ}$ 11444. Arbuste sarmenteux, fl. blanc jaunâtre. Février-mars. R.

30. C. pipericarpa Mart.; Fl. Bras. V, I, p. 32. - Curimatahy, dans le campo, Mısas, $n^{\circ}$ 15357. Arbuste sarmenteux, fl. blanchâtres. Février-mars. G.

31. C. ramosissima Wedd.; Fl. Bras. V, I, p. 11. - Serra do Caraça, dans le bois, Mıxas, $\mathrm{n}^{\circ}$ 19767. Arbuste sarmenteux, fl. blanchâtres. Juin-juillet. C.

32. C. populifolia Wedd.; Fl. Bras. V, I, p. 40. - Restinga de Copacabana, Rio-Jan., $\mathrm{n}^{0 \mathrm{~s}}$ 49, 4208. Arbuste sarmenteux, il. blanc jaunâtre. Janvier-mars. G.

33. G. erecta Glaz. n. sp.? in herb. Paris., Berol, kew., Genev., etc. 
- São Gonçalo, daus le bois, Mrxas, $1^{\circ}$ 14220. Arbuste droit, fl. blanc jaunâtre. Août-septembre. C.

34. C. Warmingii Heissn. in Engler Bot. Jahrl. XIII (1890), p. 199. — Entre Piedade et Santa Luzia do Rio das Velhas, Mrsas, $n^{\circ} 20438$. Arbre à tronc droit, 11. blanchàtres. Novembre-décembre. C.

33. C. Schnackeana Lind. in Engler Bot. Jahrb. XIII (1890), P. 200. - São Christoviou, à Pedregulho, Rio-Jax., nº 14219. Grande liane, fl. blanc jaunàtre. Octobre-novembre. R.

36. G. lanceolata Lind.n. sp. in lerb. Paris., Berol., Kew., Brux., etc. - Riacho das Varas, au bord de la rivière, Mixas, n 19764. Liane, t1. blanchàtres, fruit noir. Mars-avril. C.

37. C. floribunda Lind. in Engler Bot.Jahrb. Xul (1890), p. 217. Cachoeira, dans le bois, Espintro $\mathrm{S}_{\mathrm{A}} \mathrm{nto}, \mathrm{n}^{\circ}$ 11443. Arbuste sarmenteux, fl. blanc jaunâtre. Février-mars. G. Vulg. : P'áo ponte = Tipuiú.

38. Triplaris surinamensis Cham.; Fl. Bras. V, I, p. 49. -- Quinta da Boa Vista, Sĩo Christovão, Rı-JAn., n ${ }^{\circ}$ 10028. Grand arbre cultivé, fl. blanches. Février-mars. R.

39. Tr. tomentosa Wedd.; Fl. Bras. V, I, p. ̋̈1. - Biribiry, près Diamantina, Mıxas, $n^{\circ}$ 19758; As Estacas, près Jaragua, Goyaz, nos 21976 , 21977. Grand arbre, fi. blanchâtres. Juin-juillet. C.

40. Tr. speciosa Taub. in Engler Bot. Jahrb. XII (1890), Beibl. 27, p. 14. - Araruama, près Cabo Frio, Rio-Jax., n ${ }^{\circ}$ 11442. Grand arbre, 11. blanchàtres. Février-mars. R. Vulg. : Pajuú.

41. Tr. macrocalyx Casar.; Fl. Bras. V, I, p. :2. - Sapopemba, dans les broussailles, Rio-JAv., n ${ }^{\text {ss }} 6703$, 8905. Arbrisseau, 11. blanchâtres. Octobre-novemirre. C.

42. Ruprechtia laurifolia Mey.; Fl. Bras. V, I, p. 5\%. - São Pedro dus Indios, près Cabo Frio, Rio- $\coprod_{A x}$., $1^{\circ} 12116$. Arluuste sarmenteux, fl. blanc jamâtre. Avril-mai. C.

43. R. laxiflora Neisn. in Fl. Bras. Y, I, p. 56. - Alto Nacahé de Nova Friburgo, Rı-Jax., nos 14218, 19759, 19760. Arbre énorme, 17. blanchâtres. Juin-juillet. C.

44. R. Jamesonii Meisn. in DC. Prodr. XIV, p. 179. - Nova Friburgo, au Alto da Boa Vista, Rro-Jax., $n^{\circ} 14218$ a. Arbre, fl. blanc jaunâtre. Juin-juillet. C.

45. R. Cumingii Meisn. in DG. Prodr. XIV, p. 179. - Alto Macahé de Nova Friburgo, R10-Jav., ${ }^{o s} 12115$, 19761. Arbre, 11. blanc jaunâtre. Juin-juillet. C. 
46. Ruprechtia fagifolia Meisn.? in Fl. Bras. V, I, p. :8. - Rio

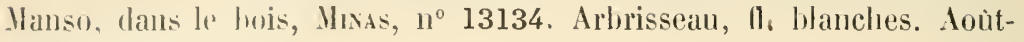
septembre. C.

\section{Fani. 110. - Podostémacées.}

1. Tristicha hrpnoides Tul.; Fl. Bras. IV, I, p. 272; Warm. Fam. I'odosl., p. ̈̈. - Rio Negro, à Ronca Pão, près de Cantagallo, Rio-Jax $11^{\text {os }} 13140$, 15442; Piracicala, S. Paulo, no 19817; Pio Arassuahy, Mixas, $n^{0}$ 13137; Rio Douradinho, Rio Bacalho, Rio Vermelho, Rio das Almas, ele., Goraz, $n^{\text {os }} 21993,21995,21996,21999,22000$, 22002, 22004, 22005, 22006, 22007 et 22010. Herbacé, fl. verdâtres. Juin-septemlıre. CC.

2. Mourera aspera Bong.; Fl. Bras. IV, I, p. 236; Warm. Fam. Podost., p. 30, tal. 26, 27. - Rio Arassuahy, Mnsas, ${ }^{\circ} 13136$; Cachoeira de Ronca Páo, près Cantagallo, Rio-JAx., $11^{\circ}$ 13139. Herbacé, f1. roses. Juin-juillet. C. Vulg. : Couve d'agua.

3. Mourera fluviatilis Aubl. Hist. des Pl. Guiane Franc., p. 582, t. 233. - Cachoeira do Rasgão, près Corumba, Goyaz, $\mathbf{n}^{\circ}$ 21983. Herbacé, fi. roses. Juillet-août. R.

4. M. Glazioviana Warm. in herb. Havniensi, inédit. - Rio Urucuia, entre Tahorfuinha et Taquaril. Goyaz, $n^{\circ}$ 21984, a. Herbacé, fi. roses. Mai-juin. R.

5. Ligia Glaziovii Warm. in Fam. Podost., p. 39, t. 22-23. Serra do Caraça, en bas de la Cachoeira, Mixas, $n^{\circ} 15444$. Herbacé, f1. blanchâtres. Juin-juillet. R.

6. Apinagia Gardneriana Tul.? in Fl. Bras. IV, I, p. 24.̈ et in Warm. Fam. Podost, p. t. 21. Fig. 1-10. - Itatiaia, dans le Rio Parahyba, sur les rocher's du fond de l'eau, Rı-JAv., no 8078; Rio Arassuahy, Minss, $n^{0} 13138$. Herbacé, fl. verdâtres. Mai-juin. C.

7. A. fucoides Tul.; Fl. Bras. IV, I, p. 246. - Rio Lrucuia, entre Taquaril et Taboquinlıa, Goraz, $n^{\circ} 21984,21990$. Herbacé, 1 l. blanchâtres. Juin-juillet. C.

8. A. Crulsiana Warm. n. sp.? in herlo. Harn., Paris., Berol., Brux., etc. - Haut du Rio Paranana, Goraz, n" 21982. Herbacé, f1. blanchâtres. Yai-juin. R.

9. A. intermedia Warm. n. sp.? in herb. Havn., Paris., Berol., Brux., etc. - Bas du Rio Gama, Goyaz, n 21992. Herbacé, fl. verdâtres. Novemlıre-décembre. C. 
10. A. Riedelii Tul.: Fl. Bras. IV, I, p. 246; Warm. Fan. Podost., p. 19, t. fig. 11-12. - Rio Negro, prìs Cantagallo, Rio-Jav., $n^{\text {os }} 13141,13145$; Cachoeira do Rio dos Indios, Rio Uruhú, etc. Goyaz, $n^{\text {ns }}$ 21981. 21985, 21987, 21989. Ilerbacé, fl. rouges. Juin-juillet. CC.

11. A. Warmingii Glaz. n. sp.? in herb. Harn., Paris., Berol., Kew., etc. Rio Ponte Alta, Goraz. $1^{\circ}$ 21991. Herbacé, 11. rose pâle. Juinjuillet. C.

12. A. uruhuana Glaz. n. sp.? in herl, Hawn., Paris., Berol., Kew., etc. - Rio Uruhú, près Jaragua, Goyaz, $n^{\circ}$ 21986. Herbacé, fl. blanchâtres. Juin-juillet. C.

13. A. parahybensis Glaz. II. sp.? in herb. Harn., Berol., Parris., Kew., etc. - Rio Parahy̧a, près Boa Vista, Rı-Jax., nº 13143. Herbacé, f1. roses. Juin-juillet. C.

14. A. pygmaa Tul.?; Fl. Bras. IV, I, p. 247. - Rio Parnahỵa, all passage, Mrxas, $n^{\circ}$ 22001. Herbaré, fl. roses. Juillet-aoùt. C.

1.̆. Lophogyne arculifera Tul.; Fl. Bras. IV, I, p. 2ö0; Warm. Fam. Podost.. p. 20, t. 24-20̈. - Rio Bengala, près Nova Friburco, Serra Estrella iu Rio Quitandinha, etc., Ro-Jax., nos 12195, 12196, 13142, 13147, 15441, 16316. 17226, 17776. Herbace, sans f1. en aohtdécembre. CC.

16. Podostemon Muelleri Warm. n. sp.? in herb. Havn., Paris., Berol., Kew., etc. - Rio Piracicaha et Rio Iporanga. Säo Paclo, $\mathrm{n}^{\text {os }}$ 15443, 16358, 19816. Herbacé, fl. verdâtres. Juin-juillet. C.

17. P. Galvonis Warm. 11. sp.? in herb. Havn., Paris., Berol., Kew, etc. - Rio Ignape, à Iporanga, São Pavbo, no 16359. Herbacé, 11. verdâtres. Juin-juillet. C.

18. P. Schenkii Wirm. Fam. P'odost., 1. 9, t. 18 et 19. - Rio Douradinha, entre Pontra el Joño Vieira, Goraz, nº 21988. Herbacé, 11. blanchaitres. Juin-juillet. C.

19. P. Glaziovii Warm. n. sp.? in herh. Harn., Paris., Berol., Kew., ete. - Rio Trinidade, au passage, Goyz, n 21993. Herbacé, f. blanchâtres. Juillet-aoùt. R.

20. Mniopsis Saldanhana Warm. Fam. Podost., p. 16, tah. XX, fig. 10-29. - liio Bengala, entre le Alto da Serra et Novia Friburgo, Rro-Jax., $1^{\text {os }} 13146,17225$. Herbacé, f1. verdâtres. Aoùt-septenbre. C.

21. Mn. Gląioviana Warm. Fam. I'odostem., p. ̋̈, tab. W, fig. 16. - Serra dos Orgãos, au Rio Solherbo, Boa Vista dans le Rio Paralıyba, Rio-Jax., $1^{\text {os }}$ 12191. 12193, 12197, 13144: Rio das Almas, 
pres de Meia Ponte, et liio dos Indios, Goriz, nos 22008, 22009. Herbacé, n. verditres. Août-septembre. CC.

29.9. Mniopsis scaturiginum Mart. et Z.; Fl. Bras. IY, 1, p. 257 . Rio Trinidale, Rio Corumba, Rio Uruhú, Ribeirĩo de Galdas, Goraz, $n^{\circ}$ 21994, 21997, 21998, 22003, 22011, 22012, 22013. Herbacé, fl. lıanchâtres. Juillet-aoùt. CG.

23. Mn. Weddelliana Tul.; Fl. Brus. IV, I, p. 298. - Rio Piabanha et Rio Santo Antonio, à Petropolis, Rio-Jan., $n^{\text {os }} 7398,12192$, 12194. Herbacé, fl. verdàtres. Mai-juin. C.

24. Castelnavia princeps. Tul. et Wedd.; Fl. Bras. IV, I, p. 264. Rio Urulın, près Jaragua, Goraz, no 22014, Acaule, 11. blanclıatres. Juinjuillet. R.

26. G. Warmingii Glaz. n. sp.? in herb. Harn., Paris., Berol., liew, etc. - Rapide du Rio Macaco, à Siriaco, Goraz, no $22004 a$. Herbacé, fl. verdàtres. Juin-juillet. R.

\section{Fam. 111. - Cytinacées.}

1. Apodanthes Casearice Poit.; Mart. Fl. Bras. IV, II, p. 129. Serra da Babylonia, Misas, sans nunıéro. Parasite, ll. rousses. Juilletseptemlıre. R.

2. Pilostyles Blanchetti R. Br.; Fl. Bras. IV, II, p. 12ั5. - Biribiry, près Diamantina, Mrsas, ${ }^{\circ}$ 19819; Morro Grande, près Meia Ponte Goyaz, no 22027 a. Parasite. Janvier-mars. CC.

3. P. Inga Hook. f.; Fl. Bras. IV, II. p. 1250. - Serra dos Pyreneos, Vargem Grande, Ciganos, etc., Goraz, n ${ }^{\text {os }}$ 22027, 22028, 22029, 22030. Parasite, 1h. rousses. Décembre-janvier. CC.

4. P. Calliandree R. Br.; Fl. Bras. IV, II, p. 126. - Entre Lage et le Rio Tocantins, Goyaz, $\mathrm{n}^{\circ} 22030$ a. Parasite, fl. rousses. Décembrejanvier. R.

\section{Fam. 112. - Aristolochiacées.}

1. Holostylis reniformis Duchre.; Fl. Bras. IV, II, p. 81. - Barra du Rio Paranalıyba, dans le bois, Goyaz, $n^{\circ} 22034$. Herbacé sarmenteux, 11. verdâtres. Juillet-septembre. R.

2. A. Ruiziana Duchre. : Fl. Bras. IV, II, p. 88. - Quinta da Boa Vista, à São Cilıristovióo, Rı-Jax., $n^{o s} 13163,14230$. Sous-frutescent volubile, fl. brunes, Juillet-aoùt. R. 
3. A. gigantea Nart. et Zuce.; Fl. Bras. IV, II, p. 89. - Santa Barbara, dans le loois, Mrsas, $n^{0 s}$ 14227. 15386. Sous-frutescent, grande liane, 11. blanc verdàtre. Août-septembre. C.

4. A. Gląinuii Mast. in Fl. Bras. IV, II, p. 90. - Serra do Tingua, dans le loois, Rio-JAx., $11^{\text {os }} 5520,14241$. Sous-frutescent volubile, fl. blanchâtres. Novembre-décembre. C. Vulg. : Jarrinha.

¿. A. macroura Gomez.; Fl. Bras. IV, II, p. 90. - liestinga de Copacabana, Rro-Jıx., $n^{\circ}$ 3788. Sous-frutescent volubile, fl. blanchâtres. Aoùt-septembre. C.

6. A. trilobata L.: Fl. Bras. IV, II, p. 91. - Quinta da Boa Vista, à Sĩo Christuvão. Rro-JAN., nº 10034. Sous-frutescent, volubile, cultivé. Aoùt-septembre. C. Vulg. : Jarrinha.

7. A. prrence Taub., in Beitrige Fl. centr. Bras., p. 426. Meia Ponte, dans le cerrado, Goyaz, $\mathrm{n}^{\circ}$ 22031. Sous-frutescent, fl. blanchâtres. Norembre-décembre. R.

8. A. cordifolia Glaz. n. sp.? in lıerb. Paris., Berol., Kew., Brux., etc. - Serra do Lenheiro, dans le campo, Mrsas, ${ }^{\circ} 17209$. Sous-frutescent, fl. blanchâtres. Mar's-avril. C.

9. A. Chamissonis Duchre; Fl. Bras. IV, 11, p. 93. - Fazenda do Lamarão. Goraz, $1^{\circ}$ 22033. Frutescent volulile, 11. blanchàtres. Septembre-octobre. C.

10. A. smilacina Duchre; Fl. Bras. IV, I1, p. 9\%. - Calchoeira, dans le bois. Espruto Sivro, no 10032. Sous-frutescent, f1. blanchâtres. Novembre-décembre. R.

11. A. odora Steud.; Fl. Bras. IV. II, p. 99. - Fazenda do Rio Douro, dans le bois, Rio-JAx., $n^{0 s} 9575,13161$. Sous-frutescent volubile, fl. blanchâtres. Octobre-novembre. C.

12. A. micrantha Glaz. n. sp.? in herb. Paris., Berol., Kew. Brux., ete. - Carandahy, dans le bois et le campo, Mixas, $\mathrm{n}^{0} 14229$. Sous-frutescent volubile, fl. violacées. Juin-juillet. C.

13. A. runicifolia Mlart. et Zuce.; Fl. Bres. IV, II, p. 99. - Entre Belem et Queimado et au Alto lacahé de Nova Friburgo, Rio-Jax., $n^{05}$ 8913, 16321, 19820. Sous-frutescent volubile, fl. blanc jaunâtre. Novembre-décembre. CG.

14. A. Gisneroii Glaz. n. sp.? in herb. Paris., Berol., Kew., Genev., etc. - Serra dos Purys dans le bois, Espirito Saxto, no 10031. Sous-frutescent volul,ile, fl. blanc-jaunâtre. Octobre-novembre. R.

18̈. A. cynanchifolia Mart. et Zuce.; Fl. Bras. IV, II, p. 103. - 
Horro Queimato of Tijuci, Rio-JAx., ${ }^{\text {os }}$ 2099, 4186. Sous-frutescent volubile. 11. blanchâlres. Novembre-décembre. C.

16. Aristolochia triangularis Cham. et Schlt.; Fl Bras. IV, II, p. 10'年. - Nto Macahé de Nova Friburgo, Rio-Jav., $n^{\text {os }}$ 16322, 18468. Sous-frutescent sarmenteux, hl, blanchâtres, C. Vulg. : Mil homens.

17. A. Raja Mart.: Fl. Bras. IV, II, p. 10̋̈. - Audaralıy Grande et Praia de Fora, Rio-Jax., ${ }^{\circ}$ 13164. Sous-frutescent volubile. h. blanchâtres. Janvier-févier. CiC.

18. A. eriantha Nart. et Zuce.; Fl. lires. IV, II, p. I0\%̈. - Norru Velho, près Sabara, dans les bois, Mlivas. $\mathrm{n}^{\text {os }} 13160$, 14228. Sous-frutescent, liane, fl, blanchâtres. Octobre-novembre. C.

19. A. brasiliensis llart. et Zucc.; Fl. Bras. IV, II, p. 107. Cachoeira et Cantagallo, Rio-JAx, $\mathrm{n}^{\text {os }} 4185,7871,8912,12142$. Sousfrutescent, liane, fl. blanchattres. Septembre-octobre. CG. Vul. : I'apo de piru, Jarminha.

20. A. crmbifera Mart. et Zucc.; Fl. Preas. IV, II, p. 108. - Quinta da Boa Vista, à São Christovio, Rio-Jax., $n^{\circ}$ 12143. Sous-frutescent, liane, 11. blanchâtres. Novembre-décembre. G. Vulg. : Papo de piru, Jarrinha.

21. A. Warmingii Mast. in Fl. Bras. IV, II, p. 109. - Corrego do Brejo, au campenent, Govaz, $n^{\circ}$ 22032. Suus-frutescent, fl. blanchàtres. Oetolse-novembre. R. Vulg. : Jarrinha.

22. A. galeata Nart. et Zucc.; Fl. Bras. IV, II, 1. 109. - Ipanema, dans le lois, Säo Pavlo, $\mathrm{n}^{\circ}$ 13162. Sous-frutescent, 11. blanchàtres. Jars-avili. G. Vurg. : Jarrinha.

23. A. trilabiata Glaz. n. sp.? in herb. Paris., Berol., Kew., Genev., ete. - Serra da Itabapoana, Espulto Savto, dans le bois, $n^{\circ}$ 10033. Sous-frutescent, liane, fl. Hanchatres. Septembre-octobre. R.

Fam. 113. - Pipéracées.

1. Piper ceanothifolium Kunth in DC. Prodr. XVI, I, p. 247. Floresta da Tijuca et Coreovalo, Rio-Jan., $\mathrm{n}^{\circ}$ 3118; Gandarela, Mlıxas, $n^{\circ}$ 15440. Frutescent, 11. Blanchâtres. Jauvier-mars. CC.

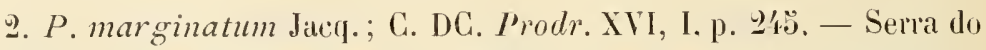
Picú, au Palınital, Rı-JAx.. $n^{\circ}$ 11575. Frutescent, 11. blanchâtres. Octobre-novembre. R.

3. P. Jaborandi Vell.; DG. Prodr. XVl, I, p. 292. -- Floresta da Tijuca, 
Corcorado, Rio-Jas., $1^{\text {os }} 1163,3117$. Frutescent, f1. blancliâtres. Janviermars. CG. Vulg. : Jaborandi.

4. P. sebastianopolitense C. DC. in DC. Prodr. Syst. XVI, I, P. 20̈2. Floresta da Tijuca, Rio-Jas., no 6004. Frutescent, fl. blanchâtres. Octobrenovembre. C. Vulg. : Jaborandi.

๑. P. Hayneanum C. DC. in Prodr. XVI, I. p. 2:33. - Congonhas do Campo, dans le bois, Irsss, $n^{\circ}$ 15436. Frutescent, 11. blanchàtres. Novembre-décemhre. C.

- Val. macrophylum C. DC. in Prodr. XVl, I, p. 233. - Haut de la Gavea, Rı-JAn., nº 8074. Frutescent, fl. blanchâtres. Juin-juillet. R.

6. P. Gardnerii C. DC. in Prodr. XVI, I, p. 204. - Floresta da Tijuca, Rio-JAx., n ${ }^{\text {os }} 4202,6805$. Frutescent, t1. blanchâtres. Octobre-norembre. CC. Vulg. : Jaborandi.

7. P. corcovadense C. DC. in Prodr. XVI, I, p. 2ö. - Serra da Estrella, Rio-Jas., $11^{\circ} 6001$. Frutescent, fl. blanchâtres. Norembredécembre. C. Vulg. : Jaborandi.

8. P. latum C. DC. in Prodr. XVI, I, p. 256. - Corcovallo, Jurujuba, Gavea, etc., lio-Jax., nos 196, 8075, 8076. Fiutescent, fl. lilanchâtres. Octobre-novembre. C.C. Vulg. : Jaborandi.

9. P. exserens C. DC. in Prodr. XVI, I, p. 261. - Campo Bello, au bas Itatiaia, Riı-JAx., I $^{\circ}$ 6688. Frutescent, fl. blanchâtres. Mar's-arril. C.

10. P. lanceolatum Ruiz et Pav. var. latifolium C. DC. in Prodr. XVI, I, n. 263. - Itatiaia, dans le bois vierge, Rı-Jax., nº 7845. Frutescent, 11. blanchâtres. Avril-mai. R.

11. P. obumbratum C. DC. in Prodr. XVI, I, p. 263. - Floresta da Tijuca, Rı-JAx., n 7841. Frutescent, fl. blanchâtres. Octolre-novembre. R.

12. P. tuberculatum Jacq.; C. DC. Prodr. XVI, I, p. 26ö. - São João da Barra, Rı-JAx., $n^{\circ} 11574$. Frutescent, f1. blanchâtres. Octobrenovembre. $\mathrm{R}$.

13. P. geniculatum Sw.; C. DC. Prodr. XVI, I, p. 266. - Frutescent, fl. blanchâtres. Lagoinha, an Corcovado, Rı-JAx., nos 197, 8947, 9594. Frutescent, f1. blanchâtres. Juin-juillet. CC.

- Var. latifolicu C. DC. in Prodr. XV1, p. 267. - Serla dos Orgãos, à Theresopolis, Rio-Jax., $\mathbf{n}^{\text {os }} 6690,19866$. Frutescent, fl. blanchàtres. Octolse-novembre. C.

14. P. amazonicum C. DC. in Prodr. XVl, I, P. 272. - Possos de Caldas, dans le bois, Ilivas, n ${ }^{0}$ 10064. Frutescent, I1. Hanchâtres. Novmbre-décembre. R. 
13. Piper estrellense G. DG. in Prodr. XVI, 1, p. 27巳. - Serra do

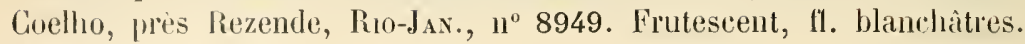
Nosentbre-décentre. C.

16. P. apiculatum G. DG. in Prodr. XVI, I, p. 273. - São Gonçalo, près Cantagallo, Rio-Jax., n" 8945. Frutescent, fl. blanchâtres. Aoùt-sejtembre. C.

17. P. hirsutum Sivartz; G. JG. Prodr. XV1, 1, p. 276. - Serra de José Vaz, près Rezende, Rio-JAN., $n^{\circ}$ 7844. Frutescent, l1. blanchâtres. Aoùt-septembre. C.

I8. P. Gaudichaudianum Kunth in G. DG. Prodr. XVI, I, p. 277. Corcovado, au ruisseau Carioca, Rio-J $\mathrm{J}_{A \mathrm{~N}}$, $\mathrm{n}^{\text {os }}$ 7846, 7847. Frutescent, fl. blanchâtres. Octobre-novembre. GC.

19. P. Pisoense G. DG. in Prodr. XVI, I, p. 2278. - Floresta da Tijuca, Rı-JAx., nº 8948. Frutescent, 11. blanchâtres. Février-mars. C. Vulg. : Apertaruão.

20. P. Sprengelianum C. DC. in Prodr. XVI, I, p. 283. - Corcovado et Petropolis, Rio-Jan., $n^{0 s} 3119,15439$. Frutescent, ll. blanchâtres. Juin-juillet. C.

21. P. aduncum L.; C. DG. Prodr. XVI, I, p. 283. -- Fazenda to Itatiaia, dans le bois, Rio-Jax., $n^{\circ} 4921$. Frutescent, 11. blanchâtres. Juin-juillet. R.

22. P. angustifolium Ruiz et Pav. var. Ossanum G. DG. in Prodr. XY1, I, p. 286. - Caéthé, dans le bois, Mixas, n 13218; Fazenda da Boa Vista, Goraz, n ${ }^{\circ} 2035$. Frutescent, 11. blanchâtres. Janvier-février. C.

23. P. subflavirameum C. DC. in Ann. Conserv. Jard. Bot. Genère, 1898, p. 220. - Santa Barbara, dans le bois, Minas, nº 15438. Frutescent, fl. blanchatires. Août-septembre. C.

24. P. Bennettianum C. DG. in Prodr. XVI, I, p. 287. - Serra do Picú, au Paulo, Rio-Jax., no 11576. Frutescent, fl. blanchâtres. Avrilmai. C.

2马. P. coccoloboides Kunth. in C. DG. Prodr. XVI, I, p. 288. - Serra do Batatal ou do Capanema, Mhxas, nos $15440 a$, 19867. Frutescent, 11. blanchâtres. Juin-juillet. R.

26. P. pseudo-pothifolium C. DG. in Prodr. XVI, I, p. 289. - Patrucinio, dans le bois, Rı-JAN., $n^{\circ}$ 10067. Frutescent, fl. blanchâtres . Octobre-novembre. C.

27. P. pothifolium Kunth in G. DG. Prodr. XVI, I, p. 289. - Serra dos Orgàos, à Theresopolis, Rio-Jan., nº 17229. Frutescent, fl. blanchàtres. Janvier-février. R. 
28. P. amplectens C. DC. in Prodr. XVI, I, p. 293. - Itabira do Campo, au bord du Rio das Velhas, Mısas, n 17227 . Frutescent, fl. blanchâtres. Septembre-octolire. C.

29. P. Rorhii C. DC. in Prodr. XVI, I, p. 296. - Gavea, dans le bois, Rio-daN., $\mathrm{n}^{\text {s }}$ 195, 1162, 7842. Frutescent, fl. blanchàtres. Aoùt-septembre. R.

30. Piper phthinotrichon C. DC. in Prodr. XVI, I, p. 298. - Entre Cabo frio et Araruama, Rio-Jav., $n^{\circ} 10063$ Sous-frutescent, fl. blanchâtres. Février-mars.

31. P. anoncefolium Kunth in C. DC. Prodr. XVI, I, p. 298. - Entre Araruama et Calıo Frio, Rio-JAx., $n^{\circ}$ 10066. Frutescent, fl. blanchâtres. Aoùt-septembre. R.

32. P. diosprrifolizm Kunth in C. DG. Prodr. XVI, I, p. 300. Entre Belem et Queimados, dans les bourbiers, Rio-JAv., $n^{0 s} 8073,8944$. Frutescent, 11. blanchâtres. Octobre-novembre. R.

33. P. cernumm Vell.; in DG. Prodr. XVI, I, p. 306. - Corcovado, à Paineiras, Rı-Jav., nº 12177. Frutescent, fl. blanchàtres. Juin-juillet. C.

34. P. obliquum Ruiz et Pav. var. exmmum G. DC. in Prodr. XVl, I, p. 307. - Serra do Mar, à Palmeiras, Rio-Jax., no 7833. Frutescent, f1. blanchâtres. Août-septembre. C.

3气. P. Regnellii C. DG. in Prodr. XVI, I, p. 307. - Serra do Picú, à Engenlıo da Serra, Mixas, nos $11575 a, 11577$. Frutescent, fl. blanchàtres. Octobre-novembre. $\mathbf{k}$.

36. P. mollicomum Kunth in C. DC. Prodr. XVI, I, p. 316. - Fazenda de Itatiaia, dans le bois, Rı-Jav., n 4920 . Frutescent, f1. blanchâtres. Juin-juillet. G.

37. P. salicariafolium Kunth in C. DG. Prodr. XVI, I, p. 317. Corcovado et Petropolis, Rio-JAx, n ${ }^{05}$ 7849. 7850, 8072. Frutescent, f1. blanchâtres. Octobre-novembre. CG.

38. P. colubrinum Link; C. DC. Prodr. XVI, I, p. 319. - Serra do Tingua, au Rio Douro, Ruó-JAv., $n^{\circ s} 3120,9596,12178$. Frutescent, fl. blanchâtres. Octobre-novembre. CG.

39. P. caldense C. DC. in Linnæa, XXX (1871-73), p. 343. - Floresta da Tijuca. Rı-J $\mathrm{J}_{\mathrm{x}}, \mathrm{n}^{\circ} 6687$. Frutescent, fl. blanchâtres. Novembredécembre. R.

40. P. lepturum Kunth in C. DG. Prodr. XVI, I, p. 320, - Floresta da Tijuca et Corcovado, Rio-Jax., $n^{o s} 3121,6003$. Frutescent, fl. blanchâtres. Octobre-novembre. CG. Vulg. : A pertaruäo. 
11. Piper Gläionii C. WC. in Ann. Conserv. Jard. Bot. Genève, 1898, 1. 263. - Floresta di Tijuca et Corcovado. Rio-J $\mathrm{JN}_{\mathrm{N}}, \mathrm{n}^{\circ} 7848$. Frutescent, ll. Wanchattres. Octobre-novembre. C.

42. P. Hilarianum C. DG. in Prodr. XV1. I, 321. - Fazenda de Itatiaiil, Rio-J $J_{A N}, 1^{\text {os }} 2706,4922$. Frutescent, 11. hlanchâtres. Juin-juillet. C.

43. P. Luccanmm Kunth in C. DC. Prodr. XVI. I, p. 349. - Floresta da Tijuca et Corcovado, Rio-Jav., $n^{\circ} 7849$ a. Frutescent, fl. blanchâtres. Août-septembre. C.

4'. P. crassinervimm Kunth in C. DC. Prodr. XVI, I, p. $323 .-$ Entre Cabo Frio et Araruama, Rı-Jax., no 10062. Frutescent, 11. blanchâtres. Novembre-décembre. C.

49. P. glabrmm Hill. Gard. Dict. édit. VIH, n. 12. - Petropolis, au Retiro, Rio-JAx.. $n^{\circ}$ 8946. Frutescent, fl. hlanchâtres. Janvier-février. R.

46. P. Riedelii C. DC. in Prodr. XVI, I, p. 325. - Corcovado, au ruisseau Carioca, Rı--JAN., n ${ }^{0}$ 7843. Frutescent, fl. blanchâtres. Octobrenovembre. R.

47. P. concinnm C. DC. in Prodr. XVI, I, P. 328. - Serra da Estrella, a Mandioca, liro-JAN., ${ }^{\text {os }} 6686,9593$. Frutescent. fl. blanchàtres. Juilletaoùt. G.

48. P. umbellatum L.; C. DC. Prodr. XVI, I, p. 332. - Serra de Mambucaha, Rı-JAN., $n^{\circ}$ 15437. Frutescent. fl. blanchâtres. Janvierfévrier. C. Vulg. : Pariparoba.

49. P. subpeltatum Willd.; DC. Prodr. XVI, I, p. 333. - Floresta da Tijuca, Rı-JAx., $n^{0}$ 8071. Frutescent, fl. blanchâtres. Juin-juillet. C. Vulg. : Pariparoba.

50. P. Botrytes Vahll; C. DC. Prodr. XVI, I, p. 379. - Floresta da Tijuca et à Nyctheroy, Rio-J $J_{A x}, n^{0} 3120 a$. Frutescent, fl. blanchàtres. Février-mars. R.

51. Peperomia hispidnla A. Dietr. in C. DC. Prodr. XVI, I, p. 397. Serra do Alto Nacalıé, sur les arbres et les rochers, Rio-Jan., $n^{\circ} 2702$. Herbacé, I1. Blanchâtres. Mai-juin. C.

92. P. argyera Mlorr. in Belgique Hort. XII (1867), p. 2. - Coreovado, sur les rochers humides, Rio-JAs., $n^{\circ} 7840$. Herbacé, fl. blanchàtres. Octobre-norembre. C.

53. P. pellucida Kunth; C. DC. Prodr. XVI, I. p. 402. - Floresta da Tijuca, dans le bois humide, Rı-JরN., nº 5998. Herbacé, fi. blanchâtres. Mai-juin. CG.

§\%. P. talmifolia Kuntı; C. DC. Prodr. XVl, I, p. 406. - Alto 
Macahé, sur lés vieux arbres. Rio-Jax, $\mathrm{n}^{0 .}$ 11573, 17775. Herbacé, 11. blanchattres. Mars-avril. C.

53. P. trinervis R. et P' C. DC. Prodr. XVI, I, p. 417. - Serra dos Orgãos, sur les arbres et les rochers. Rio-Jav., $n^{\circ} 2913$. Herbacé. 11. blanchattres. Octobre-novembre. C.

56. P. alata R. et P.; C. DC. Prodr. XV1, I, p. 418. - Serra do Mar. à Rodeio sur les rochers, Rio-Jax., no 8950 a. Herbacé, ll. blanchâtres. Janvier-tévrier. R.

57. P. acuminatissima Miq.; C. JC. Prodr. XV1, I, p. 418. - Serra da Bica, près Cascadura, sur les rochers humides, Rı-Jax, no 8950 , 14282. Herlacé, fl. blanchâtres. Novembre-décembre. C.

š8. P. nummularifolia Kunth; C. DC. Prodr. XVI, I, p. 420. Petropolis, sur les arbres et les rocher's, Rio-Jax., $n^{0 s} 6691$, 14283. Herbacé, fl. blanchùtres. Mars-avril. CC.

59. P. delicalula Hensch. in Yova Act. Soc. Upsal. Ser. III, VIII (1873), p. 28. - Cascatinlıa, à Petropolis sur les arbres et les rochers, Rı-Jax.. no $6691 a$. Herbacé, fl. blanchâtres. Octobre-septembre. C.

60. P. Martiana Niq.; C. DG. Prodr. XVI, I, p. 422. - Serra da Estrella, sur les arbres et les rochers, Rio-JAN., $n^{0 s} 5995$, 13216. Herbacé, fl. blanchâtres. Mars-avril. C.

61. P. obtusifolia C. DC. in Prodr. XVI, I, p, 429. - Serra da Estrella, sur les rochers, Rio-Jax., $n^{\circ}$ 9597. Herbacé, fl. blanchâtres. Août-septembre. C.

62. P. rupestris Kunth; C. DC. Prodr. XVI, I, p. 431. - Cascatinlı, a Petropolis, sur les rochers, Rı-JAx., n ${ }^{\circ s} 1164,6692$. Herbacé, fl. blanchâtres. Octobre-novembre. C.

63. P. incana A. Dietr. : C. CD. Prodr. XVI. I, p. 432. - Copacabana, sur les rocher's, Rio-Jax., n ${ }^{\circ}$ 5997. Herbacé, fl. blanchàtres. Juin-juillet. R.

64. P. major C. DC. in Prodr. XVI, 1, 1. 432. - Corcovado, sur les rochers à Paineiras, Rio-JAs., nos 876. 5994, 8956. Herbacé, t'l. blanchâtres. Mai-juiı. C.

69. P. myrtifolia A. Dietr.; C. DC. Prodr. XVI, I, p. 438. - Floresta da Tijuca, Gavea et Petropolis, Ruo-Jas.. no* 6002, 7834, 7955. Herbacé, il. blanchâtres. Oitohre-novembre. CG.

66. P. Gląinyii G. DC. in Linnea, XXXVII (1871-73), p. 380.Serra dos Or'̣ãos, Petropolis, etc., sur les arlures et les rochers, Rio-Jax., nos $2914,8938,8952,8954$, 11578. Herbacé, 11. blanchàtres. Marsarril. CC. 
67. P. Langsdorffii Miy.; C. DC. Prodr. XV1, 1, p. 443. - Corcovado et Serra dos Orgãos, sur les arlures et les rochers, Rı-Jax., $n^{0 .}$ 7838, 7839. 8937. Herbacé, fl. llanchâtres. Octobre-novembre. C.

68. P. circinata Link; C. JC. Prodr. XVI, I, p. 444. - Floresta da Tijuca, sur les arbres et les rochers, Rı-Jax., nº 9595. Herbacé, fl. blanchâtres. Octolıre-novembre. C.

69. P. reflexa A. Dietr. C. DC. Prodr. XVI, I, p. 4.51. - Serra dos Orgĩos et Corcovado, sur les vieux arbres, Rı-J JN., $n^{\text {os }} 1562,6689$, 7835, 7836, 7837, 17228. Herbacé, f1. blanchâtres. Octobre-novembre. C.

- Var. valantordes C. DC. in Prodr. XVI, I, p. 45\%. - Andarahy Grande, à Villa Bella, sur les arbres, R10-JAx., nº 6912. Herbacé, f1. blanchâtres. Novembre-décembre. R.

70. P. trichophylla Bak. in Journ. Linn. Soc. XXI (1805)), p. 436. Petropolis, au Palatinato sur les rochers, Rio-Jax., $11^{\text {os }} 8939,8940$, 11579. Herluacé, ll. blanchâtres. Mai-juin. C.

71. P. peresticefolia Kunth; C. DG. Prodr. XVI, I, p. 40ั3. - Gavea, entre les rochers, Rı-Jav., n 5999. Herbacé, f1. blanchâtres. Mai-juin. R.

72. P. quadrifolia Kunth; C. DC. Prodr. XVI, I, 1. 44. - Fazenda do Rio Preto, sur les arbres, Minas, ${ }^{0 s} 8943,8951$. Herbacé, fl. blanchâtres. Octobre-novembre. C.

73. P. agapatensis C. DC. in Prodr. XVI, I, p. 4ồ̈. - Itatiaia, sur les arbres et les rochers, Rı-JAN., $\mathrm{n}^{\circ}$ 5996. Herbacé, fl. blanchâtres. Juin-juillet. C.

74. P. oreophila Hench. in Nova acta Soc. se. Upsal. Sér. III, VIII, $n^{\circ} 8(1873)$, p. 28. - Haut du Rio Preto, sur les arbres et les rochers, Mixas, $n^{\circ} 8951$ a. Herbacé, fl. blanchâtres. Novembre-décembre. R.

7.. P. loxensis Kunth. in DG. Prodr. XVI, I, p. 45ั7. - Petropolis, au Retiro sur les arbres et les rochers, Rio-J $\mathrm{J}_{\Lambda x}, \mathrm{n}^{\circ}$ 8941. Herbacé, 11. blanchâtres. Mai-juin. C.

76. P. blanda Kunth; C. DC. Prodr. XVI, I, p. 4อั8. - Serra da Estrella, à Mandioca, sur les rochers. Rio-Jan., $n^{\circ} 9597$ a. Herbacé, fl. blanchâtres. Juillet-août. C.

77. P. augescens Miq. in Arch. Néerl. VI (1871), p. 171. - Serra da Estrella, à Mandioca, sur les rochers, Rio-JaN., $n^{\circ}$ 9598. Herbacé, 11. blanchâtres. Juillet-septemlire. C.

78. P. crinicaulis C. DC. in Ann. Conserv. Jard. Bot. Genève (1898), p. 286. - Petropolis, au Palatinato sur les vieux arbres, Rio-dan., $n^{\circ}$ 8942. Herbacé, fl. blanchâtres. Mai-juin. C. 


\section{MEMOIRES PLBLIES (Suite).}

11. P. Guérin, Études sur les Diptérocarpées, 93 p. (décembre 1907), terminé.

3c. Glazıov, Plantes du Brésil central, pp. $201-296$ (févlier 1908), à suivre.

12. Hue (abbé), Lichens Tarbelliens, 19 p. (avril 1908), terminé.

13. 0. Lignier, Le fruit des Bennettitées et l'ascendance des Angiospermes, 17 p. (avril 1908), terminé.

8b. Chevalier, Novitates flore africanæ (2e partie), pp. 31-109 (aoü 1908), à suivre.

14. Pans (Général), Florule bryologique de la Guinée firançaise, 66 p. (novembre 1908), terminé.

3d. Glazıou, Plantes du Brésil central, pp. 297-392 (juin 1909), ì suivore.

15. Laubr, Nouvelle méthode technique pour l'étude paléophylologique des formations sédimentaires anciennes, 110 p. (janvier 1910), lerminé.

16. Dubaro. Recherches sur le genre Palaquium, 24 p. (décenbre 1909), terminé.

3e. Guaziov, Plantes du Brésil central, pp. 393-488 (mars 1910), à suivre.

8c. Chevalier, Novitates floræ africanæ ( $3^{\mathrm{e}}$ partie). pp. 111-136 (juin 1910), à suivre.

17. Dismer, Revision des Philonotis de l'Amérique, 37 p. (septembre 1910), terminé.

18. Bovati, Contribution à l'étude du genre Pedicularis, 35 p. (novembre 1910), termine.

19. Dop, Contribution à l'étude des Loganiacées asiatiłues de l'herbier du Nuséum de Paris (novembre 1910).

20. Ed. Bonnet, Énumération des plantes recueillies par M. R. Chudeall, dans la région de Tombouctou et du Moren-Niger, 19 p. (anut 1911).

21. R. HAMET, Observations sur la germination des Crassulacees, 13 p. (aoùt 1911).

22. Pitard et Haruand, Contribution à l'étude des Lirhens des iles Canaries, 72 p. (octolire 1911).

8d. Cuevalier, Novitates flore a fricanx (4" partie), pillaithal prochainement. 


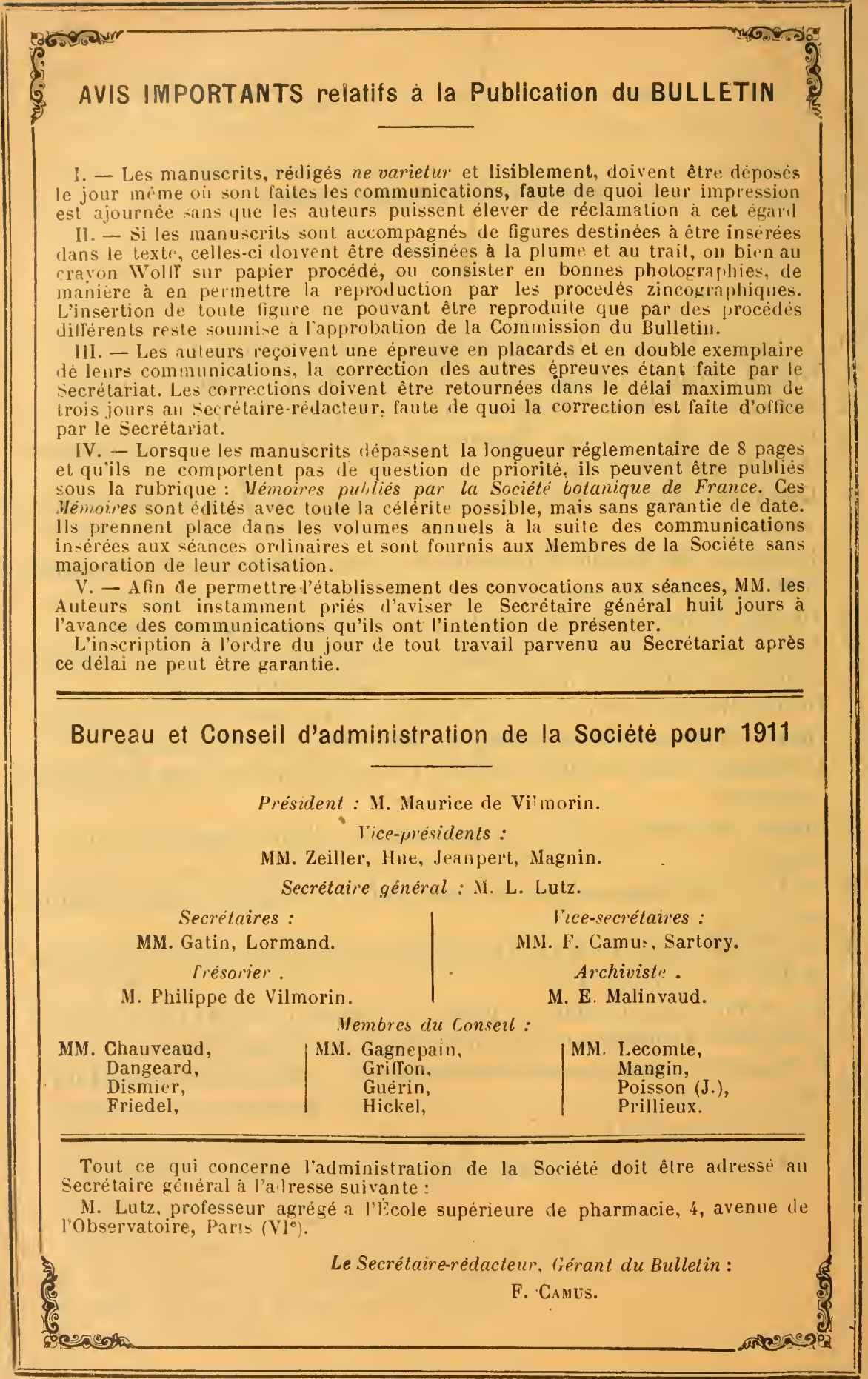

Coulommiers. - Imp. PAUL BRODARD. 


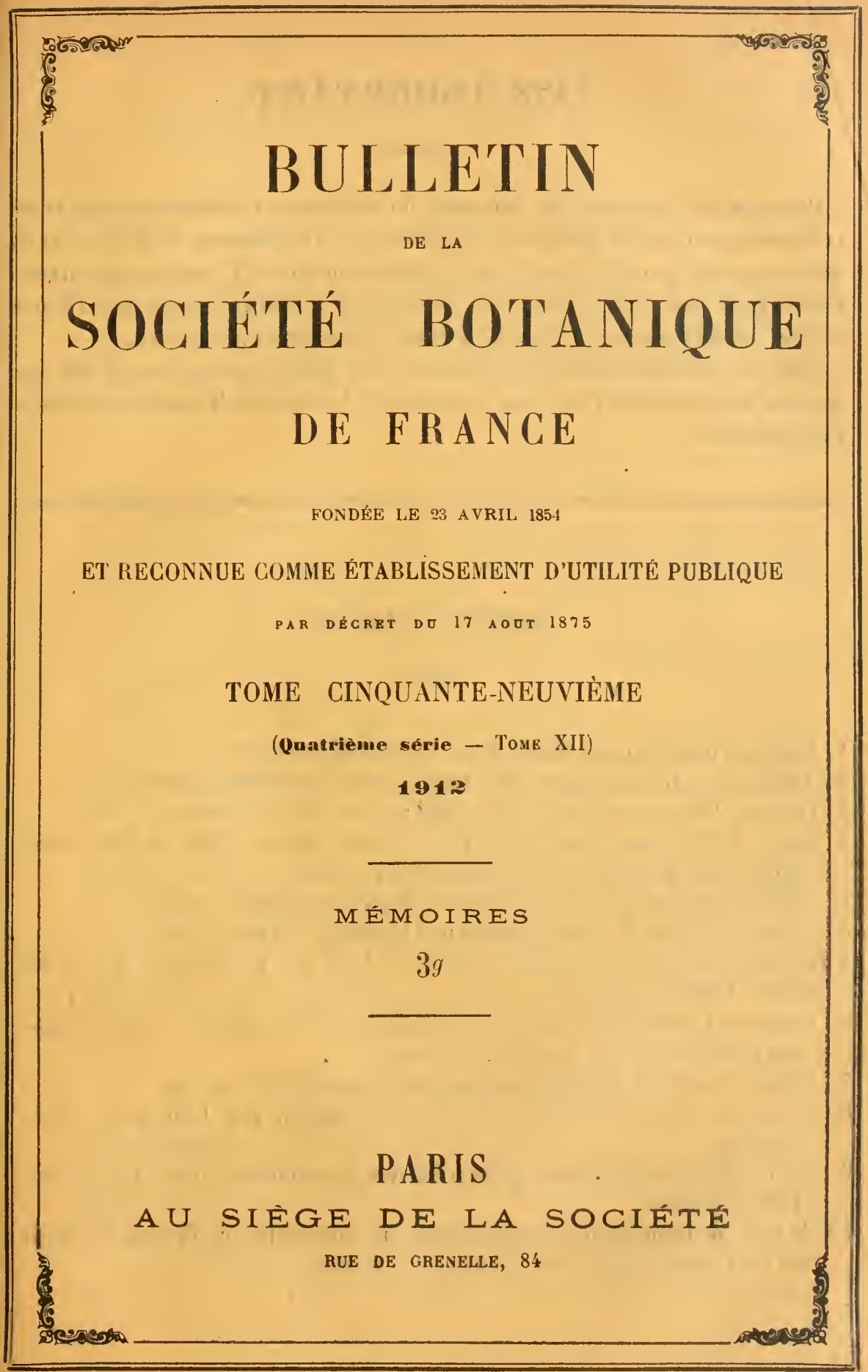

Le Bulletin de la Socièté botanique de France paraît par livraisons mensuelles. Le Bon à tirer de ce numéro a été donné le 13 septembre 1913. 


\section{AVIS IMPORTANT}

Par suite de l'augmentation croissante du nombre des communications et de sa répercussion sur les finances de la Société, la Commission du Bulletin croit devoir rappeler à nos Confrères que la Règlement limite la longueur des manuscrits à huit pages d'impression par séance et à quarante pages pour l'année entière, au delà desquelles l'auteur doit sa collaboration pécuniaire.

Dans un intérêt commun, la Commission prie donc très instamment iil. les Auteurs de condenser le plus possible le texte des Notes destinées à l'impression.

\section{MÉMOIRES PUBLIÉS}

1. Ghrist, Fougères de la Chine, 69 p. (mai 1905), terminé.

2. Terracciano, Gagea du nord de l'Afrique, 26 p. (nov. 190כ), terminé.

3. Glazıov, Plantes du Brésil central, 112 p. (nov. 1905), à suivre.

4. Finet et Gagnepain, Flore de l'Asie orientale, 54 p.; 8 pl. (I-VIII) distribuées avec la table de 190ð (mars 1906), à suivre.

5. Lignier, Anatomie des Renonculacées, 38 p. (juin 1906), terminé.

3b. Guazıov, Plantes du Brésil central, p. $113-200$ (juil. 1906), à suivre.

4 (2e partie). Finet el Gagnepain, Fl. de l'Asie or., p. 5ૅ5ั-170, pl. IX-XX (déc. 1906), à suivre.

6. Perrot et Gérard, Anatomie du tissu ligneux dans ses rapports avec la diagnose des bois, 43 p.; 6 pl. (juin 1907), terminé.

7. Pitard, Muscinées des iles Canaries, 44 p. (juin 1907), terminé.

8. Ghevalier, Novitates floræ africanæ (1 ${ }^{\mathrm{re}}$ partie), pp. 1-30 (aoùt 1907), à suivre.

9. Finet, Orchidées africaines de la tribu des Sarcanthées, 63 p.; 12 pl. (nov. 1907), terminé.

10. Fuiche, Monocotylédones arborescentes ou frutescentes de France, d'Algérie ou de Tunisie, 26 p.; 1 pl. (août 1907), terminé. 
A.-F.-M. GLHHOL. - LATE DES PLANTES DU BHESL CENTRAL.

79. P. orbicularis C. DG. in Prodr. XVI, I, p. 463. - Ilto do Pien do Retiro, à Petropolis, sur les vieus arbres, Rio-Jax., no 8953. Herbacé, îl. blanchâtres. Avril-mai. Ri.

Fam. 11\%. - Chloranthacées.

1. Hedyosmum brasiliense Mart.; Fl. Bras. IV, 1, p. 3. - Floresta

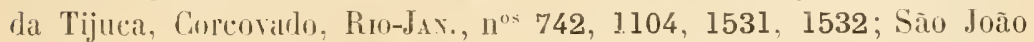
Baptista, dans les bois, Mlovs, $n^{0 s} 13215,15435$. Frutescent, fl. blanchàtres. Juillet-aoùt. CG.

Fam. 11\%. - Myristicacées.

I. Virola (Myristica) sebifera Warb. in Vova Acta Nat. Cur. LXVIII, „1. 169. - Lagoa Feia, près Formosa, Goraz, n² 22037. Gland arbre, fl. rousses. Norembre-décembre. C. Vulg. : Bicuiba.

2. V. (M.) Urbaniana Warb. in Nova Acta Nat. Cur. LXVIII, p. 168. - Entre le Rio Uruhú et Villa Pella, Goyaz, n 22036. Grand arlore, f1. jaunàtres. Arût-septembre. R. Vulg. : Virola.

3. Y. (M.) Bicuhyba Warb. in Nova Acta Nat. Cur. LXVIII, p. 19't. - Serra da Estrella, Corcovado, Alto Ylacahé, Rio-Jax., nos 799, 1027, 2519, 11593, 12140, 16317; Rio Novo, Nixus, nos 20464, 20465. Grand arbre, fl. jaunâtres. Février-mar's. CG. Vulg. : licuiba.

4. (M.) Glaziovii Warl. in. Nova Acte Nat. Cur. LXVIII, p. 219. Porto do dequitiba, près Santa Luzia do Rio das Velhas, Nısas, no 20463. Grant arbre, fl. jaunattres. Novembre-décembre. C. Vulg. : Bicuiba.

כ. V. (M.) Gardneri Warb. in Nova Acta Nat. Cur. LXVIII, p. I92. - Fazenda de Sant'Inna, prés Juiz de Fora, Minas, $1^{\circ}$ 20466. Grand arbre, fl. rousses. Novembre-décembre. C. Vulg. : Biemba.

\section{Fam. 116. - Monimiacées.}

1. Mollinedia oligantha Perk. in Monogr. der Gutt. Mollin., p. 22. - Alto Vacalié de Nova Friburgo, Rı-Jax., $n^{\circ}$ 18487. Arbuste, fl. verdâtres. Janvicr-février. C.

2. M. dentata Flaz. II. sp. in herls. Paris., Berol., Kew., Brux., ete. - Floresta dia Tijuca et Corcorado, Rio-Jax., $n^{\circ} 836$. Arbuste, fl. verdâtres. Février-mars. R. 
3. Mollinedia undulata Perk. in Monoyg. der Gintt. Mollin, 1) 22. liestinga de Mauri et Villat Nova, Rı-dax., $11^{0 .} 8092,14269$. Arbuste, 11. verdatres. Novenbre-janvier. C.

4. M. Longionspidata Perk. in Monngr. der Giall. Mollin., p. 29. Alo Nacahé de Nova Friburgo, Rio-Jas., $n^{\circ}$ 17763. Arbuste, fl. brunes. Dérembre-janvier. C.

5. M. mriantha Perk. in Monogr. der Gall. Mollin. p. y't. - Alto Macahé de Nova Friburgo, dans le bois vierwe, Rio-Jax., no 19859. Arbrisseau, fl. brunes. Janvier-février. C.

6. M. heteranthera Perk. in Monogr. der Gall. Mollin., p. 2's. Corcovadı, à Paineilas, Rio-JAv., no: 6010, 8091, 18485. Arbrissean, fl. brunes. (octobre-novembre. C.

7. M. lamproplyylla Perk. in Monogr. der Gall. Nollin., p. 20. Larangeiras, au Cosme Velho, Riro-Jax., ${ }^{\circ}{ }^{0}$ 18484. Arbrisseau à odeur fétide, fl. verdâtres. Juin-juillet. C.

8. M. Saldanhæi Glaz. n. sp. in herb. suo et in Escola Polsteclınica. - Serra dos Orgĩos, au Frade, Rio-Jax., no 17218 a. Arbuste, fl. brunes. Anùt-septembre. C.

9. M. Gilgiana Perk. in Monogr. der Gatı. Mollin., p. 20̈. - Alto Hacalıé de Nova Friburgo, Rio-Jdx., $n^{0.5}$ 17218, 17771, 19858. Arbrisseau, fl. Brunes. Février-mars. C.

10. M. Glaziovii Perk. in Monogy. der Gull. Mollin., p. 26. - Alto Macalié de Noval Friburgo, dans la lorêt vierge, près des cours d'aux, Rio $J_{A x}, n^{\circ s} 17219,17220,17770,18488$. Arbrisseau, fl. rousses. Décembrejanvier C.

H. M. salicifolia Perl. in Monogr. der Gall. Mollin., p. 28. - Alto Macahé de Nova Friburgo, Rio-Jax., no 17765. Arbuste, 11. verdâtres. Août-septembre. R.

- Var. campanulacea Perk. in Monogr. der Gall, Mollin., p. 28. Alto Macalı́ de Nova Friburgo, en baut de la Serra, Rio-JAx., $n^{\circ} 18489$. Arbuste, fl. verdâtres. Anùt-septembre. C.

12. M. pachrpoda Perk. in Monogr. der Gatt. Mollin., p. 28. Alto Nacalıé de Nova Friburgo, en liaut de la Serra, Rio-dav., $n^{0} 18490$. Arbuste, fl. verditres. Aoù-septembre. li.

13. M. Engleriana Perk. in Monogr. der Gutt. Mollin., p. 29. Alto Macalıé de Nova Friburgo, Rı-JAx., nº 17766. Arbuste, fl. brunes. Aoùt-septembre. C.

14. M. spharantha Perk, in Monogr. der Gatl. Mollin., p. 29. - 
Cova da Onea, au Corcovalo, Rio-Jax., n 1521. Arbuste, fi. verdàtres. doit-septembre. R.

13. M. argyrogrna Perk. in Monogr. der Galt. Mollin., p. 30. Serra dos Orgitos et Alo Macahé, Rio-JAx., us 1591, 17768 a. Arbuste, fl. blanchatres. Septemlne-ortobre. C.

- Var. tomentosa Glaz.? in lierl. Paris., Berol., Kew.. etc. - Campo de Saio Sebastià, pres Ouro Preto, Mras, $n^{\circ}$ 15422. Arbuste, ll. blanchàtres. Juin-juillet. C.

16. M. corcovadensis Perk. in Monogr. der Gatt. Mollin., p. 3\%.Corcovado, à Lagoninha dos Porcos, Rio-Jas., no 3111. Arbuste, fl. verdàtres. Janvier-férrier. R.

17. M. Widgrenii A. DG; Perk. Monogr. der Galt. Mollin., p. 33. Floresta da Tijuca, liı-Jax., no 1321 a. Arbuste, fl. rousses. Juinjuillet. G.

18, M. Lontheriana Perk. in Monogr. der Gatt. Mollin., p. 33. Alto Macallé de Nova Friburgo. Rio-Jax., n 17764. Arbuste, fl. rousses. Novembre-décrmbre. C.

19. M. elegans Tul.; Perk. Monogr. der Gialt. Mollin., p. 37. Alto Macalıé de Novi Kriburgo, hı-Jas., n 17760 a. Arbuste, ff. brunes. Norembre-décembre.

20. M. ligustrina 'Tul. val. friburgensis val. nov. Perk. in herh. Paris., Berol., Kew., Brux, Gener, etr. - Alto llacahé de Nova

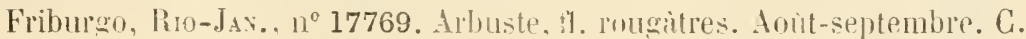

- Vai. dentata l'erk. var. nov. in herb. Paris., Berol., hew., Genev., Brux., etr. - Serra dos Uroilos, Rio Jax., nos 4203, 11551, 17222. Arbuste, fl. rougatres. Norenlore-décenbire. CC.

- Var. grandifiora Perk. Var. mor. ill herl, Paris., Berol., Kew., Gener. Brux., etc. - Cabareiras to Rio las Pedras, Goraz, no 22040. Arbrisseau, 11. rougeàtres. Aout-septembrt. C.

- Var. oxyphylia Perk. rar. nor. in hert. Parrs, Berl., Kew., Genev., Brux., elc. - Itarolum, pres Ouro Preto, Mists, no 18482. Arlsuste, 11. rougeatres. Inin-juillet. R.

21. M. miciantha Perk. in Monogr. der Gatt. Hollin., p. 37. - Alto

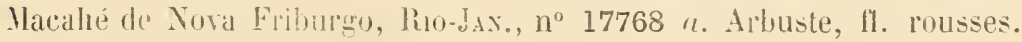
Octobre-norembre. R.

22. M. stennphylla Pelk. in Monogr. der Fall. Mollin., p. 38. Alto Harahé de Tora Fribureno, Ro-idx., $\|^{\circ}$ 17768, 20220. Petit aribuste, 11. brunes. Octoline-novemble. C.

23. M. fasciculata Perk. in Monogr. der Gatt. Mollin., p. $40 .-$ 
Alto Macahé de Nova lribur@o, Rio-Jas., nos 17221, 17761, 18486, 19860. Arbuste, 11. brunes. Janvier-février. C.

24. Mollinedia acutissima Perk. in Monogr. der Gatt. Mollin., p. 41. - Alto Nacahe de Nova Friburgo, Rı-Jax., I $^{\circ}$ 17760. Arbrisseau, f1. brunes. Novembre-décentre, C.

25. M. pachysandra Perk. in Monogr. der Gatt. Mollin., p. 41. Floresta da Tijuca et Corcovado, Rio-Jan., II ${ }^{\circ s} 837$, 1321, 1463, 7830. Arlırisseau, fl. blanchâtres. Aoùt-septembre. CG.

26. M. laurina TuI. var. friburgensis Perk. var. nov. in herb. Paris., Berol., Kew., Genev., Brux., etc. - Alto Nacahé de Nova Friburgo, RroJAN., ${ }^{\text {os }} 818,20485$. Arbuste, ll. rougetitres. Octobre-novembre. R.

27. M. floribunda Tul.; Perkins Monogr. der Gatt. Moll., p. 4t. Alto Nacalié de Nova Friburgo, Rio-JAx., $n^{\circ}$ 19861. Arbrisseau, fl. verdâtres. Février-mars. C.

28. M. longifolia Tul.; Perhins Monogr. der Gatı. MolI., p. 48. - Cova da Onega, au Corcovado, Rio-Jax., ${ }^{05}$ 1388, 1528. Arbuste, fl. rousses. Juin-juillet. C.

29. M. Canfieldice Perk. in Monogr, der Gatl. Mollin., p. 45. - FI0resta da Tijuca et Corcovado, Rio-Jax., nos 15423, 17767. Arbuste, fl. rousses. Aoùt-septembre. C.

30. M. cuneata Perk. in Monogr. der Gatl. Mollin., p. 4.. - Alto Nacahé de Nova Friburgo. Rio-Jax., ${ }^{\circ}$ 18483. Arbrisseau, fl. brunes. Octobre-novembre. R.

31. M. polyantha Perk. in Monogr. der Gall. Mollin., p. 46. Alto Nacabé de Nova Friburgo, Rio-Jax., $n^{0}$ 17762. Arbrisseau, f1. rousses. Aout-septembre. C.

32. M. nmbellata Tul.; Perkins Monoyr. der Gatt. Moll., p. 47. - Entre Gavea et Pedra Bonita, Rı-JAx., n 4201 a. Arbuste, f1. brunes. Octobre-novembre. C.

33. M. crathantha Perk. in Monogr. der Gall. Mollin., p. 48. Cachoeira, à Boca do Malto, prés la rivière, Rio-Jax., no 14270. Arbrisseau, fl. brunes. Juillet-aout. C.

34. M. hylophila Perk. in Monogr. der Gatl. Mollin., p. 49. Morro da Gavea, Rı-Jax., n 4201. Arbrisseau, ti. brunes. Novembredécembre. C.

3:. Siparuna erythrocarpa A. DG; Perk. in Engler Bot. Jahrb. XXXVIII (1901), p. 67\%. - Serra da Estrella, a Mamminha, Rı-Jdx., $n^{\circ}$ 12158. Frutescent, fi. blanchâtres. Nai-juillet. C. 
A.-F.-M. GLAZIOU. - LISTE DES PLANTES DU BRESIL CLNTRAL.

36. S. minutiflora Perk. in Engler Bot. Jahrb. XXXVIII 1901), p. 674. - Serra da Estrella, près Mamminha, Rio-Jix., $1^{0}$ 11553. Frutescent, fl. verdâtres. Mar's-juillet. C.

37. S. brasiliensis A. DC. : in Engler Bot. Jahrb. XXXYIII (1901), p. 673̈. - Fazenda de Sant' Anoa, près Juiz de Fora, Hasas, no 7828. Frutescent, fi. verdâtres. Janvier-férrier. C. Vulg., : Limão do matto.

38. S. chlorantha Perk. in Engler Bot. Jahrb. XXXVIII (1901), p. 677. - Alto Macahé de Nova Friburgo, Rio-Jax., nº 4068. Frutescent, fl. verdàtres. Mars-arril. C.

39. S. hylophila Perk. in Engler Bot. Jahrb. XXXVIII (1901), p. 683. - Nova Frihurgo, dans les loois humides, Rio-Jax., nº 18491. Frutescent, fi. verdâtres. Octobre-novembre. $R$.

40. S. cujabana A. DG.; Perk. in Engler Bot. Jah\%. XXXVIIl (1901), p. 693. - Entre Queluz et Piranga, Mıxds, nº 18492; Rio Vaga Lume, près Neia Ponte, Goraz, $n^{\circ}$ 22038. Frutescent, 11. rousses. Juillet-septembre. GG.

- Var. folrosa (Tul.) Perk. in Engler Bot. Jahrb. XXXVHI (1901), p. 69' $\%$ - Nova Friburgo, au Conego, Ruo-JAx., $1^{\circ} 12157$ a. Frutescent, fl. brunes. Octobre-novembre. R.

41. S. apiosyce A. DG.; Perk. in Engler Bot. Jahrb. XXXVIII (1901), p. 69.\%. - Floresta da Tijuca et Corcovado, Rio-JAv., nos 756, 7829, 11552, 12157. Frutescent, [1. verdâtres. Octobre-novembre. CC.

42. S. regince A. DC.; Perk. in Engler Bot. Jahrb. XXXVIII (1901), p. T00. - Aruruoea, dans le bois, Misas, $n^{\circ}$ 19857. Arbuste, fl. blanrhâtres. Janvier-mar's. R.

43. S. guianensis Aubl.: Perk, in Engler Bot. Jahrb. XXXVII (1901), p. 703. - Florestat da Tijuca et Corcorato. Rio-Jar., nos 851, 5988, 14272; São Joĩo Baptista, dans le bois et le campo, Mrisas, nº 13207. Arbuste, fl. verdattes. Février-mar's. C. Vulg, : Vegra mina.

- Var. divergentreolis A. DC.; Perk, in Engler Bot. Jahrb. XXXVIII (1901), p. 703. - Entre Bernardo Lobo et Jaragua, dans le bois et le campo, Goraz, n²2039. Arhuste, ll. blanchâtres. Juin-juillet. C.

\section{Fam. 11דi. - Lauracées.}

1. Cryptocarya moschata Mart. in Mez Monogr. Luurac. Amer., p. 8. - Floresta da Tijuca et Corcovado, Rro-JAv., $1^{\text {os }}$ 120, 1516. Grand arbre, ll. blanc jaunàtre. Aoùt-septembre. C. Vulg. : Canella branca.

2. Cr. longistyla Hez in Engler Botan. Jahrb. (I893), p. ̋̈18. - 


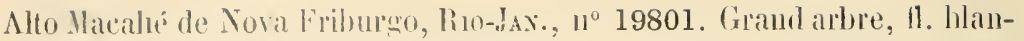
chattres. Décemblo-jamvier. C.

3. Comptniama saligna Vez in Honogr. Lamue. Amer., P. 13. Alto Warahé de Nora Friburgon. Rio-dax., $10^{\circ}$ 14205. Grand arbre, fl. blanchilles. Norembre-decembre.

4. Cr. minutiflora Nez in Botan. Jahrb., 1). 11. - Nto Nacahé de Nova Friburgo, Rio-Jax., no 18437. Frand arbor, il. blanchâtres. duinjuillet. C.

5. Cr. subcorymbosa Hez n. sp. in herb. Paris., Berol., Kew., Brux., ete. - Alto Macahes de Nova Frihmeg, Rio-Jux., $11^{\circ} 18436$. Grand arbre, fl. blanchatres. Aout-septenbre. Vulg. : Canella.

6. Hufelanaia rigida Mez in Engler Bot. Jahrb. (1893). p. ऽا9. Alto Macahé de Nora Frihurgo, et Serra da Estrella. Rio-Jax., nos 19790, 19793. 20444. Grand arhe, H. blanc jaunatre. Octoble-norembre. C.

7. Aniba Panurensis Hez in Konogr. Laurac. Amer., p. šs. - Villa Nova, pres Porto das Caixas, Rio-Jax., n' 7809. Grand arbre, Hl. hlanchâtres. Aviril-mai R.

8. A. firmula Mez loc cit., p. פ̌s. - Nova Friburgo, au Conego, Rro-Jax., $11^{\circ}$ 17193. Grand arbre, fl. blanchâres. Novembre-décembre. C.

9. A. Gardneri Nez. loc. cit. 1. 60. - Petropolis, Corcovado et la Tijuca. liı-JAx., nos $861.8104,12118$. Tlès grand artore, fl. blanchâtres. Janvier-mars. C.C. Vulg. : Canella sassafra.

10. A. viridis Mez, loc. cit., p. 61. - Coleovado, à Paineiras, Rio-Jan., no 12117. Grand arlure, fl. blanchàtres. Jauvier-février. C.

11. A. citrifolia Mez, loc. cit., p. T't. - Serra de Itabapoana, Espirito Saxto, no 10027. Arbrisseau, fl. blanchàtres. Aout-sepiembre. C.

12. Endlicheria hirsuta Nees; Mez Monogr. Lanrac. Amer., p. 119. - Petropolis, Rio-Jax., $11^{\text {os }} 7811,8105$, 12120; Paranaú, Goyaz. no 22056. Grand arbire, fl. blanchatres. dauvier-févier. CG. Vulg. : Canella de Cheirosa.

Var. robusta Glaz. in herh. Paris., Kerol., Kew., ete. - Biribiry, près Dianantina, Mlsss. no 19795. Grand arbre, fl. Janchảtres. Févier-mars. C. Vulg. : Canella perolua.

Var. glabrata Glaz. in hell, Paris.. Berol., Kew., etc. - Floresla da Tijuca et Concovado, Rio-JAx., nos 3092, 16315. Grand arbre, fl blanchatres. Novembre-décembre. C. Yulg. : Canella.

13. Endl. glomerata Mez in Monogr. Laurac. Amer., 11. 127. Restinga de Mauá, Morno da Viracão, Rı-Jav., nº* 7781, 8093, 18451. 
Arbrisseati, li. blanches cupule rose. Novembre-décembre. CC. Vulg. : Canella jacua.

14. Endl. macrophy-lla Mez, loc. cit., p. 128. - Quinta de São Chris-

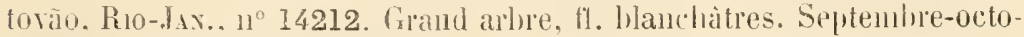
hre. R. Vulg: Canella cullivé.

13. Endl. anomala Nees; Hez Monogr. Laurac. Amer.. p. 133. Quinta da Bua Vista. à S. Gristovio, Rio-JAx., $1^{\circ}$ 14210. Arbisseau, fll. blanchaitres, cultivé. Juin-juillet.

16. Ajouea saligna Meissn.: Mez, loc. cit., p. is. - Floresta da Tijuca, Serra dos Oroũos. Curcorado etc., lio-Jax., nos 1071, 1128, 1174 , 11475, 12123, 15366, 20458. Grand arbre. fl. blanc verdatre. Marsarril. CC.

17. A. trineruis Heissn.; Mez loc. cit. p. 41. - Pedra de Amolar, pres Ouro Preto, Mixas, no 20441. Arbrisseau, fl. blanchâtres. Uctobrenovembre. $\mathrm{R}$.

18. A. brasiliensis Meissn.; Hez, loc. cit. p. 4.3. - Abbade, près Heia Ponte, Goraz, n 22053. Tres srand alore, fl. blane jaunâtre. Aocit-septembre. C. Vulg. : Canella.

19. A. marginata Mez, in Bol. Jahrb., p. 13. - Entre Alere el Passa Tres, dans les cerrados, Goraz, $n^{\circ}$ 22050. Arbrisseau, ll. blanchàtres. Aoùt-septembre. C.

20. A. Warmingii Mez in Monogr. Laurac. Amer., p. 46. - Collegio, près Campos, Rı-Jan., $1^{\circ}$ 11460. Grand arhre, fl. blanchàtres. Septembre-octolire. C..

21. A. Meissneri Nez. loc. cit.. p. 46. - Fazenda dos Pyreneos,

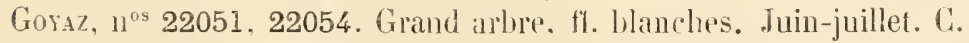

2.- Urbanodendron verrucosum Mez, loc. cit., p. 43 - Floresta da Tijuca et Petropolis, Rro-dAx.. n ${ }^{\circ} 8102,11472$, Grand arbre, fl. blanclies. Mlars-avril. C.

23. Siivia nas'alium Fr. Allem. in Nez Honogr. Laurac. Amer., p. 106. - Serra dos Orgâos, Rio-Jax.. nos 11470, 11473, 12124, 12125. Grand arbre, 11. Blant jaunatre. Janvier-février. C. Vulg. : Tapinhoam.

2'́. Acrodiclidium geminiflorum Mez, loc. cil., p. 8'́t. - Corrovado, à Paineiro, Riı-Jax., nº 6016. Grand arbre, fl. blancliâtres. Octobre-norembre. C.

20. A. Appelii Mez in Engler Bot. Jahrb. 1893), p. 319. - Biriliry, jures Diamantina, Miss, no 19778. Arbrisseau, fl. blanc jaunâtre. Février-mars. C. 
26. Mezilaurus Lindaviana Sichw. et Mez in herh Paris., Berol., liew, Brux., ple. - Serra de Antonio Pereirat, press Guro Preto, Hoxas, nº 19798. Arbrisseau, fl. blanchàtres. Décentre-janvier. R.

27. Cinnamomum Camphora Burm. in Flora zeyl., 1. 62. -- Quinta da lioa Vista, à Sío Christovaro, Rı-Jax., $11^{\circ}$ 12138. Grand arbre cultivé, fl. blanches. Novenulre-décembre. Vulg. : Camphoreira.

28. C. zeylanicum Breyn, in Fl. Brus. V, II, , 1' 1'7. - Quinta da lioa Vista, à S. Christovio, Rio-Jux., nº 6909. Grand arbre cultivé, (1. blanches. Février-mars. C. Vulg. : Canella da India.

99. Persea rufoionentosa Nees; Hez, Ionorgr. Laurac. Amer., p. 141. - Perpetua, près Diamantina, Mısas, $n^{\text {os }} 15360$, 19779. Arbrisseau, fl, rousses. Malrs-arril. C.

30. P. gratissima Grertn.: Mez, loc. cit., p. 14ă. - Passeio Publico, Rio-Jax.. $11^{\text {os }} 814,1286,1515$. Allıre cultivé, fl. blanchatres. CG. Vulgo: Abacaleiro.

31. P. alba Nees; Mez, loc. cit., p. 10\%. - Floresta da Tijuci, RıJax., $n^{\text {os }} 820,3096,7808,17196$; Rasgão prés Corumba, Goyaz, $n^{\circ}$ 22043. Grand ilrore. fl. blanchâtres. Fúvier-avril, CC.

32. P. punctata Neissn.; Hez, loc. cit., p. 193. - Serra dos Orgãos et Petropolis, Rin-JAs., nos 14203, 17178, 17727; Pico d'Ttabira do Campo, Mixas, $n^{\circ}$ 20461. Arbrisseau, fl. blane jaunitre. Janvier-mars. CG.

33. P. pedunculosa Meissn. : Mez,loc. cit., p. 161. - Itacolumy, près ()uro Preto, Mixas, no 15374. Arbrisseau, fl. rousses. Février-mars. C.

34. P. fusca Mez in Bot. Jahrb., p. 1't. - Entre Lamario et Palmital, au Buritisinlo, Goraz, no 22068. Grand arbre, fl. rousses. Juinjuillet. C.

Var. angustrolia Mez in Bol. Jahrb. p. 1\%. - Corrego dlo Brejo, dans les bourbiers, Goyaz, nº 22069. Arbrisseau, 11. rousses. Mai-juin C.

33. P. fuliginnsa Nees; Hez, Monogr. Laurac. Imer., p. 163. - Alto Macahé de Nova Friburgo; Rı-JAx., nos 17177, 17183. Grand arbre, II. rousses. Février-mars. C.

36. P. cordata Vez loc. cit., p. 16.3. - Petropolis, au Morin dans le bois vierge, lin-J1v, no 14208. Gäand arbre, fl. rousses. Janvicr-férrier. C. Vulg. : Canella rosa.

Var. yajor Hez loc. cit., p. 166. - Serra dos Orgãus et Nito Nacahé, Rio-dan., $\mathrm{u}^{0 \mathrm{~s}} 8096,17738,18452$. Grand arbre, ft. rousses. Janvierfévrier. CG. Vula. : Canella cedro. 
A.-F. - GLIZIOU. - LISTE DES PIAYTES DU BRLAII CENTRAL.

- Var. pubescens Glaz.? in herb. Paris., Berol., Kew., Brux., etc. - Entre Lagoa do Cercado et Sĩo José de Ilatosinho, Mısas, $11^{\circ} 22070$. Grand arbre, fl. rousses. ()etobre-novembre. C. Vulg. Abacatarana.

- Var. glabra Mez in herb. Paris., Berol., Kew., Brux, etr. - Altu Macalte de Nova Friburgo, Rio-dax., $11^{\circ}$ 17731. Grand arbre, fl. rousses. Octobre-novembre. G. Vulg.: Canella.

- Var. microphylla Nez in Monogr. Laurac. Amer., p. 166. - Alto Macahé de Nova Friburgo, Rio-dsx:, nos 17182, 17741. Grand albre, 10. hauchâtres. Février-mars. C.

37. P. Tranninensis Glaz. 11. sp.? in herb. Paris., Berol., Kew., Genev., ete. - Alto Naeahé de Nova Friburgo, Rio-J.s., n² 20453. Grand arbre, fi. rousses. Janvier-février. R.

38. P. racemosa Vez in Lonogr. Laurac. Amer., p. 172. - Entre Quelız et Carandalı, dans le campo, Mtros, no- 13157, 15364. Arbre, fi. blanches. Octobre-norembre. C.

39. Phobe tetragona Mez, lor. cit., p. 18\%. - Campo do Pires, près Sabara. Mıvas, no 18435 . Arbuste, fl. blanches. Janvier-février. C.

40. Ph. tomentosa Meissu.: Mez Monogr. Laurac. Amer., p. 188. - Entre Horro Redondo et Manoel Juato, Goraz, no 22060. Arbuste, fl. blanches. Oetobre-novembre. C.

41. Ph. oleifolia Mlez 11. sp. in herb. Paris.. Berol., Kew., Brux., ete. - Morro da Gloria, près Sabara, Mrsas, no 18434. Arbrisseau, f1. blanrhes. Janvier-février. C.

42. Ph. erythropus Hez in Monogr. Lauruc. Amer., p. 189. Gambil, pres Ouro Preto, Mlixis, us ${ }^{0 s} 15373,19775$. Arbrisseau, t1. blanchâtres. Fèrier-mars. C.

43. Ph. Tanbertiana Vez et Sch. in Engler Bot. Jahrb., XXI, p. 位T. - Gamba, près Ouro Preto, Mrxs, no 20455 a. Arbrissean, fl. blanches. Aoùt-septembre. R.

44. Ph. Riedelii Her in Honogr. Laurac. Amer., p. 197. - Alto Macahé de Nova Friburgo, Rio-J.s., no 18445. Grand arhre, fl. blane jaunâtre. Anùt-septembre. C..

4.). Ph. pauciflora llez in Engler Bot. Jahrb. (1893), p. :020. Alto Narahé de Nova Friburgo, Rro-Jax., $1^{\circ}$ 19792. Grand arbre, fi. blane jaunâtre. Octolne-norembre. C.

46. Ph. estrellensis .lez in Monogr. Laurac. Amer., p. 198. Ato Hacahé de Nova Friburgo el au Retiro pres Petropolis, Rio-Jax, $n^{\text {os }} 8907,15379$ a, 20445. Grand arbre, fl. blanchatres. Anut-septembre. C. Vulg. : Canellu meg!\% 
47. Phobe reticulata Hez n. sp. in herh. Paris.. Berol., Kew., Brux. ele. - Alto Matealré de Nova firibnrgo, lio-Jax., no 18432. Grand andore. fl. blanchattres. Janvier-fírrier. R.

48. Ph. brasiliensis Me\% in Monogr. Laurac. Amer., p. 198. - Entre Lagoa do Peise et lio Bonito. Rı-Jax., n"s 12132, 13153. Grand arlore, II. blanc jaunattre. Aoutt-septembre. G.

49. Ph. Glariovii Nez, ioc. cit., 1. 216. - Petropolis et Alto Macahé, Rio-dax., nos 6668. 8097, 15368, 18439. Grand arbre, fl. lianches. Septembre-octolire. CG.

50. Ocotea aciplyylla Mlez, loc. cil., p. ํㅕ․ - Alto Nacahé de Nora Friburgo, Rio-Jax., $11^{\circ} 17733,18443$; lio dos Cuuros, au passage, Goraz, $n^{0}$ 22055. Grand arbre, fl. blanchâtres. Décembre-janvier, CG. Vulg. : Canella amarella.

- Var. robusta Mez in herb. Paris., Berol., Kew., Gener., Brux., etc. - Alto Nacialué de Nova Frilurgo, Rro-dax., $1^{\text {os }}$ 18463, 19794. Grand arbre, fl. blanchâtres. Décembre-janvier. C. Vulg. : Tapinhoan.

51. O. ensifolia Nez in Engler Bot. Jahrb. (1893), 1. 521. - Serra do Cipó, près Congonlıas, da Serra, Mrvas, $n^{\circ}$ 19776. Arbrisseau, fl. blanc jaunuttre. Mars-avril. R.

32. O. Sassafras $11 \%$ in Monogr. Laurac. Amer, p. 247. - Larangeiras, au Cosme Velho, Rio-Jax., no 16316. Grand arbre, fl. brunes. Octobre-novembre. C. Vulg. : Canella Sassafras.

53. O. fasciculata $\mathrm{Me}$, loc. cit., p. 248. - Guaximdiba, Rro-Jax., $n^{\circ} 12135$. Artbre, fl. blanc, jaunatre. Septembre-octobre. C.

5'4. O. indecora Schott: Hez, loc. cit.. 1. 219. - Alto Macahé et Serra da Estrella, Rio-dAx., $n^{\text {os }} 886$, 6020, 14206, 17732, 18384. Grand arlure, 11. Hrunes. Janvier-mar's. GC.

Y.). O. pretiosa Mez, loc. cit., p. 250. - Diamantina, au Tombador, Mısas, n" 19773. Grand arbre, fl. blanthes. Hars-irril. R.

56. O. nitidula Nes, loc. cit., p. 9̈L1. - Nlto Maeahé de Nova Friburgo, Rı-Jav., nº 19799. Grand arbre, li. brunes. Janvier-février. C.

57. O. vaccinioides $11 \mathrm{e}$, loc. cit., p. 2:9. - Serra dos Orgãos, au sommet, Rio-JAx., $1^{\circ s} 6019,17184,17726,17739$. 18450. Arbrisseau, fi. blanthâtres. Férrier-mars. C.

8. O. clegans lez, loc. cit., p. 203. - Alto Marahé de Nora Friburge, Serra dil Estrella, Rio-Jax., $1^{\circ 0}$ 821, 12121, 12133. 17192, 18431, 19791. Grant arbre, fl. brunes. Juin-aoùt. CG.

39. O. squarosa liart; Hez, loc. cit., p. „5ö. - Restingua de 
Cabo Frio, Run-Jax., $1^{\circ}$ 13154. Arbrisseau, f1. blanchâtres. Aoùt-septembre. R.

60. O. frondosa Mez. lor cit.. p. 2006. - Serra dus Oroãos, au Frade, Ruo-Jax., nº 9774 a. Gralid arbre, th. hrunes. Mars-avril. R.

61. O. Spixiana Hez in Honogr. Lawae. Amer., 11. 2601. - Serral

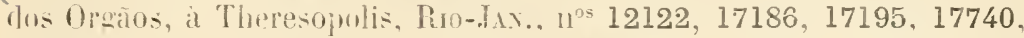
19774; Bento Rodlique\% à Ouro Preto, Mrxas, no 19781. Grand arbre. fi. rousses. Hars-arril. CC.

- Var. goyazensis Hez in herb. Paris.. Berol., Kew., Gener., Brux.. ete. - Cabeceiras du lio Gama et Serra dus Cristaes. Goxaz, $n^{\circ s}$ 22064, 22065, 22066, 22067. Grand arine, fl. rousses. Très bel arbre. Mars-arril. CC.

62. O. L'rbaniana Hez in Monngr. Laurac. 1mer., p. 262. - Ito Macahé de Nova Friburgo, liro-J.x.. nos 17187, 19769. Grand arbre, fl. rousses. Mars-juillet. C.

63. O. insignis Mez, loc. rit., p. „263. - Serra da Estrella, Corcorado, etc., Rio-Jیx., $n^{05} 11469,14207,15369,18444$. Trés grand arbre. fl. blanchâtres. Août-septembre. CC.

64. O. Eichleri liez, loc. cit. p. 277. - Entre Rezende et Jose Vaz, Alto Hacahé de Nova Fribur@o, Rı-dAx., nos 7810, 18440, 20446. Grand arbre, fl. blanchâtres. Septembre-octobre. C.

63. O. Gląiovii Me», loc. cit., p. 81. - Floresta da Tijuca, Corcovado, Alto Nacalué de Nova Friburgo, etc., R!o-Jux., nos 8485, 957l, 11467, 11468, 12126, 12134, 13152, 17736. 18449, 19789. Grant arbre, fl. blanchâtres. Janvier-mai. CG. Vulg. : Canella preta. Canella jacú, Canella amarella.

65. O. pallida Mez, loc. cit., p. 282. - Serra de Itabapoana, Espilito Savto, no 11461, ex. p.. 11462. Graind arbre, ff. blanches. Aoùtseptembre. R.

67. O. rigida Itez, loc. cit., p. $₫ 84$. - Serra d'Itabira do Campo et Serra do Ouro Branco, Mrsis, n's 15371, 17191. Arbrisseau, f1. blanchâtres. Septembre-octobre. C.

68. O. casia Hez, loc. cit., 1. 287. - Meuria, dans la Serra du Caraça, Mrxis, no 15378. Arbrissenu, f1. blanches. Juin-juillet. R.

69. O. variabilis Mart.: Mez, loc. ril.e p. 288. - Biribiry dans le campo, pris Diamantina. Visss, nos 13155, 14216, 19777. Grand arbre. fl. blanches. Janvier-mal's. CC.

70. O. lancifolia Hez, loc. cit., p. 289. - Serra do Caraça, tlans le bois, Miras, no 15375. Arbrisseau, fl. blanchàtres. Février-mars. C. 
71. Ocotea grandifolia Hez, loc. cit., p. 290. - Serra de Itaba-

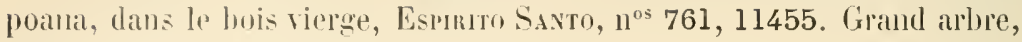
11. blanchlittres. Aout-septembre. C.

72. O. opifera Mart.; Mez, loc. cit., p. 291. - Colonia Leopoldina, Espritro Sasto. $1^{\circ}$ 14213. Grand arbre, ll. blanchattes. Avril-nai. R.

73. O. glomerata $\mathrm{Hez}$, loc. cit., p. 29'. - Serra do Funil, près Diamantina, Mlsws, nos 11464 , 19770. Arbre, Il. blanc jauntatre. Marsavril. C.

74. O. pomaderrioides Ilez, loc. cit., p. 302. - Serra do Ouro Branco, Mlısas, $1^{\circ}$ 18459. Arbrisseau, l'. blane jaunatre. Mars-avril. C.

73. O. tarapotana llez, loc. cit., p. 30't. - Floresta da Tijuca, RioJax., $1^{\circ}$ 11471. Grand arbre, 1l. blanchâtres. Aoùt-septembre. R.

76. O. Schnackeana Mez, loc. cit., p. 30\%̆. - Serra da Estrella, près de Mamminha, Rio-Jax., no 7812. Grand arbre, fl. lulanclıâtres. Janvierfévrier. Ci.

77. O. Minarum Mart.; Nez Honogr. Laurac. Amer., p. 303. Serra do Ouro Branco et Rio das Pedras, Minas, $n^{\circ}{ }^{\circ} 11458$, 15362, 18458, 19782 ; Lagoinha, près Santa Luzia, Goraz, nº 22057. Arbre, 11. Blanchâtres.s. Mars-avril. CG.

78. O. daphnifolia Mez, loc. cit., p. 307. -- Alto Macahé de Nova Friburgo et Corcovado, Rir-JAN., nos 1316, 2675, 5978, 6021, 8103 et 18461. Grand arbre, I1. blanches. Juin-juillet. CC.

79. O. myristicifolia Yez n. sp. in herb. Paris., Berol., Kew., Brux., etc. - Alto Macahé de Nova Frihurgo, ho-JAx., $n^{\text {os }} 18457$, 20447. Arbre, fl. blanchatres. Février-mars. C.

80. O. rerruculosa Ilez in Monogr. Laurac. Amer., p. 308. Alto Nacahé de Nova Friburgo, Rio-Jav., $n^{\text {os }} 17194$, 19803. Grand arbre, fl. blanchâtres. Norembre-décembre. C.

81. O. reticulata Ilez, loc. cit., p. 308. - Petropolis, au Morro da Carangola, Rio-dav., $n^{\circ}$ 14204. Arbre, fl. blanches. Novembre-décembre. C.

82. O. florulenta Nez, loc. cit., p. 309. - Alto Nacalé de Nova Friburgo, Rio-Jav., $11^{o s} 17185,20448$. Grand arhre, fl. brunes. Marsarril. C.

83. O. Langsdorffii Nez, loc. cit., 11. 312. - Serra d'Ouro Petro, dans le bois, Mrxis, nº 19788 a. Arbre, fl. blanchâtres. Févier-mar's.

84. O. mummularia Hez, loc. cit., p. 313. - Serra de São José, près de Sío Joño d'El Rei, Mrsas, no 17179 a. Arbuste, fl. blane jaunàtre. Janvier-février. R. 
A.-F.-M. GLAZIOU. - LISTE DES PLAYTES DL IRESIL CEYTRAL.

85. O. cordata Mez, loc. cit. p. 313. - Serra do Lenleiro, au Rio da Marta Petfuena, Mrsss, nos 17179. 17725. Arbrisseau, fl. blanches. Janvier-lévrier. C.

86. O. phillyraoides Mez, loc. cit., p. 31.ั. - Fazenda da Bocaina, Säo Paulo, nº 8095. Arbrisseau, fl. blanches. Janvier-février. C.

87. O. tristis Mart.; Mez, Monogr. Laurac. Amer., p. 316. - São Sebastiâo, près Ouro Preto, Ilxis, nos 15379, 19771, 20454. Arbuste, f1. blanches. Février-mars. CC.

88. O. polyantha Mart.: Mez, loc. cit., p. 34วั. - Restinga de Macahé, Rio-Jax., n ${ }^{0} 18464$.

89. O. pulchella Mart.; Mez, Monogr. Laurac. Amer., 1. 317. Mogy das Cruzes et Campos da Bocaina, São Paulo, nos 8094, 17181, 17734; entre Formosa et Quituto. Goraz, n $^{\circ}$ 22063. Grand arbre, 11. blanchảtres. Novembre-(lécembre. CC.

- Var. ferruginea teste Ilez in herb. Paris., Berol., Kew., Genev., Brux., etc. - Serra d'Ouro Preto, Sĩo Julião, Sĩnta Luzia do Rio das Velhas. Misas, $\mathrm{n}^{\text {os }} 5976$, 14214, 15359, 15363, 15372, 17728, 19797, 20460. Grand arbre, 11. blanc jaunâtres. Novembre-détembre. CG.

90. O. sylvatica Vez, loc. cit., p. 320. - Fazenda do Rio Preto, Mixas, $n^{\circ s} 8908,11457$. Grand arbre, fl. blanchàtres. Novembre-décembre. C.

91. O. organensis Mez, loc. cit., p. 321. - Alto Macahé de Nova Friburgo, Rin-Jax., no 18433 a. Grand arbre, 11. blanchâtres. Juinjuillet. R.

92. O. corymbosa Mez, loc. cit., p. 321. - Alto Wacahé de Nova Friburgo, Rro-Jax, ${ }^{\circ 5}$ 17743, 18433, 18460. Grand arbre, 11. blanchâtres. Janvier-février'. C. Vulg. : Canella.

93. O. Schottii Mez, loc. cit., p. 324. - Serra dos Orãos et Floresta da Tijuca, Rio-JAs., ${ }^{\text {os }}$ 2905, 5979. Grand arbre, 11. blanches. Février-mar's. C.

94. O. Martiana Mez, lor cil., p. 324. - Curcovado, Alto Macahé. líro-Jax., nos 2669, 6666, 13151, 19802 ; São João d'El liei, Mısas, n 17188. Grand arbre. Férrier-mars. C.

9:. O. acutangula Yez, loc. cit., 1. 330. - Floresta da Tijuca, RioJax. nos 11450,11454 . Frand arlse, fl. brumes. Février-mars. C. Vulg. : Canella.

96. O. brachybotra Ilez, loc. cit., p. 332. - Curcovado et Floresta da Tijuca, Rro-Jیx., ${ }^{05}$ 1283, 7806, 9570. Gratrl arbre, 11. brunes. Juin-juillet. CG. 
97. Ocoter lanceolata Yees: Mez, Laurar. Amer., p. 394. - São

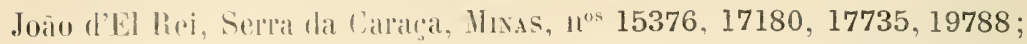
Riacho Findo, dans le bois, foryaz, $11^{\text {ou }}$ 22052, 22059. (irand arbre, fl. blanches. Fir riel-mats. Cit.

98. O. Gardneri He\% loce cil., p. 338. - Restinga da Tijura, RuJax., $1^{\circ=}$ 6015, 20452. Arbrisseau, fi. blanchâtres. Avril-nai. C. Vulg.: Canella da liestinga.

99. O. notata Mez, loc. cit., p. 339. - Taipú dans les sables, RioJax, $\mathrm{H}^{\circ}$ 1285. Arbrissean, fl. blanches. Juin-juillet. R.

100. O. domatiata Nez in Engler Bol. Jahro. (1893), p. \$20. Alto Nacahé de Nova Friburgo, Rio-Jax., n 19805. Grand arbre, fl. jaunâtres. Novembre-décenbre. R.

101. O. glaucina Nez; Monogr Laurac. Amer., p. 340. - Floresta da Tijuca, Alto Macahé et Petropolis, Liro-Jax., $10^{05} 12127,14209$, 17737, 19787, 20449, 20450, 20451; Cerratào da Lagoa Feia près Formosa, Goraz. $1^{\circ}$ 22058. Grand arbre, t1. blanchâtres. Mars-111ai. CC. Vulg. : Canella lápinhoan.

102. O. microbotiys Nlez, loc. cit., p. 341. - Praia Grande, à Santa Rosa, Rio-Jax., nos 1291, 9569. Grand arbre, fl. blanchâtres. Juinjuillet. C.

10\%. O. puberula Nees; Hez, Honogr. Lamac. Amer., p. 143. Petropolis, à Santo Antonio et Alto Nlacahé, Rı-JAx., $n^{\text {os }} 6667,8101$, 15370, 18430, 18462. Grand arbre, 11. jaunes. Avut-septembre. CC.

10\%. O. areolata Mez n. sp. in herb. Paris., Berol., Kew., Genev., etr. - Alto Warahé de Nova Friburgo, Ruo-Jas., nos 18455, 18456. Arlorisseau, fl. blanclıatres. Mars-avril. C.

103̈. O. argentea llez in Monogr. Laurac. Amer., p. 346. - Copacabana et Corrovato, firo-dAx., no 1287, 1288. 1289, 6018, 17744. Grand arbre, It. blanchatres. Juin-octubre. CG.

106. O. Telloziana hez, loc. cil., 1. 3'ti. - Serra da Caraça, dans les bois, Hwas, nos 15358, 15365: Caheceiras do Rio das Pedras, Goraz, $n^{0}$ 22062. Arinissean, 17. Hrunes. Mars-avril. C.

107. O. macropoda Mez, loc. cit., p. 348. - Serra dos Orgĩos, à Theresopolis, Rin-Jix., nos 1064, 8098. 19785; Innte Alegre, au Passa Tres, Gorxz, 17 a2051. Chand arbre, li. Wanchâtres. Loût-sepiembre. CC.

108. O. citrosmioides Mart.; Mez, Monogr. Laurac. Amer., p. 3 19. - Ipanema, dans les buis, São Paulo, no 13148. Grand arbre, fl. blanchâtres. Avril-mai. C. 
109. O. umbrosa Mart.; Hez, Monogr. Laurac. Amer., p. 9öo. Alto Macahri de Nova Friburgo. Rio-Jax., $0^{\circ} 17730$; Itacolums, près Ouro Preto et Bento Rodrigues, Msas, nos 15377, 19783. Grand arbre, fl. brumes, Juin-aotit. CG.

110. O. Blanchetii Mez, loc. cit., p. 33̈. - Congonha do Campo, Misas, nos 15361, 19784. Arbre, 11. rousses. Mai-juillet. C. Vulı. : C'anella fedegosa.

111. O. bracteosa Mez, lor. cit., p. 336. - Itahapoana, Espurito S.xтo, $n^{\text {os }} 11452,11461$, exp., 11463, 11466. Arbre, fl. blanchâtres. Février-mars. C. Vulg. : Louro.

112. O. dispersa Hez, loc. cit., P. 33\%. - Alto Macahé de Nova Friburgo, Rı-JAx., nos 11451,18441 . Arbre, fl. blanchâtres. Novembredécembre. C.

13. O. glauca Nez, loc. cit., p. 362. - Praia do Arpoador, à Gavea, Riro-Jax., n 4907. Arbuste, fl. blanchatres. Mars-arril. C.

114. O. mutans Nlez, loc. cit., p. 362. - Norro do liomão, près Sabara, Mrxas, nos 19786, 20457. Arbrisseau, fl. blanc jaunattre. Marsarril. C.

113. O. macrocalyx .lez, loc. cit., 1). 367. - Corcovado, Petropulis, Alto Macahé, Riı-JAı., nos 822, 824, 1290, 12119, 12128. 15367, 17742, 18454. Grand arbre, fl. blanchatres. Janvier-avril. CC. Vulg. : Canella cedro.

116. O. Hooteriana Mez, loc. cit., p. 368. - Corcovado, d Caixa l'Agua, Ro-JA木., n 5981. Grand arbre, fl. brunes. Arril-mai. C. Vulg. : Canella.

117. O. spectabilis Hez, loc, cit., p. 372. - Nora Friburgo, au Conego, Rio-dax. nos 12137, 17724. 18442. Grand arbre, fl. blanc jaunàtre. Novembre-1lécembie. C.

1IS. O. diospyrifolia Mez, loc. cit., p. 37t. - Serra dos Orgitos. à Theresopolis, Ro-Jix., n ${ }^{\text {os }} 4181,8961$. Arbre, fl. blanchâtres. Novembre-décembre. C.

119. O. subalpina Mez, loc. cit., p. 37̈̈. - Serra do Alto Macahé, Rro-JAx., $11^{\circ}$ 8095. Arbrisseau, fl. blanchatres. Janvier-lívier. R.

120. O. lava Pax; Mez, toc. cit., p. 381. - Serra do Conto, près Petropolis, Puo-Jax., nos 3091, 19876. Arbre, ll. blanchâtres. Décembrejamier. C.

121. O. Telciandra Jez, loc. cit., p. 282. - Floresta da Tijuca, Corcovado et Serra dos Orcãos, Pio-Jax., nos 825, 3097, 3907, 4945, 
7813, 7814 et 11474. Arhe, fl. bhandhâtres. Novembre-dóembre. CC. Vulg. : Camplla Iacua, Louro, Camella Limão.

12.2. Ocotea temuiflora Mez, loc. cil., p. 383. - Corrovado el Florestal da Tijuca, Rio-dan., no 6017. Cramd arbre, fl. blanc jaunâtre. Aoùt-septembre. C.

123. O. inconspicua Yez in Bot. Jalerb., p. 20. - Riu Novo, dans la foret, Minas, $n^{\circ}$ 20456. Grand arbre. 11. blanchattres. Octolsrenorembre. $\mathrm{C}$.

124. O. pubescens Mez in Monogr. Lamrac. Amer., 13. 384. - Petropolis, à Santo Antonio, Rio-J $\mathrm{JN}_{\mathrm{N}}, \mathrm{n}^{\text {os }} 8100,2459$. Arbre, fl. blanchâtres. Aout-septembre. C.

125. O. divaricata Hez, loc. cit., p. 38\%. - Alto Macahé de Nova Friburgo, Rin-Jan., ${ }^{\circ s}$ 18447, 18448. Grand arbre. fl. blanchitres. Aoùt-septembre. C. Vutg. : Canella.

- Form. rhamnoides (Weissner) Mez, Monogr. Laurac. Amer., p. 386. Nova Friburgo, an Conego, Rio-Jas., no 12129. Grand arbre, 11. blanches. Septembre-octobre. CG. Vulg. : Canella branca.

- Form. ;izyphoides (Meissner) Nez, Monogr. Laurac. Amcr., p. 386. - Serra de Jacarepacua et Floresta ta Tijuca, Rı-Jax., nos 3093, 6714. Grand arbrc, ll. blanchatres. Novembre-décembre. C. Vulg. : Canelleira.

126. O. Lindbergii Mez, loc. cit., 1. 386. - Alto Macahé de Nova Friburgo, Rio-Jax., $n^{\circ}$ 18446. Grand arbre, fl. blanchatres. Norembredécembre. C.

127. Nectandra anmmala Nez, in Monogr. Laurac. Amer., p. 401. - Petropolis, au Alto do Imperador. Rio-Jax., $n^{\circ}$ 13150. Très grand arbre, fï. blanchâtris. Février-mars. R.

128. N. firma Mez n. sp. in lrerb. Paris., Berol., Kew., Genev., etc - Amoreira, au Cilparo da Cabeceira, Gosaz, $1^{\circ}$ 22044. Très grand arbre, fl. blanches. Mai-juin. C.

129. N. reticulata Hez, in Nonogr. Lamac. Amer., p. 404. - Jacuacango, Parahyba to Sul. Valence. etc., Rio-Jax., nos 2674, 2676, 4906, 9568, 13149, 20455. Grand arbre, fl. blauches. Juin-juillet. CC. Vulg. : Canella.

130. N. rigida Nees; Hez, Monogr. Laurac. Amer., p. 40\%. - Petropolis au Jacob, Jacareprigua, Serra dos Orgãus, Alto Marahé, Riro-Jin., $n^{\text {os }}$ 2672, 2673, 5977, 8106: Arupuoca, Congonhas da Serra. Misas, $n^{0 s}$ 9567, 11453, 16314, 19780 et 19806. Grand arbre. fl. blanches. Mar's-mai. C.C. Vulg. : Canella.

131. N. lanceolata Nees; Hez, loc. cit., p. \$11. - Corcovado et 
Serra dos Orgãos, Rio-Jax., nos 7807, 7808, 12130. Grand arbre, f1. blanches. Septembre-octobre. CC.

12-2. N. Warmingii Meissn.; I. Glaziovii Mez in Monogr. Laurac. Amer., p. 41 ) (Cl. Mez, Zusatze z. m. Mon. am. Laur., in Arb. K. Bot. Gurt., Breslau, 1892, p. 129). - Sĭu João Baptista, Hrxas, nos 13156 , 14215. Grand athre, f1. blanclıes. Juin-juillet. C. Vulg. : Canella.

133. N. puberula Nees: Me\%, loc. cil., p. 413. - Floresta da Tijuca et Alto Nacahé de Nova Friburgo. Rio-JAx., nos 1112, 2670, 2671, 6704, 6810, 8107, 18453. Grand arlore, fl. blanches. Arril-mai. CC. Vulg. : Canella amarella.

134. N. globosa Mez, loc. ciı., p. 4. Goraz, $n^{\circ \mathrm{s}} 22045,22046$. Grand arbre, fl. blanclıes. Nai-juillet. C.

- Tar. Barbeyand Mez, loc cil., p. 416. - Alto Nacallé de Nora Friburgo, Rro-Jax., n 1389. Grand arbre, fl. blanches. Juillet-aoùt. R.

13\%. N. ambigna Meissn.; Mez, loc. cit., p. 416. - Colonia São Leopoldo, Esplitтo Saxтo, no 10026 a. Grand arbre, fl. blanches. Septembre-octobre. R. Vulg. : Canella.

136. N. urophylla Meissn.; Mez, loc. cit., p. 417. - Serra Affonsinho. Espinto Saxto, no 10026. Grand arbre, fl. blanches. Septembreoctobre. C.

137. N. leucantha Nees: Me\%, loc. cit., p. 431. - Floresta da Tijuca et Corcovado, Rio-JAx., $n^{03} 3094$, 4908. Grand arbre, 1l. blanches. Marsavil. C.

138. N. psammophila Nees; Me\%, loc. cil., 1). 43'. - Floresta da Tijuea et Gavea, Rı-JAx., nos 5980,12136 . Grand arbre, fl. blanches. Férrier-mar's. C.

139. N. nitidula Nees: Mez, loc. cil., p. 436. - Cachoeira do Campo, Sĩo João d'El liei, Barbacena, Mıxas, nos 17189, 17190, 19804. 20442: Alto Macahé, Rı JAx., n² 20443. Arbrisseau, fl. blanches. Septembre-octobre. CC.

1'40. $N$ debilis Mez; Monogr. Laurac. Amer., p. 't6. - Maxambomba, Rio-Jax., nº 8906. Arlurisseau, f1. blanchâtres. Octobre-novemhre. C.

141. N. Twecdiei Me\%. loc. cil., p. 446. - Serra do Lenheiro, près São Joîto d'El Rei, Mrras, no 17189 a. Arbre, fl. blanchâtres. (Octolorenovembre. C.

14.2. N. lencothyrsus Meissn.; Mez, loc. cit., p. 4'ti. - Sauta Luzia do Rio das Velhas, Mrvas, $n^{\circ}$ 20462. Grand arbre, f1. blanchitres. Octobre-novembre. C. Vulg. : Canella. 
143. Nectandra Pichurim Hez, loc. cil., p. 49. - Colonia Santa Isal, Espluto Sax10, $11^{05} 2670,11465,14211$. Grand arlore, fl. llanchâtres. Septembre-octobre. CC. Vulg. : Pichurim.

144. N. myriantha Meissn.; Mez, loc. cil., p. 402. - Entre Buraco da Onça et Alegre', Goyaz, n' 22047, 22048, 22049. Graud arbre, 11. blanches. Juillet-octohre. CC.

1/3. Cassytha americana Nees; Nez, loc. cil., p. 490. - Quinta da Boa Vista, à S. Clnistovio, Rio-Jax, nos 9929, 11278. Parasite sur les arlustes, f1. blanchâtres. Janvier-mars. Cli. Vulg̣. : Cipo chumbo.

- Form. pubcrula Meissı. in Fl. Bras. V, II, p. 996. - Biribiry, près Diamantina, Mixas, n" 19807. Parasite sur les arbustes, l1. blanchittres. danvier-mar's. CC. Vulg. : Cipo cleumbo.

146. C. dissitiflora Meissn. in Kjoeb. Vidensk. Medd. (1870), p. 1430. - Morro do Ramão, près de Sabara, Minas, no 19808. Parasite sur les arbustres, ll. jaunâtres. Mai-juin. CG. Vulg. : Cipo clumbo.

\section{Fam. 118. - Protéacées.}

1. Andriapetalum rubescens Schott.; Fl. Bres. V, I, p. 77. Quinta da Boa Vista, à S. Clıristovão, Rı-Jan., no 14223. Arbuste cultivé, fl. jaunâtres. Novembre-décembre. li.

2. A. multiflorum Schott.; Fl. Bras. V, I, p. 77. - Alto Nacahé de Nova Friburgo, Rio-Jax., nos 8 ] 08, 17197, 20469. Arbrisseau, fl. blanc rougeàtre. Férrier-mars. C.

3. A. cayennense Klotz. in Mart. Fl. Bras. V, I, p. 78. - Quinta da Boa Vista, à S. Christovio, Rı-JAx., no 8108 a. Arbuste cultivé, fl. blanc jaunâtre. Mars-avril. R.

4. Rhopala suaveolens Klotz.; Fl. Liras. V, I, p. 80. - Flo resta da Tijuca, Riso-JAn., nos $681,2681,2682$. Grand arbre, fl. blanc jaumatre. Mai juin. C. Vulg. Catucanhem.

5. Rh. obtusa Klotz.; Fl. Bras. Y, I, p. 80. - Hloresta da Tijuca et Corcovado, Rio-JaN., nos 1305, 4944. Arbrisseau. fl. blane jaunâtre. Octobre-novembre. C. Vulg. : Calucanhem.

6. Rh. acuminata Glaz. 11. sp. in herb. Paris., Berol., kew., Brux., etc. - Corrego do Brejo, au Chico Lobo, Goraz, $n^{\circ} 22018$. Arlrisseau des cerradus. Juin juillet. C.

7. Rh. Gardneri Mleisn.; Fl. Bras. V, I, p. 83. - Serra dos Vertentes et Ouro Preto, Mrsas, $11^{\text {os }} 6670,11479,11480,13158,15381$, 20467. Arbuste, fl. verdâtres. Octohre-novembre. CG. 
A.-F.-M. GLAZIOU. - LISTE DES PLANTES DU BRÉSIL CENTR.AL.

- Val. integrifolia Meisn. in Fl. Bras. V, I, p. 83. - Floresta da Tijuca, Riı-JAx., $1^{\circ} 8909,11476$. Arbrisseat, f1. rerlâtres. Novembredécembre. C.

8. Rh. Incens Meisn.; Fl. Bras. V, I, p. 8't. - Campos da Bocaina, Sĩo-PAvıo, nos 4910,13159 . Arbuste, fl. blanc jaunàtre. Juinjuillet. G.

9. Rh. rluombifolia llart. in Fl. Bras. V, 1, p. S̈. - Serra dos Orgãos et Alto Macalıé, Rio-Jax., nos 3735, 4184, 8109, 19809, 20468. Arbrisseau, f1. blàñ verdâtre. Novembre-décembre. CC.

10. Rh. pallida K. Sch. n. sp. in herb. Paris., Berol., Kew., Genev., etc. - Serra da Bocaina, Sĩo-PALlo, nº 8109 a. Arbrisseau, 11. blanchâtres. Janvier-mar's. R.

11. Rh. longepetiolata Pohl; Fl. Bras. V. I, p. Sö. - Lagoinlıa, au Corcovado, Rio-JAx., $\mathrm{n}^{0 \mathrm{~s}}$ 1306, 2665. Arbuste, fl. blanc verdâtre. Juin-juillet. C.

12. Rh. brasiliensis Klotz.; Fl. Bras. V, I, p. 86. - Mendanha dans le campo, Mıxas, $n^{\circ}$ 14224; Floresta de Tijuca, Rio-Jax., nos 4943, 11477, 19810. Arbrisseau, f1. blanc jaunàtre. Novembre-técembre. CC.

- Var. pubescens Glaz. in lıerb. Paris. et Berol. - Floresta da Tijuca

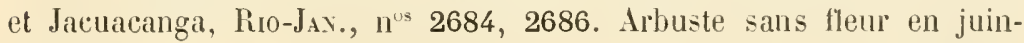
juillet. li.

- Var. velutra Meisn. in Fl. Bras. V, I, p. 86. - Petropolis, au Morro do Cubiçado, Rio-Jax., nos 4909 , 11478. Arbuste, 11. rousses. Novembre-décembre. C. Vulg. : Catucanhem.

13. Rh. Martii val. sumpicifolia Meisn. in Fl. Bras. V, I, p. 87. Biribiry prìs 1)iamantina, Misss, 19811. Arbrisseau, fl. blanc jaunâtre. Mar's-avril. R.

14. Rh. heterophrlla Polıl; Fl. Bras. VI, I, p. 88. - Haut du Corowado, Rio-Jan., ${ }^{\circ}$ 6024. Arbuste, fl. blanchâtı's. Septembreoctobre. C.

13. Rh. heterophylla val. pinvata Polll in Fl. Bras. V, 1, p, 88. Floresta da Tijura et Corcorado, Rio-Jax., nos $683,2683,6025$. Arbrisseau, sans fleur en janvier-mars. C. Vulg. : Catuconhem.

16. Rh. Warmingii Vleisn. in herl. Paris., Berol., Kew., Hau-

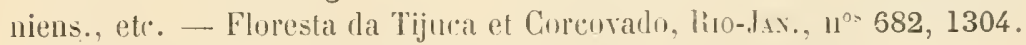
Arbrisseau, sans fleur. Janvier-mars. C. Vulg. : Catuconh'm.

17. Rh. Pohlii Heisu. in Fl. Bras. V, I, p. 89. - Hant du Corcovado, Riro-Jax., nos 6026, 8910. Arbrisseau, fl. rousses. Anut-septenbre. C. Vulg. : Catucanhem. 
- Var. dimorphopungla Fl. Bras. V. I, p. 89. - Coreovalo et Boca do Matto, Pun-Jax., n's 684, 2679, 2680. Arbrissenu, sans fleur en lévriermai. C. Vulg. : Catucunhem.

18. Adenostephanus incequalis Endl.; Fl. Bras. V, I, p. 92. Entre Villa Nova et Porto das Caixas, Rio-Jıx., $1^{\circ}$ 7816. Arbrisseau, fl. rousses. Mai-juin. C. Vulg. : Catucanhem cabelludo.

19. A. Sellonii Klotz; Fl. Bras. Y, I, p. 92. - Solnadinho, dans le bois, Goraz, no 22015. Arbrisseau, 11. rousses. Aout-septembre. C.

20. A. Glaziovii Hez in Engler Bot. Jahrb. (1890), p. 10. - Serra do Tingua, Rio-JAx., no 13490. Arbrisseau, fl. rousses.

21. A. Tanbertiana K. Sch. in Engler Bot. Jahrb. (1901), p. 28. Floresta da Tijuca et Jacarepagua, Rio-Jas., $n^{0}$ 17745. Arlurisseau, 11. rousses. Novembre-décembre.

22. A. incana Klotz.; Fl. Bras. V, I, p. 93. - Floresta da Tijuca et Corcovado Ro-Jax., no 17745 a. Arbrisseau, fl. rousses. Mai-juillet. CC. Vulg. : Catucanhem.

23. A. Loeseneriana Taub. n. sp. in herb. Paris., Berol., Kew., Gener., etc. - Serra do Cipo, près Congonhas do Campo, Misas, $n^{\circ}$ 19812. Grand arbre, fl. rousses. Mars-avril. C.

24. A. obversiflora Hez in Engler Bot. Jahrb. (1890), 1. 9. Alto Narabé de Nova Friburgo, Rio-Jiv., $n^{05} 6910$, 14225. Arbre, fl. rousses. Décembre-janvier. C.

9.. A. rufa Luesener n. sp. in herl. Paris., Berol., Kew., Brux., etc. - Alto Macahé de Nova Friburgo et Serra dos Orgãos, RioJax., $n^{05} 3734,17199,20470$. Arlrrisseau, fl. rousses. Norembre-décembre. C.

26. A. laxiflora Meisu.; Fl. Bras. V, I, 1. 94. - Serra de São José d'El Rei et Morro te Silo Vicente, Mlwas, nos 1582, 17198. Arlure, tr. rousses, Avril-juin. C.

2i. A. emarginata Glaz. n. sp. in herb. Paris., Berol., Kew., Brux., etc. - Burds du Rio Gama, Gonz, $11^{\circ}$ 22016. Arlsrisseau, f1. verdàtres. Novembre-décembre. R.

28. A. gorazensis K. Sch. in Engler Bot. Juhrb. (1901), p. 298. Serra dos Pyreneos, Gosaz, $1^{\circ}$ 22017. Grand arbre, fl. llanc jaunatre. Aoùt-septembre. li. 


\section{Fam. 119. - Thyméléacées.}

1. Daphnopsis Martii Meissn. Fl. Bras. V, I, p. 66. - Colcovado et Floresla da Tijuca, Rio-JAx., nos 2633, 9572, 18466, 20472. Arbuste, 11. blanc jaunâtre. Norembre-décembre. CC.

2. D. Schnackeana Taub. in Engler Bol. Jahrb. (1890), p. 6. - Alto Macahé et Serra da Estrella, Rı-JAx., n ${ }^{\text {os }} 4765,6698,8251,18467$. Albuste, 11. blane iaunatre. Octolse-novemiore. CC.

3. D. coriacea Taub. in Engler bot. Jahrb. (1890), p. T. - Serra los Orgĩos et do Tingua, Pio-JAx., n ${ }^{\text {os }}$ 3639, 8911, 14226, 18465. Arbrisseau, fl. blanchâtres. Mai-juillet. C. Vulgr. : Embira.

4. D. Beta Taub. in Engler Bot. Jahrb. (1890), p. ö. - Fazenda de Santa Cruz, Nova Friburgo, Rio-Jax., nos 11481. 19813: Bord du lio Bananal, Gorız, nos 20471, 22019. Arbuste, fl. blanches. Février-avril. CG. Vulg. Beta.

๖. D. Selloniana Taub. in Engler. Brot. Jahrb. (I890), p. 7. Entre Sitio et Barbacena, dans le campo, Mixas, $1^{\circ}$ 15383. Arbuste, f1. blanches. Juin-juillet. C.

6. D. longifolia Taub. in Englel Bot. Jahrb. (1890), p. 9. - Alto Narabé de Nova Friburgo, Rı-Jax., no 8252: Campos da Bocaina, SÃo P.ưo, $1^{0}$ 12141. Septembre-octobre. C. Vulg. : Embira branca.

7. D. sessiliflora Taub. in Engler. Bot. Jahrb. (1890, p. 8. - Serra dos Orọ̃os. Rio-Jax., n 17747. Arbuste, ll. blanches. Janvier-févier. R.

8. D. utilis Warm. in Symb. ad Fl. Bras centr. cogn., \%. 198. Alto Nacahé de Nova Friburgo, Riı-Jax., n² 2963. Arbuste, fl. blanches. Férrier-mars. $\mathrm{h}$.

9. D. racemosa Griseb. in Goett. Abh. XXIV (1879), 1. 1\%4. - Serra da liociuna dans le bois. Sĩo Pacuo, no 19814. Arbuste, ll. blanclies. Novembre-décembre. li.

10. D. alpestris Benth. pt Hook. in Gen. Plant. III, p. 192. - Serra dos Orgãos et Petropolis, Rio-JAx., nºs 3654, 17200, 17746. Arbuste, 11. blanc jaunatre. Mars-arril. C.

11. D brasiliensis Mart. Fl. Bras. V, I, p. 66. - Rego d'Agua entre Ayuruoca et Cachambú, Mixas, $11^{\circ}$ 16318; Nova Friburgo, Rio-Jax., n² 17201. Arbuste, 11. blanchâtres. Janvier-décembre. CC.

12. Funifera utilis Leandr. in Fl. Bras. V, I, p. 67. - Corrovarlo et Floresta da Tijuca, Iiı-JAN., $1^{\circ 5} 860,2485,20473$. Arbuste, fl. blanchâtres. Novembre-décembre. CG. Vulg. : Embira. 
13. Funifera fasciculata Meissul. in Fl. Bras. V, I, p. 68. - Nova Friburgo, au Conego, Rio-Jav., II $^{\circ} 12141$ a. Arbuste, 11. blanc jauntitre. Octolnre-nurembre. C. Vulg. : Embira.

14. Linostoma calophylloides Meissn. in Fl. Bras. V, 1, p. 72. Quinta da Boa Vista, à S. Christovĩo, Rio-Jیx., $11^{\circ} 14080$. Arbuste cultivé, f1. blanches. Mars-arril. R.

\section{Fam. 120. - Loranthacées.}

1. Psittacanthus robustus Nart.; Fl. Bras. V, II, p. 23. - Nova Friburgo, au Alto da Serra, Rio-Jax., $n^{0 s}$ 12756, 12757, 13456, 16106. Parasite, fl. jaunes. Novembre-décembre. CC.

2. Ps. Collum-cygni Eichl, in Fl. Bras. V, II, p. 33. - Restinga de Calıo Frio, Rio-Jax., no 10899. Parasite, fl. blanclies. Janvier-décembre. R.

3. Ps. dichrous Nart.; Fl. Bras. V, II, 1. 38. - Lagoa de Freitas et Fazenda de Santa Cruz, liso-Jas., $n^{\text {os }} 1430,1461,2143,6074$ et 9859. Parasite, fl. blanchâtres. Juin-juillet. CC.

4. Ps. flavo-viridis Bl, in Fl. Brus. V, Il, p. 42. - Alto da Serra de Nova Friburgo, Rio-J $\Lambda$., nos 6892 , 17025. Parasite, fl. verdâtres. Janvier-février. C.

ö. Ps. cucullaris Blume in $\mathrm{Fl}$. Bras. V, II, p. 42. - Itapemirim, Esprito Santo, nos 9860 , 13925. Parasite, f1. orange. Juin-juillet. C.

6. Ps. bicalyculatus Mart.; Fl. Bras. V, II, p. 44. - Serra de Itabapoana, Espirıto Saxto, nos 10900, 12755. Parasite, fl. jaunâtres. Juin-juillet. C.

7. Ps. cordatus Blume in Fl. Bras. V, II, p. 44. - Corrego Novo, Mlsas, no 13927. Parasite, fl. blanc verdâtre. Janvier-février C.

8. Phrygilanthus cuneifolius R. P. in Fl. Bras. V, II, p. 49. Ipanema, près la mine de fer, Säo Paulo, $11^{\circ}$ 19418. Parasite, fl. blanc jaunâtre. Juin-juillet. $\mathrm{R}$.

9. Phr. eugenioides H. B. K.; Fl. Bras. V, II, p. 50. - Serra dos Orgãos et Petropolis, lỉı-Jax., nos 8727, 10897, 14888, 17024; Entre Buraco da Onça et Alegre, Goyaz, $11^{\circ}$ 22020. Arbrissean terrestre, fl. verdâtres. Nlars-avilil. ClC.

- Var. robustus Gla\%. in herb., Paris., Berol., Kew., Brux., etc. Alto Nacahé de Nova Friburgo, Rio-JAx., n 18271. Arbuste, fl. blanc verdâtre. Novembre-décembre. R. 


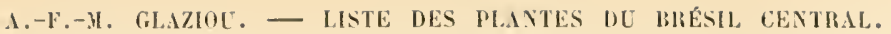

10. Plır. flagellaris Cham. : Fl. Bras. V. II, p. ̌̈l. - Itatiaia, près Campo Bello, Rı-J.x., n 3643 a. Epiphỵte, hl. verditres. Janvier-février. R. Vulg. : Erva de passarinho.

11. Phthirusa pirifolia H. B. K.; Fl. Bras. V, II, p. 63. - Serra de Itabapanna, Espmro Saxto, $n^{\circ}$ 10901. Parasite, 11. verdattres. Janvierfévrier. R.

12. Pl. alternifolia Eichl, in Fl. Bras. V, II, p. 66. - Restinga de Copacabana, Rio-dsx., nos 2142. 4011. Parasite, fl. blanc verdâtre. Ociobre-novembre. C.

13. Plı. clandestina Mart.; Fl. Bras. V, II, p. 66. - Lagoa Rodrigo de Freitas. Rio-J $\mathrm{J}_{\mathrm{x} .,} \mathrm{n}^{0}$ 1469. Parasite, f1. blanc verdâtre. Juin-juillet. C.

1't. Plı. papillosa Pilg. in Engler Bot. Jahrl. (1903). p. 15̆. - Rio Areis, dans le bois, Goraz, $n^{\circ}$ 22022. Parasite, fi. blanches à très bonne ndenr. Aont-septembre. C.

1.i. Struthanthus polyrrhizzus Nart.; Fl. Bras. V, II, p. 7l. - Curimatahy, dans le campo, Mrsas, $n^{\circ} 14886$. Épiphyte, l1. verdatres. Septembre-octobre. CG. Vulg. : Erva de passarinho.

16. Str. flexicaulis Mart.: Fl. Bras. V, II, p. TI. - Passeio Publico, - $11 r^{\circ}$ les Manguiers, Rio-Jax., $n^{\circ}$ 3643. Epiphyte, fl. verdâtres. Janvierfévrier. CG. Vulg. : Erva de passarinho.

17. Str, andrastylus Eichl. in Fl. Bras. V, II, p. T4. - Floresta da Tijuca et au Corcorado, Rio-Jax., $1^{\circ}$ 1072. Épiphyte, fl. verdattres. Juinjuillet. Vulg. : Erea de passarinho. C.

18. Str. marginatus Blume in Mart. Fl. Bras. V, II, p. 77. Quintil da Boa Vista, à S. Christorĩo, sur les Manguiers, Rio-JAx., $n^{\text {os }}$ 135, 5881. Épiphyte, f1. verdàtres. Mars-avril. CG. Vulg. : Erva de passarinho.

19. Str. syringifolins Mart.: Fl. Bras. V, II, 1). 78. - Villa Nova, Rio-Jax., $1^{\circ}$ 7657. Epiphyte. Avril-mai. C. Vulg. : Erva de passarinho.

20. Str. salicifolizes Mart.; Fl. Bras. V, II. 1. 80. - Petropolis, a Itamaraty et au Corcovalo, Rio-JAN., ${ }^{\text {os }} 816,1434,5882,7862,8244$. Parasite, fl. banc verdàtre. Mars-mai. CG.

21. Str. concinnus Mart.; Fl. Bras. V, II, p. 82. - Nlto Nacahé de Nova Friburgo, Rio-JAx., $n^{\circ s} 6895,12754$. Fl. blanchitres. Novembredécembre. Vulg. : Erva de passarinho. CG.

22. Str. ptery gopus Nirt.; Fl. Bras. V. II, p. 82. - Corcovado, à Santa Theresa, Rıo-JAx., nos 2599, 4821; OHı d'Agua, Mixas, $1^{05} 13929$, 14885. Parasite, il. blanchàtres. Aoitt-septembre. CC. 
23. Struthanthus confertus Mart.; Fl. Bras. V, II, P. 83. - Serra da Estrellit, it Manıliocil, Rio-JAx., $11^{\circ}$ 7658. Parasite, Juillet-août. R.

24. Str. tanbatensis Eichl.?; Fl. Bras. V. II, p. 84. - Entre Lagoa du Peixe et le liio Bonito, Rio-Jax., no 12753. Palasite, fl. blanchâtres. Aoitt-septenubre. C.

23. Str. J'ulgaris Ilart.; Fl. Bras. V, II, p. 8̈. - Rio Trapixeiro, Eloresta dil Tijuca, Gavea, Rio-dax., nos 1127, 1436. 4006, 7660. Epiphyte, fl. blanches à tris bonne odeur. Février-juin. CC.

26. Str. Mrichophrllus Eiclll. in Nart. Fl. Bras. V, II, p. 8\%.Villa Nora, Rio-JAx., $1^{\circ}$ 7659. Epiphyte, 11. blanches. Avril-mai. R.

27. Str. orbicularis Blum.; Fl. Bras. V, II, p. 86 . - Olho d'Agua, pres Serrinha, Maxas, no 13926. Epiplyyte, fl. blanchàtres. Avrilmai. R.

28. Phoradendron tmacerorme (DC.) Eichl. in Fl. Bras. V, II, p. 108. - Fazenda dos Porcos, au bord lu Rio Pizarão, Goyaz, nº 22024. Parasite, fl. blanc jaunatre. Janvier-févier. C.

29. Ph. platycaulon Eichl. in Fl. Bras. V, II, p. 108. - Serra dos Purys, Esplitro Santo, $n^{\circ} 13925$ a. Parasite, ll. blane jaunâtre. Octobrenovemhre. R.

30. Ph. fragilis Urb. in Engler Bot. Jahth. (1897). p. 13. - Petropolis, Rı-JAN., $n^{\circ}$ 10898; Gampos da Boraina, São P.ulo, nº 11608 ; Cabeceiras do Rio Gama, Goyaz, $1^{\circ}$ 22023. Parasite sur Mélastomatacées. Novembre-mars, C.

31. Ph. Perrottetii Eichl. in Fl. Bras. V, II, p. 112. - Nlto Mlacahé de Nova Friburgo, Rio-Jan., no 18272. Parasite, fl. blanchàtres. Septembre-octobre. C.

32. Ph. Crulsii Unt. in Engler Bot. Jahrb. (1897), p. 11. - Entre Jaragua et Corrego Fundo, Goyaz, $n^{\circ} 22021$. Parasite, fl. blanc jaunâtre. Juin-juillet. C.

33. Ph. linearifolinm Eichl, in Fl. Bras. V, II, p. 115. - Pico da Tijuca, Caminho do Nacaco, Nova Friburgo, Rio-Jıx., nos $9468,12032$. 12033, 13926, 19419. Parasite, fl. blanchâtres. Octobre-novennhre. CC.

34. Ph. Selloii Eichl. in Fl. Bras. V, II, p. 116. - Serra dos Orgàos, au Frade, Rio-JAx., no 4013. Parasite, 11. blanc jaunitre. Avril-mai. R.

30ั. Ph. acinacifolium Mart. in Fl. Rras. V, II, p. 117. - Restinga da Tijuca, Rio-dax., no 6073. Parasite sur Sapotacée, fl. jaunàtres. Aoùtseptembre. C.

36. Ph. reticulatum Urb. in Engler Bot. Jalerb. (1897), p. 15. Villa Nova, Rio-Jax., $11^{\circ}$ 7664. Parasite, fl. blanc jaunâtre. Avril-mai. C.. 
37. Ph. emarginatum Mart. in Fl. Brus. V, II, p. 118. - Restinga de Caho Frio, Rio-JAx., ${ }^{\circ}$ 9861; Itacambira, dans le campo, Mixas, $n^{\circ}$ 14887. Parasite, t1. Hanches. Mai-juin. C.

38. Ph. rubrum Giriseb.; Mart., Fl. Bras., V, II, p. 120. - Serra de Jacarepagna, Rio-Jax., $n^{0 s}$ 2598, 8728, Parasite, 11. blanchâtres. Férrier-mar's. C.

39. Ph. coriaceum Mart. in Fl. Bras. V, II, p. 121. - Quinta da lioa Vista. à S. Christorão, Rio-Jax., n 4009; Fazenda do Rio Preto, Hixis, no 8729. Parasite, fl. blanchâtles. Norembre-tlécembre. C.

- Var. Quixtense Urb. in Bot. Jahrl. (1897, p. 13. - Q Quinta da Boa Vista, ì S. Christorão, Rio-JAx., n 4010. Parasite, fl. blanc jaunàtre. Févier-mars. C.

40. Ph. alophyllum Eichl. in herb., Paris., Berol., Kew., Gener., etc. - Villa Xova, Rı-JAx, $n^{\circ}$ 7663. Parasite, f1. blanchâtres. Juin-juiliet. C.

41. Ph. undulatum (Pohl) Eichl. in Fl. Bras. V, 11, p. 122. Floresta da Tijuca et Alto Macahé de Nova Friburgo, Rin-JAx., n ${ }^{\circ} 4003$, 6893, 8243. Parasite, fi. blanc jaunâtre. Janvier-férrier. CC.

42. Ph. craspedophrllum Eichl. in Fl. Bras. V, II, p. 12:. - Sì Gonçalo, it Larangeiras, Rio-Jax., nº 8730. Parasite, fi. blane jaunâtre. Août-septembre. R.

43. Ph. rugulosum Urb. in Engler Bot. Jahrb. (1897), p. 13. -Serra dos Orgãos, au Frade, Rio-Jax., nº 4012. Parasite, f1. blanc jaunàtre. Mar's-arril. C.

4'. Ph. crassifolium (Pohl) Eichl. in Fl. Bras. V, II, p. 12̈. - Floresta da Tijuca, Corvovado, Rio-JAs., $n^{\circ s} 1405,1432,1433,1460$, 7666 ; São Domingo, Mıxıs, no 14884. Parasite, fl. blanchaitres. Toute l’année. CC.

4... Ph. latifolium Griseb.; Fl. Bras. V, II, p. 126. - Serra dos Org̣ãos, São Christorão, Gavea, Rı-J.ıx., $\mathrm{n}^{\text {os }}$ 4008, 1428, 1431, 1435, 7661. Parasite, fl. blanchâtres. Férrier-juillet. CG.

46. I\%. Glaziovii Urb. in Engler Bot. Jahrh. (1897), p. 12. Floresta da Tijuca, Rio-Jan., $\mathbf{1}^{\circ}$ 4004. Parasite, 11. blanchàtres. Férriermars. li.

47. Ph. pteroneuron Eichl.: Fl. Bras. V, II, p. 127. - Corcorado, à Paineiras, Pio-Jay., nos 1462, 9858. Parasite, fl. blane jaunatre. Juillet-aoùt. C.

48. Dendrophthora clliptica Krug et Urb. in Ber. Deutsch. Bol. Ges., p. 28:3. - Serra dos Oroños et Alto liacahé de Nora Friburgo, 
Rio-JAx., $11^{\text {ps }} 2880,3642,6894,8726$, 17023. Parasile, 11. blanches. Aoùtseptembre. C.

49. Basicarpus Glaziovii Van Tiegh. in Bull. Soc. bot. Fr. (189:), p. 562. - Campos da Bocaina, à Vaca Cahio, São Paxlo, nos 7665, 8242. Parasite, fl. llanches. Férrier-mars. R.

50. Eubrachion brasiliense Eichl. in Fl. Bras. V, II, p. 133. Serra dos Orgĩos, au sommet, Rio-Jax, $n^{o s} 4014$, 6075. Parasite sur Mritacée, fl. blanchìtres. Septembre-octobre. C.

Fam. 121. - Santalacées.

1. Thesium brasiliense A. DG.; Fl. Bras. V, I, p. 103. - Campos da Bocaina el Hogy das Cruzes, S̃̃o PAulo, nos 8478, 17751; Diamantina, dans le campo, Mıvas, nº 19815; Chapadão dos Veadeiros, Govaz, nº 22025. Frutescent, fl. blanches. Mars-avril. C.

2. Th. Glaziovii K. Sch. n. sp. in herh. Paris., Berol., Kew., Brux., ete. - Chico Costa, dans le campo, Goraz, nº 22026. Frutescent, fl. blanrhes. Septembre-octobre. C.

3. Iodina cuneifolia Miers in Journ. Limn. Soc. XVII, p. 84. Mogy das Cruzes, dans le campo, São Pacto, no 18989. Arbuste, fl. blanchâtres. Janvier-février. R.

4. Osyris spinescens Mart. et Eichl.; Fl. Bras. XIII, 236. - Serra do Lenheiro, près São João d'El d'Rei, Mixas, no 18988. Arbuste, fl. blanchâtres. Juillet-aoùt. IR.

Fam. 122. - Balanophoracées.

1. Langsdorffia hrpogaca Hart.; Fl. Bras. IV, I, p. 10. - Serra da Estrella, à Mandioca, Rio-J JN., nº 4669. Parasite. Mai-juin. C.

2. Scybalium Gląiovii Eichl. in DG. Prodr. XVII, p. 133. - Alto Vacalıé de Nova Friburgo, Rio-JAx., ${ }^{0 s} 4070 b$ et 4700 . Parasite sur racines de Myrsinées, fr. roses. Janvier-février. C.

3. Sc. fungiforme Sch. et Endl. in Fl. Bras. IV. I, p. 36. - Alto Macahé de Nova Friburgo, Rı-JAN., n 4070 a. Parasite sur Myrsinées, fl. roses. Septembre-octohre. C.

4. Helosis guyanensis Rich.; Fl. Bras. IV, I, p. 23. - Serra do Arirn, près Angra dos Reis, Rio-Jax., nº 4969 a. Parasite sur Légumimeuse. Février-mars. C. 
¿. Lophophytum mirabile Sch. et Endl.; Fl. Bras. IV, 1, P. 46. - Serra dos Orgãos, au Rio Soberbo, Riı-Jax. Sans numéro. Juilletseptembre. C.

\section{Fam. 193. - Euphorbiacées.}

1. Savia dictyocarpa Müll. Arg. in Mart. Fl. Bras. XI, JI. p. 704. - Corcovado, à Santa Theresa, Rio-Jax., 1105 3947, 5986 et 18473. Arbrisseau, fl. verdàtres. Octobre-novembre. C.

2. Richeria grandis Müll. Arg.; Fl. Bras. XI, II, p. 15.. - Santo Antonio da Itinga, dans les bourbiers, Mixis, $n^{\text {os }} 15384,16319,19868$; Formosa, dans les bourbiers, Gordz, $n^{\circ} 22141$. Arbrisseau, fl. blanc jaunâtres. Octolore-novembre. C.

3. Freireodendron sessiliflormm Mïll. Arg. ; Fl. Bras. XI, II, p. 19. - Corcovarlo, i Cara da Onça, Rio-Jax., nos 1469, 8326, 12151. Arbrisseau, fl. verdatres. Octobre-novembre. C.

4. Hieronyma ferruginea Tulasne; Fl. Bras. XI, II, p. 21.Ayuruoca, Mıss, n 16342. Grand arbre, 11. rousses. Janvier-février. C. Vulg. : Quina do matto.

¿.. H. mollis Müll. Arg.; Fl. Bras. XI, II, 1. 21. - Pao d'Alho, EsprRito SAxto, $n^{\circ}$ 11525. Grand arbre, fl. rousses. Novembre-décembre. R.

6. H. oblonga Müll. Arg.; Fl. Bras. XI, 1I, p. 22. - Villa Nora, dans les sables, Rio-J $J_{\text {Ax. }} n^{\prime \prime s} 11526,14268$. Arbre, fl. rousses. Novembredécembre. C. Vulg. : Urucurana.

7. H. alchorneoides Fr. All.; Fl. Bras. XI, II, p. 24. - Corcovado et Alto Iacahé, Pio-Jax., nos 2697, 2698, 17217. Grand arbre, 11. rousses. Novembre-décembre. CC. Vulg. : Urucurana.

8. Phyllanthus Riedelianus Müll. Arg.; Fl. Bras. XI, II, p. 26. Entre Queimado et Rio Douro, Rı-JAx., n' 9581 . Arbrisseau, 11. brunes. Octobre-novembre. C.

9. Pl. grandifolins Müll. Arg. ; Fl. Bras. XI, II, p. 28. - Collegio, près Campos, Rı-Jax., n 13491. Arbrisseau, fl. brunes. Janvier-février. R.

10. Ph. corcovadensis Müll. Arg.; Fl. Bras. XI, II, p. 30. - Floresta da Tijuca et Corcurado, Rio-Jax., $n^{\text {os }} 229,4913,4977$. Frutescent, f1. blanclıâtres. Mai-juin. C.C. Vulg. : Erva pombinha.

11. Ph. Lindbergii Mïll. Arg. in Fl. Bras. XI, II, 1. 30̈. - Serra de Jacarepagua, Rı-Jan., $n^{\circ} 4913 a$. Frutescent, fl, verdâtres. Novembredécenbre. C. Vulg. : Erva pombinha. 
12. Phyllanthus macahensis Glik. 11. sp.? in herl. Paris., Berol., kew., Brux., ete. - Nacalué, dans la Restinga pries de la mer, Ruo-Jas., $n^{0}$ 1157. Arluste, fl. verdâtres. Juillet-aoùt. R.

13. Ph. racemigerus Müll. Arg.; Fl. Bras. XI. II, p. 34. - Serra dos Pulys. Esprato Saxto, $11^{\circ}$ 11506. Arbuste, 11. blanchâtres. Octobrenovembre. R.

14. Ph. parahybensis Glaz. n. sp.? in herb. Paris., Berol., Kew., Brux., ete. - Lit du Rio Parahyba, entre les pierres, Rı-Jax., no 12189. Frutescent, fl. hlanchâtres. Novembre-clécembre. C.

1\%. Ph. guyanensis Müll. Arg.; Fl. Bras. XI, II, p. 39. - Serra da Ilantiqueira, Monss, n* 9614. Arbuste, fl. blanchatres. Janvier-févirier. C.

16. Ph. cladotrichus Müll. Arg.; Fl. Bras. XI, II, p. 41. - Sans localité $11^{\text {os }} 11499,11530$.

17. Ph. Glaziovii Nlüll. Arg. in Fl. Bras. XI, II, p. 41. - Serra dos Orgãos, à Tabơiuha, Rio-Jax., nº 2892. Arbuste, ll. blanc verdâtre. Aoùtseptembre. R.

18. Ph. acuminatus Vahl; Fl. Bros. XI, II, p. 42. - Serra dos Oroãos et Altu Nacahé, Rio-JAx., ${ }^{03}$ 9589, 17556. Arbuste, fll. blanc jaunâtre. Aoùt-septembre. CC.

19. Ph. Ternauxii Glaz. n. sp.? in herb. Paris., Berol., Kew., Brux, etc. - Fazenda Ingleza, à Petropolis, Lho-Jas., no 8928. Arbuste, 11. blanc jaunttre. Janvier-février. C.

20. Ph. brasiliensis Mïll. Arg. : Fl. Bras. XI, II, 1) 44. - Serra de Itabapoana, Espreito Santo, $\mathrm{n}^{0 s} 10046,11500,11503,11504$. Arbuste, fl. blanc jaunittre. Août-septembre. C.

21. Ph. alegrensis Glaz. n. sp.? in herb. Paris., Berol., Kew., Havn., ete. - Alegre, dans le bois, Esplatro Saxto, $1^{\circ}$ 11505. Arbuste, fl. blanc verdâtre. Septembre-octobre. R.

22. Ph. Blanchetianus Mïll. Arg.; Fl. Bras. XI, II, p. 40. - Floresta da Tijuca, au Pico, Rio-das., 1 $^{\circ}$ 4976. Frutescent, fl. blane jaunâtre. Aotit-septembre. C.

23. Ph. janeirensis Vhïl. Arg. in Fl. Bras. XI, II. 11. 43. - Restinga da Tijuca et Petropolis, Ro-Jax., ${ }^{05}$ 1467, 7818. Frutescent, fl. blanclıttres. Juin-juillet. C.

24. Ph, montevidensis var. inundatus IIüll. Arg. in Fl. Bras. XI, II, p. 46. - Lit du Rio Parahyba, près Boa Vista, Rio-Jax., nº 13168. Frutescent, fl. blanchâtres. Juin-juillet. C.

28. Ph. Schombungkianus Nüll. Arg.; Fl. Bras. XI, II, p. 46. - 
Passage du Rio Indaia au Porto da Bandeir"i, Goyaz, 11" 22091. Frutescent, fl. Hlanchàtres. Septembre-octobre. C.

26. Ph. avicularis Müll. Ar@.; Fl. Bras. XI, II, p. 49. - Apiahy, dans les endroits humides, Sĩo Patro, $n^{\circ} 16330 a$. Loût-septembre. Frutescent, ll. blanc jaunâtre. Ii.

27. Ph. lathyroides Müll. Arg.: Fl. Bras. XI, II, p. こ̈1. - Floresta da Tijuca, au Pico, Rio-Jax., nos 6124,17757 . Frutescent, fl. blanchittes. Juin-juillet. CC.

- Var. genurus Müll. Arg.: Fl. Bras. XI, II, p. ¿̈. - Cachoeira do Campo et Serra da Piedade, Mixas, $n^{\text {os }}$ 13192, 20475, 20480. Frutescent, fl. blanchàtres. Novembre-décembre. CC.

28. Ph. Niruri Vüll. Arg.; Fl. Bras. XI, II, p. dans le campo et Itatiaia, Mrss, $n^{\circ s} 8927$, 14248. Frutescent, 1l. blanchâtres. Avril-juillet. CC.

- Var. genuinus Müll. Arg.: Fl. Bras. XI, II, p. ̈̈4. - Oninta da Boa Vista, à S. Christorão, Rio-Jax., $n^{0}$ 4978. Frutescent, ll. blanchâtres. Septembre-octobre. C. Vula. : Erva pombinha.

29. Ph. minusculus Glaz. 1. sp. in herb. Paris., Berol., Kew., Brux., ete. - Serra dos Pyreneos, sous les rochers, Goraz, n² 22089. Herbacé, li. blanchàtıes. Juin-juillet. R.

30. Ph. fastigiatus Muill. Arg.; Fl. Bras. XI, II, p. 57. - Itacolamy, près Ouro Preto, Mrisa, $n^{\text {os }} 15413,17758,18477,19445,19446$. Frutescent, fl. blanchàtres. Juin-juillet. CC.

31. Ph. Regnellianus Müll. Are. ; Fl. Bras. XI, II, p. ̈̈8. - Tripulı̣. près Ouro Preto, Mrsas, $n^{0}$ 20478. Frutescent, fl. blanc jaunâtre. Novembre-décembre. C.

32. Ph. ericoides Glaz. n. sp. in herb. Paris., Beroł., Kew., Brux., etc. - Serra da Baliza, lans le rampo, Goyaz, nos 22093, 22095. Filescent, fl. blancliatres. Janvier-mars. C.

33. Ph. pinifolius Baill. in Adansonia, V (1864-63), p. 33̈3. - Serra do Caparĩo, dans le rampuo, Nixas, $n^{\text {os }} 17755$; 18816 ; Selra dos Veadeiros, entre les rochers, Goraz, $n^{\circ}$ 22094. Frutescent, t1. blanc jaunattre. Décembre-janvier. C.

34. Ph. rosmarinifolius llüll. Aræ. in Fl. Bras. XI, II, Р. 60. Serra dos Orgãos, au sommet, Rio-JAx., nos $2879,6131,16330,17210$. Frutescent, fl. blanclies. Décembre-janvier. C.

33. Ph. orbiculatus Vüll. Arg.; Fl. Pras. XI, II, p. 62. - Serra da Picdade et Barreira Grande, Mrsas, nos 19843, 19844, 20479. Frutescent, f1. Jlauches. Novembre-décembre. C. 
36. Phy ylanthus arenicola Casar.; Fl. Bras. XI, II, P. 64. - Restinga de Taipú dans le sable. Rio-dax., no 18478. Frutescent, fl. blanclualtres. Mars-arril. C.

37. Ph. Senæi Glaz. n. sp. ? in herb. Paris., Berol., Kew., Genév, etc. - Serra de Ouro Branco, à São Julião, Mısas, no 19842. Frutescent, fl. blanchàtres. Mars-avril. R.

38. Pl. subemarginatus Müll. Arg.; Fl. Bras. XI, II, p. 66. Copacabana, à Pedra dos Cabritos et au Morro Queimado, Rio-Jax., $11^{\text {os }} 11544,12153,15412,17284$. Frutescent. fl. blanchâtres. Janvierjuin. CG.

39. Ph. amœnns Miill. Ars. in Fl. Bras. XI, II, p. 66. - Paranaúa, dans le campo, Goraz, n² 22090. Frutescent, fl. Hanchàtres. Mars-avril. C.

40. Ph. minensis Glaz. n. sp.? in herb. Paris., Berol., Kew., Havn., etc. - Vinas Novas, dans le bois, Mras, $n^{\circ}$ 13193. Arbuste, fl. blanchàtres. Novembre-décembre. C.

41. Ph. nobilis var. Riedelianus Mïll. Arg.: Fl. Bras. XI, II, p. 69. - Corcovado, au Silvestre, Rio-Jax., ${ }^{\circ}$ 6132. Grand arbre, fl. blanc jaunâtre. Septembre-octobre. C.

42. Ph. choretroides Miill. Arg.; Fl. Bras. XI, II, 1. 70. - Serra do Cipó, clans le campo, Mrisa, $n^{\circ}$ 19824. Frutescent, fl. brunes. Marsavril. $\mathrm{C}$.

43. Ph. Klotzchianus Mïll. Arg.; Fl. Bras. XI, II, p. 7I. - Serra da Caraça, pres Alegria, ilsss, 15410. Arbuste, fl. blanchâtres. Févriermars. C.

44. Ph. angustissimus Müll. Arg.; Fl. Brus. XI, II, p. 73. - Biribiry, priss Diamantina, Mıss, n 19847 . Frutescent, fl. blanchâtres. Marsaviil. C.

4\%. Ph. casuarinoides Glaz. n. sp. in herh. Paris., Berol., Kew., Brux., etc. - Serra da Baliza, à Vargem Grande, Goysz, nº 22092. Arbuste de 1 à 2 m. fl. blanches. Janvier-févier. R.

46. Ph. flagelliformis Miill. Arg.; Fl. Bres. XI, II, p. T4. - Arassuahy, dans les bourbier's, Mlıss, $n^{\circ} 15411$. Frutescent. fl. blanc verdâtre. Juillet-aont. C.

47. Piranhea trifoliolata Baill.; Fl Bras. XI, II, p. 80. - Quinta da Boa Vista, à S. Chrristorão, Rio-J.ıx., nº 14232. Grand arbre cultivé, 11. blanchâtres. Juillet-aoùt. R. Vulg. : Piranha uba.

48. Croton exuberans Miill. Arg. in Fl. Bras. XI, II, p. 83. - Entre Sitio et Barbarena, Mrss, $n^{\circ} 5933$ a. Arbuste, ll. rousses. Juin-juillet. C. Vulg. : Assare. 
A.-F.-I. GIAZIOU. - IISTE DES PLIYTES DE BRESIL CEYTRAL.

49. Cr. Nettoanus Glaz. n. sp.? in herb., Paris., Berol., Kew.. Harn., ete. - Páo đAlıo, Espirito Saxto, $1^{\circ}$ 11521. Frutescent, 11. blanchàtres. Juin-juillet. C.

50. Cr. hemiargyrens Mïll. Arg.; Fl. Bras. XI, II, p. 87. - Petro. polis, à Itamaraty, Rio-Jar, n ${ }^{0}$ 16341. Grand arbre, fl. blanc jaunâtre. Novembre-rlécembre. C.

:1. Cr. caldensis Müll. Aro. in Fl. Bras. XI, II, p. 93. - Nova Friburgo, au Alto da Serra Rio-JAx., nº 12154; entre Queluz et Carandahy, Mris, $11^{9}$ 15391. Arhuste, f1. lousses. Octobre-novembre. C.

:2. Cr. Glaziovii Vüll. Arg. in Fl. Bras. XI. II, 1).94. - Entre Nova Friburgo et le Alto, Rio-JA... $n^{\circ}$ 2691. Arbuste, fl. rousses. Arril-mai. R.

33. Cr. Novi-Friburgi Jïll. Al re. in Fl. Bras. XI, II, p. 97. - Nova Friburgo, près du Alto da Serra, Rio-Jax., n² 2690. Arłuste, t1. rousses. Mai-juin. C. Vulg. : Sangue de drago.

ö4. Cr. hecatonandrus Müll. Arg. in Fl. Bras. XI, II, p. 70... - Itatiaia, dans le bois et le campo, Rio-JAr., n ${ }^{03}$ 4916, 5983, 5984, 6680. Arbrisseau, fl. rousses. Juin-juillet. CG. Vulg. : Sangue de drago.

:̈. Cr. celtidifolius Baill.; Fl. Bras. XI, II, p. 98. - Bords du Rio Parahyba, Rio-Jax., no 2110 . Arbrisseau, fl. rousses. Sejptembre-octobre. C. Vulg. : Sangue de drago.

5̈6. Cr. lagnensis Müll. Arg. in Fl. Bras. XI, II, j. 99. — Santa Luzia do Rio das Vellas, Mrss, $n^{\circ}$ 20481. Arbrisseau, f1, rousses. Novembredécembre. C. Vulğ. : Sangue de drago.

97. Cr. spharogynus Baill.: Fl. Bras. XI, II, p. 101. - Floresta da Tijuca et Corcovalo, Rio-Jix., $1^{\circ}$ 782. Arbrisseau, 11. blanchitres. Juinjuillet. C.

¿8. Cr. organensis Baill.; Fl. Bras. XI, II, p. 103. - Serral dos Or.wios, d̀ Theresopolis, Rio-J.x., n's 1153, 1607, 6129. Arbre, fl. blanclitutres. Octolıre-novembre. CG.

39. Cr. palanostigma Klotz.; F. Bras. XI, II. I. 106. - Santo Antonio da Itinga, dans le bois, Mrss, $n^{\text {os }} 13182.14257,14258,15393$. Arlue, fl. rousses. Janvier-férrier. CC.

60. Cr. pungens Jacy. ; Fl. Bras. XI, II, p. 107. - Villa Nova, près Portu das Caixas, Rio-Jax., 11" 7821. Albre, f1. rousses. Mai-juiı. C.

61. Cr. macrobotrys Baill. ; F. Bras. XI, II, p. 108. - Corcovado et Petropolis, Rio-Jav., ${ }^{\text {os }}$ 14267, 15395. Grand arlore, ll. lousses. Janvier-fervier. CC. Vulw. : Sangue de drago.

- Var. Microbotrys Glaz. rar. nov.? in herb. Paris., Berol., Kew., etr. 
- Sào Domingo, prés de Conceiçan, dans le bois, Misas, no 13180. Arbuste, fl. blanchâtres. Novembre-décembre. C.

6․․ Groton alegrensis Glaz. n. s]1.? in herl. Berol., Kew., Paris., etc. - Alegre, dans le campo, Espirito Savro, $n^{0}$ 11511. Petit arbuste, fl. blanchâtres. Septembre-octolnre. C.

63. Cr. Regelianus Müll. Arg. in Limnen, XXXIV (1863-66), p. 192. - Abbadia, près Arassualyy, Nlxis, $1^{0 s} 11512,11513,13185,13186$, 14256, 14261. Arbuste, fl. blanchâtres. Octohre-novembre. G.

6ł. Cr. echinocarpus Müll. Arg.: Fl. Bras. XI, I, p. 109. Serra dos Mrỡos, à Theresopolis, Rio-dan., nos 2692, 4195, 9586. Grand arbre, fl. rousses. Octobre-décembre. CC. Vulg. : Sangue de drago.

63. Cr. Urucurana Baill.; Fl. Bras. X, II, p. 111. - Santo Antonio da Itinga, Mwss, $1^{\text {os }} 13183,13184$; et entre Queluz et Carandalry, dans le campo, $n^{\circ}$ 15392. Arbre, fl. rousses. Mars-arril. CG.

- Var. genurnus Vüll. Argg. in Fl. Bras. XI, II, p. 111. - Volta Redonta, Rı-Jan., no 4917. Arbrisseau, fi. rousses. Juin-juillet. C. Vulg.. : Sangue de drago.

66. Cr. gracilipes Baill.; Fl. Bras. XI, II, p. 113. - Bords du Rio Paralyba, Rio-Jax., $1^{0} 13184$ a. Arbrisseau, fl. rousses. Septembreoctobre. C. Vulg. : Sangue de drago.

67. Cr. paracnsis Mü̈l. Arg. in Fl. Bras. XI, I, p. 116. - Entre Ararnamo el Rio Rontoto, Rio-JAx., no 10039. Arbuste, f1. roux blanchâtre. Octobre-novembre. R.

68. Cr. matourensis ilüll. Arg.; Fl. Pras. XI, II, p. 118. - Près de São Pedro dos Indios, hro-Jax., n 10047. Arbrisseau, nl. Blanchâtres. Norembre-décembre. Ii.

69. Cr. floribundus Spreng.; Fl. Bras. XI, II, P. 128. - Petropolis, au Padre Correia, liro-Jax., $n^{\text {os }} 785$, 8919, 15396. Ar!srisseau, fl. blanchâtres. Novembre-décembre. C.

70. Cr. micans Müll. Argg.: Fl. Bras. XI, II, p. 121. - São João Baptista, pres Arassuahy. Mixas, nos 11514,14253 . Arlurisseau, fl. rousses. Févier-mars. C.

71. Cr. tricolor Müll. Are; ; Fl. Bras. XI, H. p. 123. - Abbadia, près Arassualıy, Mnsas, nos 15394 , 19833. Arbrissrau, fi. blanchâtres. Mars-avril. C.

72. Cr. compressus Lank: Fl. Bres. X1, II, P. 127. - Floresta do Tijuca et Corcovado, Rro-JAx., nos $345,756,11520$. Arbuste, fl. blanchâtres. Janvier-férrier. CG.

73. Cr. montevidensis Spreng.; Fl. Bras. XI, II, p. 130. - Biribiry, 
près Diamantina, Mıras, no 19830. Arbuste, 11. rousses. Avril-mai. R.

íf. Cr. glaber Glaz. n. sp.? in herb. Paris., Berol., Kew., Brux., etc. - Serra de São José d'El Rei, IIrsas, $1^{\circ}$ 16338. Petit arbuste, f1. blanchâtres. Novembre-décembre. G.

73. Cr. salutaris Casar.; Fl. Bros. XI, II, p. 134. - Serra dos Orgãos et Itatiaia, Rio-Jax., nos 1609, 2689, 6679, 19832. Grand arbre. 11. rousses. Janvier-février. CC. Vulg. : Sangue de drago.

76. Cr. pycnocephalus Müll. Arg.; Fl. Bras. XI, II, p. 136. - Diamantina, an Tombador, Hrisas, $n^{\circ}$ 19829. Arbuste, 11. blanchàtres. Avrilmai. C.

77. Cr. migrans Casar.; Fl. Bras. XI, II, p. 139. - Nova Friburgo, à Pedra do Conego et à Restincra da Tijuca, Rio-Jax., n ${ }^{\text {os }} 728,6128$, 7825, 13174, 13175, 17216. Petit arbuste, fl. rousses. Septembreoctobre. CC.

78. Cr. dichrous Mäll. Arg.; Fl. Bras. XI, II, p. I'40. - Serra do Ouro Branco, dans le campo, Dhras, $1^{\circ}$ 15402. Frutescent, f1. blancllâtres. Février-mars. C.

79. Cr. occidentalis Hüll. Arg. Fl. Bras. XI, II, p. 199. - Entre Diamantina et As Dattas, Hisas, $n^{\circ}$ 19828. Frutescent, fl. rousses. Avill-mai. C.

80. Cr. piauhyensis Müll. Aro. Fl. Bras. XI, II, p. 161. - Serra do Palnital, dans le campo, Mrsas, $1^{\circ}$ 15399. Frutescent, f1. rousses. Férrier-mars. R.

81. Cr. inversus Baill. in Adans. IV (1863-64), p. 321. - Entre Rio Tocantis et Os Porcos, dans le cerrado, Goxaz, $1^{\circ} 22109$. Frutescent, f1. Blanchâtres. Janvier-lévrier. C.

82. Cr. Pohlianus Mäll. Aræ̣.; Fl. Bras. XI, II, p. 16.). - Santa Luzia do Rio das Velhas, Mrsas, $1^{\circ \mathrm{s}} 20482,22103$. Frutescent, fl. rousses. Norembre-décembre. C.

83. Cr. insignis Glaz. 11. sp.? in herb. Paris., Berol., Kew., etc. Fazenda Cova, daus le campo, Goyaz, $n^{0} 22102$. Frutescent, 11. rousses. Novenbre-décembre. R.

8't. Cr. campestris Nüll. Aro.; Fl. Bross. XI, II, p. 166. - Serra de Sĩo José d'El Rei, Mrr.s, $n^{0}$ 16335. Arbuste, fl. rousses. Norembre-dérembre. C.

8ə.. Cr. subacutus Müll. Arr.; Fl. Bras. XI, II, 1) 167. - Serra do Lenhriro, près São João d'EI Rei, Mıxas, nº 16335 a. Arbuste, f1. rousses. Février-mars. C. 
86. Groton albescens. Glaz. 11. sp.? in berh. Paris., Berol., kew., Birus., ete. - Serral d'labira do Canıjo, Mris, $11^{\circ} 17759$ a. Arluste, f1. blanches. Novembre-décentre. R.

87. Cr. tejucensis Vüll. Aro. in Fl. Bras. X1, II, p. 176, - Formosa da linperatri\%, dins le campo, Goraz, $1^{\prime \prime}$ 22105. Arbuste, fl. Wanchàtres. Novembre-décembre. C.

88. Cr. Regnellianus Ilüll. Arg.; Fl. Bras. XI, II. p. 79. - Paranpeba, près Barbacena, Mrxas, no 20482 a. Arbuste. fl. blanchàtres. Novembre-decembre. C.

59. $\mathrm{Cr}$. timandroides Müll. Arg. in Fl. Breas. XI, II, p. 18\%. Caraça, au Cianpo de Fora, Mixas, $n^{\circ} 15397$. Frutescent, 11. bJanchattres. Février-mar's. C.

90. Cr. melanoleucus Müll. Arg. in Fl. Brus., XI, II, P. 185. Curalinho, près Diamantina, dans le campo, Mrxas, n 19834 a. Frutescent, fl. błancluâtres. Avril-mai. R.

91. Cr. erythroxyloides Müll. Arg.; Fl. Bras. XI, II, p. 190. Serra do Inficionado, près Caraça, Misıs, n" 19831. Frutescent, fl. rousses. Avril-mai. R.

92. Cr. vestitus Spreng. in Fl. Bras. XI, II, p. 19\%. - Serria do Caraça et Serra de São José d'El Rei, Mixas, nos 15398 , 16336. Frutescent, fl. blanchâtres. Décembre-janvier. C.

93. $\mathrm{Cr}$. adenocaly $x$ Baill.; Fl. Bras. XI, II, p. 201. - Itapemirim, Fspirito Sarto, no 11508. Frutescent, f1. rougeattres. Septembre-octohre. C. Vulg. : Catinga de porco.

94. Cr. urticefolius Lamk; Fl. Brrs. XI, II, p. 203. - Morro do Ramão, près de Sabara. Mrxis, no 14255. Arbuste, fl. blanchattres. Janvier-fóvrier. C.

- Var. interneuius Mïll. Arg. in Fl. Bras. Mi, II, p. 0.4. - Serra da Mantiqueira, dans le hois, Mras, $n^{\circ}$ 14254. Albuste, fl. hanchatres. Septembre-uctobre. C.

- Var. genulaus Müll. Arg. in Fl. Bras. XI, II, p. 204 . - Santa Theresa, an Corcovalo, Rio-Jax., ${ }^{\text {os }} 21,228,346,787$. Arbuste, fl. blanchâtres. Janvier-férier. GC.

9\%. Cr. antisyphiliticus 》lüll. Arg.; Fl. Bras. XI, II, p. ำT. Entre Sitio et Illeos. Nıxas, no 16333. Frutescent, fi. rousses. Novembredécembre. Vulg. : Hercurio do campo. C.

- Var. gexunus Müll. Arg.; Fl. Bras. XII, II, p. 209. - Congonhas do Campo, Minas, no $16333 a$. Frutescent, fl. rousses. Octobre-novembre. Vulg. : Mercurio do campo. C. 
96. Cr. chatocalyx Müll. Arg.; Fl. Bras. XI, II, p. 211. - Capelinha de Santo Antonio, au Rio Descoberto, Goyaz, n 22107. Arbuste, 11. blanchàtres. Octohre-novembre. C.

97. Cr. nepetcefolizs Baill.; Fl. Bras. XI, II, p. 213. - Itacambira, dans les bois, Mrsas, $n^{\circ} 13181$. Arbuste, f1. blanches. Novembre-décembre. C.

98. Cr. betaceus Baill.; Fl. Bras. XI, II, p. 213. - Agua Branca, dans le bois, Mrvas, no 16337. Arbuste, f1. rousses. Septembre-octobre. C.

99. Cr. longinervizs Müll. Arg. in Fl. Bras. XI, II, p. 215\%:Paracatu, dans les bois et les campos, Mrsas, $n^{\circ} 15400$. Frutescent, f1. hanchàtres. Septembre-octobre. C.

100. Cr. goyazensis Niïll. Arg.; Fl. Bras. XI, II, p. 217. - Colline centrale, près du campement, Goraz, $\mathrm{n}^{\circ}$ 22101. Arbuste, fl. blanchâtres. Juin-juillet. C.

- Var. rotundifolius Glaz. in herb. Paris., Berol., Kew., Brux., etc. - Siriaco, près du Rio Nacaco, Goxaz, $n^{\circ}$ 22104. Arbuste, fl. blanchâtres. Avût-septembre. C.

101. Cr. corchoropsis Baill.; Fl. Bras. XI. II, D. 221. - Entre Barbacenit et Queluz, daus le campo, Mixas, $n^{\circ}$ 10038. Petit arbuste, fl. rousses. Juin-juillet. CC.

102. Cr. angustifrons Nüll. Arg. in Fl. Bras. XI, II, p. 222. - São Domingo, près Conceição, Mrsas, $n^{0 s}$ 14259, 14206. Arbuste, fl. rousses. lanvier-mars. CC.

108. Cr. Lundianus var. pubescens Müll. Arg.: Fl. Bras. XI, II, 1. 230. - Serra dos Puris, Esprito Sasto, $\pi^{\circ}$ 4980. Pelit arbuste, fl. rousses. Octobre-novembre. C.

101. Cr. comoszis var. masor Nüll. Arg.; Fl. Bras. XI, II, p. 234. Serra da Caraça, dans le campo, Misas, $n^{\circ s} 15390$, 19827. Frutescent, II. blanchâtres. Février-mars. C.

10\%. Gr. glaber Glaz. n. sp.? in herl, Paris., Berol., Kew., Gener., etr. - Santo Antonio das Salvas, Misas, $1^{\circ}$ 15403. Arbuste, f1. blanchitres. Noveınhre-décembre. CC.

106. Cr. Gardneri Vüll. Arg.; Fl. Bras. XI, II, p. 2933. - Entre Barbatcena et Sitio, daus le campo, Mtınas, n 11510 . Frutescent, fl. blanchâtres. Février-mar's. C.

107. Cr. lobatus var. Masinor Müll. Arg.; Fl. Bras. XI, II, 1. 2937. Itatiaia, dans le bois, Rto-Jax., nos 686,13200 . Frutescent, fi. blanchitres, Novembre-décembrè. C. 
- Var. digrtates Müll. Arer.; Fl. liras. XI, II, p. 238. — Floresta da Tijuca el Petropolis, Rı-Jav., $n^{0}$ 11509, 14246. Sous-frutescent, fl. blilld lattes. Farrier-mars. C.

- Val\%. gracilis Mlïll. Arg.; Fl. Bras. XI, II, p. 298. - Serra dos Orgãos, an Imbuhy, Rro-JAx., $n^{0}$ 9588. Sous-frutescent, fl. blanchâtres. Mar's-avril. C.

108. Croton squamulosus Müll. Arg. in Fl. Bras. XI, II, p. 244. Serra dos Orgĩos, à Pedra Assú, Rı-Jax., no 3742 . Petit arbuste, fl. rousses. Aoutl-septembre. C.

109. Cr. puncticulatus Nüll. Arg. in Fl. Bras. XI, II, p. 249. - Pico do Andarahy, ì Tijura, Rio-JAx., nos 891 , 2710. Petit arbuste, 11. rousses. Février-mars. C.

110. Cr. buxifolius Muill. Arg.; Fl. Brus. XI, II, p. 2:31. - Ciampos da Bocaina, entre les rocher's, São Paulo, $n^{\text {os }}$ 6681, 11550; Serra dos Orgãos, an Grand Plateau, Rio-Jax., $n^{\circ 5} 3743$, 15401, 16334. Petit arbuste, fl. rousses. Aout-septembre. CG.

111. Gr. rotundifolius Glaz. 11. sp.? in herb. Paris., Berol., kew., Brux., etc. - Pico d'Italira do campo, llisas, $n^{\circ}$ 17759. Petit arbuste, f1. blanchâtres. Novembre-décembre. C.

119. Cr. Wildgrenianus Hüll. Arg.; Fl. Bras. XI. II, p. 299. - Alto da Serra do Palmital, Mısas, $11^{\circ} 16334$ a. Petit arbuste, 11. rousses. Septembre-octobre. C.

113. Cr. lanatus Lamk; Fl. Bros. XI, II, p. 20ั7. - Barbacena, dans le campo et Diamantina au Tombador, Mrsas, nos $11518,19834$. Petit arbuste, fl. rousses. Avril-mai. G.

114. Cr. bidentatus 1lüll. Arg.; Fl. Bras. XI, II, p. 266. - Entre Silio et Barbacena, dans le campo, Mrvas, $n^{\circ}$ 11519. Arbuste, fl. blanchatres. Septembre-octolure. R.

11:. Gr. Decarianus Pilg. n. sp. in herb. Paris., Berol., Kew., Brux., etc. - Serra do Arruda, pres Meia Ponte, Goraz. $1^{0 s} 22106$, 22108. Frutescent, li. rousses. Aoùt-septembre. C.

116. Cr. glandulosus Müll. Arg.: F7. Bras. XI, II, p. 967. - Entre Cabo Frio et São Pedro dos Indios, Rio-Jas., nº 11517. Sous-frutescent, fl. blinchâtres. Aoùt-septembre. C.

- Var. nretus Müll. Aræ. ; Fl. Brus. XI, II, p. 267. - Santa Luzia do Rio das Velhas, dans le campo, Mixas, $n^{05} 11515,20483$. Sous-flutescent, 17. blanchâtres. Novembre-décentire. C.

- Var. scordiordes Müll. Arg.; Fl. Bras. XI, II, p. 296. — Quinta da 
Boa Vista, à Sao Christovĩo, Rı-Jax., no 6130. Sous-frutescent, f1. blanchatres. Septembre-octobre. CG.

117. Cr. chamadry folius Griseb. : Fl. Bras. XI, II, p. 271. - Floresta da Tijuca et Mataruna, Rio-J.x., n 6676, 10040. Sous-lirutescent, fl. rousses. Mai-juin. C.

118. Cr. verbenafolizes Viill. Arg.; Fl. Bras. XI, II, p. 272. Petropolis, à Cils:atinlıa, hiro-Jax., n ${ }^{\circ}$ 6675. Sous-frutescent, fl. rousses. Août-septembre. CC.

119. Julocroton verbascifolius Mïll. Agr. ; Fl. Bras. XI, II, p. 279. - Faria, au Morro do Pires, près de Sabara, Mixas, no $18475 a$. Sousfrutescent, fl. rousses. Dícembre-janvier. R.

120. J. Ackermannianus Vüll. Alog. var. minsutus Müll. Al’o.; Fl. Bras. Xl, II, j. 283. - Acampamento do Rio Turto, Gova\%, n 22100. Frutescent, Il. brunes. Septembre-octobre. C.

121. J. triqueter Baill.; Fl. Bras. XI. II, p. 28'. - Corcovado et Floresta da Tijuca, Rio-Jax., $n^{0}$ 1542. Arbuste, fl. rousses. Septembreoctobre. C.

- Var. subulatus Mïll. Arg.: Fl. Bras. XI, II, p. 286. - Santo Antonio da Itinga, Mrsas, $n^{\circ}$ 14252. Frutescent, fl. blanchâtres. Hars avril. C.

122. J. fuscescens Baill.; Fl. Bras. XI, II, p. 286. - Atalaia et Copacabana, Rio-Jax., $n^{\text {os }} 126,880,2693$. Frutescent, f1. brunes. Janvier février. C.C.

123. J. microcalyx Nüll. Arg.; Fl. Bras. XI, I1, p. 287. - Morro do Pires, pris Sabara, Mrss, $n^{\circ}$ 18475. Frutescent, fl. rousses. Janviel févriel. C.

124. Micrandra elata Müll. Arg. ; Fl. Bras. XI, II, p. 200. - Mogy las Cruzes, dans les bois, São Paulo, no $18470 a$. Arbrisseau, 11. blanchâtres. Juillet-aocit. $\mathbf{R}$.

12.\%. Johannesia princeps Vell.; Fl. Bras. Xl, II, p. 296. - Floresta da Tijuca et an Passein Publico, Rı-Jis., no 781. Graud arbre, 11. blanchàtres. CC. Vulg. : Anda assú.

126. Hevea discolor Müll. Ar@.; Fl. Brus. XI, II. p. 299. - Quinta da Boa Vista, à S. Christovão, Rio-JAx., n" 14240. Grand arbre cultivé, 11. blanchâtres. Octohre-novemlire. Arbre planté par Riedel.

127. H. janeirensis Müll. Arg. in Fl. Bras. XI, 11, 1). 706. - Quinta da Boa Vista, S. Christovĩo, liı-JAx., nos 4911, 8921. Grand arbre cultivé, 11. blanchitres. Ortobre-novembre. R. 
128. Aleurites cordata Steul. in Nonencl. Bol. éd. 2, I, p. 49. -Quinta da Boa Vista, S. Christoviou, Rıo-Jan., $11^{\circ}$ 12150. Arbrisseau cultivé, fl. blancles. Loùt-septembre. R.

129. A. moluccana Willd.; Fl. Bras. XI, II, p, 30\%. - Floresta da Tijuca et au Passeio Publico, Rio-Jax., nos 783, 11547. Grand arbre, cultivé, fl. blanches. Mars-avril. CG. Vulg. : Nogueira.

130. Argyrothamnia brasiliensis Müll. Irg.; Fl. Bras. XI, II, p. 308. - Serra da Bica, près Cascadira, Rio-J $\mathrm{JN}_{\text {. }}, \mathrm{n}^{\text {os }}$ 16692, 18987. Arbuste, f1. blanc jaunâtre. Aoùt-septembre. C.

131. A. Simoniana Vüll. Arg.; Fl. Bras. XI, II, p. 311 . - Corcovado, à Paineiras, Rio-Jax., $n^{\circ}$ 236. Arbuste, fl. blanchâtres. Juin-juillet. C.

132. Caperonia heteropetala var. lanceolata Müll. Arg.; Fl. Bras. XI, II, p. 318. - Collegio, près campos, Rio-Jan., no 13491 6. Frutescent, fl. blane jaunâtre. Octobre-novembre. R. Vulg. : Urtiga.

133. C. buettneriacea Müll. Arg. in Fl, Bras. XI, II, p. 320. Belem, dans les grands bourbiers, Rı-Jax., n 8572 . Frutescent, fl. blanc jaunâtre. Octubre-novembre. C.

134. C. castaneafolia St.-Hil, ; Fl. Bras. XI, II, p. 323. - Norro do Coco, près S. Francisco de Paula, Rio-Jax., nº 11507. Frutescent, f1. blanc verdàtre. Août-septembre. C.

133. C. palustris St.-Hil.; Fl. Bras. XI, 11, p. 324. - Curimatahy, dans les bourbier's, Mixas, $n^{\circ}$ 14262. Frutescent, fl. blanchàtres. Janviermars. CC.

136. Centrodiscus grandifolizs Müll. Arg.; Fl. Bras. XI, II, p. 327. - Corcovado, Gavea, Jacarepagua, etc. - Rio-JAs., nos 1438 , $3110,6708,7827,8325$. Arbrisseau, fl. blanc verdâtre. Octobre-norembre. CC.

137. Plukenetia tamnoides Müll. Arg.; Fl. Bras. XI, II, p. 335. Caminho do Macaco entre Lagoa de Freitas et Tijuca, Rio-JaN., $\mathrm{n}^{\circ} 67$. Sarmenteux, fl. blanc jaunâtre. Octobre-novembre. C.

138. Pl. verrucosa Smith; Fl. Bras. XI, II, p. 335े. - Quiçaman, près Lagoa Feia, Rı-Jax., nº 10076. Sarmenteux, fl. blanchâtres. Septembre-octol)re. R.

139. Fragariopsis scandens St.-Hil.: Fl. Bras. XI, II, p. 337. Gorcovado, à Lagoinha dos Porcos, Rio-Jax., nº 2701. Sarmenteux, th. blanc jaunâtre. Février-mars. C.

140. Acalypha macrostachya var. sid zfolia Mïll. Arg.; Fl. Bras. XI, II, p. 345. - Serra do Picú, Ilıxas, no $13190 a$. Frutescent, fl. blanchâtres. Juillet-aoùt. C. 
A.-F-.M. GLAZIOL. - LISTE DES PLAYTES IU BRÉsLL CENTRAL.

1'41. A. conmmunis Ilïl. Arg.; Fl. Bras. XI, II, p. 349. - Congonhas do Campo, dans le bois, Hixis, $n^{0}$ 13190. Sous-frutescent, t1. rousses. Novembre-décenulsre. CC.

- Vall. tomentella Viüll. Arg.; Fl. Bras. Xl. II, p. $3 \% 0$. - Fazenda do Ilorro Azul, dans le bois. Sĩo Patlo, no 14251 a. Sous-frutescent, fl. rousses. Septembre-octubre. C.

142. A. goyazensis Glaz. n. sp.? in herb. Paris., Berol., Kew., Brux, etc. - Serra dos Veadeiros, dans le campo, Goraz, no 22113. Sous-frutescent, ti. blanchatres. Janvier-février. C.

1'3. A. Clansseni Müll. Aro.; Fl. Bras. XI, II, p. 3333. - Ponte Alta, dans le campo. Goraz, n 22112. Sous-frutescent, fl. blanchâtres. Septembre-octobre. C.

144. A. pruriens Nees; Fl. Bras. Xl, II. p. 3.9.. - Tripuhy, près Ouro Preto, lisss, no 14251. Sous-fiutescent, fi. rousses. Septenbreoctobre. C.

143. A. diversifolia Müll. Arg.; Fl. Bras. XI, Il, p. 33̈7. - Abbade pres Meia Ponte, Goraz, $1^{\circ} 22114$. Frutescent, f1. rousses. Septembreactobre. C.

- Var. eeptostachy Müll. Arọ.; Fl. Bras. XI, II, p. 35̌8. - Fazenda de Sant'Anna, dans le bois, Mrsas, no 7824 . Frutescent, fl. rousses. Janrier-févier. C.

146. A. prunifolia Nees et Mart.; Fl. Bras. Xl, II, p. 349. - Corcorado, au Cosme Velho, Rio-Jax., no 14267 a. Arbuste, fl. rousses. Octobre-norembre. R.

147. A. brasiliensis Müil. Arg.; Fl. Bras. XI, 11. p. 363. - Entre Cabo Frio et Araruama, Rio-Jax., $n^{\text {os }}$ 11533. 11534. Frutescent, 11. rousses. Octobre-novembre. CG.

- Var. Loxátpes Müll. Aro.; Fl. Bras. XI, II, p. 363. - Floresta da Tijuca, à Cascatinha, Rio-dax., n 1012. Sous-frutescent, fleurs rousses. Septembre-nctobre. C.

- Var. maxima Müll. Arg.; Fl. Bras. XI, II, 1).36't. - Araruama, dans le bois liumide. Riu-JAx., no 10041. Frutescent, 11. rousses. Octobrenorembre. C.

1'48. A. Weddelliana Müll. Arg.; Fl. Bras. XI, II, p. 36t. - Serra da Estrella, à Hamminha, Rio-Jax., $n^{\circ}$ 6674. Sous-frutescent, fl. rousses. Juin-juillet. CC.

1'49. A. amblyodonta Müll. Arg.; Fl. Bras. XI, II, p. 36\%̈. - Entre Gavea et Lagroa de Freitas, Rio-Jax., nº 3802. Sous-frutescent, fl. rousses. Septembre-octolsre. C. 
- Var. vilzosa Müll. Arg., ibid.p. 366. - Corcovarlo, à Santa Theresa,

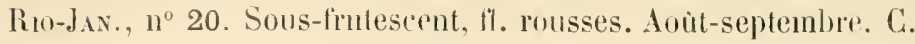

150. Acalypha Poirctii Spreng.; Fl. Bras. XI, II, p. 368. - Guinta da Boa Vista, à S. Chrislovão, Riı-JAx., nos 770, 8316, 11542. Sousfrulescent. 11. rousses. Avril-juillet. CC.

13̈1. Alchornea cordata Müll. Arr.; Fl. Bras. Xl, II, 1). 376. Villa Nova, daus les sables, Tijuca, Rio-Jav., $n^{0.8} 3101,10044,10045$; Morada Nova, Mtosas, $n^{\text {os }} 14264$, 15417. Grand arlore, fl. rousses. Octobrenovembre. CG.

139. A. sida folia Nüll. Arg.; Fl. Bras. XI, II, p. 377. - Nova Friburgo, près la rivière, Rio-JAx., nos 13172, 13173. Grand arbre, fl. rousses. Avut-septembre. CC.

153. A. pyonogyne Müll. Arg.; Fl. Bras. XI, II, p. 378. - Alto da Serra de Nova Friburgo, Rio-JAx., $n^{\circ} 13172$ a. Grand arbre, fl. blane jaunâtre. Septembre-octobre. R.

15\%. A. Iricurana Casar.; Fl. Bras. XI, II, p. 379. - Floresta da Tijuca ef Corcovado, Rio-JAx., n ${ }^{\text {os }}$ 19, 1352, 1353, 16343; Gandarela, près des plantes fossiles, Hixas, $n^{\circ}$ 15418. Grand arbre, fl. rousses. Juin-juillet. CC. Vulg. : Iricurana.

155. A. triplinervia Müll. Arg.; Fl. Bras. XI, II, p. 379. - Alto Macalıé de Nova Frilıurgo, Rio-JAx., nº 19854. Grand arbre, fl. rousses. Janvier-février. C.

- Var. glabra? Glaz. in herb. Paris., Berol., Kew., Brux. - Quinta da Boa Vista, à S. Christovão, Rı-JAx, n 2898. Grand arbre cultivé, fl. rousses. Octobre-novembre. R.

- Var. janeirensis Mïll. Arg.; Fl. Bras. XI, II, p. 380. - Taipú, dans les grands bourbiers et Gavea, Rio-J.x., $\mathrm{n}^{\text {os }}$ 18, 1351, 3102, 3103. Arbrisseau, fl. rousses. Octobre-décembre. CC.

- Var. parvifolia Müll. Arg.; Fl. Brels. XI, II, p. 381. - Restinga de Hauá, Rio-IAx.. nos 8328,8920 . Arbrisseau, fl. blanc jaunâtre. Octobre-novembre. C.

- Var. goyazensis? Glaz. in. leerb. Paris., Berol., Kew. - Sommet de la Serra dos Pyreneos, près Nleia Ponte, Goraz, $n^{\circ}$ 22140. Arbuste, fl. blanc jaunâtre. Juin-jnillet. R.

156. A. castanea folia Juss.; Fl. Bras. XI, II, p. 383. - Natividade, dans la forêt, Rı-Jax., nº 10043. Arbrisseau, fl. blanchâtres. Janvierfévrier. C.

157. A. Schomburgkii Kilotz; Fl. Bras. XI, II, p. 384. - Pedra Formosa, près la rivibre, Espirito Saxto, $n^{0}$ 14237. Arbrisseau, 11. rerdâtres. Janvier-février. C. 
1:is. Pachystroma ilicifolium valr. Longrfolium Müll. Arg.; Fl. Bras. XI, II, 1. 388. - Floresta da Tijuca et Corcovado, Rio-JAx., nos 790 , 5987. Grand arbre, fl. rerdàtres. Décembre-janvier. C. Vulg. : Mata olho.

- Var. heterophyllum Mïll. Arg. in Fl. Mras. XI. II, 1. 388. Caminho do Macaco, pres Vista Clnineza, lio-lax., $n^{\circ}$ 2695. Grand arbre, il. verdittes. Novembre-décembre. C. Vulg. : Mata olho.

- Var. elcipticum Mäll. Arg.: Fl. Bras. XI, II, p. 388. - Copacabana, Rio-Jav., no 2111 . Grand arbre, ll. verdatres. Octobre-nuvembre. C. Vulg. : Matu olho.

- Var subintegrum Mï̈ll. Arg.; Fl. Bras. XI, II, p. 389. - Serra de Jacarepagua, Rio-JAx., no 6712. Grand arbre, fi. verditres. Octobrenovembre. C. Vilg. : Matre olho.

159. Bernardia crassifolia Miill. Arg. in F\%. Brus. XI, II, p. 39\%. - Serra dos Cristaes, près Dianantina, Minas, $1^{\circ}$ 19849. Arluste, 11. rousses. Mars-atril. C.

160. B. Gardneri Miill. Arg. in Fl. Bras. XI, Il, p. 394. - Birihiry, près Diamantina, Huxs, $n^{\circ 5} 16345$, 19848. Arbuste, fl. rousses. Mar'savril. C.

161. B. scabra Müll. Arg. in Fl. Bras. XI, II, p. 396. - Caminho do Enforcado, au Corcovado, Rio-J.s., nos 11538, 12159. Arbuste, fl. rousses. Juin-juillet. C.

162. B. celastrinea var. intermedia Mïll. Arg.; Fl. Bras. XI, II, p. 397. - Morro Queimado, Corcovado et la Tijuca, Rio-Jax., nos 1349 , 3105. Arbuste, fl. rousses. Mars-juillet. C.

163. B. peduncularis var. uresutssma Mïll. Arg.: Fl. Bras. XI, II, p. 399. - Alto da Serra dos Prreneos, Goraz, nos 221.10, 22111. Sousfiutescent, 1\%, rousses. Aoit-septembre. C.

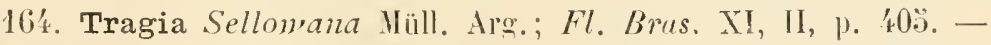
Santa Theresa, au Corcovado, Rio-Jax., ${ }^{\circ}$ 4191, 11532. Sarmenteux, fl. blanchâtres. Novembre-décembre. C.

16.. Tr. Pohlii Müll. Arg.; Fl. Bras. XI, II, p. 410. - Paracatu, dans le bois, Mrnas, no 22071. Sous-frutescent, 11. blanchâtress. Aoutseptembre. C.

166. Tr. pubescens Glaz. n. sp.? in herb. Paris., Berol., Kew., Havn., ptc. - Itapemirim, près Cachoeira, Espluto Sax?o, no 11531. Volubile, fl. rousses. Octohre-septembre. Ii.

167. Tr. volubilis Nhüll. Arg̣.; Fl. Bras. XI, II, p. \&[Q. - Cantagallo, a Larangeiras, Rro-Jux., $1^{\text {os }}$ 14249, 14250. Volnbile, fl. hlanchittes. C. Janvier'mar's. Vulg. : Uiliga. 
- Var. Serra Müll. Arre; Fl. Bras. XI, II, p. 413. - Serra da Estrella, à Mandioca, Ro-Jax., $n^{\circ} 4192$. Volubile, H. blanchatres.

168. Ricinus commnnis Müll. Arg.: Fl. Bras. XI, II, P. 420.Quintar da lioa Vista, à S. Cluristovão, Rio-Jav., $11^{\circ}$ 6125. Sons-firutescent, f1. rousses. cultivé. Norembre-décembre. CG. Vulg. : Azeitona.

169. Pera Leandri Baill.; Fl. Bras. XI, II, p. 498. - Norro di Viraçio, Itaboratıy, Corcovado, ete., Pı-JAx., $1^{\circ}$ 5724, 6682, 8324. Arbre, 11. rousses. Décembre-janvier. CG.

170. P. glabrata Baill.; Fl. Bras. X1, II, p. 429. - Villa Nova el Corcovarlo, Rio-Jax., $n^{\text {os }}$ 129, 7572; Bom-Fim, Mrsas, nos 13206, 16344. Arbrisseau, ll. vertâtres. Mai-juin. CC.

- Var. petropolrtana? Glaz. in lierl. Paris., Berol., etc. - Petropolis, au Retiro, Ro-Jan., $1^{\circ 5} 1116,5985$. Grand arbre, fl. rousses. Avril-mai. C. Vulg. : Catucanhem.

-- Virr. parvifolia Glaz. in herb. Paris., Berol., etc. - Serra dos Orgios, à Theresopolis. Rio-Jax., I $^{\circ}$ 8327. Arbrisseau, fl. verdâtres. min-juillet. C.

17I. P. Glazioviana Taul. n. sp. in herl. Paris., Berol., Kew., Brux., elle. - Serra da Estrella, à Quitandinhal, Rı-Jax., n 7826. Arbre, fl. rousses. Novembre-décembre. C.

172. P. Bailloniana Nüll. Arg.?; Fl. Bras. XI, II, p. 430. - Biriliry, près Diamantina, Mras, no 19850. Arbre, fl. rousses. Février-mar's. C.

173. P. obovata Baillon; Fl. Bras. XI, II, P. 431. - Alto Nacahé de Nora Friburgo. Rio-Jan., nos 6901,11524 ; Serra de Ouro Preto, Minas, $17^{\circ}$ 15415. Avril-juiı, C.

174. P. ferruginea Nüll. Arg.; Fl. Bras. XI, II, p. 431. - Restinga d'Itaijú, pris de la mer, Riso-Jas., nos 9579,12155 , 18471. Arbrisseau, f1. rousses. Arril-mai. CG.

173. P. parrifolia Nüll. Arg.; Fl. Bras. XI, II, p. 432. - Alto Nacahé de Nova Friburgo, Rio-Jax., nº 14265. Arbrisseau, 1l. blanchaàtres. Janvier-février. li.

176. P. corcovadensis Glaz. n. sp.? in herl. Paris., Berol., Kew., Brux., etc. - Sommei du Corcovado, après le leu, Rio-Jax., nos 9357 , 12156, 15414. Joli arbuste, fl. blanchâtres. Janvier-février. R.

177. Pogonophora Schomburghiana Miers.; fil. Bras. Xl, Il, p. 430. - Entre Cabo Frio et Aldèa de Sĩo Pedro dos Indios, Rı-JAn., no 9708. Arbrisseau, fl. blanchâtres. Septembre-octobre. R.

178. P. Glaziovii Tauh. II. sp. in herls. Paris., Berol., Kew., Genev., ete. - Restinga de Nauá, près la mer, Rı-Jan., nos 7544, 8306; 
Abbadia, près Alassuahy, dans le campo, Mıss, no 15419. Arlorisseau, fl. blanchàtres. Décembre-janvier. C.

179. Manihot quinqueloba Pohl; Fl. Bras. XI. II, p. 446. - As Brancas, entre les loclers, Goraz, $n^{\circ} 22133$. Frutescent, fl. verdâtres. Janrier-février. C.

180. M. Glaziovii Müll. Arg. in Fl. Bras. X1, II, p. 4.16. - Muribeca, Espruto Santo, $n^{0}$ 1022; Quinta da Boa Vista, à S. Christovio et au Passeio Publico, culta, Rio-JAx., nº 9585. Arbrisseau, fl. blanc verdâtre. Janvier-févriel. C. Vulı̈. : Wanicolıa.

181. Mr. pilosa Pohl; Fl. Bras. XI, II, p. 449. - Abbadia, jrès Arassuahy, dans le bois, Nisas, nos 13203 , 14242, 14243. Frutescent, 1 . blanc verdâtre. Novembre-décembre. C.

182. M. amaroleitensis Baill.; Fl. Bras. XI, II, 1. 4332. - Entre Taboquinla et As Lages, Goraz, $n^{08} 22134,22135$. Frutescent, fl. blanc verdâtre. Février-avril. CC.

183. M. utilissima Pohl; Fl. Bras. XI, II, p. 45̆̈. - Atalaia, à Praia Grande, Rı-JAx., n ${ }^{\text {os }}$ 2694, 9583. Frutescent, fl. blanc verdâtre, cultivé. CC. Vulg. : Nandioca.

184. M. palmata Müll. Arg.; Fl. Bras. XI, II, p. 4ö8. - Juiz de Fora, dans le bois, Mixas, $n^{\text {os }} 8322$, 18476 . Arbuste, fl. blanc rerdâtre. Décembre-janvier. C.

- Var. multifida Müll. Arg. : Fl. Bras. XI, II, p. 499. - Petropolis, près de la Cascatinha d'Itamaraty, Rio-Jax., n ${ }^{0 s} 8321$, 14244. Frutescent, 11. blanc verdâtre. Janvier-février. CC.

185. M. pusilla Polıl; Fl. Bras. XI, II, p. 460. - Entre Fazenda da Boa Vista et Paraizo, dans les pâturages, Goraz, nº 22127. Presque acaule. fl. verdâtres. C. Vul@. : Mandioquimha. Plante très vénéneuse?.

186. M. longepetiolata Glaz. n. sp.? in herb. Paris., Berol.. Kew., Brux., etr. - Guariroba, dans les pâturages, Goyaz, no 22128. Presque acaule, f1. blanc verdàtre. Octolsre-novembıe. CG. Vulg. : Jandioquinha.

187. M. multifida Glaz. n. sp.? in herb. Paris., Berol., Kew., Brux., etc. - Guarioba, au Morro Cubatio entre les pierres, Goraz, $n^{0} 22137 a$. Frutescent, fl. blanc noiràtre. Octobre-norembre. R.

188. M. gracilis var. genuma Müll. Aræ. ; Fl. Bras. XI, II, p. 46.3.Guariroba et au hio Gama, dans le campo, Goyaz, no 22130. Frutescent, fl. blanc verdatre. Octobre-novembre. CC.

189. M. anomala Pohl; Fl. Bras. XI, II, p. 46ö. - Folmosa, ¿ Itiquira, dans le bois, Goraz, $1^{0} 22125$. Albuste, fl. blanchàtres. Févielmars. CC. 
190. Manihot tomentosa Pohl; Fl. Bras. XI, II, P. 46ï. - São João d'Ẽ Rei. dans le camuo, Musas, $1{ }^{\circ s}$ 16329, 17553: entre Cocal et Lambary, Goraz, nº 22136. Frutescent, 11. rousses. Janvier-février. C.

191. M. canastrana Glar. sp. n.? in lerl,. Paris., Berol., Kew., Brux., ete. - Somnet du Morro Canastra, près Mestre d'Armaz, Goraz, $n^{\circ}$ 22137, 22137 a. Jírutescent, 11. blanc verdâtre. Novembre-dícembre. R.

192. H. violacea Nüll. Arg.; Fl. Bras. XI, 11, p. 467. - Lintre Barreira et Helancias, Mwas, $n^{\circ}$ 19856: Serra ders Pyreneos, Goraz, $11^{\circ} 22132$. Frutescent, f7. blanc verdatre. Février-mars. C.

193. M. jacobinensis Müll. Arg.; Fl. Bras. Xl, 11, p. 471. - Vìo Jo Parana, à Itiquira, Goraz, no 22131. Frutescent, fl. blanc verdâtre. Février-mars. C.

194. M. pentaphylla Pohl; Fl. Bras. XI, II, P. 473. - Serra da Baliza. près de Cachoeiras, Goyaz, n" 22129. Frutescent, 11. blanchâtres. Janvier-février. C.

19.. M. rigidula Hüll. Arg. in Fl. Bras. XI, II, p. 474. - Serra dos Cristars, près Dimmantina, Mixis, $n^{\circ} 19855$. Frutescent, fl. blanc verdattre. Avril-mai. R.

196. M. tripartita Müll. Arg. ; Fl. Bras. XI, II, p. 476. - Bom Fim, dans le campo, Mnsas, $n^{\circ}$ 13201: Tiborno, entre Ciganos et As Brancas, Govaz, $\mathrm{n}^{0 \mathrm{~s}} 22138,22139$. Frutescent, f1. blanc verdâtre. Novembredécembre. C.

- Var. genuna llüll. Arg.; Fl. Bras. XI, 1I, p. 476. - Entre Santa Luzia do Rio das Vellas et Piedade, dans le campo, Mras, nos $18476 a$, 20484. Frutescent, fl. blanchâtres. Novembre-décembre. C.

197. M. Weddelliana Baill.; Fl. Bras. XI, II, p. 486. - Chapadĩo dos Peadeiros, entre les rochers, Goraz, $n^{n}$ 22126. Frutescent, fl. blanc noirâtre. Janvier-février. R.

198. Jatropha Curcas L.; Fl. Bros. XI, II, p. 487. - Quinta da Boa Vista à S. Christovão, Rı-Jav.. n ${ }^{\circ}$ 8923. Arbuste cultivé; Santo Antonio da Itingal, dans le bois, Misas, $n^{\circ}$ 14245. Arbuste, fl. blanc rosé. Décembre-janvier. CG. Vulg. : Cansancão.

199. J. clliptica Müll. Arg.; Fl. Bras. XI, II, p. 489. - Entre Ponso to Rilseirão et Porto du Rio Paracatú, dans le campo, Misas, no 22122. Sous-frutescent, 1i. blanchâtres. Aonit-septembre. C.

200. J. gossypiifolia var'. staphrsagrifolia Müll. Arm.; Fl. Bras. XI, II, p. 4:11. - Q Quinta da Boa Vista, à S. Christovĩo, Rio-JAx., nº 3648. Frutescent, ll. violacées. Aoùt-septembre. C.

- Var. elegans Müll. Arg.; Fl. Bras. XI, II, p. 492. - Diviza, près Horriuhos, Goyaz, ॥ $^{\circ} 22124$. Frutescent, fl. violacées. Aoùt-septembre. C. 
A.-F,-M. GLAZIOU, - I.ISTE DLS PLAYTES DU BRESIL CENTRAL.

201. J. multifida L.; Fl. Brees. XI, II, p. 498̈. - Quinta tar Boa Vista, à S. Christovão, Rto-Jax., nº 9584. Frutescent, fl. rouges, rultivé. Novembre-décembre. CC. Vulg. : Flor de coral.

202. J. vitifolia Müll. Arg.: Fl. Bras. XI, II, p. 497. - Carialeica, Espirito Saxto, $1^{\circ} 11522$; Monte Alegre, à Passa Tres, Goyaz, no 22123. Frutescent, 11. rouge pâle. Août-septembre. C. Vulg. : Cansancũo.

03. J. urens Müll. Arg.; Fl. Bras. XI, II, p. כ̈00. - Serra d'Ouro Branco, dans le bois, Misis, nos 13198, 14241. Sous-frutescent, fl. blanchatres. Loùt-septembre. C. Vulg. : Cansanção.

- Var. neglecta Müll. Arg.; Fl. Bras. XI. II, p. 50) - - Sĩo Paulo de Muriabé, dans le bois, Mnsss, $1^{0 s} 1386,11523,12152$. 13199. Sous-frutescent, 11. blanches. Octobre-novembre. CG. Vulg. : Cansancão.

204. J. arborea Glaz. n. sp.? in herb. Paris., Berol., Kew., Harn., ete. — Larangeira, près Cantagallo, dans le bois vierge, Rio-Jax., $\mathrm{n}^{0}$ 16328. Arbre, fl. blanchâtres. Octohre-novembre. C. Vulı. : Arra Diabo. C.

200̈. Pausandra Morisiana Radlh.; Fl. liras. XI, II, p. 803. - Corcovado et Jacarepag̃ui, Rio-Jax., nos 2524, 3100, 6140, 7564, 9582, 17211. Grand arbre, fl. blane jannâtre. Septembre-octobre. CC. Vulı. : Gunco.

06. P. megalophylla Hüll. Arg.; Fl. Bras. XI, II, 1. כ0\%'. - Serra dos Orgĩos, au Morro das Aralras, Rio-Jax., no 17211 u. Grand arbre, íl. hanchàtres. Décemìre-janvier. R.

0․ Tetrorchidium parvulum Nüll. Aro. in Fl. Bras. XI, II, p. ö13. - Serra da Estrella, près Petropolis et Alto Macahé, Rı-Jax., nos 8087, 8904, 17754. Arbrisseau, fl. blanc rerditre. Octobre-norembre. C.

208. Omphalea diandra L. : $\%$. Brus. XI, II, p. s1\%. - Cantagallo, à Larangeira et cultivé ai Passein Publico, Rio-Jax., no ${ }^{\text {s }} 784,1522$. Arbuste sarmenteux. fl. blanc verdâtre. Septembre-octobre. I.

209. Mabea fistulifera Hart.; Fl. Bras. XI, II, p. ö1S. - Carrangola. près Campos, Rio-JAx., nos 8924, 11501; Corrego Fundo, prés Jaragua, Gorsz, nº 22119. Arbre, fl. blanchattres. Juin-aout. C.

210. M. angustifolia Benth.; Fl. Bras. XI, II, p. ̈̈19. - O nuinta da Bon Vista, à S. Christovão, Ru-JAx., $11^{\circ}$ 10037. Arbrisseau cultivé, fi. blane jamnattre. Juillet-aoùt. R.

- Var. sasor Мüll. Arg.; Fl. Bras. XI, II. p. ¿̈20. - Quinta da Boa Vista, à S. Christovão, Rro-dx., no 14239. Arbrisseatu pultivé, fl. llante jannitre. Juin-juillet. R.

211. M. speciosa Müll. Arg.; Fl. Brus. XI, II, 1. З̌20. - Passeio Publico, Rio-Jax., no 10036. Arbre cullivé venu du Paral, fl. blanchàtres. Aont-septembre. R. 
212. Manihol occidentalis var. oвоvata Müll. Arg.; Fl. Bras. XI, II,

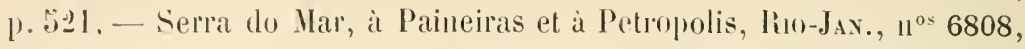
6677, 8925. Grand arbre, ll. blanchitres. Anut-septembre. CG.

213. M. brasiliensis Müll. Arg.; Fl. Brus. XI, II, p. :32?. - Corcovado, it Paineilis, Ruo-Jax., $11^{\circ} 1464$; Sucuriu, dans le campo, Mixas, $n^{0 \lesssim}$ 14247, 15420. Grand arbre, fl. blatc jaunâtre. Anùt-septembre. C.

21'1. M. anomala Müll. Arg. in Fl. Bras. XI, II, p. 气̈26. - Itaunas, près Barra, Esprato Saxro, no 10035. Arbrissean, fl. blanc jaunảtre. Septembre-octohre. C.

2I5. Senefeldera dodecandra Mïll. Aro. in Fl. Bras. XI, II, p. 599. - Cosme Velho, à Larangeiras, Rı-JAx., no 1543. Arbrisseau, 11. blanphâtres. Juillet-aouit. C.

216. S. maltiflora Hüll. Arg.; Fl. Bras. XI, II. p. 329. - Guaximdiba, près Villa Nova, Rıo-Jax., 11"s 121, 12149; Rio Manso, Mlnas, $n^{\circ}$ 15416. Arbrisseau, t1. blanchatres. Octobre-novembre. Vulg. : Canella de veado. C.

217. Ophthalmoblapton macrophyllum Fr. Allem.; Fl. Bras. XI, II, p. 532. - Floresta da Tijuca, Rio-JAx., $n^{05} 17215$, 17752. Grand arbre, f1. blanchatres. Mars-avril. C. Vulg. : Sanla Luzia.

218. O. megaphyllum Müll. Arg. in Fl. Bras. Xl, II, p. 707. - Nictherolıy, à Praia de Fóra, Rio-J $\mathrm{Jx}_{\text {. }}, \mathrm{n}^{03} 5982$, 13169. Arbre, fl. blanc jaunatre. Avril-mai. R. Vulg. : Santa Luzia.

219. O. pedunculare Hüll. Arg. in Fl. Bres. XI, II, p. 5333 . - Serra de Jacarepagua, Rio-Jax., no 6807. Arbrisseat, li. brunes. Octolıre-novembre. $R$.

2刃0. Tetraplandra Leandri Baill.; Fl. Bras. XI, II, p. $334 .-$ Serra do Couto, prés Petropolis, Ro-JAN., $1^{\circ} 3107$. Arimisseau, fl. brunes. Mars antil. R.

221. T. Riedeliz Vüll. Arg. in Fl. Bras. XI, II, p. 334 . - Entre Lagoa do Peixe et Rio Bonito, Ro-Jax., no 13171. Arbrisseau, fl. brunes. Septenibre-octobre. C.

- Var. subcuxeata Müll. Arg. in Fl. Brrs. XI, II, p. C3.3. - Corcovado, a Lagoinha dos Porcos, Rio-Jan., $11^{\circ} 3108$. Arbrisseau, fl. brunes. Septembre-octobre. R.

⒉2․ T. grandifolia Glaz. n. sp. in herb. Paris., Berol., Kew., Brux., etc. - Entre Lagoa do Peixe et Rio Bonito, Rı-Jıx., no 13170. Grand athre, fl. brumes. Août-septembre. C.

2923. Algernonia obovata Müll. Arg., ; Fl. Bras. XI, II, 1. 536. - 
Nossa Sembora da Penha, Rio-Jas.. 11" 8323. Arbrisseau. Il. brunes. Aout-septembre. C.C.

2ّ4. A. brasiliensis Müll. Alg.; Fl. Bras. XI, II. p. ö36. - Lagoinha dos Porcos au Corrovalo, lino-Jax., no 3109. Arbuste. fl. brunes. Févriermars. C.

220ั. Stillingia dichotoma Müll. Arg.; Fl. Bras. XI, II, p. 389. Fortaleza do Pico de Santa Cruz, Rio-Jix.. n 6126. Arbuste, ll. blanchatres. Aroit-seprtembre. C.

226 . St. saxatilis IIüll. Arı.; Fl. Bras. XI. II, p. :̈39. - Quartel do Biribiry, pres de Diamantiua, Mras, $n^{\circ}$ 19852. Arbuste, fl. blanchitres. Mars-arril. C.

207. Maprounea brasiliensis St.-Hil.; Fl. Bras. XI, II, p. 菇3.Curimataly, dans le campo, Mrsas, $n^{\text {os }} 13204$, 13205, 18472. Arbrisseau, fl. blane jaunatre. Novembre-décembre. CC. Vulg. : Mamelinho do campo.

228. M. guyanensis Müll. Arg.; Fl. Bras. XI, I1, 1) 丂ૅ43. - Serra do Leuheiro, près São Joũo d'El liei, Mssas, nos 11502, 11529; Pasgão, pries Corumba, Goyaz, $n^{o s} 22120,22121$. Arbrisseau, ll. blanchàtres. doùt-septembre. C.C.

- Var. gevurna Müll. Aro.; Fl. Bras. XI, II, p. ¿43. - Serra do Var, ¿ Palmeilas et à Rodeio, Rı-JAx., nos 8926, 19853. Arbrisseau, fl. blanchâtres. Décembre-janvier. C.

229. Sebastiania marginata Müll. Arg.; Fl. Bras. XI, II, p. :'46. Biribiry, at Mocotú près de Diamantina, Mrsıs, no 19838. Irbuste, fl. blanchàtres. Février-mars. C.

230. S. daphnoides Müll. Are.; Fl. Bras. XI, II, p. ̈̌́t. - Serra dos Cristaes, près Diamantina, Уrss, n 19840. Petit arbuste, t1. blanchattres. Ferrier-mars. C.

231. S. servilata Müll. Aræ.; Fl. Bras. XI, li, p. ö48. - Pico d'Itabira do Campo, Mnss, no 17213. Petit arbuste, 11. blanc jaundtre. Aout-septentore. C.

232. S. corniculata vall. scabra IIüll. Alg.; Fl. Bras. Xl, II, J. ̈̈̈l. - Restinca da Tijuca, Ro-Jax., n 729. Petit arbuste, fl. blanc jauntre. Jamvier-février. C.

- Var. Frscheri Müll. Arge.; Fl. Bras. XI, II, p. ש̈.'t. - Restinga da Tijuea, Rio-Jax., 11² 6127. Petit arbuste, fl. hanc jaunatre. Aout-septembre. CC.

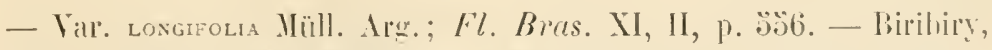
pres Jianantina et Rio Mansu, ete., Mixss, $11^{\text {os }} 11541,15406,16340$, 19839. P'etit arluste, ll. blanchâtı'es. Janviel-mars. CG. 


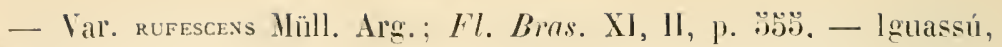
prìs de la rivière, Rio-Jıs., nº 8929. Arbuste, fl. blanc jaunâtre. Juinjuillet. C.

- Var. tomentosa Müll. Arg.; Fl. Bras. XI, II, p. 5.58 . - Itacolumy pris Ouro Preto et Caraça, Mixas, $1^{\circ s} 13194,15404$, 15405. Arbuste, fl. blanc jaunâtre. Février-nars. CC.

- Var. cata Müll. Arg.; Fl. Bras. XI, II, p. 5099. - Entre Morro Redondo et João Nanoel, dans le carascal, Gornz, $n^{\circ} 22099$ a. Arbuste, fi. blanc jaunatre. Octobre-novembre. R.

- Var. actlyphoides Müll. Arær. : Fl. liras. XI, II, p. כ̋61. - Piestinga de Copacabana, Ro-J Jx., $n^{0}$ 1354. Petit arbuste, fl. blanc jaunàtre. Hai-juillet. C.

- Var. glabrata Hïll. Arg.; Fl. Bras. XI, II, p. 562. - Restinga de Cabo Frio, pris du phare, Rio-Jax., no 11535. Petit arbuste, fl. blanchâtres. Juillet-août. C.

233. Sehastiania virgata Müll. Arr.; Fl. Bras. XI, Il, p. 3̈64. 一 Entre Riacho Novo et Taboquinha, Mixas, $n^{\circ}$ 19841. Sous-frutescent, fl. blanchàtres. Février-mars. C.

- Var. odontococca Vüll. Arg.; Fl. Bras. XI, II. p. כ̈64. - Sĩo Mignel, dans le campo, Mrss, $1^{\circ}$ 19836. Frutescent, fl. blanclàtres. Février-mars. R.

93ł. S. diamantinensis Glaz. n. sp.? in herb. Paris., Berol., Kew., Brux., etc. - Diamantina, à Formação, dans le campo pierreux, Mrxas. $n^{\circ}$ 19460. Petite plante de 8 à 10 cent., f1. blanchâtres. Mars-arril. C.

230. S. ditassoides Müll. Arg. rar. villosa Glaz. in herb. Paris., Berol., Kew., ete. - Serra das Divisies ou do Lrbano, Goyaz, nº 22096. Sous-frutescent, fl. blanc jaunâtre. Aoùt-septembre. C.

- Var. glabrata Müll. Arg.: Fl. Bros. XI, II, p. 365. - Guariroba, au Morro Cubatio, entre les pierres, Goraz, $n^{05}$ 19851, 22097. Sous-frutescent, fl. blanchâtres. Octobre-norembre. GC.

236. S. Schottiana Müll. Arg.: Fl. Bras. X, II, p. 568. - Campo Bello, dans le lit du lío Parahṛl)a, Rıo-Jax., nº 8320 ; São José d'El Rei, au hord du Rio das Morter, Mrxs, $n^{0} 17212$; Rasgão, près Corumba, Goyaz, n 22099. Arbuste, fl. blanches. Septembre-octobre. CC.

237. S. Gandichaudii Müll. Ar.;.; Fl. Bras. XI, II, p. .69. - Entre Relem et Queimados, Rio-Jax.. n" 8922. Arbuste, fl. blanchâtres. Octobre-novembre. C.

¿38. S. stipulacea Müll. Arg.; Fl. Bras. XI, II, p. ว̈68. - Riachı das Varas, près liamantina, Minas, $n^{0}$ 19835. Petit arbuste, fl. blanc jaunâtre. Février-mars. R. 
239. S. heteroica Mn̈ll. Arg. in Fl. Bras. XI, II, p. 708. - Entre Cabo Frio et Araruama, Rio-J $\mathrm{J}_{\mathbf{x}}, \mathrm{n}^{\circ}$ 4979. Arbuste, f1. blane jaunâtre. Férrier-mars. C.

240. S. multiramea Vüll. Arg.; Fl. Bras. XI, II, p. 3̈70. - Entre Garea et Tijuca, Rio-Inx., $\mathrm{n}^{0 \mathrm{~s}}$ 2696, 13492. Arbuste, fl. blanchàtres. Novembre-décembre. CG.

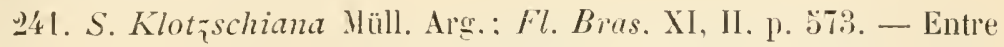
Soledade et Cachambú, liı-JAx., n"s 16339 . 19837. Arbuste, 11. blanc jaunâtre. Janvier-février. C.

242. S, vestita Müll. Arg. in Fl. Bras. XI, II, 1. 57\%. - Entre Rodrigo Silva el Ouro P'reto. Mıxas, no $19837 a$. Arbuste, fl. blanchâtres. Mars-avril. G.

943. S. rigida Müll. Arg.; Fl. Bras. XI, II, p. b7̈̈. - Itatiaia, dans le campo. Pro-JAx.. $11^{\circ} 4912$ a. Arbuste rabougri, fl. blanc jaunâtre. juillet-août. C.

24'. S. membranifolia Müll. Arg. in $\mathrm{Fl}$. Bras. XI, II, p. 379. Serra do Lenheiro, près São Juĩo d'El Rei, Hrxas, u" 13195 a. Arbuste, 11. blanc jaunàtre. Aoùt-septembre. R.

245. S. nervosa Müll. Arg.; Fl. Bras. XI, II. p. 581. - Rio Comprida, Catumby, Rı-Jax., no 4912. Arbuste, fl. blanchâtres. Janvierfévirier. GC.

246. S. brasiliensis Vüll. Arg.; Fl. Bras. XI. İ, 11. 584. - Jurujuba et Cabo Frio, Ro-ldx., nos 6806, 11540, 11548; Santo Antonio do Monte, Mris, 11" 13195. Arbuste, fl. blanc jaunâtle. Norembre-décembre. CG.

- Var. obovata Müll. Arg.; ; Fl. Bras. XI, II, p. 38\%. - Ponte Queimada, dans le campo, Mıxas, $n^{n}$ 13196. Arluste, f1. jaunâtres. Nurembredécembre. C. Vulı. : Marmelo.

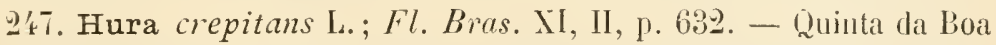
Vista, à S. Christovão, Rı-Jan., $n^{\circ} 14238$ a. Arbre cultivé venu du Para, 11. blanc verdâtre. Février-mars.

2'18. Actinostemon concolor Müll. Arg.; Fl. Liras. XI, II, p. こั93. - Larangeiras, au Cosme Velho, Rio-Jax., nos 111. 1465, 18470. Arbuste, f1. blane jaunàtre. Aoùt-septemlıre. C.

- Var. Rieberr Mïll. Arg.; Fl. Bras. XI, II, 1. :39\%. - Floresta da Tijuea, Rio-Jax., no 7822. Arbuste, il. blanc jaunditre. Avut-septembre. C. - Var. genunus Müll. Arg.; ; Fl. Bras. XI, II, p. \%9. - Larangeiras, an Cosme Velho, Rio-Jax., $1^{\circ}$ 3104. Arbuste, I1. blanc jaunàtre. Févriermars. CC.

249. A. grandifolizs Baill.; Fl. Bras. XI, II, p. 896 . - Fazenda da 
Serra Vermetha, près de Cantagallo el Caho Frio, Rio-Jax., $11^{\circ 5} 9578$, 16346, 16347. Arbrisseat, 11. Hanc jaunàtre. Mars-avril. G.

2气ั0. Actinostemon verrucosus (iłaz. n. sp.? in herb. Paris., Berol., kew., Brux., etc. - Nossa Senhora da Penla, dans le bois, Mixas, $n^{0}$ 13481. Arbuste, Il. blanchîtres. Juin-juillet. C.

2:3. A. tortuosus Glaz. n. sp.? in herb. Paris., Berol., Kew., Brux.. etc. - Serra da Mantiqueira, dans le bois, Mlsas, $n^{\circ} 9580$. Arbuste tortueux, 17. brunes. Juillet-anut. C.

2019. A. cantagallensis Glaz. n. sp.? in herb. Paris., Berol., Kew, Brux., etc. - Cantagallo, à Larangeiras, Pio-JAx., n ${ }^{\circ}$ 16354. Arbuste, fl. blanc jaunâtre. Mars-arril. C.

9̈3. A. multiflorus Mlüll. Arg.; Fl. Bras. XI, II, p. ̋97. - Serra da Bica, près de Cascadura, Rio-JAx., $n^{05} 6911$, 14263. Arbuste, 1t. blanc jaunitre. Novembre-décemblre. C.

20\%4. A. lanceolatus Sald.; Fl. Bras. XI, II, p. 598. - Fazenda do Sobral, à Parahylua do Sul, Rio-Jax., $n^{0 s} 13179$, 13493. Arbrisseau, fl. blanc jaunâtre. Novembre-décembre. CC. Vulg. : Canella de Veado.

2\%). Dactylostemon verticillatus Klot\%. Fl. Bras. XI, II, p. 603. - Entre Lagoa do Peixe et Cabo Frio, et Restinga de Copacabana, Rio$J_{A x}, n^{0 s} 3815,13177,13178$. Arbuste, fl. blane jaunâtre. Septembreoctobre. C.

2506. D. Klotzchii var. Weddellianus Vüll. Arg.; Fl. Bras. XI, II, p. 603. - Corcovado, au Silvestre, Rı-JAx., nos 1345, 3106, 364َ'. Arbuste, fl, blanc jaunattre. Mars-mai. CC.

257. D. brasiliensis Ilüll. Arg.; Fl. Bras. XI, II, p. 611. - Entre Barbacena et Sitio, Mlsas, $n^{0}$ 15407. Arbrisseau, fl. blanc jaunâtre. Novembre-lécembre. R.

2:38. Excœearia obovata Müll. Arg.; Fl. Bras. XI, II, p. 613. Cabeceiras do Rio Gama, an Riacho Fundo, Govaz, nos 22116, 22118. Arbrisseau, f1. błanchâtres. Octohre-novembre. C.

2:9. E. marginata Уüll. Arg.; Fl. Bras. XI, II, p. 616. - Cachoeira do Campo. Misas, no 20477 a; Rio Bananal, à Chico Loho, Goraz, $\mathrm{n}^{\circ}$ 22117. Arbuste, fl. blanches. Novembre-décembre. CC.

- Var. intermedia Müll. Arg.; Fl. Bras. XI, II, p. 617. - Corrego do Brejo, dans le campo, Goraz, $n^{0:} 22115,22116$ a. Petit arbuste, fl. blanchâtres. Novembre-técembre. R.

- Var. grandifolia 1 lüll. Arg.; Fl. Bras. XI, II, p. 61S. - Cachoeira do Campo, dans le bois, Mıxas, $n^{\circ}$ 20477. Arbrisseau, f1. blanc jaunâtre. Novembre-décembre. C. 
260. E. biglandulosa Min̈ll. Arg.; Fl. Bras. XI, II, p. 618. - Fazenda de Santa Cruz et Floresta da Tijuca, Rio-Jav., nos 9587, 14266. Arbre, fl. blanc jaunittre. Novembre-décembre. CG.

- Var. leptadenta Müll. Arg.; Fl. Bras. XI, II, p. 620. - Caceição, près Sĭo Domingo, Mlsas, $n^{\circ}$ 13197. Arbrisseau, fl. blanc jamnàtre. Novembre-décembre. C.

- Var. Klotschiana Vüll. Arg.; Fl. Bras. XI, II, p. 619. - Corcovado, it Paineiras, Rı-Jan., n 789; Cacloeira do Campo, dans le bois, Nıxis. $n^{\circ}$ 20476. Arbre, fl. blanc jaunâtre. Janvier-février. C. Vulı̣.: Massaranduba vermelho.

- Var. serrata Müll. Arg.; Fil. Bras. XI, II, p. 620. - Nova Friburgo, au Suspiro, Rro-JAv., $n^{\circ}$ 13494. Arbrisseau, blanc jaunâtre. Novembredécemln'e. R.

- Var. petrolaris Müll. Arg.; Fl. Bras. XI, II, p. 621. - Floresta da Tijuca et Corcovado, Rı-JAx., n ${ }^{\circ}$ 4190. Arbrisseau, fl. blanc jaunâtre. Novembre-décembre. C.

- Var. sublanceolata Müll. Arg.; Fl. Bras. Xi, II, p. 621. - Petropolis, a Santo Antonio au Mundemo, Rio-Jax., n 11546. Arbre, fl. blanc jaunâtre. Norembre-décembre. C.

- Var. grandifolia Müill. Arg. : Fl. Bras. XI, II, p. 692. - Corrego do Brejo, dans le bois, Goyaz, no 22118 a. Arbrisseau, l1. blanc jaunâtre. Octobre-novembre. R.

261. E. (Sapium) scelerata Iiidl. in Journ. Linn. Society (1888), p. 60. = Excecaria biglandulosa var. serrata teste Barb. Rodr. Qruinta da Boa Vista, à São Christovão, Rio-Jax., no 20476 a. Arbuste, cultivé sans ti. en janvier. C. Vulg. : Burra leiteiro.

262. Dalechampia goyazensis Müll. Arg.; Fl. Bras. XI, II, p. 6ł3. - Ponte Alta, près Areas, Goxaz, $n^{\circ} 22073$. Herbacé, fl. blanc verdàtre. Août-septembre. C.

263. D. caperonioides Müll. Ar r.; Fl. Bras. XI, II, p. 642. - Entre Alexandre et As Antas dans le campo, Goraz, n 22072. Herbacé, 11. verdâtres, bractees roses. Aout-septembre. C.

- Var. obovata Mïll. Arg.? Fl. Bras. XI, II, p. 6q2. - Serra dos Pyreneos, entre les rochers, Goyaz, nº 22072 a. Herbacé, fl. blancliâtres, bractées roses. Août-septemlıre. C.

- Var. hanceolata Müll. Arg.; Fl. Bras. XI, II, p. 643. - Entre Morro Canatra et Mestre d'Armas, Goraz, n² 22076. Herlacé, fl. blanchàtres. Octobre-norembre. C.

26't. Dalechampia goyazensis Müll. Arg. in Fl. Bras. XI, II, p. 6'3. - Ponte Alta, près d'Areas, Goxaz, n² 22073. Herlacé, vivace. Septembre. 
260. Dalechampia Riedeliana Müll. Arg. : Fl. Bras. XI, II, 1. 644. - Morro do Ouro Fino, entre les rochers, Goraz, $1^{\circ} 22075$. Herluacé, I1. blanchatres. Juillet-août. C.

266. D. pentaphylla Lamk; Fl. Bras. XI, II, p. 645. - Floresta da Tijuca et Corcovado, Rio-Jan., $n^{\circ}$ 4188. Petite liane sous-frutescente, f1. blanchâtres. Novembre-décembre. CG.

267. D. triphylla Lamk; Fl. Bras. XI, II, p. 6:0. - Entre Tijuca, et Jacarepagua, Rio-JAx., $n^{\circ} 4188$ a. Petite liane sous-frutescente, fl. blanchâtres. Novembre-décembre. C.

268. D. micromeria Baill.; Fl. Bras. XI, II, p. 632. - Floresta da Tijuca et Corcovado, Rio-J Ax., ${ }^{08} 25,4198$. Petite liane sous-frutescente, 11. blanc verdâtre. Octobre-novembre. C.

269. D. ficifolia Lank; Fl. Bras. XI, II, p. 653. - Rio Douro et Serra da Estrella, R10-JAx., nos $194,4189,11549$. Grande liane, f1. blanc verdâtre. Août-septembre. CG. Vulg. : Pó de mico

270. D. tiliafolia Lamk; Fl. Bras. XI, II, p. 634. - Entre Araruama et Cabo Frio, Rio-Jax., n ${ }^{\circ s}$ 1049, 11536. Grande liane, fl. blanchâtres. Novembre-décembre. C.

271. D. stipulacea var. major Müll. Arg. : Fl. Bras. XI, II, p. 656 . Serra da Estrella, près Nandioca, Rı-JAx., no $194 a$. Volubile, fl. blanc verdâtre. Août-septembre. G.

272. D. brasiliensis var. geneina Müll. Arg.; Fl. Bras. XI, II, p. 657. - Serra de Luro Branco, au Cesario, Monas, nos 11537, 13191. Liane sous-frutescente, fl. blanchâtres. Février-mars. C.

273. D. arciana Baill.?; Fl. Bras. XI, II, p. 661. - Morrinhos, dans le campo, Goraz, no 22074. Petite liane, fl. blanc verdàtre. Juillet-aoùt. C.

274. D. Leandri Baill.; Fl. Bras. XI, II, p. 662. - Entre Gavea et Pedra Bonita, Rı-Jax., $\mathrm{n}^{\circ}$ 4199. Longue liane, fl. blane verdàtre. Janvier-février. R.

27ð. Euphorbia setosa Müll. Arg.; Fl. Bras. XI, II. p. 672. - Entre Barreira do Veado et Morro Redondo dans le campo, Goyaz, n² 22079; Serra do Funil, près du Rio Paraúna, Minas, $n^{\circ}$ 19825. Juillet-aoùt. CG. Vulg. : P'oya do campo.

276. Euph. angustifolia Glaz. 11. sp.? in herb. Paris., Berol., Kew., Brux., eic. - Rio das Pedras, dans le campo, Míxas, n 19826. Sousfrutescent, fl. blanchâtres. Août-septembre. G.

277. Euph. cœcorum Mart.; Fl. Bras. XI, II, p. 67こ. - Serra d'Ouro Branco, dans le campo, Nisss, $n^{0 s}$ 11543, 15408; Corrego do Brejo, Goyaz, $n^{\circ}$ 22086. Herbacé, fl. blanches. Juillet-septembre. GG. 
278. Euph. potentilloides Boiss.; Fl. Bras. XI, II, p. 678. Capelinha de Santo Antonio, près du Rio Descolserto, Goyaz, $11^{\circ} 22087$. Herlatcé, fl. blanches. Aout-septembre. C.

279. Euph. macrorrhiza Glaz. n. sp.? in herb. Paris., Berol., Kew., Brux., ete. - Entre As Antas et Pedro Sardinhal, dans le campo après l'incendie, Goyaz, $n^{\circ 5} 16363,22085$. Herbacé à grosse racine, 17. blanches. Aout-septembre. C.

280. Euph. filifolia Glaz. n. sp.? in leerb. Paris., Berol., Kew., Brux., etc. - Guariroba, an Jloro Cubatão dans le campo entre les

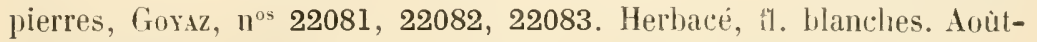
septemlire. CC.

281. Euph. verticillata Glaz. n. sp.? in herb. Paris., Berol., Kew., Brux., etc. - Entre les rivières Vicente Pires et Riacho Fundo, dans le campo, Goyaz, no 22084. Herbacé, fl. blanches. Aoùt-septembre. C.

282. Euph. brasiliensis Lank; Fl. Bras. XI, II, p. 676. - Restinga de Copacabana et de Maui, Ruo-Jax., nos 230, 4973, 10048, 18480; Serra dos Vertentes à Folha Larg̨a, Misas, $1^{\circ}$ 20474. Herbacé, 1l. blanches. Juillet-aoùt. CG. Vulg.. : Erva de Santa Luzia.

- Var. pulchella Boiss; Fl. Bras. Xl, II, p. 677. - Praia de Piratiningal et Copacabana, Rı-Jav., nos 8319, 9577, 11545. Herbacé, 11. blanches. Anutt-septembre. CC. Vulg. : Erva de Santa Luzia.

283. Euph. sabulicola Boiss.: Fl. Bras. XI, II, p. 679. - Restinga de Copacabana près de la mer, Rio-J $\mathrm{JN}_{\mathrm{N}}, \mathrm{n}^{\circ} \mathbf{2 4}$. Sous-fítescent, fl. blanches. Janvier-février. G.

284. Euph. serpens H. B. K.; Fl. Bras. XI, II, p. 682. - Aldeia de São Pedơ dos Indios, près Cabo Frio, Rio-Jax., nº 13176. Herbacé, fi. blanchâtres. Août-septembre. R.

28.. Euph. prostrata Aiton; Fl. Bras. XI, II, p. 683. - Quinta da Boa Vista, à S. Christovão et au campo da Acclamação, Rıo-Jav., n ${ }^{\circ 5} 518$, 9576. Herbacé, fl. blanches. Aoùt-septembre. CC.

286. Euph. thrmifolia Burm.; Fl. Bras. XI, II, p. 68't. - Entre Porto Rio Paracatu et le Rio São Francism. Mrxas, $1^{05}$ 13188, 22080. Herhacé, 11. blanc jaunâtre. Aoùt-septembre. C.

287. Euph. pilulifera; Fl. Bras. XI, II, P. 68't. - Floresta da Tijuca et S. Christovão, Rio-JAN., nos $344,1468,4975$. Herhacri, f1. blanchâtres. Anout-septembre. CC. Vulg. : Erva de andorinha.

- Var. procumbens Boiss.; Fl. Bras. XI, II, p. 68.\%. - Curimatahy, dans le bois, Mrvas, $1^{\circ}$ 13187. Herluacé, fr. blanches. Novembre-décembre. C. 
288. Euphorbia lanata Glaz. 11. sp.? in herb. Paris., Berol., Kew., Brux., ete. - Entre Tijuca et Gingibre, après l'incendie du eampo, Govaz, no 22078. Herbacé, 11. blanches. Juillet-aoutt. C.

989). Euph. lasiocarpa Klotz. in Nova Acl. Nal. Cur. XIX. Supp. p. 414. - Serra da Balyylonia, Misas, n 7817. Herlacé, f1. Blanches. Janvier-février. R.

990. Euph. insulana Vell.; Fl. Bras. XI, II, p. 688. - Ensiada de Sepitiba, près Macahé, Rio-Jav., $n^{\circ}$ 18481. Herlacé, fl. blanchâtres. Juillet-aonit. R.

- Var. minor Müll. Arg.; Fl. Bras. XI, II, p. 689. - Gavea, entre les rochers au bord de la mer, Puo-Jav., $11^{\prime \prime} 4196$. Herbacé, ft. blanches. Février-mars. C.

291. Euph. rhipsaloides Glaz. 11. sp. in lierb. Paris., Berol., liew., Genev, etc. - Biribiry, près Diamantina entre les rochers, IIsas, $n^{0}$ 18479. Sous-frutescent, fl. verdâtres. 11 ars-avril. C. Vulg. : Archote. Cette plante très laiteuse donne une petite lumière lorsqu'elle est à deni desséchée.

292. Euph. comosa Vell.; Fl. Bras. XI, II, p. 693. - Floresta da Tijuca et Garea, Rio-Jax., $n^{0 s} 4197,7819,13189$. Herbacé, fl. blanchìtres. Janvier-février. CG.

293. Euph. prunifolia Vüll. Aræ...; Fl. Bros. XI, II, p. 694. - Serra da Bica, près Cascadura, Rio-Jax., no ${ }^{0 s} 343$, 4974. Herbacé, 11. blanchấtres. Février-mar's. C.

294. Euph. Peplus L. Species Plant., p. 456. - Petropolis, au bord des chemins, Rio-Jax., $n^{\circ}$ 6673. Herbacé, ft. blanchàtres. Aoùtseptembre. CiG.

298. Euph. helodes Boiss.; Fl. Bras. XI, II, p. 698. - Serra dos Orgãos, au sommet, Rı-JAx., nos 4193 , 16331. Herbaeé, f1. blanchâtres. Janvier-février. C.

996. Euph. chrysophylla Boiss.; Hi. Bras. XI, II, p. 698. - Sĩo João d'El Rei et Itacolumy près Ouro Preto, Misas, $11^{\text {os }} 15409,16332$, $19825 a$; Campos da Bociina, Säo P'Aúlo, nº 8318. Herbacé, fl. blanc verdâtre. Janvier-févier. C.

297. Euph. paludosa Glaz. n. sp.? in herl. Paris., Berol., Kew., Brux., ete. - Corrego do Brejo, dans les bourbiers, Goraz, nº 22088. Herbacé, f1. blanc jaunâtre. Février-mars. C. 


\section{Fam. 12't. - Urticacées.}

1. Phyllostylon brasiliensis Ca1. in Hook. et Benth. Gen. Plant. III, p. 3อัュ. - São Christovĩo, entre les rocher's près de la mer, Ruo-Jax., nos 8930, 16353, 17223, 18509. Arbre, fl. blanc verdatre. Nai-juin. C.

2. Celtis aculeata Swartz; Fl. Bras. IV, I, p. 173. - Corcovado, au Silvestre, Rio-Jax., n' ${ }^{\circ}$ 4918. Arbuste, fl. blanchattres. Octobre-novembre. C.

3. C. glycycarpa Nart.; Fl. Bras. IV, I, p. 174. - Serra do Aryro, près Capyvary, Rio-Jax., $n^{\circ} 13909$ a. Arluuste sarmenteux, fl. blanc jaunâtre. Janvier-férrier. l.

4. C. alnifolia Miq.? Fl. Bras. IV, I, p. 176. - Quartel do Biribiry, pres Diamantina, Jlxas, $n^{\circ}$ 19862. Arbuste sarmenteux, fl. rousses. Féviel'-mar's. C.

¿. C. brasiliensis Gardn.; Fl. Bras. IV, I, p. 177. - Serra dil Estrella et Corcovado, Rio-J $\mathrm{J}_{\mathrm{A} .}, \mathrm{n}^{\text {os }} 4960$, 15427. Arbuste sarmenteux, 11. blanc jaunattre. Novembre-décembre. C.

6. C. morifolia Planch.; Fl. Bras. IY, I, p. 178. - Itacolumy, pres Ouro Preto, Hixas, $1^{\text {os }} 12171$, 13209; Corcovado. cu Silvestre, Rio-Jax., $n^{\circ} 240$.

7. Sponia micrantha Desne: Fl. Bras. IV, I, p. 171. - Floresta da Tijuca et Corcovado, Rio-Jax., $n^{\text {os }} 125,1139,10051,14278$. Arbrisseau, 11. rousses. Mars-avril. CG. Vulg. : Corendiba ou Curindinba.

8. Sp. mollis Desne; Fl. Pras. IV, I, p. 179. - Congonlias do Campo, dans le hois, Mıras, $\left.n^{0 s}\right] 133 a$, 13208. Arbrisseau, 11. blanchìtres. Uctolire-norembre. CC. Vulg. : Corendiba.

9. Cannabis sativa L.; DC. I'rodr. XVI, I, p. 30. - Rin-Jar., $10^{0}$ 5993. Herb. annuelle, f1. blanchâtres. Cultivé par les nègres en guise de talıac. Février-mar's. C. Vulg. : Pongo.

10. Maclura tinctoria Endil.; F\%. Bres. IV, I, p. 19ั. - Illa de Govemador, Rio-Jax., $\mathrm{n}^{\circ}$ 7880; Marlianna près Ouro Preto, Mlixas, $11^{0}$ 14281. Arbrisseau, fl. jaunes. Mars-avril. CC. Vulg. : Tatayiba.

11. M. affinis Niquel.; Fl. Bras. IV, I, p, L3. - Corcovadu et Florestar da Tijuca, Rio-Jax., no $766 a$. Arbrissean, fruit blanchâtre. Férier-mars. C.

12. M. xainthoxylon Endl.; Fl. Bras. IV, 1, p. Ï̈6. - Sanla Thereza, au Corcovado, Rio-Jax., nº 766 . Albrisseau, fruit blanchâtre. Janvier-févier. CC. 
13. Dorstenia clata Gardı.; Fl. Bras. IV, I, 1. 160. - Serra dos

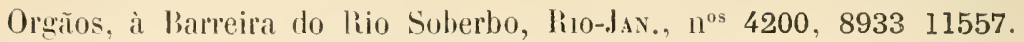
Sous-frutescent, fruit roux. Avril-nati. C.

I4. D. macahensis Glaz. 11. sp.? in herl, Paris., Berol., Kew., Brux., etc. - Alto Nacahé de Nova Friburgaro, Rı-Jux., n²0495. Sousfrutescent, fruit brun. Septembre-octohre. R.

I马. D. erecta var. Hispida Bur. in DG. Prodr. XVII, p. 267. - Floresta da Tijnea, Rio-Jas., n² 2705. Sous-frutescent, firuit brun. Juin-juillet. R.

16. D. nervosa Desv. : Fl. Bras. VI, I, 1. 161. - Serra I'Estrella, au Rio Quintiuha, Rı-JAv.. nos 1016, 8080. Herbacé, fruit brun. Octobrenovembre. C.

17. D. Cayapia Vell.: DC. Prodr. XVII, p. 262. - Entre Sitio et Barbacena, dans le bois, Mixas, ${ }^{\circ} 13211$ a. Herbacé, fruit lorun. Novembre-décembre. C.

- Var. oprfera Bur. in DG. Prodr. XVII, p. 263. - Atalaia, à Praia Grande, Rio-Jax., $n^{\circ} 3114$; Entre Barbacena et Sitio, dans le bois, Mixas, $n^{\circ s}$ 13211, 14277. Herbacé, fruit brun. Novembre-décembre. C.

- Var. asarordes Bur. in DG. Prodr. XVII, உ63. - Entre Sitio et Barbacena, dans le campo, Misas, no 13212. Près de Formosa, Goyaz, $\mathrm{n}^{\circ} 22143$. Herbacé, fruit brun. Novembre-décembre. C.

18. D. brasiliensis Lamk. Fl. Bras. VI, I, p. 168. - Entre Sitio et Barbacena, dans le bois et le campo, Misus, n 16348. Herbacé, fruit noirâtre. Norembre-décembre. G.

19. D. hispida var. glabra Hook.; Fl. Bras. IY, I. 1. 163. - Floresta la Tijuca, Rı-JAx., nº 777 . Sous-frutescent. fruit verlâtre. Mars-avril. R.

20. D. monteridensis Gardn.; Fl. Bras. IV, I, p. 170. - Nossa Senhora da Penha, Ro-Jan., no 8079. Herhacé, fruit brun. Septembreoctobre. CG. Vulg. : Cachiapia.

21. D. multiformis Miq.; Fl. Bras. [V, I, p. 163. - Corcovalo, au ruisseau Carioca, Rro-lax., $1^{0}$ 1014. Herbacé. fruit brun. Septembreoctobre. C.

- Var. ficifolia Bur. in DC. Prodr. XVII, p. 26I. - Petropolis, it Cascatinla, Rı-Jax., nº 7831. Herbacé, fruit brun. Juin-juillet. C.

- Var. ranosa Bur. in DC. Prodr. XVII, 1. Q61. - Corcovado ì Paineiras, Rı-lax., no 779, 1015. Herbacé, fruit brun. Mars-avril. C. Vulg. : Contrairva.

22. D. arifolia Lamk. Fl. Bras. IV, I, P, 166. - Floresta da Tijuca ef Petropolis, liıo-Jan., nos 778, 7832. Herbacé, fruit brun. Juinjuillet. C. 
- Valr. pinnatifida Bul. : Fl. Birls. IV, I, p. 167. - Grotte de Laye, entre Guariroba et le Rio Descoberto, Goraz, n² 22142. Herbacé, fruit brin. Octobre-novembre R.

23. D. opifera Nart.; Fl. Bras. IV, I, p. 169. - Itatiaia dans le campo entre les rochers, Rı-Jav., no 8079 a. Herbacé, fruit brun. Juilletoctobre. R.

24. D. tubicina R. et P. Flora Peruv. I, p. 60̈, tab. 102. - Serra do Tingua, dans la forêt, Rio-Jax., $n^{\circ} 11571$. Herbacé, fruit brun. Novembre-décembre. $\mathrm{R}$.

2马. Ficus anacardiffolia Kith et Bouc. Ind. sem. Hort. Berl. (18'6), p. 10̆. - Restinga de Maua et Corcovado, prés des Dous Irmàus, Rio-Jax., $\mathrm{n}^{08} 8082,11562,18495$. Grand arbre, fruit jaunàtre. Janvier-février. CC.

26. F. Gardneriana Miq.; Fl. Bras. IV, I, p. 91. - Buryti Vermelho of Vargem, Goysz, $n^{\circ}$ 22146. Grand arbre, fruit roux. Juinjuillet. C.

27. F. doliaria Martius; Fl. Bras. IV, I, p. 92. - Serra d'Estretla, près Petropolis, Rio-Jav., $n^{\circ} 12162$ a. Grand arbre fruit jaunatre. Majjuillet. C. Vulg. : Gamelleira.

28. F. fulva Viquel; Fl. Bras. IV, I, p. 93. - Larangeiras, au Cosme Vello entre les rochers, Rı-JAN., $n^{\circ}$ 6006. Grand arbre, fruit roux. Octoble-novembre. R.

99. F. subtriplinervia Mir.; Fl. Brus. IV, I, p. 99. - Fazenda de Bernardo, près Meia Ponte, Goraz, $n^{\circ}$ 22148. Grand arbre, fruit vert. Juin-juillet. C.

30. F. Polnliana Miquel in Fl. Bras. IV, I, p. 100 (sul) Urostigma). - Corcovado, à Paineiras, Pio-JAx, nos 6005, 8083, 20492. Arbrisseau, fruit blanc jaunâtre. Octubre-novembre. CC.

31. F. hirsuta Veli. : Fl. Bres. IV, I, p. 103. - Corcovado et Larangeiras, rntre les rocher's, Rito-Jav., nos 82 , 1499. Arbrisseau, fruit brun. Février-avril. C.

32. F. organensis Mlip. in Fl. Bras. IV, I, p. 10: (sul, Urostigma). - Bas du Corcuvado, all Rio Trapixeiro, Rio-Jix., nos 11564, 12163, 20490. Grand arbre cultivé, fruit jaunâtre. Novembre-décembre. CG.

33. F. fluminensis Warb. n. sp. - Petropolis, à Itamaraty, RioJAs., $11^{\text {os }} 12162$, 15433. Grand arbre, fruit blanchatte. Mai-juin. C.

34. F. griseo-puberula Warb. ॥. sp. - Morro de Sãu Vicente, pres Ourn Preto, Mcxas, $n^{0}$ 15434. Arbre, fruit roux. Février-mar's. R.

3\%. F. immersa Warb. II. sp. - Corcovalo, alu Dous Irmios, RioJax., $n^{05} 214,765$. Arbrissean, fruit verdatre. Férrier-mars. C. 
36. Ficus Warburgii Glaz. n. sp. - Floresta da Tijuca, à Soledarle, Rio-Jar., $1^{\circ}$ 20494. Grand et bel anbre, fruit roux. Octobre-novembre. R.

37. F. goyazensis Warb. n. sp. - Entre Burity Vermelho et Vargem, Goraz, $n^{0}$ 22145. Grand arbre. fruit roux. Juin-juillet. C.

38. F. substipitata Warb. n. sp. - Restinga de Cabo Frio, RıJax., no 13213. Grand arbre, fruit roux. Septembre-octobre. C.

39. F. erubescens Warb. n. sp. - Alto Nacahé de Nova Friburgo, Rı-JAx., no 13495. Grand arbre, fruit blanchâtre. Octobre-novembre. C.

40. F. fulvisemma Warb. 11. s]. - Corcovado, au Dous Irmãos, Rı-JAx, nos 11561, 12161. Graut arbre, fruit jaunâtre. Janvier-février. C.

41. F. subaporuloides Warb. n. sp. - Floresta da Tijuca, Rio$J_{A x}, n^{\circ}$ 14273; Entre Goyaz et Rio Cruhú, Goraz, $1^{\circ}$ 22147. Arbre, fruit jaunàtre. Aoùt-septembre. C.

42. F. inclusa Warb. n. sp. - Larangeiras, près Cantagallo, RioJAx., $11^{\circ}$ 16351. Grand arbre, iruit jaunâtre. Octobre-novembre. C.

43. F. sclerostipula Warb. n. sp. - Rio das Flores, Station do Commercio, Rio-J Ax., $^{o s}$ 15429, 17773. Grand arbre, fruit roux. Novembre-décembre. C.

44. F. laureola Warb. n. sp. - Itabira do Campo, dans le bois, Mras, $n^{0}$ 17772. Arbre, fruit blanc jaunâtre. Novembre-décembre. C.

4ว. F. sapiifolia Warb. n. sp. - Rodrigo Silva, près Ouro Preto, Mrsas, $n^{\circ}$ 19864. Grand arbre, fruit irun. Mai-juillet. C.

46. F. nigripes Warb. n. sp. - Bas du Corcovado. au Rio Trapixeiro, Ru-Jax., no 11569. Arlurisseau, lruit jaunatre. Mars-avril. R.

47. F. obovata Warb. n. sp. - Paço lsabel. à Larangeiras, RroJAx.. $n^{\circ}$ 20491. Grant arbre, fruit blanchâtre. Aoutt-septenbre. C.

48. F. melocarpa Warb. n. sp - Serra dos Vertentes, à Folha larga pris Oliveira, Mixas, no 20493. Grand arbre, fruit roux. Juinjuillet. C.

49. F. doratophylla Warb. n. sp. - Floresta da Tijuca, en bas du Pico, Rio-Jax., no 18496. Grand arbre, fruit jaunattre. Juin-juillet. R.

50. F. rectinervis Warb. n. sp. - Corcovado, à Paineiras et à Caixa d'Agua, Rto-Jax., $n^{\text {os }}$ 5991, 6685. Arbrisseau, fruit roux. Harsmai. CC.

51. F. involucrata Warb. n. sp. -- Gavea, près de la mer, Rı$J_{A x}, n^{\circ}$ 5992. Grand arbre, fruit brun. Aoùt-septembre. C. 
:.2. F. Mouræ Wab. n. sp. - Petropolis, près de la cascade d'Itamaraty, hio-J Ax., $n^{\circ}$ 15430. Grand arlre, fruit blanchâtre. Octolsrenovembre. C.

53. F. fulvistipula Warb. n. sp. - Parahỵluna, près de la rivière, Hıxs, $\mathbf{I}^{\circ}$ 17774. Grand anbre, fruit blanchatre. Octobre-novembre. C.

̈̈'. Pharmacosycea anthelminthica Miџ. : I'l. Bras. IV, I, p. 83. Floresta da Tijuca et Corcovado, Rio-Jax.. nº 763; Gandarela, prís des plantes fossiles, Mıxas, $n^{\text {os }} 12165$, 15431. Arbrisseau, Septembre-octolre. CC. Vulg. : Gamelleira.

- Var. microcarpa Glaz.? in herb. Paris., Berol., kew., etc. - Ypirangá, au bord du Rio Parahyba et a Campos, Rro-JAx., $1^{\text {os }} 10059,12165$. Aribre, fruit vert. Octobre-norembre. C. Vulg. : Gamelleira.

ö.. Ph. adhatodafolia Miị.; Fl. Bras. IV, I, p. 86. - Florestil da Tijuca et Corcovado, Rio-Jax., $10^{\circ 5}$ 763, 6007. Grand arbre. Octobrenorembre. CC. Vulg. : Gamelleira.

56. Ph. duplojuncta War. 13. sp. in herb. Paris., Berol., Kew., Brux., etc. - Corcorado, à Paineiras, Rro-Jax., nos 11563, 12164. Tres bel et grand arbre. Janvier-février. C.

57. Ph. crebrinervis Warb. n. sp. in herb. Paris., Berol., Kew, Brux., ete. - Entre Lagoa de Freitas et Vista Chineza, Rio-Jax., $n^{\circ}$ 11560. Grand et bel arbre. Janvier-février. C.

88. Ph. vermifuga Miı. in Fl. Bras. IV, I, 1) 8̈. - Nyctherohy, à Praia te Fora, Rino-JAx., no 13214. Grand arbre, fruits verts. Mars-avril. C. Vulg. : Gamelleira.

59. Brosimum Gaudichaudii Trér.; Fl. Bras. IV. I, p. 108. Serra do Inficionado, dans le campo, Mixas, n 16349 ; Entre Alegre et Joìo Lolı, Goya, n² 22149. Arbrisseau, fl. blanchâtres. Aoùt-septembre. CG. Vule. : Vaquinhr.

Forna parvifolia Niq. in $\mathrm{Fl}$. Bras. IV, I, p. 109. - Cabo Frio et São Joño la Barra, Rio-JAx., nos 11572, 12170. Arbuste, 11. blanchâtres. Février-mars. C.

60. Br. discolor Schutt. Fl. Bras. IV, !, p. 110. - Atalaia, Tijuca et Petropolis, Rin-Jax., n ${ }^{05}$ 2704, 5990, 11559, 20487. Arbuste, 11. blanchâtres. Jauvier-mars. CG. Vulg. : Oiti do matu.

61. Br. Glazinvii Taub. in Engler Bot. Juhrb. (1890), p. 3. Floresta da Tijuca of Serra do Mlar a liodeio, Rio-JAx., Hos 8081, 13496. Arbrissean, fl. lianchâttes. Novenubre-décembre. C.

62. Br. glaucum Taub. in Engler Bot. Jahrb. (1890), 1) 4. Serla do Caraça, daus le campo, Maxas, $n^{0}$ 15428. Aririssealu, fi. blanchàtres. luin-juillet. C. 
63. Brosimum rubescens Tatul, in Engler, lnc. cil., p. 4. - Entre Nendanha et Realengn, Rio-JAx., $11^{\text {os }} 12167,12168,12169$. Gr. arbre, 11. brunes. Anut-sept. C. Vulg. : P'io vermelho ou Candurí.

6\%. Pseudolmedia ferruginea Tréc.; Fl. Bras. IV, I, p. 116. Campos de Sito Fidelis, Ro-Jav., nº 10056. Arbrisseau, fl. brunes. Fóvier-mars. R.

63. Sorocea nitida Fr. Allem. (teste Warb.) = Soaresia nitida Frei Allem. in Palestr. Scient., p. 142 (1858). - Corcovado et Cosme Velho, B10-JAN., ${ }^{\text {os }} 859,8289,20489$. Grand et bel arbre, fl. brunes. Octobre-novembre. L. Vulg. : Oilicica cica.

66. S. Uriamem Mart.; Fl. Bras. IV, I, p. 113. - Gavea, chez Frei Gustodio Serrio, Rio-Jax., no 73. Arduste, It. brunes. Mars-avril. C. Vulg. : Uriamem.

67. S. micranthera Warb. n. sp. in herb. Paris., Berol., Kew., Brux, etc. - Entre Mendanha et Realengo, Rı-Jax., n 12172. Arbuste, f1. blanchitres, Aoùt-septembre. R. Vulg. : Bainha d'espada.

68. S. spinosa Warb. 11. sp. in Iterb. Paris., Berol., Kew., Brux., etc. - Alto Macahé, Petropolis et Corcovado, Rı-JAx., nos 7851, 11565 , 18493, 18494. Arbrisseau, fl. blanchâtres. Juillet-aoùt. CG. Vulg. : Santa Lu:ia.

69. S. ilicifolia Miınel; $F l$. Bras. IY, I, 1. 114. - Floresta da Tijuca et Corcovado, Rio-das., nos 4919, 16356. Arlore, fl. brunes. Marsavril. G. Yulg. : Sorococo.

- Var.. Hrlari (Gaud.) Miquel in Fl. Bras. IV, I, p. 213. - Tijuca, Quinta, Rı-JAx., ${ }^{\circ s} 110,1470,3112$. Petit arbre. Septembre-novembre.

70. S. Guilleminiana Gaud.; Fl. Bras. IV, I, p. 213. - Cava da Onça, au Corcovalo, Rio-Jax., nos 1471,5989 . Arbuste, f1. brumes. Septembre-octobre. C.

71. S. grandis Warh. n. sp. in herb. Paris., Berol., Kew., Brux., etc. -- Rio Santo Antonio, au Tingua, Rio-JAx., n ${ }^{\text {os }}$ 1137, 11566, 11567. Arbrisseau, fl. brunes. Aont-septembre. R.

72. S. racemosa Gaud.? Fl. Bras. IV, I, p. 213. - Floresta da Tijuea, Rio-JAv., $11^{\circ} 110 a$. Arbuste, fl. blanchàtres. Aont-septembre: R.

73. Cecropia carbonaria Mart.; Fl. Bras. IV, I, p. 1'4t. - Fazenda do Lamarão, dans le bois, Goyaz, $n^{\circ}$ 15426, 22144. Arbre élevé. fl. rousses. Janvier-mars. G. Vulg. : Ambaiba.

74. C. pachystachya Tréc.: Fl. Bras. IV, I, p. 143. - São João d'El Rei et Rello Ilorizonte, Msxss, $n^{08} 6684,10060$, 17224. Arbre élevé, fl. rousses. Mars-avril. CG. Vulg. : Ambaiba. 
78. C. adenopus Vart. : Fl. Bras. IV. I, p. 147. - Floresta da Tijuca, Serra da Estrella, Corcovado, Nova Friburgo, etc., Iiı-JAn., ${ }^{0 s} 11559$, 18499. 18500, 18501, 18502, 18503, 18504, 18505, 18506, 18507. Arre élevé, fl. rousses. Janvier-arril. CG. Vulg. : Ambaiba.

76. G. paludosa Warb. n. sp. in lierb. Paris., Berol, Kew., Brux., etc. - Nito Macahé de Nova Friburgo, Rio-Jan., $1^{\circ}$ 19863. Arlore élevé, fl. rousses. Novembre-décembre. R. Vulg. : Ambaiba.

77. C. hololeuca Miq.; Fl. Bras. IV, I, p. 148. - Corcovado et Floresta da Tijuca, Rio-JAx., n ${ }^{05} 18497$, 18498. Grand arbre, ll. brunes. Juin-octolsre. C. Vulg. : Ambaiba branca.

78. C. macranthera Warb. n. sp. in herb. Paris., Berol., Kew., Brux., etc. - Serra dos Orgãos et Rodeio, Rio-Jan., nos 8935, 12173. Grand arbre, fi. blanchàtres. Mar's-avril. R.

79. Coussapoa Schottii Niquel; Fl. Bras. IV, I, 1. 137. - Gavea, Floresta da Tijuca. Serra dos Orgãos, etc., Rı-JAx., nos $81,1013,1138$, $4937,4938,6009,8936,12166,16350$. Arbrisseau, 11. rousses. Aoùtseptembre. CC. Vulg. : Mata Pao ou Fruteira.

80. G. obovata Warb. n. sp. in lierb. Paris., Berol., Kew., Brux., etc. - Serra da Estrefla, près Petropolis, Rı-JAN., $1^{\circ}$ 8934. Très grand arbre, fl. rousses. Mai-juillet. C.

81. C. microcephala Tréc.; Fl. Bras. IV, I, p. 136. - Quinta da Boa Vista, à S. Christovão, Rı-JAN., n ${ }^{\circ} 10070$ a. Arbrisseat cultivé, fl. rousse's. Janvier-férrier. R.

89. C. latifolia Aubl.; Fl Bras. IV, I, p. 133. - Q Quinta da Boa Vista, à S. Cihristovão, Rı-dav., $11^{\circ}$ 6008. Arlurisseau cultivé, fl. brumes. Aoutt-septembre. C.

83. Pourouma acutiflora Tréc.; Fl. Bras. IV, I, p. 126. - Serra da Estrella, a Mandioca, Rı-JAx., $n^{\circ}$ 12174, 20488. Grand arbre, fl. rousses. Avril-mai. Vulg. : Ambaiba fruteira.

84. P. acuminata Nart.; Fl. Bras. IV, I, 1. 130. - Itapemirim, dans la forêt, Esplitito Saxto, no 10070. Arbre. fl. blanchâtres. Férrier-mar's. C.

8\%. Urtica urens L.: Fl. Rras. IV, I, p. 198. - Petropolis, dans les roças incultes, Rio-Jax., $n^{o s} 14275$ a. Herbacé, fl. blanchâtres. Aoùtseptembre. C.

86. Fleurya astuans Gaud.; Fl. Bras. IV, I, p. 196. - Floresta da Tijuca et Corcorado, hio-J $J_{A x}, 1^{0 s} 771$, 8085. Herbacé, fl. blane jaunatre. Avril-mai. GC.

87. Urera Punu Weddell; Fl. Bras. IV, I, 1. 189. - Itabapoana, Espritito Saxto, $1^{\circ}$ 10058. Sous-frutescent, fl. blanchâtres. Février-mar's. C. 
88. Urera caracasana Wedl. in DG. Prodr. XVI, p. 89. - Floresta da Tijuca el Corcovado, Rio-JAx., n ${ }^{\circ}$ 768. Sous-frutescent, fl. blanchàtres. Janvier-février. C.

89. U. mitis Miquel; Fl. Bras. IV, I, p. 194. - Serra dla Estrella, Rio-J $J_{A x} . n^{\circ s} 8932,15424$. Sous-frutescent, fl. blanchâtres. Décembrejanvier. C.

90. U. baccifera Gaud.; Fl. Bras. IV, I, p. 192. - Serra da Estrella et Corcovado, Rro-JAN., nos 6683, 8084, 11556, 13210, 14276. Sous-fiutescent, fl. blanchâtres. Janvier-mar's. CG.

9I. Pilea hyalina Fenzl.; Fl. Bras. IV, 1, p. 200. - Juiz de Fora, dans les bourbiers, Minas, $n^{\circ}$ 14275. Herbacé, fl. blanclıâtres. Juinjuillet.

92. P. grossecrenata Miq.; Fl. Bras. IV, I, p. 199. - Nova Friburgo, dans les roças, liıo-Jas., $n^{\circ} 855$ a. Herbacé, fl. blanchâtres. Janrier-février. C.

93. P. pubescens Liebm.; Fl. Bras. IV, I, p. 201. - Floresta da Tijuca, S. Christovão, Rı-JAx., nos 855, 16348 a. Herluacé, fl. rousses. Mars-avril. CG.

94. P. muscosa Lindl.; Fl. Bras. IV, I, p. 203. - Quinta da Boa Vista, à S. Christovio, Rı-J J Octobre-novembre. C.

95. P. serpyllifolia Wedd. in DC. Prodr. XVI, p. 107. - Sete Pontes, au Barreto, Riı-Jax., nº 12176. Herbacé, fl. blanchâtres. Juinjuillet. C.

96. Bœhmeria candata Sw.; Fl. Bras. IV, I, p. 18̈. - Corcovado, Floresta da Tijuca, Serra da Estrella, Rio-JAx., $11^{05} 773,775,776,3115$, 3116, 9592. Sous-frutescent, tl. blanc jaunàtre. Novembre-décembre. CG.

97. B. stipulata Glaz. n. sp.? in herb. Paris., Berol., Kew., Brux., etc. - Floresta da Tijuca, Rı-JAx., no 774. Sous-frutescent, fl. blane jaunâtre. Novembre-récembre. R.

98. B. Paronii Wedd. in DC. Prodr. XVI, I, p. 198. - Serra da Estrella, à Mamminha, Rio-Jav., no 959]. Sous-frutescent, fl. blane jaunâtre. Août-septembre. C.

99. B. arguta Marl. in Fl. Bras. IV, I, p. 186. - Corcovado, à Paiueiras, Rı-J.x., $n^{\circ}$ 1558. Sous-frutescent. fl. Hanchàtre. Aoùt-septembre. C.

100. B. cylindrica Wedd. in DG. Prodr. XVI, I, p. 202. - Serra da Mantiqueira, dans le bois, Mixas, $n^{\circ}$ 15425. Sous-frutescent, fl. blanc jaunâtre. Novembre-décembre. C. 
101. Myriocarpa longipes Wedd. in I)C. Prodr. XVI, 1. 29:. Petropolis, dans le bois, au lietiro, Rio-Jax., nos 11554 , 14274. Sousfrutescent, tl. blanchattres. Juin-juillet. C.

102. M. densiflora Wedt.? in DC. Prodr. XVI, p. 2230̈. - Passeio Publico, Rio-Jax., no 1524. Sous-frutescent, cultivé, ft. blane jaunàtre. Septembre-octobre. R.

103. M. stipitata Wedd. in DC. Prodr. XVI, p. 233. - Corcovado, à Paineiras, Pio-Jax., $\mathrm{n}^{\text {os }} 767,1491,12175$. Sous-frutescent, fl. blan:hâtres. Juillet-août. CC.

104. Phenax Sonneratii Wedd. in DC. Prodr. XVI, P. 뽀.j. Coreovado, près du ruisseau Carinca, Rio-Jax., nos 772,8487 . Sous-frutescent, fl. rousses. Juin-juillet. C.

108ั. Ph. debilis Glaz. n. sp.? in herh. Paris., Berol., Kew., Brux, etc. - Serra da Estrella, à Handioca, Rio-JAv., n 11568. Herbacé, f1. rousses. Janvier-février. C.

106. Ph. organensis Glaz. n. sp.? in herb. Paris.. Berol., Kew,, Brux., etc. - Serra dos Orgãos, à Theresopolis, Rio-JAx., n ${ }^{\circ}$ 8931. Sousfrutescent, 11. rousses. Arril-mai. C.

107. Parietaria officinalis L.; DG. Prodr. XVI, 1. 230̈; Fl. Flum. Xl, tab. 47. - Sĩo Christorão, sur les vieux murs, Rio-JAx., $11^{\circ} 1155$, 10057. Herbacé vivace, fl. blanchâtres. Juin-juillet.

108. Hemistylis brasiliensis Wedd. in Warm. Symb. ad Fl. Bras. p. 404. - Valença, dans le bois, Rı-Jax., n 9592 a. Sous-frutescent, 11. blanc jaunitre. Septembre-octobre. R.

109. Tramoia lactifera Schaw et Taub. sp. nov. in herb. Paris., Berol., Kew., Brux., ete. - Piau, près Juiz de Fora, Misas, nº 20486; Cabo Frio, Rio-J.x., n ${ }^{\circ}$ 11570. Grand arbre, fruit rougeâtre. Septembreoctobre. C.

\section{Fam. 12:- - Platanacées.}

1. Platanus orientalis L.; I)C. Prodr. XVI (2), p. 1:38. - Petropolis, dans les jardins, Rio-Jax., no 17780. Grand arbre, fruit roux. Octolsre-novembre. R.

\section{Fam. 126. - Casuarinées.}

1. Casuarina equisetifolia L.; DC. Prodr. XV1 (⿻上丨), p. 338. - RiuJaneiro et Petropolis, dans les jardins, $n^{\circ} 6000$. Grand arbre, fr. blan jaunatre. Septembre-octobre. CC. 
2. S. Martiana Leyhold.; Fl. Bras. IV, I, p. 228. - Quinta da Boa Vista, S. Christovio, Rio-Jav., n ${ }^{\circ} 10050$. Grand arbre cultivé, fl. blanchâtres. Nurembre-décembre. R.

\section{Fam. 12T. - Salicacées.}

1. Salix Humboldtiana Kunth. Fl. Bras. IV, I, p. 227. - Rancho do Marçal, près São João d'El Rei, au hord de la rivière, Mınas, $11^{0 \mathrm{~s}} 16352$, 18508. Grand arbre, 11. Wlanchâtres. Norembre-décembre. C.

\section{Fam. 128. - Lacistémacées.}

1. Lacistema myricoides Sw.; Fl. Bras. IV, I, p. 282. - Quinta da Boa Vista, São Christovão, Rio-Jax., nos $10053,10054,14280$. Arbuste cultivé, fl. rousses. Janvier-février. C.

2. L. grandifolium Schnizl.; Fl. Bras. IV, I, p. 284. - Serra da Itabapoana, Espirito Sinto, $\mathbf{n}^{\circ}$ 10052. Arbuste, f1. rousses. Septembreoctobre. R.

3. L. cllipticum Schn.? Fl. Bras. IV, I, p. 283. - Congonhas do Campo, dans le bois, Misas, $n^{\circ}$ 14279. Arbuste, fl. rousses. Octobrenovembre. G.

Fam. 129. - Cératophyllacées.

1. Ceratophyllum demersum L. - Lagoa da Tijuca ou d'Itapeva, Rio-J Jx., no 6230 . Herbacé, aquatique. Sans fleur en septembre. C. 


\section{ERRATA}

Les fiches de Glazioc, qui ont servi de texte pour l'impression de ce Mémoire, laissaient beaucoup à désirer comme rédaction, d'où le nombre considérable des fautes qui se sont glissées dans l'impression, surtout dans les trois premières parties (pp. 1T-200). Après l'entrée au Muséum d'Histoire naturelle de Paris de l'herbier de Glazioc, la comparaison des fiches avec les échantillons de cet herbier a permis de réduire dans le Mémoire imprimé le nombre des fautes au minimum.

Nous donnons ci-après deux errata. Le premier est relatif aux noms des plantes et quelquefois des auteurs. Le premier numéro indique la page à laquelle on renvoie; le second, le numéro d'ordre de l'espèce citée dans chaque famille. Le premier nom, (placé entre parenthèses), est le nom fantif; il est suivi du nom correct, non placé entre parenthèses et séparé par le signe $=$. On a renoncé à la correction des noms géographiques.

Le second errata, particulièrement important, est consacré aux numéraux erronés. Ici encore les numéros inexacts sont placés entre parenthèses et suivis des numéros exacts précédés du signe $=$.

Le nüméro placé au commencement de chaque alinéa désigne, dans chaque famille, le numéro d'ordre de l'espice citée. (Note de la Rédaction.)

Le présent fascicule termine le Mémoire 3, GLAziou n'ayant rédigé de fiches que pour les Dicotylédones.

171 [Nymphéacées](Cabom$\mathrm{bo}$ ) Cabomba.

213 (Selloana $=$ Sellowiana.

21 6 (subdimiata) $=$ subdimidiata.
2329 (Lavardia) = Lavradia.

31 2: $(V$. herbacea $)=$ Vochysia herbacea.

3235 (fucanorum) $=$ tucanorum. 


\begin{tabular}{|c|c|c|}
\hline 37 & 16 & $($ Rouhl. $)=$ Ruhl. \\
\hline $3 \pi$ & 3 & (Crimua) $=$ Cruiva. \\
\hline 38 & 21 & $\begin{array}{l}(\text { pyrifolia })=\text { pirifo- } \\
\text { lia. }\end{array}$ \\
\hline 39 & 27 & (GLAZIOVII) = Glaziorm. \\
\hline 41 & 13 & $\begin{array}{l}(\text { var... })=\text { var. parlifo- } \\
\quad \text { lia. }\end{array}$ \\
\hline 4 & 12 & $\begin{array}{l}(\text { panniculata })=p a n i- \\
\text { culata. }\end{array}$ \\
\hline ; & 27 & $\begin{array}{l}\text { Bastardea }) \\
\text { tardia. }\end{array}$ \\
\hline 48 & $6 \pi$ & $\begin{array}{l}\text { (panniculata })=\text { pani- } \\
\text { culata. }\end{array}$ \\
\hline & 109 & $\begin{array}{l}\text { (callopluyllum })=\text { calo- } \\
\text { phyllum. }\end{array}$ \\
\hline 3 & 11 & $\begin{array}{l}\text { (Barnensis) }=\text { barnen- } \\
\text { sis. }\end{array}$ \\
\hline 4 & 21 & (Lupulina) $=$ lupulina. \\
\hline & 26 & (REGNELII) $=$ REGNELII. \\
\hline & ५0 & (Loefl.) $=$ L.f. \\
\hline & 4 & $\begin{array}{l}\text { (allhavides) }=\text { althœ- } \\
\text { oides. }\end{array}$ \\
\hline 8 & 8 & (Luhea) $=$ Luehea. \\
\hline 59 & 18 & (Cruicis) $=$ Crucis. \\
\hline & 20 & $\begin{array}{l}(\text { Garchea })=\text { Garchea }- \\
\text { na. }\end{array}$ \\
\hline 62 & 27 & $\begin{array}{l}\text { (caloplulebinm) }=\text { Co- } \\
\text { loplulebinm. }\end{array}$ \\
\hline 60 & 1 & $\begin{array}{l}\text { (panniculata) }=\text { pani- } \\
\text { culata. }\end{array}$ \\
\hline 63 & 6 & $\begin{array}{l}\text { (Saccoglotis })=\text { Sac- } \\
\text { coglottis. }\end{array}$ \\
\hline & 12 & $\begin{array}{l}(\text { viminalifolia) }=\text { vimi- } \\
\text { nifolia. }\end{array}$ \\
\hline
\end{tabular}

6620 (myrcifolia) = myricifolia.

67 25 (nonlifera) $=$ uvulifera.

6726 (bryoniifolia) $=$ lyoniifolia.

6727 (cocolobifolia) $=$ coccolobifolia.

67 29 (Byrsomima uroceras. Niedz. in Arb. de bot. Inst., p.42). Uroceras, à la page 42 du travail cité de Niedenzu, est un nom de sous-section et non un nom spécifique.

67 3' (Amanthera) $=$ Acmanthera.

I1 83 (Lalandinnm) $=$ Lalandianmm.

72 89 (psilocarpodinm) $=$ psilocardium.

74114 (multifoliata) $=$ multifoliolata.

78 $106 \quad$ (Schwania) $=$

Schwannia.

80 2: (Barelieri) $=$ Barrelieri.

$843 \ddot{3}$ (chiloperone) $=$ Chiloperone.

84 42 (pinnatifolins) $=$ pennatifolius.

8:) 49 (intermededia) $=$ intermedia.

$86 \quad 60 \quad$ (anrantiola) $=$ Aurantiola.

$86 \quad 63$ (anrantium) $=$ Aurantium.

$878 \quad($ trichiliodes $)=$ trichilioides.

$89 \quad 17 \quad(T)=$.$O . [Oxalis ]$.

$928($ Almecega $)=$ Almecago.

$101 \div$ (suber $)=$ Suber.

10215 (MARTIANA) = MarTiana.

10219 (GLAZIOVIANA) = GLAZIOVIANA.

$10220 \quad$ (sOBILIS) $=$ SORBILIS.

10324 (AUgUStI) = AUgUSTI.

$1032 \dot{2}$ (WARMINGIANA) $=$ WARMINGIANA.

$10 \div 32 \quad($ SEN.EI $)=$ SEN.II.

112 (Ressekia) $=$ Reissekia).

11416 (Laroutteana $)=$ Laruotteana.

11636 (mansiana) $=$ Mansiana.

11971 (Diatenopterix) $=$ Diatenopteryx. 


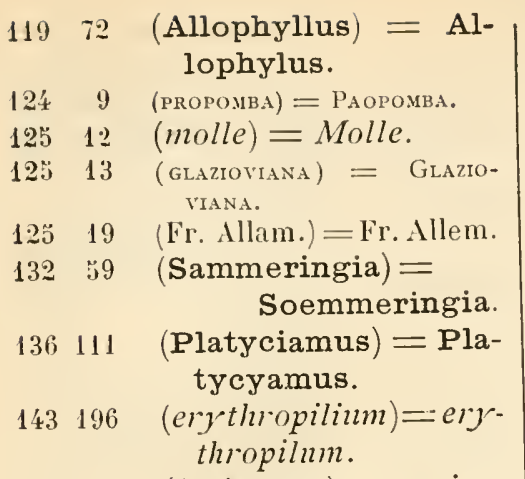

143219 (incinatum) $=$ nncinatum.

143227 (formum) = firmum. $147250 \quad$ (cristacastrensis) $=$ Crista-castrensis.

148259 (ancyclocaly $x=$ ancylocalyx.

$1001291 \quad$ (anthelmintica) $=$ anthelminthica.

154336 (Swartia) = Swartzia.

157363 (Cenostiama)=Cenostigma.

158379 (Diconynia) $=$ Dicorynia.

160401 (Sophera) = Sophora.

161414 (LindLeyana) = Lindleyana.

$167487 \quad$ (gygophylloides) $=z \boldsymbol{r}$ gophylloides.

$168510 \quad($ potentilla $)=$ Potentilla.

169 ӭь5 (chamecrista) $=$ Chamacrista.

170531 (cuiabensis) $=$ cuyabensis.

176607 (perigrina) $=$ peregrina.

177610 (Puiggrii) $=$ Puiggarii.

177616 (Pavonina) $=$ pavonina.

178 621 (Sensitiva) $=$ sensitiva. $\quad 28 \div 451$
185719 (multispinoides) $=$ multipinnoides.

18.5 722 (parvisensis) $=$ parai zensis.

187743 (Colliandra) = Calliandra.

$188750 \quad$ (Colliandra) $=$ Calliandra.

189 76. (Avaremotemo) $=$ Auaremotemo.

$193815 \quad($ uragensis $)=$ uragulensis.

19618 (brasiliensis) $=$ brasiliense.

20731 (guineensis) $=$ guineense.

$20950 \quad$ (acuminatus) $=$ acuminata.

$20951 \quad($ Grotheanus $)=G œ-$ theana.

209 :2 (angustifolius) $=$ angustifolia.

$209: 38 \quad$ (tomentosus) $=$ tomentosa.

$21290 \quad$ (oxyacanthophylla $=$ oxyentophylla.

214107 [deuxième ligne]. Reporter le mot "Havn " après le mot "Brux."

216132 (calmmbaënsis) $=c a-$ humbaensis.

$220179 \quad$ (Miyrcia) $=$ Myrcia. 222 204 (Caparoana) = caparoana.

230299 (Pianlyensis) $=$ piauhiensis.

236368 (xanthochloa) $=$ xanthochlora.

$23737 \% \quad($ Nettiana $)=$ Nettoana.

238390 (Babesiana $)=$ Rabeniana.

239403 (Lecytropsis) $=$ Lecythopsis.

$256 \quad 149 \quad$ (cllamapitys) $=$ Chamapitys.

$(S)=.L .[$ Leandra $]$ 


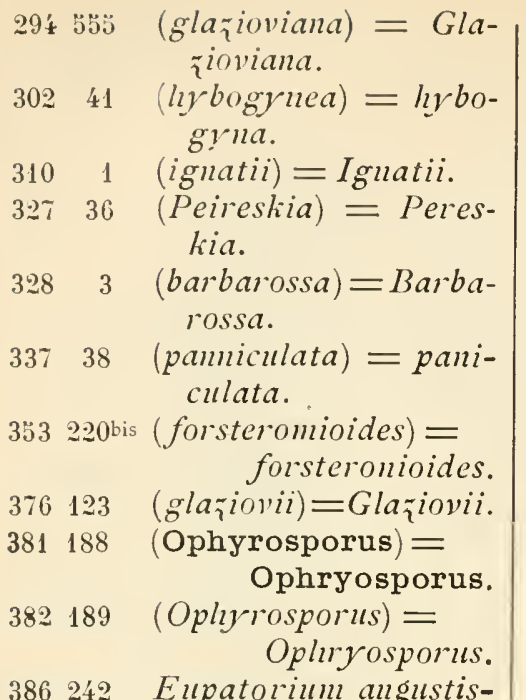

Renonculacées.

3. Clematis dioica var, antillensis. - Ajouter 18121 (R.-J.).

4. Ranunculus flagelliformis. $(6080)=6080 a$.

\section{Dilléniacées.}

3. Davilla elliptica. - Ajouter 12402,18124 . - Supprimer 20633.

14. Doliocarpus sessiliflorus. $(11782)=18122$.

15. D. elegans. $-(1882 \%)=18837$.

16. Tetracera calophylla. - Ajouter 18836.

\section{Magnoliacées.}

1. Drymis Winteri var. granatensis. - Ajouter 3853 .

2. Talauna ovata. $-(8226)=$ 8256 .

Anonacées.

4. Guatteria psilopus. - $(7507 a)$ $=\tau 506 a$. simmum fait double emploi avec le no $2: 38$. $392303 \quad$ (regnelli) $=$ Regnellii . 396357 (gnaphaliodes) = gnaplialioides.

397371 (notobelliastrum= no tobellidiastrum. 403426 (cassincefolia) $=$ cassinefolia.

417 598 (apocepliala $)=$ apodocepliala.

$\begin{array}{lll}438 & 27 & (\text { nitida })=\text { nitidula. }\end{array}$

44410 (integerima) = integerrima.

$448 \quad 8 \quad(S)=L$. [Linociera]. $₫ 79 \quad 59 \quad$ (plivllicoides) $=$ phylicoides.

46242 (Gompholobus) $=$ Gomphocarpus.

15. G. pogonopus. - Supprimer 3835.

17. G. ferruginea. $-(6690)=$ 16690 .

40. Rollinia emarginata. $-(685)$ $=6857$.

46. Anona monticola. - (14446) $=1446$.

58. A. Cherimolia. - $\left(\begin{array}{lll}750 & b\end{array}\right)=$ $7509 \mathrm{~b}$.

\section{Ménispermacées.}

10. Cissampelos ovalifolia.-Ajouter $13402,144 \pi 1$.

11. C. Pareira. - Ajouter $20612 a$.

16. C. fasciculata. - Ajouter 9609.

19. Pachygone oblongifolia.Ajouter 12410.

21. Botryopsis platyphylla. $(4487)=2487 .-$ Ajouter 527.

Berbéridées.

1. Berberis laurina. $-(6645)=$ 6465 . 
Capparidées.

8. Cleome rosea, $-(233)=223$.

9. C. affinis. $-(343)=342$.

10. Physostemon intermedium. $(14776)=14476$.

17. Capparis lineata. $-(6801)=$ 6081 .

19. C. flexuosa.- $(13241)=102 * 1$.

Violacées.

22. Alsodeia guianensis. - (1086) $=10086$.

2.5. Sauvagesia racemosa. - (1 275) $=10275$.

27. S. erecta. $-(739)=5739$.

29. Lavradia glandulosa. - Ajouter $1+497$.

30. L. Velloziana. - Ajouter 6858 .

Pittosporacées.

2. Xylosma Salzmanni. -- (14 477) $=1+478$. - Ajouter 10252 , $11787,14477$.

3. X. ciliatifolia. - Ajouter 11588 .

Polygalacées.

6. Polygala grandifolia. - (' 925 ) $=4952$.

16. P. atropurpurea. $-(27661)=$ 20661.

41. P. coriacea. $-(20668)=20678$.

43. P. revoluta. $-(1+448)=14488$. - Ajouter $14487,15831,16696$. 44. P. campestris - Ajouter 4757. 45. Acanthocladus brasiliensis. $(14493 a)=\left(\begin{array}{l}149 a \\ 4\end{array}\right)$.

50. Bredemeyera brevifolia. -

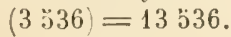

\section{Vochysiacées.}

8. Qualea grandiflora. $-(17112)$ $=17612$.

10. Q. multiflora. - Ajouter 20684 .

21. Q. Glaziovii. - Ijouter 2113.

26. Vochysiarufa. - Ajouter 20687.

27. V. elliptica. - Ajouter 20691.

31. V. maguifica. - Ajouter 10732.

32. Trigonia Glazioviana. - Ajouter วั 79 t, 6877 .
Portulacacées.

2. Portulaca mucronata. - Ajouter 10889 .

Hypéricacées.

6. Hypericum cordiforme.-

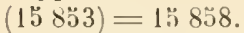

7. I1. brasiliense. - Ajouter 1020 .

9. Vismia micrantha. - (1 532) $=$ 14333.

14. V. Martiana. $-12+63)=12465$.

Guttifères.

3. Clusia Cruiva. - Ajouter 15863. 10. C. organensis. - Ajouter 17481.

13. Tovomitopsis Saldanhæ. $(13404)=13408$.

Ternstrœmiacées.

12. Souroubea guianensis. - Ajouter 9666 .

13. Ternstrœmia brasiliensis. Supprimer 20709.

18. Laplacea tomentosa.-Ajouter $14 \breve{2} 27 a$.

26. Kielmeyera coriacea. - Ajouter 12461 .

30. K. petiolaris. $-(1 \div 620)=$ 14520.

Malvacées.

4. Gaya Gaudichaudiana. - (1243) $=124+3$.

7. Sida ciliaris. - Supprimer le premier nombre 10290.

13. S.micrantha. - Ajouter 10318.

19. S. aurantiaca. $-(1883)=$ (18 88:3).

20. S. decumbens. - Supprimer le premier nombre 1240.

30. Wissadula hernandioides. Ajouter 10284 .

44. Abutilon rufinerve. - Supprimer 18136.

4ว. \. Irufivelum. - $(18138)=$ 18136 .

51. A. Regnellii.- $(13779)=3779$.

60. Paronia rosea. - גjouter 10288 .

61. P.sessiliflora.-Ajouter 20711. 
62. P'. speciosir var. polymorpha. - Supprimer 20711.

64. P. Schrankii. - Ajouter 18890.

72. P. cancellata. - Ajouter 10293.

76. P. malacophylla. - Ajouter 18885.

82. Hibiscus Rosa-sinensis. $(15555)=1$

97. Pachira petropolitana.-(9309) $=10309$.

108. Bombax endecaphyllum. $(18442)=18142$.

113. Ceiba erianthos. - Supprimer $18145 a$.

118. Chorisia crispiflora. - (2 494) $=2499$.

\section{Sterculiacées.}

1. Sterculia Chicha. - Ajouter 18147.

21. Melochia Lupulina. - (1 560) $=13560$.

27. M. cordiformis. - Ajouter 13533.

48. Ayenia Riedeliana. - Supprimer 20731.

\section{Tiliacćes.}

3. Triumfetta semitriloba. $(13539)=135: 89$.

7. Chorchorus hirtus. - (9332) $=9632 .-$ Ajouter 8573,13538 .

15. Mollia speciosa. - Ajouter 13562 .

16. M. lepidota. $-(13563 a)=$ $13562 a$.

21. Sloanea obtusifolia. - Ajouter 13483 .

22. Sl. monosperma. - Supprimer 7317 .

Linacées.

5. Linum junceum. $-(8283)=$ 8285.

9. Erythroxylon betulaceum var. amplifolia. - Ajouter 1359 a.

22. E. cincinnatum. - Ajouter 6112.

27. E. colophlebium. - Ajouter 9362.

30. E. Coca. - Ajouter $753 \pi$.
31. E. citrifolium. - Ajouter 2942 , $7 \$ 39,96 \pi 1$.

\section{Malpighiacées.}

11. Byrsonima variabilis. - Supprimer 10355 .

32. Burdachia prismatocarpa. Ajouter 13592.

35. Pterandra pyroidea. - (18930) $=18932$.

41. Heteropteris confertiflora. $(18944 a)=18944$.

59. H. nitida. $-(720)=718-$ $(10367)=10368$. Supprimer $8590,10359,13595,16730$.

68. H. anomala. - Supprimer 10369 .

77. H. anoptera. - Ajouter 10378.

138. Tetrapteris crebriflora. $(8583)=8585$. - Ajouter 6850 .

144. T. multiglandulosa. - Ajouter $18940 a$.

153. Mascagnia sepium. - Ajouter 5764 .

156. Hiræa Salzmanniana. - (9 696) $=9686$.

166. Schwannia elegans. - (20758) $=20753$.

Géraniacées.

18. Oxalis densifolia. - Ajouter 20784.

22. 0. campestris. $-(133647)=$ $1364 \%$.

Rutacées.

2. Almeidea longifolia. - Ajouter 122.

3. A. cerulea. - Supprimer 122, 677.

5. Erythrochiton brasiliensis. $(1589)=15891$.

23. Zanthoxylum hiemale. - Ajouter 17585,17610 .

26. Z. subserratum. - Supprimer 11863.

34. Z. acutifolium. - Ajouter 2119.

39. Pilocarpus subcoriaceus. $(14)=41$.

42. P. pennatifolius. $-(20798 a)$ $=20799 a$. 
44. Esenbeckia febrifuga. - Sup-

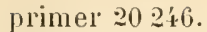

49. E. intermedia. $-(10438)=$ 10438.

53. Metrodorea nigra. - $(48 \% 0)$ $= \pm 780$.

60. Triphasia Aurantiola. - Ajouter 6839.

\section{Simarubacées.}

3. Simaba cuneata. - Ajouter 2 959, 12525.

6. S. floribunda. - Supprimer 2959 .

8. S. trichilioides. $-(15869)=$ 13889 .

12. Picræna Vellozii. $-(1192)=$ 1592 .

13. Dictyoloma incanescens. Ajouter 9383.

13. Picramnia Spruceana. $(13638 b)=136: 38$.

\section{Ochnacées.}

2. Ouratea castaneæfolia. - Supprimer 9717.

13. 0. spectabilis. - (11866, $13661 a=11866 a, 13661$.

19. 0. gigantopliylla. - $(25894)$ $=13084$. Ajouter 20250 .

25. 0 . cuspidata. $-(1083)=1083$. - Supprimer 3 920. - Ajouter 20808.

33. Luxemburgia speciosa. $18781=18981$.

\section{Méliacées.}

39. Trichilia tetrapetala. - (3903) $=3905$.

40. Tr. Schumanniana. - (2934) $=29 \mathrm{os}^{\mathrm{x}}$.

\section{bichapétalacées.}

1. Dichapetalum vestitum. $(1080)=10080$.

\section{Olacinées.}

3. Heisteria densifrons. - Supprimer 20824 et remplacer par 1 \& 529 .
18. Cathedra rubricaulis. - (853) $=858$.

20. Schopfia obliquifolia. $(18154)=18153$.

31. Villaresia megaphylla.-(1851) $=181 . \% 1$.

32. V. paniculata. $-(1226)=1126$ $-(7529)=7: 323$.

\section{Ilicinées.}

4. Hex Vitis-idara. $-(9006)=$ 19006.

14. J. subcordata var. nummularioides. $-(1899)=1899$.

15. J. asperula var. Martiana. Supprimer 18996 a et remplacer par 12932 .

19. J. cerasifolia var. Glazioviana. $-(11878)=11872$.

20. J. paraguariensis var. confusa. - Supprimer 18187.

21. J. brasiliensis var. pubiflora. $-(2831)=20831$.

31. J. affinis. - Supprimer $2083 \%$.

Célastrinées.

24. Maytenus obtusifolia. - (8812, $8813)=8312,8313$.

liippocratéacées.

1. Hippocratea ovata var. grandiflora. - Ajouter n ${ }^{0} 10409$.

10. Salacia cognata. - Ajouter 13583.

23. S. grandifolia. - Ajouter 6718 . 25. S. affinis. - Supprimer 18917.

Rhamnacées.

3. Tizyphus Allemaovii. - 18991 $=18991 a$.

17. Gouania Blanchetiana.-Ajouter 10456.

\section{Sapindacées.}

1. Serjania tenuis. $-(13626)=$ 13624 .

4. S. communis. - Ajouter 8593.

5. S. gracilis. - Ajouter 10433 .

13. S. dentata. - Supprimer 3898.

23. S. fuscifolia. $-(8292)=8298$.

- Ajouter 859 . 
60. Urvillea triphylla. $-(2429)=$ $29: 8$.

70. Thinouia scandens. - Ajouter 3898.

76. Allophylus edulis. $-(8608)=$ 8606 .

77. A. petiolulatus. $-(10424)=$ 1024

93. Cupania paniculata. - (13:301) $=12501$.

100. C. racemosa. $-(5766)=5777$.

106. Matayba sylvatica. - (1584) $=1588$.

\section{Sabiacées.}

4. Meliosma sinuata. - Ajouter 12401 .

5. Spondias purpurea var, venulosa. $-(10494)=(10492) .-$ Ajouter 10 '93.

6. Sp. lutea var.glabra. - Ajouter 1049 '.

8. Tapiriria guianensis. - Ajouter 3903 .

9. T. Marchandi var. Paopomba. $-(1675)=16750$.

\section{Connaracées.}

11. Connarus guianensis.-- (13876) $=13676$.

12. C. ruber. - Ajouter 13673.

13. C. Beyrichii. - Ajouter 13672.

\section{Légumineuses.}

43. Chatocalyx polyphylla. $(10 \tau 07)=10507$.

49. Eschynomene sensitiva. Supprimer le premier nombre 8629.

64. Stylosanthes guyanensis. $(650)=6509$. - var. gracilis $(19033)=19033 a$.

100. Periandra dulcis. - (12 525$)$ $=12585$.

102. P. acutifolia. $-11902 b$.

113. Erythrima falcata. - (6906) $=2906$.

123. Galactia pyrenæa. - Suppriiner 20906.

130. Colla speciosa. - (16 725) $=16752$.
137. C. Nartii. - Ajouter 19035 a.

153. Canavalia picta. - $(8508$ a $)$ $=6: 308 a$.

1:8. C. gladiata. - Ajouter 18215 a.

167. Phaseolus longifolius. - (9372) $=9392$.

181. Rhynchosia minima. $-(12526)$ $=12536-(1537)=15037$.

186. Eriosema stipulare. - Supprimer 20893.

187. E. crinitum.-Ajouter $19024 a$.

208. Dalbergia foliolosa. - Ajouter 17596.

216. Nachærium angustifolium. Ajouter 10539 .

228. M. legale. - Ajouter \$807.

236. H. brasiliense. - Ajouter 2530.

246. II. ovalifolium. - Ajoute ${ }^{\circ}$ 14663.

252. Tipuana heteroptera. - Ajouter 9397.

2ว6. Centrolobium tomentosum. Ajouter 581 .

260. Pocilanthe grandiflora. $(12: 9)=12591$.

275. Lonchocarpus obtusus. - Supprimer 14658.

277. L. subglaucescens. - (11910) $=11901$.

292. Andira Pisonis. $-(19050)=$ 19051.

297. Geofiroya superba. - (16 546) $=10546$.

303. Pterodon emarginatus. $(19023)=19052$.

30\%. Baphia ovalifolia. - (18916) $=18216$.

308. Sophora tomentosa. - Ajouter 3927.

317. Bowdichia virgilioides.-Ajouter $1367,9747$.

321. Myrocarpus frondosus. $(8449)=8649 .-$ Ajouter 11908 .

323. Sweetia dasycarpa. - Ajouter 17602.

Id. val. glabrata. $-(1263)=$ 12603.

331. Zollernia falcata. $-(3941)=$ 3944.

332. Z. ilicifolia. $-(11596)=11598$ $-(3730)=13730$. 
343. Swartzia theiodora. - Ajouter 13731.

356. Sclerolobium rugosum . $(18642)=10642$.

372. Casalpinia peltophoroides. (3943) $=394 \%$.

375. Schizolobium excelsum. Ajouter 6183.

396. Cassia lavigata. $-(28289)=$ 20289. - Supprimer 8415. Ajouter 15936.

400. C. occidentalis. - $(8415$ a $)$ $=8415$.

418. C. racemosa. $-(9661)=9761$.

423. C. Aponconita. - Ajouter 10632 .

442. C. ochnacea. - $(19160 \quad a)=$ $19106 u$.

44x. C. nummulariæfolia.-Ajouter 20931 .

465. C. ursina. $-(19076)=19075$.

473. C. uniflora. $-(1908)=19088$.

502. C. trachyclada. $-(2906 \pi)=$ 20967.

511. C. flexuosa. - Ajouter 9749.

3̈14. C. mucronata. - $(2087)=$ 20287.

54. Bauhinia angulosa. - Ajouter $8+19$.

55\%. Macrolobium acaciafolium. $(14755)=13753$.

362. IIymenaa stilbocarpa. - Supprimer 1067 .

571. Plerogyne nitens. -8639$)=$ 8639 .

572. Cynometra bauhiniafolia. $(3426)=13426$.

603. Piptadenia leptostachya. (8 +43$)=8$ ' ‘ 3.

605. P. macrocarpa. $-(1368 \dot{\xi})=$ $1378 \%$.

611. P. flava. $-(10679=10619$.

631. Mimosa pudica. $-(626)=623$.

65\%. M. incana. $-(1058)=1058 \%$.

660. M. calodendron. - Ajouter 1706.

681. M. invisa. - Ajouter 13777.

688. II. vernicosa. - $(2912 i)=$ 19127.

692. M. I.useneriana. - $(2105$ a $)$ $=210 \% 0 a$.
708. II.albolanata. - Ajouter 21083 .

i19. M. multipinnoidles. - Ajouter 21094.

727. Leucina glauca. $-\left(\begin{array}{l}1498) \\ \text { (1) }\end{array}\right.$ 1493.

732. Acacia grandistipula. - Ajouter 8434 .

739. A. glomerosa. - Ajouter 12636 .

747. Calliandra brevipes. - ( 3787$)$ $=\tau 587$.

766. Pithecolohium lusorium. $(13 \mathrm{t} 3)=13$ t31. - Ajouter 19110 .

767. P. Langsdorffii. $-\left(\begin{array}{l}6 \\ 6\end{array} 25\right)=$ $6192 .-(10662)=10602$.

769. P. Saman. - $(3515)=6315$.

775. P. cauliflorum. $-(12792)=$ 13792.

776. P. tortum. $-(13636)=12634$.

777. P. dumosum. $-(1630)=12630$.

$80 \%$. Inga ciliata. - Ajouter 10637 .

Rosacées.

45. Rubus brasiliensis. - ( 1468 $=14684$.

Saxifragacées.

2. Escallonia organensis. - (3761) $=3 \tau+1$.

4. E. montevidensis. - (8 725$)$.

Droséracées.

3. Drosera communis. - Ajouter 10258 .

Rhizophoracées.

1. Rhizophora Mangle. - (1.1 55ว ) $=1159 \%$.

Combrétacées.

2. Terminalia australis. - Ajouter 6834 .

Myrtacées.

6. Britoa Glazioviana. - $(9246$, $9249=9426,9429$.

110. Myrcia pulchira. - Ajouter 9428.

120. M. longipes forma obovata. $(138 \pi)=13871$.

123. II. rosulans. - Ajouter 12010. 
163. II. obtecta. - Supprimer le second nombre $1079 \%$ - $-\Lambda$ jouter 16061 .

179. H. lenheirensis. $-(160 \div 9)=$ 16048 .

193. M. Ilookeriana. - Ajouter $160 \% \pi$.

233. M. grandifolia. $-(1207)=$ $1200 \%$.

252. Eugenia pungens. - Ajouter $12735,14842$.

254 . E. Lvalha. $-(16158)=6158$.

259. E. Klotzschiana. $-(10443)=$ 10343.

268. E. Kunthiana. - Supprimer $2118 \%$.

287. E. bimarginata. - Ajouter 12726.

30\%. E. compactiflora. $-(7)=95$.

331. E. Michelii. - Ajouter 1: 72́

3ว0. E. acutiflora. - $-(1388)=$ (13 888$)$.

387. E. tenella var. Glazioviana. $(1386)=13886$.

398. Lecythis angustifolia. - (2:992) $=2593$.

401. L. ovata. $-(1484 i)=14849 a$.

405. Couratari estrellensis. - Ajouter $6163,19379$.

\section{Mélastomacées.}

千́. Nicrolicia multicaulis. $(19281)=19218$. Ajouter 21228.

4.. M. isophylla. $-(1475)=14713 \%$.

49. U. arenarixfolia. $-(834)=$ 8341.

56. If. doryphylla var. puberula. $-(15738)=14738$.

66. II. serrulata. $-(21231)=$ $21241 .-$ Supprimer 21232.

67. M. hirsutissima. - Ajouter $21 \geq 3$.

68. M. vestita. - Supprimer 21233 .

78. M. euphorbioidesvar. ionan tha. $-(9458)=9$ 千33. - Supprimer 14751.

93. M. fulva. - Supprimer le premier nombre 16771.

109. Trembleya capitata var. genuina. $-(8376)=8373$.
112. Lavoisiera robusta. - (19210) $=19270$.

123. L. confertiflora var. longifolia. $-(19262)=19261$.

134. L. serrulata. - Ajouter $192: 88$.

135. I. Bergii. $-(1672)=16782$.

143. L. cataphracta var. calycina. $-(19259)=19253$.

154. Rhynchanthera montana. $(21323)=21326$.

181. Acisanthera variabilis var. glabriuscula. - $(\mathbf{1} 603)=\mathbf{1 6} 036$.

188. Microlepis olerfolia.-Ajouter 12691.

194. Pterolepis trichotoma. $(11936)=11956$.

199. Pt. glomerata. - $(8567)=$ 8506 .

ld. var.angustifolia. - Supprimer 21347 et 21348 .

222. Tibouchina Gardneriana. Supprimer le premier nombre 19298.

240. T. Candolleana. $-(16496)=$ $16796 .-(22373)=21373$.

24\%. T. fissinervia. $-(17582)=$ 17 : 22.

268. T. goyazensis . $-(21360)=$ 21366.

275. T. Benthamiana. $-(1192)=$ $119 \pi 2$.

304. Marcetia taxifolia. - (1 3/4 $=(13440)$.

313. II. acerosa. - (19885) 19485.

318. Iluberia ovalifolia. - Supprimer 13833 .

325. Bisglaziovia behurioides. $(1828)=18228$.

33\%. Neriania paniculata. - (1 753) $=17330$.

367. Leandra foveolata. - Supprimer 16 s't.

368. L. polychata. - Ajouter 16841 et $21+10$.

4วัวิ. Miconia Langsdorffii. - Ajouter $17: 46 \mathrm{~b}$.

473. M. stenostachya. - (16905) $=16903$.

476. M. Cilazioviana. $-(16936)=$ 16943.

48\%. M. ibaguensis. - Ajouter 3973 . 
491. M. rubiginosa. $-(160$ \% r $)=$ $1694 \dot{4}$.

493. M. Pohliana. $-(21304)=$ 2139 '.

498. M. pepericarpa. $-(16043)=$ 16943.

307. M. chartacea var. brevifolia. $(1881)=16881$.

512. M. Saldanhæi. - $(18896)=$ 16896.

524. M. paulensis. $-(17562)=$ $17562 a$.

5ั26. M. subvernicosa. - Supprimer $1693 \%$.

527. M. Iongicuspis. $-(16916)=$ 16918.

566. Tococa formicaria. - Supprimer 21403 .

576. Clidemia spicata. - (15696) $=12696$.

Araliacées.

2. Aralia fluminensis. - 1893$)$ $=10895$.

Rubiacées.

207. Psychotria nem orosa. $(13950)=13960 .-(16163)=$ 16123.

Composées.

74. Vernonia lacunosa. - (14938) $=14983$.

83. V. obovata. - Supprimer 8144 .
12. Piptocarpha masropoda. $(816)=8116$.

154. Lychnophora Blancheti .-$(19432)=19+82$.

24.2. Fait double emploi avec le numéro 258.

318. Wedelia paludosí. - Ajouteı 9480 .

Lobéliacées.

11. Siphocampylus corymbiferus. $-13150=15165$.

22. Haynaldia organensis. $-(8744)$ $=878$.

Vacciniacées.

13. Gaylussacia reticulata.$(19589)=19579$.

\section{Sapotacées.}

19. Lucuma minutillora. - $20+1$ $=20401$.

Styracacées.

44. Styrax Martii. $-(16147)=$ 16247.

Apocynacées.

80. Forsteronia brasiliensis. $(14062)=14063$.

81. F. pubescens. - . ljouter 12939.

Convolvulacées.

53. Ifomiea glabra. $-(13124)=$ 13024 . 


\section{TABLE ALPHABETIQUE DES FAMILLES}

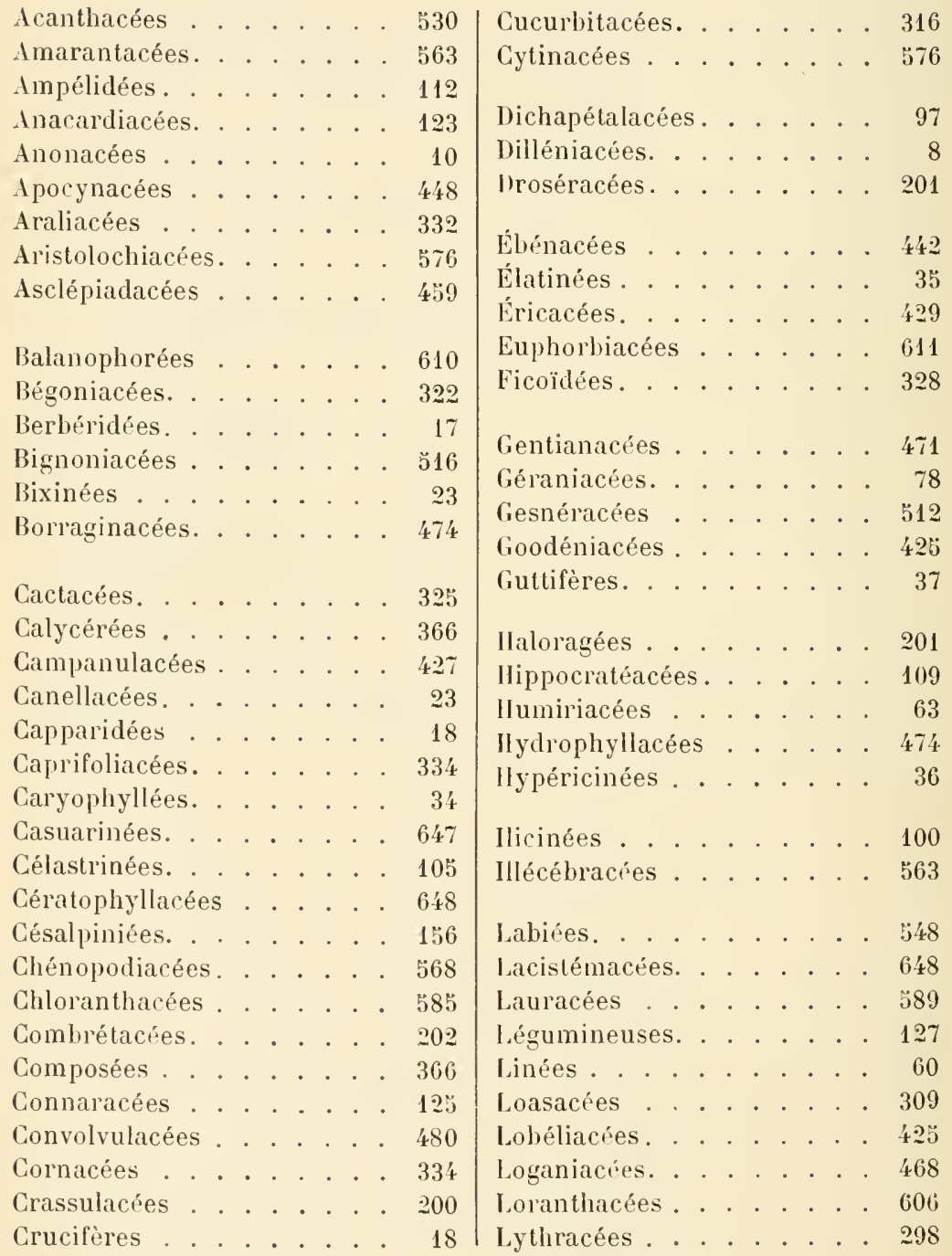


Magnoliacées . . . . . . 9

Malpighiacées. . . . . 64

Malvacées. . . . . . . 43

Mélastomacées . . . . 240

Méliacées. . . . . . 92

Ménispermées. . . . . 15

Minnosées. . . . . . . 174

Monimiacées . . . . 585

Myristicées . . . . . 585

Myrsinacee. . . . . . 432

Myrtacées. . . . . . . . 205

Nyctaginées. . . . . . 560

Nymphéacées . . . . . 17

Ochnacées ...... 88

Olacinées. . . . . . . 98

Oléacées ...... . 447

Ombellifères . . . . . . . 328

Onagrariées. . . . . . 305

Papavéracées . . . . . 18

Papilionacées. . . . . . 127

Passifloracées. . . . . . 313

Pédalinées . . . . . . 530

Phytolaccacées . . . . . 569

Pipéracées . . . . . . 578

Pittosporées . . . . . . 24

Plantaginacées . . . . . 560

Platanacées. . . . . 647

Plumbaginées. . . . . 431

Podostémacées . . . . . 574

Polygalacées . . . . . . 21

Polygonacées . . . . . . 570

Portulacacées. . . . . . 35

Primulacées
Protéacées . . . . . . 602

Renonculacées . . . . . 7

Rhamnées . . . . . 110

Rhizophoracées . . . . . 202

Rosacées . . . . . . . 194

Rubiacées . . . . . 334

Rutacées . . . . . . 81

Sabiacées....... 123

Salicacées . . . . . 648

Samydacées . . . . . 307

Santalacées. . . . . . 610

Sapindacées . . . . . 113

Sapotacées . . . . . 436

Saxifragacées . . . . . . 198

Scrofulariacées . . . . . 506

Simarubacées. . . . . 86

Solanacées . . . . . . . 491

Sterculiacées . . . . . 52

Styracacées. . . . . . 443

Ternstrœmiacées . . . . 40

Thyméléacées. . . . . . 605

Tiliacées . . . . . . 58

Turneracíes ..... . 310

Urticacées . . . . . . 639

Utriculariacées . . . . . 511

Vacciniacées . . . . . 427

Valérianées. . . . . . 365

Verbénacées . . . . . . . 539

Violariées. . . . . . . 20

Vochysiacées . . . . . . 29

Zygophyllées . . . . . 78 





\section{MÉMOIRES PUBLIES (Suite).}

11. P. Guérñ, Études sur les Diptérocarpées, 93 p. (décenbre 1907), terminé.

3c. Glaziov, Plantes du Brésil central, pp. $201-296$ (février 1908), à suivre.

12. Hce (abbé), Lichens Tarbelliens, 19 p. (avril 1908), terminé.

13. O. Ligner, Le fruit des Bennettitées et l'ascendance des Angiospermes, 17 p. (avril 1908), terminé.

8b. Chevalier, Novitates floræ africanæ (2e partie), pp. 31-109 (aoùt 1908), da suivire.

1'. Paris (Général), Florule bryolog̣ique de la Guinée française, 66 p. (novembre 1908), terminé.

3d. Glazıov, Plantes du Brésil central, pp. 297-392 (juin 1909), à suivre.

15. Lacbr, Nourelle méthode technique pour leétude praléphytologique des formations sédimentaires anciennes. 110 p. (janvier 1910), terminé.

16. Dúaro, Recherches sur le genre Palaquium, 2q p. (décembre 1909), terminé.

3e. Guazrou, Plantes du Brésil central, pp. 393-488 (mar's 19101, à suivre.

Sc. Cuevalier, Vovitates floræ africanæ (3e partie), pp. 1/1-136 (juin 1910), à suivre.

17. Dismer, Revision des Philonotis de l'Amérique, 37 p. (septembre 1910), terminé.

18. Bovatr, Contribution à l'étude du genre Pedicularis, 3. p. (novembre 1910), terminé.

19. Dop, Contribution à l'étude des Loganiacées asiatiques de l'herbier du Huséum de Paris (novembre 1910), termine.

20. Ed. Bonnet, Enumération des plantes recueillies par II. R. Chudeau, dans la région de Tombouctou et du Hoven-Niger, 19 p. aloùt 1911). terminé.

21. R. HaMet, Observations sur la germination des Crassulacres, i3 p. (aout 1911).

22. Pitard et Harmand, Contribution à l'eflude des Lichens des iles Canaries, 72 p. (octobre 1911), terminé.

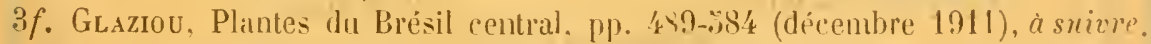
8d. Cuevalier, Novitates florix a fricanæ ('te partie) [inclus W. T. Swingle. Le

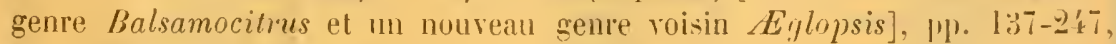
pl. I-V (mars 1912), à suivere.

23. C. Gerber, Les diastases du latex du Fïguier (Ficus Carica L.). Leur comparaison arec celles du latex du .Hùrier ì papier (Broussonetia papyjrifera L.), 48 p. juillet 1912), terminé.

24. O. Lignier, Le Stauropteris oldhamia Bimey et les Comoptéridées à la lumière de la théorie du mériphỵte, 33 p. (septembe 1912) terminé.

$3 g$. Glazioc, Plantes du Brésil Central, 1p. 58\%-661 (septenlre 1913) termine. 


\section{AVIS IMPORTANTS relatifs a la Publication du BULLETIN}

I. - Les minnuscrits, rédigés ne varietur et lisihlement, doivent être déposés le jour mint oil sunt fatites les communicalions, fante de quoi leur impression est ajournee sins 'pue les auteurs puissent elever de réclamation a cet égard.

11. - Si les mannscrits sont accompannes de ligures destinées a ftre insẻrées daus le texte, celles-ci doivent ètre dessinérs a la plune et au trait, ou hien au crayon Wullf sur papier procédé. on consister en bunnes photographies, de maniere a en perinctue la reproduction par les procedés zincographiques. L'insertion de tonte figure ne pouvant ètre reproduite que par des procédés dilférents reste soumi-e a l'approbation de la Commission du Bulletin.

III. - Les aıteul's recoivent ıne éprenve en placards et en touhle exemplaire de leurs communications, la correction des autres épreuves étant faite par le Secrétariat. Les corrections luivent etre retournées dans le delai maximum de trois jours an secrétaire-rédacteur, faute de quoi la correction est faite d'office par le Secrétariat.

IV. - Lorsque les manıscrits dépassent la Jongueur réglementaire de 8 pages et quils ne comportent pas de question de priorite. ils renvent être publiés sous la rubrique: Mémoires publiés par la sirriélé brilanique de France. Ces Jémoires sont éditès avec toute la cèlérité possible, mais sans garantie de date. lls prennent place dans les volumes annuels a la suite des communications insèrèes allx séances ordinaires et sont fonrnis aux Hembres de la Société sans majoration le deur cotisation.

V. - Afin de permellre l'ètahlissement des convocations aux séances, MM. les Auteurs sont instamment priés l'aviser le secretaire général huit jours à l'avance des communications qu'ils ont l'intention de présenter.

Linscription à l'ordre du jour de tout travail parvenu au Secretariat apres ce télai ne peul être garantit.

\section{Bureau et Conseil d'administration de la Société pour 1913}

\section{Président : Y. Chauveaud.}

Vice-présidents :

MW. Dangearil, Grand'Eury, Gagnepain, Guérin.

secréiaire général : $\mathbf{1 1}$. L. Lulz.

Secréluires :

MM. Lormand, F. Camus.

$$
\text { Trésorier : }
$$

11. Philippe de Vilmorin.
Vice-secrétaires :

Mil. Sartory, Combes.

\section{Archiviste :}

M. E. Malinvaud.

Vembres du Conseil :

MM. Bois,

Ed. Bonnet,

Dumée,

Dismier,
M.I. Friedel,

Gatin,

Hibon,

Hickel,
MM. Lecomte,

Patouillard,

M. de Vilmorin.

Zeiller,

Tout ce qui concerne l'administration de la Société doit être adressé au Secrétaire gènéral à l'adresse suivante:

M. Lutz, professeur agrégé à l'École supèrieure de pharmacie, 4, avenue de l'observatoire, Paris $\left(\right.$ VI $\left.^{\circ}\right)$.

Le Secrétaire-rédacteur, Gérant du Bulletin, F. inuus. 






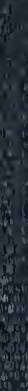

405 (5) 2. 1. 3.

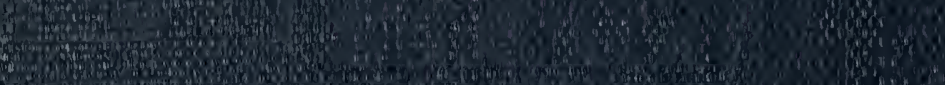

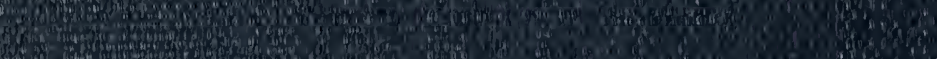

